\title{
Long-Term Carbon Injection Field Test for $>90 \%$ Mercury Removal for a PRB Unit with a Spray Dryer and Fabric Filter
}

\author{
Final Scientific/Technical Report \\ Reporting Period: April 1, 2006 - December 31, 2008 \\ Principal Authors: Sharon Sjostrom, Jerry Amrhein
}

Issued: April 2009

DOE Award Number DE-FC26-06NT42774

Report Number 42774R12

ADA-ES, Inc.

8100 SouthPark Way, Unit B

Littleton, Colorado 80120 


\section{DISCLAIMER}

This technical report was prepared with the support of the U.S. Department of Energy, under Award No. DE-FC26-06NT42774. However, any opinions, findings, conclusions, or recommendations expressed herein are those of the author(s) and do not necessarily reflect the views of the DOE.

This report was prepared as an account of work sponsored by an agency of the United States Government. Neither the United States Government nor any agency thereof, nor any of their employees, makes any warranty, express or implied, or assumes any legal liability or responsibility for the accuracy, completeness, or usefulness of any information, apparatus, product, or process disclosed, or represents that its use would not infringe privately owned rights. Reference herein to any specific commercial product, process, or service by trade name, trademark, manufacturer, or otherwise does not necessarily constitute or imply its endorsement, recommendation, or favoring by the United States Government or any agency thereof. The views and opinions of authors expressed herein do not necessarily state or reflect those of the United States Government or any agency thereof. 


\section{TABLE OF CONTENTS}

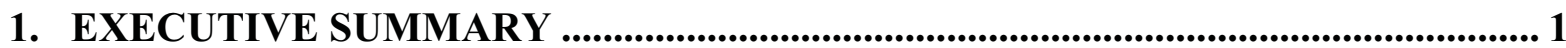

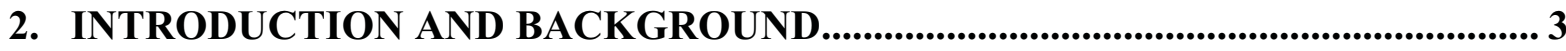

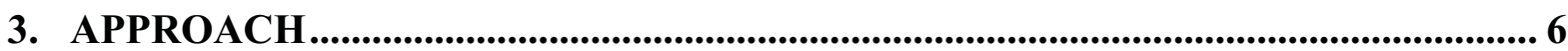

3.1. Objectives............................................................................................................. 9

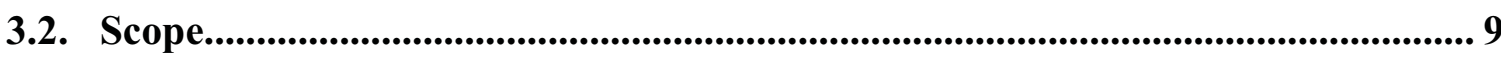

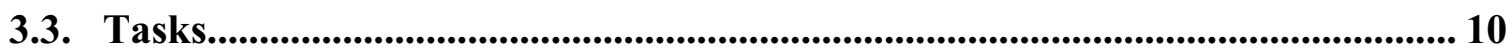

3.3.1. Test Coordination, QA/QC, and Test Plan Development ..................... 10

3.3.2. Equipment Installation ............................................................................... 11

3.3.3. Technology Transfer............................................................................ 13

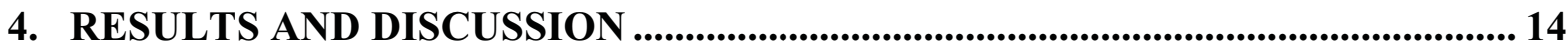

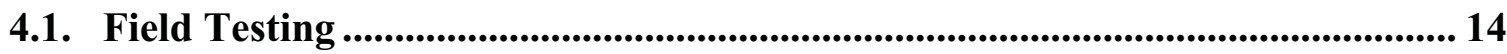

4.1.1. Silo and Hg-CEM Operation ................................................................ 14

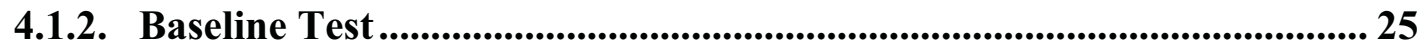

4.1.3. Co-Benefits Analysis ......................................................................................... 31

4.1.4. Parametric Test ..................................................................................................... 39

4.1.5. Optimization Test................................................................................... 40

4.1.6. Long-Term Test ................................................................................ 43

4.2. Coal and Coal Byproduct Sample Evaluation ....................................................... 54

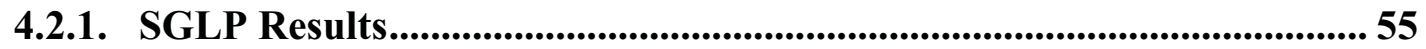

4.2.2. Ash Analysis With and Without PAC ........................................................... 57

4.2.3. Coal Properties.....................................................................................................6 60

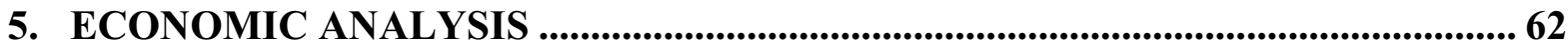

5.1. System Description................................................................................6 63

5.2. Cost and Economic Methodology ........................................................................... 64

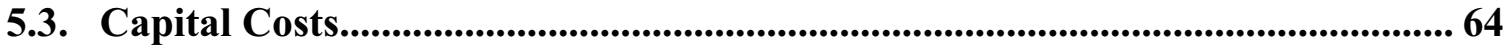

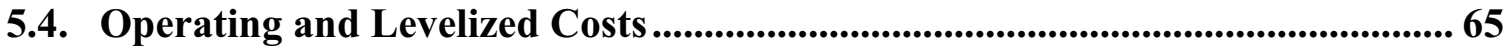

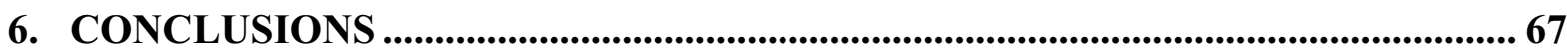

LIST OF ACRONYMS AND ABBREVIATIONS .................................................69

APPENDIX A： PROJECT TEST PLAN ................................................................... 71

APPENDIX B: HG-CEM QA/QC PROTOCOLS .......................................................... 90

APPENDIX C: M30A RESULTS...................................................................................... 94

APPENDIX D: MANUAL GAS SAMPLING RESULTS ........................................... 100

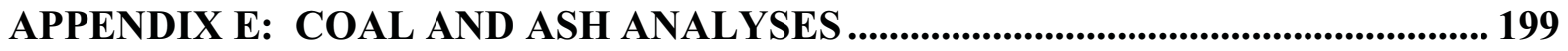

APPENDIX F: STANDARD CALCULATIONS......................................................... 2320 


\section{LIST OF TABLES}

Table 1. Key Parameters of the Hardin Station......................................................6

Table 2. Hardin Project Timeline..................................................................................8

Table 3. Linearity Check Results. ..........................................................................................16

Table 4. Results of the First M30A RATA. ................................................................17

Table 5. Results of the Second M30A RATA. ..........................................................18

Table 6. Results of the Third M30A RATA. ........................................................19

Table 7. Manual Measurements Conducted during Baseline Testing.........................27

Table 8. Summary of First Set of Baseline Gas Measurements. ...............................29

Table 9. Summary of the Second Set of Baseline Gas Measurements..........................30

Table 10. Summary of Baseline $\mathbf{P M}_{10} / \mathbf{P M}_{2.5}$ Measurements. .......................................31

Table 11. Summary of Coal Blending Runs. ..........................................................33

Table 12. Timeline for the Long-Term Test....................................................................44

Table 13. Comparison of Baseline and Long-Term Gas Measurements at the SDA Inlet at Hardin. .........................................................................52

Table 14. Comparison of Baseline and Long Term Gas Measurements at the Stack at Hardin.

Table 15. Comparison of Baseline and Long-Term PM and $\mathrm{SO}_{3}$

Measurements at the Stack at Hardin. .54

Table 16. SGLP Results on Baseline and Long-Term Ash Samples............................56

Table 17. Absaloka Coal Properties at Hardin .........................................................61

Table 18. Design Criteria for the Mercury Control System at Hardin ........................62

Table 19. Mercury Removal Efficiencies and Costs for Different APC Configurations, Coals, and Sorbents.......................................................63

Table 20. Capital and O\&M Cost Estimate for the ACI System at Hardin................65

Table 21. Levelized Costs ..................................................................................66 


\section{LIST OF FIGURES}

Figure 1. Schematic of the Hardin Station with Sample Locations..............................6

Figure 2. The ACI System and Stack Hg-CEM Probe Installed at Hardin.................12

Figure 3. The Hg-CEM, Probe, Sample Ports and New Platform Installed at the AH Outlet/SDA Inlet Location...............................................................13

Figure 4. Effect of $\mathrm{N}_{2}$ as a Dilution Gas on Hg-CEM Noise. ......................................20

Figure 5. Humidifier and Nitrogen Generator Upgrades on the Stack HgCEM.

Figure 6. Photo of the Mercuric Chloride Generator in the Stack Probe at Hardin. .22

Figure 7. Mercury Control System Performance without Feedback Control. .24

Figure 8. Mercury Control System Performance with Feedback Control. .................25

Figure 9. Baseline Mercury and Load Trends for Hardin Station, 2Q07...................26

Figure 10. Results from the First Set of Baseline Gas Measurements. ..........................28

Figure 11. Results of the Second Baseline Mercury Test...............................................30

Figure 12. Effect of Load on Hg Speciation and Native Removal. ...............................32

Figure 13. Portable Coal Conveying System at Hardin Station. .......................................33

Figure 14. Mercury Removal for the West Elk Coal Blend Test...................................34

Figure 15. Mercury Removal for the Coal Additive Test...........................................36

Figure 16. Hg-CEM Trends for the Coal Additive Test. ...............................................37

Figure 17. Effect of Ammonia Flow on Mercury Removal, 09/16/08...........................38

Figure 18. Effect of Ammonia Flow on Mercury Removal, 09/23/08...........................38

Figure 19. Mercury Removal for the Parametric Test. ..................................................40

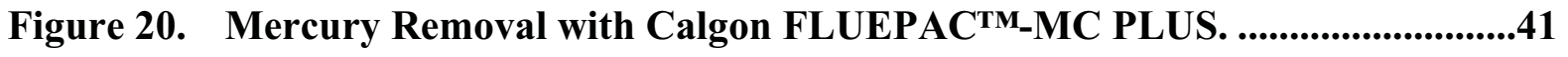

Figure 21. Mercury Removal with DARCO ${ }^{\circledR}$ Hg-LH.................................................42

Figure 22. System Performance after the Start of the Long-Term Test.......................45

Figure 23. 4Q07 Long-Term Mercury Removal with DARCO ${ }^{\circledR}$ Hg-LH. .......................46

Figure 24. 1Q08 Long-Term Mercury Removal with DARCO ${ }^{\circledR}$ Hg-LH........................47

Figure 25. 2Q08 Long-Term Mercury Removal with DARCO ${ }^{\circledR}$ Hg-LH.......................49

Figure 26. 3Q08 Mercury Removal with Hg-LH and MC PLUS....................................50

Figure 27. 4Q08 Mercury Removal with MC PLUS and ADA Power PAC PREMIUM....................................................................................51

Figure 28. Sampling Locations at Hardin..................................................................55 
Figure 29. Results of the SGLP Leaching Test on Ash Samples with and without Carbon Injection.................................................................................57

Figure 30. Comparison of LOI, Total, and Organic Carbon in Ash with SDA Solids.

Figure 31. CEGRIT In-Situ Ash Analyses Downstream of the ACI

Location. .

Figure 32. Mercury in FF Ash Samples during the Optimization Test. .......................59

Figure 33. Hg and Br in FF Ash before and during the KNX Test. .............................60 


\section{EXECUTIVE SUMMARY}

The power industry in the U.S. is faced with meeting regulations to reduce the emissions of mercury compounds from coal-fired plants. Injecting a sorbent such as powdered activated carbon (PAC) into the flue gas represents one of the simplest and most mature approaches to controlling mercury emissions from coal-fired boilers. The purpose of this test program was to evaluate the long-term mercury removal capability, long-term mercury emissions variability, and operating and maintenance $(\mathrm{O} \& \mathrm{M})$ costs associated with sorbent injection on a configuration being considered for many new plants. Testing was conducted by ADA Environmental Solutions (ADA) at Rocky Mountain Power's (RMP) Hardin Station through funding provided by DOE/NETL, RMP, and other industry partners. The Hardin Station is a new plant rated at $121 \mathrm{MW}$ gross that was first brought online in April of 2006. Hardin fires a Powder River Basin (PRB) coal and is configured with selective catalytic reduction (SCR) for $\mathrm{NO}_{\mathrm{x}}$ control, a spray dryer absorber (SDA) for $\mathrm{SO}_{2}$ control, and a fabric filter (FF) for particulate control. Based upon previous testing at PRB sites with SCRs, very little additional mercury oxidation from the SCR was expected at Hardin. In addition, based upon results from DOE/NETL Phase II Round I testing at Holcomb Station and results from similarly configured sites, low native mercury removal was expected across the SDA and FF.

The main goal of this project was met—sorbent injection was used to economically and effectively achieve $90 \%$ mercury control as measured from the air heater $(\mathrm{AH})$ outlet to the stack for a period of ten months. This goal was achieved with DARCO ${ }^{\circledR} \mathrm{Hg}-\mathrm{LH}$, Calgon FLUEPAC $^{\mathbb{B}}$-MC PLUS and ADA Power PAC PREMIUM brominated activated carbons at nominal loadings of 1.5-2.5 lb/MMacf. An economic analysis determined the twenty-year levelized cost to be $0.87 \mathrm{mills} / \mathrm{kW}-\mathrm{hr}$, or $\$ 15,000 / \mathrm{lb} \mathrm{Hg}$ removed. No detrimental effects on other equipment or plant operations were observed. The results of this project also filled a data gap for plants firing PRB coal and configured with an SCR, SDA, and FF, as many new plants are being designed today.

Another goal of the project was to evaluate, on a short-term basis, the mercury removal associated with coal additives and coal blending with western bituminous coal. The additive test showed that, at this site, the coal additive known as KNX was affective at increasing mercury removal while decreasing sorbent usage. Coal blending was conducted with two different western bituminous coals, and West Elk coal increased native capture from nominally $10 \%$ to $50 \%$.

Two additional co-benefits were discovered at this site. First, it was found that native capture increased from nominally $10 \%$ at full load to $50 \%$ at low load. The effect is believed to be due to an increase in mercury oxidation across the SCR caused by a corresponding decrease in ammonia injection when the plant reduces load. Less ammonia means more active oxidation sites in the SCR for the mercury. The second co-benefit was the finding that high ammonia concentrations can have a negative impact on mercury removal by powdered activated carbon. For a period of time, the plant operated with a high excess of ammonia injection necessitated by the plugging of one-third of the SCR. Under these conditions and at high load, the mercury control system could not maintain $90 \%$ removal even at the maximum feed rate of $3.5 \mathrm{lb} / \mathrm{MMacf}$ (pounds of mercury per million actual cubic feet). The plant was able to demonstrate that mercury removal was directly related to the ammonia injection rate 
in a series of tests where the ammonia rate was decreased, causing a corresponding increase in mercury removal. Also, after the SCR was refurbished and ammonia injection levels returned to normal, the mercury removal performance also returned to normal.

Another goal of the project was to install a commercial-grade activated carbon injection (ACI) system and integrate it with new-generation continuous emissions monitors for mercury (Hg-CEMs) to allow automatic feedback control on outlet mercury emissions. This was accomplished and the plant can now be operated to control carbon injection based on either the overall mercury removal or an outlet mercury emission rate. By integrating these systems, it was determined that the plant could reduce powdered activated carbon consumption, especially at low load, because, at Hardin, native mercury capture increases from less than $20 \%$ to about $50 \%$ at low load and the carbon injection rate can be decreased accordingly. Currently, the plant is operating to automatically control emissions to below $0.9 \mathrm{lb} / \mathrm{TBtu}$ (pounds of mercury per million British thermal units) at carbon loadings of 0.5 to $1.5 \mathrm{lb} / \mathrm{MMacf}$. During the final phase of the Long-Term test, the ACI system was operated by plant personnel. The estimated O\&M cost for a single Hg-CEM system is $\$ 15,500 / y r$.

The Hg-CEMs performed well throughout the project. This project began shortly after Thermo Fisher first offered the Mercury Freedom System ${ }^{\mathrm{TM}}$ on a commercial basis and progressed though several iterations, improvements, and upgrades to the hardware and software. Indeed, there was a ten-fold increase in the precision and accuracy of the units during the course of the project due to several successful upgrades. In their present condition, the $\mathrm{Hg}$-CEMs measure mercury to a precision of about $\pm 0.05 \mu \mathrm{g} / \mathrm{wscm}$ (micrograms of mercury per wet standard cubic meter of gas), and only require occasional fine-tuning of the calibration coefficients. The quality assurance/quality control (QA/QC) protocol required to keep the units operating at their optimal performance was also developed and perfected during the course of the project. ADA Environmental Solutions (ADA) developed a daily calibration procedure that surpasses the requirements specified in the Clean Air Mercury Rule (CAMR), and a weekly diagnostic program that ensures that the systems are operating properly and receive the necessary maintenance. For the most part, the systems passed the daily, weekly, and quarterly QA/QC requirements as well as four performance verification tests using the Ontario Hydro $(\mathrm{O}-\mathrm{H})$ and Sorbent Trap Methods (STM) for the first test and the EPA Method 30A (M30A) procedure for the remaining three. However, some improvements are still necessary before the system can meet all of the requirements. These involve tests that challenge the system with oxidized mercury $(\mathrm{Hg}+2)$. These tests could not be passed at Hardin in spite of trying several improvements suggested by ADA or Thermo Fisher. 


\section{INTRODUCTION AND BACKGROUND}

Rocky Mountain Power, Inc. (RMP), a wholly owned subsidiary of Colorado Energy Management, brought a new plant on line in the spring of 2006 near Hardin, Montana. The plant, Hardin Generating Station, fires subbituminous Powder River Basin (PRB) coal and is configured with low- $\mathrm{NO}_{\mathrm{x}}$ burners and selective catalytic reduction (SCR) for $\mathrm{NO}_{\mathrm{x}}$ control, a spray dryer absorber (SDA) for $\mathrm{SO}_{2}$ control, and a fabric filter (FF) for particulate control. RMP is working with the Montana Environmental Information Center (MEIC), the Montana Department of Environmental Quality (M-DEQ), and other interested parties to assess the costs and effectiveness of activated carbon injection (ACI) to optimize mercury emissions reduction. They partnered with the Department of Energy National Energy Technology Lab (DOE/NETL) and ADA Environmental Solutions (ADA) to determine whether 90\% mercury control could be achieved for a 10 -month period and to provide valuable long-term performance data on mercury control.

There was a twofold purpose to the program. First, this Phase III program provided the opportunity to assemble expertise from DOE, technology development companies, and power generators to assist in the transition from shorter-term, proof-of-concept tests conducted in DOE's Phase I and II programs to long-term performance testing of the most advanced mercury control technology for this configuration. Second, this program permitted the expansion of RMP's original scope of work for technology evaluation to include the evaluation of additional, promising, new technologies that have had limited field testing. This program provided the opportunity to:

1. Perform a co-benefit analysis to define the range of native mercury removal achievable by natural operational variations of the SCR and SDA.

2. Assess the extent to which native mercury removal can be increased using coal additives or coal blending.

3. Evaluate the effectiveness of enhanced or bromine-treated carbon injection for mercury control.

4. Evaluate the viability of automatic feedback control using a new generation of continuous emission monitors for mercury (Hg-CEMs) and a commercial ACI system to maintain mercury emissions at a set level and optimize activated carbon usage.

5. Provide DOE/NETL and industry with long-term operating and maintenance requirements for an ACI system for ten months of continuous operation. During the final months of the Long-Term test, the ACI system was operated by plant personnel.

6. Provide valuable information to RMP, DOE, and industry on the operating and maintenance requirements for $\mathrm{Hg}$-CEMs using the QA/QC procedures outlined in the Clean Air Mercury Rule and compliance monitoring requirements included in 40 CFR Part 60.49a and Part 75.

7. Provide the necessary data for RMP, MEIC, and M-DEQ to make well-informed decisions on the level of mercury control economically possible with ACI.

On March 15, 2005, the U.S. Environmental Protection Agency (EPA) issued a final regulation to control mercury from coal-fired power plants known as the Clean Air Mercury 
Rule (CAMR). Although this regulation was vacated by the courts in 2008, it was the guiding document throughout this program and many of the performance requirements for mercury measurement are still followed by the industry in lieu of new a new regulation. Congress is currently working on a maximum achievable control technology (MACT) regulation for mercury. Any new regulation will affect the existing fleet of nearly 1,100 boilers. These plants are relatively old with an average age of more than 40 years. Although most of these units are capable of operating for many additional years, there is a desire to minimize large capital expenditures because of the reduced (and unknown) remaining life of the plant to amortize the project. Therefore, the industry needs environmental control technologies that:

- Take advantage of existing equipment and minimize the need for installing new major capital equipment

- Effectively meet regulations on units firing coal with a wide range of characteristics

- Will not require additional manpower or specialized technical expertise

- Can be installed and operated without jeopardizing the reliability of the generating facility

The injection of powdered activated carbon (PAC) into the flue gas represents one of the simplest and most extensively tested technologies for controlling mercury emissions from coal-fired boilers. NETL sponsored full-scale field tests conducted by ADA and others have proven the effectiveness of ACI for reducing mercury emissions on a variety of coals and unit configurations. These tests have also shown that mercury removal across the particulate collection devices can vary significantly depending on coal type and flue gas properties.

Evaluating the most advanced mercury control technology for the configuration at Hardin, SCR-SDA-FF, was important to the industry because it is favored by the industry for the majority of new plants firing PRB coal. Testing at Hardin provided an opportunity to evaluate $90 \%$ mercury control with enhanced technologies and the associated operating and maintenance (O\&M). Specifically, this program advanced the knowledge base in seven areas.

1. 90\% Mercury Control on a PRB-SCR-SDA-FF Configuration - This program provided the opportunity to evaluate several advanced mercury control technologies such as coal additives and treated PAC.

2. Effect of SCRs on Mercury Control - As more SCRs are put into service it is important to gather information on how mercury control is affected by an SCR. At the beginning of this project, no ACI tests had been conducted on a unit firing PRB and configured with an SCR, SDA, and FF.

3. Commercial-Grade Equipment - The ACI system and Hg-CEMs installed at Hardin were commercial-grade systems that were integrated to achieve continuous mercury control with minimal operator interface.

4. Long-Term Testing (10 months) - Long-term performance testing was the critical next step in the commercialization process for mercury control technologies. The Long-Term test period of this program lasted ten months and progressed through all seasons and through several major operational issues at the plant. 
5. Coal Blending - High mercury removal was achieved at Holcomb Station (PRB coal, SDA-FF) by blending West Elk western bituminous coal with PRB coal. Short-term blending tests with two western bituminous coals were conducted at Hardin.

6. Economic Analysis - This determined the costs of $90 \%$ mercury control for a site configured with PRB-SCR-SDA-FF.

7. Systems Integration - This project evaluated the integration of ACI systems with $\mathrm{Hg}$ CEMs to simplify operation and reduce PAC usage. Long-term data were obtained on the operability, maintainability, and reliability of ACI systems and compliance $\mathrm{Hg}$-CEMs. Plant personnel were trained in the operations and maintenance of the systems. 


\section{APPROACH}

Sorbent injection was used to effectively achieve and maintain mercury control at $90 \%$ as measured from the air heater $(\mathrm{AH})$ outlet to the stack for a period of ten months. A short-term evaluation included tests with coal additives, and coal blending with western bituminous coal. A commercial-grade ACI system was installed and integrated with Hg-CEMs to allow automatic feedback control based on mercury removal. The project test plan that includes a detailed description of the site and test equipment is reproduced in Appendix A. Figure 1 is a schematic of the Hardin Station showing the various sampling locations for ash, coal, slurry, and flue gas. The key parameters of Hardin are listed in Table 1.

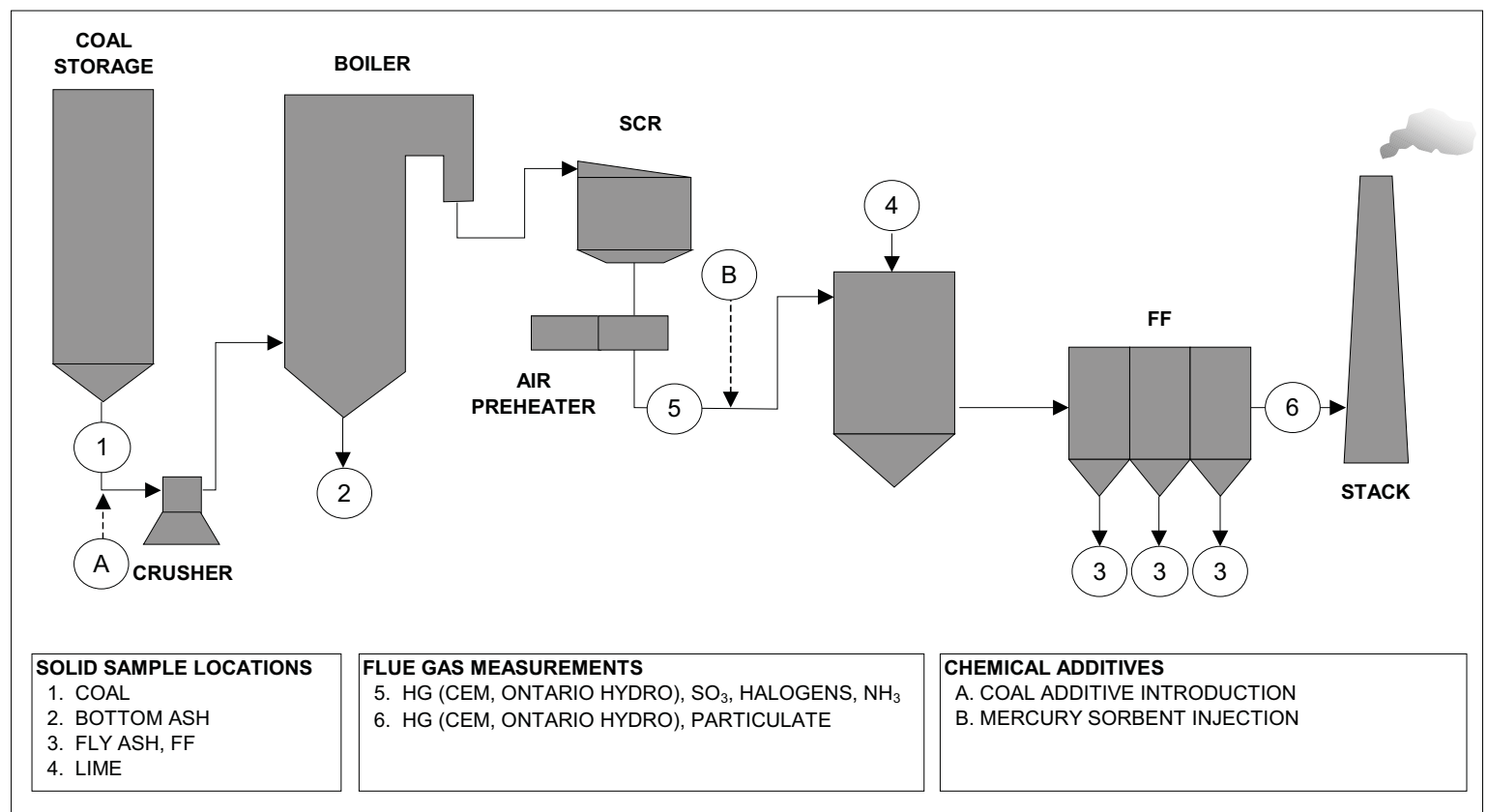

Figure 1. Schematic of the Hardin Station with Sample Locations.

Table 1. Key Parameters of the Hardin Station.

\begin{tabular}{|l|c|}
\hline Test Period & August 2006-November 2008 \\
\hline Unit & 1 \\
\hline Unit Size & PRB, Absaloka Mine \\
\hline Coal & Fabric Filter \\
\hline Particulate Control & 550,000 \\
\hline Gas Flow Rate, full load $(\mathrm{acfm})$ & Spray Dryer with Recycle \\
\hline Sulfur Dioxide $\left(\mathrm{SO}_{2}\right)$ Control & Low-NO ${ }_{x}$ Burners and SCR \\
\hline Nitrogen Oxides $\left(\mathrm{NO}_{\mathrm{x}}\right)$ Control & Disposal \\
\hline Ash Reuse & $121 \mathrm{MW}$ \\
\hline Test Portion of Unit & $2-12$ \\
\hline Typical Inlet Mercury Range $(\mu \mathrm{g} / \mathrm{wscm})$ & $<20 \%$ \\
\hline Typical Native Mercury Removal & \\
\hline
\end{tabular}


Table 2 is a project timeline to provide the reader with a better sense of the important events of a project that spanned nearly three years. Notably, three events are so important to the general understanding of the project that they are listed and discussed separately at this point.

1. Hg-CEM Nitrogen Generators (NG) - On September 5, 2007, nitrogen generators were installed on the Hg-CEMs as an upgrade offered by Thermo Fisher. The purpose of the NGs is to create an oxygen-free gas for use as a carrier gas for calibrations and as a sample dilution and carrier gas. This event is important because it significantly increased the reliability and precision of the Hg-CEM measurements. Up to this time, signal variation was on the order of $\pm 0.5 \mu \mathrm{g} / \mathrm{wscm}$. This made it difficult to perform accurate calibrations and to interpret results when the mercury concentration at the stack fell below $0.5 \mu \mathrm{g} / \mathrm{wscm}$, which was often the case during coal additive and parametric testing. The NGs reduced signal variation to nominally $\pm 0.05 \mu \mathrm{g} / \mathrm{wscm}$.

2. Step-Up Transformer Failure - The Long-Term test began on September 26, 2007. On December 15, 2007, the plant's step-up transformer failed. On February 5, 2008, this transformer was replaced with a temporary, smaller unit that limited operation to $106 \mathrm{MW}$ out of $121 \mathrm{MW}$. This is important because at low load the native mercury capture and, therefore, overall mercury capture increases at Hardin. This was discussed with the project team and it was decided to continue the Long-Term test in spite of the consequence to the interpretation of results. The original transformer was repaired and reinstalled on July 22, 2008.

3. SCR Deposition - On March 13, 2008, shortly after the Long-Term test resumed with the temporary transformer, a tube leak caused $>25 \%$ of the SCR to be plugged with ash. To compensate for the reduced available SCR surface area, the plant increased ammonia flow to maintain $\mathrm{NO}_{\mathrm{x}}$ emission levels. However, the ammonia flow meter was not functioning properly and this significant operational change went unnoticed by ADA until the original transformer was reinstalled on July 22, 2008. At this time, mercury capture performance decreased significantly and it was discovered that excess ammonia negatively affects capture at full load (121 MW). The SCR was refurbished and the unit returned to "normal" operation on October 26, 2008. The Long-Term test ended on November 17, 2008.

Taken in combination, these events reduced the time the unit was operating normally during the 12-month (total duration) Long-Term test to about two months. However, valuable information was gained about the effect of the SCR and excess ammonia on mercury capture. 
Table 2. Hardin Project Timeline.

\begin{tabular}{|c|c|}
\hline $1 Q 06$ & Project awarded \\
\hline $2 Q 06$ & $\begin{array}{l}\text { Site kickoff meeting at Hardin } \\
\text { Signed Cooperative Agreement with DOE/NETL } \\
\text { Signed Host Site Agreement }\end{array}$ \\
\hline $3 Q 06$ & $\begin{array}{l}\text { DOE kickoff at DOE NETL (July 2006) } \\
\text { Completed the Cost Share Agreement with RMP } \\
\text { Platform installed at the SDA inlet } \\
\text { Test Trailer installed } \\
\text { SDA Inlet and Stack Hg-CEM installed }\end{array}$ \\
\hline $4 Q 06$ & $\begin{array}{l}\text { Quality Assurance Project Plan completed } \\
\text { Sample and Data Management Plan completed } \\
\text { Site Safety Plan completed } \\
\text { Poster presented at the DOE/NETL conference in Pittsburgh (December 2006) } \\
\text { Baseline Source Test completed (December 2006) } \\
\text { Coal Blending Tests completed (December 2006) }\end{array}$ \\
\hline 1Q 07 & $\begin{array}{l}\text { KNX Licensing Agreement obtained to test KNX - B\&W declined test of their additive } \\
\text { Trained RMP personnel on } \mathrm{Hg} \text {-CEM ops } \\
\text { Gave tour to utility personnel interested in Thermo Hg-CEMs } \\
\text { First quarterly Hg-CEM linearity check failed - } \mathrm{Hg} \text {-CEMs repaired }\end{array}$ \\
\hline 2 Q 07 & $\begin{array}{l}\text { Baseline Ontario Hydro (O-H) and STM Tests repeated (April 2007) } \\
\text { Coal additive test with ALSTOM's KNX (April 2007) } \\
\text { Carbon silo, transport piping, and injection lance installed } \\
\text { Parametric Test with DARCO }{ }^{\circledR} \mathrm{Hg}-\mathrm{LH} \text {, Calgon FLUEPAC }{ }^{\text {TM }} \text {-MC PLUS, and PAC+KNX (May, June 2007) } \\
\text { Smaller screws installed on ACI system to facilitate lower feed rates }\end{array}$ \\
\hline $3 Q 07$ & $\begin{array}{l}\text { Optimization Tests with Calgon FLUEPAC }{ }^{\mathrm{TM}}-\mathrm{MC} \text { PLUS and NORIT DARCO }{ }^{\circledR} \mathrm{Hg}-\mathrm{LH} \text { (August 2007) } \\
\text { Baseline Stack Test for PM2.5, PM10, and Controlled Condensate }\left(\mathrm{SO}_{3}\right)(\text { September 2007) } \\
\text { 9/5/07: Nitrogen Generators installed on Hg-CEMs - performance significantly improved } \\
\text { 9/26/07: Began Long Term Test with DARCO } 8 \mathrm{Hg}-\mathrm{LH} \\
\text { Trained RMP operators on ACl system operation }\end{array}$ \\
\hline 4Q 07 & $\begin{array}{l}\text { Presentation given at the DOE/NETL Conference (December 2007) } \\
\text { 12/15/07: Step-up transformer failed causing } 2 \text {-mo outage } \\
\text { Upgraded ACI system logic for Hg-CEMs feedback control to automatically maintain } 90 \% \mathrm{Hg} \text { removal } \\
\text { Mercuric Chloride Generator installed on Stack Hg-CEM }\end{array}$ \\
\hline $1 Q 08$ & $\begin{array}{l}\text { Presented paper at the EUEC Conference (January 2008) } \\
\text { 2/5/08: Plant resumed operation at } 106 \mathrm{MW} \text { of } 121 \mathrm{MW} \\
\text { 2/25/08: Resumed Long Term Tests with Hg-LH } \\
\text { 3/13/08: Major tube leak plugged } 25+\% \text { of SCR } \\
\text { Periods of poor performance may have been due to a batch of PAC with low bromine levels }\end{array}$ \\
\hline $2 Q 08$ & $\begin{array}{l}\text { Trained plant personnel on } \mathrm{Hg}-\mathrm{CEM} \text { and } \mathrm{ACl} \text { system operations. } \\
\text { 4/21/08: First Method 30A RATA Test }\end{array}$ \\
\hline $3 Q 08$ & $\begin{array}{l}\text { Presented paper at the Mega Symposium (August 2008) } \\
\text { Trained additional plant personnel in Hg-CEM operations } \\
\text { 7/4/08-7/22/08: Outage to install refurbished step-up transformer. } \\
\text { Could not maintain } 90 \% \text { removal w/excess ammonia and } 121 \mathrm{MW} \text {. } \\
\text { 8/19/08: Long Term Test concluded with DARCO }{ }^{\circledR} \mathrm{Hg}-\mathrm{LH} \\
\text { DARCO }{ }^{\circledR} \mathrm{Hg}-\mathrm{LH} \text { was tested for } 167 \text { days during which } 208,731 \mathrm{lb} \text { was fed } \\
\text { 8/26/08: BeganCalgon FLUEPAC }{ }^{\mathrm{M}} \text {-MC PLUS for } 2-m o \text { test } \\
\text { Could not maintain } 90 \% \text { removal at } 2.75-3.0 \mathrm{lb} / \mathrm{MMacf} \text { w/excess ammonia and } 121 \mathrm{MW} \text {. } \\
\text { 9/22/08: Long Term source sampling test and second M30A RATA. } \\
\text { ACl system operation assumed by plant }\end{array}$ \\
\hline $4 Q 08$ & $\begin{array}{l}\text { 10/13/08: Final M30A RATA Test. Dynamic Spike Test. } \\
\text { 10/19/08-10/26/08: Outage to refurbish SCR. } \\
\text { 10/29/08: Resume test w/Calgon MC PLUS } \\
\text { 11/17/08: Long Term Test completed } \\
\text { Calgon FLUEPAC }{ }^{\text {TM }-M C ~ P L U S ~ w a s ~ t e s t e d ~ f o r ~} 60 \text { days during which } 110,431 \mathrm{lb} \text { was fed } \\
\text { Began Test with ADA Power PAC Premium (not part of DOE Project) }\end{array}$ \\
\hline $1 Q 09$ & $\begin{array}{l}\text { Presented paper at the EUEC Conference (February 2009) } \\
1 / 14 / 08-\ldots . . . \text { Running in auto with emissions control. Emissions under } 0.9 \mathrm{lb} / \mathrm{TBtu} \text { at } 1.0-3.0 \mathrm{lb} / \mathrm{MMacf} \\
\text { Final Report issued }\end{array}$ \\
\hline
\end{tabular}




\subsection{Objectives}

The purpose of this test program was to evaluate the long-term mercury removal capability, long-term mercury emissions variability, and O\&M costs associated with sorbent injection on a plant configuration being considered for many new plants. Hardin fires a PRB coal and is configured with an SCR and low- $\mathrm{NO}_{\mathrm{x}}$ burners for $\mathrm{NO}_{\mathrm{x}}$ control, an $\mathrm{SDA}$ for $\mathrm{SO}_{2}$ control, and an FF for particulate control. Based upon previous tests at other PRB sites with SCRs, very little additional mercury oxidation was expected at Hardin. The primary objectives of this project were:

- Demonstrate that $90 \%$ mercury removal was sustainable with ACI.

- Integrate a commercial Hg-CEM with an ACI system to simplify operation and reduce carbon usage.

- Train plant personnel to operate the Hg-CEMs and ACI equipment.

Secondary objectives included:

- The evaluation of co-benefits (e.g., effect of the SCR).

- The evaluation of coal additives to enhance mercury removal.

- The evaluation of coal blending with western bituminous coal.

- The determination of the cost reduction potential of using automatic feedback control from the Hg-CEMs to control ACI rate and maintain a fixed mercury emission rate independent of plant operations and coal variations.

- The evaluation of the impact of enhanced carbons on ash disposal.

- Providing data to support RMP and M-DEQ in a BACT analysis of technology implementation.

\subsection{Scope}

To achieve the objectives stated above, ADA installed a mercury sorbent injection system and two Hg-CEM systems at the Hardin Generating Station. This equipment, described in Appendix A, provided the means to evaluate a series of co-benefit enhancements and to conduct baseline and parametric tests to assess the potential for reducing mercury emissions by $90 \%$. The co-benefits analysis characterized the range of mercury removal achievable by studying the affects of the SCR, SDA, and FF under normal variations in operation. The effectiveness of coal additives to enhance mercury oxidation across the SCR and subsequent removal in the SDA-FF was also studied. During parametric testing, the effectiveness of sorbent injection for mercury control was evaluated with and without enhanced co-benefit mercury removal. Since sorbent injection demonstrated that $90 \%$ mercury control was feasible, DOE/NETL approved a 10-month, long-term test to establish steady-state operation and assess potential maintenance and operational problems. 


\subsection{Tasks}

The program was accomplished by following a series of technical tasks.

Task 1. Site Coordination, Kickoff Meetings, Develop Test Plan and QA/QC Plan

Task 2. Design, Procure, and Install Equipment

Task 3. Field Testing

Task 3.1. Hg-CEM and Silo Operations

Task 3.2. Baseline Tests

Task 3.3. Co-Benefits Analysis

Task 3.3.1. Effect of Low Load on Hg Removal

Task 3.3.2. Coal Blending Test

Task 3.3.3. Coal Additive Test

Task 3.3.4. Effect of Ammonia on Hg Removal

Task 3.4. Parametric Tests

Task 3.5. Optimization Test

Task 3.6. Long-Term Test

Task 4. Coal, Ash, and By-Product Sample Evaluation

Task 5. Technology Transfer

Task 6. Management and Reporting/Economic Analysis

\subsubsection{Test Coordination, $\mathrm{QA} / \mathrm{QC}$, and Test Plan Development}

Efforts within this task included test planning with input from the host site, DOE/NETL, and other contributing team members. The planning process included meeting with plant, corporate, and environmental personnel to agree upon an overall scope of the program, the potential impact on plant equipment and operation, and to gather preliminary information necessary to develop a detailed test plan and scope of work. Efforts included developing a QA/QC plan, identifying potential mercury sorbents and coal additives, finalizing the scope for each of the team members, and putting subcontracts in place for manual measurement services. The list of accomplishments within this task is below.

- Signed Cooperative Agreement and Host Site Agreement (April 27, 2006)

- Kickoff meeting held at the Hardin Generating Station (June 26, 2006)

- Developed Site Sampling Plan and Installation Plan (June 26, 2006)

- Contract for Services Agreement with RMP

- DOE Kickoff meeting at DOE/NETL (July 18, 2006)

- Reaction Engineering completed a preliminary Modeling Study to determine potential mercury oxidation and removal at baseline conditions across the SCR, SDA, and FF, and the effects of coal additives and coal blending on mercury oxidation.

- Completed the Quality Assurance Project Plan including Hg-CEM operating procedures to follow CAMR requirements. 
- Completed a Sample and Data Management Plan.

- Arranged to test two western bituminous coals during the coal blending tests.

- Obtained a Licensing Agreement to test KNX. B\&W declined to participate in a test of their coal additive.

\subsubsection{Equipment Installation}

There were two main components to Task 2; the design, procurement, and installation of an ACI system as well as the procurement and installation of two Thermo Fisher Hg-CEMs. Figure 2 and Figure 3Error! Reference source not found. show the ACI system, and HgCEMs installed at Hardin. Upon completion of the project, the ACI system and stack HgCEM will remain at the site and be operated by the plant as a compliance mercury removal system.

The ACI system included a refurbished carbon storage and feed system, piping to transport the carbon to the injection location, and an injection lance. The piping was standard carbon steel pipe but the elbows used were long-radius, and ceramic lined. The single injection lance consisted of an open-ended, stainless steel pipe with the discharge located in the center of the duct after the AH and before the SDA. A new platform was also installed at the injection location to facilitate lance and $\mathrm{Hg}$-CEM maintenance and manual flue gas measurements.

The Hg-CEMs were commercial Thermo Fisher Mercury Freedom Systems ${ }^{\mathrm{TM}}$. However, since this project began shortly after these systems became commercially available, several upgrades were made during the course of the project. These upgrades increased the reliability and accuracy of the $\mathrm{Hg}-\mathrm{CEMs}$ and will be described more completely below.

An important component of Task 2 was to integrate the ACI and Hg-CEM systems to produce a system capable of automatically controlling mercury emissions to a specified set point. This was accomplished in the fall of 2007 and, afterwards, the integrated system was able to automatically achieve and maintain $90 \%$ mercury removal during normal operating conditions. Carbon injection concentrations ranging from of 1.5 to $3.5 \mathrm{lb} / \mathrm{MMacf}$ were used to maintain mercury removal between $89-91 \%$ during periods of constant full load. 

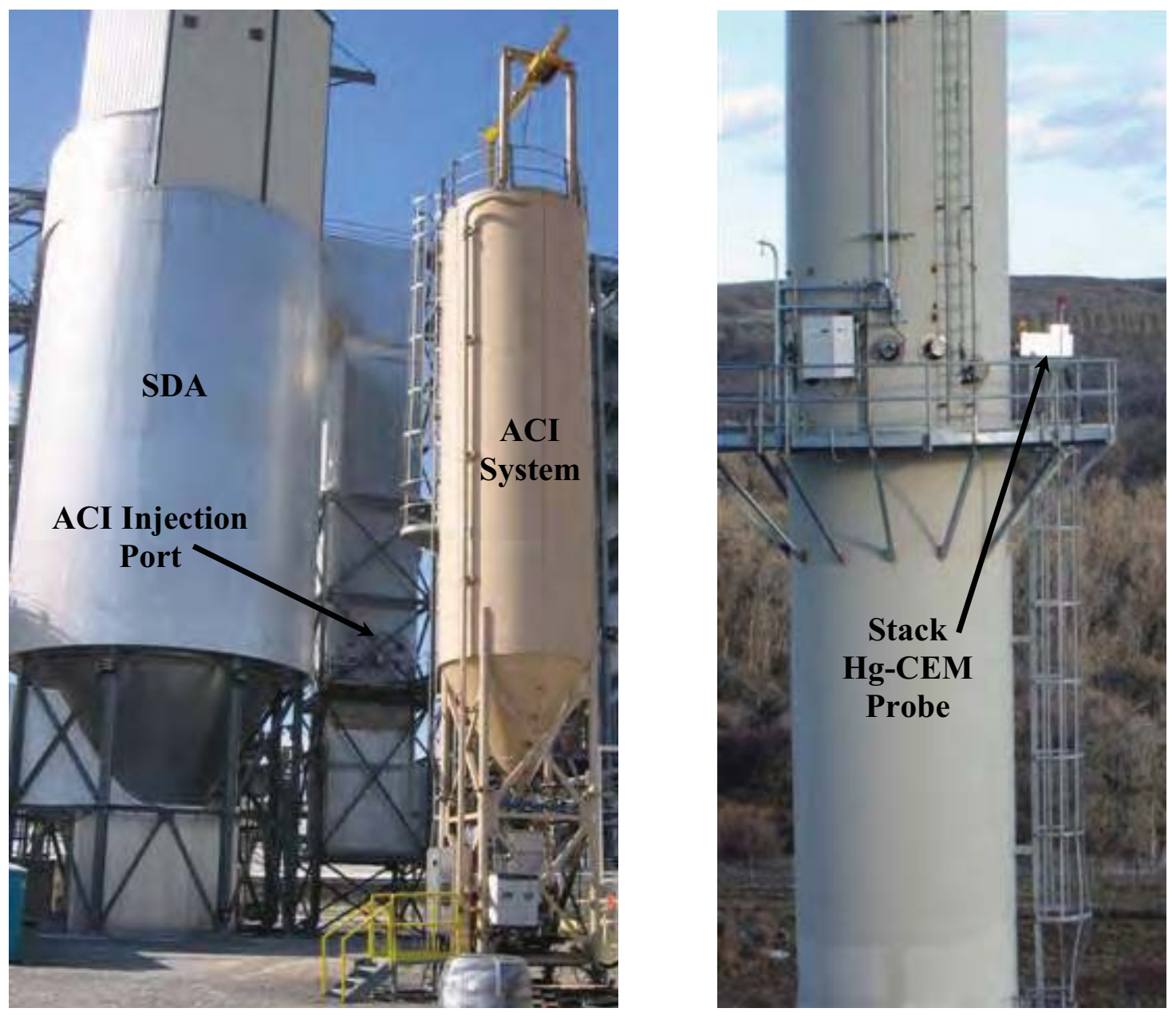

Figure 2. The ACI System and Stack Hg-CEM Probe Installed at Hardin. 

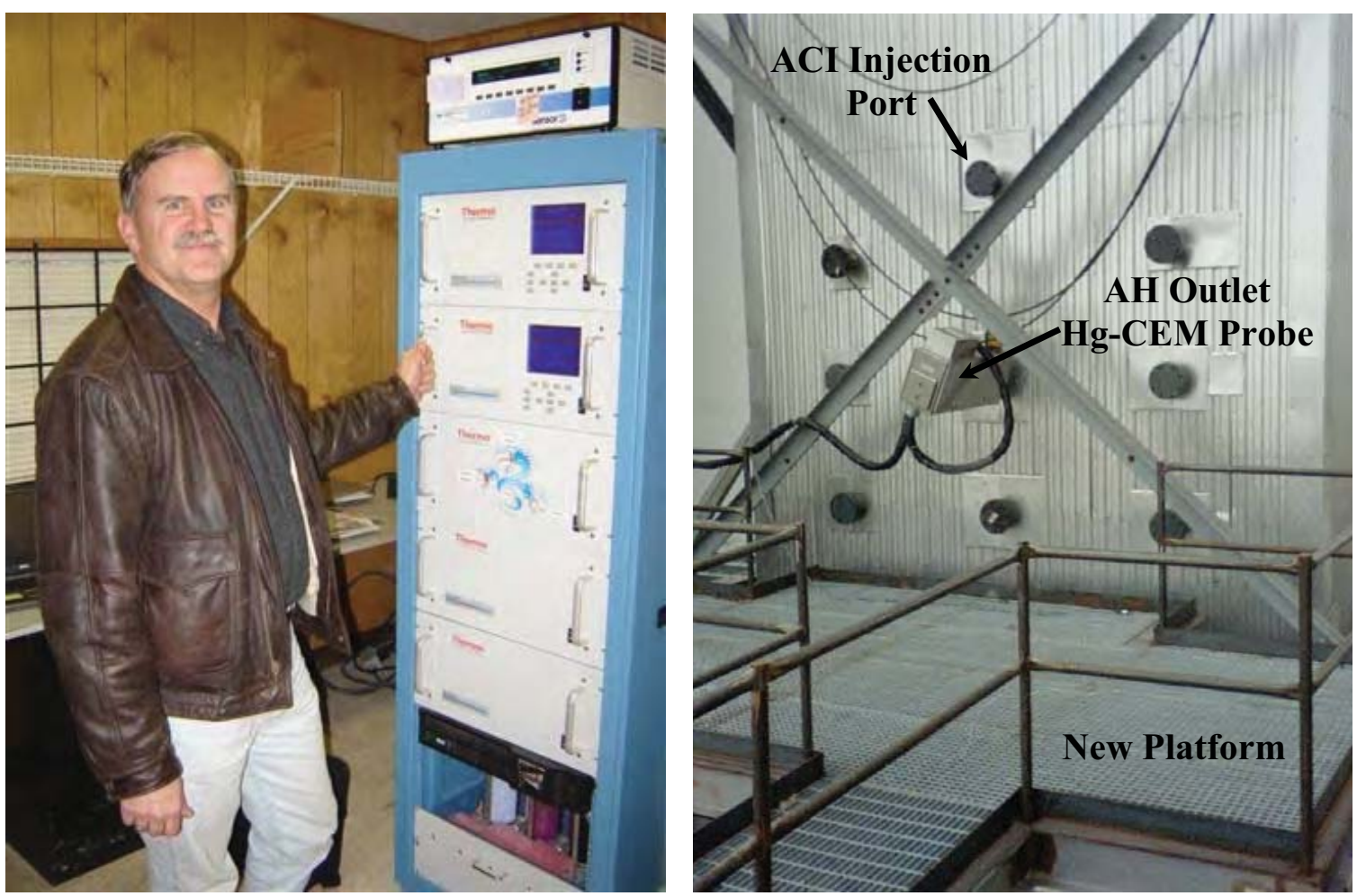

Figure 3. The Hg-CEM, Probe, Sample Ports and New Platform Installed at the AH Outlet/SDA Inlet Location.

\subsubsection{Technology Transfer}

Transferring the information and observation from the research completed under this project to coal-fired utility customers was an important part of the program. Presentations were given at selected conferences to increase exposure of the test results and receive comments on the applicability of mercury removal with ACI from industry. The ultimate goal of technology transfer was to make results available to the public as quickly, comprehensively and accurately as possible.

- Connie Senior of Reaction Engineering presented a paper at the Electric Power Conference held in May 2007 concerning a model to predict the speciation and removal at Hardin and associated actual emissions measurements.

- ADA presented a poster at the DOE/NETL Mercury Control Technology Meeting in December 2006.

- At the request of RMP, ADA gave a tour to utility personnel interested in Thermo HgCEMs.

- ADA met with the new president of Colorado Energy Management to present an overview of the Hardin project.

- ADA presented a paper at the DOE/NETL conference in December 2007.

- ADA presented a paper at the EUEC Conference in January 2008.

- ADA presented a paper at the Mega Symposium in August 2008.

- ADA presented a paper at the EUEC Conference in February 2009. 


\section{RESULTS AND DISCUSSION}

\subsection{Field Testing}

Field testing was conducted from September 2006 to November 2008, and included baseline measurements, co-benefits analysis with coal additives and coal blending, parametric tests with different carbons, and Long-Term testing. Mercury removal performance and balanceof-plant impacts were quantified by analyzing plant operating data, Hg-CEM measurements, collection, and analysis of solid samples (i.e., coal and ash), and through independent flue gas measurements. Operating parameters included flow rates, temperatures, pressures, and the emission values of all measured gases. The following sections discuss the results of all testing.

Please note that the units used flue gas mercury concentration throughout this report are micrograms of mercury per wet standard $\left(1 \mathrm{~atm}, 68^{\circ} \mathrm{F}\right)$ cubic meter of flue gas $(\mu \mathrm{g} / \mathrm{wscm})$ at the oxygen concentration of the raw flue gas. This was necessary because there were no oxygen or carbon dioxide monitors at the inlet location to allow conversion to $\mathrm{lb} / \mathrm{MBtu}$. Also, most of the graphs in the following sections show mercury values for both the inlet and outlet locations and it would have been awkward to present them in different units.

However, unit conversion calculations at the stack indicate that the difference between $\mu \mathrm{g} / \mathrm{wscm}$ and $\mathrm{lb} / \mathrm{TBtu}$ at this site is less than 0.1 . Therefore, given the uncertainty in such measurements and the variability in coal composition and plant operations, the units can be considered to be interchangeable for the Hg-CEM mercury measurements at the stack. Examples of the standard calculations used in this section are included in Appendix B.

\subsubsection{Silo and Hg-CEM Operation}

Since the story of this project is closely connected with the story of the Hg-CEM and ACI systems, a separate section is included that discusses the successes, improvements, and maintenance issues that were gradually developed over the course of this project. The QA/QC protocol developed by ADA for the $\mathrm{Hg}$-CEMs is included in Appendix C.

\subsubsection{Hg-CEM Quarterly Linearity Checks}

Linearity checks were performed to access the response of the system with the low-, mid-, and high-level reference gas injected ahead of the inertial filter in non-repetitive, triplicate runs. Part 75 states that the CEM is required to meet a performance specification of $10.0 \%$ of reference or a difference of $\pm 1.0 \mu \mathrm{g} / \mathrm{m}^{3}$, whichever is less restrictive. Linearity checks are required each quarter and at least 30 days apart and must be completed within 24 unit operating hours. Linearity checks were performed manually by changing the span concentration of the calibrator.

Table 3 shows the results of all linearity checks performed during the project. The first linearity check performed at Hardin was in January 2007. This linearity check failed, but an investigation found problems with the configuration of the CEMs and performance of the calibrators; these problems were corrected and a subsequent linearity test passed. Some linearity checks were not performed in a quarter-year because there was uncertainty regarding specific federal QA/QC requirements (2007) and/or because of plant outages that 
disrupted the test schedule (2008). The stack CEM failed a few linearity checks in the ten quarters spanned by the project. These can be attributed to the use equipment that was later upgraded (June 2007), the use of incorrect calibration concentrations (the test was initiated with incorrect settings in the calibrator and could not be stopped as per the rule), and calibrator maintenance activities (early in the project, the calibrators were found to be nonlinear due to degradation of the mercury reservoir in the calibrator that was later corrected by use of nitrogen as the calibration carrier gas). 
Table 3. Linearity Check Results.

\begin{tabular}{|l|l|l|l|}
\hline \multicolumn{4}{|c}{ HARDIN Hg-CEM LINEARITY CHECK - SDA INLET } \\
\hline Quarter & Data & High Error & Result \\
\hline 1 Q07 & $03 / 17 / 07$ & $1.6 / 9.1 \%$ & PASS \\
\hline 2 Q07 & N/A & N/A & N/A \\
\hline $3 Q 07$ & $09 / 19 / 07$ & $0.50 / 4.1 \%$ & PASS \\
\hline $4 Q 07$ & N/A & N/A & N/A \\
\hline 1 Q08 & N/A & N/A & PASS \\
\hline 2 Q08 & $04 / 04 / 08$ & $0.31 / 3.8 \%$ & PASS \\
\hline & $04 / 28 / 08$ & $0.31 / 4.0 \%$ & PASS \\
\hline $3 Q 08$ & $07 / 25 / 08$ & $0.45 / 7.2 \%$ & PASS \\
\hline $4 Q 08$ & $09 / 17 / 08$ & $0.39 / 4.7 \%$ & PASS \\
\hline
\end{tabular}

\begin{tabular}{|l|l|l|l|}
\hline \multicolumn{5}{|c|}{ HARDIN Hg-CEM LINEARITY CHECK - STACK } \\
\hline Quarter & Data & High Error & Result \\
\hline 1Q07 & $03 / 17 / 07$ & $4.48 / 47.0 \%$ & FAIL * \\
\hline & $03 / 25 / 07$ & $0.25 / 2.0 \%$ & PASS \\
\hline 2 Q07 & N/A & N/A & N/A \\
\hline 3Q07 & $07 / 20 / 07$ & $1.48 / 24.0 \%$ & FAIL * \\
\hline & $09 / 19 / 07$ & $1.71 / 9.3 \%$ & PASS \\
\hline 4Q07 & N/A & N/A & N/A \\
\hline 1Q08 & N/A & N/A & FAIL $*$ \\
\hline 2Q08 & $04 / 04 / 08$ & $4.81 / 35.4 \%$ & PASS \\
\hline & $04 / 28 / 08$ & $0.32 / 10.7 \%$ & PASS \\
\hline 3Q08 & $07 / 25 / 08$ & $0.77 / 8.5 \%$ & PASS \\
\hline 3Q08 & $09 / 18 / 08$ & $0.38 / 8.7 \%$ & PASS \\
\hline 4Q08 & $11 / 18 / 08$ & $0.40 / 5.0 \%$ & \\
\hline
\end{tabular}

* Failed tests that were repeated after corrections were made. 


\subsubsection{Hg-CEM RATA Results (M30A)}

ADA conducted three sets of Relative Accuracy Test Audit (RATA) tests on the Hg-CEMs using regulations outlined in 40 CFR Part 75.20. Method 30A was the instrumental reference method (IRM) employed to conduct the RATA on the stack Hg-CEM, and a modified Method 30A was used for the RATA on the AH outlet Hg-CEM. A full accounting of each RATA is presented in Appendix D.

The first RATA was conducted during the week of April 21, 2008. The stack Hg-CEMs passed the RATA and all performance tests conducted during this evaluation except the 3Level System Integrity Check and the Bias Test. The AH outlet CEMs passed the RATA and all applicable performance tests except the Bias Test. The IRM analyzer passed all of the system checks except the Dynamic Spiking Test. A summary of these results is presented in Table 4. It should be noted that the results in Tables 4, 5, and 6 refer to both the IRM CEM (indented in the table) and the Hg-CEMs installed at Hardin (not indented).

Table 4. Results of the First M30A RATA.

\begin{tabular}{|l|c|c|}
\hline \multicolumn{1}{|c|}{ Test } & $\begin{array}{c}\text { Stack Hg-CEMs } \\
\text { (downstream of ACI) }\end{array}$ & $\begin{array}{c}\text { Air Heater Outlet Hg-CEMs } \\
\text { (upstream of ACI) }\end{array}$ \\
\hline Linearity Check & PASS & PASS \\
\hline 7-Day Calibration Error Test & PASS & PASS \\
\hline Cycle Time Test & PASS & PASS \\
\hline 3-Level System Integrity Check & FAIL & N/A \\
\hline Relative Accuracy Test Audit & PASS & PASS \\
\hline IRM System Performance Tests & & - \\
\hline Interference Check (Optional) & - & - \\
\hline 3-Point System Calibration Error Test & PASS & - \\
\hline System Integrity Check & PASS & - \\
\hline Measurement System Response & PASS & FAIL \\
\hline Dynamic Spiking Test & FAIL & FAIL \\
\hline Bias Test & & \\
\hline
\end{tabular}

Note: The 3-Level System Integrity Check is not applicable to the AH outlet CEM because there is no mercuric chloride generator on this unit.

The failure of the 3-Level System Integrity Check on the stack Hg-CEM was attributed to improper insulation of the mercuric chloride generator. This unit was upgraded and tested before the second RATA but continued to fail the integrity check. The failure of the Bias Tests was attributed to a flaw in the design of the heating ventilation and air conditioning system on the IRM that made it difficult to maintain constant temperature within the housing. This flaw was repaired and the Bias Test was repeated during the next RATA test. No Bias Adjustment Factor was implemented at this time. 
A Linearity Check performed on the Stack Hg-CEM prior to first M30A test failed due to calibrator non-linearity. As a result, the IRM calibrator was used to calibrate the stack HgCEM for the test period, and was later installed into the stack system after the RATA so the non-linear unit could be serviced.

The Dynamic Spiking Test failure was attributed to difficulties in maintaining vapor-phase oxidized mercury in the sample gas stream. Recovery of the oxidized mercury proved unsuccessful as evident in failure of both mean percentage recovery and absolute difference criteria. This test was further evaluated during the final RATA.

The second M30A RATA test was conducted during the week of September 24, 2008. Method 30A requires an Initial Measurement System Performance Test described in Section 8.2 [Method 30A] in order to ascertain proper function of the IRM analyzer. A summary of these tests (indented) and the RATA tests are presented in Table 5.

The Dynamic Spiking Test was not performed because it was not required until January 1, 2009. Also, the Dynamic Spiking Test failed during the previous test of April 20, 2008. Its merit will be reevaluated, with direction from the EPA, at a later date.

Both the stack and the AH outlet Hg-CEMs successfully met performance criteria for RATA testing. Bias was evaluated as out of specification; however, adjustment factors were not implemented because the bias was likely in the IRM unit. The Hg-CEMs installed at Hardin were subject to the scrutiny of a well-developed QA/QC program, described in Appendix C, which included daily calibration checks, and, as such, implementation of any correction from this Bias Test was deemed unnecessary.

Table 5. Results of the Second M30A RATA.

\begin{tabular}{|l|c|c|}
\hline \multicolumn{1}{|c|}{ Test } & $\begin{array}{c}\text { Stack Hg-CEMs } \\
\text { (downstream of ACI) }\end{array}$ & $\begin{array}{c}\text { Air Heater Outlet Hg-CEMs } \\
\text { (upstream of ACI) }\end{array}$ \\
\hline Relative Accuracy Test Audit (RATA) & PASS & PASS \\
\hline Interference Check (Optional) & - & - \\
\hline 3-Point System Calibration Error Test & PASS & PASS \\
\hline System Integrity Check & PASS & PASS \\
\hline Measurement System Response & PASS & PASS \\
\hline Dynamic Spiking Test & Not Performed & Not Performed \\
\hline
\end{tabular}

Note: The System Integrity Check on the CEM installed at the AH outlet was performed with elemental mercury in lieu of oxidized because there is no mercuric chloride generator on this unit.

The Final M30A RATA Test was conducted on the Hg-CEMs during the week of October 15, 2008. Challenges with successful completion of oxidized calibrations during System Integrity Tests on the IRM analyzer necessitated substituting elemental mercury standards. Again, since the Dynamic Spiking Test was not required until January 1, 2009, it was not performed as part of this RATA. A summary of the tests performed is presented in Table 6. 
Both the stack and the AH outlet Hg-CEMs successfully met performance criteria for RATA testing. Bias was evaluated as out of specification for the AH outlet CEM; however, bias adjustment factors were not implemented as stated before.

Table 6. Results of the Third M30A RATA.

\begin{tabular}{|c|c|c|}
\hline \multicolumn{1}{|c|}{ Test } & $\begin{array}{c}\text { Stack Hg-CEMs } \\
\text { (downstream of ACI) }\end{array}$ & $\begin{array}{c}\text { Air Heater Outlet Hg-CEMs } \\
\text { (upstream of ACI) }\end{array}$ \\
\hline Relative Accuracy Test Audit (RATA) & PASS & PASS \\
\hline Interference Check (Optional) & - & - \\
\hline 3-Point System Calibration Error Test & PASS & PASS \\
\hline System Integrity Check & PASS & PASS \\
\hline Measurement System Response & PASS & PASS \\
\hline Dynamic Spiking Test & Not Performed & Not Performed \\
\hline
\end{tabular}

Note: The System Integrity Check on the CEMS installed at the AH outlet was performed with elemental mercury in lieu of oxidized because there is no mercuric chloride generator on this unit.

\subsubsection{Hg-CEM Maintenance/Advancements}

During the course of this project, several advancements were made to the Hg-CEM hardware and software that significantly improved their performance. Several issues also arose that required troubleshooting and/or on-site or factory maintenance. The following timeline discusses some of the more important issues and improvements.

$1 \mathrm{Q} 07$

The first set of quarterly linearity checks performed on the Hg-CEMs failed. Upon further investigation and fine-tuning, the inlet system was repaired, but the calibrator on the stack CEM continued to be non-linear. A new calibrator was installed and was found to be linear at all ranges.

ADA was on site February 27-28, 2007, to investigate the cause of periodic spikes in the $\mathrm{HgT}$ value on the stack CEM. It was found that a unique combination of two, periodic, small leaks in the probe allowed undiluted flue gas into the system.

$\underline{2 Q 07}$

In June 2007, a test was conducted using nitrogen, instead of air, for a calibration carrier gas and as the dilution gas on the stack $\mathrm{Hg}$-CEM. This greatly improved measurement precision and calibration performance as compared to the AH outlet CEM. Figure 4 shows the mercury concentrations measured by the two Hg-CEMs. The two traces in the upper portion of the graph represent the $\mathrm{AH}$ outlet $\mathrm{Hg}$-CEM values of $\mathrm{HgT}$ and $\mathrm{Hg} 0$. The traces fall on top of each other and are indistinguishable indicting that all mercury was in the elemental form. These concentrations were measured using air as the carrier and dilution gas and have a typical "noise" range of about $\pm 0.5 \mu \mathrm{g} / \mathrm{wscm}$. The two traces below the inlet traces represent the stack $\mathrm{Hg}-\mathrm{CEM}$ values of $\mathrm{HgT}$ and $\mathrm{Hg} 0$. Again, these traces fall on top of each other and are indistinguishable. These stack measurements were recorded using nitrogen as the carrier and dilution gas and show that the "noise" range was reduced to approximately $\pm 0.1 \mu \mathrm{g} / \mathrm{wscm}$. A permanent nitrogen generation system was ordered for both units. 
The dilution orifices in the sample probes were replaced to lower the dilution ratio from 60 to 40. This further decreased the noise at the low mercury concentrations $(<0.5 \mu \mathrm{g} / \mathrm{wscm})$ measured during carbon injection.
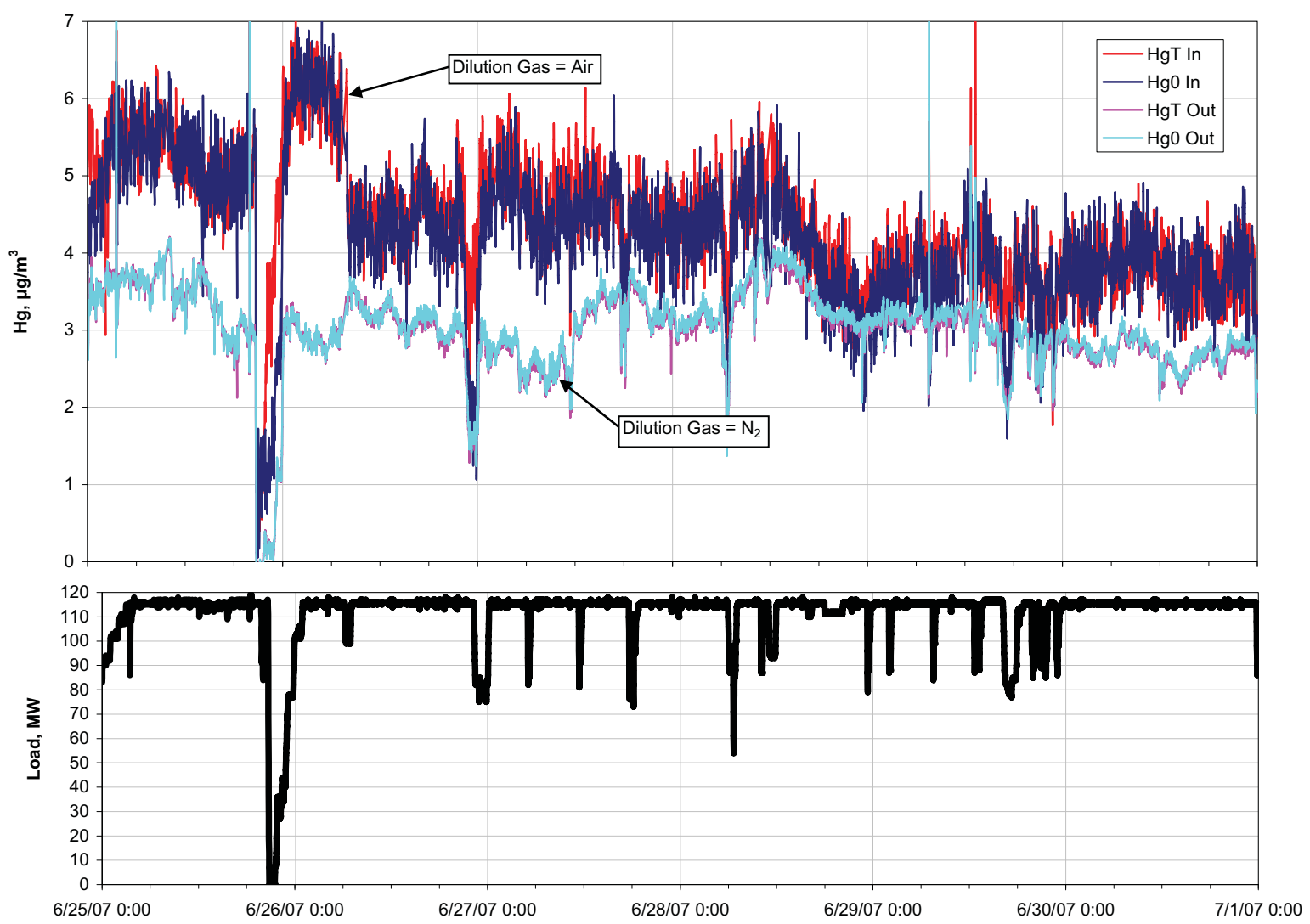

Figure 4. Effect of $\mathrm{N}_{2}$ as a Dilution Gas on Hg-CEM Noise.

3Q07

The inlet and stack Hg-CEMs were fully upgraded with all of the latest innovations from Thermo Fisher, including:

- A nitrogen generator, shown in Figure 5, to supply the dilution and calibration gas.

- A lamp heater to maintain consistent mercury vapor bulb temperature. It was found that small changes in ambient temperature could affect mercury measurements. The lamp heater significantly reduced this effect.

- A humidifier to add moisture to the calibration gas to maintain a consistent humidity level across the inertial filter. In previous testing at other sites, it was found that performance could be affected when calibrating with a dry gas and then measuring a moist gas. This innovation maintained a consistent humidity from calibration to sampling.

- A new motherboard in the probe controller with a noise dampening circuit for the probe TCs and the programming required to operate a mercuric chloride generator (MCG). 


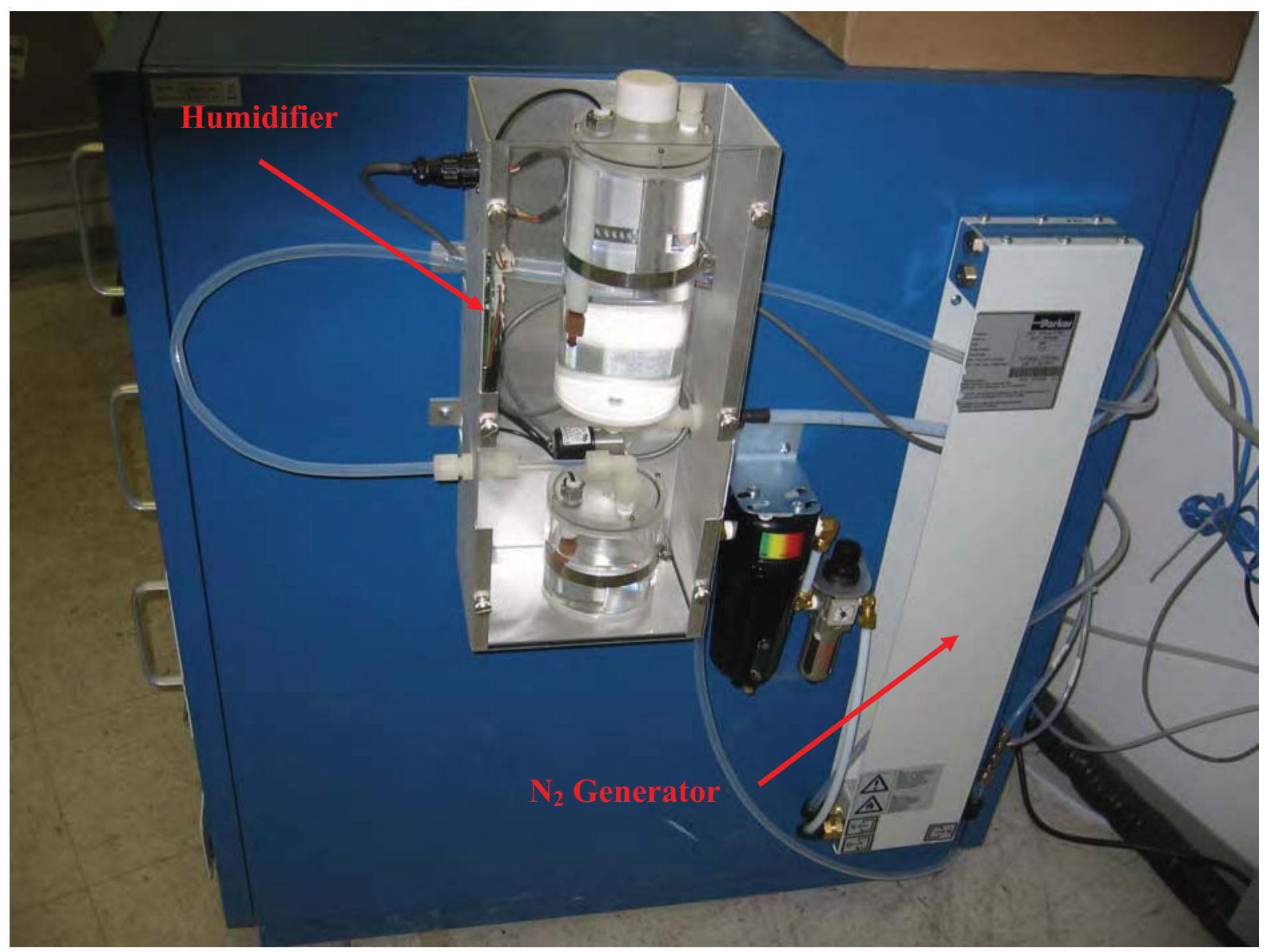

Figure 5. Humidifier and Nitrogen Generator Upgrades on the Stack Hg-CEM.

4Q07

The stack Hg-CEM was upgraded with the addition of a mercuric chloride generator so that the performance of the converter could be verified as required by the CAMR. The MCG was installed in December, but problems with the stack CEM and an unexpected outage prevented shakedown and testing of this system until April 2008. A photo of the MCG is included as Figure 6. 


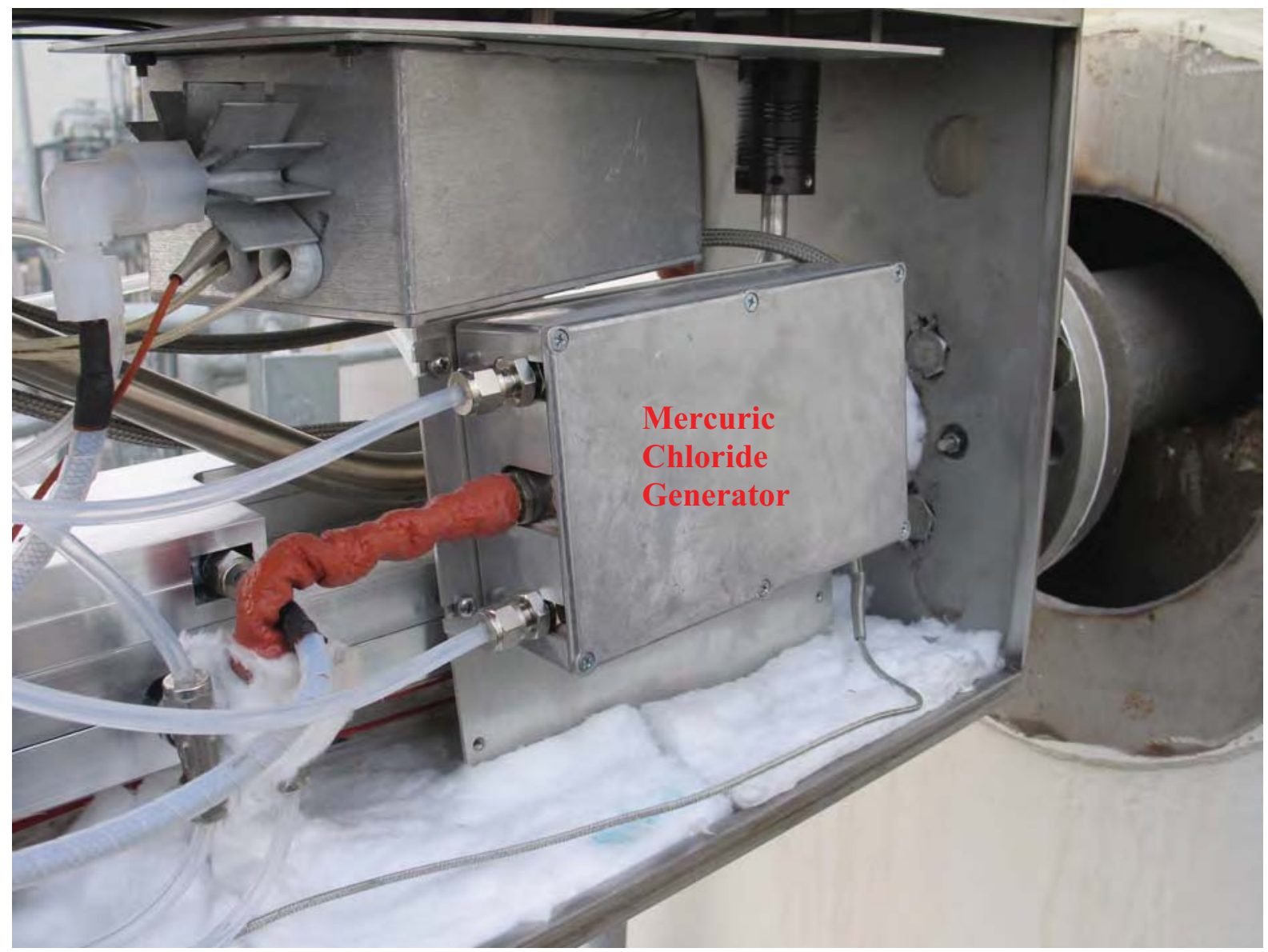

Figure 6. Photo of the Mercuric Chloride Generator in the Stack Probe at Hardin.

$\underline{\text { QQ08 }}$

Repairs and maintenance included:

- A new power distribution board for the probe controller in the inlet CEM that failed because of a short in the probe that was caused when a heater wire in the probe fused to, and shorted out on, a heating rod that had vibrated out of the heating block.

- A new thermostat in the inlet probe.

- Replacement of the inlet probe converter core.

- Replacement of the I/O board in the stack CEM that failed during an electrical overload.

- Replacement of the stack probe converter core.

$\underline{2 \mathrm{Q} 08}$

The MCG was tested and found to achieve only $82 \%$ recovery even though it showed $100 \%$ conversion of the oxidized mercury back to elemental mercury. This problem was investigated over several months with help from Thermo Fisher and, although improvements were made, $90 \%$ conversion was never achieved with the MCG. 


\subsubsection{ACI System Performance}

The activated carbon injection system performed well throughout the project. Some routine maintenance was required as exemplified by issues such as a failed speed sensor, a blower motor that locked up, and debris that caused a false reading on a level sensor. Overall, the injection system performed as expected.

At the conclusion of the Long-Term test, the total actual operating time and amount of carbon fed were:

$\underline{\text { DARCO }}{ }^{\circledR} \mathrm{Hg}-\mathrm{LH}$

a) Operating Time

b) Carbon Fed

c) Average Feed Rate

Calgon FLUEPAC ${ }^{\circledR}$-MC PLUS
a) Operating Time
60 days
b) Carbon Fed
$110,431 \mathrm{lb}$
c) Average Feed Rate
$77 \mathrm{lb} / \mathrm{hr}$

167 days

$208,731 \mathrm{lb}$

$52 \mathrm{lb} / \mathrm{hr}$

One of the goals of the project was to investigate the potential savings of using feedback control from the Hg-CEMs to control the carbon loading. In the fall of 2007, the feeder control system was integrated with feedback from the $\mathrm{Hg}$-CEMs to automatically maintain mercury removal at $90 \%$. Prior to this, the carbon feed rate was maintained at a constant value and only updated a few times a week. Figure 7 and Figure 8 show the performance of the mercury control system with and without feedback control, respectively. The top graph in each figure shows the data from the $\mathrm{Hg}$-CEMs including the total gaseous mercury $(\mathrm{HgT})$ and elemental gaseous mercury $(\mathrm{Hg} 0)$ in micrograms per wet standard $\left(\right.$ at $\left.68^{\circ} \mathrm{F}\right)$ cubic meters $(\mu \mathrm{g} / \mathrm{wscm})$ measured at the $\mathrm{AH}$ outlet and stack. The difference in the two values is the oxidized mercury $(\mathrm{Hg}+2)$. The graph in the middle shows the plant load in gross MW. The bottom graph shows the carbon loading in the gas stream in pounds per million actual cubic feet (lb/MMacf) and the percent mercury removal calculated as:

$$
\% \text { Hg Removal }=100 *(\operatorname{HgT} \text { In }-\mathrm{HgT} \text { Out }) / \mathrm{HgT} \text { In }
$$

A comparison of Figure 7 and Figure 8 leads to the conclusion that linking the Hg-CEM readings to the carbon injection rate can help optimize mercury removal and reduce carbon usage. For example, Figure 7 shows that during periods when the inlet mercury changed significantly, and during low load operation, the carbon loading was not at the optimal rate to achieve $90 \%$ removal. At low load, removal increased to $95 \%$, indicating that there was a potential to save carbon at these conditions. Figure 8 shows that under normal conditions mercury removal was maintained in a tight band around $90 \%$ removal. More importantly, it shows that at low load, carbon loading was reduced from 1.5 to $0.75 \mathrm{lb} / \mathrm{MMacf}$, a $50 \%$ savings in carbon usage. 

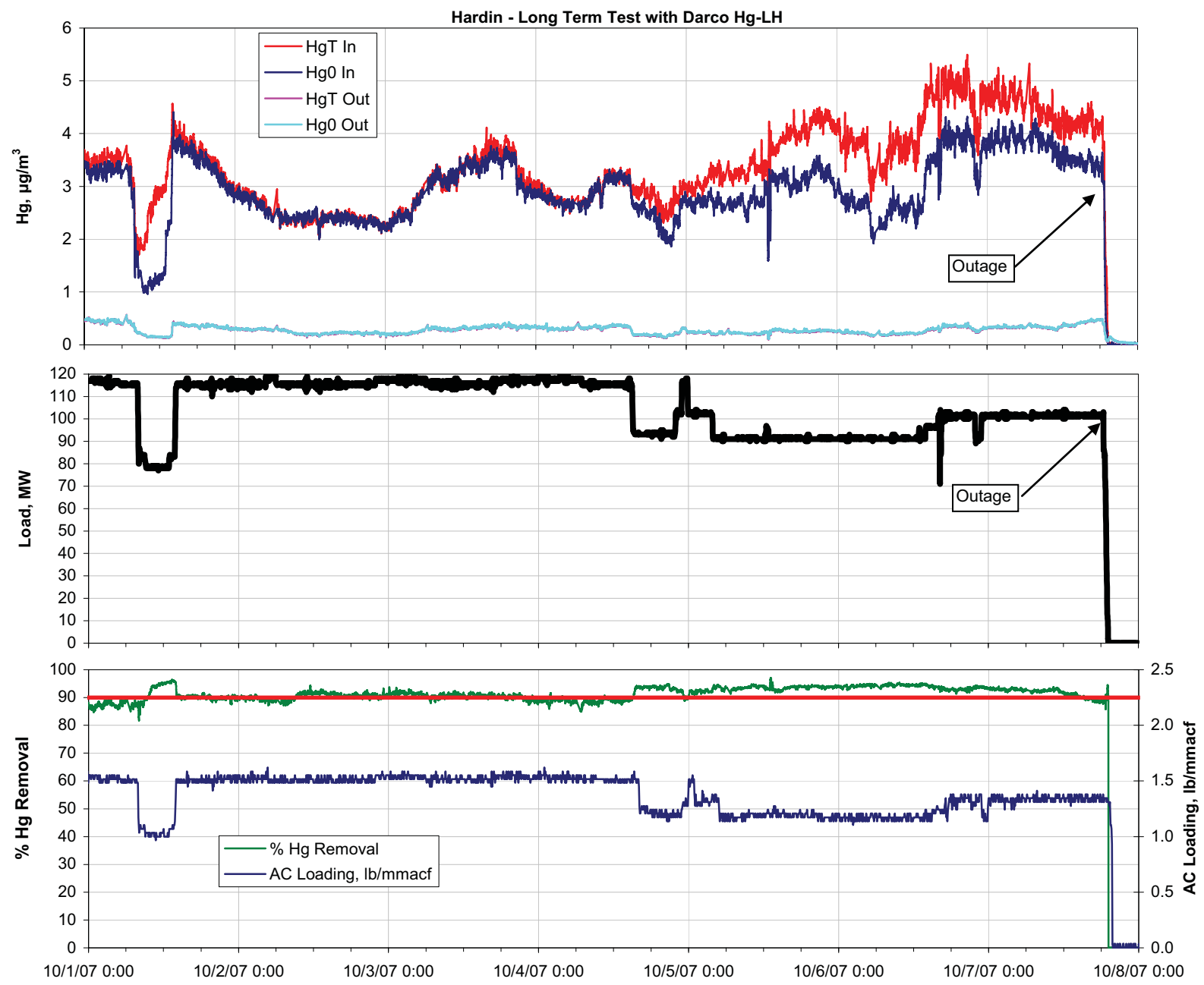

Figure 7. Mercury Control System Performance without Feedback Control. 


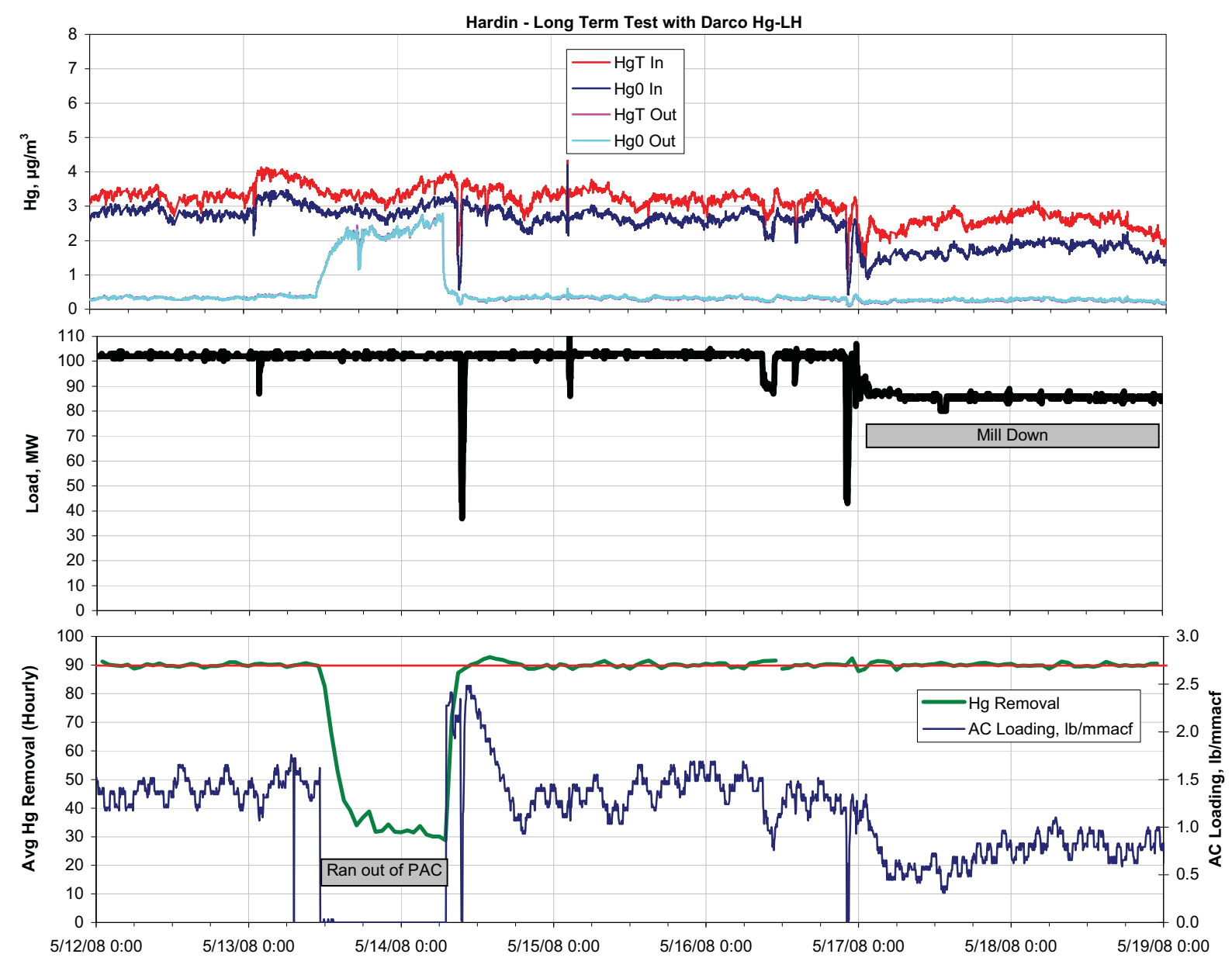

Figure 8. Mercury Control System Performance with Feedback Control.

\subsubsection{Baseline Test}

After installation of the Hg-CEMs, baseline measurements were made over the next several months to establish the native mercury removal during typical plant operating conditions. During this time, no sorbent injection or other chemical additives were used. Baseline testing also provided the opportunity to determine if there were any co-benefits that could be utilized during the normal and variable operation of the boiler and pollution control equipment.

Baseline testing also included one full set of manual flue gas measurements and solid sample collection. Flue gas measurements included AH outlet and stack Hg-CEM measurements and manual sampling by an independent contractor for particulate, mercury, halogens, condensables, and ammonia. Solid samples included coal, ash from all six of the FF hoppers, and slurry from the SDA. The accuracy of the $\mathrm{Hg}$-CEMs was verified with the Ontario Hydro method $(\mathrm{O}-\mathrm{H})$ and the sorbent trap method (STM).

\subsubsection{Baseline Hg-CEM Data}

Figure 9 presents typical baseline $\mathrm{Hg}$-CEM data for Hardin. It shows that native mercury capture at high load is less than $20 \%$ (lower trace in the bottom graph), and that most of the mercury is in the elemental form (i.e., $\mathrm{HgT}=\mathrm{Hg} 0$ ). However, at low load, the native mercury 
removal can be as high as $40 \%$, with a corresponding amount of oxidized mercury at the AH outlet. This was one of the most significant co-benefit findings for the project. It is believed that, at low load, the plant reduces the amount of ammonia to the SCR and, consequently, the mercury is more able to successfully compete for active sites in the SCR and, therefore, a larger portion of the mercury is oxidized. The oxidized mercury is then adsorbed by unburned carbon in the fly ash.

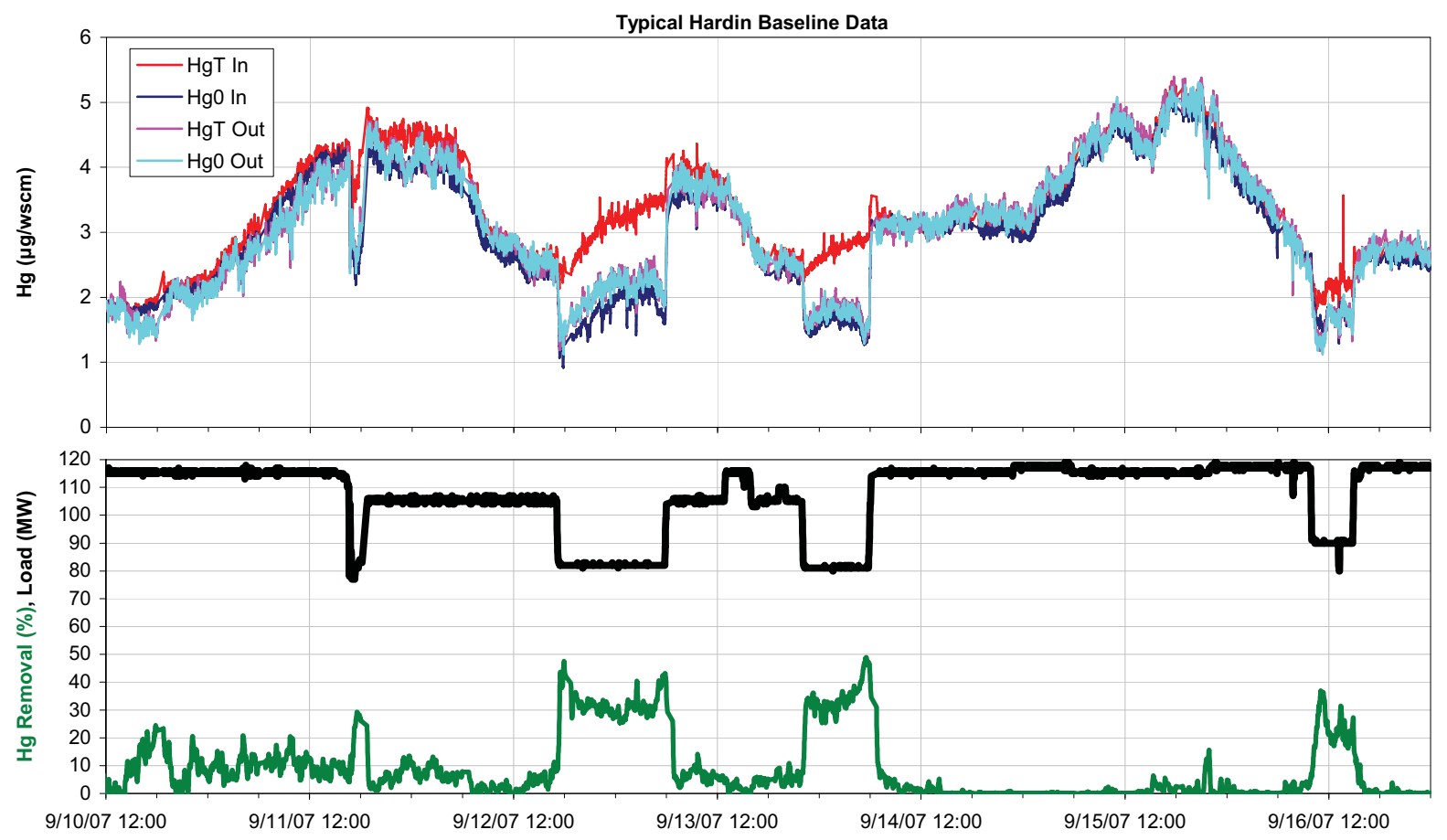

Figure 9. Baseline Mercury and Load Trends for Hardin Station, 2 Q07.

\subsubsection{Baseline Manual Source Testing}

The first set of baseline flue gas measurements was collected from November 30 through December 2, 2007. Test methods are shown in Table 7. Some testing difficulties and delays were encountered due to inclement weather $\left(-15^{\circ} \mathrm{F}\right)$ that impacted both plant operation and sampling efforts. Initial results from ASTM D6784 (Ontario Hydro) measurements suggest $<10 \%$ native mercury removal across the SDA-FF. 
Table 7. Manual Measurements Conducted during Baseline Testing.

\begin{tabular}{|l|l|l|}
\hline \multicolumn{1}{|c|}{ Method } & \multicolumn{1}{c|}{ Description } & \multicolumn{1}{c|}{ Location } \\
\hline EPA M5/17 & Total Particulate & SDA Inlet, Stack \\
\hline EPA M26A & Halogens and Halides & SDA Inlet, Stack \\
\hline CTM027 & Ammonia & SDA Inlet \\
\hline ASTM D6784 & Speciated Mercury & SDA Inlet, Stack \\
\hline STM & Total Mercury & SDA Inlet, Stack \\
\hline NCASI 8A & Sulfur Trioxide & SDA Inlet \\
\hline
\end{tabular}

Figure 10 is a comparison of the mercury data collected during the first baseline test. The O$\mathrm{H}$ data are presented as stacked bars showing the various mercury species separately. The STM and CEM data are shown as single points representing total vapor-phase mercury. Several conclusions can be drawn from the data given in Figure 10. In general, the CEM data were higher than the STM and O-H data, although the stack CEM data agree much better than the inlet CEM data. This difference was investigated and found to be caused by problems in calibration routine and non-linear calibration modules. After correcting these issues, the inlet and stack CEM values agreed more closely. Because of the poor agreement 'between the three test methods, this test was repeated in April 2007 (see section 4.3.2.3).

Notably, both the STM and O-H had data pairs that indicated that the stack mercury was higher than the inlet mercury, especially if discounting the contribution of the particulatephase mercury that would have been removed in the FF. The inlet $\mathrm{O}-\mathrm{H}$ also shows a higher concentration of $\mathrm{Hg}+2$ that was not measured by the CEM. If this amount of oxidized mercury actually existed in the flue gas, it would likely be scrubbed in the SDA-FF (as is seen at low load), and the stack concentration would be correspondingly lower. It is more likely that both the particulate and oxidized fractions of the inlet $\mathrm{O}-\mathrm{H}$ measurements are due to a sampling artifact of the $\mathrm{O}-\mathrm{H}$ method. In the $\mathrm{O}-\mathrm{H}$ method, the gas is sampled through a particulate filter and the filter cake that builds up can alter the speciation and particulate fraction of the mercury. 


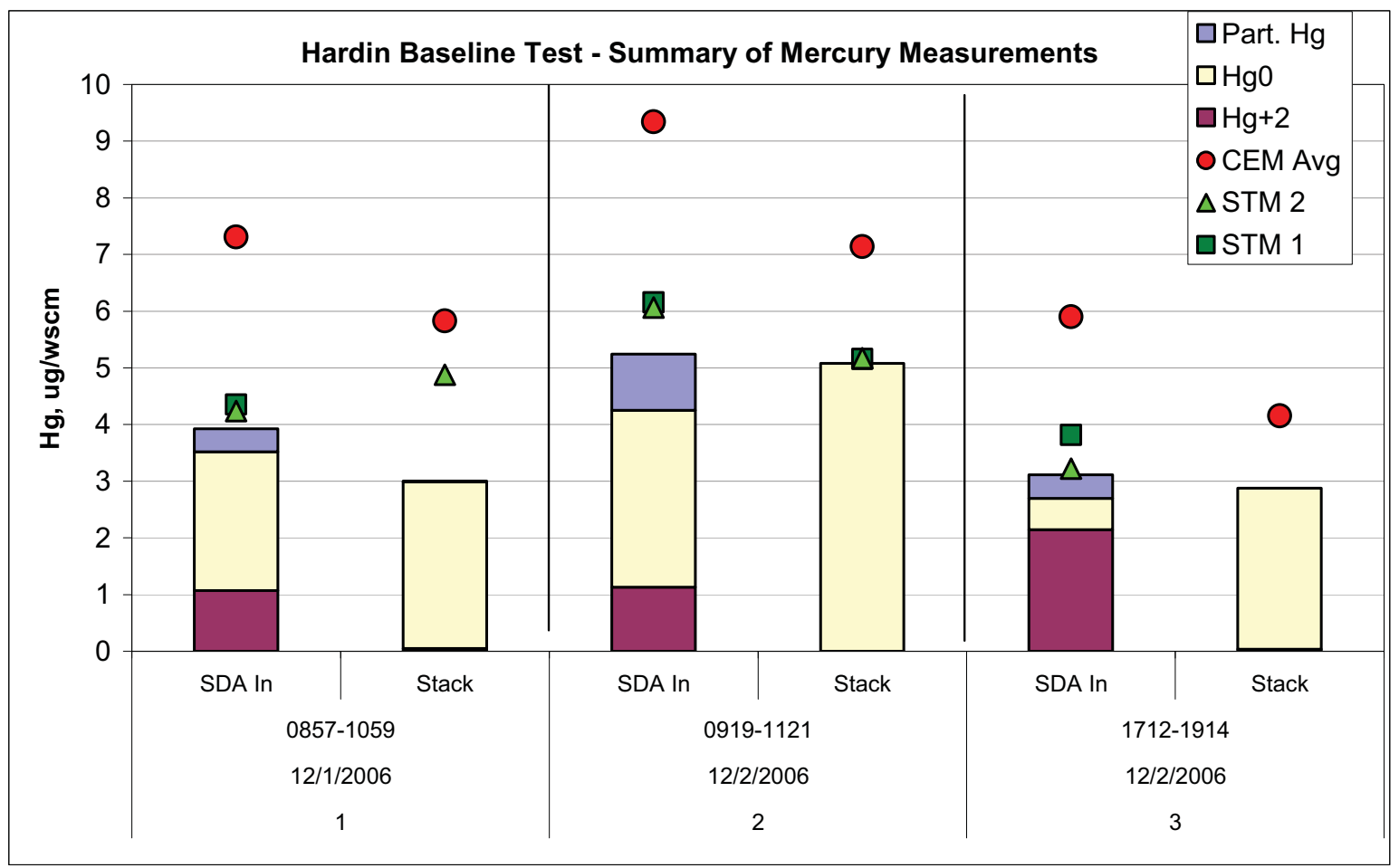

Figure 10. Results from the First Set of Baseline Gas Measurements.

Table 8 is a summary of the source testing results for the first set of baseline gas measurements. In general, good agreement was observed between the flow and moisture data measured by the different methods. Particulate measurements indicate that the baghouse is $99.8 \%$ efficient. The only halogen detected at either the SDA inlet or stack was chlorine (no $\mathrm{HCl}, \mathrm{HBr}, \mathrm{HF}, \mathrm{Br}$ ) and it was present in concentrations just above the detection limit. The ammonia concentration at the SDA inlet was $3.2 \mathrm{ppm}$. The sulfur trioxide reported at the stack was $3.5 \mathrm{ppm}$. However, the method used reports all sulphate species as sulfur trioxide and it is likely that the sulfur was in the form of an ammonia salt due to the ammonia introduced into the flue gas to control $\mathrm{NO}_{\mathrm{x}}$ in the SCR. 
Table 8. Summary of First Set of Baseline Gas Measurements.

\begin{tabular}{|l|r|r|}
\hline & SDA Inlet & Stack \\
\hline EPA 5B & & 14.8 \\
\hline Moisture (\%) & & 294,956 \\
\hline Flow Rate (DSCFM) & & 32.22 \\
\hline Particulate Matter (lbs/hr) & & 15.07 \\
\hline EPA 5/17/26A/CTM027 & 10.69 & 293,809 \\
\hline Moisture (\%) & 292,800 & 22.09 \\
\hline Flow Rate (DSCFM) & $10,640.09$ & 0.384 \\
\hline Particulate Matter (lbs/hr-front half) & 0.263 & 14.72 \\
\hline Chlorine (mg/dscm) & 3.2 & 295,482 \\
\hline Ammonia (ppm) & 10.18 & 20.49 \\
\hline EPA 5/17/ASTM D6784-02 & 291,987 & 3.745 \\
\hline Moisture (\%) & $8,837.89$ & \\
\hline Flow Rate (DSCFM) & 3.965 & \\
\hline Particulate Matter (lbs/hr - front half) & & \\
\hline Total Mercury (lbs/TBtu) & 10.47 & \\
\hline NCASI 8A & 3.5 & \\
\hline Moisture (\%) & & \\
\hline Sulfur Trioxide (ppm)* & & \\
\hline
\end{tabular}

* $\mathrm{SO}_{3}$ was likely in the form of an ammonia salt

\subsubsection{Repeat of Baseline Flue Gas Measurements}

The Baseline Source Test was repeated in April 2007 and the results are shown in Figure 11. In general, there is much better agreement between the CEM, STM, and O-H data than during the first test. Curiously, although the CEMs and STM data showed that the SDA inlet and stack concentrations were nearly equal, the O-H data showed slightly higher concentrations at the stack for each run. 


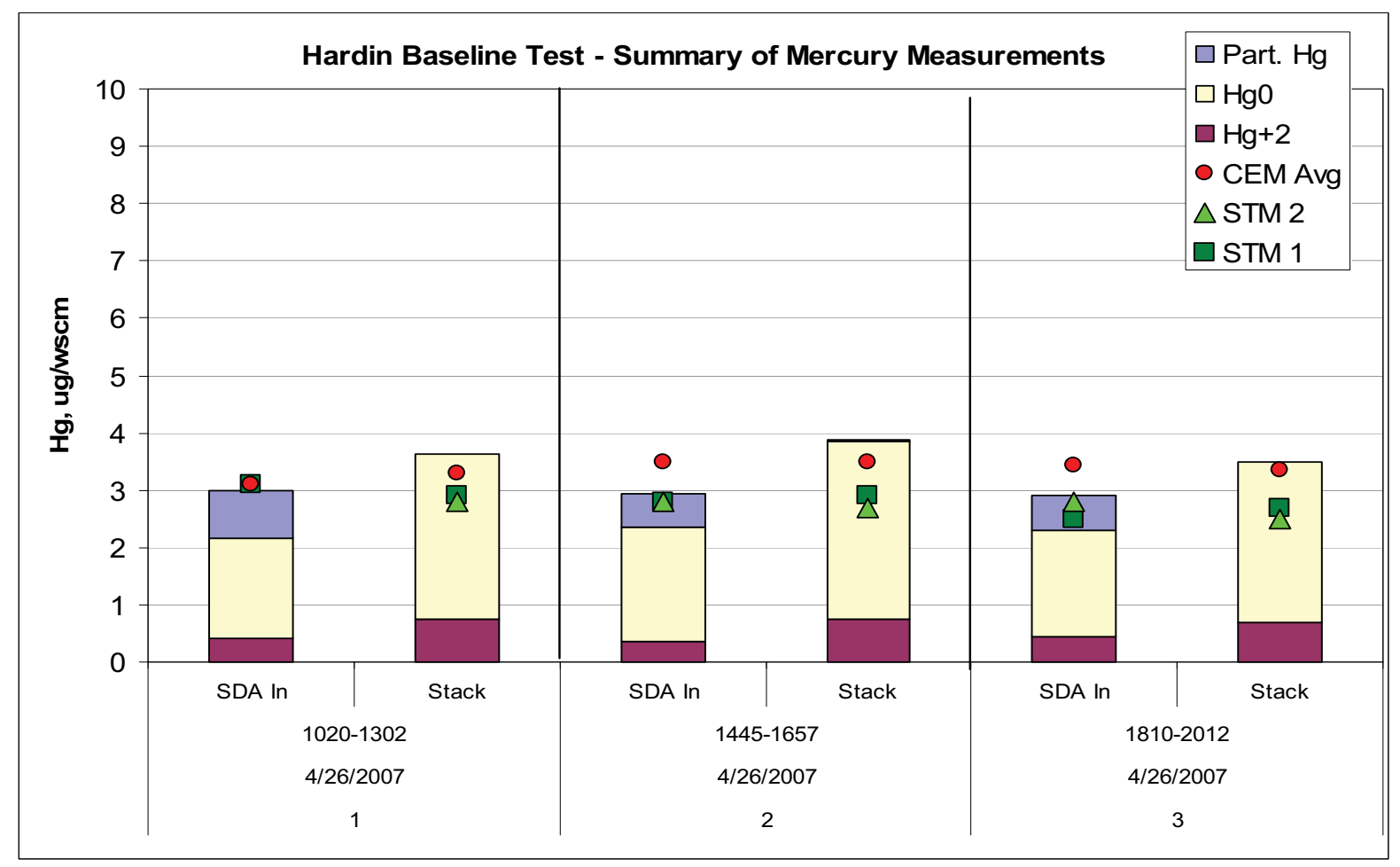

Figure 11. Results of the Second Baseline Mercury Test.

Table 9 is a compilation of both sets of baseline gas measurements. Again, good agreement was observed between different testing methods. The stack flue gas concentrations of halogens and SO3 were similar to the first test.

Table 9. Summary of the Second Set of Baseline Gas Measurements.

\begin{tabular}{|l|r|r|r|r|}
\hline & \multicolumn{2}{|c|}{ November '06 } & \multicolumn{2}{|c|}{ April '07 } \\
\cline { 2 - 5 } Sampling Trains - Parameters & $\begin{array}{c}\text { SDA Inlet } \\
\text { Average }\end{array}$ & $\begin{array}{c}\text { Stack } \\
\text { Average }\end{array}$ & $\begin{array}{c}\text { SDA Inlet } \\
\text { Average }\end{array}$ & $\begin{array}{c}\text { Stack } \\
\text { Average }\end{array}$ \\
\hline EPA 5B & & & & \\
- Moisture (\%) & & 14.80 & & \\
- Flow Rate (DSCFM) & & 294956 & & \\
- Particulate Matter (Ibs/hr-total) & & 32.22 & & \\
\hline EPA 5 / 17 I 26A / CTM027 & 10.69 & 15.07 & & 14.74 \\
- Moisture (\%) & 292,800 & 293,809 & & 295,494 \\
- Flow Rate (DSCFM) & 10,640 & 22.09 & & 18.34 \\
- Particulate Matter (Ibs/hr-front half) & 0.263 & 0.384 & & $<0.393$ \\
- Chlorine (mg/dscm) & 3.2 & NA & & NA \\
- Ammonia (ppm) & 10.18 & 14.72 & 10.85 & 15.21 \\
\hline EPA 5 I 17 I ASTM D6784-02 & 291,987 & 295,482 & 305,317 & 310,113 \\
- Moisture (\%) & 8,837 & 20.49 & 9,184 & 28.29 \\
- Flow Rate (DSCFM) & 3.965 & 3.745 & 2.944 & 3.926 \\
- Particulate Matter (Ibs/hr-front half) & & & & \\
- Total Mercury (Ibs/TBtu) & 10.47 & & & \\
\hline NCASI 8A & 3.5 & & & \\
- Moisture (\%) & & & \\
- Sulfur Trioxide (ppm) & & & \\
\hline
\end{tabular}

$* \mathrm{SO}_{3}$ was likely in the form of an ammonia salt 


\subsubsection{Results of Additional Baseline Testing (PM $\left.M_{10} / M_{2.5}\right)$}

Additional gas measurements were made in September 2007 at the request of a new project partner. Triplicate measurements were made at the stack for $\mathrm{PM}_{10}, \mathrm{PM}_{2.5}$, and controlled condensate $\left(\mathrm{SO}_{3}\right)$. Table 10 is a summary of the results showing that the particulate and $\mathrm{SO}_{3}$ concentrations were very low. These tests were repeated during the Long-Term test to determine the effect of carbon addition.

Table 10. Summary of Baseline $\mathbf{P M}_{10} / \mathbf{P M}_{2.5}$ Measurements.

\begin{tabular}{|l|c|l|}
\hline \multicolumn{1}{|c|}{ Parameter } & Results Average & \multicolumn{1}{c|}{ Units } \\
\hline \multirow{2}{*}{ Particulate $\left(>\mathrm{PM}_{10}\right)$} & 0.0030 & $\mathrm{gr} / \mathrm{dscf}$ \\
\cline { 2 - 3 } & 7.90 & $\mathrm{lbs} / \mathrm{hr}$ \\
\hline \multirow{2}{*}{ Particulate $\left(<\mathrm{PM}_{10},>\mathrm{PM}_{2.5}\right)$} & 0.0030 & $\mathrm{gr} / \mathrm{dscf}$ \\
\hline \multirow{2}{*}{ Particulate $\left(\mathrm{PM}_{2.5}\right)$} & 7.90 & $\mathrm{lbs} / \mathrm{hr}$ \\
\cline { 2 - 3 } & 0.0023 & $\mathrm{gr} / \mathrm{dscf}$ \\
\hline Particulate (Total Catch) & 6.31 & $\mathrm{lbs} / \mathrm{hr}$ \\
\hline Sulfur Trioxide & 0.0494 & $\mathrm{gr} / \mathrm{dscf}$ \\
\cline { 2 - 3 } & 131.10 & $\mathrm{lbs} / \mathrm{hr}$ \\
\hline
\end{tabular}

\subsubsection{Co-Benefits Analysis}

The co-benefit analysis involved studying how mercury removal was affected by normal variations in plant operations or by the use of coal additives or different blends of coal. Normal variations in the plant operations provided an opportunity to investigate how native mercury capture was affected by changes to the SCR, SDA, and FF. Coal additives, to increase the oxidation across the SCR and, subsequently, the mercury capture in the SDA-FF, were also studied. A short test was also conducted to determine the potential of blending western bituminous coal with the PRB coal used by the plant for enhanced mercury removal.

\subsubsection{Effect of Low Load on Hg Removal}

One of the focus areas for these tests was to determine whether any co-benefits to mercury removal could be achieved by varying operation of the other air pollution control devices. Early in the project, data from periods at low boiler load showed that the fraction of oxidized mercury at the inlet to the SDA increased, and, correspondingly, higher mercury removal was achieved across the SDA-FF. This was one of the most significant co-benefit discoveries of the project since little oxidation was expected across the SCR given the low halogen content of PRB coal.

Native mercury removal trends (no carbon injection) for the week of September 11, 2007, are presented in Figure 12. The increased mercury removal at low load can be clearly seen during times when the plant reduced load. Native capture increased from less than $20 \%$ to near 50\% during these periods. At low load, the fraction of oxidized mercury at the SDA inlet increases significantly and higher mercury removal is achieved across the SDA-FF. It is theorized that, at low load, the plant reduces ammonia flow to the SCR and, consequently, more active sites are available to oxidize mercury. 


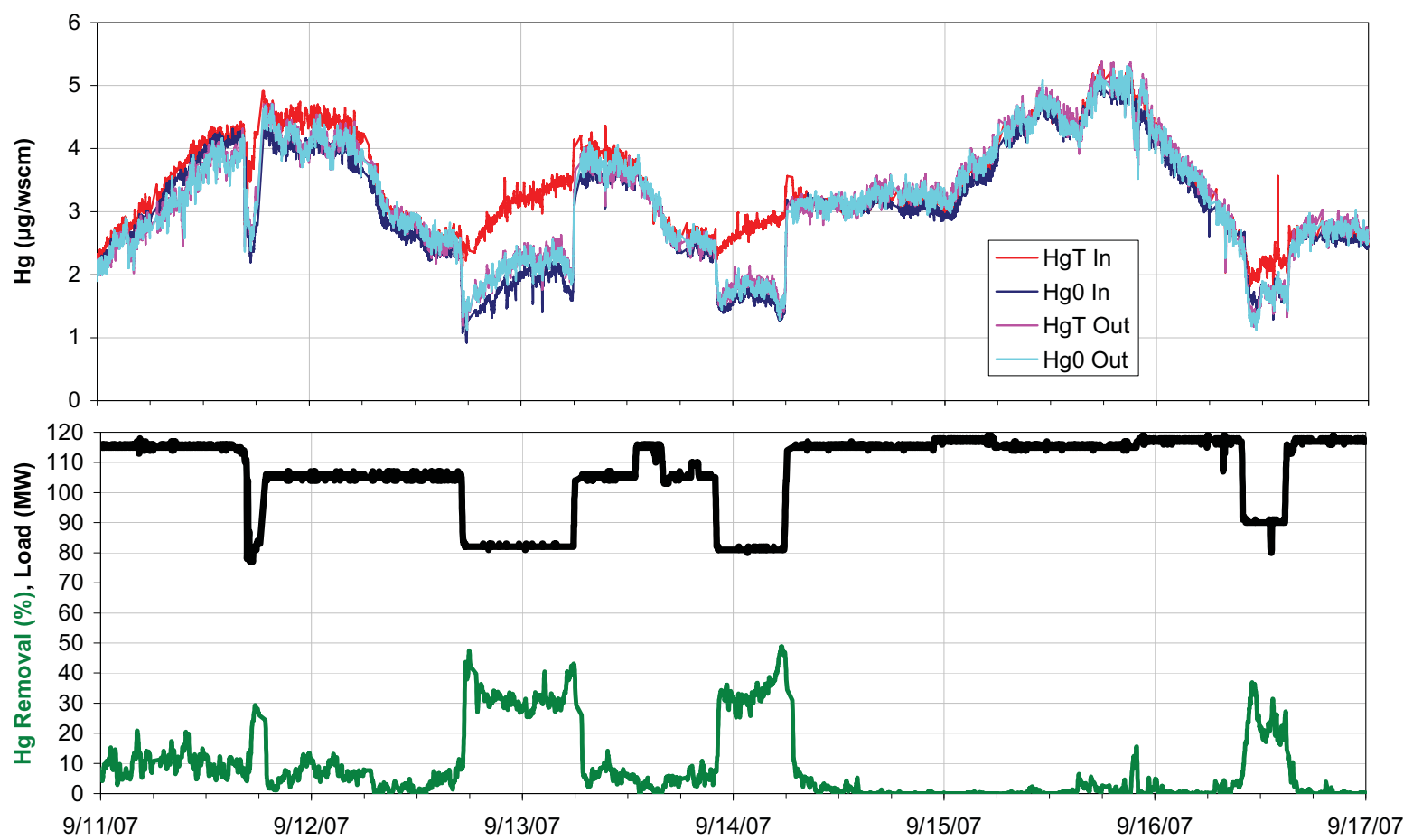

Figure 12. Effect of Load on Hg Speciation and Native Removal.

\subsubsection{Coal Blending Tests}

Coal blending tests were conducted from December 4 through December 7, 2007. Two companies provided approximately 250 tons of western bituminous coal. Arch Coal provided coal from their West Elk mine near Gunnison, Colorado, and Roundup Trading International provided coal from the Bull Mountain mine near Roundup, Montana. The test matrix included evaluating each coal at $7 \%$ and $14 \%$ western bituminous mixed with a balance of PRB from the Absaloka mine. Each blend test was scheduled for nominally 16 hours with 8 hours of system recovery time between tests.

Hardin receives all its coal by truck from the nearby Absaloka mine. Coal from the truck unloading station is conveyed into a large storage silo (there is no coal pile at Hardin). The storage silo feeds the main coal belt, which is directed to discharge into one of three bunkers at a time. Each bunker feeds one of three coal mills. For the coal blending tests, the bunkers were emptied until approximately 16 hours of storage was available for the blended coal. Since only one bunker can be filled at a time, it is difficult for the plant to maintain the same level in each bunker. Consequently, for the coal blending tests, it is likely that the blended coal from each bunker reached the boiler at different times and was depleted at different times. This made it difficult to clearly define the beginning and end of each test.

A portable belt conveyor, supplied by the plant, was operated to feed the blend coal onto the main coal belt. A photograph of the portable belt conveyor is shown in Figure 13. The portable conveyor included an adjustable gate at the bottom of the hopper to control coal flow, a weigh scale, and a panel with feed rate and totalizer readouts. 


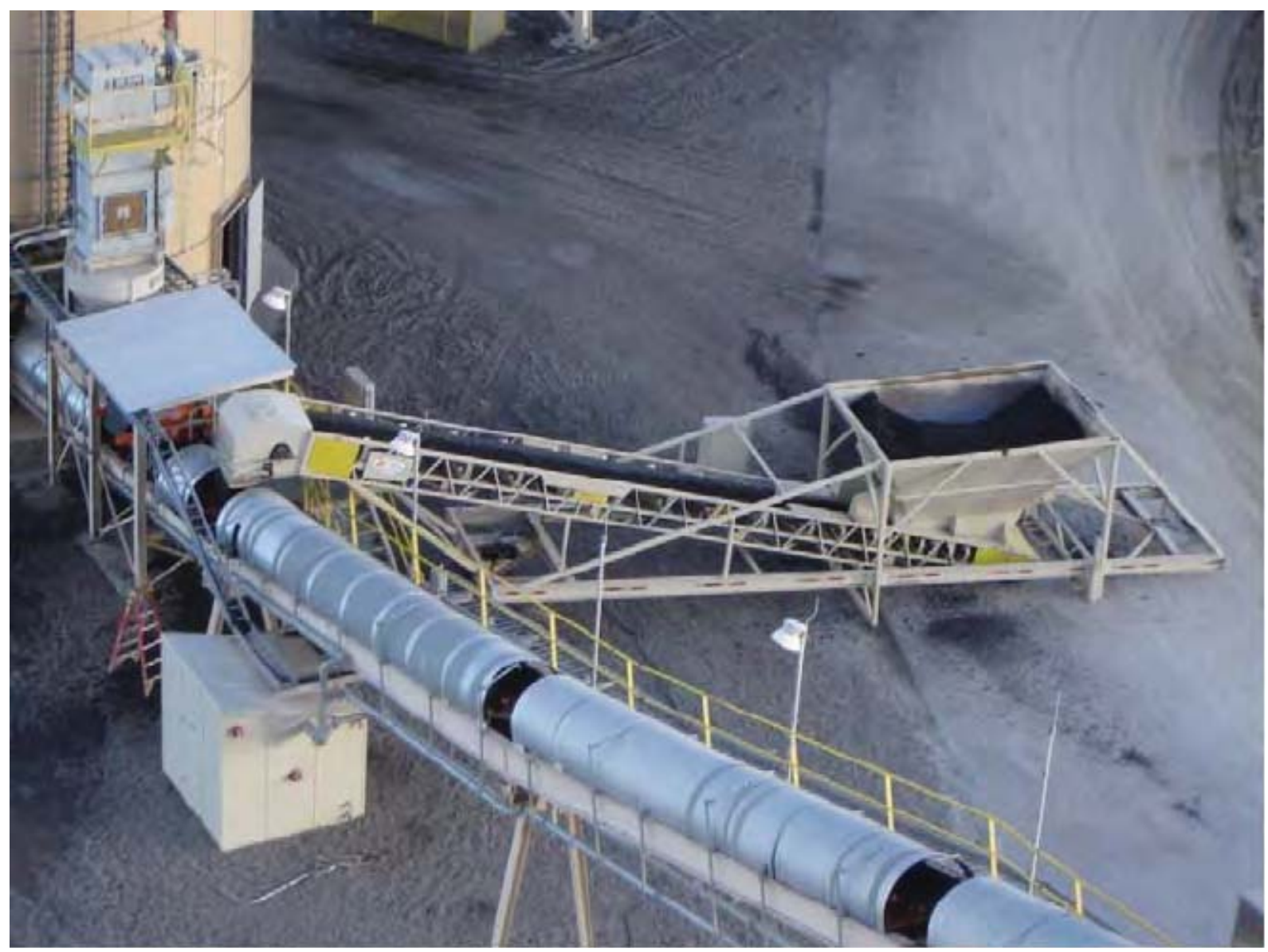

Figure 13. Portable Coal Conveying System at Hardin Station.

Table 11 shows the weights of the various coals blended for each test. The goal was to blend enough coal to test for 16 hours ( 1200 tons) with an 8-hour period between tests to allow conditions to recover. The target blend percentages were $7 \%$ and $14 \%$.

Table 11. Summary of Coal Blending Runs.

\begin{tabular}{|l|c|c|c|c|c|c|}
\hline Test Date & $\begin{array}{c}\text { Absaloka } \\
\text { Ton }\end{array}$ & $\begin{array}{c}\text { West Elk } \\
\text { Ton }\end{array}$ & $\begin{array}{c}\text { Bull Mtn. } \\
\text { Ton }\end{array}$ & $\begin{array}{c}\text { Blended } \\
\text { Ton }\end{array}$ & $\begin{array}{c}\text { Blend } \\
\text { \% }\end{array}$ & $\begin{array}{c}\text { Est. Time } \\
\text { in Unit, hr. }\end{array}$ \\
\hline $12 / 04 / 06$ & 928 & 72 & & 1000 & 7.2 & 13.9 \\
\hline $12 / 05 / 06$ & 1141 & 174 & & 1315 & 13.2 & 18.3 \\
\hline $12 / 06 / 06$ & 1039 & & 174 & 1213 & 14.3 & 16.8 \\
\hline $12 / 07 / 06$ & 1036 & & 86 & 1122 & 7.7 & 15.6 \\
\hline
\end{tabular}

Mercury removal during coal blending tests was calculated several ways using values from the Hg-CEMs, coal flow rate, ash mercury content, and estimated vapor-phase mercury concentration calculated from coal mercury values. In most cases, it was possible to determine when the blend coal was being fired based on a decrease in the coal feed rate (western bituminous has a higher Btu content). The mercury content in the coal was 
calculated from coal samples taken from the two conveyors at the beginning of each blend run. However, no samples were taken during the first run, so the mercury value is based on samples from the blend coal pile and from the main conveyor several hours after the run was complete.

For the first blend test (West Elk at 7.2\%), there was a significant decrease in both the SDA inlet and stack mercury concentrations at the beginning of the test. However, there was no increase in $\mathrm{Hg}+2$, which would suggest that if this decrease was due solely to the coal blend, mercury removal occurred in the particulate phase before reaching the SDA inlet sampling location. Based on this assumption, the mercury removal for the first test was about $50 \%$, calculated using the mercury concentration at the beginning of the test and at its lowest point during the test. If removal is calculated strictly based on inlet and outlet mercury concentrations (i.e., assuming that the drop in the SDA inlet and stack concentrations was due to a change in the coal mercury), then removal increased from $10 \%$ to $27 \%$ due to coal blending. This was considered the more likely of the two scenarios since between the first and second tests, the mercury concentration did not recover to pretest levels, but coal measurements indicated that there was a drop in coal mercury at this time.

During the second test (West Elk at 13.2\%), the stack mercury levels gradually decreased, but the inlet did not. Also, a mill trip halfway through the test caused a large upset and made the results for the second half of the test difficult to interpret. Based on the inlet and outlet concentrations, the mercury removal for the second test increased from $15 \%$ to $51 \%$. Figure 14 shows mercury removal as a function of blend percentage for the West Elk tests, calculated from the SDA inlet and stack mercury CEM values. The value of $0 \%$ blend percentage is an average of the mercury removal before the blended coal reached the boiler.

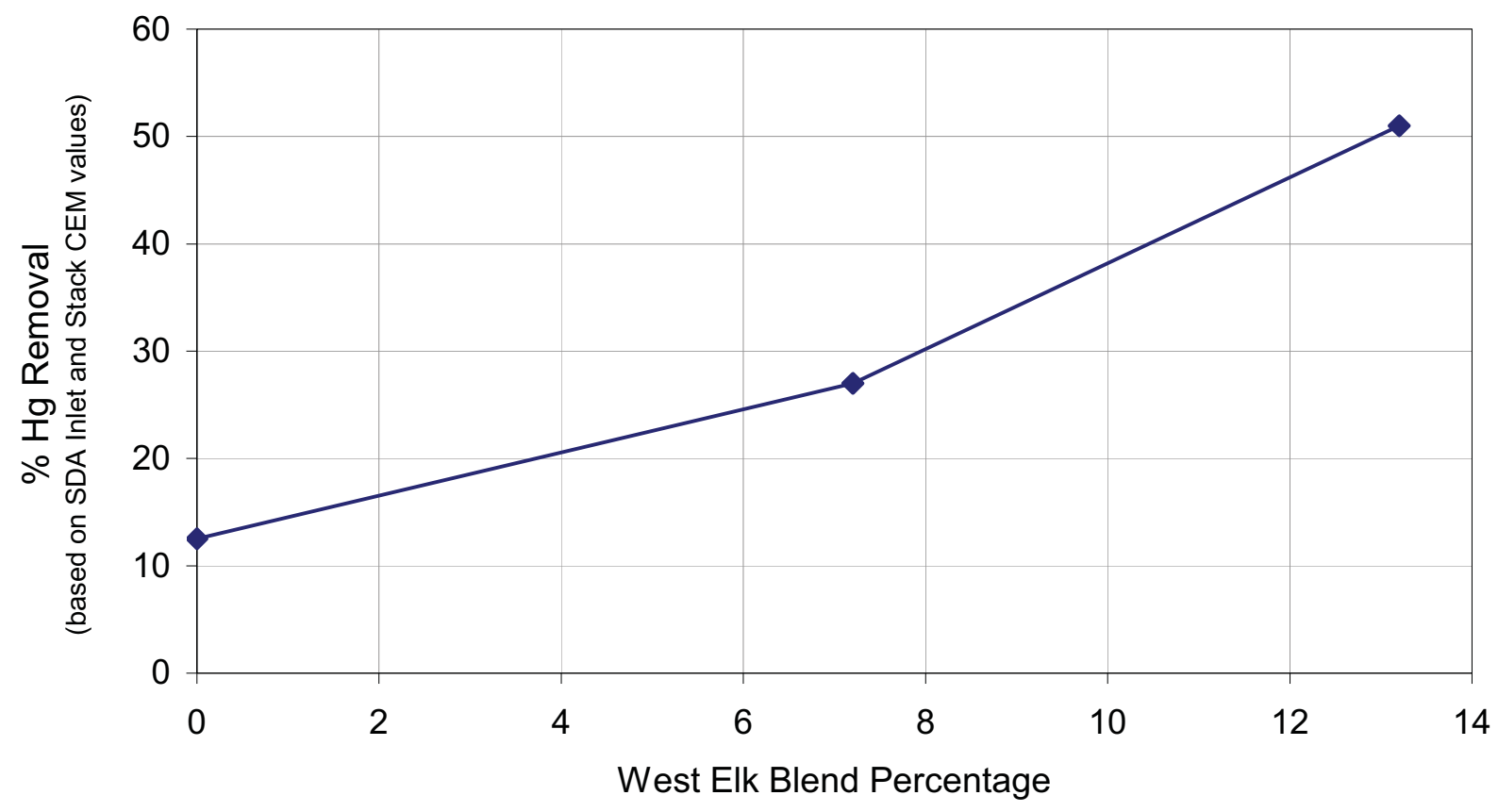

Figure 14. Mercury Removal for the West Elk Coal Blend Test. 
During the third test (Bull Mountain at 14.3\%), the mercury concentration rose steadily throughout the entire run (from 4 to $12 \mu \mathrm{g} / \mathrm{wscm}$ ) so it is difficult to estimate removal based on a starting background mercury level. However, based on the inlet and outlet concentrations at the beginning and near the end of the run, the mercury removal for this test only changed from $19 \%$ to $22 \%$. The carbon monoxide values during this test were also higher than the other tests, indicating a change in combustion characteristics.

During the final test (Bull Mountain at 7.7\%), the mercury removal remained relatively constant throughout the test at about $17 \%$. However, it was difficult to determine exactly when this blend was fired because the coal feed rate did not show the pronounced drop as with the other tests.

Another way in which the native mercury capture was determined for the coal blending was to analyze for mercury in baseline and blending test ash samples from the FF. It should be stressed, however, that it was very difficult to obtain a representative ash sample at Hardin because the FF ash system had difficultly keeping up with the ash loading from the SDA, so the hoppers were often full. And since ash samples were drawn from a port at the bottom of the hopper, it was not possible to judge how long a sample had been in the hopper, or to correlate it to any particular set of operating conditions.

Two sets of baseline hopper samples were collected prior to the blend tests and compared with samples from Hopper B collected during coal blending. A comparison of ash mercury indicates that the mercury removal increased from 5\% to 58\% during the West Elk tests, which compares well to the CEM data. Unfortunately, during the Bull Mountain tests, the native coal mercury content increased significantly during the test and there is no ash sample that can be used as a reliable baseline indicator. However, if 5\% is used for a typical value for native removal, the ash mercury measured during the Bull Mountain tests corresponds to a mercury removal increase from 5 to $14 \%$.

\subsubsection{Coal Additive Test}

Coal Additive Testing was conducted during the week of April 23, 2007. KNX was added directly to each of the three coal feeders just ahead of the pulverizers. Testing began at the vendor's recommended KNX rate. However, it quickly became apparent that this rate was too high for this site so the flow was reduced in stages. Figure 15 shows the mercury removal for several KNX rates. The maximum mercury removal shown was $85 \%$ at a KNX rate of $0.5 \mathrm{x}$ of the vendor recommended rate. 


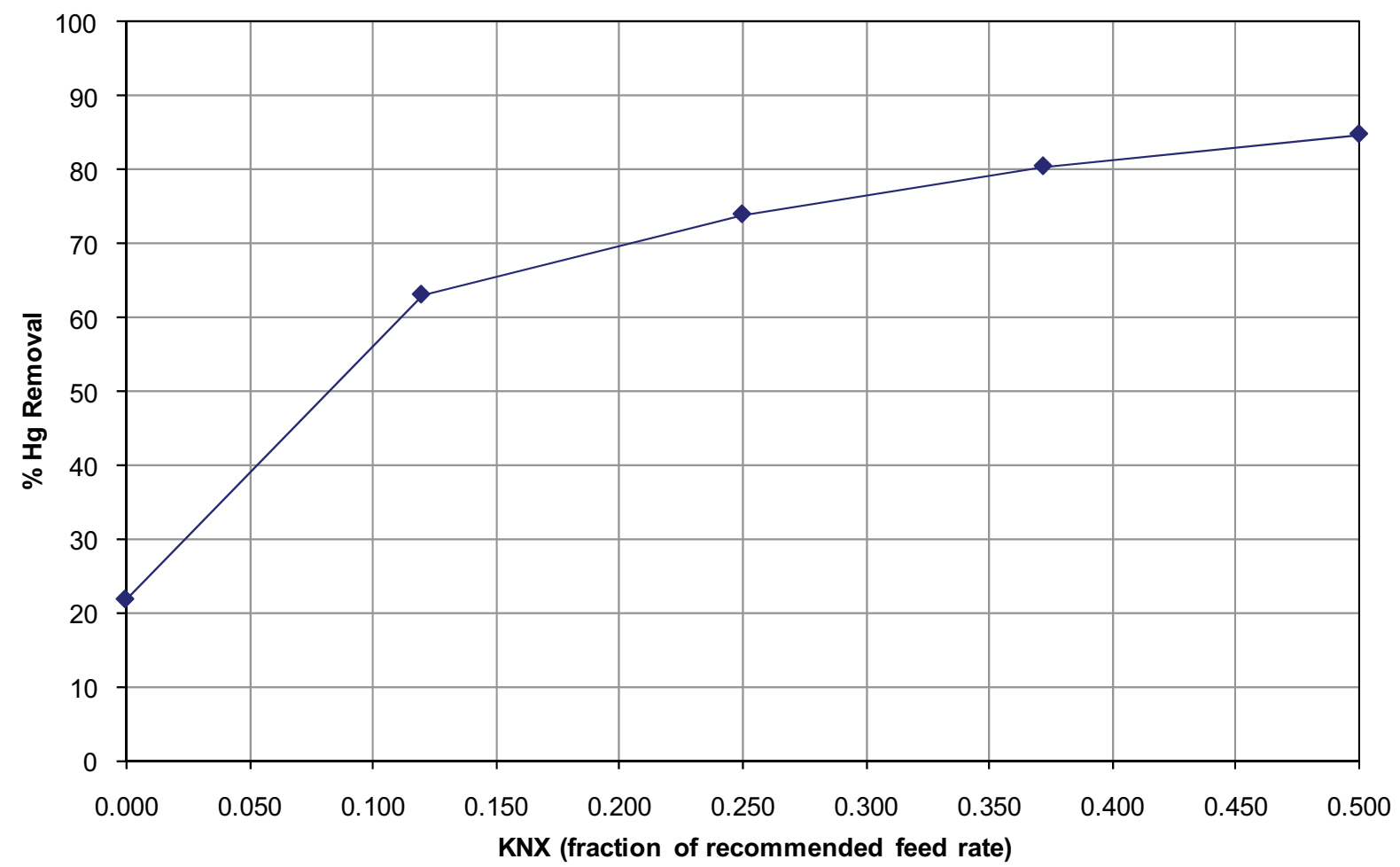

Figure 15. Mercury Removal for the Coal Additive Test.

Figure 16 shows the mercury trends during a four-hour period in which four different KNX injection rates were tested. The figure shows that it only took a few minutes for the effects of KNX addition to register on the Hg-CEMs. The system also recovered very quickly after stopping KNX flow. The trends also show that the KNX affected the SDA inlet mercury concentration as well as the stack concentration, indicating the mercury removal was occurring in the SCR, AH, or on the fly ash before the SDA inlet. This result indicates that the fly ash at Hardin, which contains about $0.5 \%$ unburned carbon, has an affinity for oxidized mercury. Finally, the figure shows that the oxidized mercury formed by KNX addition is completely scrubbed in the SDA-FF. Based upon these results, KNX was later tested in combination with carbon injection during the Parametric test. 


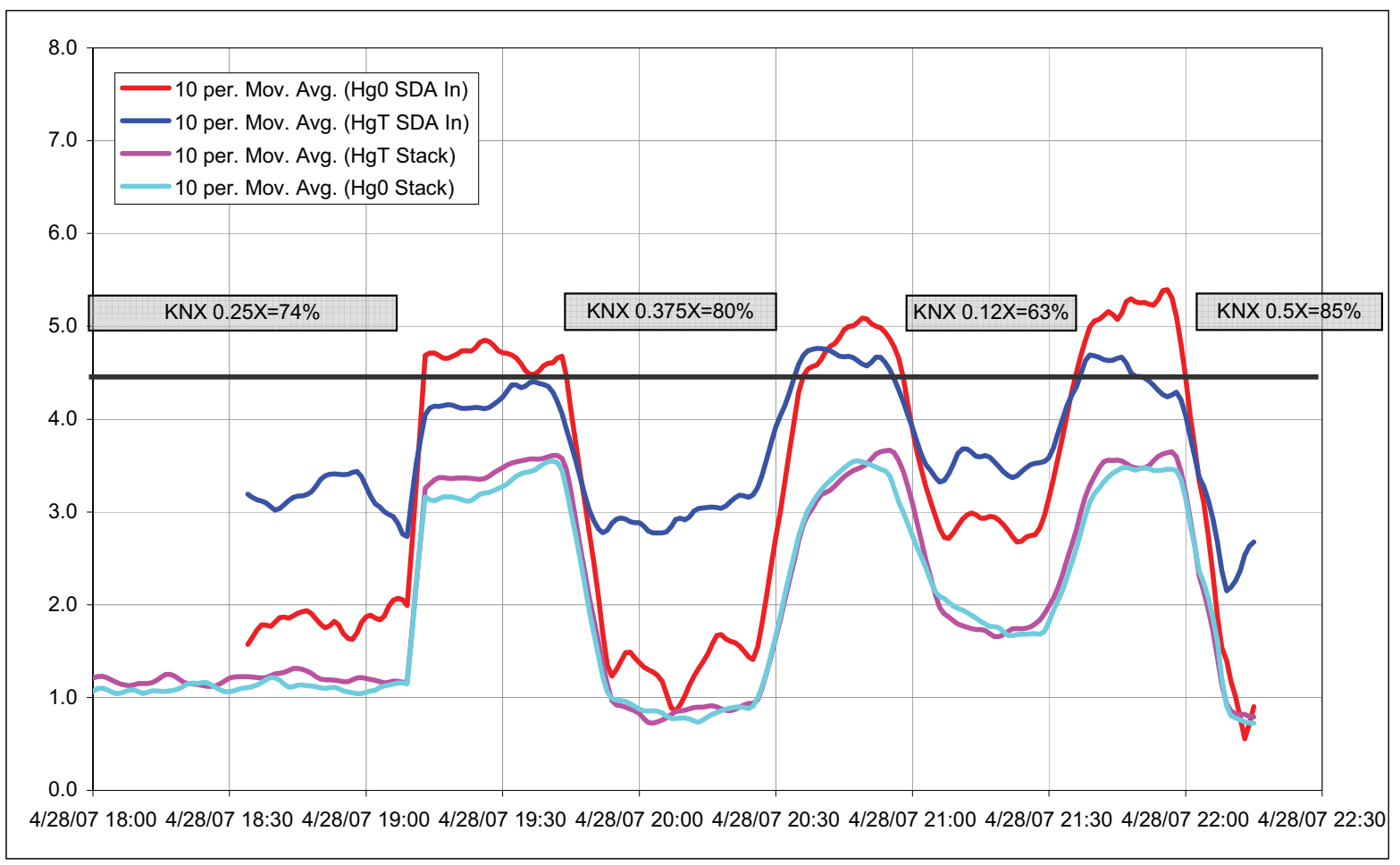

Figure 16. Hg-CEM Trends for the Coal Additive Test.

\subsubsection{Effect of Ammonia on Hg Removal}

The Hardin Station spent much of 2008 operating at $105 \mathrm{MW}$ out of $121 \mathrm{MW}$ due to a failure of the step-up transformer and its subsequent, temporary replacement with a smaller unit. When the plant returned to full-load operation, however, the mercury removal was often less than the targeted $90 \%$ even though the activated carbon injection rate was at maximum for screw size installed in the injection system. A larger screw was installed on one feed train to increase the maximum feed rate, but maintaining $90 \%$ mercury control was still a challenge.

It is believed that atypically high ammonia concentration at the SCR outlet was impacting the performance of the PAC because:

- Plant personnel reported that during a tube leak in March 2008, more than $25 \%$ of the SCR was plugged with ash. Consequently, it became necessary to increase ammonia injection to the SCR to maintain $\mathrm{NO}_{\mathrm{x}}$ levels.

- On September 16, 2008, an operator noticed that the amount of ammonia being fed to the SCR affected mercury control performance. Figure 17 shows that when the ammonia flow was reduced, mercury removal increased.

- During the source tests in September 2007, a characterization of ammonia feed rate versus mercury control was conducted by measuring ammonia concentration at the $\mathrm{AH}$ outlet. During three tests, the plant changed the position of the ammonia control valve from $67 \%$ open to $55 \%$ open and to $45 \%$ open, and the ammonia concentration at the AH outlet decreased proportionally. Figure 18 clearly shows that ammonia affects mercury control performance. It should be noted the ammonia flow rate could not be 
measured directly because the flow meter installed for this purpose was found to be over-ranged and not indicating properly.

- After the SCR was refurbished, mercury control performance returned to normal levels.

The mechanism for the ammonia interference may simply be that the ammonia competes with the mercury for sites on the activated carbon. Mercury is present in ppb concentrations while ammonia was measured at ppm levels. The effect ammonia can have on mercury control performance was another significant finding of the co-benefit analysis.

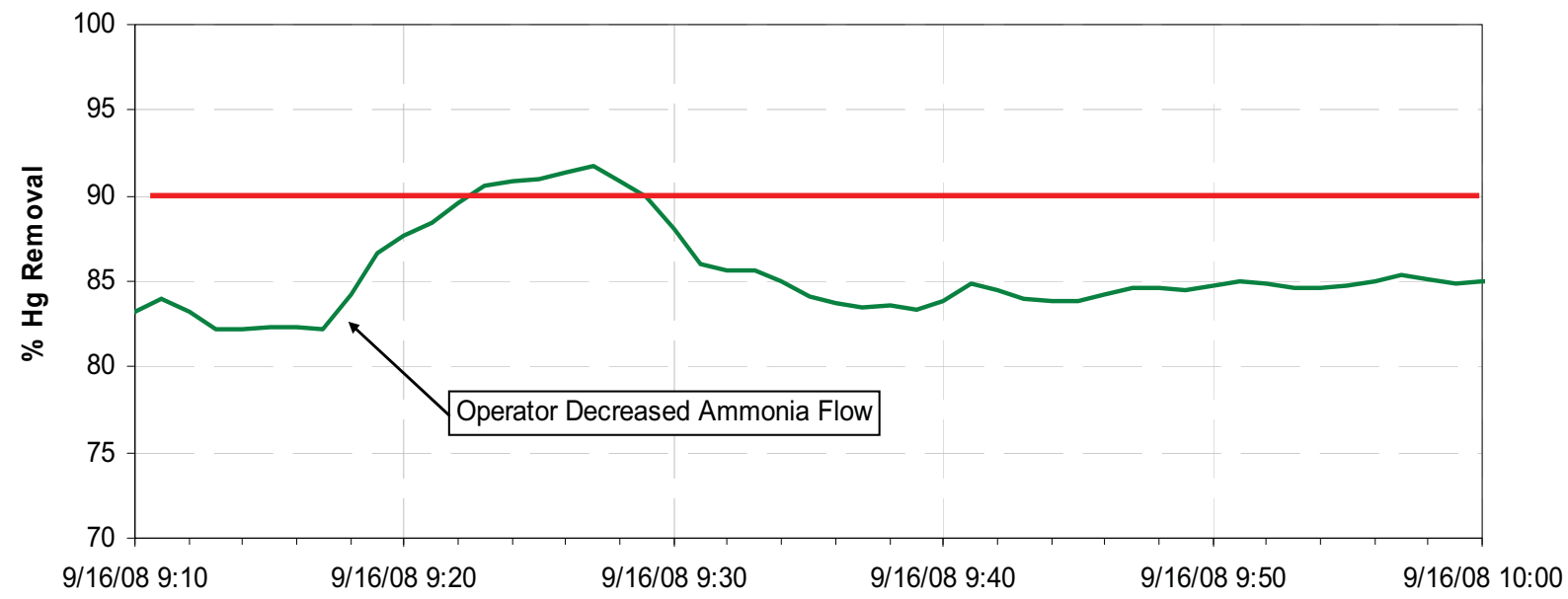

Figure 17. Effect of Ammonia Flow on Mercury Removal, 09/16/08.

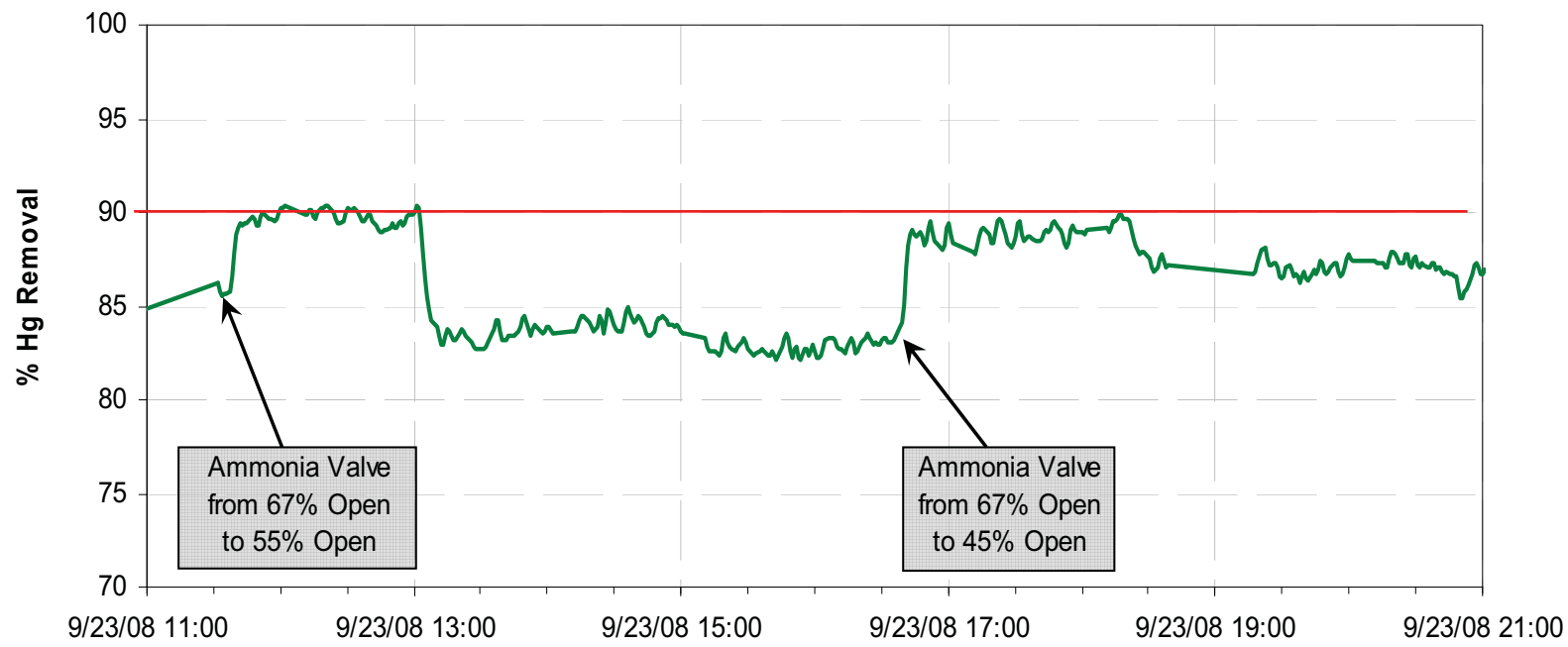

Figure 18. Effect of Ammonia Flow on Mercury Removal, 09/23/08. 


\subsubsection{Parametric Test}

The goal of the Parametric test was to evaluate the best candidate sorbents under various operating conditions. Parametric tests involved injecting sorbents into the flue gas upstream of the SDA for short periods (four hours) or until the stack Hg-CEM indicated steady performance. The Hg-CEMs were the basis for all Parametric test results. Parameters that were studied included:

- Sorbent type

- Sorbent injection concentration

- Unit combustion parameters

- Co-benefit enhancement additives

Parametric testing was conducted during the weeks of May 21, May 28, and June 18, 2007. Tests included three activated carbons: DARCO ${ }^{\circledR} \mathrm{Hg}$, DARCO ${ }^{\circledR} \mathrm{Hg}-\mathrm{LH}$, and Calgon FLUEPAC ${ }^{\text {TM}}$-MC PLUS, as well as one test combining PAC with KNX injection. MC PLUS and $\mathrm{Hg}-\mathrm{LH}$ are brominated carbons while DARCO ${ }^{\circledR} \mathrm{Hg}$ is not treated. Unfortunately, due to a super sack malfunction while loading MC PLUS, the results with DARCO ${ }^{\circledR} \mathrm{Hg}$ were actually a mixture of MC PLUS and DARCO ${ }^{\circledR} \mathrm{Hg}$ and had to be discounted. Also, the tests combining PAC injection with KNX coal additive are identified only as PAC $+\mathrm{KNX}$ because this PAC was also a mixture of the two carbons.

Figure 19 shows very similar performance between the two brominated carbons. Both $\mathrm{Hg}$ LH and MC PLUS removed $90 \%$ of mercury at an injection concentration slightly below $1.0 \mathrm{lb} / \mathrm{MMacf}$, which agrees well with results collected in the DOE Cooperative Agreement DE-FC26-03NT41986 at Sunflower Electric's Holcomb Station in 2004, as reported in Topical Report No. 41986R07, June 28, 2005.

When combining the mixed PAC and KNX addition, mercury removal levels were nearly $90 \%$ at a PAC loading of only $0.14 \mathrm{lb} / \mathrm{MMacf}$ and a relatively low KNX rate. Nearly $100 \%$ removal was obtained at a higher KNX rate and $0.14 \mathrm{lb} / \mathrm{MMacf}$ of the PAC mix. 


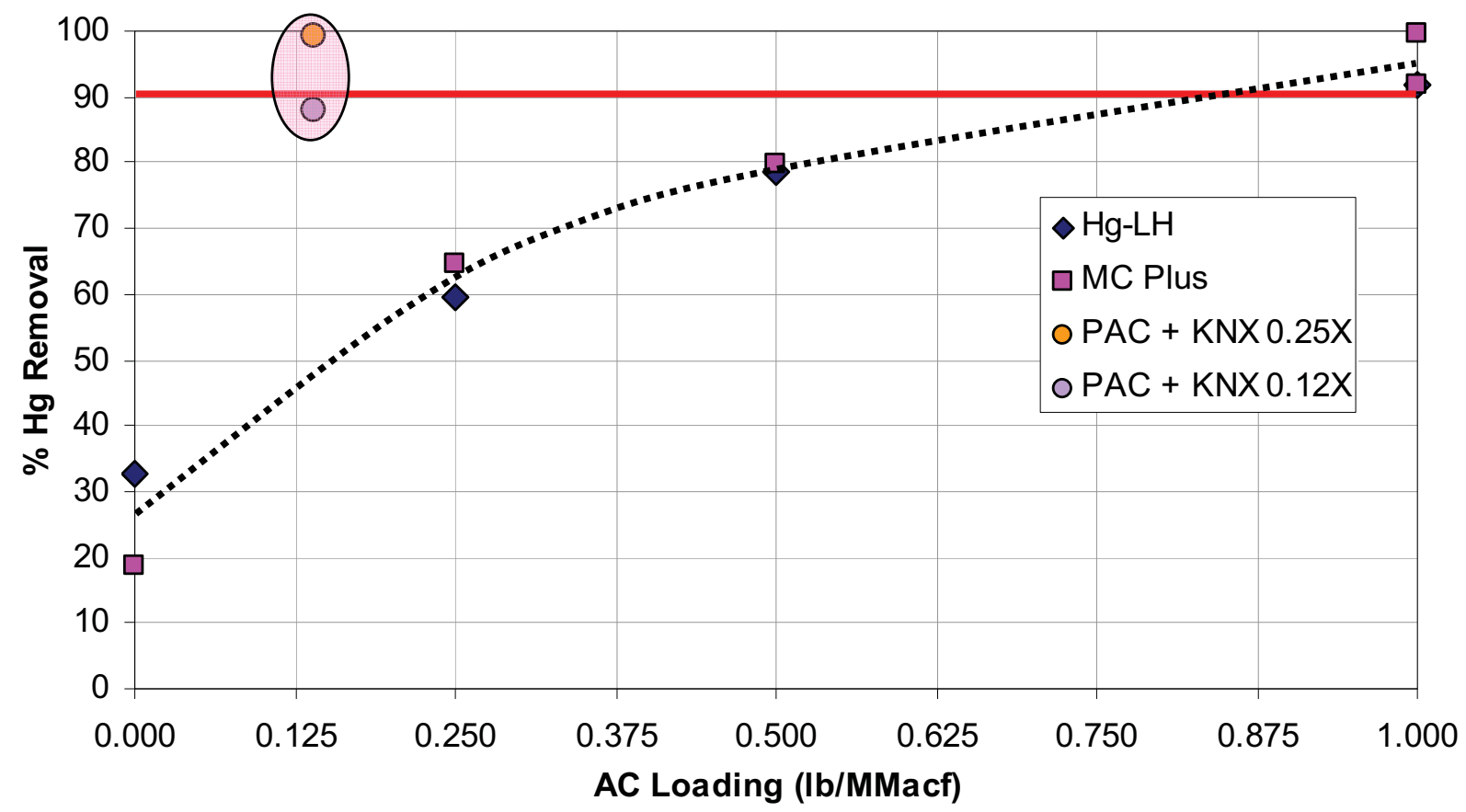

Figure 19. Mercury Removal for the Parametric Test.

\subsubsection{Optimization Test}

Upon completion of the Parametric tests, ADA reviewed results with the project team and identified the most promising options to achieve $90 \%$ mercury removal. Each option was then tested for a two-day period to verify performance. Following these tests, ADA compiled an informal report summarizing the results to guide the project team and DOE in choosing the system parameters for the Long-Term activated carbon injection test.

The Optimization test was conducted August 6-9, 2007. Two brominated sorbents were tested: Calgon FLUEPAC ${ }^{\text {TM}}$-MC PLUS and NORIT DARCO ${ }^{\circledR} \mathrm{Hg}-\mathrm{LH}$. Figure 20 and Figure 21 show that the sorbents performed about the same and achieved $90 \%$ mercury removal at a loading of $2.0 \mathrm{lb} / \mathrm{MMacf}$ during the two-day tests. When analyzing these figures, it is important to take boiler load into consideration. At low load (90 MW), the sorbents performed better because of the higher amount of oxidized mercury formed at this plant at low load. 

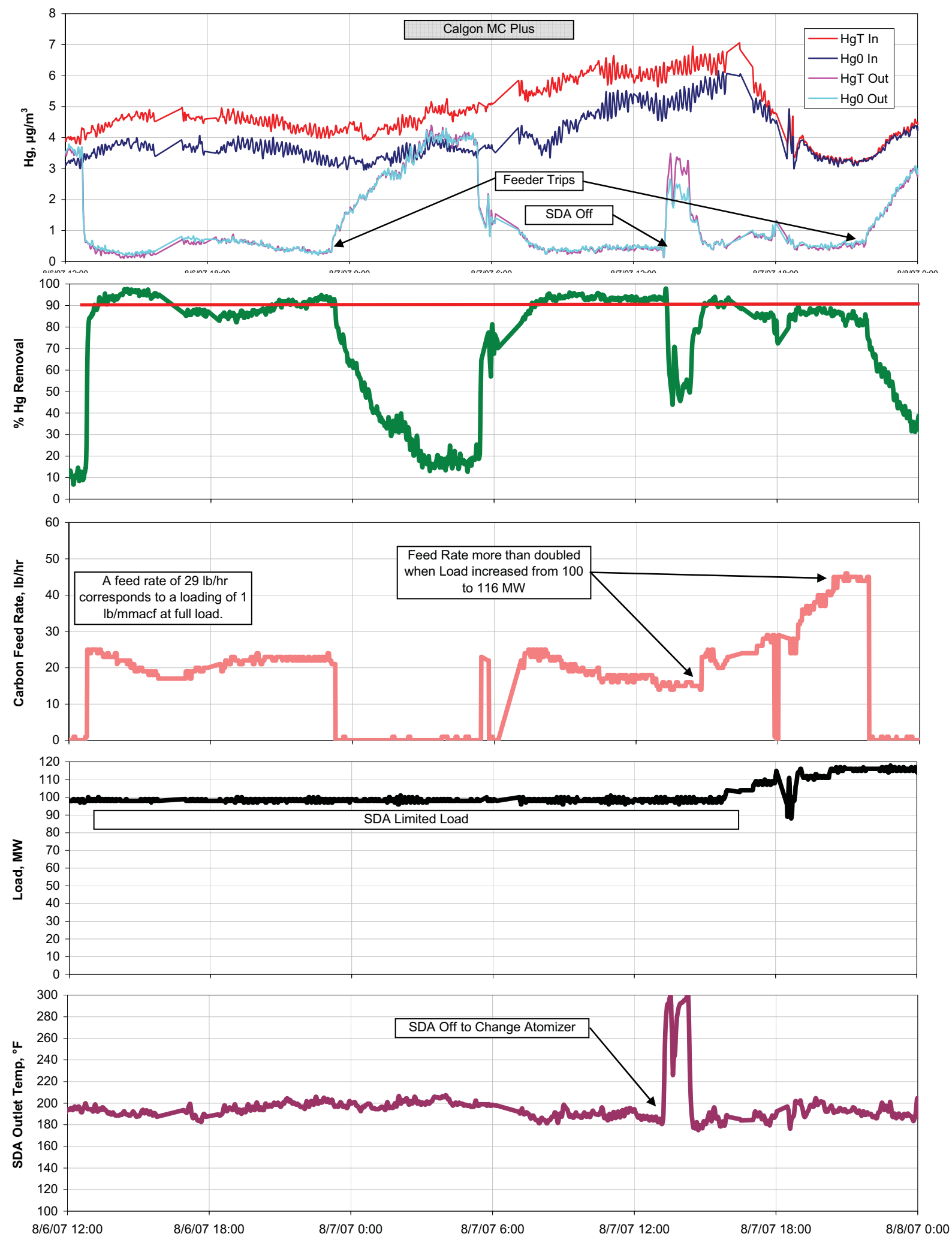

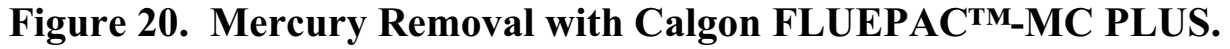



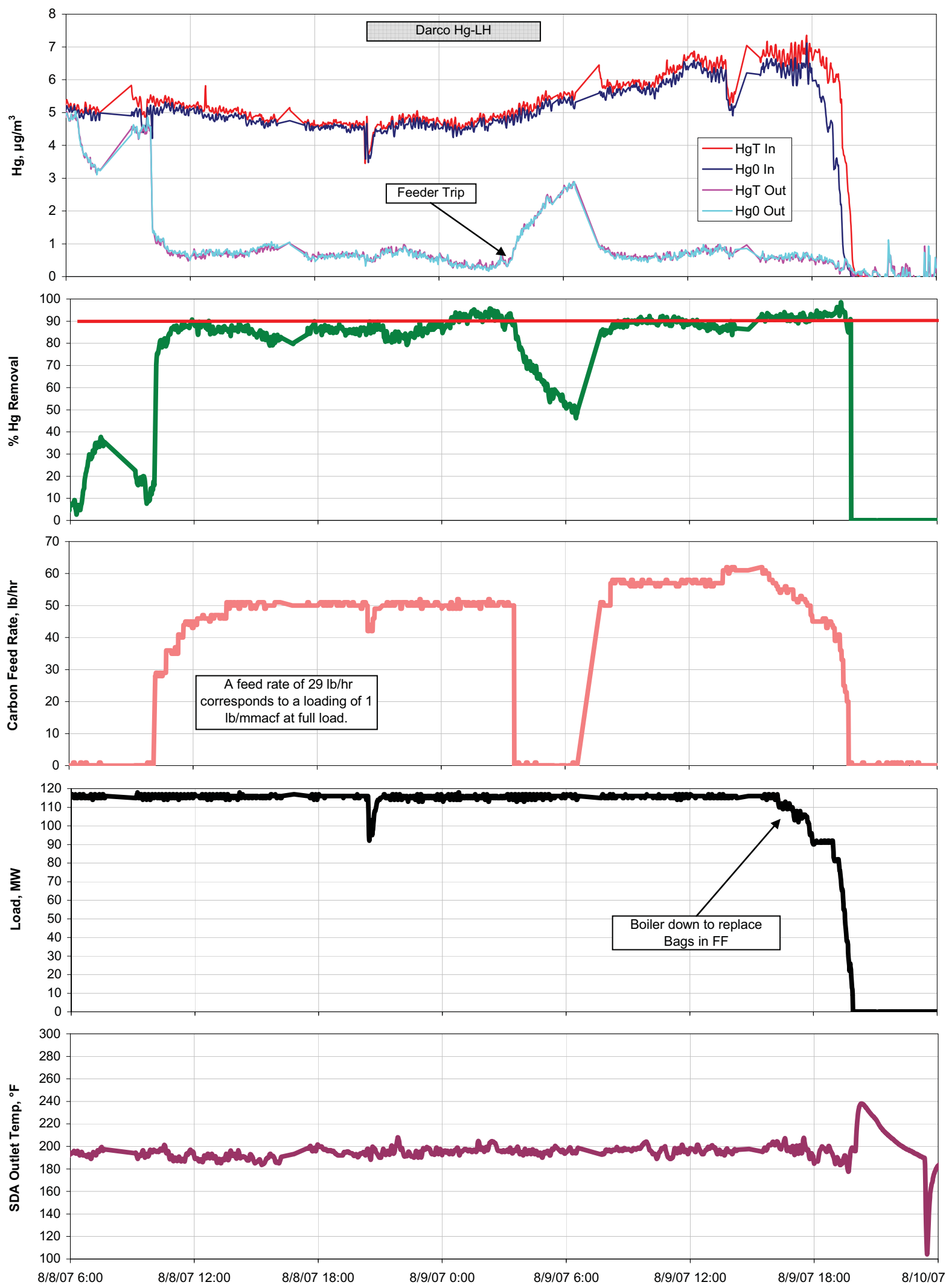

Figure 21. Mercury Removal with DARCO ${ }^{\circledR}$ Hg-LH. 


\subsubsection{Long-Term Test}

After approval from the DOE project officer, the selected sorbent identified in Task 3.4, HgLH, was continuously injected into the flue gas over a period eight months. A second sorbent, MC PLUS, was then tested for a two-month period. The Long-Term test was designed to collect the data necessary to evaluate whether sorbent injection created any longterm operational problems, whether $90 \%$ mercury control was sustainable, and to ascertain O\&M costs.

Long-Term test measurements included a second full suite of manual flue gas measurements (presented in 4.1.6.2) at the SDA inlet and stack involving Hg-CEM measurements, particulate, halogens, sulfur trioxide, and ammonia measurements. The accuracy of the HgCEM was verified via a Method 30A RATA, in lieu of O-H measurements, using a mercury analyzer approved as an instrumental reference method (IRM) under 40 CFR Part 75.22.

Notably, three events are so important to the general understanding of the project they are listed and discussed separately at this point.

1. Hg-CEM Nitrogen Generators (NG) - On September 5, 2007, nitrogen generators were installed on the Hg-CEMs as an upgrade offered by Thermo Fisher. The purpose of the NGs is to create an oxygen-free gas for use as a carrier gas for calibrations and as a sample dilution and carrier gas. This event is important because it significantly increased the reliability and precision of the $\mathrm{Hg}$-CEM measurements. Up to this time, signal variation was on the order of $\pm 0.5 \mu \mathrm{g} / \mathrm{wscm}$. This made it difficult to perform accurate calibrations and to interpret results when the mercury concentration at the stack fell below $0.5 \mu \mathrm{g} / \mathrm{wscm}$, which was often the case during coal additive and Parametric testing. The NGs reduced signal variation to nominally $\pm 0.05 \mu \mathrm{g} / \mathrm{wscm}$.

2. Step-Up Transformer Failure - The Long-Term test began on September 26, 2007. On December 15, 2007, the plant's step-up transformer failed. On February 5, 2008, this transformer was replaced with a temporary, smaller unit that limited operation to $106 \mathrm{MW}$ out of $121 \mathrm{MW}$. This is important because at low load the native mercury capture and, therefore, overall mercury capture increases at Hardin. This was discussed with the project team and it was decided to continue the Long-Term test in spite of the consequence to the interpretation of results. The original transformer was repaired and re-installed on July 22, 2008.

3. SCR Deposition - On March 13, 2008, shortly after the Long-Term test resumed with the temporary transformer, a tube leak caused $>25 \%$ of the SCR to be plugged with ash. To compensate for the reduced available SCR surface area, the plant increased ammonia flow to maintain $\mathrm{NO}_{\mathrm{x}}$ emission levels. However, the ammonia flow meter was not functioning properly and this significant operational change went unnoticed by ADA until the original transformer was reinstalled on July 22, 2008. At this time, mercury capture performance decreased significantly and it was discovered that excess ammonia negatively affects capture at full load (121 MW). The SCR was refurbished and the unit returned to "normal" operation on October 26, 2008. The Long-Term test ended on November 17, 2008. 
Taken in combination, these events reduced the time at which the unit was operating normally during the 12-month (total duration) Long-Term test to about two months. However, valuable information was gained about the effect of the SCR and excess ammonia on mercury capture.

The section below presents the long-term data from shortly after start-up and for every quarter thereafter. Operating data for the quarterly results are presented as bulleted highlights for each quarter. Some important information is given in these highlights such as when outages occurred and when upgrades to the Hg-CEMs were implemented, etc. Table 12 presents the entire timeline for the Long-Term test.

Table 12. Timeline for the Long-Term Test.

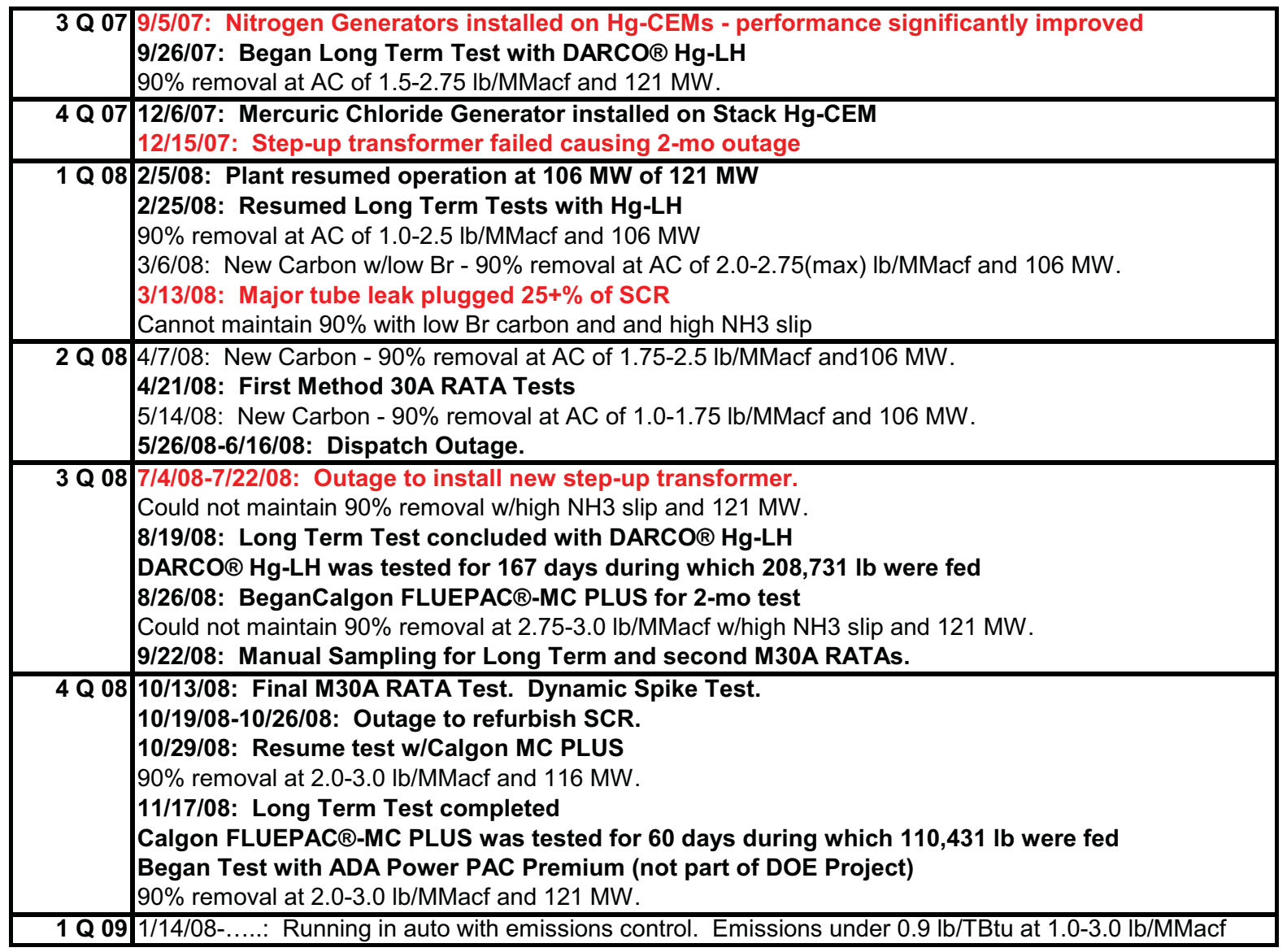




\subsubsection{Long-Term Test Data}

The first phase of the Long-Term test began on September 26, 2007. Shortly after start-up using DARCO ${ }^{\circledR} \mathrm{Hg}-\mathrm{LH}, 90 \%$ mercury removal was consistently achieved at a carbon loading of $1.5 \mathrm{lb} / \mathrm{MMacf}$ as shown in Figure 22. Removal increased to $95 \%$ at low load even though the carbon feed rate was automatically reduced by a ratio of the current load to full load.
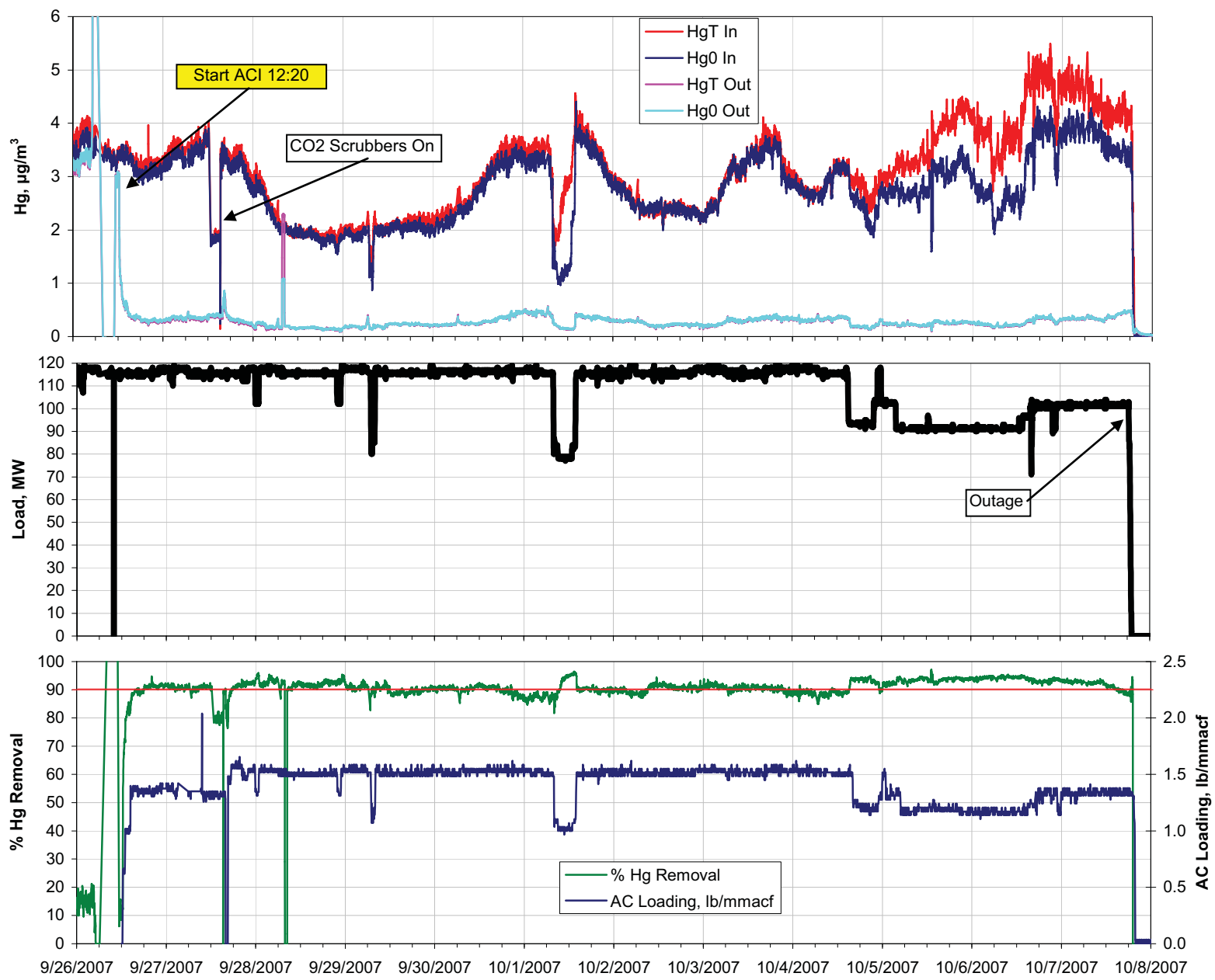

Figure 22. System Performance after the Start of the Long-Term Test. 
4Q07 Performance trends are presented in Figure 23.

- The goal of $90 \%$ mercury removal was achieved and often exceeded with DARCO ${ }^{\circledR} \mathrm{Hg}$ LH. At full load (121 MW), 90\% removal was maintained at ACI of 2.0-2.5 lb/MMacf.

- Inlet mercury concentration varied from $2-10 \mu \mathrm{g} / \mathrm{wscm}$.

-12/17/07: The plant's step-up transformer failed, leading to a 2-month outage.
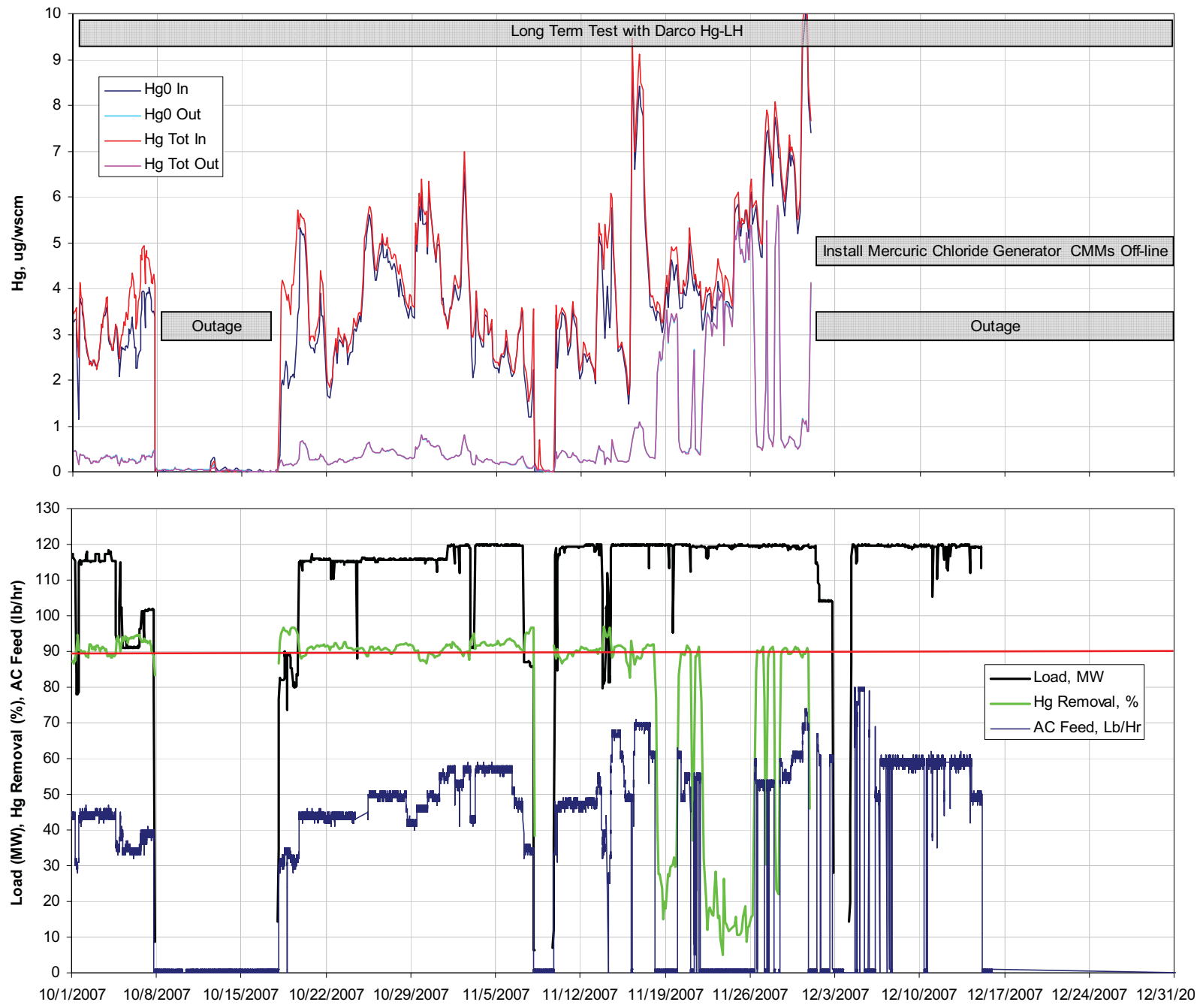

Figure 23. 4Q07 Long-Term Mercury Removal with DARCO ${ }^{\circledR}$ Hg-LH. 
1Q08 Performance trends are presented in Figure 24.

- Outage: $12 / 15 / 07-02 / 05 / 08$ : step-up transformer failure. A temporary, smaller transformer installed that limited load to $106 \mathrm{MW}$ out of $121 \mathrm{MW}$.

- 02/25/08: Resumed Long-Term tests with Hg-LH.

- At "full" load (106 MW), achieved 90\% removal at ACI of 1.5-2.75 lb/MMacf.

- 03/06/08: A new batch of PAC was received with low Br concentration; could not always achieve $90 \%$ removal with this PAC.

- 03/13/08: Tube leak plugged $25+\%$ of the SCR.

- Inlet mercury concentration varied from $2-12 \mu \mathrm{g} / \mathrm{wscm}$.

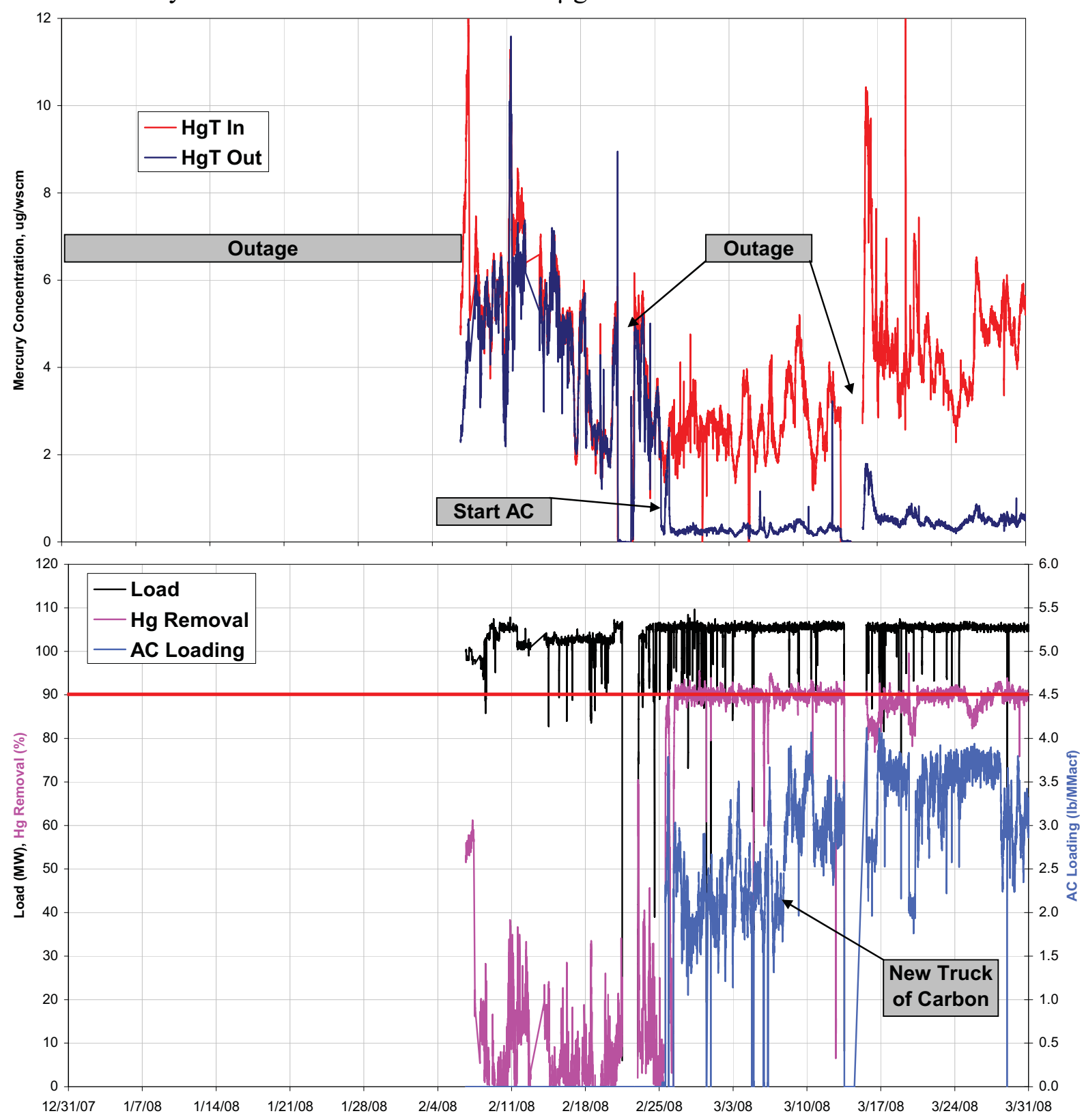

Figure 24. 1Q08 Long-Term Mercury Removal with DARCO ${ }^{\circledR}$ Hg-LH. 
There were several instances during 1Q08 when the system could not maintain $90 \%$ removal at the maximum feed rate of the screw feeder (about $3.75 \mathrm{lb} / \mathrm{MMacf}$ ). This was normally not an issue. Three theories were developed as to the cause of the poor performance. The first two were checked and discounted as discussed below.

1. Higher Baghouse Temperature - There was no significant difference in the baghouse temperature during this period compared to previous periods.

2. Poor inlet $\mathrm{Hg}$-CEM Measurements - The inlet CEM was operating well during this period according to the daily QA checks. An ADA representative inspected the system to assure proper operation and noted that the inlet stinger heater had failed. This was repaired but did not change the relative mercury measurements.

3. Inconsistent Batch of PAC - The poor performance appeared to correlate with the receipt of a new truckload of activated carbon. During a routine comparison of feed rates calculated by a) the loss in weight of the silo as determined by load cells, and b) the screw speed and a typical value for sorbent density, the difference in feed rate was found to be about $10 \%$ when, historically, the difference was less than $1 \%$. Further analyses of samples from the suspect batch and batches that performed well indicated leachable bromine content for the suspect batch of $2.5 \%$ when, historically, this value is around $5.5 \%$.

Later in the project, it was discovered that during this quarter, a tube leak in March plugged $25^{+} \%$ of the SCR with ash. This resulted in higher ammonia injection rates to maintain permitted $\mathrm{NO}_{\mathrm{x}}$ levels. The high ammonia levels were later determined to affect PAC performance (see section 4.1.3.4). However, because the boiler was de-rated to $106 \mathrm{MW}$ and the ammonia flow meter was not operating properly, the full effects of the compromised SCR were not realized until the original transformer was reinstalled and $121 \mathrm{MW}$ operations resumed. It is possible that the high ammonia rates, combined with the lower bromine content of one batch, resulted in the relatively poor performance observed during the latter part of this quarter. 
2Q08 Performance trends are presented in Figure 25.

- 04/21/08: The first Method 30A RATA test was performed on the Hg-CEMs.

- 05/14/08: A new batch of PAC gave 90\% removal at 1.0-1.75 lb/MMacf.

- Upgrade: Feedback control was implemented into the ACI control logic. The system was able to maintain $90 \%$ mercury removal in automatic.

- Inlet mercury concentration varied from $1-8 \mu \mathrm{g} / \mathrm{wscm}$.

- Outage: $05 / 26-06 / 16 / 08$ due to dispatch.
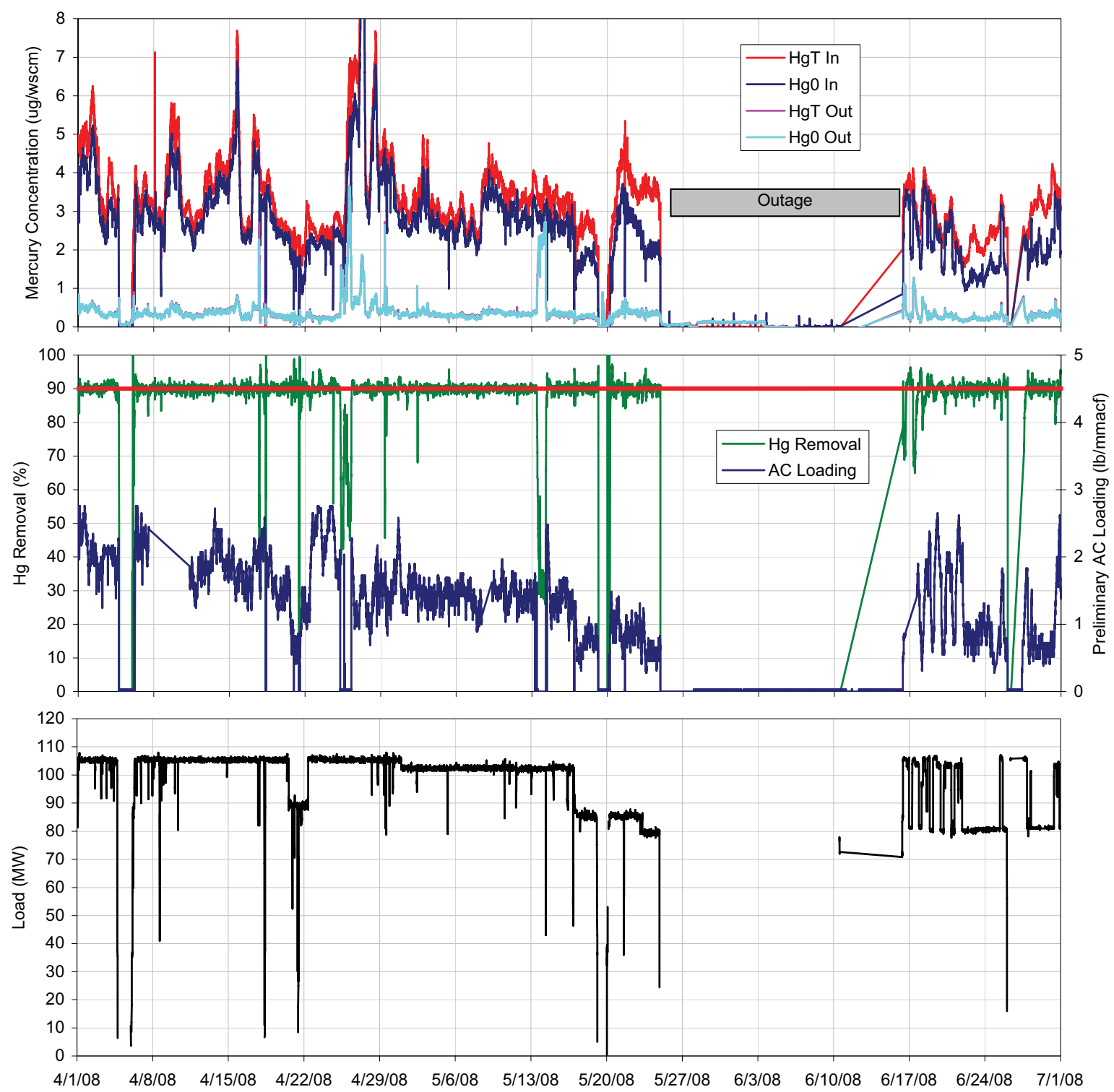

Figure 25. 2 Q08 Long-Term Mercury Removal with DARCO ${ }^{\circledR}$ Hg-LH 
3Q08 Performance trends are presented in Figure 26.

- 07/04-22/08: Outage to reinstall the $121 \mathrm{MW}$ step-up transformer.

- 90\% removal was not achieved at $121 \mathrm{MW}$ due to excess ammonia (see 4.1.3.4).

- 08/19/08: Long-Term test concluded with DARCO ${ }^{\circledR}$ Hg-LH. It was injected for 167 days during which $208,731 \mathrm{lb}$ were fed.

- 08/26/08: Began injecting Calgon FLUEPAC ${ }^{\text {TM}-M C ~ P L U S ~ f o r ~ a ~ t w o-m o n t h ~ t e s t . ~}$

- Could not maintain 90\% removal due to excess ammonia when operating at $121 \mathrm{MW}$.

- 09/22/08: Completed the manual sampling tests with ACI and the second M30A RATA.

- Inlet mercury concentration varied from $2-9 \mu \mathrm{g} / \mathrm{wscm}$.

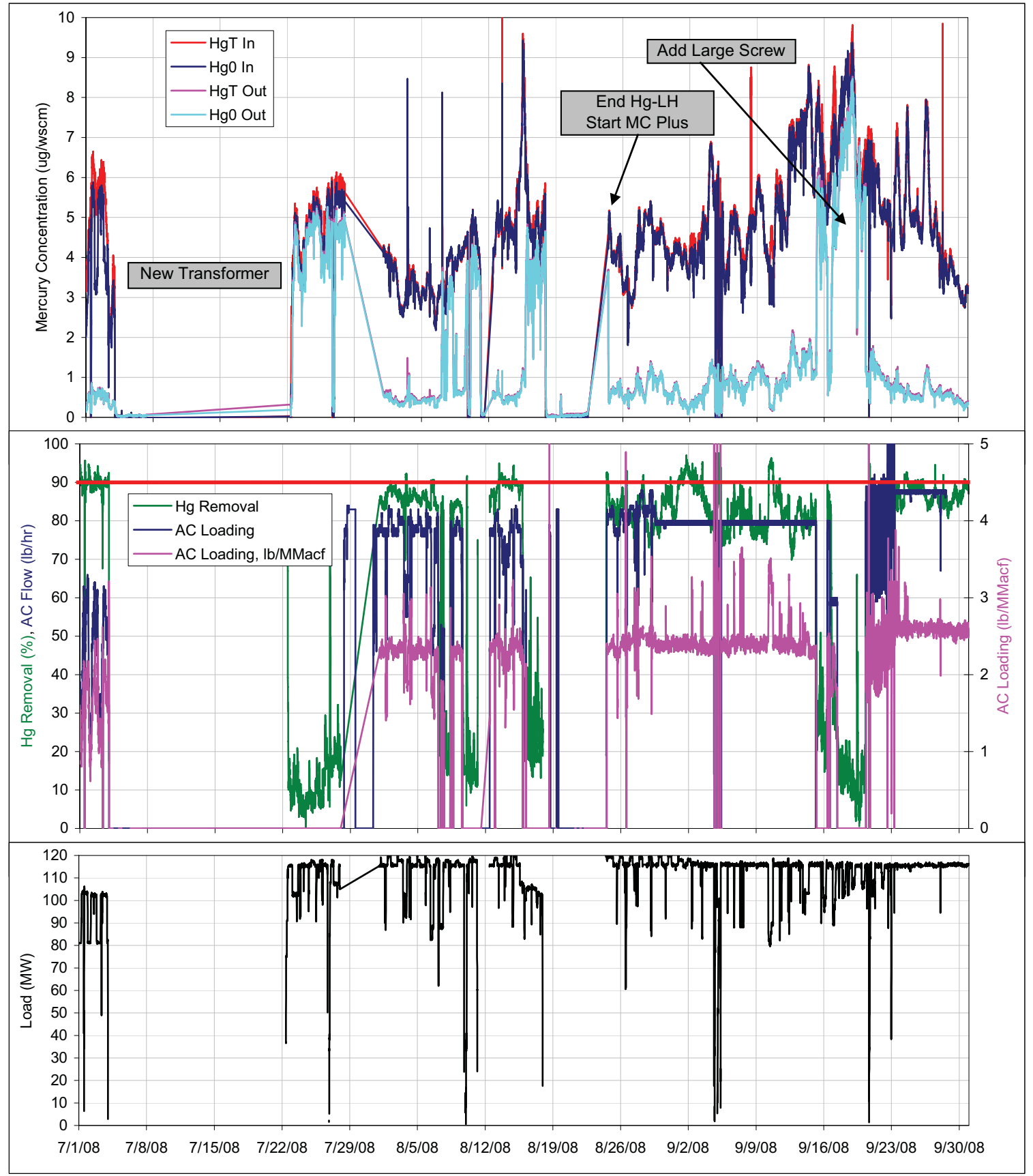

Figure 26. 3Q08 Mercury Removal with Hg-LH and MC PLUS. 
4Q08 Performance trends are presented in Figure 27.

-10/13/08: Completed the final M30A RATA Test including a Dynamic Spike Test.

- 10/19-26/08: Outage to refurbish the SCR.

- 10/29/08: Resume test with Calgon MC PLUS.

- Achieved 90\% removal at 2.0-3.0 lb/MMacf (116 MW).

-11/17/08: Completed the Long-Term test. Calgon FLUEPACTM-MC PLUS was tested for 60 days, during which 110,431 lb were fed.

- Began a test with ADA's Power PAC PREMIUM carbon (not part of the DOE project). Initial results showed $90 \%$ mercury removal at ACI of 1.0-2.0 lb/MMacf.

- Inlet mercury concentration varied from $2.5-8.5 \mu \mathrm{g} / \mathrm{wscm}$.

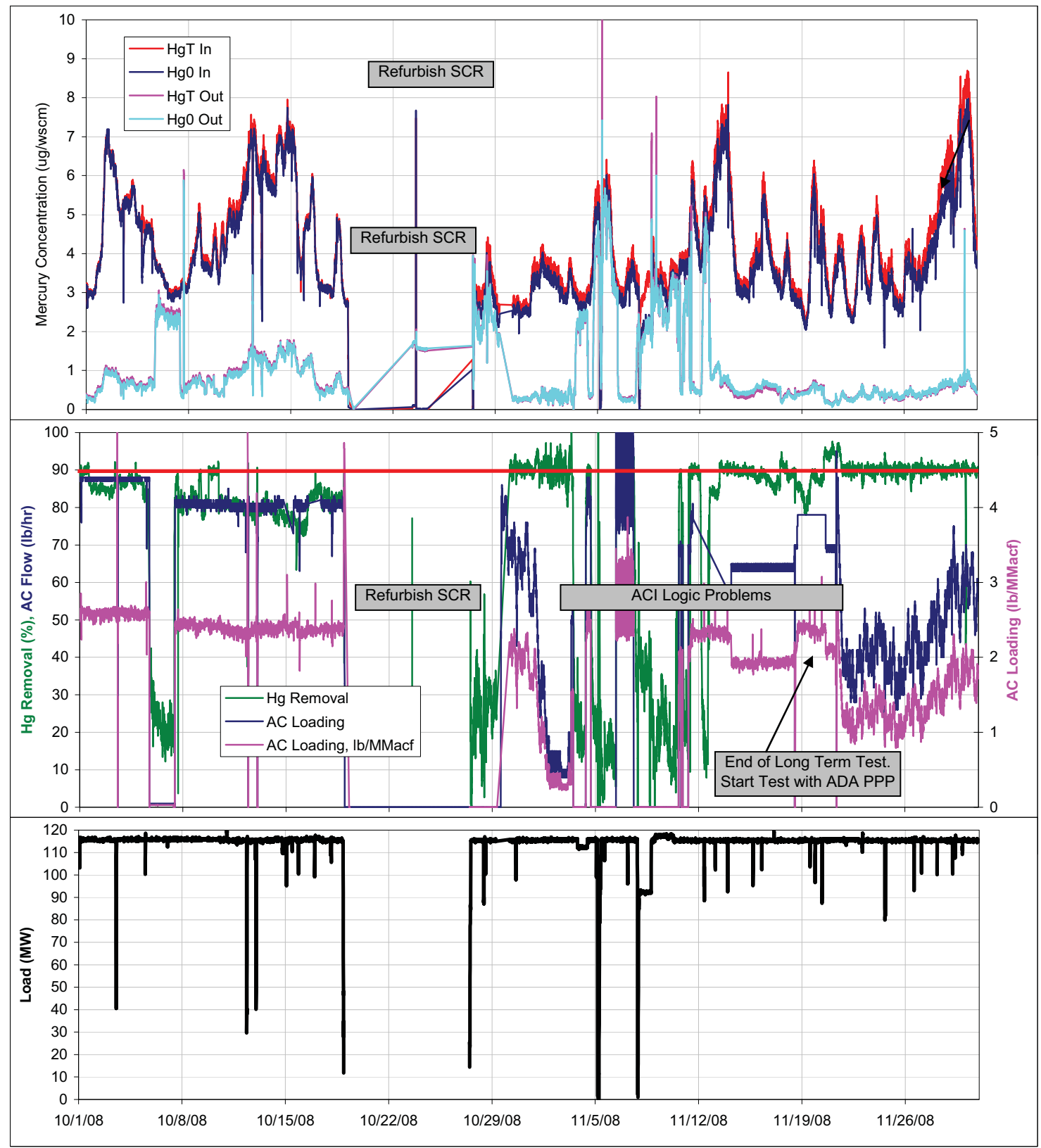

Figure 27. 4Q08 Mercury Removal with MC PLUS and ADA Power PAC PREMIUM. 


\subsubsection{Comparison of Baseline and Long-Term Source Testing}

Manual gas measurements were collected during baseline testing and after several months of ACI to determine the effects of ACI on emissions. Sampling was conducted at the AH outlet ahead of the ACI location and at the stack. Measurements at the AH Outlet included particulates, condensables $\left(\mathrm{SO}_{3}\right)$, halogens $(\mathrm{Cl}, \mathrm{HCl}, \mathrm{Br}, \mathrm{HBr}$, and $\mathrm{F})$, and ammonia. Measurements at the stack included particulates (including $\left.\mathrm{PM}_{10} / \mathrm{PM}_{2.5}\right)$, condensables $\left(\mathrm{SO}_{3}\right)$, and halogens $(\mathrm{Cl}, \mathrm{HCl}, \mathrm{Br}, \mathrm{HBr}$, and $\mathrm{F})$. Complete tables of all the sampling results are included in Appendix E.

Table 13 lists the sampling results at the AH Outlet/SDA Inlet. There was generally good agreement between the two test dates except that the $\mathrm{Cl}$ and $\mathrm{SO}_{3}$ values were slightly higher during the Long-Term tests, but this is likely caused by a difference in boiler operation and coal properties than as a result of PAC injection. It should be noted that the high ammonia value for the Long-Term test is unrepresentative of normal operations. The plant was injecting at high ammonia rates during this period because the SCR was more than $25 \%$ plugged with ash and the high rates were needed to maintain permitted $\mathrm{NO}_{\mathrm{x}}$ levels. After the SCR was refurbished, ammonia usage dropped significantly.

Table 13. Comparison of Baseline and Long-Term Gas Measurements at the SDA Inlet at Hardin.

\begin{tabular}{|c|c|c|}
\hline Particulate, Ammonia, Halogens, $\mathrm{SO}_{3}$ & Baseline & Long Term \\
\hline Test Date & $12 / 2006$ & $9 / 2008$ \\
\hline Flow Rate - DSCFM (STP=29.92"Hg, 68 F) & 292,800 & 293,196 \\
\hline Gas Temp. $-{ }^{\circ} \mathrm{F}$ & 319 & 333 \\
\hline $\mathrm{O}_{2}-\%$ Vol. (dry) & 5.6 & 5.6 \\
\hline $\mathrm{CO}_{2}-\%$ Vol. (dry) & 13.8 & 13.9 \\
\hline Moisture Content - \% & 10.69 & 11.12 \\
\hline $\begin{array}{ll}\text { Particulate } & -\mathrm{gr} / \mathrm{dscf} \text { (Front Half) } \\
& -\mathrm{lbs} / \mathrm{hr} \text { (Front Half) }\end{array}$ & $\begin{array}{r}4.2394 \\
10640\end{array}$ & $\begin{array}{r}4.6874 \\
11786\end{array}$ \\
\hline Ammonia - ppm & 3.2 & 57.34 \\
\hline Chlorine & $\begin{array}{l}0.175 \\
0.263\end{array}$ & $\begin{array}{l}0.611 \\
0.836\end{array}$ \\
\hline Hydrogen Chloride & $\begin{array}{l}\mathrm{ND} \\
\mathrm{ND}\end{array}$ & $\begin{array}{l}0.676 \\
0.914\end{array}$ \\
\hline Bromine & $\begin{array}{l}\mathrm{ND} \\
\mathrm{ND}\end{array}$ & $\begin{array}{l}<0.080 \\
<0.110\end{array}$ \\
\hline Hydrogen Bromide & $\begin{array}{l}\text { ND } \\
\text { ND }\end{array}$ & $\begin{array}{l}<0.024 \\
<0.034\end{array}$ \\
\hline Hydrogen Fluoride & $\begin{array}{l}\text { ND } \\
\text { ND }\end{array}$ & $\begin{array}{l}<0.027 \\
<0.038\end{array}$ \\
\hline $\begin{array}{l}\text { Sulfur Trioxide } \\
\text { - Moisture Content - \% } \\
\text { - Sample Volume - DSCM } \\
\text { - ppm }\end{array}$ & $\begin{array}{r}0.555 \\
10.48 \\
3.50\end{array}$ & $\begin{array}{r}0.514 \\
10.50 \\
5.99\end{array}$ \\
\hline
\end{tabular}


Table 14 lists the particulate and halogen values measured at the stack. The table shows that there was no significant difference in the particulate concentration at the stack during Baseline $(22.1$ and $18.9 \mathrm{lb} / \mathrm{hr}$ ) and ACI testing $(20.1 \mathrm{lb} / \mathrm{hr})$. It also shows that there was no measurable amount of halogens, including bromine, in the stack gas except for some $\mathrm{Cl}$ measured during the final tests in concentrations just above the detection limit.

Table 14. Comparison of Baseline and Long Term Gas Measurements at the Stack at Hardin.

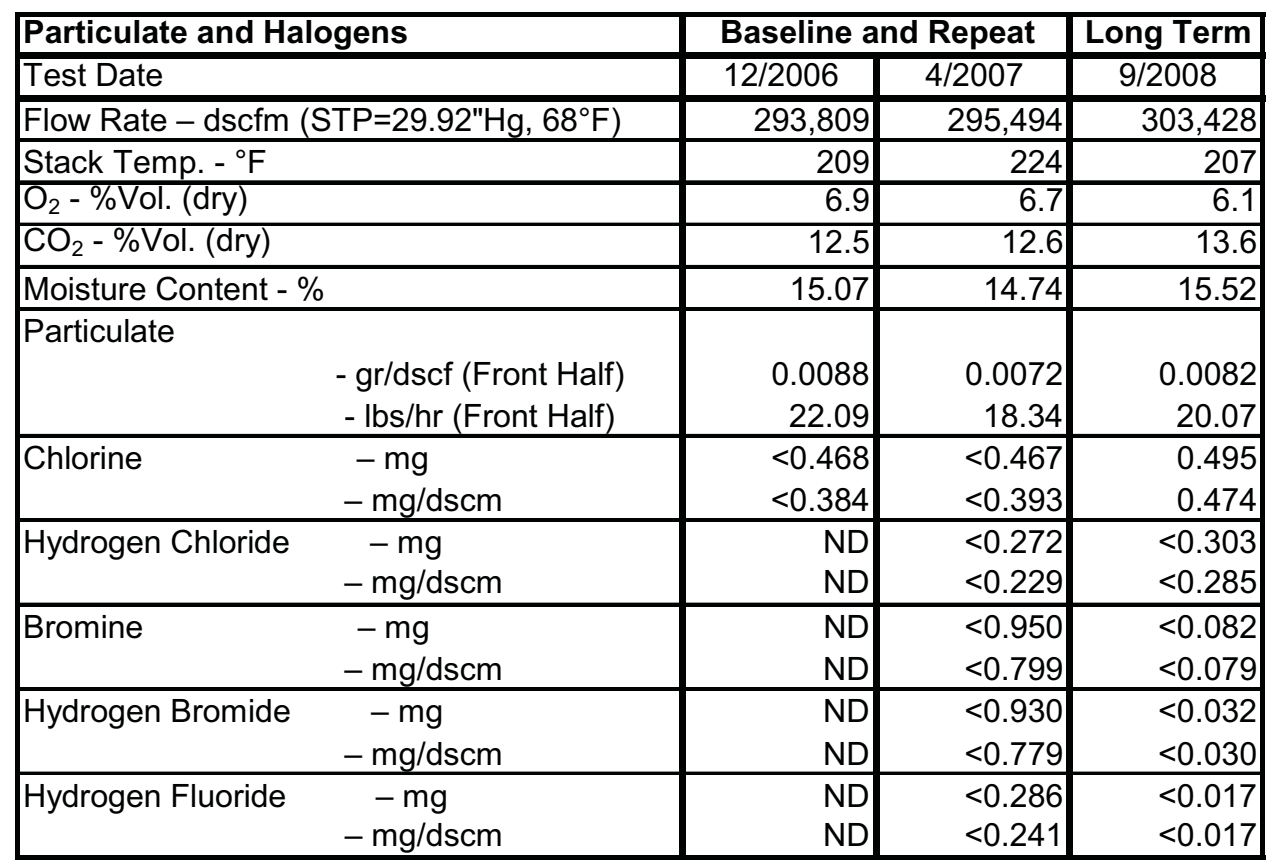

Table 15 lists the results of $\mathrm{PM}_{10} / \mathrm{PM}_{2.5}$ and $\mathrm{SO}_{3}$ measurements. The table shows a slight increase in the $>\mathrm{PM}_{10}$ level and slight decreases in the $<\mathrm{PM}_{10}>\mathrm{PM}_{2.5}$ and $\mathrm{PM}_{2.5}$ levels. These results indicate the $\mathrm{ACI}$ had no significant effect on fine particulate emissions. 
Table 15. Comparison of Baseline and Long-Term PM and $\mathrm{SO}_{3}$ Measurements at the Stack at Hardin.

\begin{tabular}{|c|c|c|}
\hline Particulate $\mathrm{PM}_{10} / \mathrm{PM}_{2.5}$ and $\mathrm{SO}_{3}$ & Baseline & Long Term \\
\hline Test Date & 09/2007 & $9 / 2008$ \\
\hline Flow Rate - dscfm $\left(\mathrm{STP}=29.92 " \mathrm{Hg}, 68^{\circ} \mathrm{F}\right)$ & 311,182 & 285,972 \\
\hline Stack Temp. $-{ }^{\circ} \mathrm{F}$ & 220 & 212 \\
\hline O2 - \%Vol. (dry) & 6.7 & 6.2 \\
\hline CO2 - \%Vol. (dry) & $\overline{12.8}$ & $\overline{13.4}$ \\
\hline Percent Excess Air & 46.1 & 41 \\
\hline Moisture Content - \% & 15.18 & 15.24 \\
\hline Particulate (>PM10) & $\begin{array}{r}0.0030 \\
7.90 \\
\end{array}$ & $\begin{array}{r}0.0044 \\
10.76 \\
\end{array}$ \\
\hline $\begin{array}{cc}\text { Particulate (<PM10>PM2.5) } & -\mathrm{gr} / \mathrm{dscf} \\
& -\mathrm{lbs} / \mathrm{hr} \\
\end{array}$ & $\begin{array}{r}0.0030 \\
7.90 \\
\end{array}$ & $\begin{array}{r}0.0031 \\
7.70 \\
\end{array}$ \\
\hline Particulate (PM2.5) & $\begin{array}{r}0.0023 \\
6.31\end{array}$ & $\begin{array}{r}0.0022 \\
5.27\end{array}$ \\
\hline Particulate Total & $\begin{array}{r}0.0083 \\
22.11 \\
\end{array}$ & $\begin{array}{r}0.0097 \\
23.73 \\
\end{array}$ \\
\hline $\begin{array}{l}\text { Sulfur Trioxide } \\
\text { - Moisture Content - \% } \\
\text { - Sample Volume - DSCM } \\
\text { - ppm }\end{array}$ & $\begin{array}{r}14.88 \\
0.508 \\
1.10\end{array}$ & $\begin{array}{r}15.66 \\
0.518 \\
1.22\end{array}$ \\
\hline
\end{tabular}

\subsection{Coal and Coal Byproduct Sample Evaluation}

Samples of coal and ash were collected and analyzed in conjunction with the baseline and Long-Term tests. Sample locations at Hardin are shown in Figure 28. Ultimate, proximate, and calorific analyses were performed on select coal samples as well as determinations for mercury and halogen content. Fly ash, bottom ash, and SDA slurry samples were analyzed for mercury content, LOI carbon, total carbon, and organic carbon. Ash sample from Baseline and Long-Term tests were analyzed by the synthetic groundwater leaching procedure (SGLP) for mercury and other trace constituent stability. Several large FF ash samples (five gallon) were also collected in accordance with DOE/NETL requirements from the Baseline and Long-Term tests and sent to DOE. A complete accounting of all chemical analyses is included in Appendix F. 


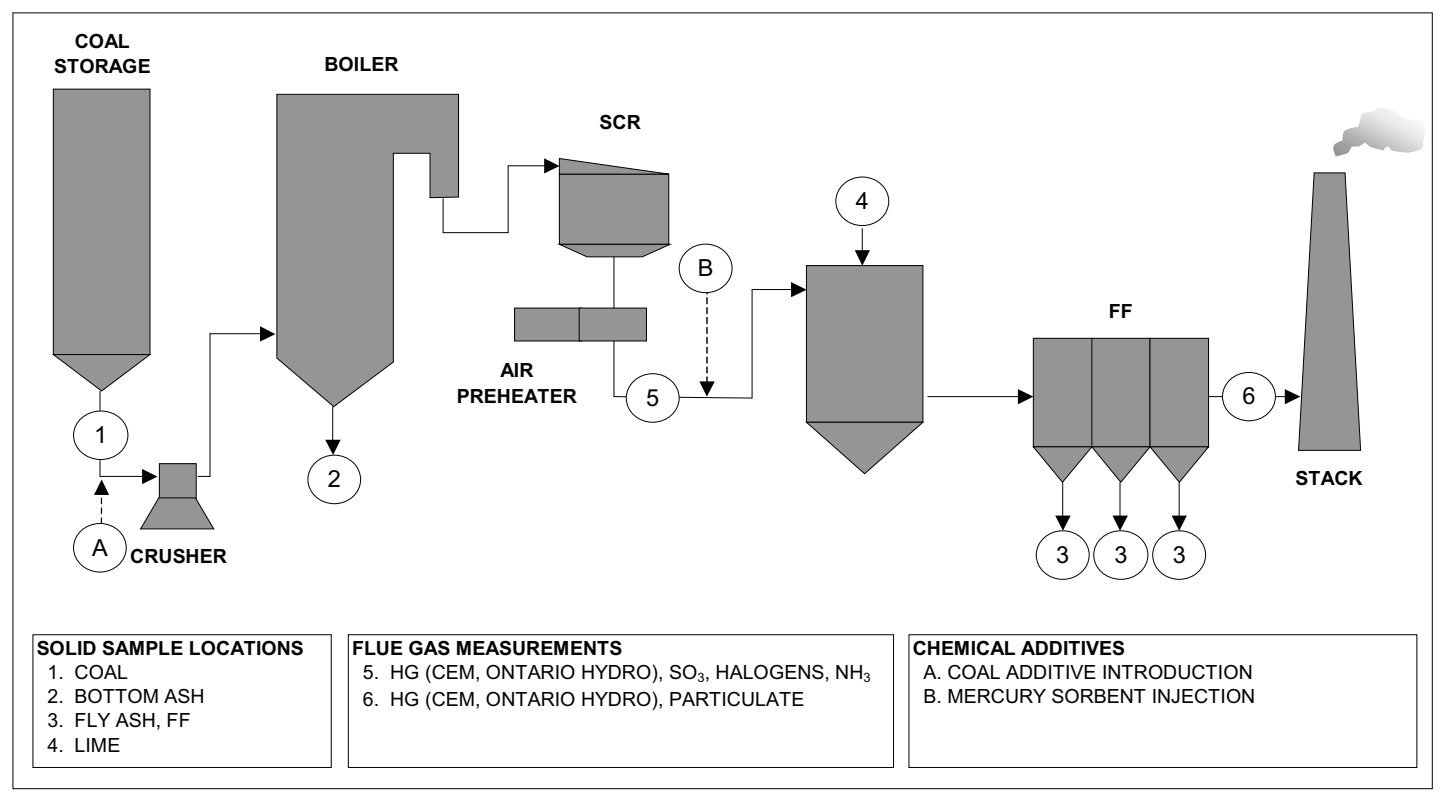

Figure 28. Sampling Locations at Hardin.

\subsubsection{SGLP Results}

The synthetic groundwater leaching procedure (SGLP) was developed at the University of North Dakota Energy and Environmental Research Center (EERC). It was designed to simulate the leaching of coal combustion byproducts (CCB) under more realistic conditions than the toxicity characteristic leaching procedure (TCLP). SGLP is modeled after TCLP, but uses deionized water for leaching, instead of an acidic solution, to more closely simulate the conditions found in a sanitary landfill. In the SGLP, samples are diluted 20:1 (liquid to solid ratio) and then agitated end-over-end. Samples are extracted after 18 hours and 20 days and analyzed for trace constituents. Hydration reactions that can take days or weeks to complete often incorporate trace toxins so that the 30-day concentration of these species is often lower than the 18-hour concentration.

An SGLP was conducted on a baseline (no ACI) ash sample and a sample collected after months of ACI with a brominated PAC. Trace materials, including bromide, chloride, fluoride, arsenic, selenium, and mercury, were measured after 18 hours and 30 days of agitation. The concentrations of these species were also measured in the raw samples to determine a maximum possible concentration for the leachate. These values are represented by "Max" in the following table and figure.

Table 16 and Figure 29 show the results of the SGLP. The leachate concentrations in the six figures are compared to EPA's maximum containment level (MCL) for drinking water for all species except chloride and bromide that have no MCL. MCL levels are much stricter than the RCRA leaching values for sanitary landfills. In all cases, the leachate concentrations are below the MCL and decrease over time due to slow reactions with other ash constituents. The figures also show that, although the use of a brominated PAC increases the mercury concentration in the waste ash, the mercury does not leach from the sample. The table also gives the percentage of total constituent (Max) that was measured in the leachate. 
Table 16. SGLP Results on Baseline and Long-Term Ash Samples.

\begin{tabular}{|c|r|r|r|r|}
\hline Arsenic & \multicolumn{4}{|c|}{ FF-B Ash } \\
\cline { 2 - 5 } mg/L & Baseline & $\%$ Leach & Long Term & \% Leach \\
\hline Max & 0.25 & & 0.35 & \\
\hline 18-hr & $<0.01$ & \#N/A & $<0.01$ & \#N/A \\
\hline 30-day & $<0.01$ & \#N/A & $<0.01$ & \#N/A \\
\hline
\end{tabular}

\begin{tabular}{|c|r|r|r|r|}
\hline Bromide & \multicolumn{4}{|c|}{ FF-B Ash } \\
\cline { 2 - 5 } mg/L & Baseline & \% Leach & Long Term & \% Leach \\
\hline Max & 1.00 & & 6.5 & \\
\hline 18-hr & 1.33 & 133 & 5.35 & 82 \\
\hline 30-day & 0.29 & 29 & 3.26 & 50 \\
\hline
\end{tabular}

\begin{tabular}{|c|r|r|r|r|}
\hline \multirow{2}{*}{$\begin{array}{c}\text { Chloride } \\
\mathrm{mg} / \mathrm{L}\end{array}$} & \multicolumn{4}{|c|}{ FF-B Ash } \\
\hline Max & 31 & & 27 & \\
\hline 18-hr & 24 & 77 & 17 & 63 \\
\hline 30-day & 23 & 74 & 16 & 59 \\
\hline
\end{tabular}

\begin{tabular}{|c|r|r|r|r|}
\hline \multirow{2}{*}{$\begin{array}{c}\text { Fluoride } \\
\mathrm{mg} / \mathrm{L}\end{array}$} & \multicolumn{4}{|c|}{ FF-B Ash } \\
\cline { 2 - 5 } & Baseline & \% Leach & Long Term & \% Leach \\
\hline Max & 16.5 & & 19.5 & \\
\hline 18-hr & 2.33 & 14 & 2.33 & 12 \\
\hline 30-day & 0.05 & 0 & 0.12 & 1 \\
\hline
\end{tabular}

\begin{tabular}{|c|r|r|r|r|}
\hline \multirow{2}{*}{$\begin{array}{c}\text { Selenium } \\
\mathrm{mg} / \mathrm{L}\end{array}$} & \multicolumn{5}{|c|}{ FF-B Ash } \\
\cline { 2 - 5 } & Baseline & \% Leach & Long Term & $\%$ Leach \\
\hline Max & 0.25 & & 0.2 & \\
\hline 18-hr & 0.01 & 4 & $<0.01$ & \#N/A \\
\hline 30-day & $<0.01$ & \#N/A & $<0.01$ & \#N/A \\
\hline
\end{tabular}

\begin{tabular}{|c|r|r|r|r|}
\hline Mercury & \multicolumn{4}{|c|}{ FF-B Ash } \\
\cline { 2 - 5 } $\mathrm{mg} / \mathrm{L}$ & Baseline & $\%$ Leach & Long Term & $\%$ Leach \\
\hline Max & 0.00373 & & 0.0133 & \\
\hline 18-hr & 0.000113 & 3 & $3.37 \mathrm{E}-05$ & 0 \\
\hline 30-day & $5.4 \mathrm{E}-07$ & 0 & $9.9 \mathrm{E}-07$ & 0 \\
\hline
\end{tabular}



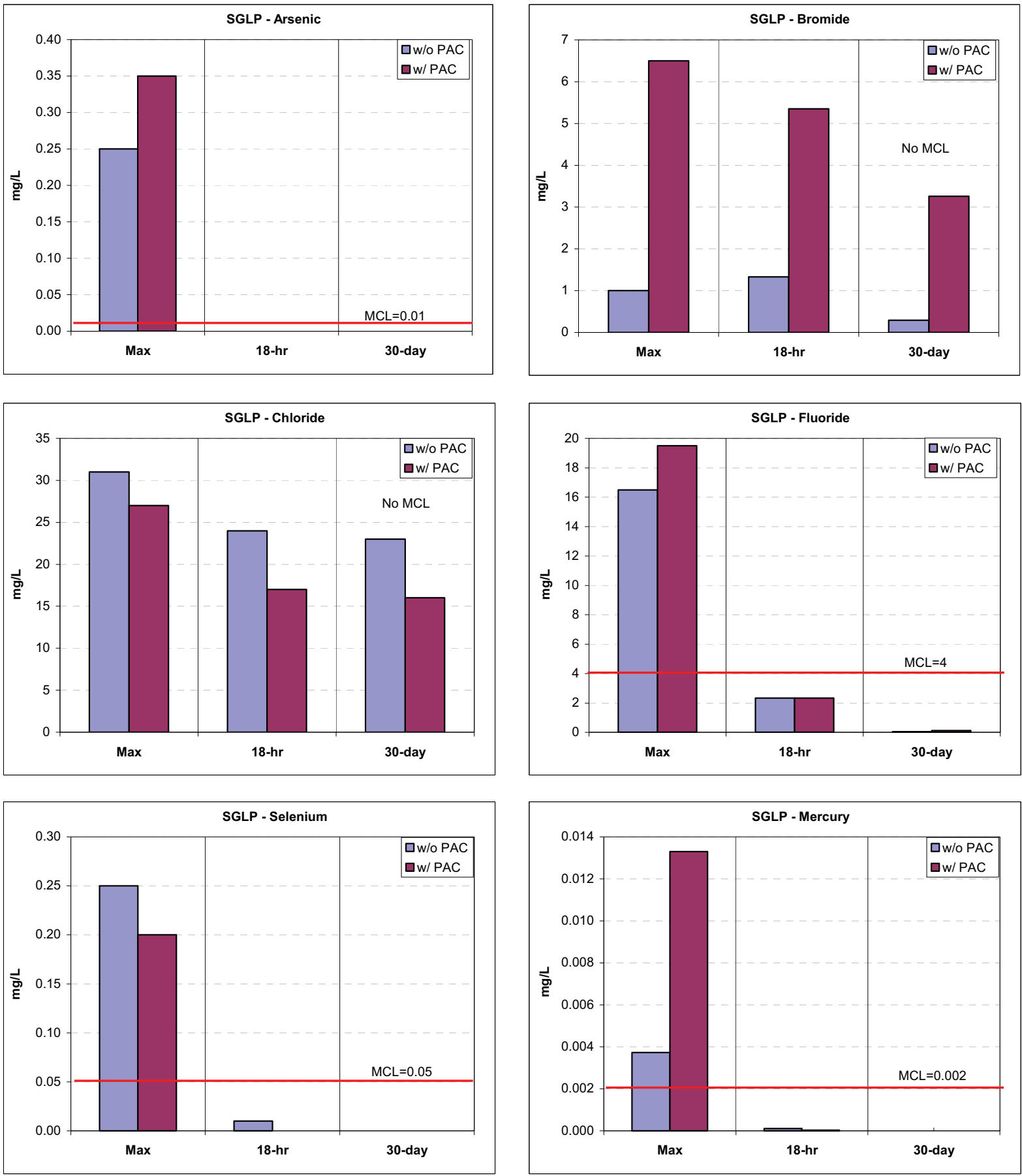

Figure 29. Results of the SGLP Leaching Test on Ash Samples with and without Carbon Injection.

\subsubsection{Ash Analysis With and Without PAC}

Ash samples were collected from the six FF hoppers on several occasions and from the B hopper on a regular basis. The samples were analyzed for moisture, carbon, and mercury. Samples of bottom ash and SDA slurry were also analyzed for mercury and found to contain less than the detection limit. 
Early in the test, the values obtained for carbon concentration in the ash were uncharacteristically high. The method used to determine the carbon levels was the loss on ignition (LOI) test. This test involves weighing, drying, weighing, and then heating the sample to drive off carbon, followed by a final weighing. However, it is known that for ash containing SDA solids, this method produces falsely high values probably because the heating process also drives off waters of hydration bound to the calcium sulphite and sulphate formed in the SDA. Therefore, the test procedure was changed to one that determines total carbon. However, these values also seemed high and the reason was traced to the fact that SDA solids contain a small amount of calcium carbonate from the lime used in the scrubbing process. Finally, a test was chosen that measures only organic carbon, not carbon tied up with other species like carbonates. This test produced results consistent with LOI values obtained from ash samples collected upstream of the SDA. Figure 30 shows the results of three analyses performed on the same ash samples.

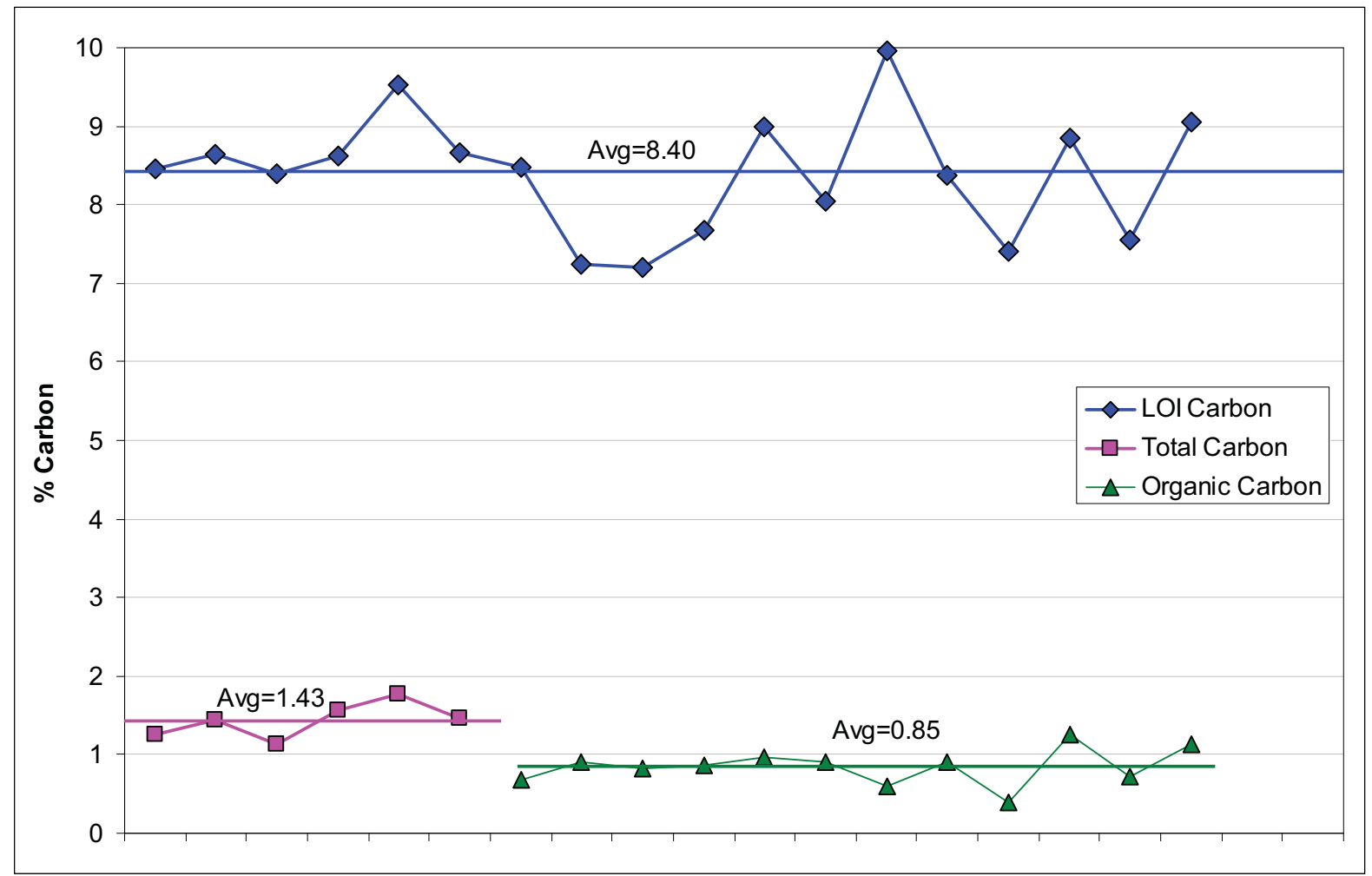

Figure 30. Comparison of LOI, Total, and Organic Carbon in Ash with SDA Solids.

Figure 31 shows the results of analyses performed on ash samples taken in-situ from the duct upstream of the SDA and downstream of the ACI location. The ash was collected with a device known as a CEGRT. The figure shows that both carbon and mercury concentration increases as carbon loading increases. The carbon increase was expected, however the increase in ash mercury indicates that mercury was being absorbed onto the carbon even before the SDA and FF. 


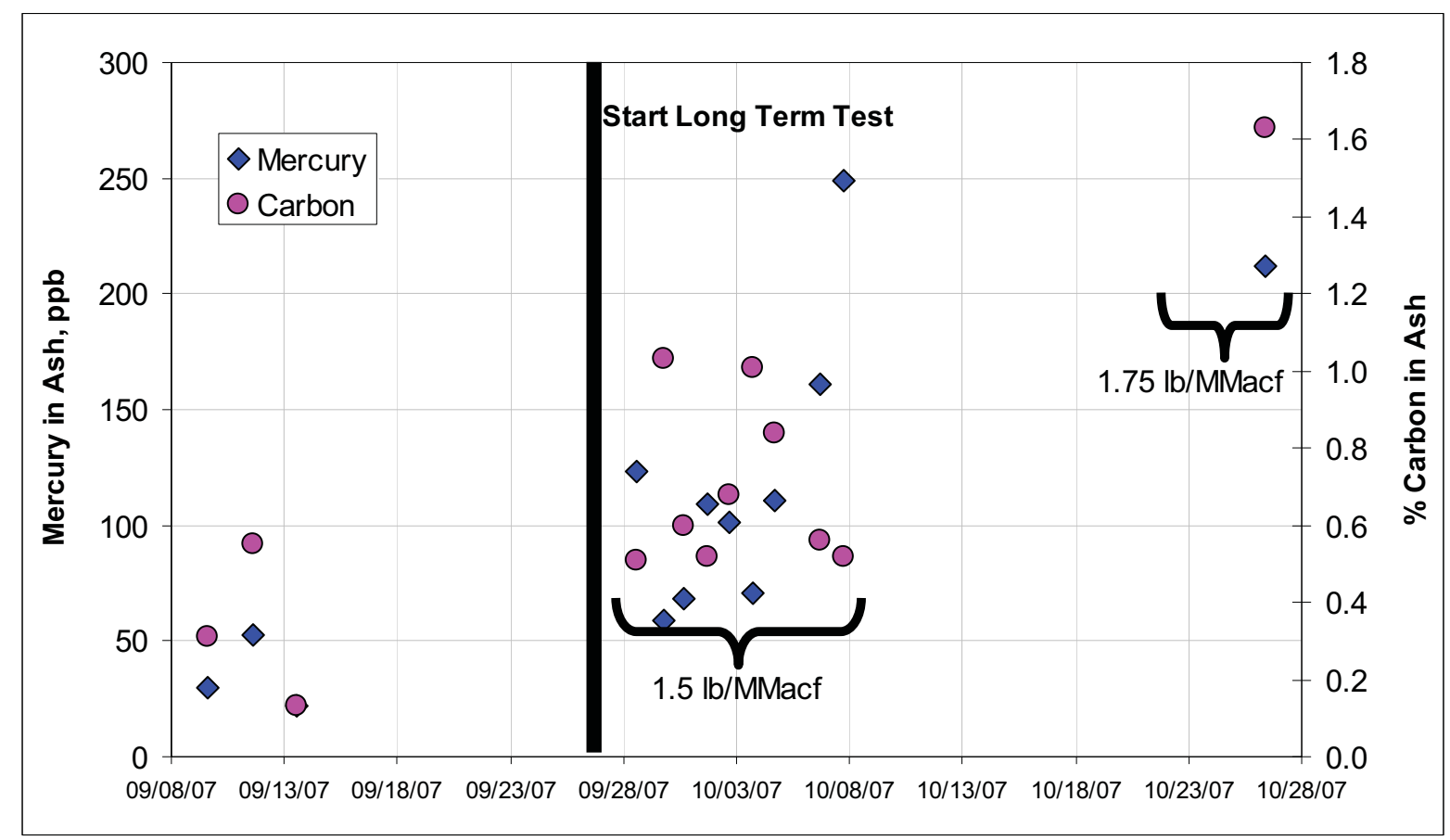

Figure 31. CEGRIT In-Situ Ash Analyses Downstream of the ACI Location.

Figure 32 is included to demonstrate the time required for the mercury concentration in the FF ash to reach a steady value. A large portion of the ash at Hardin is re-slurried and reinjected into the SDA to increase lime utilization and to increase the solids concentration of the lime/ash slurry mixture. The large hold-up of material in the ash slurry tanks increases the time required for the mercury in the ash to reach a steady level. It also makes it difficult to obtain a representative sample of ash from the hoppers for any short-term test. The figure shows that it takes at least several days for the ash mercury to reach a steady value.

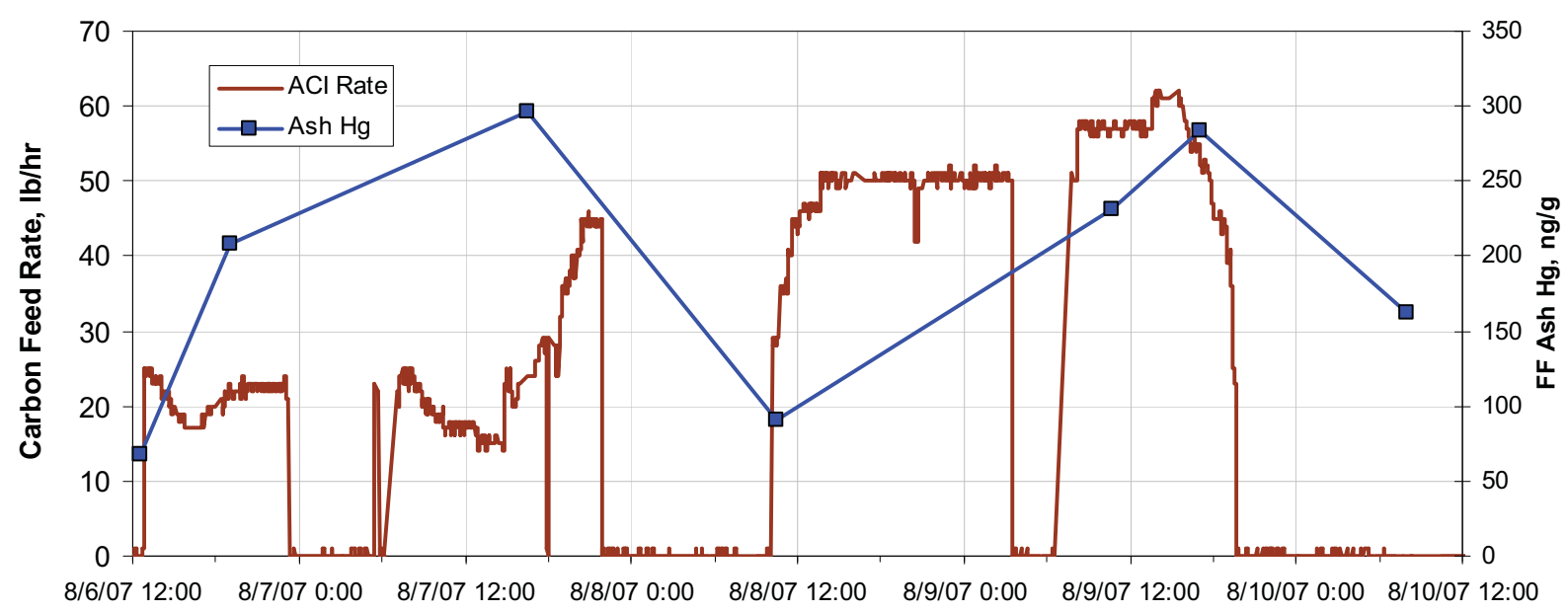

Figure 32. Mercury in FF Ash Samples during the Optimization Test. 
Figure 33 shows how the mercury and bromine concentration in the ash increased during the coal additive test with KNX. Mercury concentration increased from an average of 53 to 158 $\mathrm{ppb}$ and bromine increased from 4 to $181 \mathrm{ppm}$.

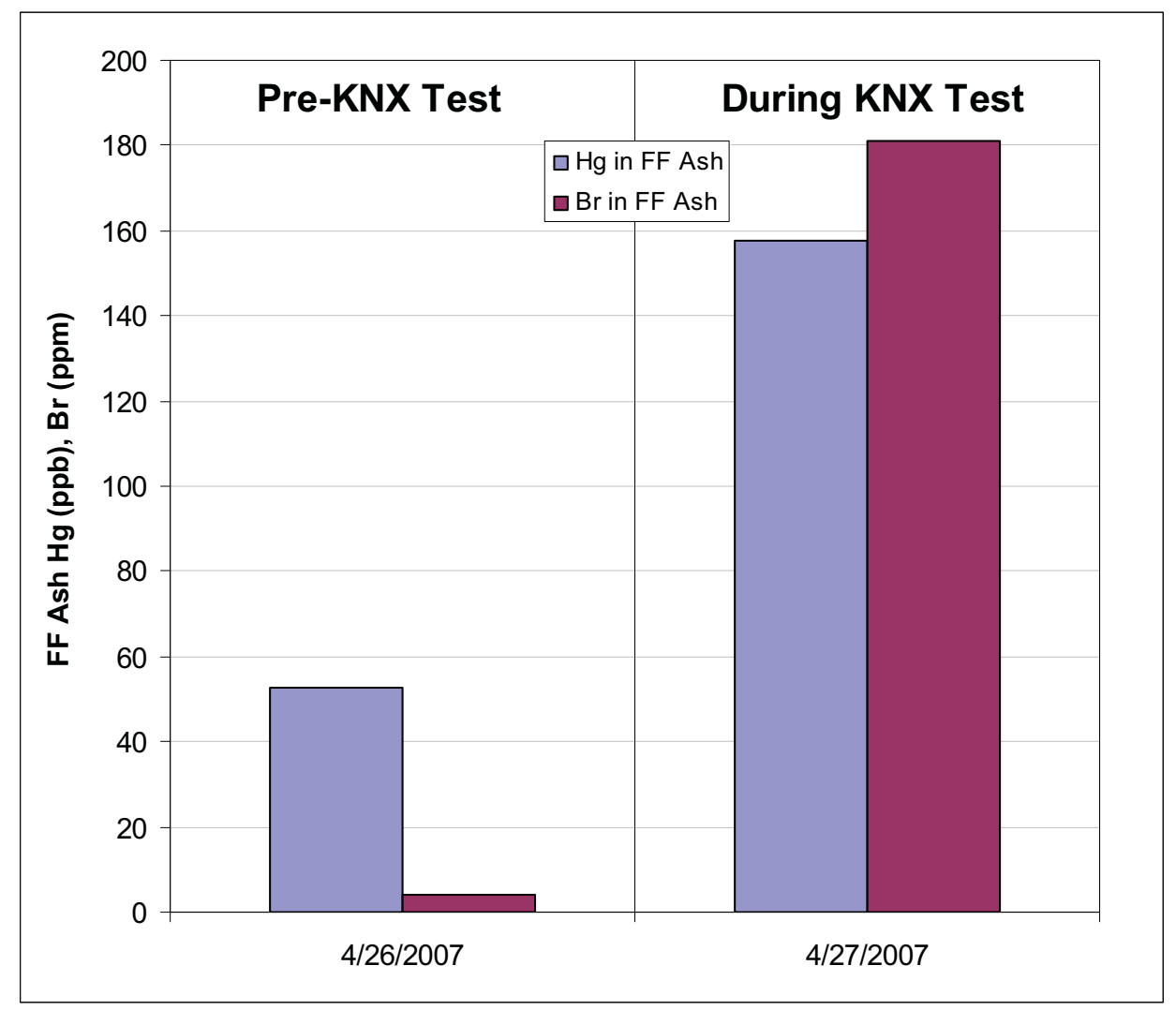

Figure 33. $\mathrm{Hg}$ and $\mathrm{Br}$ in $\mathrm{FF}$ Ash before and during the $\mathrm{KNX}$ Test.

\subsubsection{Coal Properties}

Hardin burns a PRB coal from the local Absaloka mine. Coal samples were collected from the main feed belt leading to the three coal bunkers. The coal bunkers have a nominal 16hour capacity at full load. Table 17 shows the average, minimum, maximum, standard deviation, and sample size for all of analyses completed on Absaloka coal. For the samples taken, mercury averaged $46 \mathrm{ppm}$ with a high of $94 \mathrm{ppm}$ and a low of $14 \mathrm{ppm}$. This corresponds well to minimum and maximum mercury concentrations measured at the SDA inlet, nominally $2-10 \mu \mathrm{g} / \mathrm{wscm}$ (as a general rule of thumb for Hardin, and as confirmed by combustion calculations, the mercury concentration of the gas can be estimated by dividing the coal mercury, in ppm, by 10 to give the gas concentration in $\mu \mathrm{g} / \mathrm{wscm}$ ). The coal table in Appendix $\mathrm{F}$ also shows that coal mercury was variable from sample to sample, which accounts for the day-to-day variations recorded by the Hg-CEMs. 
Table 17. Absaloka Coal Properties at Hardin.

\begin{tabular}{|r||r|r|r||r|r|r|r|r|r|r|}
\hline Absaloka Coal & \% H2O & $\begin{array}{c}\text { Hg as rec } \\
\text { (ng/g) }\end{array}$ & $\begin{array}{c}\text { Hg dry } \\
\text { (ng/g) }\end{array}$ & $\begin{array}{c}\text { \% Ash } \\
\text { (as rec) }\end{array}$ & $\begin{array}{c}\text { \% FC } \\
\text { (as rec) }\end{array}$ & $\begin{array}{c}\text { \% H2O } \\
\text { (as rec) }\end{array}$ & $\begin{array}{c}\text { \% S } \\
\text { (as rec) }\end{array}$ & $\begin{array}{c}\text { \% Vo } \\
\text { (as rec) }\end{array}$ & $\begin{array}{c}\text { Btu/lb } \\
\text { (as rec) }\end{array}$ & $\begin{array}{c}\text { MAF } \\
\text { (Btu/lb) }\end{array}$ \\
\hline Average & 11.73 & 40.82 & 46.16 & 8.22 & 37.84 & 24.38 & 0.55 & 29.55 & 8807 & 13066 \\
\hline Min & 7.80 & 12.00 & 13.60 & 5.85 & 35.37 & 23.29 & 0.40 & 27.04 & 8533 & 12695 \\
\hline Max & 16.10 & 84.31 & 94.10 & 10.04 & 39.81 & 26.55 & 0.70 & 31.82 & 9231 & 13268 \\
\hline Std Dev & 2.31 & 17.12 & 18.99 & 1.14 & 1.36 & 0.76 & 0.08 & 1.15 & 192 & 142 \\
\hline No. of Samples & 32 & 32 & 32 & 19 & 19 & 19 & 19 & 19 & 19 & 19 \\
\hline
\end{tabular}

\begin{tabular}{|c|c|c|c|c|c|c|c|c|c|c|}
\hline Absaloka Coal & $\begin{array}{c}\mathrm{Br} \\
\text { (ug/g) }\end{array}$ & $\begin{array}{c}\mathrm{Cl} \\
\text { (ug/g) }\end{array}$ & $\begin{array}{c}F \\
(\mathrm{ug} / \mathrm{g})\end{array}$ & $\begin{array}{l}\% \text { Ash } \\
\text { (as rec) }\end{array}$ & $\begin{array}{c}\% \mathrm{C} \\
\text { (as rec) }\end{array}$ & $\begin{array}{c}\% \mathrm{H} \\
\text { (as rec) }\end{array}$ & $\begin{array}{l}\% \mathrm{H} 2 \mathrm{O} \\
\text { (as rec) }\end{array}$ & $\begin{array}{c}\% \mathrm{~N} \\
\text { (as rec) }\end{array}$ & $\begin{array}{c}\% 0 \\
\text { (as rec) }\end{array}$ & $\begin{array}{c}\% \mathrm{~S} \\
\text { (as rec) }\end{array}$ \\
\hline Average & 1.72 & 30.75 & 42.50 & 8.22 & 51.12 & 3.46 & 24.38 & 0.66 & 11.61 & 0.55 \\
\hline Min & 1.20 & 6.00 & 25.00 & 5.85 & 49.73 & 3.22 & 23.29 & 0.48 & 10.68 & 0.40 \\
\hline Max & 2.80 & 77.00 & 60.00 & 10.04 & 53.40 & 3.61 & 26.55 & 0.74 & 13.48 & 0.70 \\
\hline StdDev & 0.67 & 22.64 & 24.75 & 1.14 & 0.91 & 0.11 & 0.76 & 0.07 & 0.55 & 0.08 \\
\hline No. of Samples & 5 & 8 & 2 & 19 & 19 & 19 & 19 & 19 & 19 & 19 \\
\hline
\end{tabular}




\section{ECONOMIC ANALYSIS}

After completion of testing and analysis of the data, the requirements and costs for full-scale, permanent commercial implementation of the necessary equipment for mercury control using sorbent injection at the 121-MW Hardin Generating Station were determined. The related process equipment was sized and designed based on the Long-Term test results for $90 \%$ mercury control. Plant-specific requirements (sorbent storage capacity, plant arrangement, retrofit issues, winterization, controls interface, etc.) were also considered when determining the final cost. The system design was based on the criteria listed in Table 18.

Table 18. Design Criteria for the Mercury Control System at Hardin (50 lb/hr PAC Injection, $\mathbf{9 0 \%}$ Mercury Control).

\begin{tabular}{|l|c|}
\hline \multicolumn{1}{|c|}{ Parameter } & Activated Carbon \\
\hline Number of silos & 1 \\
\hline Number of injection trains & 2 \\
\hline Design feed capacity/train $(\mathrm{lb} / \mathrm{hr})$ & 100 \\
\hline Operating feed capacity/train $(\mathrm{lb} / \mathrm{hr})$ & 50 \\
\hline Sorbent storage capacity $(\mathrm{lbs})$ & 40,000 \\
\hline Conveying distance $(\mathrm{ft})$ & 250 \\
\hline Sorbent & DARCO $^{\circledR} \mathrm{Hg}-\mathrm{LH}$ \\
\hline Aerated density $\left(\mathrm{lb} / \mathrm{ft}^{3}\right)$ & 18 \\
\hline Settled density $\left(\mathrm{lb} / \mathrm{ft}^{3}\right)$ & 28 \\
\hline Particle MMD $(\mathrm{microns})$ & 18 \\
\hline
\end{tabular}

The estimated uninstalled cost for an activated carbon injection system and storage silo for the 121-MW unit is $\$ 781,000$. Costs were estimated based on a long-term activated carbon injection concentration of $1.75 \mathrm{lb} / \mathrm{MMacf}$. For Hardin, this would require an injection rate of nominally $50 \mathrm{lbs} / \mathrm{hr}$ of activated carbon at full load. Assuming a unit capacity factor of $81 \%$ and a delivered cost of $\$ 1.00 / \mathrm{lb}$ for DARCO ${ }^{\circledR} \mathrm{Hg}$-LH sorbent, the annual sorbent cost for injecting upstream of the existing SDA and FF would be about $\$ 355,000$. This corresponds to a nominal sorbent cost of $\$ 7,250$ per pound of mercury removed.

Results from the field tests conducted to date indicate different levels of mercury removal can be achieved depending on the air pollution control equipment and different flue gas conditions. Data collected from the Phase I DOE tests at Gaston indicate mercury removal levels of up to $90 \%$ were obtained with COHPAC ${ }^{\circledR}$ (a baghouse installed downstream of an ESP) and DARCO ${ }^{\circledR} \mathrm{Hg}$ sorbent injection. At Pleasant Prairie, 50-70\% removal while injecting DARCO ${ }^{\circledR} \mathrm{Hg}$ was the maximum achievable mercury control, with the configuration of an ESP collecting PRB ash. At Brayton Point, mercury removal levels of up to $90 \%$ were obtained with an ESP collecting bituminous ash with DARCO ${ }^{\circledR} \mathrm{Hg}$ sorbent injection. DOE Phase II testing at Holcomb showed mercury removal levels of $90 \%$ were obtained with an SDA and FF while injecting DARCO ${ }^{\circledR} \mathrm{Hg}-\mathrm{LH}$. Data from Hardin and seven other sites are summarized in Table 19. 
Table 19. Mercury Removal Efficiencies and Costs for Different APC Configurations, Coals, and Sorbents.

\begin{tabular}{|c|c|c|c|c|c|}
\hline Plant & $\begin{array}{c}\text { APC } \\
\text { Equipment }\end{array}$ & Coal & Sorbent & $\begin{array}{c}\text { Removal } \\
\%\end{array}$ & $\begin{array}{l}\text { Sorbent Cost } \\
(\mathbf{m i l l s} / \mathbf{k W h})\end{array}$ \\
\hline Gaston & COHPAC $^{\circledR}$ & Bituminous & DARCO $^{\circledR} \mathrm{Hg}$ & 90 & 0.43 \\
\hline Pleasant Prairie & ESP & PRB & DARCO $^{\circledR} \mathrm{Hg}$ & 67 & 1.2 \\
\hline Brayton Point & ESP & Bituminous & DARCO $^{\circledR} \mathrm{Hg}$ & 90 & 2.4 \\
\hline Holcomb & SDA-FF & PRB & DARCO $^{\circledR} \mathrm{Hg}-\mathrm{LH}$ & 90 & 0.44 \\
\hline Meramec & ESP & PRB & DARCO $^{\circledR} \mathrm{Hg}-\mathrm{LH}$ & 90 & 0.74 \\
\hline Independence & TOXECON II ${ }^{\mathrm{TM}}$ & PRB & DARCO ${ }^{\circledR} \mathrm{Hg}$-LH & 80 & 1.14 \\
\hline Merrimack & ESP & Bituminous & $\begin{array}{l}\text { DARCO }{ }^{\circledR} \mathrm{Hg}-\mathrm{LH} \\
\text { with trona }\end{array}$ & 70 & 1.31 \\
\hline Hardin & SDA-FF & PRB & DARCO $^{\circledR} \mathrm{Hg}$-LH & 90 & 0.41 \\
\hline
\end{tabular}

The results from Hardin indicate that using DARCO ${ }^{\circledR} \mathrm{Hg}-\mathrm{LH}$ would result in similar mercury removal $(90 \%)$ at less cost than at Holcomb. Both units have an SDA and FF and fire PRB coals; however, Hardin uses ash recycle to the SDA whereas Holcomb does not. A critical difference in the sorbent costs is the improved effectiveness of brominated carbon over unbrominated carbon, the only sorbent available during testing at Brayton Point. These results are presented as mills $/ \mathrm{kWh}$ in Table 20 and as $\$ / \mathrm{kWh}$ in Table 21. The use of DARCO $^{\circledR} \mathrm{Hg}-\mathrm{LH}$ at Hardin resulted in mercury removal at projected costs similar to what would be expected at sites using an SDA and FF for emissions control combusting PRB coal.

\subsection{System Description}

For this cost estimate, the permanent PAC injection system for Hardin will consist of one bulk storage silo and two dilute-phase pneumatic conveying systems. DARCO ${ }^{\circledR} \mathrm{Hg}-\mathrm{LH}$ sorbent will be received in 40,000-pound batches delivered by pneumatic bulk tanker trucks. The silo is equipped with a pulse jet type bin vent filter to contain dust during the loading process. The silo is a shop-built, dry-welded tank with two mass flow discharge cones. Point level probes and weigh cells monitor sorbent level and inventory. Silo sizing was based on the capacity to hold approximately one truckload of DARCO ${ }^{\circledR} \mathrm{Hg}$ LH sorbent, sufficient for 33 days of operation at the design injection rate.

The sorbent is fed from the discharge cone by a rotary valve into feeder hoppers. From the hoppers the sorbent is metered into the conveying lines by volumetric feeders. Conveying air 
supplied by regenerative blowers passes through an eductor, which provides suction to draw the sorbent into the conveying piping and carry it to the injection lance. The blowers and feeder trains are contained beneath the silo.

A Programmable Logic Controller (PLC) is used to control all aspects of system operation. The PLC and other control components will be mounted in a NEMA4 control panel. The control panel, motor control centers (MCCs), and disconnects will be housed in a prefabricated power and control building located adjacent to the silo.

\subsection{Cost and Economic Methodology}

Costs for the sorbent storage and injection equipment were provided by ADA based on the design requirements in Table 18. ADA has built and installed many similar systems at coalfired power plants for mercury control. Estimated costs for the distribution manifold, piping and injection lances, installation man-hour and crane-hour estimates, and an estimate for foundations including pilings are also included. As construction costs are rising rapidly, these costs are tentative and very dependent upon local labor conditions as well as current national demand for related equipment.

EPRI Technical Assessment Guide (TAG) methodology was used to determine the indirect costs. A project contingency of $15 \%$ was used. Since the technology is relatively simple and well proven on similar scale, the process contingency was set at 5\%. Based upon requested guarantee language, that contingency may increase to cover anticipated risks for a newer technology. ACI equipment can be installed in a few months; therefore, no adjustment was made for interest during construction, a significant cost factor for large construction projects lasting several years.

Operating costs include sorbent costs, electric power, operating labor, maintenance (labor and materials), and spare parts. An average incremental operating labor requirement of one hour per day per injection system was estimated to cover the incremental labor to operate and monitor the ACI injection system. The annual maintenance costs were based on $5 \%$ of the uninstalled equipment cost.

Levelized costs were developed based on a twenty-year book life and are presented in constant dollars.

\subsection{Capital Costs}

The uninstalled activated carbon storage and feed equipment costs are estimated at $\$ 781,000$. The estimated cost for the sorbent injection system and storage silo installed at the 121-MW unit is $\$ 1,574,000$ and includes all process equipment, foundations, support steel, plant modifications utility interfaces, engineering, taxes, overhead, and contingencies. The capital and O\&M costs are summarized in Table 20. 
Table 20. Capital and O\&M Cost Estimate for the ACI System at Hardin. Annual Basis 2008.

\begin{tabular}{|c|c|}
\hline \multicolumn{2}{|l|}{ Capital Costs Summary } \\
\hline Equipment, FOB Hardin & $\$ 781,000$ \\
\hline Site Integration (materials and labor) & $\$ 95,000$ \\
\hline Installation (ACI silo and process equipment, foundations) & $\$ 250,000$ \\
\hline Taxes $(6 \%)$ & $\$ 56,000$ \\
\hline Indirects/Contingencies & $\$ 393,000$ \\
\hline Total Capital Required & $\$ 1,574,000$ \\
\hline$\$ / \mathbf{k W}$ & $\$ 13.01$ \\
\hline
\end{tabular}

\begin{tabular}{|r|c|}
\hline \multicolumn{2}{|c|}{ Operating and Maintenance Costs Summary } \\
\hline Sorbent @ \$1.00/lb, DARCO ${ }^{\circledR} \mathrm{Hg}-\mathrm{LH}$ & $\$ 355,000$ \\
\hline Power, labor, maintenance & $\$ 85,000$ \\
\hline Variable O\&M for $\mathbf{2 0 0 8} \mathbf{( \$ / k W )}$ & $\$ 3.64$ \\
\hline Variable Mills/kW-hr & 0.51 \\
\hline
\end{tabular}

\subsection{Operating and Levelized Costs}

The most significant operational cost of sorbent injection for mercury control is the DARCO ${ }^{\circledR}$ Hg-LH sorbent. Sorbent costs were estimated for $90 \%$ mercury control based on the long-term sorbent injection concentration of $1.75 \mathrm{lbs} / \mathrm{MMacf}$ for activated carbon. For Hardin, this would require an injection rate of nominally $50 \mathrm{lbs} / \mathrm{hr}$ of activated carbon at full load. Assuming a unit capacity factor of $81 \%$ and a delivered activated carbon cost of $\$ 1.00 / \mathrm{lb}$, the twenty-year levelized annual cost of injecting sorbent at the SDA and FF inlet would be $\$ 744,000$. Included in this is other annual operating levelized costs including electric power, operating labor, and maintenance.

Based on the test program results and assuming that sorbent injection at the SDA inlet for mercury control is sustainable, an average of $90 \%$ mercury control can be attained at Hardin for an initial capital investment of $\$ 1,574,000$ with first year operating costs of $\$ 5.68 / \mathrm{kW}$, or annual twenty-year constant-dollar levelized costs of $\$ 6.15 / \mathrm{kW}$. This information is summarized in Table 21. 
Table 21. Levelized Costs

\begin{tabular}{|c|r|}
\hline \multicolumn{2}{|c|}{ Twenty-Year Levelized Costs Summary-\$ Constant } \\
\hline Fixed Twenty-Year Levelized Costs & $\$ 184,000$ \\
\hline Variable O\&M Twenty-Year Levelized Costs & $\$ 560,000$ \\
\hline Total Twenty-Year Levelized Costs & $\$ 744,000$ \\
\hline Fixed Levelized Costs \$/kW & $\$ 1.52$ \\
\hline First-Year Operating Levelized Costs \$/kW & $\$ 3.64$ \\
\hline Total Twenty-Year Levelized Costs \$/kW & $\$ 6.15$ \\
\hline First-Year Operating Levelized Costs mills/kW-hr & 0.51 \\
\hline Total Twenty-Year Levelized Costs mills/kW-hr & 0.87 \\
\hline Total Twenty-Year Levelized Cost \$/lb Hg removed & $\$ 15,000$ \\
\hline
\end{tabular}




\section{CONCLUSIONS}

The main project objective of $90 \%$ mercury removal was achieved with two brominated PACs, DARCO ${ }^{\circledR} \mathrm{Hg}-\mathrm{LH}$ and Calgon FLUEPAC ${ }^{\text {TM}}$-MC Plus. Shorter-term results with ADA Power PAC PREMIUM also indicate that it is capable of $90 \%$ mercury removal at similar ACI rates. At full load (121 MW) and under normal operating conditions, 90\% mercury removal was maintained at carbon loadings of 1.5 to $2.5 \mathrm{lb} / \mathrm{MMacf}$ depending on the inlet mercury flue gas concentration. Much less carbon is needed at lower loads due to the higher mercury oxidation across the SCR. The twenty-year levelized cost was determined to be $0.87 \mathrm{mills} / \mathrm{kW}$-hr or $\$ 15,000 / \mathrm{lb}$ mercury removed.

- Manual Gas Measurements

- The only halogen detected at either the SDA Inlet or Stack was chlorine and it was present in low concentrations (no $\mathrm{HCl}, \mathrm{HBr}, \mathrm{HF}, \mathrm{Br}$, or F). The ammonia concentration at the SDA Inlet was $3.2 \mathrm{ppm}$ and the sulfur trioxide was 3.5$6.0 \mathrm{ppm}$ (all sulphates are reported as $\mathrm{SO}_{3}$ but were likely ammonia salts). The sulfur trioxide measured at the Stack was $1.2 \mathrm{ppm}$ (also likely that $\mathrm{SO}_{3}$ was present as ammonia salts). The particulate measurements at the stack, including $\mathrm{PM}_{10} / \mathrm{PM}_{2.5}$ were not impacted by ACI.

○ Baseline Ontario Hydro and STM measurements agreed well with the Hg-CEMs.

- Co-Benefit Analysis

- Mercury removal trends show that mercury removal increases at low load from less than $20 \%$ to as high as $50 \%$ due to the increased oxidation across the SCR. All of the oxidized mercury is scrubbed in the SDA-FF. It is theorized that the increase in mercury oxidation at low load results from the corresponding decrease in ammonia flow. With less ammonia in the SCR, mercury is able to more successfully compete for oxidation sites on the catalyst.

- High levels of ammonia were found to negatively impact mercury removal during ACI. It is believed that the ammonia competes with mercury for active sites on the PAC. Ammonia is present in ppm quantities whereas mercury is at ppb levels.

- Coal Blending Tests - Blends with West Elk coal increased native mercury capture from 10 to $27 \%$ at a $7 \%$ blend, and from 15 to $51 \%$ at a $14 \%$ blend. Blends with Bull Mountain coal showed only marginal increases in mercury removal.

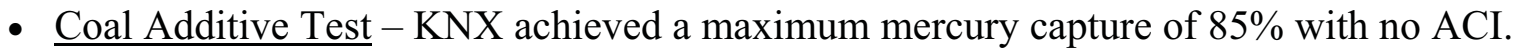

- $\underline{\text { Parametric Test }}$

- Both DARCO ${ }^{\circledR}$ Hg-LH and Calgon FLUEPAC ${ }^{\text {TM}}-$ MC Plus achieved 90\% mercury capture at a carbon loading of about $1.0 \mathrm{lb} / \mathrm{MMacf}$.

- The test combining KNX addition with PAC injection achieved $90 \%$ removal at a carbon loading of $0.14 \mathrm{lb} / \mathrm{MMacf}$ and a low $\mathrm{KNX}$ rate. When the KNX was increased, $>95 \%$ mercury removal was achieved. 
- Hg-CEM Upgrades - The addition of Nitrogen Generators on the Hg-CEMs increased the precision from nominally $\pm 0.5 \mu \mathrm{g} / \mathrm{wscm}$ to less than $\pm 0.1 \mu \mathrm{g} / \mathrm{wscm}$.

- Integration of PAC Silo Control and Hg-CEMs - The control scheme for the PAC silo was successfully integrated with feedback from $\mathrm{Hg}$-CEMs. As much as a 50\% reduction in carbon usage was realized at low load. Plant personnel were successfully trained in the operations of the Hg-CEMs and ACI systems. Plant personnel operated the ACI system during the last portion of the Long-Term test.

- $\quad$ Method 30A RATA - The Hg-CEMs installed at Hardin passed three RATA tests conducted by the EPA Method 30A. 


\section{LIST OF ACRONYMS AND ABBREVIATIONS}

ACI Activated carbon injection

$\mathrm{AH} \quad$ Air heater

CAMR Clean Air Mercury Rule

CCB Coal combustion byproducts

CEM Continuous emission monitor

DOE Department of Energy

EPA Environmental Protection Agency

FF Fabric filter

$\mathrm{Hg}+2 \quad$ Oxidized gaseous mercury

$\mathrm{Hg} 0 \quad$ Elemental gaseous mercury

Hg-CEM Mercury continuous emission monitor

HgT Total gaseous mercury

IRM Instrumental Reference Method

LOI Loss on ignition

M30A EPA Method 30A

MACT Maximum Achievable Control Technology

MCC Motor control center

MCG Mercury chloride generator

MCL Maximum containment level

MW Megawatt

NETL National Energy Technology Laboratory

NG Nitrogen generator

NOx Nitrogen Oxide

O-H Ontario Hydro Method

O\&M Operating and Maintenance

PAC Powdered activated carbon

PLC Programmable logic controller

PRB Powder River Basin

QA/QC Quality Assurance/Quality Control

RATA Relative Accuracy Test Audit

RMP Rocky Mountain Power 


$\begin{array}{ll}\text { SCR } & \text { Selective catalytic reduction } \\ \text { SDA } & \text { Spray dryer absorber } \\ \text { SGLP } & \text { Synthetic Groundwater Leaching Procedure } \\ \mathrm{SO}_{2} & \text { Sulfur Dioxide } \\ \text { STM } & \text { Sorbent Trap Method } \\ \text { TAG } & \text { Technical Assessment Guide } \\ \text { TCLP } & \text { Toxicity Characteristic Leaching Procedure }\end{array}$




\section{APPENDIX A: PROJECT TEST PLAN}




\section{PHASE III MERCURY CONTROL TECHNOLOGY FIELD TESTING AND RELATED MERCURY CONTROL RESEARCH AND DEVELOPMENT}

Long-Term Carbon Injection Field Test for $>90 \%$ Mercury Removal for a PRB Unit with a Spray Dryer and Fabric Filter

\section{Test Plan}

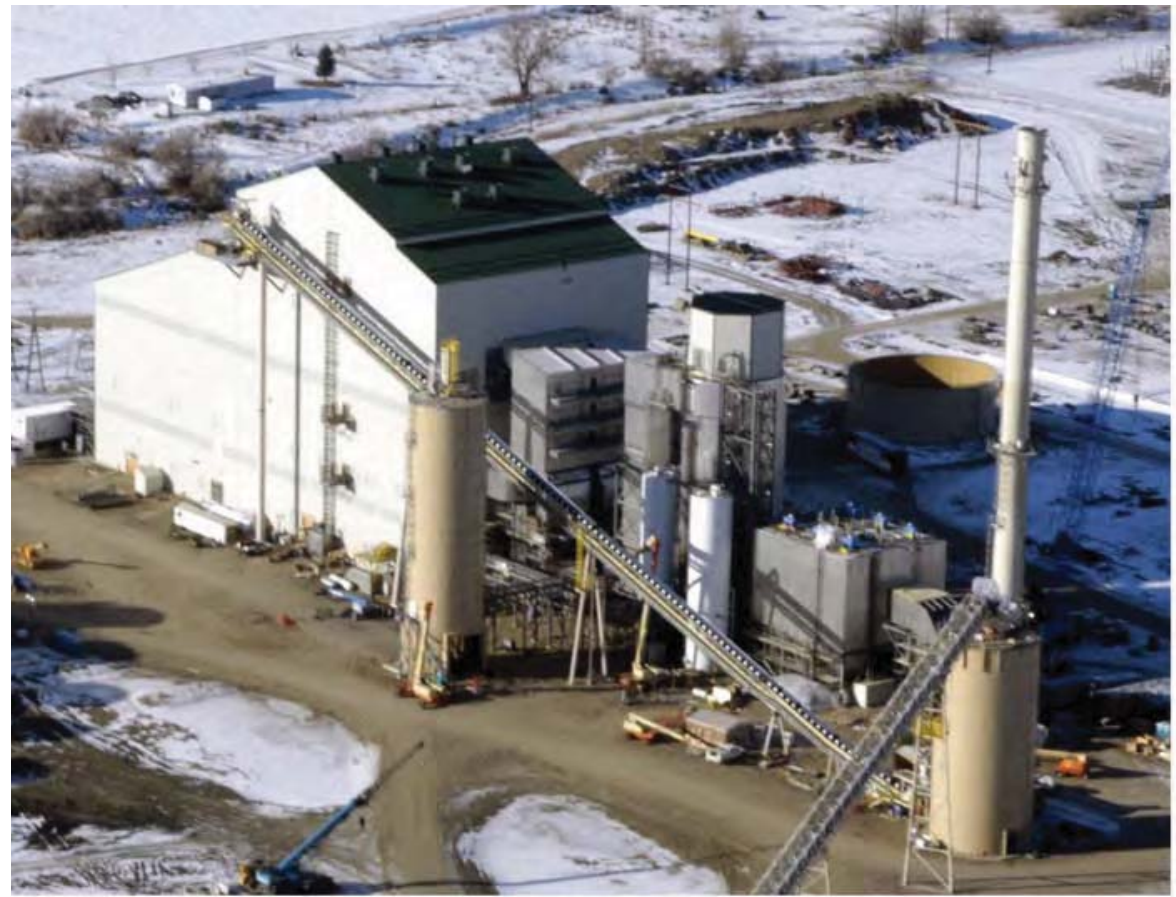

Prepared for:

Rocky Mountain Power, Inc.

DOE NETL (DE-FC26-06NT42774)

EPRI

Prepared by:

ADA Environmental Solutions, Inc.

8100 SouthPark Way, Unit B

Littleton, CO 80120

June 23, 2006 


\section{Table of Contents}

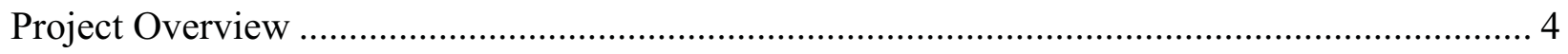

Host Site Description .............................................................................................. 5

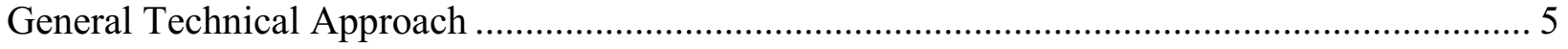

Task 1. Site Coordination, Kick-Off Meetings, Develop Test Plan and QA/QC Plan ............. 5

Task 2. Design, Procure and Install Equipment............................................................. 6

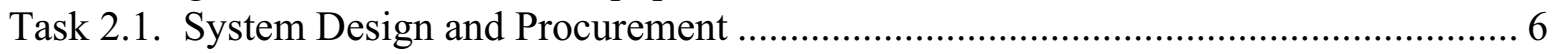

Task 2.2. Installation.......................................................................................... 7

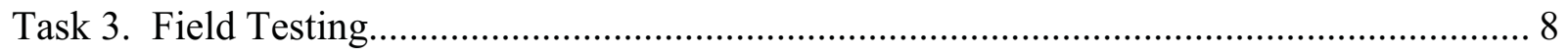

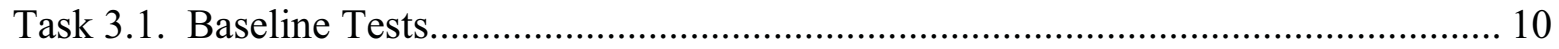

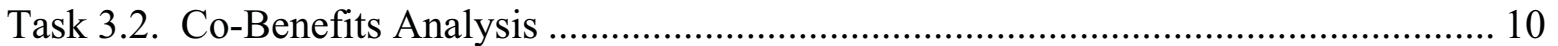

Task 3.3. Parametric Tests ........................................................................................... 11

Task 3.4. Choose Long-Term Test Parameters.............................................................. 11

Task 3.5. Long-Term Test ......................................................................................... 12

Task 4. Coal, Ash, and By-Product Sample Evaluation ................................................ 12

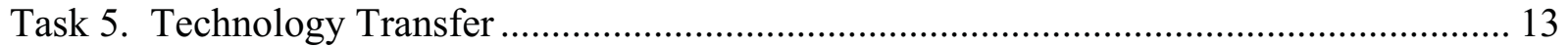

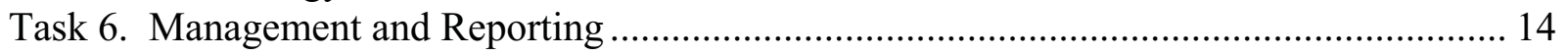

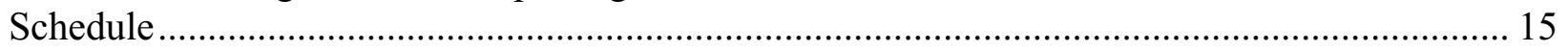

Key Personnel and Contact Information........................................................................... 15

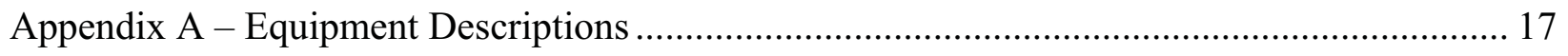

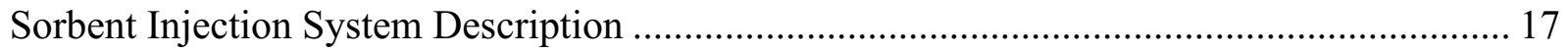

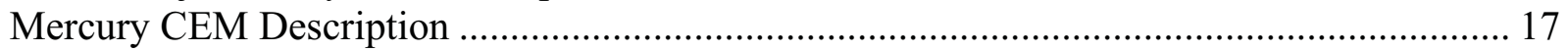




\section{List of Tables and Figures}

Table 1: Key Parameters of the Hardin Power Plant .............................................................. 5

Figure 1. Sorbent Injection Silo w/Outline of Proposed Shelter ........................................ 7

Table 2. Work Breakdown Between RMP and ADA-ES …........................................... 8

Table 3. Proposed Test Sequence for Hardin.............................................................. 9

Table 4. Sample Schedule for Hardin Testing ................................................................. 10

Figure 2. Sampling Locations for Hardin .................................................................. 13

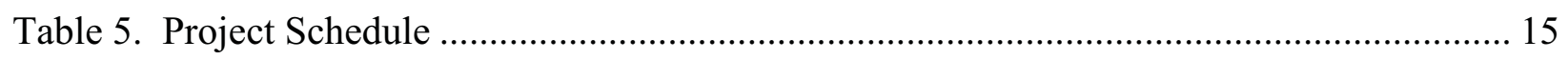

Table 6. Key Project Personnel for Hardin Project........................................................... 15

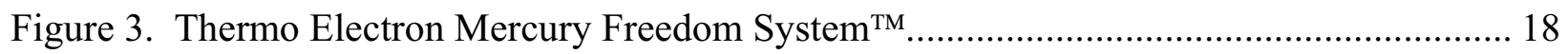




\section{Project Overview}

Hardin Generating Station was chosen to be included in Phase III of DOE's mercury control evaluation program. The overall objective for the Phase III program is to achieve $90 \%$ mercury control in excess of native removal. The goal of the testing at Hardin is to demonstrate $>90 \%$ mercury removal for a period of 10 to 12 months using sorbent injection. This will allow an evaluation of long-term mercury removal capability, emissions variability, and the O\&M costs associated with sorbent injection at a power plant with a configuration representative of many new plants. The project will also access the potential benefits of coal additives and coal blending with Western bituminous coal to increase mercury removal. During this project, a commercial-grade activated carbon injection system will be integrated with a new-generation mercury analyzer to allow automated feedback control of the outlet mercury emissions. The cost savings associated with feedback control will be assessed. Testing will be conducted at Rocky Mountain Power's Hardin Station that burns a PRB coal and is configured with an SCR (selective catalytic reduction) for NOx control, an SDA (spray dryer absorber) for $\mathrm{SO}_{2}$ control, and a FF (fabric filter) for particulate control. The unit was brought on line in January 2005.

Based upon previous results at PRB sites with SCRs, very little additional mercury oxidation is expected across the SCR at Hardin. In addition, results from DOE/NETL Phase II Round 1 at the Holcomb Station and similar sites, showed low native mercury removal across the SDA and FF. However, there is little data on the synergistic effects at PRB sites configured with an SCR, SDA and FF. However, it is possible that the use coal blending or coal additives will increase mercury oxidation across the SCR and enhance the subsequent mercury capture in the SDA and FF.

ADA-ES will design and procure a mercury sorbent injection system and mercury CEM for the Hardin Generating Station. This equipment, along with other portable equipment, will be used to conduct a series of tests to evaluate various combinations of potential mercury removal technologies including:

- Baseline Test - Perform speciated baseline mercury measurements across the SCR, SDA and FF,

- Co-Benefit Analysis - Characterize the range of mercury removal achievable by varying the operation of the SCR and SDA, and access the effectiveness of coal additives and coal blending to enhance mercury oxidation across the SCR and subsequent removal in the SDA and FF,

- Parametric Test - Evaluate the effectiveness of sorbent injection for mercury control with and without co-benefit enhancements.

The Parametric Test may be followed by an 11-month, Long-Term Test, with approval from DOE/NETL, if a technology is identified that meets the goal of $>90 \%$ mercury removal. Upon completion of testing, ADA-ES will submit a comprehensive final report and participate in all functions required by DOE/NETL, including technology transfer to the industry. 


\section{Host Site Description}

Hardin is a $116 \mathrm{MW}$, pulverized coal boiler that burns PRB coal from the nearby Absaloka Mine. The coal contains approximately $0.65 \%$ sulfur, 0.04 ppmd mercury and $<20$ ppm chlorine. The unit is configured with low NOx burners and an SCR for NOx control, an $\mathrm{SDA}$ for $\mathrm{SO}_{2}$ control and a $\mathrm{FF}$ for particulate control. Key characteristics of the configuration at Hardin are included in Table 1.

Table 1: Key Parameters of the Hardin Power Plant

\begin{tabular}{|l|c|}
\hline Size $\left(\mathrm{MW}_{\text {gross }}\right)$ & 116 \\
\hline Coal (typical) & $\begin{array}{c}\text { PRB, } \\
\text { Absaloka Mine }\end{array}$ \\
\hline Boiler Type & $\begin{array}{c}\text { PC Boiler } \\
\text { Opposing wall-fired }\end{array}$ \\
\hline Sulfur Control & Spray Dryer with Recycle \\
\hline Nitrogen Oxide Control & Low NOx Burners/SCR \\
\hline Particulate Control & Fabric Filter \\
\hline $\begin{array}{l}\text { Gas Flow Rate, full load (acfm) at injection } \\
\text { location }\end{array}$ & $\sim 550,000$ \\
\hline Flue Gas Temperature, Injection Location $\left({ }^{\circ} \mathrm{F}\right)$ & $260-320$ \\
\hline
\end{tabular}

\section{General Technical Approach}

A series of six tasks are planned to accomplish the objectives of this project. These tasks provide the outline for the test plan. A brief description of each task is provided below.

\section{Task 1. Site Coordination, Kick-Off Meetings, Develop Test Plan and QA/QC Plan}

The purpose of this task is to develop a detailed test plan agreed upon by contributing team members, personnel from the host site, environmental agencies and DOE/NETL. The planning process includes meetings with the appropriate personnel to gather the information necessary to develop the test plan and define the potential impact on plant equipment and operation. Efforts include identifying any permit requirements, developing a QA/QC plan, identifying potential mercury sorbents and coal additives, finalizing the scope for each of the team members, and putting subcontracts in place for manual measurement services.

As part of the proposed scope, QA/QC will be documented and specific procedures adhered to. The primary objectives of the QA/QC effort will be to control, evaluate, and document data quality to ensure that data generated are of sufficient quality to meet program objectives. Specific key parts of the QA/QC plan will include:

- QA/QC in sample collection, analytical and data analysis

- Integral performance evaluation and verification of mercury removal

- Procedural remedies for identified data deficiencies 
- Oversight and documentation of all QA/QC

ADA-ES has developed and implemented successful QA/QC plans for other DOE/NETL projects. These shall serve as a general framework for this project's plan.

This task began upon award of the contract and the progress to date includes:

- Requesting a quote for the mercury Continuous Emissions Monitors (CEM)s,

- Scheduling a Site Visit/Meeting for June 26, 2006,

- Developing a preliminary equipment installation package based on previous projects,

- Writing the initial draft of the Test Plan.

\section{Task 2. Design, Procure and Install Equipment}

There are two major systems associated needed for this project, a mercury CEM system and a sorbent injection system (SIS). Descriptions of these systems are included in the appendix.

Two Thermo Electron CEMs will be used during this program. One CEM will be installed downstream of the air preheater with a secondary extraction location downstream of the SDA. The second CEM will be installed downstream of the FF at the stack.

The SIS will include a silo for sorbent storage, a metering system, sorbent distributor, injection grid in the duct upstream of the SDA, and the interconnecting piping. The output of both mercury CEMs will be interfaced with the silo control system for automatic control of the sorbent feed rate. The stack CEM will be interfaced with the plant data handling system (DHS) to allow real-time monitoring of mercury concentration by plant personnel.

Another system that will be required at Hardin is a coal additive injection skid for the introduction of additives upstream of the pulverizers. For liquid additives, this will be a simple pump arrangement. For dry additives, a small volumetric feeder will be used.

Coal blending will be achieved either by using a secondary coal storage silo.

\section{Task 2.1. System Design and Procurement}

The purpose of this task is to acquire and install the necessary equipment to complete the project. Some equipment will be site-specific and, by necessity, will be designed for Hardin. Examples may include the sorbent storage silo, sorbent distribution manifold, and injection lances. Figure 1 shows a typical activated carbon storage silo and feeding system with an outline of a proposed shelter around the bottom of the silo to protect the controls from the harsh Montana winters. ADA-ES engineers will work with plant engineers to develop an installation and contractor bid package for installation activities. ADA-ES will also oversee the work by contractors to ensure all installation is done properly and efficiently. Hardin will be responsible for all permitting and any variance requirements. 
ADA-ES will also oversee installation and system checkout of the mercury measurement equipment. Procedures followed in this task will be similar to those used in previous full-scale mercury control programs that ADA-ES conducted for DOE. The actual equipment installation, not including preparation tasks, is estimated to take three weeks.

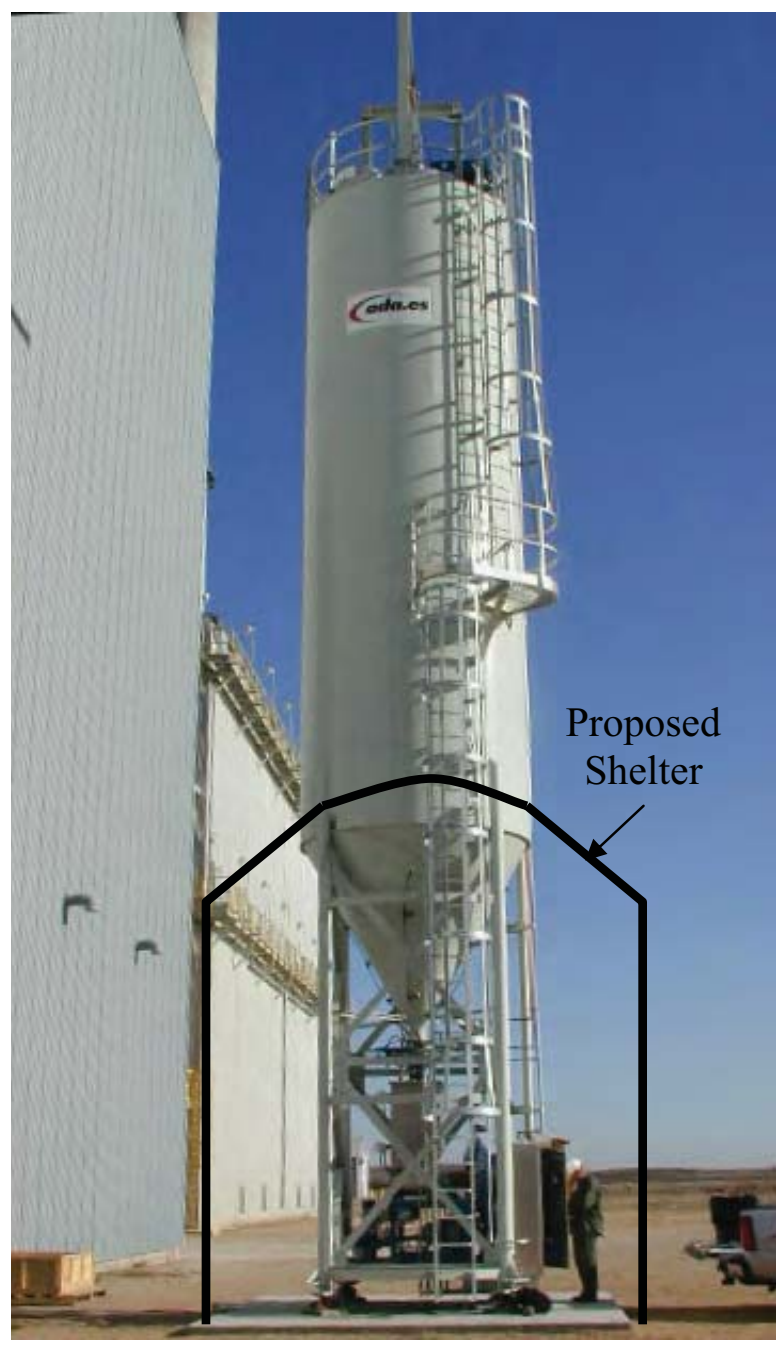

Figure 1. Sorbent Injection Silo w/Outline of Proposed Shelter

\section{Task 2.2. Installation}

A scope of work will be developed that includes a division of responsibilities between ADA-ES and RMP. A typical work split is shown in Table 2. Required site support may include the pouring of a cement platform for the silo, installation of injection and sampling ports (if not available), erection of any needed platforms and scaffolding to access the ports, supplying compressed air, electrical power, and the appropriate plant signals, including boiler load, to the injection skid and control trailer, and balance of plant engineering. 
Table 2. Work Breakdown Between RMP and ADA-ES

\begin{tabular}{|l|l|}
\hline RMP/Hardin & ADA-ES \\
\hline $\begin{array}{l}\text { Unload and store the injection silo until } \\
\text { installation }\end{array}$ & Prepare installation document \\
\hline Install the injection silo foundation & Oversee installation of SIS \\
\hline Install the injection system & Install mercury analyzers \\
\hline Erect a shelter around the base of the silo & $\begin{array}{l}\text { Provide oversight to integrate stack Hg } \\
\text { CEM into plant DHS }\end{array}$ \\
\hline Install and/or inspect Sampling Ports & Install office trailers \\
\hline $\begin{array}{l}\text { Provide utilities such as power, instrument } \\
\text { quality air and water to testing locations } \\
\text { and office trailers }\end{array}$ & $\begin{array}{l}\text { Develop Plan to integrate stack Hg CEM } \\
\text { into plant DAS }\end{array}$ \\
\hline $\begin{array}{l}\text { Arrange for safe access to sorbent injection } \\
\text { and mercury sampling locations }\end{array}$ & Provide the coal additives system \\
\hline $\begin{array}{l}\text { Provide access to plant data } \\
\text { Provide cable and support to integrate stack } \\
\text { Hg CEM into plant DHS (additional } \\
\text { support from Monitor Labs) }\end{array}$ & $\begin{array}{l}\text { Provide portable Hg measurement systems } \\
\text { such as STMs (Sorbent Trap Method) }\end{array}$ \\
\hline
\end{tabular}

\section{Task 3. Field Testing}

Field testing shall cover a period of 20 months, and will include the Baseline Test, CoBenefit Analysis, Parametric Test, and Long-Term Test. The current test schedule is shown in Table 3. The test matrix will be developed following the Site Kickoff Meeting and included in the final test plan.

Table 4 presents the frequency of manual emissions measurements and a summary of coal and byproduct samples that will be collected during the program. Additionally, comprehensive plant data will be logged through the plant DCS system. Such data will include combustion parameters, back-end parameters, and stack CEMs data $\left(\mathrm{NO}_{\mathrm{X}}, \mathrm{SO}_{2}, \mathrm{CO}_{2}\right.$, flow). Operating parameters will include, at a minimum, flow rates, temperatures, pressures, and emission levels. A comprehensive list will be included in the final version of the test plan which will be completed following the site kickoff meeting.

The composition of all sorbents and chemical additives to be tested under this project must be provided to the DOE Project Officer prior to testing. The proprietary nature of such data will be protected by DOE/NETL. All sorbents and chemical additives must receive prior approval by the DOE Project Officer prior to testing. 
Table 3. Proposed Test Sequence for Hardin

\begin{tabular}{|l|l|l|}
\hline Test Description & $\begin{array}{l}\text { Start } \\
\text { Date }\end{array}$ & Comments/Duration \\
\hline Baseline & $10 / 06$ & $\begin{array}{l}\text { 1-month } \\
\text { Manual Sampling }\end{array}$ \\
\hline Co-benefits & $\begin{array}{l}11 / 06- \\
2 / 07\end{array}$ & $\begin{array}{l}\text { Vary System Performance (4-months) } \\
\text { Coal Additives (1 to 2 weeks) } \\
\text { Coal Blending (1-week) }\end{array}$ \\
\hline Parametric Testing & $4 / 07$ & 1 to 2-weeks \\
\hline Verify Optimum Performance & $4 / 07$ & 1 to 2 days field testing \\
\hline Break & $4 / 07$ & $\begin{array}{l}\text { Review Results } \\
\text { Request DOE Approval for Long-Term Tests }\end{array}$ \\
\hline Long-term tests & $\begin{array}{l}\text { Control to maximum emission rate 24 hours a day, } 10 \\
3 / 08\end{array}$ & $\begin{array}{l}\text { Con } 12 \text { months. Conduct Manual Sampling } \\
\text { least twice. . . }\end{array}$ \\
\hline
\end{tabular}

${ }^{a}$ Manual Sampling includes: ASTM M6784-02 (mercury), STM (modified 40 CFR, pt. 75 app.K, mercury), EPA M5 or 17 (particulate), EPA M26a (halogens), CTM-027 (Ammonnia) 
Table 4. Sample Schedule for Hardin Testing

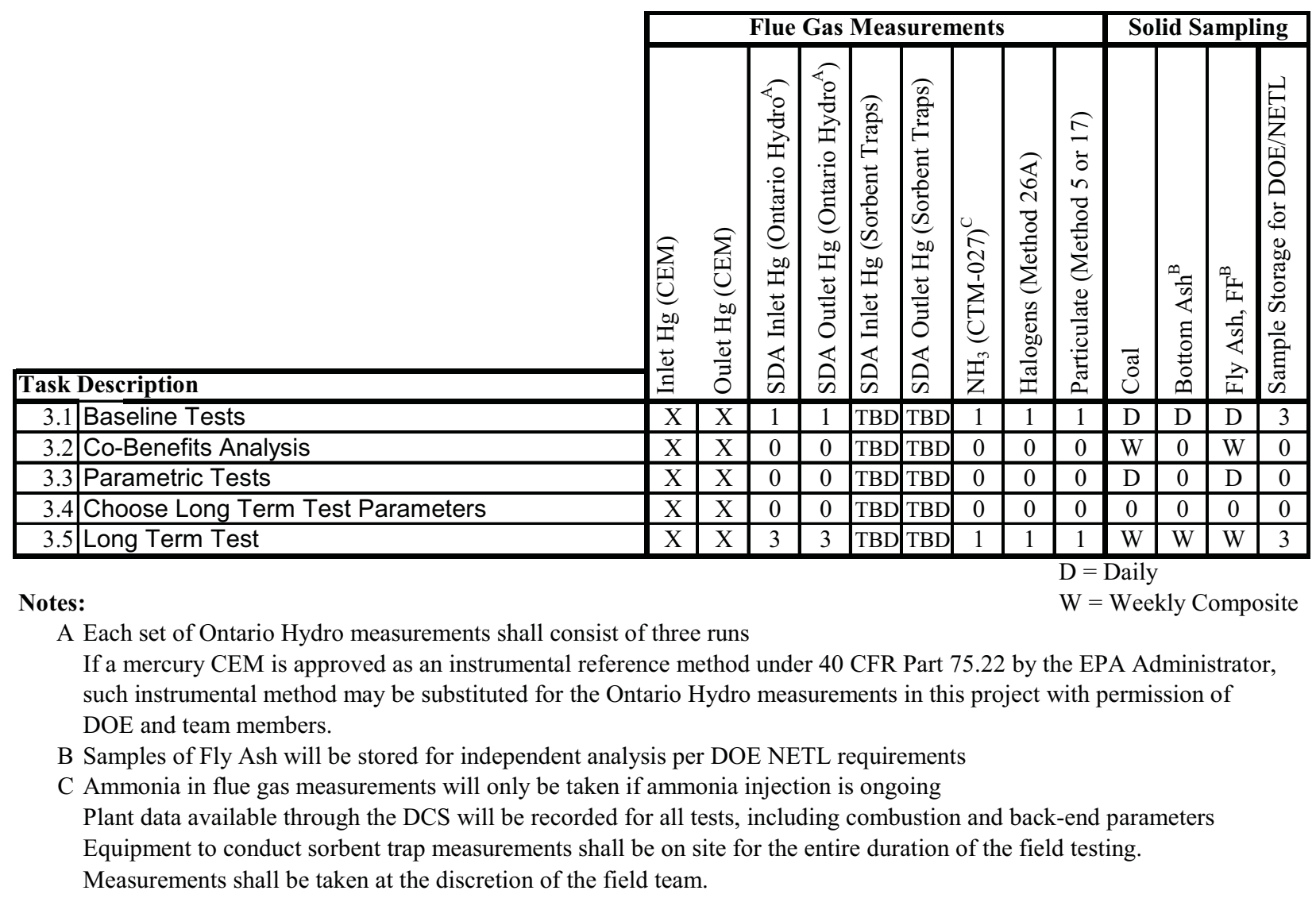

\section{Task 3.1. Baseline Tests}

After installation of the Hg CEMS, a series of baseline tests will be conducted to establish the mercury removal during typical plant operating conditions. There will be no addition of mercury sorbent or any other chemical additive during this period.

Baseline measurements will include one complete set of flue gas measurements and sample analyses. These will include Hg CEM measurements and the appropriate gas analyses, performed by an independent contractor, at the SDA inlet and FF outlet. The independent contractor will perform, at a minimum, particulate, mercury, halogen, and ammonia measurements. The accuracy of the $\mathrm{Hg}$ CEM will be verified with an appropriate reference method, such as the Ontario Hydro Method. If a mercury CEM is approved as a reference method under 40 CFR Part 75.22 prior to this test, it may be used in place of Ontario Hydros with permission from DOE and other team members.

Task 3.2. Co-Benefits Analysis

The purpose of this task is to determine if mercury capture across the SDA and FF can be enhanced by changes in plant operations or by the use of coal additives or coal blending. The first test series in this task include changes to plant operating practices and use of coal additives to determine if mercury oxidation can be increased across the SCR and, if so, if this increases the 
subsequent mercury capture in the SDA and FF. The mercury concentration will be monitored continuously while varying the performance of the SCR and SDA over the range of acceptable operating conditions. Variables may include adjusting the space velocity and temperature across the SCR by lowering the boiler load, adjusting the ammonia injection rate, and varying lime feed to the SDA. ADA-ES will work with Reaction Engineering to model the mercury oxidation potential of the SCR under various conditions, including the use of coal additives, prior to on-site testing. Another option for co-benefit mercury removal is through blending West Elk coal, a higher chlorine Western bituminous coal, with PRB coal. This combination may increase the overall mercury removal through two potential mechanisms: 1) increased oxidation across the SCR and subsequent removal in the SDA resulting from the higher chlorine content, or 2) increased removal across the FF due to unique characteristics of the West Elk coal. Mercury CEM measurements will be the sole basis for determining the success of all Co-Benefit Analyses.

\section{Task 3.3. Parametric Tests}

The goal of the parametric tests is to evaluate the mercury capture of several candidate sorbents under various operating conditions. Parametric tests will be conducted at full scale by distributing sorbents across the entire flue gas ductwork at the SDA inlet. Each sorbent will be injected at a variety of concentrations in order to closely establish the mercury control relationship. For a given sorbent, it is typical to test between two and four injection concentrations over a period lasting 4-12 hours. It is expected that the team will evaluate up to three sorbents during parametric testing. Initial parametric test runs will be conducted with the SOx and NOx control equipment operating at the standard conditions defined by the plant. The best sorbent material and optimal injection rate will be repeated with the SOx and NOx control equipment operating at conditions determined for optimal mercury removal from the Co-Benefit Analysis in Task 3.2. Key parameters include:

- Mercury sorbent

- Mercury sorbent injection concentration

- Injection location

- Unit combustion parameters

- SCR Operation - ammonia feed and space velocity

- SDA Operation - lime feed rate.

- FF Operation - cleaning cycle

Mercury CEM measurements will be the sole basis for determining the success of all Parametric Tests.

\section{Task 3.4. Choose Long-Term Test Parameters}

Upon completion of the Parametric Tests, ADA-ES will review results with the project team and identify the best options for achieving the goal of $>90 \%$ mercury removal during a long-term test. The best one or two options will then be evaluated during two-day test periods to verify the performance seen during the Parametric Test. Following the verification tests, ADAES will compile a report summarizing the results and conclusions of the testing to date. This report will provide the data and analysis necessary to guide the project team and DOE in choosing the system parameters for the long-term test. 


\section{Task 3.5. Long-Term Test}

After approval from the DOE COR, the sorbent selected in Task 3.4 will be continuously injected into the flue gas over a period of 11 months. This shall be done in conjunction with any operating changes or enhancement additives agreed to in Task 3.4. During this period, any longterm operational problems will be identified to determine if the chosen mercury control scheme is sustainable. Potential operational impacts that will be monitored include degradation of SDA or FF performance, injection system performance, and/or SCR performance if enhancement additives are used.

Long-term test measurements shall include a full set of flue gas measurements and solid sample analyses. These shall include CEM measurements at the SDA inlet and FF outlet $\mathrm{Hg}$, as well as particulate, halogen, mercury and ammonia measurements by an outside contractor. The accuracy of the Hg CEM will be verified during these tests with an appropriate reference method, such as the Ontario Hydro method. It is the intent of the test team to operate the stack $\mathrm{CEM}$ as a compliance mercury CEM using the QA/QC procedures outlined in the CAMR and compliance monitoring requirements included in 40 CFR Part 60.49a. If the analyzer does not meet all certification requirements, the reference method check will be conducted at least three times during the long-term program. If a mercury CEM is approved as an instrumental reference method under 40 CFR Part 75.22 by the EPA Administrator, such instrumental method may be substituted for the Ontario Hydro measurements with permission from DOE and team members.

During the long-term test, Hardin may choose to make the site available for assessing the performance of other mercury CEMs. No funds were allocated in the DOE program for evaluating alternative CEMs, therefore, the CEM vendor or other interested party wishes to install the CEM will be responsible for all costs associated with its operation. However, upon approval from RMP and DOE, the data from the project mercury CEM will be provided to the CEM vendor for comparison in exchange for the operational data from the test CEM.

\section{Task 4. Coal, Ash, and By-Product Sample Evaluation}

In conjunction with each of the baseline and parametric tests, samples of coal and ash will be collected and analyzed. A Sample and Data Management Plan will be completed prior to site testing and included as an appendix in the final test plan.

Potential collection points are illustrated in Figure 2. The information is needed to complete the mercury mass balance around the unit and to clarify how and where the mercury is captured. Select coal samples will be analyzed for ultimate, proximate and calorific analyses as well as mercury and chlorine content. Fly ash and bottom ash samples will be analyzed for mercury content and LOI. At least one ash sample from baseline and from long-term testing will be tested for stability. These tests will include leaching of mercury and any chemical additive (in the coal or on the activated carbon) using the synthetic groundwater leaching procedure. Thermal desorption tests will also be conducted.

Additional samples shall also be collected in accordance with DOE/NETL requirements including fly ash samples taken from the FF during the baseline and long-term tests. These samples shall be made available for analysis at DOE/NETL's discretion. Bottom ash samples may also be taken if coal additives are used. 


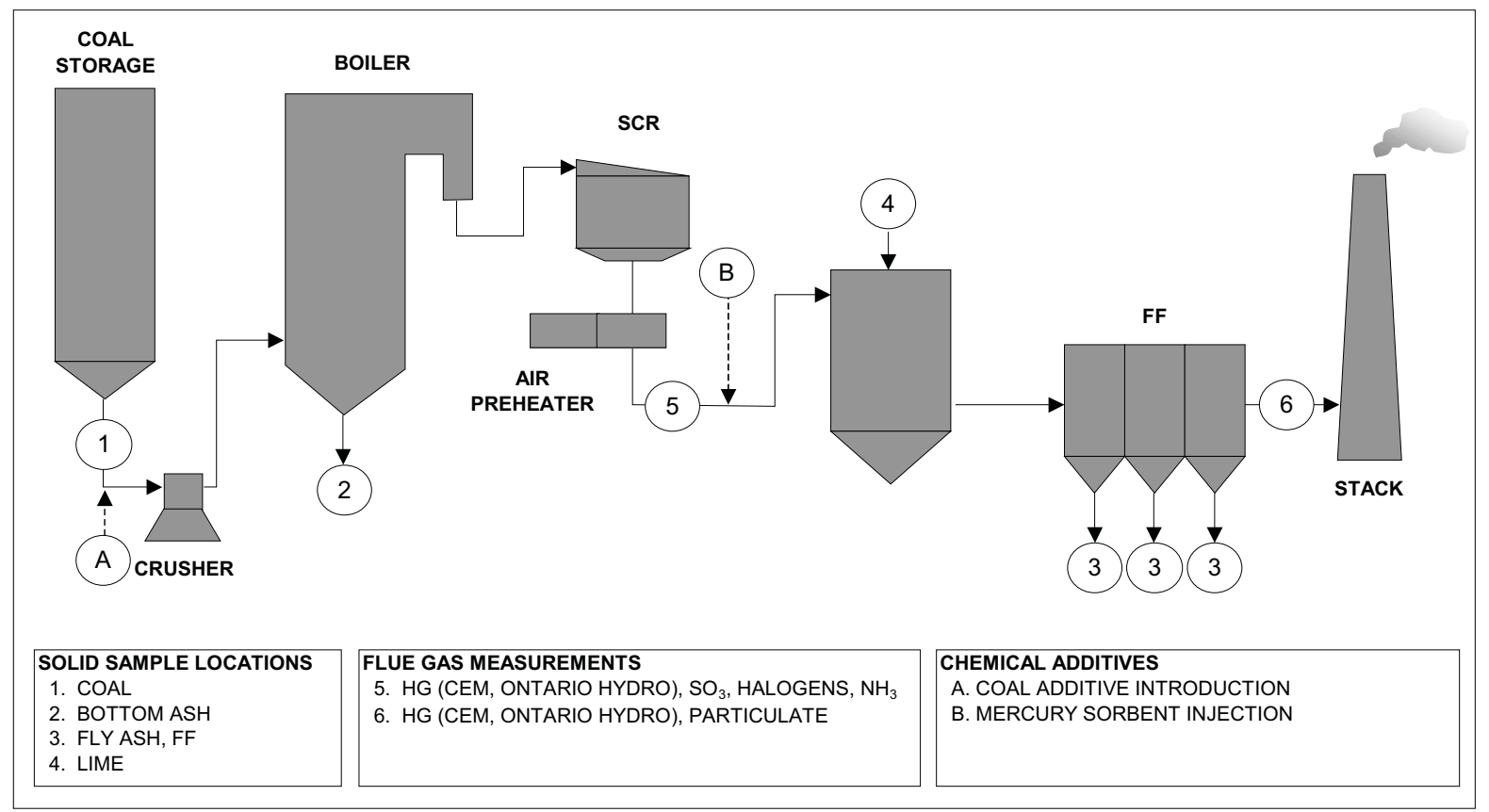

Figure 2. Sampling Locations for Hardin

Analysis of the fly ash will reflect the sorbent being injected. An important consideration for any plant contemplating sorbent injection is the impact on fly ash quality and disposal. With successful mercury capture in the FF, the fly ash mercury content will increase, as well as the sorbent content in the ash. If a chemically enhanced sorbent is used, the potential for additional ash contamination exists. Although previous test programs have shown that the byproducts mixed with activated carbon are highly stable, it is important to continue evaluating these byproducts. The primary pathways for mercury or halogen release would be vitalization and leaching, which DOE/NETL has already identified for testing

\section{Task 5. Technology Transfer}

Presentations will be made at selected conferences, with DOE approval, to increase exposure of the test results and receive comments on the applicability of the technology to the industry. Transferring the information generated during this project to the coal-fired utility customers will be an important part of the program. The ultimate goal of technology transfer is to make results available to the public as quickly, comprehensively and accurately as possible. Technology transfer activities performed in previous tests conducted by ADA-ES included participating in DOE/NETL-sponsored meetings and EPA Hg MACT Stakeholder meetings, presenting at more than 50 events or companies, hosting a Web site for project team members, presenting project information, and publication of more than 100 technical papers. ADA-ES will work with RMP and DOE/NETL in determining and supporting the key meetings, presentations and publications.

One of the key activities for Hardin's Air Quality Permit is the application for a $\mathrm{Hg}$ BACT emission limit from M-DEQ based on the performance of the mercury control equipment during the extended testing period. ADA-ES will work with RMP and M-DEQ to provide the information necessary for M-DEQ to assess the performance of the system. This includes 
providing recommended sorbent injection rates and an incremental cost analysis for the dollars per pound of mercury removed.

\section{Task 6. Management and Reporting}

This task provides time for overall program management, and preparation of financial and administrative reports. Upon completion of the field testing and receipt of the subsequent laboratory analyses, ADA-ES will issue a formal test report. The report will summarize all testing activities, results, initial economic analyses and conclusions. Periodic meetings with DOE to discuss progress and obtain direction from the DOE project manager will also be supported. 


\section{Schedule}

The schedule for the project at Hardin is included in Table 5.

Table 5. Project Schedule

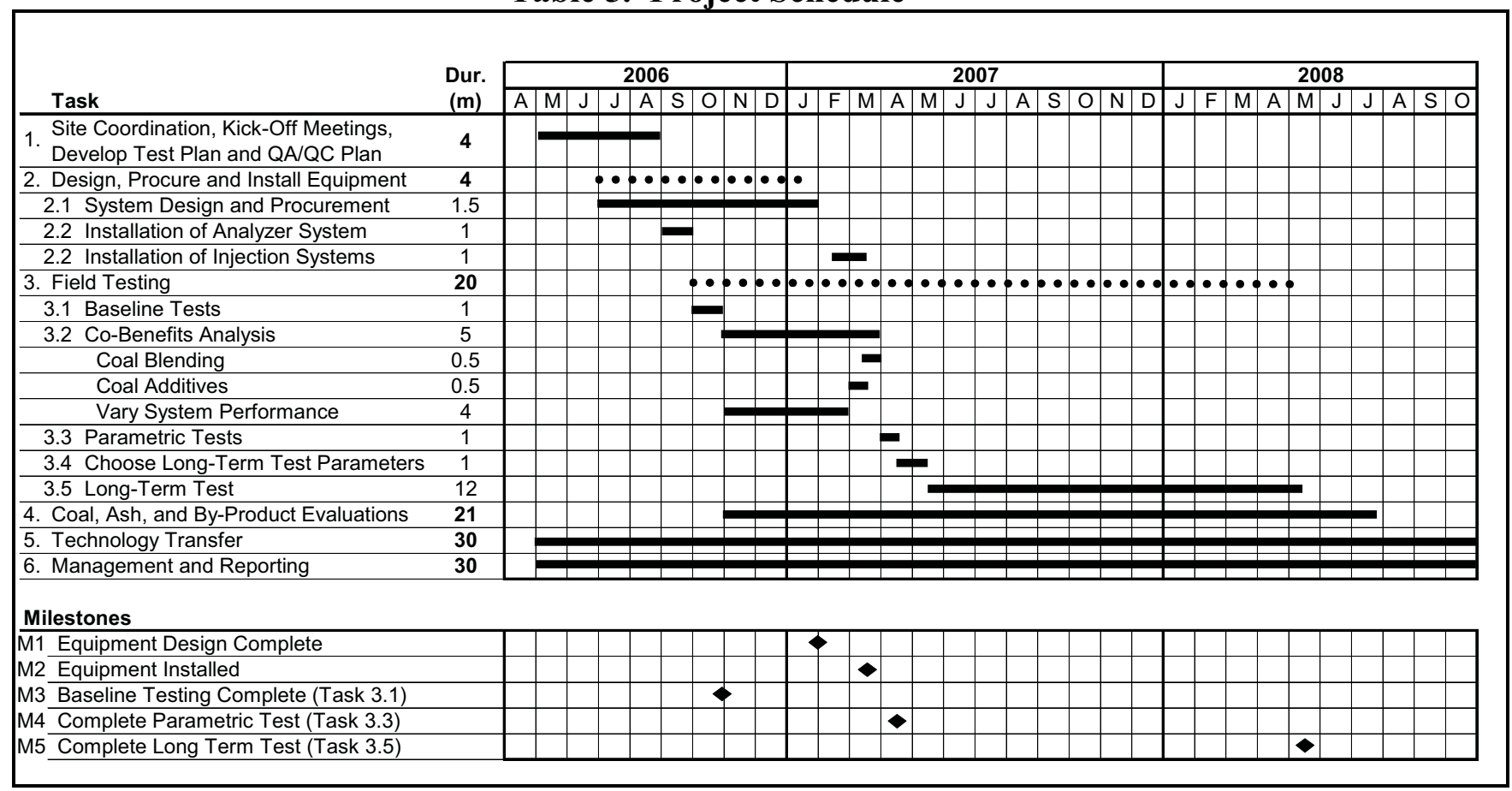

\section{Key Personnel and Contact Information}

Key personnel for the Conesville tests are identified in Table 6 .

Table 6. Key Project Personnel for Hardin Project

\begin{tabular}{|l|l|l|l|l|}
\hline Name & Company & Role & Phone \# & \multicolumn{1}{|l|}{ E-MAIL/Cell Phone } \\
\hline Andrew O’Palko & DOE/NETL & Contract Manager & $304-285-4715$ & andrew.opalko@netl.doe.gov \\
\hline Sharon Sjostrom & ADA-ES & Program Manager & $303-339-8856$ & $\begin{array}{l}\text { sharons@adaes.com } \\
303-919-8538\end{array}$ \\
\hline Rick Patzman & RMP & Project Manager & $701-221-6462$ & rick.patzman@centennialenergy.com \\
\hline Jerry Amrhein & ADA-ES & Project Engineer & $303-339-8840$ & $\begin{array}{l}\text { jerrya@adaes.com } \\
303-921-8138\end{array}$ \\
\hline Kevin Calloway & RMP & Plant Engineer & $\begin{array}{l}406638-9140 \\
\text { ext: 1038 }\end{array}$ & $\begin{array}{l}\text { kcalloway@coloradoenergy.com } \\
406679-0966\end{array}$ \\
\hline Connie Senior & $\begin{array}{l}\text { Reaction } \\
\text { Engineering }\end{array}$ & $\begin{array}{l}\text { Tech Expert: SCR } \\
\text { Modeling }\end{array}$ & $\begin{array}{l}801-364-6925 \\
\text { ext 37 }\end{array}$ & senior@reaction-eng.com \\
\hline
\end{tabular}


Hardin Generating Station Contact Information

Phone: (406) 638-9140

Fax: (406) 638-9156

Plant Manager:

Gary Arneson; garneson@,coloradoenergy.com Phone:

(406) 638-9140 ext: 1002

Cell: $\quad$ (406) 690-4777

Plant Superintendent: $\quad$ Pat Morrell; pmorrell@,coloradoenergy.com

Phone: (406) 638-9140

Cell: $\quad$ (406) 679-0963

Mailing Address: Colorado Energy Management

Hardin Generating Station

Attn: Kevin Calloway (Mercury Study)

Route 1, P.O. Box 1144A

Hardin, MT 59034

Shipping Address: Colorado Energy Management

Hardin Generating Station

Attn: Kevin Calloway (Mercury Study)

1 Sugar Factory Road

Hardin, MT 59034 


\section{Appendix A - Equipment Descriptions}

\section{Sorbent Injection System Description}

The carbon injection system, shown installed at Holcomb in Figure 1, consists of a bulk-storage silo and twin blower/feeder trains. PAC is delivered in bulk pneumatic trucks and loaded into the silo, which is equipped with a bin vent bag filter. From the discharge section of the silo, the sorbent is metered by variable speed screw feeders into eductors that provide the motive force to carry the sorbent to the injection point.

Regenerative blowers provide the conveying air. A PLC system is used to control system operation and adjust injection rates. The unit is approximately 50 feet high and 10 feet in diameter with an empty weight of 10 tons. The silo will hold 20 tons of sorbent. Flexible hose carries the sorbent from the feeders to distribution manifolds located on the flue gas ducts, feeding the injection probes. Each manifold supplies up to six injectors.

\section{Mercury CEM Description}

The Thermo Electron Mercury Freedom System ${ }^{T M}$ CEM has been chosen for flue gas mercury measurements at Hardin. Three key components of the CEM are the sample extraction probe/converter, the mercury analyzer, and the calibration module. These are described briefly below and presented in Figure 3, a schematic of the entire system, showing the key components and other supporting instrumentation.

- Sample Extraction Probe/Converter. An inertial filter is used to separate a particulate-free vapor-phase sample while minimizing the interactions with fly ash, which can cause sampling artifacts. The sample is immediately diluted with pre-heated dilution air to minimize mercury reactions with other flue gas species.

- Mercury Analyzer. Mercury is measured directly in the analyzer using Cold Vapor Atomic Fluorescence Spectroscopy (CVAFS). There is no cross interference from $\mathrm{SO}_{2}$ with CVAFS. Because the sample is diluted, it has low moisture, is relatively non-reactive and therefore has minimal interference from other gases.

- Calibration Module. The calibrator module incorporates a mercury source in a temperature-controlled chamber that can be heated or cooled to maintain the source at a precise temperature. The operator can program the calibrator to deliver zero or span gas to the analyzer, to the sample port between the inertial filter and the critical orifice, or upstream of the inertial filter. 


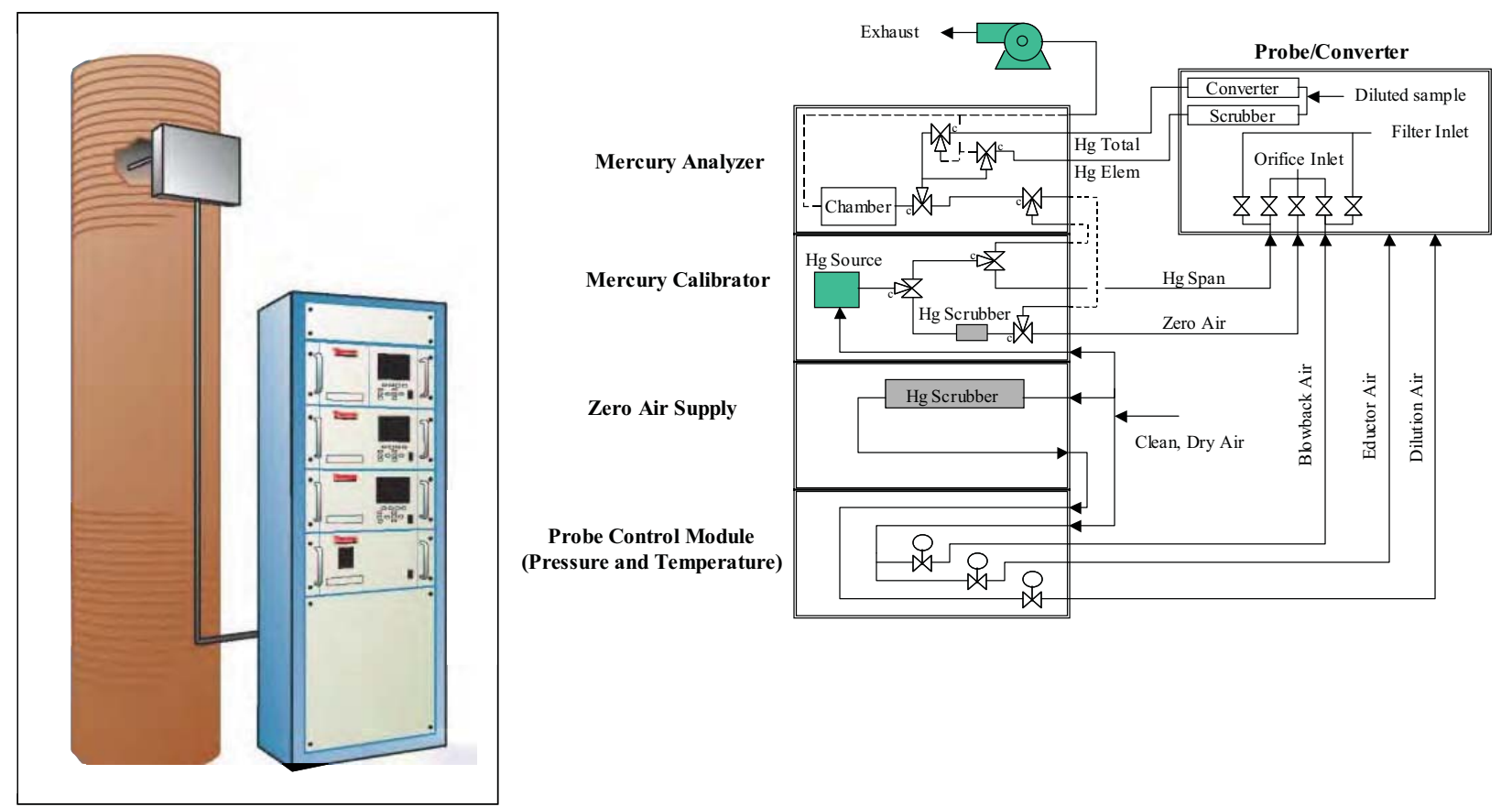

Figure 3. Thermo Electron Mercury Freedom System ${ }^{\mathrm{TM}}$.

The intent of the project team is to configure the mercury CEMs to automatically follow the QA/QC procedures for a compliance mercury CEM as defined in the CAMR. Some aspects of this requirement are not available at the time of this proposal, such as NIST traceable calibration sources. Significant advancements are expected before mercury CEMs would be installed at Hardin.

The accuracy of the CEMs will be assessed by comparing the CEM concentration with a reference method during the baseline and long-term tests. At the time of this proposal, the method that has been approved in the CAMR and provides speciation information is the Ontario Hydro Method. EPA is actively working towards an instrumental reference method, which may be available for some or all of the relative accuracy tests scheduled during the program at Hardin. If a mercury CEM is approved as an instrumental reference method under 40 CFR Part 75.22 by the EPA Administrator, an instrumental method may be substituted for the Ontario Hydro measurements in this project with permission of DOE and team members. Sorbent traps, following a modified version of 40 CFR Part 75 Appendix K, will also be run periodically to check the accuracy of the CEMs and to facilitate troubleshooting.

The CEMs will be installed prior to baseline testing and they are expected to operate continually during field testing. The overall effectiveness of the technology will be assessed by comparing mercury emissions during the parametric and long-term tests against the baseline results. These mercury control results will then be blended with estimated operating costs to determine the mercury removal costs. 


\section{APPENDIX B: STANDARD CALCULATIONS}




\section{Standard Calculations}

\section{Standard Calculations}

\subsection{Sorbent Injection Concentration}

The convention for describing the concentration of sorbent injected into a duct is pounds per million actual cubic foot of flue gas or lb/MMacf. This value is referred to as the "injection ratio" or the "injection concentration." The actual mass flow rate of sorbent is therefore dependent on the total volumetric flow of flue gas at the point of injection. The mass flow rate is determined by the following calculation:

$$
\dot{m}_{\text {sorbent }}=\frac{\dot{Q}_{\text {fluegas }}}{10^{6}} \times \text { Ratio } * 60
$$

where,

$\begin{array}{lll}\dot{m}_{\text {sorbent }} & \mathrm{lb} / \mathrm{hr} & \text { mass feed rate of sorbent } \\ \dot{Q}_{\text {fluegas }} & \text { acfm } & \text { volumetric flow rate of flue gas } \\ \text { Ratio } & \text { lb/MMacf } & \begin{array}{l}\text { sorbent injection ratio } \\ 60\end{array} \\ \text { min } / \mathrm{hr} & \text { conversion factor }\end{array}$

If the flue gas flow is provided in standard cubic feet per minute (scfm), the flowrate at actual temperature can be calculated as follows:

$$
\operatorname{acfm}=\operatorname{scfm} *(459+\mathrm{Ti}) /(459+68)
$$

where $\mathrm{Ti}=$ temperature $\mathrm{n}$ degrees Fahrenheit at the injection location.

The actual injection ratio can be calculated as follows:

$$
\text { Ratio }=\frac{\dot{m}_{\text {sorbent }} / 60}{\dot{Q}_{\text {fluegas }} / 10^{6}}
$$

\subsection{Coal Mercury Concentration Conversion}

The mercury concentration of the coal is typically reported by the lab in $\mathrm{ng} / \mathrm{g}$ or $\mu \mathrm{g} / \mathrm{g}$. To convert $\mathrm{ng} / \mathrm{g}$ to $\mathrm{lb} / \mathrm{TBtu}$, the gross calorific value (GCV) of the coal must be measured and both the mercury concentration and GCV must be on the same moisture basis (i.e. both dry or both wet). The following equation described the conversion:

$$
I_{H g}=W_{H g} \times \frac{1}{G C V} \times \frac{10^{-9} l b}{n l b} \times \frac{10^{12} B t u}{T B t u}
$$

where $I=\mathrm{Hg} \mathrm{lb} / \mathrm{Tbtu}, W=\mathrm{Hg} \mathrm{ng} / \mathrm{g}$

For example, if the coal mercury concentration were $54.3 \mathrm{ng} / \mathrm{g}$ and the GCV were 11942 , both on a dry basis, then

$$
I_{\mathrm{Hg}}=54.3 \mathrm{ng} / \mathrm{g} / 11942 * 10^{3}=4.55 \mathrm{lb} / \mathrm{Tbtu}
$$




\subsection{Flue Gas Mercury Concentration Conversion}

Thermo CEMS data are measured in $\mu \mathrm{g} / \mathrm{wetsm}^{3}$ and using guidelines provided in Method 19 in Appendix A to Part 60, which uses an EPA F Factor and $\mathrm{CO}_{2}$ values, one can convert into units of $\mathrm{lb} / \mathrm{TB}$ tu. Note than TBtu equals $10^{12} \mathrm{Btu}$, or $10^{6} \mathrm{MMBtu}$. An F factor is the ratio of combustion gas volume to heat inputs, and it is used to calculate emission rates from concentrations.

\section{$\mathrm{CO}_{2}$ based $\mathrm{F}$-factor $\left(\mathrm{F}_{\mathrm{C}}\right)$}

$\underline{\text { If the } \mathrm{CO}_{2}}$ concentration is measured on a wet basis:

$$
E=C_{W} \times F c \times \frac{100}{\% \mathrm{CO}_{2}} \times 10^{6} \mathrm{MMBtu} / \mathrm{TBtu}
$$

Where,

$\mathrm{E}=$ emission rate in $\mathrm{lb} / \mathrm{TBtu}$

$\mathrm{C}_{\mathrm{w}}=$ mercury concentration, wet basis, in $\mathrm{lb} \mathrm{Hg} / \mathrm{scf}$. Convert from the CEMS basis of $\mu \mathrm{g} / \mathrm{wsm}^{3}$ as follows:

$$
C_{W}(l b / s c f)=C_{w}\left(\mu g / w s m^{3}\right) \times \frac{1 g}{10^{6} \mu g} \times \frac{1 l b}{453.6 g} \times \frac{1 m^{3}}{35.31 f t^{3}}
$$

$\% \mathrm{CO}_{2} \mathrm{~W}=$ concentration of $\mathrm{CO}_{2}$ on a wet basis, in \%

$\mathrm{F}_{\mathrm{c}}=$ carbon dioxide-based $\mathrm{F}$ factor, in $\mathrm{scf} \mathrm{CO}_{2} / \mathrm{MMBtu}$

The $\mathrm{F}_{\mathrm{c}}$ factor is calculated using the following equation:

$$
\mathrm{F}_{\mathrm{c}}=0.321 * 10^{6 *}(\% \mathrm{C}) / \mathrm{GCV}
$$

Where,

$\% \mathrm{C}=$ concentration of Carbon in coal, $\%$ dry basis

(from ultimate analysis if available)

$\mathrm{GCV}=$ gross calorific value, Btu/lb dry basis

If the $\mathrm{CO}_{2}$ concentration is measured on a dry basis, you must adjust for the moisture fraction in the flue gas as follows:

$$
E=\frac{C_{W} \times F c}{1-B_{W S}} \times \frac{100}{\% C O_{2 d}} \times 10^{6} \mathrm{MMBtu} / \mathrm{TBtu}
$$

All terms are the same as above with the exception of $\mathrm{B}_{\mathrm{ws}}=$ moisture fraction of the flue gas, in $\%$

$\% \mathrm{CO}_{2 \mathrm{~d}}=$ concentration of $\mathrm{CO}_{2}$ on a dry basis, in $\%$ 


\section{$\mathrm{O}_{2}$ based $\mathbf{F}$-factor $\left(\mathbf{F}_{\mathrm{d}}\right)$}

If the $\mathrm{O}_{2}$ concentration is measured on a wet basis:

$$
E=C_{W} \times F d \frac{20.9}{20.9\left(1-B_{W S}\right)-\% O_{2 w}}
$$

If the $\mathrm{O}_{2}$ concentration is measured on a dry basis, you must adjust for the moisture fraction in the flue gas as follows:

$$
E=\frac{C_{W} \times F d \times 20.9}{\left(1-B_{W S}\right)\left(20.9-\% O_{2 d}\right)}
$$

The $\mathrm{F}_{\mathrm{D}}$ factor is calculated using the following equation:

$$
F_{D}=\frac{3.64 \times W_{H}+1.53 \times W_{C}+0.57 \times W_{S}+0.14 \times W_{N}-0.46 \times W_{O}}{H H V} \times 10^{6}
$$

Where $\quad W_{H}=$ fraction of hydrogen in the coal

$\mathrm{W}_{\mathrm{C}}=$ fraction of carbon in the coal

$\mathrm{W}_{\mathrm{S}}=$ fraction of sulfur in the coal

$\mathrm{W}_{\mathrm{N}}=$ fraction of nitrogen in the coal

$\mathrm{W}_{\mathrm{O}}=$ fraction of oxygen in the coal

$\mathrm{HHV}=$ higher heating value of the coal in lb/BTU

$\mathrm{Cw}$ is calculated as described above in Equation F-6.

\subsection{Mercury Removed by Fly Ash}

The mercury concentration in the fly ash is typically measured in ng/g. This can be converted to $\mathrm{lb} / \mathrm{TB}$ tu using the following technique:

$$
\mathrm{E}_{\text {ash }}=\frac{\% A / 100}{G C V} \times K_{1} \times K_{2} \times C_{a s h} \times 10^{12}(\text { Btu } / T B t u) \times 10^{-9}(l b / n l b)
$$

Where $\quad E_{\text {ash }}$ is the mercury collected by the ash in lb/TBtu $\% \mathrm{~A}$ is the fraction of ash in the coal sample

$\mathrm{GCV}$ is the gross caloric value in $\mathrm{lb} / \mathrm{Btu}$

$\mathrm{K}_{1}$ is the fraction of ash entering the ESP (nominally 0.85 for PC plants)

$\mathrm{K}_{2}$ is the collection efficiency of the first collection field (nominally 0.8 for many ESPs)

$\mathrm{C}_{\text {ash }}$ is the concentration of mercury in the ash, $\mathrm{ng} / \mathrm{g}$ 


\section{APPENDIX C: HG-CEM QA/QC PROTOCOLS}




\section{ADA Hg-CEM QA/QC Protocol}

\section{Hg-CEM QA/QC Protocol}

\section{Mercury CEMS Quality Assurance/Quality Control Program}

ADA has developed an extensive internal Mercury Continuous Emissions Monitoring System Quality Assurance and Quality Control Program that is implemented as a guideline during ADA's Thermo Fisher Mercury Freedom System ${ }^{\text {TM }}$ operation and deployment.

In order to have confidence in the individual measurements and the conclusions based on those measurements, a set of quality assurance checks were developed during the test phase. Many of the quality control requirements were used as referenced in Appendix A and Appendix B of CFR 40 Part 75. While these QA/QC checks were generally observed, they are only guidelines. ADA has significant experience and expertise in designing and conducting test programs of this nature and in conducting the subsequent analyses.

A QA/QC program for the Hg-CEMs was not in place at the beginning of the Hardin project due to the unproven history of the CEMs in 2006 as well as a lack of clearly specified performance requirements in federal regulations. The ADA QA/QC program was developed through year of experience operating these systems at Hardin and at other sites.

\section{Equipment Functionality Assessment}

Each component of the $\mathrm{Hg}$-CEMs was evaluated to ensure it was functioning according to the performance specifications supplied by the manufacturer. The CEMs were assembled and run through an exhaustive checklist to simulate and confirm typical operating conditions. The systems installed at Hardin were purchased specifically for this project and, therefore, were not used at any other facility.

\section{Installation and Acceptance Procedure}

The Hg-CEMs were installed in accordance with ADA established practices and procedures. Each step of the procedure was documented to ensure that the systems were installed and configured correctly and that components were not damaged during transportation.

An Hg-CEM was considered to be operating properly when it completed the certification procedures in Appendix A of CFR 40 Part 75, as applicable. The certification tests include a two-point calibration error test, 3-point linearity error test, a cycle time test, and a 3-point system integrity test. Periodic monitoring of the $\mathrm{Hg}$-CEMs was conducted by the ADA Technology Group.

The low-, mid-, and high-level span values used for all calibration routines may be determined from mercury concentration data collected from previous test programs. If 
this data is not available or accuracy can not be assured, then the type of coal burned may be used to determine the initial span values. ADA used previous test values during the installation procedure and made adjustments during the test program as conditions changed (e.g. fluctuations in coal mercury concentration and the onset of ACI).

ADA acquired a procedure used by ThermoFisher to evaluate their systems during production. This procedure was used by ADA during the installation of the two CEMs in September, 2006 to ensure that the systems were configured properly and to evaluate the performance of the system after installation. This procedure was later expanded to include a linearity test, cycle time test and 3-point system integrity test, and was used during the latter stages of the project.

The first Hg-CEM verification test was performed in September, 2007 after ThermoFisher released an upgrade package for the mercury system. The package included a lamp heater, calibration gas hydrator, nitrogen generator and new software packages. This upgrade did not include a mercuric chloride generator. Both systems passed the criteria for the 7-day calibration drift test, system cycle time test and the 3point linearity check during this, and subsequent verification tests.

\section{Daily Calibration Error Test}

Daily calibration checks were modeled after the regulations defined by Appendix B of CFR 40 Part 75, Section 2.1.1 and 2.1.2. The CEMs are required to meet a performance specification of $5.0 \%$ of span $O R \pm 1.0 \mu \mathrm{g} / \mathrm{wscm}$ difference between the reference gas and the analyzer response for span values $<10 \mu \mathrm{g} / \mathrm{wscm}$. The daily calibration checks are automatically initiated by the analyzer software each day, and the responses analyzed to determine if adjustments to the calibration coefficients are needed.

When a daily calibration error test failed, or when a CEM was returned to service after repair or maintenance, data were considered invalid until an additional calibration error test had been successfully completed. Small adjustments to the calibration coefficients are permitted after a successful calibration error test. These adjustments are made to maintain the highest precision possible. They can be made by means of a mathematical algorithm or by a manual calibration. However, an additional calibration error test is required if a manual calibration is performed.

To maximize the CEM availability and maintain high measurement precision, ADA developed an extensive program to analyze the calibration check responses and CEM operations. This program uses criteria that are stricter than those in federal and state regulations. The error criterion specified in CAMR is $5 \%$ or $1 \mu \mathrm{g} / \mathrm{wscm}$. The criteria used by ADA, based on the error of the calibration response, define the level of action required to maintain peak performance. If the difference in zero or span response is less than $\pm 0.1 \mu \mathrm{g} / \mathrm{wscm}$ and less than $0.5 \%$ error, the system did not require adjustment. If the error is greater than $0.1 \mu \mathrm{g} / \mathrm{wscm}$ or $0.5 \%$, then there are several possible actions depending on if it is the first occurrence of the error and on what channel (zero or span) the error occurred. An error above $0.5 \mu \mathrm{g} / \mathrm{wscm}$ or $2.5 \%$ required a calibration factor update. This procedure was not in place when the $\mathrm{Hg}$ - 
CEMs were installed at Hardin, and it changed during the life of the project due to upgrades in software and equipment. Many of the first calibration checks were unstable and inaccurate, but these improved significantly and are now a routine part of all projects.

\section{Weekly System Integrity Check}

Any ThermoFisher Mercury Freedom System may be equipped with a Mercuric Chloride Generator (MGC) depending on the intended use of the system and on state and federal regulations. At Hardin, the stack CEM is equipped with a MGC, while the AH outlet CEM is not. The MGC converts elemental mercury from the calibrator into oxidized mercury in a proprietary process. For systems equipped with a MCG, system integrity checks are required by CAMR and are performed to access the response of the system to low-, mid-, and high-levels oxidized mercury injected prior to the inertial filter in the extraction probe.

There are several criteria used to determine the validity of a system integrity check. According to Part 75, the CEM measurement must not differ from the reference value by more than $5.0 \%$ at any of the three levels. Another criterion, defined by ThermoFisher, is that the recovery efficiency for the oxidized mercury be greater than $90 \%$. A third criterion is that the response must not differ from the reference value by more than $10 \%$ of the span value (the span value is not the same as the reference value).

An MCG was installed in the stack probe at Hardin in December, 2007 shortly before the two month outage. Initial tests in April, 2008 did not meet the test criteria. Several modifications were made to the MGC, as recommended by ThermoFisher, during the course of the project, but they did not produce results that passed acceptance criteria. As of the date of this report, the system integrity checks still do not pass the requirements of the test.

\section{Quarterly Linearity Check}

Linearity checks were performed to access the response of the system with the low-, mid- and high-level reference gas injected ahead of the inertial filter in non-repetitive, triplicate runs. Part 75 states that the CEM is required to meet a performance specification of $10.0 \%$ of reference or a difference of $\pm 1.0 \mu \mathrm{g} / \mathrm{m}^{3}$, whichever is less restrictive. Linearity checks are required each quarter and at least 30 days apart and must be completed within 24 unit operating hours. Linearity checks were performed manually by changing the span concentration of the calibrator.

Table E1 shows the results of all linearity checks performed during the project. The first complete linearity check performed on the inlet and stack CEMs at Hardin was performed on January 22, 2007. This linearity check failed, but an investigation found problems with the configuration of the CEMs and performance of the calibrators which were corrected, and a subsequent linearity test passed. Some linearity checks were not performed in a quarter-year because there was uncertainty regarding specific federal quality control requirements (2007) and/or because of plant 
outages that disrupted the test schedule (2008). The stack CEM failed a few linearity checks in the ten quarters spanned by the project. These can be attributed to the use equipment that was later upgraded (June, 2007), the use of incorrect calibration concentrations (the test was initiated with incorrect settings in the calibrator and could not be stopped as per the rule), and calibrator maintenance activities (early in the project, the calibrators were found to be non-linear due to degradation of the mercury reservoir in the calibrator that was later corrected by use of nitrogen as the calibration carrier gas).

Table E1. Linearity Check Results.

\begin{tabular}{|l|l|l|l|}
\hline \multicolumn{4}{|l}{ HARDIN Hg-CEM LINEARITY CHECK - SDA INLET } \\
\hline QUARTER & DATE & HIGH ERROR & RESULT \\
\hline 1Q 2007 & $3 / 17 / 07$ & $1.6 / 9.1 \%$ & PASS \\
\hline 2Q 2007 & N/A & N/A & N/A \\
\hline 3Q 2007 & $9 / 19 / 07$ & $0.50 / 4.1 \%$ & PASS \\
\hline 4Q 2007 & N/A & N/A & N/A \\
\hline 1Q 2008 & N/A & N/A & N/A \\
\hline 2Q 2008 & $4 / 4 / 08$ & $0.31 / 3.8 \%$ & PASS \\
\hline & $4 / 28 / 08$ & $0.31 / 4.0 \%$ & PASS \\
\hline 3Q 2008 & $7 / 25 / 08$ & $0.45 / 7.2 \%$ & PASS \\
\hline & $9 / 17 / 08$ & $0.39 / 4.7 \%$ & PASS \\
\hline 4Q 2008 & $11 / 18 / 08$ & $0.15 / 2.0 \%$ & PASS \\
\hline
\end{tabular}




\begin{tabular}{|l|l|l|l|}
\hline \multicolumn{4}{|l}{ HARDIN Hg-CEM LINEARITY CHECK - STACK } \\
\hline QUARTER & DATE & HIGH ERROR & RESULT \\
\hline 1Q 2007 & $3 / 17 / 07$ & $4.48 / 47.0 \%$ & FAIL $*$ \\
\hline & $3 / 25 / 07$ & $0.25 / 2.0 \%$ & PASS \\
\hline 2Q 2007 & N/A & N/A & N/A \\
\hline 3Q 2007 & $7 / 20 / 07$ & $1.48 / 24.0 \%$ & FAIL $*$ \\
\hline & $9 / 19 / 07$ & $1.71 / 9.3 \%$ & PASS \\
\hline 4Q 2007 & N/A & N/A & N/A \\
\hline 1Q 2008 & N/A & N/A & N/A \\
\hline 2Q 2008 & $4 / 4 / 08$ & $4.81 / 35.4 \%$ & FAIL $*$ \\
\hline & $4 / 28 / 08$ & $0.32 / 10.7 \%$ & PASS \\
\hline 3Q 2008 & $7 / 25 / 08$ & $0.77 / 8.5 \%$ & PASS \\
\hline 3Q 2008 & $9 / 18 / 08$ & $0.38 / 8.7 \%$ & PASS \\
\hline 4Q 2008 & $11 / 18 / 08$ & $0.40 / 5.0 \%$ & PASS \\
\hline
\end{tabular}

* failed tests that were repeated after corrections were made 


\section{APPENDIX D: M30A RESULTS}

DOE Report No. 42774R12 
Relative Accuracy Test Audit (RATA) Utilizing EPA's Method 30A and Performance Testing at Rocky Mountain Power's Hardin Generating Station, Hardin, MT

\author{
Test Dates: April $21^{\text {st }}-24^{\text {th }}, 2008$ \\ Project Number 06-7008
}

DOE Award Number DE-FC26-06NT42774

Project Director: Sharon Sjostrom

Project Engineer: Jerry Amrhein

ADA-ES, Inc.

8100 SouthPark Way, Unit B

Littleton, CO 80120 


\section{TABLE OF CONTENTS}

EXECUTIVE SUMMARY ............................................................................................... 3

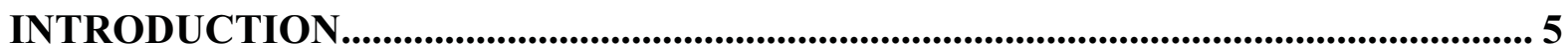

Figure 1: Hardin Facility View ...................................................................................... 5

Facility Description .................................................................................................................... 5

Mercury CEMS Description ................................................................................................. 6

Sampling Port Locations .......................................................................................................... 6

Method 30A IRM Equipment \& Description................................................................. 8

Reference Analyzer Equipment and Method Description ................................................. 8

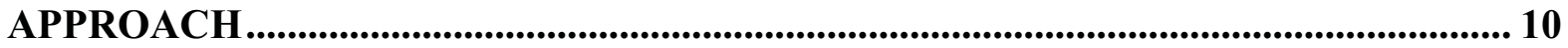

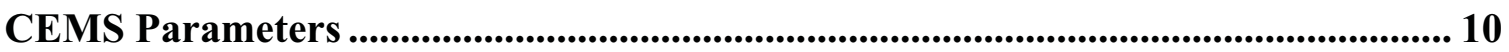

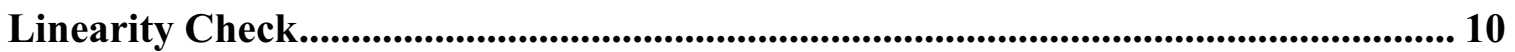

7-Day Calibration Error Test ............................................................................................. 11

Cycle Time Test....................................................................................................................... 11

3-Level System Integrity Check.............................................................................................. 12

Relative Accuracy Test Audit (RATA) \& Bias Test ........................................................ 12

Instrumental Analyzer Configuration.................................................................................. 12

Calibration Span \& Gas Concentrations ................................................................12

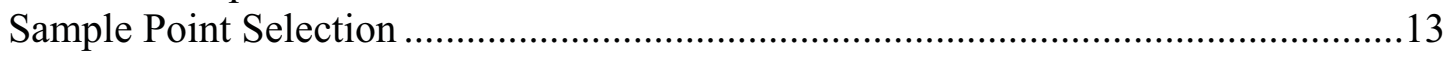

Initial Measurement System Performance Tests ............................................................ 14

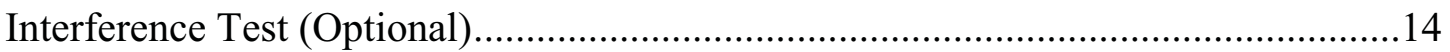

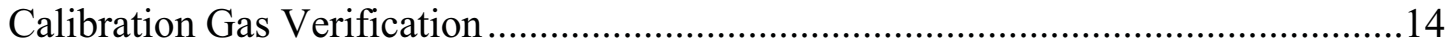

Measurement System Preparation........................................................................14

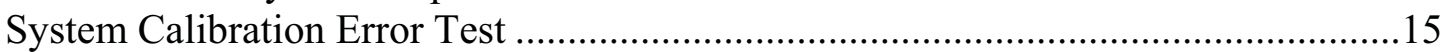

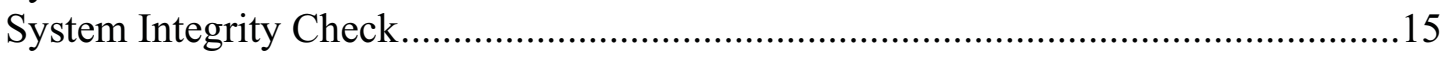

Measurement System Response Time ……………………................................15

Dynamic Spiking Test (deferred until January 1, 2009)...........................................15

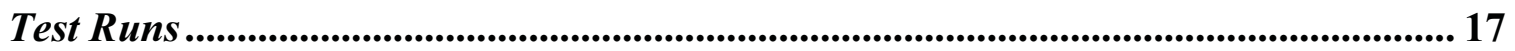

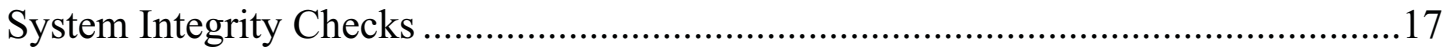

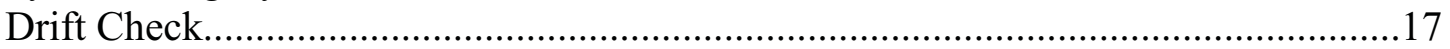

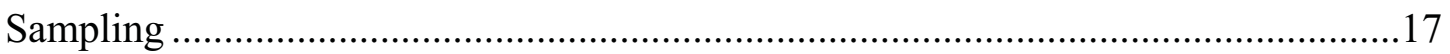

Relative Accuracy Calculation .............................................................................................. 18

Bias Determination \& Adjustment Factor Calculation........................................................ 19

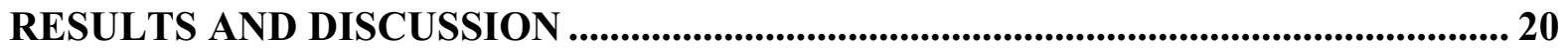

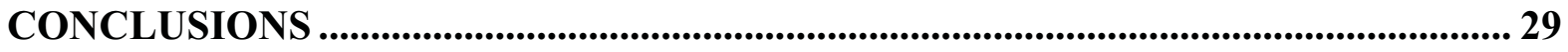

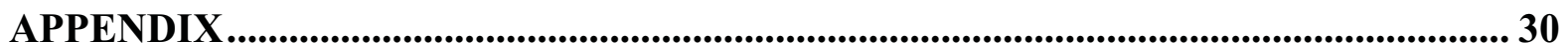

Initial Measurement System Response Tests \& Run Validations ................................ 30 
Table 1: Summary of Test Results ........................................................................................3

Table 2: Key Parameters of the Hardin Power Plant............................................................66

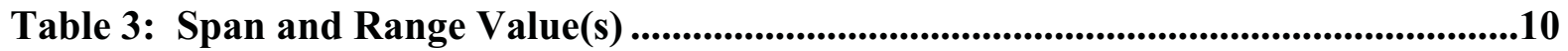

Table 4: IRM Calibration Span \& Gas Concentrations.....................................................12

Table 5: Linearity Check - Stack Hg-CEMS............................................................................20

Table 6: Linearity Check - Air Heater Outlet Hg-CEMS............................................21

Table 7: 7-Day Calibration Error Test - Stack Hg-CEMS ..................................................22

Table 8: 7-Day Calibration Error Test - Air Heater Outlet Hg-CEMS .........................23

Table 9: Cycle Time Test - Stack Hg-CEMS..................................................................24

Table 10: Cycle Time Test - Air Heater Outlet Hg-CEMS..................................................25

Table 11: 3-Level System Integrity Check - Stack Hg-CEMS...........................................26

Table 12: RATA \& Bias Test - Stack Hg-CEMS ...................................................27

Table 13: RATA \& Bias Test - Air Heater Outlet Hg-CEMS ............................................28

Table 14: IRM System Calibration Error Test .............................................................30

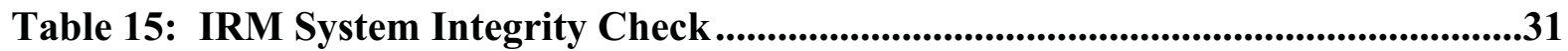

Table 16: IRM Dynamic Spiking Test ...................................................................................32

Table 17: Run Validation - Stack Hg-CEMS ...............................................................33

Table 18: Run Validation - Air Heater Outlet Hg-CEMS ................................................34

\section{LIST OF FIGURES}

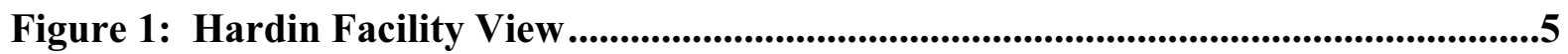

Figure 2: Stack Sampling Port Location ..........................................................................7

Figure 3: Air Heater Outlet Sampling Port Location................................................................8

Figure 4: Thermo CEMS Configured for an IRM ............................................................9

Figure 5: Filter and Conversion Unit........................................................................................9

Figure 6: IRM Probe Designed for Traversing ..........................................................................9

Figure 7: Stack Sampling Points .................................................................................13

Figure 8: Air Heater Outlet Sampling Point .......................................................................14 


\section{EXECUTIVE SUMMARY}

ADA Environmental Solutions, Inc. (ADA-ES) conducted mercury continuous emissions monitoring system (Hg-CEMS) testing during the week of April 21, 2008 at Rocky Mountain Power's Hardin Generating Station, Hardin, MT using regulations outlined in 40 CFR Part 75.20. Method 30A was the instrumental reference method (IRM) employed to conduct a Relative Accuracy Test Audit (RATA) of the Stack Hg-CEMS, downstream of Activated Carbon Injection (ACI). Modified Method 30A procedures were also used for a RATA on the Air Heater Outlet Hg-CEMS, upstream of ACI.

This technical report was prepared with the support of the U.S. Department of Energy under Award No. DE-FC26-06NT42774, to be included in the "Long-Term Carbon Injection Field Test for $>90 \%$ Mercury Removal for a PRB Unit with a Spray Dryer and Fabric Filter" project of DOE's "Phase III Mercury Control Technology Field Testing and Related Mercury Control Research and Development" program. This was the first of three RATA tests that will be performed during the Long-term Test Phase of this project as specified in the test plan.

The stack Hg-CEMS passed all performance tests conducted during this evaluation except the 3Level System Integrity Check and the Bias Test. The air heater outlet CEMS passed all applicable performance tests except the Bias Test. The instrumental analyzer failed the dynamic spiking test. A summary of these results are presented in Table 1 and details are discussed in this report.

Table 1: Summary of Test Results

\begin{tabular}{|l|c|c|}
\hline \multicolumn{1}{|c|}{ Test } & $\begin{array}{c}\text { Stack } \\
\text { Hg-CEMS } \\
\text { (downstream of ACI) }\end{array}$ & $\begin{array}{c}\text { Air Heater Outlet } \\
\text { Hg-CEMS } \\
\text { (upstream of ACI) }\end{array}$ \\
\hline Linearity Check & PASS & PASS \\
\hline 7-Day Calibration Error Test & PASS & PASS \\
\hline Cycle Time Test & PASS & PASS \\
\hline 3-Level System Integrity Check & FAIL & N/A \\
\hline Relative Accuracy Test Audit & PASS & PASS \\
\hline IRM System Performance Tests & & - \\
\hline Interference Check (Optional) & - & - \\
\hline 3-Point System Calibration Error Test & PASS & - \\
\hline System Integrity Check & PASS & - \\
\hline Measurement System Response & PASS & - \\
\hline Dynamic Spiking Test & FAIL & FAIL \\
\hline Bias Test & FAIL & \\
\hline
\end{tabular}

* Note: The 3-Level System Integrity Check is not applicable to the CEMS installed on the Air Heater Outlet because no oxidizer is installed at this location.

It is important to note that the $121 \mathrm{MW}$ plant had been operating at approximately $105 \mathrm{MW}$ due to a transformer casualty and the subsequent replacement transformer's limitations. A new transformer capable of full load is scheduled to be installed in July 2008. Despite this lower output, the plant was still operating at the "high load" deemed to be the normal load for the unit as defined in Section 6.5.2.1 [40 CFR Part 75 Appendix A]. 
The failure of the 3-Level System Integrity Check on the Stack Hg-CEMS was attributed to improper insulation of the mercuric chloride generator. This unit will be upgraded and tested before the next RATA in June 2008. The failure of the Bias Tests was attributed to a flaw in the design of the Heating Ventilation and Air Conditioning (HVAC) system on the IRM that made it difficult to maintain constant temperature within the housing. This flaw has been corrected and the Bias Test will be repeated during the June test. No Bias Adjustment Factor (BAF) was implemented into the CEMS at this time.

A Linearity Check performed the week before the site visit on the Stack Hg-CEMS failed due to calibrator non-linearity. As a result, the IRM calibrator was used to successfully calibrate the Stack Hg-CEMS for the test period, and was later installed into the Stack system after the RATAs to allow for the non-linear unit's being serviced. The remaining tests were performed remotely with the IRM calibrator.

The Dynamic Spiking Test failure was attributed to difficulties in maintaining vapor phase oxidized mercury in the sample gas stream. Recovery of the oxidized mercury proved unsuccessful as evident in failure of both mean percentage recovery and absolute difference criteria. This test is intended to be reevaluated in August 2008 and its feasibility will be reassessed.

This report documents detailed operating procedures, and includes supporting documentation in a dedicated appendix. 


\section{INTRODUCTION}

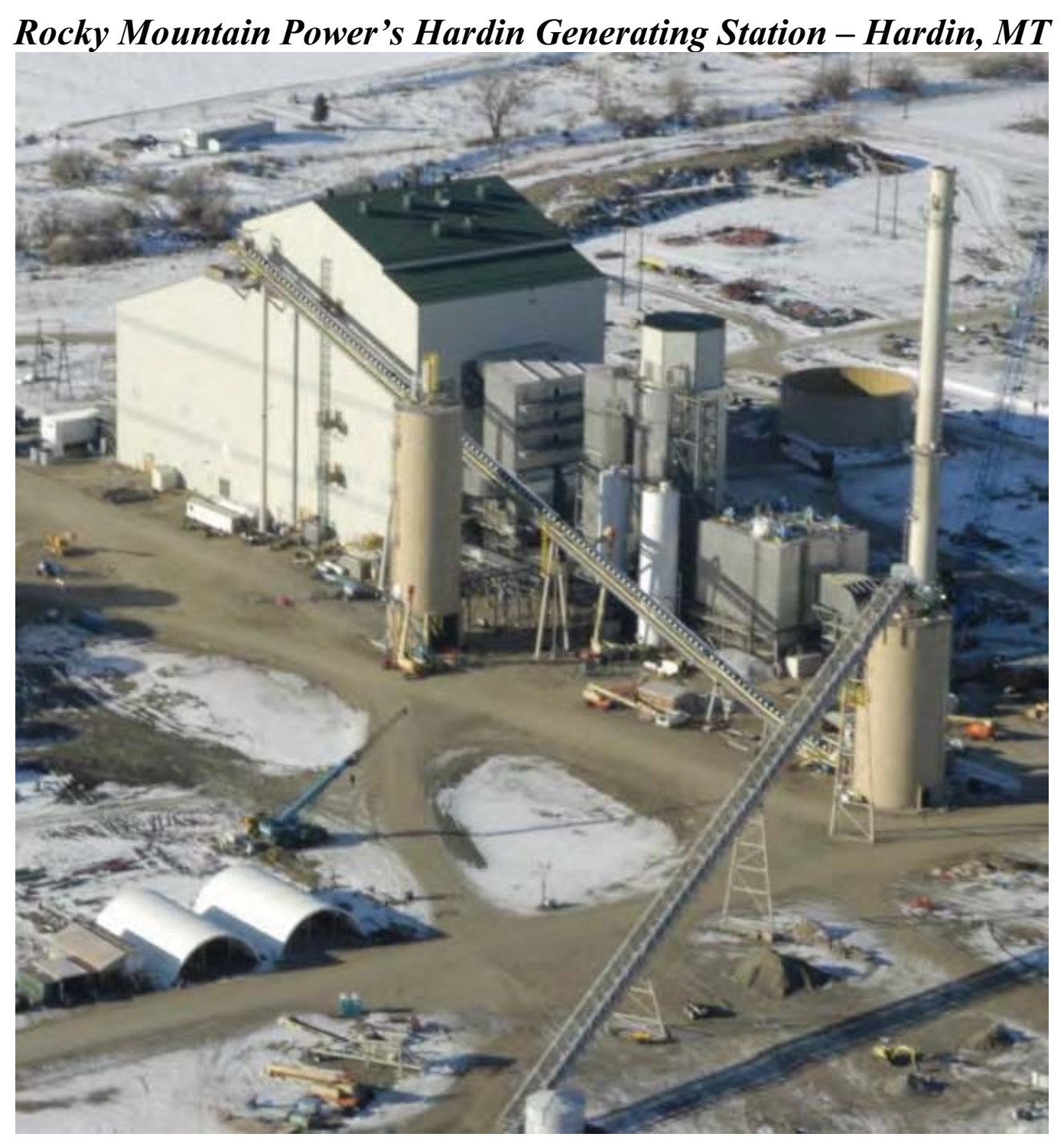

Figure 1: Hardin Facility View

\section{Facility Description}

Rocky Mountain Power's Hardin Generating Station is a new and relatively small plant (121 MW) that was first brought online in December of 2005. It fires a pulverized Powder River Basin (PRB) coal from the nearby Absaloka Mine, and is configured with low $\mathrm{NO}_{\mathrm{x}}$ burners and a Selective Catalytic Reduction (SCR) for $\mathrm{NO}_{\mathrm{x}}$ control, a Spray Dryer Absorber (SDA) for $\mathrm{SO}_{2}$ control, and a Fabric Filter (FF) for particulate control. The coal contains approximately $0.65 \%$ sulfur, $0.04 \mathrm{ppm}$ mercury and $<20 \mathrm{ppm}$ chlorine. A commercial-grade Activated Carbon Injection (ACI) system is integrated with a new-generation mercury analyzer to allow automated feedback control of the outlet mercury emissions. 
Table 2: Key Parameters of the Hardin Power Plant

\begin{tabular}{|l|c|}
\hline Rated Capacity & 121 (MW) \\
\hline Range of Operation & $81-121 \mathrm{MW}$ \\
\hline Operating Levels & $\begin{array}{c}\text { Low: } 81-93 \mathrm{MW} \\
\text { Mid: } 93-105 \mathrm{MW} \\
\text { High (Normal): } 105-121 \mathrm{MW}\end{array}$ \\
\hline Coal (typical) & $\begin{array}{c}\text { PRB } \\
\text { Absaloka Mine }\end{array}$ \\
\hline Boiler Type & $\begin{array}{c}\text { PC Boiler } \\
\text { Opposing wall-fired }\end{array}$ \\
\hline Sulfur Control & Spray Dryer with Recycle \\
\hline Nitrogen Oxide Control & Low NO Burners/SCR $^{\text {S }}$ \\
\hline Particulate Control & Fabric Filter \\
\hline $\begin{array}{l}\text { Gas Flow Rate } \\
\text { (ACI Location) }\end{array}$ & $\sim 550,000 \mathrm{acfm}$ \\
\hline $\begin{array}{l}\text { Flue Gas Temperature } \\
\text { (ACI Location) }\end{array}$ & $260-320^{\circ} \mathrm{F}$ \\
\hline
\end{tabular}

\section{Mercury CEMS Description}

The Mercury Freedom ${ }^{\mathrm{TM}}$ System manufactured by Thermo Fisher Corporation is installed at Hardin. This CEMS is being used to measure the mercury emissions at the Stack and the Air Heater Outlet. Thermo Electron's Mercury Freedom ${ }^{\mathrm{TM}}$ System is comprised of an Hg Analyzer (80i), Calibrator (81i), Probe Controller (82i), Probe (83i) and related peripheral components including an umbilical and instrument rack.

\section{Sampling Port Locations}

Air Sampling Associates, Inc. previously measured and documented the sampling port locations at the Stack and Air Heater Outlet depicted in Figures 2 and 3, respectively, during stack testing:

"The sampling ports on the SDA Inlet duct [Air Heater Outlet duct] are approximately 36 feet 9 $1 / 2$ inches above the ground. The sampling ports are located 13 feet 4 inches (1.12 equivalent duct diameters) downstream from a bend in the duct and 56 feet 3 inches (4.75 equivalent duct diameters) upstream from a bend in the duct. The sampling ports on the Stack are approximately 123 feet 1 1/2 inches above the ground. The sampling ports are located 33 feet $11 / 2$ inches (3.64 stack diameters) downstream from the inlet to the Stack and $>18$ feet $23 / 8$ inches $(>2.00$ Stack diameters) upstream from the outlet to the Stack." 


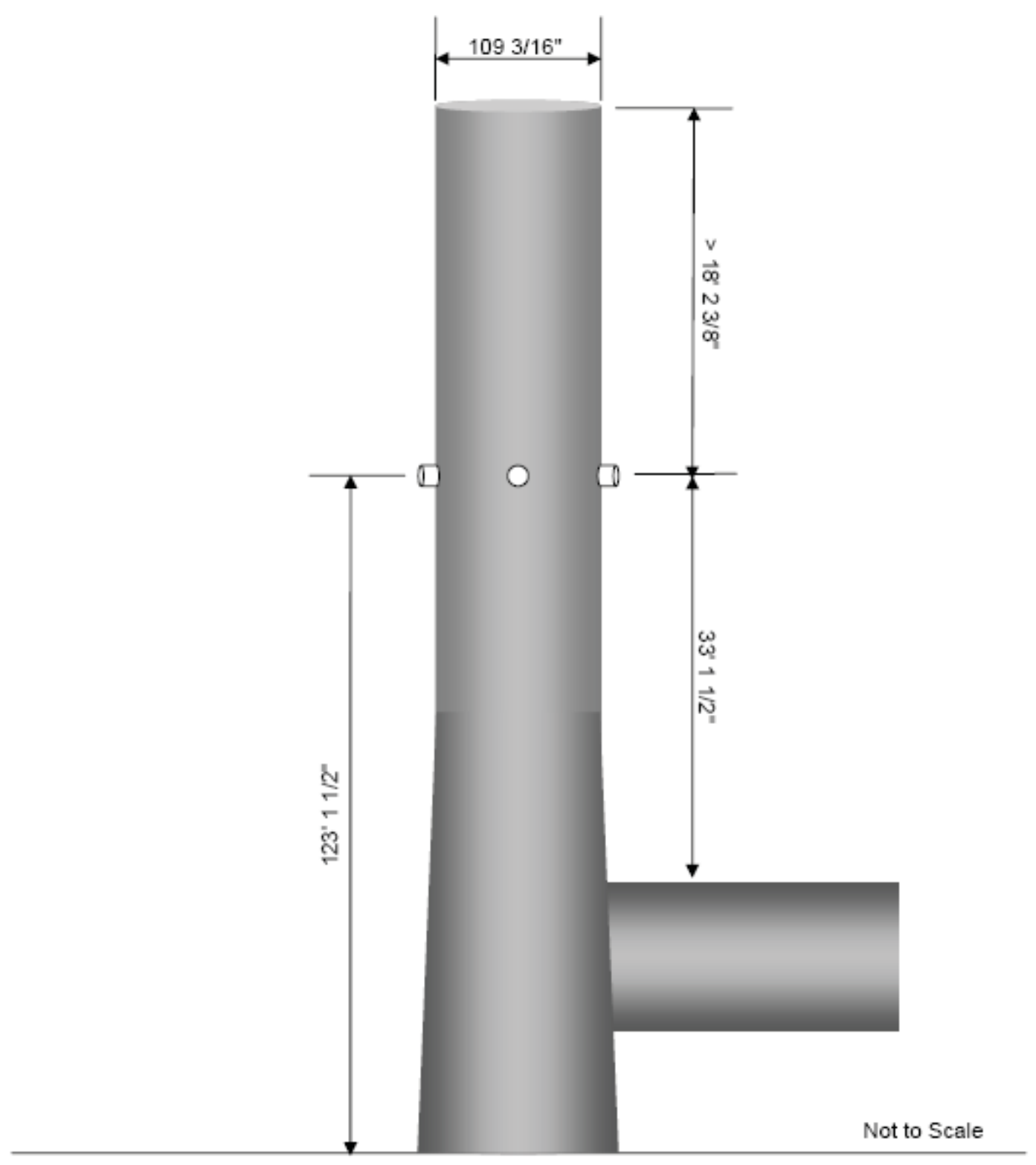

Figure 2: Stack Sampling Port Location [ASA, Inc.] 


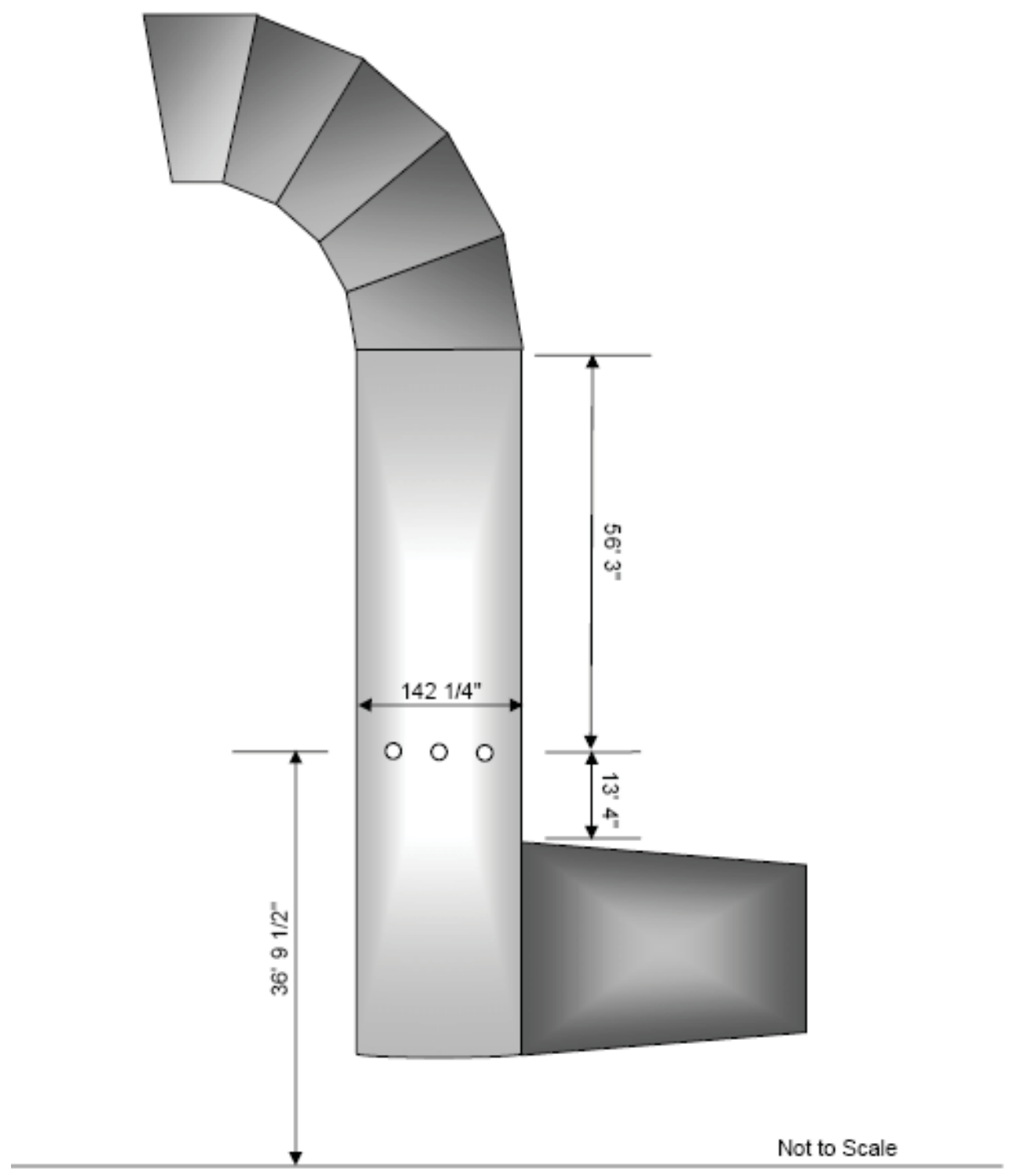

Figure 3: Air Heater Outlet Sampling Port Location [ASA, Inc.]

\section{Method 30A IRM Equipment \& Description}

A Thermo Mercury Freedom ${ }^{\mathrm{TM}}$ System has been configured for IRM testing. A photo of the unit is shown in Figure 4. The unit consists of a standard Model 80i Mercury Analyzer and Model $81 \mathrm{i}$ Mercury Calibrator installed in a temperature controlled enclosure. Probe control (temperature, flow, pressure) is achieved through analog controls installed in the environmental enclosure. A standard Model 83i Probe, shown in Figure 5, has been modified by removing the mantle and stinger, connecting calibration gas to a port upstream of the sampling filter, and adding additional pressure monitoring capabilities to the flow measurement venturi. A modified mantle/stinger portion of the probe has been fabricated to facilitate traversing. A sketch of this component is shown in Figure 6. The mantle/stinger was coupled to the other probe components 
by a 25 -foot long heated umbilical. At Hardin Generating Station, the IRM enclosure was located at ground level while the probe enclosure, 25-foot heated umbilical, and mantle/stinger were located at the sampling platform.

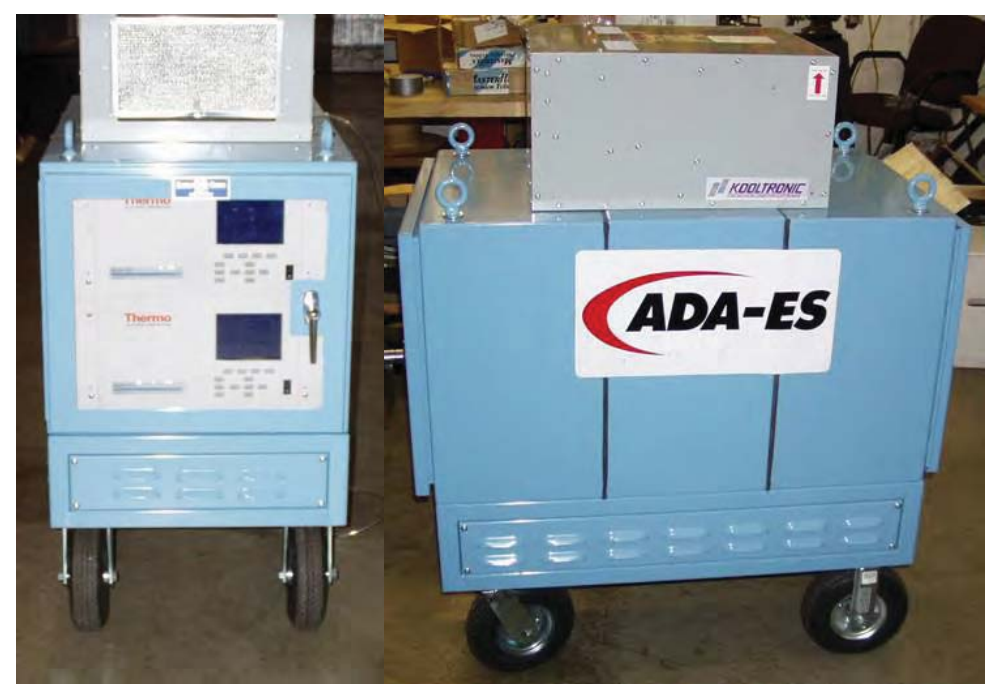

Figure 4: Thermo CEMS Configured for an IRM

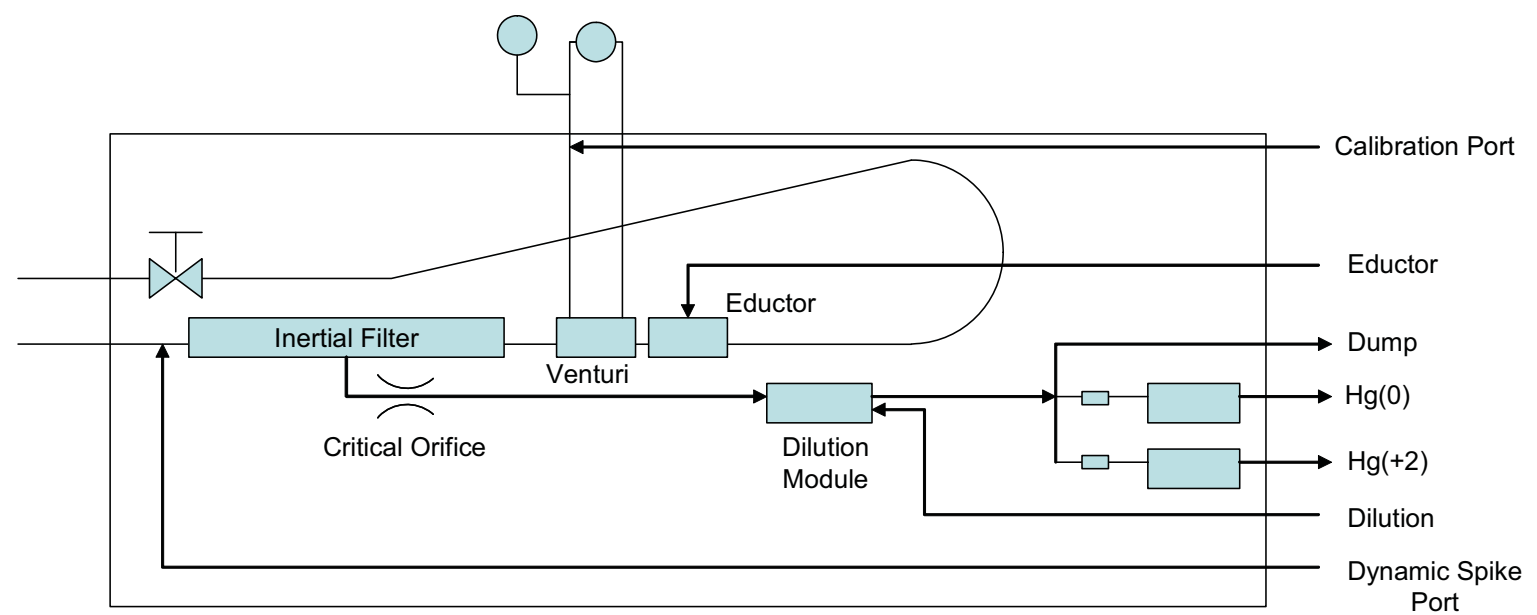

Figure 5: Filter and Conversion Unit

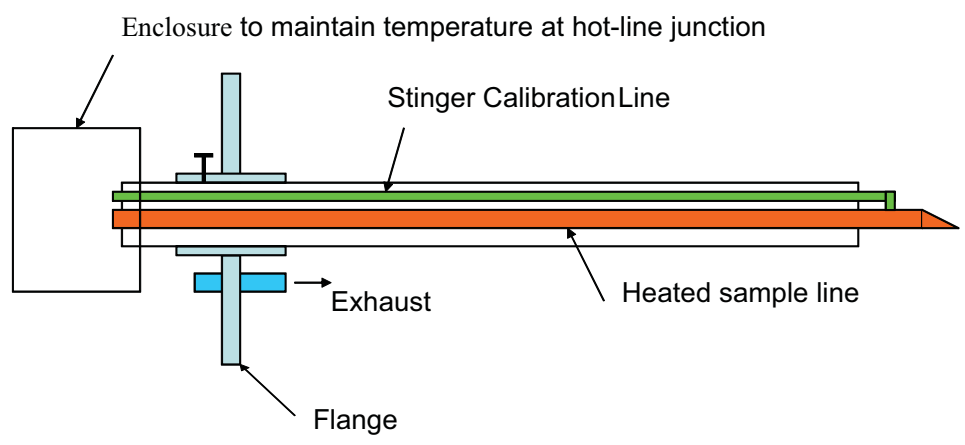

Figure 6: IRM Probe Designed for Traversing 


\section{APPROACH}

\section{CEMS Parameters}

System parameters for the installed Hg-CEMS are presented in Table 3. The Maximum Potential Concentration (MPC), Removal Efficiency (RE), and Maximum Expected Concentration (MEC) were determined in order to calculate the Span (S), Range, and appropriate concentration levels. These calculated values are necessary for calibration of the analyzer, and consequently the validation of measured data.

Table 3: Span and Range Value(s)

\begin{tabular}{|c|c|c|c|}
\hline & $\begin{array}{c}\text { Air Heater Outlet Hg-CEMS } \\
\text { (Upstream of ACI) }\end{array}$ & $\begin{array}{c}\text { Stack Hg-CEMS } \\
\text { (Downstream of ACI) }\end{array}$ & Reference \\
\hline MPC & $10 \mu \mathrm{g} / \mathrm{scm}$ & $10 \mu \mathrm{g} / \mathrm{scm}$ & $\begin{array}{c}\text { Section 2.1.7.1.1 } \\
40 \text { CFR Part 75 Appendix A }\end{array}$ \\
\hline RE & $0 \%$ & $90 \%$ & $\begin{array}{c}\text { Equation A-2, Section 2.1.1.2 } \\
40 \text { CFR Part 75 Appendix A }\end{array}$ \\
\hline MEC & $10 \mu \mathrm{g} / \mathrm{scm}$ & $1 \mu \mathrm{g} / \mathrm{scm}$ & $\begin{array}{c}\text { Section 2.1.7.2 } \\
40 \text { CFR Part 75 Appendix A }\end{array}$ \\
\hline S (High : Low) & $20 \mu \mathrm{g} / \mathrm{scm}$ & $20 \mu \mathrm{g} / \mathrm{scm}: 10 \mu \mathrm{g} / \mathrm{scm}$ & $\begin{array}{c}\text { Section 2.1.7.3 } \\
40 \text { CFR Part 75 Appendix A }\end{array}$ \\
\hline Range & $20 \mu \mathrm{g} / \mathrm{scm}$ & $10 \mu \mathrm{g} / \mathrm{scm}$ & $\begin{array}{c}\text { Section 2.1.7.3 } \\
40 \text { CFR Part 75 Appendix A }\end{array}$ \\
\hline $\begin{array}{c}\text { Zero-level Concentration } \\
(0-20 \% * \text { S) }\end{array}$ & $0 \mu \mathrm{g} / \mathrm{scm}(0 \%)$ & $0 \mu \mathrm{g} / \mathrm{scm}(0 \%): 0 \mu \mathrm{g} / \mathrm{scm}(0 \%)$ & $\begin{array}{c}\text { Section 5.2 } \\
40 \text { CFR Part 75 Appendix A }\end{array}$ \\
\hline $\begin{array}{c}\text { Low-level Concentration } \\
(20-30 \% * S)\end{array}$ & $5 \mu \mathrm{g} / \mathrm{scm}(25 \%)$ & $5 \mu \mathrm{g} / \mathrm{scm}(25 \%): 3 \mu \mathrm{g} / \mathrm{scm}(30 \%)$ & $\begin{array}{c}\text { Section } 5.2 \\
40 \text { CFR Part 75 Appendix A }\end{array}$ \\
\hline $\begin{array}{c}\text { Mid-level Concentration } \\
(50-60 \% * \text { S) }\end{array}$ & $11 \mu \mathrm{g} / \mathrm{scm}(55 \%)$ & $11 \mu \mathrm{g} / \mathrm{scm}(55 \%): 5 \mu \mathrm{g} / \mathrm{scm}(50 \%)$ & $\begin{array}{c}\text { Section } 5.2 \\
40 \text { CFR Part 75 Appendix A }\end{array}$ \\
\hline $\begin{array}{c}\text { High-level Concentration } \\
(80-100 \% * \text { S) }\end{array}$ & $18 \mu \mathrm{g} / \mathrm{scm}(90 \%)$ & $18 \mu \mathrm{g} / \mathrm{scm}(90 \%): 9 \mu \mathrm{g} / \mathrm{scm}(90 \%)$ & $\begin{array}{c}\text { Section } 5.2 \\
40 \text { CFR Part 75 Appendix A }\end{array}$ \\
\hline
\end{tabular}

* The high span value on the Outlet CEM is neglected because Hg concentrations at the stack will never exceed 2.0 $\mu \mathrm{g} / \mathrm{scm}$ by design of emissions control.

\section{Performance Tests}

The following tests were performed on the installed CEMS in accordance with applicable procedure outlined in 40 CFR Part 75 Appendix A:
(A) Linearity Check
(B) 7-Day Calibration Error Test
(C) Cycle Time Test
(D) 3-Level System Integrity Check
(E) Relative Accuracy Test Audit (RATA)/Bias Test

\section{(A) Linearity Check}

A Linearity Check was conducted on the Hg monitor with the unit combusting fuel at conditions of typical stack temperature and pressure in accordance with procedures described in Section 6.2 [40 CFR Part 75 Appendix A]. The monitor was challenged with calibration gas at the low-, mid-, and high-range concentrations, passing through all monitor components used during normal sampling and through as much of the sampling probe as practical. The monitor was challenged three times with each reference gas, without the same gas's being used twice in succession. 
Acceptance criteria:

(1) LE $\leq 10.0 \%$, where

$$
\begin{aligned}
& L E= \frac{|R-A|}{R} \times 100 \\
& \text { LE }- \text { Linear error, based upon the reference value. } \\
& \mathrm{R}-\text { Reference value of low-, mid-, or high-level concentration gas introduced into the monitoring } \\
& \quad \text { system. }
\end{aligned}
$$

(2) $|\mathrm{R}-\mathrm{A}| \leq 1.0 \mu \mathrm{g} / \mathrm{scm}$

\section{(B) 7-Day Calibration Error Test}

A 7-Day Calibration Error Test was performed according to procedures outlined in Section 6.3.1 [40 CFR Part 75 Appendix A] utilizing zero- and mid-level calibration concentration calibration gas. Mid-level has been deemed representative of the actual stack gas concentrations, and therefore selected in lieu of high-level gas. Each monitor was challenged once with calibration gas at both the low- and mid-level concentrations, passing through all monitor components used during normal sampling and through as much of the sampling probe as practical. Calibration error was calculated daily at approximately 24hour intervals and evaluated in accordance with performance specifications outlined in Section 3.1 [40 CFR Part 75 Appendix A].

Acceptance criteria:

(1) $\mathrm{CE}_{\text {zero/upscale }} \leq 5.0 \%$, where

$$
C E=\frac{|R-A|}{S} \times 100
$$

CE - Calibration error as a percentage of the span of the instrument.

$\mathrm{R}$ - Reference value of zero or upscale (high- or mid-level, as applicable) calibration gas introduced into the monitoring system.

A - Actual monitoring system response to the calibration gas.

S - Span of the instrument, as specified in Section 2 [40 CFR Part 75 Appendix A].

(2) Alternatively, if $\mathrm{S}=10 \mu \mathrm{g} / \mathrm{scm},|\mathrm{R}-\mathrm{A}| \leq 1.0 \mu \mathrm{g} / \mathrm{scm}$.

\section{(C) Cycle Time Test}

Using a zero-level and a high-level calibration gas alternately, an upscale and downscale cycle time was determined in accordance with Section 6.4 [40 CFR Part 75 Appendix A]. A zero-level concentration calibration gas was injected into the injection port until a steadystate was attained. The system was then placed in sample mode until a stable response to flue gas emissions was obtained. The upscale elapsed time was determined by evaluating the time required for a 95\% step change from the zero-level up to the flue gas emission steady-state responses. An analogous calculation was used to determine the downscale elapsed time of a steady-state high-level calibration gas response down to measured flue gas emissions. The cycle time is the higher of the two elapsed times.

Acceptance Criterion:

(1) Cycle time $\leq 15 \mathrm{~min}$. 


\section{(D) 3-Level System Integrity Check}

Oxidized mercury $\left(\mathrm{Hg}^{2+}\right)$ was utilized to conduct a 3-Level System Integrity Check with performance specifications outlined in Section 3.2(3)(iii) [40 CFR Part 75 Appendix A].

The monitor was challenged with calibration gas at the low-, mid-, and high-range concentrations, passing through all monitor components used during normal sampling and through as much of the sampling probe as practical. The monitor was challenged three times with each reference gas, without the same gas's being used twice in succession.

Acceptance Criterion:

(1) $\mathrm{CE} \leq 5.0 \%$, where

$$
C E=\frac{|R-A|}{S} \times 100
$$

CE - Calibration error as a percentage of the span of the instrument.

$\mathrm{R}$ - Reference value of zero-, mid-, and high-level calibration gas introduced into the monitoring system.

A - Actual monitoring system response to the calibration gas.

S - Span of the instrument, as specified in Section 2 [40 CFR Part 75 Appendix A].

\section{(E) Relative Accuracy Test Audit (RATA) \& Bias Test}

As suggested in Section 6.5.1(b) [40 CFR Part 75 Appendix A], for the initial certification of a gas or $\mathrm{Hg}$ monitoring system and for recertification in which one or more tests are required (i.e., a linearity test, cycle time test, or 7-day calibration error test), EPA recommends that the RATA not be commenced until the other required tests of the CEMS have been passed.

\section{Instrumental Analyzer Configuration}

Calibration Span \& Gas Concentrations

To the extent practicable the measured emissions are to be between 10 and $100 \%$ of the selected calibration span. It is recommended that the calibration span be at least twice the native concentration to accommodate the dynamic spiking procedure (Section 3.4, [Method 30A]). The selected value of the calibration span is limited by the capabilities of the calibrator. The parameters used for calibration and data validation tests of the instrumental analyzer are outlined in Table 4.

Table 4: IRM Calibration Span \& Gas Concentrations

\begin{tabular}{|c|c|c|}
\hline & \\
\hline & Native Concentration $=$ & $2 \mu \mathrm{g} / \mathrm{scm}$ \\
\hline & Calibration Span $(\mathrm{CS})=$ & $10 \mu \mathrm{g} / \mathrm{scm}$ \\
\hline $\begin{array}{c}\text { Gas } \\
\text { Concentration }\end{array}$ & Allowable Range & $\begin{array}{c}\text { Hg } \\
\text { Concentration } \\
\end{array}$ \\
\hline Zero-level & Non-detectable & $0 \mu \mathrm{g} / \mathrm{scm}(0 \%)$ \\
\hline Low-level & $10-30 \% \mathrm{CS}$ & $3 \mu \mathrm{g} / \mathrm{scm}(30 \%)$ \\
\hline Mid-level & $40-60 \% \mathrm{CS}$ & $5 \mu \mathrm{g} / \mathrm{scm}(50 \%)$ \\
\hline High-level & $100 \% \mathrm{CS}$ & $9 \mu \mathrm{g} / \mathrm{scm}(90 \%)$ \\
\hline
\end{tabular}




\section{$\underline{\text { Sample Point Selection }}$}

When Method 30A is used for relative accuracy testing of a $\mathrm{Hg}$ CEMS, the sampling site selection and sampling point layout procedures are referenced in the appropriate performance specification or applicable regulation described in Performance Specification 2, Section 8.1.3 [40 CFR Part 75 Appendix B] or Section 6.5.6 [40 CFR Part 75 Appendix A]. Alternatively, Section 8.1.3.4 [Method 30A] states that stratification testing need not be performed at a test location where it would otherwise be required to justify using fewer sample points or different sample points, if the $\mathrm{Hg}$ concentration in the stack gas is expected to be $3 \mu \mathrm{g} / \mathrm{m}^{3}$ or less at the time of a $\mathrm{Hg}$ monitoring system RATA or an $\mathrm{Hg}$ emissions test. Documentation of at least one hour of $\mathrm{Hg}$ concentration data is required just prior to the RATA or emissions test. If a particular test location qualifies for the stratification testing exemption, sampling shall be performed at three points, as described in Section 8.1.3.2.2 [Method 30A]. Since the stack diameter (or equivalent diameter, for a rectangular stack or duct) is greater than 7.8 $\mathrm{ft}$, the three Stack sampling points were therefore located at 4.4, 14.6, and 29.6 percent of the stack diameter (109 3/16") from the stack or duct wall (see Figure 2). Since only modified Method 30A procedures were performed at the Air Heater Outlet, a single sampling point depicted in Figure 3 was selected at 78.74" from the duct wall.

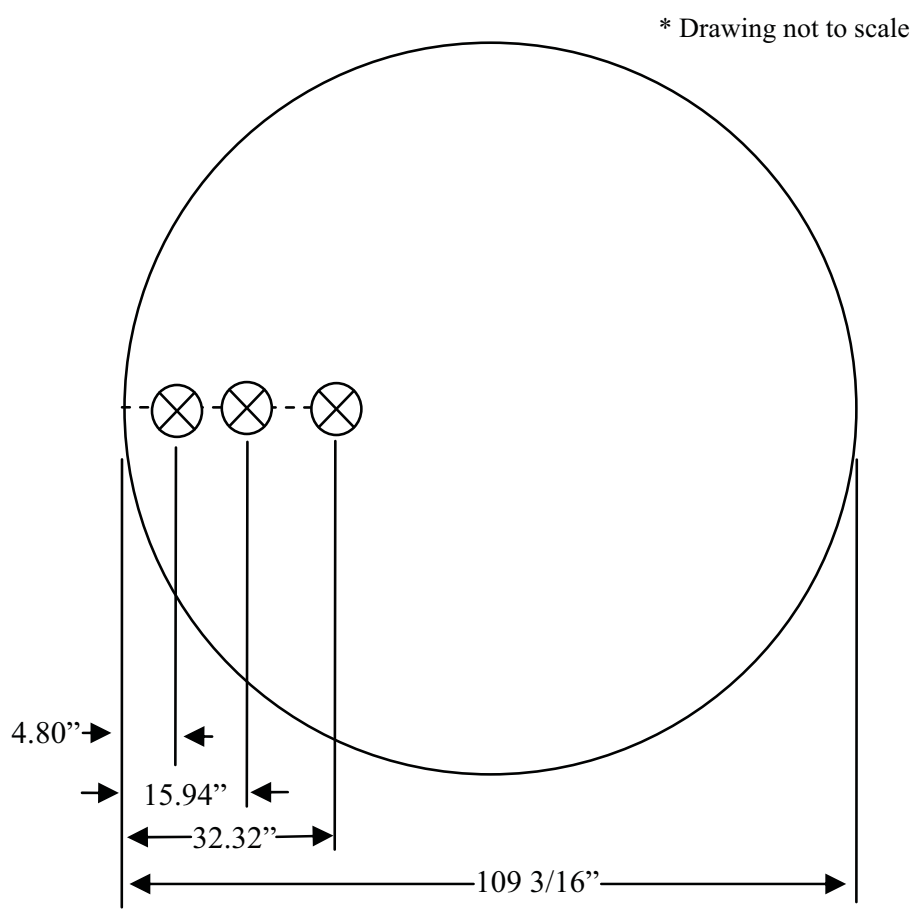

Figure 7: Stack Sampling Points 


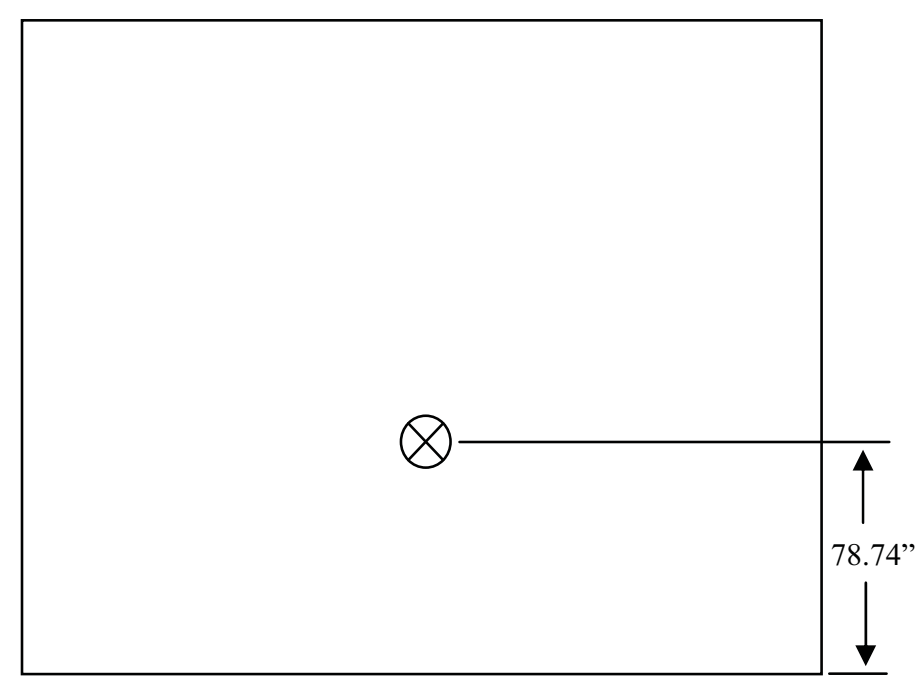

Figure 8: Air Heater Outlet Sampling Point

\section{Initial Measurement System Performance Tests}

Initial measurement system performance tests need to be met in accordance with Method $30 \mathrm{~A}$ on the instrumental analyzer prior to conducting the nine (9) required test runs and evaluating the relative accuracy. The performance requirements of this method must be met to validate data, and are listed below:

(1) Interference Testing (Optional)

(2) Calibration Gas Verification

(3) Measurement System Preparation

(4) 3-Point System Calibration Error Test

(5) System Integrity Check

(6) Measurement System Response Time Test

(7) Dynamic Spiking (deferred until January 1, 2009)

(1) Interference Test (Optional)

It is recommended that this test be conducted prior to the initial use of the measurement system in the field to verify that the candidate test instrument is free from inherent biases or interferences resulting from common combustion emission constituents. The interference test procedure is found in Section 8.6 [Method 30A]. This procedure was not performed during this test period.

(2) Calibration Gas Verification

EPA Traceability Protocol for Qualification and Certification of Elemental Mercury Gas Generators and EPA Traceability Protocol for Qualification and Certification of Oxidized Mercury Gas Generators expected publication date December 2008, see www.epa.gov/ttn/emc.

(3) Measurement System Preparation

The measurement system was assembled, prepared, and preconditioned according to standard operating procedure. 


\section{(4) System Calibration Error Test}

Using elemental mercury $\left(\mathrm{Hg}^{0}\right)$, a 3-point system calibration error test was conducted prior to the first test run. The low-, mid-, and high-level calibration gases were introduced in any order into the instrumental analyzer, and, after each gas injection, a stable response was obtained and recorded.

Acceptance criteria:

i. $\mathrm{SCE} \leq 5 \%$, where

$$
\begin{aligned}
& S C E=\frac{\left|C_{s}-C_{v}\right|}{C S} \times 100 \\
& \text { SCE - System Calibration Error [\%]. } \\
& \mathrm{C}_{\mathrm{s}} \text { - Measured concentration of the calibration gas }[\mu \mathrm{g} / \mathrm{scm}] . \\
& \mathrm{C}_{\mathrm{v}} \text { - Certified concentration of the calibration gas }[\mu \mathrm{g} / \mathrm{scm}] . \\
& \text { CS - Calibration Span }[\mu \mathrm{g} / \mathrm{scm}] .
\end{aligned}
$$

ii. Alternatively, $\left|\mathrm{C}_{\mathrm{s}}-\mathrm{C}_{\mathrm{v}}\right| \leq 0.5 \mu \mathrm{g} / \mathrm{scm}$

(5) System Integrity Check

Using oxidized mercury $\left(\mathrm{Hg}^{2+}\right)$, a two-point system integrity check was conducted as required before the first test run. The zero- and mid-level calibration gases were introduced into the instrumental analyzer, and, after each gas injection, a stable response was obtained and recorded.

Acceptance criteria:

i. $\mathrm{SCE} \leq 5 \%$, where

$$
\begin{aligned}
& S C E=\frac{\left|C_{s}-C_{v}\right|}{C S} \times 100 \\
& \text { SCE - System Calibration Error [\%]. } \\
& \mathrm{C}_{\mathrm{s}} \text { - Measured concentration of the calibration gas }[\mu \mathrm{g} / \mathrm{scm}] . \\
& \mathrm{C}_{\mathrm{v}} \text { - Certified concentration of the calibration gas }[\mu \mathrm{g} / \mathrm{scm}] . \\
& \text { CS - Calibration Span }[\mu \mathrm{g} / \mathrm{scm}] .
\end{aligned}
$$

ii. Alternatively, $\left|\mathrm{C}_{\mathrm{s}}-\mathrm{C}_{\mathrm{v}}\right| \leq 0.5 \mu \mathrm{g} / \mathrm{scm}$

\section{(6) Measurement System Response Time}

The measurement system response time provides the minimum sampling time for each sampling point. It is equal to the time that is required for the measured $\mathrm{Hg}$ concentration to increase from the stable low-level calibration gas response to a value within 5 percent of the stable high-level calibration gas response obtained during the system calibration error test in Section 8.2.4 [Method 30A], assuming the high-level calibration gas was injected immediately after the low-level.

(7) Dynamic Spiking Test (deferred until January 1, 2009)

The purpose of this procedure is to demonstrate that the site-specific flue gas matrix does not adversely affect the accuracy of the measurement system. If the specifications stated in Section 13.5 [Method 30A] are not met, the procedure must be repeated until satisfactory results are obtained. Dynamic spiking is a gas phase application of the 
method of standard additions, which involves injecting a known quantity of $\mathrm{Hg}$ into the measurement system upstream of all sample conditioning components, similar to system calibration, except the probe is not flooded and the resulting sample stream includes both effluent gas and the spike gas. A written procedure that details how the spike is added to the system, how the spike dilution factor (DF) is measured, and how the Hg concentration data are collected and processed is required.

The spike gas must be a $\mathrm{HgCl}_{2}$ calibration gas certified by an EPA traceability protocol (estimated promulgation $\sim$ December 2008), and chosen concentrations must produce the target levels while being injected at a volumetric flow rate that is $\leq 20$ percent of the total volumetric flow rate through the measurement system. The target level, $\mathrm{C}_{\text {target }}$ for spiking must be 150 to 200 percent of the native $\mathrm{Hg}$ concentration, $\mathrm{C}_{\text {native. }}$. Alternately, if the $\mathrm{Hg}$ concentration is $\leq 1 \mu \mathrm{g} / \mathrm{scm}$, the target level shall be between 1 and $4 \mu \mathrm{g} / \mathrm{scm}$ above the native concentration. At least 3 data points must be obtained, and the relative standard deviation specification must be met. Each baseline measurement must include at least 4 readings or 1 minute (whichever is greater) of stable responses.

$$
\begin{aligned}
\mathrm{C}_{\text {native }} & =0.3 \mu \mathrm{g} / \mathrm{scm} \\
\mathrm{C}_{\text {target }} & =4.27 \mu \mathrm{g} / \mathrm{scm}
\end{aligned}
$$

Since the configuration of the IRM does not allow for accurate measurement of total volumetric flow rate through the system, a spike gas that includes a tracer for measuring the dilution factor (DF) was used.

DF Calculation:

$$
\begin{aligned}
D F= & \frac{Q_{\text {probe }}}{Q_{\text {spike }}}=\frac{C_{\text {Tdir }}-C_{\text {Tnative }}}{C_{T v}-C_{\text {Tnative }}} \\
& \begin{array}{l}
\text { Q probe } \\
\text { Q Total flow rate of the stack gas sample plus the spike gas [liters } / \mathrm{min}] .
\end{array} \\
& \mathrm{Q}_{\text {spike }} \text { - Flow rate of the spike gas [liters/min]. } \\
& \mathrm{C}_{\mathrm{T} \text { dir }}-\text { Tracer gas concentration injected with spike gas [ppm]. } \\
& \mathrm{C}_{\mathrm{Tv}}-\text { Diluted tracer gas concentration measured in a spiked sample [ppm]. } \\
& \mathrm{C}_{\text {Tnative }}-\text { Measured tracer gas concentration present in native effluent gas [ppm]. }
\end{aligned}
$$

Dynamic Spike Gas Concentration Calculation:

$$
\begin{aligned}
C_{\text {spike }}^{*}= & D F \times\left(C_{t \text { arget }}-C_{\text {native }}\right)+C_{\text {native }} \\
& C_{\text {spike }}^{*}-\text { Hg concentration of the spike gas required to achieve a certain target value for } \\
& \text { the spiked sample } \mathrm{Hg} \text { concentration }[\mu \mathrm{g} / \mathrm{scm}] . \\
& \mathrm{C}_{\text {target }}-\text { Target } \mathrm{Hg} \text { concentration of the spiked sample }[\mu \mathrm{g} / \mathrm{scm}] . \\
& \mathrm{C}_{\text {native }}-\text { Vapor phase } \mathrm{Hg} \text { concentration in the source effluent }[\mu \mathrm{g} / \mathrm{scm}] .
\end{aligned}
$$

Spiked Sample Concentration Calculation:

$$
\begin{aligned}
C_{s s}^{*}= & C_{\text {native }}+\frac{C_{\text {spike }}-C_{\text {native }}}{D F} \\
& C_{s s}^{*} \text { - Expected Hg concentration of the spiked sample at the target level }[\mu \mathrm{g} / \mathrm{scm}] . \\
& C_{\text {spike }}-\text { Actual } \mathrm{Hg} \text { concentration of the spike gas }[\mu \mathrm{g} / \mathrm{scm}] .
\end{aligned}
$$


Acceptance Criterion:

i.(a) $90 \% \leq \bar{R} \leq 110 \%$, where

$$
\begin{gathered}
R=\frac{D F\left(C_{s s}-C_{\text {native }}\right)+C_{\text {native }}}{C_{\text {spike }}} \times 100 \% \\
\mathrm{R}-\text { Spike recovery [\%]. } \\
\mathrm{C}_{\mathrm{ss}}-\text { Measured Hg concentration of the spiked sample at the target level } \\
{[\mu \mathrm{g} / \mathrm{scm}] .}
\end{gathered}
$$

i.(b) Alternatively, $\left|\mathrm{C}_{\mathrm{ss}}^{*}-\mathrm{C}_{\mathrm{ss}}\right| \leq 0.5 \mu \mathrm{g} / \mathrm{scm}$

ii.(a) $\mathrm{RSD} \leq 5.0 \%$, where

$$
R S D=\frac{100 \%}{\bar{R}} \sqrt{\frac{\sum_{i=1}^{n}\left(R_{i}-\bar{R}\right)^{2}}{n-1}}
$$

\section{Test Runs}

After the instrumental analyzer has successfully met the acceptance criteria of the initial system performance tests, the minimum nine (9) test runs of the RATA were performed. One test run constitutes one sampling at each successive sample point. Run validations listed below must be performed while sampling.

\section{System Integrity Checks}

Before and after each test run, a two-point system integrity check using the same procedure as the initial system integrity check must be conducted. No adjustments may be made to the measurement system during the checks, other than to maintain the target calibration gas flow rate and the proper dilution ratio. This check may be skipped between each run provided that a system integrity check performed on completion of runs passes the allowed specification. If a post-run integrity check is failed, all test runs since the last passed system integrity check are invalid. If a check is failed, corrective action must be taken and another 3-point $\mathrm{Hg}^{0}$ System Calibration Error Test passed followed by another System Integrity Check before conducting any additional test runs.

Drift Check

Using the data from the successful pre- and post-run system integrity checks, calculate the zero and upscale drift. Exceeding the specification does not invalidate the run, but corrective action must be taken and a new 3-point $\mathrm{Hg}^{0}$ System Calibration Error Test and a System Integrity Check must be passed before any more runs are made.

\section{Sampling}

For each sample point determined from Section 8.1, Method 30A, the system must be allowed to flush and equilibrate for at least two times the measurement system response time before recording any data. The minimum sampling time at each sampling point must be at least two times the system response time, but not less than 10 minutes. 


\section{Relative Accuracy Calculation}

Acceptance criteria:

(1) $\mathrm{RA} \leq 20.0 \%$, where

Arithmetic Mean:

$$
\begin{aligned}
& d=R M-C E M \\
& \mathrm{~d}-\text { The difference between a reference method value and the } \\
& \text { corresponding continuous emission monitoring system value at a given } \\
& \text { point in time. } \\
& \text { RM }- \text { Reference method value. } \\
& \text { CEM - Continuous emission monitoring system value. } \\
& \bar{d}=\frac{\sum_{i=1}^{n} d_{i}}{n}
\end{aligned}
$$

Standard Deviation:

$$
S_{d}=\sqrt{\frac{\sum_{i=1}^{n} d_{i}^{2}-\left[\frac{\left(\sum_{i=1}^{n} d_{i}\right)^{2}}{n}\right]}{\mathrm{S}_{\mathrm{d}}-\text { Standard deviation. }}}
$$

Confidence Coefficient:

$$
\begin{aligned}
c c=t_{0.025} & \times \frac{S_{d}}{\sqrt{n}} \\
& \mathrm{cc}-\text { Confidence coefficient. } \\
& \mathrm{t}_{0.025}-\mathrm{t} \text {-value. }
\end{aligned}
$$

Relative Accuracy:

$$
\begin{aligned}
R A= & \frac{|\partial|+|c c|}{R M} \times 100 \\
& \mathrm{RA}-\text { Relative accuracy of a data set. } \\
\mathrm{RM}-\text { Arithmetic mean of the reference method values. } & \\
& \begin{array}{l}
\text { M }- \text { Mean difference between the reference method values and the } \\
\text { corresponding continuous emission monitoring system values. }
\end{array}
\end{aligned}
$$

(2) Alternatively, if $\overline{R M} \leq 5.0 \mu \mathrm{g} / \mathrm{scm}, \overline{C E M}-\overline{R M} \leq 1.0 \mu \mathrm{g} / \mathrm{scm}$ 


\section{Bias Determination \& Adjustment Factor Calculation}

If the following criterion is met for the relative accuracy test audit data set being tested, the monitoring system has passed the bias test:

(1) Acceptance criterion:

$$
\bar{d} \leq|c c|
$$

If the monitor or monitoring system fails to meet the bias test requirement, adjustment of the value obtained from the monitor is necessary using the following equation:

$$
\begin{aligned}
& C E M_{i}^{\text {Adjusted }}=C E M_{i}^{\text {Monitor }} \times B A F \\
& C E M_{i}^{\text {Adjusted }}-\text { Data value, adjusted for bias, at time i. } \\
& C E M_{i}^{\text {Monitor }} \text { - Data (measurement) provided by monitor at time i. } \\
& \text { BAF - Bias Adjustment Factor. }
\end{aligned}
$$

Bias Adjustment Factor:

$$
B A F=1+\frac{\bar{d}}{\overline{C E M}}
$$

If the monitoring system meets the normal or the alternative relative accuracy specification in section 3.3.8 of 40 CFR Part 75 Appendix A but fails the bias test, the owner or operator may either use the BAF calculated above or may use a default BAF of 1.250 for reporting purposes. Each time a RATA is passed and the appropriate BAF has been determined, the BAF is to be applied prospectively to all monitoring system data, beginning with the first clock hour following the hour in which the RATA was completed. 


\section{RESULTS AND DISCUSSION}

Data from the Linearity Checks for the Stack and Air Heater Outlet Hg-CEMS are presented in Table 5 and Table 6, respectively. The results for the CEMS installed at both locations indicate compliance with performance specifications documented in 40 CFR Part 75 Appendix A.

Table 5: Linearity Check - Stack Hg-CEMS

\begin{tabular}{|c|c|c|c|c|c|}
\hline \multicolumn{6}{|c|}{ Linearity Check } \\
\hline Facility: & \multicolumn{2}{|c|}{ Hardin Generating Station } & & $04 / 28 / 2008$ \\
\hline Project \#: & \multicolumn{2}{|c|}{$06-7008$} & \multirow{3}{*}{\multicolumn{2}{|c|}{$\begin{array}{r}\text { Unit(s) tested: } \\
\text { Test Runs: } \\
\text { Analyzer Make/Model: }\end{array}$}} & Stack Hg-CEMS \\
\hline \multirow[t]{3}{*}{ Personnel: } & & & & N/A \\
\hline & \multicolumn{2}{|l|}{ Erik Zipp } & & & Thermo Mercury Freedom \\
\hline & & & & System $^{\mathrm{TM}}$ \\
\hline \multirow[t]{5}{*}{ Span, $S=$} & 10 & $\mu \mathrm{g} / \mathrm{scm}$ & & Serial No: & 0613917173 \\
\hline & $\begin{array}{c}\text { Calibration } \\
\text { Gas Level }\end{array}$ & $\begin{array}{c}\mathbf{R} \\
{[\mu \mathrm{g} / \mathrm{scm}]}\end{array}$ & $\begin{array}{c}\mathbf{A} \\
{[\mu \mathrm{g} / \mathbf{s c m}]}\end{array}$ & $\begin{array}{c}\text { LE } \\
{[\%]}\end{array}$ & $\begin{array}{c}|\mathbf{R}-\mathbf{A}| \\
{[\mu \mathrm{g} / \mathbf{s c m}]}\end{array}$ \\
\hline & Low- & 3.00 & 2.68 & 10.67 & 0.32 \\
\hline & Mid- & 6.00 & 5.79 & 3.50 & 0.21 \\
\hline & High- & 9.00 & 8.57 & 4.78 & 0.43 \\
\hline $\begin{array}{l}\text { LE - Linear } \\
\text { R - Referen } \\
\text { A - Average } \\
\text { S - Span val }\end{array}$ & $\begin{array}{l}\text { ty error } \\
\text { e value of calit } \\
\text { of monitoring } \\
\text { de }\end{array}$ & $\begin{array}{l}\text { ration gas } \\
\text { ystem respor }\end{array}$ & & & \\
\hline $\begin{array}{l}\text { Acceptance } \\
\text { (1) LE } \leq 10 \\
\text { (2) Alternat }\end{array}$ & $\begin{array}{l}\text { criteria: } \\
0 \% \\
\text { vely, }|\mathrm{R}-\mathrm{A}| \leq 1\end{array}$ & $\mu \mathrm{g} / \mathrm{scm}$ & & & \\
\hline
\end{tabular}


Table 6: Linearity Check - Air Heater Outlet Hg-CEMS

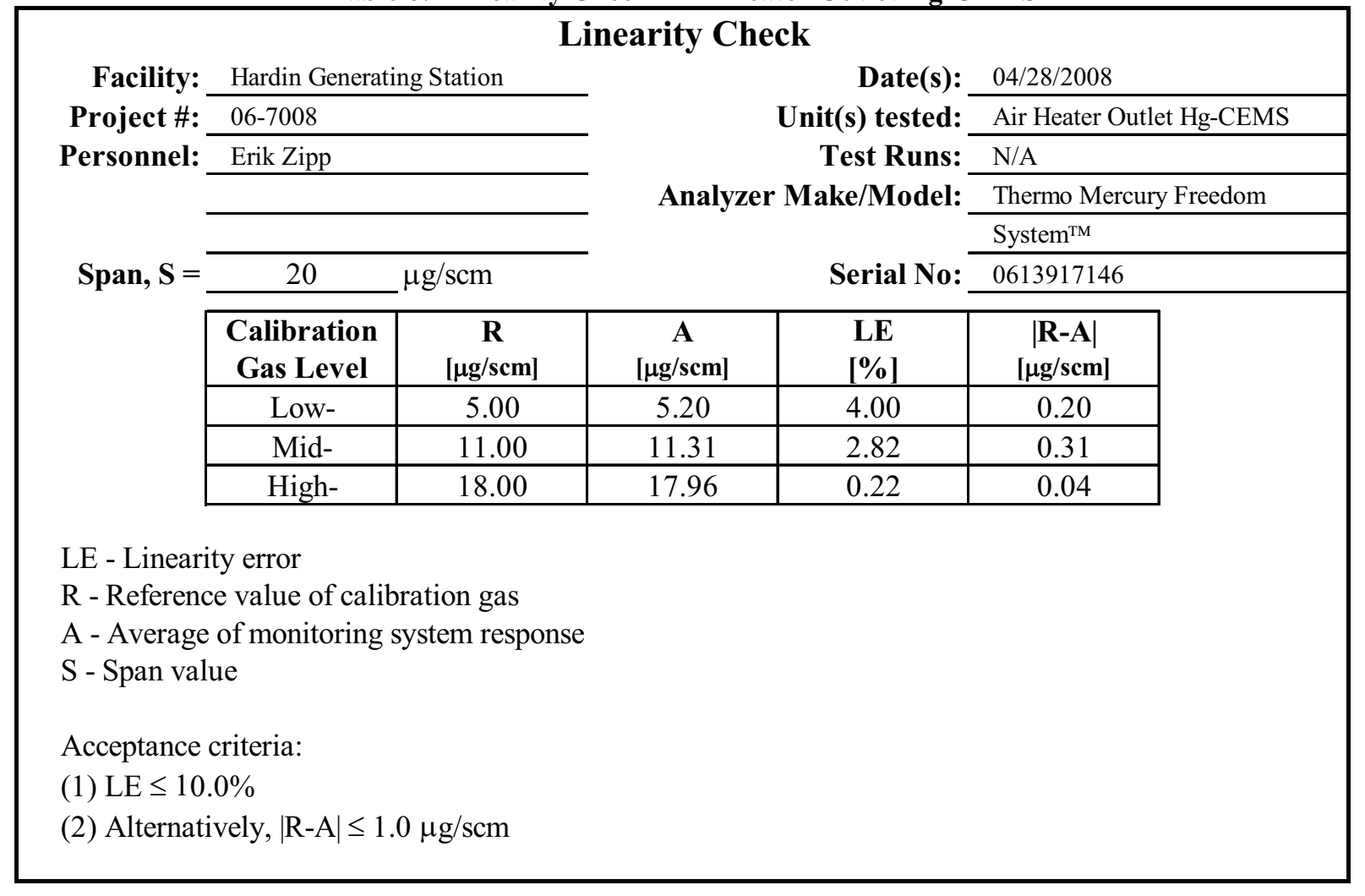


Data from the 7-Day Calibration Error Tests for the Stack and Air Heater Outlet Hg-CEMS are presented in Table 7 and Table 8, respectively. Results for the CEMS installed at both locations also indicate compliance with performance specifications documented in 40 CFR Part 75 Appendix A.

Table 7: 7-Day Calibration Error Test - Stack Hg-CEMS

\section{7-Day Calibration Error Test}

Facility: Hardin Generating Station

Project \#: 06-7008

Personnel: Erik Zipp

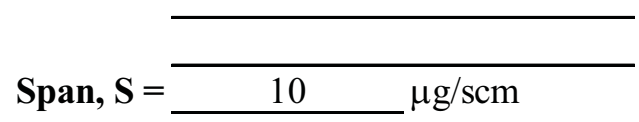

Date(s): $05 / 05 / 2008$

Unit(s) tested: Stack Hg-CEMS

Test Runs: N/A

Analyzer Make/Model: Thermo Mercury Freedom System $^{\mathrm{TM}}$

Serial No: 0613917173

\begin{tabular}{|c|c|c|c|c|c|}
\hline \multirow{2}{*}{ Day } & $\begin{array}{c}\text { Calibration } \\
\text { Gas Level }\end{array}$ & $\begin{array}{c}\mathbf{R} \\
{[\boldsymbol{\mu} \mathbf{g} / \mathbf{s c m}]}\end{array}$ & $\begin{array}{c}\mathbf{A} \\
{[\mu \mathrm{g} / \mathbf{s c m}]}\end{array}$ & $\begin{array}{c}\mathbf{C E} \\
{[\mathbf{\%}]}\end{array}$ & $\begin{array}{c}\mid \mathbf{R}-\mathbf{A}] \\
{[\boldsymbol{\mu g} / \mathbf{s c m}]}\end{array}$ \\
\hline \multirow{2}{*}{1} & Zero- & 0.00 & 0.01 & 0.10 & 0.01 \\
\cline { 2 - 6 } & Mid- & 5.00 & 4.92 & 0.80 & 0.08 \\
\hline \multirow{2}{*}{2} & Zero- & 0.00 & 0.01 & 0.10 & 0.01 \\
\cline { 2 - 6 } & Mid- & 5.00 & 4.88 & 1.20 & 0.12 \\
\hline \multirow{2}{*}{3} & Zero- & 0.00 & 0.03 & 0.30 & 0.03 \\
\cline { 2 - 6 } & Mid- & 5.00 & 4.83 & 1.70 & 0.17 \\
\hline \multirow{2}{*}{4} & Zero- & 0.00 & 0.04 & 0.40 & 0.04 \\
\cline { 2 - 6 } & Mid- & 5.00 & 4.86 & 1.40 & 0.14 \\
\hline \multirow{2}{*}{5} & Zero- & 0.00 & 0.06 & 0.60 & 0.06 \\
\cline { 2 - 6 } & Mid- & 5.00 & 4.79 & 2.10 & 0.21 \\
\hline \multirow{2}{*}{6} & Zero- & 0.00 & 0.03 & 0.30 & 0.03 \\
\cline { 2 - 6 } & Mid- & 5.00 & 4.84 & 1.60 & 0.16 \\
\hline \multirow{2}{*}{7} & Zero- & 0.00 & 0.04 & 0.40 & 0.04 \\
\cline { 2 - 6 } & Mid- & 5.00 & 4.97 & 0.30 & 0.03 \\
\hline
\end{tabular}

CE - Calibration error

$\mathrm{R}$ - Reference value of calibration gas

A - Actual monitoring system response

$\mathrm{S}$ - Span value

Acceptance criteria:

(1) $\mathrm{CE} \leq 5.0 \%$

(2) Alternatively, if $\mathrm{S}=10 \mu \mathrm{g} / \mathrm{scm}:|\mathrm{R}-\mathrm{A}| \leq 1.0 \mu \mathrm{g} / \mathrm{scm}$ 
Table 8: 7-Day Calibration Error Test - Air Heater Outlet Hg-CEMS

\section{7-Day Calibration Error Test}

Facility: Hardin Generating Station

Project \#: $06-7008$

Personnel: Erik Zipp

$$
\text { Span, } \mathbf{S}=\overline{20} \mu \mathrm{g} / \mathrm{scm}
$$

Date(s): $05 / 05 / 2008$

Unit(s) tested: Air Heater Outlet Hg-CEMS

Test Runs: N/A

Analyzer Make/Model: Thermo Mercury Freedom

Serial No: $\frac{\text { System }^{\mathrm{TM}}}{0613917146}$

\begin{tabular}{|c|c|c|c|c|c|}
\hline \multirow{2}{*}{ Day } & $\begin{array}{c}\text { Calibration } \\
\text { Gas Level }\end{array}$ & $\begin{array}{c}\mathbf{R} \\
{[\mu \mathbf{g} / \mathbf{s c m}]}\end{array}$ & $\begin{array}{c}\mathbf{A} \\
{[\mu \mathbf{g} / \mathbf{s c m}]}\end{array}$ & $\begin{array}{c}\mathbf{C E} \\
{[\mathbf{\%}]}\end{array}$ & $\begin{array}{c}|\mathbf{R}-\mathbf{A}| \\
{[\boldsymbol{\mu g} / \mathbf{s c m}]}\end{array}$ \\
\hline \multirow{2}{*}{1} & Zero & 0.00 & -0.02 & 0.10 & 0.02 \\
\cline { 2 - 6 } & Mid- & 11.00 & 10.86 & 0.70 & 0.14 \\
\hline \multirow{2}{*}{2} & Zero & 0.00 & -0.03 & 0.15 & 0.03 \\
\cline { 2 - 6 } & Mid- & 11.00 & 10.79 & 1.05 & 0.21 \\
\hline \multirow{2}{*}{3} & Zero & 0.00 & -0.05 & 0.25 & 0.05 \\
\cline { 2 - 6 } & Mid- & 11.00 & 10.84 & 0.80 & 0.16 \\
\hline \multirow{2}{*}{4} & Zero & 0.00 & 0.02 & 0.10 & 0.02 \\
\cline { 2 - 6 } & Mid- & 11.00 & 10.87 & 0.65 & 0.13 \\
\hline \multirow{2}{*}{5} & Zero & 0.00 & -0.03 & 0.15 & 0.03 \\
\cline { 2 - 6 } & Mid- & 11.00 & 10.74 & 1.30 & 0.26 \\
\hline \multirow{2}{*}{6} & Zero & 0.00 & -0.03 & 0.15 & 0.03 \\
\cline { 2 - 6 } & Mid- & 11.00 & 11.16 & 0.80 & 0.16 \\
\hline \multirow{2}{*}{7} & Zero & 0.00 & -0.06 & 0.30 & 0.06 \\
\cline { 2 - 6 } & Mid- & 11.00 & 10.61 & 1.95 & 0.39 \\
\hline
\end{tabular}

CE - Calibration error

$\mathrm{R}$ - Reference value of calibration gas

A - Actual monitoring system response

$\mathrm{S}$ - Span value

Acceptance criteria:

(1) $\mathrm{CE} \leq 5.0 \%$

(2) Alternatively, if $\mathrm{S}=10 \mu \mathrm{g} / \mathrm{scm}:|\mathrm{R}-\mathrm{A}| \leq 1.0 \mu \mathrm{g} / \mathrm{scm}$ 
Cycle Time Tests for the Stack and Air Heater Outlet Hg-CEMS are presented in Table 9 and Table 10, respectively. Both CEMS passed the performance criterion; however, improper procedure was followed in performing this test at the Stack Hg-CEMS. The mid-level concentration was used instead of the high-level, but this error does not indicate that the unit will fail when properly performed.

Table 9: Cycle Time Test - Stack Hg-CEMS

\begin{tabular}{|c|c|c|c|c|c|c|}
\hline \multicolumn{7}{|c|}{ Cycle Time Test } \\
\hline \multirow{5}{*}{$\begin{array}{r}\text { Facility: } \\
\text { Project \#: } \\
\text { Personnel: }\end{array}$} & \multicolumn{2}{|c|}{ Hardin Generating Station } & \multirow{2}{*}{\multicolumn{2}{|c|}{$\begin{array}{r}\text { Date(s): } \\
\text { Unit(s) tested: }\end{array}$}} & \multicolumn{2}{|c|}{$04 / 29 / 2008$} \\
\hline & \multicolumn{2}{|c|}{$06-7008$} & & & \multicolumn{2}{|c|}{ Stack Hg-CEMS } \\
\hline & \multicolumn{2}{|l|}{ Pattie Garcia } & \multirow{2}{*}{\multicolumn{2}{|c|}{$\begin{array}{r}\text { Test Runs: } \\
\text { Analyzer Make/Model: }\end{array}$}} & \multicolumn{2}{|c|}{ N/A } \\
\hline & & & & & \multicolumn{2}{|c|}{ Thermo Mercury Freedom } \\
\hline & & & & & \multicolumn{2}{|c|}{ System $^{\mathrm{TM}}$} \\
\hline Span, $\mathbf{S}=$ & 10 & $\mu \mathrm{g} / \mathrm{scm}$ & & Serial No: & \multicolumn{2}{|l|}{0613917173} \\
\hline $\begin{array}{c}\text { Calibration } \\
\text { Gas Level } \\
\end{array}$ & $\begin{array}{c}\mathbf{R} \\
{[\mu \mathrm{g} / \mathrm{scm}]} \\
\end{array}$ & Start Time & $\begin{array}{c}\mathbf{A}_{\mathbf{i}} \\
{[\mu \mathrm{g} / \mathbf{s c m}]}\end{array}$ & End Time & $\begin{array}{c}\mathbf{A}_{\mathbf{f}} \\
{[\mu \mathrm{g} / \mathrm{scm}]}\end{array}$ & $\begin{array}{c}\begin{array}{c}\text { Cycle Time } \\
\text { [min.] }\end{array} \\
\end{array}$ \\
\hline Zero- & 0.00 & $12: 27$ & 0.01 & $12: 47$ & 0.42 & 5 min. \\
\hline Mid- & 5.00 & $13: 08$ & 5.12 & $13: 28$ & 0.46 & $5 \mathrm{~min}$. \\
\hline \multicolumn{7}{|c|}{$\begin{array}{l}\mathrm{R} \text { - Reference value of calibration gas } \\
\mathrm{A}_{\mathrm{i}} \text { - Initial stable monitor system response } \\
\mathrm{A}_{\mathrm{f}} \text { - Final stable monitor system response } \\
\mathrm{S} \text { - Span value }\end{array}$} \\
\hline \multicolumn{7}{|c|}{$\begin{array}{l}\text { Acceptance criteria: } \\
\text { (1) Cycle Time } \leq 15 \mathrm{~min} \text {. }\end{array}$} \\
\hline
\end{tabular}


Table 10: Cycle Time Test - Air Heater Outlet Hg-CEMS

\begin{tabular}{|c|c|c|c|c|c|c|}
\hline \multicolumn{7}{|c|}{ Cycle Time Test } \\
\hline Facility: & \multicolumn{2}{|c|}{ Hardin Generating Station } & \multirow{3}{*}{\multicolumn{2}{|c|}{$\begin{array}{r}\text { Unit(s) tested: } \\
\text { Test Runs: }\end{array}$}} & \multicolumn{2}{|l|}{$05 / 21 / 2008$} \\
\hline \multirow{4}{*}{$\begin{array}{l}\text { Project \#: } \\
\text { Personnel: }\end{array}$} & \multicolumn{2}{|c|}{$06-7008$} & & & \multicolumn{2}{|c|}{ Air Heater Outlet Hg-CEMS } \\
\hline & \multicolumn{2}{|l|}{ Pattie Garcia } & & & \multicolumn{2}{|c|}{ N/A } \\
\hline & & & \multirow{2}{*}{\multicolumn{2}{|c|}{ Analyzer Make/Model: }} & \multicolumn{2}{|c|}{ Thermo Mercury Freedom } \\
\hline & & & & & \multicolumn{2}{|l|}{ System $^{\mathrm{TM}}$} \\
\hline Span, $\mathbf{S}=$ & 20 & $\mu \mathrm{g} / \mathrm{scm}$ & & Serial No: & \multicolumn{2}{|l|}{0613917146} \\
\hline $\begin{array}{c}\text { Calibration } \\
\text { Gas Level }\end{array}$ & $\underset{[\mu \mathbf{g} / \mathbf{s c m}]}{\mathbf{R}}$ & Start Time & $\begin{array}{c}\mathbf{A}_{\mathbf{i}} \\
{[\mu \mathbf{g} / \mathbf{s c m}]}\end{array}$ & End Time & $\begin{array}{c}\mathbf{A}_{\mathbf{f}} \\
{[\mu \mathrm{g} / \mathbf{s c m}]}\end{array}$ & $\begin{array}{c}\text { Cycle Time } \\
\text { [min.] }\end{array}$ \\
\hline Zero- & 0.00 & $10: 22$ & 0.03 & $10: 42$ & 4.27 & 5 min. \\
\hline High- & 18.00 & 11:05 & 18.21 & $11: 25$ & 4.37 & $5 \mathrm{~min}$. \\
\hline \multicolumn{7}{|c|}{$\begin{array}{l}R \text { - Reference value of calibration gas } \\
A_{i} \text { - Initial stable monitor system response } \\
A_{f} \text { - Final stable monitor system response } \\
S \text { - Span value }\end{array}$} \\
\hline \multicolumn{7}{|c|}{$\begin{array}{l}\text { Acceptance criteria: } \\
\text { (1) Cycle Time } \leq 15 \mathrm{~min} .\end{array}$} \\
\hline
\end{tabular}


The 3-Level System Integrity Check for the Stack Hg-CEMS is presented in Table 11. This test, which involves the injection of $\mathrm{Hg}^{2+}$ calibration gas concentrations, has proven problematic in meeting acceptance criteria. Concerns have been addressed to Thermo Fisher Corporation in attempts to resolve this problem. This unit will be upgraded and tested before the next RATA test in June 2008.

Table 11: 3-Level System Integrity Check - Stack Hg-CEMS

\section{3-Level System Integrity Check}

Facility: Hardin Generating Station

Project \#: $06-7008$

Personnel: Erik Zipp

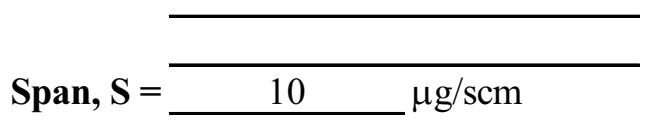

Date(s): $\quad 05 / 05 / 2008$

Unit(s) tested: Stack Hg-CEMS

Test Runs: N/A

Analyzer Make/Model: Thermo Mercury Freedom System $^{\mathrm{TM}}$

Serial No: 0613917173

\begin{tabular}{|c|c|c|c|}
\hline $\begin{array}{c}\text { Calibration } \\
\text { Gas Level }\end{array}$ & $\underset{[\mu \mathbf{g} / \mathbf{s c m}]}{\mathbf{R}}$ & $\begin{array}{c}\mathbf{A} \\
{[\mu \mathrm{g} / \mathrm{scm}]}\end{array}$ & $\begin{array}{l}\mathbf{C E} \\
{[\%]}\end{array}$ \\
\hline Low- & 3.00 & 2.13 & 8.70 \\
\hline Mid- & 6.00 & 4.49 & 15.10 \\
\hline High- & 9.00 & 6.52 & 24.80 \\
\hline
\end{tabular}

CE - Calibration error

$\mathrm{R}$ - Reference value of calibration gas

A - Actual monitoring system response

S - Span value

Acceptance criteria:

(1) $\mathrm{CE} \leq 5.0 \%$ 
The Relative Accuracy Test Audit conducted on the Stack Hg-CEMS demonstrated compliance with established performance specifications. The RATA conducted on Air Heater Outlet HgCEMS lacked the number of runs and sampling points required to meet the acceptance criteria, however the data trended to be acceptable. Bias tests on both monitoring systems failed the acceptance criterion, and bias adjustment factors were calculated but not implemented.

Table 12: RATA \& Bias Test - Stack Hg-CEMS

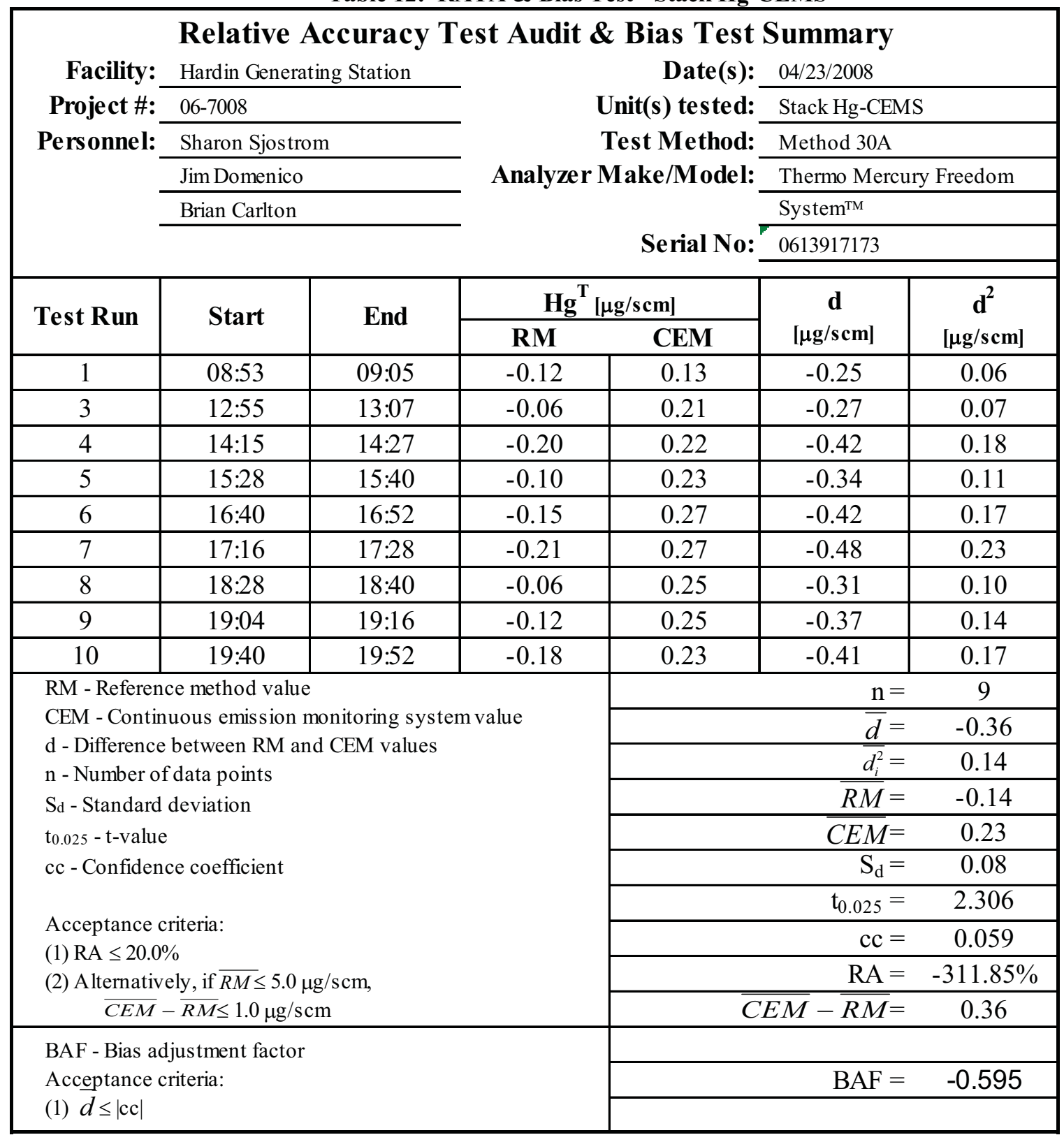


Table 13: RATA \& Bias Test - Air Heater Outlet Hg-CEMS

\section{Relative Accuracy Test Audit \& Bias Test Summary}

Facility: Hardin Generating Station

Project \#: $06-7008$

Personnel: Sharon Sjostrom

\begin{tabular}{l} 
Jim Domenico \\
\hline Brian Carlton \\
\hline
\end{tabular}

Date(s): $04 / 24 / 2008$

Unit(s) tested: Air Heater Outlet Hg-CEMS

Test Method: Method 30A

Analyzer Make/Model: Thermo Mercury Freedom System $^{\mathrm{TM}}$

Serial No: 0613917146

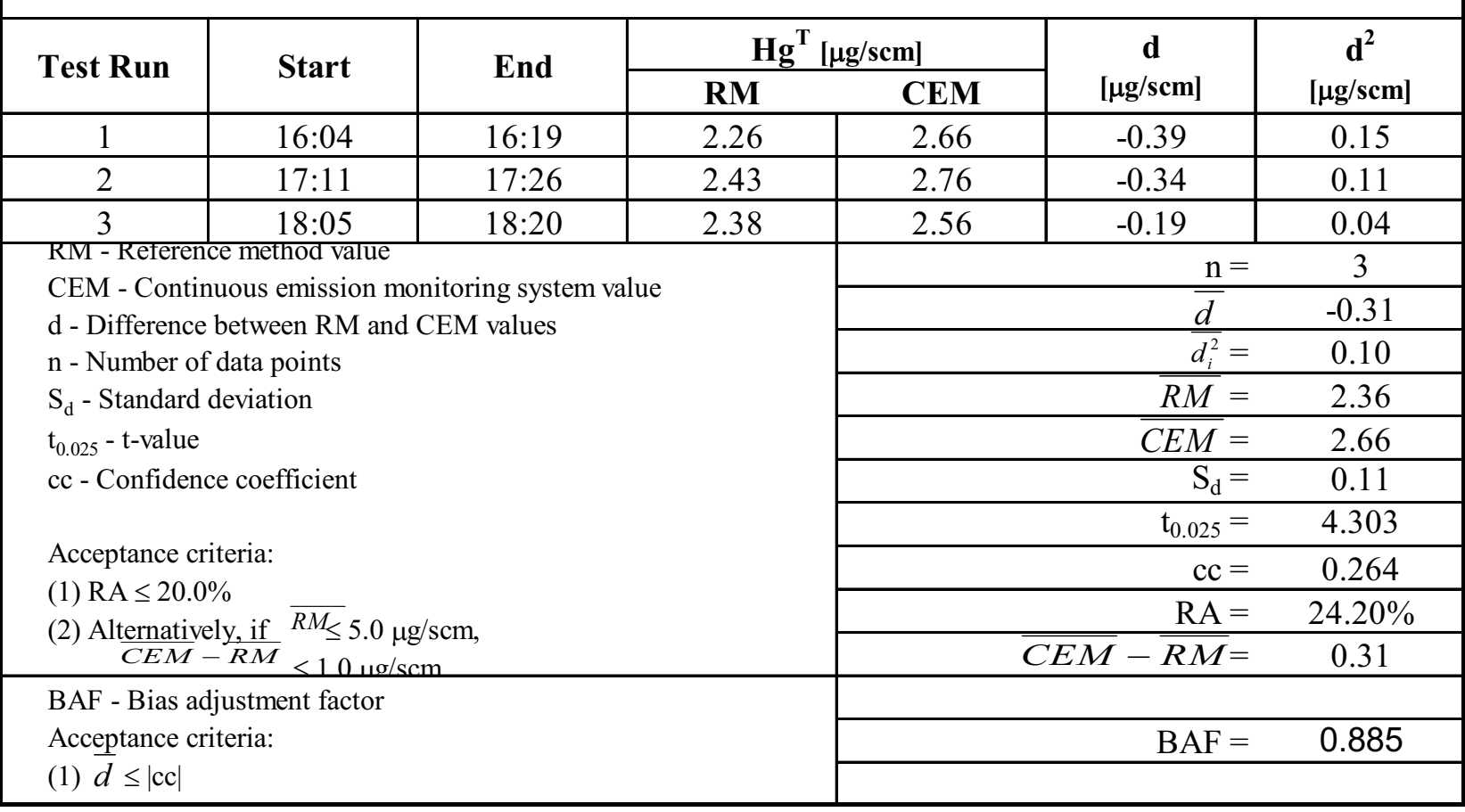




\section{CONCLUSIONS}

The Stack Hg-CEMS passed all performance tests conducted during this evaluation except the 3Level System Integrity Check and the Bias Test. The Air Heater Outlet Hg-CEMS passed all applicable performance tests except the Bias Test. The IRM analyzer failed the Dynamic Spiking Test. A duplicate of the Summary of Results from Table 1 is presented below.

\begin{tabular}{|c|c|c|}
\hline \multicolumn{3}{|c|}{ Summary of Results (From Table 1) } \\
\hline Test & $\begin{array}{c}\text { Stack } \\
\text { Hg-CEMS } \\
\text { (downstream of ACI) }\end{array}$ & $\begin{array}{c}\text { Air Heater Outlet } \\
\text { Hg-CEMS } \\
\text { (upstream of ACI) }\end{array}$ \\
\hline Linearity Check & PASS & PASS \\
\hline 7-Day Calibration Error Test & PASS & PASS \\
\hline Cycle Time Test & PASS & PASS \\
\hline 3-Level System Integrity Check & FAIL & $\mathrm{N} / \mathrm{A}$ \\
\hline Relative Accuracy Test Audit & PASS & PASS \\
\hline \multicolumn{3}{|l|}{ IRM System Performance Tests } \\
\hline Interference Check (Optional) & - & - \\
\hline 3-Point System Calibration Error Test & PASS & - \\
\hline System Integrity Check & PASS & - \\
\hline Measurement System Response & - & - \\
\hline Dynamic Spiking Test & FAIL & - \\
\hline Bias Test & FAIL & FAIL \\
\hline
\end{tabular}

This was the first of three in a series of tests to be performed at Rocky Mountain Power's Hardin Generating Station, Hardin, MT during the Long-term Test Phase of this project as specified in the test plan. The primary goal of this first round of tests was to demonstrate that the installed $\mathrm{Hg}$-CEMS will comply with future established directives as well as to provide feedback of the recently approved EPA Method 30A reference method. Calibrator difficulties have been addressed and intend to be corrected prior to the next round of tests. It is believed that once these issues are corrected, the 3-Level System Integrity Check will pass performance criteria. 


\section{APPENDIX \\ Initial Measurement System Response Tests \& Run Validations}

Results from the IRM Pre-certification tests are presented in Tables 14 through 19 below.

Table 14: IRM System Calibration Error Test

\section{System Calibration Error Test}

Facility: Hardin Generating Station

Project \#: $06-7008$

Personnel: Sharon Sjostrom

$\mathbf{C S}=\frac{\frac{\text { Jim Domenico }}{\text { Brian Carlton }}}{10 \quad \mu \mathrm{g} / \mathrm{scm}}$

$\operatorname{Date}(\mathbf{s})$ :

Unit(s) tested: Stack Hg-CEMS

Test Runs: N/A

Analyzer Make/Model: Thermo Mercury Freedom

System $^{\mathrm{TM}}$

Serial No:

\begin{tabular}{|c|c|c|c|c|}
\hline $\begin{array}{c}\text { Calibration } \\
\text { Gas Level }\end{array}$ & $\begin{array}{c}\mathbf{C}_{\mathbf{v}} \\
{[\mu \mathrm{g} / \mathbf{s c m}]}\end{array}$ & $\begin{array}{c}\mathbf{C}_{\mathbf{s}} \\
{[\mu \mathbf{g} / \mathbf{s c m}]}\end{array}$ & $\begin{array}{c}\mathbf{S C E} \\
{[\%]}\end{array}$ & $\begin{array}{c}\left|\mathbf{C}_{\mathbf{s}}-\mathbf{C}_{\mathbf{v}}\right| \\
{[\mu \mathbf{g} / \mathbf{s c m}]}\end{array}$ \\
\hline Low- & 3.00 & 3.42 & 4.20 & 0.42 \\
\hline Mid- & 5.00 & 5.39 & 3.90 & 0.39 \\
\hline High- & 9.00 & 8.97 & 0.30 & 0.03 \\
\hline
\end{tabular}

SCE - System calibration error

$\mathrm{C}_{\mathrm{v}}$ - Certified concentration of calibration gas

$\mathrm{C}_{\mathrm{s}}$ - Measured concentration of calibration gas

CS - Calibration span value

Acceptance criteria:

(1) $\mathrm{SCE} \leq 5.0 \%$

(2) Alternatively, $\left|\mathrm{C}_{\mathrm{s}}-\mathrm{C}_{\mathrm{v}}\right| \leq 0.5 \mu \mathrm{g} / \mathrm{scm}$ 
Table 15: IRM System Integrity Check

\section{System Integrity Check}

Facility: Hardin Generating Station

Project \#: $06-7008$

Personnel: Sharon Sjostrom

$\mathbf{C S}=\frac{\frac{\text { Jim Domenico }}{\text { Brian Carlton }}}{10 \quad \mu \mathrm{g} / \mathrm{scm}}$

\begin{tabular}{|c|c|c|c|c|}
\hline $\begin{array}{c}\text { Calibration } \\
\text { Gas Level }\end{array}$ & $\begin{array}{c}\mathbf{C}_{\mathbf{v}} \\
{[\mu \mathrm{g} / \mathbf{s c m}]}\end{array}$ & $\begin{array}{c}\mathbf{C}_{\mathbf{s}} \\
{[\mu \mathbf{g} / \mathbf{s c m}]}\end{array}$ & $\begin{array}{c}\mathbf{S C E} \\
{[\%]}\end{array}$ & $\begin{array}{c}\left|\mathbf{C}_{\mathbf{s}}-\mathbf{C}_{\mathbf{v}}\right| \\
{[\mu \mathbf{g} / \mathbf{s c m}]}\end{array}$ \\
\hline Zero- & 0.00 & -0.05 & 0.50 & 0.05 \\
\hline Mid- & 5.00 & 4.91 & 0.90 & 0.09 \\
\hline
\end{tabular}

SCE - System calibration error

$\mathrm{C}_{\mathrm{v}}$ - Certified concentration of calibration gas

$\mathrm{C}_{\mathrm{s}}$ - Measured concentration of calibration gas

CS - Calibration span

Acceptance criteria:

(1) $\mathrm{SCE} \leq 5.0 \%$

(2) Alternatively, $\left|\mathrm{C}_{\mathrm{s}}-\mathrm{C}_{\mathrm{v}}\right| \leq 0.5 \mu \mathrm{g} / \mathrm{scm}$
Date(s): 04/23/2008

Unit(s) tested: Stack Hg-CEMS

Test Runs: N/A

Analyzer Make/Model: Thermo Mercury Freedom System $^{\mathrm{TM}}$

Serial No:

Sys


Table 17: IRM Dynamic Spiking Test

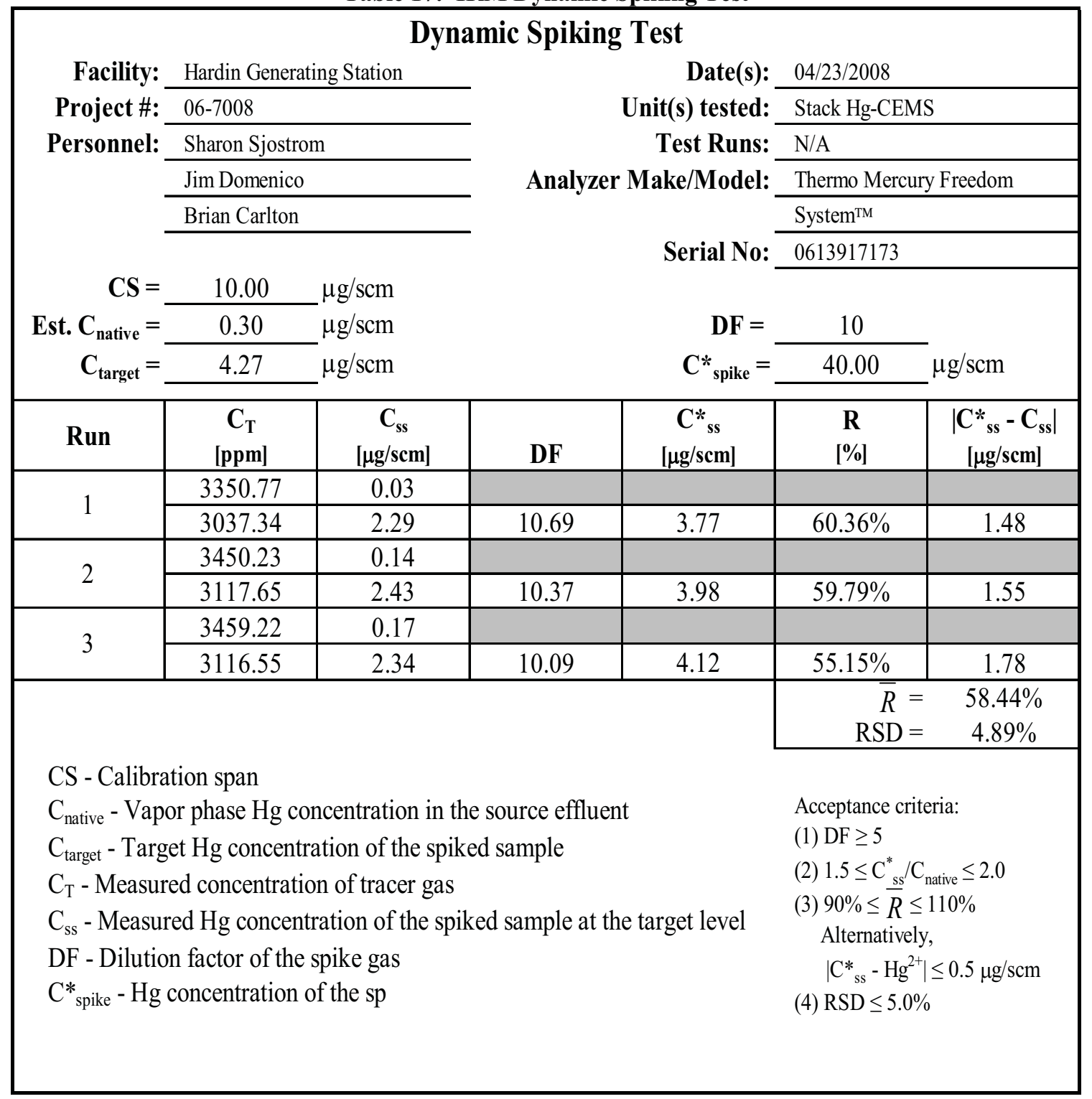




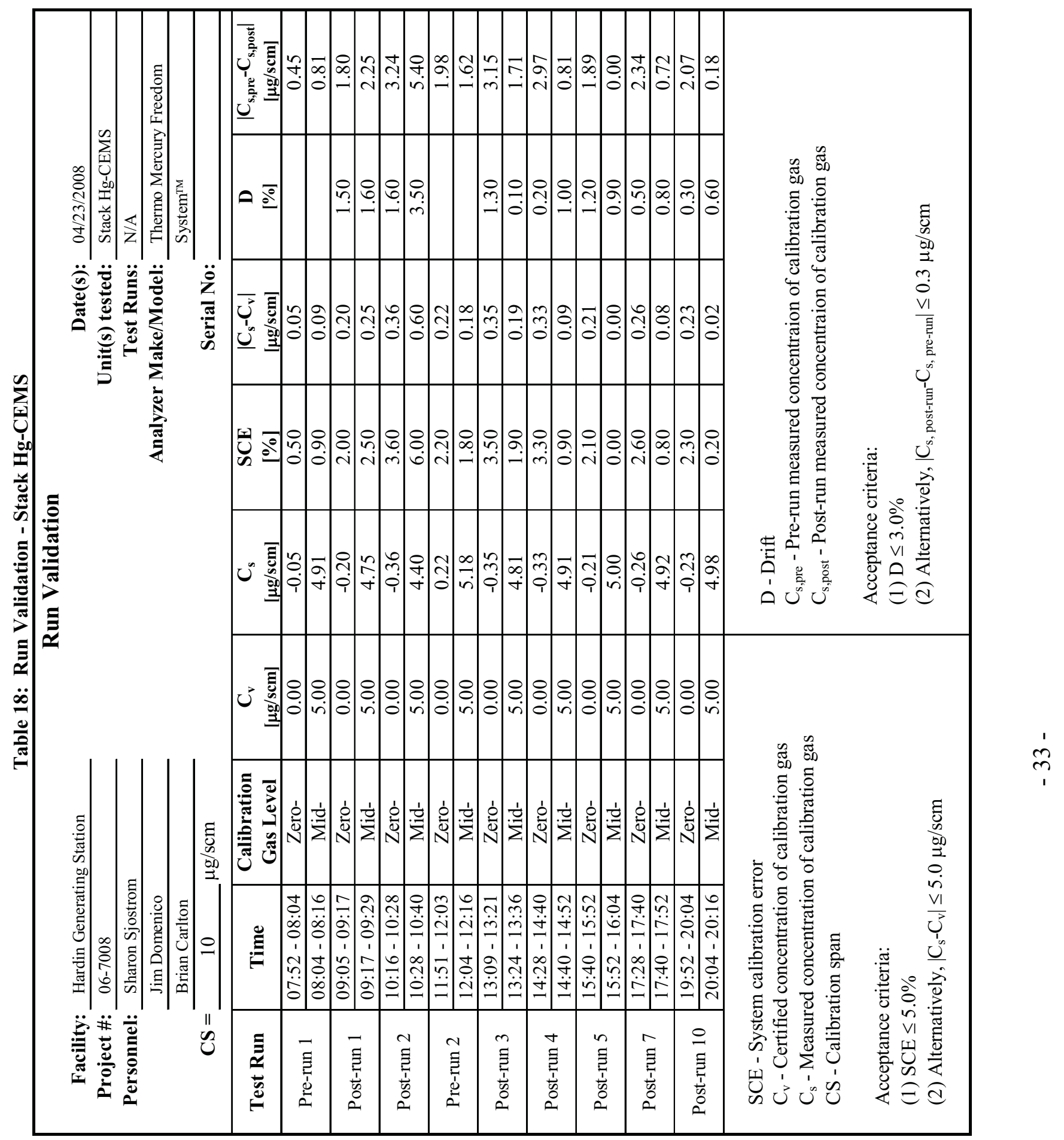




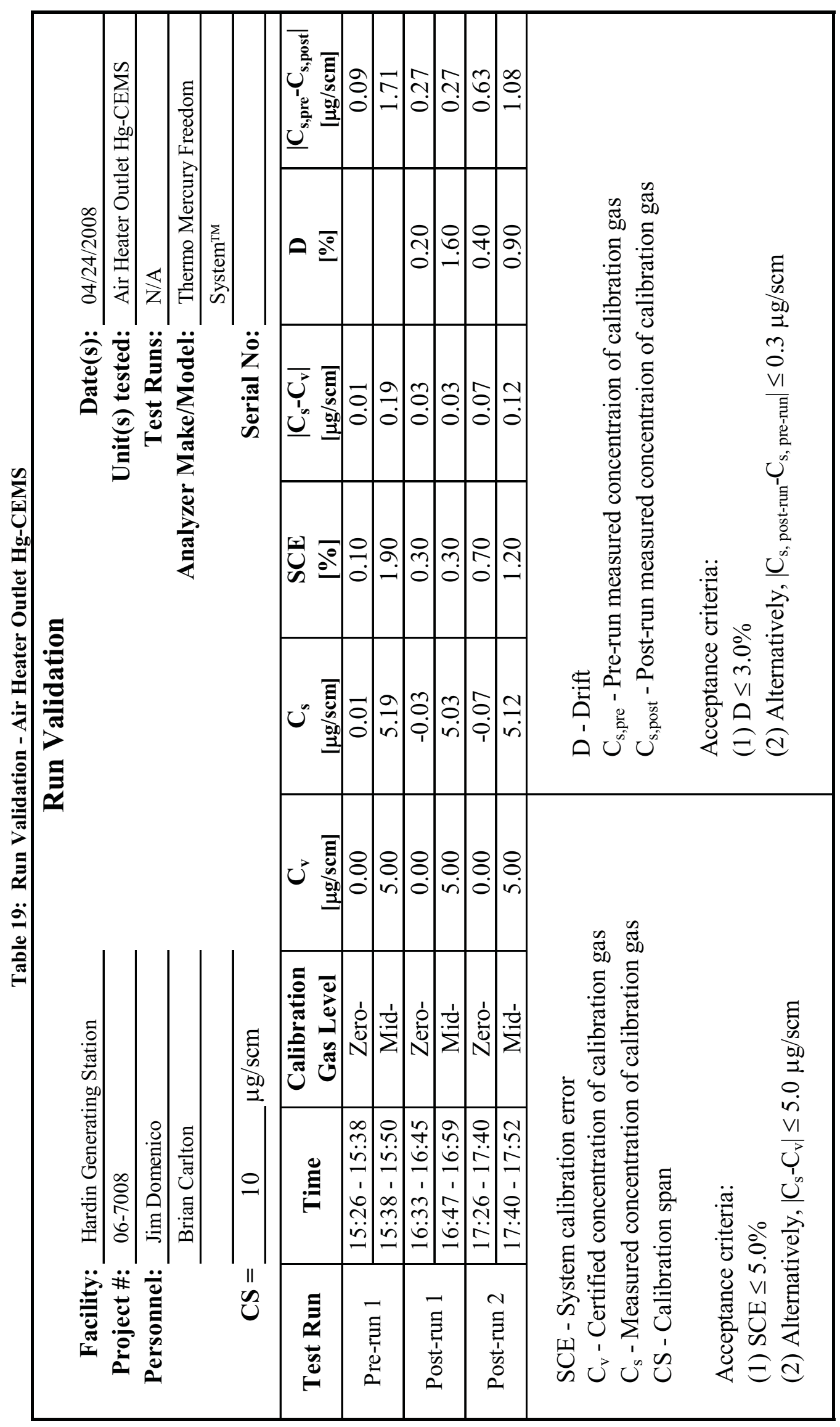




\section{ADA-ES HG CEMS: DETERMINING SPAN AND RANGE SYSTEM ID: 84 \\ DATE: $5 / 5 / 08$ \\ PROJECT \# AND LOCATION:7OO 9 HARDIN INLET DOCUMENT REVISION: 05/2008}

REFERENCE: APPENDIX A TO PART 75 - SECTION 2.1.7

DETERMINE MAXIMUM POTENTIAL CONCENTRATION (MPC): There are three options for the initial MPC determination. Check the applicable option and enter the MPC below.

1. Default values based on coal type: __ Bituminous $(9 \mathrm{ug} / \mathrm{m} 3), X$ Sub-bituminous $(10 \mathrm{ug} / \mathrm{m} 3)$,

MPC (UG/M3)

10

Lignite $(16 \mathrm{ug} / \mathrm{m} 3)$. waste coal, anthracite culm or bituminous gob $(1 \mathrm{ug} / \mathrm{m} 3)$. If different coals are blended, use highest MPC for any fuel in the blend.

2. _-_ Site-specific emission testing upstream of add-on mercury controls or FGD and at least three runs at normal operating load: use the highest total mercury concentration from Ontario Hydro or Instrumental Reference Method.

3. ___ Historical CEMS data or sorbent trap monitoring system with at least 720 operating hours upstream of add-on mercury controls or FGD and met relative accuracy specification of less than $20 \%$.

DETERMINE MAXIMUM EXPECTED CONCENTRATION (MEC): Determine the $M E C$ during normal, stable operation of the unit with emission controls with the following equation, where RE is the expected average design removal efficiency of the control equipment.

\begin{tabular}{|c|c|c|}
\hline & $(100-R E)$ & $M E C \cup G / M 3)$ \\
\hline & 100 & $N / A$ \\
\hline
\end{tabular}

DETERMINE HIGH SPAN CONCENTRATION: Round the MPC value to the next highest multiple of 10 $\mathrm{ug} / \mathrm{m} 3$. An $M P C$ of $10 \mathrm{ug} / \mathrm{m} 3$ would round to $20 \mathrm{ug} / \mathrm{m} 3$.

For add-on mercury controls of FGD (but not short-term, non-representative operating conditions): If the MEC value is less than $20 \%$ of the high span value and if the high span value is $20 \mathrm{ug} / \mathrm{m} 3$ or greater, define a second lowspan value of $10 \mathrm{ug} / \mathrm{m} 3$.

If only a high span value is required, set the full-scale range of the mercury analyzer to be greater than or equal to the span value. If two span values are required (add-on mercury controls or FGD) then (1) use two separate (high and low) measurement scales or (2) quality-assure two segments of a single measurement scale.

DETERMINE GAS LEVEL CONCENTRATIONS: Complete the table with the appropriate mercury concentrations for calibration checks. Define a second scale if applicable.

Daily calibrations are performed at zero and either the high. or mid-level concentrations if this is closer to the actual stack gas concentrations. Linearity checks are performed at the low-, mid-, and high-level gas concentrations.

\begin{tabular}{|c|c|c|c|}
\hline LEVEL & RANGE & SCALE & OPT SCALE \\
\hline ZERO & $0-20 \%$ OF SPAN & 0 & $N / A$ \\
\hline LOW & $20.30 \%$ OF SPAN & 5 & \\
\hline MID & $50.60 \%$ OF SPAN & 11 & \\
\hline HIGH & $80-100 \%$ OF SPAN & 18 & \\
\hline
\end{tabular}

TO BE COMPLETED UPON REVIEW

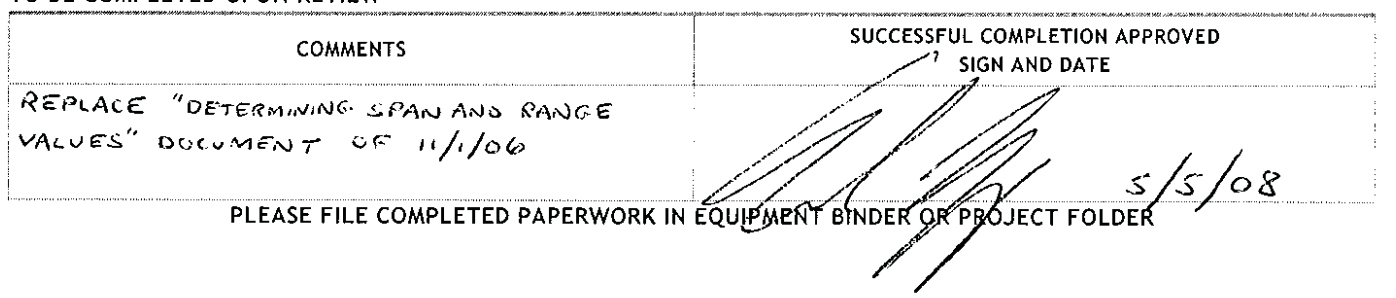




\section{ADA-ES HG CEMS: 3-POINT LINEARITY CHECK}

SYSTEM ID: 94

DATE: $4 / 28 / 08$

PROJECT \# AND LOCATION: 7OO HARIN OURET DOCUMENT REVISION: 04/2008

REFERENCE: APPENDIX A TO PART 75 - SECTION 6.2

IDENTIFICATION OF EQUIPMENT: Identify each component of the complete mercury system by serial number.

\begin{tabular}{|c|c|c|c|c|}
\hline $80 \mathrm{HG}$ ANALYZER & $81 \mathrm{HG}$ CALIBRATOR & $82 \mathrm{HG}$ CONTROLLER & $83 \mathrm{HG}$ PROBE & HG UMBILICALS \\
\hline 0613917173 & 0618117697 & 0618117711 & 0618117697 & 28849.02 .03 .01 \\
\hline
\end{tabular}

3.POINT LINEARITY CHECK: Verify that the linearity check passes the criteria below.

\begin{tabular}{|c|c|c|c|c|c|c|}
\hline RUN & SCALE & DATE AND TIME & CAL VALUE, $\mathrm{R}$ & CEM RESPONSE, A & $\begin{array}{c}\text { LIN ERROR } \\
C E=(R-A) / R \times 100\end{array}$ & $\begin{array}{c}\text { ABS ERROR } \\
(\mathrm{R}-\mathrm{A})\end{array}$ \\
\hline \multirow{3}{*}{1} & Low & $4 / 28 / 08 / 440$ & 3.0 & 2.73 & 9.0 & 0.27 \\
\hline & MID & 1450 & 60 & 5.79 & 3.5 & 0.21 \\
\hline & HIGH & 1500 & 9.0 & 8.50 & 5.6 & 0.50 \\
\hline \multirow{3}{*}{2} & LOW & $15 / 0$ & 3.0 & 2.67 & 11.0 & 0.33 \\
\hline & MID & 1520 & 6.0 & 5.85 & 2.5 & 0.15 \\
\hline & HIGH & 1531 & 9.0 & 8.66 & 3.8 & 0.34 \\
\hline \multirow{3}{*}{3} & LOW & 1541 & 3.0 & 2.65 & 11.7 & 0.35 \\
\hline & MID & 1552 & 6.0 & 5.74 & 4.3 & 0.26 \\
\hline & $\mathrm{HIGH}$ & 1602 & 9.0 & 8.54 & 5.1 & 0.46 \\
\hline
\end{tabular}

\begin{tabular}{|c|c|c|c|c|c|c|}
\hline \multirow{2}{*}{ RUN } & $\begin{array}{c}\text { ZERO } / \\
\text { UPSCALE }\end{array}$ & DATE AND TIME & CAL VALUE, R & CEM RESPONSE, A & $\begin{array}{c}\text { LIN ERROR } \\
\text { LE = (R-A)/R } \times 100\end{array}$ & $\begin{array}{c}\text { ABS ERROR } \\
(R-A)\end{array}$ \\
\hline \multirow{4}{*}{ AVG } & LOW & $4 / 28 / 08$ & 3.0 & 2.68 & 10.7 & 0.32 \\
\hline & MID & & 6.0 & 5.79 & 3.5 & 0.21 \\
\hline & HIGH & & 9.0 & 8.57 & 4.8 & 0.43 \\
\hline
\end{tabular}

PASSING CRITERIA: Linearity Error $(L E) \leq 10.0 \%$ of span OR Absolute Error $(\mathrm{R}-\mathrm{A}) \leq 1 \mathrm{ug} / \mathrm{m} 3$.

TO BE COMPLETED UPON REVIEW

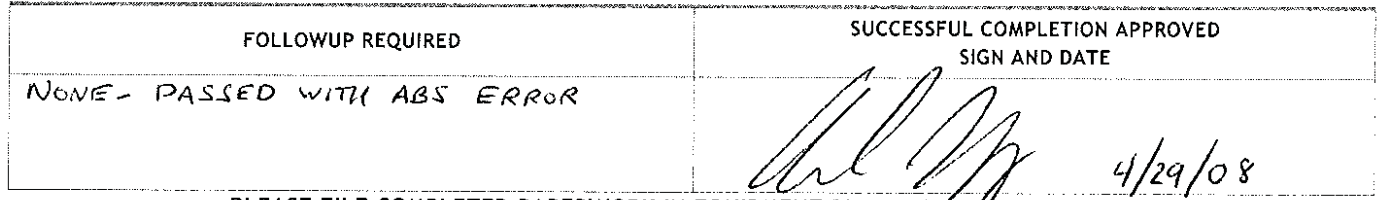

PLEASE FILE COMPLETED PAPERWORK IN EQUIPMENT BINDER OR P

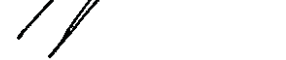




\section{ADA-ES HG CEMS: 3-POINT LINEARITY CHECK}

SYSTEM ID: $8 \cdot 1$

PROJECT \# AND LOCATION:TOOT HARDIN INLET
DATE: $4 / 28 / 08$

DOCUMENT REVISION: 04/2008

REFERENCE: APPENDIX A TO PART 75 - SECTION 6.2

IDENTIFICATION OF EQUIPMENT: Identify each component of the complete mercury system by serial number.

\begin{tabular}{|c|c|c|c|c|}
\hline $80 \mathrm{HG} A N A L Y Z E R$ & $81 \mathrm{HG}$ CALIBRATOR & $82 \mathrm{HG}$ CONTROLLER & $83 \mathrm{HG} \mathrm{PROBE}$ & HG UMBILICALS \\
\hline 06139,7146 & 0613917112 & 0618117700 & $06 / 8117719$ & $28849-02 \cdot 02 \cdot 01$
\end{tabular}

3-POINT LINEARITY CHECK: Verify that the linearity check passes the criteria below.

\begin{tabular}{|c|c|c|c|c|c|c|}
\hline RUN & SCALE & DATE AND TIME & CAL VALUE, $R$ & CEM RESPONSE, A & $\begin{array}{c}\text { LIN ERROR } \\
C E=(R-A) / R \times 100\end{array}$ & $\begin{array}{l}\text { ABS ERROR } \\
(R-A)\end{array}$ \\
\hline \multirow{3}{*}{1} & LOW & $4 / 4 / 08 \quad 703$ & 5,0 & 5.08 & 1.6 & 0.08 \\
\hline & MID & $7 / 3$ & 11.0 & 11.25 & $2 \cdot 27$ & 0.25 \\
\hline & $\mathrm{HIGH}$ & 722 & 18.0 & 17.72 & 1.56 & 0.28 \\
\hline \multirow{3}{*}{2} & LOW & 735 & 5.0 & 5.22 & 4.4 & 0.22 \\
\hline & MID & 745 & 11.0 & 11.37 & 3.36 & 0.37 \\
\hline & $\mathrm{HIGH}$ & 755 & 18.0 & 18.09 & 0.5 & 0.09 \\
\hline \multirow{3}{*}{3} & LOW & 807 & $5 \cdot 0$ & 5.30 & 6.0 & 0.30 \\
\hline & MID & 817 & 11.0 & 11.30 & $2 \cdot 73$ & 0.30 \\
\hline & $\mathrm{HIGH}$ & 827 & 18,0 & 18,08 & $0,4 / 4$ & 0.08 \\
\hline
\end{tabular}

\begin{tabular}{|c|c|c|c|c|c|c|}
\hline RUN & $\begin{array}{l}\text { ZERO / } \\
\text { UPSCALE }\end{array}$ & DATE AND TIME & CAL VALUE, $R$ & CEM RESPONSE, A & $\begin{array}{c}\text { LIN ERROR } \\
L E=(R-A) / R \times 100\end{array}$ & $\begin{array}{c}\text { ABS ERROR } \\
(\mathrm{R}-\mathrm{A})\end{array}$ \\
\hline \multirow{3}{*}{ AVG } & LOW & $4 / 4 / 08$ & $5 \cdot 0$ & 5.20 & 4.0 & 0.20 \\
\hline & MID & & 11.0 & 11.31 & 2.82 & 0.31 \\
\hline & $\mathrm{HIGH}$ & & 18.0 & 17.96 & 0.22 & 0.04 \\
\hline
\end{tabular}

PASSING CRITERIA: Linearity Error $(L E) \leq 10.0 \%$ of span OR Absolute Error $(\mathrm{R}-\mathrm{A}) \leq 1 \mathrm{ug} / \mathrm{m} 3$.

TO BE COMPLETED UPON REVIEW

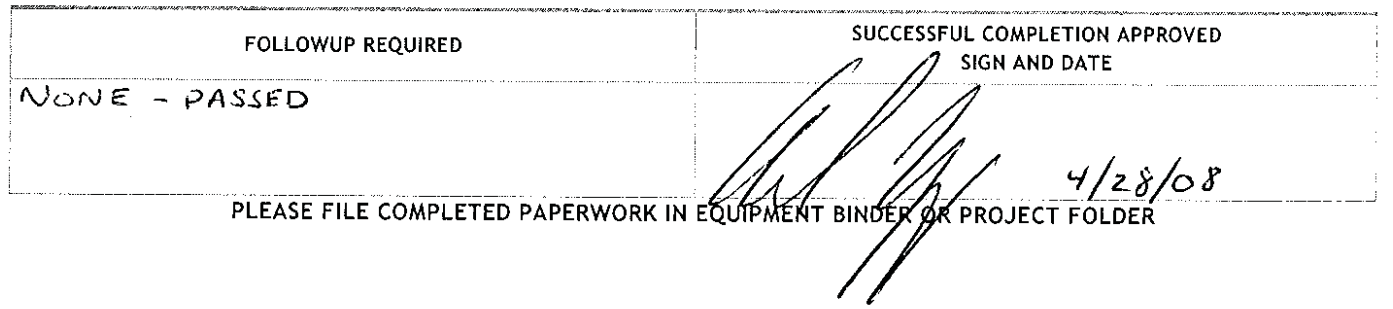




\section{ADA-ES HG CEMS: 7-DAY CALIBRATION ERROR TEST \\ SYSTEM ID: 94 \\ PROJECT \# AND LOCATION:7009 HARDIN OUIZET \\ DATE: $5 / 5 / 08$ \\ DOCUMENT REVISION: 04/2008 \\ REFERENCE: APPENDIX A TO PART 75 - SECTION 6.3}

IDENTIFICATION OF EQUIPMENT: Identify each component of the complete mercury system by serial number.

\begin{tabular}{|c|c|c|c|c|}
\hline $80 \mathrm{HG}$ ANALYZER & $81 \mathrm{HG}$ CALIBRATOR & $82 \mathrm{HG}$ CONTROLLER & $83 \mathrm{HG} \mathrm{PROBE}$ & HG UMBILICALS \\
\hline 0613917173 & 0618117697 & 0618117711 & 0618117697 & $28849.02-03.01$ \\
\hline
\end{tabular}

7-DAY CALIBRATION ERROR TEST: Verify that the calibration drift passes the criteria below. Span value is determined by APPENDIX A TO PART 75 - SECTION 2.1.4.2

SPAN VALUE, $S$

10.0

\begin{tabular}{|c|c|c|c|c|c|c|c|}
\hline DAY & $\begin{array}{l}\text { ZERO / } \\
\text { UPSCALE }\end{array}$ & & AND TIME & CAL VALUE, $R$ & CEM RESPONSE, A & $\begin{array}{c}\text { CAL ERROR } \\
C E=(R \cdot A) / S \times 100\end{array}$ & $\begin{array}{c}\text { ABS ERROR } \\
(R-A)\end{array}$ \\
\hline \multirow[t]{2}{*}{1} & ZERO & $4 / 29$ & 524 & 0.0 & 0.01 & 0.1 & 0.01 \\
\hline & UPSCALE & & 539 & 5.0 & 4.92 & 0.8 & 0.08 \\
\hline \multirow[t]{2}{*}{2} & ZERO & $4 / 30$ & 524 & 0.0 & 0.01 & 0.1 & 0.01 \\
\hline & UPSCALE & & 539 & 5.0 & 4.88 & 1.2 & 0.12 \\
\hline \multirow[t]{2}{*}{3} & ZERO & $5 / 1$ & 524 & 0.0 & 0.03 & 0.3 & 0.03 \\
\hline & UPSCALE & & 539 & 50 & 4.83 & 1.7 & 0.17 \\
\hline \multirow[t]{2}{*}{4} & ZERO & $5 / 2$ & 524 & 0.0 & 0.04 & 0.4 & 0.04 \\
\hline & UPSCALE & & 539 & 5.0 & 4.86 & 1.4 & 0.14 \\
\hline \multirow[t]{2}{*}{5} & ZERO & $5 / 3$ & 524 & 0.0 & 0.06 & 0.6 & 0.06 \\
\hline & UPSCALE & & 539 & 5.0 & 4.79 & 2.1 & 0.21 \\
\hline \multirow[t]{2}{*}{6} & ZERO & $5 / 4$ & 524 & 0.0 & 0.03 & 0.3 & 0.03 \\
\hline & UPSCALE & & 539 & 5.0 & 4.84 & 1.6 & 0.16 \\
\hline \multirow[t]{2}{*}{7} & ZERO & $5 / 5$ & 524 & 0.0 & 0.04 & 0.4 & 0.04 \\
\hline & UPSC.AL.E & & 539 & 5.0 & 4.97 & 0.3 & 0.03 \\
\hline
\end{tabular}

PASSING CRITERIA: Calibration Error (CE) $\leq 5.0 \%$ of span OR Absolute Error $(R-A) \leq 1 \mathrm{ug} / \mathrm{m} 3$.

\section{TO BE COMPLETED UPON REVIEW}

FOLLOWUP REQUIRED
NONE - PASSED T-DAY DRIFT
SEE ATTACHED WORKJHEET
PLEASE FILE COMPLETED PAPERWORK IN EQUIEMENT BIADERORPROJECT FOLDER




\section{ADA-ES HG CEMS: 7-DAY CALIBRATION ERROR TEST \\ SYSTEM ID: 84 \\ DATE: $5 / 5 / 08$ \\ PROJECT \# AND LOCATION: 7009 HARDIN INLET DOCUMENT REVISION: 04/2008}

REFERENCE: APPENDIX A TO PART 75 - SECTION 6.3

IDENTIFICATION OF EQUIPMENT: Identify each component of the complete mercury system by serial number.

\begin{tabular}{|c|c|c|c|c|}
\hline 80 HG ANALYZER & 81 HG CALIBRATOR & 82 HG CONTROLLER & 83 HG PROBE & HG UMBILICALS \\
\hline 0613917146 & 0613917112 & 0618117700 & 0618117719 & $28849-02-02.0$ \\
\hline
\end{tabular}

7-DAY CALIBRATION ERROR TEST: Verify that the calibration drift passes the criteria below. Span value is determined by APPENDIX A TO PART 75 - SECTION 2.1.4.2

SPAN VALUE, $S$ 20.0

\begin{tabular}{|c|c|c|c|c|c|c|c|}
\hline DAY & $\begin{array}{l}\text { ZERO I } \\
\text { UPSCALE }\end{array}$ & DATE & ND TIME & CAL VALUE, $R$ & CEM RESPONSE, A & $\begin{array}{c}\text { CAL ERROR } \\
C E=(R-A) / 5 \times 100\end{array}$ & $\begin{array}{c}\text { ABS ERROR } \\
(R-A)\end{array}$ \\
\hline \multirow[t]{2}{*}{1} & ZERO & $4 / 14$ & 524 & 0.0 & -0.02 & 0.1 & 0.02 \\
\hline & UPSCALE & & 539 & 11.0 & 10.86 & 0.1 & 0.14 \\
\hline \multirow[t]{2}{*}{2} & ZERO & $4 / 15$ & 524 & 0.0 & -0.03 & 0.15 & 0.03 \\
\hline & UPSCALE & & 539 & 11.0 & 10.79 & 1.05 & 0.21 \\
\hline \multirow[t]{2}{*}{3} & ZERO & $4 / 16$ & 524 & 0.0 & -0.05 & 0.25 & 0.05 \\
\hline & UPSCALE & & 539 & 11.0 & 10.84 & 0.8 & 0.16 \\
\hline \multirow[t]{2}{*}{4} & ZERO & $4 / 17$ & 524 & 0.0 & 0.02 & 0.1 & 0.02 \\
\hline & UPSCALE & & 539 & 110 & 10.87 & 0.65 & 0.13 \\
\hline \multirow[t]{2}{*}{5} & ZERO & $4 / 18$ & 524 & 0.0 & -0.03 & 0.15 & 0.03 \\
\hline & UPSCALE & & 539 & 11.0 & 10.74 & 1.3 & 0.26 \\
\hline \multirow[t]{2}{*}{6} & ZERO & $4 / 19$ & 524 & 0.0 & -0.03 & 0.15 & 0.03 \\
\hline & UPSCALE & & 539 & 11.0 & 11.16 & 0.8 & 0.16 \\
\hline \multirow[t]{2}{*}{7} & ZERO & $4 / 20$ & 524 & 0.0 & -0.06 & 0.3 & 0.06 \\
\hline & UPSCALE & & 539 & 11.0 & 10.61 & 1.95 & 0.39 \\
\hline
\end{tabular}

PASSING CRITERIA: Calibration Error (CE) $\leq 5.0 \%$ of span OR Absolute Error (R-A) $\leq 1 \mathrm{ug} / \mathrm{m} 3$.

TO BE COMPLETED UPON REVIEW

FOLLOWUP REQUIRED
NONE-PASSED 7-DAY DRIFT
SEE ATTACHED WORKSHEET

PLEASE FILE COMPLETED PAPERWORK IN EQUIPMENT BINDER OP PROJECT FOLDER 


\section{ADA-ES HG CEMS: CYCLE TIME TEST}

SYSTEM ID: 94

DATE: $4 / 29 / 08$

PROJECT \# AND LOCATION:7009 HARDIN OURET DOCUMENT REVISION: 04/2008

REFERENCE: APPENDIX A TO PART 75 - SECTION 6.4

IDENTIFICATION OF EQUIPMENT: Identify each component of the complete mercury system by serial number.

\begin{tabular}{|c|c|c|c|c|c|}
\hline $80 \mathrm{HG} A N A L Y Z E R$ & $81 \mathrm{HG}$ CALIBRATOR & $82 \mathrm{HG}$ CONTROLLER & 83 HG PROBE & HG UMBILICALS \\
\hline 0613917173 & $06181 / 7697$ & $06 / 81 / 771 /$ & $06181 / 7697$ & $28849-02.03 .01$
\end{tabular}

CYCLE TIME TEST: Verify that the linearity check passes the criteria below.

\begin{tabular}{|c|c|c|c|c|c|c|}
\hline RUN & CAL VALUE, $R$ & DATE AND TIME & STABLE START & STABLE END & $\begin{array}{l}\text { STEP CHANGE } \\
\text { START - END }\end{array}$ & $\begin{array}{l}\text { CYCLE TIME } \\
95 \% \text { STEP }\end{array}$ \\
\hline ZERO & 0,0 & $30 \% 8$ & 0.36 & 0.02 & 0.34 & 6 MINUTES \\
\hline UPSCALE & 5.0 & $1 / 20$ & 0.35 & 4.87 & 4.52 & 6 minues \\
\hline
\end{tabular}

PASSING CRITERIA: Cycle Time cannot exceed 15 minutes.

TO BE COMPLETED UPON REVIEW

FOLLOWUP REQUIRED

PLEASE FILE COMPLETED PAPERWORK IN EQUEMMENF BINDER OR PROJECT FOLDER 


\section{ADA-ES HG CEMS: CYCLE TIME TEST \\ SYSTEM ID: 84 \\ DATE: $4 / 29 / 08$ \\ PROJECT \# AND LOCATION:700 9 HARDIN INLET DOCUMENT REVISION: 04/2008}

REFERENCE: APPENDIX A TO PART 75 - SECTION 6.4

IDENTIFICATION OF EQUIPMENT: Identify each component of the complete mercury system by serial number.

\begin{tabular}{|c|c|c|c|c|}
\hline $80 \mathrm{HG}$ ANALYZER & $81 \mathrm{HG}$ CALIBRATOR & $82 \mathrm{HG}$ CONTROLLER & $83 \mathrm{HG}$ PROBE & HG UMBILICALS \\
\hline 0613917146 & $06139171 / 2$ & 0618117700 & 0618117719 & 28849.02 .02 .01 \\
\hline
\end{tabular}

CYCLE TIME TEST: Verify that the linearity check passes the criteria below.

\begin{tabular}{|c|c|c|c|c|c|c|}
\hline RUN & CAL VALUE, $R$ & DATE AND TIME & STABLE START & STABLE END & $\begin{array}{l}\text { STEP CHANGE } \\
\text { START - END }\end{array}$ & $\begin{array}{l}\text { CYCLE TIME } \\
95 \% \text { STEP }\end{array}$ \\
\hline ZERO & 0.0 & $4 / 29 / 081057$ & 4.20 & 0.04 & 4.16 & 6 Minute.s \\
\hline UPSCALE & 11.0 & 1123 & 4.65 & 10.90 & 6.25 & 7 minutes \\
\hline
\end{tabular}

PASSING CRITERIA: Cycle Time cannot exceed 15 minutes.

TO BE COMPLETED UPON REVIEW

NONE - CRITERIA PASSED




\section{ADA-ES HG CEMS: 3-POINT CONVERTER EFFICIENCY}

SYSTEM ID: 94

PROJECT \# AND LOCATION: $70 O 9$ HARDIN DURET
DATE: $5 / 5 / 08$

DOCUMENT REVISION: 04/2008

REFERENCE: PERFORMANCE SPECIFICATION 12A - SECTION 8.3

IDENTIFICATION OF EQUIPMENT: Identify each component of the complete mercury system by serial number.

\begin{tabular}{|c|c|c|c|c|}
\hline 80 HG ANALYZER & 81 HG CALIBRATOR & $82 \mathrm{HG}$ CONTROLLER & 83 HG PROBE & HG UMBILICALS \\
\hline $06 / 39 / 7173$ & $06 / 8117697$ & 0618117711 & $06 / 81 / 7697$ & $28849-02-03.01$ \\
\hline
\end{tabular}

3-POINT CONVERTER EFFICIENCY CHECK: Verify that the linearity check passes the criteria below.

\begin{tabular}{|c|c|c|c|c|c|c|}
\hline RUN & SCALE & DATE AND TIME & CAL VALUE, $R$ & CEM RESPONSE, A & $\begin{array}{c}\text { EFF ERROR } \\
\mathrm{EE}=(\mathrm{R} \cdot \mathrm{A}) / \mathrm{R} \times 100\end{array}$ & $\begin{array}{l}\text { ABS ERROR } \\
(R-A)\end{array}$ \\
\hline \multirow{3}{*}{1} & LoW & $4 / 30 \quad 1 / 59$ & 3.0 & 2.13 & 29.0 & 0.87 \\
\hline & MID & 1247 & 6.0 & 4.49 & $25 \cdot 2$ & 1.51 \\
\hline & $\mathrm{HIGH}$ & 1338 & 9.0 & 6.52 & 27.6 & 2.48 \\
\hline
\end{tabular}

PASSING CRITERIA: Efficiency Error $(E E) \leq 5.0 \%$ of span OR Absolute Error $(R-A) \leq 1 \mathrm{ug} / \mathrm{m} 3$.

ALTERNATE REFERENCE: MERCURIC CHLORIDE GENERATOR INSTRUCTION MANUAL - PAGE 3-7 "CALCULATIONS"

(THERMO SCIENTIFIC, JAN 28 2008, PART NUMBER 105648.00)

\begin{tabular}{|c|c|c|c|c|c|c|}
\hline RUN & SCALE & $\begin{array}{l}\text { CEM RESP, A1 } \\
\text { ELEMENTAL }\end{array}$ & $\begin{array}{l}\text { CEM RESP, A2 } \\
\text { OXIDIZED }\end{array}$ & $\begin{array}{l}\mathrm{CL}_{2} \text { DILUTION } \\
\text { FACTOR, CDF }\end{array}$ & $\begin{array}{l}\text { CEM RESP, B2 } \\
B 2=A 2 * C D F\end{array}$ & $\begin{array}{c}\text { EFFICIENCY } \\
E F F=B 2 * A 1\end{array}$ \\
\hline \multirow{3}{*}{1} & LOW & 2.82 & 2.13 & 1.02 & 2,17 & 77.1 \\
\hline & MID & 5.84 & 4.49 & 1.02 & 4.59 & 78.6 \\
\hline & HIGH & 8.74 & 6.52 & 1.03 & 6.70 & 76.6 \\
\hline
\end{tabular}

PASSING CRITERIA: Efficiency (EFF) should be between $95 \%$ and $105 \%$. *

\section{TO BE COMPLETED UPON REVIEW}

FOLLOWUP REQUIRED
EFFICIENCY IS LINEAR BUT DOES NOT
PASS CONUERSION CRITERIA
SEF ATTACHED WORKSHEET
PLEASE FILE COMPLETED PAPERWORK IN EQUIPMENT BINDER GR PROJECT FOLDER




\section{ADA-ES HG CEMS: 3-POINT CONVERTER EFFICIENCY}

SYSTEM ID: 84

PROJECT \# AND LOCATION: 7009 HARDIN INLET

REFERENCE: PERFORMANCE SPECIFICATION 12A - SECTION 8.3
DATE: $4 / 29 / 08$

DOCUMENT REVISION: 04/2008

IDENTIFICATION OF EQUIPMENT: Identify each component of the complete mercury system by serial number.

\begin{tabular}{|c|c|c|c|c|}
\hline $80 \mathrm{HG}$ ANALYZER & $81 \mathrm{HG}$ CALIBRATOR & $82 \mathrm{HG}$ CONTROLLER & $83 \mathrm{HG} \mathrm{PROBE}$ & HG UMBILICALS \\
\hline 0613917146 & 0613917112 & 06.8117700 & 0618117719 & $28849-02.02 .01$ \\
\hline
\end{tabular}

3-POINT CONVERTER EFFICIENCY CHECK: Verify that the linearity check passes the criteria below.

\begin{tabular}{|c|c|c|c|c|c|c|}
\hline RUN & SCALE & DATE AND TIME & CAL VALUE, $R$ & CEM RESPONSE, A & $\begin{array}{c}\text { EFF ERROR } \\
E E=(R-A) / R \times 100\end{array}$ & $\frac{A B S \text { ERROR }}{(R-A)}$ \\
\hline \multirow{3}{*}{1} & Low & & & & & \\
\hline & MID & & & & & \\
\hline & $\mathrm{HIGH}$ & & & & & \\
\hline
\end{tabular}

PASSING CRITERIA: Efficiency Error $(E E) \leq 5.0 \%$ of span OR Absolute Error $(R-A) \leq 1 \mathrm{ug} / \mathrm{m} 3$.

TO BE COMPLETED UPON REVIEW

FOLLWUP REQUIRED
NO HG OXIDIZER COMPONENTS
INSTALLED

PLEASE FILE COMPLETED PAPERWORK IN EQUIPMENT BINDER OR PRøJECT FOLDER

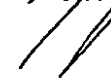




\begin{tabular}{|c|c|c|c|c|c|c|c|c|c|c|c|}
\hline \multicolumn{12}{|c|}{ ADA-ES SYSTEM FUNCTIONAL TEST REVIEW } \\
\hline \multicolumn{6}{|c|}{ SYS ID \# 30 IRM } & \multicolumn{6}{|c|}{ REVIEW DATE: $4 / 18 / 08$} \\
\hline \multicolumn{12}{|c|}{ 80i MERCURY ANALYZER } \\
\hline \multicolumn{6}{|c|}{ INST ID / SN \#: 0613917174 (SOA 033) (ADA \#30) } & \multicolumn{6}{|c|}{ TEST DATE: $4 / 10 / 08$} \\
\hline PHYS & ELEC & CONFIG & TEMPS & PRES & FLow & LEAK & LAMP & PMT & BKGS & COEFS & RESULT \\
\hline OK & OK & OK & OK & OK & OK & OK & OK & OK & OK & OK & PASS \\
\hline
\end{tabular}

\section{1i MERCURY CALIBRATOR}

INST ID / SN \#: 0613917697 (SOA 034) (ADA \#31)

TEST DATE: $4 / 15 / 08$

\begin{tabular}{|c|c|c|c|c|c|c|c|c|c|c|c|}
\hline PHYS & ELEC & CONFIG & FANS & VALVES & TEMPS & PRES & HG MFC & DIL MFC & LINEAR & CALC & RESULT \\
\hline OK & OK & OK & OK & OK & OK & OK & OK & OK & OK & OK & PASS \\
\hline
\end{tabular}

\begin{tabular}{l} 
82i MERCURY PROBE CONTROLLER \\
INST ID / SN \#: IRM 30 \\
\begin{tabular}{|c|c|c|c|c|c|c|c|c|c|c|c|}
\hline PHYS & ELEC & COMM & HEAT & VALVES & RESULT & PHYS & CLEAN & AMPHEN & TUBING & HEAT & RESULT \\
\hline N/A & N/A & N/A & N/A & N/A & INC & OK & OK & OK & OK & OK & PASS \\
\hline
\end{tabular} \\
\hline
\end{tabular}

\section{3i MERCURY PROBE}

INST ID / SN \#: 0618117722 (SOA 022) (ADA \#23)

TEST DATE: $4 / 15 / 08$

\begin{tabular}{|c|c|c|c|c|c|c|c|c|c|c|c|}
\hline CLEAN & PHYS & CMPNTS & LEAK & TEMPS & PRES & SHT DN & VALVES & BB CYC & M CAL & A CAL & RESULT \\
\hline OK & INC & INC & N/A & N/A & N/A & N/A & N/A & N/A & N/A & N/A & INC \\
\hline
\end{tabular}

\section{ADDITIONAL EQUIPMENT}

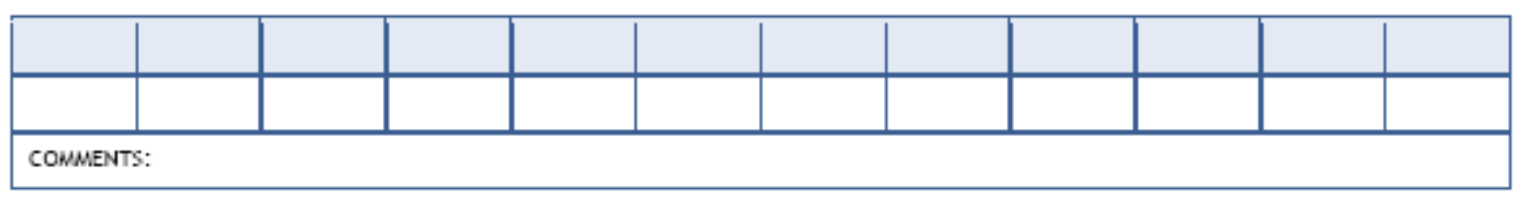

TO BE COMPLETED UPON REVIEW

\begin{tabular}{|c|c|}
\hline FOLLOWUP REQUIRED & SUCCESSFUL COMPLETION APPROVED \\
SIGN AND DATE
\end{tabular}


Relative Accuracy Test Audit (RATA) Utilizing EPA's Method 30A at Rocky Mountain Power's Hardin Generating Station, Hardin, MT

\author{
Test Dates: September $24^{\text {th }}-28^{\text {th }}, 2008$ \\ Project Number 06-7008 \\ DOE Award Number DE-FC26-06NT42774 \\ Project Director: Sharon Sjostrom \\ Project Engineer: Jerry Amrhein
}

ADA Environmental Solutions, Inc.

8100 SouthPark Way, Unit B

Littleton, CO 80120 


\section{Executive Summary}

ADA Environmental Solutions, Inc. (ADA-ES) conducted mercury continuous emissions monitoring system (Hg-CEMS) testing commencing September 24, 2008 and concluding September 28, 2008 at Rocky Mountain Power's Hardin Generating Station, Hardin, MT using regulations outlined in 40 CFR Part 75.20. Method 30A was the instrumental reference method (IRM) employed to conduct a Relative Accuracy Test Audit (RATA) of the Stack Hg-CEMS, downstream of Activated Carbon Injection (ACI). Modified Method 30A procedures were also used for a RATA on the Air Heater Outlet Hg-CEMS, upstream of ACI.

This technical report was prepared with the support of the U.S. Department of Energy under Award No. DE-FC26-06NT42774, to be included in the "Long-Term Carbon Injection Field Test for $>90 \%$ Mercury Removal for a PRB Unit with a Spray Dryer and Fabric Filter" project of DOE's "Phase III Mercury Control Technology Field Testing and Related Mercury Control Research and Development" program. This was the second of three RATA tests that will be performed during the Long-term Test Phase of this project as specified in the test plan.

Method 30A requires Initial Measurement System Performance Tests described in Section 8.2 [Method 30A] in order to ascertain proper function of the instrumental analyzer. A summary of these tests and their results are presented in Table 1.

Table 1: Summary of Test Results

\begin{tabular}{|c|c|c|}
\hline & $\begin{array}{c}\text { Stack } \\
\text { Hg-CEMS } \\
\text { (downstream of ACI) }\end{array}$ & $\begin{array}{c}\text { Air Heater Outlet } \\
\text { Hg-CEMS } \\
\text { (upstream of ACI) }\end{array}$ \\
\hline Relative Accuracy Test Audit (RATA) & PASS & PASS \\
\hline Interference Check (Optional) & - & - \\
\hline 3-Point System Calibration Error Test & PASS & PASS \\
\hline System Integrity Check & PASS & PASS \\
\hline Measurement System Response & PASS & PASS \\
\hline Dynamic Spiking Test & Not Performed & Not Performed \\
\hline
\end{tabular}

The Dynamic Spiking Test was not performed during this RATA because it is not required until January 1, 2009. Successful completion of the Dynamic Spiking Test was not attained during previous testing during the week of April 20, 2008. Its merit will be reevaluated with direction from the EPA at a later date.

Both the Stack and the Air Heater Outlet Hg-CEMS successfully met performance criteria for RATA testing. Bias was determined and evaluated as out of specification, however bias adjustment factors were not implemented. Both of these systems are subject to the scrutiny of a well-developed QA/QC program which includes daily evaluation of potentially necessary correction factors, and, as such, implementation of any correction from this Bias Test has been deemed unnecessary. 


\section{Table of Contents}

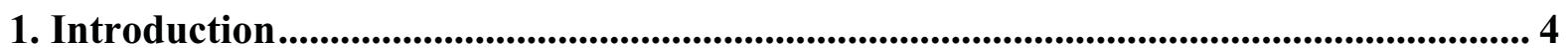

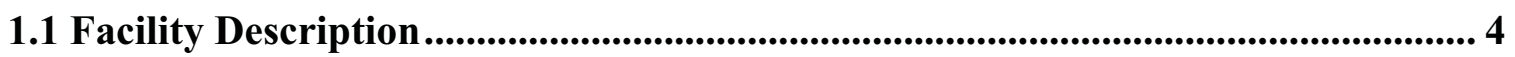

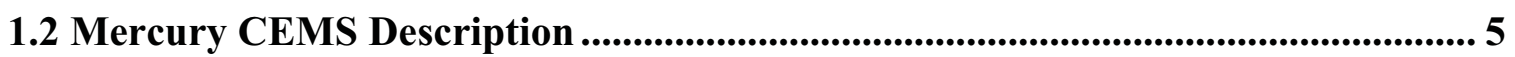

1.3 Sampling Port Locations ................................................................................................ 5

1.4 Method 30A Reference Analyzer Equipment and Method Description................. 7

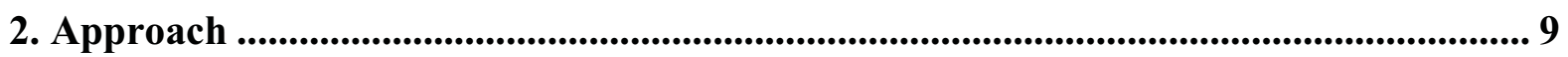

2.1 Plant-Installed CEMS Parameters............................................................................... 9

2.2 Relative Accuracy Test Audit (RATA) \& Bias Test ................................................... 10

2.2.1 Instrumental Analyzer Configuration ............................................................... 10

2.2.1.1 Calibration Span \& Gas Concentrations .............................................10

2.2.1.2 Sample Point Selection ........................................................................10

2.2.2 Initial Measurement System Performance Tests ............................................. 11

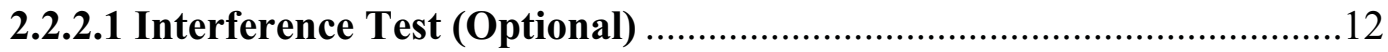

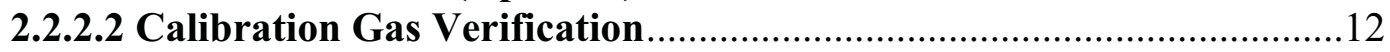

2.2.2.3 Measurement System Preparation ..................................................... 12

2.2.2.4 System Calibration Error Test ........................................................12

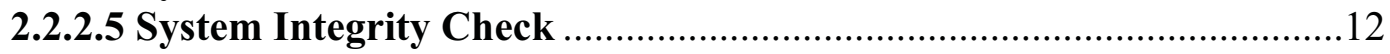

2.2.2.6 Measurement System Response Time ……………………..................13

2.2.2.7 Dynamic Spiking Test (deferred until January 1, 2009) ......................13

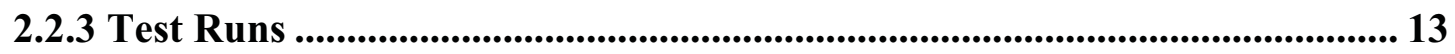

2.2.3.1 System Integrity Checks ............................................................13

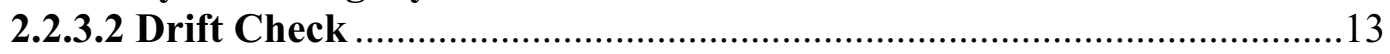

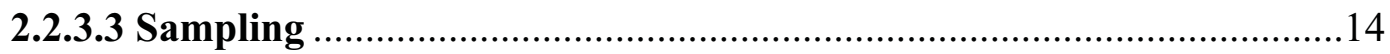

2.2.4 Relative Accuracy Calculation.......................................................................... 14

2.2.5 Bias Determination \& Adjustment Factor Calculation................................... 15

3. Results and Discussion...................................................................................................... 16

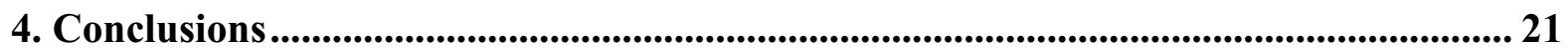

5. Appendix .............................................................................................................................. 22

Initial Measurement System Response Tests .................................................................... 22 
Table 1: Summary of Test Results ........................................................................................1

Table 2: Key Parameters of the Hardin Power Plant......................................................5

Table 3: Span and Range Value(s) ..............................................................................9

Table 4: IRM Calibration Span \& Gas Concentrations...................................................10

Table 5: RATA \& Bias Test - Stack Hg-CEMS .................................................................16

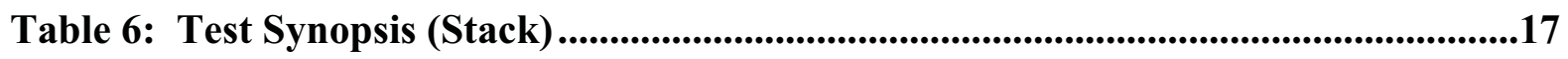

Table 7: RATA \& Bias Test - Air Heater Outlet Hg-CEMS ..............................................18

Table 8: Test Synopsis (Air Heater Outlet) ................................................................19

Table 9: IRM System Calibration Error Test (Stack)................................................23

Table 10: IRM System Calibration Error Test (Air Heater Outlet)...................................23

Table 11：IRM Measurement System Response Time (Stack) ........................................24

Table 12: IRM Measurement System Response Time (Air Heater Outlet) ....................24

Table 13: IRM System Integrity Check (Stack).................................................................25

Table 14: IRM System Integrity Check (Air Heater Outlet) ..........................................25

\section{LIST OF FIGURES}

Figure 1: Hardin Facility View ........................................................................................................4

Figure 2: Stack Sampling Port Location [ASA, Inc.] .............................................6

Figure 3: Air Heater Outlet Sampling Port Location [ASA, Inc.] ..................................7

Figure 4: Thermo CEMS Configured for an IRM .............................................................8

Figure 5: Thermo Model 83i Probe, Filter and Conversion Unit .....................................8

Figure 6: IRM Probe Designed for Traversing ...............................................................9

Figure 7: Stack Sampling Points .........................................................................................11

Figure 8: Air Heater Outlet Sampling Point .....................................................................11 


\section{Introduction}

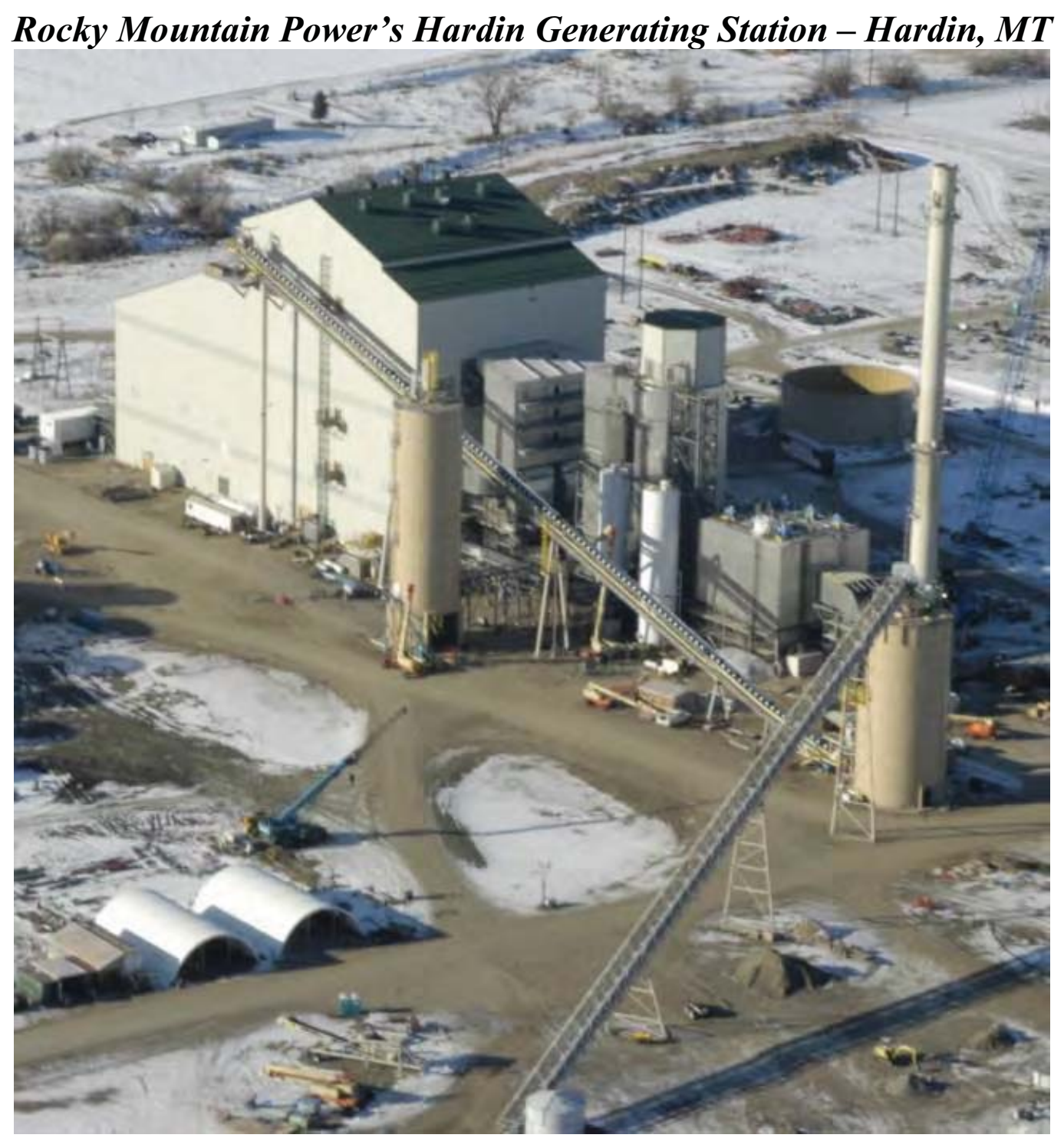

Figure 1: Hardin Facility View

\subsection{Facility Description}

Rocky Mountain Power's Hardin Generating Station is a new and relatively small plant (121 MW) that was first brought online in December of 2005. Its key operating parameters are outlined in Table 2. Firing a pulverized Powder River Basin (PRB) coal from the nearby Absaloka Mine, the Hardin plant is configured with low $\mathrm{NO}_{\mathrm{x}}$ burners and a Selective Catalytic Reduction (SCR) for $\mathrm{NO}_{\mathrm{x}}$ control, a Spray Dryer Absorber (SDA) for $\mathrm{SO}_{2}$ control, and a Fabric Filter (FF) for particulate control. The coal contains approximately $0.65 \%$ sulfur, $0.04 \mathrm{ppm}$ mercury and $<20 \mathrm{ppm}$ chlorine. A commercial-grade Activated Carbon Injection (ACI) system is integrated with a new-generation mercury analyzer to allow automated feedback control of the outlet mercury emissions. 
Table 2: Key Parameters of the Hardin Power Plant

\begin{tabular}{|l|c|}
\hline Rated Capacity & 121 (MW) \\
\hline Range of Operation & $81-121 \mathrm{MW}$ \\
\hline Operating Levels & $\begin{array}{c}\text { Low: } 81-93 \mathrm{MW} \\
\text { Mid: } 93-105 \mathrm{MW} \\
\text { High (Normal): } 105-121 \mathrm{MW}\end{array}$ \\
\hline Coal (typical) & $\begin{array}{c}\text { PRB, } \\
\text { Absaloka Mine }\end{array}$ \\
\hline Boiler Type & $\begin{array}{c}\text { PC Boiler } \\
\text { Opposing wall-fired }\end{array}$ \\
\hline Sulfur Control & Spray Dryer with Recycle \\
\hline Nitrogen Oxide Control & Low NO $\mathrm{N}_{\mathrm{x}}$ Burners/SCR \\
\hline Particulate Control & Fabric Filter \\
\hline $\begin{array}{l}\text { Gas Flow Rate } \\
\text { (ACI Location) }\end{array}$ & $\sim 550,000 \mathrm{acfm}$ \\
\hline $\begin{array}{l}\text { Flue Gas Temperature } \\
\text { (ACI Location) }\end{array}$ & $260-320^{\circ} \mathrm{F}$ \\
\hline
\end{tabular}

\subsection{Mercury CEMS Description}

The Mercury Freedom ${ }^{\mathrm{TM}}$ System manufactured by Thermo Fisher Corporation is installed at Hardin to continuously measure the mercury emissions at the Stack and the Air Heater Outlet. Thermo Electron's Mercury Freedom ${ }^{\mathrm{TM}}$ System is comprised of a Hg Analyzer (80i), Calibrator (81i), Probe Controller (82i), Probe (83i) and related peripheral components including an umbilical and instrument rack.

\subsection{Sampling Port Locations}

Air Sampling Associates, Inc. previously measured and documented the sampling port locations at the Stack and Air Heater Outlet depicted in Figures 2 and 3, respectively, during stack testing:

"The sampling ports on the SDA Inlet duct [Air Heater Outlet duct] are approximately 36 feet $91 / 2$ inches above the ground. The sampling ports are located 13 feet 4 inches $(1.12$ equivalent duct diameters) downstream from a bend in the duct and 56 feet 3 inches ( 4.75 equivalent duct diameters) upstream from a bend in the duct. The sampling ports on the Stack are approximately 123 feet $11 / 2$ inches above the ground. The sampling ports are located 33 feet $11 / 2$ inches (3.64 stack diameters) downstream from the inlet to the Stack and $>18$ feet $23 / 8$ inches ( $>2.00$ Stack diameters) upstream from the outlet to the Stack." 


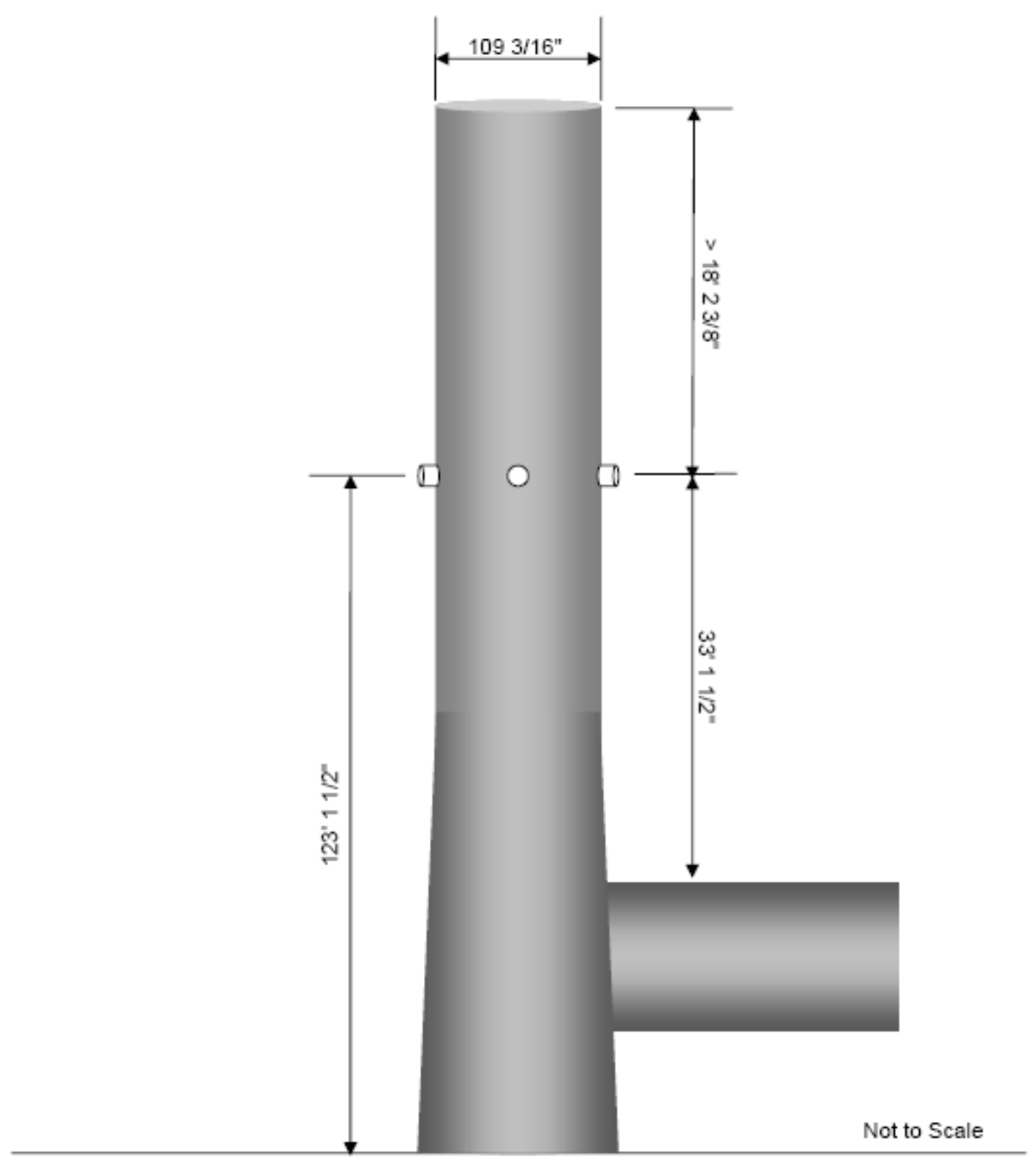

Figure 2: Stack Sampling Port Location [ASA, Inc.] 


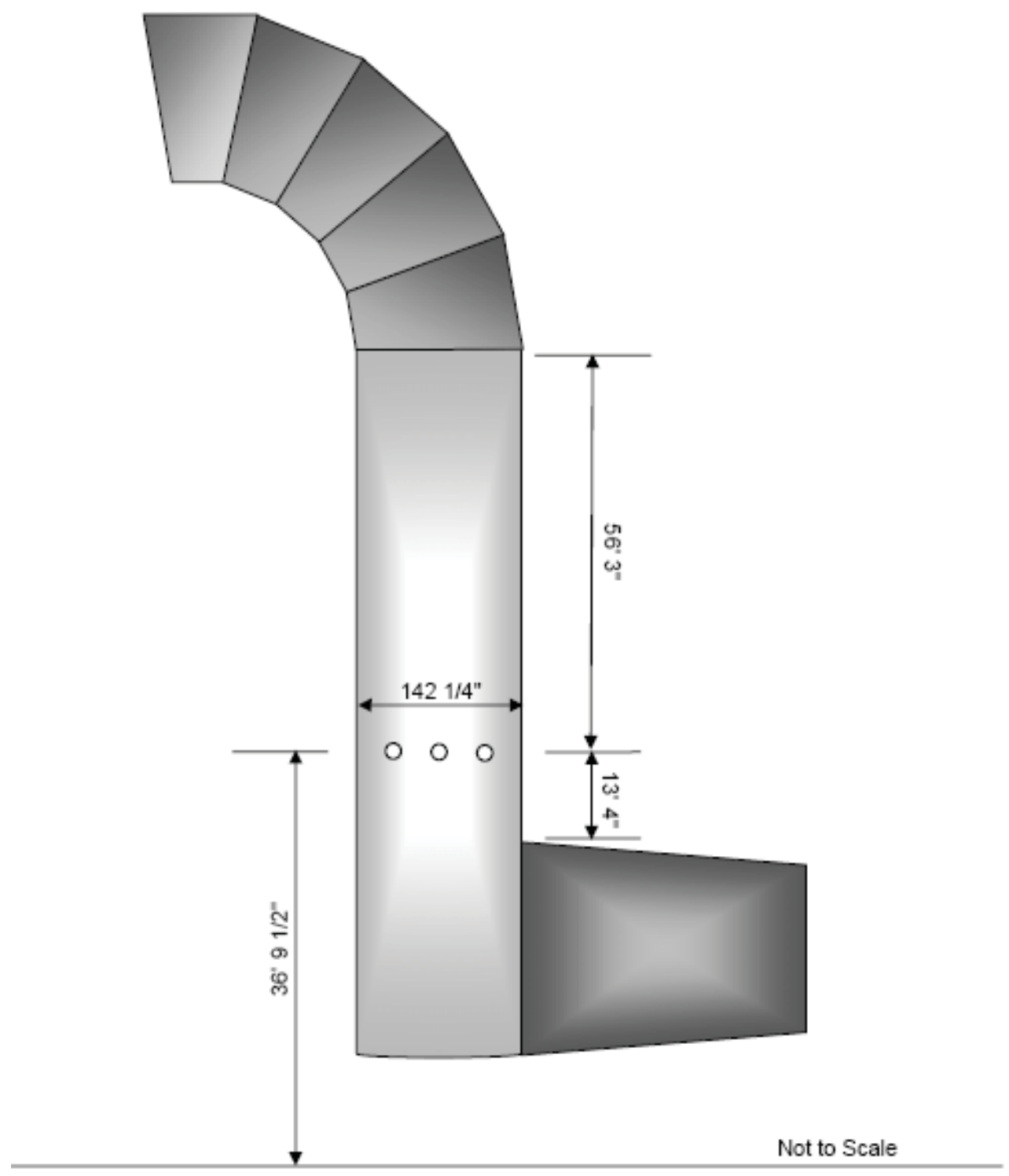

Figure 3: Air Heater Outlet Sampling Port Location [ASA, Inc.]

\subsection{Method 30A Reference Analyzer Equipment \& Method Description}

A Thermo Mercury Freedom ${ }^{\mathrm{TM}}$ System has been configured for IRM testing. A photo of the unit is shown in Figure 4. The unit consists of a standard Model 80i Mercury Analyzer and Model $81 \mathrm{i}$ Mercury Calibrator installed in a temperature controlled enclosure. Probe control (temperature, flow, pressure) is achieved through analog controls installed in the environmental enclosure. A standard Model 83i Probe, shown in Figure 5, has been 
modified by removing the mantle and stinger, connecting calibration gas to a port upstream of the sampling filter, and adding additional pressure monitoring capabilities to the flow measurement venturi. A modified mantle/stinger portion of the probe has been fabricated to facilitate traversing. A sketch of this component is shown in Figure 6. The mantle/stinger has been coupled to the other probe components by a 25 -foot long heated umbilical. At Hardin Generating Station, the IRM enclosure was located at ground level while the probe enclosure, 25-foot heated umbilical, and mantle/stinger were located at the sampling platform.

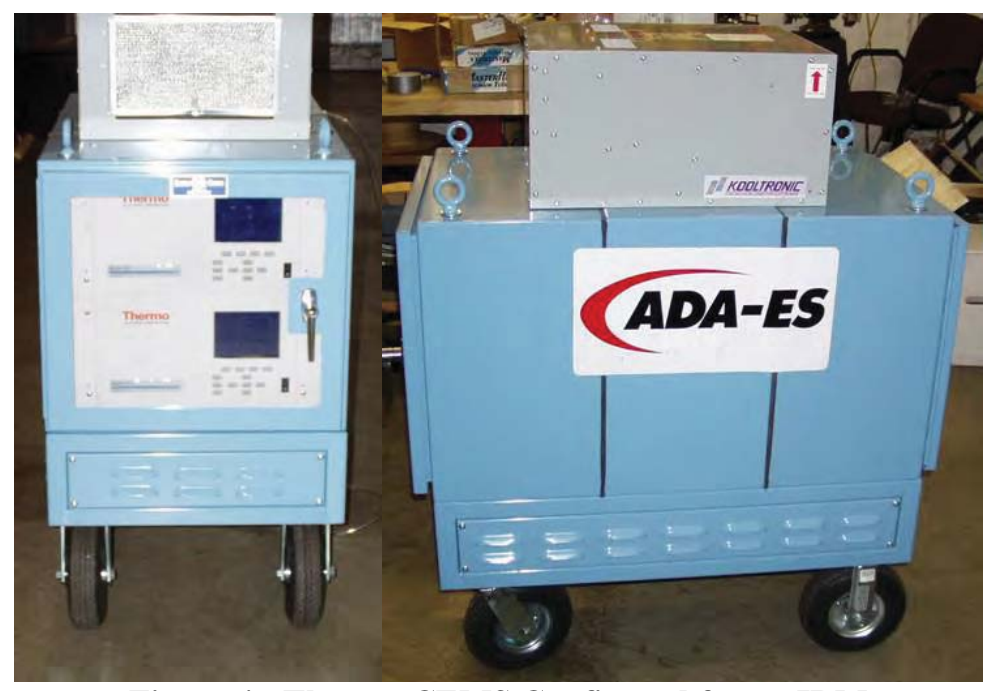

Figure 4: Thermo CEMS Configured for an IRM

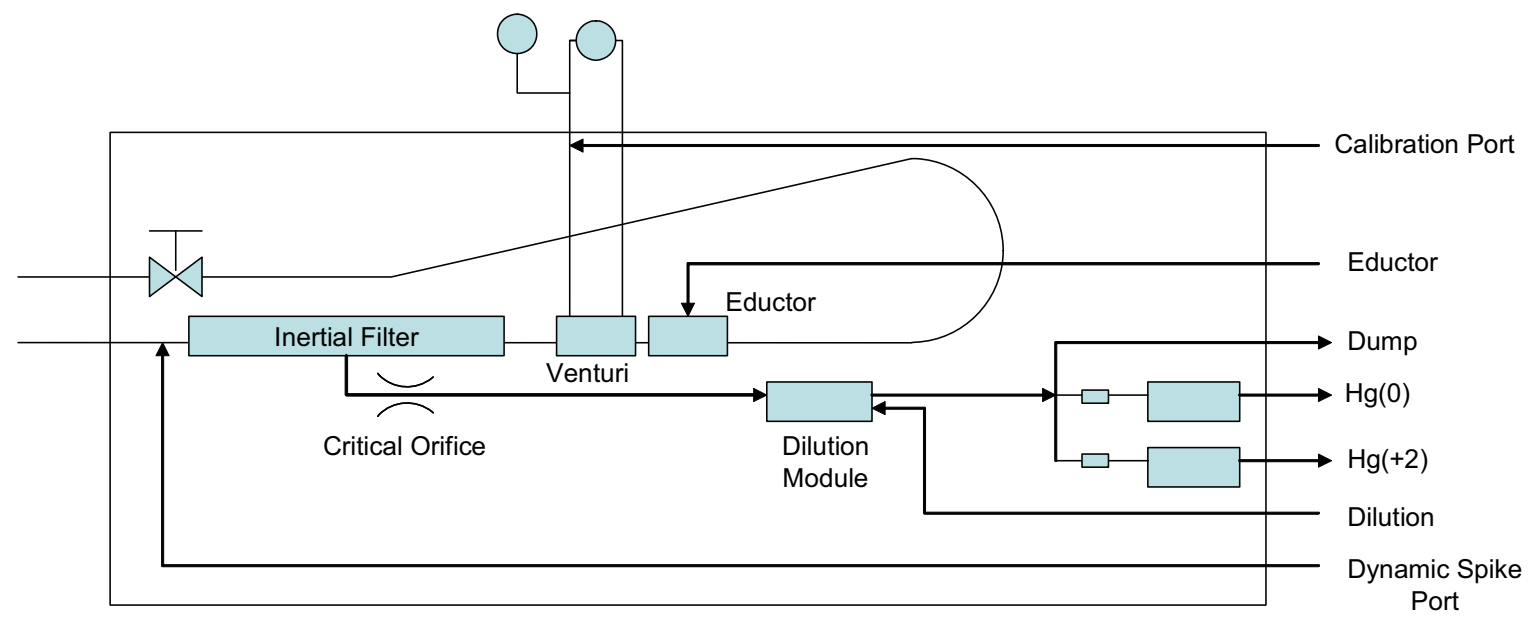

Figure 5: Thermo Model 83i Probe, Filter and Conversion Unit 


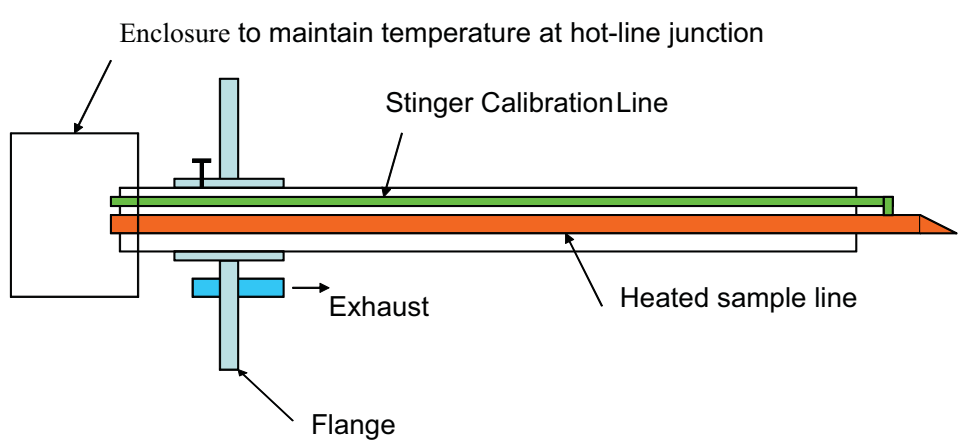

Figure 6: IRM Probe Designed for Traversing

\section{Approach}

\subsection{Plant-Installed CEMS Parameters}

System parameters for the installed Hg-CEMS are presented in Table 3. The Maximum Potential Concentration (MPC), Removal Efficiency (RE), and Maximum Expected Concentration (MEC) were determined in order to calculate the Span (S), Range, and appropriate concentration levels. These calculated values are necessary for calibration of the analyzer, and consequently the validation of measured data.

Table 3: Span and Range Value(s)

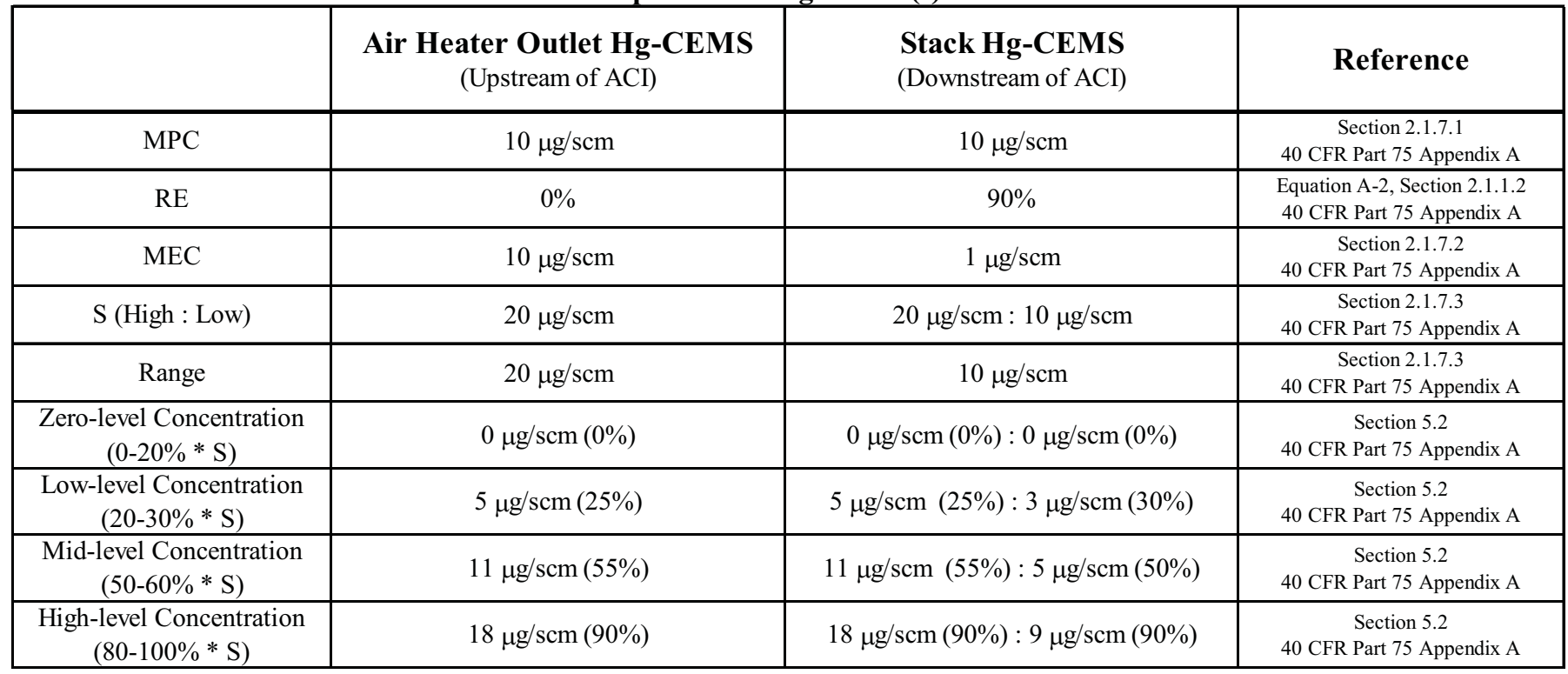

* The high span value on the Outlet CEM is neglected because $\mathrm{Hg}$ concentrations at the stack will never exceed 2.0 $\mu \mathrm{g} / \mathrm{scm}$ by design of emissions control. 


\subsection{Relative Accuracy Test Audit (RATA) \& Bias Test \\ 2.2.1 Instrumental Analyzer Configuration \\ 2.2.1.1 Calibration Span \& Gas Concentrations}

To the extent practicable the measured emissions are to be between 10 and $100 \%$ of the selected calibration span. It is recommended that the calibration span be at least twice the native concentration to accommodate the dynamic spiking procedure (Section 3.4, [Method 30A]). The selected value of the calibration span is limited by the capabilities of the calibrator. The parameters used for calibration and data validation tests of the instrumental analyzer are outlined in Table 4.

Table 4: IRM Calibration Span \& Gas Concentrations

\begin{tabular}{|c|c|c|}
\hline & Native Concentration $=$ & $2 \mu \mathrm{g} / \mathrm{scm}$ \\
\hline & Calibration Span $(\mathrm{CS})=$ & $10 \mu \mathrm{g} / \mathrm{scm}$ \\
\hline $\begin{array}{c}\text { Gas } \\
\text { Concentration }\end{array}$ & Allowable Range & Hg Concentration \\
\hline Zero-level & Non-detectable & $0 \mu \mathrm{g} / \mathrm{scm}(0 \%)$ \\
\hline Low-level & $10-30 \% \mathrm{CS}$ & $3 \mu \mathrm{g} / \mathrm{scm}(30 \%)$ \\
\hline Mid-level & $40-60 \% \mathrm{CS}$ & $5 \mu \mathrm{g} / \mathrm{scm}(50 \%)$ \\
\hline High-level & $100 \% \mathrm{CS}$ & $10 \mu \mathrm{g} / \mathrm{scm}(100 \%)$ \\
\hline
\end{tabular}

\subsubsection{Sample Point Selection}

When Method 30A is used for relative accuracy testing of a Hg-CEMS, the sampling site selection and sampling point layout procedures are referenced in the appropriate performance specification or applicable regulation described in Performance Specification 2, Section 8.1.3 [40 CFR Part 75 Appendix B] or Section 6.5.6 [40 CFR Part 75 Appendix A]. Alternatively, Section 8.1.3.4 [Method 30A] states that stratification testing need not be performed at a test location where it would otherwise be required to justify using fewer sample points or different sample points, if the $\mathrm{Hg}$ concentration in the stack gas is expected to be $3 \mu \mathrm{g} / \mathrm{m}^{3}$ or less at the time of a $\mathrm{Hg}$ monitoring system RATA or an Hg emissions test. Documentation of at least one hour of $\mathrm{Hg}$ concentration data is required just prior to the RATA or emissions test. If a particular test location qualifies for the stratification testing exemption, sampling shall be performed at three points, as described in Section 8.1.3.2.2 [Method 30A]. Since the stack diameter (or equivalent diameter, for a rectangular stack or duct) is greater than $7.8 \mathrm{ft}$, the three Stack sampling points were therefore located at 4.4, 14.6, and 29.6 percent of the stack diameter (109 3/16") from the stack or duct wall (see Figure 2). Since only modified Method 30A procedures were performed at the Air Heater Outlet, a single sampling point depicted in Figure 3 was selected at 78.74" from the duct wall. 


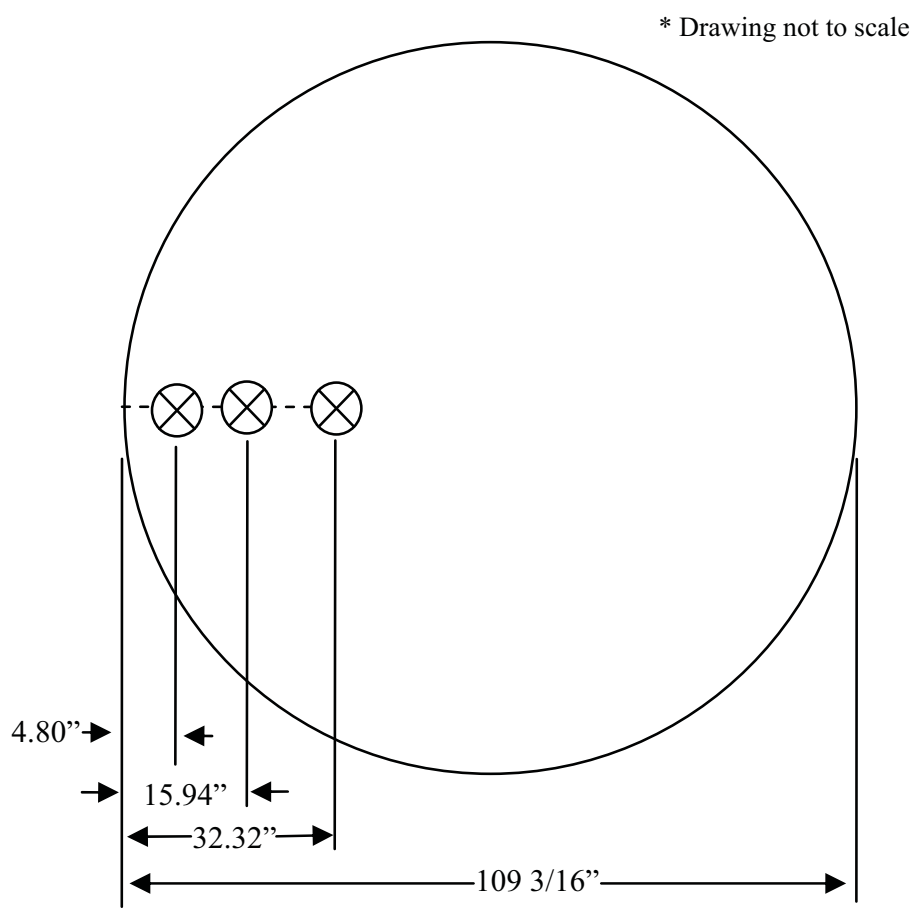

Figure 7: Stack Sampling Points

* Drawing not to scale

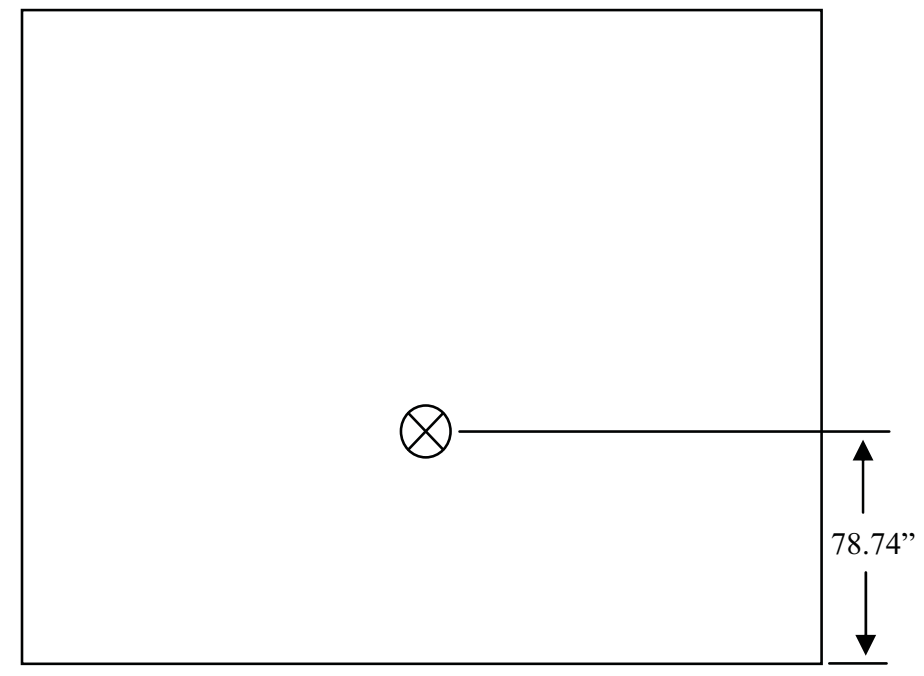

Figure 8: Air Heater Outlet Sampling Point

\subsubsection{Initial Measurement System Performance Tests}

Initial measurement system performance tests need to be conducted on the instrumental analyzer prior to starting the nine (9) required test runs. The performance requirements of this method must be met to validate data, and are described below:

(1) Interference Testing (Optional)

(2) Calibration Gas Verification

(3) Measurement System Preparation

(4) 3-Point System Calibration Error Test

(5) System Integrity Check 
(6) Measurement System Response Time Test

(7) Dynamic Spiking (deferred until January 1, 2009)

\subsubsection{Interference Test (Optional)}

It is recommended that this test be conducted prior to the initial use of the measurement system in the field to verify that the candidate test instrument is free from inherent biases or interferences resulting from common combustion emission constituents. The interference test procedure is found in Section 8.6 [Method 30A]. This procedure was not performed during this test period.

\subsubsection{Calibration Gas Verification}

EPA Traceability Protocol for Qualification and Certification of Elemental Mercury Gas Generators and EPA Traceability Protocol for Qualification and Certification of Oxidized Mercury Gas Generators expected publication date December 2008, see www.epa.gov/ttn/emc.

\subsubsection{Measurement System Preparation}

The measurement system was assembled, prepared, and preconditioned according to standard operating procedure.

\subsubsection{System Calibration Error Test}

Using elemental mercury $\left(\mathrm{Hg}^{0}\right)$, a 3-point system calibration error test was conducted prior to the first test run. The low-, mid-, and high-level calibration gases were introduced in any order into the instrumental analyzer, and, after each gas injection, a stable response was obtained and recorded.

Acceptance criteria:

i. $\mathrm{SCE} \leq \pm 5 \%$, where

$$
S C E=\frac{C_{s}-C_{v}}{C S} \times 100
$$

SCE - System Calibration Error [\%].

$\mathrm{C}_{\mathrm{s}}$ - Measured concentration of the calibration gas $[\mu \mathrm{g} / \mathrm{scm}]$.

$\mathrm{C}_{\mathrm{v}}$ - Certified concentration of the calibration gas $[\mu \mathrm{g} / \mathrm{scm}]$.

CS - Calibration Span $[\mu \mathrm{g} / \mathrm{scm}]$.

ii. Alternatively, $\left|\mathrm{C}_{\mathrm{s}}-\mathrm{C}_{\mathrm{v}}\right| \leq 0.5 \mu \mathrm{g} / \mathrm{scm}$

\subsubsection{System Integrity Check}

Using oxidized mercury $\left(\mathrm{Hg}^{2+}\right)$, a two-point system integrity check was conducted as required before the first test run. The zero- and mid-level calibration gases were introduced into the instrumental analyzer, and, after each gas injection, a stable response was obtained and recorded.

Acceptance criteria:

i. $\mathrm{SCE} \leq \pm 5 \%$, where

$$
S C E=\frac{C_{s}-C_{v}}{C S} \times 100
$$


SCE - System Calibration Error [\%].

$\mathrm{C}_{\mathrm{s}}$ - Measured concentration of the calibration gas $[\mu \mathrm{g} / \mathrm{scm}]$.

$\mathrm{C}_{\mathrm{v}}$ - Certified concentration of the calibration gas $[\mu \mathrm{g} / \mathrm{scm}]$.

CS - Calibration Span $[\mu \mathrm{g} / \mathrm{scm}]$.

ii. Alternatively, $\left|\mathrm{C}_{\mathrm{s}}-\mathrm{C}_{\mathrm{v}}\right| \leq 0.5 \mu \mathrm{g} / \mathrm{scm}$

\subsubsection{Measurement System Response Time}

The measurement system response time provides the minimum sampling time for each sampling point. It is equal to the time that is required for the measured $\mathrm{Hg}$ concentration to increase from the stable low-level calibration gas response to a value within 5 percent of the stable high-level calibration gas response obtained during the system calibration error test in Section 8.2.4 [Method 30A], assuming the high-level calibration gas was injected immediately after the low-level.

\subsubsection{Dynamic Spiking Test (deferred until January 1, 2009)}

\subsubsection{Test Runs}

After the instrumental analyzer successfully met the acceptance criteria of the Initial System Performance Tests, the minimum nine (9) test runs of the RATA were performed. One test run constitutes sampling once at each of the successive sample points. The run validations listed below must be performed while sampling.

\subsubsection{System Integrity Checks}

Before and after each test run, a two-point system integrity check using the same procedure as the initial system integrity check must be conducted. No adjustments may be made to the measurement system during the checks, other than to maintain the target calibration gas flow rate and the proper dilution ratio. This check may be skipped between each run provided that a system integrity check performed on completion of runs passes the allowed specification. If a post-run integrity check is failed, all test runs since the last passed system integrity check are invalid. If a check is failed, corrective action must be taken and another 3-point $\mathrm{Hg}^{0}$ System Calibration Error Test passed followed by another System Integrity Check before conducting any additional test runs.

\subsubsection{Drift Check}

Using the data from the successful pre- and post-run system integrity checks, calculate the zero and upscale drift. Exceeding the specification does not invalidate the run, but corrective action must be taken and a new 3-point $\mathrm{Hg}^{0}$ System Calibration Error Test and a System Integrity Check must be passed before any more runs are made.

Acceptance criteria:

i. $\mathrm{D} \leq 3.0 \%$, where

$$
\begin{aligned}
D= & \left|S C E_{f}-S C E_{i}\right| \\
& \mathrm{D}-\text { Drift [\%]. } \\
& \mathrm{SCE}_{\mathrm{i}, \mathrm{f}}-\text { System Calibration Error, pre/post-run [\%]. }
\end{aligned}
$$


ii. Alternatively, $\left|\mathrm{C}_{\mathrm{s}, \mathrm{f}}-\mathrm{C}_{\mathrm{s}, \mathrm{i}}\right| \leq 0.3 \mu \mathrm{g} / \mathrm{scm}$

$\mathrm{C}_{\mathrm{s}, \mathrm{if}}-$ Measured concentration of the calibration gas, pre/post-run $[\mu \mathrm{g} / \mathrm{scm}]$.

\subsubsection{Sampling}

For each sample point determined from Section 8.1, Method 30A, the system must be allowed to flush and equilibrate for at least two times the measurement system response time before recording any data. The minimum sampling time at each sampling point must be at least two times the system response time, but not less than 10 minutes.

\subsubsection{Relative Accuracy Calculation}

Acceptance criteria:

i. $\mathrm{RA} \leq 20.0 \%$, where

Arithmetic Mean:

$d=R M-C E M$

$\mathrm{d}$ - The difference between a reference method value and the corresponding continuous emission monitoring system value at a given point in time.

RM - Reference method value.

CEM - Continuous emission monitoring system value.

$$
\begin{aligned}
& \bar{d}= \frac{\sum_{i=1}^{n} d_{i}}{n} \\
& \mathrm{n}-\text { Number of data points. }
\end{aligned}
$$

Standard Deviation:

$$
S_{d}=\sqrt{\frac{\sum_{i=1}^{n} d_{i}^{2}-\left[\frac{\left(\sum_{i=1}^{n} d_{i}\right)^{2}}{n}\right]}{n-1} \mathrm{~S}_{\mathrm{d}}-\text { Standard deviation. }}
$$

Confidence Coefficient:

$$
\begin{aligned}
c c= & t_{0.025} \times \frac{S_{d}}{\sqrt{n}} \\
& c c-\text { Confidence coefficient. } \\
& \mathrm{t}_{0.025}-\mathrm{t} \text {-value. }
\end{aligned}
$$

Relative Accuracy:

$$
R A=\frac{|\partial|+|c c|}{\overline{R M}} \times 100
$$


RA - Relative accuracy of a data set.

$\mathrm{RM}$ - Arithmetic mean of the reference method values.

$\partial$ - Mean difference between the reference method values and the corresponding continuous emission monitoring system values.

ii. Alternatively, if $\overline{R M} \leq 5.0 \mu \mathrm{g} / \mathrm{scm}, \overline{C E M}-\overline{R M} \leq \pm 1.0 \mu \mathrm{g} / \mathrm{scm}$

\subsubsection{Bias Determination \& Adjustment Factor Calculation}

If the following criterion is met for the relative accuracy test audit data set being tested, the monitoring system has passed the bias test:

Acceptance criterion:

$$
|\bar{d}| \leq|c c|
$$

If the monitor or monitoring system fails to meet the bias test requirement, adjustment of the value obtained from the monitor is necessary using the following equation:

$$
\begin{aligned}
& C E M_{i}^{\text {Adjusted }}=C E M_{i}^{\text {Monitor }} \times B A F \\
& C E M_{i}^{\text {Adjusted }}-\text { Data value, adjusted for bias, at time i. } \\
& C E M_{i}^{\text {Monitor }} \text { - Data (measurement) provided by monitor at time i. }
\end{aligned}
$$

BAF - Bias Adjustment Factor.

Bias Adjustment Factor:

$$
B A F=1+\frac{\bar{d}}{\overline{C E M}}
$$

If the monitoring system meets the normal or the alternative relative accuracy specification in section 3.3.8 of 40 CFR Part 75 Appendix A but fails the bias test, the owner or operator may either use the BAF calculated above or may use a default BAF of 1.250 for reporting purposes. Each time a RATA is passed and the appropriate BAF has been determined, the BAF is to be applied prospectively to all monitoring system data, beginning with the first clock hour following the hour in which the RATA was completed. 


\section{Results and Discussion}

A full 9-run, 3-point RATA was successfully performed on the installed CEMS at the Stack location (see Table 5). Relative Accuracy was calculated to be $30.64 \%$ ( $\leq 20 \%$ is passing), however the difference between the average installed CEMS response and Reference Method response was $0.12 \mu \mathrm{g} / \mathrm{scm}(\leq 1.0 \mu \mathrm{g} / \mathrm{scm}$ is passing alternative criteria for average Reference Method responses $\leq 5.0 \mu \mathrm{g} / \mathrm{scm})$.

Table 5: RATA \& Bias Test - Stack Hg-CEMS

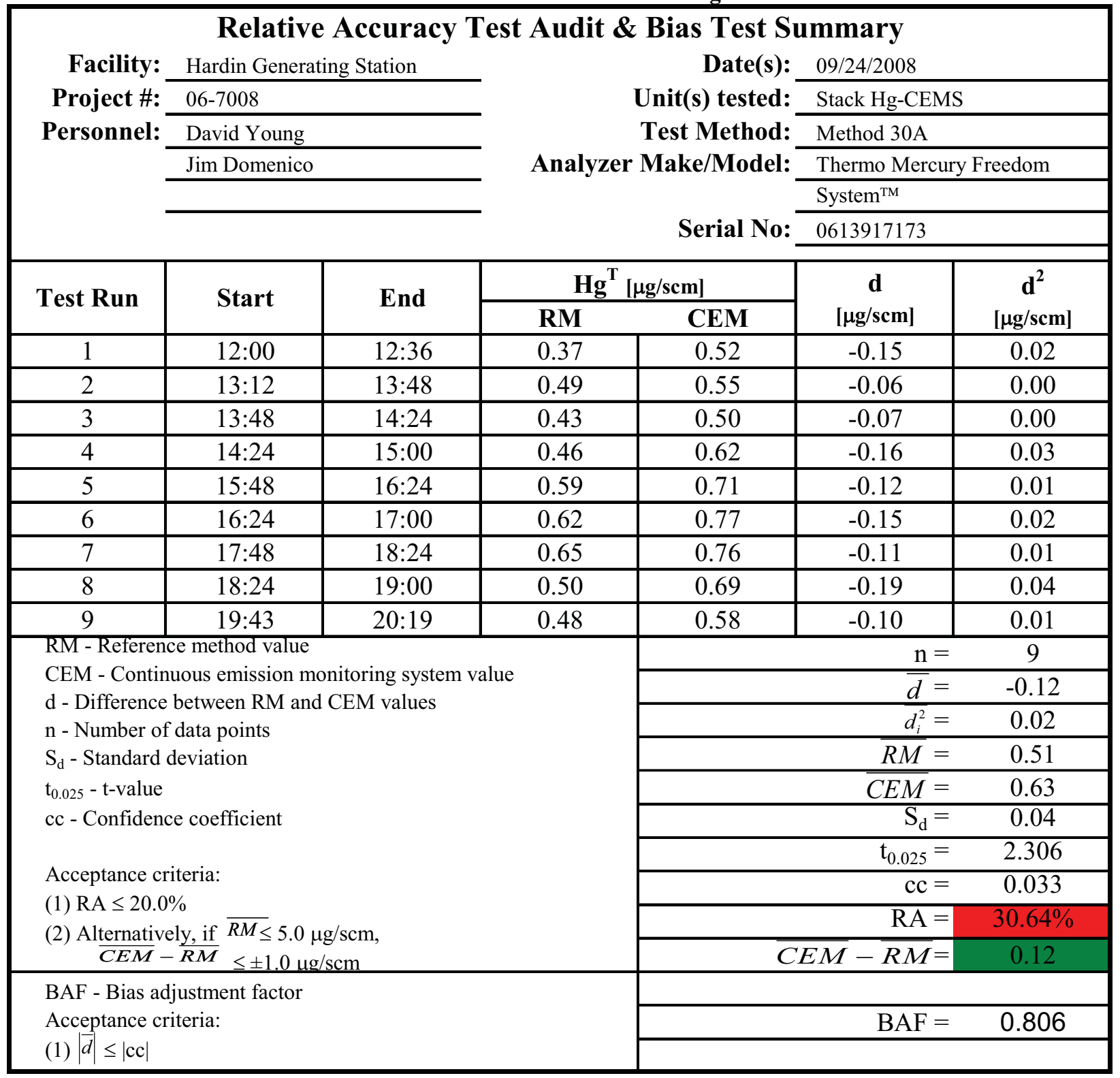

A Test Synopsis for the Stack Hg-CEMS RATA is included in Table 6. All Initial System Performance Test and Run Validation performance specifications were met. 
Table 6: Test Synopsis (Stack)

\begin{tabular}{|c|c|c|c|c|c|c|c|c|c|c|}
\hline \multicolumn{11}{|c|}{ Test Synopsis } \\
\hline \multirow{3}{*}{$\begin{array}{r}\text { Facility: } \\
\text { Project \#: } \\
\text { Personnel: }\end{array}$} & \multicolumn{3}{|c|}{ Hardin Generating Station } & & & & \multirow{3}{*}{\multicolumn{2}{|c|}{$\begin{array}{r}\text { Date(s): } \\
\text { Unit(s) tested: } \\
\text { Test Runs: }\end{array}$}} & \multicolumn{2}{|c|}{$09 / 24 / 2008$} \\
\hline & \multicolumn{3}{|c|}{$06-7008$} & & & & & & \multicolumn{2}{|c|}{ Stack Hg-CEMS } \\
\hline & \multicolumn{3}{|c|}{ David Young } & & & & & & \multicolumn{2}{|c|}{$1-9$} \\
\hline \multirow[b]{3}{*}{$\mathbf{C S}=$} & \multicolumn{3}{|c|}{ Jim Domenico } & & & & \multicolumn{2}{|c|}{ Analyzer Make/Model } & \multirow{2}{*}{\multicolumn{2}{|c|}{$\begin{array}{l}\text { Thermo Mercury Freedom } \\
\text { System }^{\mathrm{TM}}\end{array}$}} \\
\hline & & & & & & & \multirow{2}{*}{\multicolumn{2}{|c|}{ Serial No: }} & & \\
\hline & \multicolumn{3}{|r|}{$\mu \mathrm{g} / \mathrm{scm}$} & & & & & & \multicolumn{2}{|c|}{0613917173} \\
\hline Action & $\mathrm{Ti}$ & me & Calibration & $\mathrm{C}_{\mathrm{v}}$ & $\mathrm{C}_{\mathrm{s}}$ & $\mathrm{C}_{\mathrm{CEM}}$ & SCE & $\left|\mathbf{C}_{\mathrm{s}}-\mathbf{C}_{\mathrm{v}}\right|$ & $\mathbf{D}$ & $\left|\mathbf{C}_{\mathrm{s}, \mathrm{pre}}-\mathbf{C}_{\mathrm{s}, \mathrm{post}}\right|$ \\
\hline Sample Point & Start & End & Gas Level & {$[\mu \mathrm{g} / \mathrm{scm}]$} & {$[\mu \mathrm{g} / \mathrm{scm}]$} & {$[\mu \mathrm{g} / \mathrm{scm}]$} & {$[\%]$} & {$[\mu \mathrm{g} / \mathrm{scm}]$} & {$[\%]$} & {$[\mu \mathrm{g} / \mathrm{scm}]$} \\
\hline Sys Cal Error & $10: 39$ & $10: 52$ & Low & 3.00 & 2.56 & & -4.36 & 0.44 & & \\
\hline Test & $10: 52$ & $11: 02$ & High & 10.00 & 9.73 & & -2.66 & 0.27 & & \\
\hline & $11: 02$ & $11: 10$ & Mid & 5.00 & 5.19 & & 1.87 & 0.19 & & \\
\hline Meas Sys Resp & 10.52 & $11 \cdot 02$ & Low & 3.00 & 2.56 & & ve $R$ esn & $:=5 \mathrm{~min}$ & & \\
\hline Time Test & $10: 52$ & $11: 02$ & High & 10.00 & 9.73 & Measurem & ys Kesp & $=5 \mathrm{~min}$. & & \\
\hline Sys Integrity & $11: 12$ & $11: 25$ & Zero & 0.00 & 0.07 & & 0.69 & 0.07 & & \\
\hline Test & $11: 25$ & $11: 38$ & Mid & 5.00 & 5.15 & & 1.53 & 0.15 & & \\
\hline & $12: 00$ & $12: 12$ & & & 0.37 & 0.52 & & & & \\
\hline Run 1 & $12: 12$ & $12: 24$ & & & 0.37 & 0.52 & & & & \\
\hline $3-2-1$ & $12: 24$ & $12: 36$ & & & 0.38 & 0.53 & & & & \\
\hline Sys Integrity & $12: 36$ & $12: 48$ & Zero & 0.00 & -0.07 & & -0.73 & 0.07 & 1.42 & 0.14 \\
\hline Test & $12: 48$ & 13:00 & Mid & 5.00 & 4.94 & & -0.61 & 0.06 & 2.14 & 0.21 \\
\hline & $13: 12$ & $13: 24$ & & & 0.49 & 0.54 & & & & \\
\hline Run 2 & $13: 24$ & $13: 36$ & & & 0.54 & 0.54 & & & & \\
\hline $1-2-3$ & $13: 36$ & $13: 48$ & & & 0.45 & 0.57 & & & & \\
\hline & $13: 48$ & $14: 00$ & & & 0.40 & 0.54 & & & & \\
\hline Run 3 & $14: 00$ & $14: 12$ & & & 0.46 & 0.41 & & & & \\
\hline $3-2-1$ & $14: 12$ & $14: 24$ & & & 0.44 & 0.55 & & & & \\
\hline & $14: 24$ & $14: 36$ & & & 0.47 & 0.62 & & & & \\
\hline Run 4 & $14: 36$ & $14: 48$ & & & 0.45 & 0.64 & & & & \\
\hline $1-2-3$ & $14: 48$ & $15: 00$ & & & 0.45 & 0.60 & & & & \\
\hline Sys Integrity & 15:00 & $15: 12$ & Zero & 0.00 & -0.08 & & -0.82 & 0.08 & 0.09 & 0.01 \\
\hline Test & $15: 12$ & $15: 32$ & Mid & 5.00 & 4.74 & & -2.61 & 0.26 & 2.00 & 0.20 \\
\hline & $15: 48$ & $16: 00$ & & & 0.64 & 0.73 & & & & \\
\hline Run 5 & $16: 00$ & $16: 12$ & & & 0.58 & 0.70 & & & & \\
\hline $3-2-1$ & $16: 12$ & $16: 24$ & & & 0.55 & 0.69 & & & & \\
\hline & $16: 24$ & $16: 36$ & & & 0.58 & 0.73 & & & & \\
\hline Run 6 & $16: 36$ & $16: 48$ & & & 0.59 & 0.79 & & & & \\
\hline $1-2-3$ & $16: 48$ & $17: 00$ & & & 0.68 & 0.78 & & & & \\
\hline Sys Integrity & $17: 00$ & $17: 13$ & Zero & 0.00 & -0.12 & & -1.24 & 0.12 & 0.41 & 0.04 \\
\hline Test & $17: 13$ & $17: 28$ & Mid & 5.00 & 4.61 & & -3.95 & 0.39 & 1.34 & 0.13 \\
\hline$P=7$ & $17: 48$ & $18: 00$ & & & 0.68 & 0.77 & & & & \\
\hline Run 7 & $18: 00$ & $18: 12$ & & & 0.69 & 0.77 & & & & \\
\hline $3-2-1$ & $18: 12$ & $18: 24$ & & & 0.57 & 0.73 & & & & \\
\hline & $18: 24$ & $18: 36$ & & & 0.53 & 0.71 & & & & \\
\hline Run 8 & $18: 36$ & $18: 48$ & & & 0.49 & 0.69 & & & & \\
\hline $1-2-3$ & $18: 48$ & $19: 00$ & & & 0.48 & 0.68 & & & & \\
\hline Sys Integrity & $19: 00$ & $19: 15$ & Zero & 0.00 & -0.13 & & -1.34 & 0.13 & 0.10 & 0.01 \\
\hline Test & $19: 15$ & $19: 35$ & Mid & 5.00 & 4.56 & & -4.38 & 0.44 & 0.43 & 0.04 \\
\hline & $19: 43$ & $19: 55$ & & & 0.53 & 0.64 & & & & \\
\hline Run 9 & $19: 55$ & $20: 07$ & & & 0.45 & 0.51 & & & & \\
\hline $3-2-1$ & $20: 07$ & $20: 19$ & & & 0.45 & 0.59 & & & & \\
\hline Sys Integrity & $20: 19$ & $20: 34$ & Zero & 0.00 & -0.16 & & -1.61 & 0.16 & 0.38 & 0.04 \\
\hline Test & $20: 34$ & $20: 49$ & Mid & 5.00 & 4.59 & & -4.15 & 0.41 & 0.20 & 0.02 \\
\hline $\begin{array}{l}\text { SCE - Syst } \\
C_{\mathrm{V}} \text { - Certif } \\
\mathrm{C}_{\mathrm{s}} \text { - Measu } \\
\text { CS - Calib }\end{array}$ & $\begin{array}{l}\text { em calib } \\
\text { ed conc } \\
\text { ed conc } \\
\text { ation sp }\end{array}$ & $\begin{array}{l}\text { ration e } \\
\text { entratiol } \\
\text { entratio } \\
\text { an }\end{array}$ & $\begin{array}{l}\text { rror } \\
\text { of calibration } \\
n \text { of calibratio }\end{array}$ & & $\begin{array}{l}\text { D - Drif } \\
C_{s, p r e}-P \\
C_{s, p o s t}-I\end{array}$ & $\begin{array}{l}\text { un measure } \\
\text {-run measu }\end{array}$ & $\begin{array}{l}\text { centraio } \\
\text { ncentrai }\end{array}$ & alibration gas & & \\
\hline $\begin{array}{l}\text { Acceptanc } \\
\text { (1) SCE } \leq \\
\text { (2) Alterna }\end{array}$ & $\begin{array}{l}\text { criteria } \\
-5.0 \% \\
\text { ively, } \mid C\end{array}$ & $\mathrm{~s}_{\mathrm{s}}-\mathrm{C}_{\mathrm{v}} \mid \leq$ & $0.5 \mu \mathrm{g} / \mathrm{scm}$ & & $\begin{array}{l}\text { Accepta } \\
\text { (1) D } \leq \\
\text { (2) Alter }\end{array}$ & $\begin{array}{l}\text { criteria: } \\
\text { vely, } \mid \mathrm{C}_{\mathrm{s}} \text {, pos }\end{array}$ & s, pre-runl & $\mu \mathrm{g} / \mathrm{scm}$ & & \\
\hline
\end{tabular}


A modified 9-run, single-point RATA was successfully performed on the installed CEMS at the Air Heater Outlet location. Relative Accuracy was calculated to be $18.57 \%$ (20\% is passing). It was not in the original scope of the Test Plan to perform a full RATA at this location, so the test was modified to be performed at a single sample point. This particular location lacked an installed chlorine calibration gas cylinder required to properly perform System Integrity Tests on the instrumental analyzer, so elemental mercury standards were used in lieu of oxidized mercury.

Table 7: RATA \& Bias Test - Air Heater Outlet Hg-CEMS

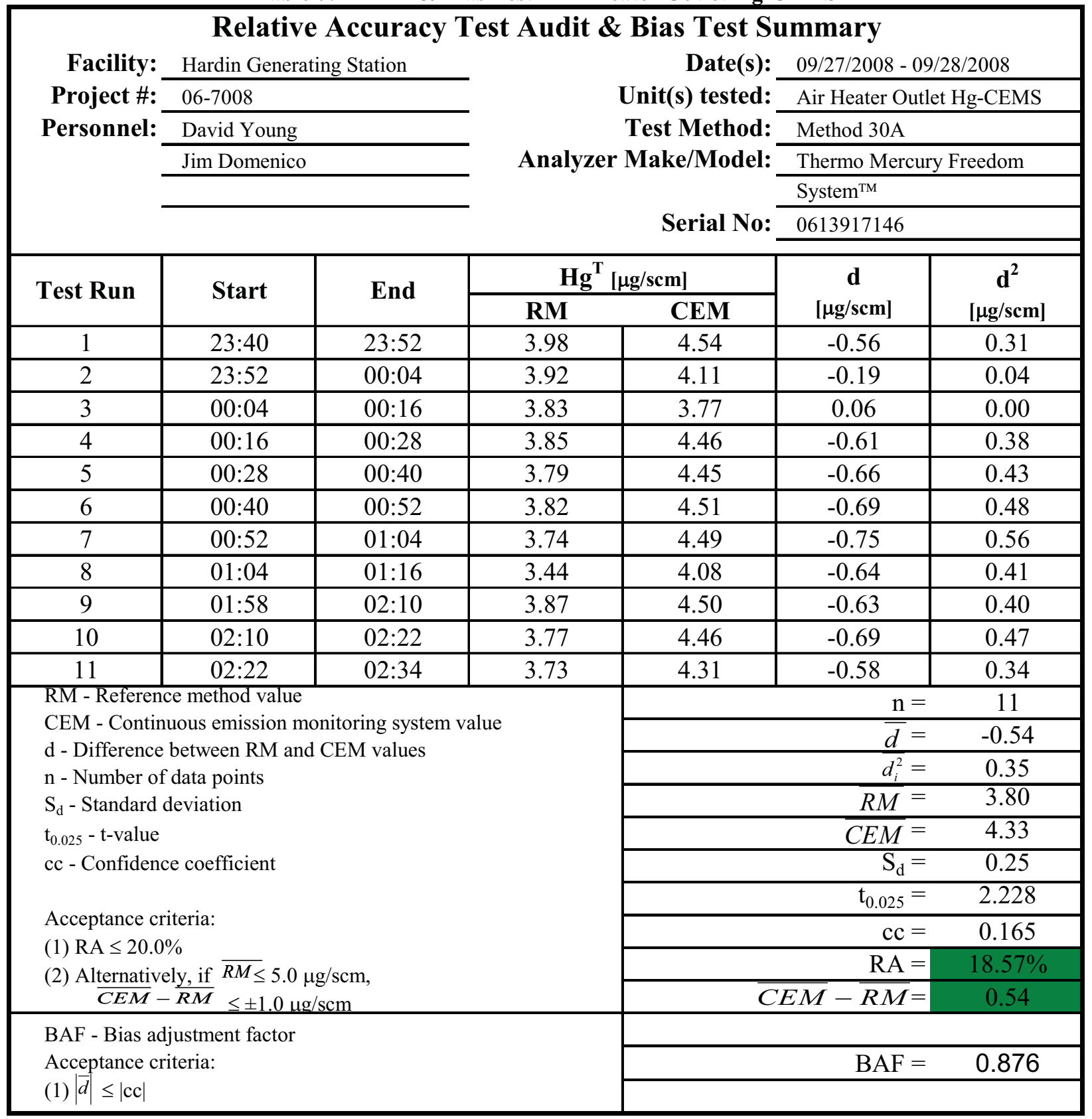

A Test Synopsis for the Air Heater Outlet Hg-CEMS RATA is included in Table 8. All Initial System Performance Test and Run Validation performance specifications were met. 
Table 8: Test Synopsis (Air Heater Outlet)

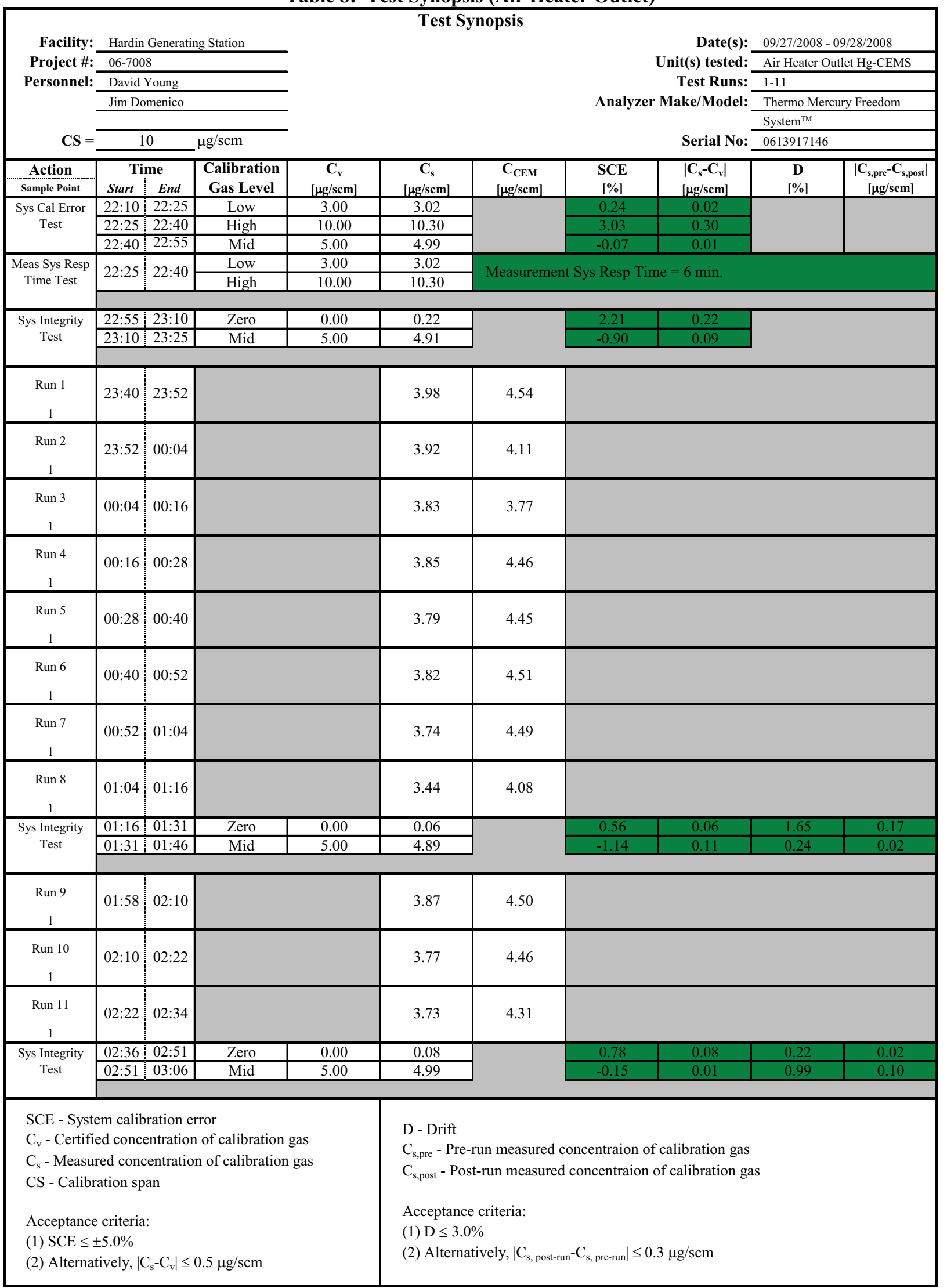


Bias tests on both monitoring systems failed the acceptance criterion, and bias adjustment factors were calculated but not implemented. In order to determine bias, the absolute value of the average difference between CEMS and RM values, $|\bar{d}|$, must be less than or equal to the confidence coefficient, cc, of the data. For the Stack Hg-CEMS RATA, $|\bar{d}|$ was determined to be 0.12 and cc was 0.033 . For the Air Heater Outlet Hg-CEMS RATA, $|\bar{d}|$ was determined to be 0.54 and cc was 0.165 . Bias Adjustment Factors were calculated but were not implemented into the installed CEMS. Both of these systems are subject to the scrutiny of a well-developed Quality Assurance/Quality Control (QA/QC) program which includes daily evaluation of potentially necessary correction factors, and, as such, implementation of any correction from this Bias Test has been deemed unnecessary. 


\section{Conclusions}

The Relative Accuracy Test Audits conducted on both the Stack and the Air Heater Outlet HgCEMS passed established performance specifications. Bias was evident between responses of both systems and the instrumental analyzer; however correction factors were not implemented because this would interfere with the daily CEMS QA/QC program.

All Initial System Performance Tests required for validation of the instrumental analyzer passed performance criteria at both locations prior to commencing each first test run. Run validations were performed as described in section 2.2.3 of this report.

A duplicate of the Summary of Test Results from Table 1 is presented below.

Summary of Test Results (From Table 1)

\begin{tabular}{|c|c|c|}
\hline & $\begin{array}{c}\text { Stack } \\
\text { Hg-CEMS } \\
\text { (downstream of ACI) }\end{array}$ & $\begin{array}{c}\text { Air Heater Outlet } \\
\text { Hg-CEMS } \\
\text { (upstream of ACI) }\end{array}$ \\
\hline Relative Accuracy Test Audit (RATA) & PASS & PASS \\
\hline Interference Check (Optional) & - & - \\
\hline 3-Point System Calibration Error Test & PASS & PASS \\
\hline System Integrity Check & PASS & PASS \\
\hline Measurement System Response & PASS & PASS \\
\hline Dynamic Spiking Test & Not Performed & Not Performed \\
\hline
\end{tabular}

This was the second of three in a series of tests to be performed at Rocky Mountain Power's Hardin Generating Station, Hardin, MT during the Long-term Test Phase of this project as specified in the test plan. The primary goal of these tests was to demonstrate that the installed $\mathrm{Hg}$-CEMS will comply with future established directives, as well as to provide feedback of the recently approved EPA Method 30A reference method. 


\section{Appendix}

5.1 Initial Measurement System Response Tests

Results from the instrumental analyzer's pre-certification tests are presented below in Tables 9 through 14. 
Table 9: IRM System Calibration Error Test (Stack)

\section{System Calibration Error Test}

Facility: Hardin Generating Station

Project \#: 06-7008

Personnel: David Young

$\mathbf{C S}=\frac{\frac{\text { Jim Domenico }}{10} \mu \mathrm{g} / \mathrm{scm}}{10}$

Date(s): $\quad 09 / 24 / 2008$

Unit(s) tested: Stack Hg-CEMS

Test Runs: N/A

Analyzer Make/Model: Thermo Mercury Freedom

Serial No: $\frac{\text { System }^{\mathrm{TM}}}{0613917173}$

\begin{tabular}{|c|c|c|c|c|c|c|}
\hline \multicolumn{2}{|c|}{$\begin{array}{c}\text { Time } \\
\text { Start }\end{array}$} & $\begin{array}{c}\text { Calibration } \\
\text { Gas Level }\end{array}$ & $\begin{array}{c}\mathbf{C}_{\mathbf{v}} \\
{[\mu \mathbf{g} / \mathbf{s c m}]}\end{array}$ & $\begin{array}{c}\mathbf{C}_{\mathbf{s}} \\
{[\mu \mathbf{g} / \mathbf{s c m}]}\end{array}$ & $\begin{array}{c}\mathbf{S C E} \\
{[\%]}\end{array}$ & $\begin{array}{c}\left|\mathbf{C}_{\mathbf{s}}-\mathbf{C}_{\mathbf{v}}\right| \\
{[\mu \mathbf{g} / \mathbf{s c m}]}\end{array}$ \\
\hline $10: 39$ & $10: 52$ & Low- & 3.00 & 2.56 & -4.36 & 0.44 \\
\hline $10: 52$ & $11: 02$ & High- & 10.00 & 9.73 & -2.66 & 0.27 \\
\hline $11: 02$ & $11: 10$ & Mid- & 5.00 & 5.19 & 1.87 & 0.19 \\
\hline
\end{tabular}

SCE - System calibration error

$\mathrm{C}_{\mathrm{v}}$ - Certified concentration of calibration gas

$\mathrm{C}_{\mathrm{s}}$ - Measured concentration of calibration gas

CS - Calibration span value

Acceptance criteria:

(1) $\mathrm{SCE} \leq \pm 5.0 \%$

(2) Alternatively, $\left|\mathrm{C}_{\mathrm{s}}-\mathrm{C}_{\mathrm{v}}\right| \leq 0.5 \mu \mathrm{g} / \mathrm{scm}$

Table 10: IRM System Calibration Error Test (Air Heater Outlet)

Facility: Hardin Generating Station

Project \#: $06-7008$

Personnel: David Young

$\mathbf{C S}=\frac{\text { Jim Domenico }}{10} \mu \mathrm{g} / \mathrm{scm}$

\section{System Calibration Error Test}

\begin{tabular}{|c|c|c|c|c|c|c|}
\hline \multicolumn{2}{|c|}{$\begin{array}{c}\text { Time } \\
\text { Start }\end{array}$} & $\begin{array}{c}\text { Calibration } \\
\text { Gas Level }\end{array}$ & $\begin{array}{c}\mathbf{C}_{\mathbf{v}} \\
{[\mu \mathbf{g} / \mathbf{s c m}]}\end{array}$ & $\begin{array}{c}\mathbf{C}_{\mathbf{s}} \\
{[\mu \mathbf{g} / \mathbf{s c m}]}\end{array}$ & $\begin{array}{c}\mathbf{S C E} \\
{[\%]}\end{array}$ & $\begin{array}{c}\left|\mathbf{C}_{\mathbf{s}}-\mathbf{C}_{\mathbf{v}}\right| \\
{[\mu \mathbf{g} / \mathbf{s c m}]}\end{array}$ \\
\hline $00: 00$ & $00: 34$ & Low- & 3.00 & 3.02 & 0.24 & 0.02 \\
\hline $00: 00$ & $07: 16$ & High- & 10.00 & 10.30 & 3.03 & 0.30 \\
\hline $00: 00$ & $23: 49$ & Mid- & 5.00 & 4.99 & -0.07 & 0.01 \\
\hline
\end{tabular}

SCE - System calibration error

$\mathrm{C}_{\mathrm{v}}$ - Certified concentration of calibration gas

$\mathrm{C}_{\mathrm{s}}$ - Measured concentration of calibration gas

CS - Calibration span value

Acceptance criteria:

(1) $\mathrm{SCE} \leq \pm 5.0 \%$

(2) Alternatively, $\left|\mathrm{C}_{\mathrm{s}}-\mathrm{C}_{\mathrm{v}}\right| \leq 0.5 \mu \mathrm{g} / \mathrm{scm}$

Unit(s) tested: Air Heater Outlet Hg-CEMS

Test Runs: N/A

Analyzer Make/Model: Thermo Mercury Freedom

$$
\text { System }^{\mathrm{TM}}
$$

Serial No: 0613917146 
Table 11: IRM Measurement System Response Time (Stack)

\begin{tabular}{|c|c|c|c|c|c|c|}
\hline & & asurement & stem Re & nse Time 1 & & \\
\hline Facility: & Hardin Gener: & g Station & & Date(s): & $09 / 24 / 2008$ & \\
\hline Project \#: & $06-7008$ & & & nit(s) tested: & Stack Hg-Cl & \\
\hline Personnel: & David Young & & & Test Runs: & $\mathrm{N} / \mathrm{A}$ & \\
\hline & Jim Domenico & & Analyz & Make/Model: & Thermo Me & y Freedom \\
\hline & & & & & System $^{\mathrm{TM}}$ & \\
\hline $\mathbf{C S}=$ & 10 & $\mathrm{ug} / \mathrm{scm}$ & & Serial No: & 0613917173 & \\
\hline $\begin{array}{c}\text { Calibration } \\
\text { Gas Level }\end{array}$ & $\begin{array}{c}\mathrm{C}_{\mathrm{v}} \\
{[\mu \mathrm{g} / \mathrm{scm}]}\end{array}$ & Start Time & $\begin{array}{c}\mathrm{C}_{\mathrm{s}, \mathrm{i}} \\
{[\mu \mathrm{g} / \mathrm{scm}]}\end{array}$ & End Time & $\begin{array}{c}\mathbf{C}_{\mathbf{s}, \mathbf{f}} \\
{[\mu \mathrm{g} / \mathbf{s c m}]}\end{array}$ & $\begin{array}{c}\text { Response Time } \\
\text { [min.] }\end{array}$ \\
\hline Low-/High- & $3.00 / 10.00$ & $10: 52$ & 2.56 & 11:02 & 9.73 & 05:00 \\
\hline $\begin{array}{l}\mathrm{SCE}-\text { Syste } \\
\mathrm{C}_{\mathrm{v}}-\text { Certifie } \\
\mathrm{C}_{\mathrm{S}}-\text { Measur } \\
\quad \text { i }=\text { initi } \\
\mathrm{CS}-\text { Calibr }\end{array}$ & $\begin{array}{l}\text { n calibration } \\
d \text { concentrati } \\
\text { ed concentrat } \\
1, \mathrm{f}=\text { final }) \\
\text { tion span val }\end{array}$ & $\begin{array}{l}\text { rror } \\
\text { of calibratic } \\
\text { n of calibrati }\end{array}$ & & & & \\
\hline $\begin{array}{l}\text { Acceptance } \\
\text { (1) Respons }\end{array}$ & $\begin{array}{l}\text { criteria: } \\
\text { Time } \leq 15 .\end{array}$ & & & & & \\
\hline
\end{tabular}

Table 12: IRM Measurement System Response Time (Air Heater Outlet)

\section{Measurement System Response Time Test}

Facility: Hardin Generating Station

Date(s): 09/27/2008 - 09/28/2008

Project \#: 06-7008

Personnel: David Young

Unit(s) tested: Air Heater Outlet Hg-CEMS

Test Runs: N/A

$\mathbf{C S}=\frac{\frac{\text { Jim Domenico }}{10 \quad \mu \mathrm{g} / \mathrm{scm}}}{10}$

Analyzer Make/Model: Thermo Mercury Freedom

\begin{tabular}{|c|c|c|c|c|c|c|}
\hline $\begin{array}{c}\text { Calibration } \\
\text { Gas Level }\end{array}$ & $\begin{array}{c}\mathbf{C}_{\mathbf{v}} \\
{[\mu \mathbf{g} / \mathbf{s c m}]}\end{array}$ & Start Time & $\begin{array}{c}\mathbf{C}_{\mathbf{s}, \mathbf{i}} \\
{[\mu \mathbf{g} / \mathbf{s c m}]}\end{array}$ & End Time & $\begin{array}{c}\mathbf{C}_{\mathbf{s}, \mathbf{f}} \\
{[\mu \mathbf{g} / \mathbf{s c m}]}\end{array}$ & $\begin{array}{c}\text { Response Time } \\
{[\mathbf{m i n} .]}\end{array}$ \\
\hline Low-High- & $3.00 / 10.00$ & $22: 25$ & 3.02 & $22: 40$ & 10.30 & $06: 00$ \\
\hline
\end{tabular}

SCE - System calibration error

$\mathrm{C}_{\mathrm{v}}$ - Certified concentration of calibration gas

$\mathrm{C}_{\mathrm{s}}$ - Measured concentration of calibration gas

( $\mathrm{i}=$ initial, $\mathrm{f}=$ final)

CS - Calibration span value

Acceptance criteria:

(1) Response Time $\leq 15.0 \mathrm{~min}$. 
Table 13: IRM System Integrity Check (Stack)

\section{System Integrity Check}

Facility: Hardin Generating Station

Project \#: 06-7008

Personnel: David Young

$\mathbf{C S}=\frac{\frac{\text { Jim Domenico }}{10} \mu \mathrm{gg} / \mathrm{scm}}{\text { Calibration }}$

Date(s): $\quad 09 / 24 / 2008$

Unit(s) tested: Stack Hg-CEMS

Test Runs: N/A

Analyzer Make/Model: Thermo Mercury Freedom System $^{\mathrm{TM}}$
0613917173

\begin{tabular}{|c|c|c|c|c|}
\hline $\begin{array}{c}\text { Calibration } \\
\text { Gas Level }\end{array}$ & $\begin{array}{c}\mathbf{C}_{\mathbf{v}} \\
{[\mu \mathrm{g} / \mathbf{s c m}]}\end{array}$ & $\begin{array}{c}\mathbf{C}_{\mathbf{s}} \\
{[\mu \mathrm{g} / \mathbf{s c m}]}\end{array}$ & $\begin{array}{c}\mathbf{S C E} \\
{[\mathbf{\%}]}\end{array}$ & $\begin{array}{c}\left|\mathbf{C}_{\mathbf{s}}-\mathbf{C}_{\mathbf{v}}\right| \\
{[\mu \mathrm{g} / \mathbf{s c m}]}\end{array}$ \\
\hline Zero- & 0.00 & 0.07 & 0.69 & 0.07 \\
\hline Mid- & 5.00 & 5.15 & 1.53 & 0.15 \\
\hline
\end{tabular}

SCE - System calibration error

$\mathrm{C}_{\mathrm{v}}$ - Certified concentration of calibration gas

$\mathrm{C}_{\mathrm{s}}$ - Measured concentration of calibration gas

CS - Calibration span

Acceptance criteria:

(1) $\mathrm{SCE} \leq \pm 5.0 \%$

(2) Alternatively, $\left|\mathrm{C}_{\mathrm{s}}-\mathrm{C}_{\mathrm{v}}\right| \leq 0.5 \mu \mathrm{g} / \mathrm{scm}$

Table 14: IRM System Integrity Check (Air Heater Outlet)

\section{System Integrity Check}

Facility: Hardin Generating Station

Project \#: $06-7008$

Personnel: David Young

$$
\mathbf{C S}=\frac{\frac{\text { Jim Domenico }}{10}}{\mathrm{~T}}
$$

Date(s): 09/27/2008 - 09/28/2008

Unit(s) tested: Air Heater Outlet Hg-CEMS

Test Runs: N/A

Analyzer Make/Model: Thermo Mercury Freedom System $^{\mathrm{TM}}$

Serial No: 0613917146

\begin{tabular}{|c|c|c|c|c|}
\hline $\begin{array}{c}\text { Calibration } \\
\text { Gas Level }\end{array}$ & $\begin{array}{c}\mathbf{C}_{\mathbf{v}} \\
{[\mu \mathrm{g} / \mathbf{s c m}]}\end{array}$ & $\begin{array}{c}\mathbf{C}_{\mathbf{s}} \\
{[\boldsymbol{\mu g} / \mathbf{s c m}]}\end{array}$ & $\begin{array}{c}\mathbf{S C E} \\
{[\%]}\end{array}$ & $\begin{array}{c}\left|\mathbf{C}_{\mathbf{s}}-\mathbf{C}_{\mathbf{v}}\right| \\
{[\mu \mathbf{g} / \mathbf{s c m}]}\end{array}$ \\
\hline Zero- & 0.00 & 0.22 & 2.21 & 0.22 \\
\hline Mid- & 5.00 & 4.91 & -0.90 & 0.09 \\
\hline
\end{tabular}

SCE - System calibration error

$\mathrm{C}_{\mathrm{v}}$ - Certified concentration of calibration gas

$\mathrm{C}_{\mathrm{s}}$ - Measured concentration of calibration gas

CS - Calibration span

Acceptance criteria:

(1) $\mathrm{SCE} \leq \pm 5.0 \%$

(2) Alternatively, $\left|\mathrm{C}_{\mathrm{s}}-\mathrm{C}_{\mathrm{v}}\right| \leq 0.5 \mu \mathrm{g} / \mathrm{scm}$ 
Relative Accuracy Test Audit (RATA) Utilizing EPA's Method 30A at Rocky Mountain Power's Hardin Generating Station, Hardin, MT

Test Dates: October $15^{\text {th }}-18^{\text {th }}, 2008$

Project Number 06-7008

DOE Award Number DE-FC26-06NT42774

Project Director: Sharon Sjostrom

Project Engineer: Jerry Amrhein

ADA Environmental Solutions, Inc.

8100 SouthPark Way, Unit B

Littleton, CO 80120 


\section{Executive Summary}

ADA Environmental Solutions, Inc. (ADA-ES) conducted mercury continuous emissions monitoring system (Hg-CEMS) testing commencing October 15, 2008 and concluding October 18, 2008 at Rocky Mountain Power's Hardin Generating Station, Hardin, MT using regulations outlined in 40 CFR Part 75.20. Method 30A was the instrumental reference method (IRM) employed to conduct a Relative Accuracy Test Audit (RATA) of the Stack Hg-CEMS, downstream of Activated Carbon Injection (ACI). Modified Method 30A procedures were also used for a RATA on the Air Heater Outlet Hg-CEMS, upstream of ACI.

This technical report was prepared with the support of the U.S. Department of Energy under Award No. DE-FC26-06NT42774, to be included in the "Long-Term Carbon Injection Field Test for $>90 \%$ Mercury Removal for a PRB Unit with a Spray Dryer and Fabric Filter" project of DOE's "Phase III Mercury Control Technology Field Testing and Related Mercury Control Research and Development" program. This was the third of three RATA tests that were performed during the Long-term Test Phase of this project as specified in the test plan.

Method 30A requires Initial Measurement System Performance Tests described in Section 8.2 [Method 30A] in order to ascertain proper function of the instrumental analyzer. Challenges with successful completion of oxidized calibrations during System Integrity Tests on the instrumental analyzer necessitated substituting elemental mercury standards. Note that the Dynamic Spiking Test is not required until January 1, 2009, and was not performed as part of this RATA. A summary of the tests performed is presented in Table 1.

Table 1: Summary of Test Results

\begin{tabular}{|c|c|c|}
\hline & $\begin{array}{c}\text { Stack } \\
\text { Hg-CEMS } \\
\text { (downstream of ACI) }\end{array}$ & $\begin{array}{c}\text { Air Heater Outlet } \\
\text { Hg-CEMS } \\
\text { (upstream of ACI) }\end{array}$ \\
\hline Relative Accuracy Test Audit (RATA) & PASS & PASS \\
\hline Interference Check (Optional) & - & - \\
\hline 3-Point System Calibration Error Test & PASS & PASS \\
\hline System Integrity Check & PASS & PASS \\
\hline Measurement System Response & PASS & Not Performed \\
\hline Dynamic Spiking Test & Not Performed & PaSS \\
\hline
\end{tabular}

* Note: The System Integrity Check on the CEMS installed at the Air Heater Outlet was performed with elemental mercury in lieu of oxidized because no chlorine bottle was installed to perform testing at this location.

Under the noted conditions, both the Stack and the Air Heater Outlet Hg-CEMS successfully met performance criteria for RATA testing using Method 30A as the reference method. Bias was determined and evaluated as out of specification at the Air Heater Outlet, however bias adjustment factors were not implemented. Both of these systems are subject to the scrutiny of a well-developed QA/QC program which includes daily evaluation of potentially necessary correction factors, and, as such, implementation of any correction from this Bias Test has been deemed unnecessary. 


\section{Table of Contents}

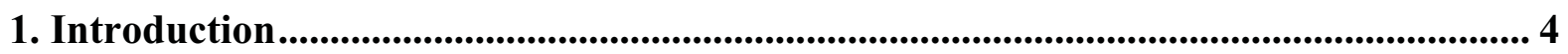

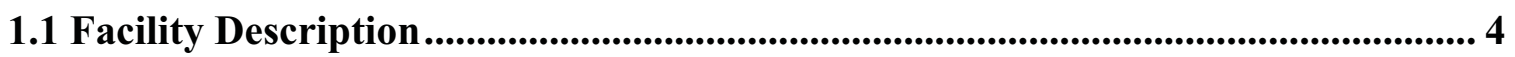

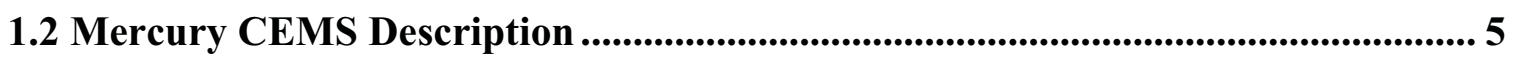

1.3 Sampling Port Locations ................................................................................................ 5

1.4 Method 30A Reference Analyzer Equipment and Method Description................. 7

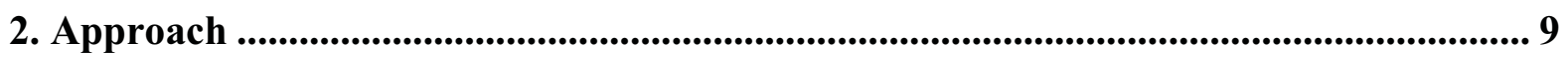

2.1 Plant-Installed CEMS Parameters............................................................................... 9

2.2 Relative Accuracy Test Audit (RATA) \& Bias Test ................................................... 10

2.2.1 Instrumental Analyzer Configuration ............................................................... 10

2.2.1.1 Calibration Span \& Gas Concentrations .............................................10

2.2.1.2 Sample Point Selection ......................................................................10

2.2.2 Initial Measurement System Performance Tests ............................................. 11

2.2.2.1 Interference Test (Optional) ..............................................................12

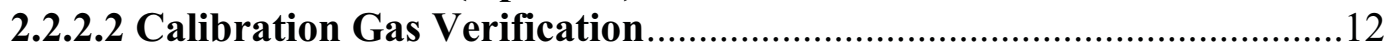

2.2.2.3 Measurement System Preparation ..................................................... 12

2.2.2.4 System Calibration Error Test ........................................................12

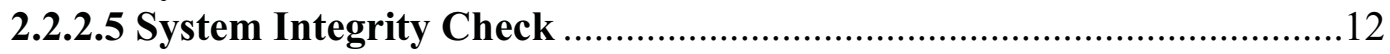

2.2.2.6 Measurement System Response Time ……………………..................13

2.2.2.7 Dynamic Spiking Test (deferred until January 1, 2009) ......................13

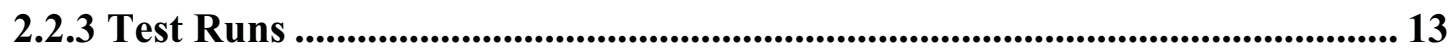

2.2.3.1 System Integrity Checks ............................................................13

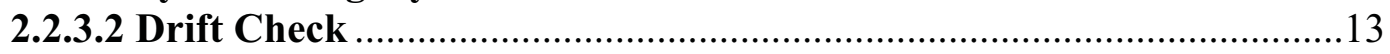

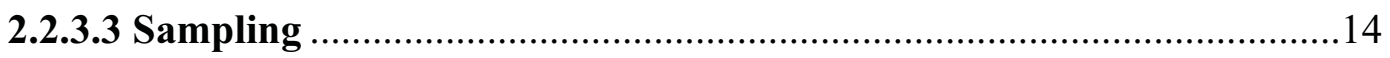

2.2.4 Relative Accuracy Calculation.......................................................................... 14

2.2.5 Bias Determination \& Adjustment Factor Calculation................................... 15

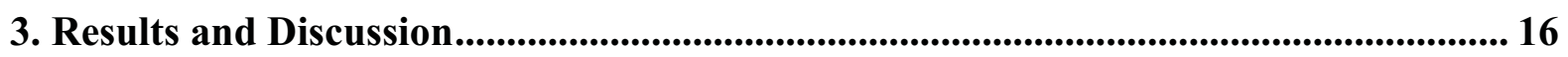

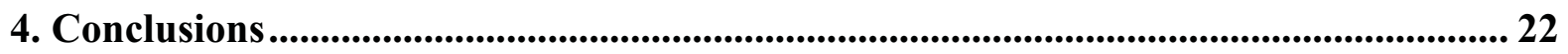

5. Appendix ............................................................................................................................... 23

Initial Measurement System Response Tests .................................................................... 23 
Table 1: Summary of Test Results ........................................................................................1

Table 2: Key Parameters of the Hardin Power Plant......................................................5

Table 3: Span and Range Value(s) ..............................................................................9

Table 4: IRM Calibration Span \& Gas Concentrations...................................................10

Table 5: RATA \& Bias Test - Stack Hg-CEMS .................................................................17

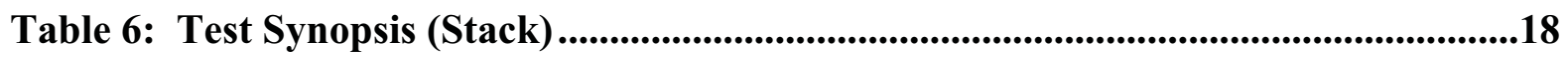

Table 7: RATA \& Bias Test - Air Heater Outlet Hg-CEMS ..............................................19

Table 8: Test Synopsis (Air Heater Outlet) ................................................................20

Table 9: IRM System Calibration Error Test (Stack)...................................................24

Table 10: IRM System Calibration Error Test (Air Heater Outlet)...................................24

Table 11: IRM Measurement System Response Time (Stack) .........................................25

Table 12: IRM Measurement System Response Time (Air Heater Outlet) ....................25

Table 13: IRM System Integrity Check (Stack).....................................................................26

Table 14: IRM System Integrity Check (Air Heater Outlet) .........................................26

\section{LIST OF FIGURES}

Figure 1: Hardin Facility View ........................................................................................................4

Figure 2: Stack Sampling Port Location [ASA, Inc.] .............................................6

Figure 3: Air Heater Outlet Sampling Port Location [ASA, Inc.] ..................................7

Figure 4: Thermo CEMS Configured for an IRM .............................................................8

Figure 5: Thermo Model 83i Probe, Filter and Conversion Unit .....................................8

Figure 6: IRM Probe Designed for Traversing ...............................................................9

Figure 7: Stack Sampling Points .........................................................................................11

Figure 8: Air Heater Outlet Sampling Point .....................................................................11 


\section{Introduction}

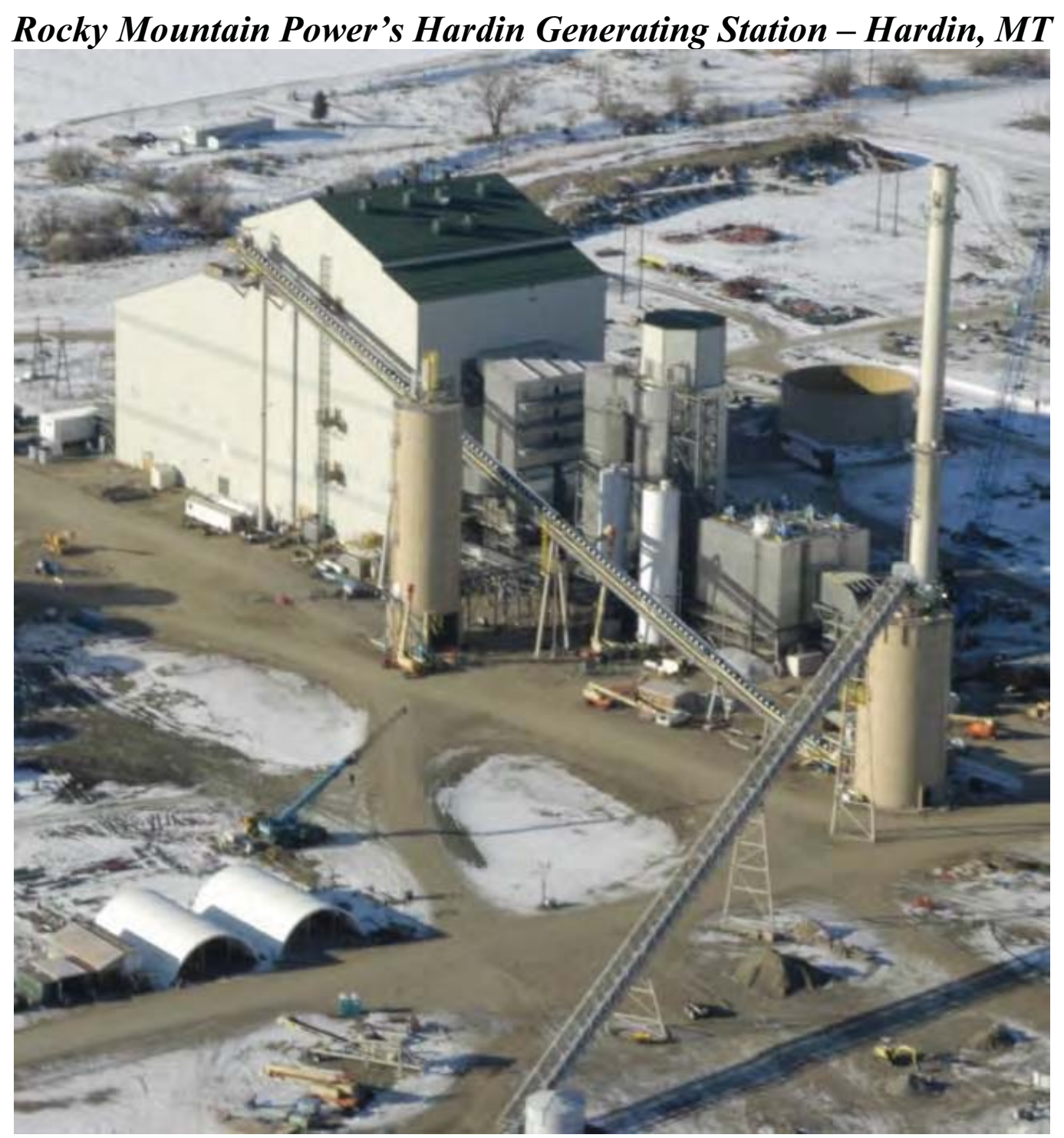

Figure 1: Hardin Facility View

\subsection{Facility Description}

Rocky Mountain Power's Hardin Generating Station is a new and relatively small plant (121 MW) that was first brought online in December of 2005. Its key operating parameters are outlined in Table 2. Firing a pulverized Powder River Basin (PRB) coal from the nearby Absaloka Mine, the Hardin plant is configured with low $\mathrm{NO}_{\mathrm{x}}$ burners and a Selective Catalytic Reduction (SCR) for $\mathrm{NO}_{\mathrm{x}}$ control, a Spray Dryer Absorber (SDA) for $\mathrm{SO}_{2}$ control, and a Fabric Filter (FF) for particulate control. The coal contains approximately $0.65 \%$ sulfur, $0.04 \mathrm{ppm}$ mercury and $<20 \mathrm{ppm}$ chlorine. A commercial-grade Activated Carbon Injection (ACI) system is integrated with a new-generation mercury analyzer to allow automated feedback control of the outlet mercury emissions. 
Table 2: Key Parameters of the Hardin Power Plant

\begin{tabular}{|l|c|}
\hline Rated Capacity & 121 (MW) \\
\hline Range of Operation & $81-121 \mathrm{MW}$ \\
\hline Operating Levels & $\begin{array}{c}\text { Low: } 81-93 \mathrm{MW} \\
\text { Mid: } 93-105 \mathrm{MW} \\
\text { High (Normal): } 105-121 \mathrm{MW}\end{array}$ \\
\hline Coal (typical) & $\begin{array}{c}\text { PRB, } \\
\text { Absaloka Mine }\end{array}$ \\
\hline Boiler Type & $\begin{array}{c}\text { PC Boiler } \\
\text { Opposing wall-fired }\end{array}$ \\
\hline Sulfur Control & Spray Dryer with Recycle \\
\hline Nitrogen Oxide Control & Low NO $\mathrm{N}_{\mathrm{x}}$ Burners/SCR \\
\hline Particulate Control & Fabric Filter \\
\hline $\begin{array}{l}\text { Gas Flow Rate } \\
\text { (ACI Location) }\end{array}$ & $\sim 550,000 \mathrm{acfm}$ \\
\hline $\begin{array}{l}\text { Flue Gas Temperature } \\
\text { (ACI Location) }\end{array}$ & $260-320^{\circ} \mathrm{F}$ \\
\hline
\end{tabular}

\subsection{Mercury CEMS Description}

The Mercury Freedom ${ }^{\mathrm{TM}}$ System manufactured by Thermo Fisher Corporation is installed at Hardin to continuously measure the mercury emissions at the Stack and the Air Heater Outlet. Thermo Electron's Mercury Freedom ${ }^{\mathrm{TM}}$ System is comprised of a Hg Analyzer (80i), Calibrator (81i), Probe Controller (82i), Probe (83i) and related peripheral components including an umbilical and instrument rack.

\subsection{Sampling Port Locations}

Air Sampling Associates, Inc. previously measured and documented the sampling port locations at the Stack and Air Heater Outlet depicted in Figures 2 and 3, respectively, during stack testing:

"The sampling ports on the SDA Inlet duct [Air Heater Outlet duct] are approximately 36 feet $91 / 2$ inches above the ground. The sampling ports are located 13 feet 4 inches $(1.12$ equivalent duct diameters) downstream from a bend in the duct and 56 feet 3 inches ( 4.75 equivalent duct diameters) upstream from a bend in the duct. The sampling ports on the Stack are approximately 123 feet $11 / 2$ inches above the ground. The sampling ports are located 33 feet $11 / 2$ inches (3.64 stack diameters) downstream from the inlet to the Stack and $>18$ feet $23 / 8$ inches ( $>2.00$ Stack diameters) upstream from the outlet to the Stack." 


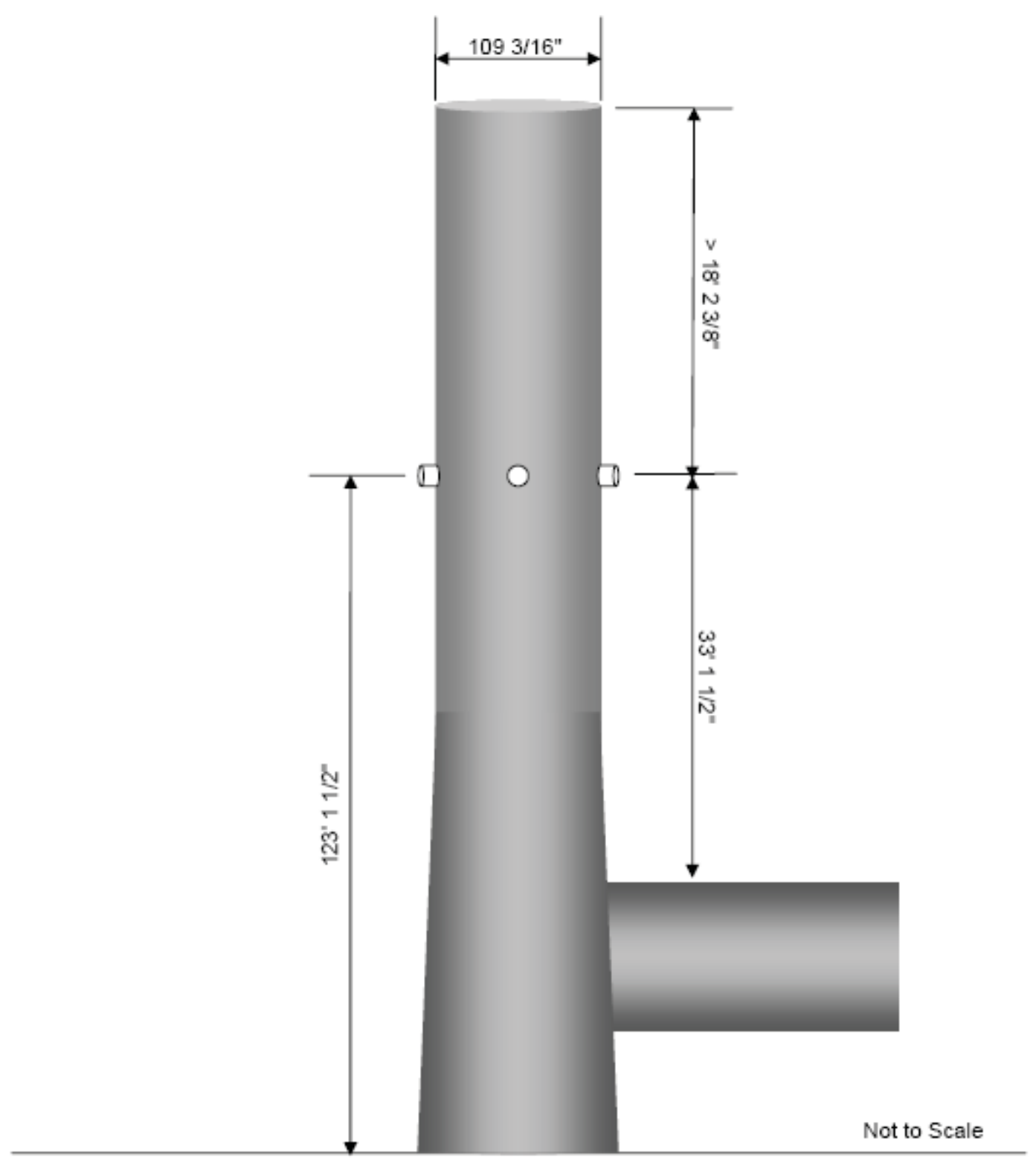

Figure 2: Stack Sampling Port Location [ASA, Inc.] 


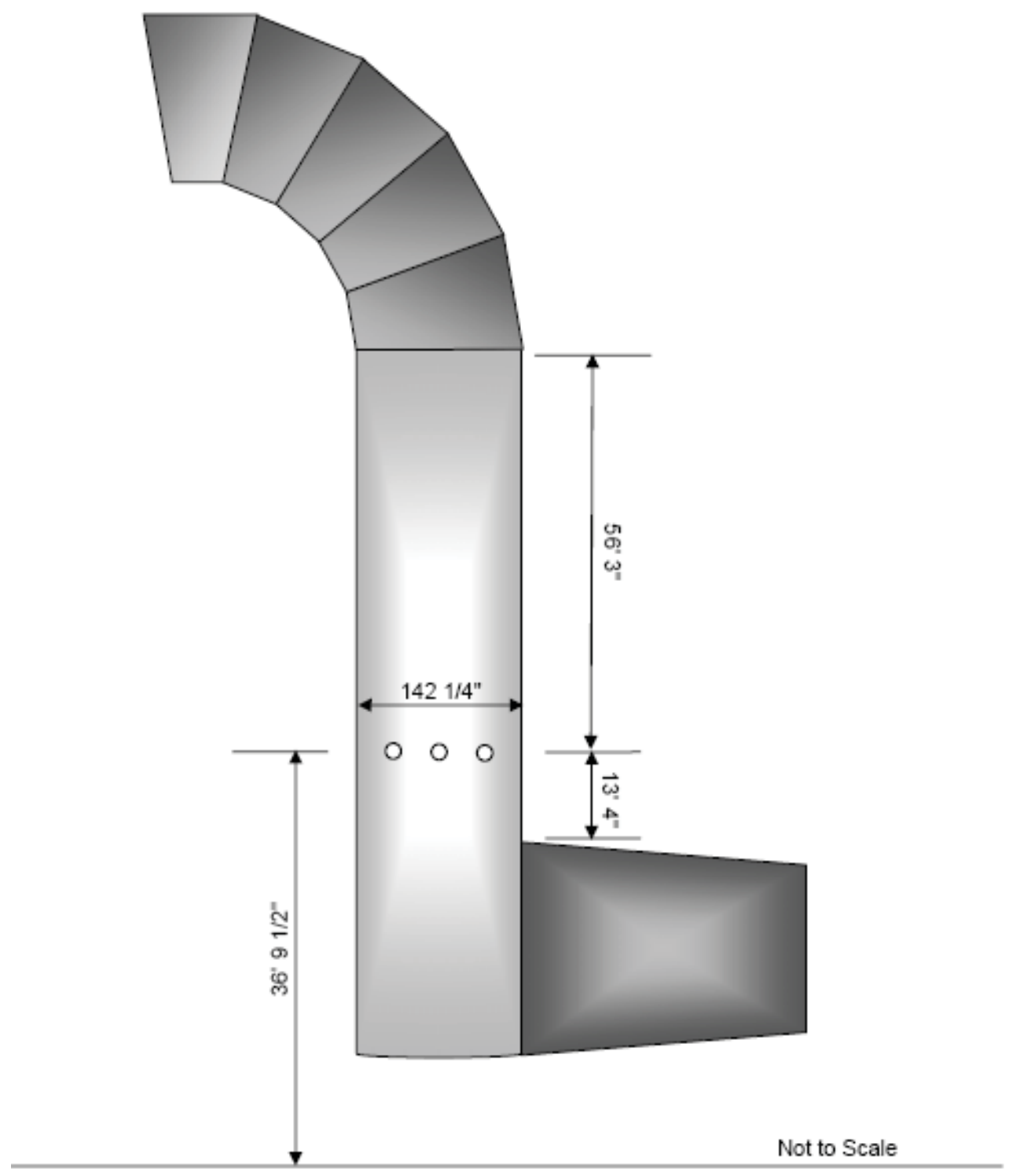

Figure 3: Air Heater Outlet Sampling Port Location [ASA, Inc.]

\subsection{Method 30A Reference Analyzer Equipment \& Method Description}

A Thermo Mercury Freedom ${ }^{\mathrm{TM}}$ System has been configured for IRM testing. A photo of the unit is shown in Figure 4. The unit consists of a standard Model 80i Mercury Analyzer and Model $81 \mathrm{i}$ Mercury Calibrator installed in a temperature controlled enclosure. Probe control (temperature, flow, pressure) is achieved through analog controls installed in the environmental enclosure. A standard Model 83i Probe, shown in Figure 5, has been 
modified by removing the mantle and stinger, connecting calibration gas to a port upstream of the sampling filter, and adding additional pressure monitoring capabilities to the flow measurement venturi. A modified mantle/stinger portion of the probe has been fabricated to facilitate traversing. A sketch of this component is shown in Figure 6. The mantle/stinger has been coupled to the other probe components by a 25 -foot long heated umbilical. At Hardin Generating Station, the IRM enclosure was located at ground level while the probe enclosure, 25-foot heated umbilical, and mantle/stinger were located at the sampling platform.

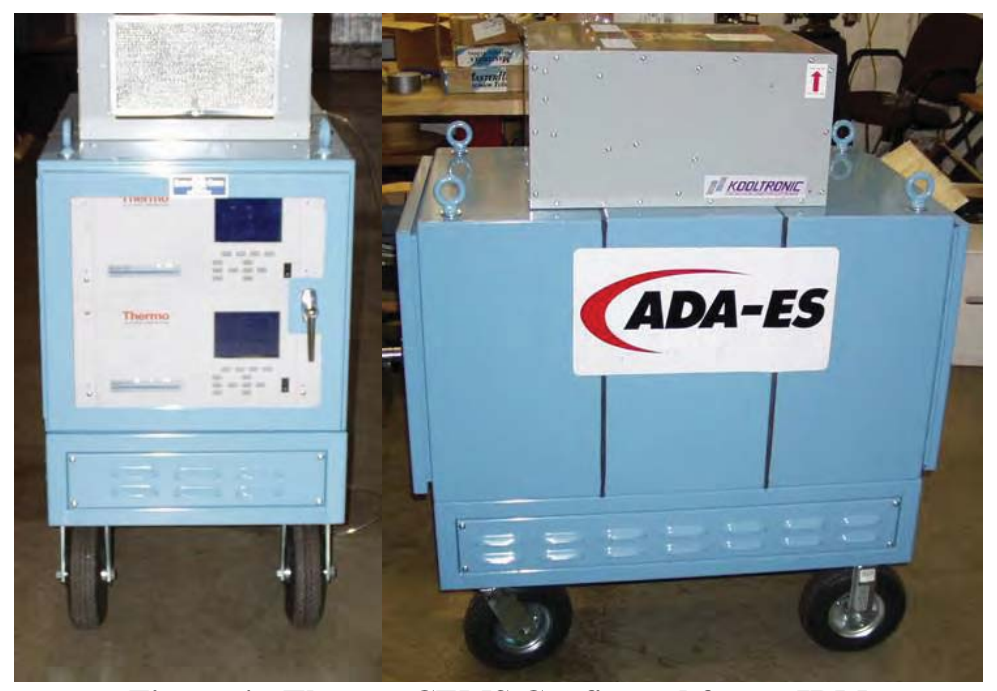

Figure 4: Thermo CEMS Configured for an IRM

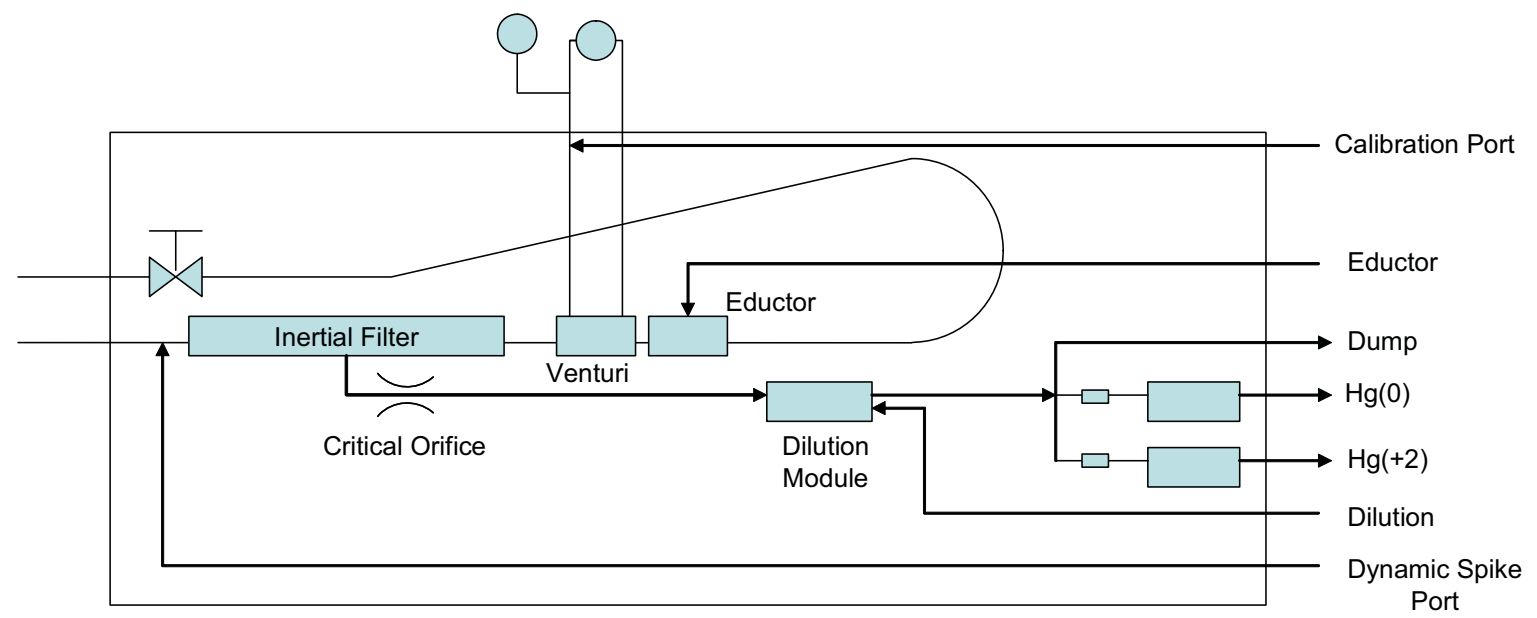

Figure 5: Thermo Model 83i Probe, Filter and Conversion Unit 


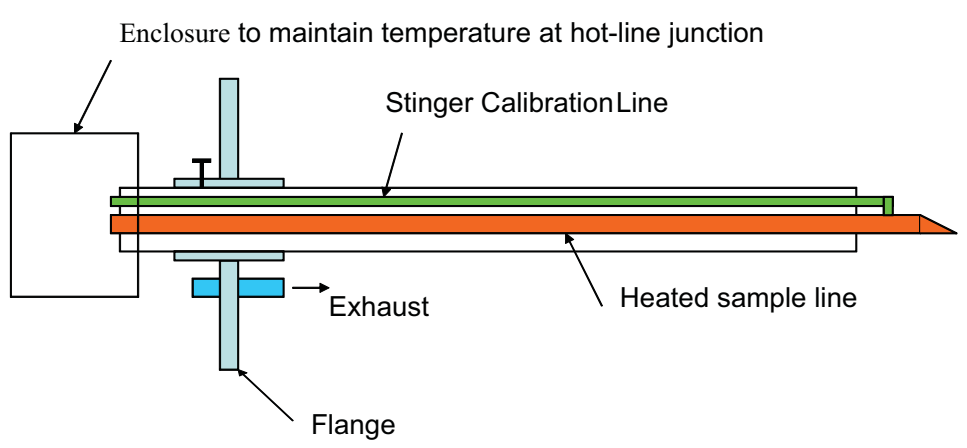

Figure 6: IRM Probe Designed for Traversing

\section{Approach}

\subsection{Plant-Installed CEMS Parameters}

System parameters for the installed Hg-CEMS are presented in Table 3. The Maximum Potential Concentration (MPC), Removal Efficiency (RE), and Maximum Expected Concentration (MEC) were determined in order to calculate the Span (S), Range, and appropriate concentration levels. These calculated values are necessary for calibration of the analyzer, and consequently the validation of measured data.

Table 3: Span and Range Value(s)

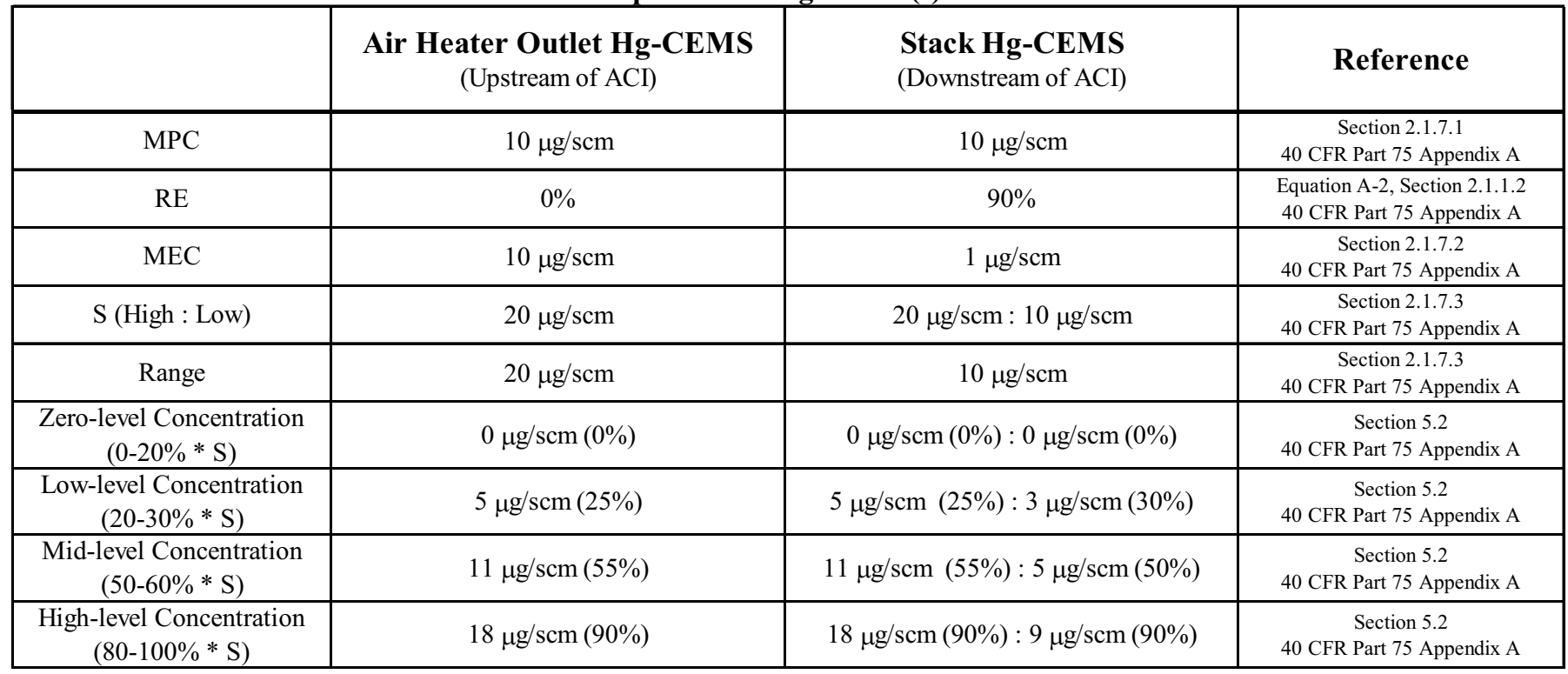

* The high span value on the Outlet CEM is neglected because $\mathrm{Hg}$ concentrations at the stack will never exceed 2.0 $\mu \mathrm{g} / \mathrm{scm}$ by design of emissions control. 


\subsection{Relative Accuracy Test Audit (RATA) \& Bias Test \\ 2.2.1 Instrumental Analyzer Configuration \\ 2.2.1.1 Calibration Span \& Gas Concentrations}

To the extent practicable the measured emissions are to be between 10 and $100 \%$ of the selected calibration span. It is recommended that the calibration span be at least twice the native concentration to accommodate the dynamic spiking procedure (Section 3.4, [Method 30A]). The selected value of the calibration span is limited by the capabilities of the calibrator. The parameters used for calibration and data validation tests of the instrumental analyzer are outlined in Table 4.

Table 4: IRM Calibration Span \& Gas Concentrations

\begin{tabular}{|c|c|c|}
\hline \multirow[b]{3}{*}{$\begin{array}{c}\text { Gas } \\
\text { Concentration }\end{array}$} & \multicolumn{2}{|c|}{ Native Concentration $=\quad 2 \mu \mathrm{g} / \mathrm{scm}$} \\
\hline & Calibration Span $(\mathrm{CS})=$ & $10 \mu \mathrm{g} / \mathrm{scm}$ \\
\hline & Allowable Range & Hg Concentration \\
\hline Zero-level & Non-detectable & $0 \mu \mathrm{g} / \mathrm{scm}(0 \%)$ \\
\hline Low-level & $10-30 \% \mathrm{CS}$ & $3 \mu \mathrm{g} / \mathrm{scm}(30 \%)$ \\
\hline Mid-level & $40-60 \% \mathrm{CS}$ & $5 \mu \mathrm{g} / \mathrm{scm}(50 \%)$ \\
\hline High-level & $100 \% \mathrm{CS}$ & $10 \mu \mathrm{g} / \mathrm{scm}(100 \%)$ \\
\hline
\end{tabular}

\subsubsection{Sample Point Selection}

When Method 30A is used for relative accuracy testing of a Hg-CEMS, the sampling site selection and sampling point layout procedures are referenced in the appropriate performance specification or applicable regulation described in Performance Specification 2, Section 8.1.3 [40 CFR Part 75 Appendix B] or Section 6.5.6 [40 CFR Part 75 Appendix A]. Alternatively, Section 8.1.3.4 [Method 30A] states that stratification testing need not be performed at a test location where it would otherwise be required to justify using fewer sample points or different sample points, if the $\mathrm{Hg}$ concentration in the stack gas is expected to be $3 \mu \mathrm{g} / \mathrm{m}^{3}$ or less at the time of a $\mathrm{Hg}$ monitoring system RATA or an $\mathrm{Hg}$ emissions test. Documentation of at least one hour of $\mathrm{Hg}$ concentration data is required just prior to the RATA or emissions test. If a particular test location qualifies for the stratification testing exemption, sampling shall be performed at three points, as described in Section 8.1.3.2.2 [Method 30A]. Since the stack diameter (or equivalent diameter, for a rectangular stack or duct) is greater than $7.8 \mathrm{ft}$, the three Stack sampling points were therefore located at 4.4, 14.6, and 29.6 percent of the stack diameter (109 3/16") from the stack or duct wall (see Figure 2). Since only modified Method 30A procedures were performed at the Air Heater Outlet, a single sampling point depicted in Figure 3 was selected at 78.74" from the duct wall. 


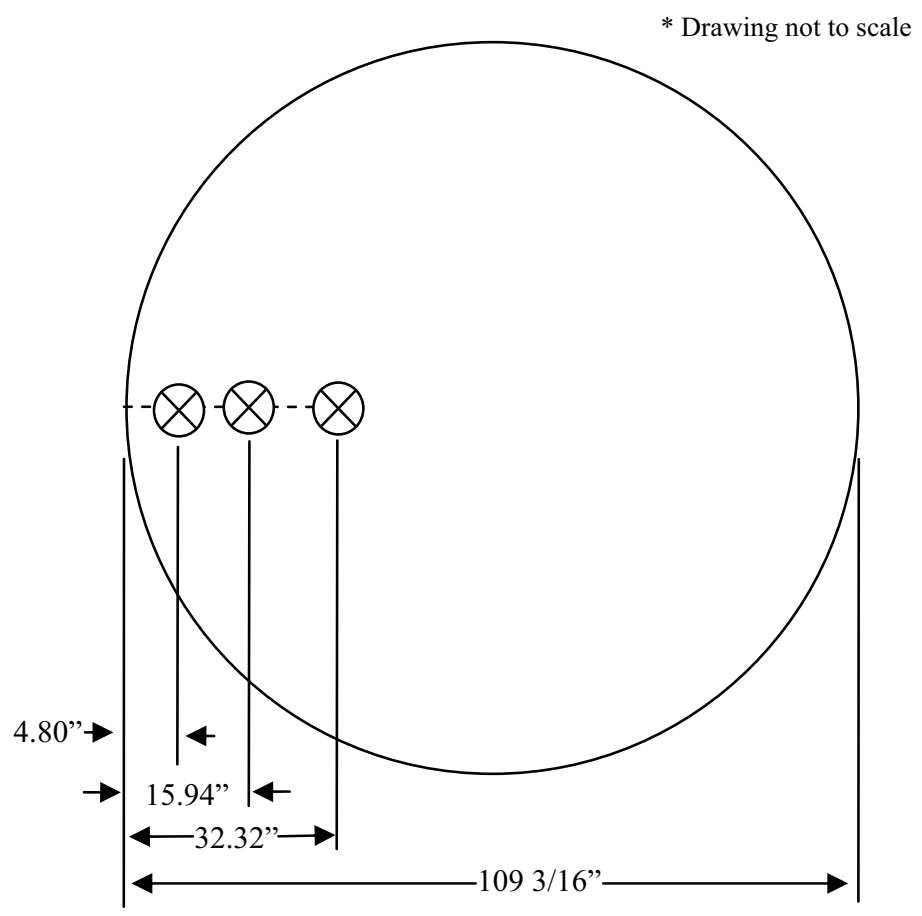

Figure 7: Stack Sampling Points

* Drawing not to scale

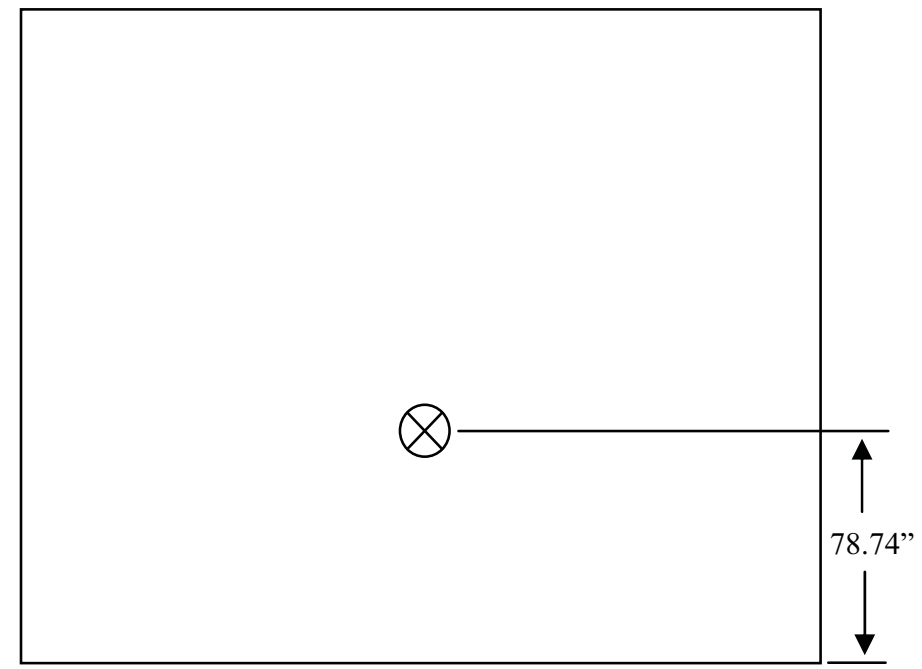

Figure 8: Air Heater Outlet Sampling Point

\subsubsection{Initial Measurement System Performance Tests}

Initial measurement system performance tests need to be conducted on the instrumental analyzer prior to starting the nine (9) required test runs. The performance requirements of this method must be met to validate data, and are described below:

(1) Interference Testing (Optional)

(2) Calibration Gas Verification

(3) Measurement System Preparation

(4) 3-Point System Calibration Error Test

(5) System Integrity Check 
(6) Measurement System Response Time Test

(7) Dynamic Spiking (deferred until January 1, 2009)

\subsubsection{Interference Test (Optional)}

It is recommended that this test be conducted prior to the initial use of the measurement system in the field to verify that the candidate test instrument is free from inherent biases or interferences resulting from common combustion emission constituents. The interference test procedure is found in Section 8.6 [Method 30A]. This procedure was not performed during this test period.

\subsubsection{Calibration Gas Verification}

EPA Traceability Protocol for Qualification and Certification of Elemental Mercury Gas Generators and EPA Traceability Protocol for Qualification and Certification of Oxidized Mercury Gas Generators expected publication date December 2008, see www.epa.gov/ttn/emc.

\subsubsection{Measurement System Preparation}

The measurement system was assembled, prepared, and preconditioned according to standard operating procedure.

\subsubsection{System Calibration Error Test}

Using elemental mercury $\left(\mathrm{Hg}^{0}\right)$, a 3-point system calibration error test was conducted prior to the first test run. The low-, mid-, and high-level calibration gases were introduced in any order into the instrumental analyzer, and, after each gas injection, a stable response was obtained and recorded.

Acceptance criteria:

i. $\mathrm{SCE} \leq \pm 5 \%$, where

$$
S C E=\frac{C_{s}-C_{v}}{C S} \times 100
$$

SCE - System Calibration Error [\%].

$\mathrm{C}_{\mathrm{s}}$ - Measured concentration of the calibration gas $[\mu \mathrm{g} / \mathrm{scm}]$.

$\mathrm{C}_{\mathrm{v}}$ - Certified concentration of the calibration gas $[\mu \mathrm{g} / \mathrm{scm}]$.

CS - Calibration Span $[\mu \mathrm{g} / \mathrm{scm}]$.

ii. Alternatively, $\left|\mathrm{C}_{\mathrm{s}}-\mathrm{C}_{\mathrm{v}}\right| \leq 0.5 \mu \mathrm{g} / \mathrm{scm}$

\subsubsection{System Integrity Check}

Using oxidized mercury $\left(\mathrm{Hg}^{2+}\right)$, a two-point system integrity check was conducted as required before the first test run. The zero- and mid-level calibration gases were introduced into the instrumental analyzer, and, after each gas injection, a stable response was obtained and recorded.

Acceptance criteria:

i. $\mathrm{SCE} \leq \pm 5 \%$, where

$$
S C E=\frac{C_{s}-C_{v}}{C S} \times 100
$$


SCE - System Calibration Error [\%].

$\mathrm{C}_{\mathrm{s}}$ - Measured concentration of the calibration gas $[\mu \mathrm{g} / \mathrm{scm}]$.

$\mathrm{C}_{\mathrm{v}}$ - Certified concentration of the calibration gas $[\mu \mathrm{g} / \mathrm{scm}]$.

CS - Calibration Span $[\mu \mathrm{g} / \mathrm{scm}]$.

ii. Alternatively, $\left|\mathrm{C}_{\mathrm{s}}-\mathrm{C}_{\mathrm{v}}\right| \leq 0.5 \mu \mathrm{g} / \mathrm{scm}$

\subsubsection{Measurement System Response Time}

The measurement system response time provides the minimum sampling time for each sampling point. It is equal to the time that is required for the measured $\mathrm{Hg}$ concentration to increase from the stable low-level calibration gas response to a value within 5 percent of the stable high-level calibration gas response obtained during the system calibration error test in Section 8.2.4 [Method 30A], assuming the high-level calibration gas was injected immediately after the low-level.

\subsubsection{Dynamic Spiking Test (deferred until January 1, 2009)}

\subsubsection{Test Runs}

After the instrumental analyzer successfully met the acceptance criteria of the Initial System Performance Tests, the minimum nine (9) test runs of the RATA were performed. One test run constitutes sampling once at each of the successive sample points. The run validations listed below must be performed while sampling.

\subsubsection{System Integrity Checks}

Before and after each test run, a two-point system integrity check using the same procedure as the initial system integrity check must be conducted. No adjustments may be made to the measurement system during the checks, other than to maintain the target calibration gas flow rate and the proper dilution ratio. This check may be skipped between each run provided that a system integrity check performed on completion of runs passes the allowed specification. If a post-run integrity check is failed, all test runs since the last passed system integrity check are invalid. If a check is failed, corrective action must be taken and another 3-point $\mathrm{Hg}^{0}$ System Calibration Error Test passed followed by another System Integrity Check before conducting any additional test runs.

\subsubsection{Drift Check}

Using the data from the successful pre- and post-run system integrity checks, calculate the zero and upscale drift. Exceeding the specification does not invalidate the run, but corrective action must be taken and a new 3-point $\mathrm{Hg}^{0}$ System Calibration Error Test and a System Integrity Check must be passed before any more runs are made.

Acceptance criteria:

i. $\mathrm{D} \leq 3.0 \%$, where

$$
\begin{aligned}
D= & \left|S C E_{f}-S C E_{i}\right| \\
& \mathrm{D}-\text { Drift [\%]. } \\
& \mathrm{SCE}_{\mathrm{i}, \mathrm{f}}-\text { System Calibration Error, pre/post-run [\%]. }
\end{aligned}
$$


ii. Alternatively, $\left|\mathrm{C}_{\mathrm{s}, \mathrm{f}}-\mathrm{C}_{\mathrm{s}, \mathrm{i}}\right| \leq 0.3 \mu \mathrm{g} / \mathrm{scm}$

$\mathrm{C}_{\mathrm{s}, \mathrm{if}}-$ Measured concentration of the calibration gas, pre/post-run $[\mu \mathrm{g} / \mathrm{scm}]$.

\subsubsection{Sampling}

For each sample point determined from Section 8.1, Method 30A, the system must be allowed to flush and equilibrate for at least two times the measurement system response time before recording any data. The minimum sampling time at each sampling point must be at least two times the system response time, but not less than 10 minutes.

\subsubsection{Relative Accuracy Calculation}

Acceptance criteria:

i. $\mathrm{RA} \leq 20.0 \%$, where

Arithmetic Mean:

$d=R M-C E M$

$\mathrm{d}$ - The difference between a reference method value and the corresponding continuous emission monitoring system value at a given point in time.

RM - Reference method value.

CEM - Continuous emission monitoring system value.

$$
\begin{aligned}
& \bar{d}= \frac{\sum_{i=1}^{n} d_{i}}{n} \\
& \mathrm{n}-\text { Number of data points. }
\end{aligned}
$$

Standard Deviation:

$$
S_{d}=\sqrt{\frac{\sum_{i=1}^{n} d_{i}^{2}-\left[\frac{\left(\sum_{i=1}^{n} d_{i}\right)^{2}}{n}\right]}{n-1} \mathrm{~S}_{\mathrm{d}}-\text { Standard deviation. }}
$$

Confidence Coefficient:

$$
\begin{aligned}
c c= & t_{0.025} \times \frac{S_{d}}{\sqrt{n}} \\
& c c-\text { Confidence coefficient. } \\
& \mathrm{t}_{0.025}-\mathrm{t} \text {-value. }
\end{aligned}
$$

Relative Accuracy:

$$
R A=\frac{|\partial|+|c c|}{\overline{R M}} \times 100
$$


RA - Relative accuracy of a data set.

$\mathrm{RM}$ - Arithmetic mean of the reference method values.

$\partial$ - Mean difference between the reference method values and the corresponding continuous emission monitoring system values.

ii. Alternatively, if $\overline{R M} \leq 5.0 \mu \mathrm{g} / \mathrm{scm}, \overline{C E M}-\overline{R M} \leq \pm 1.0 \mu \mathrm{g} / \mathrm{scm}$

\subsubsection{Bias Determination \& Adjustment Factor Calculation}

If the following criterion is met for the relative accuracy test audit data set being tested, the monitoring system has passed the bias test:

Acceptance criterion:

$$
|\bar{d}| \leq|c c|
$$

If the monitor or monitoring system fails to meet the bias test requirement, adjustment of the value obtained from the monitor is necessary using the following equation:

$$
\begin{aligned}
& C E M_{i}^{\text {Adjusted }}=C E M_{i}^{\text {Monitor }} \times B A F \\
& C E M_{i}^{\text {Adjusted }}-\text { Data value, adjusted for bias, at time i. } \\
& C E M_{i}^{\text {Monitor }} \text { - Data (measurement) provided by monitor at time i. }
\end{aligned}
$$

BAF - Bias Adjustment Factor.

Bias Adjustment Factor:

$$
B A F=1+\frac{\bar{d}}{\overline{C E M}}
$$

If the monitoring system meets the normal or the alternative relative accuracy specification in section 3.3.8 of 40 CFR Part 75 Appendix A but fails the bias test, the owner or operator may either use the BAF calculated above or may use a default BAF of 1.250 for reporting purposes. Each time a RATA is passed and the appropriate BAF has been determined, the BAF is to be applied prospectively to all monitoring system data, beginning with the first clock hour following the hour in which the RATA was completed. 


\section{Results and Discussion}

Since the last two RATAs indicated no stratification at the sampling location on the Stack, a single sample point at 32.32" from the duct wall was elected in lieu of the three points previously tested. Numerous attempts were made to successfully measure the $5.0 \mu \mathrm{g} / \mathrm{wscm}$ oxidized mercury injections of the required System Integrity Tests on the instrumental analyzer, however all of these yielded stable responses below the $4.5 \mu \mathrm{g} / \mathrm{wscm}$ lower boundary of the performance specification. Due to these difficulties, a substitution of elemental mercury standards was made. Under these noted conditions, a 9-run, single-point RATA was performed on the installed $\mathrm{Hg}$ CEMS (see Table 5). Relative Accuracy was calculated to be $32.86 \%$ ( $\leq 20 \%$ is passing), however the difference between the average installed CEMS response and Reference Method response was $0.06 \mu \mathrm{g} / \mathrm{scm}(\leq 1.0 \mu \mathrm{g} / \mathrm{scm}$ is passing alternative criteria for average Reference Method responses $\leq 5.0 \mu \mathrm{g} / \mathrm{scm}$ ). 
Table 5: RATA \& Bias Test - Stack Hg-CEMS

\section{Relative Accuracy Test Audit \& Bias Test Summary}

Facility: Hardin Generating Station

Project \#: $06-7008$

Personnel: David Young Jim Domenico
Date(s): $\quad 10 / 18 / 2008$

Unit(s) tested: Stack Hg-CEMS

Test Method: Method 30A

Analyzer Make/Model: Thermo Mercury Freedom System $^{\mathrm{TM}}$

Serial No: 0613917173

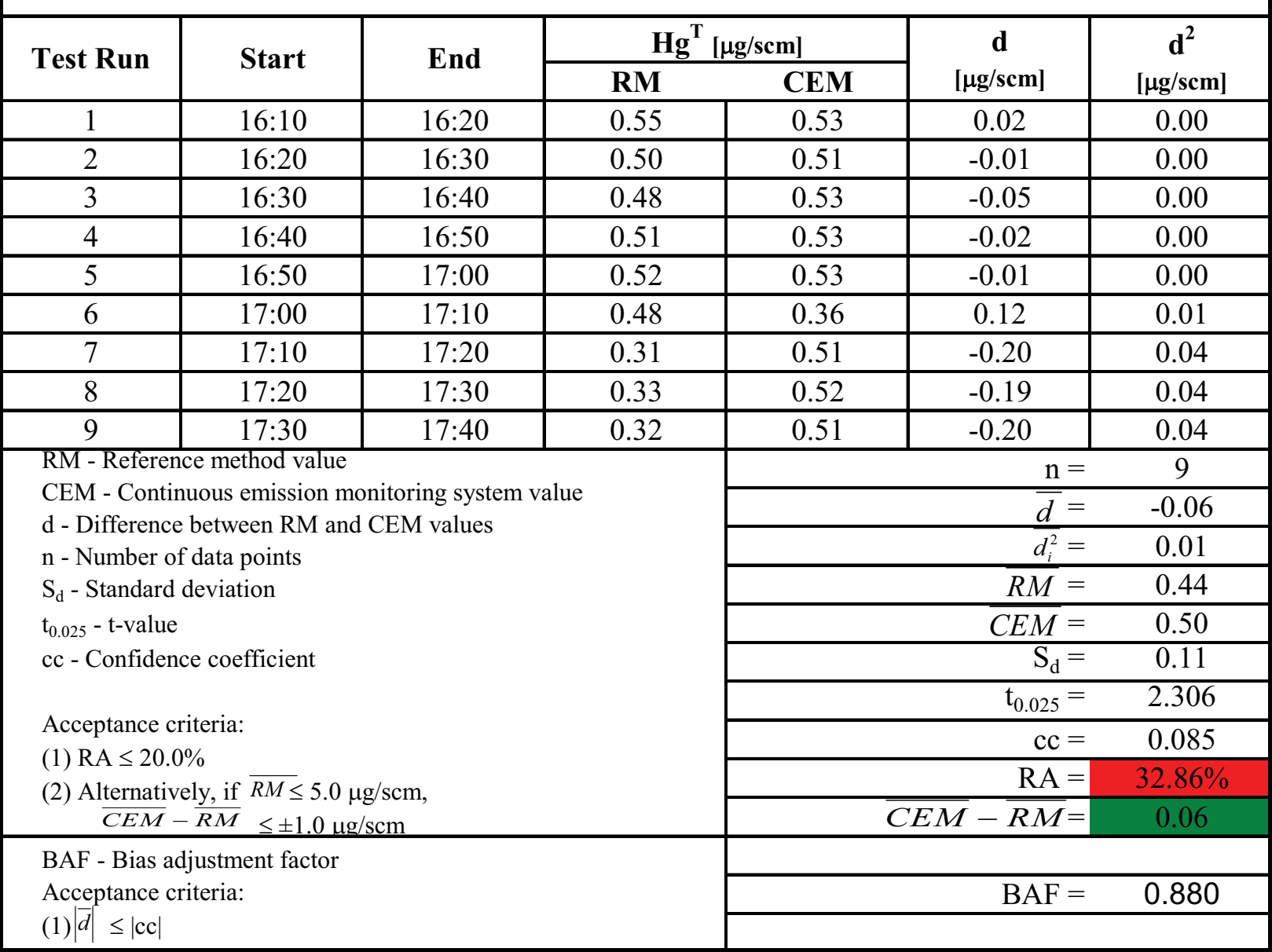


A Test Synopsis for the Stack Hg-CEMS RATA is included in Table 6. All Initial System Performance Test and Run Validation performance specifications were met; however, note that the System Integrity Tests were performed with elemental vice oxidized mercury standards.

Table 6: Test Synopsis (Stack)

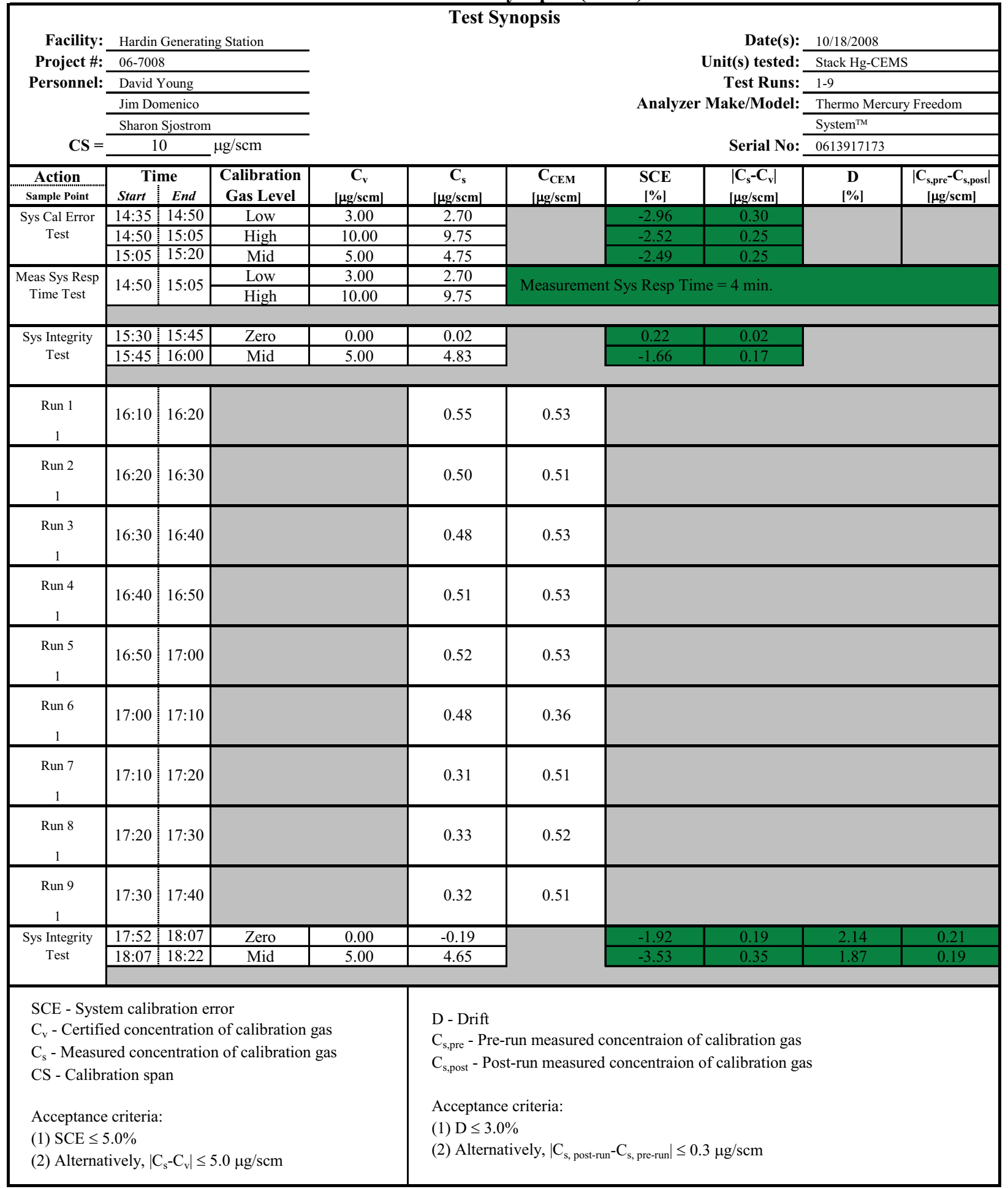


A modified 9-run, single-point RATA was successfully performed on the installed CEMS at the Air Heater Outlet location. Relative Accuracy was calculated to be $13.55 \%$ (20\% is passing). It was not in the original scope of the Test Plan to perform a full RATA at this location, so the test was modified to be performed at a single sample point. This particular location lacked an installed chlorine calibration gas cylinder required to properly perform System Integrity Tests on the instrumental analyzer, so elemental mercury standards were used in lieu of oxidized mercury.

Table 7: RATA \& Bias Test - Air Heater Outlet Hg-CEMS

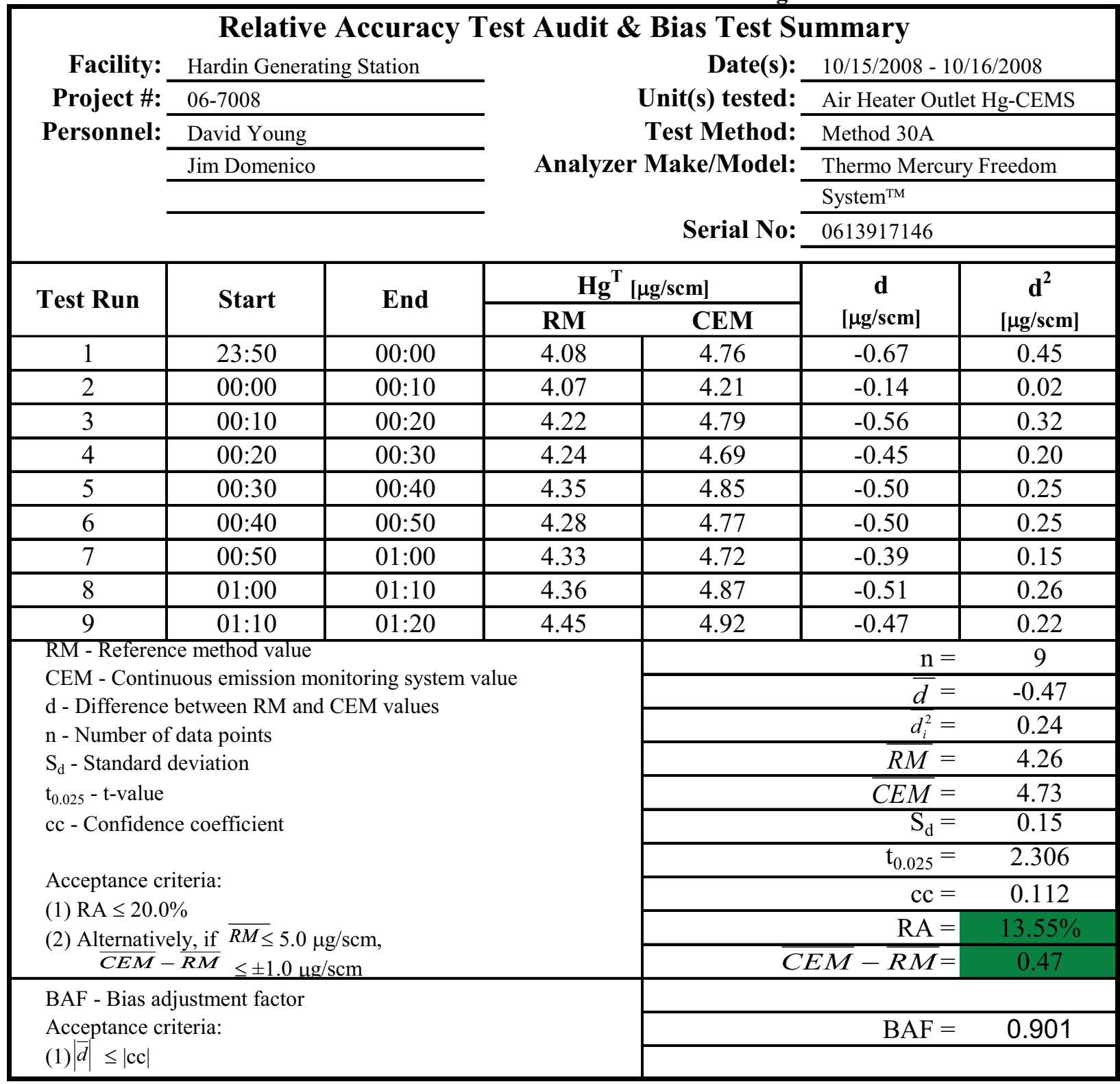


A Test Synopsis for the Air Heater Outlet Hg-CEMS RATA is included in Table 8. All Initial System Performance Test and Run Validation performance specifications were met.

Table 8: Test Synopsis (Air Heater Outlet)

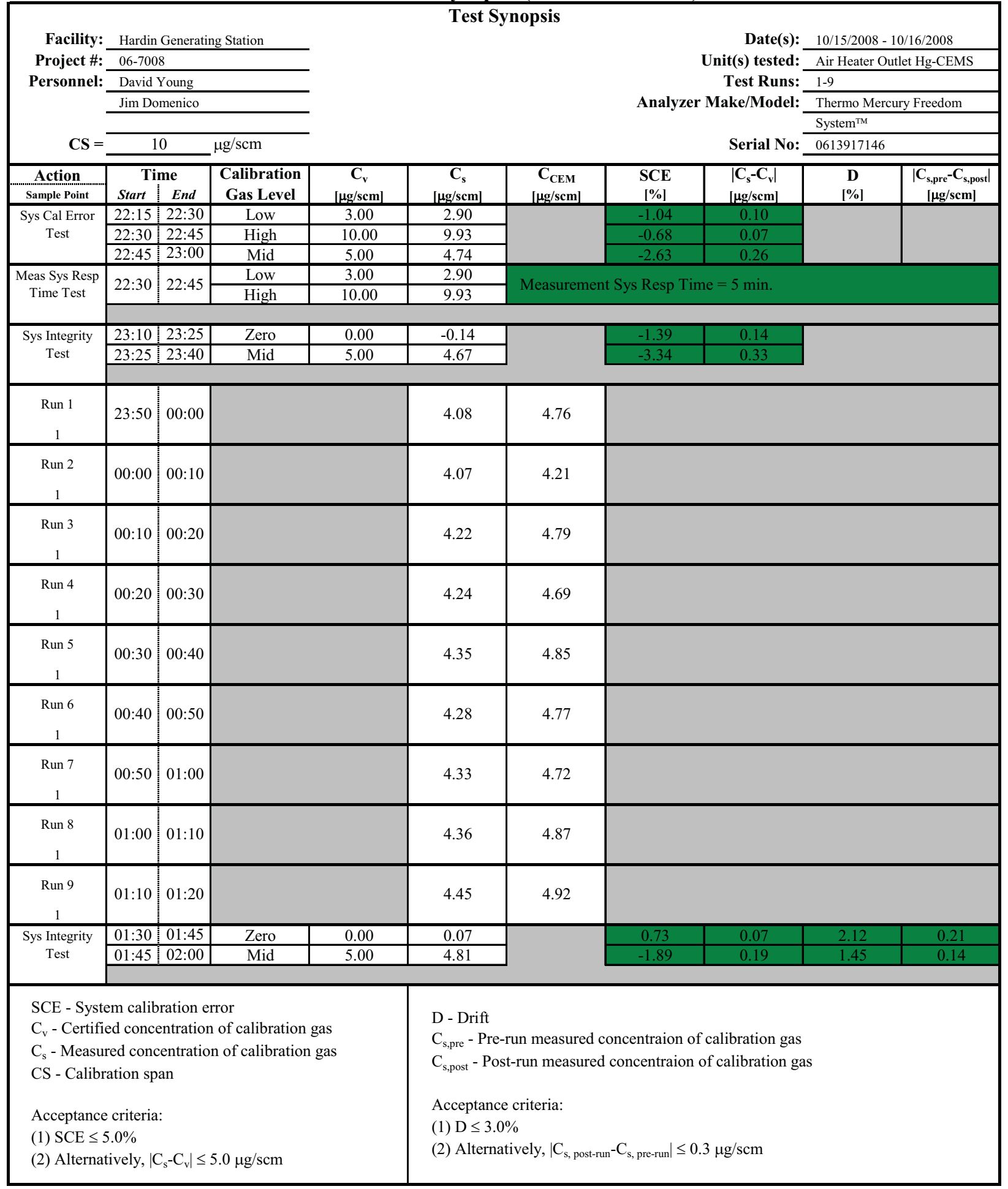


The Bias Test performed on the Stack Hg-CEMS indicated no bias. That performed on the Air Heater Outlet $\mathrm{Hg}$-CEMS, however, did reveal bias in monitor readings. In order to determine bias, the absolute value of the average difference between CEMS and RM values, $|\bar{d}|$, must be less than or equal to the confidence coefficient, cc, of the data. For the Stack Hg-CEMS

RATA, $|\bar{d}|$ was determined to be 0.06 and cc was 0.085 . For the Air Heater Outlet Hg-CEMS RATA, $|\bar{d}|$ was determined to be 0.47 and cc was 0.112 . Bias Adjustment Factors were calculated but were not implemented into the installed CEMS. Both of these systems are subject to the scrutiny of a well-developed Quality Assurance/Quality Control (QA/QC) program which includes daily evaluation of potentially necessary correction factors, and, as such, implementation of any correction from this Bias Test has been deemed unnecessary. 


\section{Conclusions}

The Relative Accuracy Test Audit conducted on Stack Hg-CEMS passed established performance specifications. Elemental mercury was used to perform the System Integrity Tests on the instrumental analyzer due to problems satisfying acceptance criteria using oxidized mercury. No bias was evident between the Stack Hg-CEMS and the instrumental analyzer.

The RATA conducted on the Air Heater Outlet Hg-CEMS also passed established performance specifications under modified conditions. No chlorine calibration gas bottle was installed at this location which is required for the oxidized mercury calibrations of the System Integrity Tests. It is also believed that similar problems to those observed at the Stack location would have challenged the tests. Bias was evident between responses of this system and the instrumental analyzer; however correction factors were not implemented because this would interfere with the daily CEMS QA/QC program.

All Initial System Performance Tests required for validation of the instrumental analyzer passed performance criteria at both locations prior to commencing each first test run, but the System Integrity Tests were performed with elemental vice oxidized mercury standards. Run validations were performed as described in section 2.2.3 of this report.

A duplicate of the Summary of Test Results from Table 1 is presented below.

Summary of Test Results (From Table 1)

\begin{tabular}{|c|c|c|}
\hline & $\begin{array}{c}\text { Stack } \\
\text { Hg-CEMS } \\
\text { (downstream of ACI) }\end{array}$ & $\begin{array}{c}\text { Air Heater Outlet } \\
\text { Hg-CEMS } \\
\text { (upstream of ACI) }\end{array}$ \\
\hline Relative Accuracy Test Audit (RATA) & PASS & PASS \\
\hline Interference Check (Optional) & - & - \\
\hline 3-Point System Calibration Error Test & PASS & PASS \\
\hline System Integrity Check & PASS & PASS \\
\hline Measurement System Response & PASS & PASS \\
\hline Dynamic Spiking Test & Not Performed & Not Performed \\
\hline
\end{tabular}

This was the third of three in a series of tests to be performed at Rocky Mountain Power's Hardin Generating Station, Hardin, MT during the Long-term Test Phase of this project as specified in the test plan. The primary goal of these tests was to demonstrate that the installed $\mathrm{Hg}$-CEMS will comply with future established directives, as well as to provide feedback of the recently approved EPA Method 30A reference method. 


\section{Appendix}

5.1 Initial Measurement System Response Tests \& Run Validations

Results from the instrumental analyzer's pre-certification tests are presented below in Tables 9 through 14. 
Table 9: IRM System Calibration Error Test (Stack)

\section{System Calibration Error Test}

Facility: Hardin Generating Station

Project \#: 06-7008

Personnel: David Young

$\mathbf{C S}=\frac{\frac{\text { Jim Domenico }}{10} \mu \mathrm{g} / \mathrm{scm}}{}$

Date(s):

Unit(s) tested: Stack Hg-CEMS

Test Runs: N/A

Analyzer Make/Model: Thermo Mercury Freedom

Serial No: $\frac{\text { System }^{\mathrm{TM}}}{0613917173}$

\begin{tabular}{|c|c|c|c|c|c|c|}
\hline \multicolumn{2}{|c|}{$\begin{array}{c}\text { Time } \\
\text { Start }\end{array}$} & $\begin{array}{c}\text { Calibration } \\
\text { Gas Level }\end{array}$ & $\begin{array}{c}\mathbf{C}_{\mathbf{v}} \\
{[\mu \mathbf{g} / \mathbf{s c m}]}\end{array}$ & $\begin{array}{c}\mathbf{C}_{\mathbf{s}} \\
{[\mu \mathbf{g} / \mathbf{s c m}]}\end{array}$ & $\begin{array}{c}\mathbf{S C E} \\
{[\%]}\end{array}$ & $\begin{array}{c}\left|\mathbf{C}_{\mathbf{s}}-\mathbf{C}_{\mathbf{v}}\right| \\
{[\mu \mathbf{g} / \mathbf{s c m}]}\end{array}$ \\
\hline $14: 35$ & $14: 50$ & Low- & 3.00 & 2.70 & -2.96 & 0.30 \\
\hline $14: 50$ & $15: 05$ & High- & 10.00 & 9.75 & -2.52 & 0.25 \\
\hline $15: 05$ & $15: 20$ & Mid- & 5.00 & 4.75 & -2.49 & 0.25 \\
\hline
\end{tabular}

SCE - System calibration error

$\mathrm{C}_{\mathrm{v}}$ - Certified concentration of calibration gas

$\mathrm{C}_{\mathrm{s}}$ - Measured concentration of calibration gas

CS - Calibration span value

Acceptance criteria:

(1) $\mathrm{SCE} \leq \pm 5.0 \%$

(2) Alternatively, $\left|\mathrm{C}_{\mathrm{s}}-\mathrm{C}_{\mathrm{v}}\right| \leq 0.5 \mu \mathrm{g} / \mathrm{scm}$

Table 10: IRM System Calibration Error Test (Air Heater Outlet)

\section{System Calibration Error Test}

Facility: Hardin Generating Station

Project \#: $06-7008$

Personnel: David Young

$$
\text { Jim Domenico }
$$

$\mathbf{C S}=$
Date(s):

Unit(s) tested: Air Heater Outlet Hg-CEMS

Test Runs: N/A

Analyzer Make/Model: Thermo Mercury Freedom System $^{\mathrm{TM}}$

Serial No: 0613917146

\begin{tabular}{|c|c|c|c|c|c|c|}
\hline $\begin{array}{c}\text { Time } \\
\text { Start }\end{array}$ & $\begin{array}{c}\text { Calibration } \\
\text { Eas Level }\end{array}$ & $\begin{array}{c}\mathbf{C}_{\mathbf{v}} \\
{[\mu \mathrm{g} / \mathbf{s c m}]}\end{array}$ & $\begin{array}{c}\mathbf{C}_{\mathbf{s}} \\
{[\mu \mathbf{g} / \mathbf{s c m}]}\end{array}$ & $\begin{array}{c}\mathbf{S C E} \\
{[\%]}\end{array}$ & $\begin{array}{c}\left|\mathbf{C}_{\mathbf{s}}-\mathbf{C}_{\mathbf{v}}\right| \\
{[\mu \mathbf{g} / \mathbf{s c m}]}\end{array}$ \\
\hline $22: 15$ & $22: 30$ & Low- & 3.00 & 2.90 & -1.04 & 0.10 \\
\hline $22: 30$ & $22: 45$ & High- & 10.00 & 9.93 & -0.68 & 0.07 \\
\hline $22: 45$ & $23: 00$ & Mid- & 5.00 & 4.74 & -2.63 & 0.26 \\
\hline
\end{tabular}

SCE - System calibration error

$\mathrm{C}_{\mathrm{v}}$ - Certified concentration of calibration gas

$\mathrm{C}_{\mathrm{s}}$ - Measured concentration of calibration gas

CS - Calibration span value

Acceptance criteria:

(1) $\mathrm{SCE} \leq \pm 5.0 \%$

(2) Alternatively, $\left|\mathrm{C}_{\mathrm{s}}-\mathrm{C}_{\mathrm{v}}\right| \leq 0.5 \mu \mathrm{g} / \mathrm{scm}$ 
Table 11: IRM Measurement System Response Time (Stack)

\begin{tabular}{|c|c|c|c|c|c|c|}
\hline \multicolumn{7}{|c|}{ Measurement System Response Time Test } \\
\hline \multirow{5}{*}{$\begin{array}{r}\text { Facility: } \\
\text { Project \#: } \\
\text { Personnel: }\end{array}$} & \multicolumn{2}{|c|}{ Hardin Generating Station } & \multirow{2}{*}{\multicolumn{2}{|c|}{$\begin{array}{r}\text { Date(s): } \\
\text { Unit(s) tested: }\end{array}$}} & \multicolumn{2}{|c|}{$10 / 18 / 2008$} \\
\hline & \multicolumn{2}{|c|}{$06-7008$} & & & \multicolumn{2}{|c|}{ Stack Hg-CEMS } \\
\hline & \multicolumn{2}{|l|}{ David Young } & & Test Runs: & \multicolumn{2}{|c|}{ N/A } \\
\hline & \multicolumn{2}{|l|}{ Jim Domenico } & \multirow{2}{*}{\multicolumn{2}{|c|}{ Analyzer Make/Model: }} & \multicolumn{2}{|c|}{ Thermo Mercury Freedom } \\
\hline & & & & & \multicolumn{2}{|c|}{ System $^{\mathrm{TM}}$} \\
\hline \multicolumn{3}{|c|}{$\mu \mathrm{g} / \mathrm{scm}$} & \multicolumn{2}{|r|}{ Serial No: } & \multicolumn{2}{|l|}{0613917173} \\
\hline $\begin{array}{c}\text { Calibration } \\
\text { Gas Level } \\
\end{array}$ & $\begin{array}{c}\mathbf{C}_{\mathbf{v}} \\
{[\mu \mathrm{g} / \mathbf{s c m}]} \\
\end{array}$ & Start Time & $\begin{array}{c}\mathrm{C}_{\mathrm{s}, \mathrm{i}} \\
{[\mu \mathrm{g} / \mathrm{scm}]}\end{array}$ & End Time & $\begin{array}{c}\mathrm{C}_{\mathrm{s}, \mathrm{f}} \\
{[\mu \mathrm{g} / \mathrm{scm}]} \\
\end{array}$ & $\begin{array}{c}\text { Response Time } \\
\text { [min.] }\end{array}$ \\
\hline Low-/High- & $3.00 / 10.00$ & $14: 50$ & 2.70 & $15: 05$ & 9.75 & $04: 00$ \\
\hline \multicolumn{7}{|c|}{$\begin{array}{l}\mathrm{SCE} \text { - System calibration error } \\
\mathrm{C}_{\mathrm{V}} \text { - Certified concentration of calibration gas } \\
\mathrm{C}_{\mathrm{s}}-\text { Measured concentration of calibration gas } \\
\quad(\mathrm{i}=\text { initial, } \mathrm{f}=\text { final) } \\
\mathrm{CS} \text { - Calibration span value }\end{array}$} \\
\hline \multicolumn{7}{|c|}{$\begin{array}{l}\text { Acceptance criteria: } \\
\text { (1) Response Time } \leq 15.0 \mathrm{~min} \text {. }\end{array}$} \\
\hline
\end{tabular}

Table 12: IRM Measurement System Response Time (Air Heater Outlet)

\begin{tabular}{|c|c|c|c|c|c|c|}
\hline \multicolumn{7}{|c|}{ Measurement System Response Time Test } \\
\hline \multirow{5}{*}{$\begin{array}{r}\text { Facility: } \\
\text { Project \#: } \\
\text { Personnel: }\end{array}$} & \multicolumn{2}{|c|}{ Hardin Generating Station } & \multirow{2}{*}{\multicolumn{2}{|c|}{$\begin{array}{r}\text { Date(s): } \\
\text { Unit(s) tested: }\end{array}$}} & \multicolumn{2}{|c|}{$10 / 15 / 2008-10 / 16 / 2008$} \\
\hline & \multicolumn{2}{|c|}{$06-7008$} & & & \multicolumn{2}{|c|}{ Air Heater Outlet Hg-CEMS } \\
\hline & \multicolumn{2}{|l|}{ David Young } & \multicolumn{2}{|c|}{$\begin{array}{r}\text { Unit(s) tested: } \\
\text { Test Runs: }\end{array}$} & \multicolumn{2}{|c|}{$\mathrm{N} / \mathrm{A}$} \\
\hline & \multicolumn{2}{|l|}{ Jim Domenico } & \multirow{2}{*}{\multicolumn{2}{|c|}{ Analyzer Make/Model: }} & \multicolumn{2}{|c|}{ Thermo Mercury Freedom } \\
\hline & & & & & \multicolumn{2}{|c|}{ System $^{\mathrm{TM}}$} \\
\hline $\mathbf{C S}=$ & 10 & $\mu \mathrm{g} / \mathrm{scm}$ & 9.4349687 & Serial No: & \multicolumn{2}{|l|}{0613917146} \\
\hline $\begin{array}{c}\text { Calibration } \\
\text { Gas Level }\end{array}$ & $\begin{array}{c}\mathbf{C}_{\mathbf{v}} \\
{[\mu \mathrm{g} / \mathrm{scm}]}\end{array}$ & Start Time & $\begin{array}{c}\mathrm{C}_{\mathrm{s}, \mathrm{i}} \\
{[\mu \mathrm{g} / \mathrm{scm}]}\end{array}$ & End Time & $\begin{array}{c}\mathrm{C}_{\mathrm{s}, \mathrm{f}} \\
{[\mu \mathrm{g} / \mathrm{scm}]}\end{array}$ & $\begin{array}{l}\text { Response Time } \\
\text { [min.] }\end{array}$ \\
\hline Low-/High- & $3.00 / 10.00$ & $22: 30$ & 2.90 & $22: 45$ & 9.93 & $05: 00$ \\
\hline \multicolumn{7}{|c|}{$\begin{array}{l}\mathrm{SCE} \text { - System calibration error } \\
\mathrm{C}_{\mathrm{v}} \text { - Certified concentration of calibration gas } \\
\mathrm{C}_{\mathrm{s}} \text { - Measured concentration of calibration gas } \\
\quad \text { (i=initial, } \mathrm{f}=\text { final) } \\
\mathrm{CS} \text { - Calibration span value }\end{array}$} \\
\hline \multicolumn{7}{|c|}{$\begin{array}{l}\text { Acceptance criteria: } \\
\text { (1) Response Time } \leq 15.0 \mathrm{~min} \text {. }\end{array}$} \\
\hline
\end{tabular}


Table 13: IRM System Integrity Check (Stack)

\section{System Integrity Check}

Facility: Hardin Generating Station

Project \#: 06-7008

Personnel: David Young

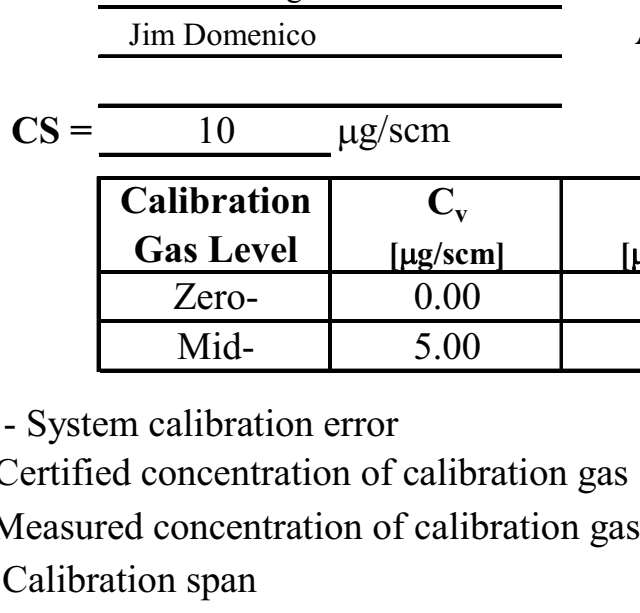

Acceptance criteria:

(1) $\mathrm{SCE} \leq \pm 5.0 \%$

(2) Alternatively, $\left|\mathrm{C}_{\mathrm{s}}-\mathrm{C}_{\mathrm{v}}\right| \leq 0.5 \mu \mathrm{g} / \mathrm{scm}$

SCE - System calibration error

$\mathrm{C}_{\mathrm{v}}$ - Certified concentration of calibration gas

$\mathrm{C}_{\mathrm{s}}$ - Measured concentration of calibration gas

CS - Calibration span
Date(s): $\quad 10 / 18 / 2008$

Unit(s) tested: Stack Hg-CEMS

Test Runs: N/A

Analyzer Make/Model: Thermo Mercury Freedom System $^{\mathrm{TM}}$

Serial No: 0613917173

Table 14: IRM System Integrity Check (Air Heater Outlet)

\section{System Integrity Check}

Facility: Hardin Generating Station

Project \#: $06-7008$

Personnel: David Young

$\mathbf{C S}=\frac{\frac{\text { Jim Domenico }}{10} \mu \mathrm{g} / \mathrm{scm}}{\text { Calibration }}$

\begin{tabular}{|c|c|c|c|c|}
\hline $\begin{array}{c}\text { Calibration } \\
\text { Gas Level }\end{array}$ & $\begin{array}{c}\mathbf{C}_{\mathbf{v}} \\
{[\mu \mathbf{g} / \mathbf{s c m}]}\end{array}$ & $\begin{array}{c}\mathbf{C}_{\mathbf{s}} \\
{[\mu \mathbf{g} / \mathbf{s c m}]}\end{array}$ & $\begin{array}{c}\mathbf{S C E} \\
{[\%]}\end{array}$ & $\begin{array}{c}\left|\mathbf{C}_{\mathbf{s}}-\mathbf{C}_{\mathbf{v}}\right| \\
{[\mu \mathbf{g} / \mathbf{s c m}]}\end{array}$ \\
\hline Zero- & 0.00 & -0.14 & -1.39 & 0.14 \\
\hline Mid- & 5.00 & 4.67 & -3.34 & 0.33 \\
\hline
\end{tabular}

SCE - System calibration error

$\mathrm{C}_{\mathrm{v}}$ - Certified concentration of calibration gas

$\mathrm{C}_{\mathrm{s}}$ - Measured concentration of calibration gas

CS - Calibration span

Acceptance criteria:

(1) $\mathrm{SCE} \leq \pm 5.0 \%$

(2) Alternatively, $\left|\mathrm{C}_{\mathrm{s}}-\mathrm{C}_{\mathrm{v}}\right| \leq 0.5 \mu \mathrm{g} / \mathrm{scm}$ 


\section{APPENDIX E: MANUAL GAS SAMPLING RESULTS}


STACK SAMPLING REPORT

FOR

PARTICULATE MATTER, HYDROGEN HALIDE \& HALOGEN, AMMONIA, MERCURY SPECIATION, AND SULFUR TRIOXIDE TESTING ON THE

ROCKY MOUNTAIN POWER HARDIN POWER PLANT

SDA INLET DUCT AND STACK

HARDIN, MONTANA

PROJECT NO. 06-057

NOVEMBER AND DECEMBER, 2006

PREPARED FOR:

ADA-ES, INC.

8100 SOUTHPARK WAY

LITTLETON, CO 80120

PREPARED BY:

AIR SAMPLING ASSOCIATES, INC.

P.O. BOX 1175

LEWISVILLE, TEXAS 75067

(Total Number of pages including cover: 904) 


\section{TABLE OF CONTENTS}

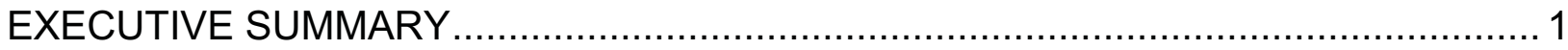

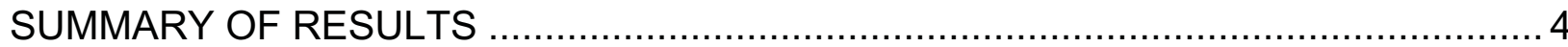

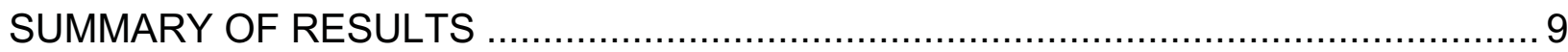

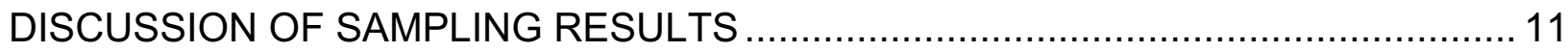

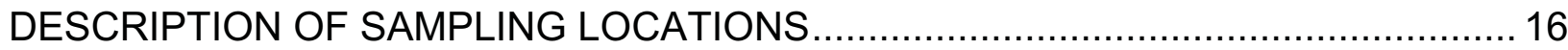

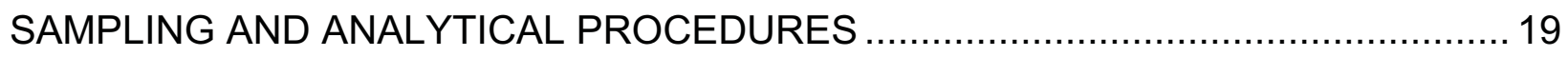

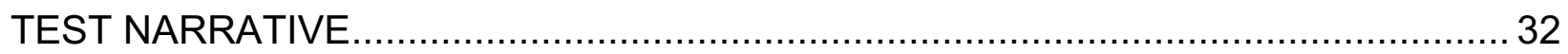

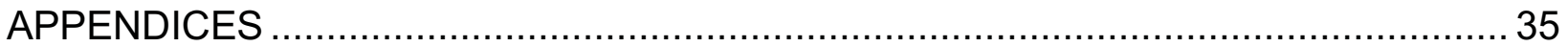

Appendix A: Location of Traverse Points ..........................................................

Appendix B: Nomenclature and Equations for Calculation of Source Emissions........B-1

Appendix C: Calibration Data ........................................................................... C-1

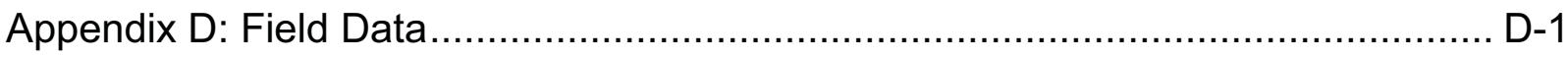

Appendix E: EPA Test Methods 5B and 202 (Particulate Matter) Analytical Data.....E-1

Appendix F: EPA Test Methods 17, 26A, and CTM027 (Particulate Matter,

Hydrogen Halides \& Halogens, and Ammonia) Analytical Data

- SDA Inlet Duct

Appendix G: EPA Conditional Test Methods 5 and 26A (Particulate Matter and

Hydrogen Halides \& Halogens) Analytical Data - Stack.

Appendix H: EPA Test Methods 5, 17 (Particulate Matter), and ASTM D6784-02

(Ontario Hydro) Mercury Speciation Test Method Analytical Data ....... H-1

Appendix I: NCASI Method 8A (Sulfur Trioxide) Analytical Data .............................. I-1

Appendix J: Chain of Custodies...........................................................................

Appendix K: Resumes of Test Personnel .................................................... K-1 


\section{TABLES}

Table 1: Summary of Sampling Results

Table 2: SDA Inlet Duct Particulate Matter, Hydrogen Halides \& Halogens,

and Ammonia Summary of Sampling Results

Table 3: SDA Inlet Duct Particulate Matter and Speciated Mercury

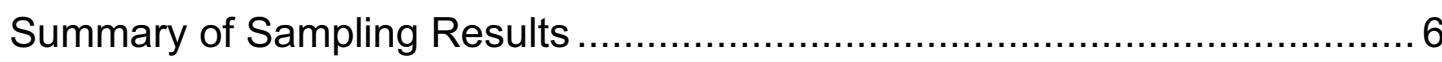

Table 4: SDA Inlet Duct Sulfur Trioxide Summary of Sampling Results ........................ 7

Table 5: Stack Particulate Matter Summary of Sampling Results .............................. 8

Table 6: Stack Particulate Matter and Hydrogen Halides \& Halogens

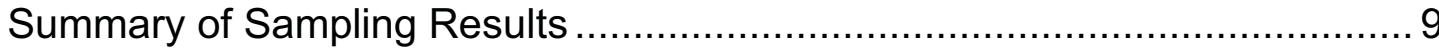

Table 7: Stack Particulate Matter and Speciated Mercury

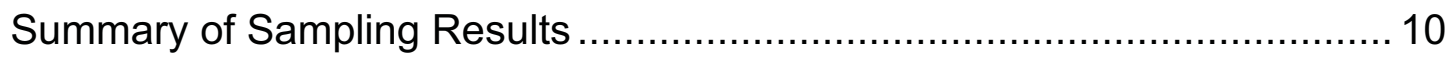

Table 8: EPA Test Methods 5B and 202 Sampling Train

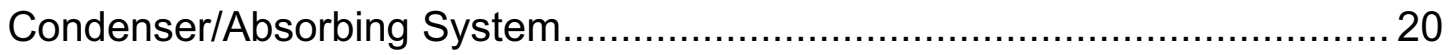

Table 9: EPA Test Method 26A Condenser/Absorbing System …….......................... 23

Table 10: ASTM D6784-02 (Ontario Hydro) Speciated Mercury Test Method

Condenser/Absorbing System............................................................ 27

Table 11: NCASI Method 8A Condenser/Absorbing System ....................................... 30

Table 12: Location Traverse Points - Stack..............................................................

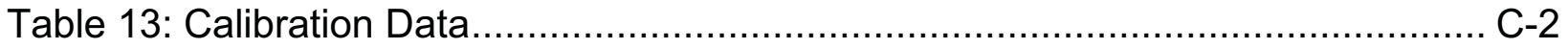




\section{FIGURES}

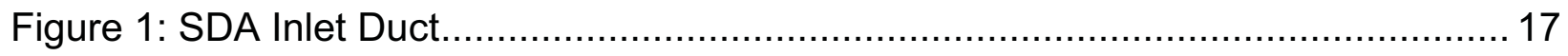

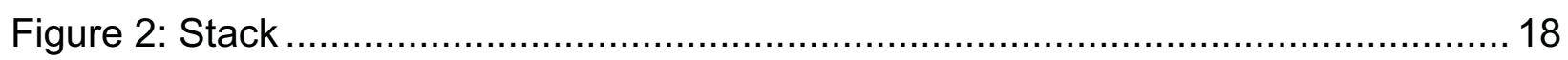

Figure 3: EPA Test Methods 5B and 202 Sampling Train ........................................ 21

Figure 4: EPA Test Methods 17, 26A, and CTM027 SDA Inlet Duct Sampling Train .... 24

Figure 5: EPA Test Methods 5 and 26A Stack Sampling Train ................................. 25

Figure 6: ASTM D6784-02 (Ontario Hydro) Mercury Speciation Test Method

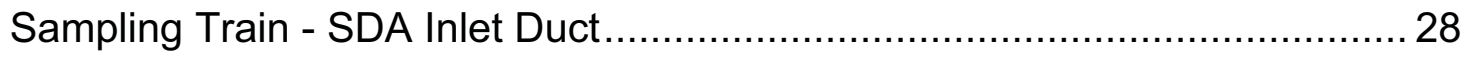

Figure 7: ASTM D6784-02 (Ontario Hydro) Mercury Speciation Test Method

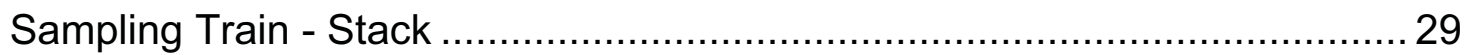

Figure 8: NCASI Method 8A SDA Inlet Duct Sampling Train ..................................... 31

Figure 9: Location of Traverse Points - SDA Inlet Duct .........................................

Figure 10: Location of Traverse Points - Stack ................................................. 


\section{EXECUTIVE SUMMARY}

Air Sampling Associates, Inc. of Lewisville, Texas conducted stack testing at the Rocky Mountain Power, Hardin Power Plant, located in Hardin, Montana. The purpose of the stack testing was to determine particulate matter emissions, hydrogen halide and halogen emissions, ammonia emissions, speciated mercury emissions, and sulfur trioxide emissions at the SDA Inlet Duct; and to determine particulate matter emissions, hydrogen halide and halogen emissions, and speciated mercury emissions at the Stack. The testing was conducted on November 27 through December 3, 2006.

The sampling team consisted of Mr. Bill Mullins, Mr. Bill Hefley, Mr. Gary Goldman, Mr. Patrick Selakovich, and Mr. Scot Jackson. Mr. Mullins was the test team leader.

Mr. Jerry Amrhein of ADA-ES was the project manager.

The procedures set forth in Title 40 of the Code of Federal Regulations, Part 60 (40CFR60), Appendix A, Test Methods 1, 2, 3, 4, 5, 5B, 17, 26A, 202, and Conditional Test Method CTM027; ASTM D6784-02 (Ontario Hydro) Mercury Speciation Method; and the National Council of the Paper Industry for Air and Stream Improvement, Inc. (NCASI) Method 8A were followed during testing.

Triplicate samples for particulate matter collected at the SDA Inlet Duct according to EPA Test Method 17, in conjunction with EPA Test Methods 26A and CTM027, indicated an average of 10,640.09 pounds per hour, based on the 'front half' analysis of the sampling train.

Triplicate samples for hydrogen halides \& halogens collected at the SDA Inlet Duct according to EPA Test Method 26A, in conjunction with EPA Test Method 17 and Conditional Test Method CTM027, indicated an average concentration of hydrogen 06-057 
bromide and an average concentration of bromine that were below the detectable limit of the sampling procedure. The sampling results indicated an average concentration of hydrogen chloride that was below the detectable limit of the sampling procedure and an average concentration of chlorine that was equal to $0.263 \mathrm{mg} / \mathrm{dscm}$. The sampling results indicated an average concentration of hydrogen fluoride and an average concentration of fluoride that were below the detectable limit of the sampling procedure.

Triplicate samples for ammonia collected at the SDA Inlet Duct according to EPA Conditional Test Method CTM027, in conjunction with EPA Test Methods 17 and 26A, indicated an average concentration of ammonia equal to $3.2 \mathrm{ppm}$.

Triplicate samples for speciated mercury collected at the SDA Inlet Duct according to the ASTM D6784-02 (Ontario Hydro) Mercury Speciation Method indicated that the average total mercury was equal to $3.965 \mathrm{lbs} / 10^{12} \mathrm{Btu}$. The average total mercury was $14.25 \%$ particulate mercury, $39.23 \%$ oxidized mercury, and $46.53 \%$ elemental mercury. Samples for particulate matter collected using the optional test procedures in the ASTM D6784-02 (Ontario Hydro) Mercury Speciation Method indicated an average of 8,837.89 pounds per hour, based on the analysis of the 'front half' of the sampling trains.

Triplicate samples for sulfur trioxide were collected at the SDA Inlet Duct according to NCASI Method 8A indicated an average concentration of sulfur trioxide was equal to $3.50 \mathrm{ppm}$.

Triplicate samples for particulate matter collected at the Stack according to EPA Test Methods 5 and 202 indicated an average of 32.22 pounds per hour, based on the analysis of the 'front half' and 'back half' of the sampling trains.

Triplicate samples for hydrogen halides \& halogens collected at the Stack indicated an average concentration of hydrogen bromide and an average concentration of bromine that were below the detectable limit of the sampling procedure. The sampling results 06-057 


\section{II}

indicated an average concentration of hydrogen chloride that was below the detectable limit of the sampling procedure and an average concentration of chlorine that was equal to $0.384 \mathrm{mg} / \mathrm{dscm}$. The sampling results indicated an average concentration of hydrogen fluoride and an average concentration of fluoride that were below the detectable limit of the sampling procedure. Samples for particulate matter collected using the optional test procedures in EPA Test Method 26A indicated an average of 22.09 pounds per hour, based on the analysis of the 'front half' of the sampling trains.

Triplicate samples for speciated mercury collected at the Stack according to the ASTM D6784-02 (Ontario Hydro) Mercury Speciation Method indicated that the average total mercury was equal to $3.745 \mathrm{lbs} / 10^{12} \mathrm{Btu}$. The average total mercury was $98.84 \%$ elemental mercury. Samples for particulate matter collected using the optional test procedures in the ASTM D6784-02 (Ontario Hydro) Mercury Speciation Method indicated an average of 20.49 pounds per hour, based on the analysis of the 'front half' of the sampling trains.

Billy J. Mullins, Jr. P.E., Q.E.P., D.E.E. 


\section{SUMMARY OF RESULTS}

\section{Table 1: Summary of Sampling Results}

\begin{tabular}{|c|c|c|}
\hline $\begin{array}{l}\text { Sampling Trains } \\
\text { - Parameters }\end{array}$ & $\begin{array}{c}\text { SDA Inlet Duct } \\
\text { Average }\end{array}$ & $\begin{array}{c}\text { Stack } \\
\text { Average }\end{array}$ \\
\hline $\begin{array}{l}\text { EPA 5B } \\
\text { - Moisture (\%) } \\
\text { - Flow Rate (DSCFM) } \\
\text { - Particulate Matter (Ibs/hr - total) }\end{array}$ & $\begin{array}{l}\text { NA } \\
\text { NA } \\
\text { NA }\end{array}$ & $\begin{array}{c}14.80 \\
294,956 \\
32.22\end{array}$ \\
\hline $\begin{array}{l}\text { EPA } 5 \text { / } 17 \text { / 26A / CTM027 } \\
\text { - Moisture (\%) } \\
\text { - Flow Rate (DSCFM) } \\
\text { - Particulate Matter (lbs/hr - front half) } \\
\text { - Chlorine (mg/dscm) } \\
\text { - Ammonia (ppm) }\end{array}$ & $\begin{array}{c}10.69 \\
292,800 \\
10,640.09 \\
0.263 \\
3.2\end{array}$ & $\begin{array}{l}15.07 \\
293,809 \\
22.09 \\
0.384 \\
\text { NA }\end{array}$ \\
\hline $\begin{array}{l}\text { EPA } 5 \text { / } 17 \text { I ASTM D6784-02 } \\
\text { - Moisture (\%) } \\
\text { - Flow Rate (DSCFM) } \\
\text { - Particulate Matter (Ibs/hr - front half) } \\
\text { - Total Mercury (Ibs/10 } 12 \text { Btu) }\end{array}$ & $\begin{array}{c}10.18 \\
291,987 \\
8,837.89 \\
3.965\end{array}$ & $\begin{array}{c}14.72 \\
295,482 \\
20.49 \\
3.745\end{array}$ \\
\hline $\begin{array}{l}\text { NCASI 8A } \\
\text { - Moisture (\%) } \\
\text { - Sulfur Trioxide (ppm) }\end{array}$ & $\begin{array}{c}10.47 \\
3.50 \\
\end{array}$ & $\begin{array}{l}\text { NA } \\
\text { NA }\end{array}$ \\
\hline
\end{tabular}




\section{II \\ ASSOCIATES, INC. \\ SUMMARY OF RESULTS}

Table 2: SDA Inlet Duct Particulate Matter, Hydrogen Halides \&

Halogens, and Ammonia Summary of Sampling Results

\begin{tabular}{|c|c|c|c|c|}
\hline Run No. & 1 & 2 & 3 & Average \\
\hline Test Date & $11 / 30 / 06$ & $12 / 01 / 06$ & $12 / 01 / 06$ & ----- \\
\hline Test Time & 1454-1559 & $1203-1305$ & $1647-1749$ & ---- \\
\hline Flow Rate-DSCFM* & 290,174 & 294,636 & 293,589 & 292,800 \\
\hline Stack Temp. - ${ }^{\circ} \mathrm{F}$ & 319 & 316 & 322 & 319 \\
\hline $\mathrm{O}_{2}$ - \% Vol. (dry) & 5.2 & 6.0 & 5.7 & 5.6 \\
\hline $\mathrm{CO}_{2}-\% \mathrm{Vol}$. (dry) & 14.3 & 13.3 & 13.8 & 13.8 \\
\hline Percent Excess Air & 32.2 & 39.0 & 36.5 & 35.9 \\
\hline Moisture Content - \% & 10.85 & 10.76 & 10.47 & 10.69 \\
\hline Percent Isokinetic & 89.3 & 95.3 & 96.4 & 93.7 \\
\hline Sample Volume-DSCM & 0.634 & 0.687 & 0.693 & 0.671 \\
\hline $\begin{array}{l}\text { Particulate Matter } \\
\text { - gr/dscf (Front Half) } \\
\text { - lbs/hr (Front Half) }\end{array}$ & $\begin{array}{c}4.1271 \\
10,263.30\end{array}$ & $\begin{array}{c}4.5853 \\
11,578.01\end{array}$ & $\begin{array}{c}4.0059 \\
10,078.95\end{array}$ & $\begin{array}{c}4.2394 \\
10,640.09\end{array}$ \\
\hline $\begin{array}{l}\text { Hydrogen Bromide } \\
-\mathrm{mg} \\
-\mathrm{mg} / \mathrm{dscm}\end{array}$ & $\begin{array}{l}\text { ND } \\
\text { ND }\end{array}$ & $\begin{array}{l}\text { ND } \\
\text { ND }\end{array}$ & $\begin{array}{l}\text { ND } \\
\text { ND }\end{array}$ & $\begin{array}{l}\text { ND } \\
\text { ND }\end{array}$ \\
\hline $\begin{array}{l}\text { Bromine } \\
-m g \\
-m g / d s c m\end{array}$ & $\begin{array}{l}\text { ND } \\
\text { ND }\end{array}$ & $\begin{array}{l}\text { ND } \\
\text { ND }\end{array}$ & $\begin{array}{l}\text { ND } \\
\text { ND }\end{array}$ & $\begin{array}{l}\text { ND } \\
\text { ND }\end{array}$ \\
\hline $\begin{array}{l}\text { Hydrogen Chloride } \\
-m g \\
-m g / d s c m\end{array}$ & $\begin{array}{l}\text { ND } \\
\text { ND }\end{array}$ & $\begin{array}{l}\text { ND } \\
\text { ND }\end{array}$ & $\begin{array}{l}\text { ND } \\
\text { ND }\end{array}$ & $\begin{array}{l}\text { ND } \\
\text { ND }\end{array}$ \\
\hline $\begin{array}{l}\text { Chlorine } \\
- \text { - mg } \\
-m g / d s c m\end{array}$ & $\begin{array}{l}0.216 \\
0.341\end{array}$ & $\begin{array}{l}0.151 \\
0.220\end{array}$ & $\begin{array}{l}0.159 \\
0.229\end{array}$ & $\begin{array}{l}0.175 \\
0.263\end{array}$ \\
\hline $\begin{array}{l}\text { Hydrogen Fluoride } \\
- \text { mg } \\
-m g / d s c m\end{array}$ & $\begin{array}{l}\text { ND } \\
\text { ND }\end{array}$ & $\begin{array}{l}\text { ND } \\
\text { ND }\end{array}$ & $\begin{array}{l}\text { ND } \\
\text { ND }\end{array}$ & $\begin{array}{l}\text { ND } \\
\text { ND }\end{array}$ \\
\hline $\begin{array}{l}\text { Fluorine } \\
\text { - } m g \\
\text { - mg/dscm }\end{array}$ & $\begin{array}{l}\text { ND } \\
\text { ND }\end{array}$ & $\begin{array}{l}\text { ND } \\
\text { ND }\end{array}$ & $\begin{array}{l}\text { ND } \\
\text { ND }\end{array}$ & $\begin{array}{l}\text { ND } \\
\text { ND }\end{array}$ \\
\hline Ammonia - ppm & 4.8 & 1.6 & 3.3 & 3.2 \\
\hline
\end{tabular}

* $29.92 " \mathrm{Hg}, 68^{\circ} \mathrm{F}\left(760 \mathrm{~mm} \mathrm{Hg}, 20^{\circ} \mathrm{C}\right)$ 


\section{II \\ ASSOCIATES, INC. \\ SUMMARY OF RESULTS}

Table 3: SDA Inlet Duct Particulate Matter and Speciated Mercury

Summary of Sampling Results

\begin{tabular}{|c|c|c|c|c|}
\hline Run No. & 1 & 2 & 3 & Average \\
\hline Test Date & $12 / 01 / 06$ & $12 / 02 / 06$ & $12 / 02 / 06$ & ---- \\
\hline Test Time & 0857-1059 & 0919-1121 & $1712-1914$ & ---- \\
\hline Flow Rate-DSCFM* & 288,573 & 292,703 & 294,686 & 291,987 \\
\hline Stack Temp. - ${ }^{\circ} F$ & 315 & 317 & 320 & 317 \\
\hline $\mathrm{O}_{2}$ - \% Vol. (dry) & 6.4 & 6.1 & 6.2 & 6.2 \\
\hline $\mathrm{CO}_{2}-\%$ Vol. (dry) & 14.2 & 13.9 & 13.1 & 13.7 \\
\hline Percent Excess Air & 43.7 & 40.4 & 40.8 & 41.6 \\
\hline Moisture Content - \% & 10.24 & 10.26 & 10.04 & 10.18 \\
\hline Percent Isokinetic & 96.0 & 95.3 & 96.9 & 96.1 \\
\hline Sample Volume - DSCM & 1.343 & 1.352 & 1.383 & 1.359 \\
\hline $\begin{array}{l}\text { Particulate Matter } \\
\text { - gr/dscf (Front Half) } \\
\text { - Ibs/hr (Front Half) }\end{array}$ & $\begin{array}{c}3.4560 \\
8,546.94\end{array}$ & $\begin{array}{c}3.8851 \\
9,745.73\end{array}$ & $\begin{array}{c}3.2552 \\
8,220.99\end{array}$ & $\begin{array}{c}3.5321 \\
8,837.89\end{array}$ \\
\hline $\begin{array}{l}\text { Particle Bound Mercury } \\
-\mu g \\
-\mu g / d s c m \\
-/ \mathrm{lbs} / 10^{12} \mathrm{Btu}^{* *}\end{array}$ & $\begin{array}{l}0.6100 \\
0.4542 \\
0.400\end{array}$ & $\begin{array}{l}1.5000 \\
1.1095 \\
0.957\end{array}$ & $\begin{array}{l}0.6400 \\
0.4628 \\
0.402\end{array}$ & $\begin{array}{l}0.9167 \\
0.6755 \\
0.586\end{array}$ \\
\hline $\begin{array}{l}\text { Oxidized Mercury } \\
-\mu g \\
-\mu g / d s c m \\
-l b s / 10^{12} B t u^{* *}\end{array}$ & $\begin{array}{c}1.6000 \\
1.1914 \\
1.049\end{array}$ & $\begin{array}{c}1.7000 \\
1.2574 \\
1.085\end{array}$ & $\begin{array}{l}3.3000 \\
2.3861 \\
2.072\end{array}$ & $\begin{array}{c}2.2000 \\
1.6116 \\
1.402\end{array}$ \\
\hline $\begin{array}{l}\text { Elemental Mercury } \\
-\mu g \\
-\mu g / d s c m \\
-l \mathrm{bs} / 10^{12} \mathrm{Btu}^{* *}\end{array}$ & $\begin{array}{l}3.6640 \\
2.7282 \\
2.402\end{array}$ & $\begin{array}{l}4.7000 \\
3.4763 \\
2.999\end{array}$ & $\begin{array}{l}0.8480 \\
0.6132 \\
0.532\end{array}$ & $\begin{array}{l}3.0707 \\
2.2726 \\
1.978\end{array}$ \\
\hline $\begin{array}{l}\text { Total Mercury } \\
-\mu g \\
-\mu g / d s c m \\
-/ b s / 10^{12} B^{* *}\end{array}$ & $\begin{array}{c}5.8740 \\
4.3738 \\
3.850 \\
\end{array}$ & $\begin{array}{c}7.9000 \\
5.8432 \\
5.040\end{array}$ & $\begin{array}{l}4.7880 \\
3.4620 \\
3.006\end{array}$ & $\begin{array}{c}6.1873 \\
4.5597 \\
3.965\end{array}$ \\
\hline
\end{tabular}




\section{SUMMARY OF RESULTS}

Table 4: SDA Inlet Duct Sulfur Trioxide Summary of Sampling Results

\begin{tabular}{|l|c|c|c|c|}
\hline Run No. & 1 & 2 & 3 & Average \\
\hline Test Date & $11 / 30 / 06$ & $11 / 30 / 06$ & $12 / 01 / 06$ & ---- \\
\hline Test Time & $1323-1423$ & $1648-1748$ & $1401-1501$ & ---- \\
Sample Volume - DSCM* & 0.549 & 0.558 & 0.557 & 0.555 \\
Moisture Content - \% & 10.06 & 10.70 & 10.67 & 10.48 \\
Sulfur Trioxide - ppm & 3.69 & 4.20 & 2.60 & 3.50 \\
\hline
\end{tabular}

* 29.92" Hg, $68^{\circ} \mathrm{F}\left(760 \mathrm{~mm} \mathrm{Hg}, 20^{\circ} \mathrm{C}\right)$ 


\section{II \\ ASSOCIATES, INC.}

\section{SUMMARY OF RESULTS}

Table 5: Stack Particulate Matter

Summary of Sampling Results

\begin{tabular}{|c|c|c|c|c|}
\hline Run No. & 4 & 5 & 6 & Average \\
\hline Test Date & $11 / 30 / 06$ & $11 / 30 / 06$ & $11 / 30 / 06$ & ----- \\
\hline Test Time & 1334-1542 & 1204-1409 & 1215-1419 & ----- \\
\hline Flow Rate - DSCFM* & 297,911 & 290,628 & 296,329 & 294,956 \\
\hline Stack Temperature - ${ }^{\circ} \mathrm{F}$ & 210 & 206 & 205 & 207 \\
\hline $\mathrm{O}_{2}-\%$ Volume dry & 7.9 & 6.2 & 6.2 & 6.8 \\
\hline $\mathrm{CO}_{2}-\%$ Volume dry & 12.1 & 13.0 & 13.3 & 12.8 \\
\hline Percent Excess Air & 59.4 & 40.8 & 41.0 & 47.1 \\
\hline Moisture Content - \% & 14.69 & 15.13 & 14.59 & 14.80 \\
\hline Percent Isokinetic & 99.6 & 99.5 & 98.2 & 99.1 \\
\hline $\begin{array}{l}\text { Particulate Matter } \\
\text { - gr/dscf (Front Half) } \\
\text { - Ibs/mmBtu (Front Half)** } \\
\text { - Ibs/hr (Front Half) }\end{array}$ & $\begin{array}{c}0.0058 \\
0.0130 \\
14.83\end{array}$ & $\begin{array}{c}0.0074 \\
0.0147 \\
18.40\end{array}$ & $\begin{array}{c}0.0078 \\
0.0155 \\
19.83\end{array}$ & $\begin{array}{c}0.0070 \\
0.0144 \\
17.69\end{array}$ \\
\hline $\begin{array}{l}\text { Particulate Matter } \\
\text { - gr/dscf (Total) } \\
\text { - Ibs/mmBtu (Total)** } \\
\text { - Ibs/hr (Total) }\end{array}$ & $\begin{array}{c}0.0135 \\
0.0580 \\
34.44 \\
\end{array}$ & $\begin{array}{c}0.0148 \\
0.0294 \\
36.81 \\
\end{array}$ & $\begin{array}{c}0.0100 \\
0.0199 \\
25.42 \\
\end{array}$ & $\begin{array}{c}0.0128 \\
0.0358 \\
32.22 \\
\end{array}$ \\
\hline
\end{tabular}

* 29.92" Hg, $68^{\circ} \mathrm{F}\left(760 \mathrm{~mm} \mathrm{Hg}, 20^{\circ} \mathrm{C}\right)$

** Calculated using an $F_{d}$ Factor of 9,780 


\section{IIf AlR SAMPLING}

\section{SUMMARY OF RESULTS}

Table 6: Stack Particulate Matter and Hydrogen Halides \& Halogens Summary of Sampling Results

\begin{tabular}{|c|c|c|c|c|}
\hline Run No. & 1 & 2 & 3 & Average \\
\hline Test Date & $11 / 30 / 06$ & $12 / 01 / 06$ & $12 / 02 / 06$ & $\begin{array}{ll}---- \\
\end{array}$ \\
\hline Test Time & $1642-1759$ & $1509-1626$ & 2025-2141 & ----- \\
\hline Flow Rate - DSCFM* & 294,798 & 297,054 & 289,575 & 293,809 \\
\hline Stack Temp. - ${ }^{\circ} \mathrm{F}$ & 211 & 204 & 213 & 209 \\
\hline $\mathrm{O}_{2}-\%$ Vol. (dry) & 7.6 & 6.7 & 6.3 & 6.9 \\
\hline $\mathrm{CO}_{2}-\% \mathrm{Vol}$. (dry) & 11.6 & 12.8 & 13.2 & 12.5 \\
\hline Percent Excess Air & 55.0 & 45.8 & 41.9 & 47.6 \\
\hline Moisture Content - \% & 15.31 & 14.98 & 14.93 & 15.07 \\
\hline Percent Isokinetic & 104.0 & 99.7 & 100.4 & 101.4 \\
\hline Sample Volume - DSCM & 1.239 & 1.197 & 1.175 & 1.204 \\
\hline $\begin{array}{l}\text { Particulate Matter } \\
\text { - gr/dscf (Front Half) } \\
\text { - Ibs/hr (Front Half) }\end{array}$ & $\begin{array}{c}0.0084 \\
21.17\end{array}$ & $\begin{array}{c}0.0091 \\
23.27\end{array}$ & $\begin{array}{c}0.0088 \\
21.83\end{array}$ & $\begin{array}{c}0.0088 \\
22.09\end{array}$ \\
\hline $\begin{array}{l}\text { Hydrogen Bromide } \\
- \text { mg } \\
-m g / d s c m\end{array}$ & $\begin{array}{l}\text { ND } \\
\text { ND }\end{array}$ & $\begin{array}{l}\text { ND } \\
\text { ND }\end{array}$ & $\begin{array}{l}\text { ND } \\
\text { ND }\end{array}$ & $\begin{array}{l}\text { ND } \\
\text { ND }\end{array}$ \\
\hline $\begin{array}{l}\text { Bromine } \\
\quad-m g \\
-m g / d s c m\end{array}$ & $\begin{array}{l}\text { ND } \\
\text { ND }\end{array}$ & $\begin{array}{l}\text { ND } \\
\text { ND }\end{array}$ & $\begin{array}{l}\text { ND } \\
\text { ND }\end{array}$ & $\begin{array}{l}\text { ND } \\
\text { ND }\end{array}$ \\
\hline $\begin{array}{l}\text { Hydrogen Chloride } \\
-m g \\
-m g / d s c m\end{array}$ & $\begin{array}{l}\text { ND } \\
\text { ND }\end{array}$ & $\begin{array}{l}\text { ND } \\
\text { ND }\end{array}$ & $\begin{array}{l}\text { ND } \\
\text { ND }\end{array}$ & $\begin{array}{l}\text { ND } \\
\text { ND }\end{array}$ \\
\hline $\begin{array}{l}\text { Chlorine } \\
\text { - mg } \\
-m g / d s c m\end{array}$ & $\begin{array}{l}0.440 \\
0.355\end{array}$ & $\begin{array}{l}0.480 \\
0.387\end{array}$ & $\begin{array}{l}0.483 \\
0.411\end{array}$ & $\begin{array}{l}0.468 \\
0.384\end{array}$ \\
\hline $\begin{array}{l}\text { Hydrogen Fluoride } \\
\text { - mg } \\
- \text { mg/dscm }\end{array}$ & $\begin{array}{l}\text { ND } \\
\text { ND }\end{array}$ & $\begin{array}{l}\text { ND } \\
\text { ND }\end{array}$ & $\begin{array}{l}\text { ND } \\
\text { ND }\end{array}$ & $\begin{array}{l}\text { ND } \\
\text { ND }\end{array}$ \\
\hline $\begin{array}{l}\text { Fluorine } \\
\text { - mg } \\
-m g / d s c m\end{array}$ & $\begin{array}{l}\text { ND } \\
\text { ND }\end{array}$ & $\begin{array}{l}\text { ND } \\
\text { ND }\end{array}$ & $\begin{array}{l}\text { ND } \\
\text { ND }\end{array}$ & $\begin{array}{l}\text { ND } \\
\text { ND }\end{array}$ \\
\hline
\end{tabular}

* 29.92" Hg, $68^{\circ} \mathrm{F}\left(760 \mathrm{~mm} \mathrm{Hg}, 20^{\circ} \mathrm{C}\right)$ 


\section{AIR ARPLLNG ASSOCIATES, INC. SUMMARY OF RESULTS}

Table 7: Stack Particulate Matter and Speciated Mercury Summary of Sampling Results

\begin{tabular}{|c|c|c|c|c|}
\hline Run No. & 1 & 2 & 3 & Average \\
\hline Test Date & $12 / 01 / 06$ & $12 / 02 / 06$ & $12 / 02 / 06$ & ---- \\
\hline Test Time & 0857-1105 & 0919-1124 & 1712-1917 & ---- \\
\hline Flow Rate - DSCFM* & 295,083 & 299,743 & 291,619 & 295,482 \\
\hline Stack Temp. - ${ }^{\circ} F$ & 212 & 207 & 212 & 210 \\
\hline $\mathrm{O}_{2}-\%$ Vol. (dry) & 6.2 & 6.4 & 6.2 & 6.3 \\
\hline $\mathrm{CO}_{2}-\%$ Vol. (dry) & 12.8 & 13.2 & 13.3 & 13.1 \\
\hline Percent Excess Air & 40.6 & 42.9 & 41.0 & 41.5 \\
\hline Moisture Content - \% & 14.77 & 14.88 & 14.52 & 14.72 \\
\hline Percent Isokinetic & 99.8 & 100.5 & 99.1 & 99.8 \\
\hline Sample Volume - DSCM & 1.983 & 2.028 & 1.945 & 1.985 \\
\hline $\begin{array}{l}\text { Particulate Matter } \\
\text { - gr/dscf (Front Half) } \\
\text { - Ibs/hr (Front Half) }\end{array}$ & $\begin{array}{c}0.0085 \\
21.57\end{array}$ & $\begin{array}{c}0.0072 \\
18.39\end{array}$ & $\begin{array}{c}0.0086 \\
21.51\end{array}$ & $\begin{array}{c}0.0081 \\
20.49\end{array}$ \\
\hline $\begin{array}{l}\text { Particle Bound Mercury } \\
-\mu g \\
-\mu g / d s c m \\
-I \mathrm{lbs} / 10^{12} \mathrm{Btu}^{* *}\end{array}$ & $\begin{array}{l}0.0380 \\
0.0192 \\
0.017\end{array}$ & $\begin{array}{l}\text { ND } \\
\text { ND } \\
\text { ND }\end{array}$ & $\begin{array}{l}0.0090 \\
0.0046 \\
0.004\end{array}$ & $\begin{array}{l}<0.0157 \\
<0.0079 \\
<0.007\end{array}$ \\
\hline $\begin{array}{l}\text { Oxidized Mercury } \\
-\mu g \\
-\mu g / d s c m \\
-I b s / 10^{12} B t u^{* *}\end{array}$ & $\begin{array}{l}0.1100 \\
0.0555 \\
0.048\end{array}$ & $\begin{array}{l}\text { ND } \\
\text { ND } \\
\text { ND }\end{array}$ & $\begin{array}{l}0.0800 \\
0.0411 \\
0.036\end{array}$ & $\begin{array}{l}<0.0633 \\
<0.0322 \\
<0.028\end{array}$ \\
\hline $\begin{array}{l}\text { Elemental Mercury } \\
-\mu g \\
-\mu g / d s c m \\
-~ / b s / 10^{12} B_{t u}^{* *}\end{array}$ & $\begin{array}{l}6.8410 \\
3.4498 \\
2.995\end{array}$ & $\begin{array}{c}12.1000 \\
5.9665 \\
5.251\end{array}$ & $\begin{array}{c}6.4640 \\
3.3234 \\
2.885\end{array}$ & $\begin{array}{c}8.4683 \\
4.2466 \\
3.710\end{array}$ \\
\hline $\begin{array}{l}\text { Total Mercury } \\
\text { - } \mu \mathrm{g} \\
-\mu \mathrm{g} / \mathrm{dscm} \\
-\mathrm{lbs} / 10^{12} \mathrm{Btu}^{\star *}\end{array}$ & $\begin{array}{c}6.9890 \\
3.5245 \\
3.059 \\
\end{array}$ & $\begin{array}{c}12.1000 \\
5.9665 \\
5.251 \\
\end{array}$ & $\begin{array}{c}6.5530 \\
3.3692 \\
2.924 \\
\end{array}$ & $\begin{array}{c}8.5473 \\
4.2867 \\
3.745\end{array}$ \\
\hline
\end{tabular}




\title{
DISCUSSION OF SAMPLING RESULTS
}

\author{
SDA Inlet Duct
}

\section{Particulate Matter, Hydrogen Halides \& Halogens, and Ammonia}

The three tests for particulate matter, hydrogen halides \& halogens, and ammonia taken at the SDA Inlet Duct appeared to be an accurate representation of the actual emissions during the tests. All leak checks performed on the reference method sampling train and pitot tubes showed no leaks before or after testing. The indicative parameters of the tests were in close agreement. The measured moisture contents $(\% \mathrm{M})$ were within $2.09 \%$ of the mean value. The measured flow rates (DSCFM) were within $0.90 \%$ of the mean value. Run No. 1 exceeded the specified rates of sampling for the test. The specified rates of sampling are $90 \%$ to $110 \%$ isokinetic. The greatest deviation from $100 \%$ isokinetic, Run No. 1 , was $10.7 \%$. Any effect on the data would be a slightly high bias.

The concentrations ( $\mathrm{gr} / \mathrm{dscf}$ - front Half) of particulate matter for the three tests showed a range of -5.51 percent to +8.16 percent variation from the mean value of 4.2394 gr/dscf - front half.

The concentrations $(\mathrm{mg} / \mathrm{dscm})$ of hydrogen bromide and bromine for the three tests were below the minimum reporting limit of the reference method.

The concentrations $(\mathrm{mg} / \mathrm{dscm})$ of hydrogen chloride for the three tests were below the minimum reporting limit of the reference method. The concentrations of chlorine $(\mathrm{mg} / \mathrm{dscm})$ of for the three tests showed a range of $-16.46 \%$ to $+29.49 \%$ variation from the mean value of $0.263 \mathrm{mg} / \mathrm{dscm}$. 
The concentrations $(\mathrm{mg} / \mathrm{dscm})$ of hydrogen fluoride and fluorine for the three tests were below the minimum reporting limit of the reference method.

The concentrations (ppm) of ammonia for the three tests showed a range of $-50.52 \%$ to $+48.45 \%$ variation from the mean value of $3.2 \mathrm{ppm}$. The high variation is due to the low concentrations of ammonia measured.

\section{Particulate Matter and Speciated Mercury}

The three tests for particulate matter and speciated mercury taken at the SDA Inlet Duct appeared to be an accurate representation of the actual emissions during the tests. All leak checks performed on the sampling train and the pitot tubes indicated no leaks before or after each test. The indicative parameters calculated from the field data were in reasonable agreement. The measured moisture contents for the three runs were within $1.37 \%$ of the mean value. The measured flow rates (DSCFM) for the tests were within $1.17 \%$ of the mean value. The rates of sampling for the three tests were within the specified limits (90 to 110 percent isokinetic). The greatest deviation from $100 \%$ isokinetic was $4.7 \%$.

The concentrations ( $\mathrm{gr} / \mathrm{dscf}$ - front Half) of particulate matter for the three tests showed a range of -7.84 percent to +9.99 percent variation from the mean value of 3.5321 $\mathrm{gr} / \mathrm{dscf}$ - front half.

The calculated emissions ( $\mathrm{lbs} / 10^{12} \mathrm{Btu}$ ) of total mercury for the three tests showed a range of $-24.19 \%$ to $+27.10 \%$ deviation from the mean value of $3.965 \mathrm{lbs} / 10^{12} \mathrm{Btu}$. 


\section{Sulfur Trioxide}

The three tests for sulfur trioxide taken at the SDA Inlet Duct appeared to be an accurate representation of the actual emissions during the tests. All leak checks performed on the reference method sampling train and pitot tubes showed no leaks before or after testing. The indicative parameters of the tests were in close agreement. The measured moisture contents (\%M) were within $3.98 \%$ of the mean value.

The concentrations (ppm) of sulfur dioxide for the three tests showed a range of -25.64 percent to +20.11 percent variation from the mean value of $3.50 \mathrm{ppm}$.

\section{Stack}

\section{Particulate Matter}

The three tests for particulate matter at the Stack appeared to be an accurate representation of the actual emissions during the tests. All leak checks performed on the reference method sampling train and pitot tubes showed no leaks before or after testing. The indicative parameters of the tests were in close agreement. The measured moisture contents $(\% \mathrm{M})$ were within $2.21 \%$ of the mean value. The measured flow rates (DSCFM) were within $1.47 \%$ of the mean value. The rates of sampling for the tests were within the specified limits (90\% to $110 \%$ isokinetic). The greatest deviation from $100 \%$ isokinetic was $1.8 \%$.

The concentrations ( $\mathrm{gr} / \mathrm{dscf}$ - total) of particulate matter for the three tests showed a range of -21.88 percent to +15.63 percent variation from the mean value of 0.0128 $\mathrm{gr} / \mathrm{dscf}$ - total. 


\section{Particulate Matter and Hydrogen Halides \& Halogens}

The three tests for particulate matter and hydrogen halides \& halogens taken at the Stack appeared to be an accurate representation of the actual emissions during the tests. All leak checks performed on the reference method sampling train and pitot tubes showed no leaks before or after testing. The indicative parameters of the tests were in close agreement. The measured moisture contents $(\% \mathrm{M})$ were within $1.57 \%$ of the mean value. The measured flow rates (DSCFM) were within $1.44 \%$ of the mean value. The rates of sampling for the tests were within the specified limits $(90 \%$ to $110 \%$ isokinetic). The greatest deviation from $100 \%$ isokinetic was $4.0 \%$.

The concentrations (gr/dscf - Front Half) of particulate matter for the three tests showed a range of -4.55 percent to +3.41 percent variation from the mean value of 0.0088 gr/dscf - front half.

The concentrations $(\mathrm{mg} / \mathrm{dscm})$ of hydrogen bromide and bromine for the three tests were below the minimum reporting limit of the reference method.

The concentrations $(\mathrm{mg} / \mathrm{dscm})$ of hydrogen chloride for the three tests were below the minimum reporting limit of the reference method. The concentrations of chlorine $(\mathrm{mg} / \mathrm{dscm})$ for the three tests showed a range of $-7.63 \%$ to $+6.94 \%$ variation from the mean value of $0.384 \mathrm{mg} / \mathrm{dscm}$.

The concentrations $(\mathrm{mg} / \mathrm{dscm}$ ) of hydrogen fluoride and fluorine for the three tests were below the minimum reporting limit of the reference method. 


\section{Particulate Matter and Speciated Mercury}

The three tests for particulate matter and speciated mercury on the Stack appeared to be an accurate representation of the actual emissions during the tests. All leak checks performed on the sampling train and the pitot tubes indicated no leaks before or after each test. The indicative parameters calculated from the field data were in reasonable agreement. The measured moisture contents for the three runs were within $1.38 \%$ of the mean value. The measured flow rates (DSCFM) for the tests were within $1.44 \%$ of the mean value. The rates of sampling for the three tests were within the specified limits (90 to 110 percent isokinetic). The greatest deviation from $100 \%$ isokinetic was $0.9 \%$.

The concentrations ( $\mathrm{gr} / \mathrm{dscf}$ - front Half) of particulate matter for the three tests showed a range of -11.11 percent to +6.17 percent variation from the mean value of 0.0081 gr/dscf - front half.

The calculated emissions ( $\mathrm{lbs} / 10^{12} \mathrm{Btu}$ ) of total mercury for the three tests showed a range of $-21.92 \%$ to $+40.21 \%$ deviation from the mean value of $3.745 \mathrm{lbs} / 10^{12} \mathrm{Btu}$. 


\section{DESCRIPTION OF SAMPLING LOCATIONS}

The sampling ports on the SDA Inlet Duct are approximately 36 feet $91 / 2$ inches above the ground. The sampling ports are located 13 feet 4 inches (1.12 equivalent duct diameters) downstream from a bend in the bend in the duct and 56 feet 3 inches (4.75 equivalent duct diameters) upstream from a bend in the duct.

The sampling ports on the Stack are approximately 123 feet $11 / 2$ inches above the ground. The sampling ports are located 33 feet 1 1/2 inches (3.64 stack diameters) downstream from the inlet to the stack and $>18$ feet $23 / 8$ inches $(>2.00$ stack diameters) upstream from the outlet to the stack. 


\section{SAMPLING LOCATION}

Figure 1: SDA Inlet Duct

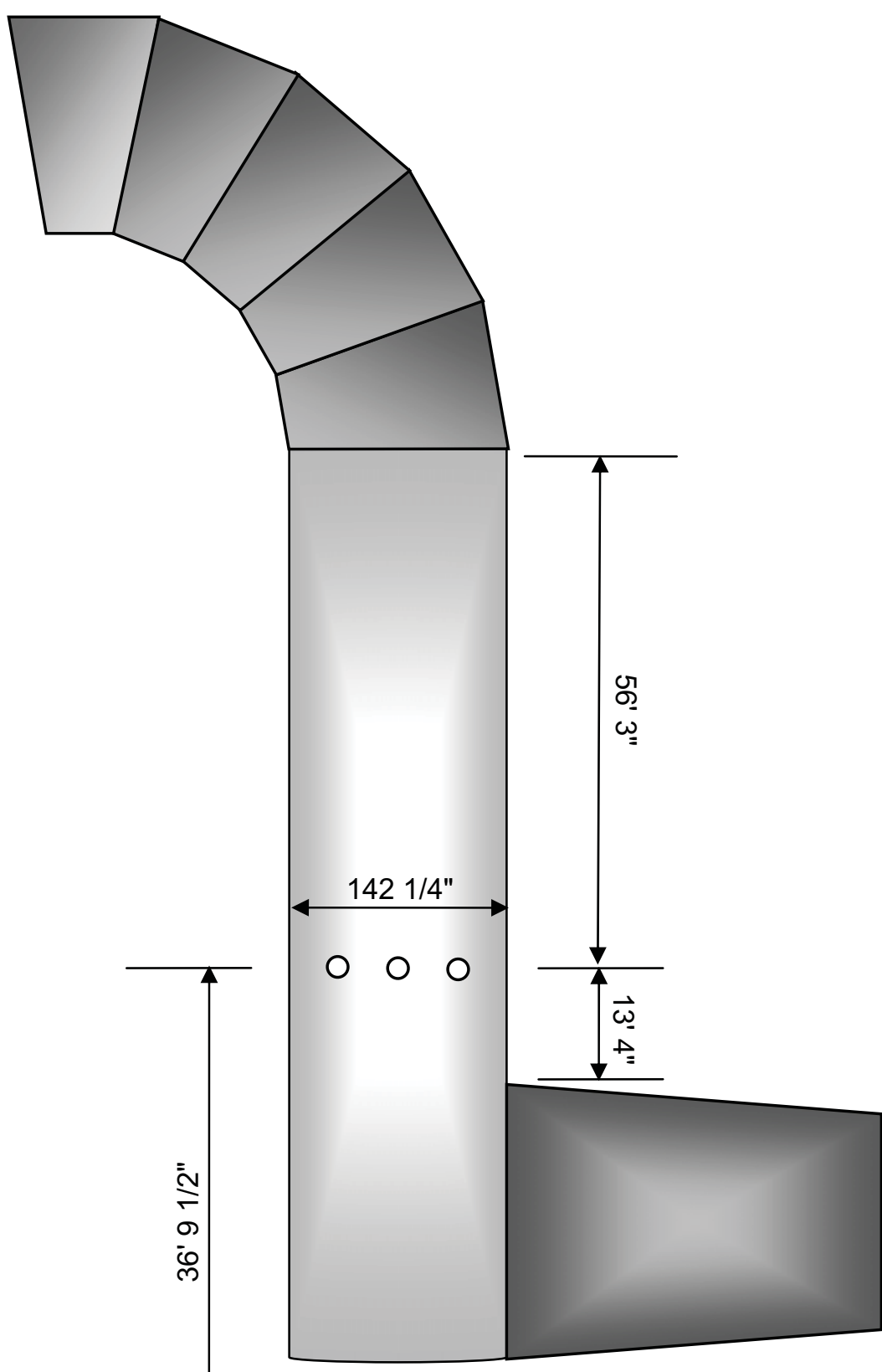




\section{SAMPLING LOCATION}

Figure 2: Stack

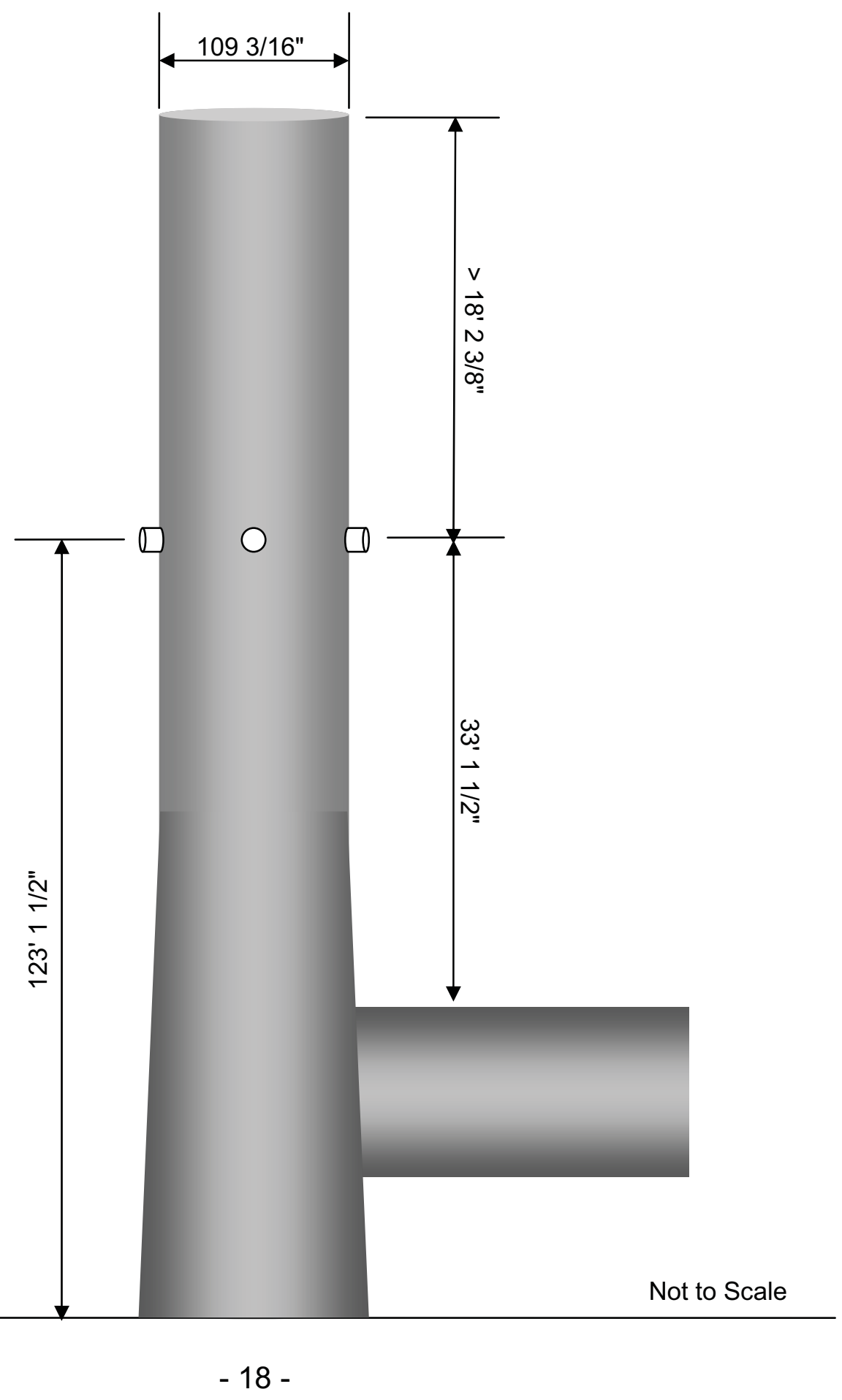




\section{SAMPLING AND ANALYTICAL PROCEDURES}

The procedures set forth in 40CFR60, Appendix A, Test Methods 1, 2, 3, 4, 5, 5B, 17, 26A, 202, and Conditional Test Method CTM027; ASTM D6784-02 (Ontario Hydro) Mercury Speciation Test Method; and the National Council of the Paper Industry for Air and Stream Improvement, Inc. (NCASI) Method 8A were followed during testing.

Four Traverse points were sampled from three ports on the SDA Inlet Duct for a total of twelve traverse points. All traverse points were checked for cyclonic flow and the average angle was equal to 2.4 degrees. The pitot tube lines were checked for leaks before and after each test under a vacuum and a pressure. The lines were also checked for clearance and the manometer was zeroed before each test.

Twelve traverse points were sampled from two ports on the Stack for a total of twenty four traverse points. All traverse points were checked for cyclonic flow and the average angle was equal to 6.0 degrees. The pitot tube lines were checked for leaks before and after each test under a vacuum and a pressure. The lines were also checked for clearance and the manometer was zeroed before each test.

\section{Particulate Matter}

Particulate matter samples were taken at the Stack sampling location according to EPA Test Methods 5B and 202. For each run, samples of five minute duration were taken at each of the twenty-four traverse points for a total sampling time of 120 minutes. Data was recorded at five minute intervals.

The sampling train was leak checked at the end of the sampling probe at 15" of mercury vacuum before each test, and again at the conclusion of each test at the highest 06-057 


\section{II}

vacuum recorded during sampling. This was done to predetermine the possibility of a diluted sample.

The "front half" of the sampling train at the Stack sampling location contained the following components:

Stainless steel nozzle Heated glass lined probe@ $320^{\circ} \mathrm{F} \pm 25^{\circ} \mathrm{F}$ Heated glass fiber filter @ $320^{\circ} \mathrm{F} \pm 25^{\circ} \mathrm{F}$ Heated Teflon line @ $248^{\circ} \mathrm{F} \pm 25^{\circ} \mathrm{F}$

The "back half" of the sampling train at the Stack sampling location contained the following components:

Table 8: EPA Test Methods 5B and 202 Sampling Train Condenser/Absorbing System

\begin{tabular}{|ccccc|}
\hline Impinger No. & $\begin{array}{c}\text { Impinger } \\
\text { Type }\end{array}$ & $\begin{array}{c}\text { Impinger } \\
\text { Contents }\end{array}$ & Amount & $\begin{array}{c}\text { Parameter } \\
\text { Collected }\end{array}$ \\
\hline $\mathbf{1}$ & Modified & H.P.L.C. $\mathrm{H}_{2} \mathrm{O}$ & $100 \mathrm{ml}$ & $\mathrm{H}_{2} \mathrm{O}$ \\
\hline $\mathbf{2}$ & Greenburg-Smith & H.P.L.C. $\mathrm{H}_{2} \mathrm{O}$ & $100 \mathrm{ml}$ & $\mathrm{H}_{2} \mathrm{O}$ \\
\hline $\mathbf{3}$ & Modified & Empty & ----- & $\mathrm{H}_{2} \mathrm{O}$ \\
\hline $\mathbf{4}$ & Modified & Silica Gel & $250 \mathrm{~g}$ & $\mathrm{H}_{2} \mathrm{O}$ \\
\hline
\end{tabular}

At the completion of each run, the "back half" of the sampling train was purged with nitrogen for 60 minutes at a rate of 20 liters per minute.

Integrated Orsat samples were collected during each test. The samples were analyzed according to EPA Method 3 to determine the stack gas molecular weight. 


\section{AIR \\ SAMPLING \\ ASSOCIATES, INC.}

Figure 3: EPA Test Methods 5B and 202 Sampling Train

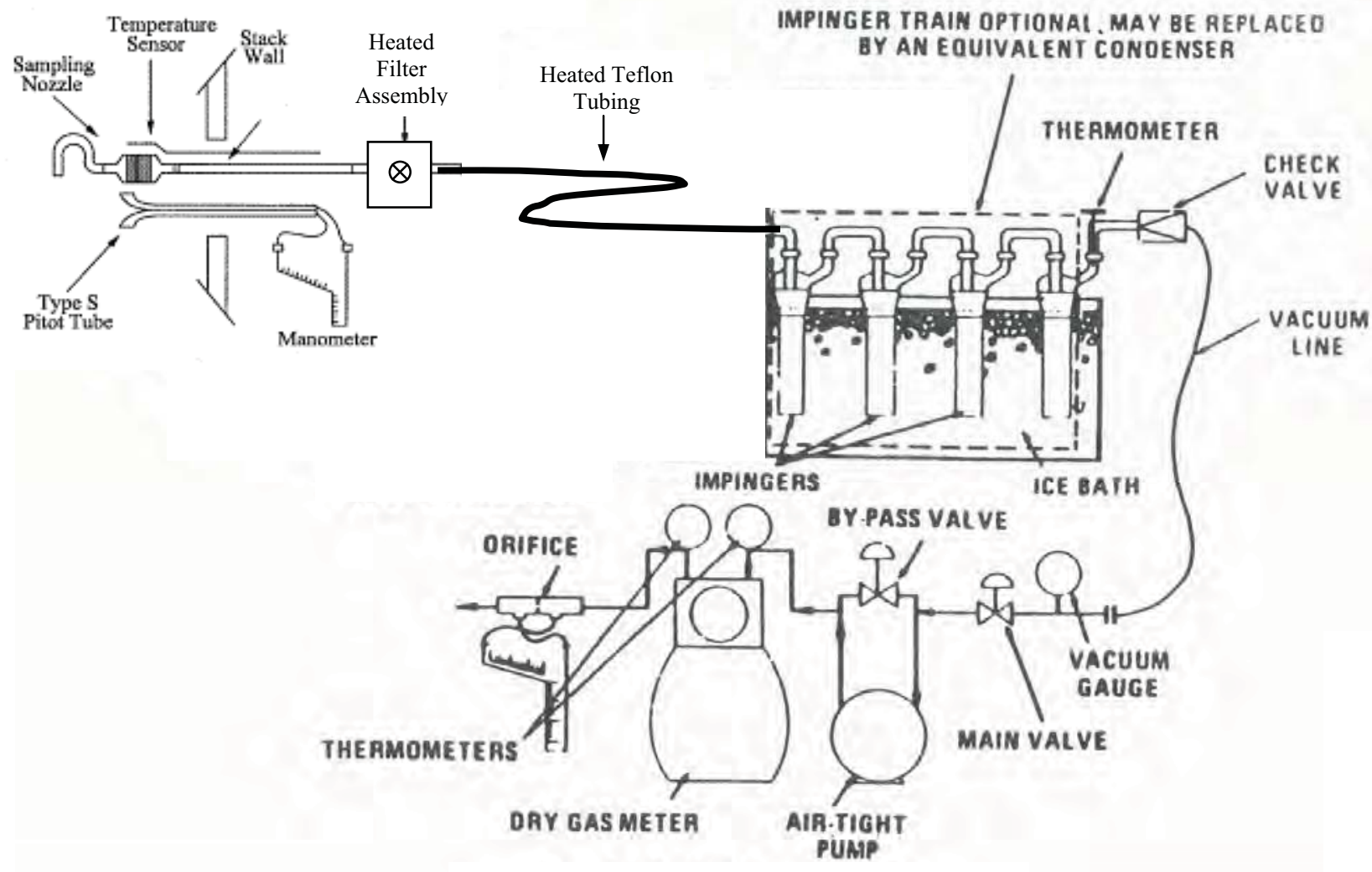




\section{Particulate Matter, Hydrogen Halides \& Halogens, and Ammonia}

Particulate matter, hydrogen halides \& halogens, and ammonia samples were taken at the SDA Inlet Duct and Stack sampling locations according to EPA Test Methods 1, 2, $3,4,5,17,26 \mathrm{~A}$, and CTM027. For each run at the SDA Inlet Duct, samples of five minute duration were taken at each of twelve traverse points for a total test time of 60 minutes. Data was recorded at five minute intervals. For each run at the Stack, samples of three minute duration were taken at each of twenty-four traverse points for a total test time of 72 minutes. Data was recorded at three minute intervals.

The sampling trains were leak checked at the end of the sampling probe at 15" of mercury vacuum before each test, and again at the conclusion of each test at the highest vacuum recorded during sampling. This was done to predetermine the possibility of a diluted sample.

The 'front half' of the sampling train at the SDA Inlet Duct contained the following components:

Glass nozzle

Fiberglass Thimble

Heated glass lined probe @ $248^{\circ} \mathrm{F} \pm 25^{\circ} \mathrm{F}$

Heated glass filter bypass @ $248^{\circ} \mathrm{F} \pm 25^{\circ} \mathrm{F}$

The 'front half' of the sampling train at the Stack contained the following components:

Glass nozzle

Heated glass lined probe @ $248^{\circ} \mathrm{F} \pm 25^{\circ} \mathrm{F}$

Heated fiberglass filter @ $248^{\circ} \mathrm{F} \pm 25^{\circ} \mathrm{F}$

Heated Teflon line @ 248 $\mathrm{F} \pm 25^{\circ} \mathrm{F}$ 
The 'back half' of the sampling trains at both sampling locations contained the following components:

Table 9: EPA Test Method 26A Condenser/Absorbing System

\begin{tabular}{|c|c|c|}
\hline Impinger No. & Impinger Type & Absorbing Solution \\
\hline 1 & Greenburg-Smith & $100 \mathrm{ml} 0.1 \mathrm{~N} \mathrm{H}_{2} \mathrm{SO}_{4}$ \\
\hline 2 & Greenburg-Smith & $100 \mathrm{ml} 0.1 \mathrm{~N} \mathrm{H}_{2} \mathrm{SO}_{4}$ \\
\hline 3 & Modified & $100 \mathrm{ml} 0.1 \mathrm{~N} \mathrm{NaOH}$ \\
\hline 4 & Modified & $100 \mathrm{ml} 0.1 \mathrm{~N} \mathrm{NaOH}$ \\
\hline 5 & Modified & 〜200 g silica gel \\
\hline
\end{tabular}

A 100 milliliter aliquot of the Impinger No. 1 and No. 2 contents was taken from each run at the SDA Inlet Duct for lon Chromatograph analysis to determine the concentrations of ammonia.

Integrated Orsat samples were collected at each sampling location during each test. The samples were analyzed according to EPA Method 3 to determine the stack gas molecular weight. 


\section{AIR ASSOCIATES, INC.}

Figure 4: EPA Test Methods 17, 26A, and CTM027 SDA Inlet Duct Sampling Train

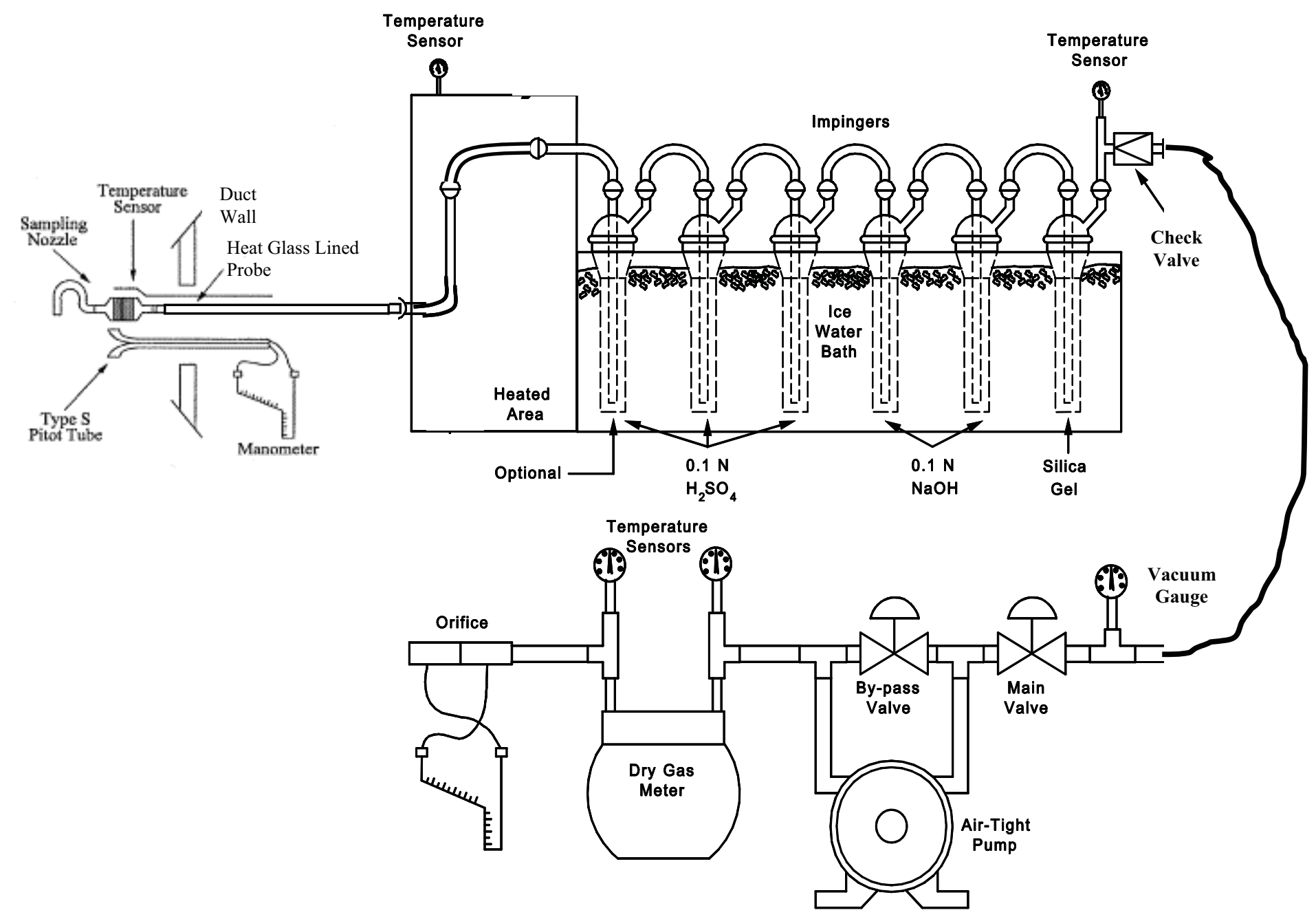




\section{Ali AIR

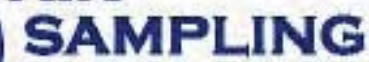 \\ ASSOCIATES, INC.}

Figure 5: EPA Test Methods 5 and 26A Stack Sampling Train

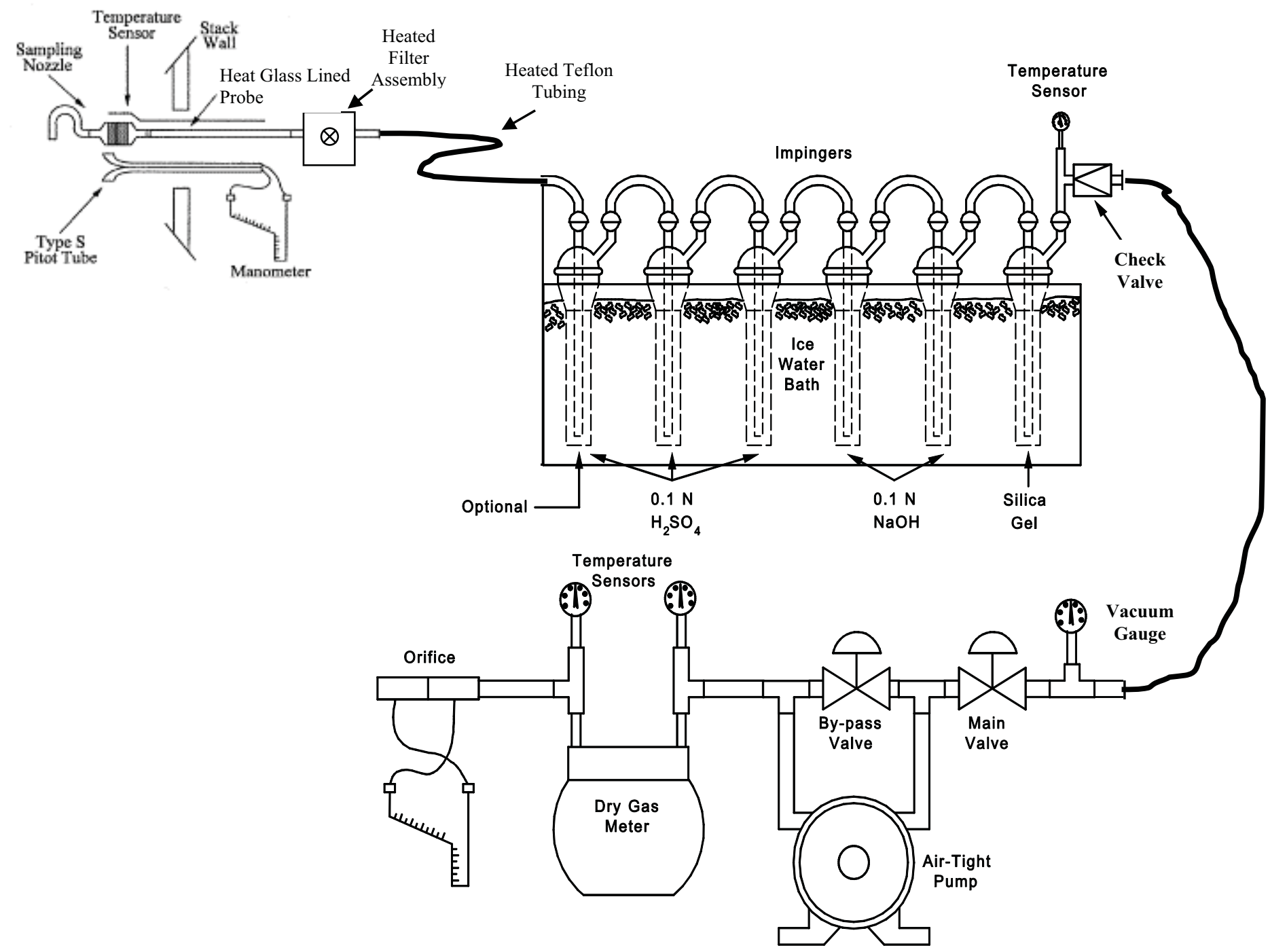




\section{Particulate Matter and Speciated Mercury}

Speciated mercury and particulate matter samples were taken at the SDA Inlet Duct and Stack sampling locations according to EPA Test Methods 1, 2, 3, 4, 5, and 17; and ASTM D6784-02 (Ontario Hydro) Mercury Speciation Test Method. For each run at the SDA Inlet Duct, samples of ten minute duration were taken at each of twelve traverse points for a total test time of 120 minutes. Data was recorded at five minute intervals. For each run at the Stack, samples of five minute duration were taken at each of twentyfour traverse points for a total test time of 120 minutes. Data was recorded at five minute intervals.

The sampling trains were leak checked at the end of the sampling probe at 15 " of mercury vacuum before each test, and again at the conclusion of each test at the highest vacuum recorded during sampling. This was done to predetermine the possibility of a diluted sample.

The 'front half' of the sampling train at the SDA Inlet Duct contained the following components:

Glass nozzle

Fiberglass Thimble

Heated glass lined probe @ $248^{\circ} \mathrm{F} \pm 25^{\circ} \mathrm{F}$

Heated glass filter bypass @ $248^{\circ} \mathrm{F} \pm 25^{\circ} \mathrm{F}$

The 'front half' of the sampling train at the Stack contained the following components:

Glass nozzle

Heated glass lined probe @ $248^{\circ} \mathrm{F} \pm 25^{\circ} \mathrm{F}$

Heated fiberglass filter @ $248^{\circ} \mathrm{F} \pm 25^{\circ} \mathrm{F}$

Heated Teflon line @ $248^{\circ} \mathrm{F} \pm 25^{\circ} \mathrm{F}$ 


\section{III}

The 'back half' of the sampling trains, contained the following components:

Table 10: ASTM D6784-02 (Ontario Hydro) Speciated Mercury Test Method Condenser/Absorbing System

\begin{tabular}{|c|c|c|}
\hline Impinger No. & Impinger Type & Absorbing Solution \\
\hline 1 & Modified & $100 \mathrm{ml} 1 \mathrm{~N} \mathrm{KCl}$ \\
\hline 2 & Modified & $100 \mathrm{ml} 1 \mathrm{~N} \mathrm{KCl}$ \\
\hline 3 & Greenburg-Smith & $100 \mathrm{ml} 1 \mathrm{~N} \mathrm{KCl}$ \\
\hline 4 & Modified & $100 \mathrm{ml} \mathrm{5 \%} \mathrm{v} / \mathrm{v} \mathrm{HNO}_{3}, 10 \% \mathrm{v} / \mathrm{v} \mathrm{H}_{2} \mathrm{O}_{2}$ \\
\hline 5 & Modified & $100 \mathrm{ml} 4 \% \mathrm{w} / \mathrm{v} \mathrm{H}_{2} \mathrm{SO}_{4}, 10 \% \mathrm{v} / \mathrm{v} \mathrm{KM}_{\mathrm{n}} \mathrm{O}_{4}$ \\
\hline 6 & Modified & $100 \mathrm{ml} 4 \% \mathrm{w} / \mathrm{v} \mathrm{H}_{2} \mathrm{SO}_{4}, 10 \% \mathrm{v} / \mathrm{v} \mathrm{KM}_{\mathrm{n}} \mathrm{O}_{4}$ \\
\hline 7 & Greenburg-Smith & $100 \mathrm{ml} 4 \% \mathrm{w} / v \mathrm{H} \mathrm{H}_{2} \mathrm{SO}_{4}, 10 \% \mathrm{v} / \mathrm{v} \mathrm{KM}_{\mathrm{n}} \mathrm{O}_{4}$ \\
\hline 8 & Modified & 〜200 g silica gel \\
\hline
\end{tabular}

Integrated Orsat samples were collected at each sampling location during each test. The samples were analyzed according to EPA Method 3 to determine the stack gas molecular weight. 
Figure 6: ASTM D6784-02 (Ontario Hydro) Mercury Speciation Test Method Sampling Train - SDA Inlet Duct

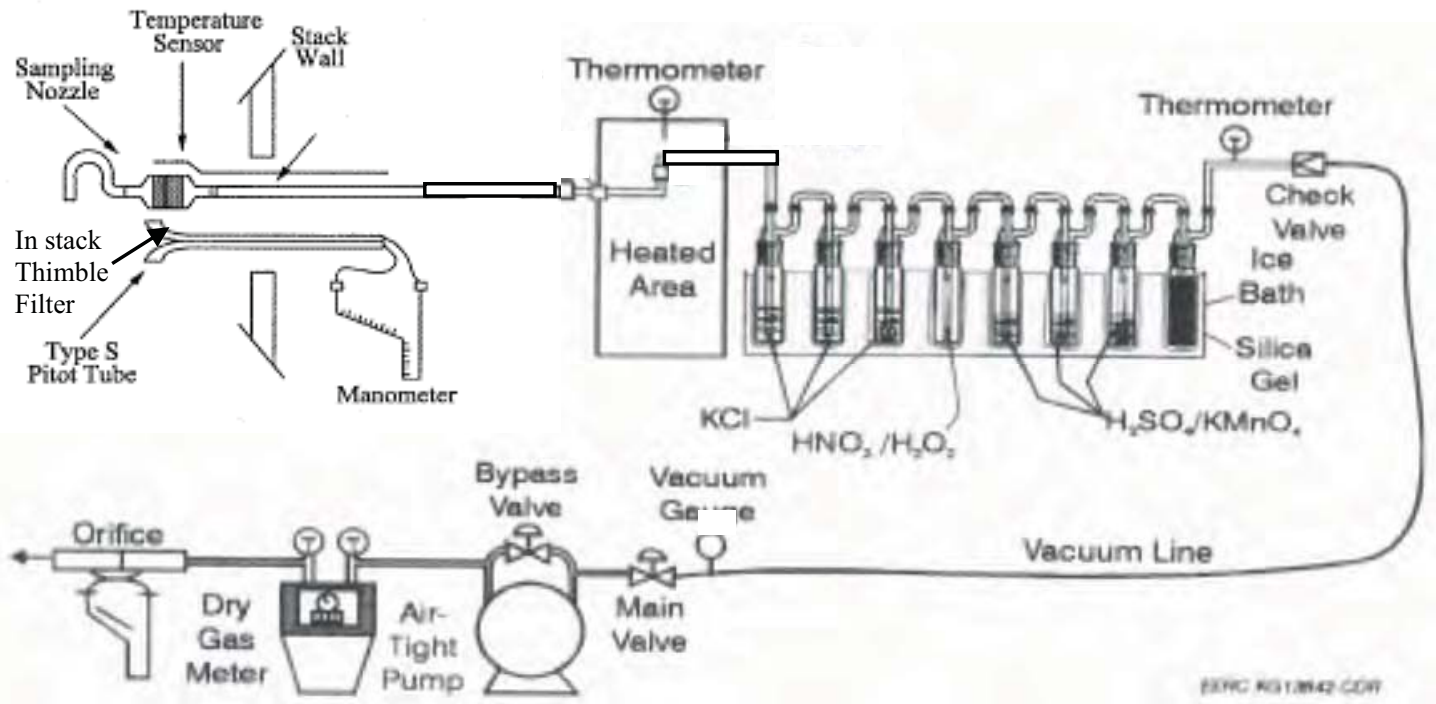




\section{II) ASSOCIATES, INC.}

Figure 7: ASTM D6784-02 (Ontario Hydro) Mercury Speciation Test Method Sampling Train - Stack

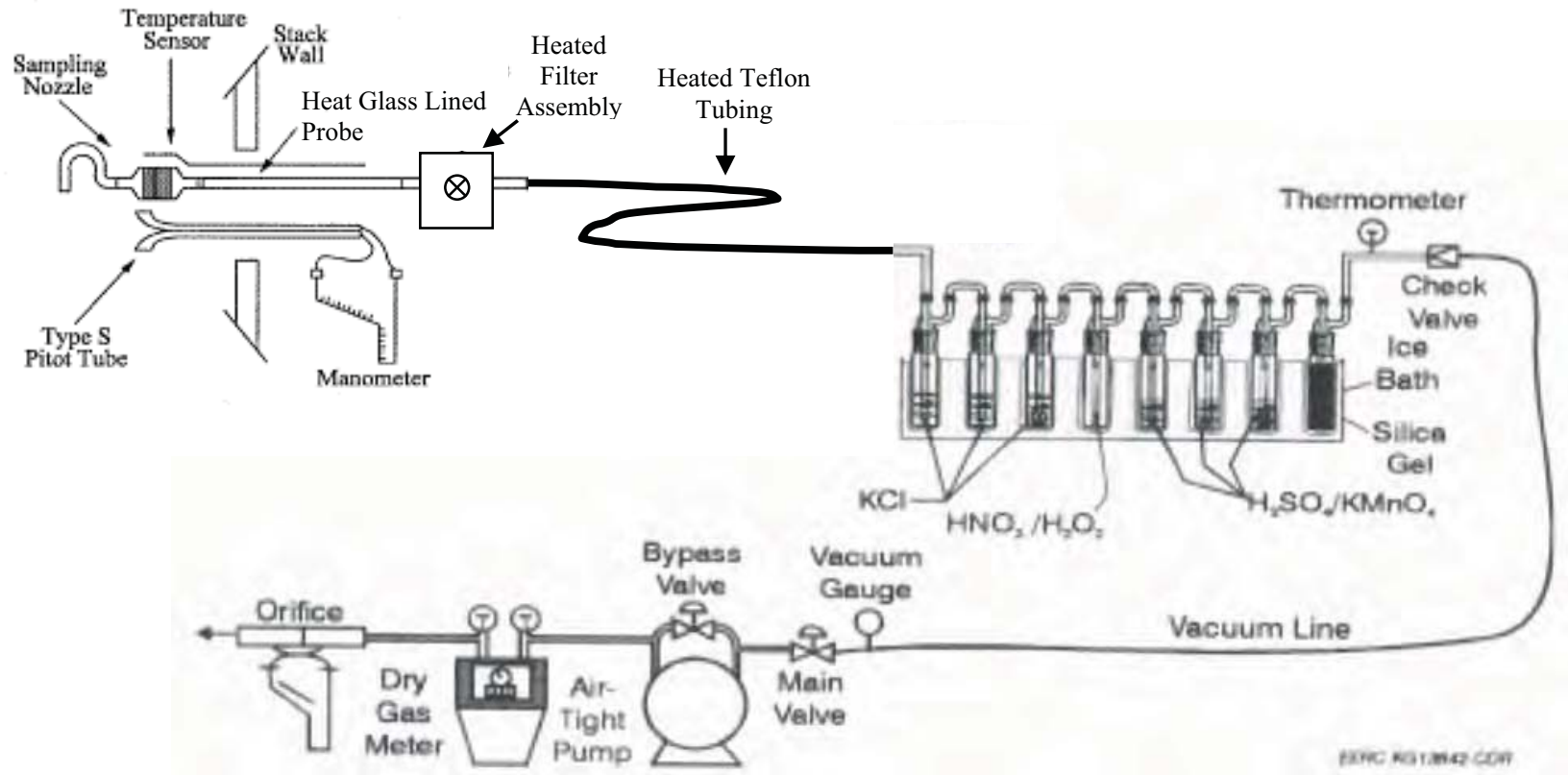




\section{III}

\section{Sulfur Trioxide}

Triplicate samples for sulfur trioxide were taken at the SDA Inlet Duct sampling location according to NCASI Method 8A. For each run, samples of 60 minute duration were taken at a single traverse point. Data was recorded at five minute intervals.

The sampling train was leak checked at the end of the sampling probe at 15 " of mercury vacuum before each test, and again at the conclusion of each test at the highest vacuum recorded during sampling. This was done to predetermine the possibility of a diluted sample.

The 'front half' of the sampling train contained the following components:

Glass Sample Probe heated to $500^{\circ} \mathrm{F}$ Quartz Filter heated to $500^{\circ} \mathrm{F}$ Glass Condenser cooled to $140^{\circ} \mathrm{F}$

Teflon tubing connected to Impingers

The 'back half' of the sampling train contained the following components:

Table 11: NCASI Method 8A Condenser/Absorbing System

\begin{tabular}{|c|c|c|}
\hline Impinger No. & Impinger Type & Absorbing Solution \\
\hline 1 & Greenburg-Smith & $100 \mathrm{ml} 3 \% \mathrm{H}_{2} \mathrm{O}_{2}$ \\
\hline 2 & Modified & $100 \mathrm{ml} 3 \% \mathrm{H}_{2} \mathrm{O}_{2}$ \\
\hline 3 & Greenburg-Smith & $100 \mathrm{ml} \mathrm{DI} \mathrm{H} \mathrm{H}_{2}$ \\
\hline 4 & Modified & $\sim 200 \mathrm{~g}$ silica gel \\
\hline
\end{tabular}

The sampling train was purged from the inlet of the condenser with clean ambient air for 15 minutes at the completion of each test run. 
Figure 8: NCASI Method 8A SDA Inlet Duct Sampling Train

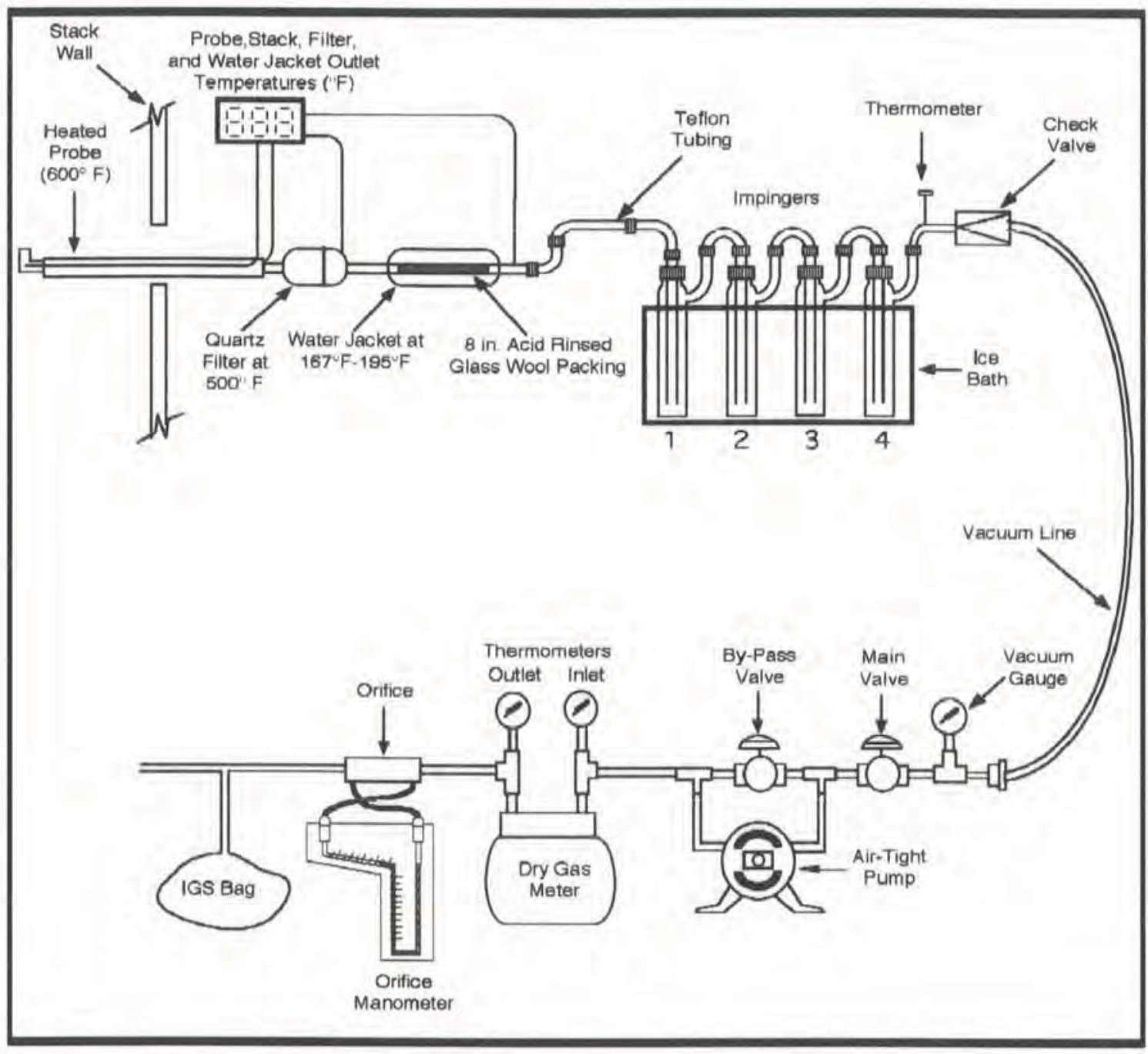




\section{TEST NARRATIVE}

Personnel from Air Sampling Associates, Inc. arrived at the Rocky Mountain Power, Hardin Power Plant, located in Hardin, Montana at 8:30 a.m. on Monday, November 27, 2006. The sampling trailer was placed into position and electrical power was established. The sampling equipment was moved onto the SDA Inlet Duct and the Stack before securing the equipment for the night at 6:30 p.m.

On Tuesday, November 28, 2006, personnel returned to the plant at 7:00 a.m. The preliminary data was collected before the plant ceased to operate at the desired level. Personnel prepared for the next day's testing before departing the plant at 4:15 p.m.

On Wednesday, November 29, 2006, personnel returned to the plant at 7:00 a.m. The sampling equipment was prepared for testing but personnel was informed that the plant was not operating at the desired level. Personnel departed the plant at 9:00 a.m. Personnel returned to the plant at 1:30 p.m. At that time, personnel was informed that the plant was still not operating at the desired level and testing would be postponed until the next day. Personnel departed the plant at 2:45 p.m.

On Thursday, November 30, 2006, personnel returned to the plant at 7:00 a.m. Personnel was informed that the plant was not operating at the desired level. Personnel waited until 10:30 a.m. and then departed the plant. Personnel returned to the plant at 1:00 p.m. The sampling equipment was prepared for testing and the first test on the SDA Inlet Duct using NCASI Method 8A was taken from 1:23 p.m. until 2:23 p.m. The first test on the Stack using EPA Test Methods 5 and 202 began at 1:34 p.m. and was completed at 3:42 p.m. The first test on the SDA Inlet Duct using EPA Test Methods 17, 26A, and CTM027 was taken from 2:54 p.m. until 3:59 p.m. The first test on the Stack using EPA Test Method 26A was taken from 4:42 p.m. until 5:59 p.m. The 
second test on the SDA Inlet Duct using NCASI Method 8A was taken from 4:48 p.m. until 5:48 p.m. The samples were recovered and personnel departed the plant at 8:00 p.m.

On Friday, December 1, personnel returned to the plant at 7:00 a.m. The sampling equipment was prepared for testing and the first simultaneous test on the SDA Inlet Duct and the Stack using the ASTM D6784-02 (Ontario Hydro) Speciated Mercury Test Method began at 8:57 a.m. Testing continued until the completion of the test on the stack at 11:05 a.m. The second test on the SDA Inlet Duct using EPA Test Methods 17, 26A, and CTM027 was taken from 12:03 p.m. until 1:05 p.m. The third test on the SDA Inlet Duct using NCASI Method 8A was taken from 2:01 p.m. until 3:01 p.m. The second test on the Stack using EPA Test Method 26A was taken from 3:09 p.m. until 4:26 p.m. The third test on the SDA Inlet Duct using EPA Test Methods 17, 26A, and CTM027 was taken from 4:47 p.m. until 5:49 p.m. The samples were recovered and personnel departed the plant at 6:30 p.m.

On Saturday, December 2, personnel returned to the plant at 7:00 a.m. The sampling equipment was prepared for testing and the second simultaneous test on the SDA Inlet Duct and the Stack using the ASTM D6784-02 (Ontario Hydro) Speciated Mercury Test Method began at 9:19 a.m. Testing continued until the completion of the test on the stack at 11:24 a.m. The third test on the Stack using EPA Test Methods 5 and 202 was taken from 12:15 p.m. until 2:19 p.m. The third simultaneous test on the SDA Inlet Duct and Stack using the ASTM D6784-02 (Ontario Hydro) Speciated Mercury Test Method was delayed due to plant operations. The test began at 5:12 p.m. Testing continued until the completion of the test on the Stack at 7:17 p.m. The third test on the Stack using EPA Test Method 26A was taken from 8:25 p.m. until 9:41 p.m. The samples were recovered and personnel departed the plant at 10:45 p.m. 


\section{III}

On Sunday, December 3, 2006, personnel returned to the plant at 7:00 a.m. The sampling equipment was moved off of the SDA Inlet Duct and the Stack and loaded into the sampling trailer. The samples were taken to Air Sampling Associates, Inc.'s office in Lewisville, Texas for analysis and shipment to the subcontracted laboratories.

Operations at the Rocky Mountain Power, Hardin Power Plant, SDA Inlet Duct and Stack, located in Hardin, Montana, were completed at 9:30 a.m. on Sunday, December 3, 2006. 


\section{APPENDICES}

Appendix A: Location of Traverse Points

Appendix B: Nomenclature and Equations for Calculation of Source Emissions

Appendix C: Calibration Data

Appendix D: Field Data

Appendix E: EPA Test Methods 5B and 202 (Particulate Matter) Analytical Data

Appendix F: EPA Test Methods 17, 26A and CTM027 (Particulate Matter, Hydrogen Halides \& Halogens, and Ammonia) Analytical Data - SDA Inlet Duct

Appendix G: EPA Conditional Test Methods 5 and 26A (Particulate Matter and Hydrogen Halides \& Halogens) Analytical Data - Stack

Appendix H: EPA Test Methods 5, 17 (Particulate Matter), and ASTM D6784-02 (Ontario Hydro) Mercury Speciation Test Method Analytical Data

Appendix I: NCASI Method 8A (Sulfur Trioxide) Analytical Data Appendix J: Chain of Custodies

Appendix K: Resumes of Test Personnel 
Appendix A:

Location of Traverse Points 


\section{Appendix A}

\section{Location of Traverse Points SDA Inlet Duct}

The sampling ports are located 13 feet 4 inches (1.12 equivalent duct diameters) downstream from a bend in the bend in the duct and 56 feet 3 inches (4.75 equivalent duct diameters) upstream from a bend in the duct. The locations of the traverse points were calculated as follows:

Figure 9: Location of Traverse Points - SDA Inlet Duct

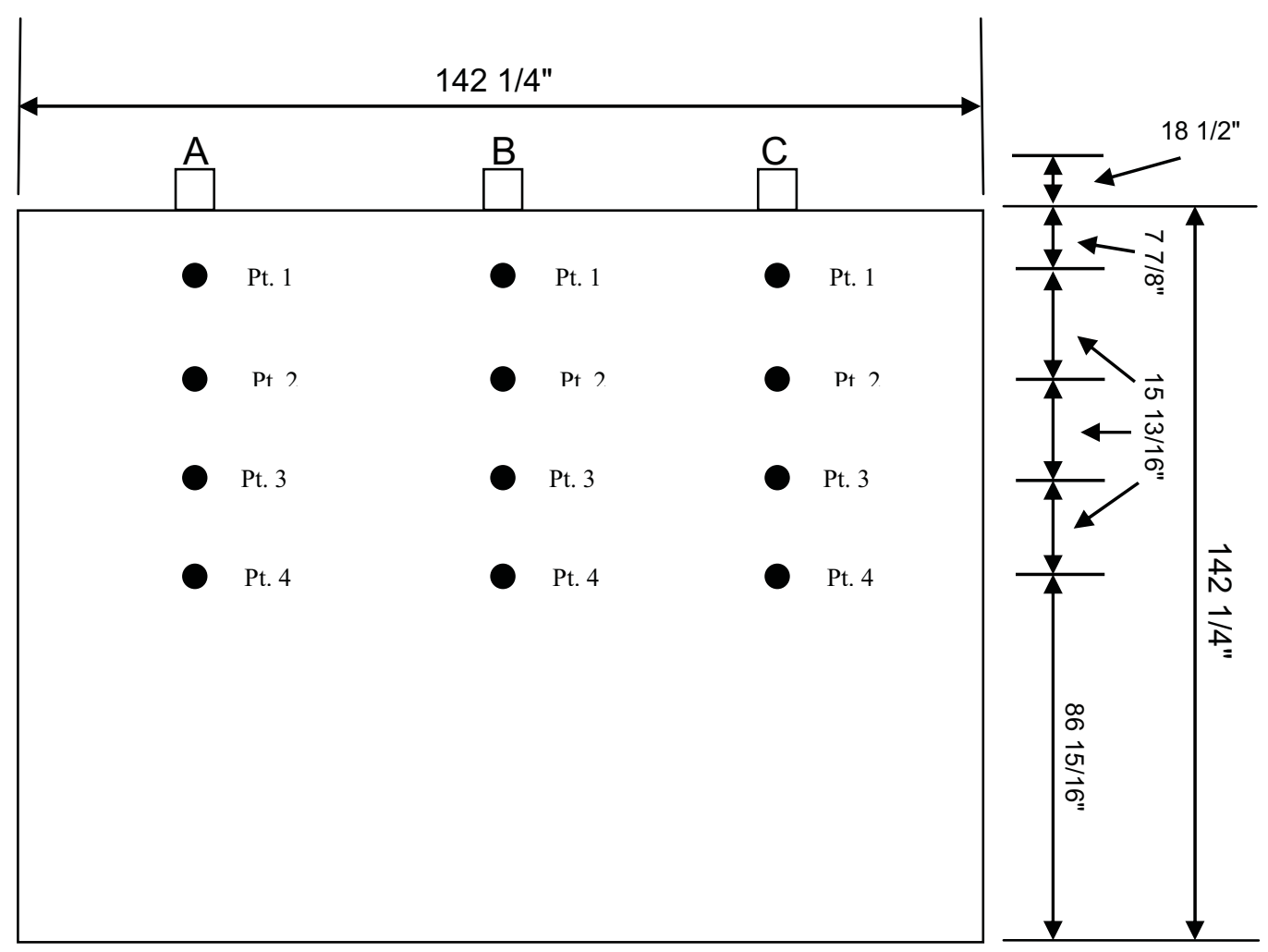

Note: Physical limitations prevented the complete traversing of the SDA Inlet Duct. 


\section{Appendix A}

\section{Location of Traverse Points Stack}

The sampling ports are located 33 feet 1 1/2 inches (3.64 stack diameters) downstream from the inlet to the stack and $>18$ feet $23 / 8$ inches ( $>2.00$ stack diameters) upstream from the outlet to the stack. The locations of the traverse points were calculated as follows:

Table 12: Location Traverse Points - Stack

\begin{tabular}{|c|c|c|}
\hline \multicolumn{3}{|c|}{$\begin{aligned} \text { Port \& Wall Thickness }= & 151 / 8 \text { inches } \\
\text { Inside Stack Diameter }= & 1093 / 16 \text { inches }\end{aligned}$} \\
\hline $\begin{array}{l}\text { Point } \\
\text { Number }\end{array}$ & $\begin{array}{c}\text { Percent of } \\
\text { Stack Diameter }\end{array}$ & $\begin{array}{l}\text { Distance } \\
\text { from Wall }\end{array}$ \\
\hline 1 & 2.1 & $25 / 16 "$ \\
\hline 2 & 6.7 & $75 / 16 "$ \\
\hline 3 & 11.8 & $127 / 8 "$ \\
\hline 4 & 17.7 & $195 / 16 "$ \\
\hline 5 & 25.0 & $275 / 16 "$ \\
\hline 6 & 35.6 & $387 / 8 "$ \\
\hline 7 & 64.4 & $705 / 16 "$ \\
\hline 8 & 75.0 & $817 / 8 "$ \\
\hline 9 & 82.3 & $897 / 8 "$ \\
\hline 10 & 88.2 & $965 / 16 "$ \\
\hline 11 & 93.3 & $1017 / 8 "$ \\
\hline 12 & 97.9 & $1067 / 8 "$ \\
\hline
\end{tabular}




\section{Appendix A}

Figure 10: Location of Traverse Points - Stack

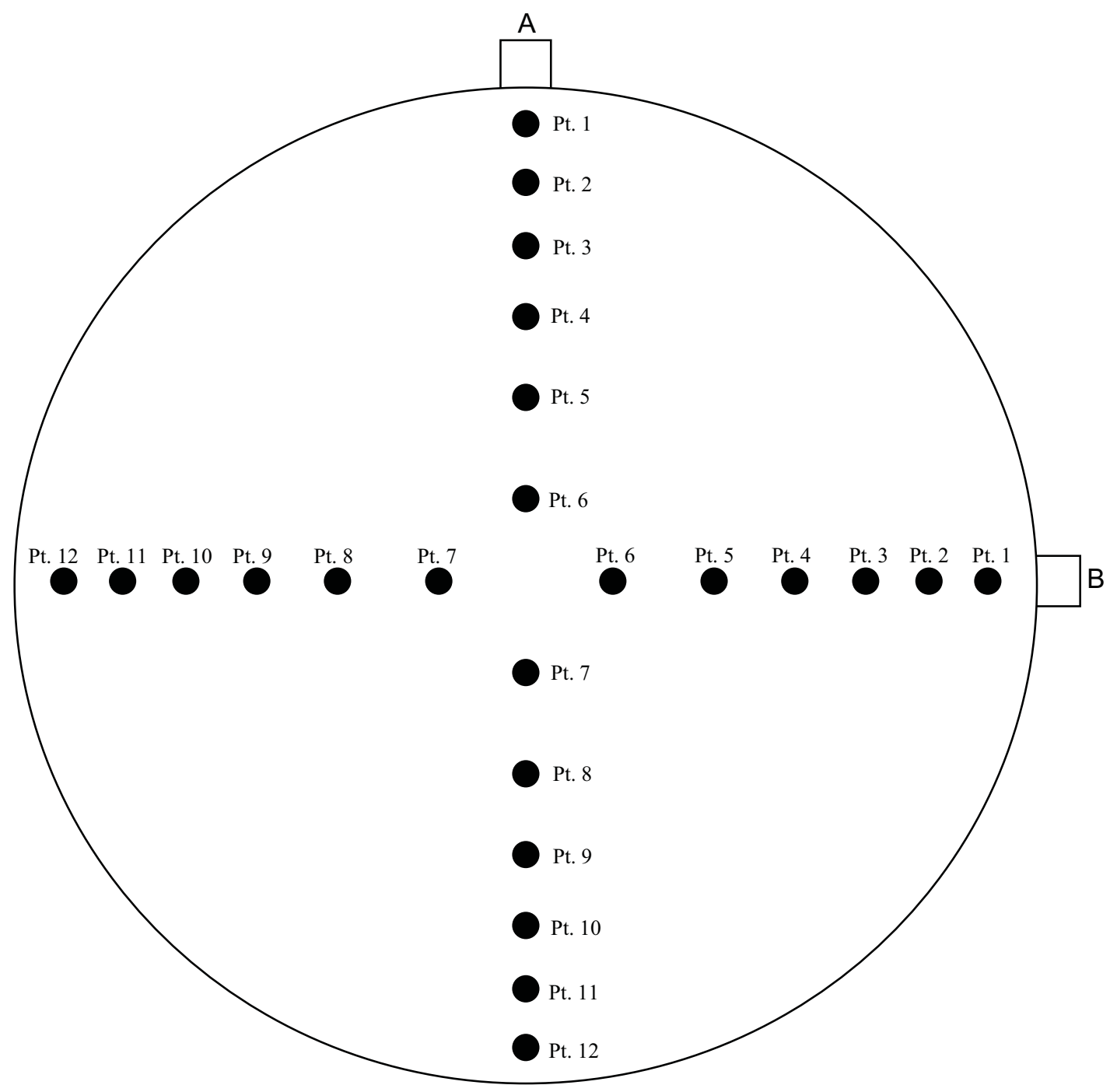

Not to scale. 
Appendix B:

Nomenclature and Equations for Calculation of Source Emissions 


\section{Nomenclature For Flow Rate and Moisture Calculations}

\begin{tabular}{|c|c|c|c|}
\hline Symbol & $\begin{array}{l}\text { English } \\
\underline{\text { Units }}\end{array}$ & $\begin{array}{l}\text { Metric } \\
\underline{\text { Units }}\end{array}$ & Description \\
\hline$A_{s}$ & in. $^{2}$ & $\mathrm{~m}^{2}$ & Stack Area \\
\hline $\mathrm{C}_{\mathrm{an}}$ & $\mathrm{gr} / \mathrm{dscf}{ }^{*}$ & $\mathrm{~g} / \mathrm{dscm}^{*}$ & $\begin{array}{l}\text { Particulate - probe, cyclone, } \\
\text { and filter }\end{array}$ \\
\hline $\mathrm{C}_{\mathrm{ao}}$ & $\mathrm{gr} / \mathrm{dscf}{ }^{*}$ & $\mathrm{~g} / \mathrm{dscm}^{*}$ & Particulate -total \\
\hline $\mathrm{C}_{\text {at }}$ & $\begin{array}{c}\mathrm{gr} / \mathrm{CF} @ \\
\text { stack conditions }\end{array}$ & $\mathrm{g} / \mathrm{m} 3$ & $\begin{array}{l}\text { Particulate - probe, cyclone, } \\
\text { and filter }\end{array}$ \\
\hline $\mathrm{C}_{\mathrm{au}}$ & $\begin{array}{c}\mathrm{gr} / \mathrm{CF} @ \\
\text { stack conditions }\end{array}$ & $\mathrm{g} / \mathrm{m} 3$ & Particulate - total \\
\hline $\mathrm{C}_{\mathrm{aw}}$ & lbs/hr & $\mathrm{kg} / \mathrm{hr}$ & $\begin{array}{l}\text { Particulate - probe, cyclone, } \\
\text { and filter }\end{array}$ \\
\hline $\mathrm{C}_{\mathrm{ax}}$ & $\mathrm{lbs} / \mathrm{hr}$ & $\mathrm{kg} / \mathrm{hr}$ & Particulate - total \\
\hline$C_{p}$ & & & Pitot Tube Calibration Factor \\
\hline$D_{n}$ & in. & $\mathrm{m}$ & Sampling Nozzle Diameter \\
\hline$\% \mathrm{EA}$ & & & $\begin{array}{l}\text { Percent Excess Air at } \\
\text { Sampling Point }\end{array}$ \\
\hline g & $32.2 \mathrm{ft} / \mathrm{sec}^{2}$ & & Acceleration of gravity \\
\hline$\% l$ & & & Percent Isokinetic \\
\hline$\% \mathrm{M}$ & & & $\begin{array}{l}\text { Percent Moisture in the Stack } \\
\text { Gas by Volume }\end{array}$ \\
\hline$M_{d}$ & & & Mole Fraction of Dry Gas \\
\hline$m_{f}$ & $\mathrm{mg}$ & $\mathrm{mg}$ & $\begin{array}{l}\text { Particulate - probe, cyclone, } \\
\text { and filter }\end{array}$ \\
\hline $\mathrm{mt}$ & $\mathrm{mg}$ & $\mathrm{mg}$ & Particulate -total \\
\hline$M_{\text {water }}$ & $18 \mathrm{lb} / \mathrm{lb}-\mathrm{mole}$ & & Molecular Weight of Water \\
\hline MW & Ib/lb-mole & g/g-mole & $\begin{array}{l}\text { Molecular Weight of Stack } \\
\text { Gas }\end{array}$ \\
\hline $\mathrm{MW}_{\text {air }}$ & $28.84 \mathrm{lb} / \mathrm{lb}-\mathrm{mole}$ & & Molecular Weight of Air \\
\hline $\mathrm{MW}_{\mathrm{d}}$ & lb/lb-mole & g/g-mole & $\begin{array}{l}\text { Molecular Weight of Dry Stack } \\
\text { Gas }\end{array}$ \\
\hline
\end{tabular}


Symbol

$P_{b}$

$P_{m}$

Ps

$\Delta \mathrm{P}$

$\mathrm{P}_{\text {std }}$

$\mathrm{Q}_{a}$

$Q_{s}$

R

$T_{m}$

$T_{t}$

$\mathrm{T}_{\mathrm{s}}$

$\mathrm{T}_{\text {std }}$

$V_{m}$

$V \mathrm{~m}_{\text {std }}$

$\mathrm{V}_{\mathrm{s}}$

$\mathrm{V}_{\mathrm{w}}$

$V w_{\text {gas }}$
English

Units

"Hg Absolute

$" \mathrm{H}_{2} \mathrm{O}$

"Hg Absolute

$" \mathrm{H}_{2} \mathrm{O}$

29.92" $\mathrm{Hg}$

ACFM

DSCFM $^{*}$

21.83" Hg-

$\mathrm{ft}^{3} / \mathrm{lb}$-mole ${ }^{\circ} \mathrm{R}$

${ }^{\circ} \mathrm{F}$

$\min$

${ }^{\circ} \mathrm{F}$

$528^{\circ} \mathrm{R}$

$\mathrm{ft}^{3}$

dscf* $^{*}$

fpm

$\mathrm{ml}$

$\operatorname{scf}^{*}$
Metric

$\underline{\text { Units }}$

$\mathrm{mm} \mathrm{Hg}$

$\mathrm{mm} \mathrm{H}_{2} \mathrm{O}$

$\mathrm{mm} \mathrm{Hg}$

$\mathrm{mm} \mathrm{H}_{2} \mathrm{O}$

$760 \mathrm{~mm} \mathrm{Hg}$

$\mathrm{m}^{3} / \mathrm{hr}$

$\mathrm{dscm} / \mathrm{hr} r^{*}$

${ }^{\circ} \mathrm{C}$

$\min$

${ }^{\circ} \mathrm{C}$

$293^{\circ} \mathrm{K}$

$\mathrm{m}^{3}$

$\mathrm{dscm}^{*}$

$\mathrm{m} / \mathrm{sec}$

$\mathrm{ml}$

$\mathrm{scm} *$
Description

Barometric Pressure

Orifice Pressure drop

Stack Pressure

Velocity Head of Stack Gas

Standard Barometric Pressure

Stack Gas Volume at Actual Stack Conditions

Stack Gas Volume at 29.92"

$\mathrm{Hg}, 528^{\circ} \mathrm{R}$, dry

Universal Gas Constant

Average Gas Meter

Temperature

Net Time of Test

Stack Temperature

Standard Temperature

Volume of Dry Gas Sampled

@ Meter Conditions

Volume of Dry Gas Sampled @ Standard Conditions

Stack Velocity @ Stack Conditions

Total Water Collected in Impingers and Silica Gel

Volume of Water Vapor Collected @ Standard Conditions 
Symbol

$\rho_{\text {air }}$

$\rho_{\text {water }}$

$\rho_{\text {man }}$
English

Units

$0.0748 \mathrm{lbs} / \mathrm{ft}^{3}$

$1 \mathrm{~g} / \mathrm{ml}$

$62.32 \mathrm{lbs} / \mathrm{ft}^{3}$
Metric

$\underline{\text { Units }}$

Description

Density of Air

Density of Water

Density of Manometer Oil

(Inches of Water)

Standard Conditions: $29.92 " \mathrm{Hg}, 68^{\circ} \mathrm{F}\left(760 \mathrm{~mm} \mathrm{Hg}, 2{ }^{\circ} \mathrm{C}\right)$ 


\section{EXAMPLE CALCULATIONS}

1. Volume of dry gas sampled at standard conditions. *

$$
\begin{aligned}
& V_{m s t d}=V_{m}\left(\frac{T_{s t d}}{T_{m}+460}\right)\left[\frac{P_{b}+\frac{P_{m}}{13.6}}{P_{s t d}}\right] \\
& V_{m s t d}=17.65 V_{m}\left[\frac{P_{b}+\frac{P_{m}}{13.6}}{T_{m}+460}\right]=d s c f \\
& V_{m s d}=d s c f \times 0.028317=d s c m
\end{aligned}
$$

2. Volume of water vapor collected at standard conditions. *

$$
\begin{aligned}
& V_{w_{g a s}}=\frac{\left(V_{w}-g m s \mathrm{SO}_{2}-g m s H_{2} S\right) \rho_{\text {water }} R T_{\text {std }}}{P_{\text {std }} M_{\text {water }} 453.6} \\
& V_{w_{g a s}}=0.0472\left(V_{w}-g m s \mathrm{SO}_{2}-g m s H_{2} S\right)=s c f \\
& V_{w_{g a s}}=s c f \times 0.028317=s c m
\end{aligned}
$$

3. Percent moisture in stack gas.

$$
\% M=\frac{V_{w_{g a s}}}{V_{m_{s t d}}+V_{w_{g a s}}} \times 100=\%
$$


4. Mole fraction of dry gas.

$$
M_{d}=\frac{100-\% M}{100}
$$

5. Average molecular weight of dry stack gas.

$$
\begin{aligned}
M W_{d}=\left[\% \mathrm{CO}_{2} \times \frac{44}{100}\right]+\left[\% \mathrm{O}_{2} \times \frac{32}{100}\right]+\left[\% N_{2} \times \frac{28}{100}\right]+\left[\% \mathrm{CO} \times \frac{28}{100}\right] & =\mathrm{lb} / \mathrm{lb}-\text { mole } \\
& =\mathrm{g} / \mathrm{g}-\mathrm{mole}
\end{aligned}
$$

6. Molecular weight of stack gas.

$$
M W=M W_{d} \times M_{d}+18\left(1-M_{d}\right)=\frac{l b}{l b-m o l e}=g / g-\text { mole }
$$

7. Percent excess air at sampling point.

$$
\% E A=\frac{100\left[\% \mathrm{O}_{2}-(0.5 \% \mathrm{CO})\right]}{0.265\left(\% \mathrm{~N}_{2}\right)-\left[\% \mathrm{O}_{2}-(0.5 \% \mathrm{CO})\right]}
$$

8. Stack Pressure.

$$
P_{s}=P_{b}+\frac{\text { Stack Pressure " } \mathrm{H}_{2} \mathrm{O}}{13.6}=" \mathrm{Hg} \text { Absolute }
$$

$$
P_{s}=" H g \text { Abs. } \times 25.4=m m H g
$$

9. Stack velocity at stack conditions.

$$
\begin{aligned}
& V_{s}=C_{p} 60\left[\frac{2 g \times \rho_{\text {man }} \times P_{\text {std }} \times M W_{\text {air }} \times\left(T_{s}+460\right) \times \Delta P}{12 \times \rho_{\text {air }} \times P_{s} \times M W \times T_{\text {std }}}\right]^{1 / 2} \\
& V_{s}=5,123.8 C_{p}\left[\frac{\left(T_{s}+460\right)}{P_{s} \times M W}\right]^{1 / 2} \sqrt{\Delta P} \text { average }=f p m \\
& V_{s}=f p m \times 0.00508=\mathrm{m} / \mathrm{sec}
\end{aligned}
$$


10. Dry stack gas volume at standard conditions. *

$$
\begin{aligned}
& Q_{s}=\frac{1}{144} V_{s} \times A_{s} \times M_{d} \times \frac{T_{s t d}}{T_{s}+460} \times \frac{P_{s}}{P_{s t d}} \\
& Q_{s}=\frac{0.123 V_{s} \times A_{s} \times M_{d} \times P_{s}}{T_{s}+460}=D S C F M \\
& Q_{s}=D S C F M \times 1.6990=\mathrm{dscm} / \mathrm{hr}
\end{aligned}
$$

11. Actual stack gas volume at stack conditions.

$$
\begin{aligned}
& Q_{a}=\frac{V_{s} \times A_{s}}{144}=A C F M \\
& Q_{a}=A C F M \times 1.6990=m^{3} / h r
\end{aligned}
$$

12. Percent Isokinetic

$$
\begin{aligned}
& \% \mathrm{l}=\frac{V_{\text {mstd }} \times\left(T_{s}+460\right) \times P_{s t d} \times 100 \times 144 i n^{2} / f^{2}}{M_{d} \times T_{s t d} \times P_{s} \times T_{t} \times V_{s}\left(\frac{\Pi \times D_{n}{ }^{2}}{4}\right)} \\
& \% \mathrm{I}=\frac{1039 \times V_{\text {sstd }} \times\left(T_{s}+460\right)}{M_{d} \times P_{s} \times T_{t} \times V_{s} \times D_{n}{ }^{2}}
\end{aligned}
$$

* 29.92" Hg, $68^{\circ} \mathrm{F}\left(760 \mathrm{~mm} \mathrm{Hg}, 20^{\circ} \mathrm{C}\right)$ 
13. Particulate - Probe, cyclone, and filter.

$$
\begin{aligned}
& \mathrm{C}_{\text {an }}=\frac{\mathrm{m}_{\mathrm{f}}}{\mathrm{V}_{\mathrm{mstd}}} \times \frac{1 \mathrm{gr}}{64.8 \mathrm{mg}} \\
& C_{a n}=0.0154 \times \frac{\mathrm{mf}}{\mathrm{V}_{\mathrm{mstd}}} \mathrm{gr} / \mathrm{dscf} \text { * } \\
& C_{\text {an }}=\mathrm{gr} / \mathrm{dscf} \times 2.290=\mathrm{g} / \mathrm{dscm} \text { * }
\end{aligned}
$$

14. Particulate total.

$$
\begin{aligned}
& \mathrm{C}_{\mathrm{ao}}=0.0154 \times \frac{\mathrm{m}_{\mathrm{t}}}{\mathrm{V}_{\mathrm{mstd}}}=g r / d s c f \text { * } \\
& \mathrm{C}_{\mathrm{ao}}=\mathrm{gr} / \mathrm{dscf} \times 2.290=\mathrm{g} / \mathrm{dscm} \text { * }
\end{aligned}
$$

15. Particulate - probe, cyclone, and filter at stack conditions.

$$
\begin{aligned}
& C_{a t}=C_{a n} \times \frac{P_{s}}{P_{\text {std }}} \times \frac{\left(T_{s t d}\right)}{\left(T_{s}+460\right)} \times M_{d} \\
& C_{a t}=\frac{17.65 \times C_{a n} \times P s \times M d}{T x+460}=g r / C F \\
& C_{a t}=g r / C F \times 2.290=g / m^{3}
\end{aligned}
$$

16. Particulate - total, at stack conditions.

$$
\begin{aligned}
& \mathrm{C}_{\mathrm{au}}=\frac{17.65 \times \mathrm{C}_{\mathrm{ao}} \times \mathrm{P}_{\mathrm{s}} \times \mathrm{M}_{\mathrm{d}}}{\mathrm{T}_{\mathrm{s}}+460}=\mathrm{gr} / \mathrm{CF} \\
& \mathrm{C}_{\mathrm{au}}=\mathrm{gr} / \mathrm{CF} \times 2.290 \mathrm{~g} / \mathrm{m}^{3}
\end{aligned}
$$


17. Particulate - probe, cyclone, and filter.

$$
\begin{aligned}
& C_{a w}=C_{a n} \times Q_{s} \times \frac{60 \mathrm{~min} .}{1 \mathrm{hr}} \times \frac{1 \mathrm{lb}}{7,000 \mathrm{gr}} \\
& \mathrm{C}_{a w}=0.00857 \times \mathrm{C}_{a n} \times \mathrm{Q}_{\mathrm{s}}=\mathrm{lbs} / \mathrm{hr} \\
& \mathrm{C}_{\mathrm{aw}}=\mathrm{lbs} / \mathrm{hr} \times 0.4536=\mathrm{kg} / \mathrm{hr}
\end{aligned}
$$

18. Particulate - total.

$$
\begin{aligned}
& C_{a x}=0.00857 \times C_{a o} \times Q_{s}=l b s / h r \\
& C_{a x}=\mathrm{lbs} / \mathrm{hr} \times 0.4536=\mathrm{kg} / \mathrm{hr}
\end{aligned}
$$

19. Mercury $-\mu \mathrm{g} / \mathrm{dscm}$

$$
\mu \mathrm{g} / \mathrm{dscm}=\mu \mathrm{g} \div\left(\mathrm{V}_{\mathrm{mstd}} \times 0.028317 \mathrm{~m}^{3} / \mathrm{ft}^{3}\right)
$$

*29.92" Hg, $68^{\circ} \mathrm{F}\left(760 \mathrm{~mm} \mathrm{Hg}, 20^{\circ} \mathrm{C}\right)$ 


\section{III sampling}

\begin{tabular}{|c|c|c|c|c|}
\hline Rocky & $\begin{array}{l}\text { Summary of } \\
\text { cury Speciat } \\
\text { thain Power - } \\
\text { SDA Inlet }\end{array}$ & $\begin{array}{l}\text { Results } \\
\text { on Results } \\
\text { tardin Powe } \\
\text { uct }\end{array}$ & Plant & \\
\hline Run No. & 1 & 2 & 3 & \\
\hline Test Date: & $12 / 1 / 2006$ & $12 / 2 / 2006$ & $12 / 2 / 2006$ & \\
\hline Test Time: & 0857-1059 & 0919-1121 & $1712-1914$ & Average \\
\hline Volume of Dry Gas Sam & @ Standard C & onditions & & \\
\hline $\mathrm{dscm}$ & 1.343 & 1.352 & 1.383 & 1.359 \\
\hline dscf & 47.420 & 47.730 & 48.842 & 47.997 \\
\hline Oxygen & & & & \\
\hline$\%$ volume & 6.4 & 6.1 & 6.2 & 6.2 \\
\hline Particulate Mercury & & & & \\
\hline$\mu \mathrm{g}$ & 0.6100 & 1.5000 & 0.6400 & 0.9167 \\
\hline$\mu g / d s c f$ & 0.0129 & 0.0314 & 0.0131 & 0.0191 \\
\hline$\mu \mathrm{g} / \mathrm{dscm}$ & 0.4542 & 1.1095 & 0.4628 & 0.6755 \\
\hline $\mathrm{lbs} / 10^{12} \mathrm{Btu}$ & 0.400 & 0.957 & 0.402 & 0.586 \\
\hline$\%$ of total $\mathrm{Hg}$ & $10.38 \%$ & $18.99 \%$ & $13.37 \%$ & $14.25 \%$ \\
\hline Oxidized Mercury & & & & \\
\hline$\mu \mathrm{g}$ & 1.6000 & 1.7000 & 3.3000 & 2.2000 \\
\hline$\mu \mathrm{g} / \mathrm{dscf}$ & 0.0337 & 0.0356 & 0.0676 & 0.0456 \\
\hline$\mu \mathrm{g} / \mathrm{dscm}$ & 1.1914 & 1.2574 & 2.3861 & 1.6116 \\
\hline $\mathrm{lbs} / 10^{12} \mathrm{Btu}$ & 1.049 & 1.085 & 2.072 & 1.402 \\
\hline$\%$ of total $\mathrm{Hg}$ & $27.24 \%$ & $21.52 \%$ & $68.92 \%$ & $39.23 \%$ \\
\hline Elemental Mercury & & & & \\
\hline$\mu \mathrm{g}$ & 3.6640 & 4.7000 & 0.8480 & 3.0707 \\
\hline$\mu \mathrm{g} / \mathrm{dscf}$ & 0.0773 & 0.0985 & 0.0174 & 0.0644 \\
\hline$\mu \mathrm{g} / \mathrm{dscm}$ & 2.7282 & 3.4763 & 0.6132 & 2.2726 \\
\hline $\mathrm{lbs} / 10^{12} \mathrm{Btu}$ & 2.402 & 2.999 & 0.532 & 1.978 \\
\hline$\%$ of total $\mathrm{Hg}$ & $62.38 \%$ & $59.49 \%$ & $17.71 \%$ & $46.53 \%$ \\
\hline Total Mercury & & & & \\
\hline$\mu \mathrm{g}$ & 5.8740 & 7.9000 & 4.7880 & 6.1873 \\
\hline$\mu \mathrm{g} / \mathrm{dscf}$ & 0.1239 & 0.1655 & 0.0980 & 0.1291 \\
\hline$\mu \mathrm{g} / \mathrm{dscm}$ & 4.3738 & 5.8432 & 3.4620 & 4.5597 \\
\hline $\mathrm{lbs} / 10^{12} \mathrm{Btu}$ & 3.850 & 5.040 & 3.006 & 3.965 \\
\hline Oxygen based $F$ factor & 9,780 & 9,780 & 9,780 & 9,780 \\
\hline
\end{tabular}




\section{(1)}

\section{Summary of Results \\ Mercury Speciation Results \\ Rocky Mountain Power - Hardin Power Plant}

Stack

\begin{tabular}{|c|c|c|c|c|}
\hline $\begin{array}{l}\text { Run No. } \\
\text { Test Date: } \\
\text { Test Time: }\end{array}$ & $\begin{array}{c}1 \\
12 / 1 / 2006 \\
0857-1105 \\
\end{array}$ & $\begin{array}{c}2 \\
12 / 2 / 2006 \\
0919-1124 \\
\end{array}$ & $\begin{array}{c}3 \\
12 / 2 / 2006 \\
1712-1917 \\
\end{array}$ & Average \\
\hline \multicolumn{5}{|c|}{ Volume of Dry Gas Sampled @ Standard Conditions } \\
\hline dscm & 1.983 & 2.028 & 1.945 & 1.985 \\
\hline dscf & 70.043 & 71.627 & 68.704 & 70.125 \\
\hline \multicolumn{5}{|l|}{ Oxygen } \\
\hline$\%$ volume & 6.2 & 6.4 & 6.2 & 6.3 \\
\hline \multicolumn{5}{|l|}{ Particulate Mercury } \\
\hline$\mu g$ & 0.0380 & ND & 0.0090 & $<0.0157$ \\
\hline$\mu \mathrm{g} / \mathrm{dscf}$ & 0.0005 & ND & 0.0001 & $<0.0002$ \\
\hline$\mu \mathrm{g} / \mathrm{dscm}$ & 0.0192 & ND & 0.0046 & $<0.0079$ \\
\hline $\mathrm{lbs} / 10^{12} \mathrm{Btu}$ & 0.017 & ND & 0.004 & $<0.007$ \\
\hline$\%$ of total $\mathrm{Hg}$ & $0.54 \%$ & ND & $0.14 \%$ & $0.34 \%$ \\
\hline \multicolumn{5}{|l|}{ Oxidized Mercury } \\
\hline$\mu \mathrm{g}$ & 0.1100 & ND & 0.0800 & $<0.0633$ \\
\hline$\mu \mathrm{g} / \mathrm{dscf}$ & 0.0016 & ND & 0.0012 & $<0.0009$ \\
\hline$\mu \mathrm{g} / \mathrm{dscm}$ & 0.0555 & ND & 0.0411 & $<0.0322$ \\
\hline $\mathrm{lbs} / 10^{12} \mathrm{Btu}$ & 0.048 & ND & 0.036 & $<0.028$ \\
\hline$\%$ of total $\mathrm{Hg}$ & $1.57 \%$ & ND & $1.22 \%$ & $1.40 \%$ \\
\hline \multicolumn{5}{|l|}{ Elemental Mercury } \\
\hline$\mu g$ & 6.8410 & 12.1000 & 6.4640 & 8.4683 \\
\hline$\mu \mathrm{g} / \mathrm{dscf}$ & 0.0977 & 0.1689 & 0.0941 & 0.1202 \\
\hline$\mu \mathrm{g} / \mathrm{dscm}$ & 3.4498 & 5.9665 & 3.3234 & 4.2466 \\
\hline $\mathrm{lbs} / 10^{12} \mathrm{Btu}$ & 2.995 & 5.251 & 2.885 & 3.710 \\
\hline$\%$ of total $\mathrm{Hg}$ & $97.88 \%$ & $100.00 \%$ & $98.64 \%$ & $98.84 \%$ \\
\hline \multicolumn{5}{|l|}{ Total Mercury } \\
\hline$\mu g$ & 6.9890 & 12.1000 & 6.5530 & 8.5473 \\
\hline$\mu \mathrm{g} / \mathrm{dscf}$ & 0.0998 & 0.1689 & 0.0954 & 0.1214 \\
\hline$\mu \mathrm{g} / \mathrm{dscm}$ & 3.5245 & 5.9665 & 3.3692 & 4.2867 \\
\hline $\mathrm{lbs} / 10^{12} \mathrm{Btu}$ & 3.059 & 5.251 & 2.924 & 3.745 \\
\hline Oxygen based $F$ factor & 9,780 & 9,780 & 9,780 & 9,780 \\
\hline
\end{tabular}


Appendix C:

Calibration Data 


\section{Appendix C}

\section{Table 13: Calibration Data}

Pre-Test Calibrations:

\section{Equipment}

Dry Gas Meter 1-1

Digital Temperature Indicator 1-1

Dry Gas Meter 1-1 Orifice

Dry Gas Meter 2-2

Digital Temperature Indicator 2-2

Dry Gas Meter 2-2 Orifice

Pitot Tube 3-1

Pitot Tube 3-2

Pitot Tube 3-3

Pitot Tube 3-4

Pitot Tube 4-1

Nozzle 4-2

Nozzle 5-2

Nozzle 5-8

Nozzle 7-2

Nozzle 7-8
Calibration Factor

0.985

0.999

0.823

0.824

0.823

0.823

0.824

0.171

0.193

0.154

0.192

0.154
Calibration Date

09/19/06

09/19/06

09/19/06

$10 / 24 / 06$

$10 / 23 / 06$

$10 / 24 / 06$

$11 / 21 / 06$

$11 / 21 / 06$

10/20/06

$10 / 20 / 06$

01/24/06

01/25/06

$11 / 28 / 06$

01/25/06

10/27/06

09/19/06 
Post-Test Calibrations:

\section{Equipment}

Dry Gas Meter 1-1

Digital Temperature Indicator 1-1

Dry Gas Meter 2-2

Digital Temperature Indicator 2-2

Pitot Tube 3-1

Pitot Tube 3-2

Pitot Tube 3-3

Pitot Tube 3-4

Pitot Tube 4-1

Nozzle 4-2

Nozzle 5-2

Nozzle 5-8

Nozzle 7-2

Nozzle 7-8
Calibration Factor

0.984

0.989

0.825

0.826

0.826

0.826

0.827

0.171

0.193

0.154

0.192

0.154

\section{Calibration Date}

$12 / 07 / 06$

$12 / 07 / 06$

$12 / 07 / 06$

$12 / 07 / 06$

12/07/06

12/07/06

$12 / 07 / 06$

12/07/06

$12 / 07 / 06$

12/07/06

12/07/06

12/07/06

12/07/06

12/07/06 


\author{
Calibration Data \\ Dry Gas Meter Calibration \\ Meter Console No. \\ ASAI 1-1 \\ Date Calibration Performed: \\ 09/19/06 \\ $\triangle \mathrm{H}$ Setting

\begin{tabular}{c}
$\left(\right.$ " $\left.\mathrm{H}_{2} \mathrm{O}\right)$ \\
\hline 0.50 \\
1.00 \\
1.50 \\
2.00 \\
3.00 \\
4.00 \\
Average
\end{tabular}

\begin{tabular}{c}
$\mathrm{C}_{\mathrm{DG}}$ \\
\hline 0.984 \\
\hline 0.986 \\
\hline 0.985 \\
\hline 0.987 \\
\hline 0.984 \\
\hline 0.983 \\
\hline 0.985 \\
\hline
\end{tabular} \\ Variation +: \\ $0.20 \%$ \\ Variation -: \\ $-0.20 \%$ \\ Certified by: \\ Gary B. Goldman 09/19/06 \\ Calibrator (Signature / Date)

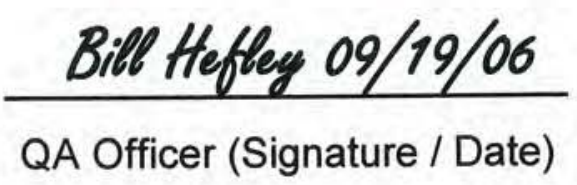




\author{
Calibration Data \\ Dry Gas Meter Calibration \\ Meter Console No. \\ ASAI 1-1 \\ Date Calibration Performed: \\ 09/19/06
}

Run $\frac{1}{1}$ at $0.5^{\prime \prime} \Delta \mathrm{H}$

Wet Test Meter $C_{f}=1.018$

$\begin{aligned} \mathrm{Pb} & =29.80 \mathrm{Hg} \\ \text { Console Pump Vacuum } & =-5.0 \mathrm{Hg}\end{aligned}$

Wet Test Meter No. ASAI-O

Meter

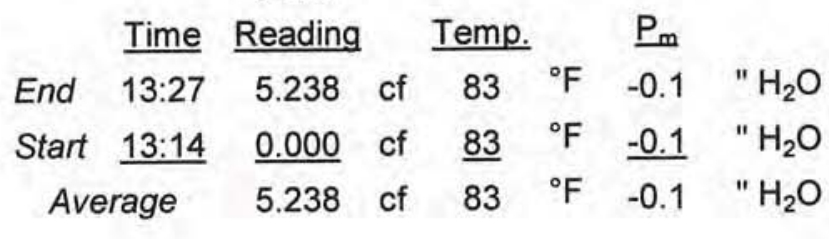

Dry Gas Meter

Meter Temperature

Reading In Out $\underline{\mathrm{P}_{\mathrm{m}}}$ 913.384 cf $82{ }^{\circ} \mathrm{F} \quad 83 \quad{ }^{\circ} \mathrm{F} \quad 0.50 \quad " \mathrm{H}_{2} \mathrm{O}$

$\underline{907.982}$ of $\underline{82}{ }^{\circ} \mathrm{F} \quad \underline{81}{ }^{\circ} \mathrm{F} \quad \underline{0.50} \quad \mathrm{H}_{2} \mathrm{O}$

5.402 cf $82{ }^{\circ} \mathrm{F} \quad 82 \quad{ }^{\circ} \mathrm{F} \quad 0.50 \quad " \mathrm{H}_{2} \mathrm{O}$

$$
\begin{aligned}
& \text { Wet Test Meter } V_{m s t d}=17.65 \times V_{m}\left[\frac{P_{b}+\frac{P_{m}}{13.6}}{\left(T_{m}+460\right)}\right] \times C_{f}=\underline{5.164} d c s f \\
& \text { Dry Gas Meter } V_{m s t d}=17.65 \times V m\left[\frac{P_{b}+\frac{P_{m}}{13.6}}{\left(T_{m}+460\right)}\right]=\underline{5.249} \text { dcsf }
\end{aligned}
$$$$
\text { Calibration Factor }\left(C_{D G}\right)=\frac{\text { Wet Test Meter } V_{\text {mstd }}}{\text { Dry Gas Meter } V_{\text {mstd }}}=\underline{0.984}
$$ 


\author{
Calibration Data \\ Dry Gas Meter Calibration
}

Meter Console No.

Date Calibration Performed:
ASAI 1-1

09/19/06

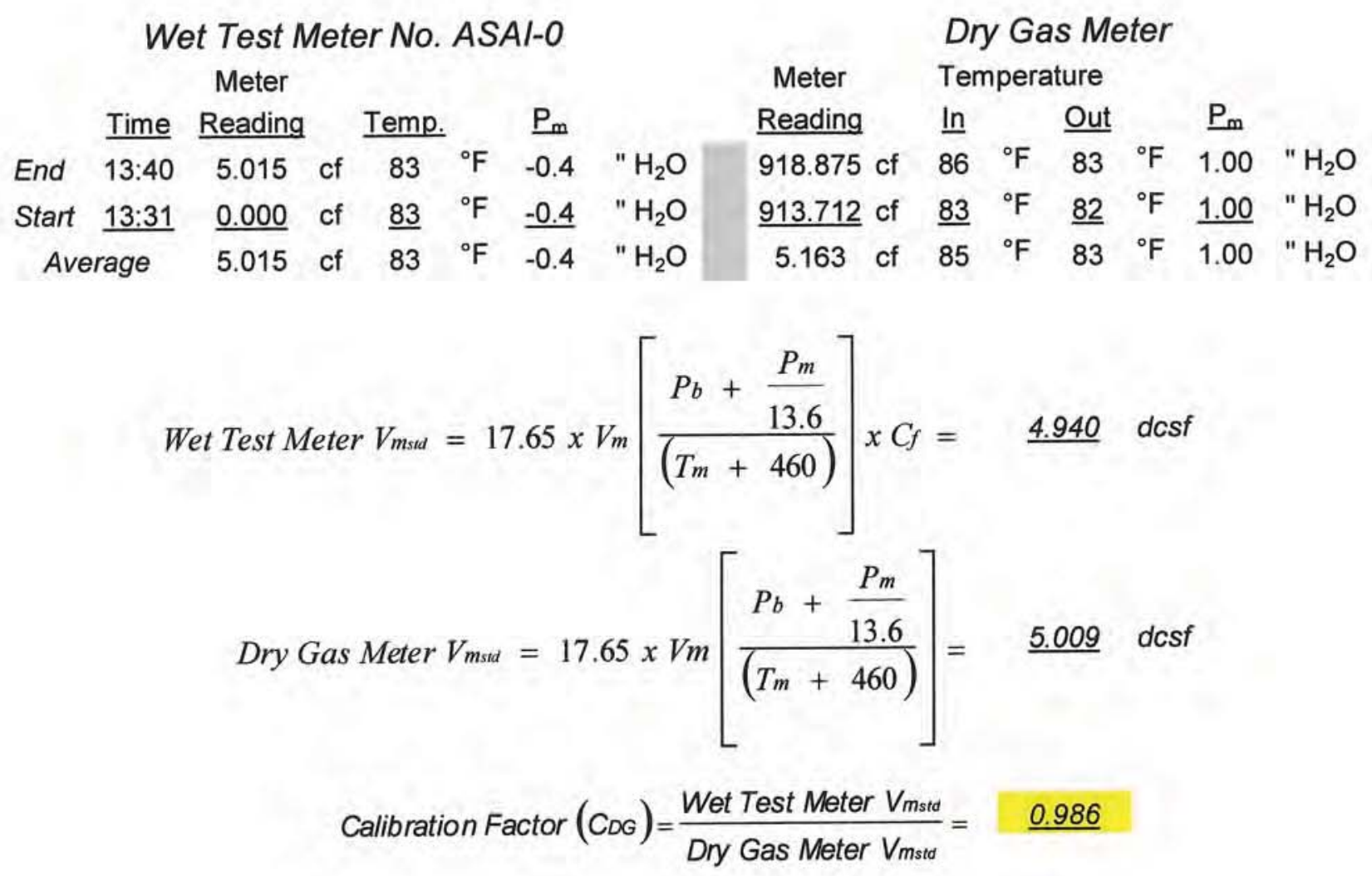




\author{
Calibration Data \\ Dry Gas Meter Calibration \\ Meter Console No. \\ ASAI 1-1 \\ Date Calibration Performed: \\ 09/19/06
}

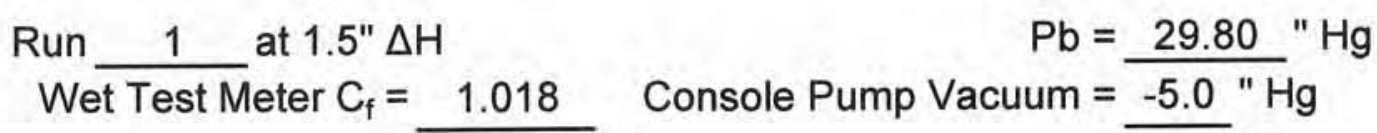

Wet Test Meter No. ASAI-0

Dry Gas Meter

Meter

Meter Temperature

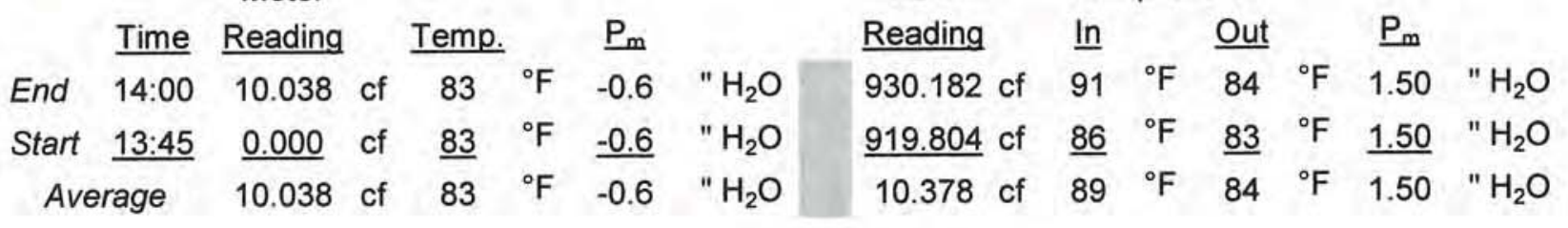

Wet Test Meter $V_{m s d}=17.65 \times V_{m}\left[\frac{P_{b}+\frac{P_{m}}{13.6}}{\left(T_{m}+460\right)}\right] \times C_{f}=\underline{9.884} \mathrm{dcsf}$

Dry Gas Meter $V_{m s d}=17.65 \times \mathrm{Vm}\left[\frac{P_{b}+\frac{P_{m}}{13.6}}{\left(T_{m}+460\right)}\right]=10.034 \mathrm{dcsf}$

Calibration Factor $(C D G)=\frac{\text { Wet Test Meter } V_{\text {mstd }}}{\text { Dry Gas Meter } V_{\text {mst }}}=\underline{0.985}$ 


\author{
Calibration Data \\ Dry Gas Meter Calibration
}

Meter Console No.

ASAI 1-1

Date Calibration Performed:

09/19/06

$$
\begin{aligned}
\text { Run } \frac{1}{\mathrm{~Pb}} & =29.80 \mathrm{Hg} \\
\text { Wet Test Meter } \mathrm{C}_{\mathrm{f}}=1.018 \text { Console Pump Vacuum } & =-5.0^{\mathrm{N}} \mathrm{Hg}
\end{aligned}
$$

Wet Test Meter No. ASAl-0 Meter

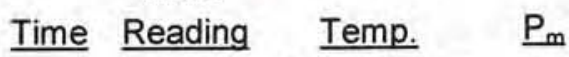

End 14:16 10.020 of $83{ }^{\circ} \mathrm{F} \quad-0.7$

Start 14:03

Average

$\underline{0.000}$ of $\underline{83} \quad{ }^{\circ} \mathrm{F} \quad \underline{-0.7} \quad " \mathrm{H}_{2} \mathrm{O}$
10.020 cf $83 \quad{ }^{\circ} \mathrm{F} \quad-0.7 \quad " \mathrm{H}_{2} \mathrm{O}$
Dry Gas Meter Meter Temperature Reading In $\underline{\text { Out }} \underline{P_{m}}$ 940.927 of $94{ }^{\circ} \mathrm{F} \quad 86 \quad{ }^{\circ} \mathrm{F} \quad 2.00 \quad " \mathrm{H}_{2} \mathrm{O}$ $\underline{930.552}$ of $\quad \underline{90}{ }^{\circ} \mathrm{F} \quad \underline{85}{ }^{\circ} \mathrm{F} \quad \underline{2.00} \quad " \mathrm{H}_{2} \mathrm{O}$ 10.375 cf $92{ }^{\circ} \mathrm{F} \quad 86 \quad{ }^{\circ} \mathrm{F} \quad 2.00 \quad " \mathrm{H}_{2} \mathrm{O}$

$$
\begin{aligned}
& \text { Wet Test Meter Vmsd }=17.65 \times V_{m}\left[\frac{P_{b}+\frac{P_{m}}{13.6}}{\left(T_{m}+460\right)}\right] \times C_{f}=\underline{9.863} d c s f \\
& \text { Dry Gas Meter Vmsd }=17.65 \times \mathrm{Vm}\left[\frac{P_{b}+\frac{P_{m}}{13.6}}{\left(T_{m}+460\right)}\right]=\underline{9.993} \mathrm{dcsf}
\end{aligned}
$$

$$
\text { Calibration Factor }\left(C_{D G}\right)=\frac{\text { Wet Test Meter } V_{\text {mstd }}}{\text { Dry Gas Meter } V_{m s t d}}=\underline{0.987}
$$




\author{
Calibration Data \\ Dry Gas Meter Calibration \\ Meter Console No. \\ ASAI 1-1 \\ Date Calibration Performed: \\ 09/19/06
}

Run 1 at 3.0" $\Delta \mathrm{H}$

Wet Test Meter $C_{f}=1.018$ Console Pump Vacuum $=-5.0 " \mathrm{Hg}$

Wet Test Meter No. ASAI-O Meter

\begin{tabular}{|c|c|c|c|c|c|c|}
\hline & Time & Reading & Temp. & & $\underline{P_{m}}$ & \\
\hline End & $14: 29$ & 10.407 cf & 84 & ${ }^{\circ} \mathrm{F}$ & -1.0 & $" \mathrm{H}_{2} \mathrm{O}$ \\
\hline Start & $14: 18$ & $\underline{0.000}$ & 84 & ${ }^{\circ} \mathrm{F}$ & -1.0 & " $\mathrm{H}_{2} \mathrm{O}$ \\
\hline$A v$ & rage & 10.407 cf & 84 & ${ }^{\circ} \mathrm{F}$ & -1.0 & $" \mathrm{H}_{2} \mathrm{O}$ \\
\hline
\end{tabular}

Dry Gas Meter

Meter Temperature

Reading In Out $\quad \underline{P_{m}}$ 952.083 cf $97 \quad{ }^{\circ} \mathrm{F} \quad 87 \quad{ }^{\circ} \mathrm{F} \quad 3.00 \quad " \mathrm{H}_{2} \mathrm{O}$ $\underline{941.298} \mathrm{cf} \quad \underline{92}{ }^{\circ} \mathrm{F} \quad \underline{86}{ }^{\circ} \mathrm{F} \quad \underline{3.00} \quad \mathrm{H}_{2} \mathrm{O}$ 10.785 cf $95 \quad{ }^{\circ} \mathrm{F} \quad 87 \quad{ }^{\circ} \mathrm{F} \quad 3.00 \quad " \mathrm{H}_{2} \mathrm{O}$

$$
\begin{aligned}
& \text { Wet Test Meter } V_{m s d}=17.65 \times V_{m}\left[\frac{P_{b}+\frac{P_{m}}{13.6}}{\left(T_{m}+460\right)}\right] \times C_{f}=\underline{10.218} d c s f \\
& \text { Dry Gas Meter } V_{m s d}=17.65 \times V m\left[\frac{P_{b}+\frac{P_{m}}{13.6}}{\left(T_{m}+460\right)}\right]=\underline{10.381} \mathrm{dcsf}
\end{aligned}
$$$$
\text { Calibration Factor }\left(C_{D G}\right)=\frac{\text { Wet Test Meter } V_{\text {mstd }}}{\text { Dry Gas Meter } V_{m_{s t d}}}=\underline{0.984}
$$ 


\author{
Calibration Data \\ Dry Gas Meter Calibration \\ Meter Console No. \\ ASAI 1-1 \\ Date Calibration Performed: \\ 09/19/06
}

$\begin{aligned} \text { Run } \frac{1}{\mathrm{~Pb}}=29.80 \mathrm{Hg} & \text { at 4.0" } \mathrm{Hg} \\ \text { Wet Test Meter } \mathrm{C}_{\mathrm{f}}=1.018 \text { Console Pump Vacuum } & =-5.0^{\mathrm{Hg}}\end{aligned}$

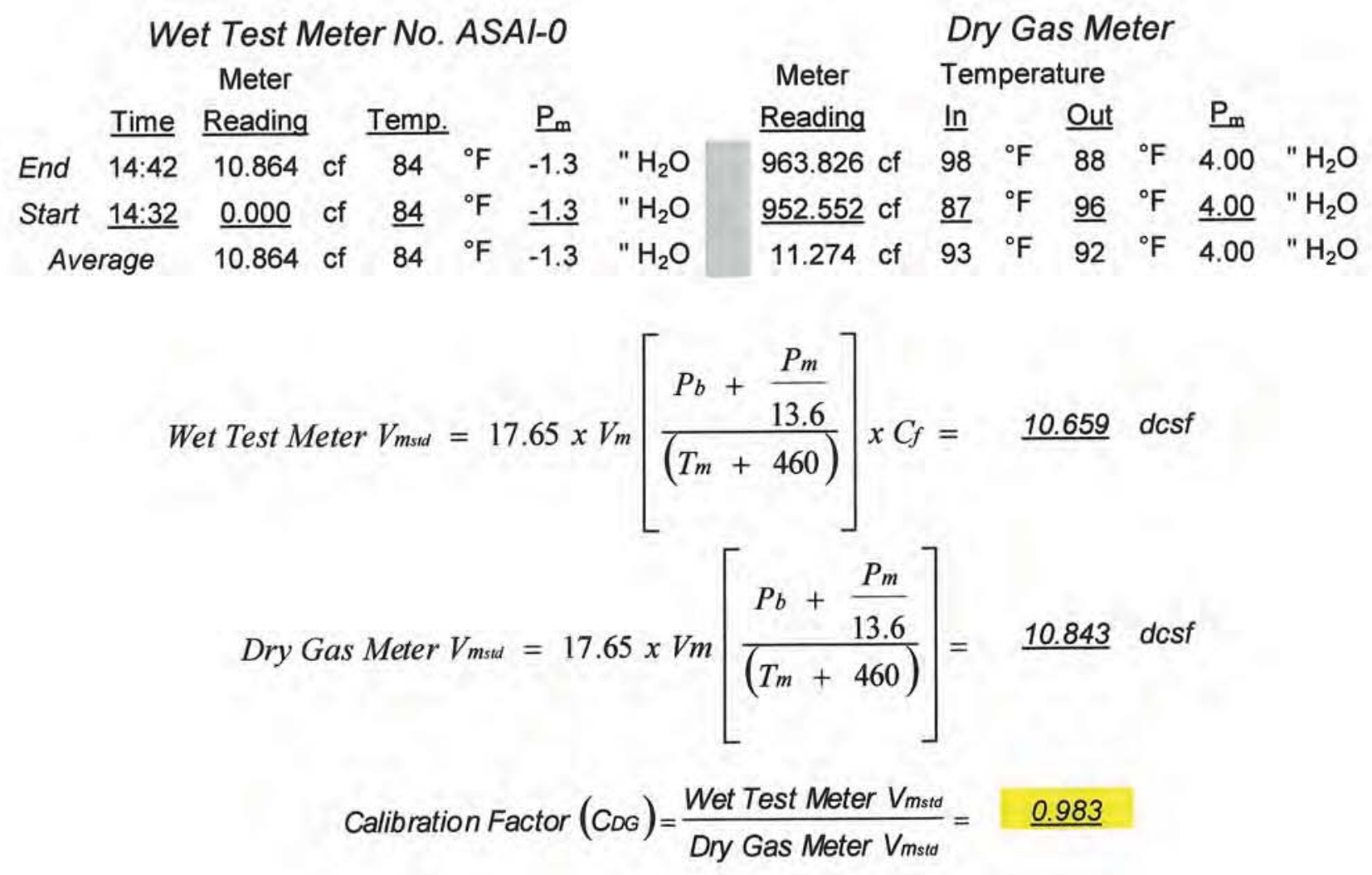


Calibration Data

Digital Temperature Indicator Calibration

DTI Unit No. ASAI 1-1

Date Calibration Performed:

\begin{tabular}{|c|c|}
\hline $09 / 19 / 06$ & \\
\hline $\begin{array}{c}\text { ASTM } \\
\text { Reference }\end{array}$ & \\
\hline Thermometer & DTI \\
\hline ( $\left.{ }^{\circ} \mathrm{F}\right)$ & $\left({ }^{\circ} \mathrm{F}\right)$ \\
\hline $33^{\circ} \mathrm{F}$ & $32^{\circ} \mathrm{F}$ \\
\hline $82^{\circ} \mathrm{F}$ & $82^{\circ} \mathrm{F}$ \\
\hline $210^{\circ} \mathrm{F}$ & $210^{\circ} \mathrm{F}$ \\
\hline $251^{\circ} \mathrm{F}$ & $252^{\circ} \mathrm{F}$ \\
\hline $298^{\circ} \mathrm{F}$ & $299^{\circ} \mathrm{F}$ \\
\hline $348^{\circ} \mathrm{F}$ & $348^{\circ} \mathrm{F}$ \\
\hline $389^{\circ} \mathrm{F}$ & $389^{\circ} \mathrm{F}$ \\
\hline
\end{tabular}

Meter Adjusted?

No

Reference Point

Ice Bath

Ambient Air

Boiling Water

Oven

Oven

Oven

Oven

ASTM Reference Thermometer:

$$
\text { Certified by: }
$$

SN: 5963

SN: 1853

SN: 992
Range: $\quad+18+89^{\circ} \mathrm{F}$

Range: $+205+310^{\circ} \mathrm{F}$

Range: $+295+400^{\circ} \mathrm{F}$
Gary B. Goldman 09/19/06

Calibrator (Signature / Date)

Bill Hefley 09/19/06

QA Officer (Signature / Date) 


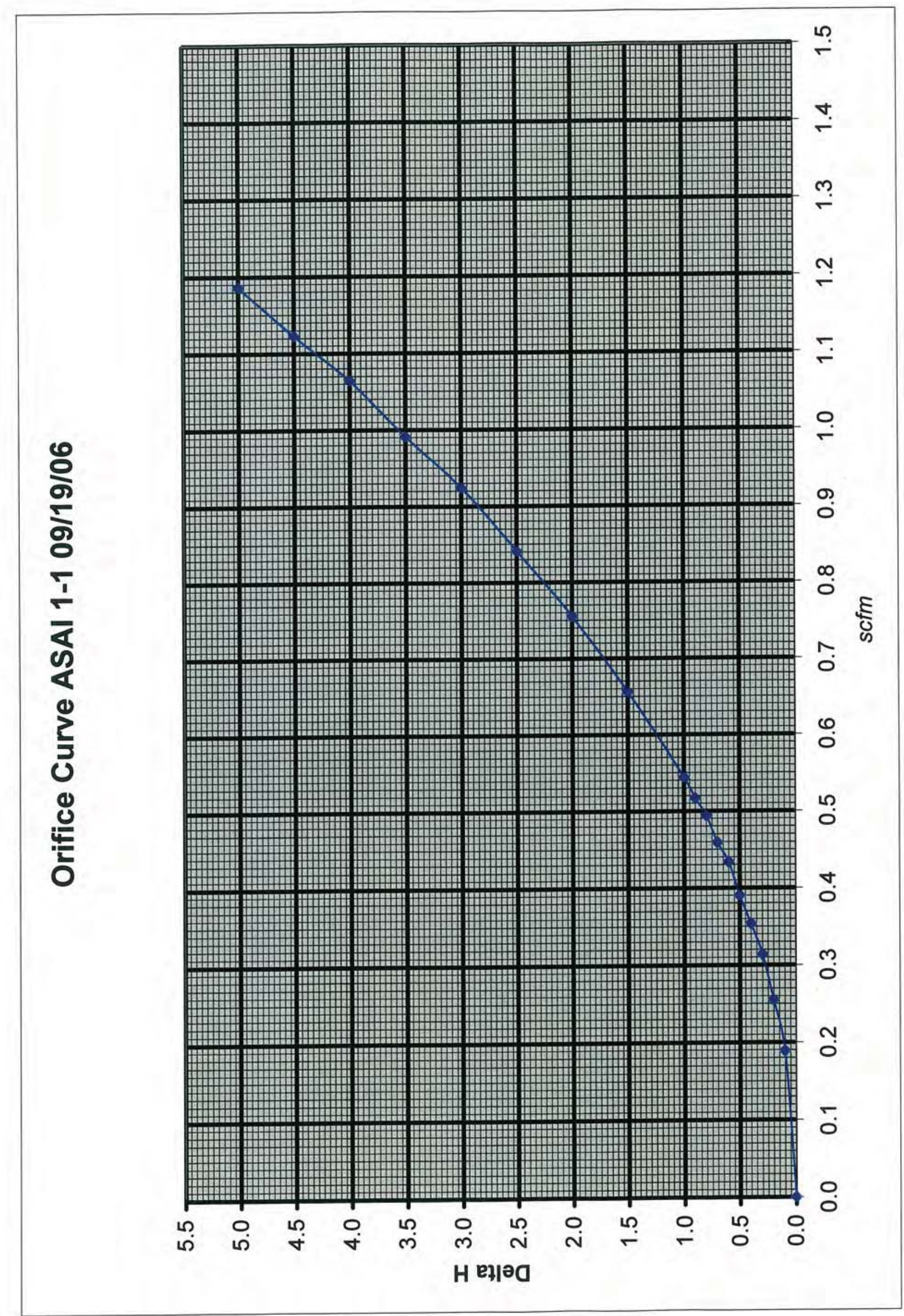




\author{
Calibration Data \\ Dry Gas Meter Calibration

\begin{tabular}{rr} 
Meter Console No. & ASAl 2-2 \\
\cline { 2 - 2 } Date Calibration Performed: & $10 / 24 / 06$ \\
\end{tabular}

\begin{tabular}{c}
$\Delta \mathrm{H}$ Setting \\
$\left(" \mathrm{H}_{2} \mathrm{O}\right)$ \\
\hline 0.50 \\
1.00 \\
1.50 \\
2.00 \\
3.00 \\
4.00 \\
Average
\end{tabular}

\begin{tabular}{c}
$\mathrm{C}_{\mathrm{DG}}$ \\
\hline 1.003 \\
\hline 1.000 \\
\hline 0.996 \\
\hline 0.998 \\
\hline 0.997 \\
\hline 0.997 \\
\hline 0.999 \\
\hline
\end{tabular}

Variation +:

Variation -:

$0.40 \%$

$-0.30 \%$

Certified by:

Patrich Selalowick 10/24/06

Calibrator (Signature / Date)

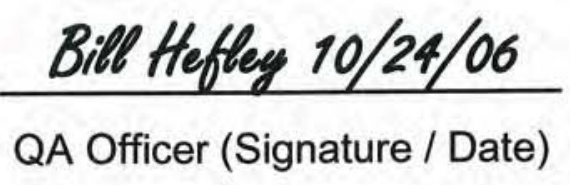




\author{
Calibration Data \\ Dry Gas Meter Calibration
}

Meter Console No.

Date Calibration Performed:
ASAI 2-2

$10 / 24 / 06$

Run 1 at $0.5^{\prime \prime} \Delta \mathrm{H}$

Wet Test Meter $C_{f}=1.018$ Console Pump Vacuum $=-5.0 " \mathrm{Hg}$

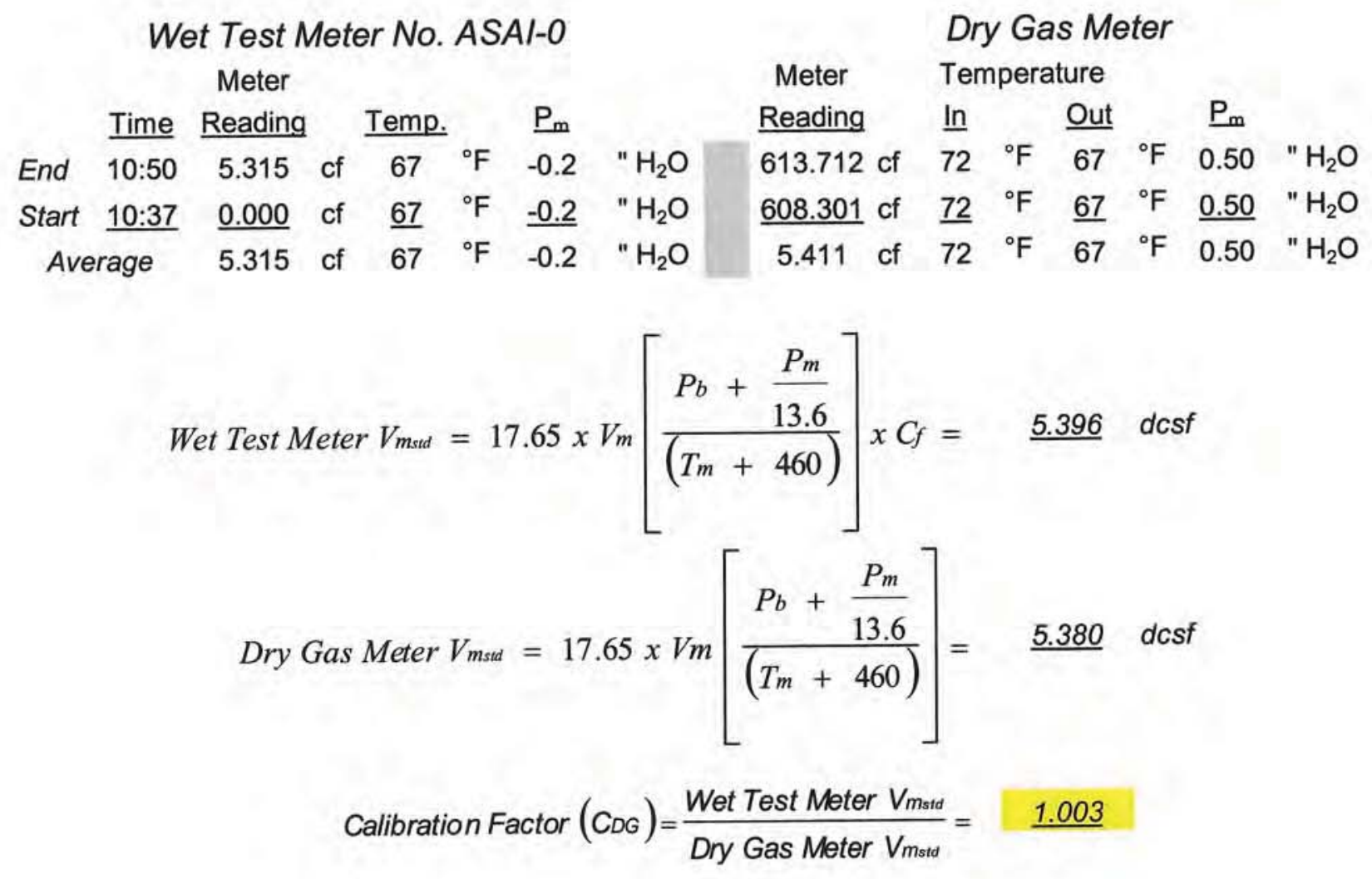




\author{
Calibration Data \\ Dry Gas Meter Calibration
}

Meter Console No.

Date Calibration Performed:

ASAI 2-2

10/24/06

Run 1 at $1.0^{\prime \prime} \Delta \mathrm{H}$

Wet Test Meter $\mathrm{C}_{\mathrm{f}}=1.018$ Console Pump Vacuum $=-5.0 \mathrm{Hg}$

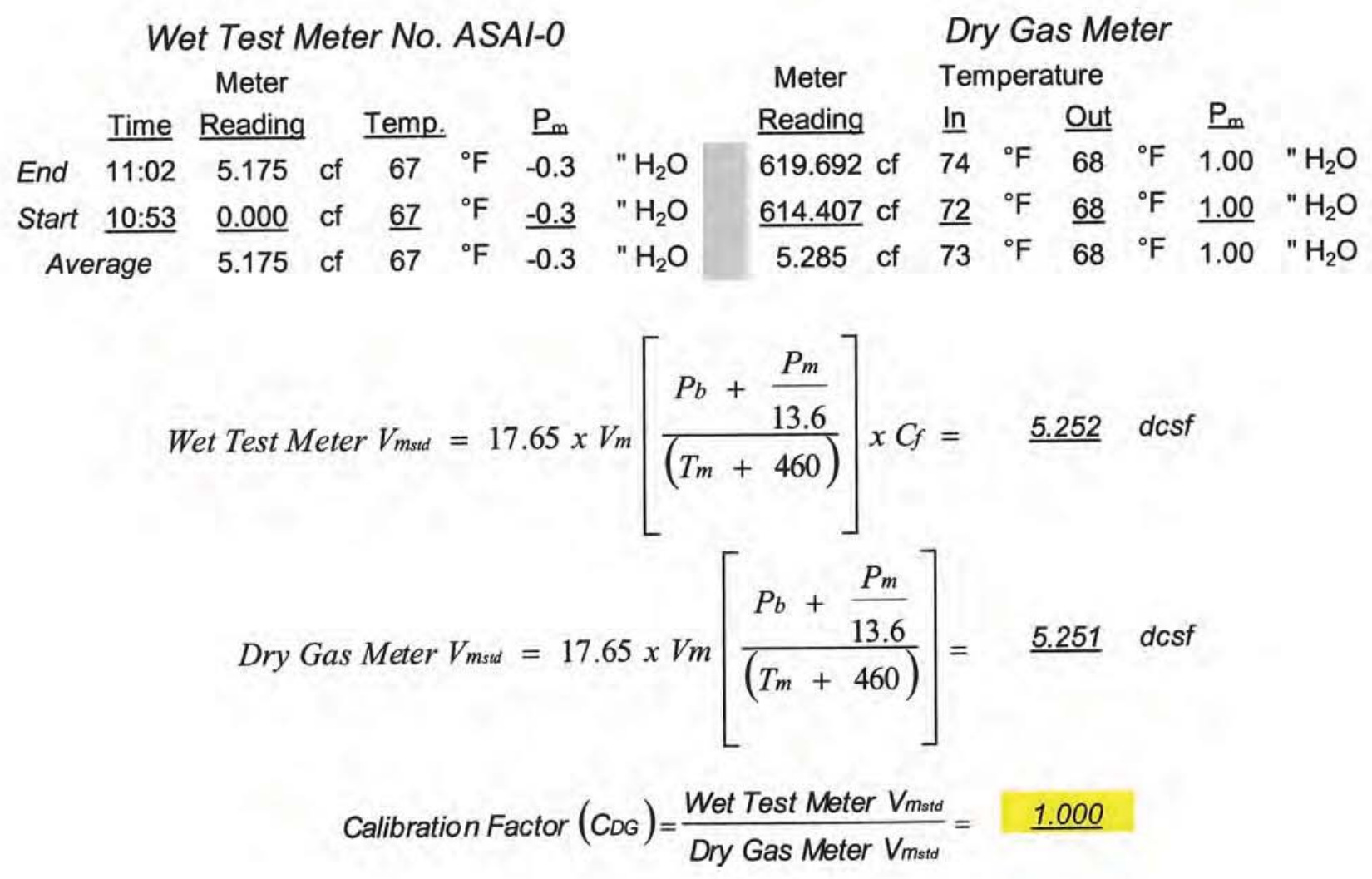




\author{
Calibration Data \\ Dry Gas Meter Calibration
}

Meter Console No.

Date Calibration Performed:

ASAI 2-2

10/24/06
Run 1 at 1.5" $\Delta \mathrm{H}$

Wet Test Meter $C_{f}=1.018$
$\mathrm{Pb}=29.79 " \mathrm{Hg}$

\footnotetext{
Wet Test Meter No. ASAI-0 Meter Meter Temperature

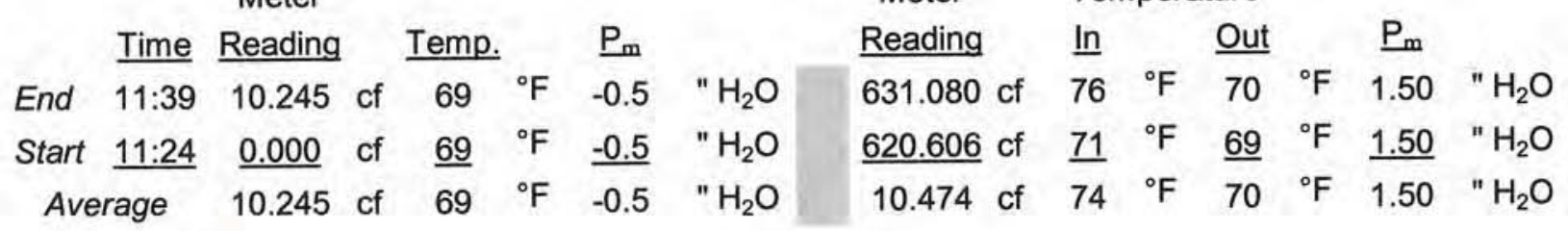

$$
\begin{aligned}
& \text { Wet Test Meter } V_{m s t d}=17.65 \times V_{m}\left[\frac{P_{b}+\frac{P_{m}}{13.6}}{\left(T_{m}+460\right)}\right] \times C_{f}=\underline{10.353} \mathrm{dcsf} \\
& \qquad \text { Dry Gas Meter } V_{m s t d}=17.65 \times V_{m}\left[\frac{P_{b}+\frac{P_{m}}{13.6}}{\left(T_{m}+460\right)}\right]=\underline{10.400} \text { dcsf }
\end{aligned}
$$$$
\text { Calibration Factor }\left(C_{D G}\right)=\frac{\text { Wet Test Meter } V_{\text {mstd }}}{\text { Dry Gas Meter } V_{\text {mstd }}}=\underline{0.996}
$$ 


\author{
Calibration Data \\ Dry Gas Meter Calibration \\ Meter Console No. \\ ASAI 2-2 \\ Date Calibration Performed: \\ 10/24/06
}

Run 1 at 2.0" $\Delta \mathrm{H}$

Wet Test Meter $\mathrm{C}_{\mathrm{f}}=1.018$ Console Pump Vacuum $=-5.0 \mathrm{Hg}$

Wet Test Meter No. ASAl-0 Meter

$\underline{\text { Time }}$ Reading Temp. $\quad \underline{\mathrm{P}}_{\mathrm{m}}$

\begin{tabular}{|c|c|c|c|c|c|c|c|}
\hline & Time & Reading & & lemp. & & $P_{m}$ & \\
\hline End & $11: 55$ & 10.205 & cf & 69 & ${ }^{\circ} \mathrm{F}$ & -0.7 & " $\mathrm{H}_{2} \mathrm{O}$ \\
\hline Start & $11: 42$ & $\underline{0.000}$ & cf & $\underline{69}$ & ${ }^{\circ} \mathrm{F}$ & $\underline{-0.7}$ & $" \mathrm{H}_{2} \mathrm{O}$ \\
\hline & & 10.205 & cf & 69 & ${ }^{\circ} \mathrm{F}$ & -0.7 & $" \mathrm{H}_{2} \mathrm{O}$ \\
\hline
\end{tabular}

Dry Gas Meter

Meter Temperature

Reading In $\underline{\text { Out }} \quad \underline{\mathrm{P}_{\mathrm{m}}}$ 641.943 cf $79{ }^{\circ} \mathrm{F} \quad 71{ }^{\circ} \mathrm{F} \quad 2.00 \quad " \mathrm{H}_{2} \mathrm{O}$ $\underline{631.509} \mathrm{cf} \quad \underline{75}{ }^{\circ} \mathrm{F} \quad \underline{70}{ }^{\circ} \mathrm{F} \quad \underline{2.00} \quad \mathrm{H}_{2} \mathrm{O}$ 10.434 cf $77 \quad{ }^{\circ} \mathrm{F} \quad 71 \quad{ }^{\circ} \mathrm{F} \quad 2.00 \quad " \mathrm{H}_{2} \mathrm{O}$

$$
\begin{aligned}
& \text { Wet Test Meter } V_{m s t d}=17.65 \times V_{m}\left[\frac{P_{b}+\frac{P_{m}}{13.6}}{\left(T_{m}+460\right)}\right] \times C_{f}=\underline{10.301} \mathrm{dcsf} \\
& \text { Dry Gas Meter } V_{m s t d}=17.65 \times V m\left[\frac{P_{b}+\frac{P_{m}}{13.6}}{\left(T_{m}+460\right)}\right]=\underline{10.322} \mathrm{dcsf}
\end{aligned}
$$$$
\text { Calibration Factor }\left(C_{D G}\right)=\frac{\text { Wet Test Meter } V_{\text {mstd }}}{\text { Dry Gas Meter } V_{\text {mstd }}}=\underline{0.998}
$$ 


\author{
Calibration Data \\ Dry Gas Meter Calibration \\ Meter Console No. \\ ASAI 2-2 \\ Date Calibration Performed:

Run 1 at 3.0" $\Delta \mathrm{H}$

Wet Test Meter $C_{f}=1.018$ Console Pump Vacuum $=-5.0 " \mathrm{Hg}$

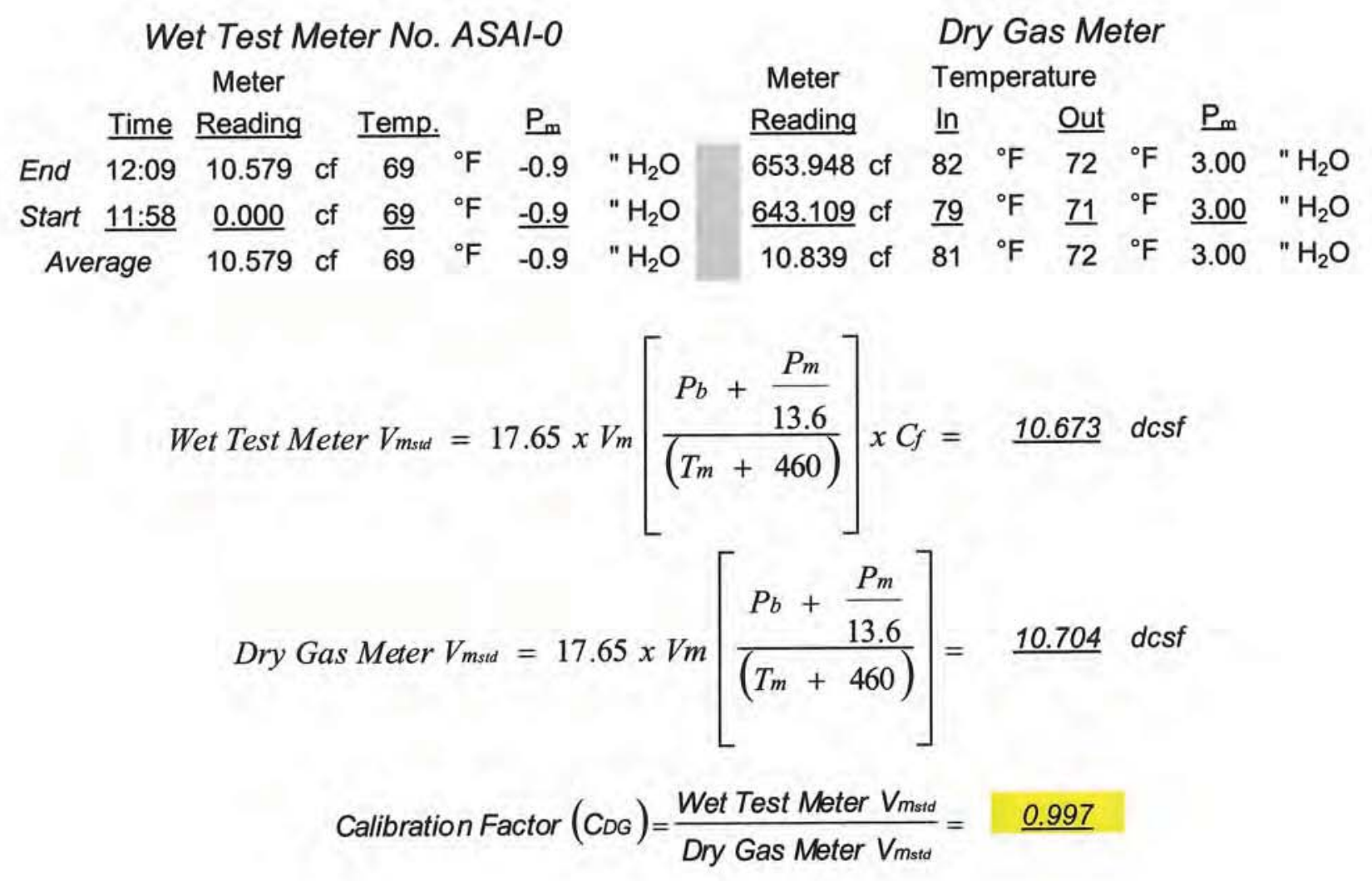




\title{
III SARMPLNG \\ ASSOCIATES, INC.
}

\author{
Calibration Data \\ Dry Gas Meter Calibration \\ Meter Console No. \\ ASAI 2-2 \\ Date Calibration Performed: \\ 10/24/06
}

Run 1 at 4.0" $\Delta \mathrm{H}$

Wet Test Meter $C_{f}=1.018$ Console Pump Vacuum $=-5.0 " \mathrm{Hg}$

$$
\mathrm{Pb}=29.77^{\mathrm{Ng}} \mathrm{Hg}
$$

Wet Test Meter $C_{f}=1.018$ Console Pump Vacuum $=\underline{-5.0 " ~ H g}$

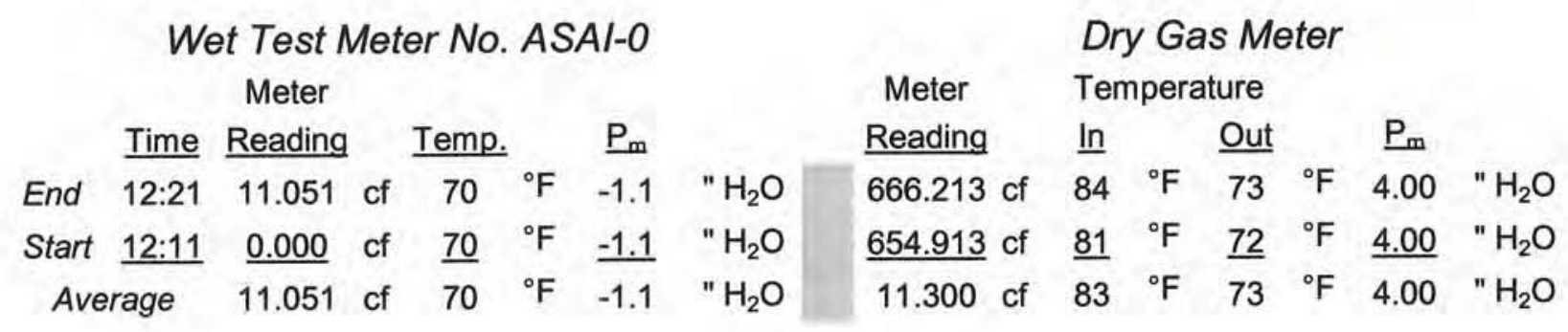

$$
\begin{gathered}
\text { Wet Test Meter V } \text { ssdi }=17.65 \times V_{m}\left[\frac{P_{b}+\frac{P_{m}}{13.6}}{\left(T_{m}+460\right)}\right] \times C_{f}=\underline{11.123} \mathrm{dcsf} \\
\text { Dry Gas Meter } V_{\text {ssd }}=17.65 \times \mathrm{Vm}\left[\frac{P_{b}+\frac{P_{m}}{13.6}}{\left(T_{m}+460\right)}\right]=\underline{11.156} \mathrm{dcsf} \\
\text { Calibration Factor }\left(C_{D G}\right)=\frac{\text { Wet Test Meter } V_{\text {mstd }}}{\text { Dry Gas Meter } V_{\text {mstd }}}=\underline{0.997}
\end{gathered}
$$


Calibration Data

Digital Temperature Indicator Calibration

DTI Unit No. ASAI 2-2

Date Calibration Performed:

$10 / 23 / 06$

Reference Point
Ice Bath
Ambient Air
Boiling Water
Oven
Oven
Oven
Oven

Meter Adjusted?

No

ASTM Reference Thermometer: $\quad$ SN: 5963 SN: 1853

Range: $\quad+18+89^{\circ} \mathrm{F}$

SN: 992

Range: $+205+310^{\circ} \mathrm{F}$

Range: $+\underline{+295+400^{\circ} \mathrm{F}}$

Certified by:

Patrick Selatovich 10/23/06

Calibrator (Signature / Date)

Bill Hefley 10/23/06

QA Officer (Signature / Date) 


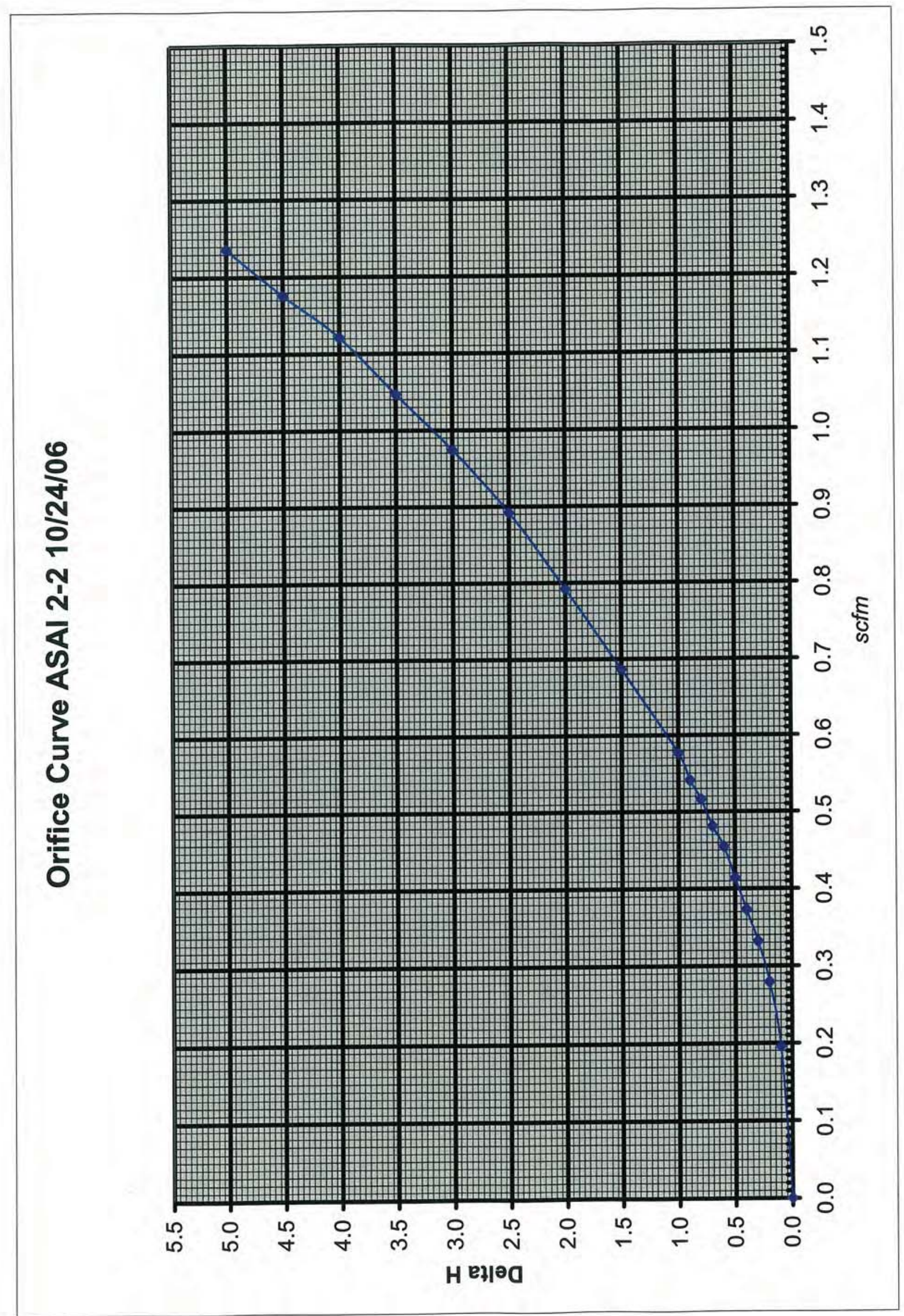




\section{AlR SAMPLENG ASSOCIATES, INC.}

CALIBRATION DATA

PITOT TUBE CALIBRATION DATA

$\begin{array}{lc}\text { Date: } \frac{11 / 21 / 06}{\text { I.D. \# }} & \text { ASAI 3-1 } \\ \text { C }_{\text {pstd }}: & 0.990\end{array}$

Time: $14: 45$

$\mathrm{T}_{\mathrm{s}}: \frac{14: 45}{68}{ }^{\circ} \mathrm{F}$

$\mathrm{Pb}: \overline{29.92} " \mathrm{Hg}$

\begin{tabular}{|c|c|c|c|c|c|c|c|c|c|c|}
\hline $\begin{array}{c}\text { fps } \\
\text { Mark }\end{array}$ & $\begin{array}{c}\text { Desired } \\
\text { Calibration } \\
\text { Standard }\end{array}$ & \multicolumn{2}{c|}{$\begin{array}{c}\text { Calibration } \\
\text { Standard } \\
\text { Start }\end{array}$} & $\begin{array}{c}\text { End Standard } \\
\text { Average }\end{array}$ & High & v High & $\begin{array}{c}\text { Cal. } \\
\text { Factor }\end{array}$ & Low & v Low & $\begin{array}{c}\text { Cal. } \\
\text { Factor }\end{array}$ \\
\hline 20 & 0.09 & 0.09 & 0.09 & 0.300 & 0.13 & 0.361 & 0.824 & 0.13 & 0.361 & 0.824 \\
\hline 30 & 0.21 & 0.21 & 0.21 & 0.458 & 0.30 & 0.548 & 0.828 & 0.30 & 0.548 & 0.828 \\
\hline 40 & 0.37 & 0.37 & 0.37 & 0.608 & 0.54 & 0.735 & 0.819 & 0.54 & 0.735 & 0.819 \\
\hline 50 & 0.57 & 0.57 & 0.57 & 0.755 & 0.83 & 0.911 & 0.820 & 0.83 & 0.911 & 0.820 \\
\hline 60 & 0.82 & 0.82 & 0.82 & 0.906 & 1.20 & 1.095 & 0.818 & 1.20 & 1.095 & 0.818 \\
\hline 70 & 1.12 & 1.10 & 1.10 & 1.049 & 1.60 & 1.265 & 0.821 & 1.60 & 1.265 & 0.821 \\
\hline 80 & 1.46 & 1.45 & 1.45 & 1.204 & 2.10 & 1.449 & 0.823 & 2.10 & 1.449 & 0.823 \\
\hline 90 & 1.85 & 1.85 & 1.85 & 1.360 & 2.65 & 1.628 & 0.827 & 2.65 & 1.628 & 0.827 \\
\hline & & & & & & & & & & \\
\hline & & & & & & & & & & \\
\hline 50 & 0.57 & 0.57 & 0.57 & 0.755 & 0.83 & 0.911 & 0.820 & 0.83 & 0.911 & 0.820 \\
\hline 50 & 0.57 & 0.57 & 0.57 & 0.755 & 0.83 & 0.911 & 0.820 & 0.83 & 0.911 & 0.820 \\
\hline & & & & & & & & & & \\
\hline & & & & & & & & & & \\
\hline \multicolumn{2}{|l|}{ Average } & & & & & & 0.823 & & & 0.823 \\
\hline
\end{tabular}

Summary of Results:

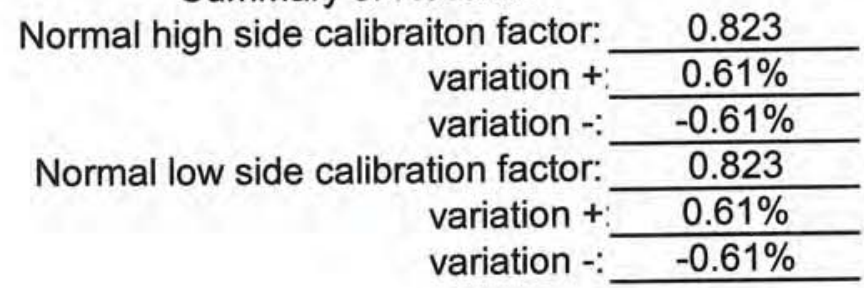

Certification:

I certify that the Type S pitot tube, the standard type pitot tube, and the calibration setup meet or exceed all specifications, criteria and/or applicable design features and hereby assign a pitot tube calibration factor $\mathrm{C}_{\mathrm{p}}$ of: $\quad \underline{0.823}$

Certified by:

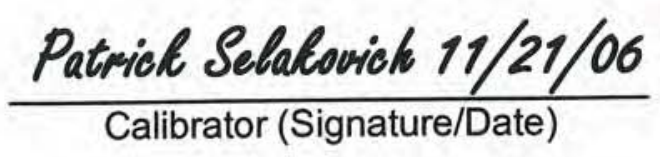




\section{TI}

CALIBRATION DATA

PITOT TUBE CALIBRATION DATA

\begin{tabular}{lc} 
Date: & $\frac{11 / 21 / 06}{\text { I.D. \# }}$ \\
C $_{\text {pstd: }}$ & ASAI 3-2 \\
\hline
\end{tabular}

Time: $15: 15$

$\mathrm{T}_{\mathrm{s}}: 68^{\circ} \mathrm{F}$

$\mathrm{Pb}: \overline{29.89} \mathrm{Hg}$

\begin{tabular}{|c|c|c|c|c|c|c|c|c|c|c|}
\hline \multirow{2}{*}{$\begin{array}{l}\text { fps } \\
\text { Mark }\end{array}$} & \multirow{2}{*}{$\begin{array}{c}\text { Desired } \\
\text { Calibration } \\
\text { Standard }\end{array}$} & \multicolumn{2}{|c|}{$\begin{array}{l}\text { Calibration } \\
\text { Standard }\end{array}$} & \multirow{2}{*}{$\begin{array}{l}\text { v Standard } \\
\text { Average }\end{array}$} & \multirow[b]{2}{*}{ High } & \multirow[b]{2}{*}{ v High } & \multirow{2}{*}{$\begin{array}{l}\text { Cal. } \\
\text { Factor }\end{array}$} & \multirow[b]{2}{*}{ Low } & \multirow[b]{2}{*}{ v Low } & \multirow{2}{*}{$\begin{array}{l}\text { Cal. } \\
\text { Factor }\end{array}$} \\
\hline & & Start & End & & & & & & & \\
\hline 20 & $\begin{array}{l}0.09 \\
\end{array}$ & 0.09 & 0.09 & 0.300 & 0.13 & 0.361 & 0.824 & 0.13 & 0.361 & 0.824 \\
\hline 30 & 0.21 & 0.21 & 0.21 & 0.458 & 0.30 & 0.548 & 0.828 & 0.30 & 0.548 & 0.828 \\
\hline 40 & 0.37 & 0.37 & 0.37 & 0.608 & 0.53 & 0.728 & 0.827 & 0.53 & 0.728 & 0.827 \\
\hline 50 & 0.57 & 0.57 & 0.57 & 0.755 & 0.82 & 0.906 & 0.825 & 0.82 & 0.906 & 0.825 \\
\hline 60 & 0.82 & 0.82 & 0.82 & 0.906 & 1.20 & 1.095 & 0.818 & 1.20 & 1.095 & 0.818 \\
\hline 70 & 1.12 & 1.10 & 1.10 & 1.049 & 1.60 & 1.265 & 0.821 & 1.60 & 1.265 & 0.821 \\
\hline 80 & 1.46 & 1.45 & 1.45 & 1.204 & 2.10 & 1.449 & 0.823 & 2.10 & 1.449 & 0.823 \\
\hline \multirow[t]{2}{*}{90} & 1.85 & 1.85 & 1.85 & 1.360 & 2.65 & 1.628 & 0.827 & 2.65 & 1.628 & 0.827 \\
\hline & & & & & & & & & & \\
\hline 50 & 0.57 & 0.57 & 0.57 & 0.755 & 0.82 & 0.906 & 0.825 & 0.82 & 0.906 & 0.825 \\
\hline 50 & 0.57 & 0.57 & 0.57 & 0.755 & 0.82 & 0.906 & 0.825 & 0.82 & 0.906 & 0.825 \\
\hline & & & & & & & & & & \\
\hline & & & & & & & & & & \\
\hline & Average & & & & & & 0.824 & & & 0.824 \\
\hline
\end{tabular}

Summary of Results:

$\begin{array}{rc}\text { Normal high side calibraiton factor: } & 0.824 \\ \text { variation }+ & 0.49 \% \\ \text { variation }-: & -0.73 \% \\ \text { Normal low side calibration factor: } & 0.824 \\ \text { variation }+ & 0.49 \% \\ \text { variation }-: & -0.73 \%\end{array}$

Certification:

I certify that the Type S pitot tube, the standard type pitot tube, and the calibration setup meet or exceed all specifications, criteria and/or applicable design features and hereby assign a pitot tube calibration factor $\mathrm{C}_{\mathrm{p}}$ of: $\quad 0.824$

Certified by:

\section{Patrich Selatorich 11/21/06}

Calibrator (Signature/Date)
Bill Heftey 11/21/06

QA Officer (Signature/Date) 
PITOT TUBE CALIBRATION DATA

$\begin{array}{lc}\text { Date: } \frac{10 / 20 / 06}{\text { I.D. \# }} & \text { ASAI 3-3 } \\ \text { C }_{\text {pstd }}: & 0.990\end{array}$

Time: $14: 50$

$\mathrm{T}_{\mathrm{s}}: \frac{14: 50}{76}{ }^{\circ} \mathrm{F}$

$\mathrm{Pb}: 29.52$ " $\mathrm{Hg}$

\begin{tabular}{|c|c|c|c|c|c|c|c|c|c|c|}
\hline $\begin{array}{c}\text { fps } \\
\text { Mark }\end{array}$ & $\begin{array}{c}\text { Desired } \\
\text { Calibration } \\
\text { Standard }\end{array}$ & \multicolumn{2}{c|}{$\begin{array}{c}\text { Calibration } \\
\text { Standard } \\
\text { Start }\end{array}$} & $\begin{array}{c}\text { V Standard } \\
\text { Average }\end{array}$ & High & $\sqrt{ }$ High & $\begin{array}{c}\text { Cal. } \\
\text { Factor }\end{array}$ & Low & V Low & $\begin{array}{c}\text { Cal. } \\
\text { Factor }\end{array}$ \\
\hline 20 & 0.09 & 0.09 & 0.09 & 0.300 & 0.13 & 0.361 & 0.824 & 0.13 & 0.361 & 0.824 \\
\hline 30 & 0.20 & 0.20 & 0.20 & 0.447 & 0.29 & 0.539 & 0.822 & 0.29 & 0.539 & 0.822 \\
\hline 40 & 0.36 & 0.36 & 0.36 & 0.600 & 0.52 & 0.721 & 0.824 & 0.52 & 0.721 & 0.824 \\
\hline 50 & 0.56 & 0.56 & 0.56 & 0.748 & 0.81 & 0.900 & 0.823 & 0.81 & 0.900 & 0.823 \\
\hline 60 & 0.80 & 0.80 & 0.80 & 0.894 & 1.15 & 1.072 & 0.826 & 1.15 & 1.072 & 0.826 \\
\hline 70 & 1.09 & 1.10 & 1.10 & 1.049 & 1.60 & 1.265 & 0.821 & 1.60 & 1.265 & 0.821 \\
\hline 80 & 1.42 & 1.40 & 1.40 & 1.183 & 2.05 & 1.432 & 0.818 & 2.05 & 1.432 & 0.818 \\
\hline 90 & 1.80 & 1.80 & 1.80 & 1.342 & 2.60 & 1.612 & 0.824 & 2.60 & 1.612 & 0.824 \\
\hline & & & & & & & & & & \\
\hline & & & & & & & & & & \\
\hline 50 & 0.56 & 0.56 & 0.56 & 0.748 & 0.84 & 0.917 & 0.808 & 0.84 & 0.917 & 0.808 \\
\hline 50 & 0.56 & 0.56 & 0.56 & 0.748 & 0.84 & 0.917 & 0.808 & 0.84 & 0.917 & 0.808 \\
\hline & & & & & & & & & & \\
\hline & & & & & & & & & & \\
\hline \multicolumn{2}{|l|}{ Average } & & & & & & 0.823 & & & 0.823 \\
\hline
\end{tabular}

Summary of Results:

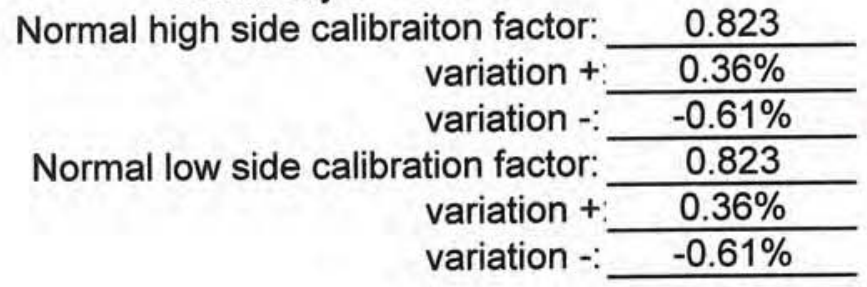

Certification:

I certify that the Type S pitot tube, the standard type pitot tube, and the calibration setup meet or exceed all specifications, criteria and/or applicable design features and hereby assign a pitot tube calibration factor $C_{p}$ of: $\quad 0.823$

Certified by: Patrick Selalovick 10/20/06 Calibrator (Signature/Date)
Bill Hefley 10/20/06 QA Officer (Signature/Date) 
CALIBRATION DATA

PITOT TUBE CALIBRATION DATA

$\begin{array}{lc}\text { Date: } & \frac{10 / 20 / 06}{\text { I.D. \# }} \\ \text { C }_{\text {pstd: }} & \frac{\text { ASAI 3-4 }}{0.990}\end{array}$

Time: $15: 15$

$\mathrm{T}_{\mathrm{s}}: 76^{\circ} \mathrm{F}$

$\mathrm{Pb}: 29.52$ " Hg

\begin{tabular}{|c|c|c|c|c|c|c|c|c|c|c|}
\hline \multirow{2}{*}{\begin{tabular}{|c|} 
fps \\
Mark
\end{tabular}} & \multirow{2}{*}{\begin{tabular}{|c|} 
Desired \\
Calibration \\
Standard \\
\end{tabular}} & \multirow{2}{*}{\multicolumn{2}{|c|}{$\begin{array}{l}\text { Calibration } \\
\text { Standard } \\
\text { Start End }\end{array}$}} & \multirow{2}{*}{$\begin{array}{c}\sqrt{ } \text { Standard } \\
\text { Average }\end{array}$} & \multirow[b]{2}{*}{ High } & \multirow[b]{2}{*}{$\sqrt{ }$ High } & \multirow{2}{*}{$\begin{array}{l}\text { Cal. } \\
\text { Factor }\end{array}$} & \multirow[b]{2}{*}{ Low } & \multirow[b]{2}{*}{$\sqrt{ }$ Low } & \multirow{2}{*}{$\begin{array}{l}\text { Cal. } \\
\text { Factor }\end{array}$} \\
\hline & & & & & & & & & & \\
\hline 20 & 0.09 & 0.09 & 0.09 & 0.300 & 0.13 & 0.361 & 0.824 & 0.13 & 0.361 & 0.824 \\
\hline 30 & 0.20 & 0.20 & 0.20 & 0.447 & 0.29 & 0.539 & 0.822 & 0.29 & 0.539 & 0.822 \\
\hline 40 & 0.36 & 0.36 & 0.36 & 0.600 & 0.52 & 0.721 & 0.824 & 0.52 & 0.721 & 0.824 \\
\hline 50 & 0.56 & 0.56 & 0.56 & 0.748 & 0.82 & 0.906 & 0.818 & 0.82 & 0.906 & 0.818 \\
\hline 60 & 0.80 & 0.80 & 0.80 & 0.894 & 1.15 & 1.072 & 0.826 & 1.15 & 1.072 & 0.826 \\
\hline 70 & 1.09 & 1.10 & 1.10 & 1.049 & 1.60 & 1.265 & 0.821 & 1.60 & 1.265 & 0.821 \\
\hline 80 & 1.42 & 1.45 & 1.45 & 1.204 & 2.10 & 1.449 & 0.823 & 2.10 & 1.449 & 0.823 \\
\hline \multirow[t]{2}{*}{90} & 1.80 & 1.80 & 1.80 & 1.342 & 2.60 & 1.612 & 0.824 & 2.60 & 1.612 & 0.824 \\
\hline & & & & & & & & & & \\
\hline 50 & & 0.56 & 0.56 & 0.748 & 0.82 & 0.906 & 0.818 & 0.82 & 0.906 & 0.818 \\
\hline 50 & 0.56 & 0.56 & 0.56 & 0.748 & 0.82 & 0.906 & 0.818 & 0.82 & 0.906 & 0.818 \\
\hline & & & & & & & & & & \\
\hline & & & & & & & & & & \\
\hline A & Average & & & & & & 0.823 & & & 0.823 \\
\hline
\end{tabular}

Summary of Results:

Normal high side calibraiton factor: 0.823

variation $+0.36 \%$

variation $-:-0.61 \%$

Normal low side calibration factor:

0.823

variation $+0.36 \%$

variation -

$-0.61 \%$

Certification:

I certify that the Type S pitot tube, the standard type pitot tube, and the calibration setup meet or exceed all specifications, criteria and/or applicable design features and hereby assign a pitot tube calibration factor $\mathrm{C}_{\mathrm{p}}$ of: $\quad 0.823$

Certified by: Patrick Selalcovick 10/20/06

Calibrator (Signature/Date)
Bill Hefley 10/20/06 QA Officer (Signature/Date) 


\section{AIR

CALIBRATION DATA

PITOT TUBE CALIBRATION DATA

$\begin{array}{cc}\text { Date: } \frac{01 / 24 / 06}{\text { I.D. \# }} & \text { ASAl 4-1 } \\ \text { C }_{\text {pstd: }} & 0.990\end{array}$

Time: $13: 55$

$$
\begin{aligned}
\mathrm{T}_{\mathrm{s}}: & \frac{68}{29.92}{ }^{\circ} \mathrm{F} \\
& \mathrm{Hg}
\end{aligned}
$$

\begin{tabular}{|c|c|c|c|c|c|c|c|c|c|c|}
\hline $\begin{array}{c}\text { fps } \\
\text { Mark }\end{array}$ & $\begin{array}{c}\text { Desired } \\
\text { Calibration } \\
\text { Standard }\end{array}$ & \multicolumn{2}{c|}{$\begin{array}{c}\text { Calibration } \\
\text { Standard } \\
\text { Start }\end{array}$} & $\begin{array}{c}\text { V Standard } \\
\text { Average }\end{array}$ & High & V High & $\begin{array}{c}\text { Cal. } \\
\text { Factor }\end{array}$ & Low & V Low & $\begin{array}{c}\text { Cal. } \\
\text { Factor }\end{array}$ \\
\hline 20 & 0.09 & 0.09 & 0.09 & 0.300 & 0.13 & 0.361 & 0.824 & 0.13 & 0.361 & 0.824 \\
\hline 30 & 0.21 & 0.21 & 0.21 & 0.458 & 0.30 & 0.548 & 0.828 & 0.30 & 0.548 & 0.828 \\
\hline 40 & 0.37 & 0.37 & 0.37 & 0.608 & 0.53 & 0.728 & 0.827 & 0.53 & 0.728 & 0.827 \\
\hline 50 & 0.57 & 0.57 & 0.57 & 0.755 & 0.82 & 0.906 & 0.825 & 0.82 & 0.906 & 0.825 \\
\hline 60 & 0.82 & 0.82 & 0.82 & 0.906 & 1.20 & 1.095 & 0.818 & 1.20 & 1.095 & 0.818 \\
\hline 70 & 1.12 & 1.10 & 1.10 & 1.049 & 1.60 & 1.265 & 0.821 & 1.60 & 1.265 & 0.821 \\
\hline 80 & 1.46 & 1.45 & 1.45 & 1.204 & 2.10 & 1.449 & 0.823 & 2.10 & 1.449 & 0.823 \\
\hline 90 & 1.85 & 1.85 & 1.85 & 1.360 & 2.65 & 1.628 & 0.827 & 2.65 & 1.628 & 0.827 \\
\hline & & & & & & & & & & \\
\hline & & & & & & & & & & \\
\hline 50 & 0.57 & 0.57 & 0.57 & 0.755 & 0.82 & 0.906 & 0.825 & 0.82 & 0.906 & 0.825 \\
\hline 50 & 0.57 & 0.57 & 0.57 & 0.755 & 0.82 & 0.906 & 0.825 & 0.82 & 0.906 & 0.825 \\
\hline & & & & & & & & & & \\
\hline & & & & & & & & & & \\
\hline \multicolumn{2}{|l|}{ Average } & & & & & & 0.824 & & & 0.824 \\
\hline
\end{tabular}

Summary of Results:

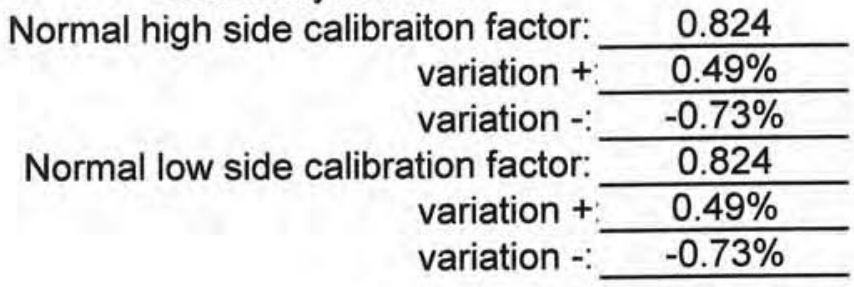

Certification:

I certify that the Type S pitot tube, the standard type pitot tube, and the calibration setup meet or exceed all specifications, criteria and/or applicable design features and hereby assign a pitot tube calibration factor $C_{p}$ of: $\quad 0.824$

Certified by: $\quad \frac{\text { Patrick Selabovick 01/24/06 }}{\text { Calibrator (Signature/Date) }}$
Bill Hefley 01/24/06

QA Officer (Signature/Date) 


\section{IIIIR

Calibration Data

Nozzle Calibration

$\begin{aligned} & \text { Nozzle Set No. } \text { ASAI - } 4 \\ & \text { Date Calibration Performed: } 01 / 25 / 06 \\ &\end{aligned}$

$\begin{array}{llllllll}-1 & -2 & -3 & -4 & -5 & -6 & -7 & -8\end{array}$

\begin{tabular}{|c|c|c|c|c|c|c|c|c|}
\hline ement 1 & 0.119 & 0.171 & 0.232 & 0.319 & 0.365 & 0.399 & 0.496 & 0.238 \\
\hline Measurement 2 & & 0.172 & 0.233 & 0.318 & 0.366 & 0.399 & 0.496 & 0.237 \\
\hline Measurement 3 & & 0.171 & 0.234 & 0.318 & 0.365 & 0.399 & 0.496 & 0.238 \\
\hline Measurement 4 & 0.120 & 0.171 & 0.233 & 0.318 & 0.366 & 0.398 & 0.494 & 0.239 \\
\hline Measurem & 0.121 & 0.171 & 0.233 & 0.319 & 0.365 & 0.399 & 0.494 & 0.239 \\
\hline Measurement 6 & 0.119 & 0.171 & 0.235 & 0.318 & 0.365 & 0.399 & 0.495 & 0.238 \\
\hline Measurement 7 & 0.120 & 0.171 & 0.233 & 0.317 & & & & 0.238 \\
\hline Measurement 8 & 0.119 & 0.171 & 0.233 & 0.317 & 0.366 & 0.399 & 0.495 & 0.237 \\
\hline Measurement 9 & 0.119 & 0.172 & 0.233 & 0.317 & 0.366 & 0.398 & 0.495 & 0.238 \\
\hline Measurement 10 & 0.119 & & 0.235 & 0.318 & 0.366 & 0.400 & 0.494 & 0.238 \\
\hline Average & 0.119 & 0.171 & 0.233 & 0.318 & 0.366 & 0.399 & 0.495 & 0.238 \\
\hline
\end{tabular}

Gavy B. Goldman 1/25/06

Calibrator (Signature / Date)

$\frac{\text { Bill Hefley 1/25/06 }}{\text { QA Officer (Signature / Date) }}$ 
Calibration Data

Nozzle Calibration
Nozzle Set No. Date Calibration Performed:

$-1 \quad-2$

Measurement 1

Measurement 2

Measurement 3

Measurement 4

Measurement 5

Measurement 6

Measurement 7

Measurement 8

Measurement 9

Measurement 10

Average
ASAl - 5

$11 / 28 / 06$

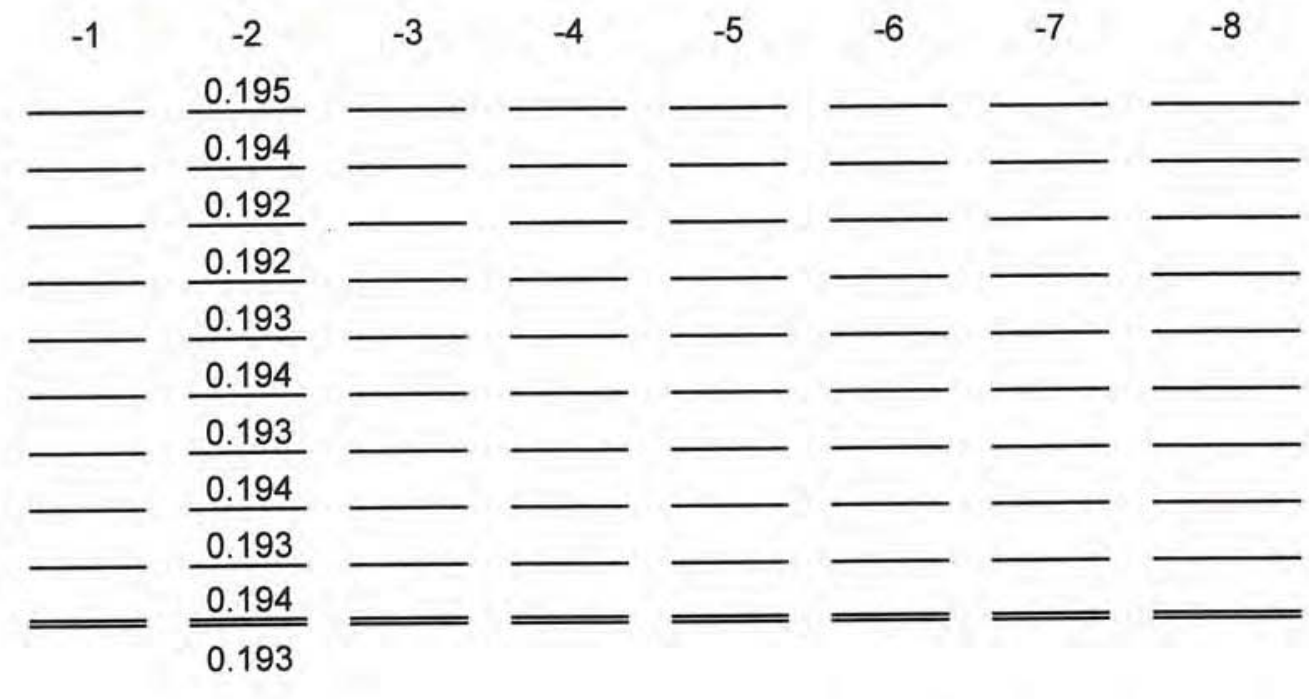

Bill Mallins 11/28/06

Calibrator (Signature / Date)

Bill Hefley 11/28/06

QA Officer (Signature / Date) 
Calibration Data Nozzle Calibration

Nozzle Set No.

Date Calibration Performed:
ASAI - 5
$01 / 25 / 06$

\begin{tabular}{|c|c|c|c|c|c|c|c|c|}
\hline & -1 & -2 & -3 & -4 & -5 & -6 & -7 & -8 \\
\hline Measurement 1 & & 0.193 & 0.255 & 0.309 & & 0.437 & 0.488 & 0.155 \\
\hline Measurement 2 & & 0.192 & 0.254 & 0.309 & & 0.437 & 0.488 & 0.154 \\
\hline Measurement 3 & & 0.192 & 0.256 & 0.310 & & 0.439 & 0.488 & 0.153 \\
\hline Measurement 4 & & 0.191 & 0.254 & 0.309 & & 0.437 & 0.490 & 0.154 \\
\hline Measurement 5 & & 0.193 & 0.255 & 0.311 & & 0.437 & 0.490 & 0.154 \\
\hline Measurement 6 & & 0.194 & 0.255 & 0.312 & & 0.437 & 0.490 & 0.153 \\
\hline Measurement 7 & & 0.192 & 0.254 & 0.312 & & 0.437 & 0.489 & 0.153 \\
\hline Measurement 8 & & 0.193 & 0.256 & 0.309 & & 0.438 & 0.489 & 0.155 \\
\hline Measurement 9 & & 0.193 & 0.256 & 0.310 & & 0.438 & 0.491 & 0.154 \\
\hline Measurement 10 & & 0.193 & 0.253 & 0.309 & & 0.438 & 0.489 & 0.154 \\
\hline \multirow[t]{5}{*}{ Average } & & 0.193 & 0.255 & 0.310 & & 0.438 & 0.489 & 0.154 \\
\hline & & & & & \multicolumn{4}{|c|}{ Gary B. Goldman 1/25/06 } \\
\hline & & & & & & \multicolumn{3}{|c|}{ Calibrator (Signature / Date) } \\
\hline & & & & & & \multicolumn{3}{|c|}{ Bill Hefley 1/25/06 } \\
\hline & & & & & & \multicolumn{3}{|c|}{ QA Officer (Signature / Date) } \\
\hline
\end{tabular}


Calibration Data

Nozzle Calibration

Nozzle Set No.

Date Calibration Performed:

Measurement 1

Measurement 2

Measurement 3

Measurement 4

Measurement 5

Measurement 6

Measurement 7

Measurement 8

Measurement 9

Measurement 10

Average $\begin{array}{lll}-1 & -2 & -3\end{array}$

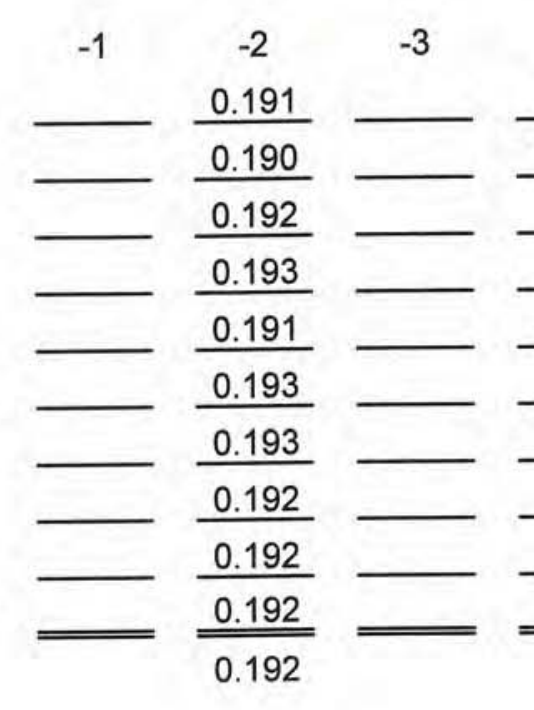

ASAI - 7

$10 / 27 / 06$ 


\section{III}

Calibration Data

Nozzle Calibration

Nozzle Set No.
Date Calibration Performed:
ASAI - 7

09/19/06

\begin{tabular}{|c|c|c|c|c|c|c|c|c|}
\hline & -1 & -2 & -3 & -4 & -5 & -6 & -7 & -8 \\
\hline Measurement 1 & 0.114 & 0.192 & 0.255 & 0.308 & 0.375 & 0.426 & & 0.154 \\
\hline Measurement 2 & 0.115 & 0.193 & 0.253 & 0.307 & 0.378 & 0.424 & & 0.155 \\
\hline Measurement 3 & 0.114 & 0.192 & 0.254 & 0.308 & 0.375 & 0.425 & & 0.155 \\
\hline Measurement 4 & 0.113 & 0.194 & 0.252 & 0.306 & 0.375 & 0.424 & & 0.155 \\
\hline Measurement 5 & 0.115 & 0.193 & 0.254 & 0.308 & 0.377 & 0.426 & & 0.153 \\
\hline Measurement 6 & 0.113 & 0.192 & 0.254 & 0.310 & 0.376 & 0.427 & & 0.153 \\
\hline Measurement 7 & 0.113 & 0.193 & 0.253 & 0.307 & 0.375 & 0.424 & & 0.152 \\
\hline Measurement 8 & 0.115 & 0.192 & 0.254 & 0.308 & 0.377 & 0.426 & & 0.153 \\
\hline Measurement 9 & 0.114 & 0.193 & 0.254 & 0.309 & 0.376 & 0.426 & & 0.155 \\
\hline Measurement 10 & 0.112 & 0.192 & 0.252 & 0.307 & 0.377 & 0.426 & & 0.153 \\
\hline Average & 0.114 & 0.193 & 0.254 & 0.308 & 0.376 & 0.425 & & 0.154 \\
\hline
\end{tabular}

\section{Gary B. Goldman $9 / 19 / 06$}

Calibrator (Signature / Date)

Bill Hefley 9/19/06

QA Officer (Signature / Date) 


\section{Post-test Calibration Data}




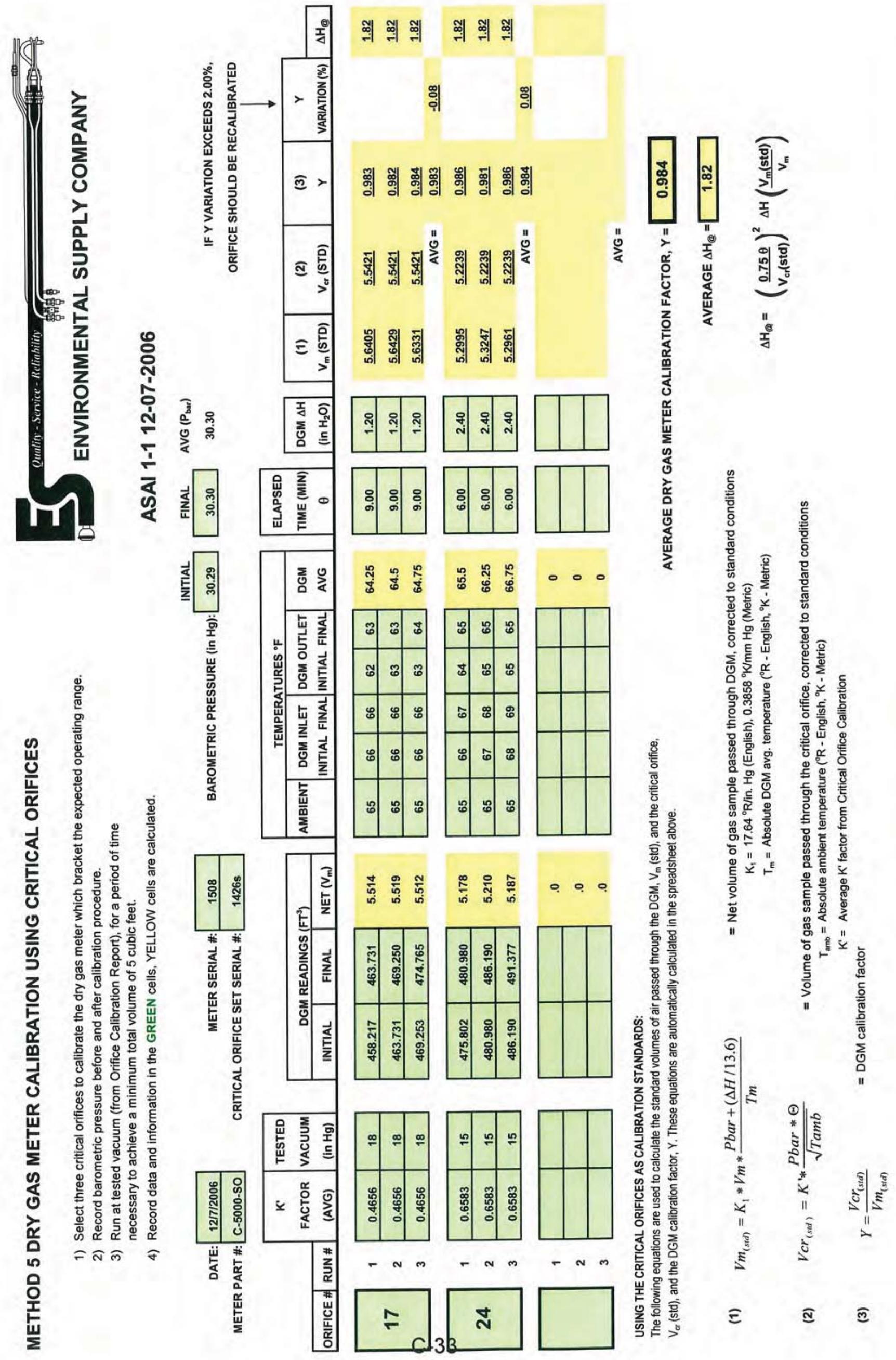


Calibration Data

Digital Temperature Indicator Calibration

DTI Unit No.

Date Calibration Performed:

Meter Adjusted?

Reference Point

Ice Bath

Ambient Air

Boiling Water

Oven

Oven

Oven

Oven

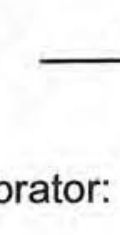

No

NIST Reference Calibrator:
$12 / 07 / 06$

ASTM

Reference

Thermometer

$\left({ }^{\circ} \mathrm{F}\right)$

\begin{tabular}{|c|c|}
\hline $32^{\circ} \mathrm{F}$ & $32^{\circ} \mathrm{F}$ \\
\hline $68^{\circ} \mathrm{F}$ & $67^{\circ} \mathrm{F}$ \\
\hline $212^{\circ} \mathrm{F}$ & $215^{\circ} \mathrm{F}$ \\
\hline $250^{\circ} \mathrm{F}$ & $254^{\circ} \mathrm{F}$ \\
\hline $300^{\circ} \mathrm{F}$ & $305^{\circ} \mathrm{F}$ \\
\hline $350^{\circ} \mathrm{F}$ & $355^{\circ} \mathrm{F}$ \\
\hline $400^{\circ} \mathrm{F}$ & $405^{\circ} \mathrm{F}$ \\
\hline
\end{tabular}

SN: 06000047

$\longrightarrow$
Range: $\quad \underline{-0.2^{\circ} \mathrm{C} \text { to } 1,360.6^{\circ}}$

Range:

Range:

Certified by:

Patrick Selatovich 12/07/06

Calibrator (Signature / Date)

Bill Hefley 12/07/06

QA Officer (Signature / Date) 

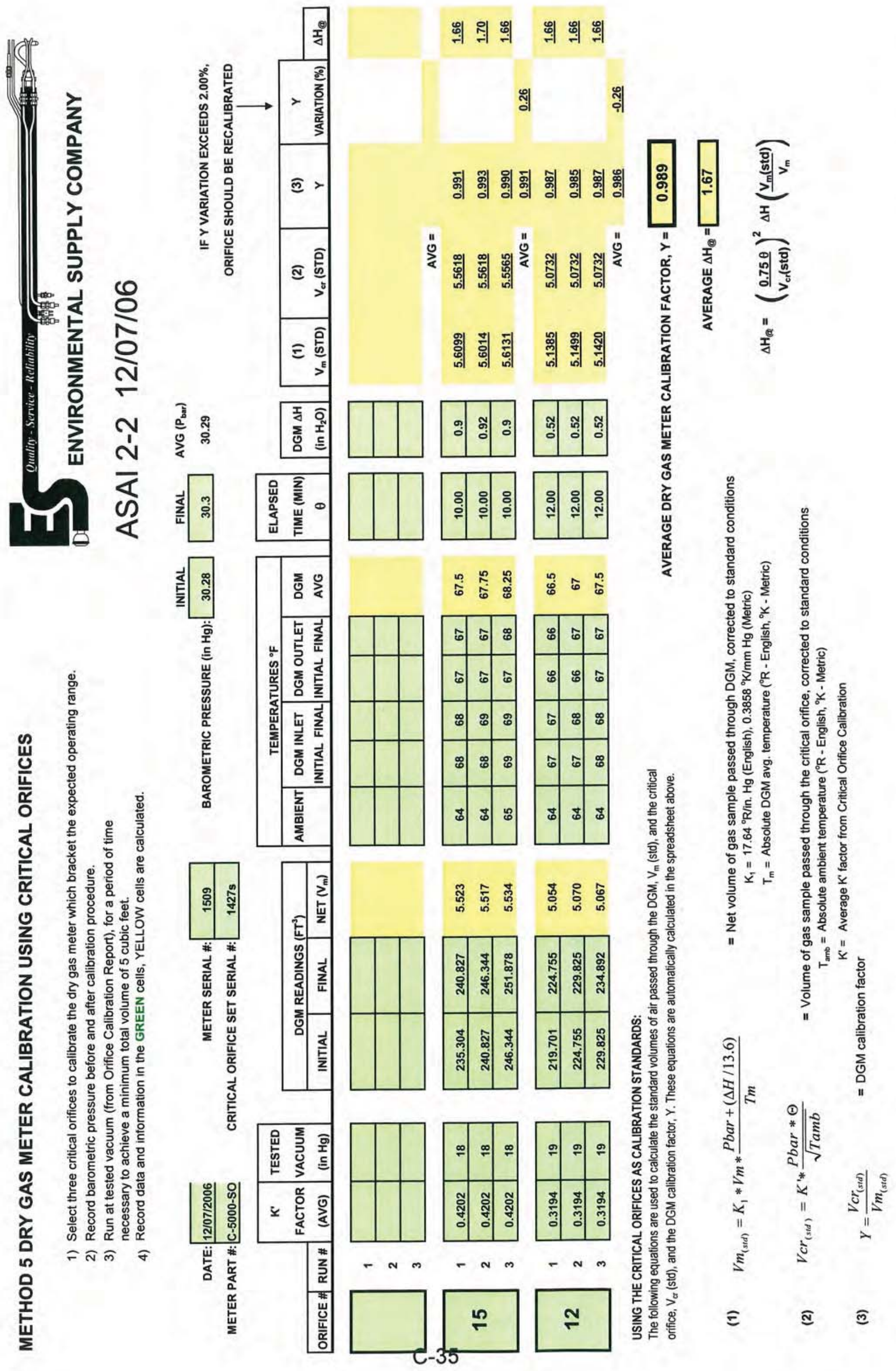
Calibration Data

Digital Temperature Indicator Calibration

DTI Unit No.

ASAI 2-2

Date Calibration Performed:

\begin{tabular}{|c|c|}
\hline $12 / 07 / 06$ & \\
\hline $\begin{array}{c}\text { ASTM } \\
\text { Reference }\end{array}$ & \\
\hline Thermometer & DTI \\
\hline$\left({ }^{\circ} \mathrm{F}\right)$ & $\left({ }^{\circ} \mathrm{F}\right)$ \\
\hline $32^{\circ} \mathrm{F}$ & $31^{\circ} \mathrm{F}$ \\
\hline $68^{\circ} \mathrm{F}$ & $67^{\circ} \mathrm{F}$ \\
\hline $212^{\circ} \mathrm{F}$ & $214^{\circ} \mathrm{F}$ \\
\hline $250^{\circ} \mathrm{F}$ & $253^{\circ} \mathrm{F}$ \\
\hline $300^{\circ} \mathrm{F}$ & $303^{\circ} \mathrm{F}$ \\
\hline $350^{\circ} \mathrm{F}$ & $353^{\circ} \mathrm{F}$ \\
\hline $400^{\circ} \mathrm{F}$ & $404^{\circ} \mathrm{F}$ \\
\hline
\end{tabular}

Meter Adjusted?

No

Reference Point

Ice Bath

Ambient Air

Boiling Water

Oven

Oven

Oven

Oven

\begin{tabular}{c}
$\frac{\text { Time }}{11: 49}$ \\
\hline $11: 48$ \\
\hline $11: 47$ \\
\hline $11: 46$ \\
\hline $11: 45$ \\
\hline $11: 44$ \\
\hline $11: 43$ \\
\hline
\end{tabular}

ASTM Reference Thermometer:

Range: $\quad-0.1^{\circ} \mathrm{C}$ to $1,360.6^{\mathrm{c}}$

Range:

Range:

Certified by:

Patrich Selatovich 12/07/06

Calibrator (Signature / Date)

Bill Hefley 12/07/06

QA Officer (Signature / Date) 


\section{II ASSOCIATES, INC.}
CALIBRATION DATA
PITOT TUBE CALIBRATION DATA

\begin{tabular}{lc} 
Date: & $\frac{12 / 07 / 06}{\text { I.D. \# }}$ \\
C $_{\text {pstd }}:$ & 0.990 \\
\hline
\end{tabular}
Time: $15: 15$
$\mathrm{T}_{\mathrm{s}}: \frac{15: 15}{6{ }^{\circ} \mathrm{F}}$
$\mathrm{Pb}: 30.29 \mathrm{Hg}$

\begin{tabular}{|c|c|c|c|c|c|c|c|c|c|c|}
\hline $\begin{array}{c}\text { fps } \\
\text { Mark }\end{array}$ & $\begin{array}{c}\text { Desired } \\
\text { Calibration } \\
\text { Standard }\end{array}$ & \multicolumn{2}{c|}{$\begin{array}{c}\text { Calibration } \\
\text { Standard } \\
\text { Start }\end{array}$} & $\begin{array}{c}\text { End } \\
\text { v Standard } \\
\text { Average }\end{array}$ & High & v High & $\begin{array}{c}\text { Cal. } \\
\text { Factor }\end{array}$ & Low & v Low & $\begin{array}{c}\text { Cal. } \\
\text { Factor }\end{array}$ \\
\hline 20 & 0.09 & 0.09 & 0.09 & 0.300 & 0.13 & 0.361 & 0.824 & 0.13 & 0.361 & 0.824 \\
\hline 30 & 0.21 & 0.21 & 0.21 & 0.458 & 0.30 & 0.548 & 0.828 & 0.30 & 0.548 & 0.828 \\
\hline 40 & 0.37 & 0.37 & 0.37 & 0.608 & 0.54 & 0.735 & 0.819 & 0.54 & 0.735 & 0.819 \\
\hline 50 & 0.58 & 0.58 & 0.58 & 0.762 & 0.84 & 0.917 & 0.823 & 0.84 & 0.917 & 0.823 \\
\hline 60 & 0.84 & 0.84 & 0.84 & 0.917 & 1.20 & 1.095 & 0.828 & 1.20 & 1.095 & 0.828 \\
\hline 70 & 1.14 & 1.15 & 1.15 & 1.072 & 1.65 & 1.285 & 0.826 & 1.65 & 1.285 & 0.826 \\
\hline 80 & 1.49 & 1.50 & 1.50 & 1.225 & 2.15 & 1.466 & 0.827 & 2.15 & 1.466 & 0.827 \\
\hline 90 & 1.89 & 1.90 & 1.90 & 1.378 & 2.75 & 1.658 & 0.823 & 2.75 & 1.658 & 0.823 \\
\hline & & & & & & & & & & \\
\hline & & & & & & & & & & \\
\hline 50 & 0.58 & 0.58 & 0.58 & 0.762 & 0.84 & 0.917 & 0.823 & 0.84 & 0.917 & 0.823 \\
\hline 50 & 0.58 & 0.58 & 0.58 & 0.762 & 0.84 & 0.917 & 0.823 & 0.84 & 0.917 & 0.823 \\
\hline & & & & & & & & & & \\
\hline & & & & & & & & & & \\
\hline \multicolumn{2}{|l|}{ Average } & & & & & & 0.825 & & & 0.825 \\
\hline
\end{tabular}

Summary of Results:

\begin{tabular}{rc} 
Normal high side calibraiton factor: & 0.825 \\
variation + & $0.36 \%$ \\
variation $-:$ & $-0.73 \%$ \\
Normal low side calibration factor: & 0.825 \\
variation + & $0.36 \%$ \\
variation $-:$ & $-0.73 \%$ \\
\hline
\end{tabular}

Certification:

I certify that the Type S pitot tube, the standard type pitot tube, and the calibration setup meet or exceed all specifications, criteria and/or applicable design features and hereby assign a pitot tube calibration factor $\mathrm{C}_{p}$ of: $\quad 0.825$

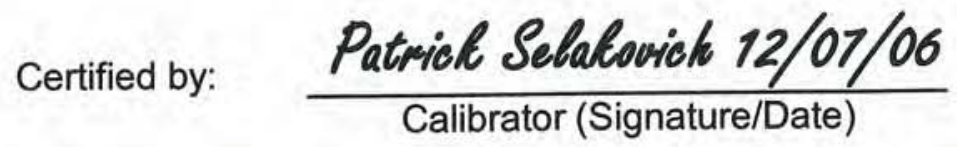




\section{AlR ASSOCIATES, INC.}
CALIBRATION DATA
PITOT TUBE CALIBRATION DATA

$\begin{array}{lc}\text { Date: } \frac{12 / 07 / 06}{\text { I.D. \# }} & \frac{\text { ASAI 3-2 }}{0.990} \\ \text { C }_{\text {pstd }}: & 0.990\end{array}$
Time: $15: 30$
$\mathrm{T}_{\mathrm{s}}: \frac{65}{6 \mathrm{Cb}}^{\circ} \mathrm{F}$
$\mathrm{30.29}$

\begin{tabular}{|c|c|c|c|c|c|c|c|c|c|c|}
\hline $\begin{array}{c}\text { fps } \\
\text { Mark }\end{array}$ & $\begin{array}{c}\text { Desired } \\
\text { Calibration } \\
\text { Standard }\end{array}$ & \multicolumn{2}{|c|}{$\begin{array}{c}\text { Calibration } \\
\text { Standard } \\
\text { Start }\end{array}$} & $\begin{array}{c}\text { End } \\
\text { v Standard } \\
\text { Average }\end{array}$ & High & v High & $\begin{array}{c}\text { Cal. } \\
\text { Factor }\end{array}$ & & & Low \\
\hline 20 & 0.09 & 0.09 & 0.09 & 0.300 & 0.13 & 0.361 & 0.824 & 0.13 & 0.361 & $\begin{array}{c}\text { Cal. } \\
\text { Factor }\end{array}$ \\
\hline 30 & 0.21 & 0.21 & 0.21 & 0.458 & 0.30 & 0.548 & 0.828 & 0.30 & 0.548 & 0.828 \\
\hline 40 & 0.37 & 0.37 & 0.37 & 0.608 & 0.53 & 0.728 & 0.827 & 0.53 & 0.728 & 0.827 \\
\hline 50 & 0.58 & 0.58 & 0.58 & 0.762 & 0.83 & 0.911 & 0.828 & 0.83 & 0.911 & 0.828 \\
\hline 60 & 0.84 & 0.84 & 0.84 & 0.917 & 1.20 & 1.095 & 0.828 & 1.20 & 1.095 & 0.828 \\
\hline 70 & 1.14 & 1.15 & 1.15 & 1.072 & 1.65 & 1.285 & 0.826 & 1.65 & 1.285 & 0.826 \\
\hline 80 & 1.49 & 1.50 & 1.50 & 1.225 & 2.15 & 1.466 & 0.827 & 2.15 & 1.466 & 0.827 \\
\hline 90 & 1.89 & 1.90 & 1.90 & 1.378 & 2.75 & 1.658 & 0.823 & 2.75 & 1.658 & 0.823 \\
\hline & & & & & & & & & & \\
\hline & & & & & & & & & & \\
\hline 50 & 0.58 & 0.58 & 0.58 & 0.762 & 0.83 & 0.911 & 0.828 & 0.83 & 0.911 & 0.828 \\
\hline 50 & 0.58 & 0.58 & 0.58 & 0.762 & 0.83 & 0.911 & 0.828 & 0.83 & 0.911 & 0.828 \\
\hline & & & & & & & & & & \\
\hline & & & & & & & & & & \\
\hline Average & & & & & & 0.826 & & & 0.826 \\
\hline
\end{tabular}

Summary of Results:

\begin{tabular}{rc} 
Normal high side calibraiton factor: & 0.826 \\
variation + & $0.24 \%$ \\
variation $-:$ & $-0.36 \%$ \\
Normal low side calibration factor: & 0.826 \\
variation + & $0.24 \%$ \\
variation $-:$ & $-0.36 \%$ \\
\hline
\end{tabular}

Certification:

I certify that the Type S pitot tube, the standard type pitot tube, and the calibration setup meet or exceed all specifications, criteria and/or applicable design features and hereby assign a pitot tube calibration factor $\mathrm{C}_{\mathrm{p}}$ of: $\quad \underline{0.826}$

Certified by:

$$
\frac{\text { Patrick Selabovick 12/07/06 }}{\text { Calibrator (Signature/Date) }}
$$

Bill Hefley 12/07/06

QA Officer (Signature/Date) 


\section{II ASSOCIATES, INC.}

\section{CALIBRATION DATA \\ PITOT TUBE CALIBRATION DATA}

\begin{tabular}{lc} 
Date: $\frac{12 / 07 / 06}{1 . D . ~ \#}$ & ASAI 3-3 \\
\hline C $_{\text {pstd }}:$ & 0.990
\end{tabular}

Time: $15: 45$

$T_{\mathrm{s}}: \frac{64}{30}{ }^{\circ} \mathrm{F}$

$\mathrm{Pb}: \underline{30.29} \mathrm{Hg}$

\begin{tabular}{|c|c|c|c|c|c|c|c|c|c|c|}
\hline fps & $\begin{array}{c}\text { Desired } \\
\text { Calibration }\end{array}$ & $\begin{array}{l}\text { Calib } \\
\text { Star }\end{array}$ & $\begin{array}{l}\text { tion } \\
\text { ard }\end{array}$ & v Standard & & & Cal. & & & Cal. \\
\hline Mark & Standard & Start & End & Average & High & v High & Factor & Low & v Low & Factor \\
\hline 20 & 0.09 & 0.09 & 0.09 & 0.300 & 0.13 & 0.361 & 0.824 & 0.13 & 0.361 & 0.824 \\
\hline 30 & 0.21 & 0.21 & 0.21 & 0.458 & 0.30 & 0.548 & 0.828 & 0.30 & 0.548 & 0.828 \\
\hline 40 & 0.37 & 0.37 & 0.37 & 0.608 & 0.53 & 0.728 & 0.827 & 0.53 & 0.728 & 0.827 \\
\hline 50 & 0.58 & 0.58 & 0.58 & 0.762 & 0.84 & 0.917 & 0.823 & 0.84 & 0.917 & 0.823 \\
\hline 60 & 0.84 & 0.84 & 0.84 & 0.917 & 1.20 & 1.095 & 0.828 & 1.20 & 1.095 & 0.828 \\
\hline 70 & 1.14 & 1.15 & 1.15 & 1.072 & 1.65 & 1.285 & 0.826 & 1.65 & 1.285 & 0.826 \\
\hline 80 & 1.49 & 1.50 & 1.50 & 1.225 & 2.15 & 1.466 & 0.827 & 2.15 & 1.466 & 0.827 \\
\hline 90 & 1.89 & 1.90 & 1.90 & 1.378 & 2.75 & 1.658 & 0.823 & 2.75 & 1.658 & 0.823 \\
\hline & & & & & & & & & & \\
\hline & & & & & & & & & & \\
\hline 50 & 0.58 & 0.58 & 0.58 & 0.762 & 0.84 & 0.917 & 0.823 & 0.84 & 0.917 & 0.823 \\
\hline 50 & 0.58 & 0.58 & 0.58 & 0.762 & 0.84 & 0.917 & 0.823 & 0.84 & 0.917 & 0.823 \\
\hline & & & & & & & & & & \\
\hline & & & & & & & & & & \\
\hline A & verage & & & & & & 0.826 & & & 0.826 \\
\hline
\end{tabular}

Summary of Results:

Normal high side calibraiton factor variation + variation -:

Normal low side calibration factor: 0.826 variation + $0.24 \%$ variation $-: \frac{0.36 \%}{-0.36 \%}$

\section{Certification:}

I certify that the Type S pitot tube, the standard type pitot tube, and the calibration setup meet or exceed all specifications, criteria and/or applicable design features and hereby assign a pitot tube calibration factor $C_{p}$ of: $\quad 0.826$

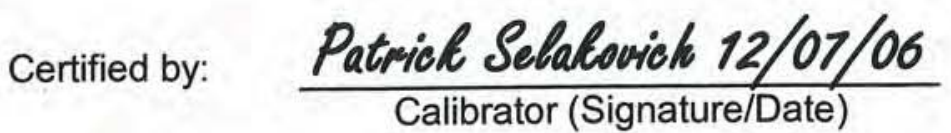




\section{Im SIR ASSOCIATES, INC.}

\section{CALIBRATION DATA \\ PITOT TUBE CALIBRATION DATA}

Date: $\frac{12 / 07 / 06}{1 . D . ~ \# \frac{A S A I}{3-4}}$
C $_{\text {pstd: }}$

Time: $16: 00$

$\mathrm{T}_{\mathrm{s}}: \frac{65}{30.30}{ }^{\circ} \mathrm{F}$

$\mathrm{Pb}: \overline{30.30} " \mathrm{Hg}$

\begin{tabular}{|c|c|c|c|c|c|c|c|c|c|c|}
\hline \multirow{2}{*}{$\begin{array}{c}\text { fps } \\
\text { Mark }\end{array}$} & \multirow{2}{*}{$\begin{array}{c}\text { Desired } \\
\text { Calibration } \\
\text { Standard }\end{array}$} & \multicolumn{2}{|c|}{$\begin{array}{l}\text { Calibration } \\
\text { Standard }\end{array}$} & \multirow{2}{*}{$\begin{array}{c}\text { v Standard } \\
\text { Average } \\
\end{array}$} & \multirow[b]{2}{*}{ High } & \multirow[b]{2}{*}{ v High } & \multirow{2}{*}{$\begin{array}{l}\text { Cal. } \\
\text { Factor }\end{array}$} & \multirow[b]{2}{*}{ Low } & \multirow[b]{2}{*}{ v Low } & \multirow{2}{*}{$\begin{array}{l}\text { Cal. } \\
\text { Factor }\end{array}$} \\
\hline & & Start & End & & & & & & & \\
\hline 20 & 0.09 & 0.09 & 0.09 & 0.300 & 0.13 & 0.361 & 0.824 & 0.13 & 0.361 & 0.824 \\
\hline 30 & 0.21 & 0.21 & 0.21 & 0.458 & 0.30 & 0.548 & 0.828 & 0.30 & 0.548 & 0.828 \\
\hline 40 & 0.37 & 0.37 & 0.37 & 0.608 & 0.53 & 0.728 & 0.827 & 0.53 & 0.728 & 0.827 \\
\hline 50 & 0.58 & 0.58 & 0.58 & 0.762 & 0.84 & 0.917 & 0.823 & 0.83 & 0.911 & 0.828 \\
\hline 60 & 0.84 & 0.84 & 0.84 & 0.917 & 1.20 & 1.095 & 0.828 & 1.20 & 1.095 & 0.828 \\
\hline 70 & 1.14 & 1.15 & 1.15 & 1.072 & 1.65 & 1.285 & 0.826 & 1.65 & 1.285 & 0.826 \\
\hline 80 & 1.49 & 1.50 & 1.50 & 1.225 & 2.15 & 1.466 & 0.827 & 2.15 & 1.466 & 0.827 \\
\hline 90 & 1.89 & 1.90 & 1.90 & 1.378 & 2.75 & 1.658 & 0.823 & 2.75 & 1.658 & 0.823 \\
\hline & & & & & & & & & & \\
\hline & & & & & & & & & & \\
\hline 50 & 0.58 & 0.58 & 0.58 & 0.762 & 0.84 & 0.917 & 0.823 & 0.83 & 0.911 & 0.828 \\
\hline 50 & 0.58 & 0.58 & 0.58 & 0.762 & 0.84 & 0.917 & 0.823 & 0.83 & 0.911 & 0.828 \\
\hline & & & & & & & & & & \\
\hline & & & & & & & & & & \\
\hline & verage & & & & & & 0.826 & & & 0.826 \\
\hline
\end{tabular}

Summary of Results:

Normal high side calibraiton factor: 0.826 variation + variation -: $0.24 \%$

Normal low side calibration factor: $-0.36 \%$ variation + 0.826 variation -: $0.24 \%$ $-0.36 \%$

Certification:

I certify that the Type S pitot tube, the standard type pitot tube, and the calibration setup meet or exceed all specifications, criteria and/or applicable design features and hereby assign a pitot tube calibration factor $C_{p}$ of: $\quad \underline{0.826}$ 


\section{IIT MiRMpLING}

CALIBRATION DATA

PITOT TUBE CALIBRATION DATA
Date:
12/07/06
I.D. \# ASAI 4-1
$\mathrm{C}_{\mathrm{pstd}}$ :
0.990
Time: $14: 50$

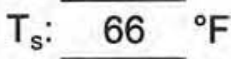
$\mathrm{Pb}: \overline{30.28} " \mathrm{Hg}$

\begin{tabular}{|c|c|c|c|c|c|c|c|c|c|c|}
\hline fps & $\begin{array}{l}\text { Desired } \\
\text { Calibration }\end{array}$ & $\begin{array}{l}\text { Cali } \\
\text { Sta }\end{array}$ & $\begin{array}{l}\text { tion } \\
\text { ard }\end{array}$ & v Standard & & & Cal. & & & Cal. \\
\hline Mark & Standard & Start & End & Average & High & v High & Factor & Low & v Low & Factor \\
\hline 20 & 0.09 & 0.09 & 0.09 & 0.300 & 0.13 & 0.361 & 0.824 & 0.13 & 0.361 & 0.824 \\
\hline 30 & 0.21 & 0.21 & 0.21 & 0.458 & 0.30 & 0.548 & 0.828 & 0.30 & 0.548 & 0.828 \\
\hline 40 & 0.37 & 0.37 & 0.37 & 0.608 & 0.53 & 0.728 & 0.827 & 0.53 & 0.728 & 0.827 \\
\hline 50 & 0.58 & 0.58 & 0.58 & 0.762 & 0.83 & 0.911 & 0.828 & 0.83 & 0.911 & 0.828 \\
\hline 60 & 0.84 & 0.84 & 0.84 & 0.917 & 1.20 & 1.095 & 0.828 & 1.20 & 1.095 & 0.828 \\
\hline 70 & 1.14 & 1.15 & 1.15 & 1.072 & 1.65 & 1.285 & 0.826 & 1.65 & 1.285 & 0.826 \\
\hline 80 & 1.49 & 1.50 & 1.50 & 1.225 & 2.15 & 1.466 & 0.827 & 2.15 & 1.466 & 0.827 \\
\hline 90 & 1.88 & 1.90 & 1.90 & 1.378 & 2.70 & 1.643 & 0.830 & 2.70 & 1.643 & 0.830 \\
\hline & & & & & & & & & & \\
\hline & & & & & & & & & & \\
\hline 50 & 0.58 & 0.58 & 0.58 & 0.762 & 0.83 & 0.911 & 0.828 & 0.83 & 0.911 & 0.828 \\
\hline 50 & 0.58 & 0.58 & 0.58 & 0.762 & 0.83 & 0.911 & 0.828 & 0.83 & 0.911 & 0.828 \\
\hline & & & & & & & & & & \\
\hline & & & & & & & & & & \\
\hline & verage & & & & & & 0.827 & & & 0.827 \\
\hline
\end{tabular}

Summary of Results:

$\begin{array}{rc}\text { Normal high side calibraiton factor: } & 0.827 \\ \text { variation } & 0.36 \% \\ \text { variation }-\frac{-0.36 \%}{\text { Normal low side calibration factor: }} & 0.827 \\ \text { variation } & 0.36 \% \\ \text { variation }-:-0.36 \%\end{array}$

Certification:

I certify that the Type S pitot tube, the standard type pitot tube, and the calibration setup meet or exceed all specifications, criteria and/or applicable design features and hereby assign a pitot tube calibration factor $C_{p}$ of: $\quad 0.827$

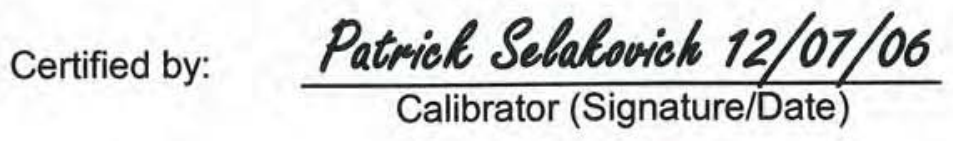




\section{Calibration Data \\ Nozzle Calibration}

Nozzle Set No. Date Calibration Performed:

$\frac{A S A I-4}{12 / 07 / 06}$

\begin{tabular}{|c|c|c|c|c|c|c|c|c|}
\hline nent 1 & & & .232 & 0.319 & 0.365 & 0.399 & 0.496 & 0.238 \\
\hline easurement 2 & & 0.172 & 0.233 & 0.318 & 0.366 & 0.399 & 0.496 & 0.237 \\
\hline leasurement 3 & & & 0.234 & 0.318 & 0.365 & 0.399 & 0.496 & 0.238 \\
\hline Measurement 4 & & 0.171 & 0.233 & 0.318 & 0.366 & & & 0.239 \\
\hline Measurement 5 & & & 0.233 & 0.319 & 0.365 & 0.399 & 0.494 & 0.239 \\
\hline Measurement 6 & 0.119 & 0.171 & 0.235 & 0.318 & 0.365 & 0.399 & 0.495 & 0.238 \\
\hline Measurement 7 & 0.120 & 0.171 & 0.233 & 0.317 & 0.366 & 0.399 & 0.494 & 0.238 \\
\hline Measurement 8 & 0.119 & 172 & 0.233 & 0.317 & 0.366 & 0.399 & 0.495 & 0.237 \\
\hline Measurement 9 & 0.1 & 0.172 & 0.233 & 0.317 & 0.366 & 0.398 & 0.495 & 0.238 \\
\hline Measurement 10 & 0.119 & 0.171 & 0.235 & & & 0.400 & 0.494 & 0.238 \\
\hline Average & 0.119 & 0.171 & 0.233 & 0.318 & 0.366 & 0.399 & 0.495 & 0.238 \\
\hline
\end{tabular}

Patrick Selatovich 12/07/06

Calibrator (Signature / Date)

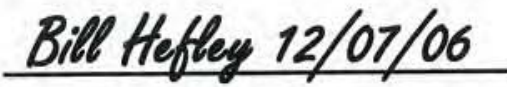

QA Officer (Signature / Date) 
 \\ II ASSOCIATES, INC.}

\section{Calibration Data}

Nozzle Calibration

Nozzle Set No.

Date Calibration Performed:
ASAI - 5

$12 / 07 / 06$

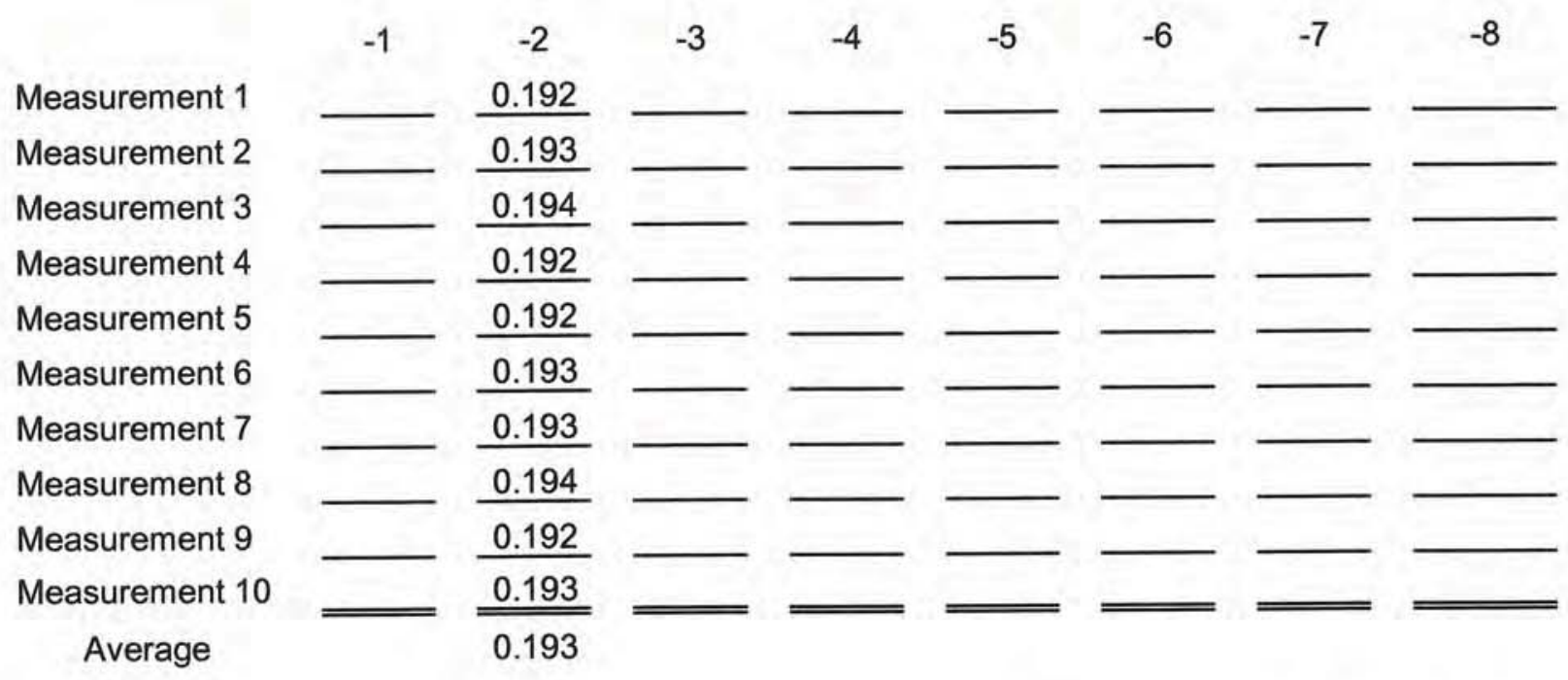

Patrich Selalovick 12/07/06

Calibrator (Signature / Date)

Bill Hefley 12/07/06

QA Officer (Signature / Date) 
Calibration Data Nozzle Calibration

Nozzle Set No.

Date Calibration Performed:
ASAI - 5
$12 / 07 / 06$

\begin{tabular}{|c|c|c|c|c|c|c|c|c|}
\hline & -1 & -2 & -3 & -4 & -5 & -6 & -7 & -8 \\
\hline Measurement 1 & & 0.193 & 0.255 & 0.309 & & 0.437 & 0.488 & 0.153 \\
\hline Measurement 2 & & 0.192 & 0.254 & 0.309 & & 0.437 & 0.488 & 0.155 \\
\hline Measurement 3 & & 0.192 & 0.256 & 0.310 & & 0.439 & 0.488 & 0.153 \\
\hline Measurement 4 & & 0.191 & 0.254 & 0.309 & & 0.437 & 0.490 & 0.155 \\
\hline Measurement 5 & & 0.193 & 0.255 & 0.311 & & 0.437 & 0.490 & 0.154 \\
\hline Measurement 6 & & 0.194 & 0.255 & 0.312 & & 0.437 & 0.490 & 0.156 \\
\hline Measurement 7 & & 0.192 & 0.254 & 0.312 & & 0.437 & 0.489 & 0.153 \\
\hline Measurement 8 & & 0.193 & 0.256 & 0.309 & & 0.438 & 0.489 & 0.154 \\
\hline Measurement 9 & & 0.193 & 0.256 & 0.310 & & 0.438 & 0.491 & 0.154 \\
\hline Measurement 10 & & 0.193 & 0.253 & 0.309 & & 0.438 & 0.489 & 0.154 \\
\hline Average & & 0.193 & 0.255 & 0.310 & & 0.438 & 0.489 & 0.154 \\
\hline
\end{tabular}

Patrich Sebalovich 12/07/06

Calibrator (Signature / Date)

Bill Hefley 12/07/06

QA Officer (Signature / Date) 


\section{II)}

Calibration Data

Nozzle Calibration

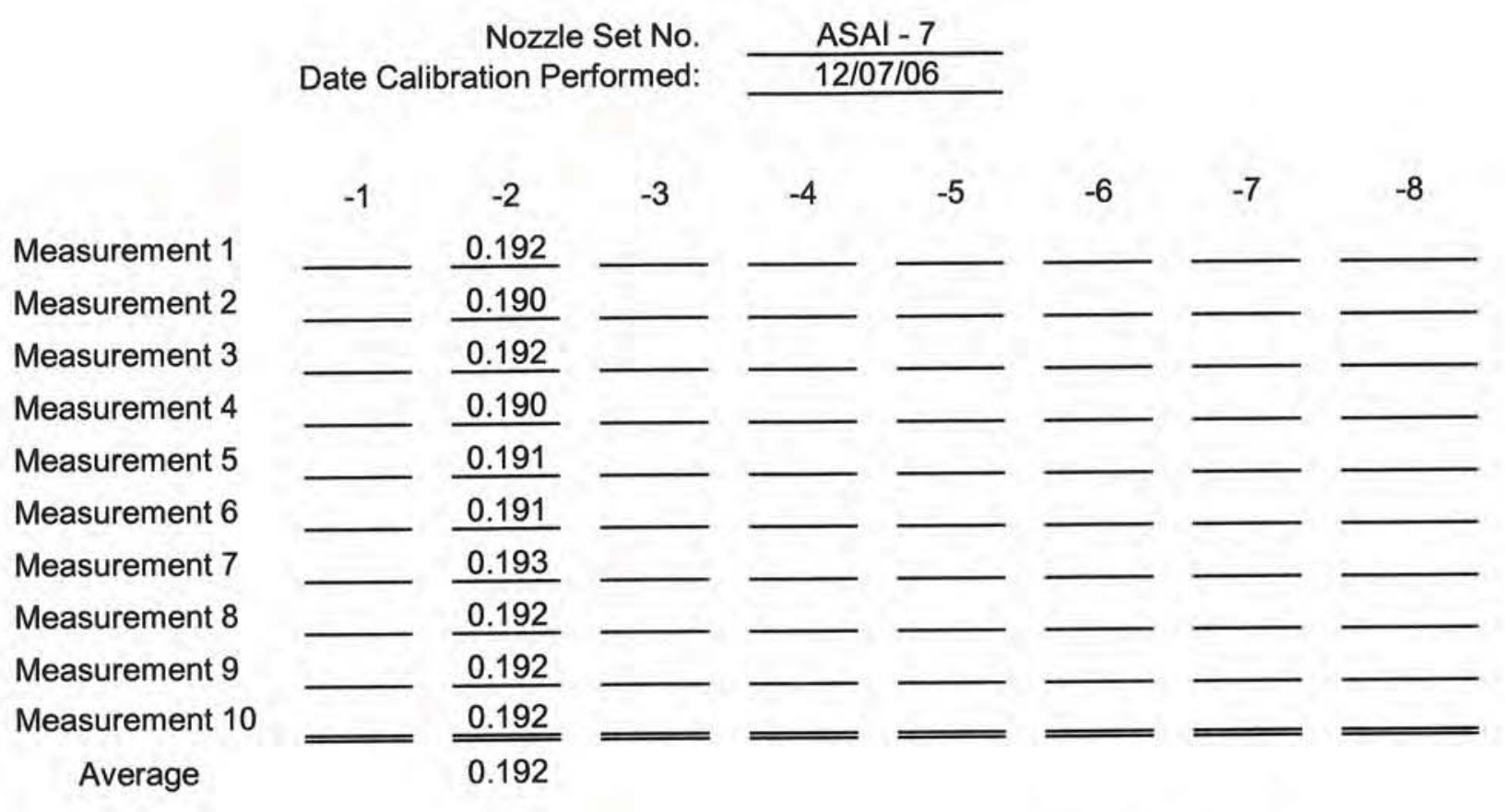

Patrich Selalovich 12/07/06

Calibrator (Signature / Date)

Bill Hefley 12/07/06

QA Officer (Signature / Date) 


\section{mint}

Calibration Data

Nozzle Calibration

$\begin{aligned} \text { Nozzle Set No. } & \frac{\mathrm{ASAl}-7}{12 / 07 / 06} \\ \text { Date Calibration Performed: } & \end{aligned}$

$\begin{array}{llllllll}-1 & -2 & -3 & -4 & -5 & -6 & -7 & -8\end{array}$

\begin{tabular}{|c|c|c|c|c|c|c|c|}
\hline Measurement 1 & 0.114 & 0.192 & 0.255 & 0.308 & 0.375 & 0.426 & 0.154 \\
\hline Measurement 2 & 0.115 & 0.193 & 0.253 & 0.307 & 0.378 & 0.424 & 0.155 \\
\hline Measurement 3 & 0.114 & 0.192 & 0.254 & 0.308 & 0.375 & 0.425 & 0.156 \\
\hline Measurement 4 & 0.113 & 0.194 & 0.252 & 0.306 & 0.375 & 0.424 & 0.155 \\
\hline Measurement 5 & 0.115 & 0.193 & 0.254 & 0.308 & 0.377 & 0.426 & 0.153 \\
\hline Measurement 6 & 0.113 & 0.192 & 0.254 & 0.310 & 0.376 & 0.427 & 0.153 \\
\hline Measurement 7 & 0.113 & 0.193 & 0.253 & 0.307 & 0.375 & 0.424 & 0.155 \\
\hline Measurement 8 & 0.115 & 0.192 & 0.254 & 0.308 & 0.377 & 0.426 & 0.155 \\
\hline Measurement 9 & 0.114 & 0.193 & 0.254 & 0.309 & 0.376 & 0.426 & 0.154 \\
\hline Measurement 10 & 0.112 & 0.192 & 0.252 & 0.307 & 0.377 & 0.426 & 0.153 \\
\hline Average & 0.114 & 0.193 & 0.254 & 0.308 & 0.376 & 0.425 & 0.154 \\
\hline
\end{tabular}

Patrick Selatovich 12/07/06

Calibrator (Signature / Date)

Bill Hefley 12/07/06

QA Officer (Signature / Date) 


\section{Appendix D:}

\section{Field Data}



Impinger Box No

$2-2$

Impinger 1

Final Weight

Initial Weight

Increase

Impinger 2

Final Weight

Initial Weight

Increase

Impinger 3

Final Weight

Initial Weight

Increase

Water Weiahl Gain

Weight

Initial Weight

Increase

Impinger 5

Final Weight

Initial Weight

Increase

Impinger 6

Final Weight

Initial Weight

Increase

Impinger 7

Final Weight

Initial Weight

Increase

$\frac{\frac{783.5}{741.4}}{42.1}$

Impinger 1

42.1

Impinger $2 \quad 5.3$

Impinger $3 \quad 1.2$

Impinger $4 \quad 1.5$

Impinger 5

7.7

Impinger 6

$\frac{718.9}{1.5}$

$\frac{932.9}{925.2}$

Thimble No.

59

$P_{b}=26.93 \mathrm{~V}$

$v_{m}=\frac{25.188 \mathrm{~V}}{57.8}$

$v_{w}=57.8$

$P_{m}=\frac{0.458 \mathrm{~L}}{0.855 \mathrm{~L}}$

Avg $\Delta \mathrm{P}=0.855$

Impinger 7

Total

$57.8=v_{w}$
$\% \mathrm{CO}_{2}=14.3$

$\% \mathrm{O}_{2}=5.2$

$\% \mathrm{CO}=0.0 \mathrm{~V}$

$\% \mathrm{~N}_{2}=80,5$

$A_{1}=20,2352$

$D_{n}=0.193$

$\begin{aligned} T_{n} & =0.193 \\ T_{1} & =60\end{aligned}$

$c_{p}=0.823$

$P_{3}=-14.7 \mathrm{~V} \mathrm{H}_{2} \mathrm{O}$

$\frac{25.85}{535}{ }^{779} \cdot{ }^{\circ} \cdot \mathrm{Hg}$

$T_{m}=75 \mathrm{O}$

$T_{s}=3190 \%$

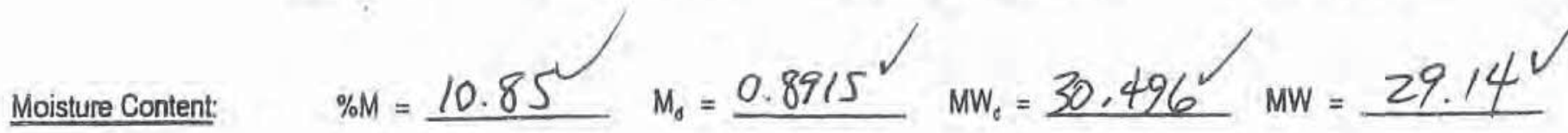

$$
V m_{s t d}=17.65 \mathrm{Vm}\left[\frac{P_{b}+\frac{P_{m}}{13.6}}{T_{m}+460}\right]=17.65 \times 25.188\left[\frac{26.93+\frac{0.458}{13.6}}{75+460}\right]=\frac{\frac{22.406}{0.373} \mathrm{sti}^{3}}{\mathrm{scm}}
$$

$V w_{\text {ges }}=0.0472 \times V w=0.0472 \times$

57.8

$=2728$

$\%$ Moisture = $\times 100$ $=\frac{2728}{22.406+2728} \times 100=$ 10.85 $\%$

$V_{3}=5123.8 \times 0.823$ $\mathrm{VW}_{\mathrm{gas}}$ $\times \underline{0.919}=3941^{\mathrm{h}} \mathrm{tm}$

$\% 1=\frac{1.039 \times 22.406 \times 779}{0.8915 \times 25.85 \times 3941 \times 60 \times(0.193)^{2}}=89.3 \%$

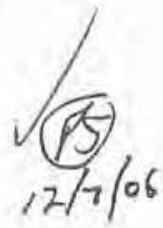

ACFM: $553,786^{\circ}$ SCFM: 299174 \%EA: 32.2 


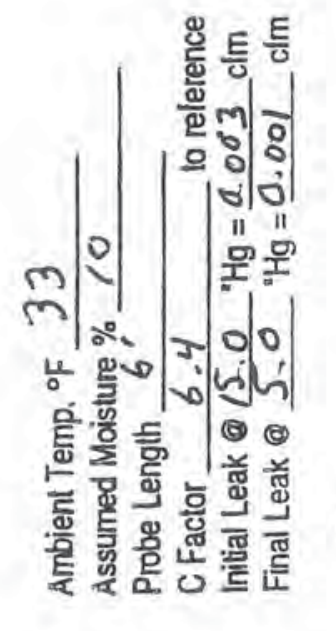

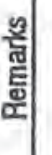

$\gamma$

$\overline{\overline{\mathrm{E}}}$

in a 11

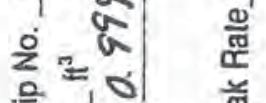

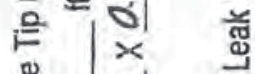

है

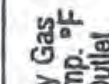

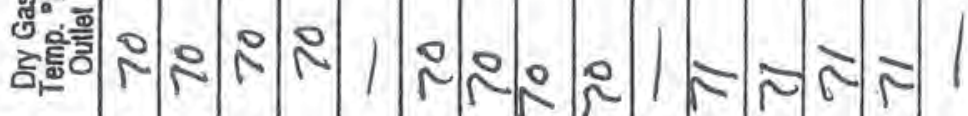
$\vdash^{E}$

ตुँ

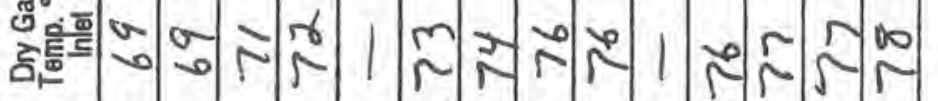

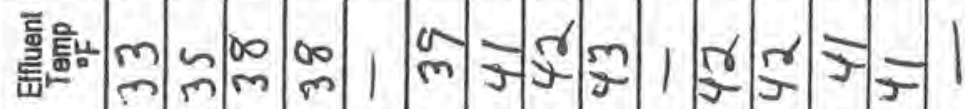

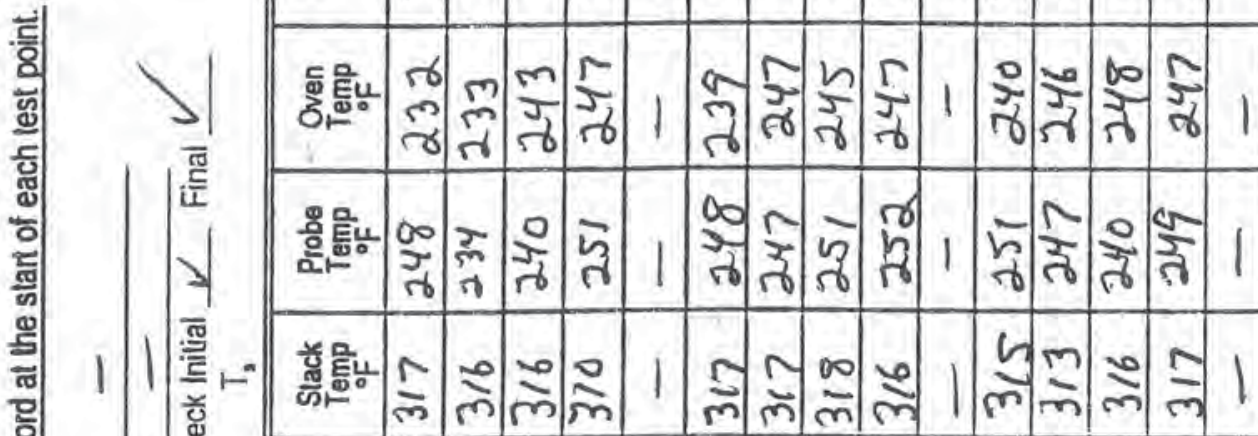

过

过 兽

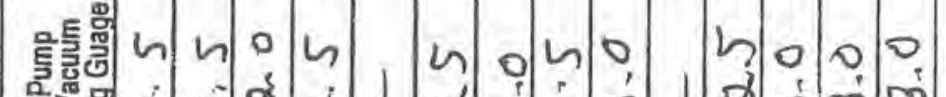

무음

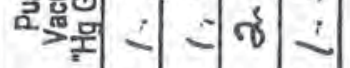
- $\dot{m} \dot{m} m$

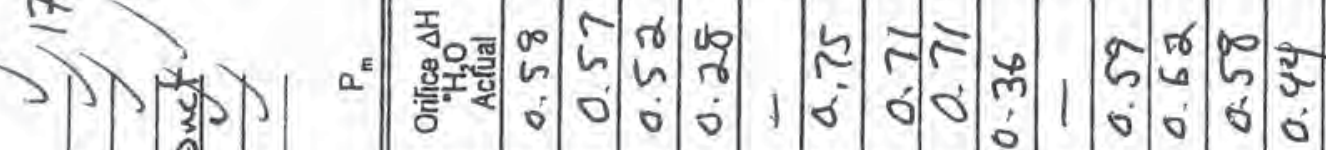

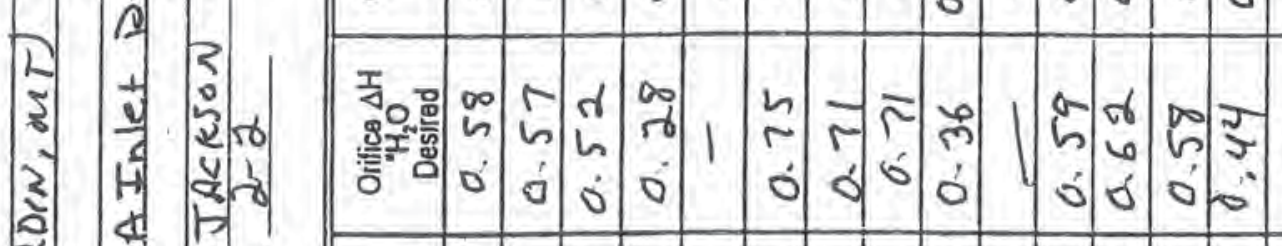

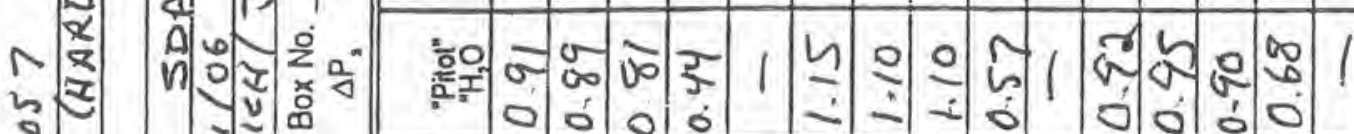

1. U

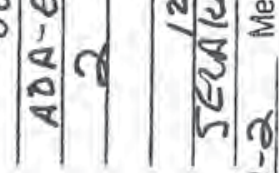

$\therefore-10$ ○́

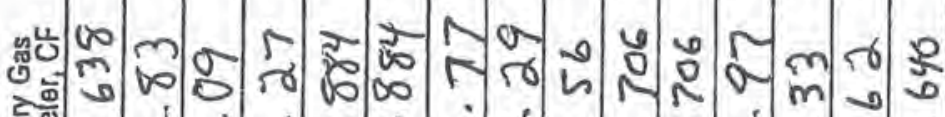

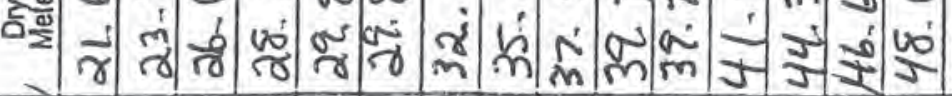

흘

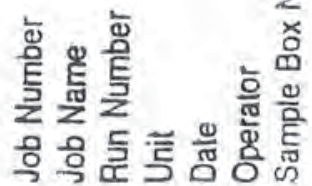

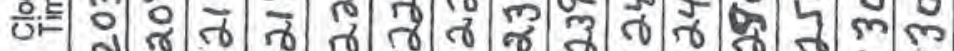

= Im -0 -

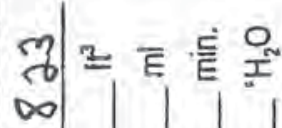

$100 m: \begin{array}{lll}0 & 0 \\ 0 & 2 & 2\end{array}$

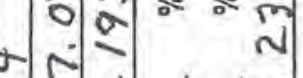

m

a com o

i

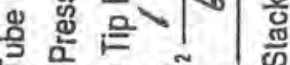

产 总

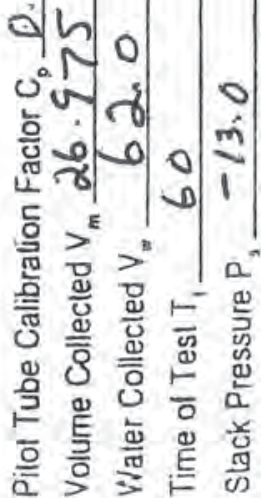


Impinger Box No. $2-2$

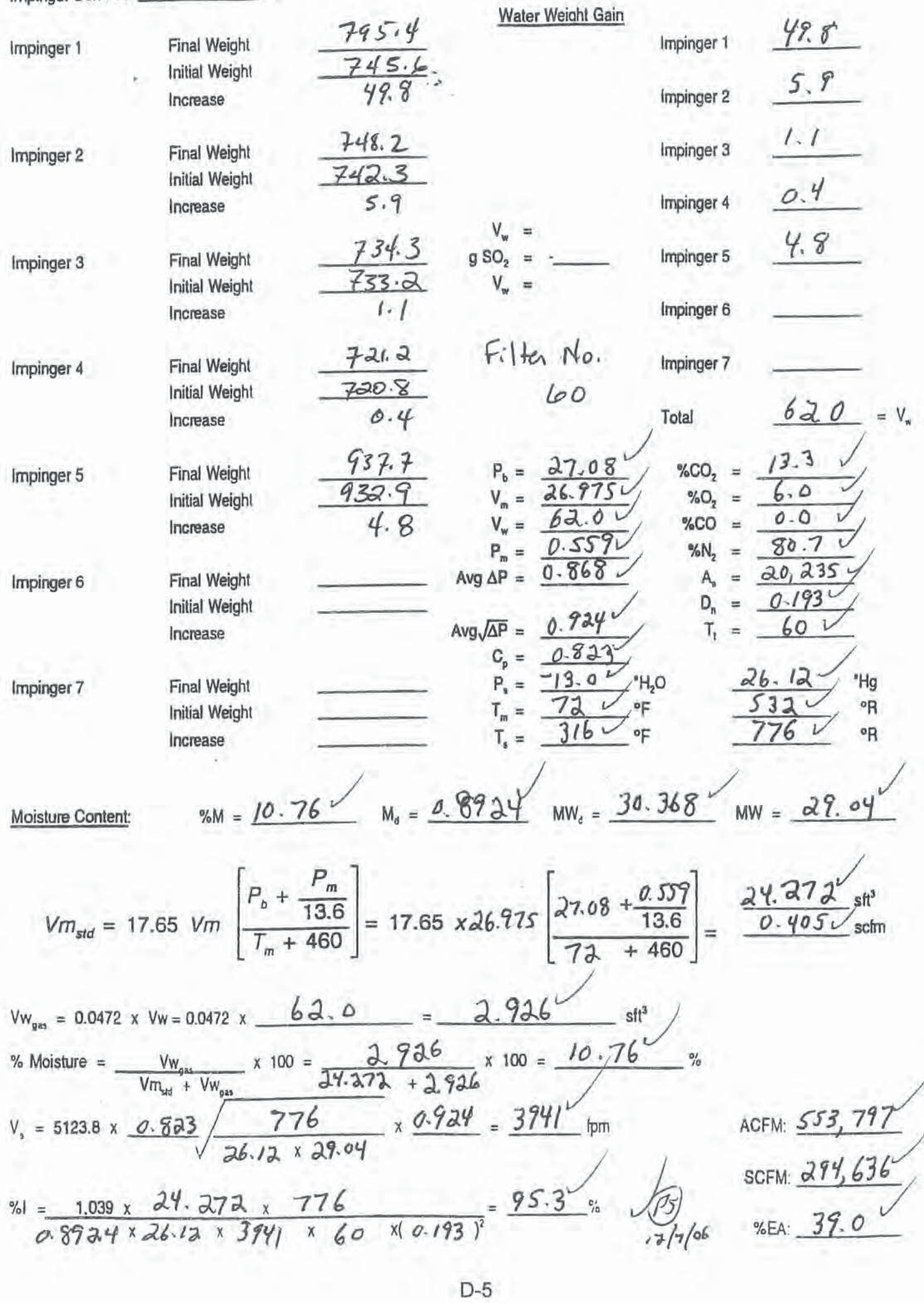



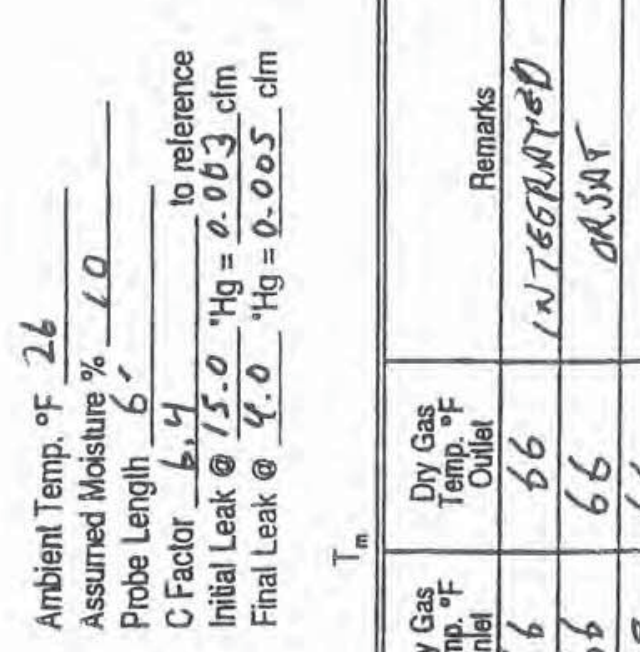

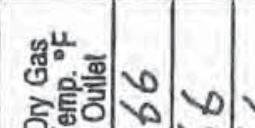

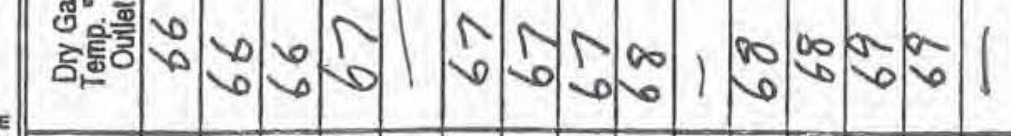

E

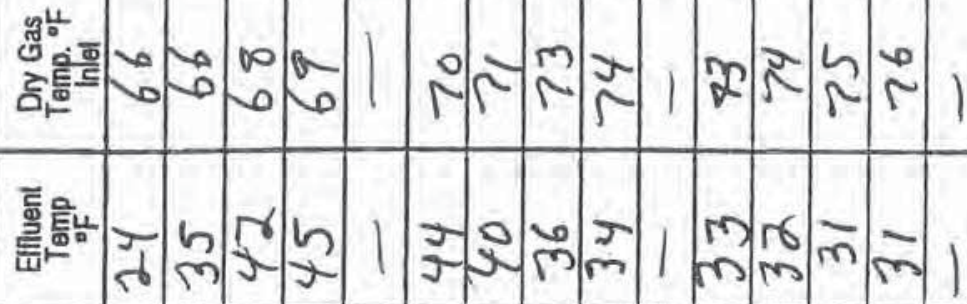

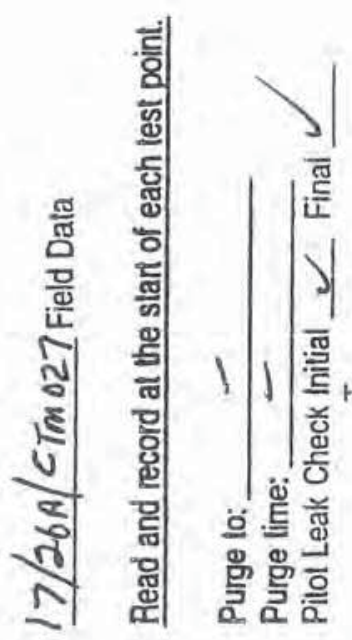

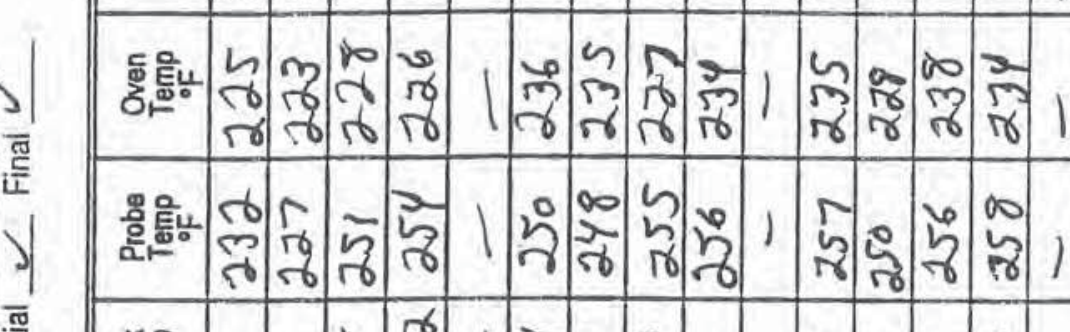

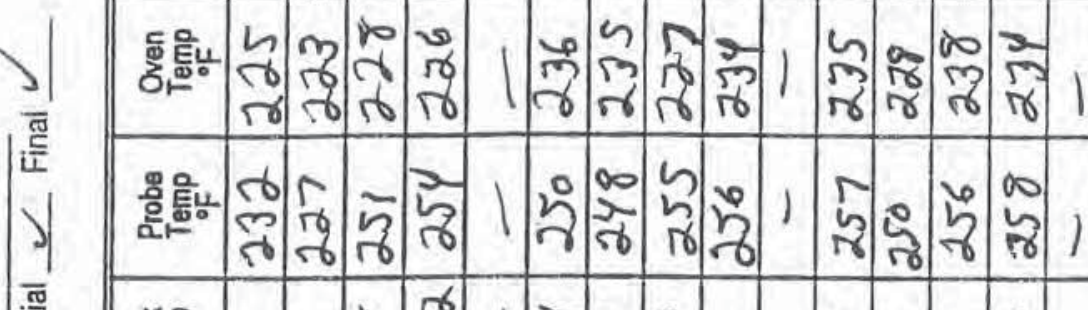

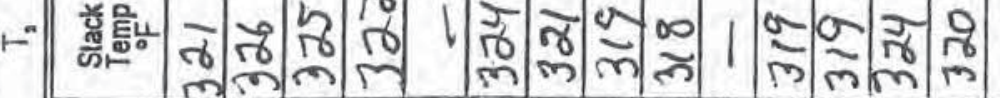

过

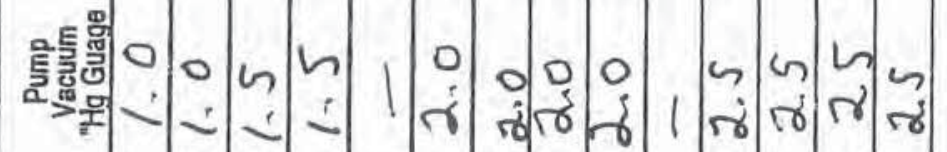

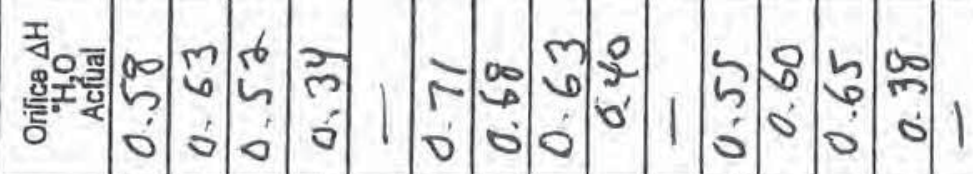

a

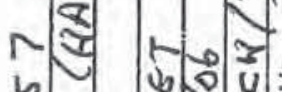

n ज.

b) हो च

○.

8 ज ज

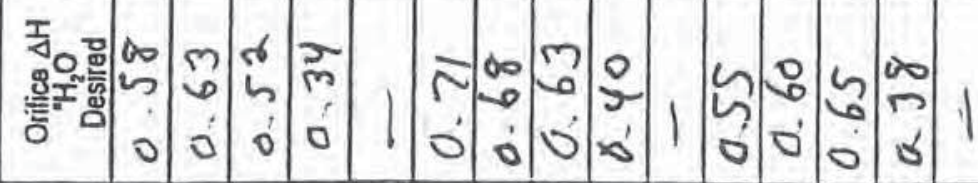

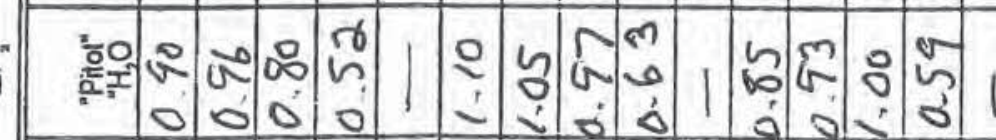

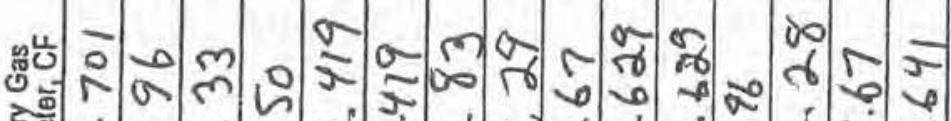

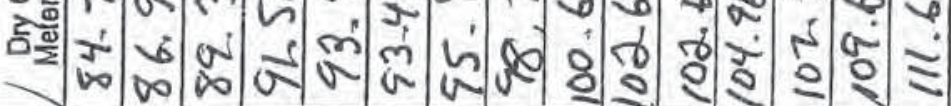

ro

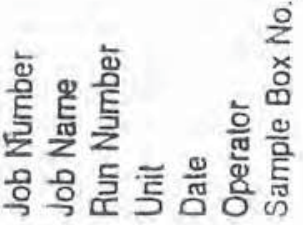

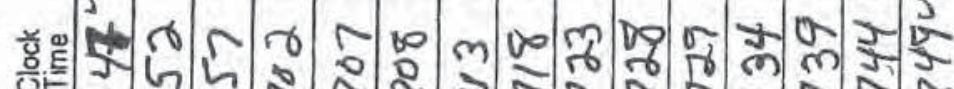

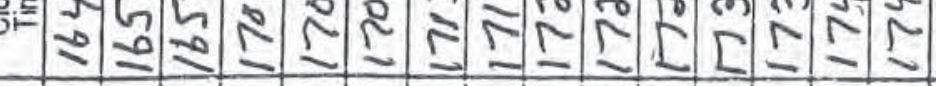

言

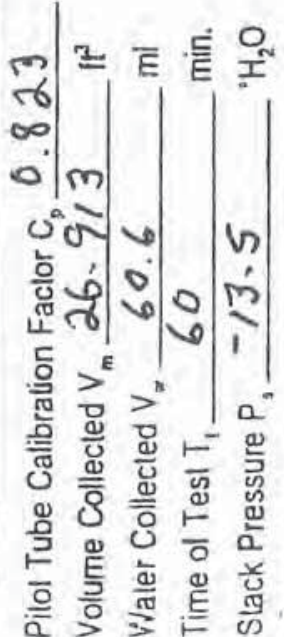


Impinger Box No. $2-2$

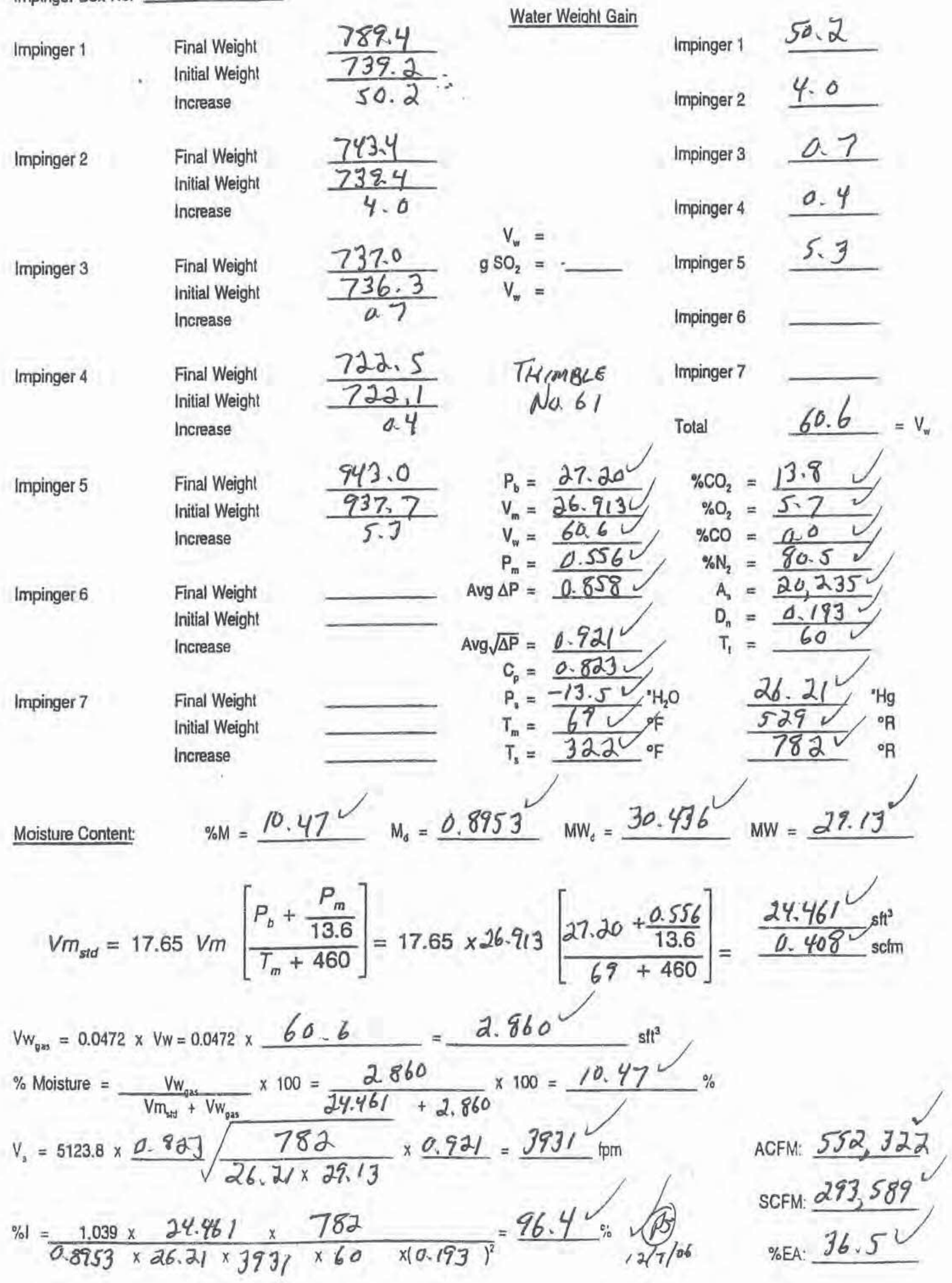




\section{ORSAT ANALYSIS DATA FORM}

$\begin{array}{ll}\text { Job \#: } & \frac{O 6-057}{\text { Aot-ES }} \\ \text { Job Name: } & \frac{\text { Handin, MT }}{\text { Location: }} \\ \text { Date: } & \frac{\text { I1-30-06 }}{\text { Hefley }} \\ \text { Operator: } & \text { HePly }\end{array}$

\begin{tabular}{|c|c|}
\hline $\begin{array}{l}\text { Sample Location: } \\
\text { Analytical Method: }\end{array}$ & Enlet \\
\hline Sample Type: Sing & ti Point Grap/Integr \\
\hline Leak Check: Time: & ( 24 minutes) Rate: \\
\hline Ambient Air Check: & \\
\hline $\mathrm{CO}_{2}-\%$ Vol. & 0.0 \\
\hline $\mathrm{O}_{2}$ - \% Vol. & 20.9 \\
\hline $\mathrm{N}_{2}-\%$ Vol. & 79.1 \\
\hline
\end{tabular}

Run \#: $\quad 1$ (17/26A $\mid$ (TMO27)

Run Time: 1545

\begin{tabular}{|l|c|c|c|c|}
\hline \hline $\mathrm{CO}_{2}$ \% Vol. & 14.3 & 14.3 & 14.3 & 14.3 \\
\hline $\mathrm{O}_{2}$ \% Vol. & 5.2 & 5.2 & 5.2 & 5.2 \\
\hline $\mathrm{CO}-\%$ Vol. & $0.0-50-3 \mathrm{H}$ & 0.0 & 0.0 & 0.0 \\
\hline $\mathrm{N}_{2}$ \% Vol. & 80.5 & 80.5 & 80.5 & 80.5 \\
\hline
\end{tabular}

\begin{tabular}{|c|c|c|c|c|}
\hline Run Time: & Analysis\#1 & Analysis \#2 & Analysis \#3 & Average - \% Volume \\
\hline $\mathrm{CO}_{2}-\%$ Vol. & 13.3 & 13.3 & 13.3 & 13.3 \\
\hline $\mathrm{O}_{2}-\%$ Vol. & 6.0 & 6,0 & 6.0 & 6.0 \\
\hline co-\% Vol. & 0.0 & 0.0 & 0.0 & 0,0 \\
\hline N & 80.7 & 80.7 & 80.7 & 80.7 \\
\hline
\end{tabular}

\begin{tabular}{|c|c|c|c|c|}
\hline Zun Time: & Analysis \#1 & Analysis \#2 & Analysis \#3 & Average - $\%$ Volume \\
\hline $3 \mathrm{O}_{2}-\%$ Vol. & 13.8 & 13.8 & 13.8 & 13.8 \\
\hline$\underline{\mathrm{J}_{2}-\% \text { Vol. }}$ & 5.6 & 5.7 & 5.7 & 5.7 \\
\hline 30 - \% Vol. & 0.0 & 0.0 & 0.0 & 0.0 \\
\hline V & 30.4 & 80.5 & 80.5 & 80.5 \\
\hline
\end{tabular}



Impinger Box No. MZ

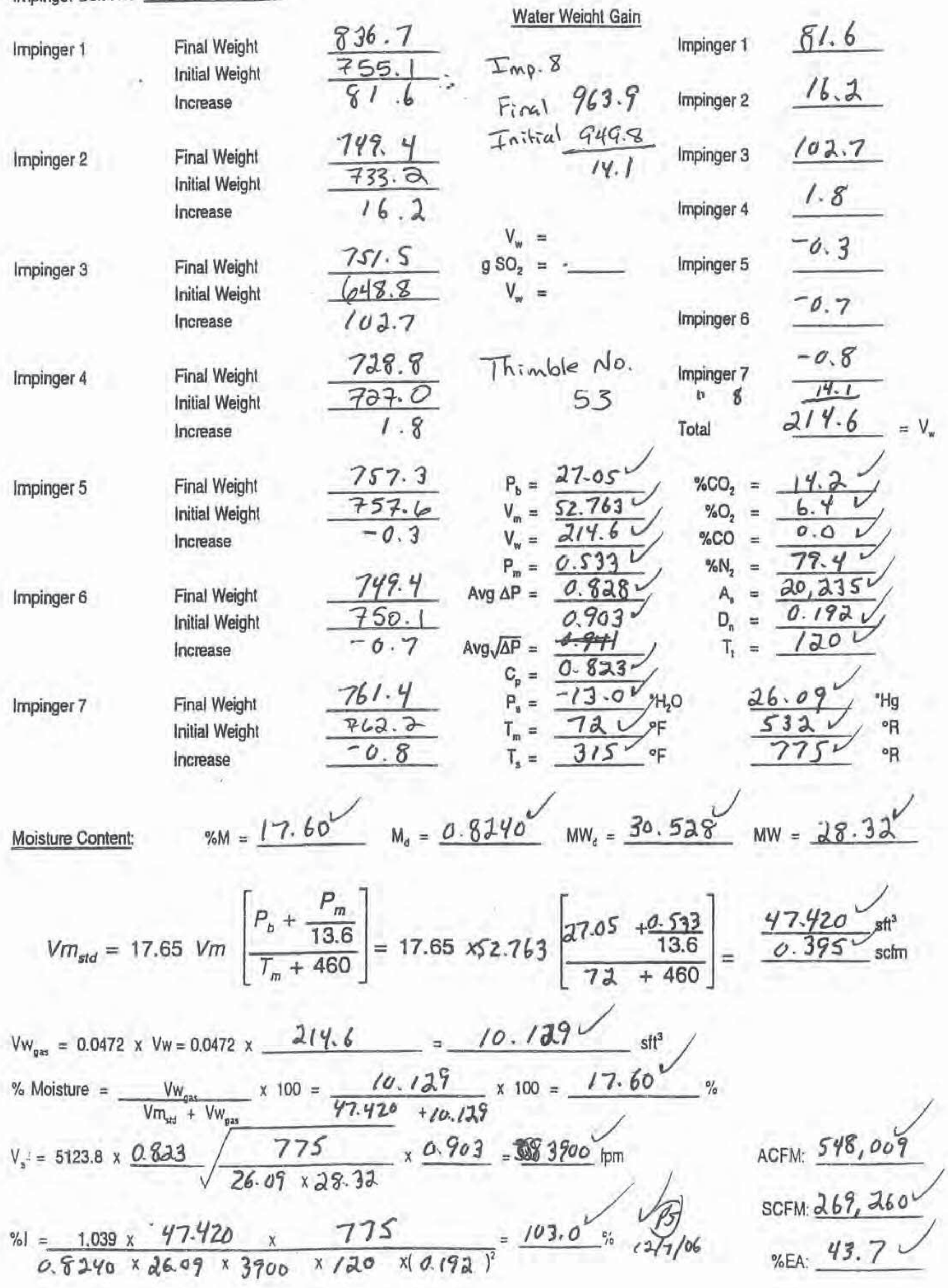




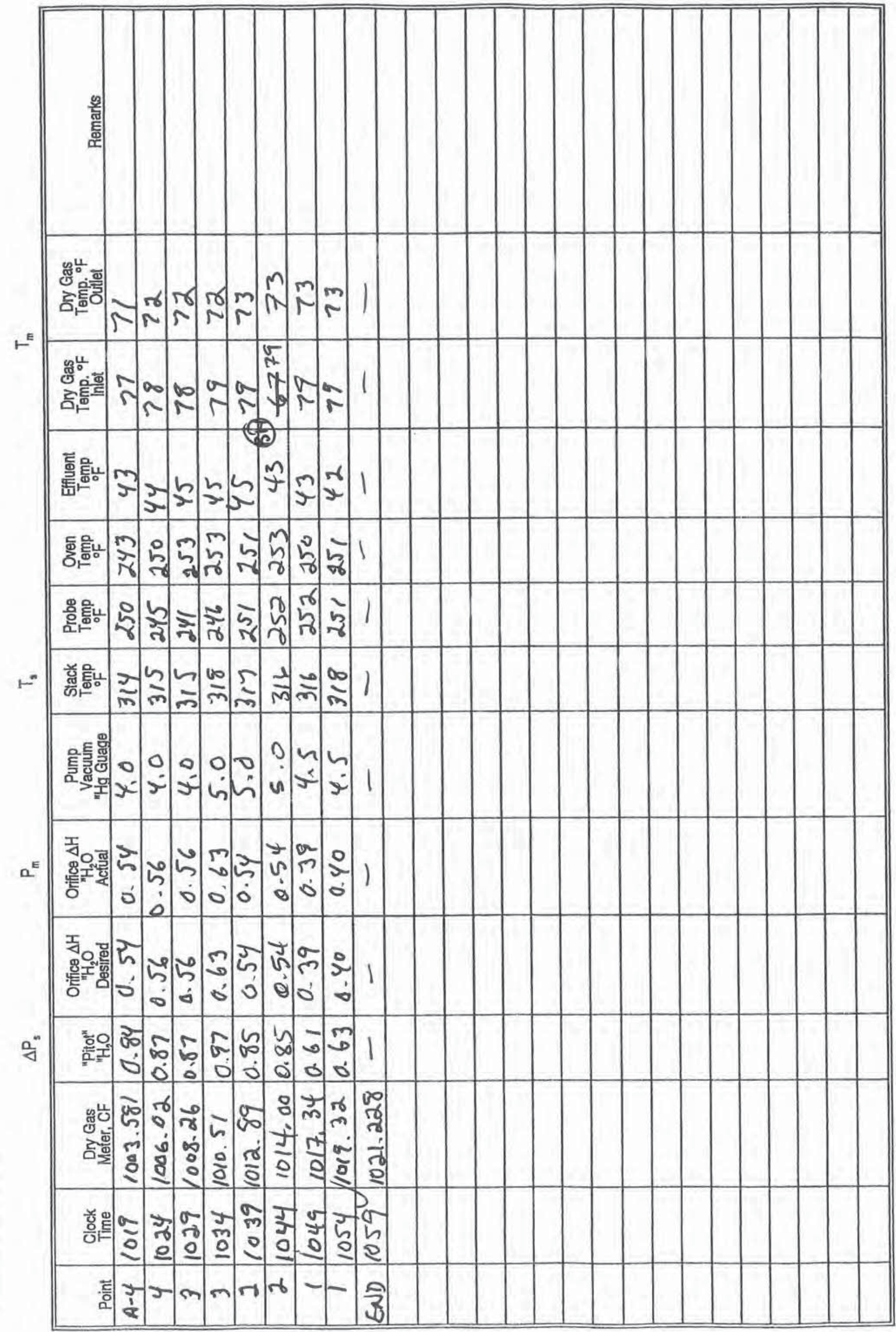



Impinger Box No. M- 2

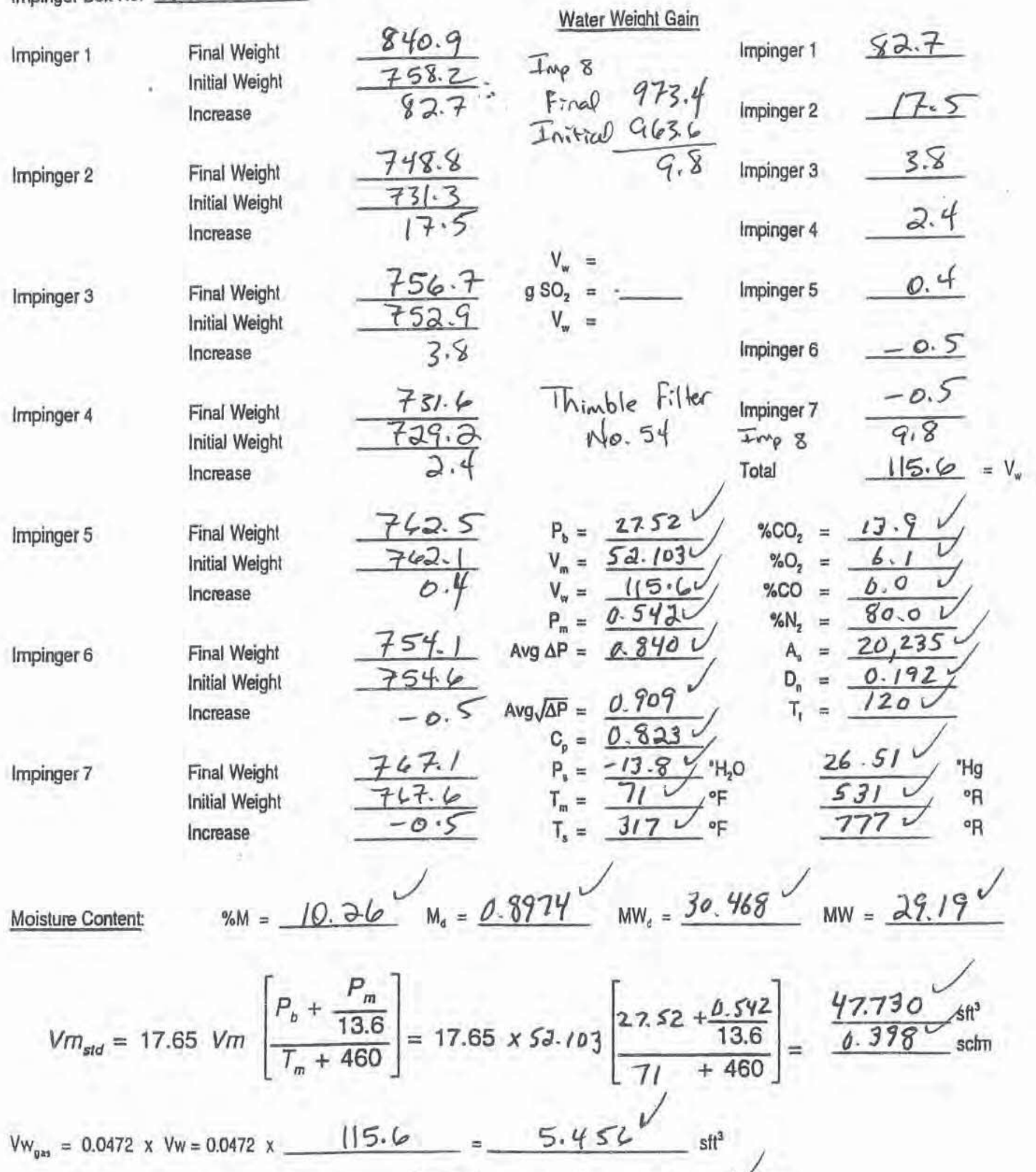

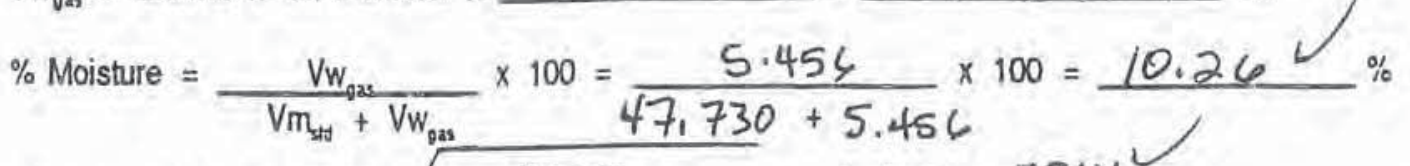

$V_{s}=5123.8 \times \frac{0.823}{\sqrt{26.51 \times 2 \% .19}} \times \underline{0.909}=3841^{2} \mathrm{pm}$

$\% 1=\frac{1.039 \times 47.730 \times 777}{0.8974 \times 26.51 \times 3841 \times 120 \times(0.192)^{2}}=\frac{95.3}{12 / 7 / 06}$

ACFM: $539,741^{\circ}$

SCFM: 292,703

\%EA: $40.4 \mathrm{~N}$ 
के

迹
号
岸

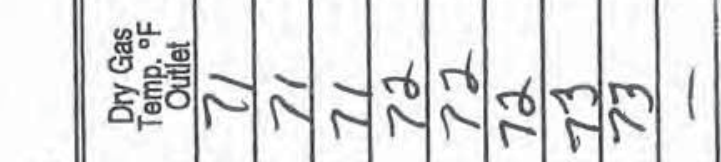

$\vdash$

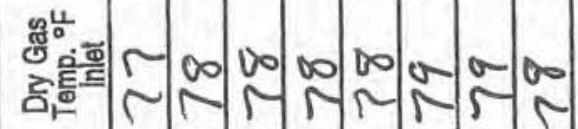

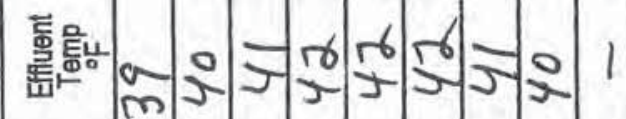

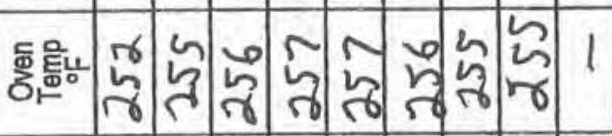

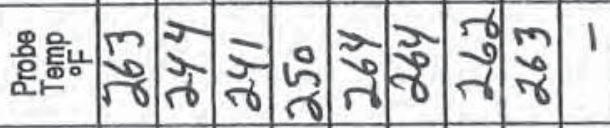

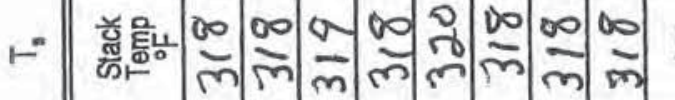

$x$

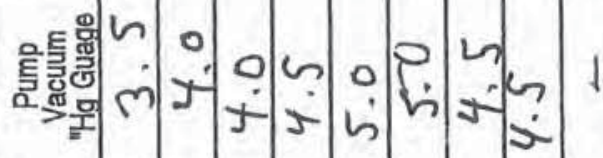

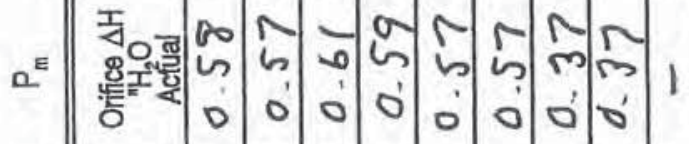

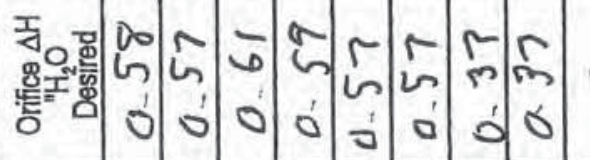

ব"

$\begin{array}{llllll} & 0 & 0 & 0 & 0 & 0 \\ 0\end{array}$

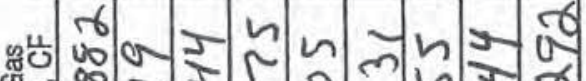

$0-\infty-2,0$,

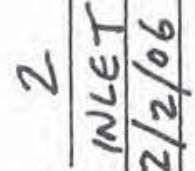

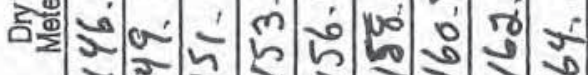

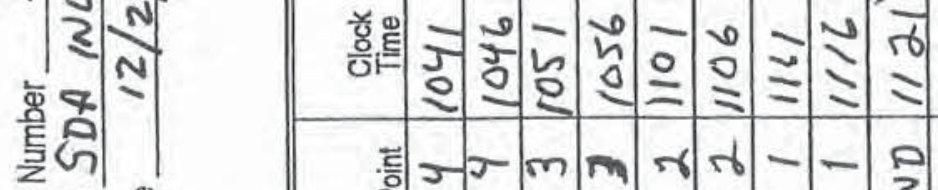

도ำ产

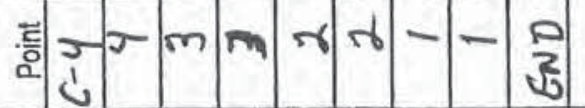




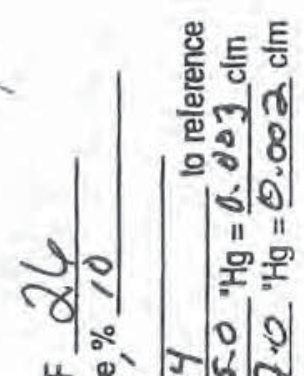

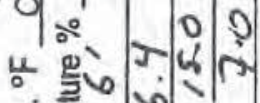

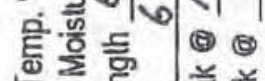

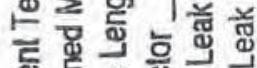

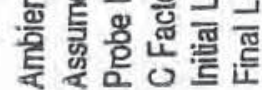

$\vdash$

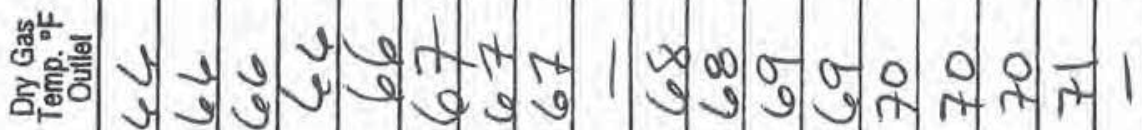

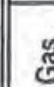

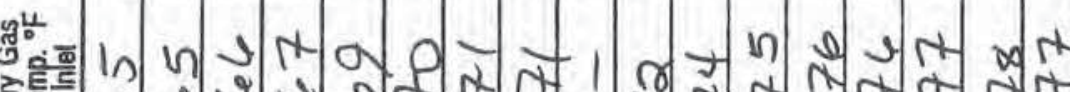

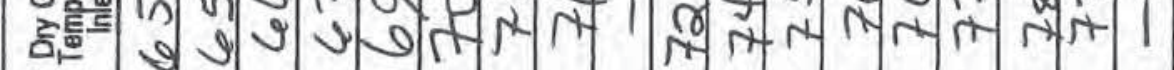

蹗

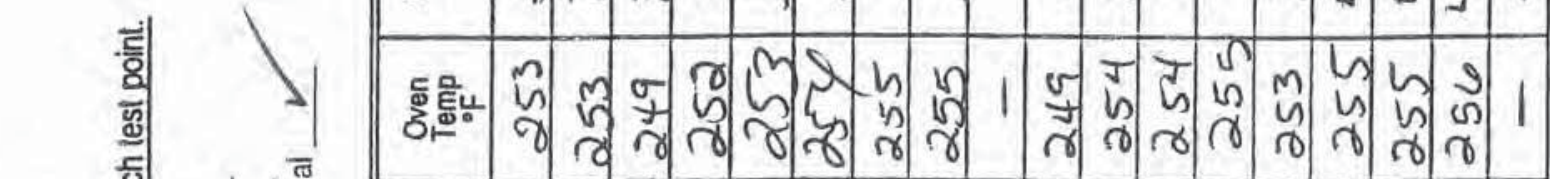

璦

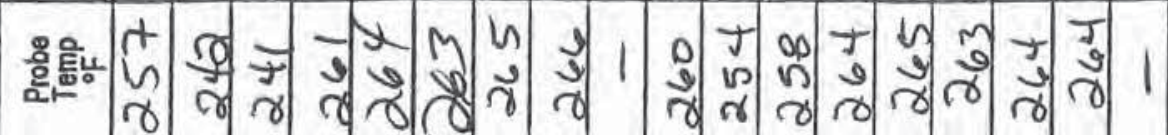

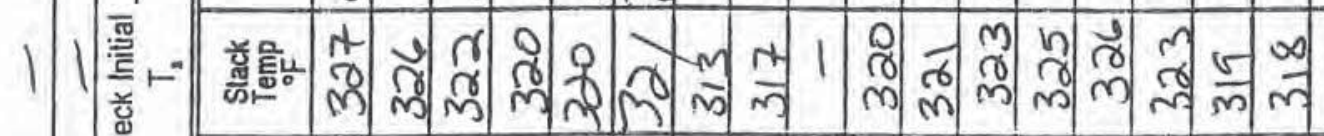

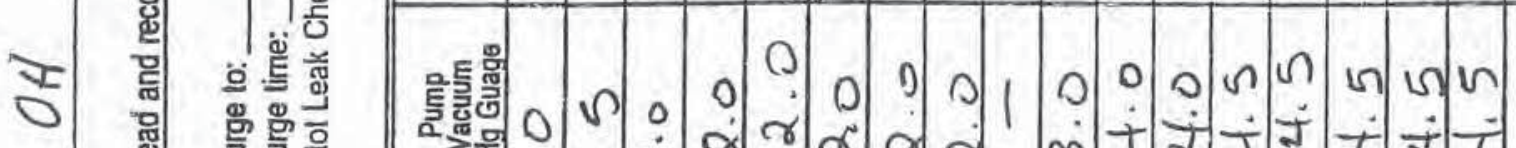

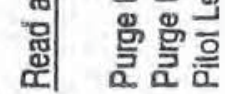

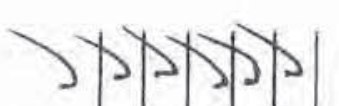

$\mathrm{a}^{\mathrm{E}}$

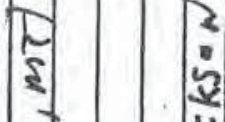

3.

- N N

N茇

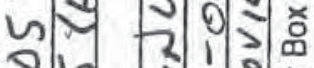

1. ये

- 1 (c)

0 व.

\&.

这

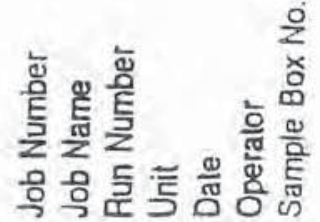

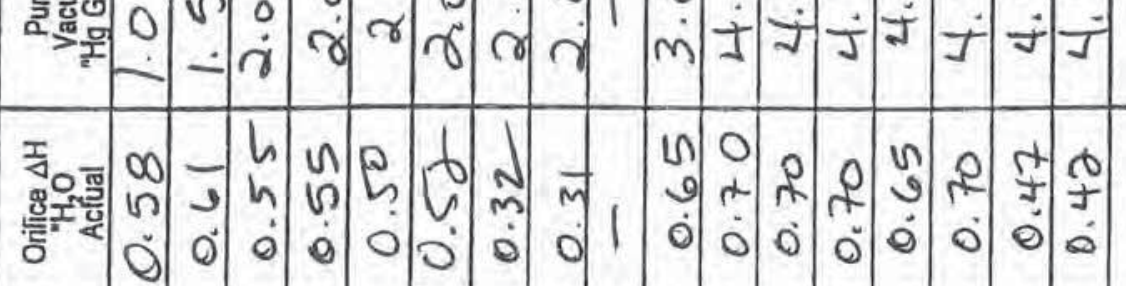

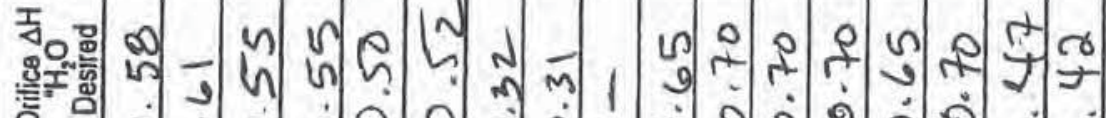

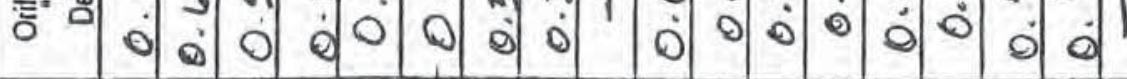

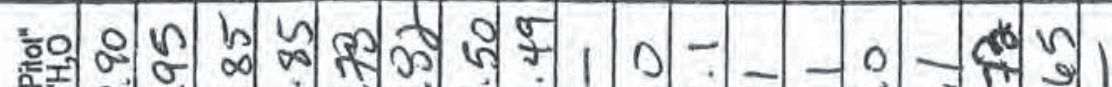

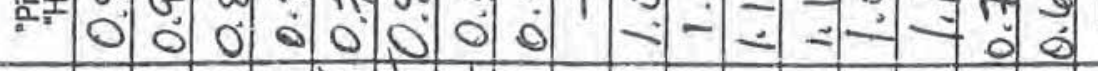

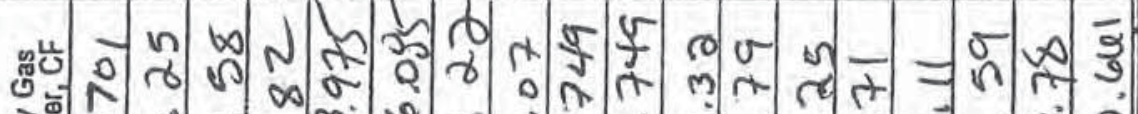

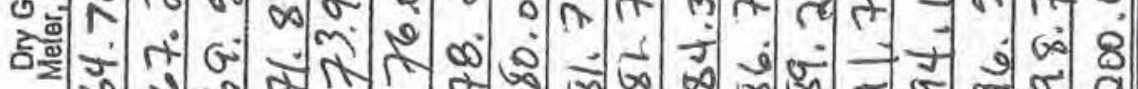

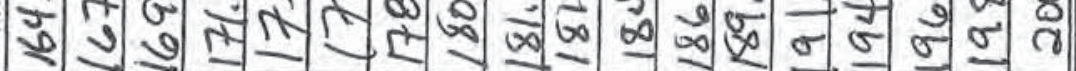

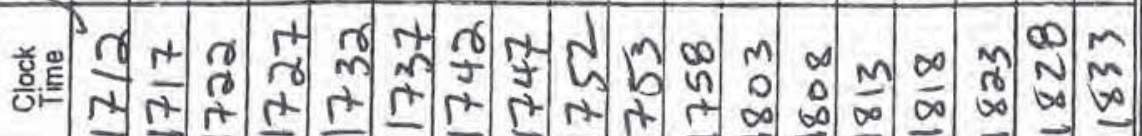

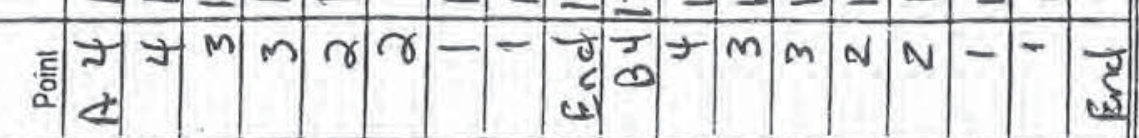

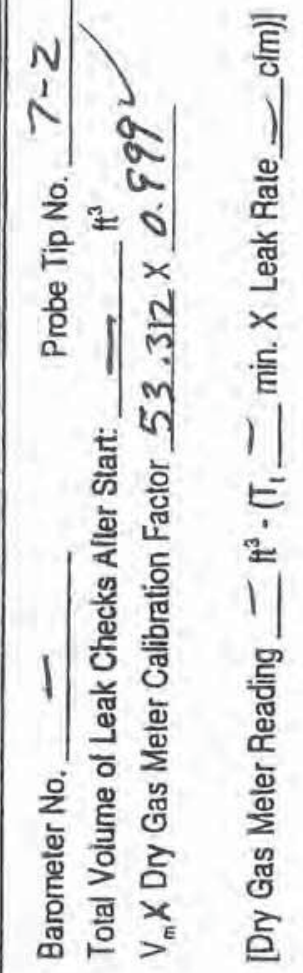

올.

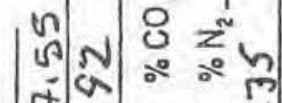
$\pi$.

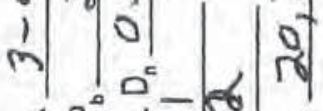
i a

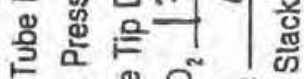
용 00

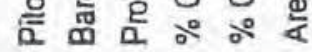

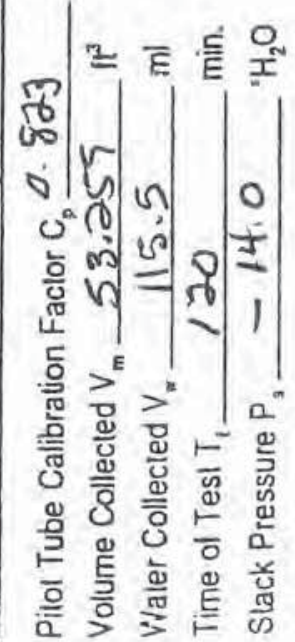


Impinger Box No. $M-Z$

$$
\begin{aligned}
& \text { Impinger } 1 \\
& \begin{array}{l}
\text { Final Weight } \\
\text { Initial Weight } \\
\text { Increase }
\end{array} \frac{839.1}{82.1}: \text { Fmp.8 } \\
& \text { Water Weiaht Gain } \\
& \text { Final } 891.7 \text { impinger } 2 \quad 16.6 \\
& \text { Impinger } 2 \\
& \text { increase } \\
& \text { Impinger } 3 \\
& \text { Increase } \\
& \text { 10. } 3 \\
& \text { Impinger } 3 \quad 3.1 \\
& \text { Impinger 4 } \\
& 2.9 \\
& \mathrm{~V}_{\mathrm{w}}= \\
& \frac{\frac{756.6}{753.5}}{3.1} \\
& \mathrm{gSO}_{2}=\text {. } \\
& \mathrm{V}_{\mathrm{w}}= \\
& 732.5 \text { Thimble No. } \\
& 55 \operatorname{Imp} 8 \\
& 2.9 \\
& V m_{s t d}=17.65 \mathrm{Vm}\left[\frac{P_{b}+\frac{P_{m}}{13.6}}{T_{m}+460}\right]=17.65 \times 53.259\left[\frac{27.55^{+\frac{10.54}{13.6}}}{71+460}\right]=\frac{48.842 \mathrm{st}^{3}}{0.407} \mathrm{scm} \\
& V_{s}=5123.8 \times 0.823 \sqrt{\frac{780}{26.52 \times 29.10}} \times 0.913=3871 \mathrm{~mm} \\
& \% 1=\frac{1.039 \times 780 \times 48.842}{0.8996^{\times} 26.52^{\times} 3871 \times 120 \times(0.192)^{2}}=96.89^{2} \% \frac{(15)}{12 / 7 / 06}
\end{aligned}
$$
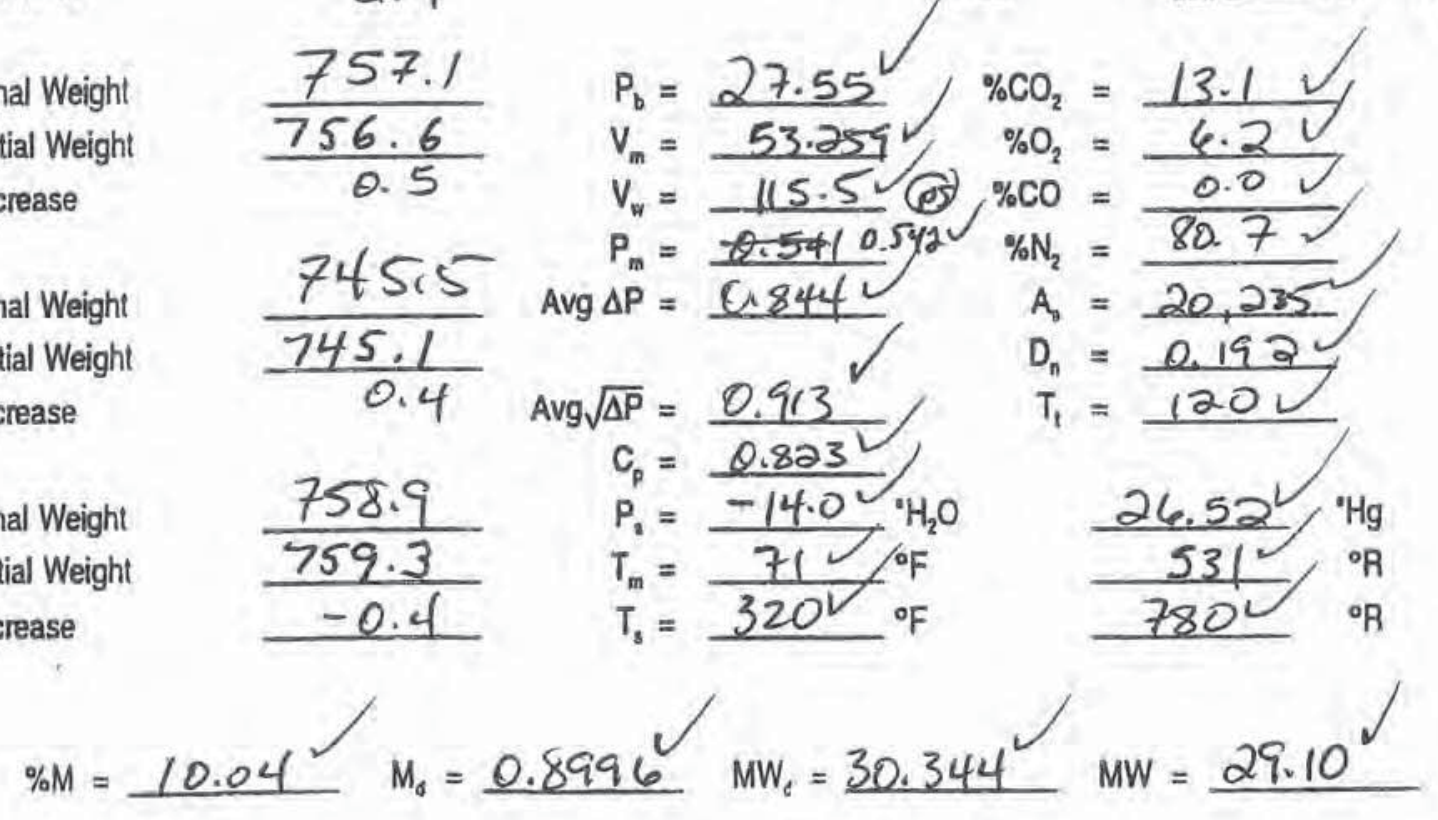


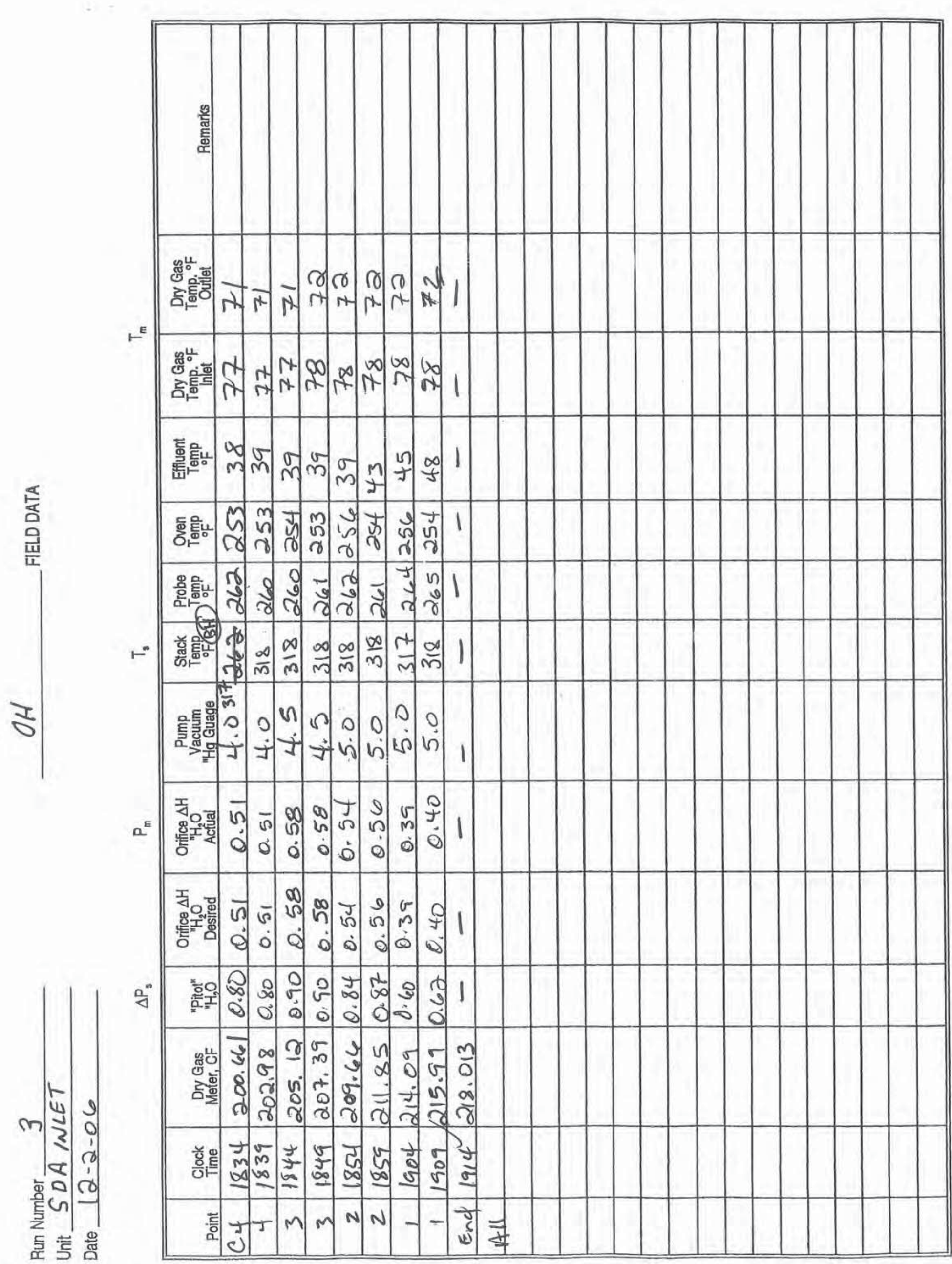




\section{ORSAT ANALYSIS DATA FORM}

$\begin{array}{ll}\text { Job \#: } & \frac{06-057}{\text { Job Name: }} \\ \text { Location: } & \frac{\text { ADA-ES }}{\text { Hardin,MT }} \\ \text { Date: } & \frac{12-1-06}{\text { Hefles }} \\ \text { Operator: } & \text { Her }\end{array}$

Sample Location: SDA Inlet

Analytical Method:

Sample Type: Single Point / Multi Point Grab Integrated

Leak Check: Time: $5 \mathrm{~min}$ ( 24 minutes) Rate: 0.0

Ambient Air Check:

\begin{tabular}{|l|c|}
\hline $\mathrm{CO}_{2}-\%$ Vol. & 0.0 \\
\hline $\mathrm{O}_{2}-\%$ Vol. & 20.9 \\
\hline $\mathrm{N}_{2}-\%$ Vol. & 79.1 \\
\hline
\end{tabular}

\section{Run \#: $\quad 1(\mathrm{OH})$}

Run Time:

\begin{tabular}{|l|l|l|l|l|}
\hline \hline $\mathrm{CO}_{2}-\%$ Vol. & & & & \\
\hline $\mathrm{O}_{2}-\%$ Vol. & & & & \\
\hline $\mathrm{CO}-\%$ Vol. & & & & \\
\hline $\mathrm{N}_{2}-\%$ Vol. & & & & \\
\hline
\end{tabular}

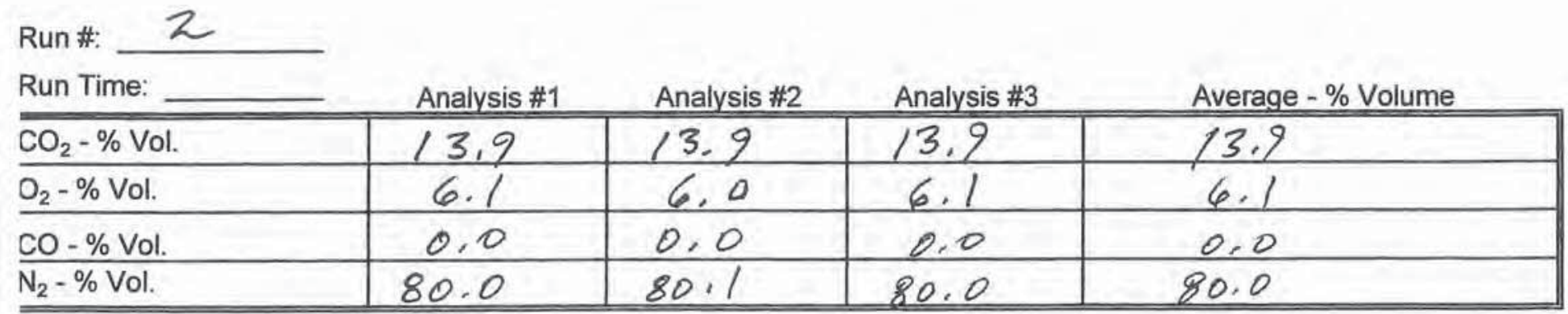

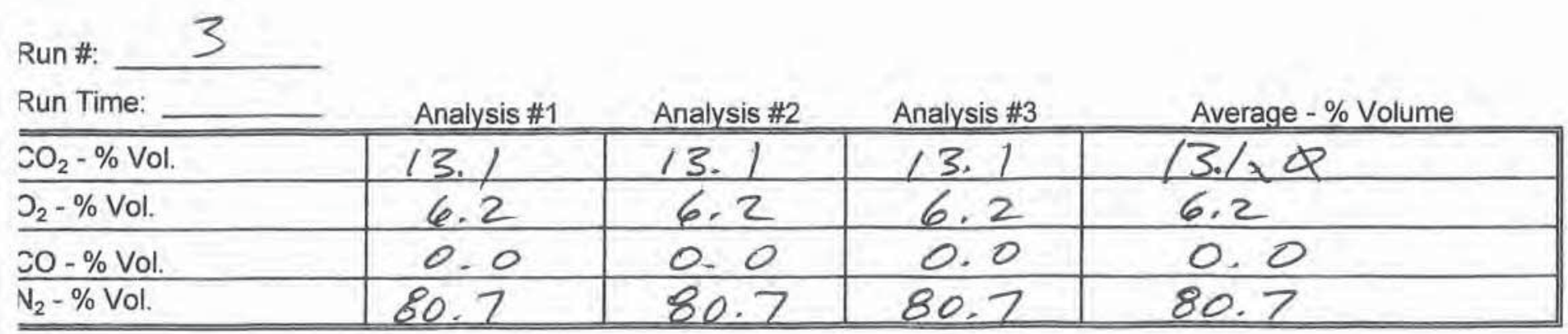



Impinger Box No. 3-1

$$
\begin{aligned}
& \text { Impinger } 1 \quad \text { Final Weight } \\
& \begin{array}{l}
\text { Initial Weight } \\
\text { Increase }
\end{array} \frac{733.4}{39.3}= \\
& \text { Impinger 2 } \begin{array}{l}
\text { Final Weight } \\
\text { Initial Weight } \\
\text { Increase }
\end{array} \quad \frac{735.0}{\frac{734.1}{0.9}} \\
& \text { Impinger } 3 \\
& \text { Increase } \\
& \text { Impinger } 4 \\
& \frac{737.9}{\frac{737.8}{0.1}} \\
& v_{w}= \\
& \begin{aligned}
g \mathrm{SO}_{2} & = \\
\mathrm{V}_{\mathrm{w}} & =
\end{aligned} \\
& \text { Avg } \triangle \mathrm{P}= \\
& A v g \sqrt{\Delta P}=- \\
& \begin{array}{l}
C_{p}=-\frac{}{-14.7} / \mathrm{H}_{2} \mathrm{O} \\
P_{2}=\frac{-14}{70}
\end{array} \\
& \mathrm{~T}_{\mathrm{m}}=70^{\circ}{ }^{\circ} \mathrm{F} \\
& T_{s}=\ldots{ }^{\circ} \mathrm{F} \\
& \% \mathrm{CO}_{2}=14.3 \\
& \% \mathrm{O}_{2}=-\mathrm{s.2} \\
& \% \mathrm{CO}=0.0 \\
& \% \mathrm{~N}_{2}=\frac{80.5}{20.535} \\
& A_{1}=20,235 \\
& \begin{aligned}
D_{n} & =- \\
T_{1} & =-60
\end{aligned} \\
& \frac{25.86}{530}{ }^{\circ \mathrm{Hg}} \\
& \% M=10.06^{\prime} \quad M_{d}=0.8994 \quad M 4_{t}=\square \quad M W=\square- \\
& V m_{s t d}=17.65 \mathrm{Vm}\left[\frac{P_{b}+\frac{P_{m}}{13.6}}{T_{m}+460}\right]=17.65 \times 21.571\left[\frac{26.94+\frac{0.350}{13.6}}{70+460}\right]=\frac{\frac{19.371}{0.323} \mathrm{sctm}^{3}}{\mathrm{scm}^{2}}
\end{aligned}
$$
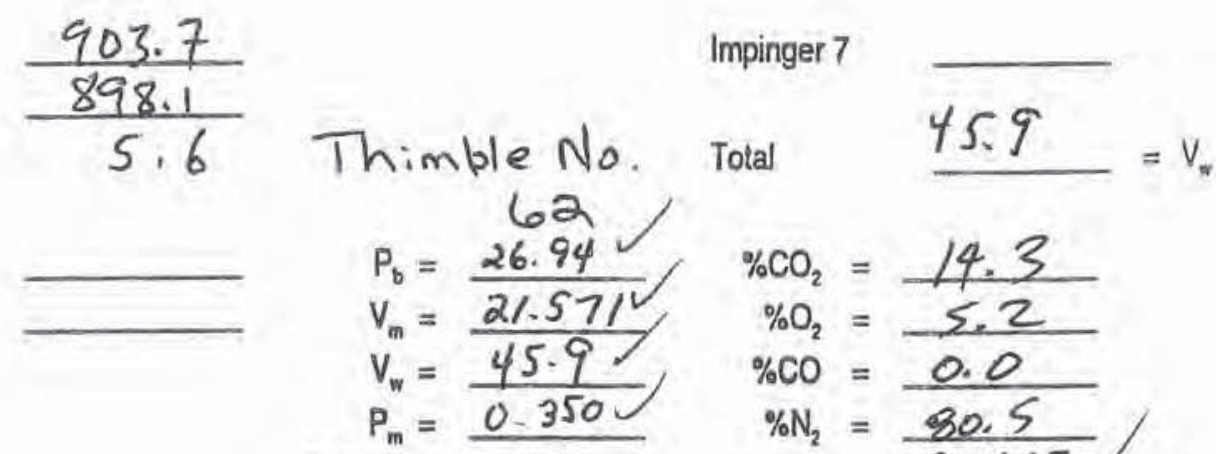

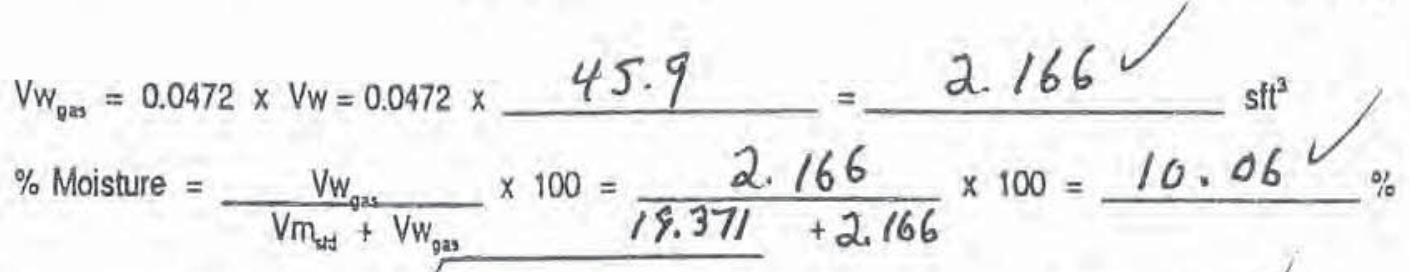

$$
\begin{aligned}
& V_{s}=5123.8 \times
\end{aligned}
$$

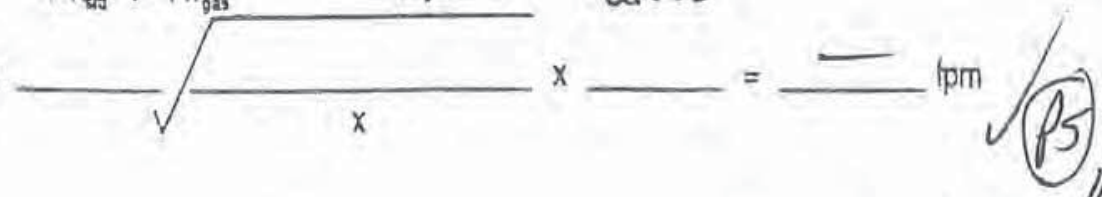

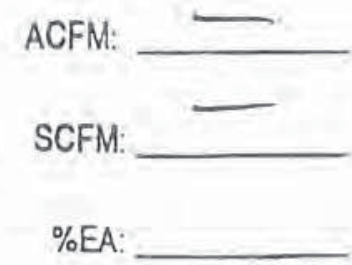

$=\frac{1.039 \times \frac{x}{x} \times(101 / 6 / 06}{1}$




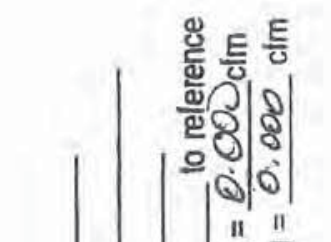

be

.

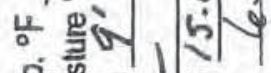

들

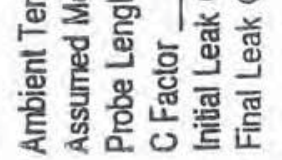
$\vdash$

등

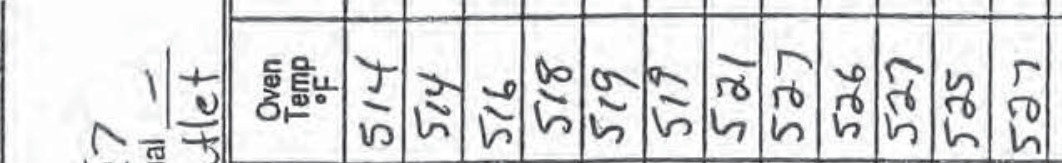

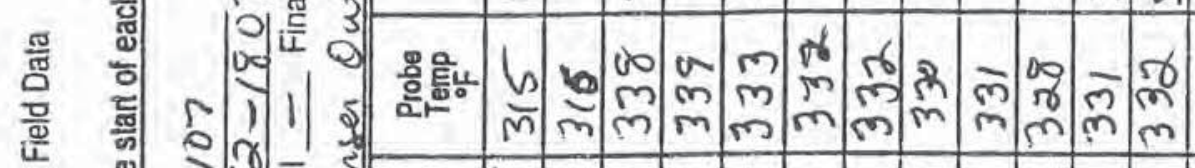

娄

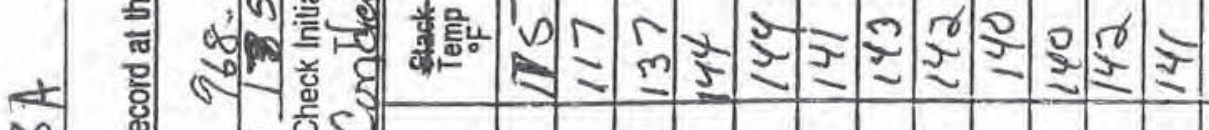

$\infty$

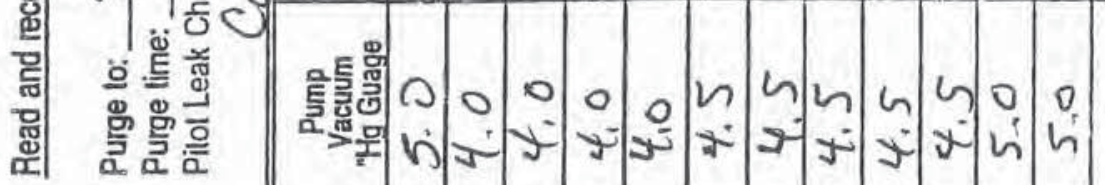

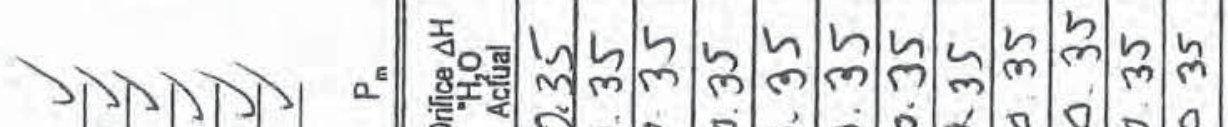

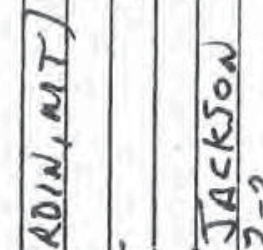

₹.

N 1 ज

ที

bid

1110

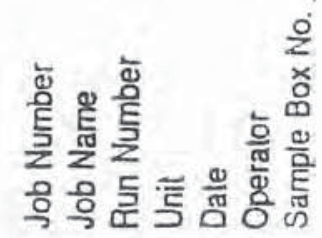

ज्ञात्रु

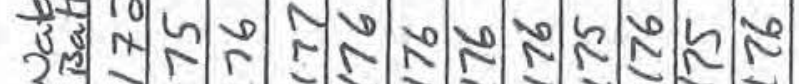

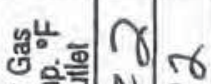

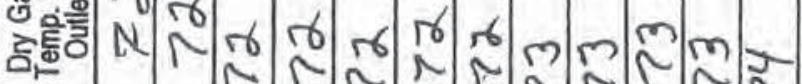

\section{go}

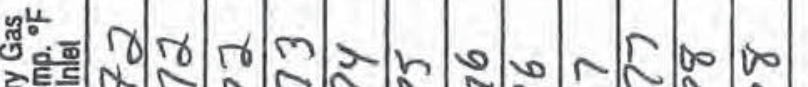

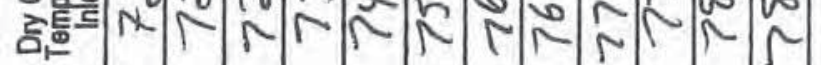

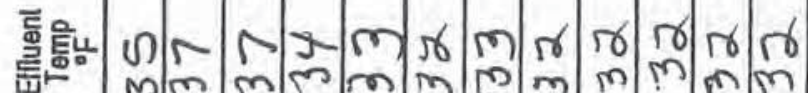

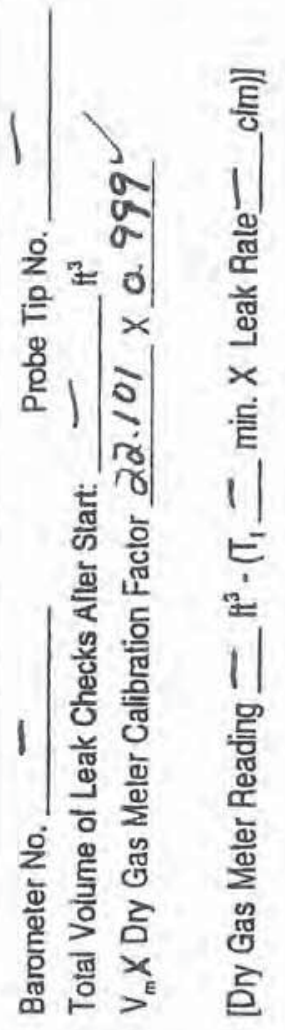

오.

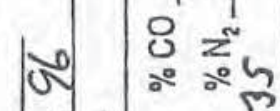

( ) 1 .

$\left.1|\pi|\right|_{0}|N| a^{0} \mid$

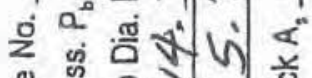

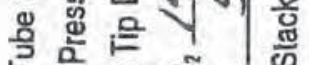

50.

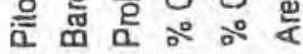

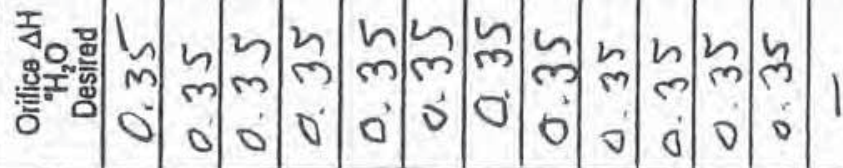

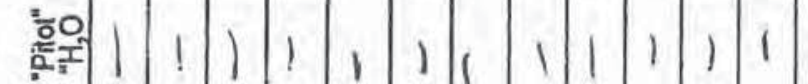

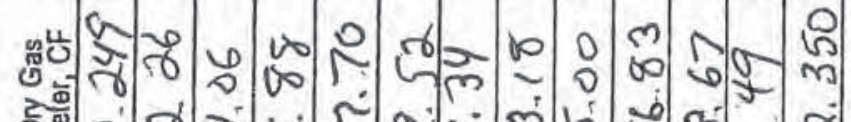

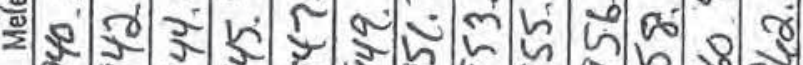

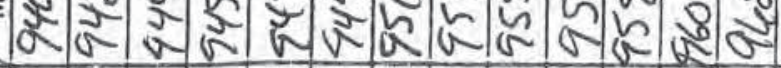

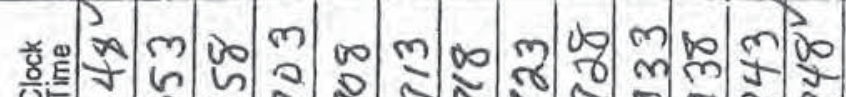

을

등

등 z. E E 을

10

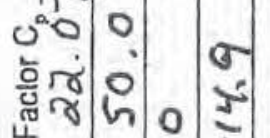

范它

음 $\vec{D}^{\mathrm{E}}>$ "

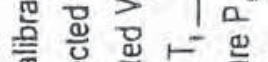

जั

今 8 흠

흘 兽总 
Impinger Box No. $3-1$

Impinger 1

Impinger 2

mpinger 3

mpinger 4

Moisture Content: mpinger 6

Impinger 7

Impinger 5

Final Weight Initial Weight

Increase

Final Weight Initial Weight

increase

Final Weight

Initial Weight

Increase
Water Weight Gain

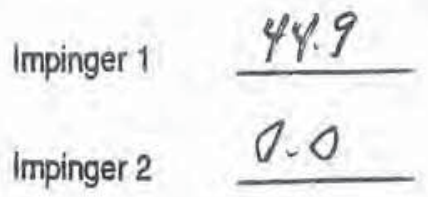

Impinger $3 \quad 0.0$

Impinger 45.1

Impinger 5

Impinger 6

Thimble No. Impinger 7 63

Total

\section{8 \\ 5. 1}

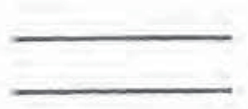

$$
\text { Avg } \Delta P=\square
$$

$$
\begin{aligned}
\operatorname{Avg} \sqrt{\Delta \mathrm{P}} & =- \\
C_{p} & =- \\
P_{2} & =-14.9 V{ }^{\circ} \mathrm{H}_{2} \mathrm{O} \\
T_{m} & =14{ }^{\circ} \mathrm{F} \\
T_{s} & =-
\end{aligned}
$$$$
\begin{aligned}
\% \mathrm{CO}_{2} & =\frac{14.3}{5.2} \\
\% \mathrm{O}_{2} & =\frac{0.0}{80.5} \\
\% \mathrm{CO}_{2} & =\frac{80.5}{20.35}
\end{aligned}
$$$$
A_{c}=20,235
$$$$
D_{n}=-
$$$$
T_{1}=60
$$

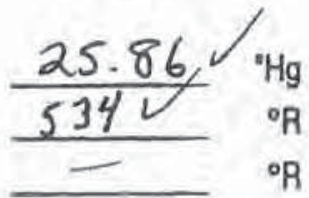

$$
V m_{s t d}=17.65 \mathrm{Vm}\left[\frac{P_{b}+\frac{P_{m}}{13.6}}{T_{m}+460}\right]=17.65 \times 22.079\left[\frac{26.96+\frac{0.350}{13.6}}{74+460}\right]=\frac{19.693^{\mathrm{stt}}}{0.328 \mathrm{scm}^{3}}
$$

$V W_{\text {gas }}=0.0472 \times V W=0.0472 \times 50.0=2.360 \mathrm{~V} \mathrm{st}^{3}$

$\%$ Moisture $=\frac{V w_{g a s}}{V m_{x+1}+V w_{g a s}} \times 100=\frac{2.360}{19.693+2.366} \times 100=10.70 \% \%$

$V_{3}=5123.8 \times \sqrt{\frac{}{x}} \times-\longrightarrow \mathrm{mm}$

$\% 1=$

$\frac{1.039 x}{x}$
$\% M=10.20 \quad M_{d}=0.8973 \quad M W_{c}=$

$M W=$ 
기

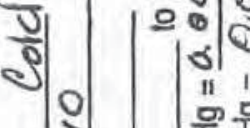

9 $\quad$ 운몬

1. 0.0

แ giv 1 in

을. 동 (호 ()

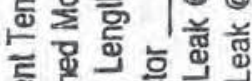

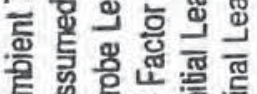

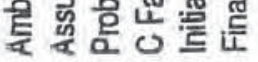

$\vdash^{E}$

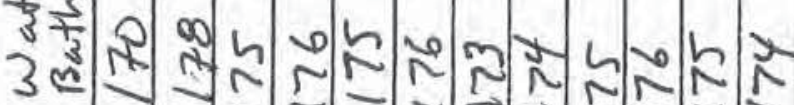

1

$\sum_{\substack{0 \\ 0}}$

$\sqrt{2} \frac{2}{2}$

的言 20 a

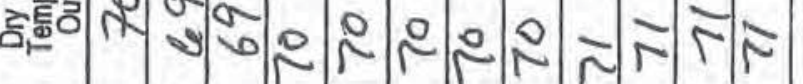

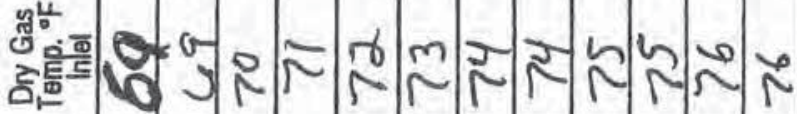

蛋憵

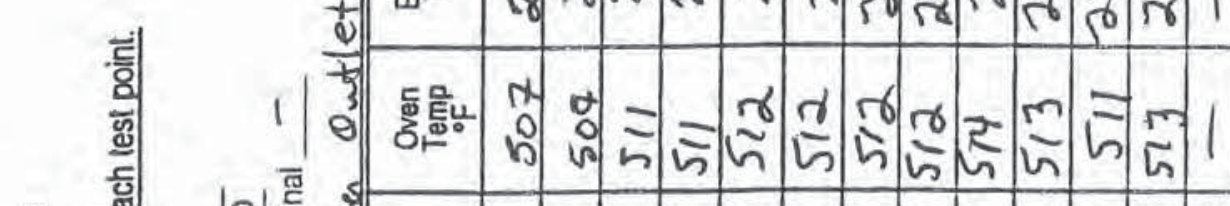

总 ㅎํㅇ a -3

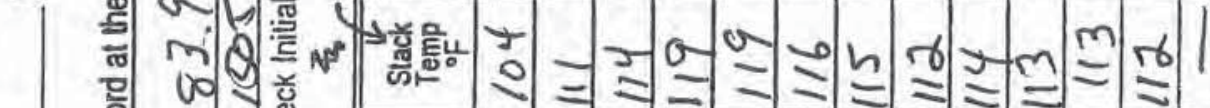

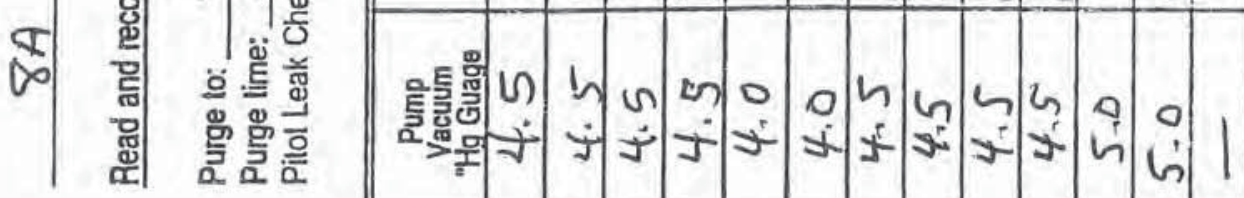

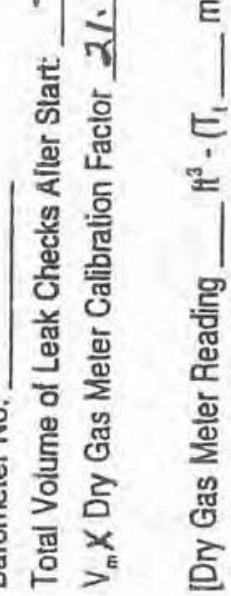

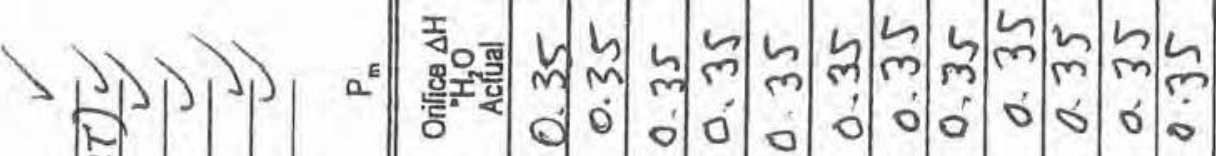

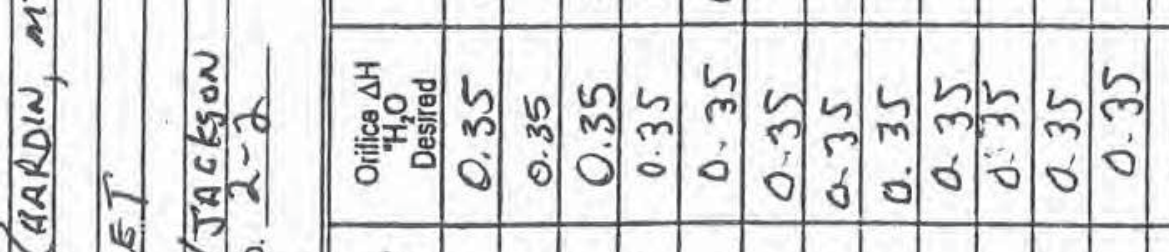

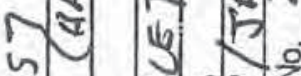

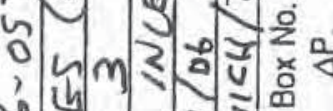

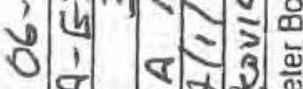

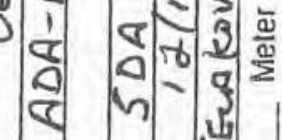

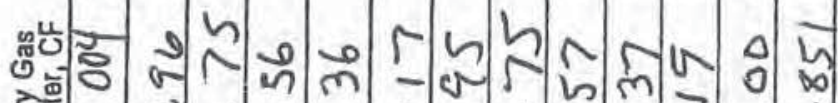

年

흔월

111

111 m

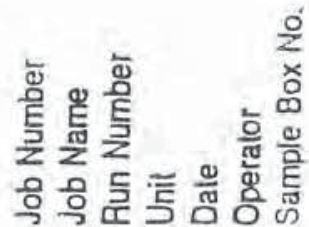

항를

올

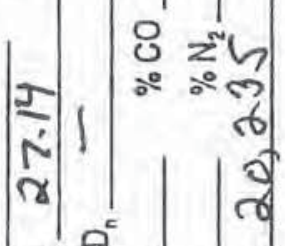

iे

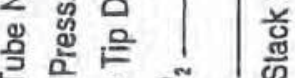

3 व

은 율

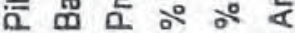


impinger Box No. $3-1$

Impinger 1

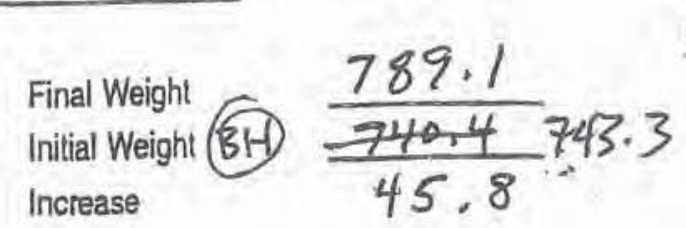

Water Weiahl Gain

Impinger 2

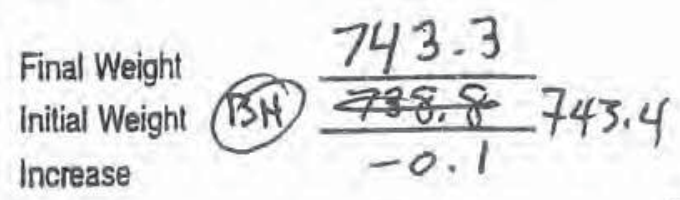

(B14) $\begin{aligned} \frac{745.5}{737.97} & \mathrm{v}_{w}= \\ \frac{\mathrm{SO}_{2}}{-0.1}= & =\end{aligned}$

Impinger 3

Final Weight

Initial Weight
Increase

impinger 145.8

Impinger $2-0.1$

Impinger $3-0,1$

Impinger 4

4.2

Impinger 5

Impinger 6

Impinger 4

Final Weight
$\begin{aligned} & \text { Initial Weight } \\ & \text { Increase }\end{aligned}$$\frac{913.0}{908.8}$

Impinger 7

Total

$\underline{49.8}=v_{n}$

Impinger 5

Final Weight

Initial Weight

Increase

$P_{b}=27.14 \mathrm{~L}$

$V_{m}=21.825$

$v_{w}=49.8 \mathrm{~V}$

$P_{m}=0.350$

Impinger 6

Final Weight

Avg $\triangle P=$

Initial Weight

Increase

$\operatorname{Avg} \sqrt{\Delta \mathrm{P}}=$

$c_{p}=\frac{-}{-13.4 V}$

$P_{0}=\frac{-13.4 V}{72} \mathrm{H}_{2} \mathrm{O}$

Impinger 7

Final Weight

Initial Weight

$T_{\mathrm{m}}=$

$72{ }^{\circ} \mathrm{F}$

Increase

$T_{\mathrm{s}}=$

- ${ }^{\circ} \mathrm{F}$

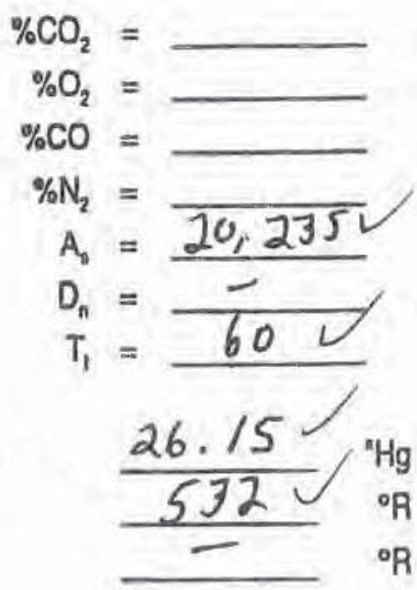

Moisture Content:

$$
\% M=10.68 / M_{0}=0.8932 / W_{c}=
$$

$M W=$

$$
V m_{s t d}=17.65 \mathrm{Vm}\left[\frac{P_{b}+\frac{P_{m}}{13.6}}{T_{m}+460}\right]=17.65 \times 21.825\left[\frac{27.14+\frac{0.350}{13.6}}{72+460}\right]=\frac{\frac{19.670}{0.328^{5}} \mathrm{sth}^{3}}{\mathrm{scm}}
$$

$V W_{\text {ow }}=0.0472 \times V w=0.0472 \times \frac{49.8}{\mathrm{stt}^{3}}$ $\%$ Moisture $=\frac{V W_{0 a 2}}{V m_{x+1}+V W_{023}} \times 100=\frac{2.351}{19.670+2.751} \times 100=10.68 \%$

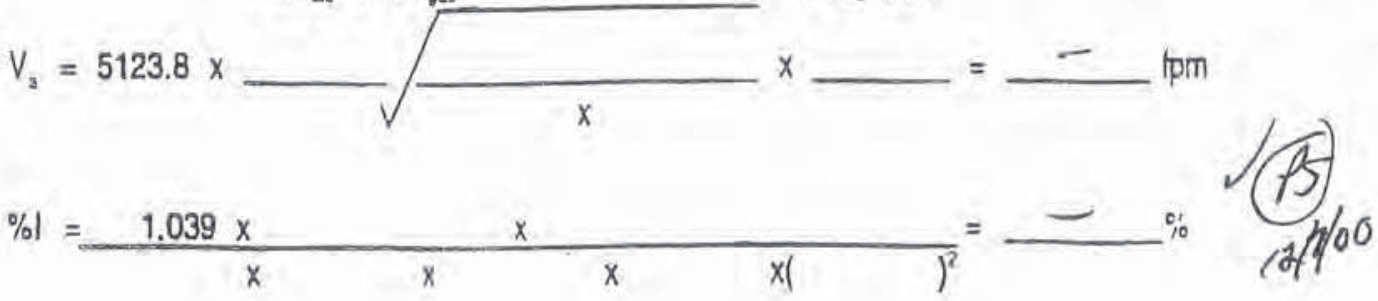

ACFM:

SCFM:

$\%$ EA: 
Job Number $06-057$

Job Name AOA ES (ARRDIN, $M T)$

Sampling Location INLET (SDA)

Date $11 / 28 / 06$ Time $0915-0940$

Port \& Inside Diameter (in.)

Port \& Wall Thickness (in.)

Inside Stack Diameter (in.)

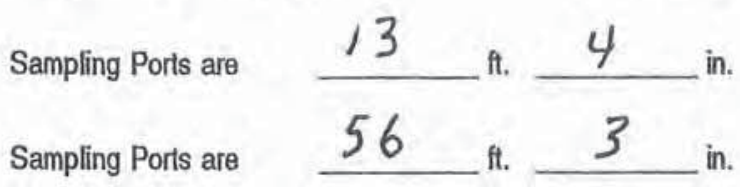

$\frac{\frac{\text { Port A }}{160.75}}{\frac{18.50}{142.25}} \quad \frac{\frac{\text { Port B }}{160.75}}{\frac{18.50}{142.25}} \quad \frac{\frac{160.75}{18.50}}{\frac{142.75}{14.25}}$

EQ.DUCT stack diameters) downstream from disfurbance (inlet, constriction, bend, expansion)

4.75 ER. QucT biack diameters) upstream from disturbance

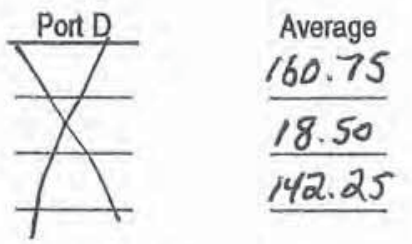
(outlet, constriction, bend, expansion)

\begin{tabular}{|c|c|c|c|c|c|c|c|}
\hline $\begin{array}{l}\text { Point } \\
\text { Number }\end{array}$ & $\begin{array}{c}\text { Percent } \\
\text { Diameter }\end{array}$ & $\begin{array}{c}\text { Distance from } \\
\text { Ref. Point } \\
\text { (decimal in.) }\end{array}$ & $\begin{array}{l}\text { Distance from } \\
\text { Ref. Point } \\
\text { (fractional in.) }\end{array}$ & $\mathrm{G}_{\Delta \mathrm{P} / \mathrm{f} / \alpha}^{\text {Port A }}$ & $\begin{array}{l}\text { Port B } \\
\Delta \mathrm{P} / \mathrm{d} / \alpha\end{array}$ & $\begin{array}{c}\text { Port C } \\
\Delta \mathrm{P} / \mathrm{s} / \alpha\end{array}$ & $\begin{array}{l}\text { Porl D } \\
\lambda P T_{s} / q\end{array}$ \\
\hline 1 & & & $77 / 8^{\prime \prime}$ & 0.813090 & $0.41,304,5$ & $0.38,307,7$ & $1 / 1$ \\
\hline 2 & & & $23 / 1 / 16^{\prime \prime}$ & $0.42,30110$ & $0.55,309,0$ & 0.49131015 & $\sqrt{\lambda}$ \\
\hline 3 & & & $391 / 2 "$ & $0.49 \beta 090$ & $0.59,310,2$ & 0.5613195 & 1 \\
\hline 4 & & & $555 / 16^{\prime \prime}$ & $0.51 / 31015$ & $0.63,310,0$ & $0.55,3080$ & 11 \\
\hline 5 & & & & 11 & 11 & 11 & -11 \\
\hline 6 & & & & 11 & 11 & 11 & 11 \\
\hline 7 & & & & 11 & 11 & 11 & 11 \\
\hline 8 & & & & 11 & 11 & 11 & 1 \\
\hline 9 & & & & 11 & 11 & 11 & 1 \\
\hline 10 & & & & 11 & 11 & 11 & 1 \\
\hline 11 & & & & 11 & 11 & 11 & 1 \\
\hline 12 & & & & 11 & 11 & 11 & 11 \\
\hline 13 & & & & 11 & 11 & 11 & 11 \\
\hline 14 & & & & 11 & 11 & 11 & 11 \\
\hline 15 & & & & 11 & 11 & 11 & 11 \\
\hline 16 & & & & 11 & 11 & 11 & 11 \\
\hline 17 & & & & 11 & 11 & 11 & 11 \\
\hline 18 & & & & 11 & $1 \mathrm{~W}$ & 11 & 11 \\
\hline 19 & & & & 11 & 11 & 11 & 11 \\
\hline 20 & & & & 11 & 11 & 11 & 11 \\
\hline 21 & & & & 1 & 11 & 11 & 11 \\
\hline 22 & & & & 1 & 1 & 1 & 1 \\
\hline 23 & & & & 1 & 1 & 1 & 1 \\
\hline 24 & & & & 11 & 1 & 1 & 1 \\
\hline
\end{tabular}

Pitol Tube No. $-3-3$

$$
\begin{aligned}
& \mathrm{C}_{\mathrm{p}}=\frac{0.823}{\mathrm{P}_{\mathrm{b}}=26.99} \\
& \mathrm{P}_{\mathrm{B}}= \\
& \mathrm{A}_{\mathrm{s}}=20,235 \mathrm{in.}^{2}
\end{aligned}
$$

Average $\triangle \mathrm{P} \quad 0.533$

Average $\Delta P^{12} 0.726$

Average $T_{x} \quad 309{ }^{\circ} \mathrm{F}$

Average $\alpha \quad 2,4 \quad$ degrees 

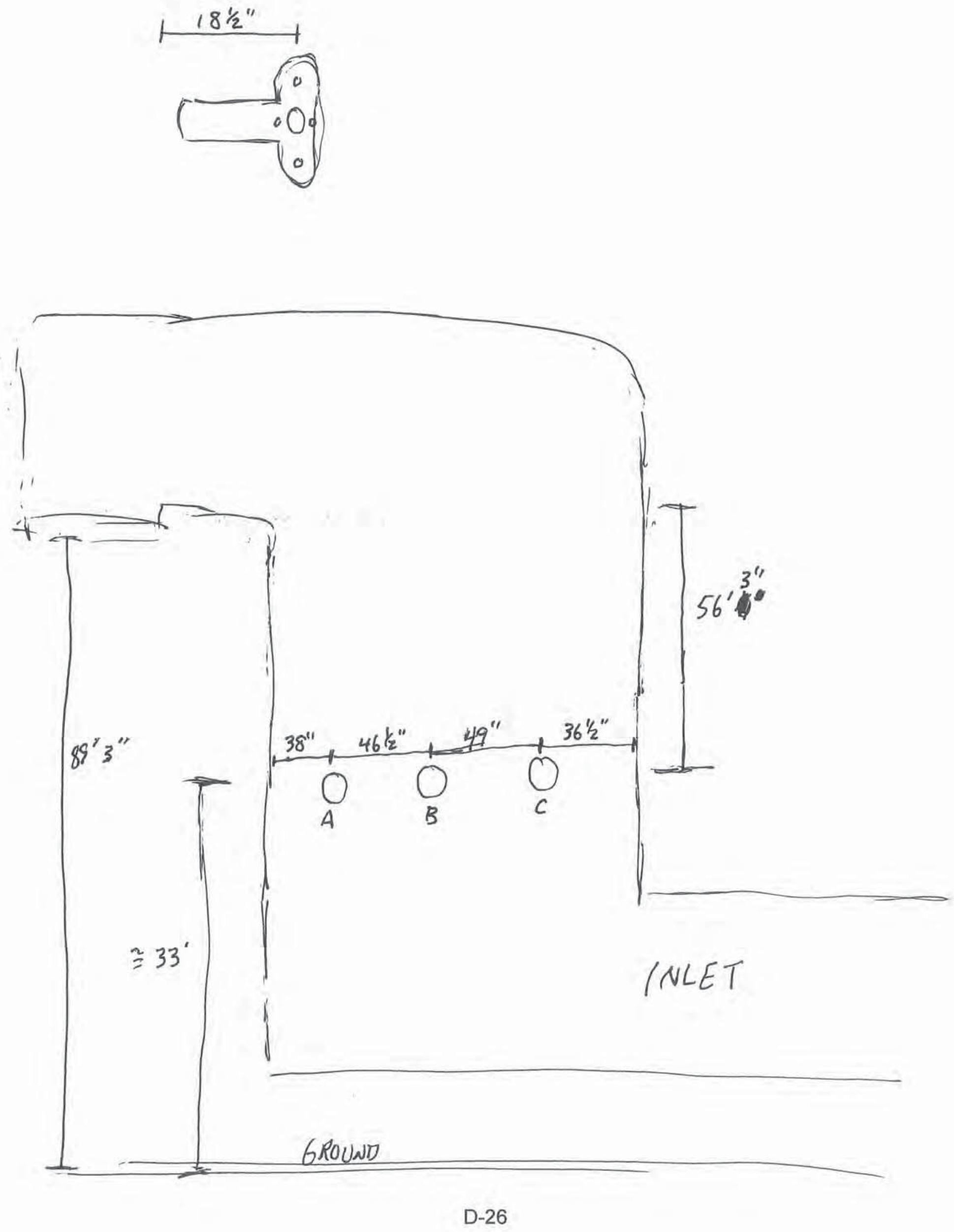
(1)

(4) $10 \%$

늘

등. 흥 ज्ञ

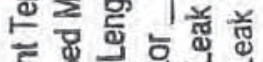

产兵要票

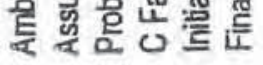

M 1 문몬

o o.
들
₹ 원 몸

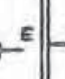

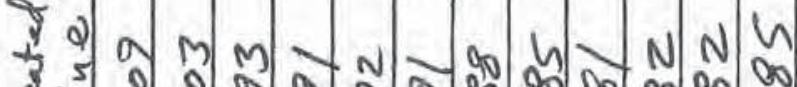

\pm .5 ก

N 1. o. a

$\infty 000$ 이

范。

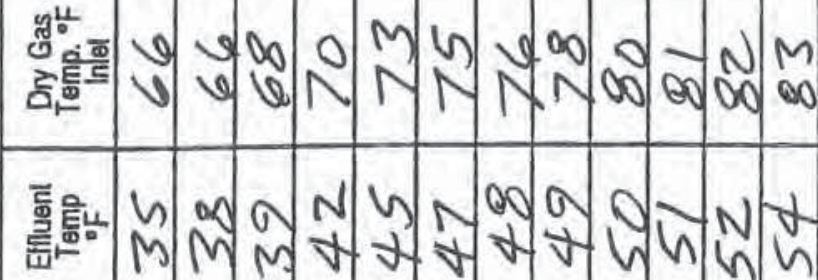

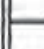

容虽 $\infty$

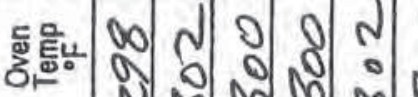

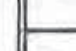

옹르 $\zeta$ 근

A

an

h $D$

0

은.

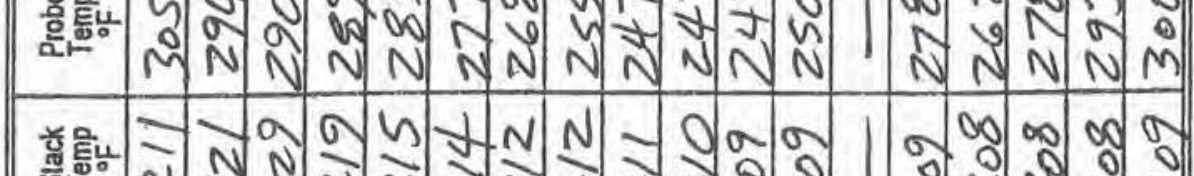
क $N$ N N N N N N N N N NNNNN

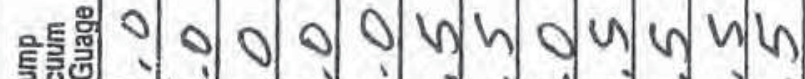
迎

0020

$\left.\Delta\right|^{3}>>D$

$a^{\mathrm{E}}$

ही

乐

$\sqrt{1}$

hy 47.

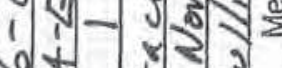

०ै मै जले

1

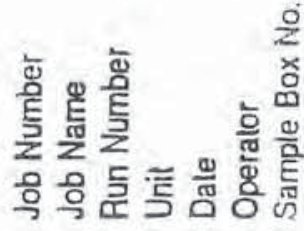

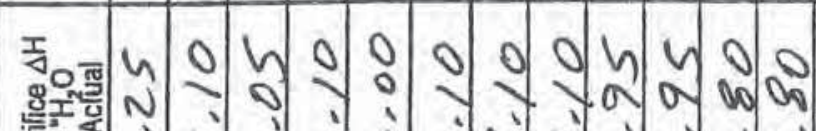
능 N

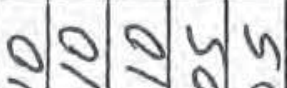
N. 00 N N N N Ni

ร。 ow do donwo o o o dwh

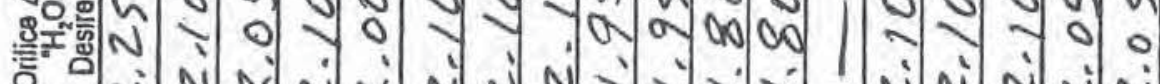
- N N N N N N N V.

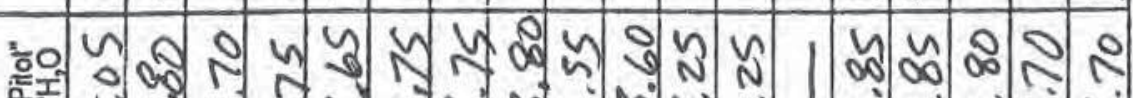

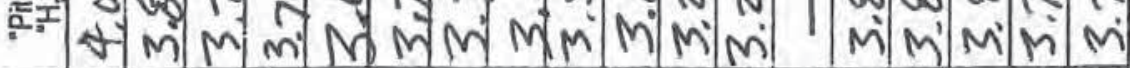

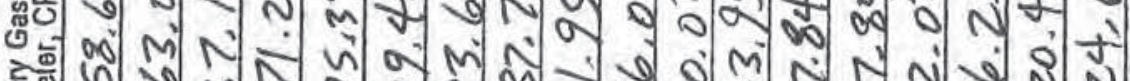
टें

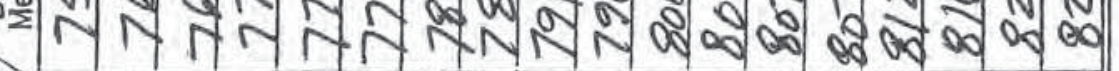

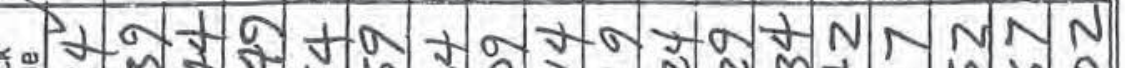
․․

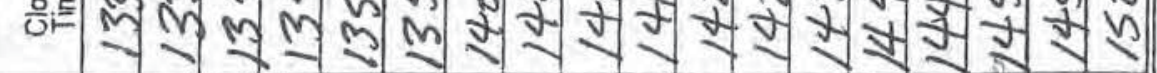

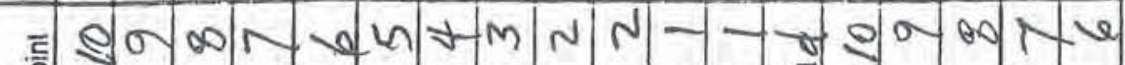
을

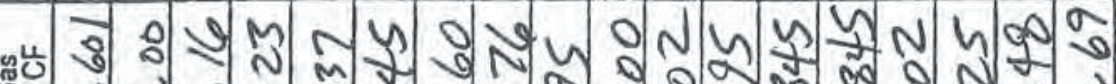

ฟ.

$\overline{\bar{E}}$

20 要

$y x$ 永

2 $y x$

0 o c 而

क्ष

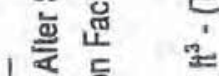

gั

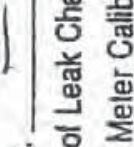

울

之哭步

흘 要

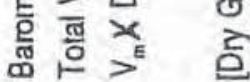

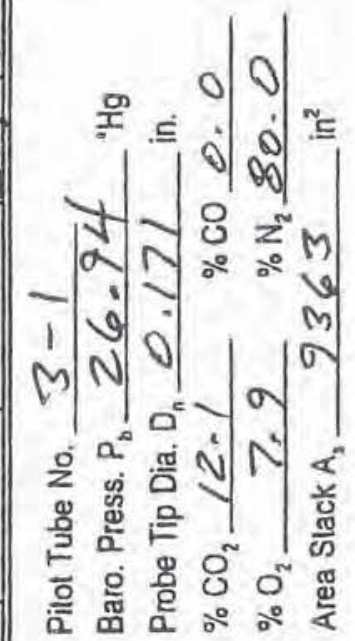

$M \quad \bar{E} \cdot \overline{O^{2}}$

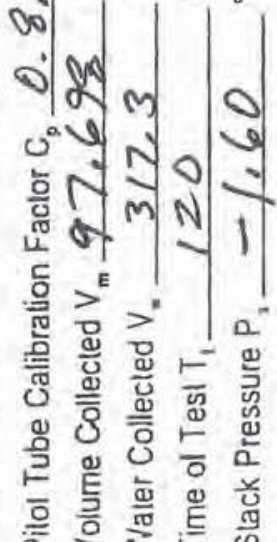


Impinger Box No. ASAI - 1-1

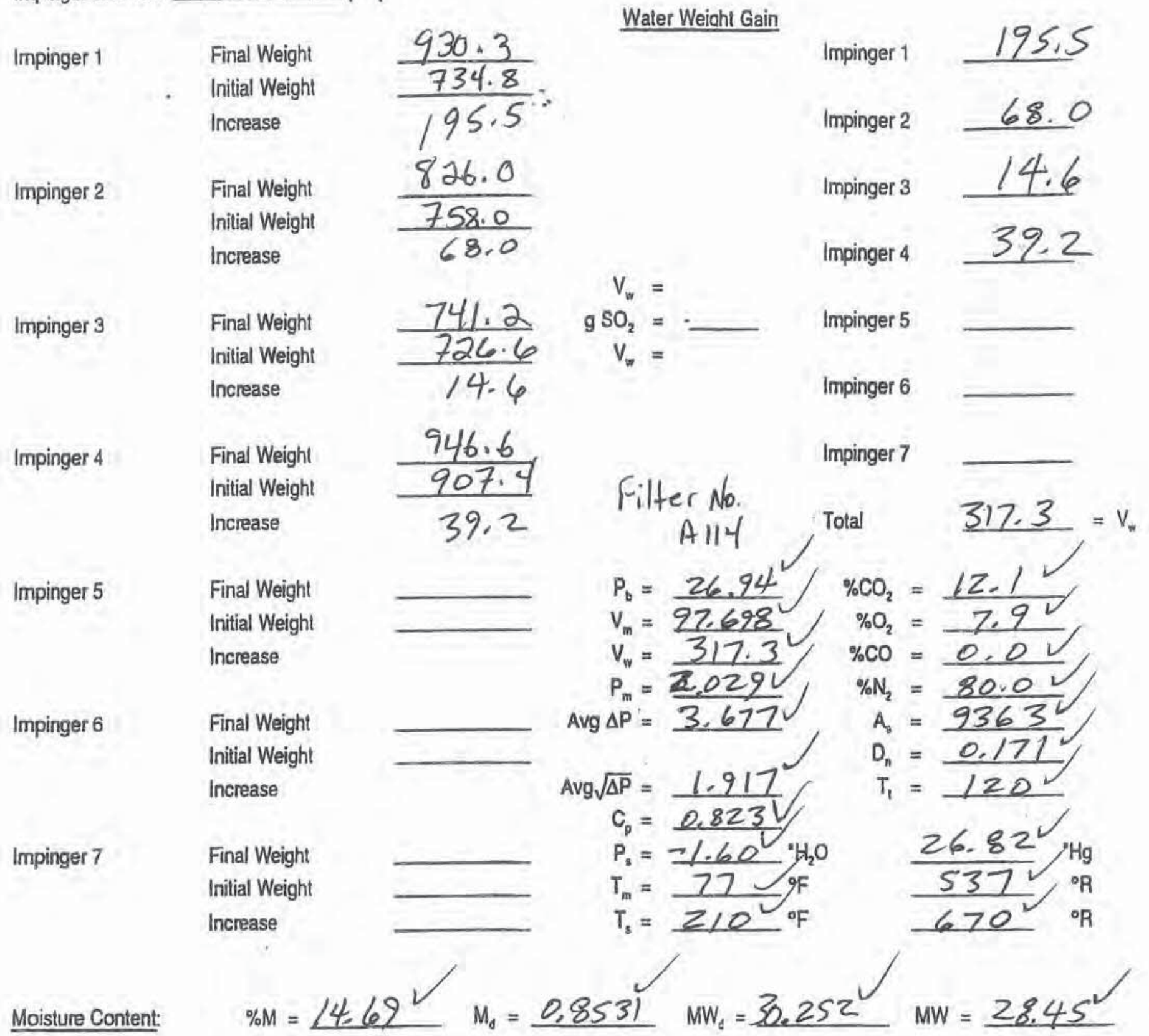

$$
V m_{s t d}=17.65 \mathrm{Vm}\left[\frac{P_{b}+\frac{P_{m}}{13.6}}{T_{m}+460}\right]=17.65 \times 97.698\left[\frac{26.94+\frac{2.029}{13.6}}{77+460}\right]=\frac{86.987}{0.725} \mathrm{sth}^{3}
$$

$\mathrm{VW}_{\mathrm{ges}}=0.0472 \times \mathrm{VW}=0.0472 \times 317.3=14.977 \mathrm{~s}=\mathrm{st}^{3}$ $\%$ Moisture $=\frac{V_{W_{a s}}}{V m_{x+1}+V_{W_{9 a}}} \times 100=\frac{14.977}{86.987}+100=\frac{14.69}{6} \%$

$v_{s}=5123.8 \times \frac{0.823}{\frac{670}{26.82 \times 28.45}} \times 1.917=7575 \mathrm{pm}$

$\%=\frac{1.039 \times 86.987 \times 670}{0.8531 \times 26.82 \times 7575 \times 120 \times(0.171)^{2}}=99.6 \%$
ACFM: $492,531^{2}$

SCFM: 297,911 \%EA: $59,4^{2}$ 

जो वै

M 192

M) ज. ज" o̊a

$\because$ 造

등ㅎㅇ

政

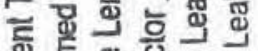

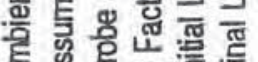

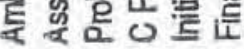

$\vdash$

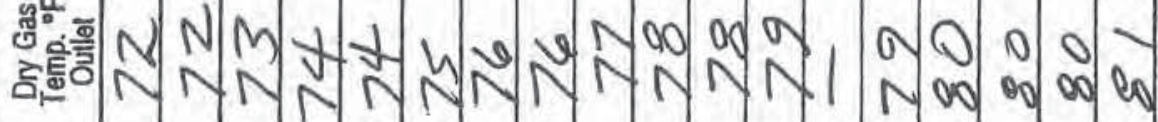

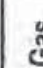

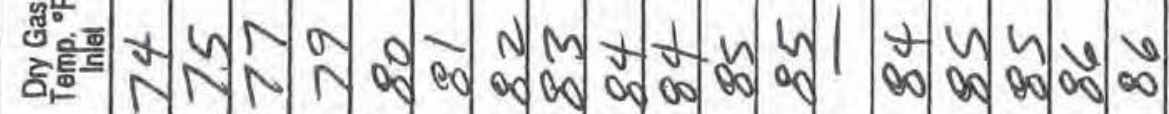

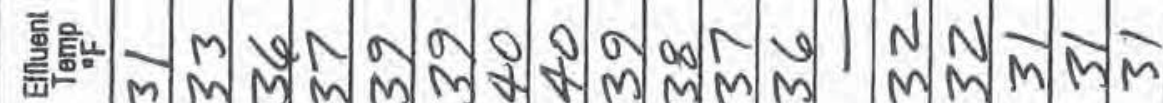

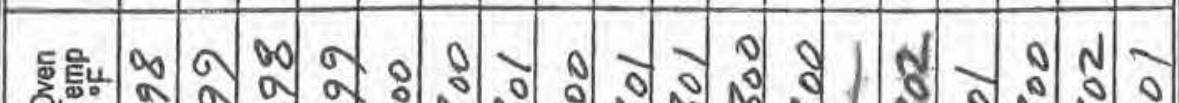

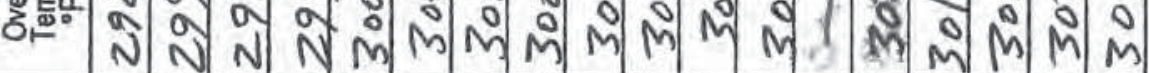

$\phi$ ल

䒼 ㅎํㄴ

훈

13

1 (

$\forall$ 능

N

ف를

学

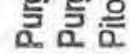

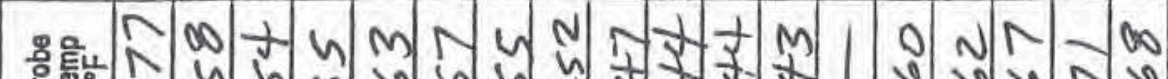

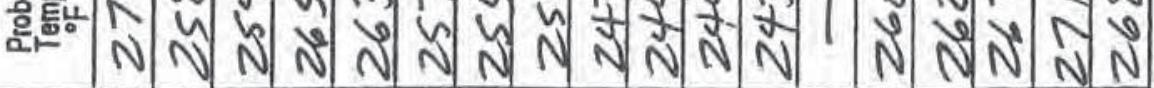

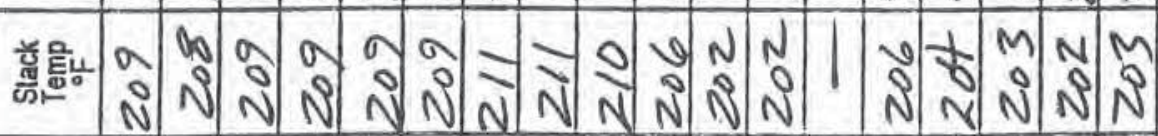

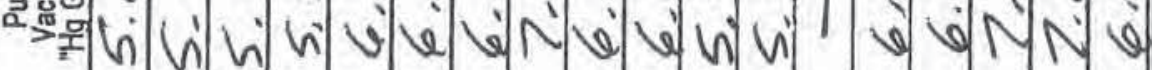

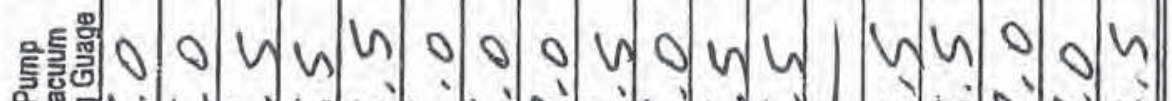

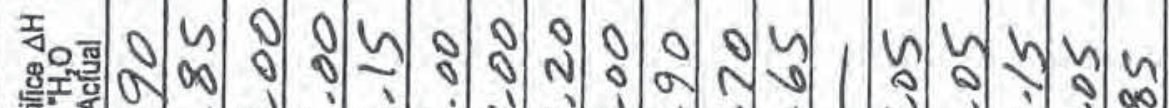

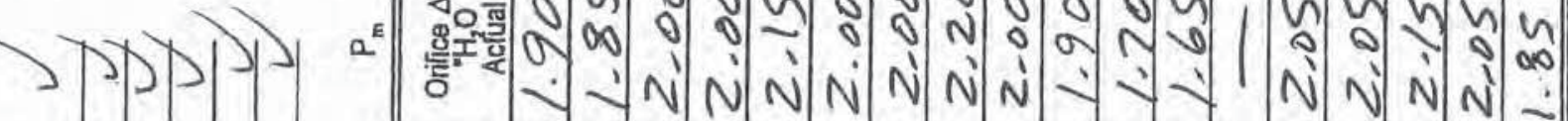

2103

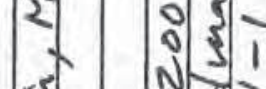

- $\frac{1}{2} \sqrt{2}$

$N=\frac{1}{4}$,

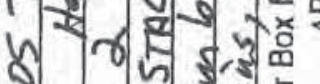

14 的

वै. 4 (3)

वर

सै

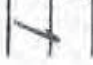

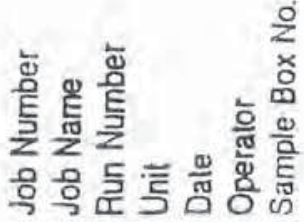

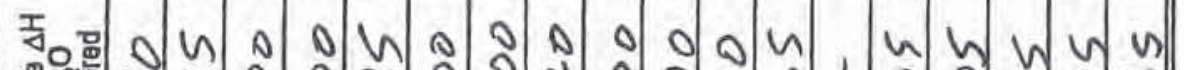

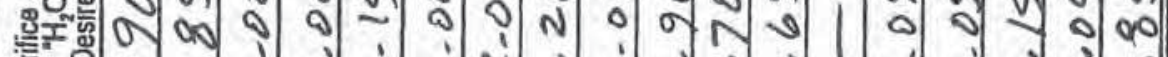

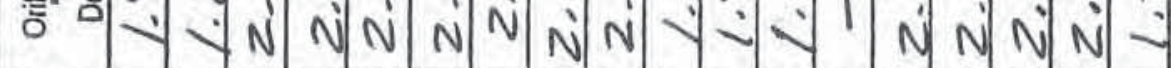

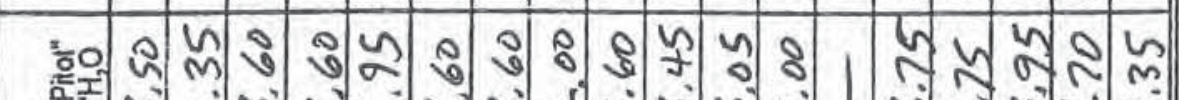
: M/M MM M

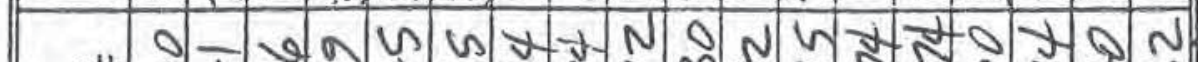
留 टक्षे

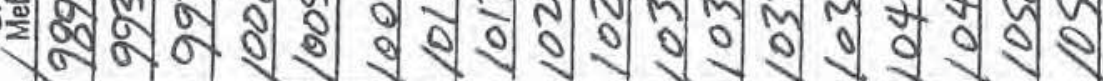
मेन + + ta

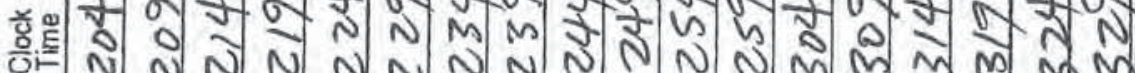
o $N$ N $N$ N $N N N N N M M M M M$

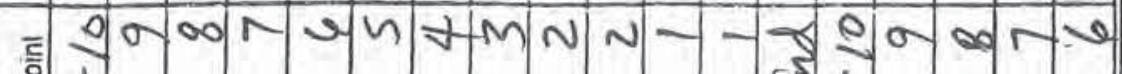

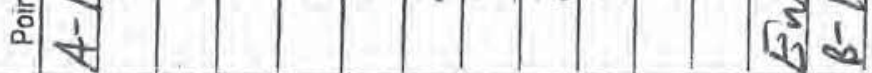

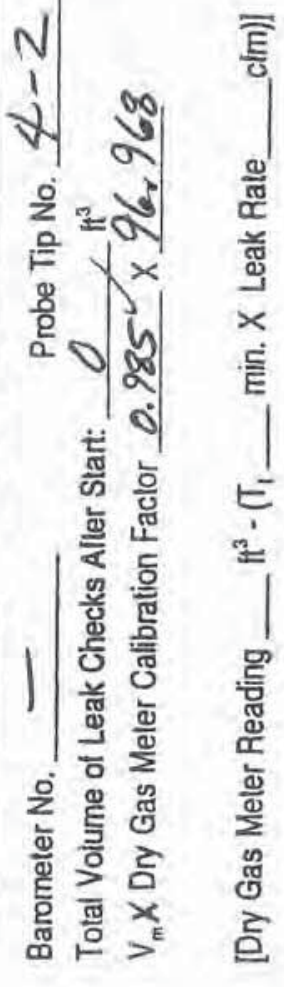

온. 5 od ad :

$\infty N \underset{0}{0}: \frac{z^{2}}{\circ} M$

m $\mathrm{N}$ वे। लै

$M N D_{0}=0$

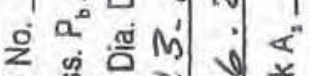

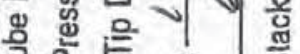

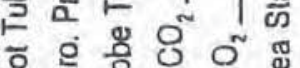

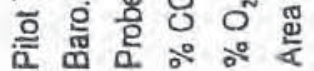

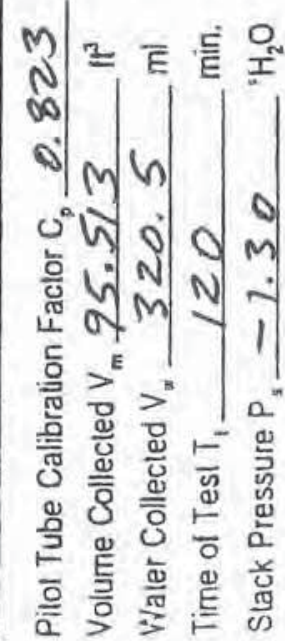




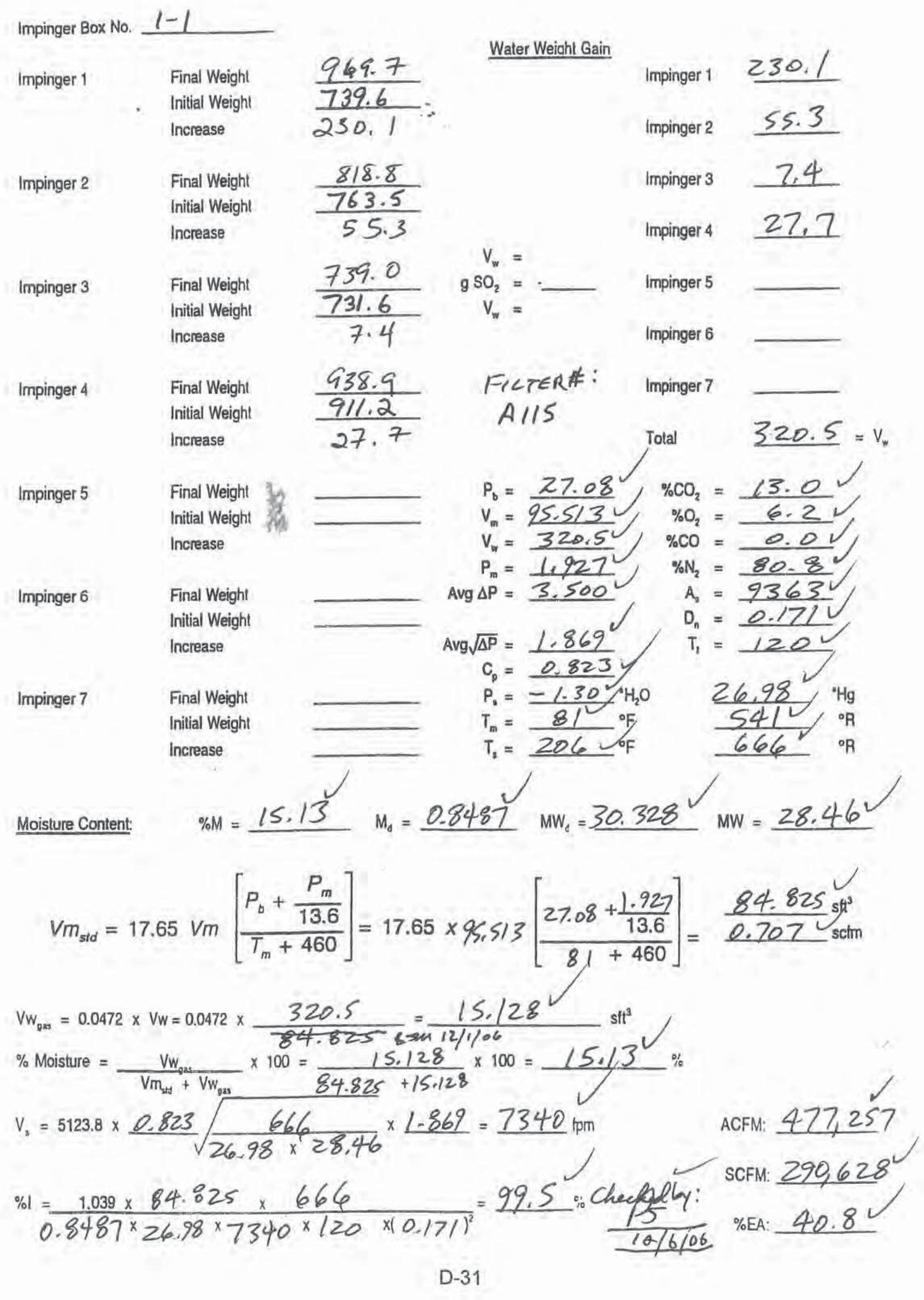




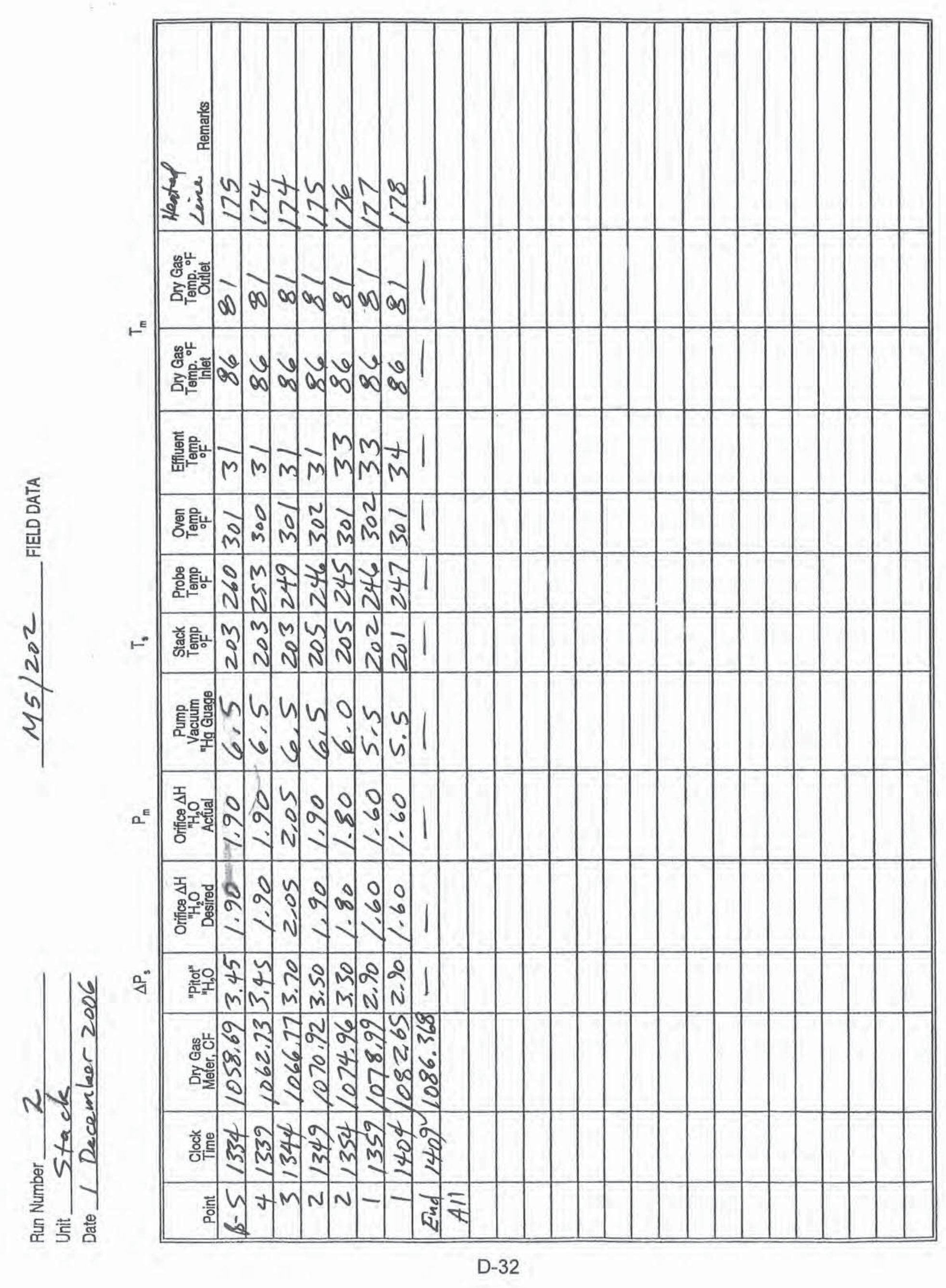




\section{X}

$\stackrel{E}{E} \frac{E}{0}$

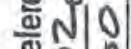

ำ

$\sqrt{10}$

3). $\quad$.

Non wow

$\because \frac{0}{2} \operatorname{vin}$

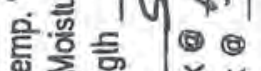

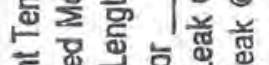

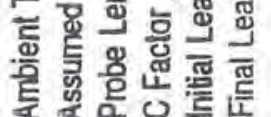
$\vdash$

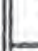

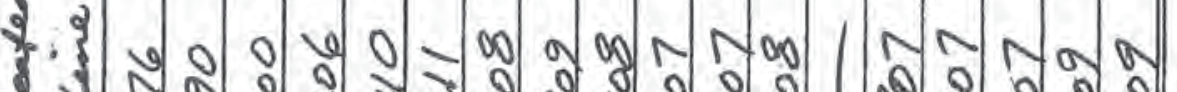

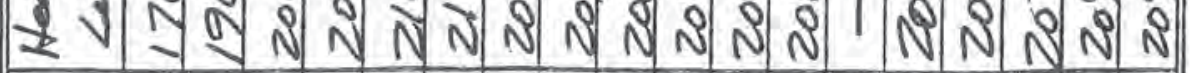

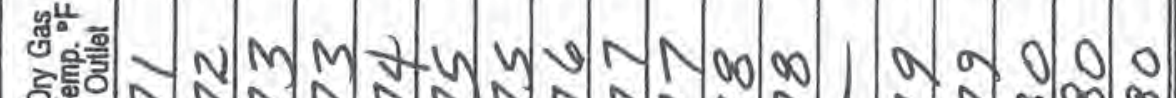

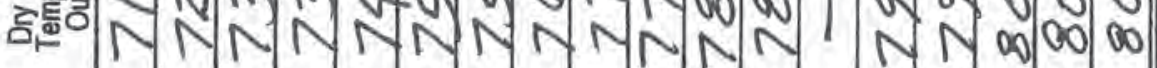

\%

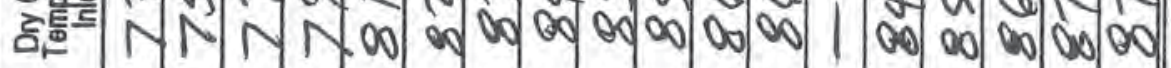

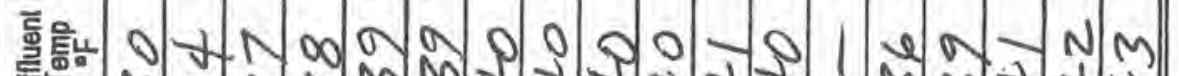

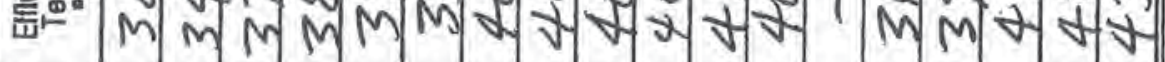

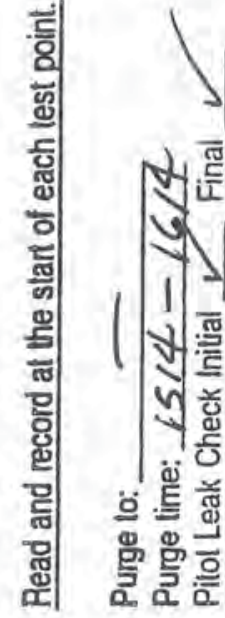

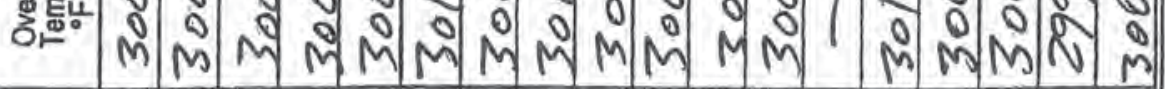

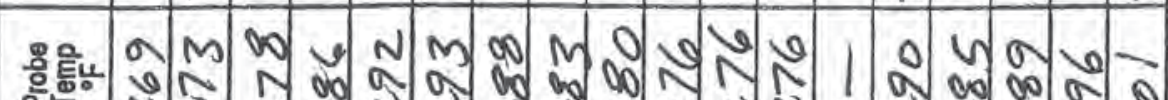
은 $N$ N N N N N N N N N N N N N N

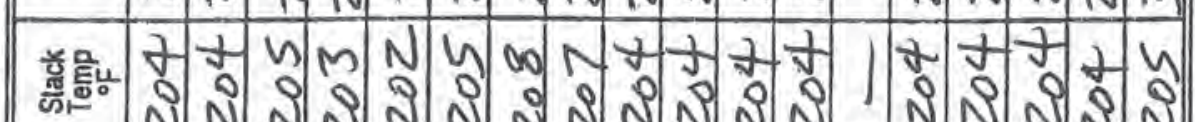
क⿻

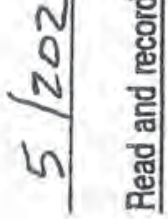

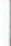

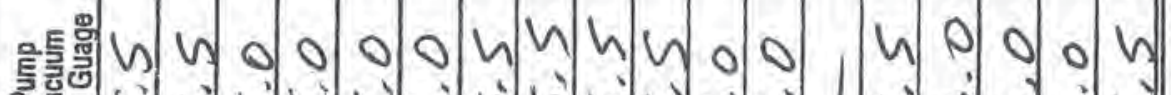
$\Rightarrow$ क्षे Wh

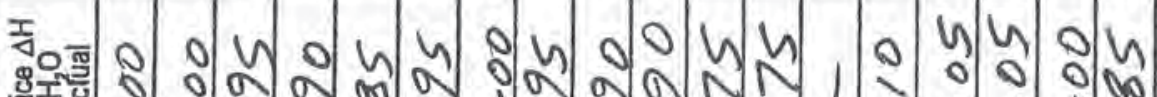

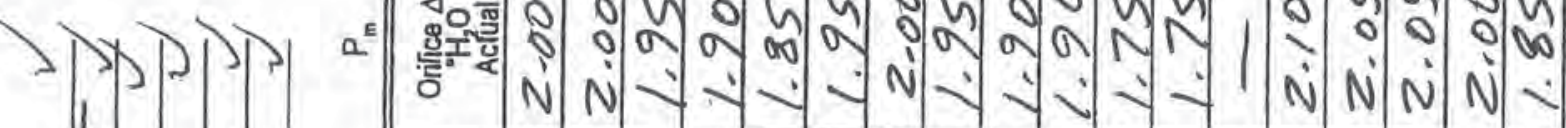

से 인

Ny +3 , 014 y 3 , s. $14 m+\sqrt{2})^{\frac{2}{2}}$ (4) $n$ 23

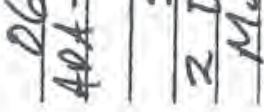

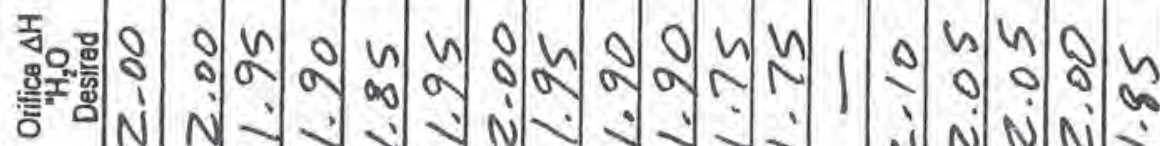

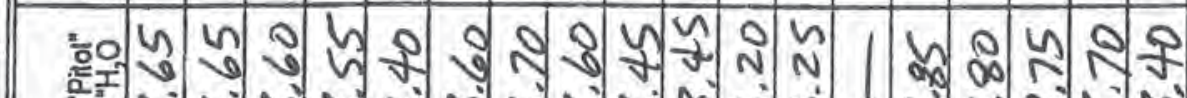

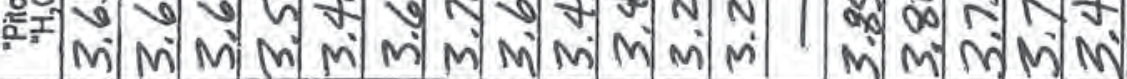

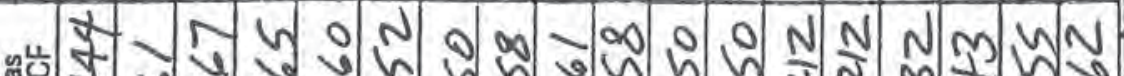
आँ

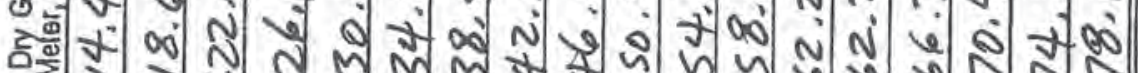

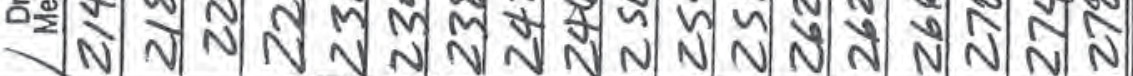
ㄴ

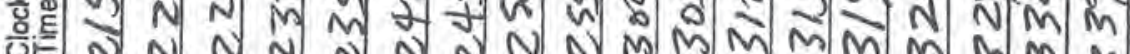

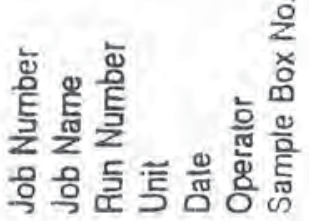

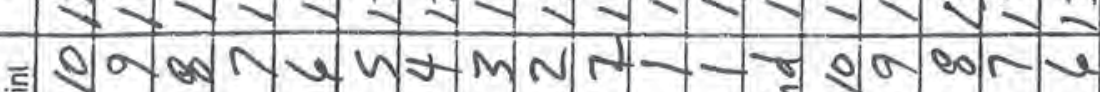
aे परा प⿺辶冋

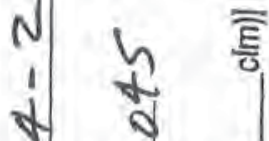

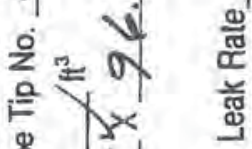
8 w O

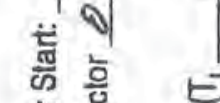
旁悹 部哭 㤠 वे व टं क्ष

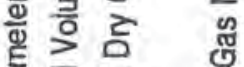

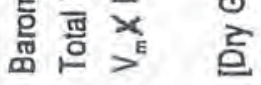
(1)

$N=E$ E of 0370 m ํำ $N$ t 近的

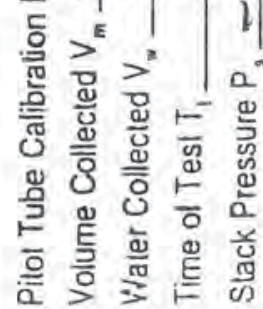




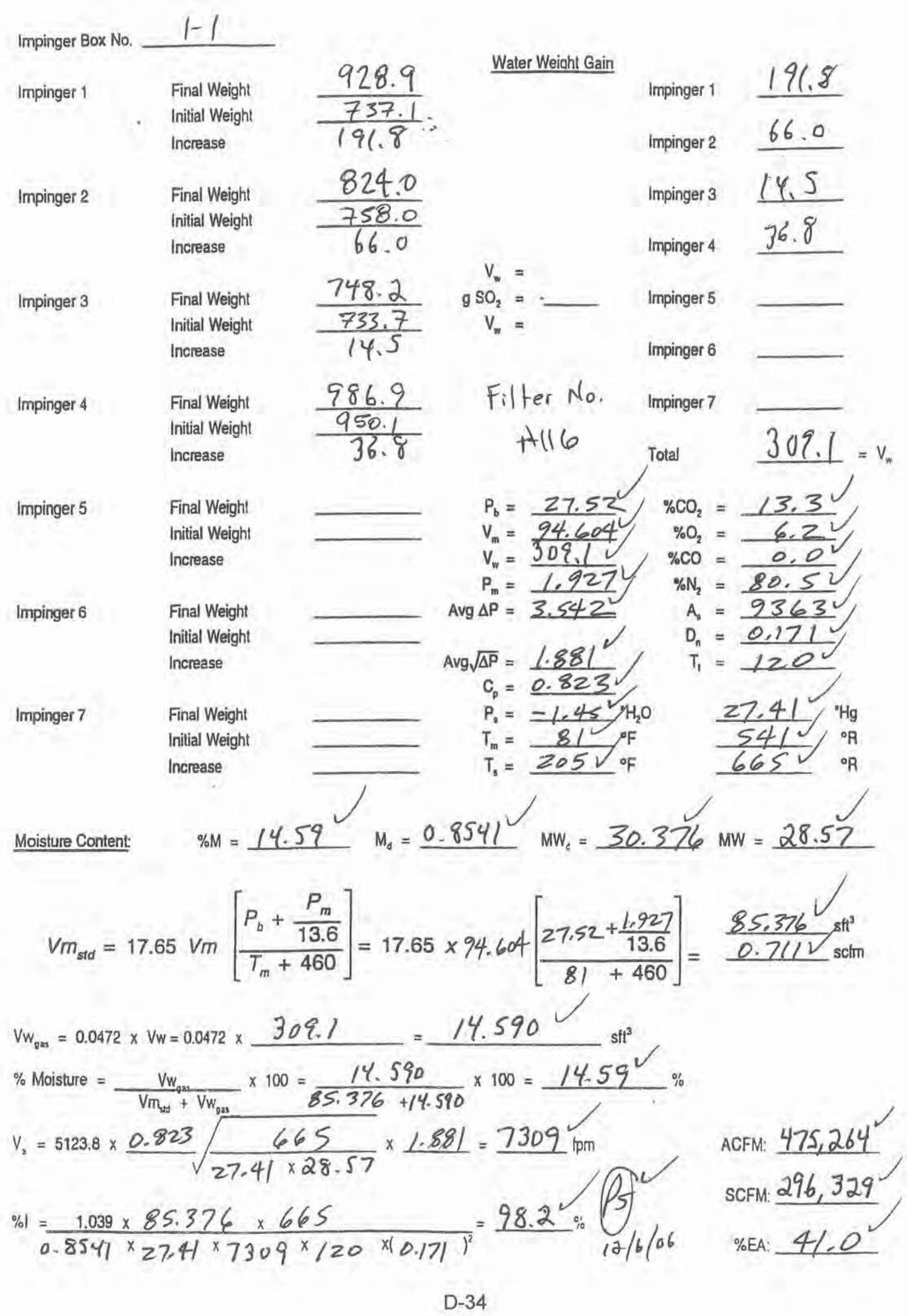




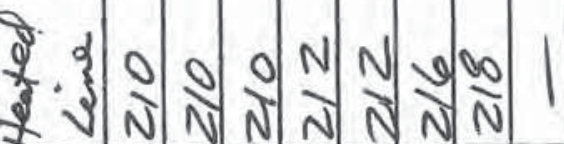

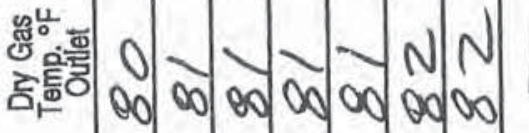

$\vdash^{E}$

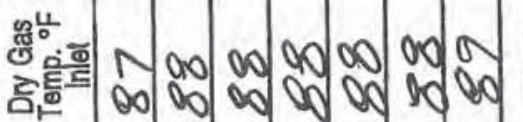

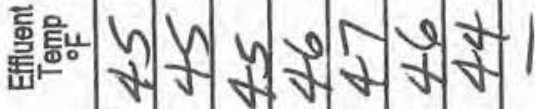

产

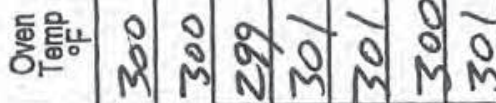

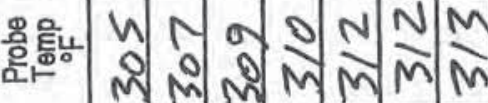

$N$

,

n

1- 酸言落

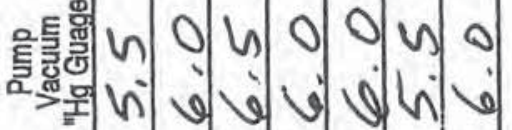

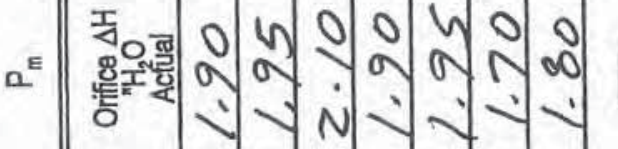

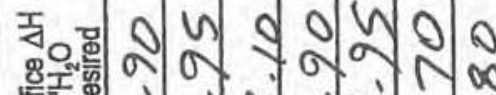

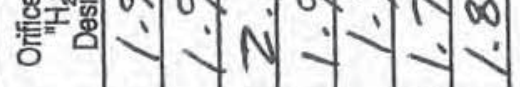

|

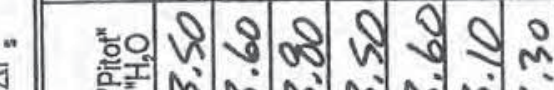

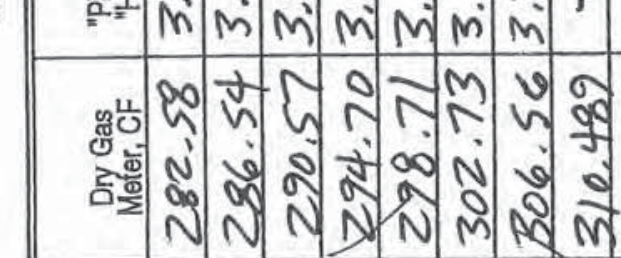

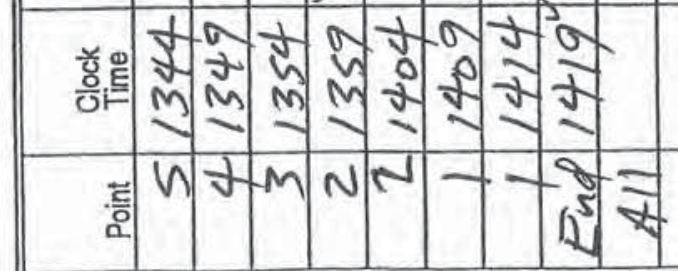


M 1 ㅇำ

Ní बึ่c

Ny 모옹

\%० Wo

u g

뭍휴을

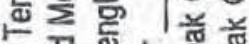

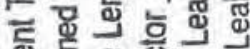

들 号焉

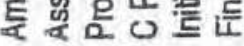
E

\%

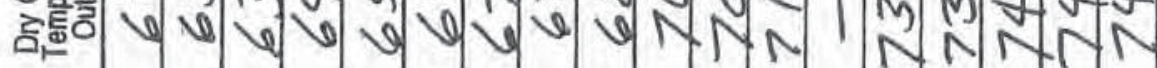

骂范

H

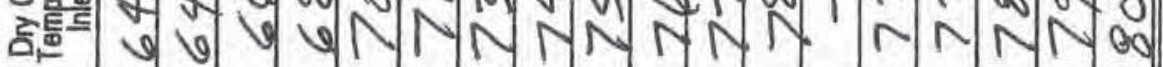

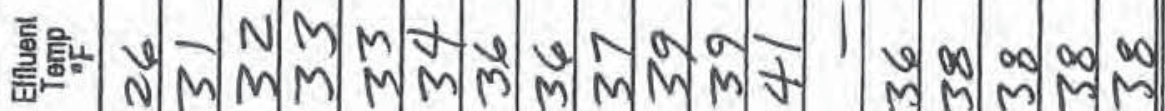

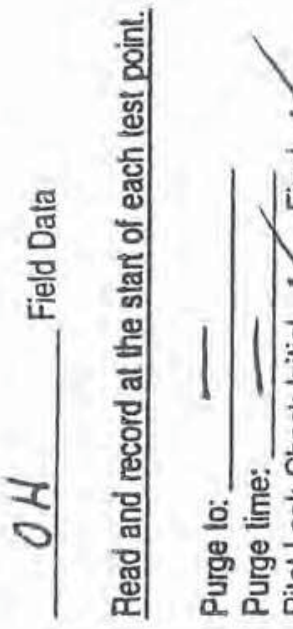

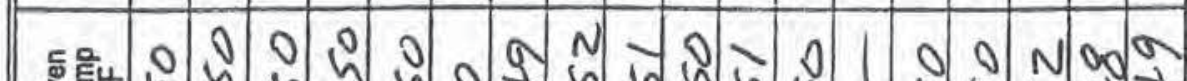

ठิ.

ल

ma

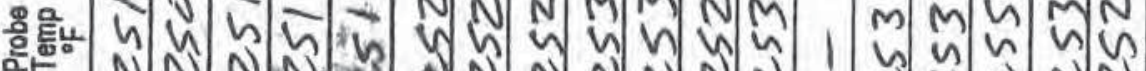

(

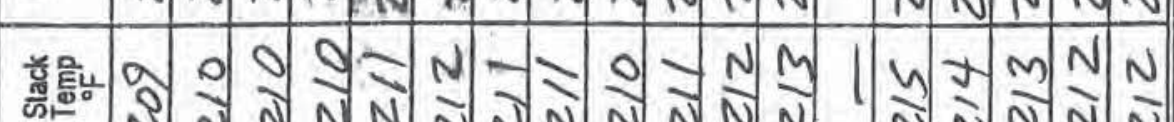
का $N$ N NN NNNNNNN N NNN N

西

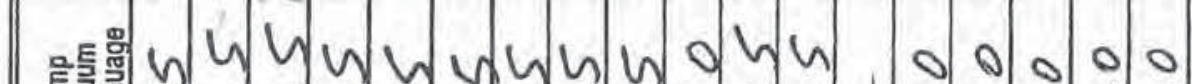

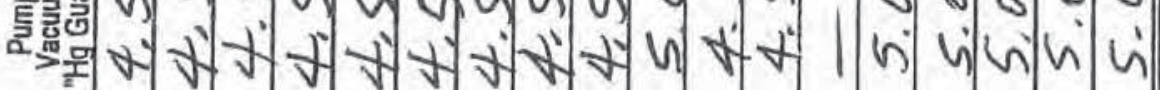

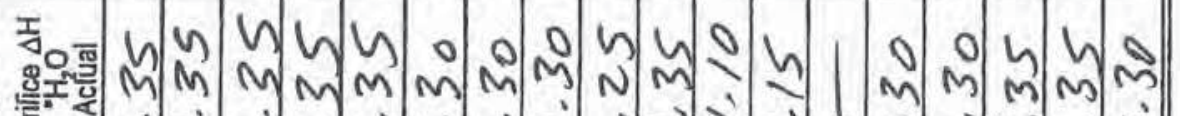

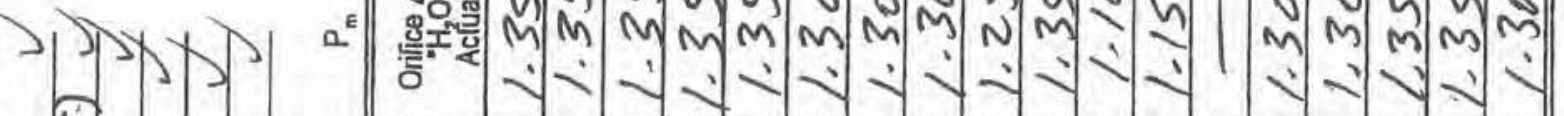

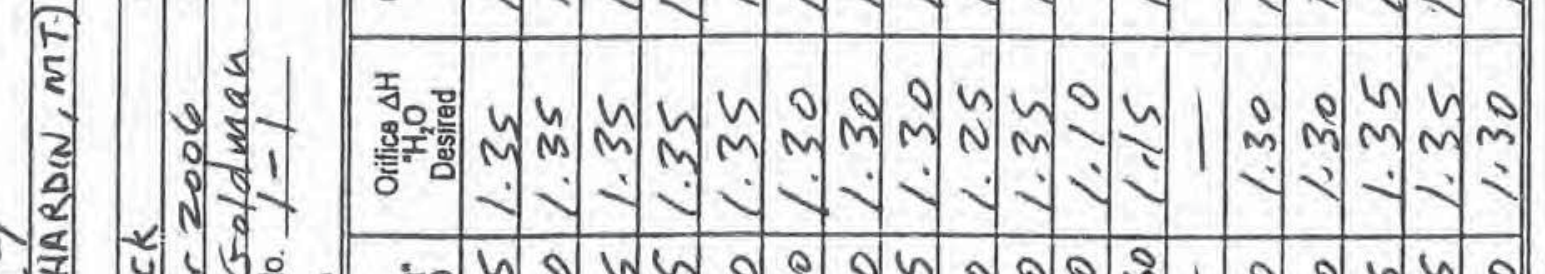

Non

, wh $\rightarrow$, w

○)

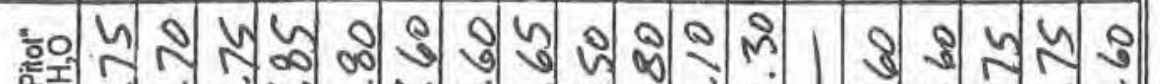

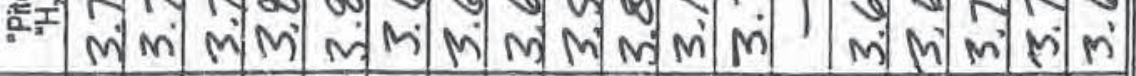

में

क्ष

A3

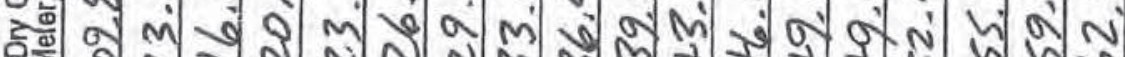
ช: ने न N N N M

$\sum^{1}$

क菩

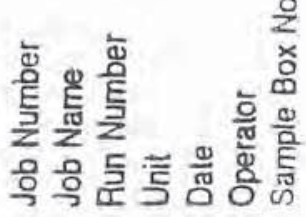

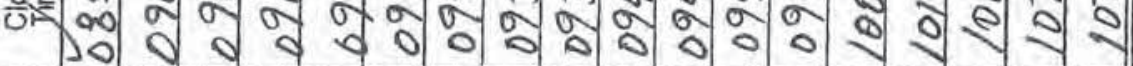

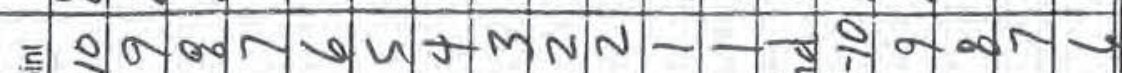

वे

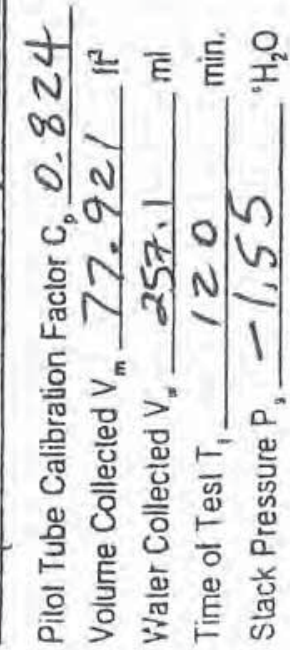


Impinger Box No. $m-3$

Impinger 1

Impinger 2

Impinger 3

Impinger 4

Impinger 5

Impinger 6

Impinger 7

Moisture Content:
Water Weight Gain

$\frac{943.6}{738.6}$

Imp .8 942.3

Impinger $2 \quad 30.0$

$\frac{-945.1}{17.2}$

$\begin{array}{ll}\text { Impinger } 3 & 4.3 \\ \text { Impinger } 4 \quad 1.7\end{array}$

$V_{w}=$

$\frac{75 \% .9}{\frac{750.6}{4.3}}$

$\mathrm{gSO}_{2}=$.

Impinger $5 \quad-0.4$

$\mathrm{V}_{\mathrm{w}}=$

Impinger $6-0.6$

FILTER 4: $\quad \frac{\text { Impinger 7 }}{\text { Impinger } 8} \frac{-0.1}{17.2}$

A 117

Total

$257.1=v_{w}$

$P_{b}=27.05$

$\% \mathrm{CO}_{2}=12.8$

$v_{m}=72.921, \quad \% 0_{2}=6.2$

$v_{w}=\frac{257.1}{294} \quad \% \mathrm{CO}=\frac{0.0 \mathrm{~V}}{81.0}$

$P_{m}=\frac{1.294}{3.606} \quad \% N_{2}=\frac{81.0}{9363}$

$A_{0}=9363 i$

$D_{n}=\frac{0.154}{120}$

Increase $\frac{74.2}{-0.6}$

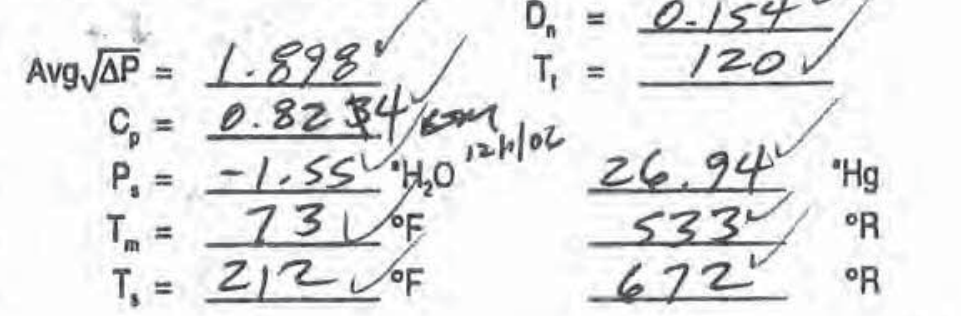

$\begin{array}{ll}\text { Final Weight } & \frac{741.5}{741.6} \\ \text { Initial Weight } & \frac{-0.1}{\text { Increase }}\end{array}$

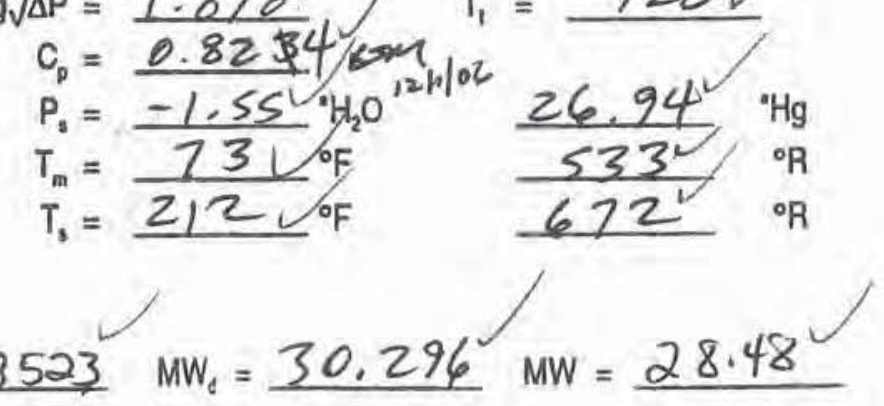

$$
\begin{aligned}
& V m_{s t d}=17.65 \mathrm{Vm}\left[\frac{P_{b}+\frac{P_{m}}{13.6}}{T_{m}+460}\right]=17.65 \times 77.921\left[\frac{27.05+\frac{1.294}{13.6}}{73+460}\right]=\frac{70.043}{0.584 \mathrm{sth}^{3}} \mathrm{scm}^{2}
\end{aligned}
$$

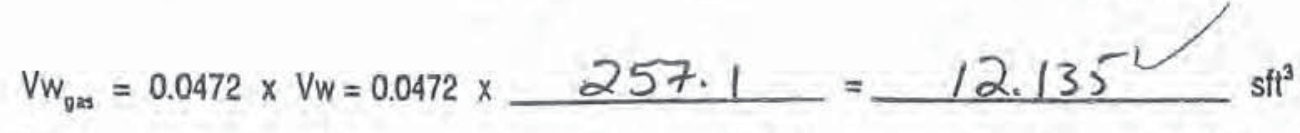

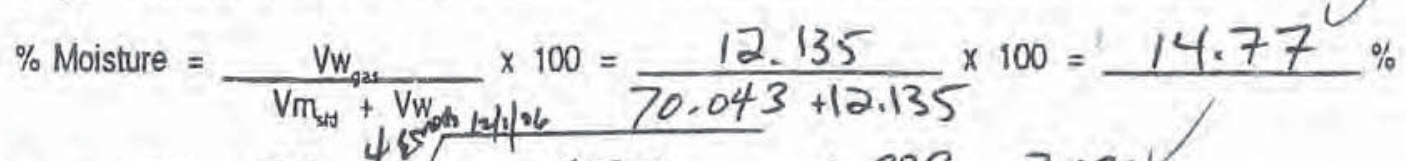

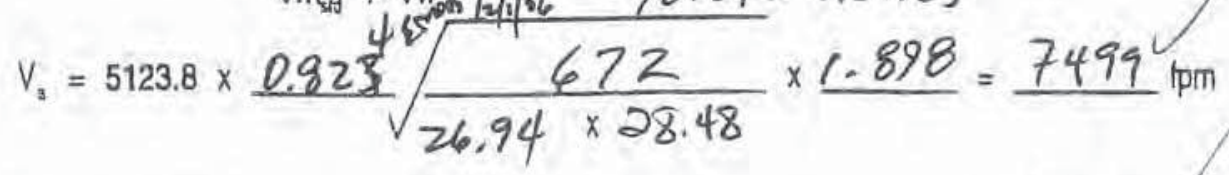

$$
\begin{aligned}
& \% 1=\frac{1.039 \times 70.043 \times 672}{0.8523 \times 26.94 \times 7495 \times 120 \times(0.154)^{2}}=
\end{aligned}
$$

D-38 


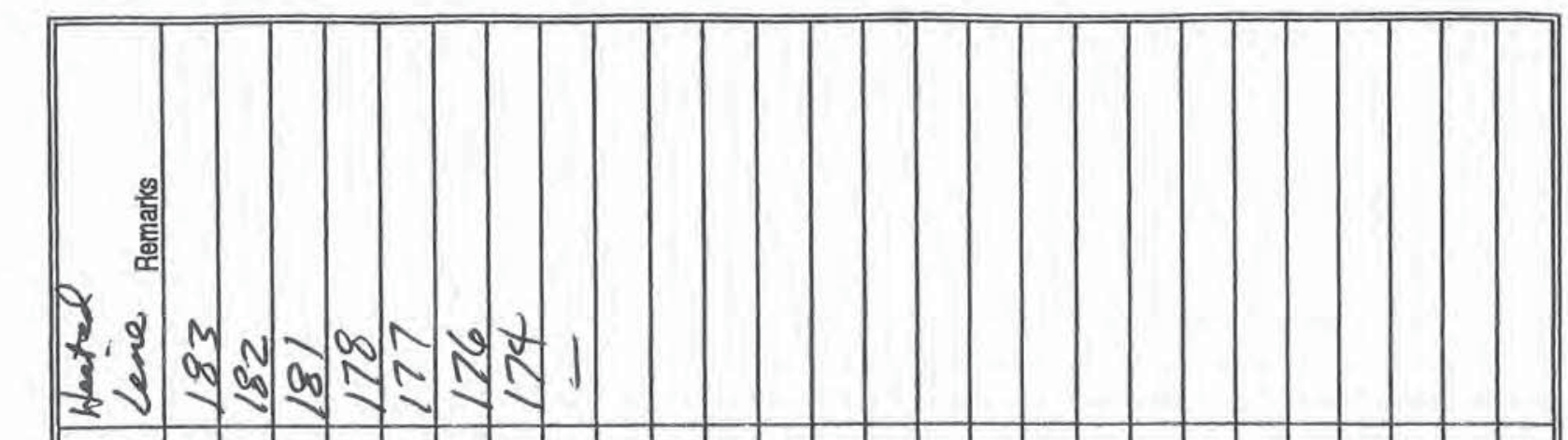

衣

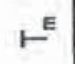$$
\text { 究空 }
$$

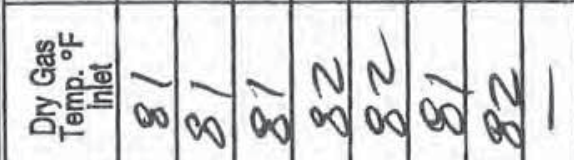

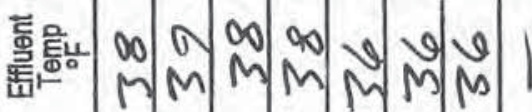

ठั.

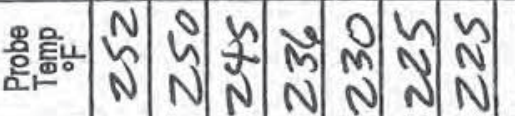

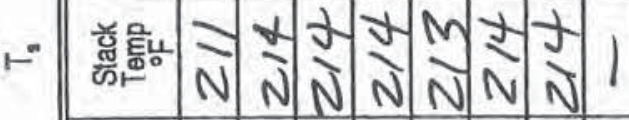

号嵒O OW O 0000

害踏

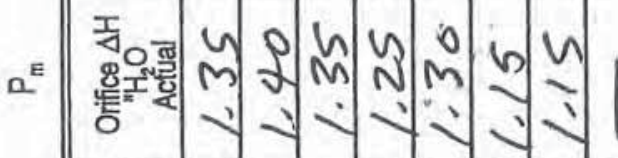

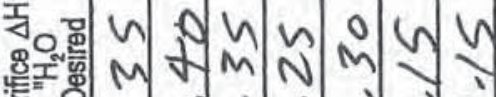

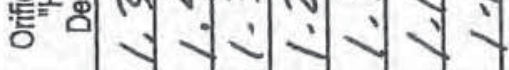

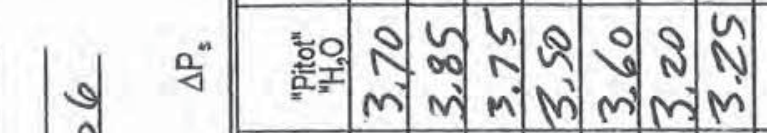

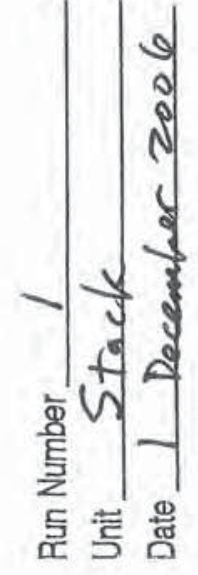

\begin{tabular}{|c|c|c|c|c|c|c|c|c|}
\hline 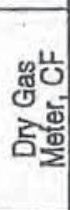 & an & $\begin{array}{l}\text { N } \\
\text { ने } \\
\text { न }\end{array}$ & $\sqrt{n}$ & $\begin{array}{l}\sqrt{0} \\
\text { v' } \\
\sigma\end{array}$ & $\stackrel{n}{m}$ & $\begin{array}{l}\text { } \\
\text { No } \\
\text { an }\end{array}$ & $\begin{array}{l}\infty \\
w \\
\infty\end{array}$ & $\begin{array}{l}N \\
D \\
\infty \\
\infty\end{array}$ \\
\hline 응트 & $m^{2}$ & $\begin{array}{l}h \\
M \\
O\end{array}$ & $\begin{array}{l}\text { A } \\
* \\
\vartheta\end{array}$ & $y$ & $\stackrel{0}{0}$ & w & 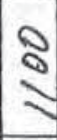 & \\
\hline 흠 & $\begin{array}{l}n \\
t\end{array}$ & 4 & $M$ & $N$ & $\sim$ & - & - & $i$ \\
\hline
\end{tabular}




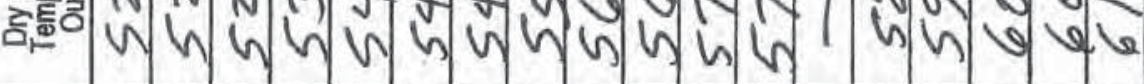

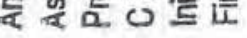

:

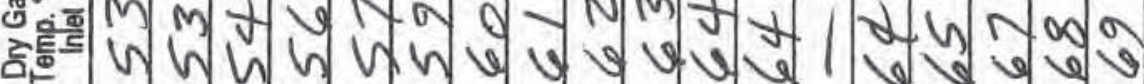

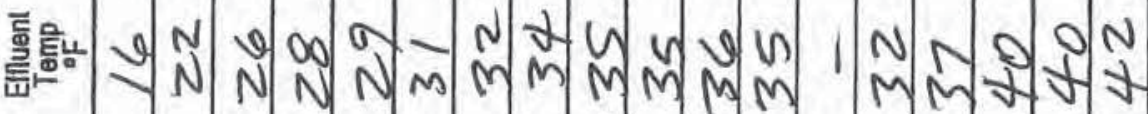

हैँ

짇

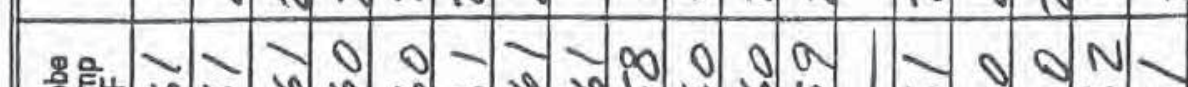
总: 覀

(

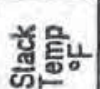

흥

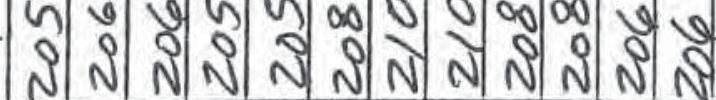

S 8000

তั

E 0000

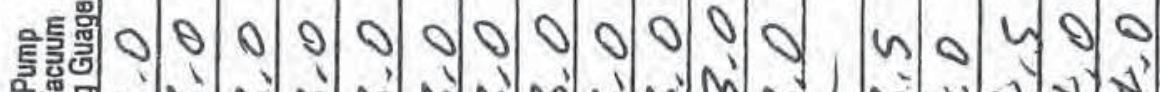

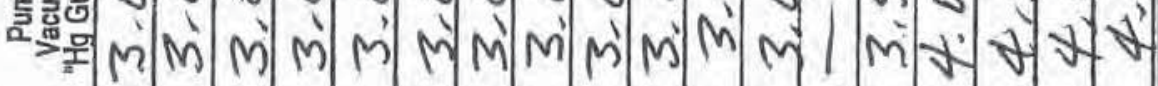

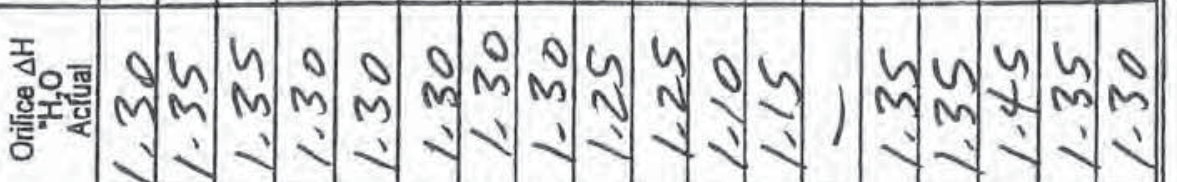

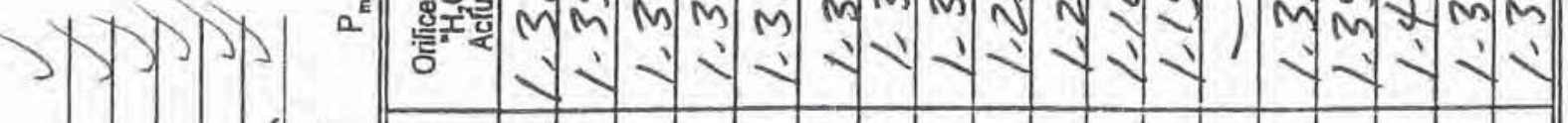

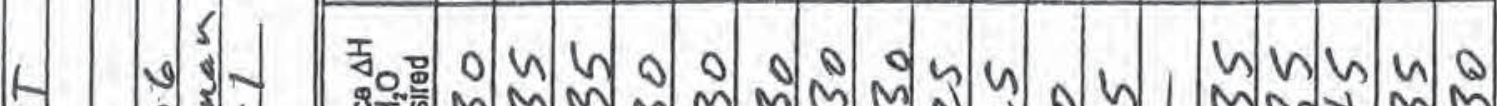

3. 0.5

-3 a

है

VN

ปู.

$96 \sqrt{y}$ y

Q

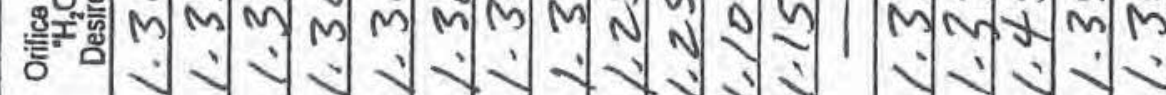

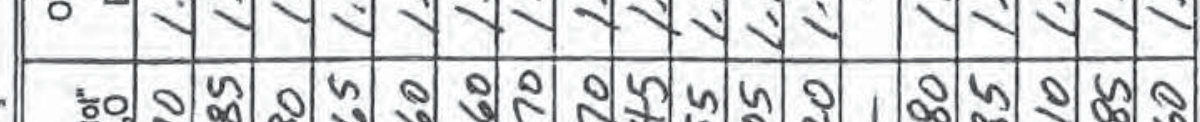

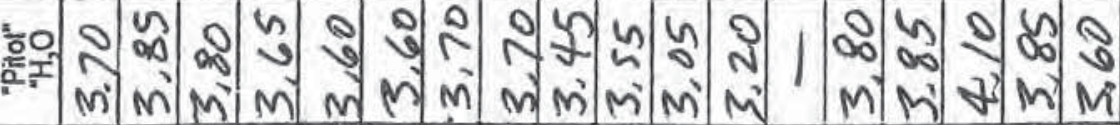

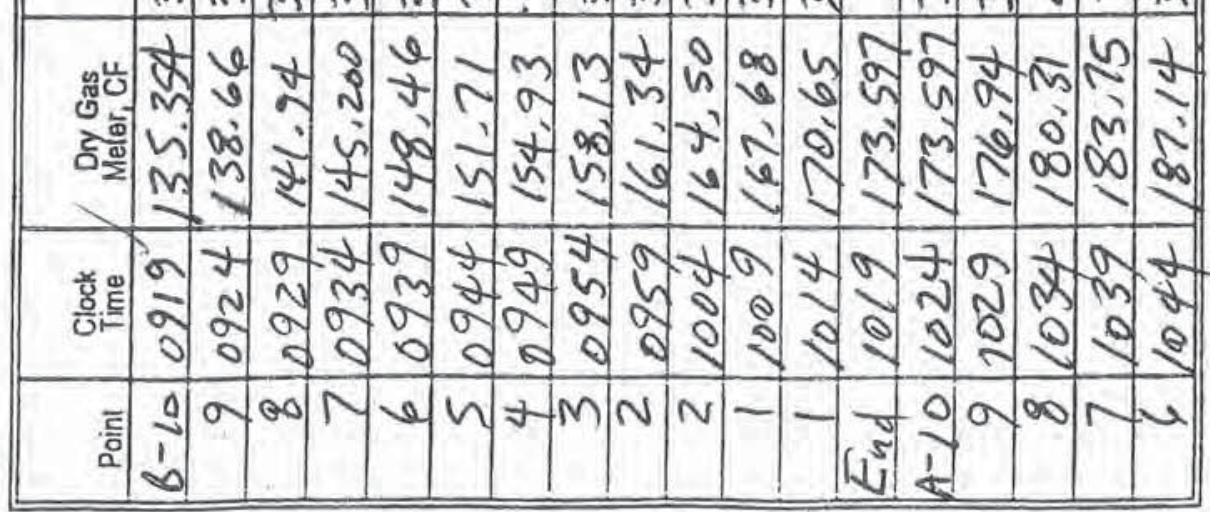

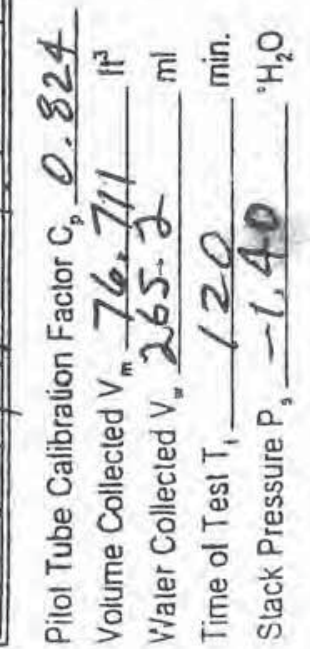


Impinger Box No. $M-3$

Final Weight $931.3 \quad$ Water Weicht Gain

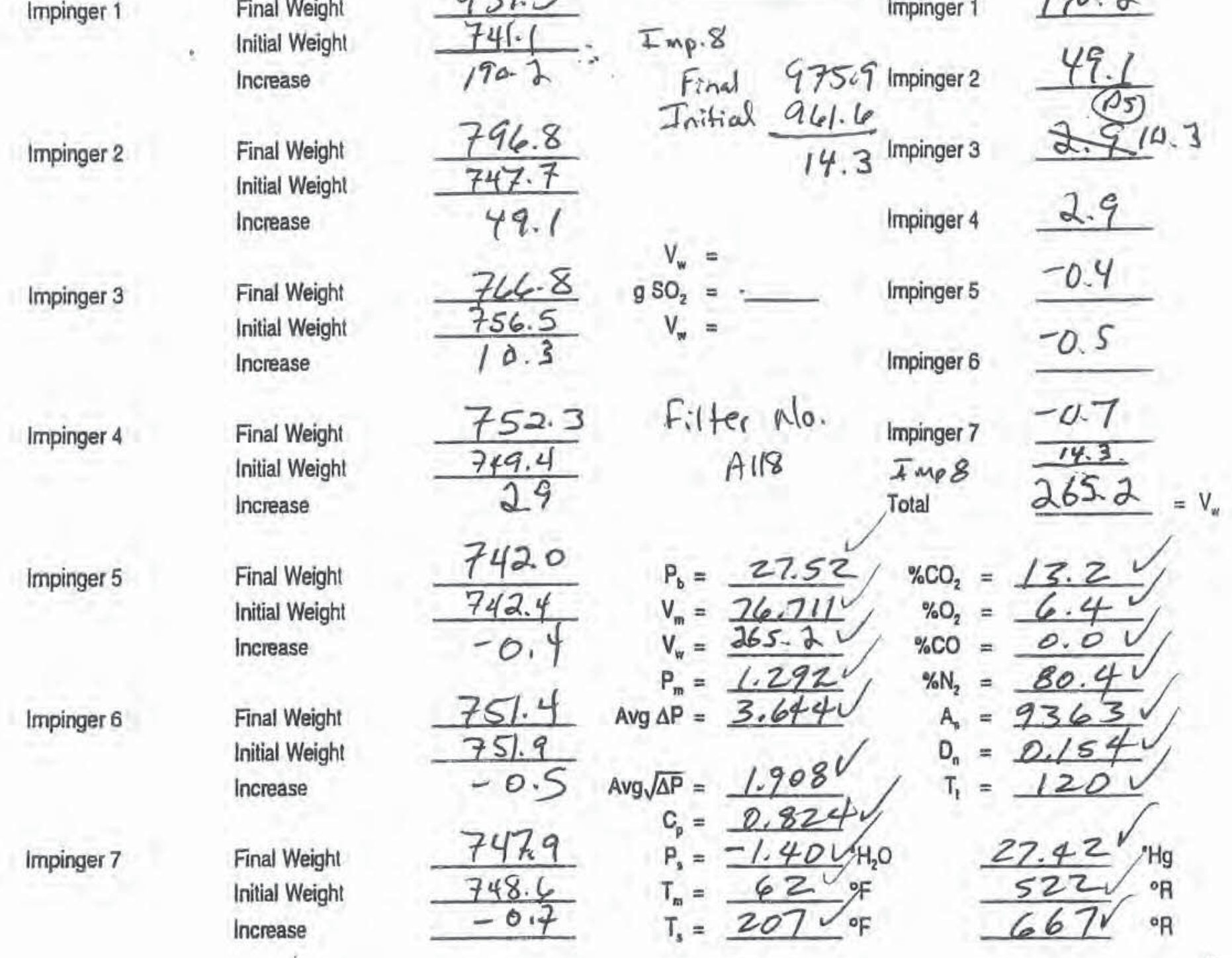

Moisture Content: $\quad \% M=14.88^{\prime} \quad M_{d}=\underline{0.8512^{\prime}} \quad M_{c}=\underline{30.368^{\prime}} \quad M W=\underline{28.53}$ $V m_{\text {sid }}=17.65 \mathrm{Vm}\left[\frac{P_{b}+\frac{P_{m}}{13.6}}{T_{m}+460}\right]=17.65 \times 76.711\left[\frac{27.52+\frac{1.292}{13.6}}{62+460}\right]=\frac{71.627^{\mathrm{stt}^{3}}}{\mathrm{sctm}}$ $V w_{\text {gas }}=0.0472 \times V w=0.0472 \times \frac{265.2}{26}=12.517^{3}$ $\%$ Moisture $=\frac{V w_{\text {gas }}}{V m_{s+1}+V w_{\text {gas }}} \times 100=\frac{12.517}{71.627+12.517} \times 100=\frac{14.88 \%}{2} \%$ $V_{2}=5123.8 \times \frac{0.824}{\frac{667}{27.42 \times 28.53}} \times 1.908=7438^{2} \mathrm{~mm}$ $\% 1=\frac{1.039 \times 71.627 \times 667}{0.8512 \times 27.42 \times 7438 \times 120 \times(0.154)^{2}}=100.5 \sum_{10}(15666$ ACFM: $\frac{483,647^{\prime}}{299,743}$ 


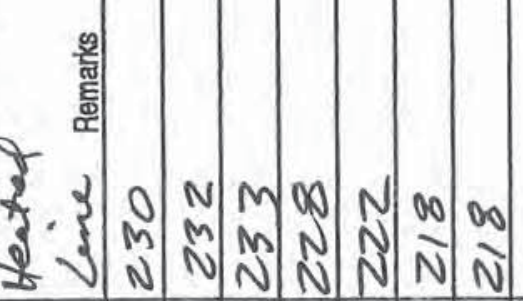

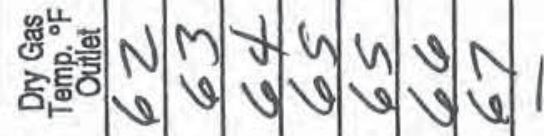

$\vdash^{\mathrm{E}}$

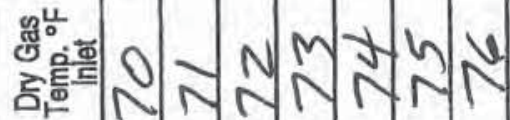

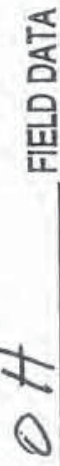

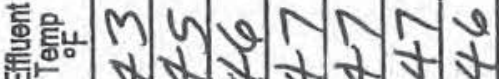

DN $N \forall \forall-$

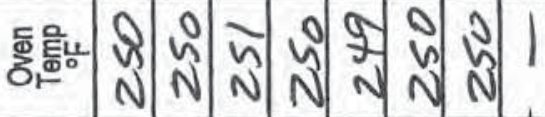

옹

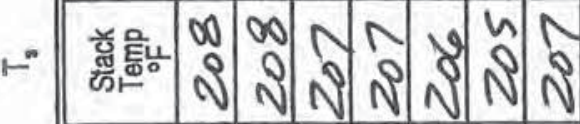

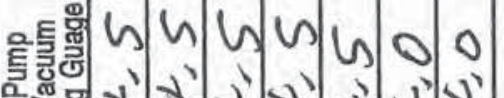

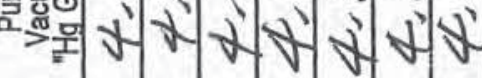

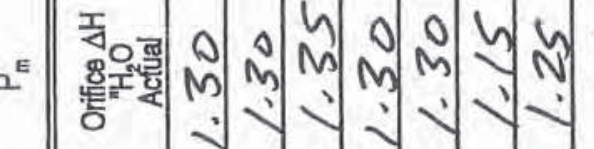

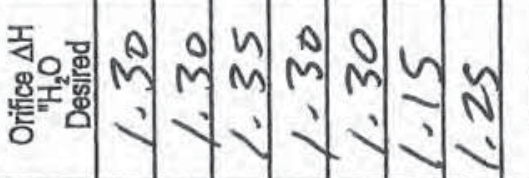

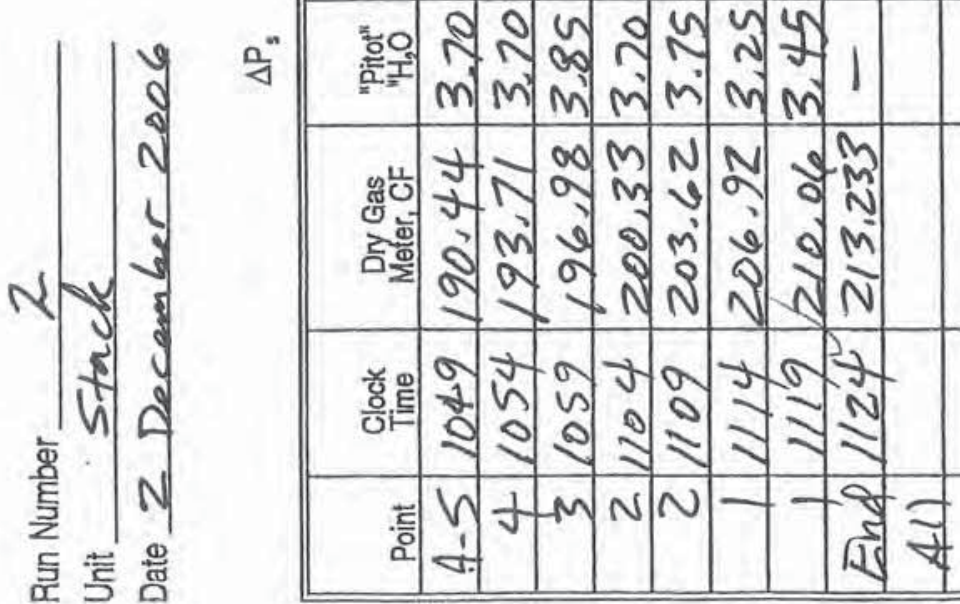




$$
\begin{aligned}
& \text { Impinger Box No. } m-3 \\
& 9304 \quad \text { Water Weight Gain } \\
& \text { Impinger } 1 \\
& \text { Final Weight } \\
& \text { Initial Weight } \overline{741.4}: \text { FINAL } 937.7 \\
& \begin{array}{ll}
\text { Increase } & \\
\text { Final Weight } & \frac{785.5}{248.4}
\end{array} \\
& \text { INITiAL } \overline{924.9} \text { impinger 2 } 37.1 \\
& \text { Impinger } 2 \\
& \text { Impinger } 3 \\
& \text { Increase } \\
& \text { INC. }
\end{aligned}
$$

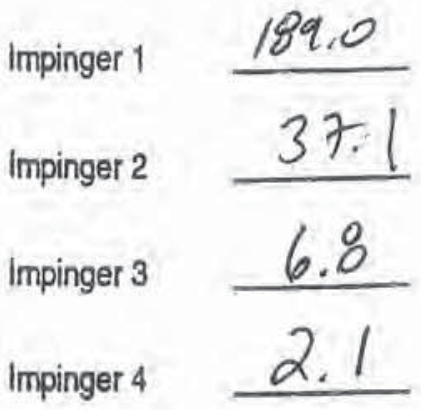

$$
\begin{aligned}
& \mathrm{V}_{\mathrm{w}}= \\
& 9 \mathrm{SO}_{2}= \\
& \text { Impinger } 5 \\
& V_{w}= \\
& \text { Increase } \\
& \text { Impinger } 4 \\
& \begin{array}{ll}
\text { Final Weight } \\
\text { Initial Weight }
\end{array} \quad \frac{739.1}{737.0} \\
& \text { FILTER \# } \\
& \text { Impinger } 6 \\
& \text { All } \\
& \text { Impinger } 7 \frac{-0.4}{12.8} \\
& \text { Increase } \\
& \text { Impinger } 5 \\
& \text { Impinger } 6 \\
& \text { Impinger } 7 \\
& \text { Total } \\
& 247.2=v_{w} \\
& P_{b}=27.55^{V} \\
& V_{m}=\frac{76,188}{247.2} \\
& v_{w}=\frac{247.2}{1.2350} \\
& \begin{aligned}
P_{m} & =\frac{1.235}{3.452}
\end{aligned} \\
& \% \mathrm{CO}_{2}=13.3 \mathrm{~V} \\
& \% \mathrm{O}_{2}=\frac{6.2}{0.2} \\
& \% \mathrm{CO}=\frac{0.0 \%}{80.51} \\
& \% \mathrm{~N}_{2}=\frac{80.5 \mathrm{~V}}{9363 \mathrm{~V}} \\
& A_{1}=93631 \\
& \begin{aligned}
D_{n} & =\frac{0.154}{120} \\
T_{1} & =\frac{27.45^{\prime}}{541} \\
& \frac{572}{672}
\end{aligned} \\
& \text { Increase } \\
& \begin{aligned}
A v g \sqrt{\Delta P} & =1.856 \\
C_{p} & =2.824 \\
P_{s} & =-1.35 \% H_{2} \mathrm{O} \\
T_{m} & =810 \mathrm{O} \\
T_{s} & =2120 \mathrm{~F}
\end{aligned} \\
& \begin{array}{l}
\text { Final Weight } \\
\text { Initial Weight } \\
\text { Increase }
\end{array}
\end{aligned}
$$

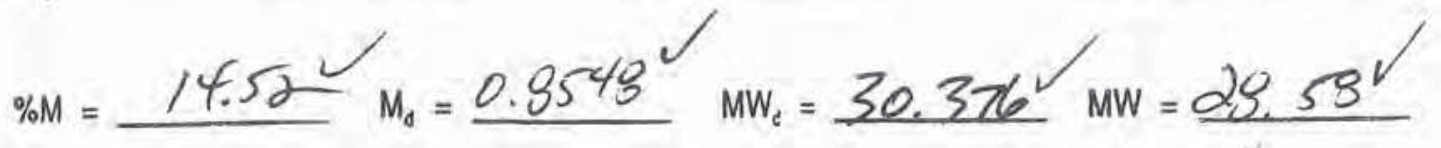

$$
\begin{aligned}
& V m_{s t d}=17.65 \mathrm{Vm} \\
& \mathrm{Vm}\left[\frac{P_{b}+\frac{P_{m}}{13.6}}{T_{m}+460}\right]=17.65 \times 76.188\left[\frac{27.55+\frac{1.235}{13.6}}{81+460}\right]=\frac{68.704^{\prime} \mathrm{st}^{3}}{0.573} \mathrm{scm} \\
& V_{W_{003}}=0.0472 \times V_{W}=0.0472 \times \frac{247.2}{2}=11.668 \mathrm{~J} \mathrm{sti}^{3}
\end{aligned}
$$

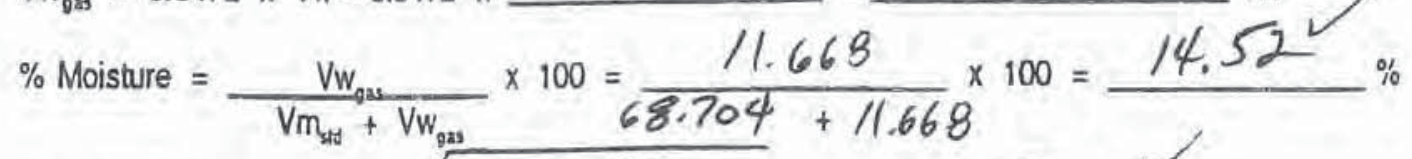

$$
\begin{aligned}
& v_{s}=5123.8 \times 0.824 \sqrt{\frac{672}{27.45 \times 28.53}} \times 1.856=7252 \mathrm{pm}
\end{aligned}
$$

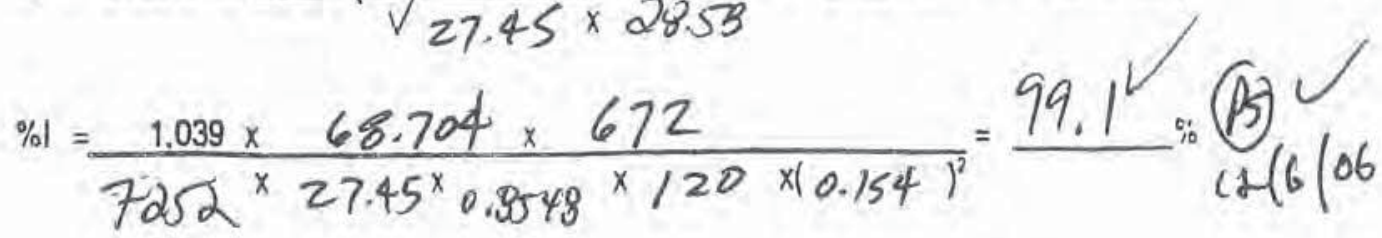




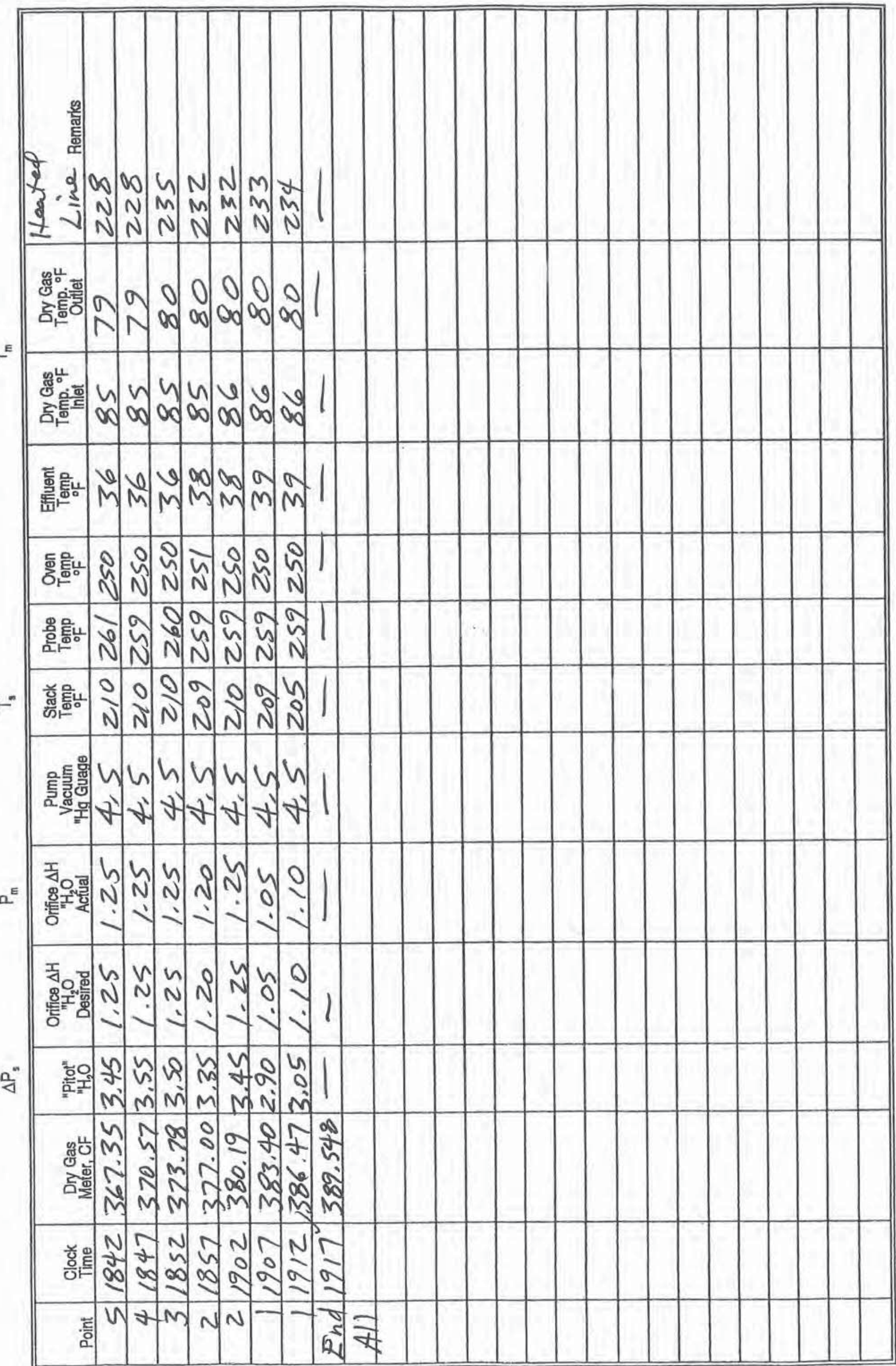




\title{
ORSAT ANALYSIS DATA FORM
}

$\begin{array}{ll}\text { Job \#: } & \frac{O 6-057}{\text { Job Name: }} \\ \text { Location: } & \frac{\text { ADA-ES }}{\text { Hardin, NIT }} \\ \text { Date: } & \frac{11-30-0 C}{\text { Operator: }} \\ \text { Operator }\end{array}$
Sample Location: Stack

Analytical Method:

3

Sample Type: Single PointPMulti Point Grabintegrated Leak Check: Time: 5 min ( 24 minutes) Rate: 0.0

Ambient Air Check:

\begin{tabular}{|l|c|}
\hline $\mathrm{CO}_{2}-\%$ Vol. & 0.0 \\
\hline $\mathrm{O}_{2}-\%$ Vol. & 20.9 \\
\hline $\mathrm{N}_{2}-\%$ Vol. & 79.1 \\
\hline
\end{tabular}

\section{Run \#: $1(26 A)$}

Run Time: 1745

\begin{tabular}{|l|c|c|c|c|}
\hline $\mathrm{CO}_{2}$ \% Vol. & 11.6 & 11.7 & 11.5 & 11.6 \\
\hline $\mathrm{O}_{2}-\%$ Vol. & 7.6 & 7.6 & 7.5 & 7.6 \\
\hline $\mathrm{CO}-\%$ Vol. & 0.0 & 0.0 & 0.0 & 0.0 \\
\hline $\mathrm{N}_{2} \%$ Vol. & 80.8 & 80.7 & 81.0 & 80.8 \\
\hline
\end{tabular}

Run \#: 2

Run Time: 1645

$$
\frac{\mathrm{CC}}{\mathrm{C}}
$$

CO

$\mathrm{N}_{2}-\%$ Vol.

Analysis \#1

Analysis \#2

Analysis \#3

Average - $\%$ Volume

12.8

6. 7

0.0
80.5

$\frac{1}{5}$

$\mid 1$

$\frac{12}{6}$

128 12.8

6.7

0.0

6.7
0.0
80.5
12,8

6. 7

0.0

80.5

\begin{abstract}
R
\end{abstract}
Run \#:

3

Run Time: 2120

$12 / 02 / 06$ Analysis \#1

Analysis \#2

Analysis \#3

Average - \% Volume

$\mathrm{CO}_{2}-\%$ Vol.

13.2

$\mathrm{O}_{2}-\%$ Vol.

$\mathrm{CO}-\%$ Vol.

6.3

0.0

80.5

13.2

13.2

13.2

0.0 0.0

6.3

0.0

80.5

80.5

805 


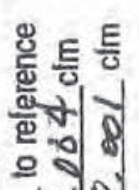

W 10 ㅇำ

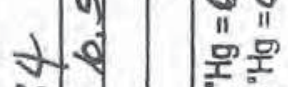

M 20 o

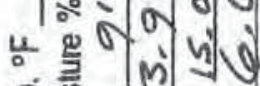

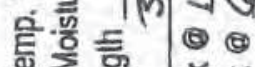

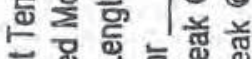

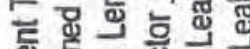

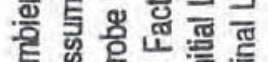

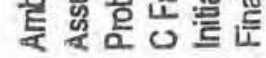

E

\section{g.}

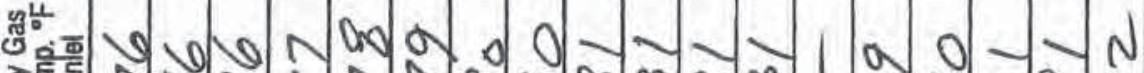

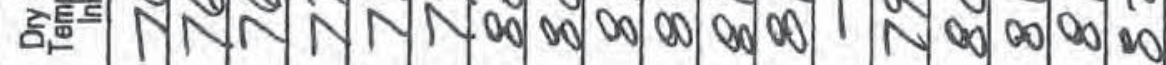

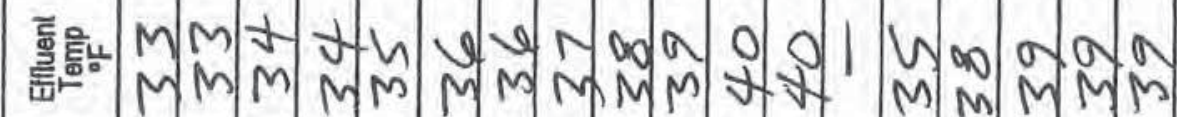

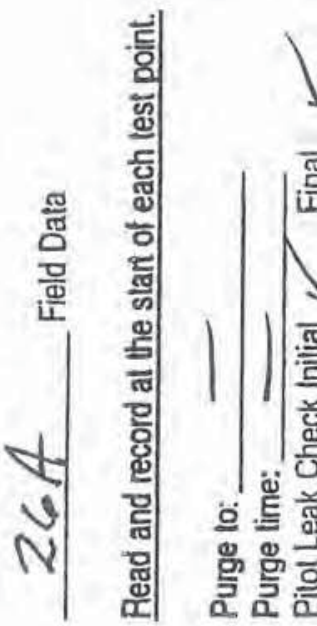

$s$ sis is

12

य 3

1 क्ष

जी की

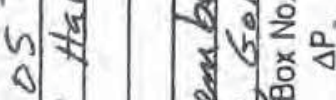

$14 x+4$ क

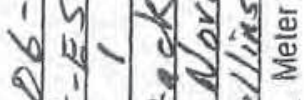

से WO

N

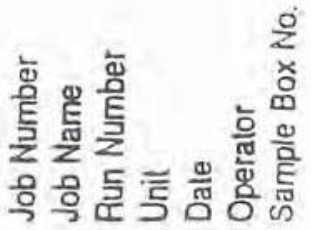

ठั.

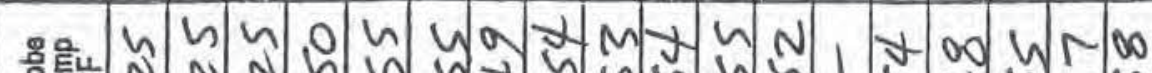
융 N N N $N$ N $N$ N N N N N

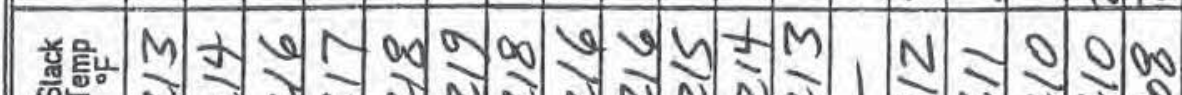
क. $N$ NN NNNNNNN N N NNN

हE

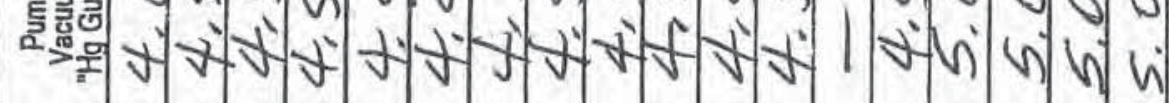

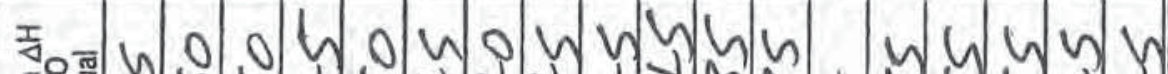

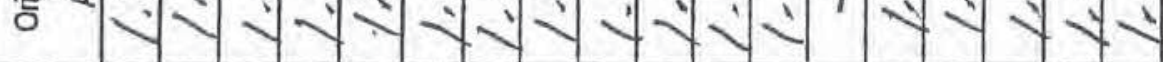

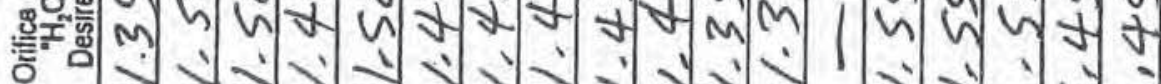

- 1070

흘ㄱำ : M MMM M MM MM MM

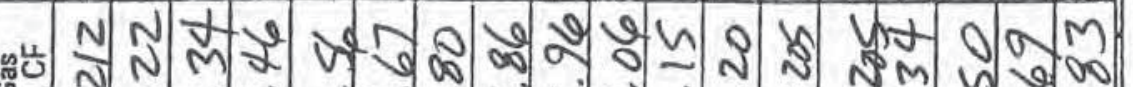

ठㄴ. N vi Na. N.

टें जै

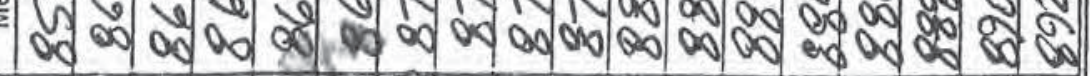

당 मूल 들 मु.

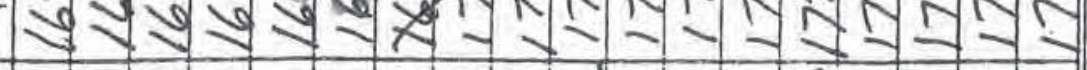

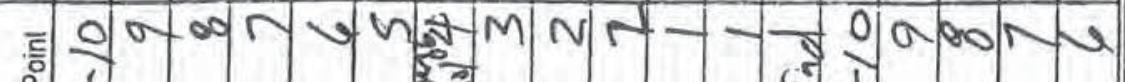
वे

오 000 $\therefore$ E

ร.
क స

$i=\ln$

象 $x$ 离

है

oq

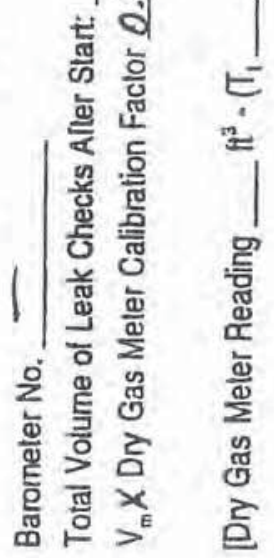
도 으

교 z

on $0 \div \mathrm{m}$

सेखे। $\mathrm{m}$

a $v$ 울 的 월은 궁 을

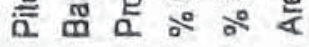


Impinger Box No.

$2-1$

Impinger 1

Final Weight

Initial Weight

Increase

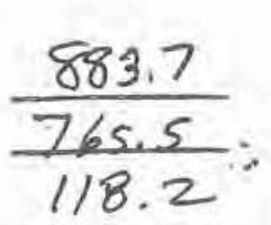

Water Weiaht Gain

Initial Weight
Increase

Impinger 2

Final Weight

Initial Weight

Increase

$\frac{761.8}{331.5}$

Impinger 1

118,2

impinger $2 \quad 30,3$

Impinger 3

Final Weight

Initial Weight

Increase

$\begin{array}{rr}\frac{74.2}{737.0} & \mathrm{v} \mathrm{SO}_{2}= \\ \frac{7.2}{5.2} & \mathrm{v}_{w}=\end{array}$

Impinger $3 \quad 5.2$

Impinger 4

$\ln 2$

Impinger $5 \quad 12-6$

Impinger 6

Impinger 4

Final Weight

Initial Weight

Increase

Impinger 5

Final Weight

Initial Weight

increase

729.6

728.4

1,2

Fil ter No.

$\frac{949.7}{937.1}$

Impinger 6

Final Weight

Initial Weight

Increase

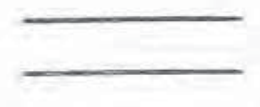

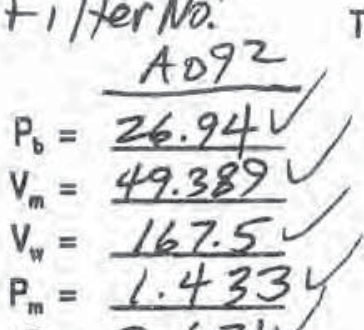

Avg $\Delta P=3.6312$

Impinger 7

$$
\begin{aligned}
\operatorname{Avg} \sqrt{\Delta \mathrm{P}} & =1.905 \\
\mathrm{C}_{\mathrm{p}} & =0.824 \\
\mathrm{P}_{s} & =-1.60 \\
T_{m} & =79 \mathrm{O}_{\mathrm{O}} \mathrm{O} \\
\mathrm{T}_{s} & =211 \mathrm{~F}
\end{aligned}
$$

Total

$162.5=v_{w}$

Impinger 7

Final Weight

Initial Weight

increase

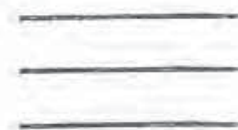

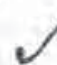

Moisture Content:

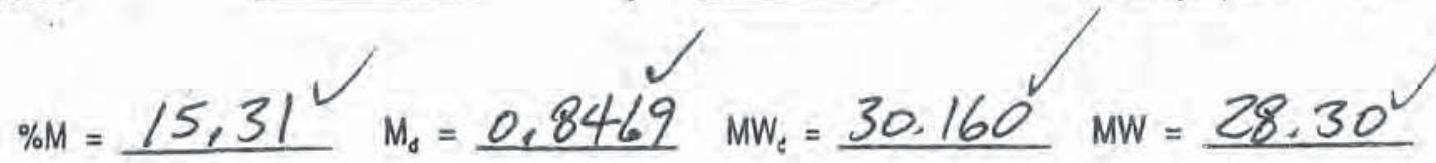

$$
V m_{\text {std }}=17.65 \mathrm{Vm}\left[\frac{P_{b}+\frac{P_{m}}{13.6}}{T_{m}+460}\right]=17.65 \times 49.389\left[\frac{26.94+\frac{1.433}{13.6}}{79+460}\right]=\frac{43.740^{1 / 3}}{0.607}
$$

$V_{w_{g e s}}=0.0472 \times V w=0.0472 \times 1.167 .5=7.906^{2} s^{3}$

$\%$ Moisture $=\frac{V_{w_{0 a}}}{V_{m_{x+1}}+V_{\text {oas }}} \times 100=\frac{7.906}{43.740+7,906} \times 100=\frac{15,31}{1} \%$

$v_{s}=5123.8 \times 0.824 \sqrt{\frac{671}{26.82 \times 28.30}} \times 1.905=\frac{7562}{8} \mathrm{pm}$

$\%=\frac{1.039 \times 43.740 \times 671}{0.8469 \times 26.82 \times 7562 \times 72 \times(0.154)^{2}}=104.0 \% \frac{(p 5)}{1216106}$

ACFM: 491,706

SCFM: 294,798

$\%$ EA: 55,0 


$$
\begin{aligned}
& \text { Impinger Box №. } \\
& 1-2 \\
& \text { Impinger } 1 \\
& \text { Final Weight } \\
& \text { Initial Weight } \\
& \text { Increase } \\
& \text { Impinger 2 } \\
& \text { Impinger } 3 \\
& \text { Impinger } 5 \\
& \text { Impinger } 6 \\
& \text { Impinger } 7 \\
& \text { Final Weight } \\
& \text { Initial Weight } \\
& \text { Increase } \\
& \text { Final Weight } \\
& \text { Initial Weight } \\
& \text { Increase } \\
& \frac{902.0}{1 \times 65.2} \\
& \text { Water Weight Gain } \\
& 3 \sin 121 / 106 \\
& \frac{\frac{745.4}{733.2}}{12.2} \\
& \begin{array}{r}
\frac{752.4}{751.1} \\
1.5 \\
\frac{734.8}{734.6} \\
0.2
\end{array} \\
& \mathrm{~V}_{\mathrm{w}}= \\
& \mathrm{gSO}_{2}= \\
& \text { Impinger } 5 \\
& \mathrm{~V}_{\mathrm{w}}= \\
& \text { Impinger } 6 \\
& \frac{956.7}{949.6} \\
& \text { FilTfe \# All Total } \\
& \text { Impinger } 7 \\
& \begin{array}{l}
\text { Final Weight } \\
\text { Initial Weight } \\
\text { Increase }
\end{array} \frac{\frac{734.8}{734.6}}{0.2} \\
& \text { Final Weight } \\
& \text { Initial Weight } \\
& \text { Increase } \\
& \text { Final Weight } \\
& \text { Initial Weight } \\
& \text { Increase } \\
& \text { Final Weight } \\
& \text { Initial Weight } \\
& \text { Increase } \\
& P_{b}=27.17 \\
& v_{m}=\frac{47.095}{157.80} \\
& v_{w}=\frac{157.81}{1.81} \\
& \begin{aligned}
P_{m} & =\frac{1.281}{3.615}
\end{aligned} \\
& \% \mathrm{CO}_{2}=12.8 \\
& \% \mathrm{O}_{2}=6,57 \% \text { \% } 11106 \\
& \% \mathrm{CO}=0.0 \\
& \% \mathrm{~N}_{2}=\frac{80,5}{9363} \\
& \text { Avg } \Delta P=3.615 \quad A_{1}=9363 \\
& \operatorname{Avg} \sqrt{\Delta P}=1.900, \quad \begin{array}{l}
D_{n}=0.154 \\
T_{1}=72 \nu
\end{array} \\
& C_{p}=0.824 \mathrm{~V} \\
& \mathrm{P}_{\mathrm{s}}=-1.80 \mathrm{H} / \mathrm{H}_{2} \mathrm{O} \\
& T_{\mathrm{m}}=76 \gamma^{\circ} \% \\
& T_{s}=2040 \% \\
& \% \mathrm{M}=14.98 \quad \mathrm{M}_{\mathrm{d}}=0.850 \mathrm{Z}^{2} \quad \mathrm{MW}_{\mathrm{d}}=30.316 \quad \mathrm{MW}=28.47^{\prime} \\
& V m_{s t d}=17.65 \mathrm{Vm}\left[\frac{P_{b}+\frac{P_{m}}{13.6}}{T_{m}+460}\right]=17.65 \times 47.095\left[\frac{27.17+\frac{1.281}{13.6}}{76+460}\right]=\frac{42.281 \mathrm{sth}}{0.587 \mathrm{scm}} \\
& V W_{\mathrm{ges}}=0.0472 \times V W=0.0472 \times \\
& 157.8= \\
& \mathrm{stt}^{3} \\
& \% \text { Moisture }=\frac{V_{W_{\text {aid }}}}{V_{m_{\mathrm{s}+1}}+V_{W_{\text {out }}}} \times 100=\frac{7.448}{42.281+7.448} \times 100=14.98 \mathrm{~V} \% \\
& V_{s}=5123.8 \times \frac{0.824}{\frac{664}{22.04 \times 28.47}} \times 1.900=7450 \mathrm{~mm}
\end{aligned}
$$




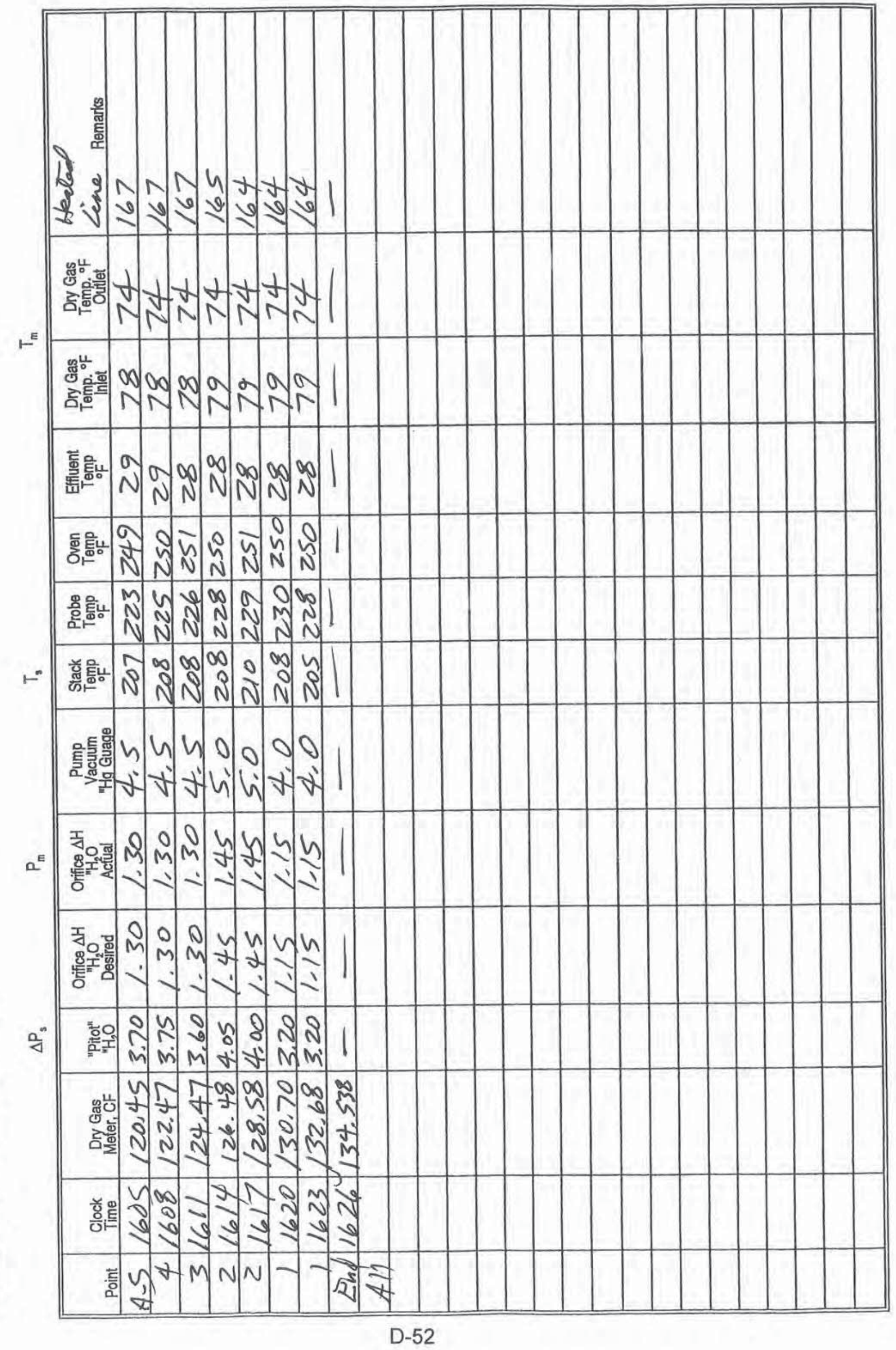




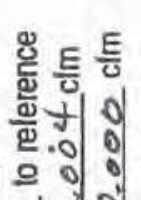

9a:

$\therefore h$ \%

แล

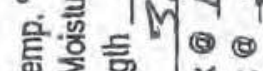

该 尊 前

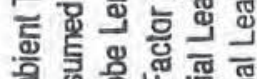

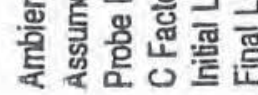

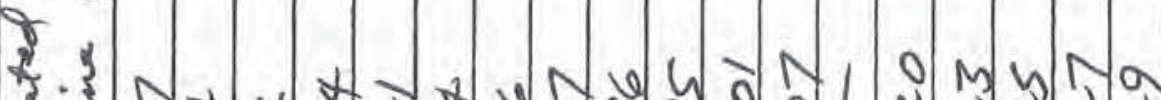
\pm .

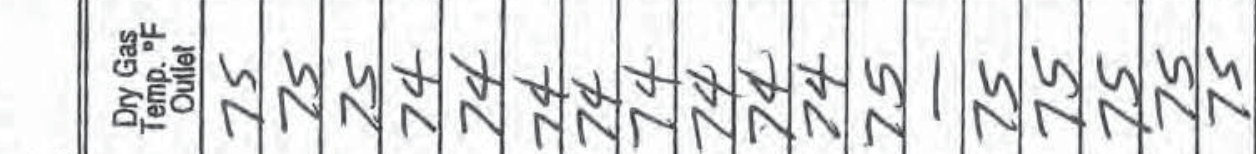

整

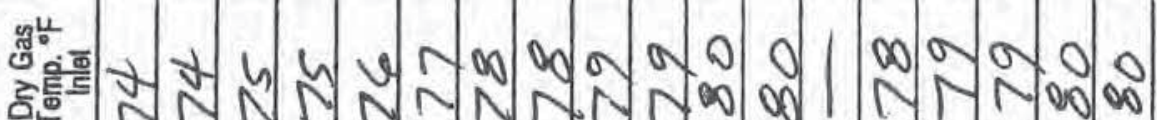

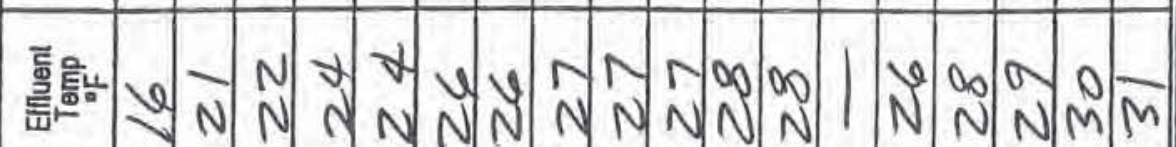

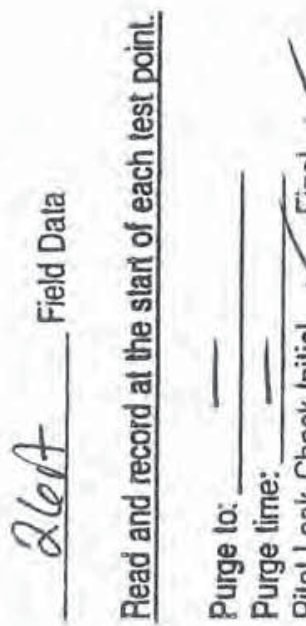

$\checkmark$

ल달

it

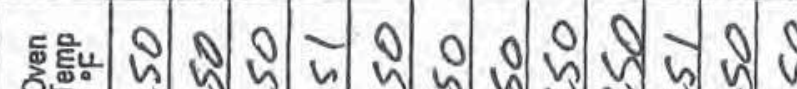

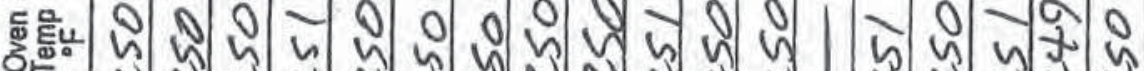
N N N N N N N N N N N N N N N

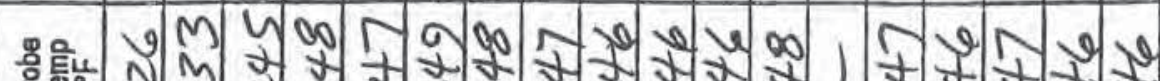
N N N N N N N N N

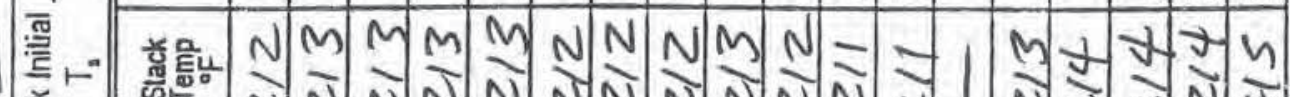
品 N N N N N NN N N N N N N N N N N

iं 을 행 몰

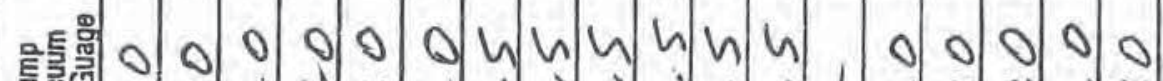

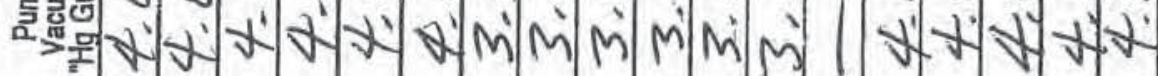

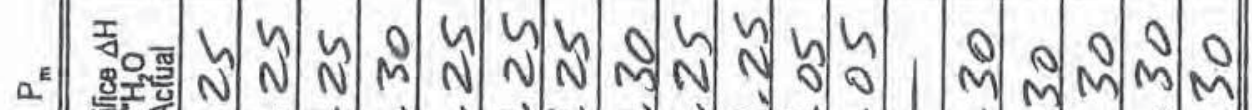
$\rightarrow A P>P$

IN 3. s. ร。ํㅐ 올 $N$ N N M N N N MNN O $M M M M$

Ny 1 1) 13 पै $4 \mathrm{~m}$ है \& $\mid \begin{array}{ll}\text { से } \\ \text { से }\end{array}$

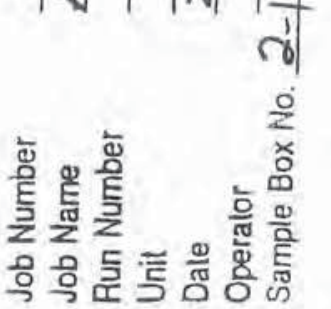

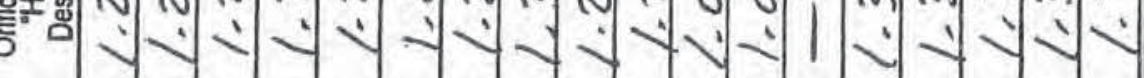

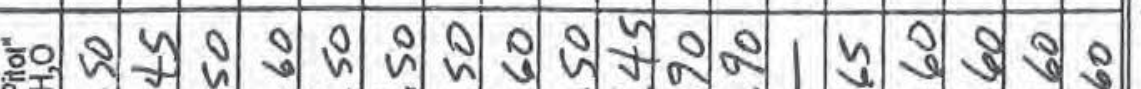

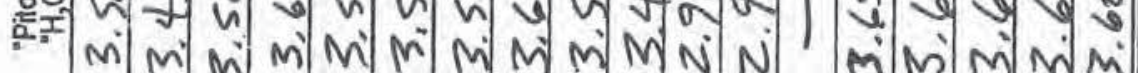

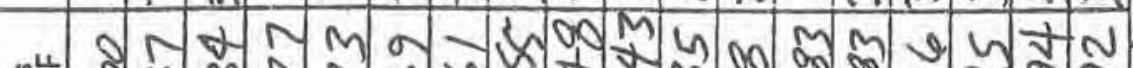

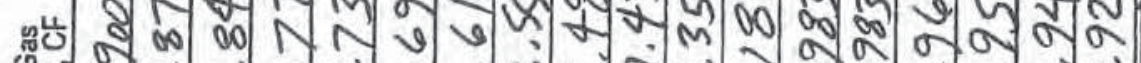
ट्ञे

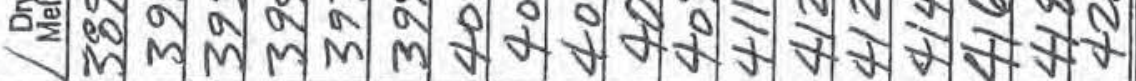

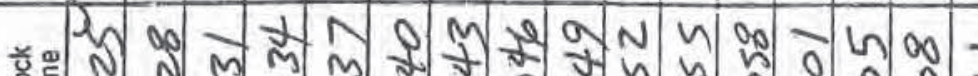

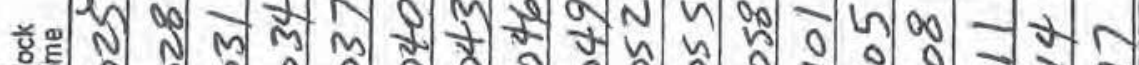

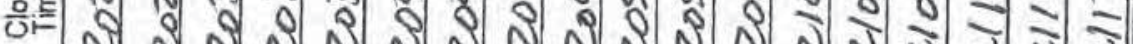

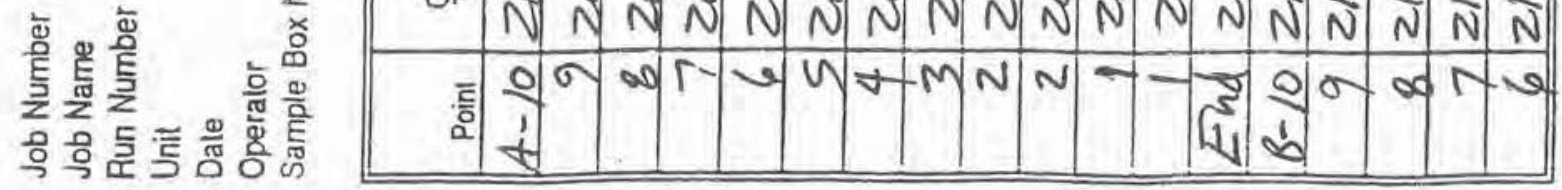

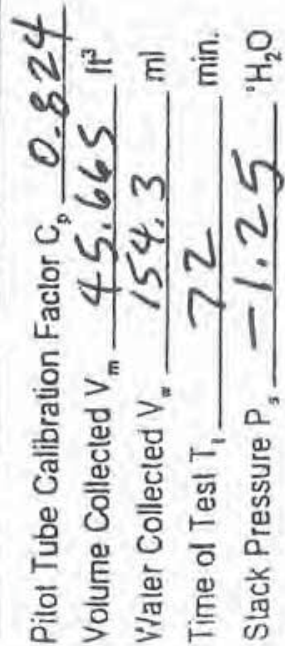


Impinger Box No. 2-1

Impinger 1

Impinger 2

Impinger 3

Impinger 4

Impinger 5

Impinger 6

Impinger 7

Moisture Content:

Final Weight

Initial Weight

Increase

Final Weight

Initial Weight

Increase
Water Weight Gain

Impinger 1 $\quad 115.0$

Impinger $3 \quad 3,9$

Impinger 4

0.7

Impinger 5

10.2

Impinger 6

Filter No. Impinger 7

Al 13

Total

$154.3=v$

$P_{1}=2755$

$\% \mathrm{CO}_{2}=\frac{13.2}{6.3}$

$v_{m}=45.665^{2}$

$v_{w}=\frac{154.3}{1.234}$

$\begin{aligned} P_{m} & =\frac{1.234}{3.431}\end{aligned}$

$\% \mathrm{O}_{2}=\frac{6.3}{0.0}$

$\% \mathrm{CO}=\frac{0.0 \mathrm{~V}}{80.5}$

$\% \mathrm{~N}_{2}=80.5$

$A_{0}=9363$

$D_{n}=0.154$

$\operatorname{Avg} \sqrt{\Delta P}=1.851 \mathrm{~V}$

$T_{1}=72$

$c_{p}=0.824$

$P_{1}=-1.25 \cdot H_{2} \mathrm{O}$

$T_{m}=77 \mathrm{~F}$

$T_{3}=2130 \%$

$\% M=14.93 \quad M_{d}=0.8507 \quad M_{t}=30.364^{\nu W}=28.52$

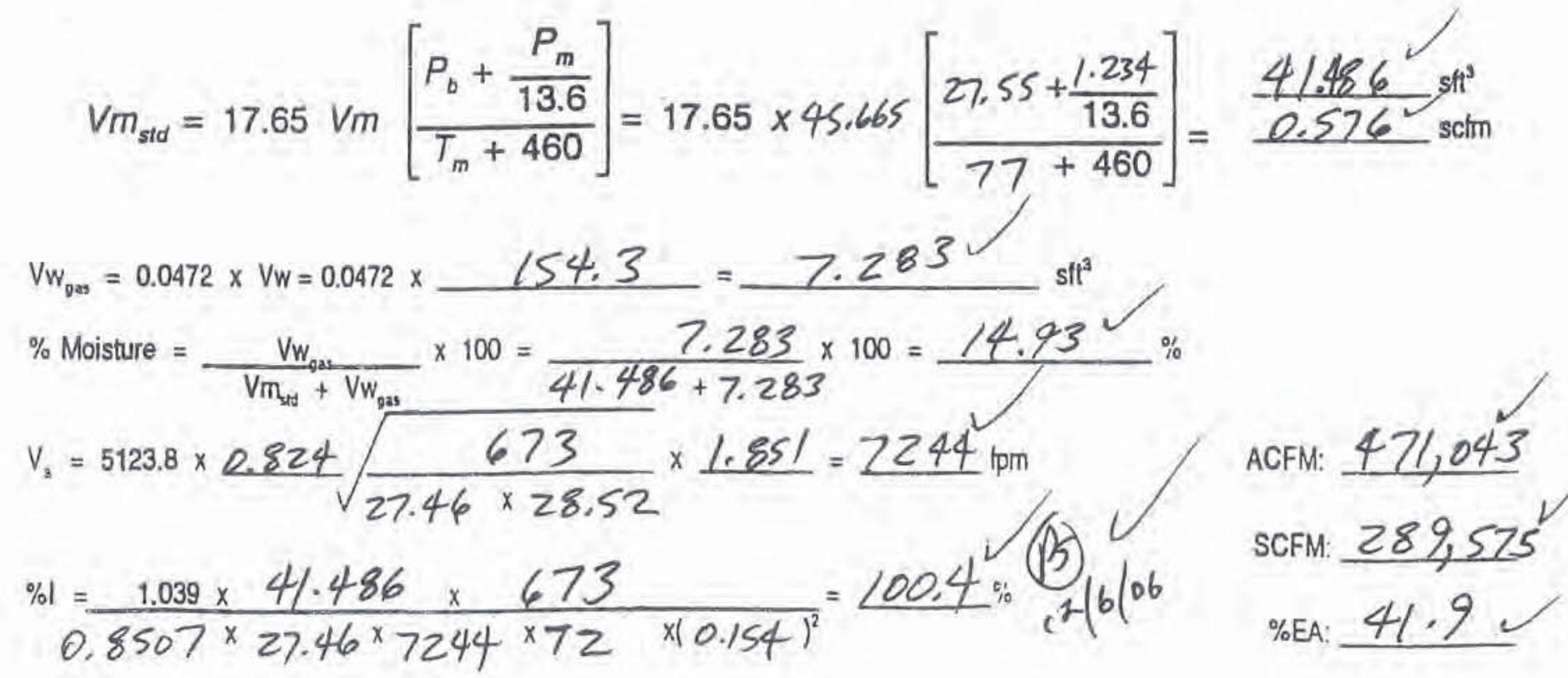

D-54 


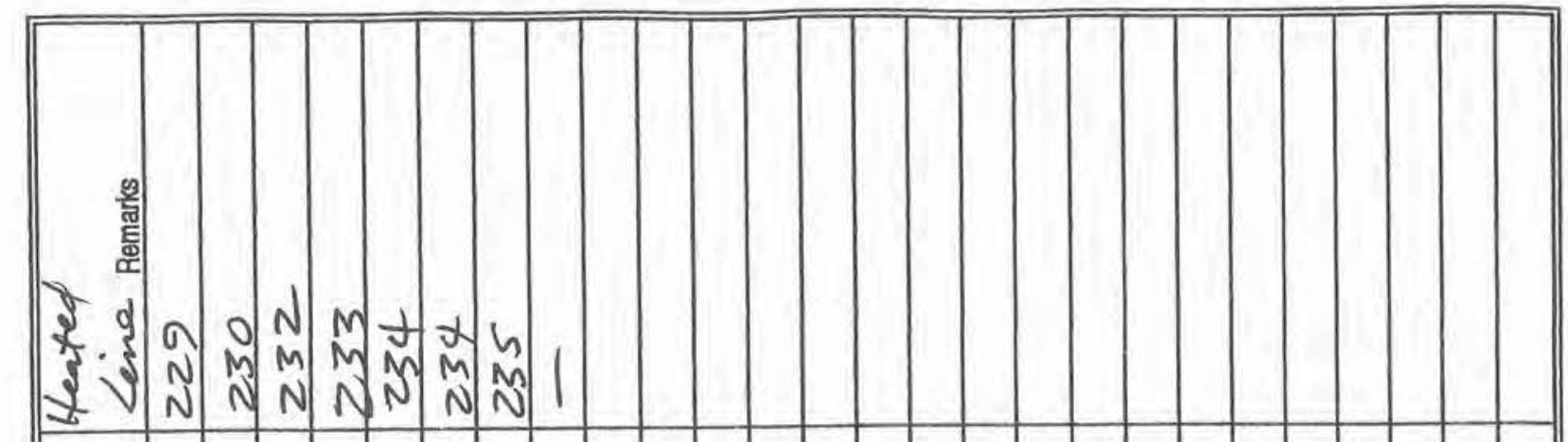

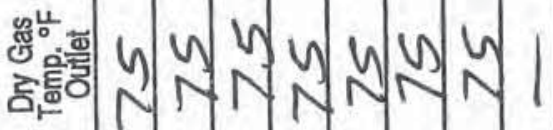

$\vdash^{\mathrm{E}}$

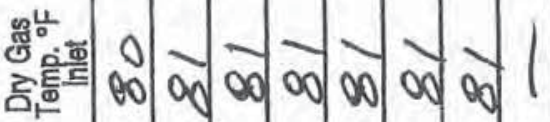

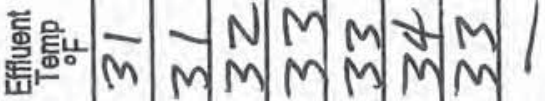

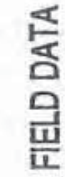

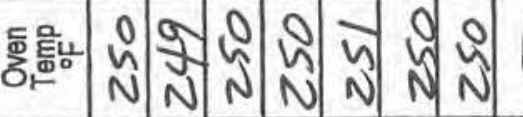

옹ํำ

N

-

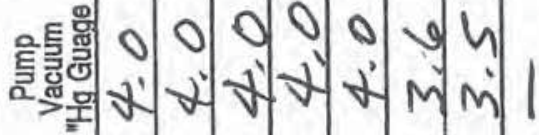

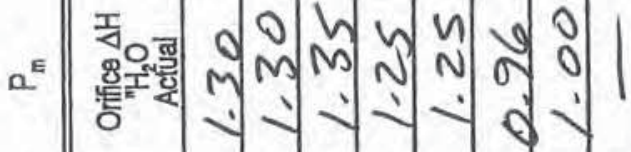

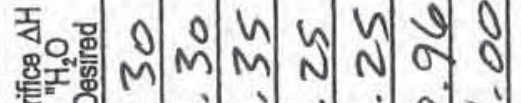

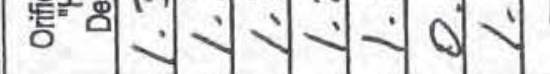

(N)

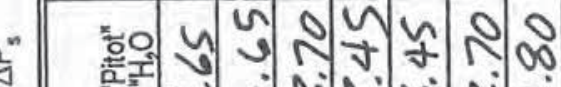

M. M M M M N N

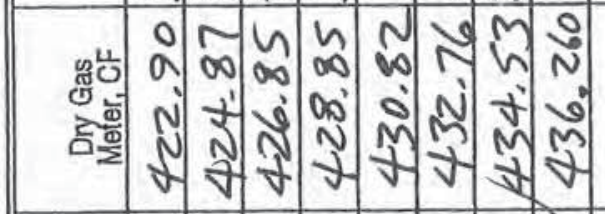

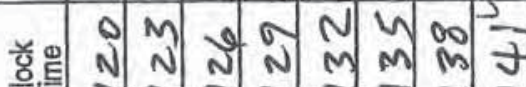

of N N N N N N

$=M \rightarrow m N \sim \rightarrow$ 


\section{ORSAT ANALYSIS DATA FORM}

\begin{tabular}{|c|c|}
\hline b\#: & $06-057$ \\
\hline Job Name & AOA-ES \\
\hline Location: & Hardin, MT \\
\hline & $12-1-06$ \\
\hline er & Hefley \\
\hline
\end{tabular}

Sample Location: $\frac{\text { Stack }}{\text { Analytical Method: } 3}$

Sample Type:Single Poind/Multi Point Grab/ntegrated Leak Check: Time: 5 min ( 24 minutes) Rate: 0.0 Ambient Air Check:

\begin{tabular}{|l|c|}
\hline $\mathrm{CO}_{2}-\%$ Vol. & 0.0 \\
\hline $\mathrm{O}_{2}-\%$ Vol. & 20.9 \\
\hline $\mathrm{N}_{2}-\%$ Vol. & 79.1 \\
\hline
\end{tabular}

\section{Run $\#: 1 \mathrm{OH})$}

Run Time:

\begin{tabular}{|l|c|c|c|c|}
\hline $\mathrm{CO}_{2}-\% \mathrm{Vol}$. & 12.8 & 12.8 & 12.8 & 12.8 \\
\hline $\mathrm{O}_{2}-\% \mathrm{Vol}$. & 6.2 & 6.2 & 6.3 & 6.2 \\
\hline $\mathrm{CO}-\% \mathrm{Vol}$. & 0.0 & 6.0 & 0.0 & 0.0 \\
\hline $\mathrm{N}_{2}-\% \mathrm{Vol}$. & 81.0 & 81.0 & 80.9 & 80.9 \\
\hline \hline
\end{tabular}

Run\#: Z

Run Time: Analysis \#1 Analysis \#2 Analysis \#3 Average - $\%$ Volume

\begin{tabular}{l|c|c|c|c|}
\hline $\mathrm{CO}_{2}-\% \mathrm{Vol}$. & 13.2 & 13.3 & 13.2 & 13.2 \\
\hline $\mathrm{O}_{2}-\% \mathrm{Vol}$. & 6.4 & 6.3 & 6.4 & 6.4 \\
\hline $\mathrm{CO}-\% \mathrm{Vol}$. & 0.0 & 0.0 & 0.0 & 0.0 \\
\hline $\mathrm{N}_{2}-\% \mathrm{Vol}$. & 80.4 & 80.4 & 80.4 & 80.4 \\
\hline \hline
\end{tabular}

Run \#:

Run Time: 1755
$\frac{\overline{\mathrm{CC}}}{\mathrm{O}_{2}}$ Analysis \#1 Analysis \#2 Analysis \#3 Average - $\%$ Volume

\begin{tabular}{|l}
13.3 \\
6.2 \\
0.0 \\
80.5 \\
\hline
\end{tabular}

\begin{tabular}{|l}
13.3 \\
6.2 \\
0.0 \\
80.5 \\
\hline
\end{tabular}

\begin{tabular}{l} 
Analysis \#3 \\
\hline \begin{tabular}{|c|}
13.3 \\
6.2 \\
0.0 \\
80.5 \\
\hline
\end{tabular}
\end{tabular}

\begin{tabular}{|c|}
\hline 13.3 \\
6.2 \\
0.0 \\
80.5 \\
\hline
\end{tabular}


Job Number $06-057$

Job Name ADA - ES

Sampling Location Stack

Date $11 / 28 / 06$ Time $0845-0900$

$\frac{\text { Port A }}{151 / 8^{\prime \prime}} \quad \frac{\text { Port B }}{151 / 8^{\prime \prime}}$

Stack Height ft.

Sampling Port Height Above Ground $123^{\prime}-1 / 2^{\prime \prime}$ ft.
Port \& Inside Diameler (in.)

Port \& Wall Thickness (in.)

Inside Stack Diameter (in.)

Sampling Ports are 3\$ $\mathrm{3} .11 / 2$ in.

Sampling Ports are
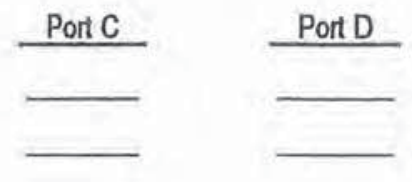

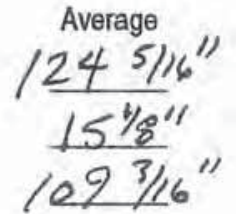

$(3.64$ stack diameters) downstream from disturbance (inlet, constriction bend, expansion)

$(>2.00$ slack diameters) upstream from disturbance (outlet,-Constriction, bend, expansion)

\begin{tabular}{|c|c|c|c|c|c|c|c|}
\hline $\begin{array}{l}\text { Point } \\
\text { Number }\end{array}$ & $\begin{array}{l}\text { Percent } \\
\text { Diameter }\end{array}$ & $\begin{array}{l}\text { Distance from } \\
\text { Ref. Point } \\
\text { (decimal in.) }\end{array}$ & $\begin{array}{l}\text { Distance from } \\
\text { Ref. Point } \\
\text { (fractional in.) }\end{array}$ & $\begin{array}{c}\text { Port A } \\
\Delta \mathrm{P} / \mathrm{d} / \alpha\end{array}$ & $\begin{array}{c}\text { Port B } \\
\Delta \mathrm{P} / T_{g} / \alpha\end{array}$ & $\begin{array}{c}\text { Port C } \\
\Delta \mathrm{P} / \mathrm{T}_{\mathbf{s}} / \alpha\end{array}$ & $\begin{array}{l}\text { Port D } \\
\Delta \mathrm{P} / \mathrm{T}_{\mathrm{s}} / \alpha\end{array}$ \\
\hline 1 & $z .1$ & 2.293 & $25 / 161$ & $2.40,214,5$ & 3.001210 & 11 & 1 \\
\hline 2 & 6.7 & 7.316 & $75 / 16^{4}$ & 280 RKLS & $3.45 \mathrm{ra} 31$ & 1 & 1 \\
\hline 3 & 11.8 & 12.884 & $127 / 8^{4}$ & $280 \mathrm{R}_{161} 3$ & 3.5001410 & 11 & 1 \\
\hline 4 & 17.7 & 19.326 & $195 / 16^{4}$ & 28012163 & $3.25 R 1313$ & 11 & 1 \\
\hline 5 & 25.0 & 27.297 & $225 / 16^{4}$ & 28081610 & 3.2001317 & 1 & 1 \\
\hline 6 & 35.6 & 38.871 & $387 / 8^{4}$ & 3.0012160 & 33081319 & 1 & 1 \\
\hline 7 & 64.4 & 70.317 & $705 / 16^{4}$ & $3,10,21599$ & $3201731 / 1$ & 1 & 1 \\
\hline 8 & 75.0 & 81.891 & $817 / 84$ & $3,45,2159$ & 3,251213110 & 1 & 1 \\
\hline 9 & 82.3 & 89.861 & $897 / 8^{\prime}$ & $3,40,21510$ & 330121310 & 1 & 1 \\
\hline 10 & 88.2 & 96.303 & $965 / 16^{4}$ & $350 \mathrm{k} / \mathrm{S} 18$ & $3.30 \mathrm{R} 121 / 3$ & 1 & 1 \\
\hline 11 & 933 & 101.872 & $1017 / 8^{4}$ & $3,20 R 1218$ & 3.101212111 & 1 & 1 \\
\hline 12 & 97.9 & 106.895 & $1067 / 8^{11}$ & 280,121115 & 3.10121114 & 1 & 1 \\
\hline 13 & & & & 11 & 11 & 11 & 1 \\
\hline 14 & & & & 11 & 11 & 11 & 11 \\
\hline 15 & & & & 11 & 11 & 11 & 11 \\
\hline 16 & & & & 11 & 11 & 11 & 11 \\
\hline 17 & & & & 11 & 11 & 11 & 11 \\
\hline 18 & & & & 11 & 11 & 1 & 11 \\
\hline 19 & & & & 11 & 11 & 11 & 11 \\
\hline 20 & & & & 11 & 11 & 11 & 11 \\
\hline 21 & & & & 11 & 11 & 11 & 11 \\
\hline 22 & & & & 11 & 11 & 11 & 11 \\
\hline 23 & & & & 11 & 11 & 11 & 11 \\
\hline 24 & & & & 1 & 1 & 1 & 11 \\
\hline
\end{tabular}

Pitot Tube No. $3-z$

$$
\begin{aligned}
& \mathrm{c}_{\mathrm{p}}=0,824 \\
& \mathrm{P}_{\mathrm{b}}=26,99 \\
& P_{\mathrm{a}}=\frac{-2.20}{92} \mathrm{H}_{2} \mathrm{O} 26,83 \mathrm{Hg} \\
& A_{2}=9363 \text { in. }
\end{aligned}
$$

Average $\triangle P \quad 3,125$

Average $\Delta \mathrm{P}^{1 / 2}-1.766$

Average $T_{x} \quad 2 / 4{ }^{\circ} \mathrm{F}$

Average $\alpha \quad 6 \quad$ degrees 

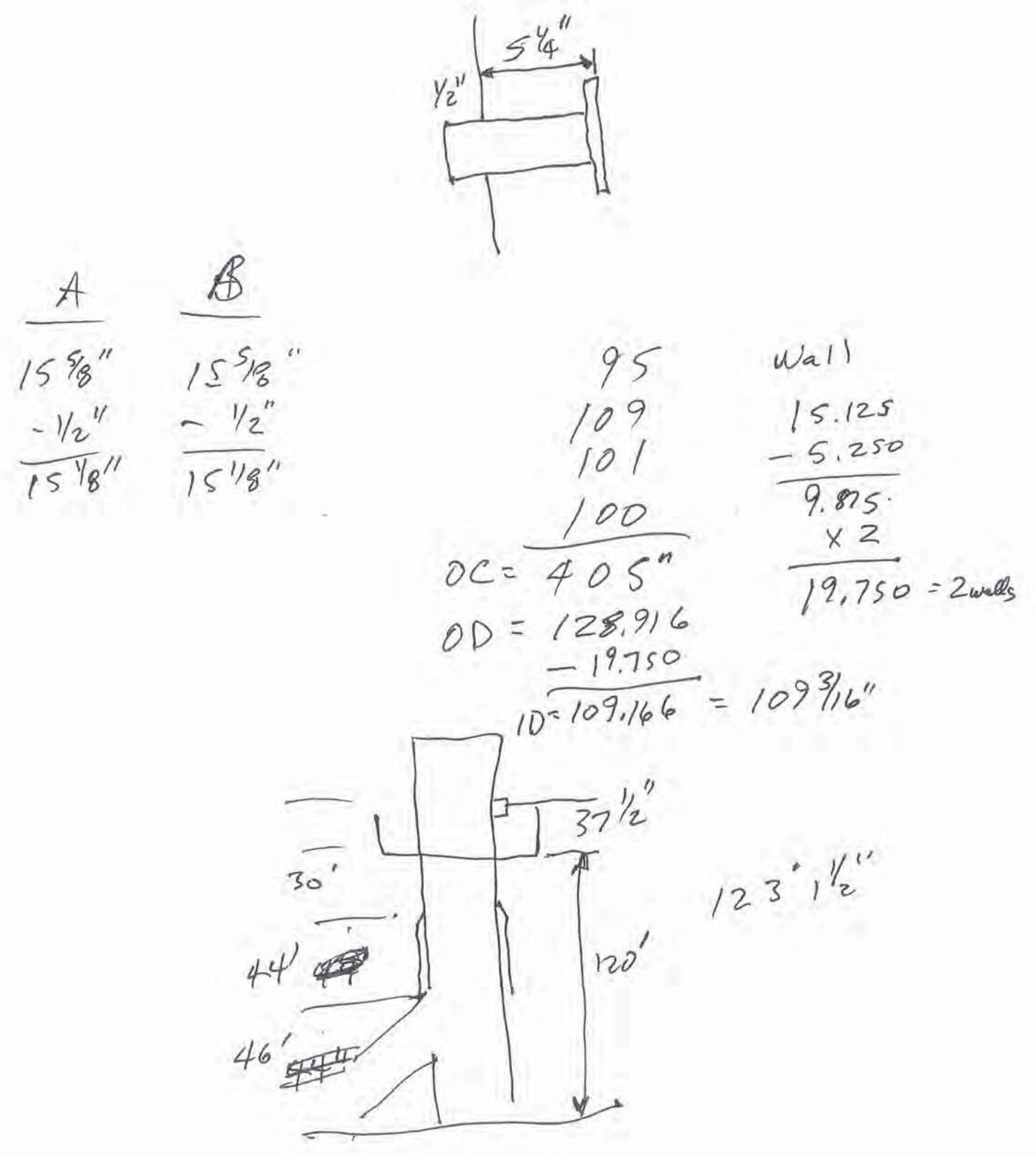

D-58 
Appendix E:

EPA Test Methods 5B and 202 (Particulate Matter) Analytical Data 
IT AIR

SAMPLING

ASSOCIATES, INC.

Air Sampling Associates, Inc.

Particulate Analysis Summary

Project Name: $A D A-E S$

Project Location: Hardin, $M T$
Project Number: $06-057$

Date Analysis Completed: $12 / 12 / 06$
Unit Tested: $\quad 5 \mathrm{tach}$

EPA Method $5 / 202$

Run Number:

Particulate Matter on Filter (mg):

Particulate Matter in Front Wash (mg):

Total Particulate Matter in "Front-Half" - MF (mg):

Particulate Matter in "Back-Half” (mg):

Total Particulate Matter in Sample - MT (mg): $\frac{1}{\frac{20.6}{12.2}} \frac{2}{\frac{29.1}{11.6}} \frac{3}{\frac{31.9}{11.4}}$

$32.8 \quad 40.7 \quad 43.3$

$\begin{array}{lll}43.4 & 37.2 \quad 12.2\end{array}$

$\begin{array}{lll}76.2 & 81.4 \quad 55.5\end{array}$
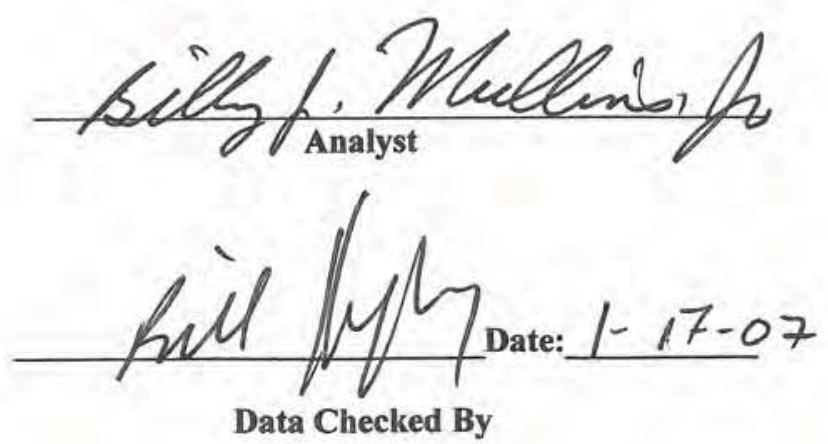

Version No. 1 5/30/06

E-2 


\section{Stack Filters}

Project No. $06-057$

Project Name ADA-ES
Location Hardin, MT Unit Tested Stack
Desiccator Time In $12 / 05 / 06 / 530$ 12/07/06 o855

Desiccator Time Out 12/07/06 0855 12/07/06 1500

\begin{tabular}{|c|c|c|c|c|}
\hline Run No. & \multicolumn{1}{c|}{ Filter No. A //4 } & \multicolumn{1}{c|}{ Sample I.D. } \\
\hline Filter \& Particulate $(\mathrm{g})$ & 0.4018 & 0.40184 & & \\
\hline
\end{tabular}

Filter \& Particulate Average (g) 0.4018 Initial Filter Weight $(\mathrm{g}) 0.381 \mathrm{z}$ Total Particulate (mg)

\begin{tabular}{|c|l|l|l|l|}
\hline Run No. Filter No. A /15 & \multicolumn{3}{c|}{ Sample I.D. } \\
\hline Filter \& Particulate $(\mathrm{g})$ & 0.3993 & 0.3991 & & \\
\hline
\end{tabular}

Filter \& Particulate Average (g) $0.399 /$ Initial Filter Weight $(\mathrm{g}) 0.3700$ Total Particulate (mg) 29,1

\begin{tabular}{|c|l|l|l|l|}
\hline Run No. & Filter No. All 6 & \multicolumn{3}{c|}{ Sample I.D. } \\
\hline Filter \& Particulate $(\mathrm{g})$ & 0.3999 & 0.3998 & & \\
\hline
\end{tabular}

Filter \& Particulate Average (g) 0.3998 Initial Filter Weight $(\mathrm{g}) 0,3679$ Total Particulate $(\mathrm{mg})$ 31.9

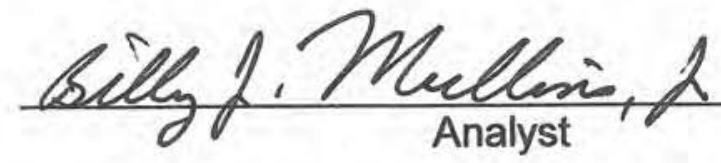




\section{IIT)}

Filter Weight Log

EPA Method 5

\begin{tabular}{|c|c|c|c|c|c|c|c|}
\hline \multirow[b]{3}{*}{ Filter No. } & Into Desicator & Weight & Weight & Weight & Weight & Weight & \multirow{3}{*}{$\begin{array}{l}\text { Weight } \\
\text { Used }\end{array}$} \\
\hline & Date & Date & Date & Date & Date & Date & \\
\hline & Time & Time & Time & Time & Time & Time & \\
\hline \multirow{3}{*}{ A105 } & & 0.3801 & 0.3801 & & & & 0.3801 \\
\hline & $10 / 2 / 06$ & $10 / 12 / 104$ & $10 / 13 / 06$ & & & & \\
\hline & 0800 & 1000 & 0826 & & & & \\
\hline \multirow{2}{*}{ A106 } & $60 / 2 / 06$ & 0,3827 & 0.3825 & & & & 0.3825 \\
\hline & 6820 & $10 / 12 / 06$ & $10 / 13 / 06$ & & & & \\
\hline \multirow{3}{*}{$A 107$} & & 1001 & 0827 & & & & \\
\hline & $10 / 2 / 06$ & 0.3808 & $0.38 / 0$ & & & & $0.38 / 0$ \\
\hline & 0800 & 1002 & 0828 & & & & \\
\hline \multirow{3}{*}{$A 108$} & & 0,3843 & 0.3845 & & & & 0.3845 \\
\hline & $10 / 2 / 06$ & $10 / 12 / 06$ & $10 / 13 / 06$ & & & & \\
\hline & 6800 & 1003 & 0829 & & & & \\
\hline \multirow{2}{*}{ A10? } & & 0.3872 & 0.3873 & & & & 0.3873 \\
\hline & $\frac{10 / 2 / 06}{0800}$ & $\frac{10 / 12 / 106}{1004}$ & $\frac{10 / 13 / 86}{0.830}$ & & & & \\
\hline \multirow{3}{*}{$A 110$} & & 0.3885 & 0,3886 & & & & 0,3886 \\
\hline & $10 / 2 / 06$ & $10 / 12 / 06$ & $10 / 13 / 06$ & & & & \\
\hline & 0860 & $\frac{10015}{1000}$ & $\frac{0}{28 \frac{1}{3} 1}$ & & & & \\
\hline \multirow{2}{*}{$A \| z$} & 10106 & $\frac{0.3833}{10 / 12106}$ & $\frac{0.3832}{10 / 1.3 / 06}$ & & & & 0.3832 \\
\hline & 0800 & $100 \mathrm{~h}$ & 6832 & & & & \\
\hline \multirow{3}{*}{$A \| 3$} & & 0.3781 & 0.3778 & & & & 0.3778 \\
\hline & $10 / 2 / 06$ & $10 / 12 / 06$ & $10 / 13 / 86$ & & & & \\
\hline & 6800 & 1007 & 6833 & & & & \\
\hline \multirow{2}{*}{$A 114$} & & 0.3814 & 0.3812 & & & & 0.3812 \\
\hline & $\frac{10 / 2 / 06}{800}$ & $\frac{10 / 12 / 06}{1008}$ & $\frac{10 / 13 / 06}{0.834}$ & & & & \\
\hline \multirow{3}{*}{ A115 } & 0800 & 0.3701 & 0,3700 & & & & 0.3700 \\
\hline & $10 / 2 / 06$ & $10 / 12 / \%$ & $10 / 13 / 06$ & & & & \\
\hline & 6860 & 1009 & 0835 & & & & \\
\hline \multirow{3}{*}{$A 116$} & & 0.3678 & 0.3679 & & & & 0,3629 \\
\hline & $10 / 2 / 06$ & $10 / 12 / 06$ & $10 / 13 / 26$ & & & & \\
\hline & 0800 & 1010 & 0836 & & & & \\
\hline \multirow{2}{*}{$A \| 7$} & & 0.3644 & 0.3644 & & & & 0.3644 \\
\hline & $\frac{10 / 2 / 06}{0800}$ & $10 / 12 / 26$ & $10 / 13 / 06$ & & & & \\
\hline \multirow{3}{*}{$A \| S$} & & 0.3636 & 0.3635 & & & & 0.3635 \\
\hline & $10 / 2 / 06$ & $11 / 20 / 06$ & $11 / 21106$ & & & & \\
\hline & 0800 & 1245 & osin 7 & & & & \\
\hline \multirow{2}{*}{$A 119$} & & 0.3655 & 0.3655 & & & & 0.3655 \\
\hline & $10 / 2 / 06$ & 11)/20/26 & $\frac{11 / 21 / 06}{38073}$ & & & & \\
\hline \multirow{3}{*}{$A 120$} & & 0.3616 & $0.36 / 5$ & & & & 0.3615 \\
\hline & $10 / 2 / 06$ & 1120106 & $11 / 21 / 26$ & & & & \\
\hline & $08^{\prime} \theta 0$ & 1247 & 0809 & & & & \\
\hline
\end{tabular}


Front Wash

Project No. 06-057

Project Name ADA-ES

Location Aarding MT

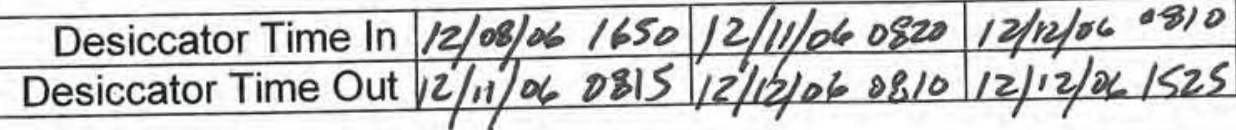

\begin{tabular}{|c|c|c|c|c|c|}
\hline Run No. & 1 & Volume $(\mathrm{ml})$ & 125 & Sample I.D. & \\
\hline Final Weight $(\mathrm{g})$ & $10 k 2852$ & 104.2788 & 104.27834 & & \\
\hline Initial Weight $(\mathrm{g})$ & 104.2651 & 104.2651 & 104.2651 & & \\
\hline Particulate Weight $(\mathrm{g})$ & & & & & \\
\hline
\end{tabular}

Particulate Average $(\mathrm{mg}) \quad 13,2$

Less Acetone Blank (mg) 1.0

Total Particulate $(\mathrm{mg}) \mathrm{l} / \mathrm{2} .2$

\begin{tabular}{|c|c|c|c|c|c|}
\hline Run No. & 2 & Volume $(\mathrm{ml})$ & 145 & Sample I.D. & \\
\hline Final Weight (g) & 91.3758 & 91.3716 & 91,37154 & & \\
\hline Initial Weight (g) & 91.3588 & 91.3588 & 91.3588 & & \\
\hline articulate Weight ( & & & & & \\
\hline
\end{tabular}

Particulate Average $(\mathrm{mg}) \quad 12.7$

Less Acetone Blank (mg)

Total Particulate $(\mathrm{mg})$

1.1

11.6

\begin{tabular}{|c|c|c|c|c|c|}
\hline Run No. & 3 & Volume (ml) & 175 & Sample I.D. & \\
\hline Final Weight (g) & 104.3077 & 104,3031 & 104.30274 & 7 & \\
\hline Initial Weight (g) & 104.2899 & 104.2899 & 104.2899 & & \\
\hline articulate Weight & & & & & \\
\hline
\end{tabular}

Particulate Average $(\mathrm{mg})$

Less Acetone Blank (mg)

Total Particulate $(\mathrm{mg})$

$\frac{12.8}{1.4}$

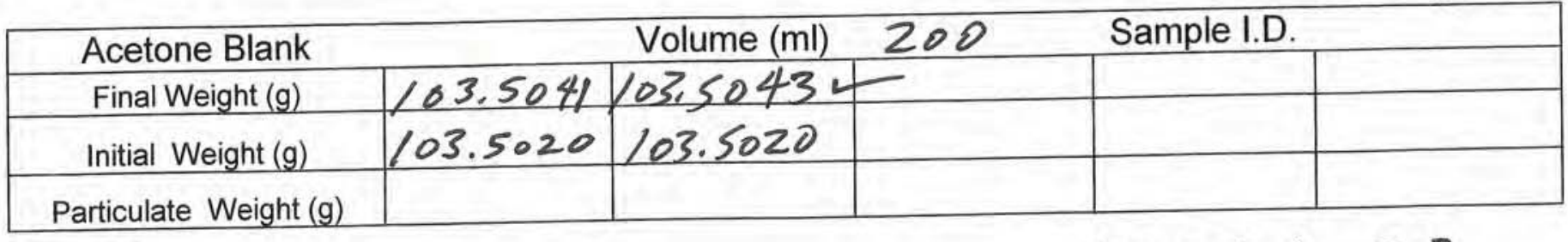

* Note: if greater than $7.9 \mathrm{mg} / \mathrm{l}$, use $7.9 \mathrm{mg} / \mathrm{l}$

$$
\begin{array}{r}
\text { Average }(\mathrm{mg}) \frac{2,3}{{ }^{*} \mathrm{mg} / \mathrm{l}} \\
1 /, 5
\end{array}
$$


Particulate Analysis EPA Method 5

Front Half Tare Weights

Project No. $06-057$

Project Name ADA-ES

Location Hardin, MT
Unit Tested $\frac{\text { Stack }}{}$

Desiccator Time In $12 / 05 / 06 / 530 / 2 / 06 / 06 / 640 / 2 / 07 / 060835$

Desiccator Time Out $12 / 06 / 06 / 635 / 2 / 00 / 060835 / 2 / 08 / 060815$

\begin{tabular}{|l|l|l|l|l|}
\hline Run No. & \multicolumn{3}{|c|}{ Sample I.D. } \\
\hline Weight (g) & $1 / 04.2659$ & 104.2649 & 104.2651 & \\
\hline
\end{tabular}

\begin{tabular}{|l|c|c|c|}
\hline Run No. & 2 \\
\hline Weight (g) & 91.3596 & 91.3585 & 91.3588 \\
\hline
\end{tabular}

Sample I.D.

Run No. Weight (g)

\begin{tabular}{l|l|l|l|}
3 & 104.2909 & 104.2899 & 104.28994
\end{tabular}

Acetone Blank Weight (g)

Sample I.D.

\begin{tabular}{l|l|l}
103.5029 & 103.5019 & 103.50204
\end{tabular}

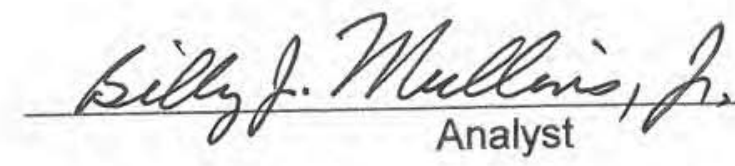




\author{
ADA-ES \\ Hardin, MT \\ 202 - Back Half Particulate Analyses
}

\begin{tabular}{|c|c|c|c|c|c|c|c|}
\hline$\frac{\text { Run No. }}{1}$ & $\begin{array}{c}\mathrm{MeCl} \\
\frac{(\mathrm{mg})}{0.4}\end{array}$ & $\begin{array}{c}\mathrm{MeCl} \\
\text { Blank } \\
\text { Correction } \\
\frac{(\mathrm{mg})}{0.0}\end{array}$ & $\begin{array}{c}\begin{array}{c}\text { DI } \\
\text { Water } \\
(\mathrm{mg})\end{array} \\
\frac{80.0}{}\end{array}$ & $\begin{array}{l}\text { DI Water } \\
\text { Blank } \\
\text { Correction } \\
\frac{(\mathrm{mg})}{60.5}\end{array}$ & $\begin{array}{l}\text { Less } \\
\text { Chlorides } \\
\frac{(\mathrm{mg})}{0.3}\end{array}$ & $\begin{array}{l}\text { Less } \\
\text { Sulfates } \\
\frac{(\mathrm{mg})}{16.8}\end{array}$ & $\begin{array}{l}\text { Total } \\
\frac{(\mathrm{mg})}{43.4}\end{array}$ \\
\hline 2 & 1.0 & 0.2 & 73.5 & 54.3 & 0.3 & 17.0 & 37.2 \\
\hline 3 & 0.5 & 0.0 & 38.9 & 19.7 & 0.3 & 7.2 & 12.2 \\
\hline Blank & 0.8 & & 15.1 & & & & \\
\hline
\end{tabular}




\section{Methylene Chloride Rinse}

\begin{tabular}{|c|c|c|c|c|c|c|}
\hline Job Number & \multirow{2}{*}{\multicolumn{2}{|c|}{$\begin{array}{l}06-4108 \\
\text { Air Sampling Associates }\end{array}$}} & \multicolumn{3}{|c|}{ Run Date } & \multirow[t]{2}{*}{$11 / 30 / 2006$} \\
\hline Client Name & & & & & & \\
\hline Unit Name & Hardin Sta & & Method: & 202 & & \\
\hline RUN 1 & BEAKER & 9612 & VOLUME & $\mathrm{ml}$ & 243 & AVERAGE \\
\hline Beaker + Particulate $(\mathrm{g})$ & & 120.9275 & 120.9270 & & & 120.9273 \\
\hline Beaker Tare (g) & & 120.9269 & 120.9268 & & & 120.9269 \\
\hline Particulate Weight (g) & & 0.0006 & 0.0002 & & & 0.0004 \\
\hline RUN 2 & BEAKER & 9614 & VOLUME & $\mathrm{ml}$ & 252 & AVERAGE \\
\hline Beaker + Particulate $(\mathrm{g})$ & & 109.5722 & 109.5717 & & & 109.5720 \\
\hline Beaker Tare $(\mathrm{g})$ & & 109.5710 & 109.5710 & & & 109.5710 \\
\hline Particulate Weight (g) & & 0.0012 & 0.0007 & & & 0.0010 \\
\hline RUN 3 & BEAKER & 9616 & VOLUME & $\mathrm{ml}$ & 249 & AVERAGE \\
\hline Beaker + Particulate $(\mathrm{g})$ & & 116.7404 & 116.7403 & & & 116.7404 \\
\hline Beaker Tare $(\mathrm{g})$ & & 116.7400 & 116.7398 & & & 116.7399 \\
\hline Particulate Weight (g) & & 0.0004 & 0.0005 & & & 0.0005 \\
\hline Blank & BEAKER & 9610 & VOLUME & $\mathrm{ml}$ & 266 & AVERAGE \\
\hline Beaker + Particulate $(\mathrm{g})$ & & 108.6839 & 108.6834 & & & 108.6837 \\
\hline Beaker Tare $(9)$ & & 108.6829 & 108.6829 & & & 108.6829 \\
\hline Particulate Weight (g) & & 0.0010 & 0.0005 & & & 0.0008 \\
\hline Analyst & FIN & L REPORT & & $\begin{array}{l}\text { arted } \\
\text { ompleted }\end{array}$ & & $\begin{array}{c}12 / 4 / 2006 \\
12 / 12 / 2006\end{array}$ \\
\hline
\end{tabular}


DI Water Analysis (Back)

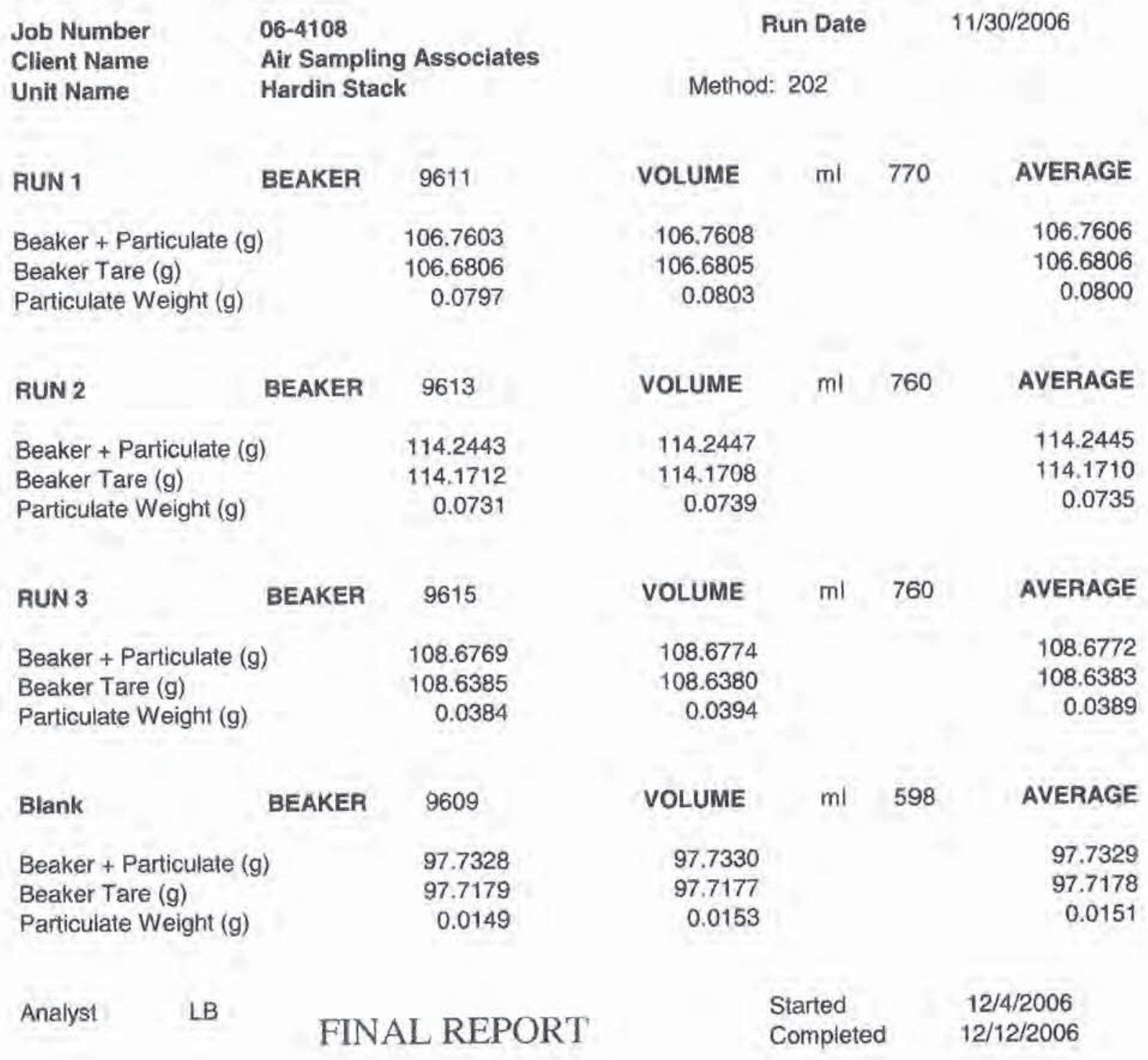


Results,

Lab mg

Results, Corrected

ug Blank, ug to $\mathrm{NH} 4 \mathrm{Cl}$

\begin{tabular}{lcccc}
\multicolumn{5}{c}{ Sample No. } \\
Run 1 & 9611 & 7.29 & 202 & -0.294 \\
Run 2 & 9613 & 8.84 & 202 & -0.291 \\
Run 3 & 9615 & 0.842 & 202 & -0.304
\end{tabular}

Blank $9609 \quad 202$ 


$\begin{array}{ccccc}\text { Sample } & \text { Lab } & \text { Lab } & & \text { Final } \\ \text { Volume, } & \text { Volume, } & \text { Results, } & \text { Blank, } & \text { Results, } \\ \mathrm{ml} & \mathrm{ml} & \mathrm{ug} / \mathrm{ml} & \mathrm{ug} / \mathrm{ml} & \mathrm{mg}\end{array}$

Sample No.

$\begin{array}{lcccccc}\text { Run 1 } & 4108-1 & 770 & 20 & 61.8 & 0.115 & 16.814 \\ \text { Run 2 } & 4108-2 & 760 & 20 & 63.3 & 0.115 & 16.999 \\ \text { Run 3 } & 4108-3 & 760 & 20 & 27 & 0.115 & 7.233 \\ & & & & & & \\ \text { Blank } & 4108-4 & 598 & 20 & 0.115 & & 0.024\end{array}$




\section{Appendix F:}

EPA Test Methods 17, 26A, and CTM027 (Particulate Matter, Hydrogen Halides \& Halogens, and) Analytical Data - SDA Inlet Duct 
11. SlR SAMPLing

ASSOCIATES, INC.

Air Sampling Associates, Inc.

Particulate Analysis Summary

Project Number: $06-057$

Project Name: $A D A-E S$

Project Location: Hardin, MT
Date Analysis Completed: $12 / 8 / 06$

Unit Tested: SDA Inlet
Run Number:

Particulate Matter on Filter (mg):

Particulate Matter in Front Wash (mg):

Total Particulate Matter in "Front-Half" - MF (mg):

Particulate Matter in "Back-Half” (mg):

Total Particulate Matter in Sample - MT (mg):
EPA Method 17

123

$4,554.7 \quad 5,056.9 \quad 4,302.8$

$1,450.0 \quad 2,170.0 \quad 2,060.0$

$6,004.7 \quad 7,226.9 \quad 6,362.8$
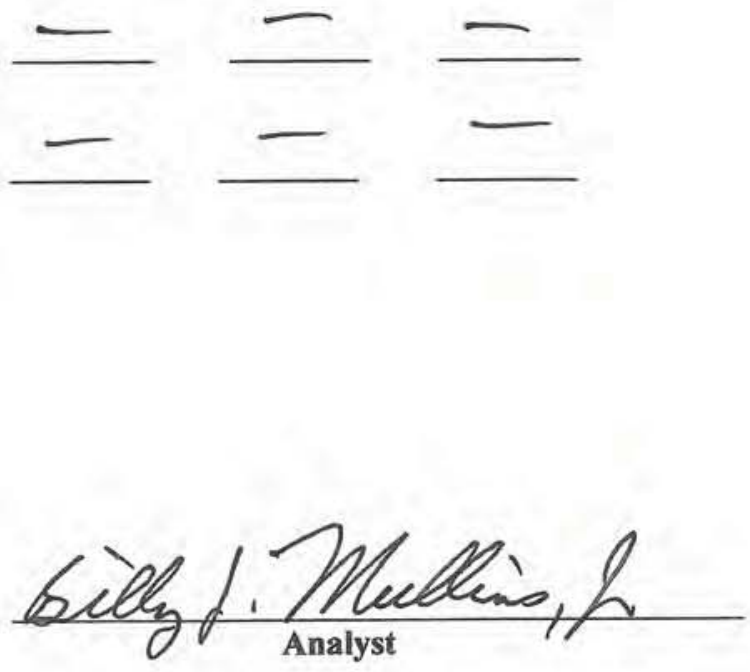

thill thy

Data Checked By

Version No. 1 5/30/06

F-2 
AIR

SAMPLING

ASSOCIATES, INC.

Particulate Analysis EPA Method 17

Stack Filters

Project No. $06-057$

Project Name ADA -ES
Location Hardin, MT

Unit Tested SDA Inlet

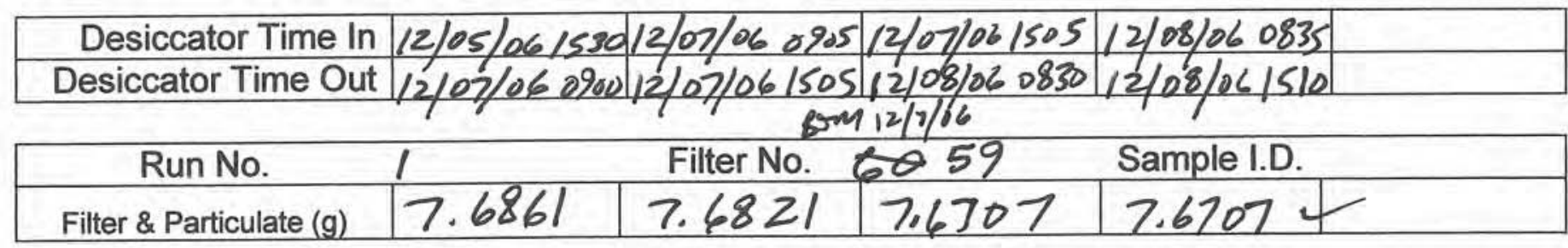

Filter \& Particulate Average (g) 7.6707 Initial Filter Weight $(\mathrm{g}) 3.1 / 60$ Total Particulate $(\mathrm{mg}), 4,554.7$

\begin{tabular}{|c|c|c|c|c|}
\hline Run No. 2 & Filter No. 60 & Sample llD. \\
\hline Filter \& Particulate (g) & 7.7854 & 7.7825 & 7.7784 & 7.7779 \\
\hline
\end{tabular}

Filter \& Particulate Average (g) 7,7779 Initial Filter Weight $(\mathrm{g}) \mathrm{2.7210}$ Total Particulate (mg) $5,056.9$

\begin{tabular}{|l|l|l|l|l|}
\hline Run No. 3 & Filter No. 61 & Sample I.D. \\
\hline Filter \& Particulate (g) & 7.0722 & 7.0680 & 7.0563 & 7.05584 \\
\hline
\end{tabular}

Filter \& Particulate Average (g) 7.0558 Initial Filter Weight $(\mathrm{g}) 2.7530$ Total Particulate $(\mathrm{mg}) \frac{2,302.8}{4,8}$

$\underset{\text { Billy f. Mullins, }}{\text { Analyst }}$

F-3 
ASSOCIATES, INC.

Thimble Tare Weight Log

EPA Method 17

\begin{tabular}{|c|c|c|c|c|c|c|c|}
\hline \multirow[b]{3}{*}{ Filter No. } & Into Desicator & Weight & Weight & Weight & Weight & Weight & \multirow{3}{*}{$\begin{array}{l}\text { Weight } \\
\text { Used }\end{array}$} \\
\hline & Date & Date & Date & Date & Date & Date & \\
\hline & Time & Time & Time & Time & Time & Time & \\
\hline \multirow{3}{*}{45} & & 2.944 & 2.7944 & & & & $2.79+4$ \\
\hline & 9129100 & $10 \mathrm{k} / \alpha_{6}$ & $10 / 3106$ & & & & \\
\hline & 1200 & 1635 & 1100 & & & & \\
\hline \multirow{3}{*}{46} & 1 & 2.7987 & $2.7990^{\circ}$ & & & & 2.7990 \\
\hline & & $10 / 2 / 06$ & $10 / 3 / 04$ & & & & \\
\hline & & 1636 & 1101 & & & & \\
\hline \multirow{3}{*}{47} & & $2,55 / 4$ & 2.55147 & & & & 2.5514 \\
\hline & & $10 / 2 / 04$ & $10 / 3106$ & & & & \\
\hline & & 1637 & 1102 & & & & \\
\hline \multirow{2}{*}{48} & & 2.7781 & 2.7785 & & & & 2.7785 \\
\hline & & $10 / 2 / 06$ & 1013106 & & & & \\
\hline \multirow{3}{*}{49} & & $\frac{1638}{2.7795}$ & $\frac{1103}{2.7799}$ & & & & 2.7799 \\
\hline & & $10 / 2 / 06$ & $10 / 3106$ & & & & \\
\hline & & 1639 & 1104 & & & & \\
\hline \multirow{3}{*}{50} & & 2.6485 & 2.6487 & & & & 2.6487 \\
\hline & & $10 / 2 / 06$ & $10 / 3106$ & & & & \\
\hline & & 1640 & 1105 & & & & \\
\hline \multirow{3}{*}{51} & & 2.8600 & 2.8605 & & & & 2.8605 \\
\hline & & $10 / 2106$ & 1013106 & & & & \\
\hline & & 1641 & 1106 & & & & \\
\hline \multirow{3}{*}{52} & & $2.8+70$ & 2.8474 & & & & 2.8474 \\
\hline & & $10 / 2 / 06$ & $10 / 3104$ & & & & \\
\hline & & 1642 & 1107 & & & & \\
\hline \multirow{2}{*}{53} & & $2.73+9$ & 2.7352 & - & & & 2.7352 \\
\hline & \pm & $10 / 2 / 06$ & 1013106 & & & & \\
\hline \multirow{3}{*}{54} & & $\frac{16243}{2.5794}$ & $\frac{1108}{3.5795}$ & $\bar{C}$ & & & \\
\hline & $11 / 20106$ & $11 / 21 / 06$ & nI/22/06 & & & & 3,5795 \\
\hline & 1360 & 1350 & 0745 & & & & \\
\hline \multirow{3}{*}{55} & & 2.8785 & 2,8788 & $\angle$ & & & 2.8788 \\
\hline & & $11 / 21 / 06$ & $11 / 22 / 06$ & & & & \\
\hline & & 1351 & $07+6$ & & & & \\
\hline \multirow[t]{2}{*}{56} & & 2.4725 & 2.4724 & $\simeq$ & & & 2.4724 \\
\hline & & $11 / 21 / 06$ & $\frac{11 / 22 / 06}{0747}$ & & & & \\
\hline \multirow{2}{*}{57} & & 2.9916 & 2.9911 & E & & & 2.9911 \\
\hline & & $11 / 21 / 06$ & $11 / 22 / 06$ & & & & \\
\hline \multirow{3}{*}{58} & & 1353 & 2748 & & & & \\
\hline & & $\frac{3.4660}{121106}$ & 3.4656 & 8 & & & 3,4656 \\
\hline & & $\frac{11 / 21 / 06}{254}$ & $11 / 22 / 06$ & & & & \\
\hline \multirow{3}{*}{59} & & $\frac{1354}{3.1165}$ & $\frac{0749}{3.1160}$ & $\bar{Y}$ & & & 3.1160 \\
\hline & & $11 / 2 / 0^{6}$ & $11 / 22 / 06$ & & & & \\
\hline & & 1355 & 6750 & & & & \\
\hline
\end{tabular}




\section{II) ASSOCIATES, INC.}

Thimble Tare Weight Log

EPA Method 17

\begin{tabular}{|c|c|c|c|c|c|c|c|}
\hline \multirow[b]{3}{*}{ Filter No. } & Into Desicator & Weight & Weight & Weight & Weight & Weight & \multirow{3}{*}{$\begin{array}{l}\text { Weight } \\
\text { Used }\end{array}$} \\
\hline & Date & Date & Date & Date & Date & Date & \\
\hline & Time & Time & Time & Time & Time & Time & \\
\hline \multirow{3}{*}{60} & & 2.7215 & 2,7210 & t & & & 2.7210 \\
\hline & $11 / 20 / 06$ & $11 / 21 / 06$ & $11 / 22 / 86$ & & & & \\
\hline & 1300 & 1358 & 6752 & & & & \\
\hline \multirow{3}{*}{61} & & 2.7531 & 2.75304 & $=$ & & & 2.7530 \\
\hline & $11 / 20 / 06$ & $11 / 21 / 06$ & $11 / 22 / 06$ & & & & \\
\hline & 1360 & 1359 & 07531 & & & & \\
\hline \multirow[b]{2}{*}{62} & & 2,7516 & 2.75144 & ᄃ & & & 2.7514 \\
\hline & $11 / 20 / 06$ & $11 / 21 / 06$ & $11 / 22 / 06$ & & & & \\
\hline \multirow{3}{*}{63} & $1 / 360$ & 1400 & 0254 & & & & \\
\hline & 11720106 & 2.7876 & 2,78484 & & & & 2.7848 \\
\hline & 1300 & 1401 & 0755 & & & & \\
\hline \multirow{3}{*}{64} & & 2.9993 & 2.9992 & 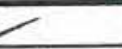 & & & 2.9992 \\
\hline & $1 / 120 / 06$ & $11 / 21 / 06$ & $11 / 22 / 06$ & & & & \\
\hline & 1360 & 1402 & 6756 & & & & \\
\hline \multirow{2}{*}{65} & & 2.6385 & 2.63814 & ᄃ & & & 2.6381 \\
\hline & $11 / 20 / 06$ & $11 / 21 / 06$ & $11 / 2 z / 06$ & & & & \\
\hline \multirow{3}{*}{66} & 1360 & $\frac{1403}{2.12}$ & $\frac{6757}{3860}$ & $=$ & & & 78660 \\
\hline & $11 / 20 / 06$ & $\frac{2.8663}{11 / 2106}$ & $11 / 22 / \alpha$ & & & & \\
\hline & 1300 & 1404 & 6860 & & & & \\
\hline \multirow{3}{*}{67} & & 2.9442 & 2.94394 & - & & & 2.9439 \\
\hline & $11 / 20 / 06$ & $11 / 21 / 06$ & $11 / 22 / 06$ & & & & \\
\hline & 1300 & 1404 & 0801 & & & & \\
\hline \multirow[b]{2}{*}{68} & & 2.5183 & $2.5 / 82$ & $\angle$ & & & 2.5182 \\
\hline & $11 / 20 / 06$ & $11 / 21 / 06$ & $11 / 22 / 06$ & & & & \\
\hline \multirow{3}{*}{69} & 1300 & $\frac{1405}{27292}$ & $\frac{0862}{27291}$ & $=$ & & & 2,7291 \\
\hline & 11120106 & $11 / 21 / 06$ & $11 / 22 / 06$ & & & & \\
\hline & 1300 & 1406 & 6803 & & & & \\
\hline \multirow{3}{*}{70} & & 2,5250 & 2.52484 & & & & 2,5248 \\
\hline & $11 / 20 / 06$ & $11 / 21 / 06$ & $11 / 22 / 06$ & & & & \\
\hline & $1 / 360$ & 1407 & 0804 & & & & \\
\hline \multirow{2}{*}{71} & & 2.4725 & 2.47214 & - & & & 2.4721 \\
\hline & $11 / 20 / 06$ & $(1 / 2) / 16$ & $11 / 22 / 06$ & & & & \\
\hline \multirow{3}{*}{72} & 1300 & $\frac{1408}{27091}$ & $\frac{6805}{77989}$ & $=$ & & & 2.7988 \\
\hline & $11 / 20 / 06$ & $11 / 21 / 06$ & 1122106 & & & & \\
\hline & $1 / 300$ & 1409 & 78806 & & & & \\
\hline \multirow[b]{2}{*}{73} & & 3.1339 & 3,13364 & E & & & 3.1336 \\
\hline & $11 / 20 / 06$ & $11 / 21 / 66$ & $11 / 22 / 06$ & & & & \\
\hline \multirow{3}{*}{74} & 1300 & $14^{\prime} 10$ & 0807 & & & & \\
\hline & $11 / 20 / 06$ & 2.8562 & 2.85614 & 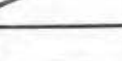 & & & 2.8561 \\
\hline & (500 & 1410 & 0868 & & & & \\
\hline
\end{tabular}


H6L110106 Analytical Report............................................. 1

Sample Receipt Documentation ....................................... $\quad 27$

Wet Chemistry ................................................................ 33

Sample Summary .................................................. 34

QC Summary …...................................................... 4

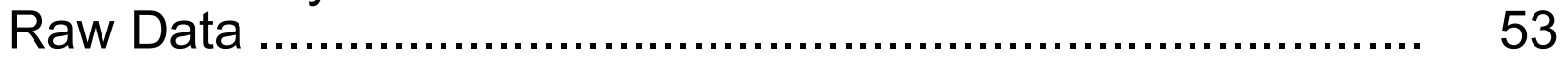

Subcontract STL- North Canton ........................................ 180

General Chemistry Data ............................................. 181

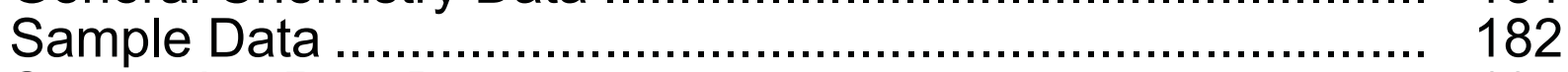

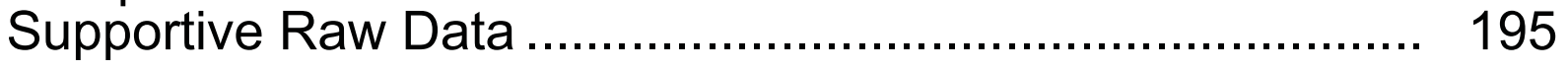

Sample Receipt Documentation ........................................ 199

Total Number of Pages ....................................................... 206 


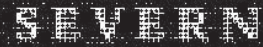

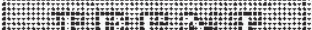 (1) \\ STL Knoxville \\ 5815 Middlebrook Pike \\ Kroxville, TN 37921 \\ Tel: 8652913000 Fax: 8655844315 \\ www.stl-inc.com
}

\section{ANALYTICAL REPORT}

\author{
REVISED \\ PROJECT NO. 06-057 \\ Hardin, Montana SDA Inlet Duct \\ Lot \#: H6L110106 \\ Bill Hefley \\ Air Sampling Associates, Inc. \\ 407-2B Holford's Prairie Road \\ Lewisville, TX 75056
}

SEVERN TRENT LABORATORIES, INC.

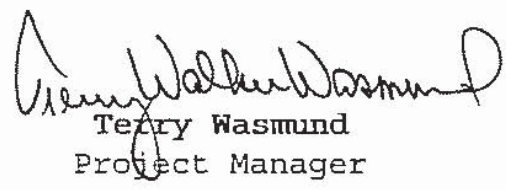

January 22, 2007 


\section{ANALYTICAL METHODS SUMMARY}

H6L110106

\begin{tabular}{|c|c|}
\hline PARAMETER & $\begin{array}{l}\text { ANALYTICAL } \\
\text { METHOD }\end{array}$ \\
\hline Ammonia Nitrogen & MCAWW 350.3 \\
\hline Bromine Emissions & KNOX $0050 / 26 \mathrm{~A}$ Mod \\
\hline Chlorine Emissions & KNOX $0050 / 26 \mathrm{~A}$ Mod \\
\hline Hydrogen Bromide Emissions & KINOX $0050 / 26 \mathrm{~A}$ Mod \\
\hline Hydrogen Chloride Emissions & KNOX $0050 / 26 \mathrm{~A}$ Mod \\
\hline Hydrogen Fluoride Emissions & KNOX $0050 / 26 \mathrm{~A}$ Mod \\
\hline Particulate Emissions & CFR60A 5 \\
\hline \multicolumn{2}{|l|}{ References: } \\
\hline "Test Methods", 40 CFR, Part 60, Appendix & A, July 1, 1993. \\
\hline $\begin{array}{l}\text { Severn Trent Laboratories Knoxville, Facil } \\
\text { Operating Procedure. }\end{array}$ & lity standard \\
\hline $\begin{array}{l}\text { "Methods for Chemical Analysis of Water ar } \\
\text { EPA-600/4-79-020, March } 1983 \text { and subsequer }\end{array}$ & $\begin{array}{l}\text { and Wastes", } \\
\text { ent revisions. }\end{array}$ \\
\hline
\end{tabular}




\title{
QC DATA ASSOCIATION SUMMARY
}

\author{
H6L110106
}

Sample Preparation and Analysis Control Numbers

\begin{tabular}{|c|c|c|c|c|c|}
\hline SAMPLE\# & MATRIX & $\begin{array}{l}\text { ANALYTICAL } \\
\text { METHOD }\end{array}$ & $\begin{array}{l}\text { LEACH } \\
\text { BATCH \# }\end{array}$ & $\begin{array}{l}\text { PREP } \\
\text { BATCH \# }\end{array}$ & MS RUN\#\# \\
\hline 001 & AIR & CFR60A 5 & & 6349313 & \\
\hline \multirow[t]{3}{*}{002} & AIR & KNOX $0050 / 26 \mathrm{~A}$ Mod & & 6361375 & 6362029 \\
\hline & AIR & KNOX $0050 / 26 \mathrm{~A}$ Mod & & 6363147 & 6363102 \\
\hline & AIR & KNOX $0050 / 26 \mathrm{~A}$ Mod & & 6361376 & 6362031 \\
\hline 003 & WATER & MCAWW 350.3 & & 6348460 & 6348277 \\
\hline \multirow{3}{*}{004} & AIR & KNOX $0050 / 26 \mathrm{~A}$ Mod & & 6356347 & 6356196 \\
\hline & AIR & KNOX $0050 / 26 \mathrm{~A}$ Mod & & 6356350 & 6356197 \\
\hline & AIR & KNOX $0050 / 26 \mathrm{~A}$ Mod & & 6356352 & 6356198 \\
\hline 005 & AIR & CFR60A 5 & & 6349313 & \\
\hline \multirow[t]{3}{*}{006} & AIR & KNOX $0050 / 26 \mathrm{~A}$ Mod & & 6361375 & \\
\hline & AIR & KNOX $0050 / 26 \mathrm{~A} \operatorname{Mod}$ & & 6363147 & \\
\hline & AIR & KNOX $0050 / 26 \mathrm{~A}$ Mod & & 6361376 & \\
\hline 007 & WATER & MCAWW 350.3 & & 6348460 & 6348277 \\
\hline \multirow[t]{3}{*}{008} & AIR & KNOX $0050 / 26 \mathrm{~A}$ Mod & & 6356347 & 6356196 \\
\hline & AIR & KNOX $0050 / 26 \mathrm{~A}$ Mod & & 6356350 & 6356197 \\
\hline & AIR & KNOX $0050 / 26 \mathrm{~A}$ Mod & & 6356352 & 6356198 \\
\hline 009 & AIR & CFR60A 5 & & 6349313 & \\
\hline \multirow[t]{3}{*}{010} & AIR & KNOX $0050 / 26 \mathrm{~A}$ Mod & & 6361375 & \\
\hline & AIR & KNOX $0050 / 26 \mathrm{~A}$ Mod & & 6363147 & \\
\hline & AIR & KNOX $0050 / 26 \mathrm{~A}$ Mod & & 6361376 & \\
\hline $0 I I$ & WATER & MCAWW 350.3 & & 6348460 & 6348277 \\
\hline \multirow[t]{3}{*}{012} & AIR & KNOX $0050 / 26 \mathrm{~A}$ Mod & & 6356347 & 6356196 \\
\hline & AIR & KNOX $0050 / 26 \mathrm{~A}$ Mod & & 6356350 & 6356197 \\
\hline & AIR & KNOX $0050 / 26 \mathrm{~A}$ Mod & & 6356352 & 6356198 \\
\hline \multirow[t]{3}{*}{013} & AIR & KNOX $0050 / 26 \mathrm{~A}$ Mod & & 6361375 & \\
\hline & AIR & KNOX $0050 / 26 A$ Mod & & 6363098 & \\
\hline & AIR & KNOX $0050 / 26 \mathrm{~A}$ Mod & & 6361376 & \\
\hline 014 & WATER & MCAWW 350.3 & & 6348460 & 6348277 \\
\hline
\end{tabular}

(Continued on next page) 


\section{QC DATA ASSOCIATION SUMMARY}

H6L110106

Sample Preparation and Analysis Control Numbers

\begin{tabular}{|c|c|c|c|c|c|}
\hline SAMPLE\# & MATRIX & $\begin{array}{l}\text { ANALYTICAL } \\
\text { METHOD }\end{array}$ & $\begin{array}{l}\text { LEACH } \\
\text { BATCH \# }\end{array}$ & $\begin{array}{l}\text { PREP } \\
\text { BATCH \# }\end{array}$ & MS RUN\# \\
\hline \multirow[t]{3}{*}{015} & AIR & KNOX $0050 / 26 \mathrm{~A}$ Mod & & 6356347 & 6356196 \\
\hline & AIR & $\mathrm{KNOX} 0050 / 26 \mathrm{~A} \operatorname{Mod}$ & & 6356350 & 6356197 \\
\hline & AIR & KNOX $0050 / 26 \mathrm{~A} \operatorname{Mod}$ & & 6356352 & 6356198 \\
\hline \multirow[t]{3}{*}{016} & AIR & KNOX $0050 / 26 \mathrm{~A}$ Mod & & 6361375 & \\
\hline & AIR & KNOX $0050 / 26 \mathrm{~A}$ Mod & & 6363098 & \\
\hline & AIR & KNOX $0050 / 26 \mathrm{~A}$ Mod & & 6361376 & \\
\hline
\end{tabular}


SAMPLE SUMMARY

H6L110106

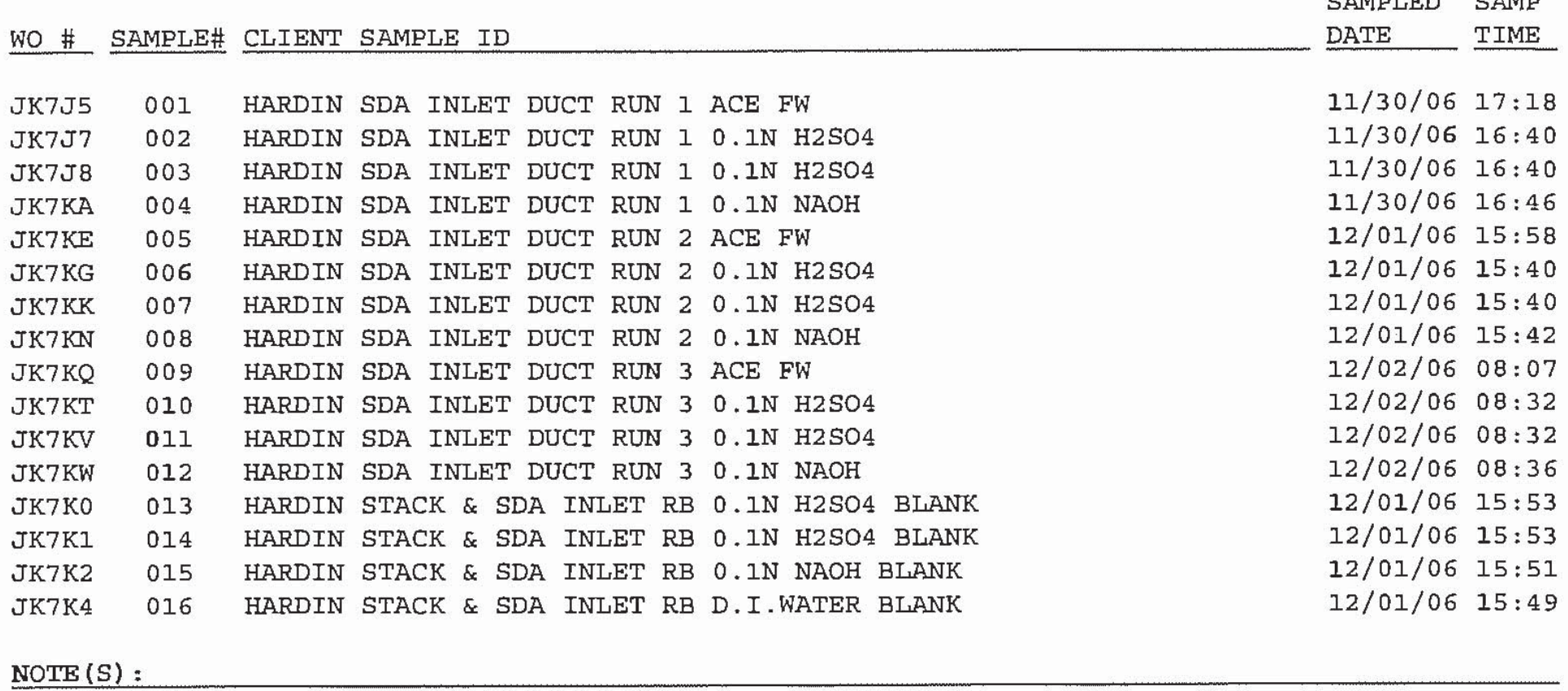

- The anaiyticas results of the samples listed above are presented on the following pages.

- All calculations are performed before rounding to avoid round-off errors in calculated results.

- Results noted as "ND" were not detected at or above the stated limit.

- This report must not be reproduced, except in full, without the written approval of the laboratory.

- Results for the following parameters are never reported on a dry weight basis: color, corrosivity, density, Masiapoint, ignitability, layers, odor,

paint filter test, pH, porosity pressure, reactivity, redox potential, specific gravity, spot tests, solids, solubility, temperature, viscosity, and weight. 


\section{PROJECT NARRATIVE \\ H6L110106 \\ Revised \\ 01/19/07}

\section{NOTE: This data package has been revised to include ammonia results that were inadvertently omitted from the original package.}

The results reported herein are applicable to the samples submitted for analysis only.

This report shall not be reproduced except in full, without the written approval of the laboratory.

The original chain of custody documentation is included with this report.

\section{Sample Receipt}

The chain of custody documentation shows that container number 2 was retained by ASAI. However, container number 2 was received.

Custody seals were not present upon sample receipt at STL Knoxville.

\section{Subcontract}

The following analyses were performed by the STL North Canton Laboratory (NELAP Accrediting Authority: FLDOH; Lab ID E87225), 4101 Shuffel Drive, NW, North Canton, $\mathrm{OH}$ 44720, (330) 497-9396, Opal Johnson, Laboratory Director: Ammonia Nitrogen (MCAWW 350.3)

\section{Quality Control and Data Interpretation}

Unless otherwise noted, all holding times and QC criteria were met and the test results shown in this report meet all applicable NELAC requirements.

Samples were analyzed for chloride $\left(\mathrm{Cl}^{-}\right)$, fluoride $\left(\mathrm{F}^{-}\right)$and bromide $\left(\mathrm{Br}^{-}\right)$by ion chromatography using SOP number KNOX-WC-005 (based on EPA methods 9056, 9057 and 26A). Results for the $\mathrm{H}_{2} \mathrm{SO}_{4}$ impinger samples were reported as total $\mu \mathrm{g}$ hydrogen chloride $(\mathrm{HCl})$, total $\mu \mathrm{g}$ hydrogen fluoride $(\mathrm{HF})$ and total $\mu \mathrm{g}$ hydrogen bromide $(\mathrm{HBr})$.

STL Knoxville maintains the following certifications, approvals and accreditations: Arkansas DEQ Cert. \#05-043-0, California DHS ELAP Cert. \#2423, Colorado DPHE, Connecticut DPH Cert. \#PH-0223, Florida DOH Cert. \#E87177, Georgia DNR Cert. \#906, Hawaii DOH, Illinois EPA Cert. \#000687, Indiana DOH Cert. \#C-TN-02, Iowa DNR Cert. \#375, Kansas DHE Cert. \#E-10349, Kentucky DEP Lab ID \#90101, Louisiana DEQ Cert. \#03079, Louisiana DOHH Cert. \#LA030024, Maryland DHMH Cert. \#277, Massachusetts DEP Cert. \#M-TN009, Michigan DEQ Lab ID \#9933, New Jersey DEP Cert. \#TN001, New York DOH Lab \#10781, North Carolina DPH Lab ID \#21705, North Carolina DEHNR Cert. \#64, Ohio EPA VAP Cert. \#CL0059, Oklahoma DEQ ID \#9415, Pennsylvania DEP Cert. \#68-00576, South Carolina DHEC Lab ID \#84001001, Tennessee DOH Lab ID \#02014, Utah DOH Cert. \# QUAN3, Virginia DGS Lab ID \#00165, Washington DOE Lab \#C120, West Virginia DEP Cert. \#345, Wisconsin DNR Lab ID \#998044300, Naval Facilities Engineering Service Center and USDA Soil Permit \#S-46424. This list of approvals is subject to change and does not imply that laboratory certification is available for all parameters reported in this environmental sample data report. 


\section{PROJECT NARRATIVE \\ H6L110106 \\ Revised \\ 01/19/07}

Results for the $\mathrm{NaOH}$ impinger samples were reported as total $\mu \mathrm{g}$ chlorine $\left(\mathrm{Cl}_{2}\right)$, total $\mu \mathrm{g}$ hydrogen fluoride (HF) and total $\mu \mathrm{g}$ hydrogen bromine $\left(\mathrm{Br}_{2}\right)$.

Please note that the halogen fluorine $(\mathrm{F})$ is not expected to be present in stack gas as diatomic fluorine $\left(\mathrm{F}_{2}\right)$. Fluorine reacts with water vapor in a favored reaction that forms $\mathrm{HF}: 2 \mathrm{~F}_{2}+2 \mathrm{H}_{2} \mathrm{O} \rightarrow 4 \mathrm{HF}+\mathrm{O}_{2}$. Therefore, the results from the $\mathrm{H}_{2} \mathrm{SO}_{4}$ impingers and the $\mathrm{NaOH}$ impingers are reported as $\mathrm{HF}$, and no $\mathrm{F}_{2}$ is expected in the samples.

Results were calculated using the following equations:

$$
\begin{aligned}
& \mathrm{HX}, \mathrm{ug}=\left(\mathrm{X}^{-}, \mathrm{ug} / \mathrm{mL}\right) *(\text { Sample Volume }, \mathrm{mL}) *\left(\frac{\text { Molecular Weight HX }}{\text { Molecular Weight } \mathrm{X}^{-}}\right) *(\text { Bench Dilution }) \\
& \mathrm{Cl}_{2}, \mathrm{Br}_{2} \mathrm{ug}=\left(\mathrm{X}^{-}, \mathrm{ug} / \mathrm{mL}\right) *(\text { Sample Volume } \mathrm{mL}) *(\text { Bench Dilution })
\end{aligned}
$$

$\mathrm{NaOH}$ impinger samples were treated with sodium thiosulfate $\left(\mathrm{Na}_{2} \mathrm{~S}_{2} \mathrm{O}_{3}\right)$ prior to the final analysis in order to convert residual hypochlorite $\left(\mathrm{OCl}^{-}\right)$to chloride ion. The presence of hypobromite is also assumed to be converted to bromide under these conditions.

Note: A sample volume of $100 \mathrm{~mL}$ was used to convert the results to total $\mu \mathrm{g}$ for the method blanks, laboratory control samples, and client reagent blanks.

For demonstration of analytical method performance on these samples, STL Knoxville analyzed matrix spikes (MS) and matrix spike duplicates (MSD). Acceptable recoveries of these spikes demonstrate that quantitation from this particular stack gas matrix is accurate and acceptable. Impinger samples containing $0.1 \mathrm{~N} \mathrm{H}_{2} \mathrm{SO} 4$ and $0.1 \mathrm{~N} \mathrm{NaOH}$ display matrix interference effects causing poor method performance and possibly giving unreliable data unless the interference is removed. Therefore, the samples were diluted in the lab to remove the interference for a more accurate chloride response. The samples may be analyzed at increasing dilutions along with matrix spikes until matrix spikes recover from the sample within laboratory control limits. The ion chromatograph

STL Knoxville maintains the following certifications, approvals and accreditations: Arkansas DEQ Cert. \#05-043-0, California DHS ELAP Cert. \#2423, Colorado DPHE, Connecticut DPH Cert. \#PH-0223, Florida DOH Cert. \#E87177, Georgia DNR Cert. \#906, Hawaii DOH, Illinois EPA Cert. \#000687, Indiana DOH Cert. \#C-TN-02, Iowa DNR Cert. \#375, Kansas DHE Cert. \#E-10349, Kentucky DEP Lab ID \#90101, Louisiana DEQ Cert. \#03079, Louisiana DOHH Cert. \#LA030024, Maryland DHMH Cert. \#277, Massachusetts DEP Cert. \#M-TN009, Michigan DEQ Lab ID \#9933, New Jersey DEP Cert. \#TN001, New York DOH Lab \#10781, North Carolina DPH Lab ID \#21705, North Carolina DEHNR Cert. \#64, Ohio EPA VAP Cert. \#CL0059, Oklahoma DEQ ID \#9415, Pennsylvania DEP Cert. \#68-00576, South Carolina DHEC Lab ID \#84001001, Tennessee DOH Lab ID \#02014, Utah DOH Cert. \# QUAN3, Virginia DGS Lab ID \#00165, Washington DOE Lab \#C120, West Virginia DEP Cert. \#345, Wisconsin DNR Lab ID \#998044300, Naval Facilities Engineering Service Center and USDA Soil Permit \#S-46424. This list of approvals is subject to change and does not imply that laboratory certification is available for all parameters reported in this environmental sample data report. 


\section{PROJECT NARRATIVE \\ H6L110106 \\ Revised \\ 01/19/07}

calibration range used to quantitate the sample results permits a standard ten-fold sample dilution while supporting the reporting limit with the low calibration standard.

The dilution factor reported on the sample result form does not represent the bench dilution factor. It is actually the combination of factors required by the method to convert the anion reporting limit and method detection limit from $\mu \mathrm{g} / \mathrm{mL}$ to total $\mu \mathrm{g}$. It may appear to be elevated because it includes the total sample volume in $\mathrm{mL}$.

All holding times and QC criteria were met.

The $\mathrm{pH}$ for several samples was adjusted prior to analysis. Refer to the STL Knoxville Source Air Analysis Sample Information form in the Raw Data section of the deliverable.

The measurement of the mass of particulate matter trapped by the probe rinses derived from M-5 sampling trains was performed using SOP number KNOX-WC-0006 (based on EPA Methods 0050 and 5). $150 \mathrm{~mL}$ beakers are carefully inspected and tare weighed to constant weight. The acetone probe rinse solution is evaporated to dryness, and then weighed to constant weight to determine the total particulate mass collected in the rinse.

STL Knoxville maintains the following certifications, approvals and accreditations: Arkansas DEQ Cert. \#05-043-0, California DHS ELAP Cert. \#2423, Colorado DPHE, Connecticut DPH Cert. \#PH-0223, Florida DOH Cert. \#E87177, Georgia DNR Cert. \#906, Hawaii DOH, Illinois EPA Cert. \#000687, Indiana DOH Cert. \#C-TN-02, Iowa DNR Cert. \#375, Kansas DHE Cert. \#E-10349, Kentucky DEP Lab ID \#90101, Louisiana DEQ Cert. \#03079, Louisiana DOHH Cert. \#LA030024, Maryland DHMH Cert. \#277, Massachusetts DEP Cert. \#M-TN009, Michigan DEQ Lab ID \#9933, New Jersey DEP Cert. \#TN001, New York DOH Lab \#10781, North Carolina DPH Lab ID \#21705, North Carolina DEHNR Cert. \#64, Ohio EPA VAP Cert. \#CL0059, Oklahoma DEQ ID \#9415, Pennsylvania DEP Cert. \#68-00576, South Carolina DHEC Lab ID \#84001001, Tennessee DOH Lab ID \#02014, Utah DOH Cert. \# QUAN3, Virginia DGS Lab ID \#00165, Washington DOE Lab \#C120, West Virginia DEP Cert. \#345, Wisconsin DNR Lab ID \#998044300, Naval Facilities Engineering Service Center and USDA Soil Permit \#S-46424. This list of approvals is subject to change and does not imply that laboratory certification is available for all parameters reported in this environmental sample data report. 
Sample Data Summary 
Air Sampling Associates, Inc.

client Sample ID: HARDIN SDA INLET DUCT RUN 1 0.IN H2SO4

General Chemistry

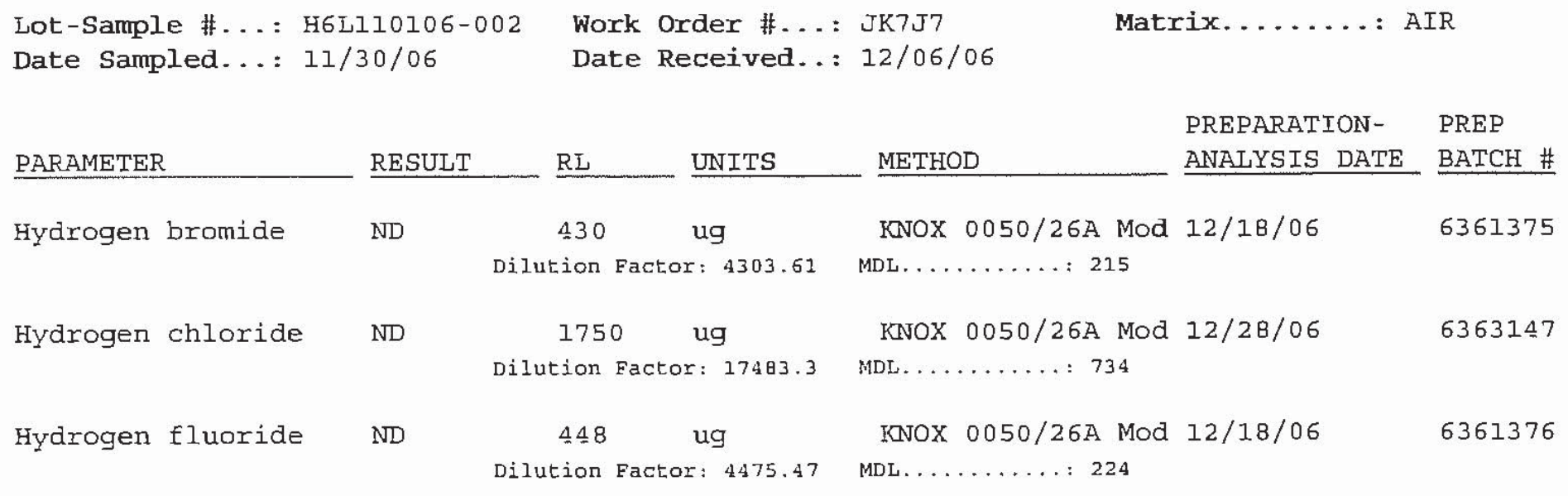


Air Sampling Associates, Inc.

Client Sample ID: HARDIN SDA INLET DUCT RUN 1 0.IN NAOH

General Chemistry

Lot-Sample \#... : H6L110106-004

Work Order \#...: JK7KA

Matrix....... AIR

Date Sampled...: 11/30/06

Date Received..: 12/06/06

\begin{tabular}{|c|c|c|c|c|c|c|}
\hline PARAMETER & RESULT & $\underline{\mathrm{RL}}$ & UNITS & METHOD & $\begin{array}{l}\text { PREPARATION - } \\
\text { ANALYSIS DATE }\end{array}$ & $\begin{array}{l}\text { PREP } \\
\text { BATCH \# }\end{array}$ \\
\hline \multirow[t]{2}{*}{ Bromine } & ND & 295 & ug & KNOX $0050 / 26 \mathrm{~A} \operatorname{Mod}$ & $12 / 19 / 06$ & 6356347 \\
\hline & & Dilution & Factor: 2950 & MDL. . . . . . 70.8 & & \\
\hline \multirow[t]{2}{*}{ Chlorine } & $216 \mathrm{~B}$ & 295 & ug & KNOX $0050 / 26 \mathrm{~A}$ Mod & $12 / 19 / 06$ & 6356350 \\
\hline & & Dilution & Factor: 2950 & MDL.......... 124 & & \\
\hline \multirow[t]{2}{*}{ Hydrogen fluoride } & ND & 311 & ug & KNOX $0050 / 26 \mathrm{~A}$ Mod & $12 / 19 / 06$ & 6356352 \\
\hline & & Dilution & Factor: 3106.5 & MDL . . . . . . . 155 & & \\
\hline \multicolumn{7}{|l|}{ NOTE (S) : } \\
\hline
\end{tabular}

RL. Reporting Limit

B Estimated result. Result is less than RL. 
Air Sampling Associates, Inc.

client Sample ID: HARDIN SDA INLET DUCT RUN 20. IN H2SO4

General Chemistry

Lot-Sample \#...: H6L110106-006

Date Sampled...: 12/01/06
Work Order \#...: JK7KG

Date Received..: 12/06/06
Matrix....... AIR

PREPARATION - PREP

PARAMETER

RESULT

$\underline{\mathrm{RL}}$

UNITS

METHOD

$405 \quad \mathrm{ug}$

Dilution Factor: 4050.46

KNOX 0050/26A Mod 12/18/06

MDL......... 203

Hydrogen chloride ND

1650 ug

KNOX 0050/26A Mod 12/28/06

Dilution Factor: 16454.87 MDL......... 691

Hydrogen fluoride ND
$421 \quad$ ug

Dilution Factor: 4212.21
KNOX 0050/26A Mod 12/18/06

MDL......... 211
BATCH \#

6361375

6363147

6361376 
Air Sampling Associates, Inc.

Client Sample ID: HARDIN SDA INLET DUCT RUN $20.1 \mathrm{~N}$ NAOH

General Chemistry

Lot-Sample \#...: H6L110106-008

Work order \#...: JK $7 \mathrm{KN}$

Date Received. .: 12/06/06

Date Sampled...: 12/01/06

RESULT

ND

$\underline{R L}$

UNITS

METHOD

KNOX 0050/26A Mod 12/19/06

PREPARATIONANALYSIS DATE BATCH

Bromine

280

ug

Dilution Factor: 2800

$151 \mathrm{~B}$

280

ug

Dilution Factor: 2800

ND

295

ug

Dilution Factor: 2948.55
MDL. . . . . . : 67.2

KNOX 0050/26A Mod 12/19/06

MDL....... $: 118$

KNOX 0050/26A Mod 12/19/06

MDL........ : 147
6356347

6356350

6356352

NOTE (S) :

RI. Keparmin limit

B Estimated result. Result is less than RI. 
Air Sampling Associates, Inc.

Client Sample ID: HARDIN SDA INLET DUCT RUN 30. IN H2SO4

General Chemistry

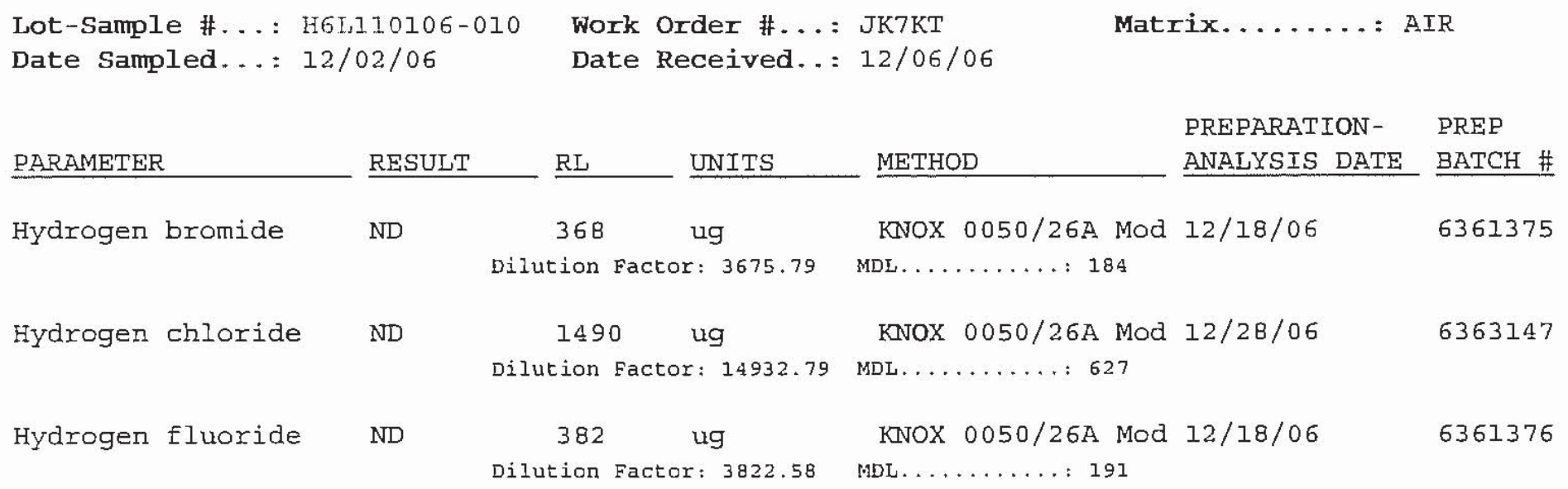


Air Sampling Associates, Inc.

Client Sample ID: HARDIN SDA INLET DUCT RUN 30. IN NAOH

General Chemistry

Lot-Sample \#...: H6L110106-012 work Order \#...: JK7KW

Date Sampled...: 12/02/06

Date Received..: 12/06/06

Matrix......: AIR

\begin{tabular}{|c|c|c|c|c|c|c|}
\hline PARAMETER & RESULT & $\underline{\mathrm{RI}}$ & UNITS & METHOD & $\begin{array}{l}\text { PREPARATION- } \\
\text { ANALYSIS DATE }\end{array}$ & $\begin{array}{l}\text { PREP } \\
\text { BATCH \# }\end{array}$ \\
\hline \multirow[t]{2}{*}{ Bromine } & ND & 270 & ug & KNOX 0050/26A Mod & $12 / 19 / 06$ & 6356347 \\
\hline & & Dilution & Factor: 2700 & MDL. . . . . . 64.8 & & \\
\hline \multirow[t]{2}{*}{ Chlorine } & $159 \mathrm{~B}$ & 270 & ug & KNOX 0050/26A Mod & $12 / 19 / 06$ & 6356350 \\
\hline & & Dilution & Factor: 2700 & MDL . . . . . . 113 & & \\
\hline Hydrogen fluoride & ND & 284 & ug & KNOX $0050 / 26 \mathrm{~A}$ Mod & $12 / 19 / 06$ & 6356352 \\
\hline
\end{tabular}

NOTE (S) :

RL. Reporting Limit

B Estimated result, Result is less tha RL. 
Air Sampling Associates, Inc.

client Sample ID: HARDIN STACK \& SDA INLET RB $0.1 \mathrm{~N}$ H2SO4 BIANK

General Chemistry

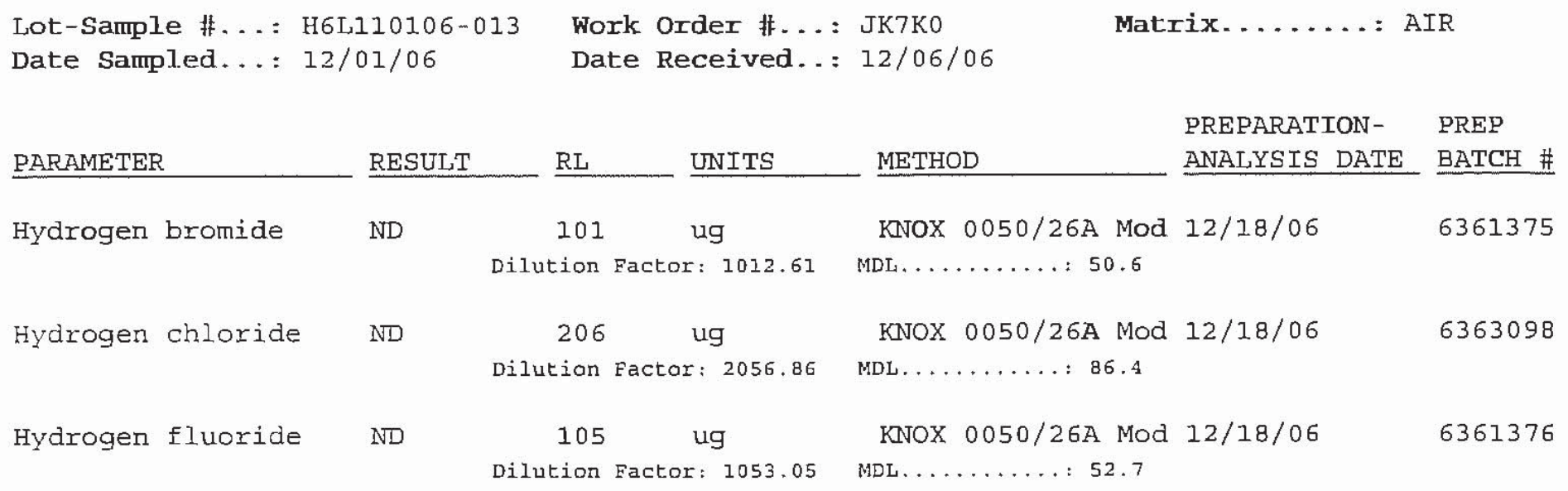


Air Sampling Associates, Inc.

Client Sample ID: HARDIN STACK \& SDA INLET RB $0.1 \mathrm{~N}$ NAOH BLANK

General Chemistry

Lot-Sample \#... : H6L110106-015

Work Order \#...: JK7K2

Matrix........ AIR

Date Sampled...: 12/01/06

Date Received..: 12/06/06

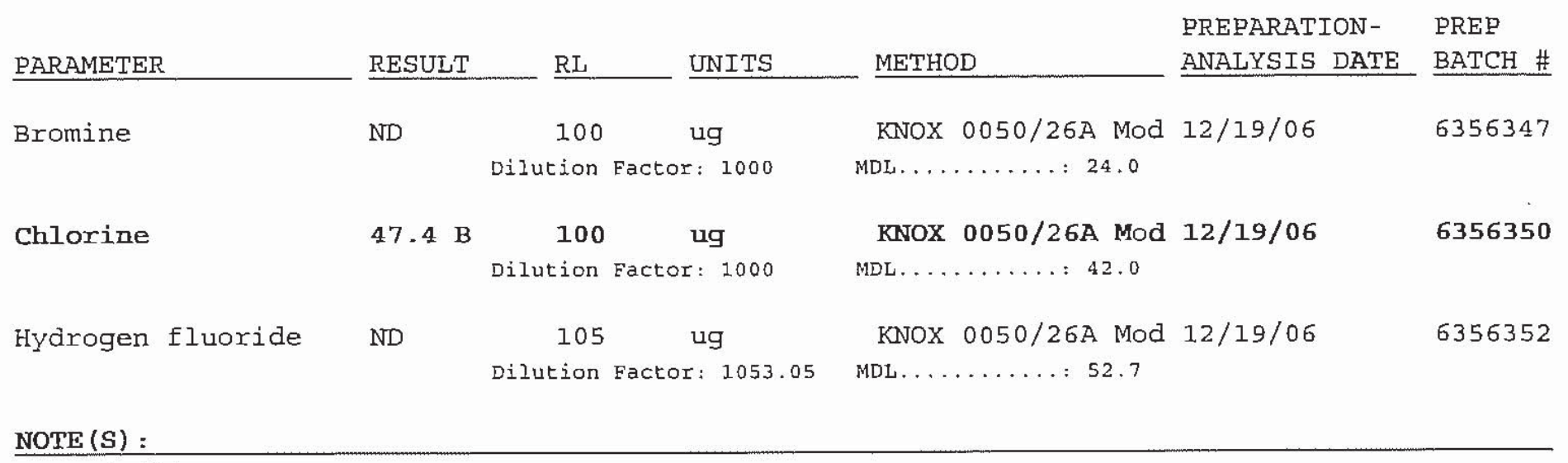

RL. Reporting Limit

B Estimated result. Result is less than RL. 
Air Sampling Associates, Inc.

Client Sample ID: HARDIN STACK \& SDA INLET RB D.I.WATER BLANK

General Chemistry

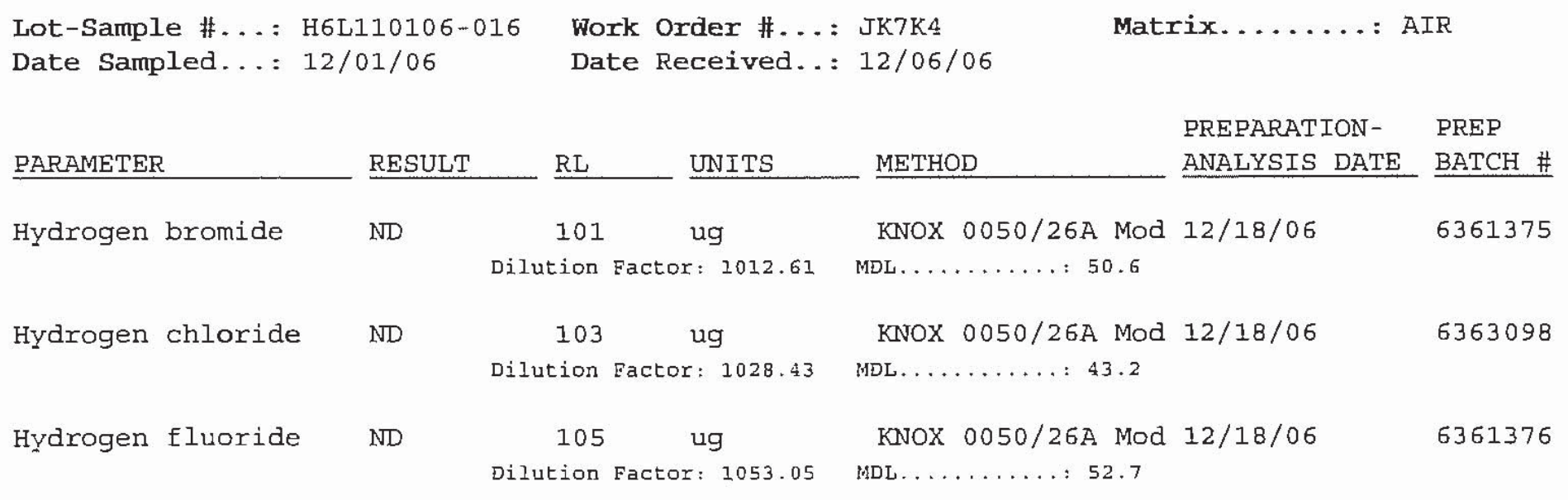




\section{METHOD BLANK REPORT}

General Chemistry

\begin{tabular}{|c|c|c|c|c|c|}
\hline & RESULT & $\begin{array}{l}\text { REPORTING } \\
\text { LIMIT UNITS }\end{array}$ & METHOD & $\begin{array}{l}\text { PREPARATION- } \\
\text { ANALYSIS DATE }\end{array}$ & $\begin{array}{l}\text { PREP } \\
\text { BATCH \# }\end{array}$ \\
\hline \multirow{3}{*}{$\frac{\text { PARAMETER }}{\text { Bromine }}$} & & Work Order \#: JL2IFIAA & MB Lot-Sample \#: & H6L $220000-347$ & \\
\hline & ND & $10.0 \quad$ ug & KNOX $0050 / 26 \mathrm{~A}$ Mod & $12 / 19 / 06$ & 6356347 \\
\hline & & Dilution Factor: 100 & & & \\
\hline \multirow[t]{2}{*}{ Chlorine } & ND & $\begin{array}{l}\text { Work Order \#: JL21W1AA } \\
10.0 \quad \text { ug }\end{array}$ & $\begin{array}{l}\text { MB Lot-Sample \#: } \\
\text { KNOX 0050/26A Mod }\end{array}$ & $\begin{array}{l}\text { H6L 220000-350 } \\
12 / 19 / 06\end{array}$ & 6356350 \\
\hline & & Dilution Factor: 100 & & & \\
\hline \multirow[t]{2}{*}{ Hydrogen bromide } & ND & Work Order \#: JL69FIAA & MB Lot-Sample \#: & H6L $270000-375$ & 6361375 \\
\hline & & Dilution Factor: 101.2 & & & \\
\hline \multirow[t]{3}{*}{ Hydrogen chloride } & & Work Order \#: JL8TM1AA & MB Lot-Sample \#: & H6L 290000-098 & \\
\hline & ND & $10.3 \quad$ ug & KNOX $0050 / 26 \mathrm{~A}$ Mod & $12 / 18 / 06$ & 6363098 \\
\hline & & Dilution Factor: 102.8 & & & \\
\hline \multirow[t]{3}{*}{ Hydrogen chloride } & & Work Order \#: JL9AA1AA & MB Lot-Sample \#: & H6I $290000-147$ & \\
\hline & ND & $10.3 \quad$ ug & KNOX $0050 / 26 \mathrm{~A}$ Mod & $12 / 28 / 06$ & 6363147 \\
\hline & & Dilution Factor: 102.8 & & & \\
\hline \multirow[t]{3}{*}{ Hydrogen fluoride } & & Work Order \#: JL69GIAA & MB Lot-Sample \#: & H6I $270000-376$ & \\
\hline & ND & $10.5 \quad$ ug & KNOX $0050 / 26 \mathrm{~A}$ MOd & $12 / 18 / 06$ & 6361376 \\
\hline & & Dilution Factor: 105.3 & & & \\
\hline \multirow[t]{2}{*}{ Hydrogen Eluoride } & & Work Order \#: JI22 $\mathrm{H} 1 \mathrm{AA}$ & MB Lot-Sample \#: & H6L $220000-352$ & \\
\hline & ND & 10.5 & KNOX $0050 / 26 \mathrm{~A}$ Mod & $12 / 19 / 06$ & 6356352 \\
\hline
\end{tabular}

NOTE $(S)$ :

Calculations are perfomed before roundiog to avoid round-off errors in calculated results. 
LABORATORY CONTROL SAMPLE EVALUATION REPORT

General Chemistry

Lot-Sample \#...: H6L110106

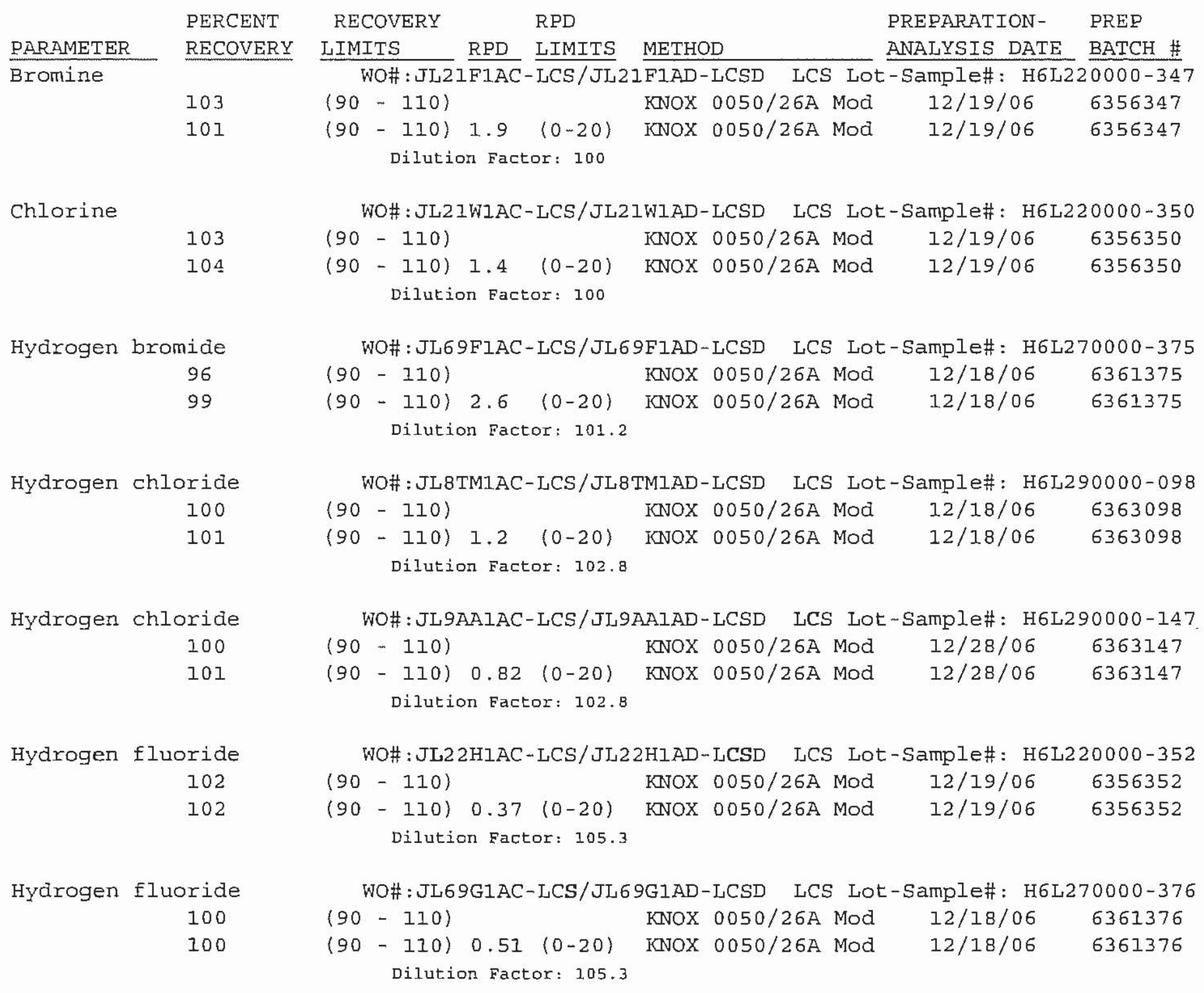




\section{LABORATORY CONIROL SAMPLB DATA REPORT}

\section{General Chemistry}

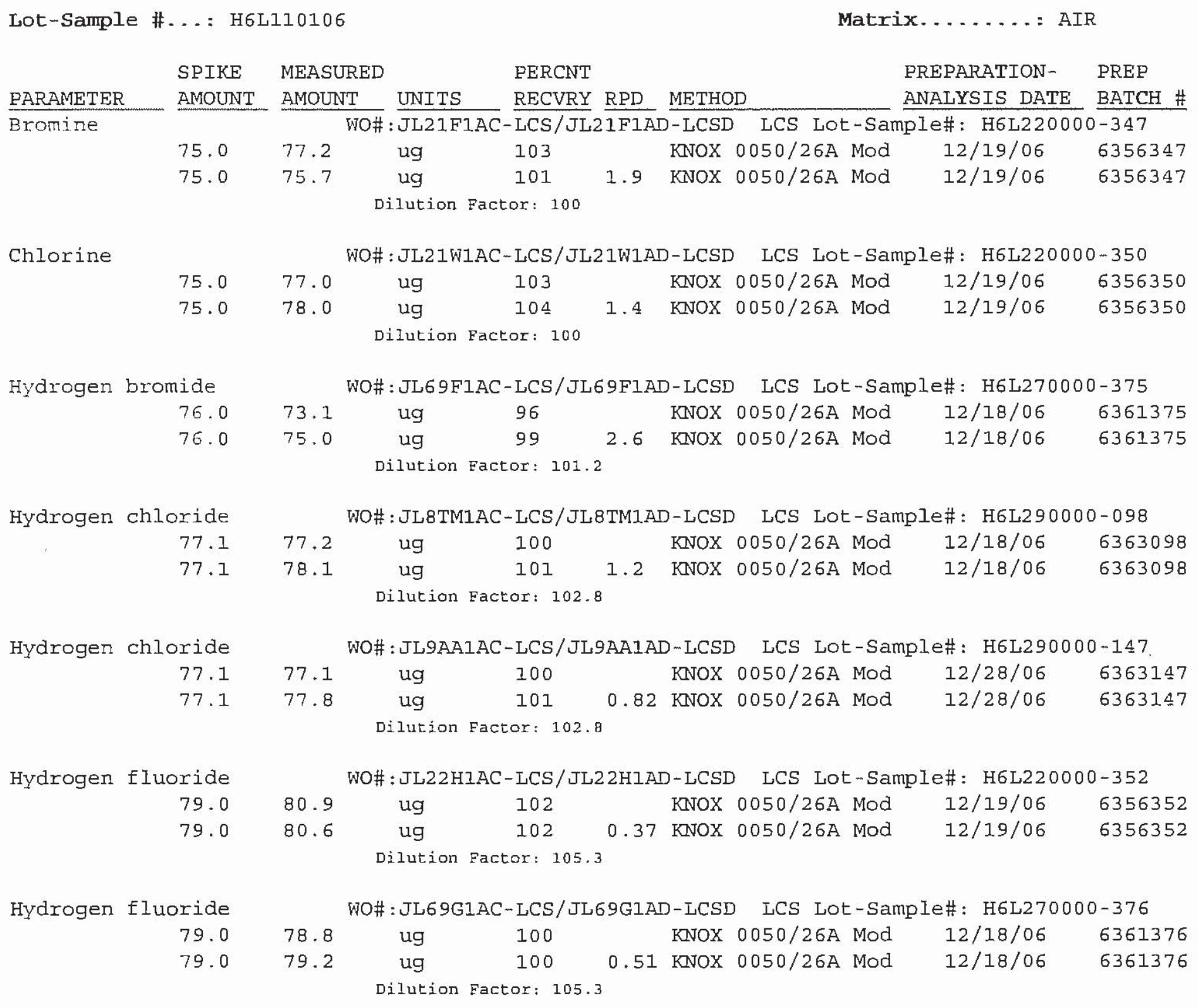

NOTE (S) :

Calculations are performed before rounding to avoid round-off errors in calculated results. 


\section{MATRIX SPIKE SAMPLE EVALUATION REPORT}

\section{General Chemistry}

Client Lot \#...: H6L110106

Date Sampled...: 11/30/06
Date Received..: 12/06/06
Matrix......: AIR

PREPARATION- PREP ANALYSIS DATE BATCH \#

PARAMETER PERCENT RECOVERY RECOVERY LIMITS

RPD RPD LIMITS METHOD WO\#:

$(75-125)$

JK7KAIAE-MS/J

101

$(75-125) 8.4 \quad(0-20)$ KNOX 0050/26A Mod

KNOX 0050/26A Mod Dilution Factor: 2950

Chlorine

$$
95
$$

95

Hydrogen bromide 104 105

Hydrogen chloride 99

99

Hydrogen fluoride 105 107

Hydrogen fluoride

$$
102
$$

105
WO\#: JK7KAIAG-MS/JK7KAIAH-MSD MS Lot-Sample \#: H6L110106-004

$$
\begin{array}{llll}
(75-125) & \text { KNOX 0050/26A Mod } & 12 / 19 / 06 \\
(75-125) 0.35(0-20) & \text { KNOX 0050/26A Mod } & 12 / 19 / 06 \\
& \text { Dilution Factor: 2950 } & &
\end{array}
$$

WO\#: JK7J71AE-MS/JK7J71AF-MSD MS Lot-Sample \#: H6L110106-002

$\begin{array}{lllll}(75-125) & \text { KNOX 0050/26A Mod } & 12 / 18 / 06 & 6361375 \\ (75-125) 0.69(0-20) & \text { KNOX 0050/26A Mod } & 12 / 18 / 06 & 6361375 \\ & \text { Dilution Factor: 4303. }\end{array}$

Dilution Factor: 4303 .

WO\#: JK7J71AJ-MS/JK7J71AK-MSD MS Lot-Sample \#: H6L110106-002

(75 - 125) KNOX 0050/26A Mod $12 / 28 / 06 \quad 6363147$

$(75-125) 0.59(0-20) \quad K N O X \quad 0050 / 26 \mathrm{~A} \operatorname{Mod} \quad 12 / 28 / 06 \quad 6363147$

Dilution Factor: 17483

WO\#: JK7J71AG-MS/JK7J71AH-MSD MS Lot-Sample \#: H6L110106-002

(75 - 125) KNOX 0050/26A Mod 12/18/06 6361376

$(75-125) 1.7(0-20)$ KNOX 0050/26A Mod $12 / 18 / 06 \quad 6361376$

Dilution Factor: 4475 .

WO\#: JK7KA1AJ-MS/JK7KA1AK-MSD MS Lot-Sample \#: H6L110106-004

$(75-125) \quad$ KNOX 0050/26A Mod 12/19/06 6356352

$(75$ - 125) $2.5(0-20)$ KNOX 0050/26A Mod $12 / 19 / 06 \quad 6356352$

NOTE (S) :

Calculations are performed before rounding en avoid round-off errors in calculared results. 


\section{MATRIX SPIKE SAMPLE DATA RBPORT}

\section{General Chemistry}

Client Lot \#...: H6L110106

Date Sampled...: 11/30/06
Date Received..: 12/06/06
Matrix....... AIR

NOTE (S) :

SAMPLE SPIKE MEASRD PERCNT PREPARATION- PREP

PARAMETER AMOUNT AMT

AMOUNT UNITS RECVRY RPD METHOD ANALYSIS DATE BATCH \#

ND $\quad 590$

WO\#: JK7KAIAE-MS/JK7KAIAF-MSD MS L

596 ug 101

KNOX $0050 / 26 A$

ND $\quad 590$

548

ug 93

8.4 KNOX 0050/26A

$12 / 19 / 06$

6356347

Dilution Factor: 2950

Chlorine

$216 \quad 590$

$216 \quad 590$

WO\#: JK7KAIAG-MS/JK7KAlAH-MSD MS Lot-Sample \#: H6L110106-004

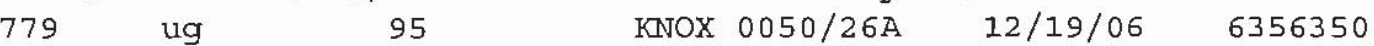

776 ug 95

oilution Factor: 2950

0.35 KNOX 0050/26A $12 / 19 / 06$

6356350

Hydrogen bromide

ND 861

ND 861

Hydrogen chloride

ND $\quad 3500$

ND $\quad 3500$

Hydrogen fluoride

ND 895

ND 895

Hydrogen fluoride

$\begin{array}{ll}\text { ND } & 621 \\ \text { ND } & 621\end{array}$
WO\#: JK7J71AE-MS/JK

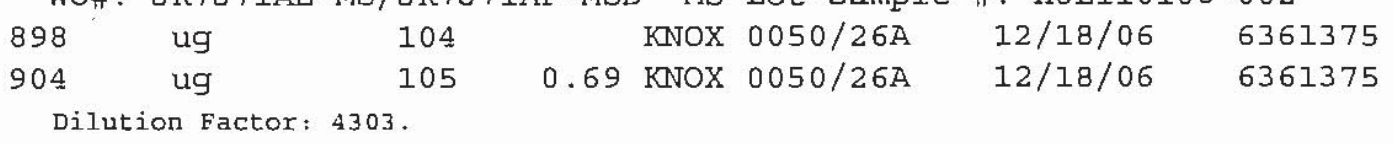

WO\#: JK7J71AJ-MS/JK7J71AK-MSD MS Lot-Sample \#: H6L110106-002

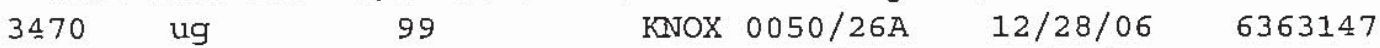

3450 ug 9

Dilution Factor: 17483

0.59 KNOX $0050 / 26 \mathrm{~A} \quad 12 / 28 / 06$

6363147

WO\#: JK7J7IAG-MS/JK7J71AH-MSD MS Lot-Sample \#: H6L110106-002

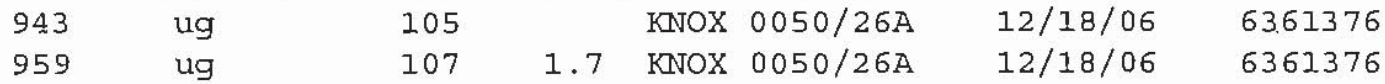

Dilution Factor: 4475.

WO\#: JK7KA1AJ-MS/JK7KA1AK-MSD MS Lot-Sample \#: H6I110106-004

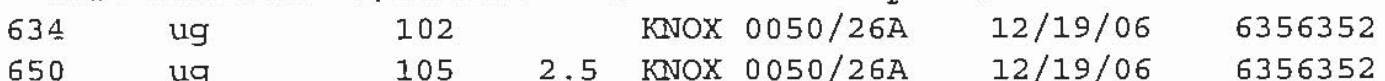

Dilution Factor: 3106. 
Air Sampling Associates, Inc.

client Sample ID: HARDIN SDA INLFT DUCT RUN 1 ACB FW

General Chemistry

Lot-Sample \#...: H6L110106-001 work Order \#...: JK7J5

Date sampled...: 11/30/06
Matrix........ AIR

Date Received..: 12/06/06

\begin{tabular}{|c|c|c|c|c|c|c|}
\hline PARAMETER & RESULT & $\underline{\mathrm{RL}}$ & UNITS & METHOD & $\begin{array}{l}\text { PREPARATION- } \\
\text { ANALYSIS DATE }\end{array}$ & $\begin{array}{l}\text { PREP } \\
\text { BATCH \# }\end{array}$ \\
\hline$\overline{\text { Particulates (total) }}$ & 1450 & 0.50 & mg & CFR60A 5 & $\overline{12 / 15-12 / 18 / 06}$ & $\overline{6349313}$ \\
\hline & & tion $\mathrm{F}$ & I: 1 & MDL . . . . . . . & & \\
\hline
\end{tabular}


Air Sampling Associates, Inc.

Client Sample ID: HARDIN SDA INLFT DUCT RUN 2 ACE FW

General Chemistry

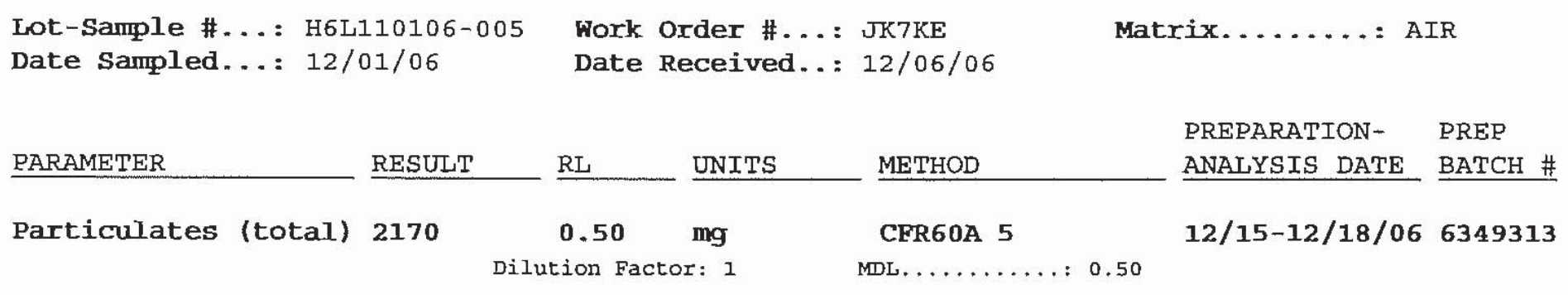


Air Sampling Associates, Inc.

client Sample ID: HARDTN SDA INLET DUCF RUN 3 ACE FW

General Chemistry

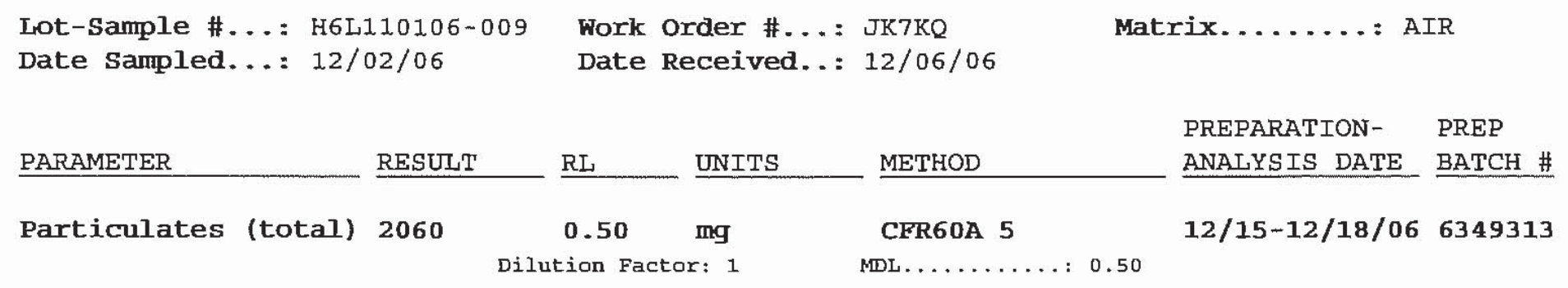


Sample Receipt Documentation 


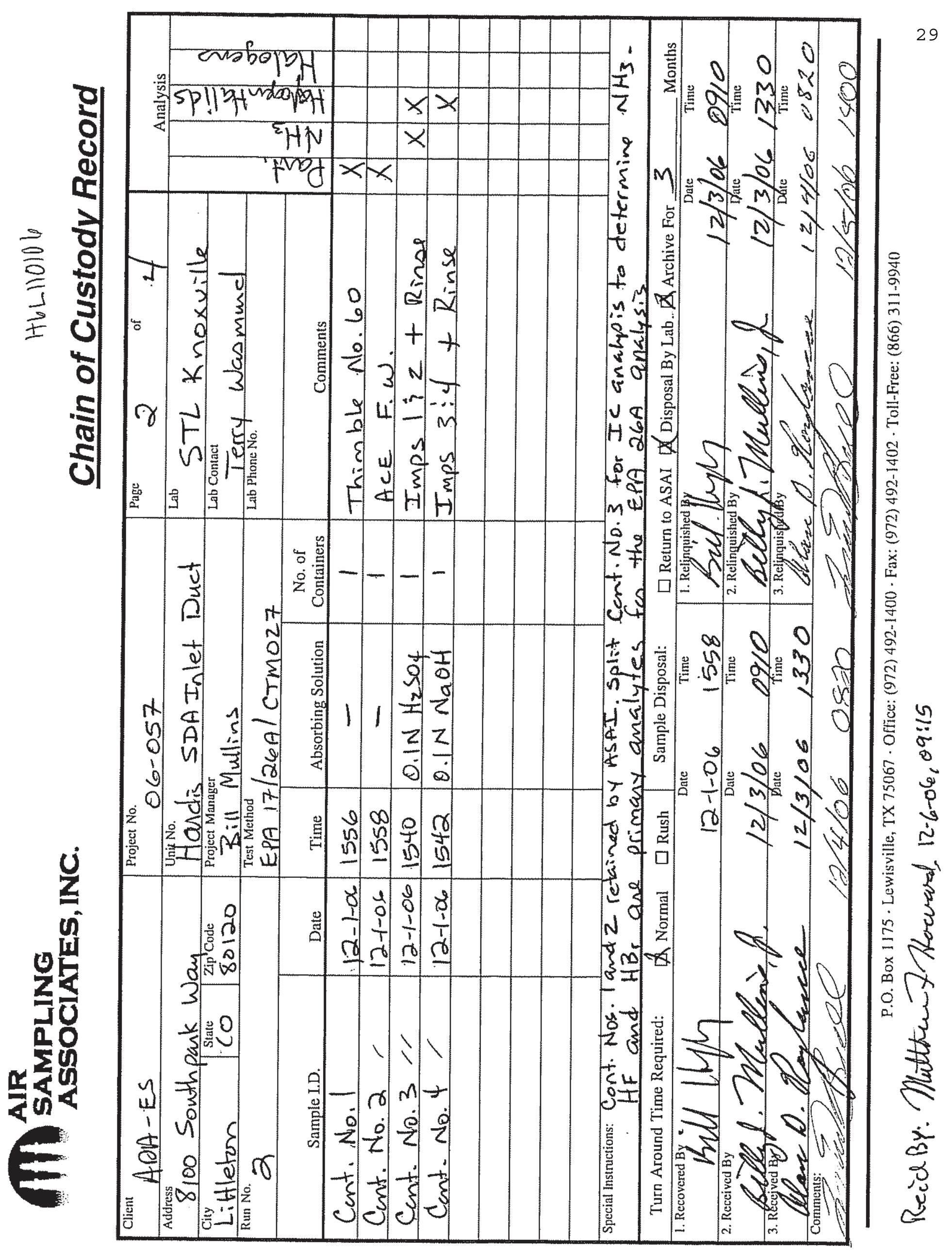




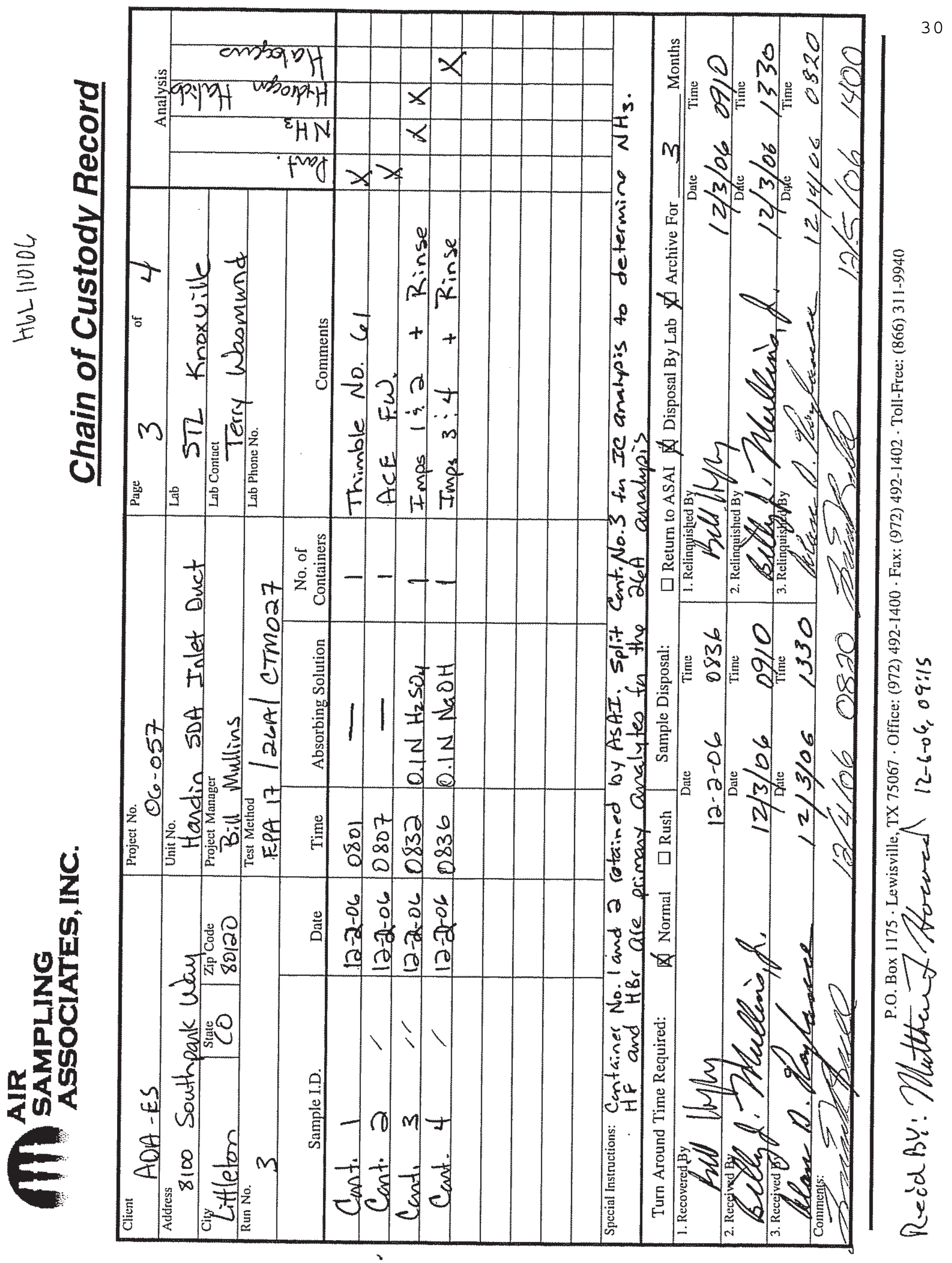




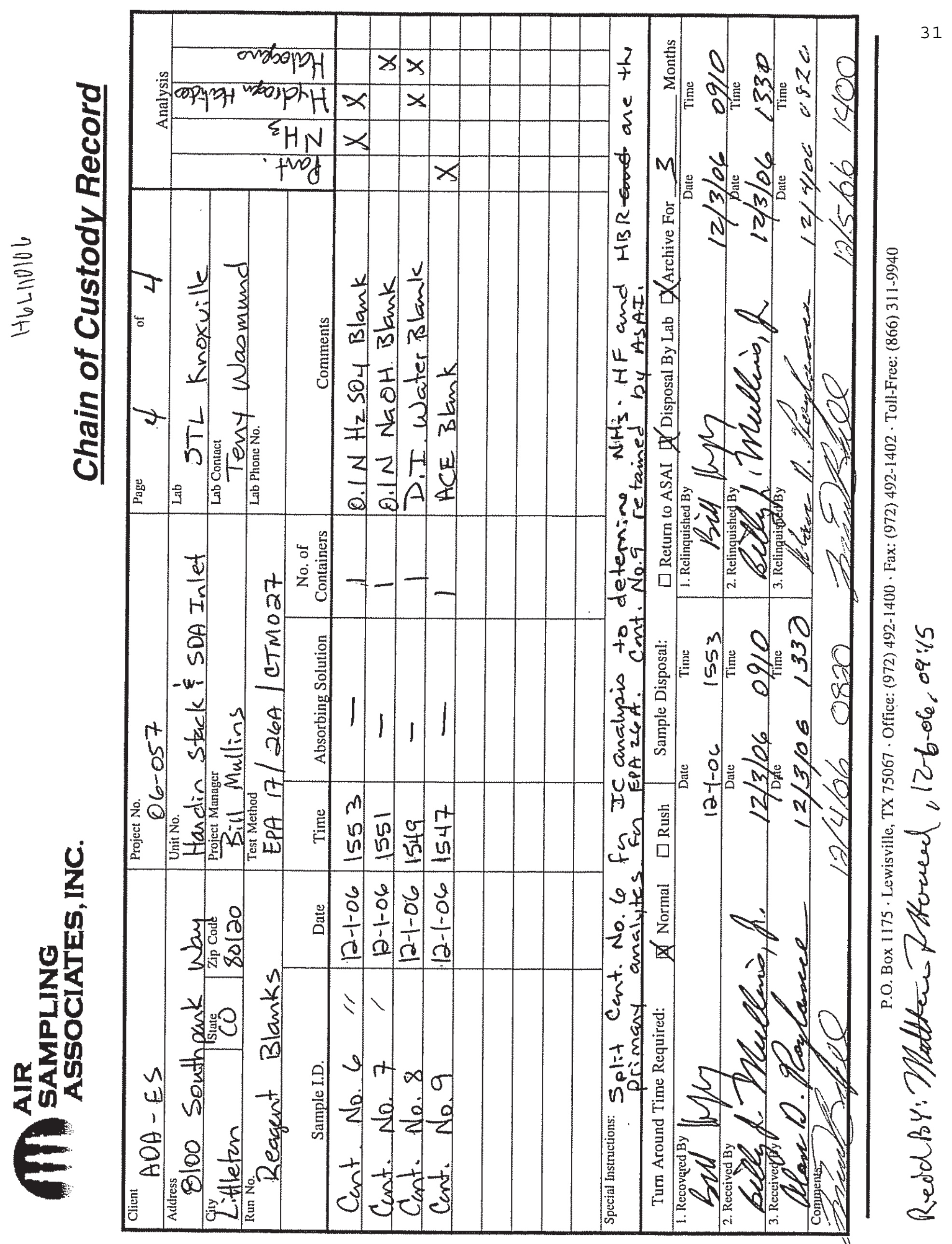




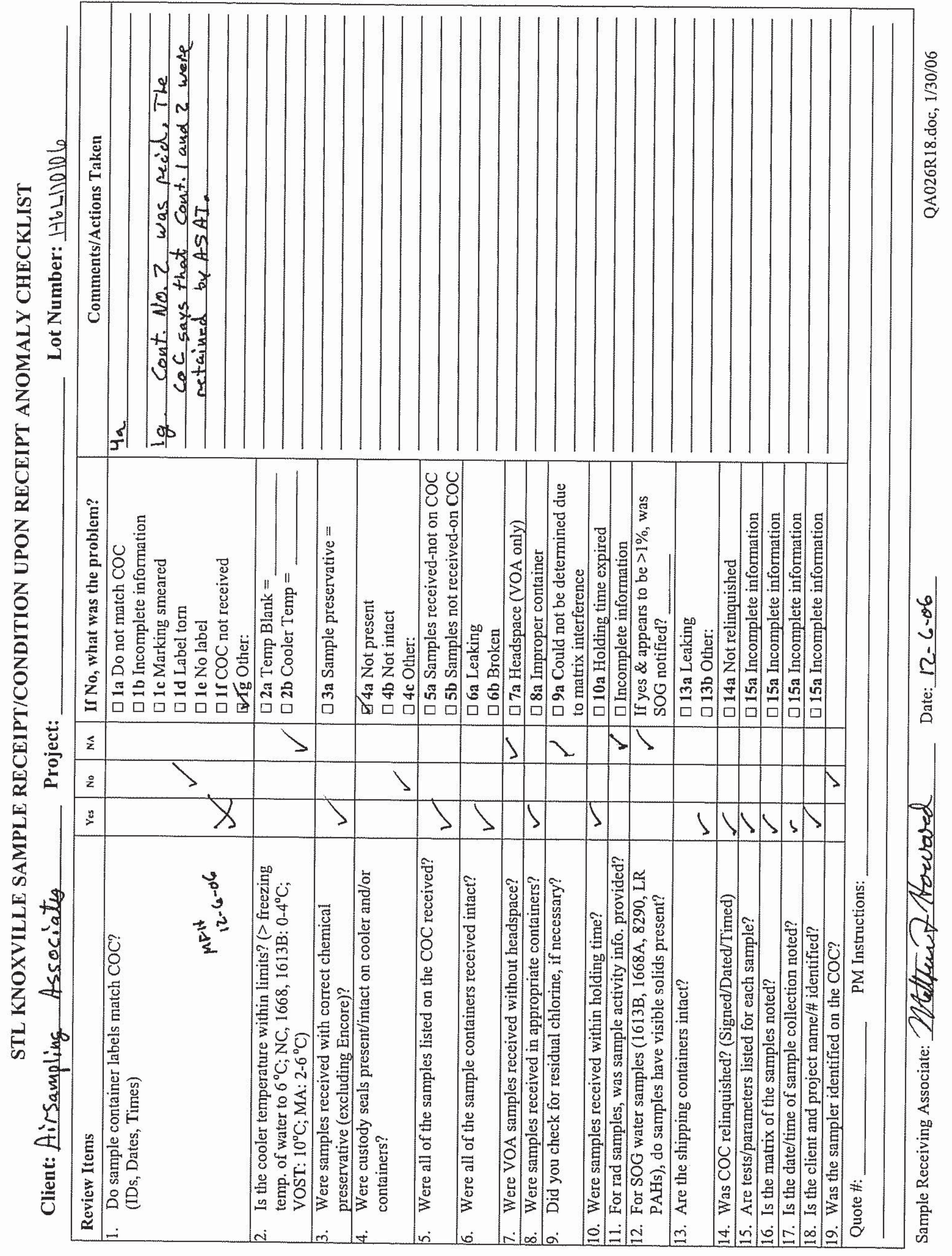


Wet Chemistry 
Sample Summary 
Air Sampling Associates, Inc.

client sample ID: HARDIN SDA TNLET DUCT RUN 1 ACE FW

General Chemistry

Lot-Sample \#...: H6L110106-001

Date Sampled...: 11/30/06
Work Order \#...: JK7J5

Date Received. .: 12/06/06
Matrix........ AIR

PREPARATION- PREP ANALYSIS DATE BATCH \#
PARAMETER

Particulates (total) 1450

\section{RESULT} $\mathrm{RI}$ 0.50 mg Dilution Factor: 1
METHOD CFR60A 5 
Aix Sampling Associates, Inc.

Client Sample ID: HARDIN SDA INLET DUCT RUN 1 . 0. IN H2SO4

\section{General Chemistry}

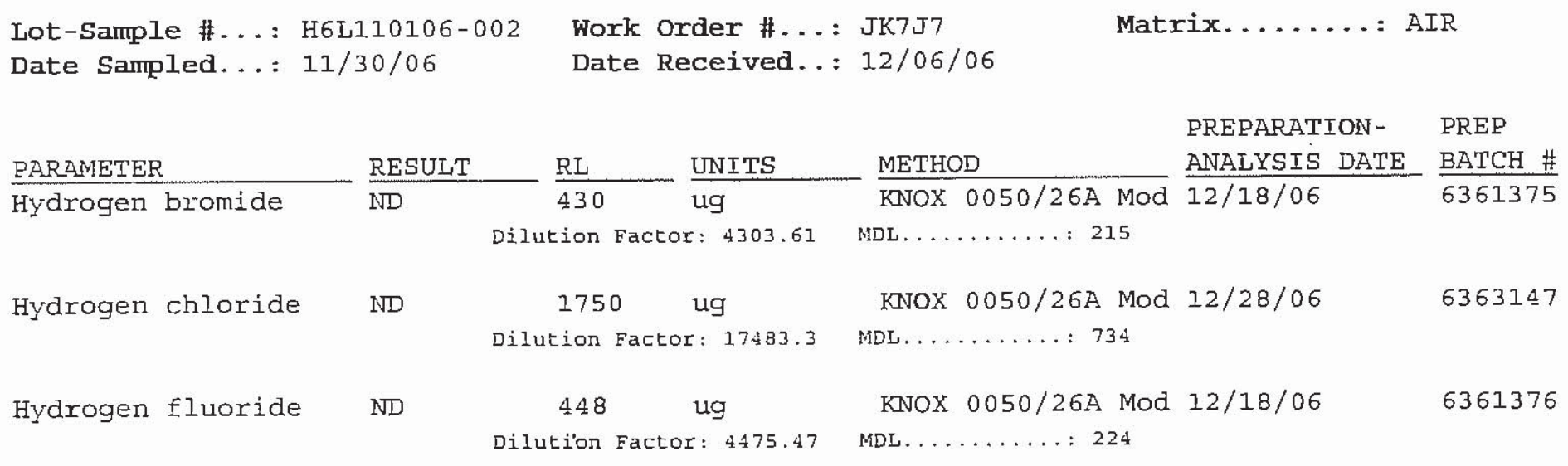


Air Sampling Associates, Inc.

Client Sample ID: HARDIN SDA INLET DUCT RUN 1 0.IN NAOH

\section{General Chemistry}

Lot-Sample \#...: H6L110106-004
Date Sampled...: 11/30/06
Work Order \#...: JK7KA

Date Received. . : 12/06/06
Matrix....... AIR

PREPARATION - PREP ANAIYSIS DATE BATCH \#

PARAMETER RESULT

ND

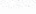

Dilution Factor: 2950

216 B

295

ug

Dilution Factor: 2950

Hydrogen fluoride
$\mathrm{ND}$

311
METHOD

KNOX 0050/26A Mod 12/19/06

MDL. . . . . . . : 70.8

KNOX 0050/26A Mod 12/19/06

MDL......... 124

KNOX 0050/26A Mod 12/19/06

MDL......... 155
6356347

6356350

6356352

NOTE (S) :

RL Reporting Limis

B Estimated resuin. Result is less than RL. 
Air Sampling Associates, Inc.

client sample ID: HARDIN SDA INLFT DUCT RUN 2 ACB FW

General Chemistry

Lot-Sample \#...: H6L110106-005 Work Order \#...: JK7KE

Date sampled...: 12/01/06
Date Received. . : 12/06/06
Matrix........ A AIR

PREPARATION- PREP ANALYSIS DATE BATCH \#

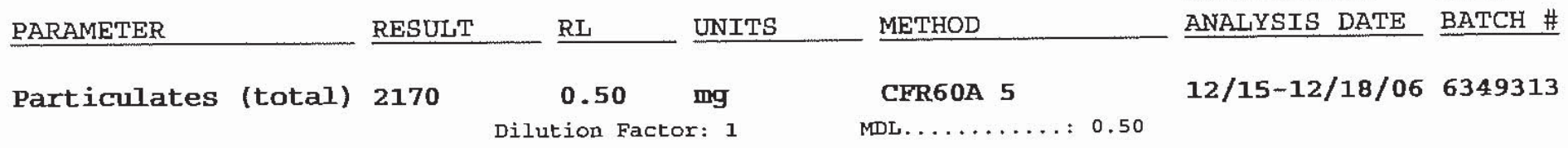


Air Sampling Associates, Inc.

Client Sample ШD: HARDIN SDA INLET DUCT RUN $20.1 \mathrm{~N}$ H2SO4

General Chemistry

Lot-Sample \#..: H6L110106-006
Date Sampled...: 12/01/06
Work Order \#...: J JK7KG

Date Received..: 12/06/06
Matrix....... AIR

PREPARATION - PREP

PARAMETER

RESULT

RL

UNITS

METHOD

$405 \quad 49$

Dilution Factor: 4050,46

KNOX 0050/26A Mod 12/18/06

MDL......... 203

Hydrogen chloride ND

ND
KNOX 0050/26A Mod 12/28/06

MDL......... 691

Dilution Factor: 16454.87

421

Dilution Factor: 4212.21
KNOX 0050/26A Mod 12/18/06

MDL......... 211 
Air Sampling Associates, Inc.

\section{Client Sample ID: HARDIN SDA INLET DUCT RUN $20.1 \mathrm{~N}$ NAOH}

\section{General Chemistry}

Lot-Sample \#...: H6L110106-008
Date Sampled...: 12/01/06

Work Order \#...: JK7KN

Date Received. .: 12/06/06

\begin{tabular}{|c|c|c|c|c|c|c|}
\hline PARAMETER & RESULT & $\underline{\mathrm{RL}}$ & UNITS & METHOD & $\begin{array}{l}\text { PREPARATION- } \\
\text { ANALYSIS DATE }\end{array}$ & $\begin{array}{l}\text { PREP } \\
\text { BATCH \# }\end{array}$ \\
\hline \multirow[t]{2}{*}{ Bromine } & ND & 280 & ug & KNOX 0050/26A Mod & $12 / 19 / 06$ & 6356347 \\
\hline & & Dilution & Factor: 2800 & MDL. . . . . . . : 67.2 & & \\
\hline \multirow[t]{2}{*}{ Chlorine } & 151 B & 280 & ug & KNOX 0050/26A Mod & $12 / 19 / 06$ & 6356350 \\
\hline & & Dilution & Factor: 2800 & MDL. . . . . . . : 118 & & \\
\hline \multirow[t]{2}{*}{ Hydrogen Eluoride } & ND & 295 & ug & KNOX $0050 / 26 \mathrm{~A}$ Mod & $12 / 19 / 06$ & 6356352 \\
\hline & & Dilution & Factor: 2948.55 & MDL . . . . . . : 147 & & \\
\hline
\end{tabular}

RL. Reporting Limit

B Estmated result. Result is less than RL.

Matrix....... AIR

PREPARATION - PREP ANALYSIS DATE BATCH \# 
Air Sampling Associates, Inc.

Client Sample ID: HARDIN SDA INLET DUCT RUN 3 ACE FW

General Chemistry

Lot-Sample \#...: H6L110106-009 work Order \#...: JK7KQ

Date sampled...: 12/02/06
Date Received. . : 12/06/06

METHOD

CFR60A 5
Matrix........ A AIR

PREPARATION- PREP ANALYSIS DATE BATCH \#

$0.50 \mathrm{mg}$
Dilution Factor: 1

$\mathrm{mg}$ 
Air Sampling Associates, Inc.

Client Sample ID: HARDIN SDA INLET DUCT RUN 3 o.1N H2SO4

General Chemistry

Lot-Sample \#...: H6L110106-010

Date Sampled...: 12/02/06
Work Order \#...: JK7KT

Date Received..: 12/06/06
Matrix....... AIR

PREPARATION- PREP

\section{PARAMETER}

RESULT

RL

UNITS

METHOD

$368 \quad$ ug

Dilution Factor: 3675.79

KNOX 0050/26A Mod 12/18/06

MDL......... : 184

Hydrogen chloride ND

ND
KNOX 0050/26A Mod 12/28/06

Dilution Factor: 14932.79

382

Dilution Factor: 3822,58
MDL........ 627

KNOX 0050/26A Mod 12/18/06

MDL......... 191
BATCH \#

6361375

6363147

6361376 
Air Sampling Associates, Inc.

Client Sample ID: HARDIN SDA INLET DUCT RUN 30. IN NAOH

General Chemistxy

Lot-Sample \#...: H6L110106-012

Work Order \#. . : JK7 KW

Matrix........ AIR

Date Sampled...: 12/02/06

Date Received. . : 12/06/06

PREPARATION- PREP

PARAMETER

RESULT

$\underline{R L}$

UNITS

METHOD

ANAIYSIS DATE BATCH \#

Bromine

ND

270

ug

KNOX 0050/26A Mod 12/19/06

6356347

Dilution Factor: 2700

MDL ........ $64 . B$

Chlorine

$159 \mathrm{~B}$

270

ug

KNOX 0050/26A Mod 12/19/06

6356350

Dilution Factor: 2700

MDL......... 113

Hydrogen fluoride

ND

$284 \quad u g$

KNOX 0050/26A Mod 12/19/06

Dilution Factor: 2843.24

MDL......... 142

NOTE $(S)$ :

RL. Reporting Limit

B Estinated result. Result is less than RL. 
Air Sampling Associates, Inc.

client Sample ID: HARDIN STACK \& SDA INLET RB $0.2 N$ H2SO4 BLANK

General Chemistry

\begin{tabular}{|c|c|c|c|c|c|c|}
\hline \multicolumn{3}{|c|}{$\begin{array}{l}\text { Lot-Sample \#...: H6L110106-013 } \\
\text { Date Sampled...: } 12 / 01 / 06\end{array}$} & $\begin{array}{l}\text { rk Order \#... } \\
\text { te Received.. }\end{array}$ & $\begin{array}{l}\text { JK7KO } \\
12 / 06 / 06\end{array}$ & \multicolumn{2}{|c|}{ Matrix....... AIR } \\
\hline PARAMETER & RESULT & $\underline{\mathrm{RL}}$ & UNITS & METHOD & $\begin{array}{l}\text { PREPARATION- } \\
\text { ANALYSIS DATE }\end{array}$ & $\begin{array}{l}\text { PREP } \\
\text { BATCH \# }\end{array}$ \\
\hline \multirow[t]{2}{*}{ Hydrogen bromide } & ND & 101 & ug & KNOX $0050 / 26 \mathrm{~A}$ Mod & $12 / 18 / 06$ & 6361375 \\
\hline & & Dilution & Factor: 1012.61 & MDL. . . . . . . 50.6 & & \\
\hline \multirow[t]{2}{*}{ Hydrogen chloride } & $\mathrm{ND}$ & 206 & ug & KNOX $0050 / 26 \mathrm{~A}$ Mod & $12 / 18 / 06$ & 6363098 \\
\hline & & Dilution & Factor: 2056.86 & MDL.......... 86.4 & & \\
\hline \multirow[t]{2}{*}{ Hydrogen fluoride } & ND & 105 & ug & KNOX $0050 / 26 \mathrm{~A}$ Mod & $12 / 18 / 06$ & 6361376 \\
\hline & & Dilution & Eactor: 1053.05 & MDL. . . . . . : 52.7 & & \\
\hline
\end{tabular}


Air Sampling Associates, Inc.

\section{client Sample ID: HARDIN STACK \& SDA INLET RB $0.1 \mathrm{~N}$ NAOH BLANK}

General Chemistry

Lot-Sample \#... : H6L110106-015

Date Sampled...: 12/01/06
Work Order \#...: JK7K2

Date Received. .: 12/06/06
Matrix....... AIR

PREPARATION- PREP

ANALYSIS DATE BATCH \#

PARAMETER

Bromine

RESULT

$\underline{R L}$

UNITS

METHOD

100 ug

Dilution Factor: 1000

KNOX 0050/26A Mod 12/19/06

MDL ......... 24.0

Chlorine

47.4

100

ug

Dilution Factor: 1000

Hydrogen fluoride

ND
KNOX 0050/26A Mod 12/19/06

MDL......... 42.0

KNOX 0050/26A Mod 12/19/06

MDL. . . . . . 52.7 $\mathrm{ug}$

Dilution Factor: 1053.05

NOTE (S) :

R1. Reporing Linit

B Estimated result. Result is fess than RL. 
Air Sampling Associates, Inc.

Client Sample ID: HARDIN STACK \& SDA INLET RB D.I.WATER BLANK

General Chemistry

Lot-Sample \#...: H6L110106-016

Date Sampled...: 12/01/06
Work Order

Date Received... 12/06/06
Matrix....... AIR

PREPARATION- PREP ANALYSIS DATE BATCH \#

PARAMETER RESULT $\underline{R L}$ UNITS METHOD

KNOX 0050/26A Mod 12/18/06

Hydrogen bromide

$\mathrm{ND}$

101

$\mathrm{ug}$ Dilution Factor: 1012.61 $M D$

Hydrogen chloride

$\mathrm{ND}$

103

ug Dilution Factor: 1028.43

KNOX 0050/26A Mod 12/18/06 MDL......... 43.2

Hydrogen fluoride
ND
6361375

6363098

6361376
KNOX 0050/26A Mod 12/18/06 Dilution Factor: 1053.05 MDL........ 52.7 
QC Summary 


\section{MFTHOD BLANK REPORT}

\section{General Chemistry}

Client Lot \#...: H6L110106

Matrix........ AIR

\begin{tabular}{|c|c|c|c|c|c|}
\hline PARAMETER & RESULT & $\begin{array}{l}\text { REPORTING } \\
\text { LIMIT }\end{array}$ & METHOD & $\begin{array}{l}\text { PREPARATION- } \\
\text { ANALYSIS DATE }\end{array}$ & $\begin{array}{l}\text { PREP } \\
\text { BATCH \# }\end{array}$ \\
\hline \multirow[t]{3}{*}{ Bromine } & & Work Order \#: JL21F1AA & MB Lot-Sample \#: & H6L $220000-347$ & \\
\hline & ND & $10.0 \quad$ ug & KNOX $0050 / 26 \mathrm{~A}$ Mod & $12 / 19 / 06$ & 6356347 \\
\hline & & Dilution Factor: 100 & & & \\
\hline \multirow[t]{3}{*}{ Chlorine } & & Work Order \#: JL21WIAA & MB Lot-Sample \#: & H6L $220000-350$ & \\
\hline & ND & 10.0 & KNOX $0050 / 26 \mathrm{~A}$ Mod & $12 / 19 / 06$ & 6356350 \\
\hline & & & & & \\
\hline \multirow[t]{2}{*}{ Hydrogen bromide } & & Work Order \#: JL69F1AA & MB Lot-Sample \#: & H6L $270000-375$ & \\
\hline & ND & 10.1 & INOX 0050/26A Mod & $12 / 18 / 06$ & 6361375 \\
\hline \multirow{3}{*}{ Hydrogen chloride } & & & & & \\
\hline & & $\begin{array}{l}\text { Work Order \#: JL8TMIAA } \\
10.3\end{array}$ & $\begin{array}{l}\text { MB Lot-Sample \#: } \\
\text { KNox } 0050 / 26 A \text { Mod }\end{array}$ & $\begin{array}{l}\text { H6L } 290000-098 \\
12 / 18 / 06\end{array}$ & 6363098 \\
\hline & & Dilution Factor: 102.8 & & & \\
\hline \multirow[t]{3}{*}{ Hydrogen chloride } & & Work Order \#: UL9AAIAA & MB Lot-Sample \#: & H6L $290000-147$ & \\
\hline & ND & $10.3 \quad$ ug & KNOX $0050 / 26 \mathrm{~A}$ Mod & $12 / 28 / 06$ & 6363147 \\
\hline & & Dilution Factor: 102.8 & & & \\
\hline \multirow[t]{3}{*}{ Hydrogen fluoride } & & Work Order \#: JL69G1AA & MB Lot-Sample \#: & H6L $270000-376$ & \\
\hline & ND & $10.5 \quad$ ug & KNOX $0050 / 26 \mathrm{~A}$ Mod & $12 / 18 / 06$ & 6361376 \\
\hline & & Dilution Factor: 105.3 & & & \\
\hline \multirow[t]{2}{*}{ Hydrogen fluoride } & & Work Order \#: JL22H1AA & MB Lot-Sample \#: & H6L $220000-352$ & \\
\hline & ND & $\begin{array}{cc}10.5 & \text { ug } \\
\text { Dilution Factor: } & 105.3\end{array}$ & KNOX $0050 / 26 \mathrm{~A}$ Mod & $12 / 19 / 06$ & 6356352 \\
\hline
\end{tabular}

$\operatorname{NOTE}(S):$

Calculations ate performed before rounding to avoid round-off errors in calculated resuits. 
ILABORATORY CONTROL SAMPLE FVALUATION REPORT

General Chemistry

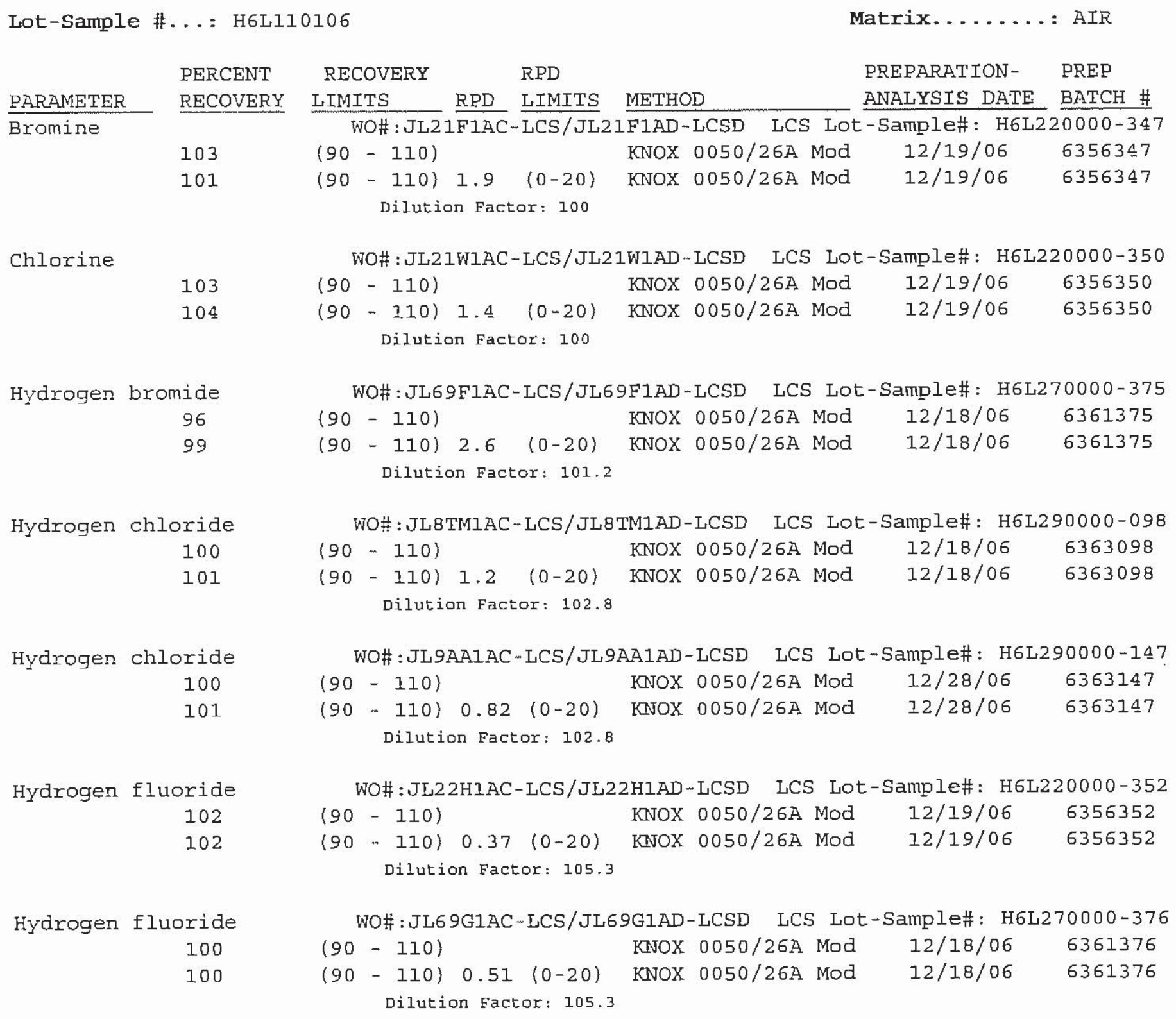

NOTE (S) :

Calculations are performed before rounding to avoid round-off errors in calculated results. 


\section{I.ABORATORY CONTROL SAMPLE DATA REPORT}

\section{General Chemistry}

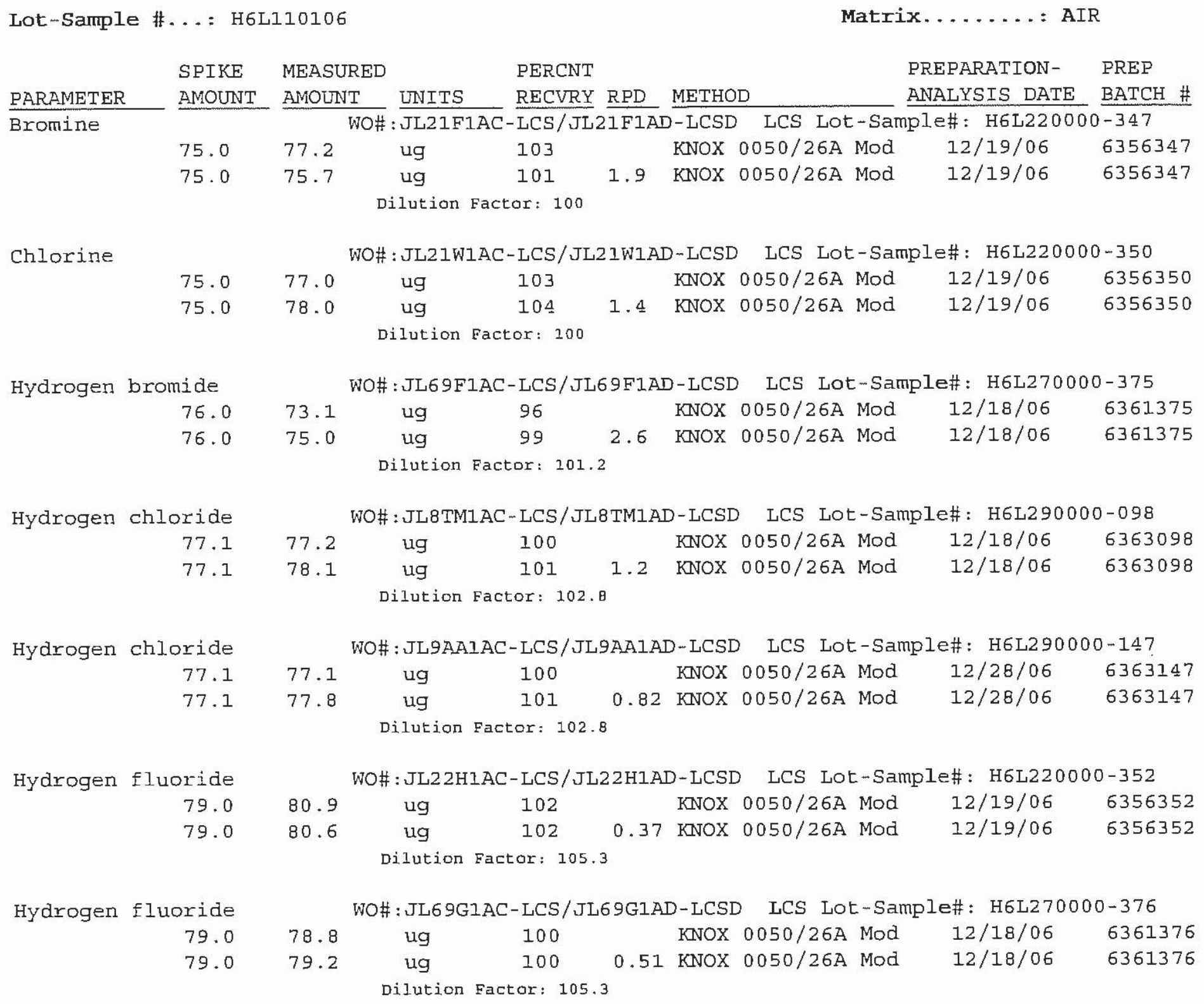

NOTE (S) :

Colculations are performed before rounding to avoid round-off errors in calculated results. 


\section{MATRIX SPIKE SAMPLE EVAUUATION REPORT}

\section{General Chemistry}

Client Lot \#...: H6L110106

Date Sampled...: 11/30/06
Date Received..: 12/06/06

Matrix....... AIR

PREPARATION - PREP ANALYSIS DATE BATCH \#

PARAMETER PERCENT RECOVERY

RPD RPD LIMITS METHOD WO\#: JK7KAIAE-MS/JK7KAIAF-MSD MS Lot-Sample \#: H6L110106-004

Bromine RECOVERY LIMITS WOF : KNOX 0050/26A Mod $12 / 19 / 06$ 6356347 101 $(75-125)$ KNOX 0050/26A Mod $12 / 19 / 06$ 6356347 Dilution Factor: 2950

Chlorine 95 95

$$
\begin{aligned}
& (75-125) \\
& (75-125) 0.35 \quad(0-20) \\
& \\
& \text { Dilution Factor: } 2950
\end{aligned}
$$
WO\#: JK7KAIAG-MS/J KNOX 0050/26A Mod KNNOX 0050/26A Mod $12 / 19 / 06$ $12 / 19 / 06$

H6L110106-004

Hydrogen bromide 104 105 WO\#: JK7J71AE-MS/J $(75-125)$ $(75$ - 125) $0.69 \quad(0-20)$ K7J71AF-MSD MS LO Sample \#: KNOX 0050/26A Mod $12 / 18 / 06$ 6356350 6356350 Dilution Factor: 4303.

Hydrogen chloride 99

99

Hydrogen fluoride 105 107

Hydrogen fluoride 102 105
WO\#: JK7J71AJ-MS/JK7J71AK-MSD MS Lot-Sample \#: H6L110106-002 $(75$ - 125) KNOX 0050/26A Mod 12/28/06 $(75$ - 125) $0.59(0-20)$ KNOX 0050/26A Mod 12/28/06 Dilution Factor: 17483

WO\#: JK7J71AG-MS/JK7J71AH-MSD MS Lot-Sample \#: H6L110106-002

$\begin{array}{llllll}(75-125) & \text { KNOX 0050/26A Mod } & 12 / 18 / 06 & 6361376 \\ (75-125) 1.7 \quad(0-20) & \text { KNOX 0050/26A Mod } & 12 / 18 / 06 & 6361376 \\ & \text { Dilution Factor: } 4475 \text {. }\end{array}$

WO\#: JK7KAIAJ-MS/JK7KAlAK-MSD MS Lot-Sample \#: H6L110106-004 $(75$ - 125) KNOX 0050/26A Mod $12 / 19 / 06 \quad 6356352$

$(75$ - 125) $2.5(0-20)$ KNOX 0050/26A Mod 12/19/06 6356352
6363147

6363147 Dilution Factor: 3106 .

NOTE (S) :

Calculations are performed before rounding to avoid round-off errors in calculated results. 


\section{MATRIX SPIKF SAMPLE DATA REPORT}

\section{General Chemistry}

Client Lot \#...: H6L110106 Date Sampled...: 11/30/06
Matrix....... AIR

Date Received..: 12/06/06

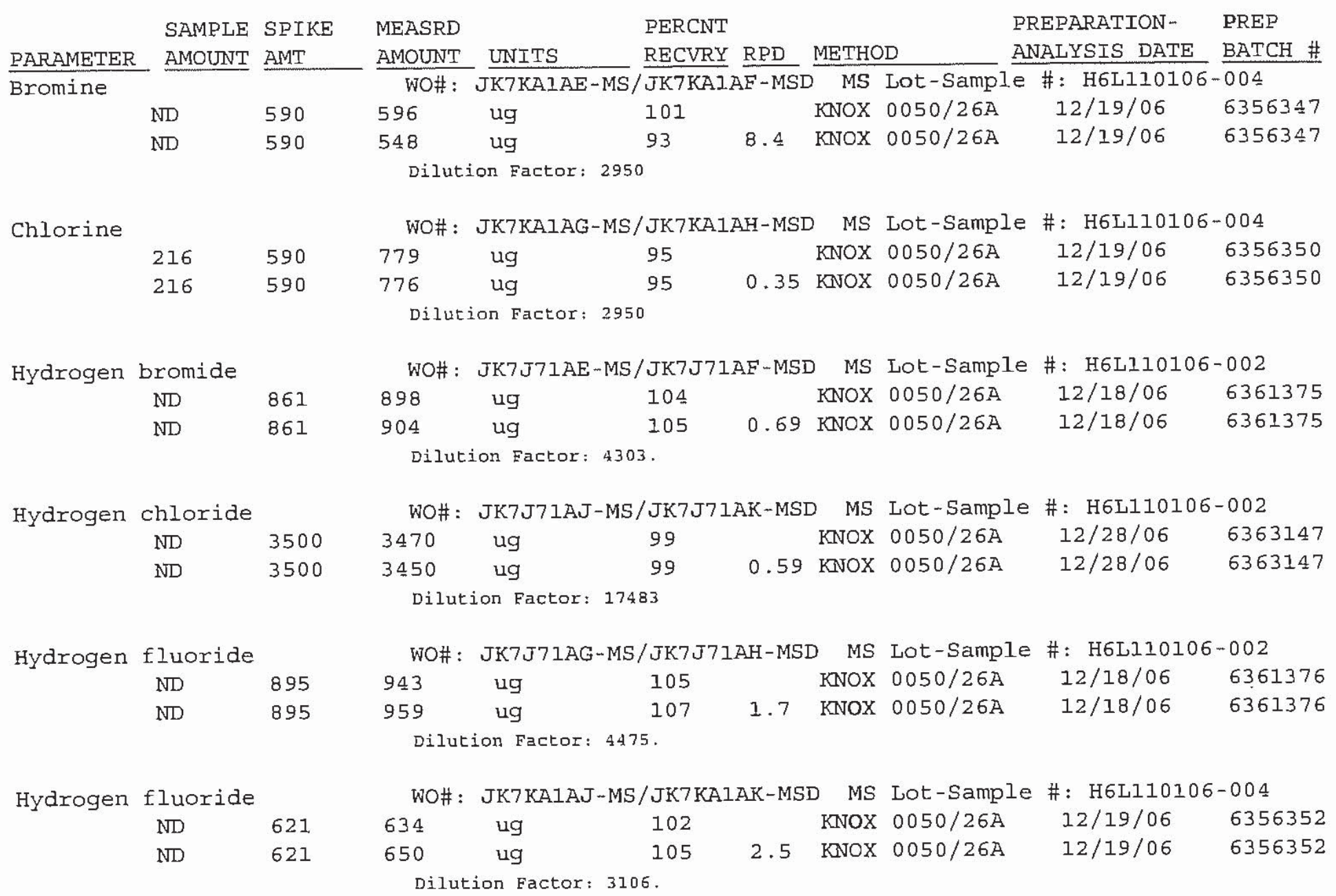

NOTE (S) :

Calculations are performed before founding to avoid round-off errors in colculated results. 
Raw Data 
Anions 


\section{STL Knoxville IC Initial Calibration Data Review / Narrative Checklist \\ Methods: 300.0, 9056, 9057 and 26A, SOP: KNOX-WC-0005, Rev. 8}

\section{Page 1 of 1}

(ICS- 1500)

Analvsis Date: $10 / 18 / 06$

File ID: 518 - LOWLEVEL- FULNOZBRNO3-101806

\begin{tabular}{|c|c|c|c|c|c|}
\hline Initial Calibration Review Items & N/A & Yes & No & If No, why is data reportable? & 2nd \\
\hline 1. Were at least 5 levels of each analyte analyzed? & & & & & \\
\hline 2. Is low level standard concentration $\leq R L$ ? & & & & & $\checkmark$ \\
\hline $\begin{array}{l}\text { 3. Are the correlation coefficients }(r) \geq 0.995 \text {; } \\
r^{2} \geq 0.990 \text { ? }\end{array}$ & & & & . & \\
\hline $\begin{array}{l}\text { 4. For method } 300.0 \text {, was the calibration curve } \\
\text { processed using linear reqression? }\end{array}$ & $I$ & & & & $N A$ \\
\hline $\begin{array}{l}\text { 5. For manual integrated standards, are before/after } \\
\text { cliromatograms provided with initials/date/reason? }\end{array}$ & $\checkmark$ & & & $\begin{array}{l}\text { Reasons: } \mathrm{S}=\text { Split peak, } U=\text { Undetected peak, I=Incorrect } \\
\text { peak integration, } \mathrm{B}=\mathrm{B} \text { aseline correction, } \mathrm{W}=\text { Wrong peak } \\
\text { chosen by data system }\end{array}$ & $N A$ \\
\hline
\end{tabular}

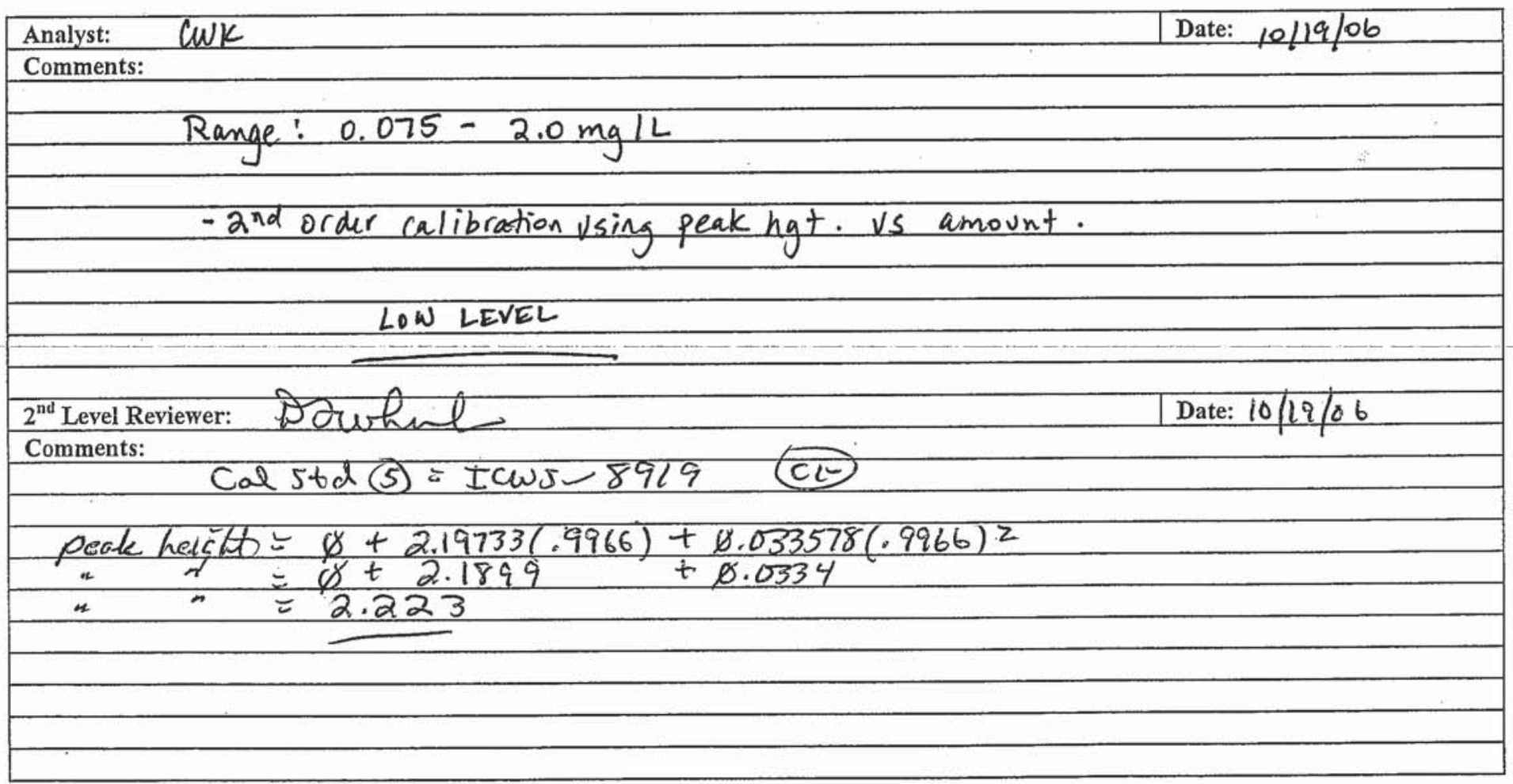

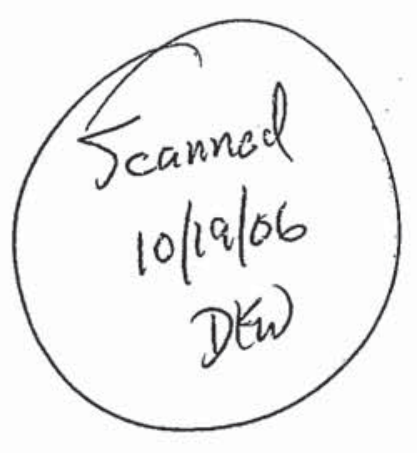




\section{CAL STD \#1 ICWS-8915}

Sample Name: $\quad$ CAL STD \#1 ICWS-8915

Vial Number:

Sample Type:

Control Program: AS14A ANIONS METHOD

Quantif. Method: AS4A-SC ANION METHOD

Recording Time: $\quad$ 10/18/2006 9:14

Run Time ( $\mathrm{min}$ ): $\quad 15.00$
Injection Volume: $\quad \mathbf{5 0 . 0}$

Channel:

Wavelength:

ECD_1

Bandwidth:

n.a.

Dilution Factor: $\quad 1.0000$

Sample Weight: $\quad \mathbf{1 . 0 0 0 0}$

Sample Amount: $\quad 1.0000$

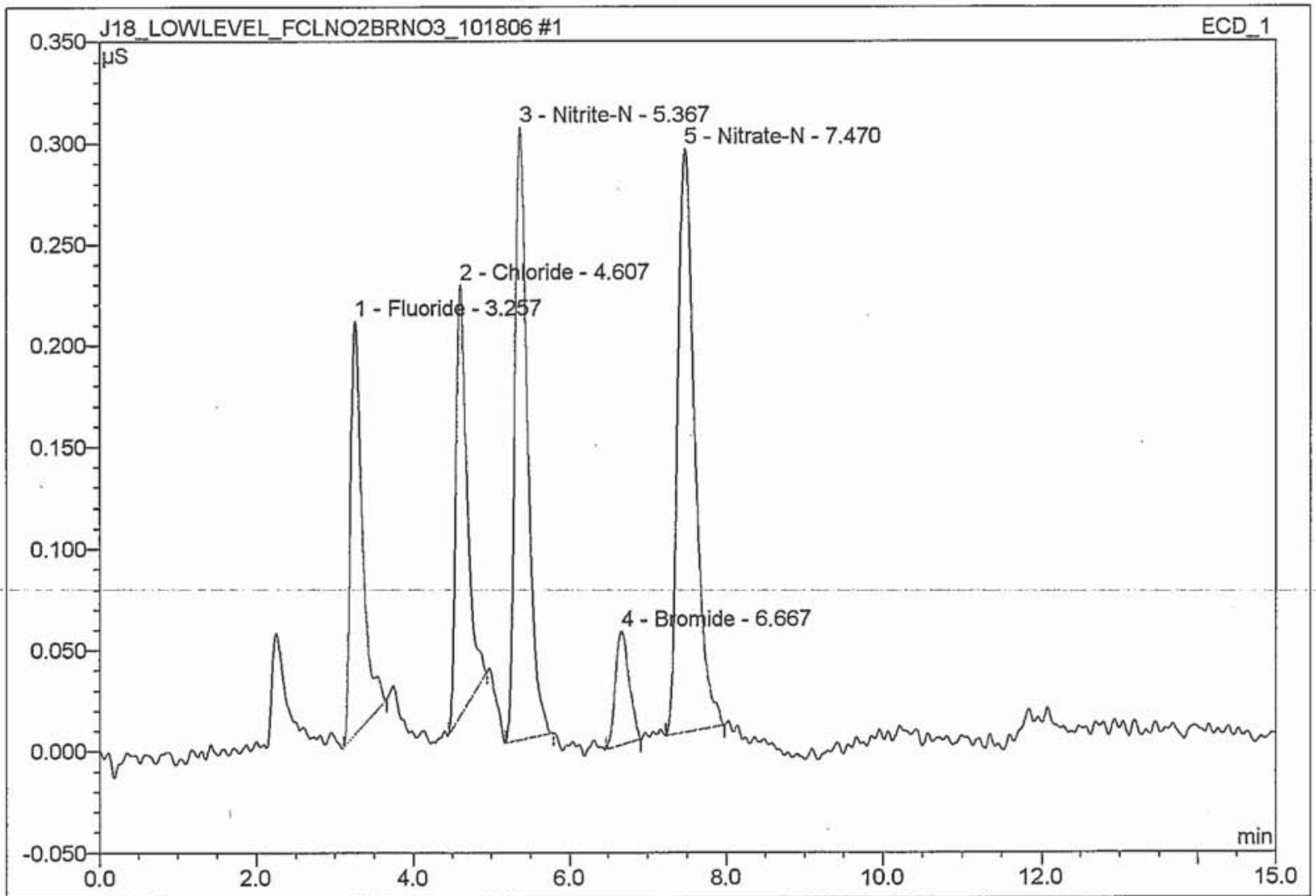

\begin{tabular}{|c|c|l|r|r|r|r|c|}
\hline No. & $\begin{array}{c}\text { Ret.Time } \\
\text { (min.) }\end{array}$ & \multicolumn{1}{|c|}{ Peak Name } & $\begin{array}{c}\text { Height } \\
\text { (uS) }\end{array}$ & $\begin{array}{c}\text { Area } \\
\mu \mathbf{S}^{*} \text { min }\end{array}$ & $\begin{array}{c}\text { Rel.Area } \\
(\%)\end{array}$ & $\begin{array}{c}\text { Amount } \\
\text { (mg/L) }\end{array}$ & $\begin{array}{c}\text { Peak } \\
\text { Type }\end{array}$ \\
\hline 1 & 3.26 & Fluoride & 0.20347 & 0.035 & 16.69 & 0.0752 & BMB \\
\hline 2 & 4.61 & Chloride & 0.21212 & 0.036 & 16.87 & 0.0964 & BMB \\
\hline 3 & 5.37 & Nitrite-N & 0.30167 & 0.057 & 26.98 & 0.0791 & BMB \\
\hline 4 & 6.67 & Bromide & 0.05610 & 0.011 & 5.39 & 0.0791 & BMB \\
\hline 5 & 7.47 & Nitrate-N & 0.28758 & 0.072 & 34.07 & 0.0828 & BMB \\
\hline
\end{tabular}




\section{CAL STD \#2 ICWS-8916}

Sample Name: $\quad$ CAL STD \#2 ICWS-8916

Vial Number:

Sample Type:

Control Program: AS14A ANIONS METHOD

Quantif. Method:

Recording Time:

Run Time (min):
1293

standard

AS4A-SC ANION METHOD

10/18/2006 9:32

15.00
Injection Volume: $\quad \mathbf{5 0 . 0}$

Channel: ECD_1

Wavelength: n.a.

Bandwidth: n.a.

Dilution Factor: $\quad \mathbf{1 . 0 0 0 0}$

Sample Weight: $\quad \mathbf{1 . 0 0 0 0}$

Sample Amount: $\quad 1.0000$

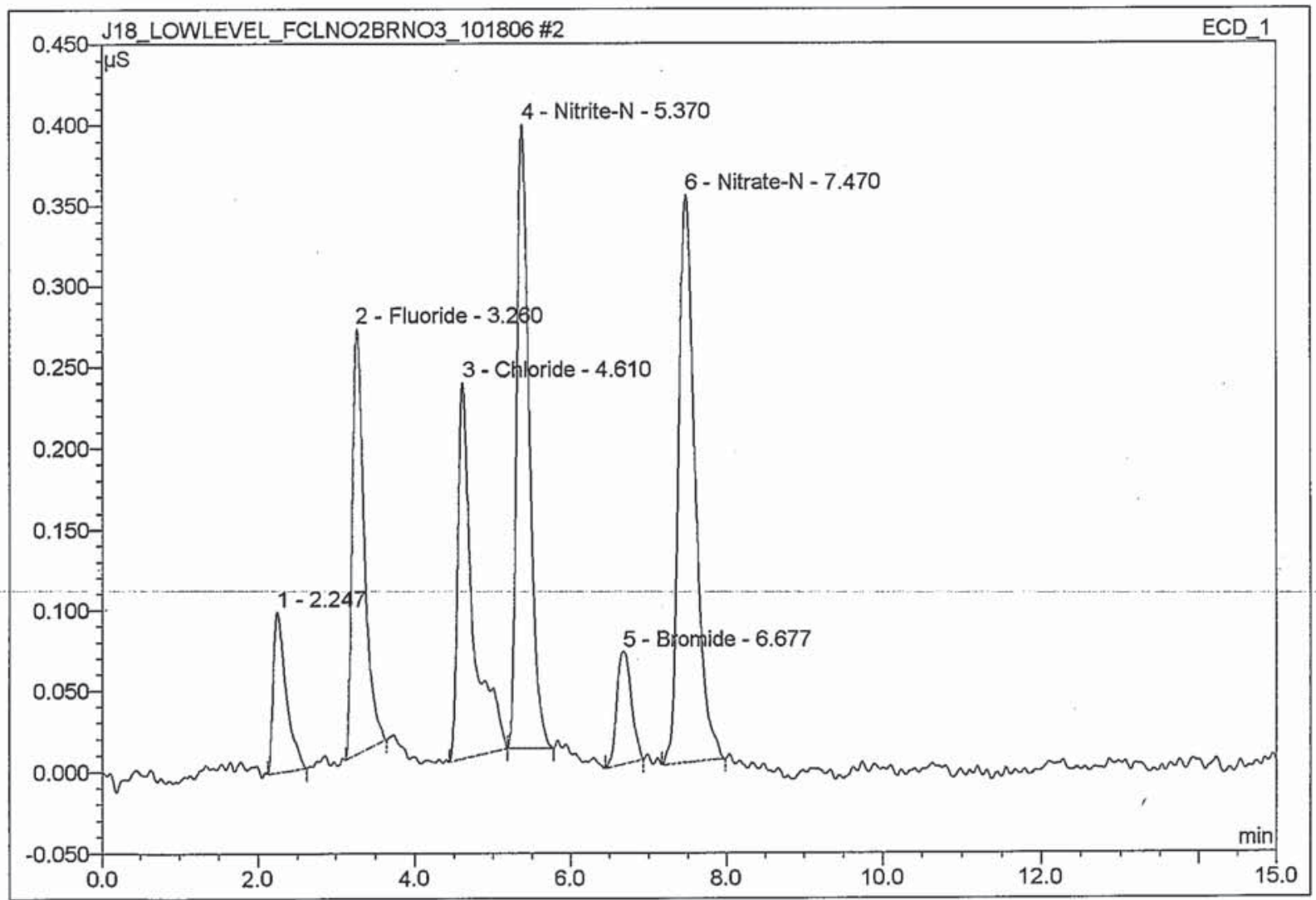

\begin{tabular}{|r|c|l|r|r|r|r|r|}
\hline No. & $\begin{array}{c}\text { Ret.Time } \\
\text { (min.) }\end{array}$ & \multicolumn{1}{|c|}{ Peak Name } & $\begin{array}{c}\text { Height } \\
\text { (uS) }\end{array}$ & $\begin{array}{c}\text { Area } \\
\mu \mathbf{S}^{*} \text { min }\end{array}$ & $\begin{array}{c}\text { Rel.Area } \\
(\%)\end{array}$ & $\begin{array}{c}\text { Amount } \\
\text { (mg/L) }\end{array}$ & $\begin{array}{r}\text { Peak } \\
\text { Type }\end{array}$ \\
\hline 1 & 2.25 & n.a. & 0.09910 & 0.019 & 6.45 & n.a. & BMB \\
\hline 2 & 3.26 & Fluoride & 0.26277 & 0.046 & 15.73 & 0.0970 & BMB \\
\hline 3 & 4.61 & Chloride & 0.23228 & 0.052 & 17.83 & 0.1055 & BMB \\
\hline 4 & 5.37 & Nitrite-N & 0.38584 & 0.072 & 24.74 & 0.1012 & BMB \\
\hline 5 & 6.68 & Bromide & 0.06928 & 0.015 & 5.09 & 0.0977 & BMB \\
\hline 6 & 7.47 & Nitrate-N & 0.35086 & 0.088 & 30.16 & 0.1009 & BMB \\
\hline
\end{tabular}




\section{CAL STD \#3 ICWS-8917}

\begin{tabular}{llll|}
\hline Sample Name: & CAL STD \#3 ICWS-8917 & Injection Volume: & $\mathbf{5 0 . 0}$ \\
Vial Number: & $\mathbf{1 2 9 3}$ & Channel: & ECD_1 \\
Sample Type: & standard & Wavelength: & n.a. \\
Control Program: & AS14A ANIONS METHOD & Bandwidth: & n.a. \\
Quantif. Method: & AS4A-SC ANION METHOD & Dilution Factor: & $\mathbf{1 . 0 0 0 0}$ \\
Recording Time: & $\mathbf{1 0 / 1 8 / 2 0 0 6 ~ 9 : 4 9}$ & Sample Weight: & 1.0000 \\
Run Time (min): & $\mathbf{1 5 . 0 0}$ & Sample Amount: & $\mathbf{1 . 0 0 0 0}$ \\
\hline
\end{tabular}

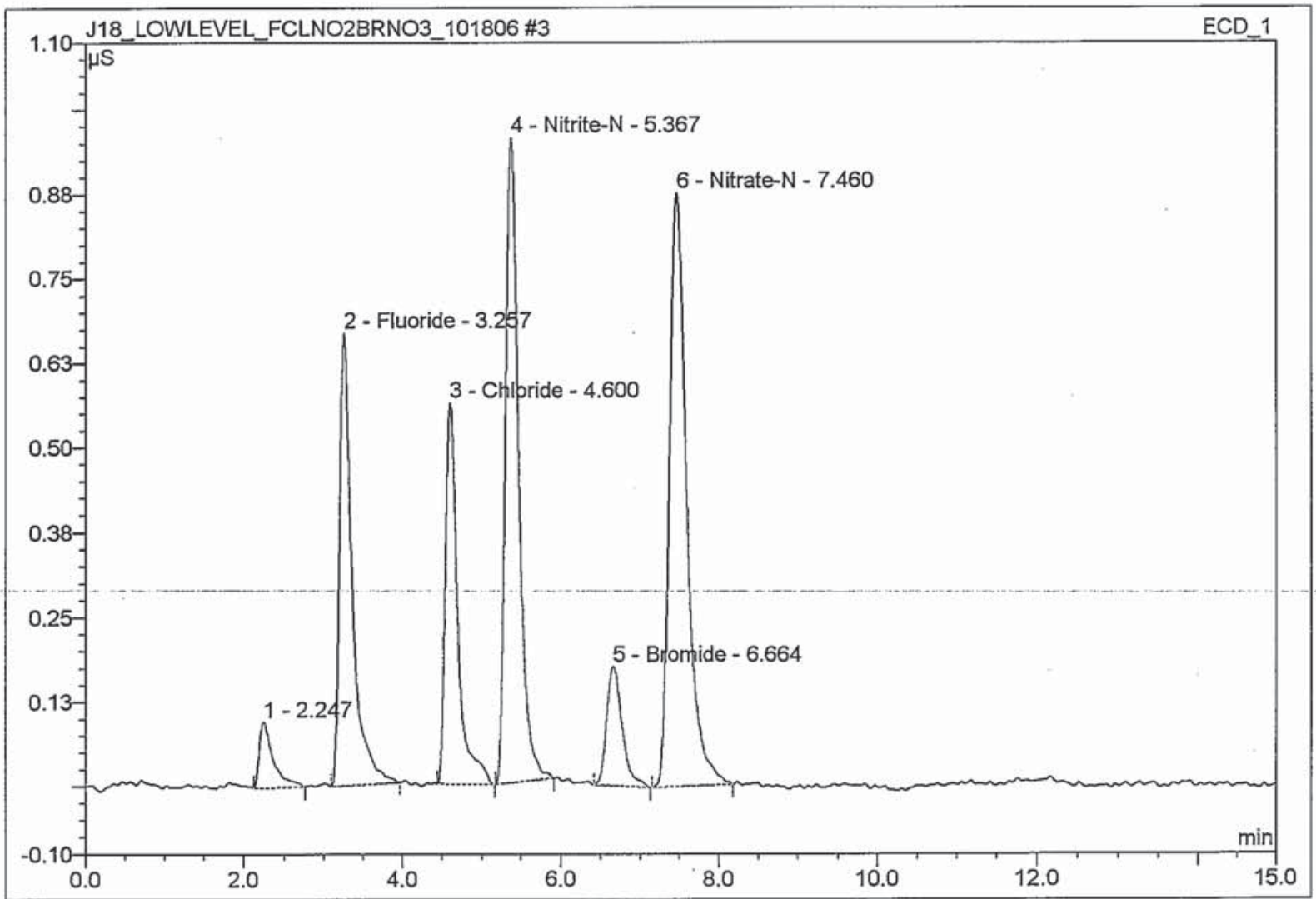

\begin{tabular}{|r|c|l|r|r|r|r|r|}
\hline No. & $\begin{array}{c}\text { Ret.Time } \\
\text { (min.) }\end{array}$ & \multicolumn{1}{|c|}{ Peak Name } & $\begin{array}{c}\text { Height } \\
\text { (uS) }\end{array}$ & \multicolumn{1}{c|}{$\begin{array}{c}\text { Area } \\
\mu \mathbf{S}^{*} \text { min }\end{array}$} & $\begin{array}{c}\text { Rel.Area } \\
(\%)\end{array}$ & $\begin{array}{c}\text { Amount } \\
\text { (mg/L) }\end{array}$ & $\begin{array}{r}\text { Peak } \\
\text { Type }\end{array}$ \\
\hline 1 & 2.25 & n.a. & 0.09667 & 0.019 & 2.79 & n.a. & BMB \\
\hline 2 & 3.26 & Fluoride & 0.66838 & 0.127 & 18.21 & 0.2438 & BMB \\
\hline 3 & 4.60 & Chloride & 0.56206 & 0.103 & 14.73 & 0.2548 & BMB \\
\hline 4 & 5.37 & Nitrite-N & 0.95211 & 0.184 & 26.44 & 0.2484 & BMB \\
\hline 5 & 6.66 & Bromide & 0.17667 & 0.040 & 5.79 & 0.2488 & BMB \\
\hline 6 & 7.46 & Nitrate-N & 0.87649 & 0.223 & 32.04 & 0.2502 & BMB \\
\hline
\end{tabular}




\section{CAL STD \#4 ICWS-8918}

\section{Sample Name: $\quad$ CAL STD \#4 ICWS-8918}

Vial Number:

Sample Type:

Control Program: AS14A ANIONS METHOD

Quantif. Method:

Recording Time:

Run Time (min):
1295

standard

AS4A-SC ANION METHOD

10/18/2006 10:07

15.00
Injection Volume: $\quad \mathbf{5 0 . 0}$

Channel: $\quad$ ECD_1

Wavelength: n.a.

Bandwidth: n.a.

Dilution Factor: $\quad \mathbf{1 . 0 0 0 0}$

Sample Weight: $\quad \mathbf{1 . 0 0 0 0}$

Sample Amount: $\quad \mathbf{1 . 0 0 0 0}$

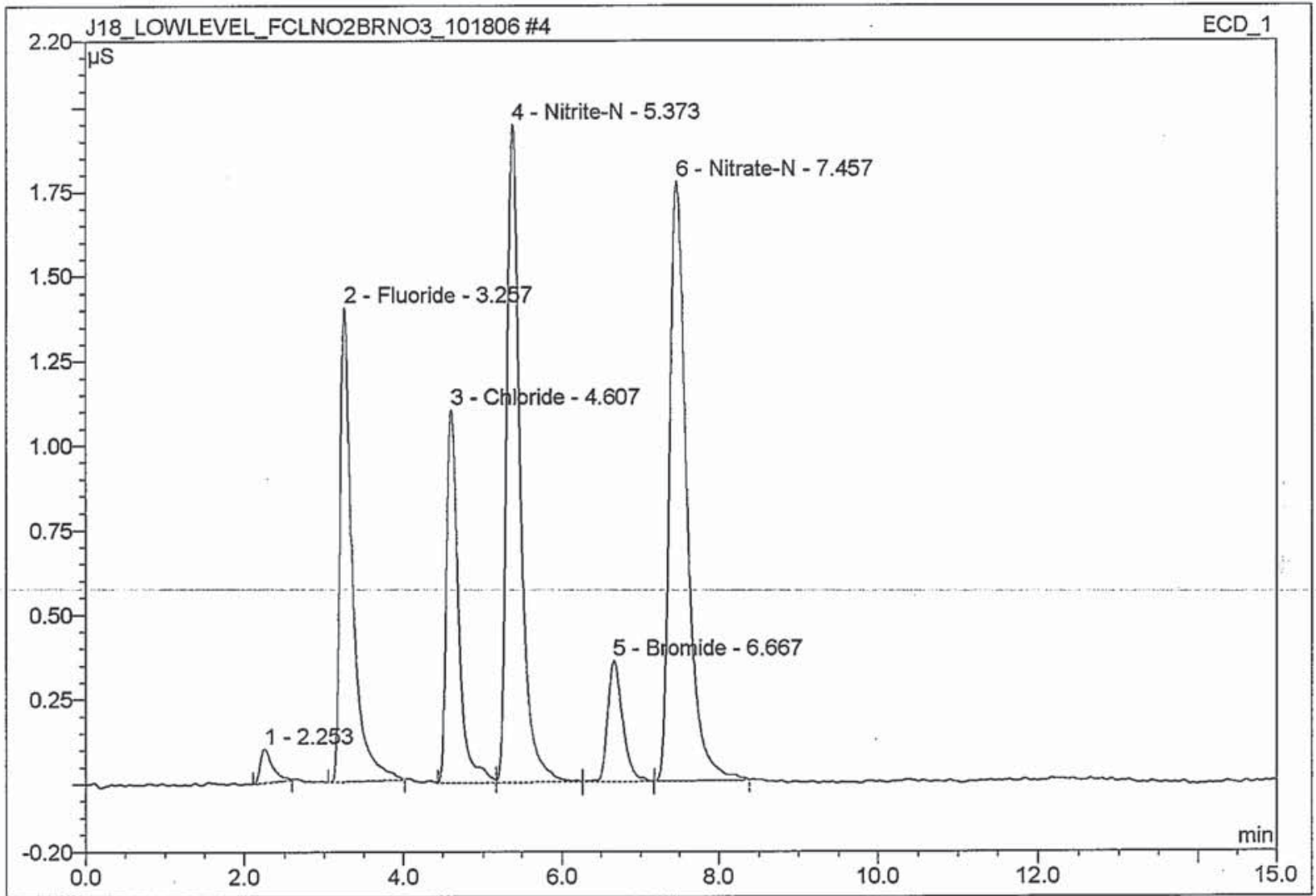

\begin{tabular}{|c|c|l|r|r|r|r|c|}
\hline No. & $\begin{array}{c}\text { Ret.Time } \\
\text { (min.) }\end{array}$ & \multicolumn{1}{|c|}{ Peak Name } & $\begin{array}{c}\text { Height } \\
(\mathbf{u S})\end{array}$ & $\begin{array}{c}\text { Area } \\
\mu \mathbf{S}^{*} \mathrm{~min}\end{array}$ & $\begin{array}{c}\text { Rel.Area } \\
(\%)\end{array}$ & $\begin{array}{c}\text { Amount } \\
(\mathrm{mg} / \mathrm{L})\end{array}$ & $\begin{array}{c}\text { Peak } \\
\text { Type }\end{array}$ \\
\hline 1 & 2.25 & n.a. & 0.10012 & 0.018 & 1.29 & n.a. & BMB \\
\hline 2 & 3.26 & Fluoride & 1.39754 & 0.256 & 18.63 & 0.4996 & BMB \\
\hline 3 & 4.61 & Chloride & 1.09898 & 0.191 & 13.89 & 0.4964 & BM \\
\hline 4 & 5.37 & Nitrite-N & 1.94194 & 0.385 & 27.97 & 0.5022 & M \\
\hline 5 & 6.67 & Bromide & 0.35570 & 0.078 & 5.68 & 0.4998 & MB \\
\hline 6 & 7.46 & Nitrate-N & 1.76858 & 0.448 & 32.55 & 0.4985 & BMB \\
\hline
\end{tabular}




\section{CAL STD \#5 ICWS-8919}

Sample Name: Vial Number:

Sample Type:

Control Program:

Quantif. Method:

Recording Time:

Run Time (min):
CAL STD \#5 ICWS-8919

1295

standard

AS14A ANIONS METHOD

AS4A-SC ANION METHOD

10/18/2006 10:24

15.00
Injection Volume: $\quad \mathbf{5 0 . 0}$

Channel: $\quad$ ECD_1

Wavelength: n.a.

Bandwidth: n.a.

Dilution Factor: $\quad \mathbf{1 . 0 0 0 0}$

Sample Weight: $\quad \mathbf{1 . 0 0 0 0}$

Sample Amount: $\quad \mathbf{1 . 0 0 0 0}$

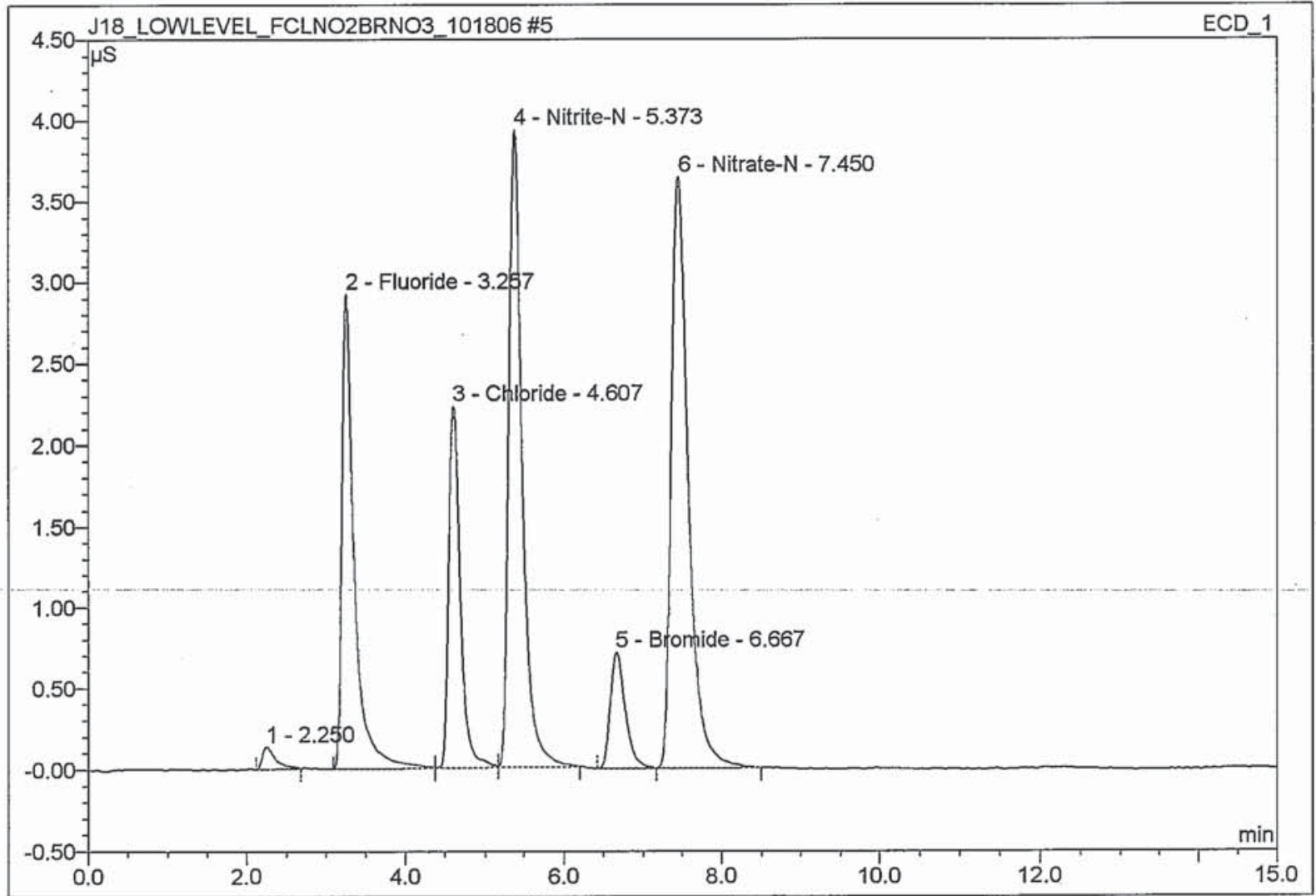

\begin{tabular}{|c|c|l|r|r|r|r|c|}
\hline No. & $\begin{array}{c}\text { Ret.Time } \\
\text { (min.) }\end{array}$ & \multicolumn{1}{|c|}{ Peak Name } & $\begin{array}{c}\text { Height } \\
\text { (uS) }\end{array}$ & $\begin{array}{c}\text { Area } \\
\mu \mathbf{S}^{*} \text { min }\end{array}$ & $\begin{array}{c}\text { Rel.Area } \\
(\%)\end{array}$ & $\begin{array}{c}\text { Amount } \\
(\mathbf{m g} / \mathbf{L})\end{array}$ & $\begin{array}{r}\text { Peak } \\
\text { Type }\end{array}$ \\
\hline 1 & 2.25 & n.a. & 0.13527 & 0.026 & 0.94 & n.a. & BMB \\
\hline 2 & 3.26 & Fluoride & 2.91620 & 0.530 & 19.16 & 1.0032 & BM \\
\hline 3 & 4.61 & Chloride & 2.22320 & 0.373 & 13.49 & 0.9966 & M \\
\hline 4 & 5.37 & Nitrite-N & 3.92501 & 0.773 & 27.95 & 0.9983 & MB \\
\hline 5 & 6.67 & Bromide & 0.71491 & 0.156 & 5.62 & 1.0005 & Ru \\
\hline 6 & 7.45 & Nitrate-N & 3.63765 & 0.908 & 32.83 & 0.9998 & BMB \\
\hline
\end{tabular}




\section{CAL STD \#6 ICWS-8920}

Sample Name: $\quad$ CAL STD \#6 ICWS-8920

Vial Number:

Sample Type:

Control Program: AS14A ANIONS METHOD

Quantif. Method:

Recording Time:

Run Time (min):
1295

standard

AS4A-SC ANION METHOD

10/18/2006 10:41

15.00
Injection Volume: $\quad \mathbf{5 0 . 0}$

Channel:

Wavelength:

ECD_1

n.a.

Bandwidth: n.a.

Dilution Factor: $\quad \mathbf{1 . 0 0 0 0}$

Sample Weight: $\quad \mathbf{1 . 0 0 0 0}$

Sample Amount: $\quad \mathbf{1 . 0 0 0 0}$

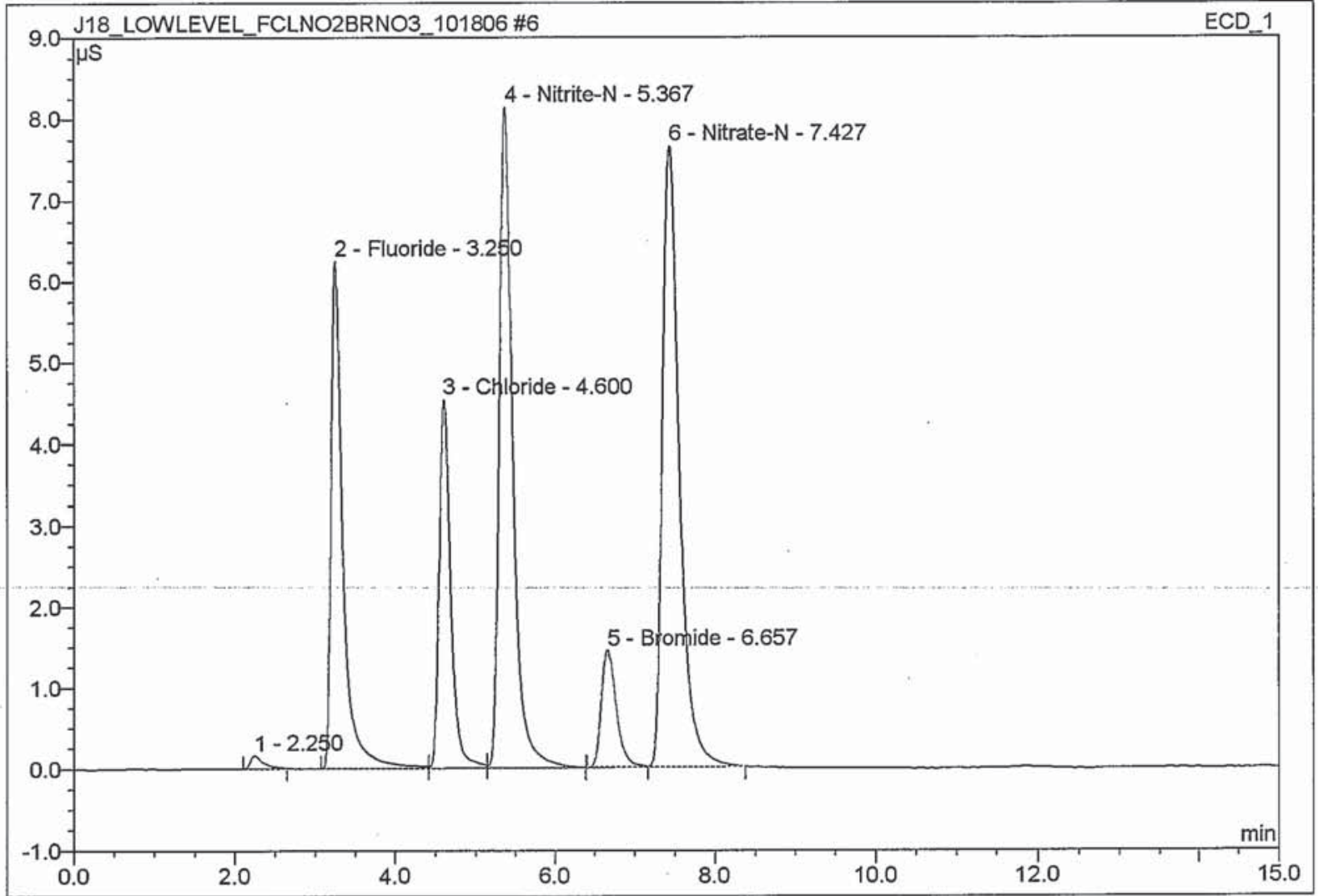

\begin{tabular}{|c|c|l|r|r|r|r|c|}
\hline No. & $\begin{array}{c}\text { Ret.Time } \\
\text { (min.) }\end{array}$ & \multicolumn{1}{|c|}{ Peak Name } & $\begin{array}{c}\text { Height } \\
\text { (uS) }\end{array}$ & $\begin{array}{c}\text { Area } \\
\mu \mathbf{S}^{*} \text { min }\end{array}$ & $\begin{array}{c}\text { Rel.Area } \\
(\%)\end{array}$ & $\begin{array}{c}\text { Amount } \\
\text { (mg/L) }\end{array}$ & $\begin{array}{r}\text { Peak } \\
\text { Type }\end{array}$ \\
\hline 1 & 2.25 & n.a. & 0.15975 & 0.030 & 0.53 & n.a. & BMB \\
\hline 2 & 3.25 & Fluoride & 6.24513 & 1.086 & 19.22 & 1.9994 & BM \\
\hline 3 & 4.60 & Chloride & 4.53115 & 0.754 & 13.35 & 2.0009 & $\mathrm{M}$ \\
\hline 4 & 5.37 & Nitrite-N & 8.12633 & 1.598 & 28.28 & 2.0003 & $\mathrm{M}$ \\
\hline 5 & 6.66 & Bromide & 1.44051 & 0.306 & 5.42 & 1.9999 & $\mathrm{Ru}$ \\
\hline 6 & 7.43 & Nitrate-N & 7.63891 & 1.876 & 33.19 & 2.0001 & $\mathrm{MB}$ \\
\hline
\end{tabular}




\begin{tabular}{|lllll|}
\hline 4 CALSTD-\#4-ICWS-8918-DIW & & \\
& & & \\
& & & \\
\hline Sample Name: & CAL STD \#4 ICWS-8918 & Injection Volume: & 50.0 \\
Vial Number: & 1295 & Channel: & ECD_1 \\
Sample Type: & standard & Wavelength: & n.a. \\
Control Program: & AS14A ANIONS METHOD & Bandwidth: & n.a. \\
Quantif. Method: & AS4A-SC ANION METHOD & Dilution Factor: & 1.0000 \\
Recording Time: & \#\#\#\#\#\#\#\#\#\# & Sample Weight: & 1.0000 \\
Run Time (min): & 15.00 & Sample Amount: & 1.0000 \\
\hline
\end{tabular}

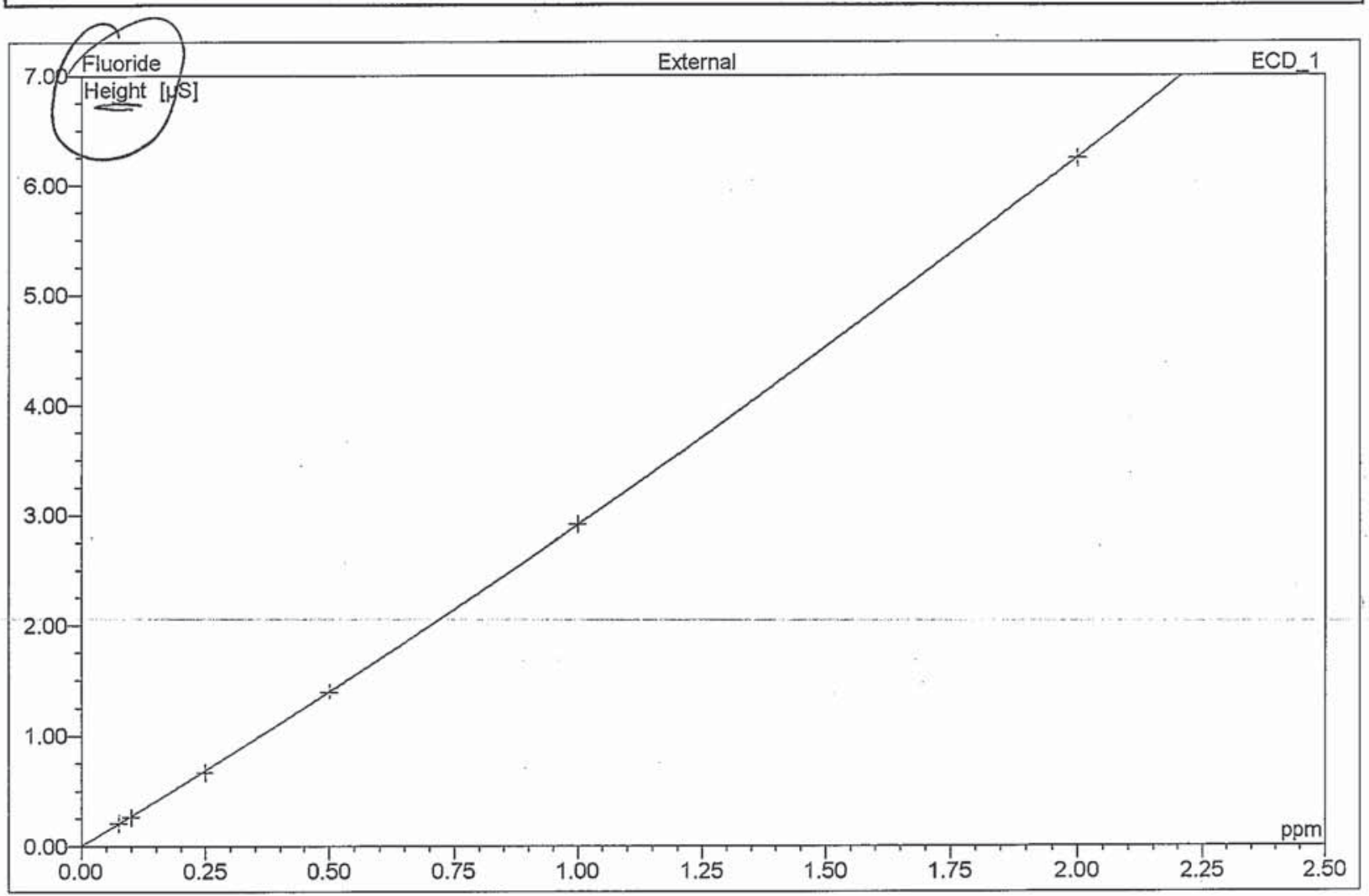

\begin{tabular}{|r|rlrrrrrr|}
\hline No. & $\begin{array}{c}\text { Ret.Time } \\
\text { min }\end{array}$ & Peak Name & Cal.Type & Points & R-Square & Offset & Slope & Curve \\
\hline 1 & 2.25 & n.a. & n.a. & n.a. & n.a. & n.a. & n.a. & n.a. \\
2 & 3.26 & Fluoride & Quad & 6 & $\checkmark 1.0000$ & 0.000000 & 2.68877 & 0.217432 \\
3 & 4.61 & Chloride & Quad & 6 & 0.9998 & 0.000000 & 2.19733 & 0.033578 \\
4 & 5.37 & Nitrite-N & Quad & 6 & 1.0000 & 0.000000 & 3.80119 & 0.130678 \\
5 & 6.67 & Bromide & Quad & 6 & 1.0000 & 0.000000 & 0.70878 & 0.005755 \\
6 & 7.46 & Nitrate-N & Quad & 6 & 1.0000 & 0.000000 & 3.45770 & 0.180759 \\
\hline Average: & & & & & 1.0000 & 0.0000 & 2.5708 & 0.1136 \\
\hline
\end{tabular}




\begin{tabular}{|lllll|}
\hline 4 CAL STD\#4-ICWS-8948-(DFw \\
& & & \\
& & & \\
\hline Sample Name: & CAL STD \#4 ICWS-8918 & Injection Volume: & 50.0 \\
Vial Number: & 1295 & Channel: & ECD_1 \\
Sample Type: & standard & Wavelength: & n.a. \\
Control Program: & AS14A ANIONS METHOD & Bandwidth: & n.a. \\
Quantif. Method: & AS4A-SC ANION METHOD & Dilution Factor: & 1.0000 \\
Recording Time: & \#\#\#\#\#\#\#\#\#\# & Sample Weight: & 1.0000 \\
Run Time (min): & 15.00 & Sample Amount: & 1.0000 \\
\hline
\end{tabular}

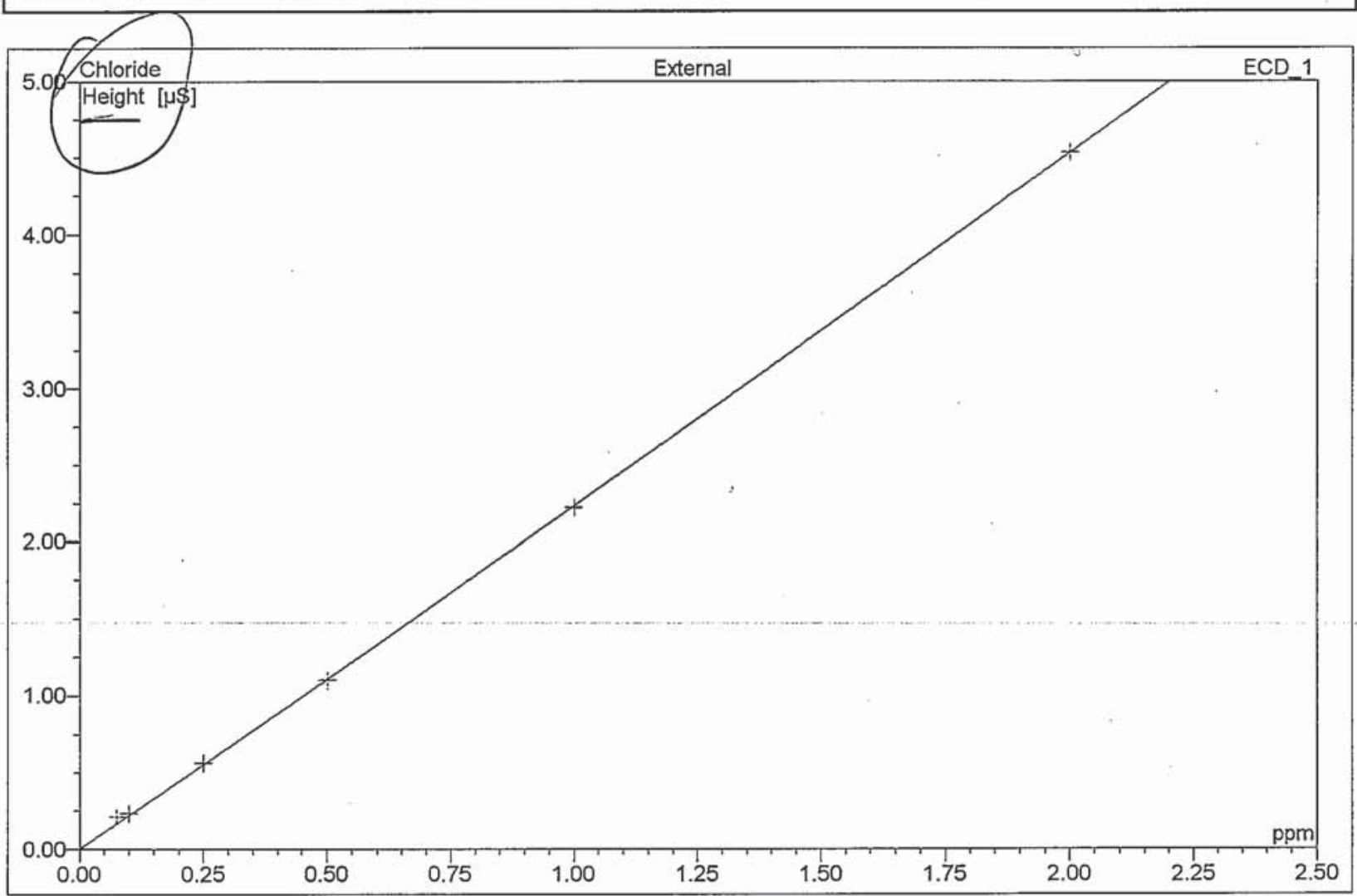

\begin{tabular}{|c|ccccccrr|}
\hline No. & $\begin{array}{c}\text { Ret.Time } \\
\text { min }\end{array}$ & Peak Name & Cal.Type & Points & R-Square & Offset & Slope & Curve \\
\hline 1 & 2.25 & n.a. & n.a. & n.a. & n.a. & n.a. & n.a. & n.a. \\
2 & 3.26 & Fluoride & Quad & 6 & 1.0000 & 0.000000 & 2.68877 & 0.217432 \\
3 & 4.61 & Chloride & Quad & 6 & 0.9998 & 0.000000 & 2.19733 & 0.033578 \\
4 & 5.37 & Nitrite-N & Quad & 6 & 1.0000 & 0.000000 & 3.80119 & 0.130678 \\
5 & 6.67 & Bromide & Quad & 6 & 1.0000 & 0.000000 & 0.70878 & 0.005755 \\
6 & 7.46 & Nitrate-N & Quad & 6 & 1.0000 & 0.000000 & 3.45770 & 0.180759 \\
\hline Average: & & & & & 1.0000 & 0.0000 & 2.5708 & 0.1136 \\
\hline
\end{tabular}




\begin{tabular}{|c|c|c|c|}
\hline \multicolumn{2}{|c|}{4 CALSTD\#41CWS-8918 } & \multirow{3}{*}{$\begin{array}{l}\text { Injection Volume: } \\
\text { Channel: }\end{array}$} & \multirow{3}{*}{$\begin{array}{l}50.0 \\
\text { ECD_1 }\end{array}$} \\
\hline Sample Name: & CAL STD \#4 ICWS-8918 & & \\
\hline Vial Number: & 1295 & & \\
\hline Sample Type: & standard & Wavelength: & n.a. \\
\hline Control Program: & AS14A ANIONS METHOD & Bandwidth: & n.a. \\
\hline Quantif. Method: & AS4A-SC ANION METHOD & Dilution Factor: & 1.0000 \\
\hline Recording Time: & \#\#\#\#\#\#\#\#\#\#\#\# & Sample Weight: & 1.0000 \\
\hline Run Time (min): & 15.00 & Sample Amount: & 1.0000 \\
\hline
\end{tabular}

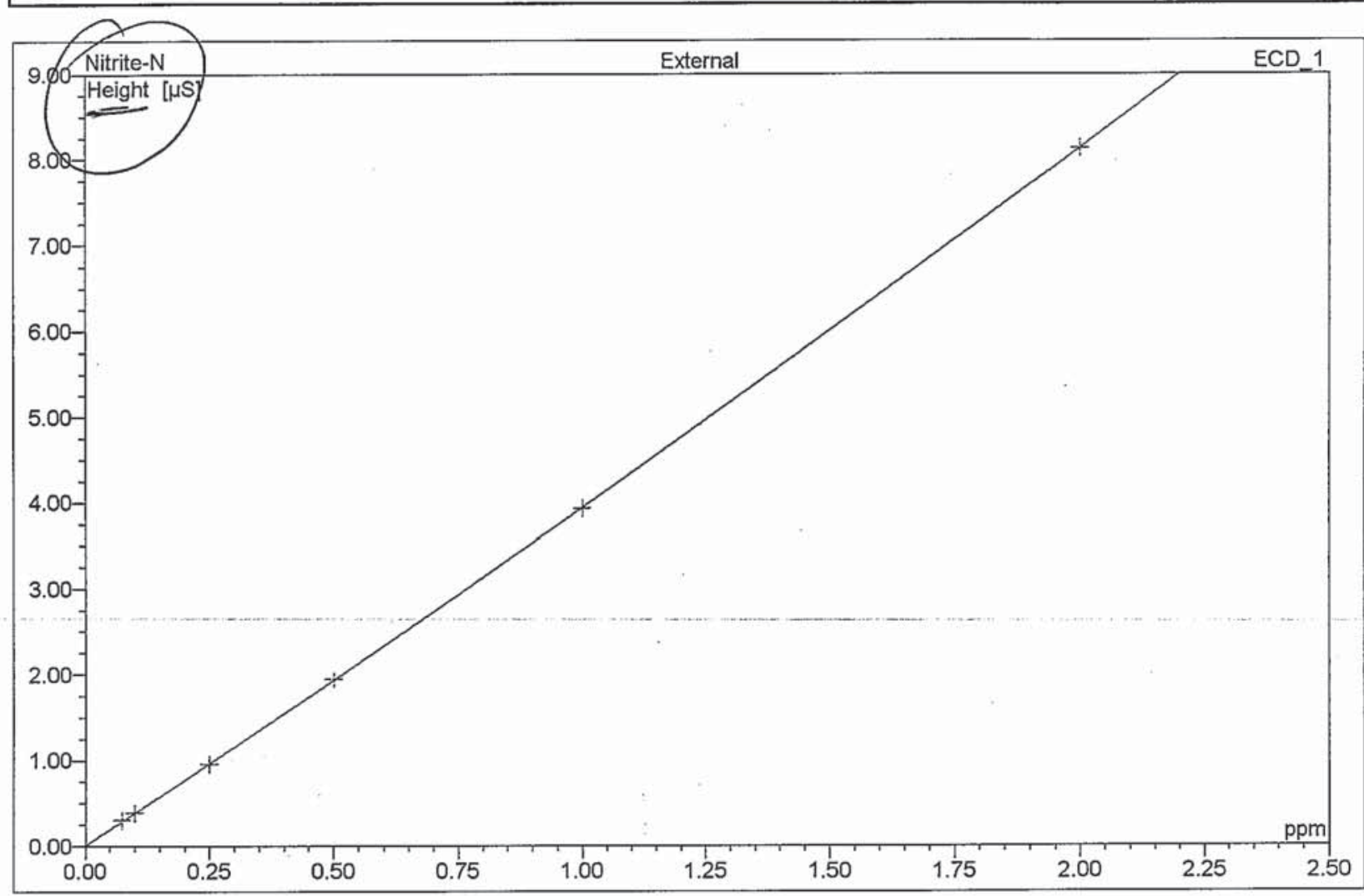

\begin{tabular}{|c|ccccccrrr|}
\hline No. & $\begin{array}{c}\text { Ret.Time } \\
\text { min }\end{array}$ & Peak Name & Cal.Type & Points & R-Square & Offset & Slope & Curve \\
\hline 1 & 2.25 & n.a. & n.a. & n.a. & n.a. & n.a. & n.a. & n.a. \\
2 & 3.26 & Fluoride & Quad & 6 & 1.0000 & 0.000000 & 2.68877 & 0.217432 \\
3 & 4.61 & Chloride & Quad & 6 & 0.9998 & 0.000000 & 2.19733 & 0.033578 \\
4 & 5.37 & Nitrite-N & Quad & 6 & -1.0000 & 0.000000 & 3.80119 & 0.130678 \\
5 & 6.67 & Bromide & Quad & 6 & 1.0000 & 0.000000 & 0.70878 & 0.005755 \\
6 & 7.46 & Nitrate-N & Quad & 6 & 1.0000 & 0.000000 & 3.45770 & 0.180759 \\
\hline Average: & & & & & 1.0000 & 0.0000 & 2.5708 & 0.1136 \\
\hline
\end{tabular}




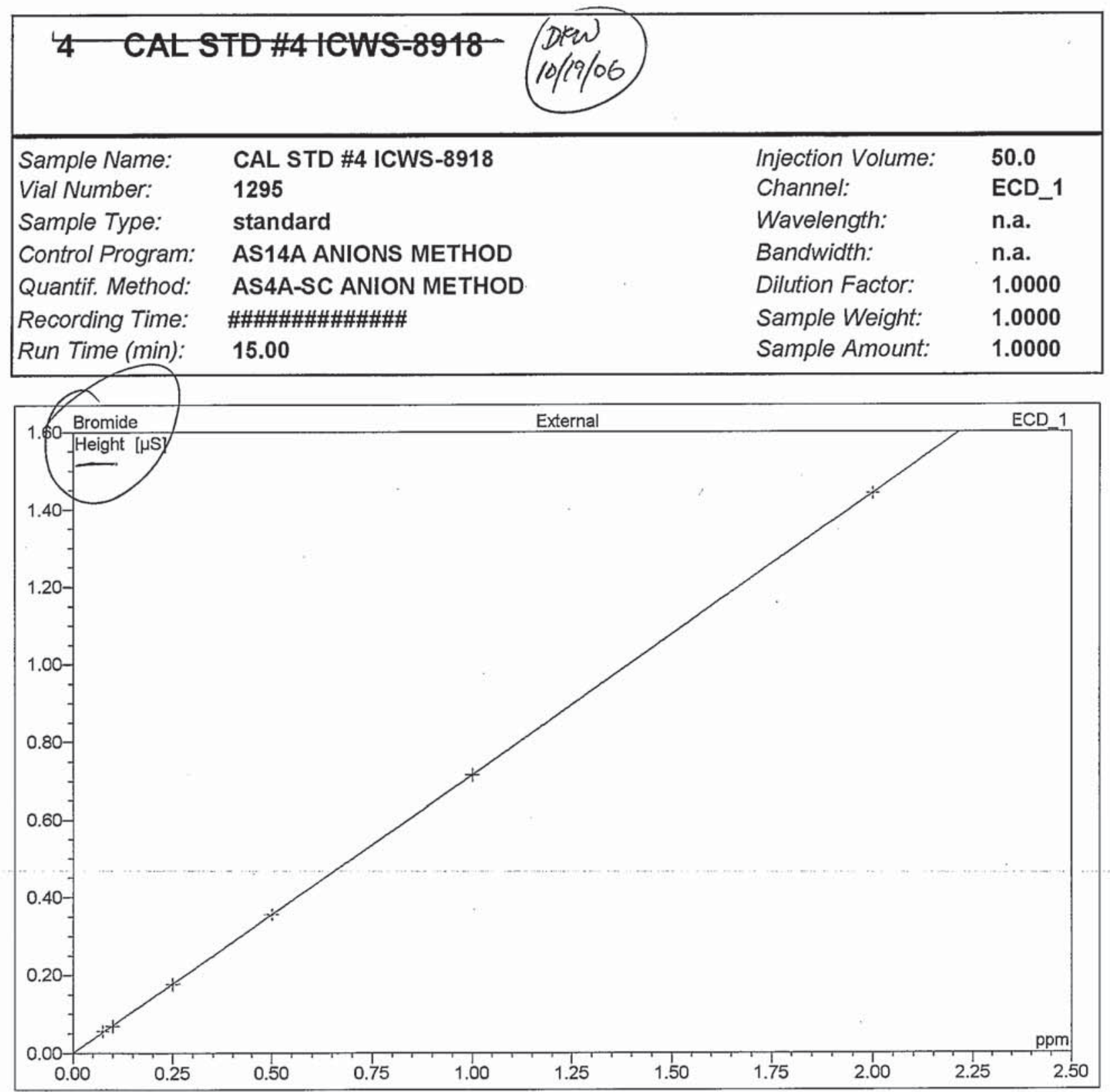

\begin{tabular}{|c|rlcrrrrr|}
\hline No. & $\begin{array}{c}\text { Ret.Time } \\
\text { min }\end{array}$ & Peak Name & Cal.Type & Points & R-Square & Offset & Slope & Curve \\
\hline 1 & 2.25 & n.a. & n.a. & n.a. & n.a. & n.a. & n.a. & n.a. \\
2 & 3.26 & Fluoride & Quad & 6 & 1.0000 & 0.000000 & 2.68877 & 0.217432 \\
3 & 4.61 & Chloride & Quad & 6 & 0.9998 & 0.000000 & 2.19733 & 0.033578 \\
4 & 5.37 & Nitrite-N & Quad & 6 & 1.0000 & 0.000000 & 3.80119 & 0.130678 \\
5 & 6.67 & Bromide & Quad & 6 & $\checkmark 1.0000$ & 0.000000 & 0.70878 & 0.005755 \\
6 & 7.46 & Nitrate-N & Quad & 6 & 1.0000 & 0.000000 & 3.45770 & 0.180759 \\
\hline Average: & & & & & 1.0000 & 0.0000 & 2.5708 & 0.1136 \\
\hline
\end{tabular}




\begin{tabular}{|c|c|c|c|}
\hline \multicolumn{4}{|c|}{4 - CALSTD \#4 ICWS-8918 } \\
\hline Sample Name: & CAL STD \#4 ICWS-8918 & Injection Volume: & 50.0 \\
\hline Vial Number: & 1295 & Channel: & ECD_1 \\
\hline Sample Type: & standard & Wavelength: & n.a. \\
\hline Control Program: & AS14A ANIONS METHOD & Bandwidth: & n.a. \\
\hline Quantif. Method: & AS4A-SC ANION METHOD & Dilution Factor: & 1.0000 \\
\hline Recording Time: & \#\#\#\#\#\#\#\#\#\#\#\# & Sample Weight: & 1.0000 \\
\hline Run Time (min): & 15.00 & Sample Amount: & 1.0000 \\
\hline
\end{tabular}

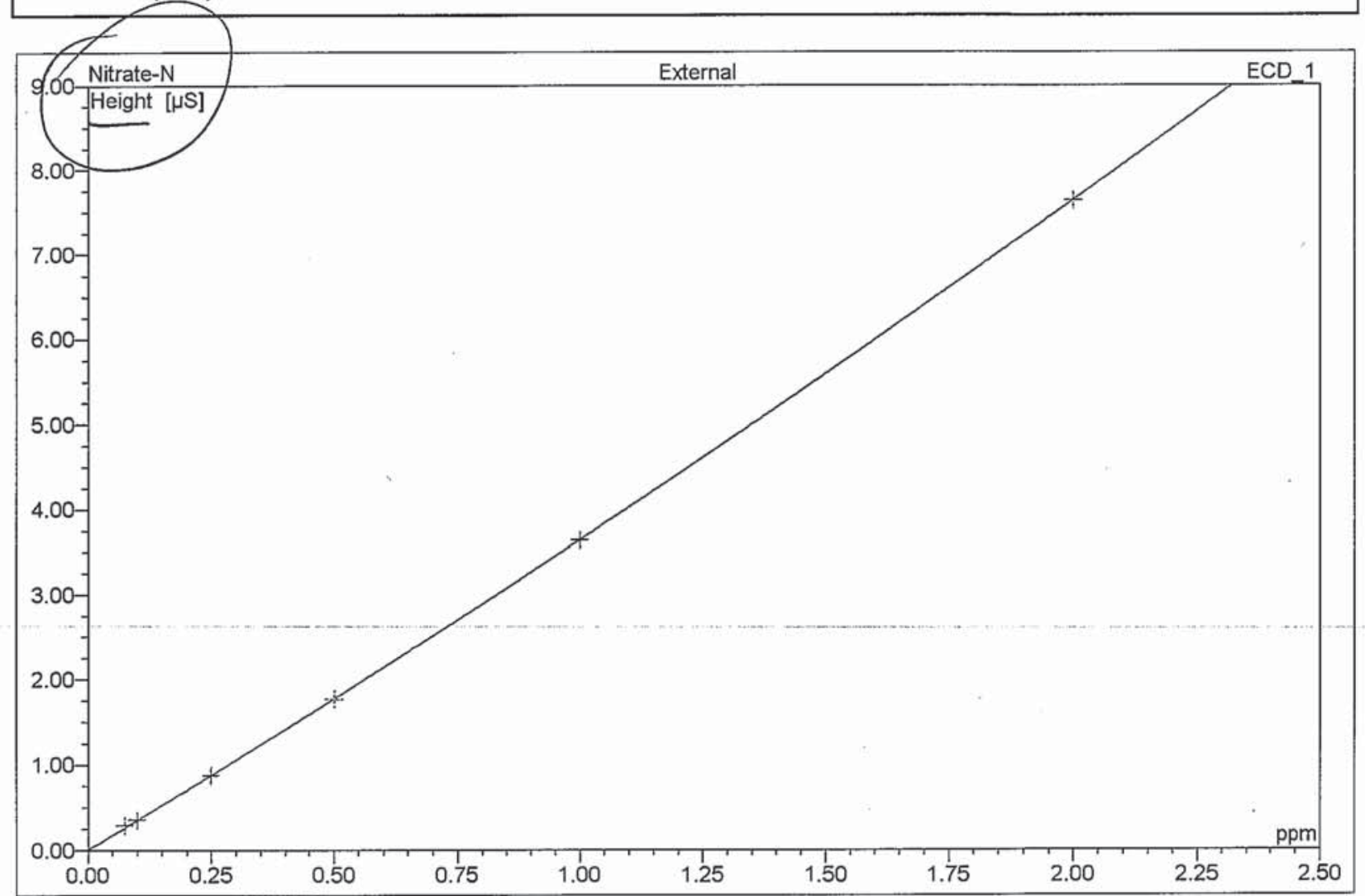

\begin{tabular}{|c|clcrrrrr|}
\hline No. & $\begin{array}{c}\text { Ret.Time } \\
\text { min }\end{array}$ & Peak Name & Cal.Type & Points & R-Square & Offset & Slope & Curve \\
\hline 1 & 2.25 & n.a. & n.a. & n.a. & n.a. & n.a. & n.a. & n.a. \\
2 & 3.26 & Fluoride & Quad & 6 & 1.0000 & 0.000000 & 2.68877 & 0.217432 \\
3 & 4.61 & Chloride & Quad & 6 & 0.9998 & 0.000000 & 2.19733 & 0.033578 \\
4 & 5.37 & Nitrite-N & Quad & 6 & 1.0000 & 0.000000 & 3.80119 & 0.130678 \\
5 & 6.67 & Bromide & Quad & 6 & 1.0000 & 0.000000 & 0.70878 & 0.005755 \\
6 & 7.46 & Nitrate-N & Quad & 6 & $\checkmark 1.0000$ & 0.000000 & 3.45770 & 0.180759 \\
\hline Average: & & & & & 1.0000 & 0.0000 & 2.5708 & 0.1136 \\
\hline
\end{tabular}




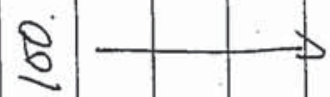

5

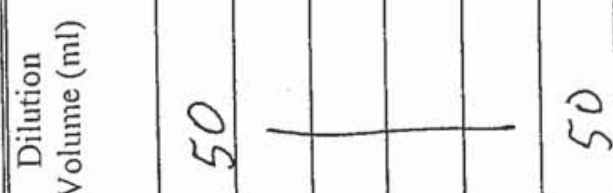

究全售

ह

Z

능

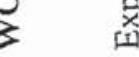

|

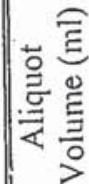

$\begin{array}{llll}0 & & \\ & \end{array}$

b

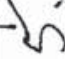
高

$\frac{5}{8}$ ลे

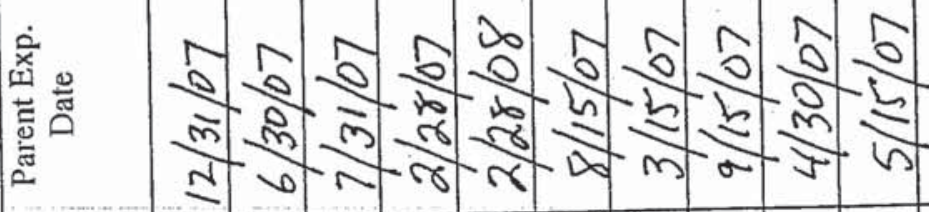

崖异

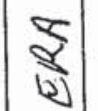

竞离

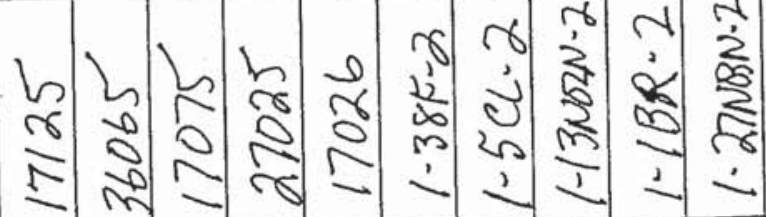

譬递

$\frac{2}{3}$

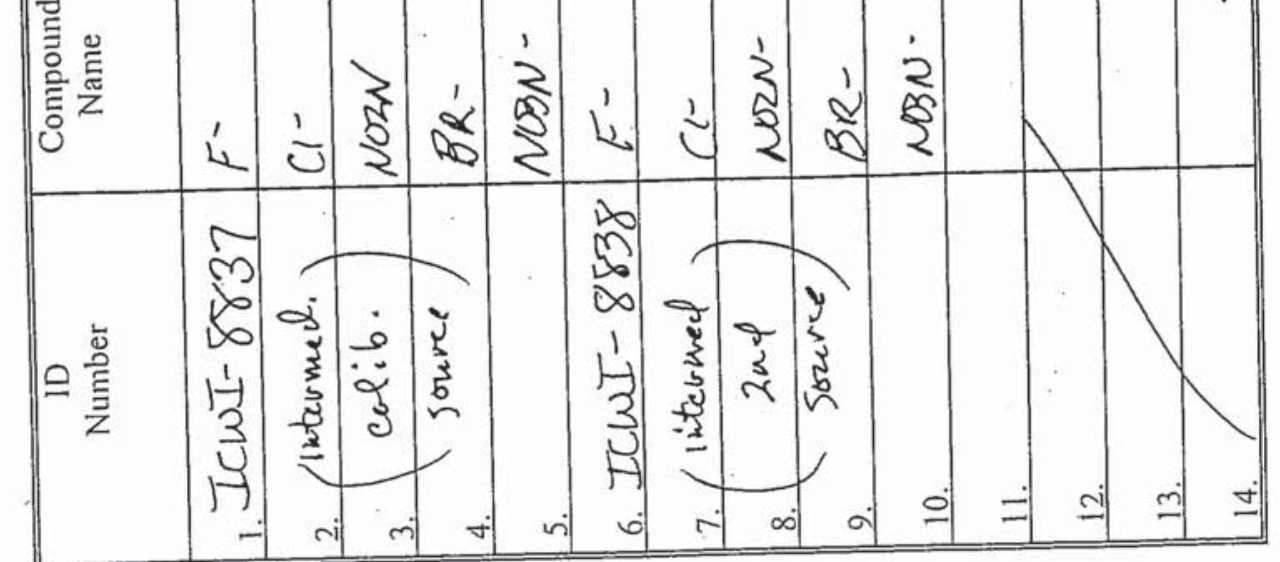




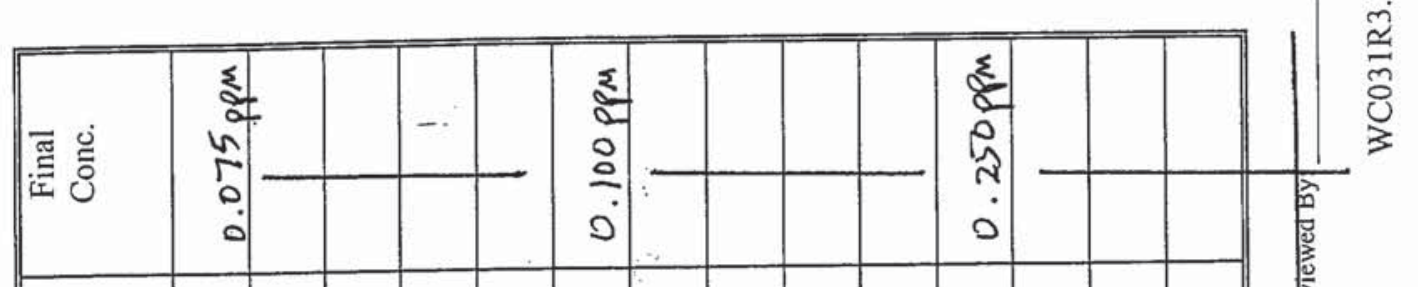

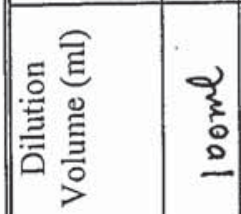

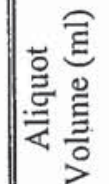

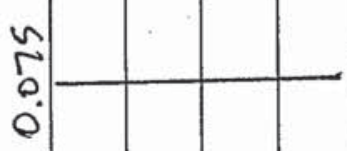

움

คิ

言高

క

음

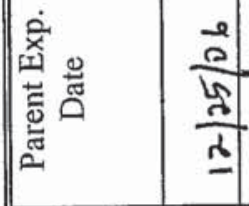

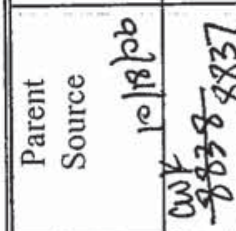

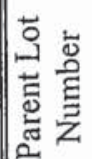

雚

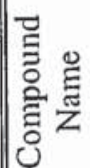

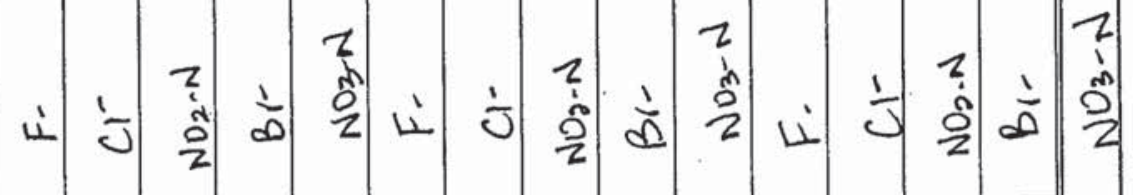

$\frac{2}{\frac{0}{0}}$

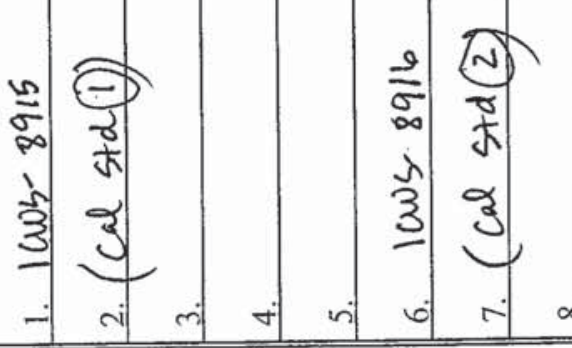

ญ्ञ

|ق

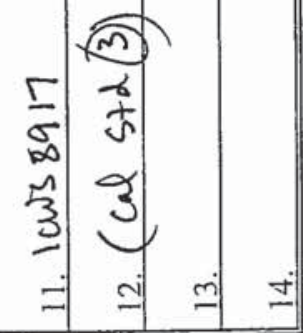




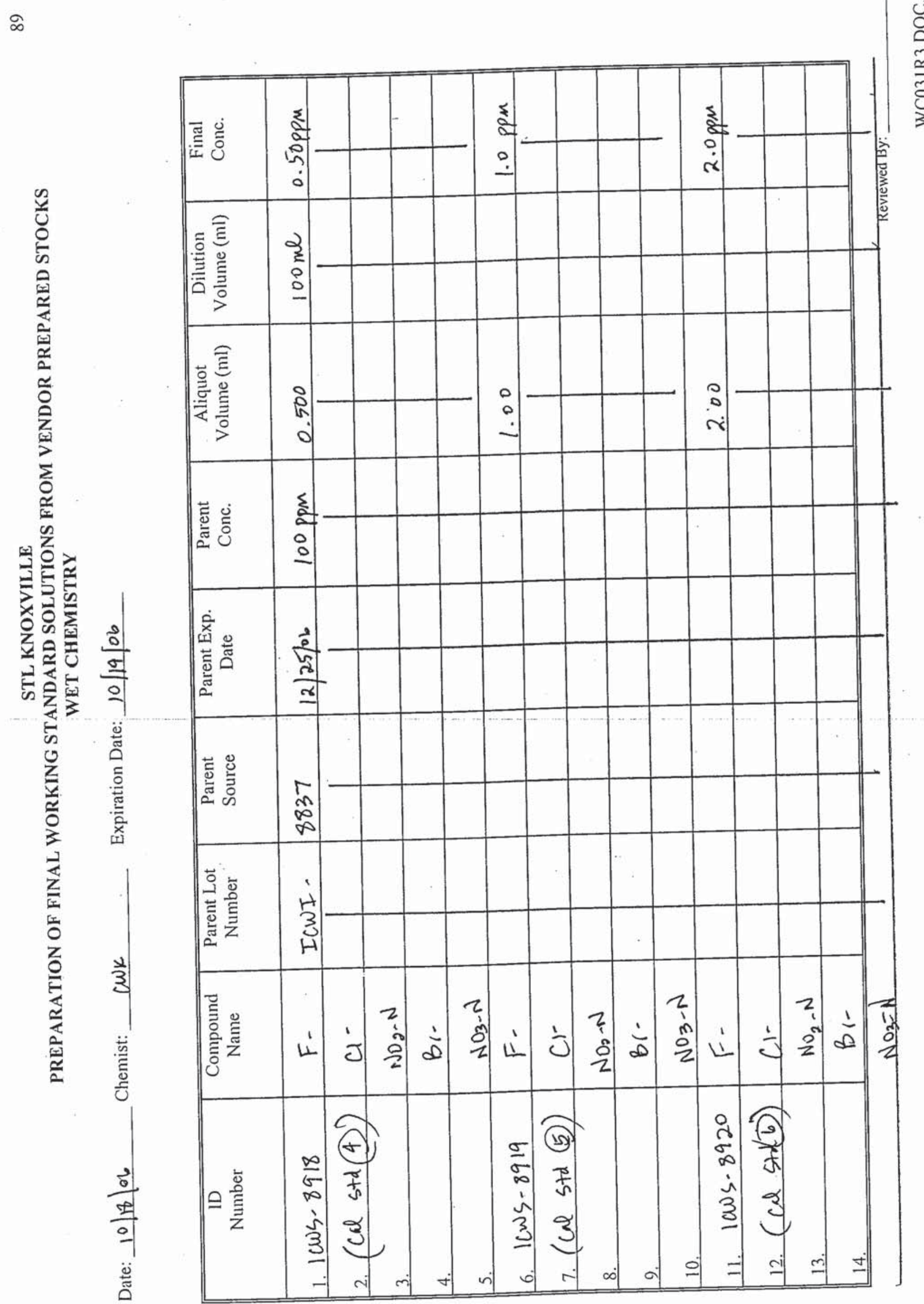




\section{STL Knoxville IC Initial Calibration Data Review / Narrative Checklist \\ Methods: 300.0, 9056, 9057 and 26A, SOP: KNOX-WC-0005, Rev. 8 \\ Page 1 of 1 \\ DXGUO (ARKGORN)}

Analysis Date:

$12 / 14 / 06$

File D: $\quad$ L14A-COW_AIR-ANIÓNS - 121406

\begin{tabular}{|c|c|c|c|c|c|}
\hline Initial Calibration Review Items & N/A & Yes & No & If No, why is data reportable? & $\begin{array}{c}\text { 2nd } \\
\sqrt{ }\end{array}$ \\
\hline 1. Were at least 5 levels of each analyte analyzed? & & $\checkmark$ & 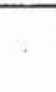 & & \\
\hline 2. Is low level standard concentration $\leq \mathrm{RL}$ ? & & & & & \\
\hline $\begin{array}{l}\text { 3. Are.the correlation coefficients }(r) \geq 0.995 \text {; } \\
r^{2} \geq 0.990 \text { ? }\end{array}$ & & $\checkmark$ & & . & \\
\hline $\begin{array}{l}\text { 4. For method } 300.0 \text {, was the calibration curve } \\
\text { processed using linear reqression? }\end{array}$ & $\checkmark$ & & - & & $N$ \\
\hline $\begin{array}{l}\text { 5. For manual integrated standards, are before/after } \\
\text { cluromatograms provided with initials/date/reason? }\end{array}$ & & $\mathcal{J}$ & & $\begin{array}{l}\text { Reasons: } S=\text { Split peak, } U=\text { Undetected peak, } I=\text { Incorrect } \\
\text { peak integration, } B=\text { =Baseline correction, } W=\text { Wrong peak } \\
\text { chosen by data system }\end{array}$ & \\
\hline
\end{tabular}

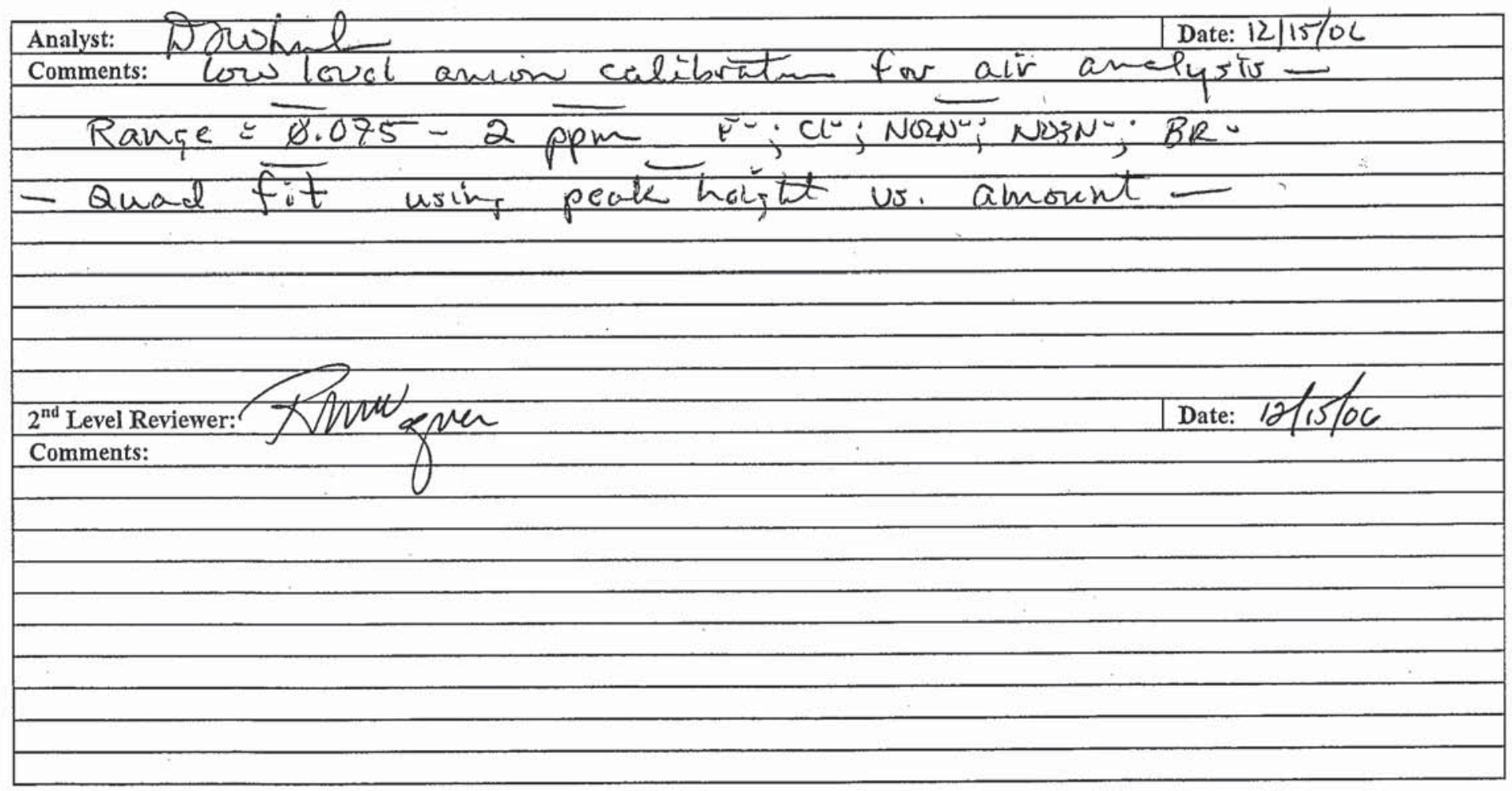




\section{CAL STD $1=$ ICWS-9045 @ (0.075ppm)}

\section{Sample Name:}

Vial Number:

Sample Type:

Control Program:

Quantif. Method:

Recording Time:

Run Time ( $\mathrm{min})$ :

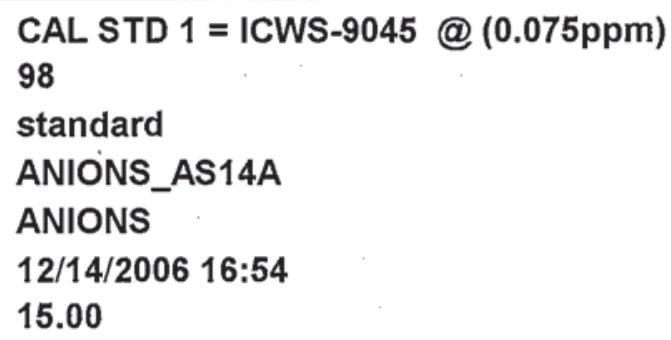

98

standard

ANIONS_AS14A

ANIONS

12/14/2006 16:54

15.00

Injection Volume: $\quad \mathbf{5 0 . 0}$

Channel: ECD_1

Wavelength: n.a.

Bandwidth: n.a.

Dilution Factor: $\quad \mathbf{1 . 0 0 0 0}$

Sample Weight: $\quad 1.0000$

Sample Amount: $\quad 1.0000$

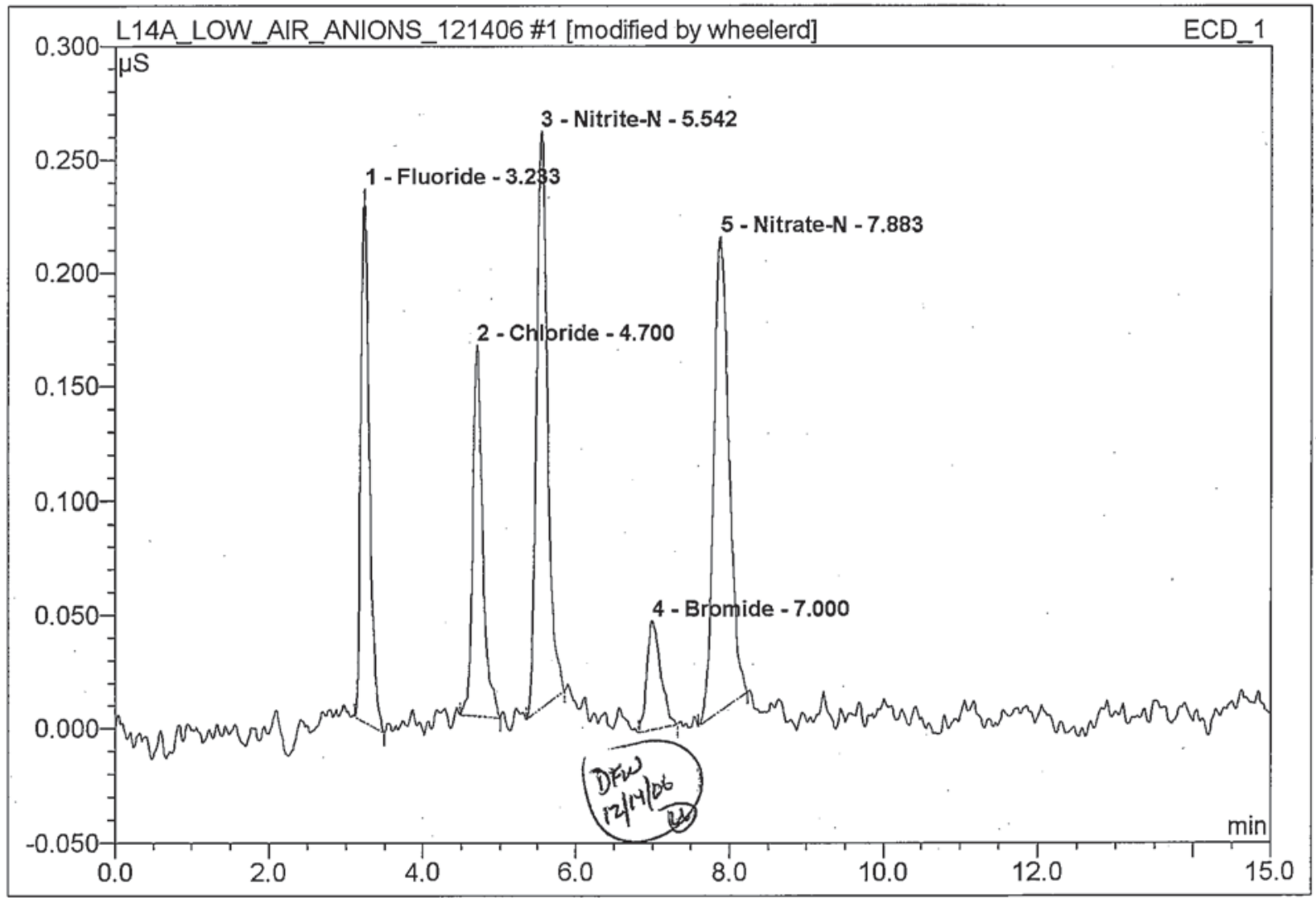

\begin{tabular}{|c|c|l|r|r|r|r|c|}
\hline No. & $\begin{array}{c}\text { Ret.Time } \\
(\mathbf{m i n} .)\end{array}$ & \multicolumn{1}{|c|}{ Peak Name } & $\begin{array}{c}\text { Height } \\
(\mathbf{u S})\end{array}$ & $\begin{array}{c}\text { Area } \\
\boldsymbol{\mu} \mathbf{S}^{*} \min \end{array}$ & $\begin{array}{c}\text { Rel.Area } \\
(\%)\end{array}$ & $\begin{array}{c}\text { Amount } \\
(\mathrm{mg} / \mathrm{L})\end{array}$ & $\begin{array}{c}\text { Peak } \\
\text { Type }\end{array}$ \\
\hline 1 & 3.23 & Fluoride & 0.23417 & 0.030 & 19.30 & 0.0748 & BMB \\
\hline 2 & 4.70 & Chloride & 0.16248 & 0.024 & 15.76 & 0.0868 & BMB \\
\hline 3 & 5.54 & Nitrite-N & 0.25345 & 0.043 & 27.70 & 0.0748 & BMB \\
\hline 4 & 7.00 & Bromide & 0.04768 & 0.010 & 6.42 & 0.0837 & BMB $^{*}$ \\
\hline 5 & 7.88 & Nitrate-N & 0.20803 & 0.048 & 30.83 & 0.0756 & BMB \\
\hline
\end{tabular}




\section{CAL STD $1=$ ICWS-9045 @ $(0.075 \mathrm{ppm})$}

Sample Name:

Vial Number:

Sample Type:

Control Program:

Quantif. Method:

Recording Time:

Run Time (min):
CAL STD $1=$ ICWS-9045 @ $(0.075 \mathrm{ppm})$

98

standard

ANIONS_AS14A

ANIONS

12/14/2006 16:54

15.00
Injection Volume:

Channel:

Wavelength:

Bandwidth:

Dilution Factor:

Sample Weight:

Sample Amount:
50.0

ECD_1

n.a.

n.a.

1.0000

1.0000

1.0000

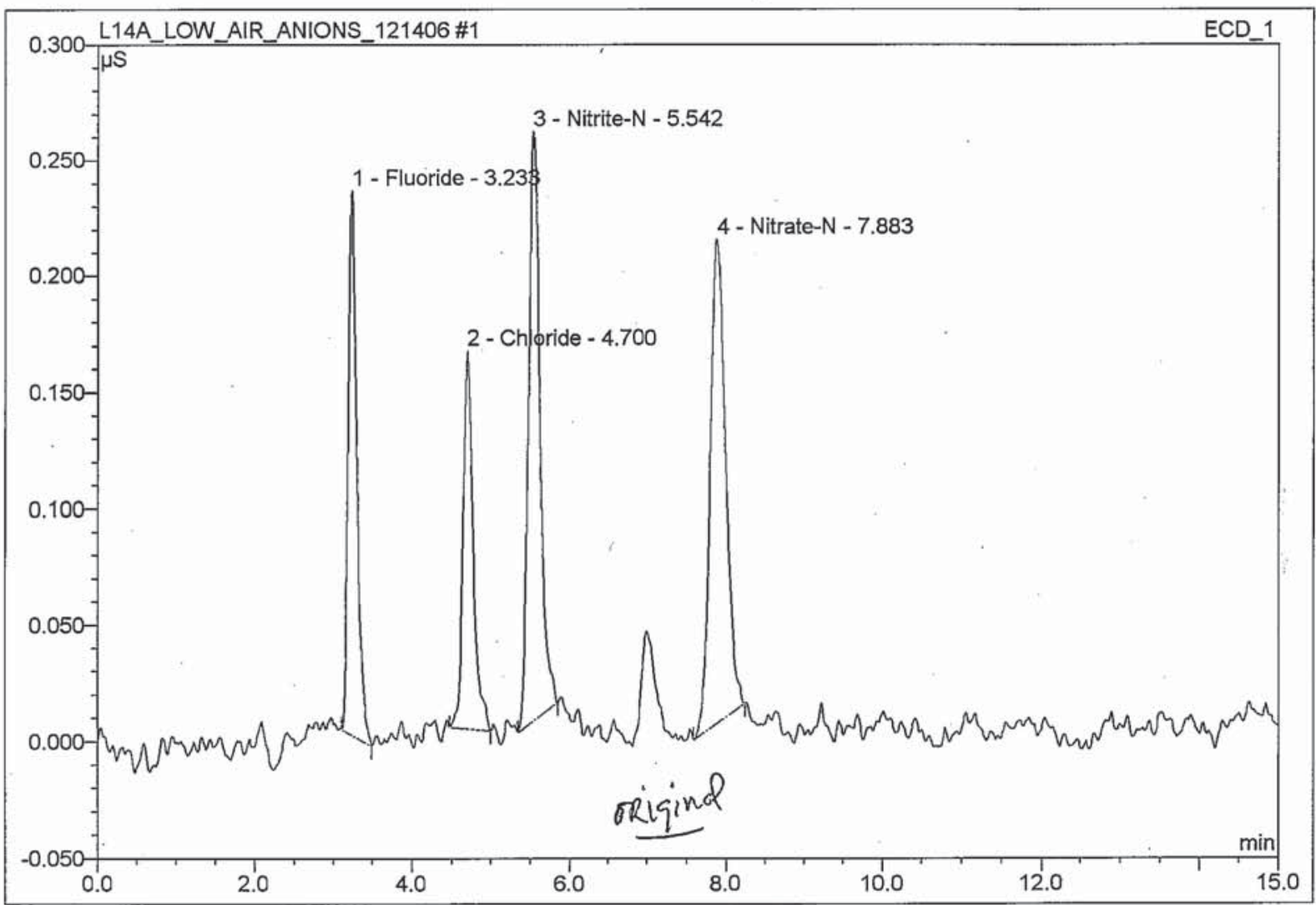

\begin{tabular}{|c|c|l|r|r|r|r|c|}
\hline No. & $\begin{array}{c}\text { Ret.Time } \\
\text { (min.) }\end{array}$ & \multicolumn{1}{|c|}{ Peak Name } & $\begin{array}{c}\text { Height } \\
\text { (uS) }\end{array}$ & $\begin{array}{c}\text { Area } \\
\text { IS }^{\star} \text { min }\end{array}$ & $\begin{array}{c}\text { Rel.Area } \\
(\%)\end{array}$ & $\begin{array}{c}\text { Amount } \\
\text { (mg/L) }\end{array}$ & $\begin{array}{c}\text { Peak } \\
\text { Type }\end{array}$ \\
\hline 1 & 3.23 & Fluoride & 0.23417 & 0.030 & 20.62 & n.a. & BMB \\
\hline 2 & 4.70 & Chloride & 0.16248 & 0.024 & 16.84 & n.a. & BMB \\
\hline 3 & 5.54 & Nitrite-N & 0.25345 & 0.043 & 29.60 & n.a. & BMB \\
\hline 4 & 7.88 & Nitrate-N & 0.20803 & 0.048 & 32.94 & n.a. & BMB \\
\hline
\end{tabular}




\section{CAL STD 2 = ICWS-9046@ (0.10ppm)}

Sample Name: Vial Number:

Sample Type:

Control Program:

Quantif. Method:

Recording Time:

Run Time ( $\mathrm{min})$ :
CAL STD 2 = ICWS-9046@ (0.10ppm)

99

standard

ANIONS_AS14A

ANIONS

12/14/2006 17:11

10.00
Injection Volume: $\quad \mathbf{5 0 . 0}$

Channel: ECD_1

Wavelength: n.a.

Bandwidth: n.a.

Dilution Factor: $\quad \mathbf{1 . 0 0 0 0}$

Sample Weight: $\quad \mathbf{1 . 0 0 0 0}$

Sample Amount: $\quad \mathbf{1 . 0 0 0 0}$

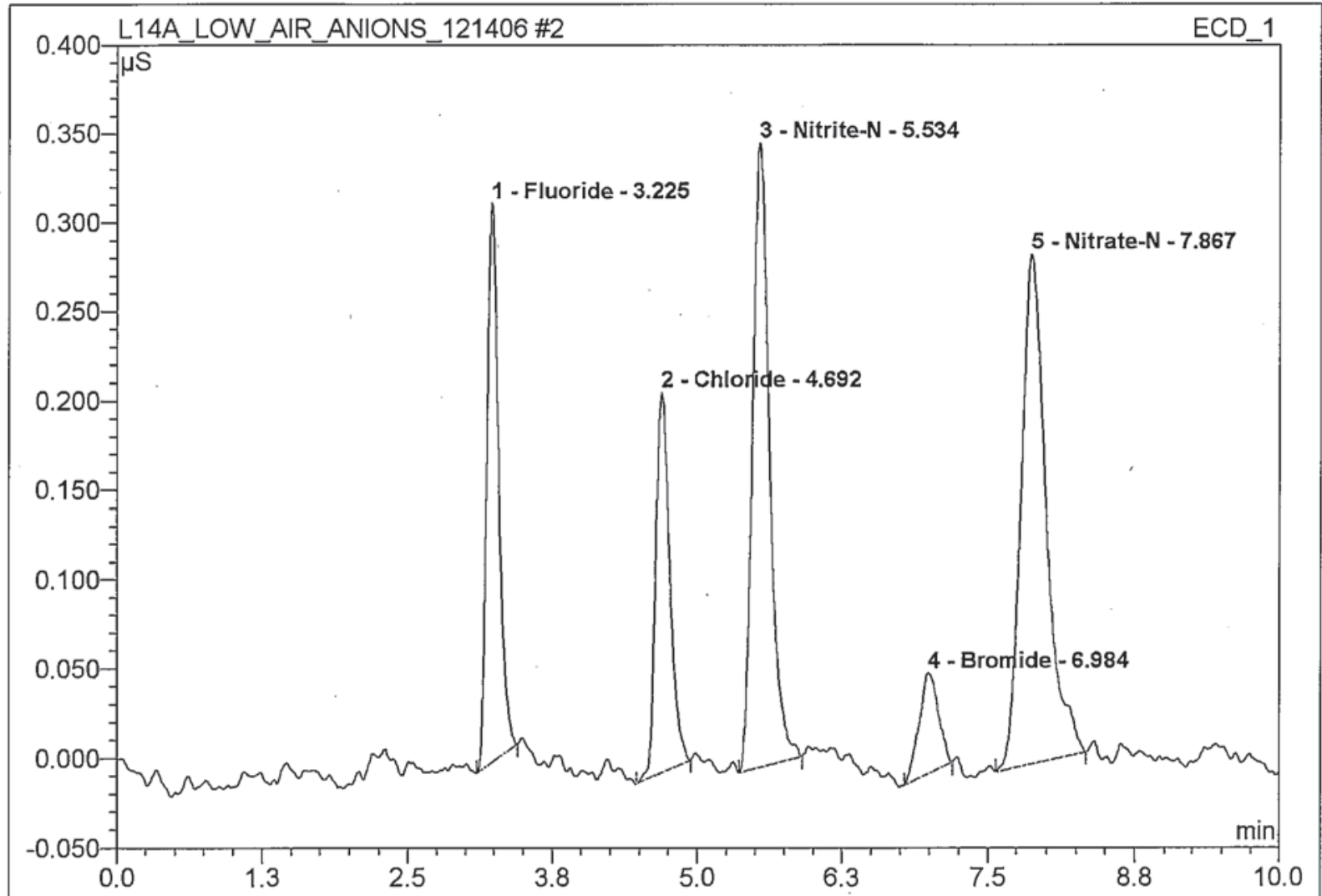

\begin{tabular}{|c|c|l|r|r|r|r|c|}
\hline No. & $\begin{array}{c}\text { Ret.Time } \\
(\mathbf{m i n} .)\end{array}$ & \multicolumn{1}{|c|}{ Peak Name } & $\begin{array}{c}\text { Height } \\
(\mathbf{u S})\end{array}$ & $\begin{array}{c}\text { Area } \\
\boldsymbol{\mu} \mathbf{S}^{*} \mathrm{~min}\end{array}$ & $\begin{array}{c}\text { Rel.Area } \\
(\%)\end{array}$ & $\begin{array}{c}\text { Amount } \\
(\mathrm{mg} / \mathrm{L})\end{array}$ & $\begin{array}{c}\text { Peak } \\
\text { Type }\end{array}$ \\
\hline 1 & 3.23 & Fluoride & 0.31346 & 0.037 & 18.04 & 0.0999 & BMB \\
\hline 2 & 4.69 & Chloride & 0.21253 & 0.030 & 14.47 & 0.1134 & BMB \\
\hline 3 & 5.53 & Nitrite-N & 0.34978 & 0.059 & 28.59 & 0.1031 & BMB \\
\hline 4 & 6.98 & Bromide & 0.05646 & 0.011 & 5.19 & 0.0991 & BMB \\
\hline 5 & 7.87 & Nitrate-N & 0.28533 & 0.070 & 33.71 & 0.1036 & BMB \\
\hline
\end{tabular}




\section{CAL STD $3=$ ICWS-9047 @ (0.25ppm)}

Sample Name:

Vial Number:

Sample Type:

Control Program:

Quantif. Method:

Recording Time:

Run Time ( $\mathrm{min})$ :

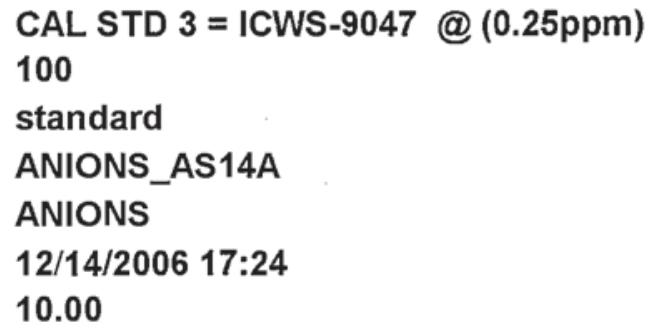

CAL STD $3=$ ICWS-9047@ (0.25ppm) 100 standard

ANIONS_AS14A

ANIONS

12/14/2006 17:24

10.00

Injection Volume:

Channel:

Wavelength:

Bandwidth:

Dilution Factor:

Sample Weight:

Sample Amount:
50.0

ECD_1

n.a.

n.a.

1.0000

1.0000

1.0000

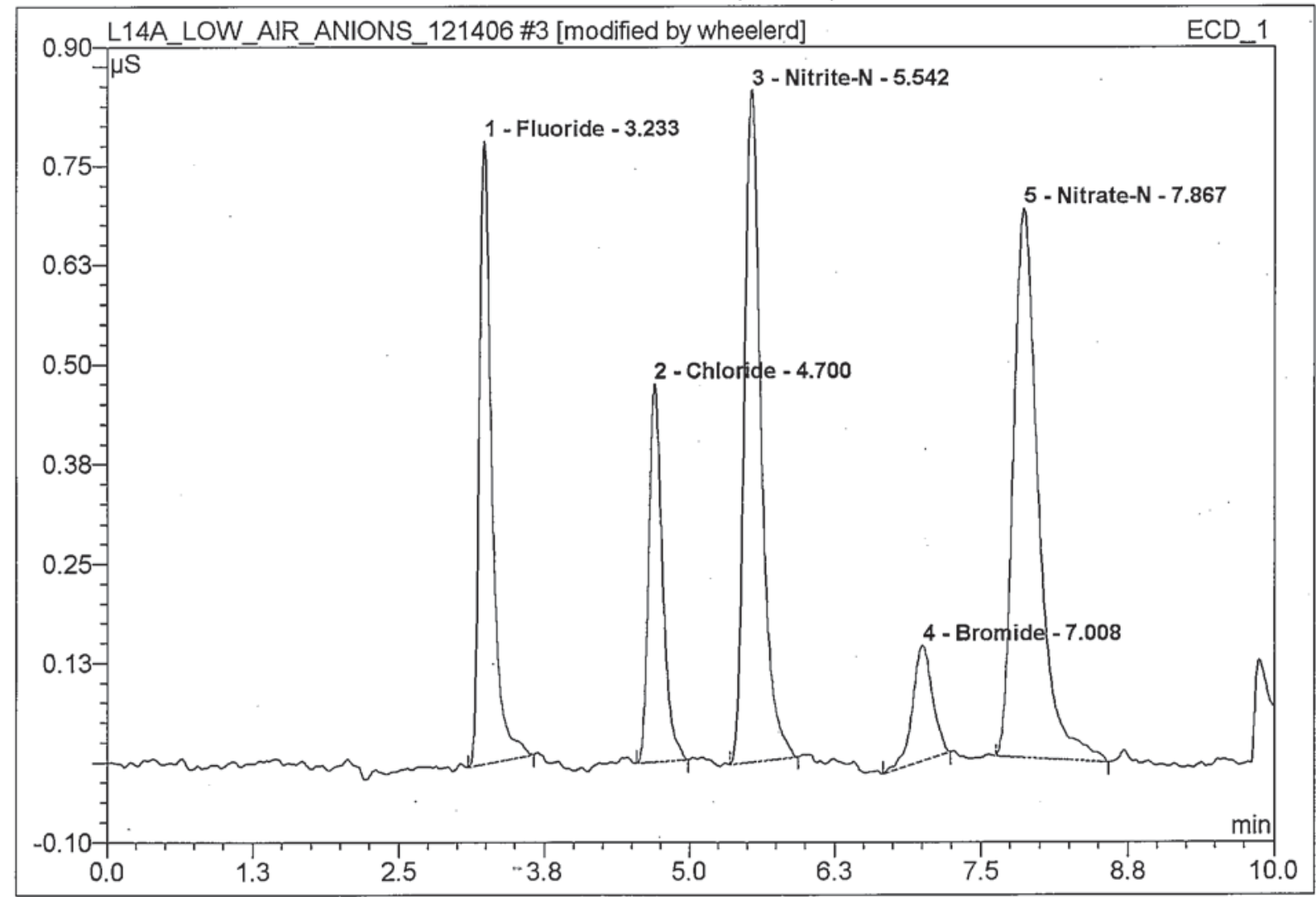

\begin{tabular}{|c|c|l|r|r|r|r|c|}
\hline No. & $\begin{array}{c}\text { Ret.Time } \\
\text { (min.) }\end{array}$ & \multicolumn{1}{|c|}{ Peak Name } & $\begin{array}{c}\text { Height } \\
\text { (uS) }\end{array}$ & $\begin{array}{c}\text { Area } \\
\text { is*min }\end{array}$ & $\begin{array}{c}\text { Rel.Area } \\
(\%)\end{array}$ & $\begin{array}{c}\text { Amount } \\
\text { (mg/L) }\end{array}$ & $\begin{array}{c}\text { Peak } \\
\text { Type }\end{array}$ \\
\hline 1 & 3.23 & Fluoride & 0.78262 & 0.100 & 19.79 & 0.2477 & BMB \\
\hline 2 & 4.70 & Chloride & 0.47425 & 0.066 & 13.11 & 0.2518 & BMB \\
\hline 3 & 5.54 & Nitrite-N & 0.84353 & 0.144 & 28.39 & 0.2473 & BMB \\
\hline 4 & 7.01 & Bromide & 0.14435 & 0.029 & 5.64 & 0.2526 & BMB \\
\hline 5 & 7.87 & Nitrate-N & 0.68927 & 0.167 & 33.06 & 0.2483 & BMB \\
\hline
\end{tabular}




\section{CAL STD 4 = ICWS-9048 @ (0.50ppm)}

\begin{tabular}{llll|}
\hline Sample Name: & CAL STD 4 = ICWS-9048 @ (0.50ppm) & Injection Volume: & $\mathbf{5 0 . 0}$ \\
Vial Number: & $\mathbf{1 0 1}$ & Channel: & ECD_1 \\
Sample Type: & standard & Wavelength: & n.a. \\
Control Program: & ANIONS_AS14A & Bandwidth: & n.a. \\
Quantif. Method: & ANIONS & Dilution Factor: & 1.0000 \\
Recording Time: & $\mathbf{1 2 / 1 4 / 2 0 0 6 ~ 1 7 : 3 6}$ & Sample Weight: & 1.0000 \\
Run Time (min): & $\mathbf{1 0 . 0 0}$ & Sample Amount: & $\mathbf{1 . 0 0 0 0}$ \\
\hline
\end{tabular}

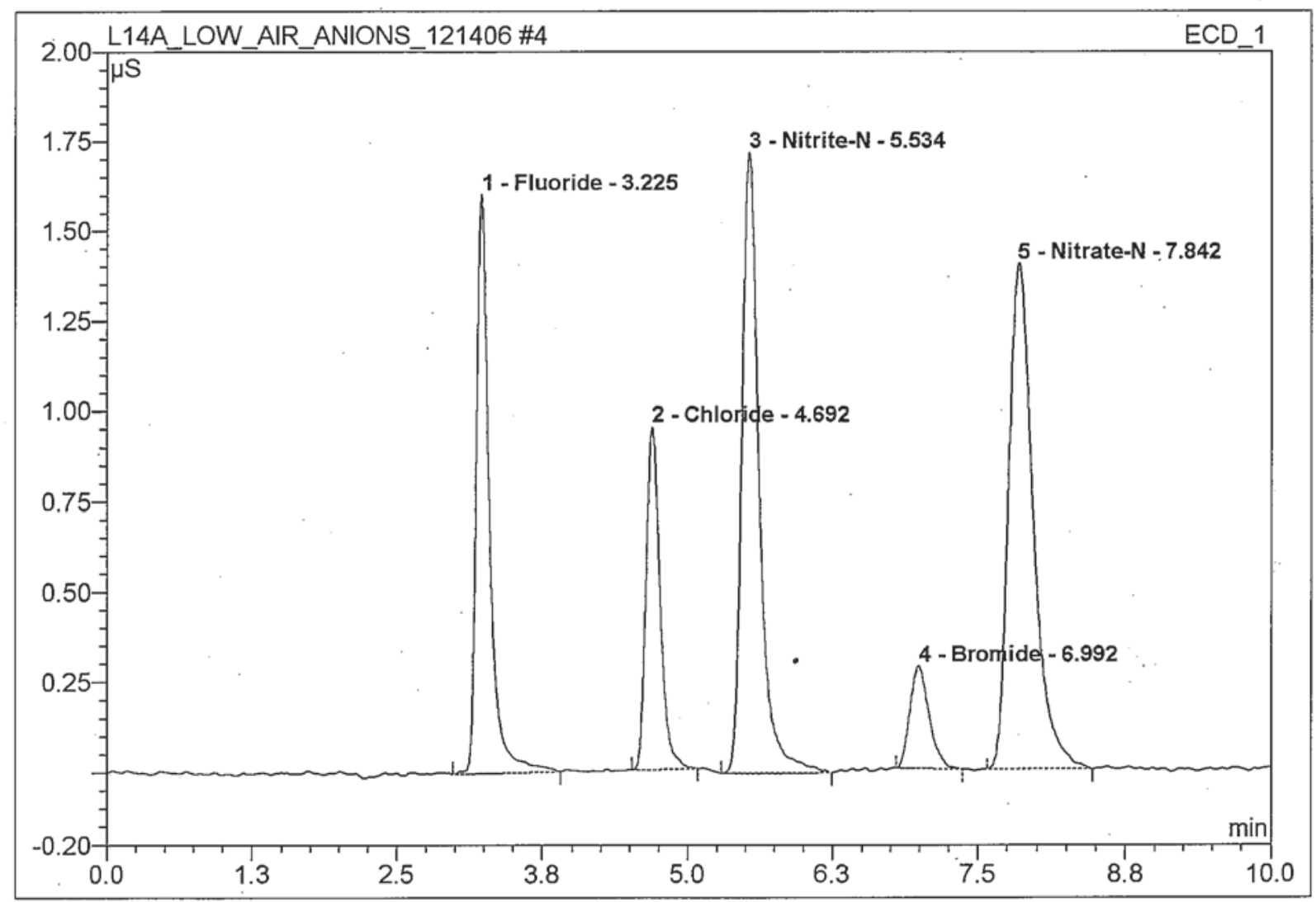

\begin{tabular}{|c|c|l|r|r|r|r|c|}
\hline No. & $\begin{array}{c}\text { Ret.Time } \\
\text { (min.) }\end{array}$ & \multicolumn{1}{|c|}{ Peak Name } & $\begin{array}{c}\text { Height } \\
\text { (uS) }\end{array}$ & $\begin{array}{c}\text { Area } \\
\mu \mathbf{S}^{*} \text { min }\end{array}$ & $\begin{array}{c}\text { Rel.Area } \\
(\%)\end{array}$ & $\begin{array}{c}\text { Amount } \\
\text { (mg/L) }\end{array}$ & $\begin{array}{c}\text { Peak } \\
\text { Type }\end{array}$ \\
\hline 1 & 3.23 & Fluoride & 1.60279 & 0.210 & 20.40 & 0.5010 & BMB \\
\hline 2 & 4.69 & Chloride & 0.94632 & 0.132 & 12.83 & 0.4981 & BMB \\
\hline 3 & 5.53 & Nitrite-N & 1.71930 & 0.302 & 29.30 & 0.4988 & BMB \\
\hline 4 & 6.99 & Bromide & 0.28167 & 0.054 & 5.25 & 0.4908 & BMB \\
\hline 5 & 7.84 & Nitrate-N & 1.39855 & 0.332 & 32.22 & 0.4972 & BMB \\
\hline
\end{tabular}




\section{$5 \quad$ CAL STD 5 = ICWS-9049 @ (1.ppm)}

Sample Name:

Vial Number:

Sample Type:

Control Program:

Quantif. Method:

Recording Time:

Run Time (min):

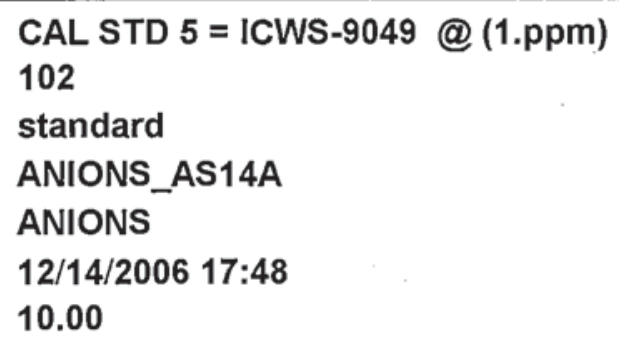

ANIONS

12/14/2006 17:48

10.00

Injection Volume:

Channel:

Wavelength:

Bandwidth:

Dilution Factor:

Sample Weight:

Sample Amount:
50.0

ECD_1

n.a.

n.a.

1.0000

1.0000

1.0000

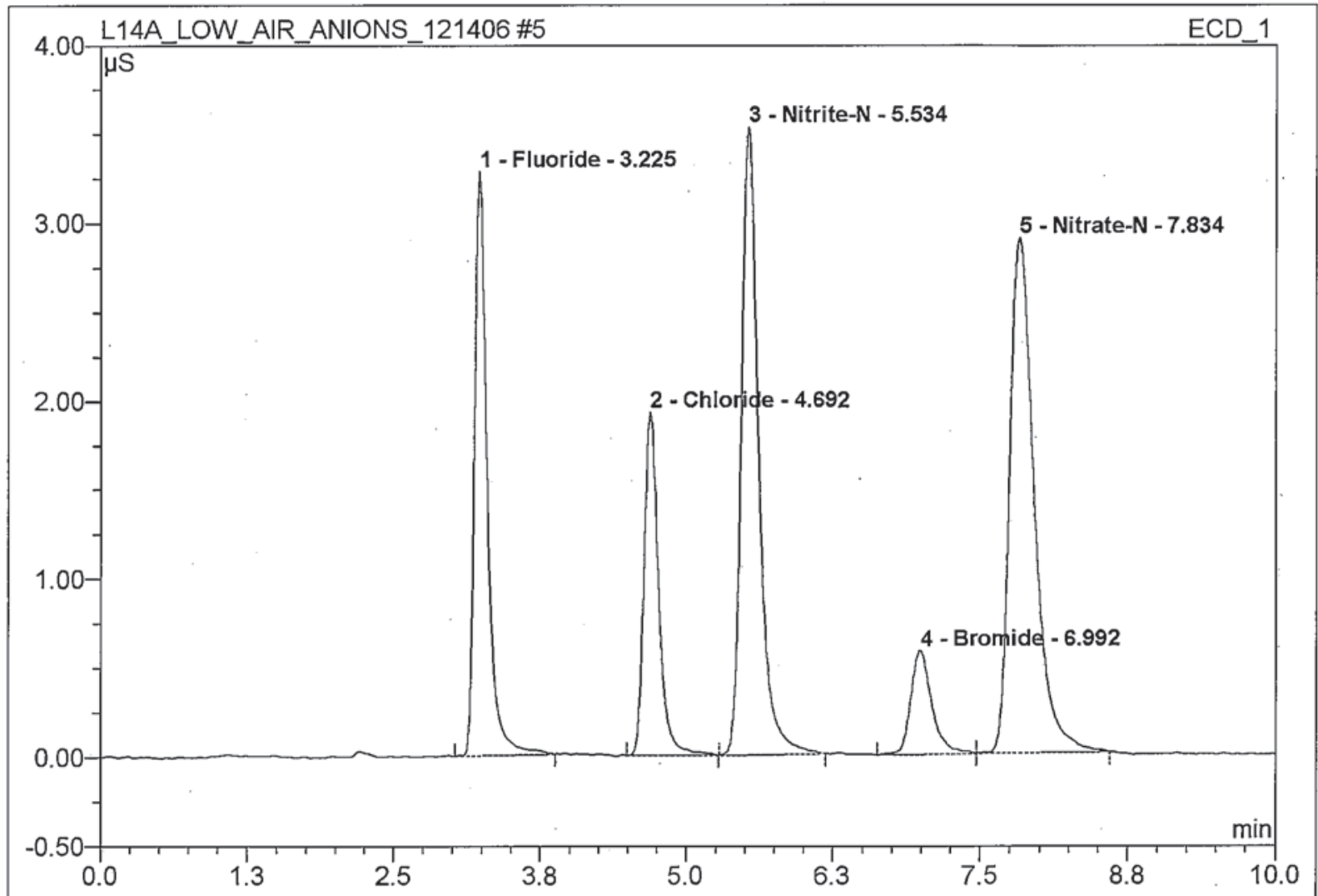

\begin{tabular}{|c|c|l|r|r|r|r|c|}
\hline No. & $\begin{array}{c}\text { Ret.Time } \\
\text { (min.) }\end{array}$ & \multicolumn{1}{|c|}{ Peak Name } & $\begin{array}{c}\text { Height } \\
\text { (uS) }\end{array}$ & $\begin{array}{c}\text { Area } \\
\mu \mathbf{S}^{*} \text { min }\end{array}$ & $\begin{array}{c}\text { Rel.Area } \\
(\%)\end{array}$ & $\begin{array}{c}\text { Amount } \\
\text { (mg/L) }\end{array}$ & $\begin{array}{c}\text { Peak } \\
\text { Type }\end{array}$ \\
\hline 1 & 3.23 & Fluoride & 3.27751 & 0.412 & 19.61 & 1.0002 & BMB \\
\hline 2 & 4.69 & Chloride & 1.92630 & 0.278 & 13.23 & 0.9967 & BMB \\
\hline 3 & 5.53 & Nitrite-N & 3.52256 & 0.606 & 28.87 & 1.0015 & BMB \\
\hline 4 & 6.99 & Bromide & 0.58187 & 0.122 & 5.80 & 1.0046 & BM \\
\hline 5 & 7.83 & Nitrate-N & 2.89372 & 0.682 & 32.48 & 1.0020 & MB \\
\hline
\end{tabular}




\section{CAL STD $6=$ ICWS-9050 @ (2.ppm)}

\begin{tabular}{llll|}
\hline Sample Name: & CAL STD 6=ICWS-9050 @ (2.ppm) & Injection Volume: & $\mathbf{5 0 . 0}$ \\
Vial Number: & $\mathbf{1 0 3}$ & Channel: & ECD_1 \\
Sample Type: & standard & Wavelength: & n.a. \\
Control Program: & ANIONS_AS14A & Bandwidth: & n.a. \\
Quantif. Method: & ANIONS & Dilution Factor: & $\mathbf{1 . 0 0 0 0}$ \\
Recording Time: & $\mathbf{1 2 / 1 4 / 2 0 0 6 ~ 1 8 : 0 1}$ & Sample. Weight: & $\mathbf{1 . 0 0 0 0}$ \\
Run Time (min): & $\mathbf{1 0 . 0 0}$ & Sample Amount: & $\mathbf{1 . 0 0 0 0}$ \\
\hline
\end{tabular}

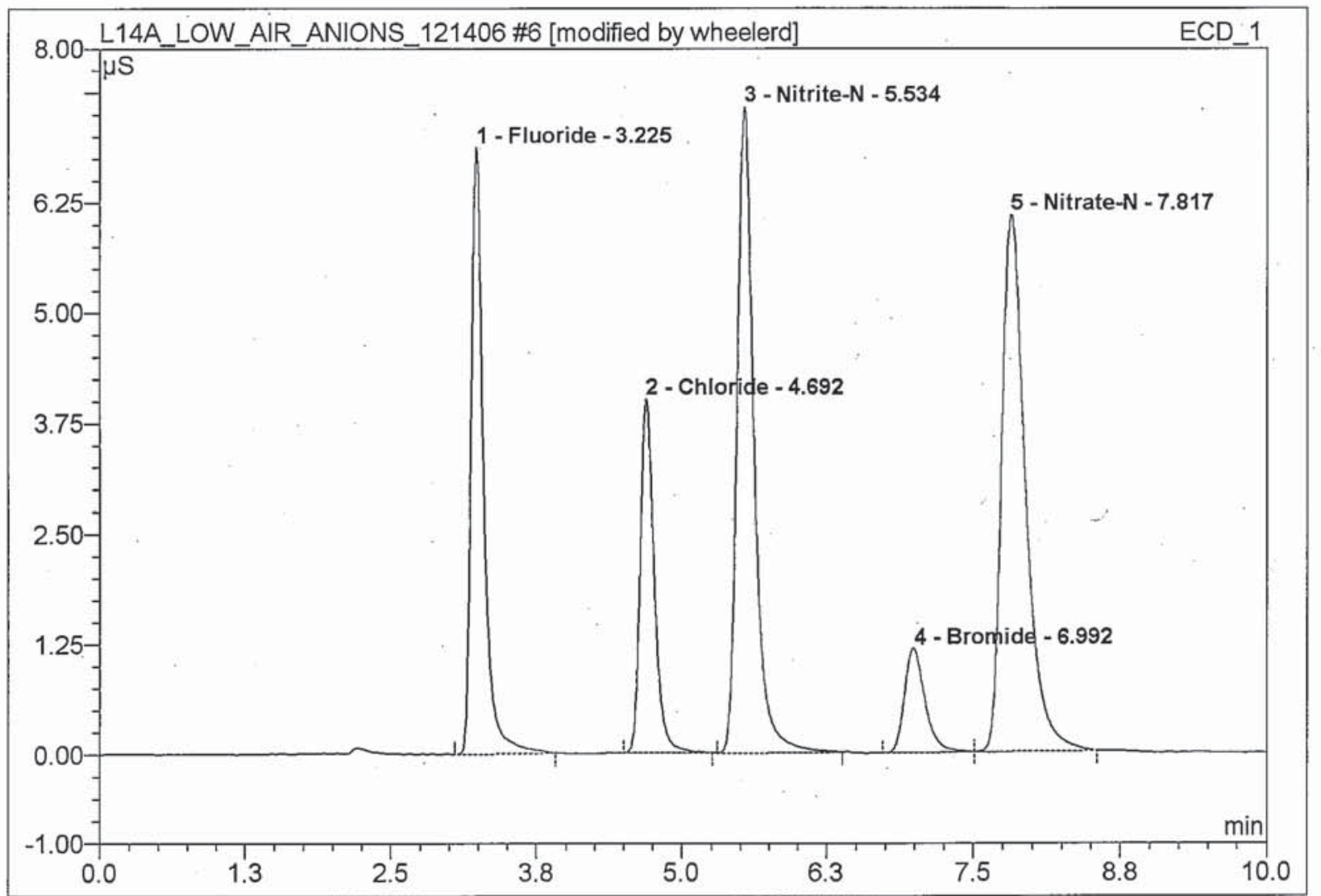

\begin{tabular}{|c|c|l|r|r|r|r|c|}
\hline No. & $\begin{array}{c}\text { Ret.Time } \\
\text { (min.) }\end{array}$ & \multicolumn{1}{|c|}{ Peak Name } & $\begin{array}{c}\text { Height } \\
\text { (uS) }\end{array}$ & $\begin{array}{c}\text { Area } \\
\mu \mathbf{S}^{*} \text { min }\end{array}$ & $\begin{array}{c}\text { Rel.Area } \\
(\%)\end{array}$ & $\begin{array}{c}\text { Amount } \\
(\mathbf{m g} / \mathbf{L})\end{array}$ & $\begin{array}{c}\text { Peak } \\
\text { Type }\end{array}$ \\
\hline 1 & 3.23 & Fluoride & 6.86489 & 0.858 & 19.88 & 1.9999 & BMB \\
\hline 2 & 4.69 & Chloride & 3.99899 & 0.564 & 13.08 & 2.0008 & BMB \\
\hline 3 & 5.53 & Nitrite-N & 7.31424 & 1.247 & 28.92 & 1.9998 & BMB \\
\hline 4 & 6.99 & Bromide & 1.17848 & 0.240 & 5.56 & 1.9994 & BM \\
\hline 5 & 7.82 & Nitrate-N & 6.07244 & 1.404 & 32.55 & 1.9997 & MB \\
\hline
\end{tabular}




\begin{tabular}{|c|c|c|c|}
\hline \multicolumn{4}{|c|}{ 6_GALSTB6-1CWS-9050-@(2.ppm) } \\
\hline Sample Name: & CAL STD $6=$ ICWS-9050 @ (2.ppm) & Injection Volume: & 50.0 \\
\hline Vial Number: & 103 & Channel: & ECD_1 \\
\hline Sample Type: & standard & Wavelength: & n.a. \\
\hline Control Program: & ANIONS_AS14A & Bandwidth: & n.a. \\
\hline Quantif. Method: & ANIONS & Dilution Factor: & 1.0000 \\
\hline Recording Time: & \#\#\#\#\#\#\#\#\#\#\# & Sample Weight: & 1.0000 \\
\hline Run Time (min): & 10.00 & Sample Amount: & 1.0000 \\
\hline
\end{tabular}

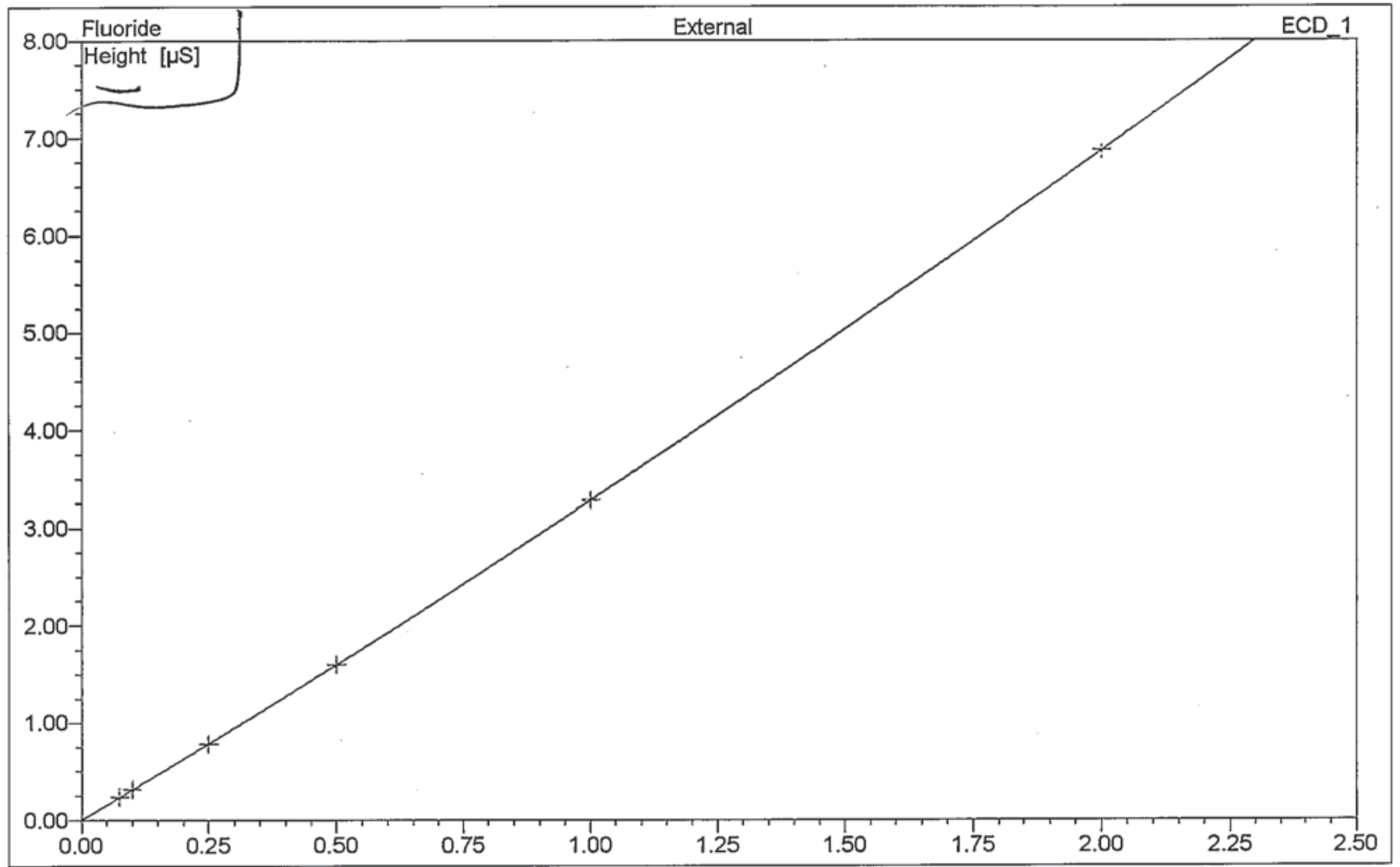

\begin{tabular}{|c|cccccccc|}
\hline No. & $\begin{array}{c}\text { Ret.Time } \\
\text { min }\end{array}$ & Peak Name & Cal.Type & Points & $\begin{array}{c}\text { Corr.Coeff. } \\
\text { (R) }\end{array}$ & Offset & Slope & Curve \\
\hline 1 & 3.23 & Fluoride & Quad & 6 & 0.9997 & 0.0000 & 3.120830 & 0.155880 \\
2 & 4.69 & Chloride & Quad & 6 & 0.9997 & 0.0000 & 1.867234 & 0.065694 \\
3 & 5.53 & Nitrite-N & Quad & 6 & 0.9998 & 0.0000 & 3.376824 & 0.140386 \\
4 & 6.99 & Bromide & Quad & 6 & 0.9999 & 0.0000 & 0.568855 & 0.010287 \\
5 & 7.82 & Nitrate-N & Quad & 6 & 0.9997 & 0.0000 & 2.738783 & 0.148955 \\
\hline Average: & & & & & 0.9998 & 0.0000 & 2.3345 & 0.1042 \\
\hline
\end{tabular}




\section{CALSTD 6 $=1$ CWS-9050@(2.ppm)- $\left(\begin{array}{l}D K \omega \\ 12 / 15 \% 6\end{array}\right)$}

Sample Name: $\quad$ CAL STD 6 = ICWS-9050 @ (2.ppm)

Vial Number:

Sample Type:

Control Program:

Quantif. Method:

Recording Time:

Run Time ( $\min )$ :
103

standard

ANIONS_AS14A

ANIONS

\#\#\#\#\#\#\#\#\#\#\#

10.00
Injection Volume: $\quad \mathbf{5 0 . 0}$

Channel:

Wavelength:

Bandwidth:

Dilution Factor:

Sample Weight:

Sample Amount:
ECD_1

n.a.

n.a.

1.0000

1.0000

1.0000

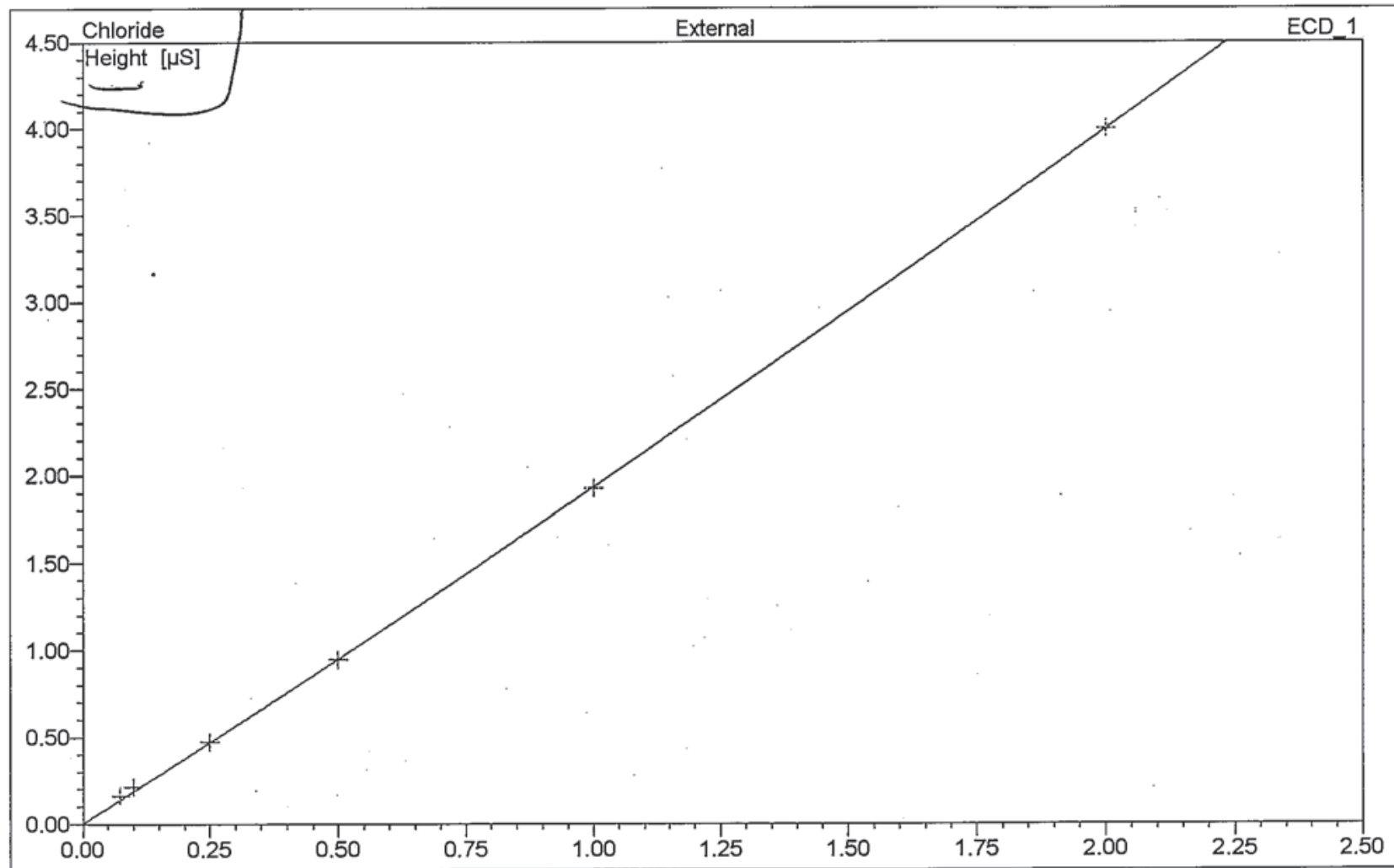

\begin{tabular}{|r|cllccccc|}
\hline No. & $\begin{array}{c}\text { Ret.Time } \\
\text { min }\end{array}$ & Peak Name & Cal.Type & Points & $\begin{array}{c}\text { Corr.Coeff. } \\
\text { (R) }\end{array}$ & Offset & Slope & Curve \\
\hline 1 & 3.23 & Fluoride & Quad & 6 & 0.9997 & 0.0000 & 3.120830 & 0.155880 \\
2 & 4.69 & Chloride & Quad & 6 & 0.9997 & 0.0000 & 1.867234 & 0.065694 \\
3 & 5.53 & Nitrite-N & Quad & 6 & 0.9998 & 0.0000 & 3.376824 & 0.140386 \\
4 & 6.99 & Bromide & Quad & 6 & 0.9999 & 0.0000 & 0.568855 & 0.010287 \\
5 & 7.82 & Nitrate-N & Quad & 6 & 0.9997 & 0.0000 & 2.738783 & 0.148955 \\
\hline Average: & & & & & 0.9998 & 0.0000 & 2.3345 & 0.1042 \\
\hline
\end{tabular}




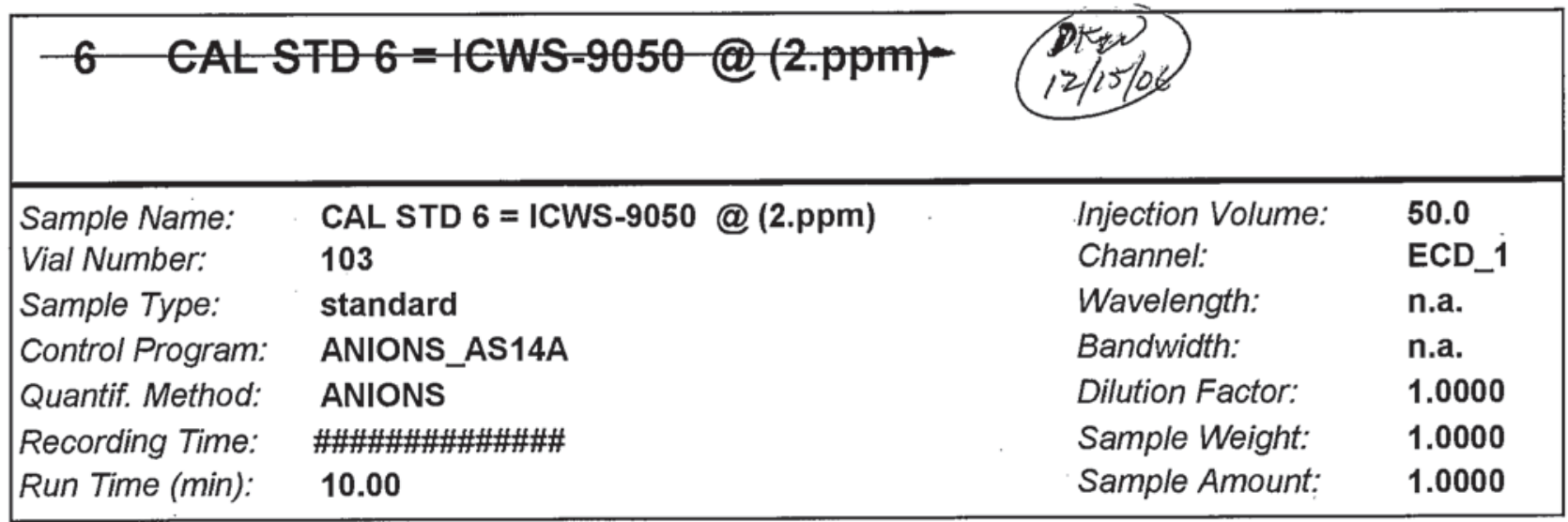

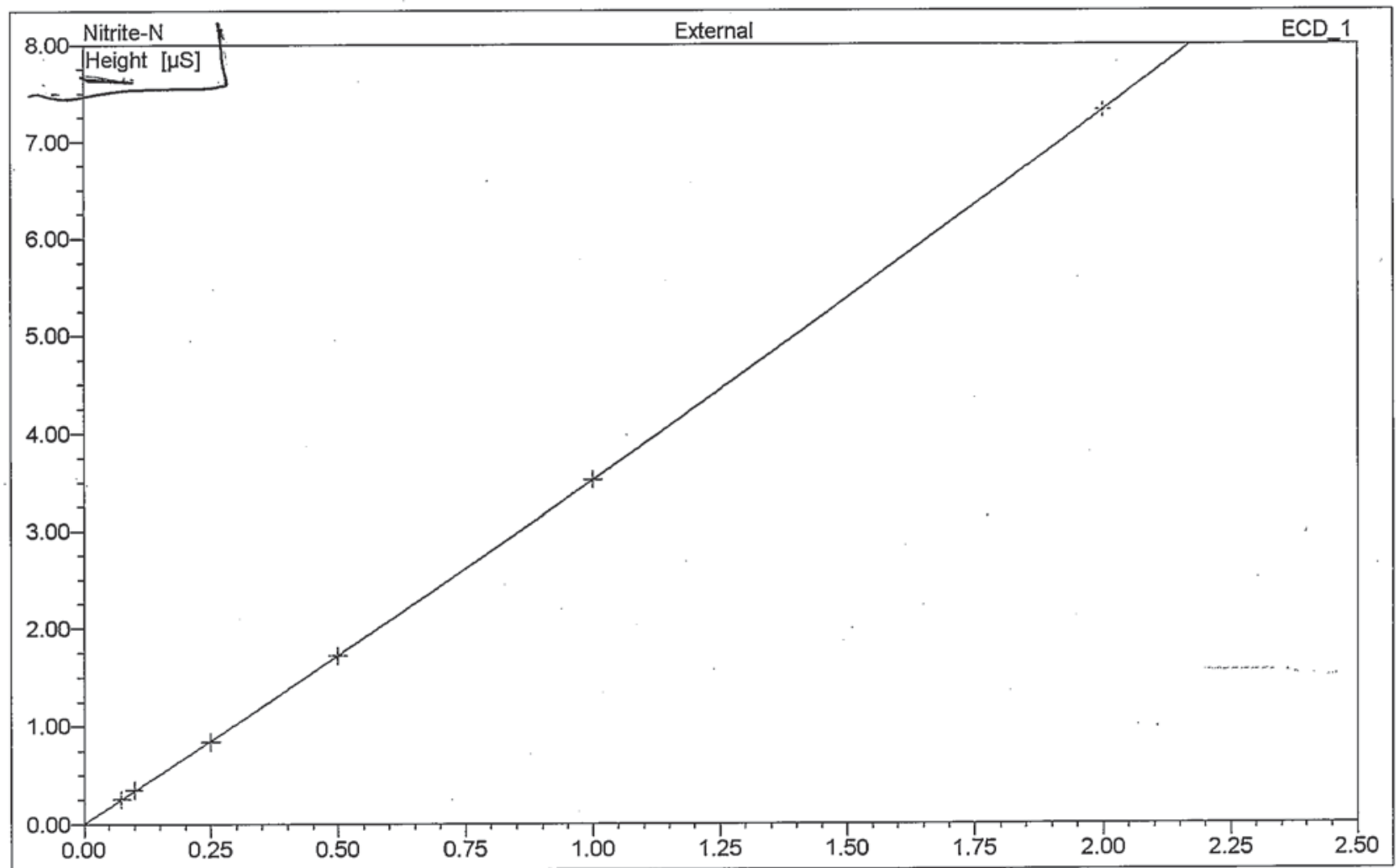

\begin{tabular}{|c|cccccccc|}
\hline No. & $\begin{array}{c}\text { Ret.Time } \\
\text { min }\end{array}$ & Peak Name & Cal.Type & Points & $\begin{array}{c}\text { Corr.Coeff. } \\
\text { (R) }\end{array}$ & Offset & Slope & Curve \\
\hline 1 & 3.23 & Fluoride & Quad & 6 & 0.9997 & 0.0000 & 3.120830 & 0.155880 \\
2 & 4.69 & Chloride & Quad & 6 & 0.9997 & 0.0000 & 1.867234 & 0.065694 \\
3 & 5.53 & Nitrite-N & Quad & 6 & 0.9998 & 0.0000 & 3.376824 & 0.140386 \\
4 & 6.99 & Bromide & Quad & 6 & 0.9999 & 0.0000 & 0.568855 & 0.010287 \\
5 & 7.82 & Nitrate-N & Quad & 6 & 0.9997 & 0.0000 & 2.738783 & 0.148955 \\
\hline Average: & & & & & 0.9998 & 0.0000 & 2.3345 & 0.1042 \\
\hline
\end{tabular}




\section{CALSTD $6=1 C W S-9050 @(2 . p P m)=$

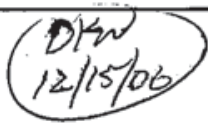

Sample Name:

Vial Number:

Sample Type:

Control Program:

Quantif. Method:

Recording Time:

Run Time ( $\mathrm{min})$ :

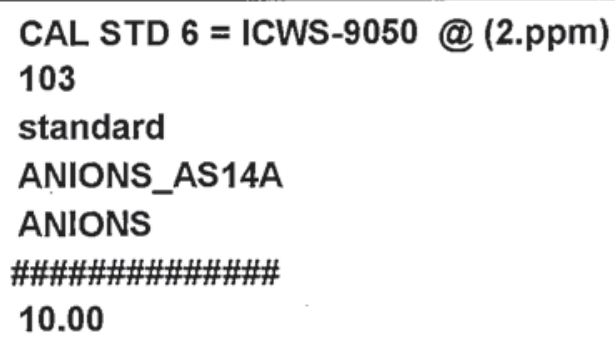

$\begin{array}{ll}\text { Injection Volume: } & \mathbf{5 0 . 0} \\ \text { Channel: } & \text { ECD_1 } \\ \text { Wavelength: } & \text { n.a. } \\ \text { Bandwidth: } & \text { n.a. } \\ \text { Dilution Factor: } & \mathbf{1 . 0 0 0 0} \\ \text { Sample Weight: } & \mathbf{1 . 0 0 0 0} \\ \text { Sample Amount: } & \mathbf{1 . 0 0 0 0}\end{array}$

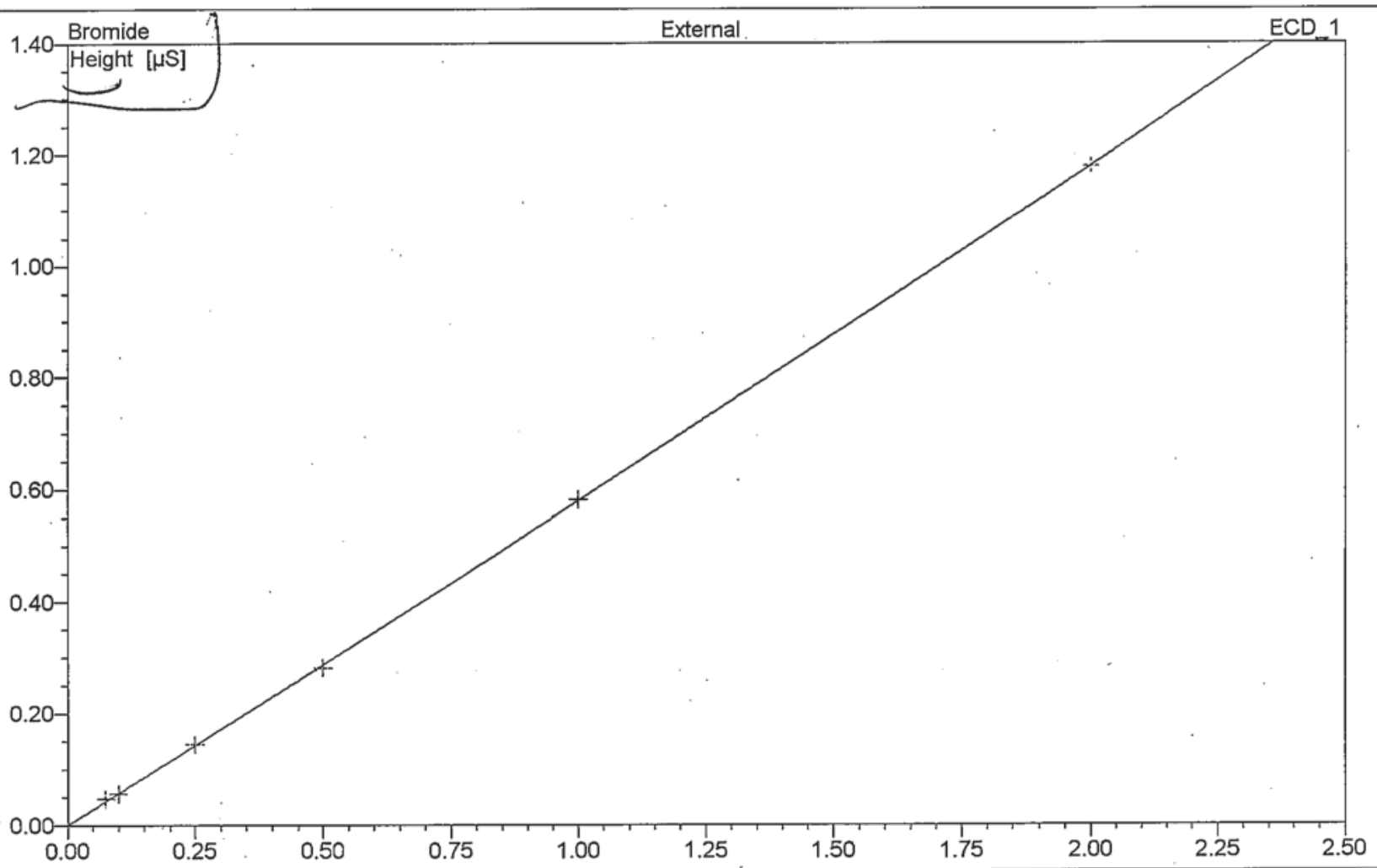

\begin{tabular}{|c|cccccccc|}
\hline No. & $\begin{array}{c}\text { Ret.Time } \\
\text { min }\end{array}$ & Peak Name & Cal.Type & Points & $\begin{array}{c}\text { Corr.Coeff. } \\
(\mathbf{R})\end{array}$ & Offset & Slope & Curve \\
\hline 1 & 3.23 & Fluoride & Quad & 6 & 0.9997 & 0.0000 & 3.120830 & 0.155880 \\
2 & 4.69 & Chloride & Quad & 6 & 0.9997 & 0.0000 & 1.867234 & 0.065694 \\
3 & 5.53 & Nitrite-N & Quad & 6 & 0.9998 & 0.0000 & 3.376824 & 0.140386 \\
4 & 6.99 & Bromide & Quad & 6 & 0.9999 & 0.0000 & 0.568855 & 0.010287 \\
5 & 7.82 & Nitrate-N & Quad & 6 & 0.9997 & 0.0000 & 2.738783 & 0.148955 \\
\hline Average: & & & & & 0.9998 & 0.0000 & 2.3345 & 0.1042 \\
\hline
\end{tabular}

default_letter_CHROME/Calibration(Curr.Peak) 


\begin{tabular}{|c|c|c|c|}
\hline \multicolumn{4}{|c|}{ 6 CALSTD6 =1CWS-9050@(2.ppm) } \\
\hline Sample Name: & CAL STD $6=$ ICWS-9050 @ (2.ppm) & Injection Volume: & 50.0 \\
\hline Vial Number: & 103 & Channel: & ECD_1 \\
\hline Sample Type: & standard & Wavelength: & n.a. \\
\hline Control Program: & ANIONS_AS14A & Bandwidth: & n.a. \\
\hline Quantif. Method: & ANIONS & Dilution Factor: & 1.0000 \\
\hline Recording Time: & \#\#\#\#\#\#\#\#\#\#\#\# & Sample Weight: & 1.0000 \\
\hline Run Time (min): & 10.00 & Sample Amount: & 1.0000 \\
\hline
\end{tabular}

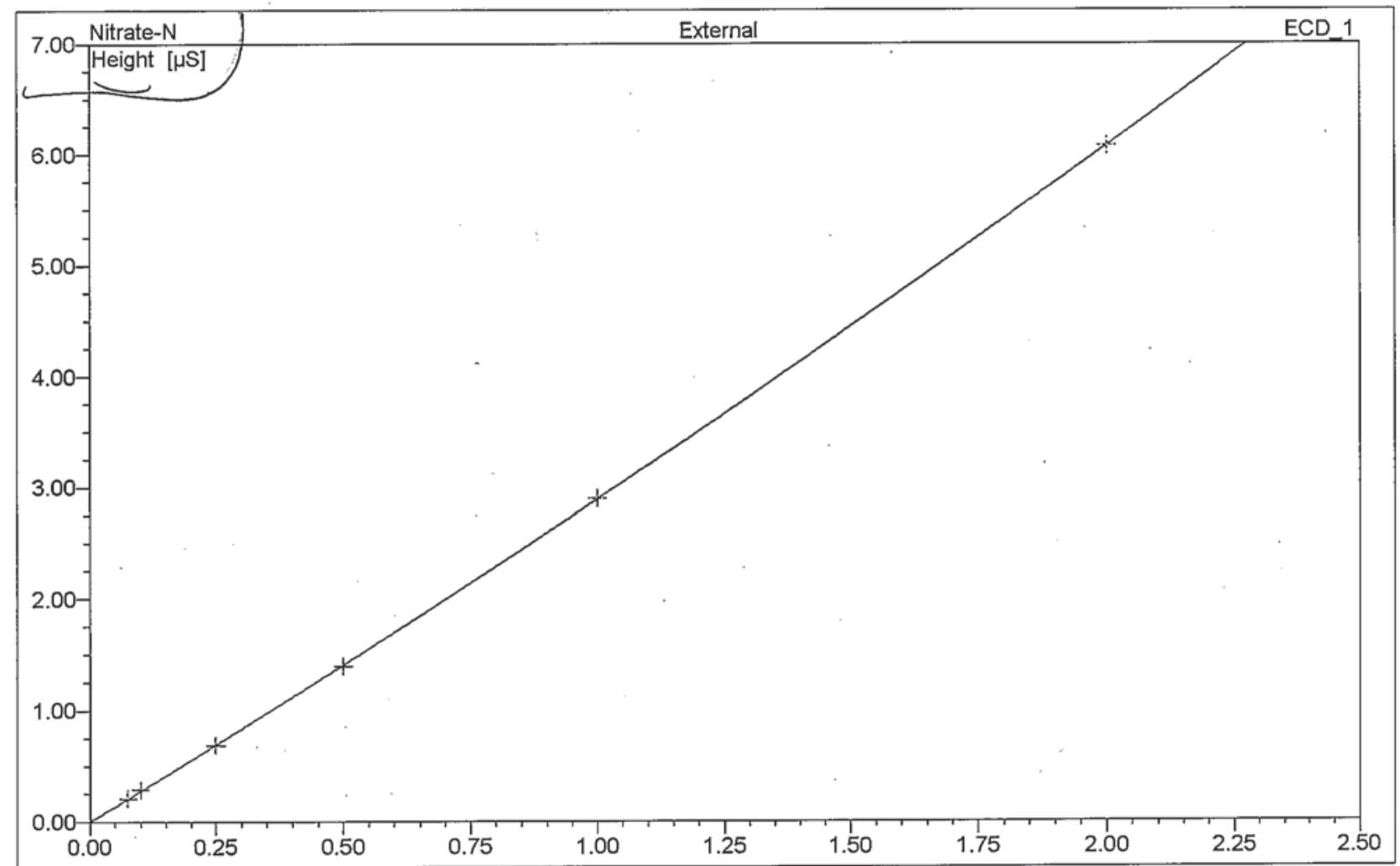

\begin{tabular}{|r|clcccccc|}
\hline No. & $\begin{array}{c}\text { Ret.Time } \\
\text { min }\end{array}$ & Peak Name & Cal.Type & Points & $\begin{array}{c}\text { Corr.Coeff. } \\
\text { (R) }\end{array}$ & Offset & Slope & Curve \\
\hline 1 & 3.23 & Fluoride & Quad & 6 & 0.9997 & 0.0000 & 3.120830 & 0.155880 \\
2 & 4.69 & Chloride & Quad & 6 & 0.9997 & 0.0000 & 1.867234 & 0.065694 \\
3 & 5.53 & Nitrite-N & Quad & 6 & 0.9998 & 0.0000 & 3.376824 & 0.140386 \\
4 & 6.99 & Bromide & Quad & 6 & 0.9999 & 0.0000 & 0.568855 & 0.010287 \\
5 & 7.82 & Nitrate-N & Quad & 6 & 0.9997 & 0.0000 & 2.738783 & 0.148955 \\
\hline Average: & & & & & 0.9998 & 0.0000 & 2.3345 & 0.1042 \\
\hline
\end{tabular}


Ii

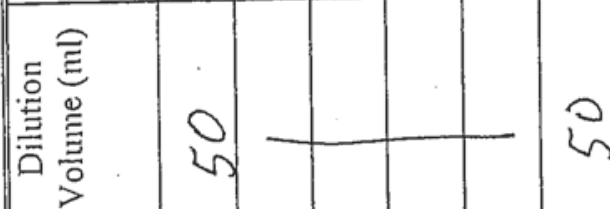

兽
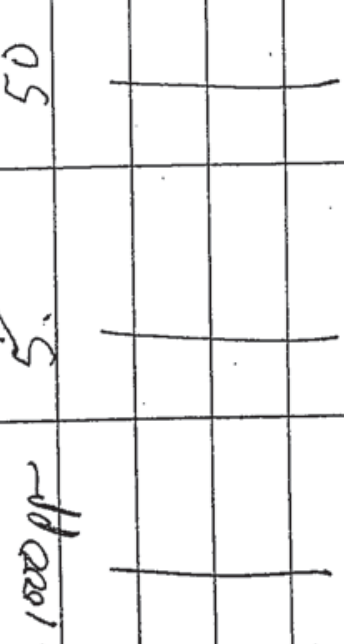

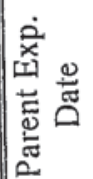

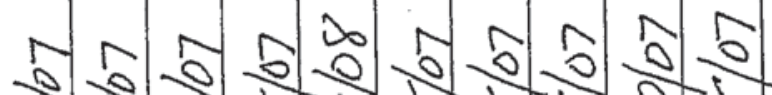

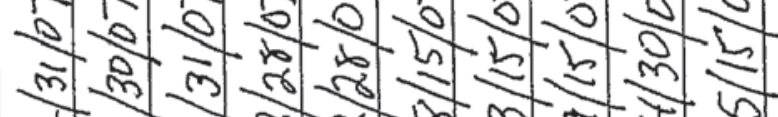

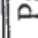

तो

䒕

হू্

12

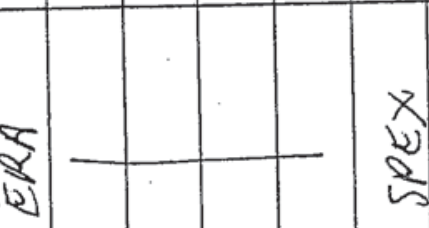

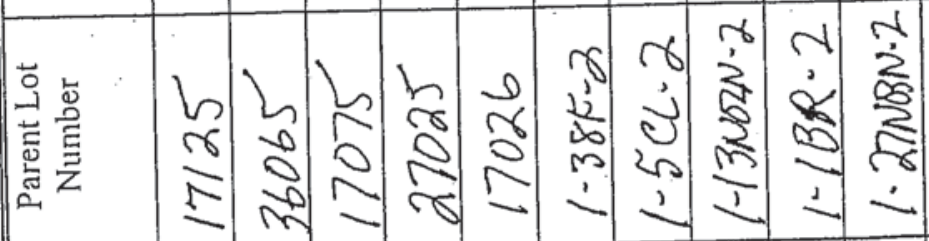

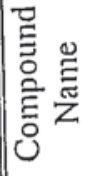

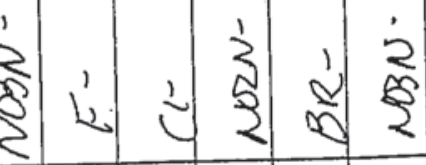

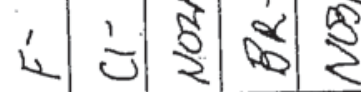
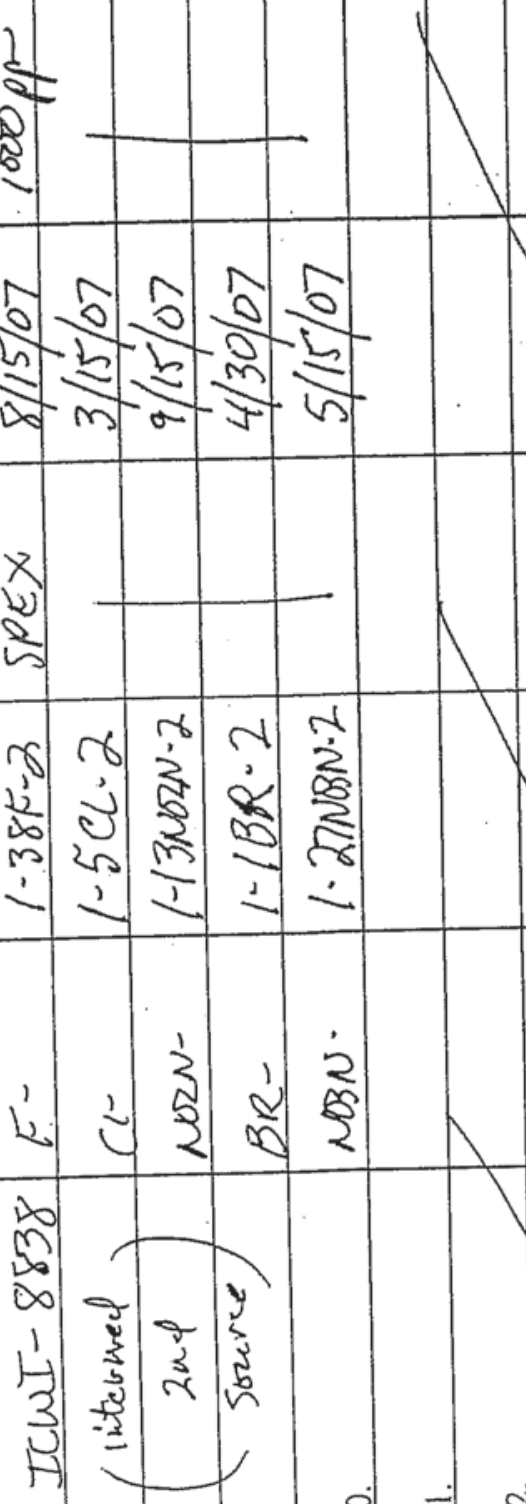

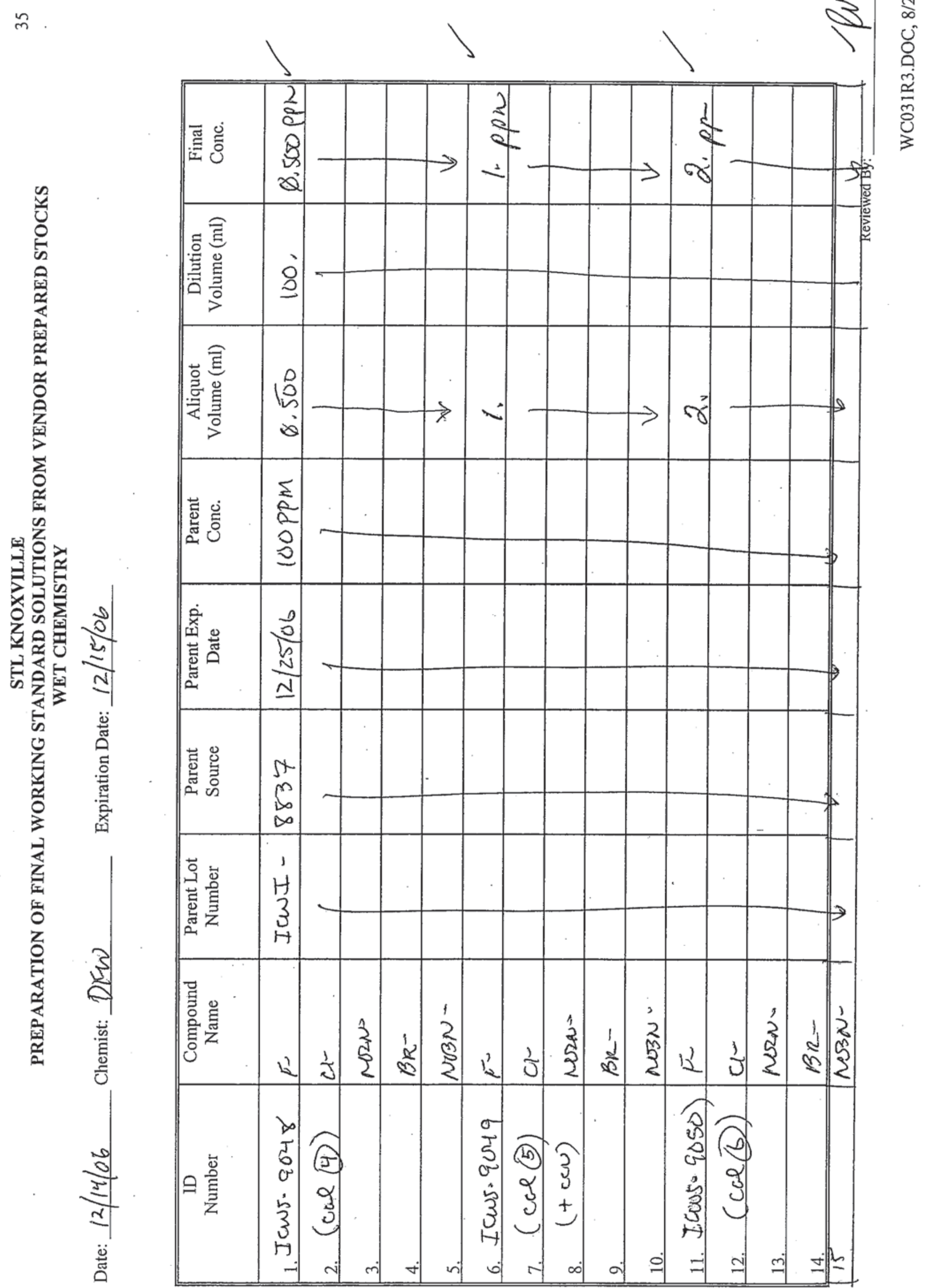

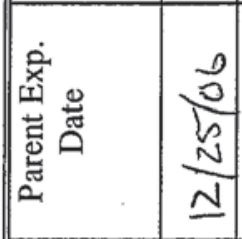

泀递

$\sum_{\infty}^{\infty}$

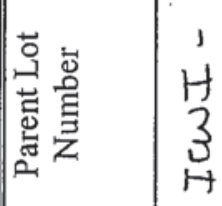

壱

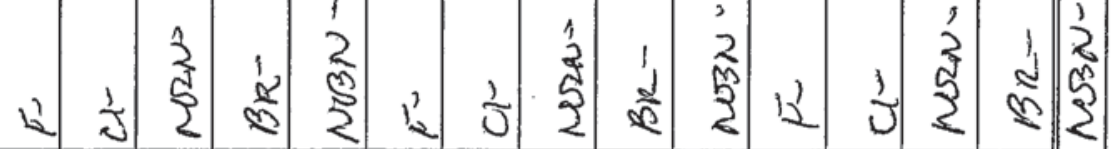

$\frac{\sqrt{3}}{\frac{3}{2}}$

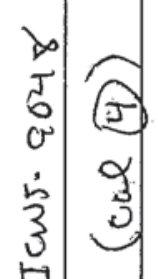

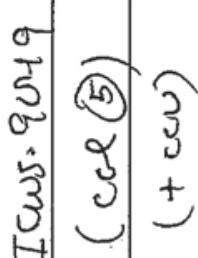

$\ddot{\ddot{\omega}}$

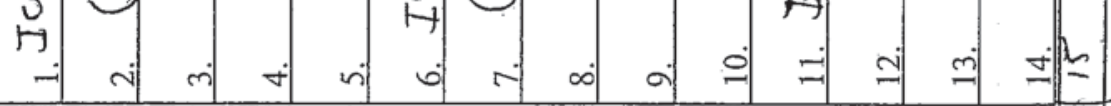




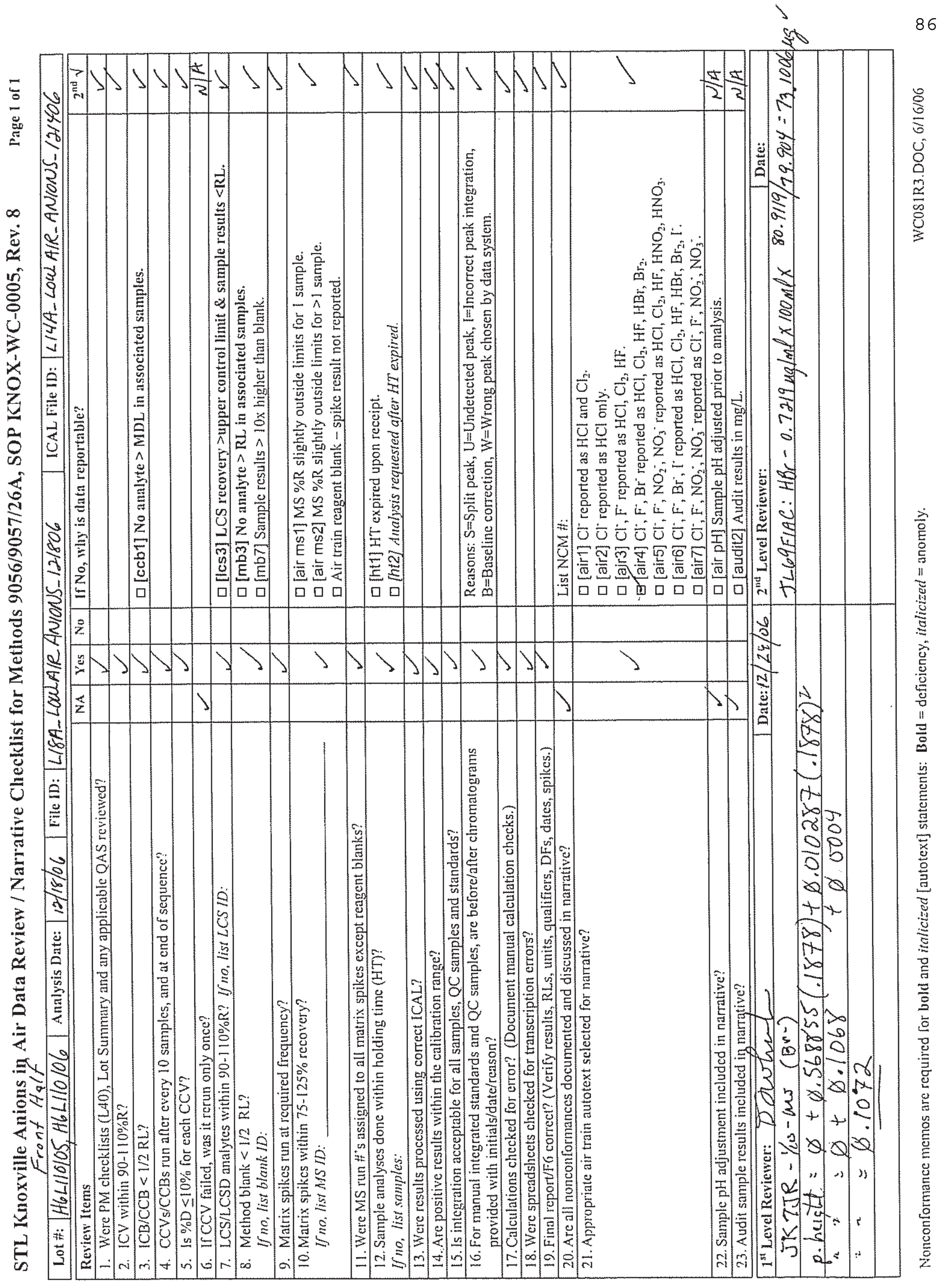




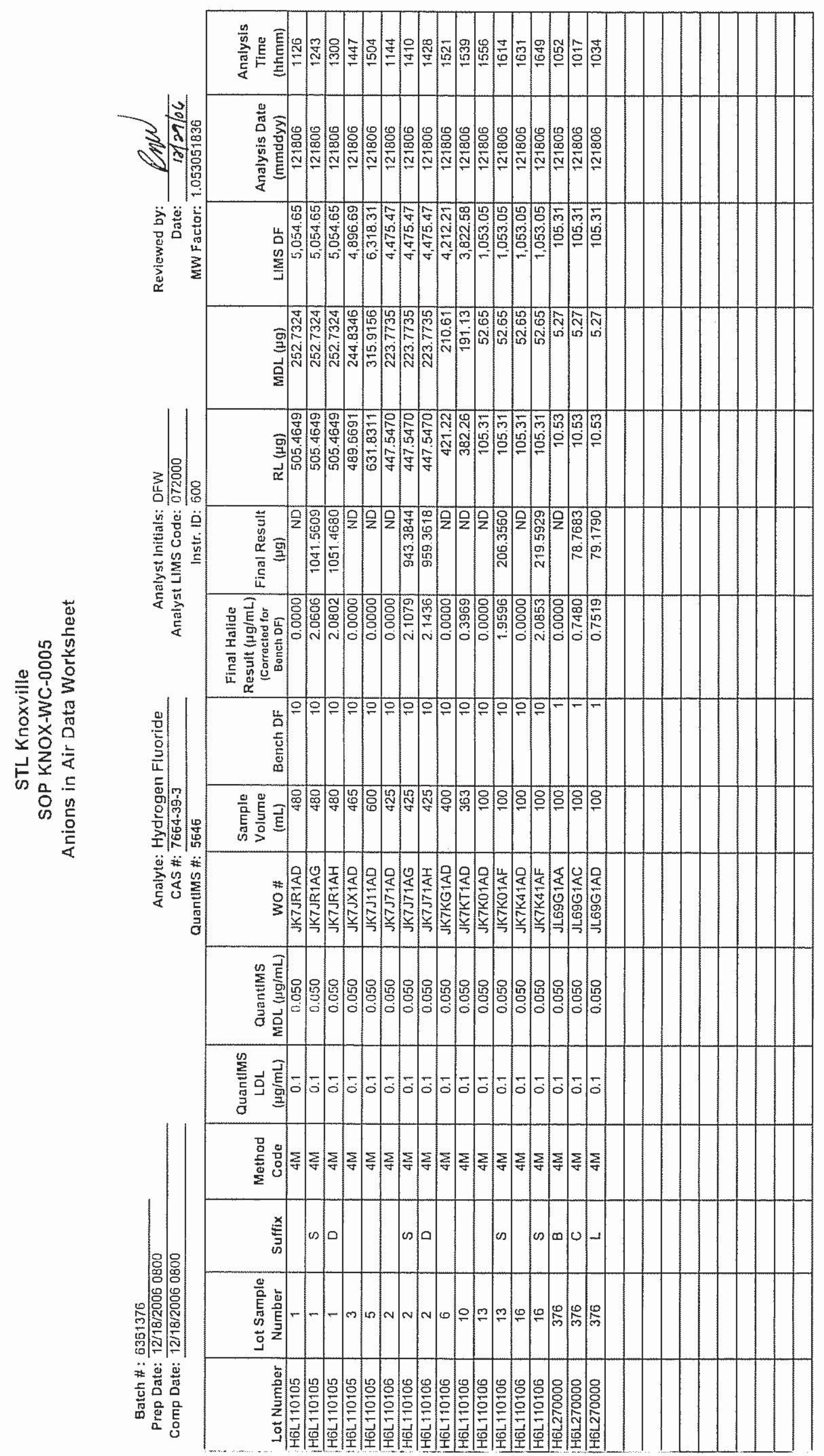




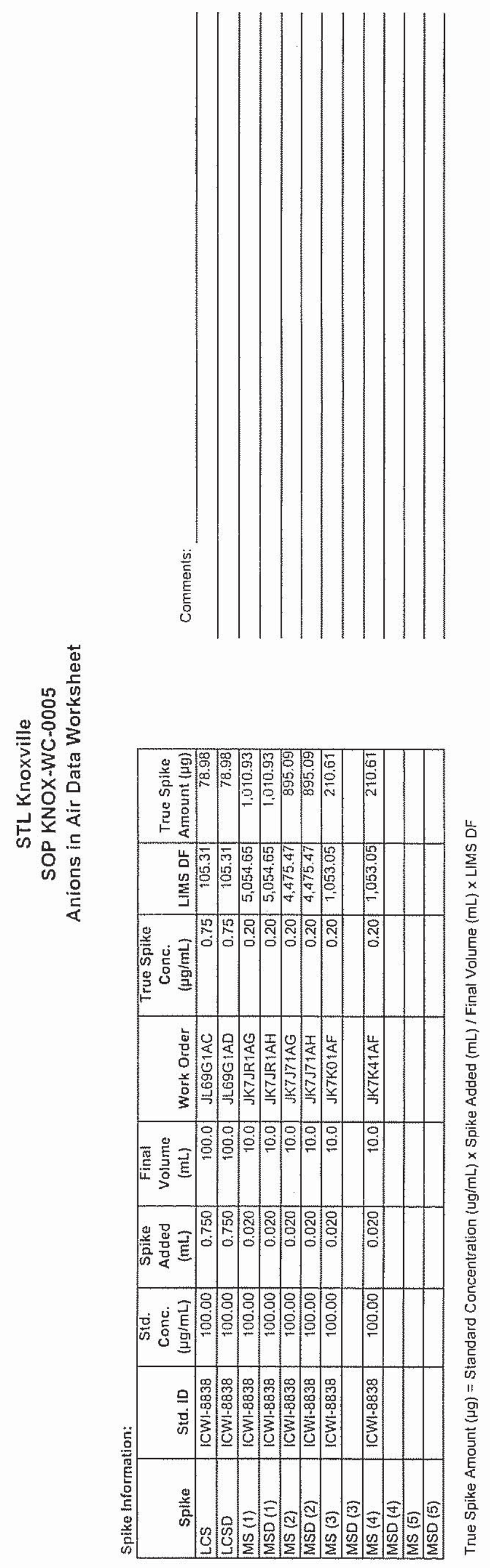




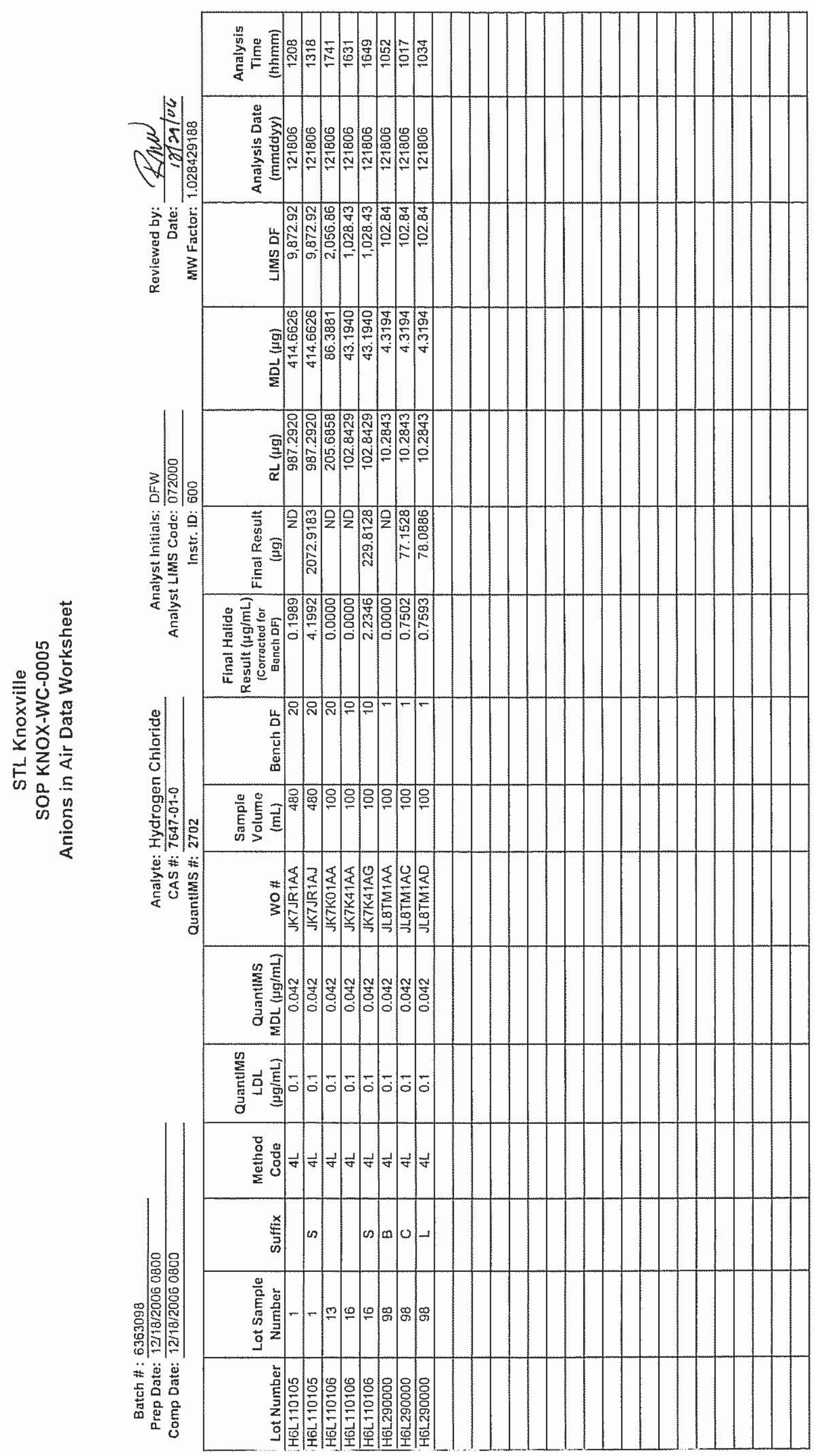




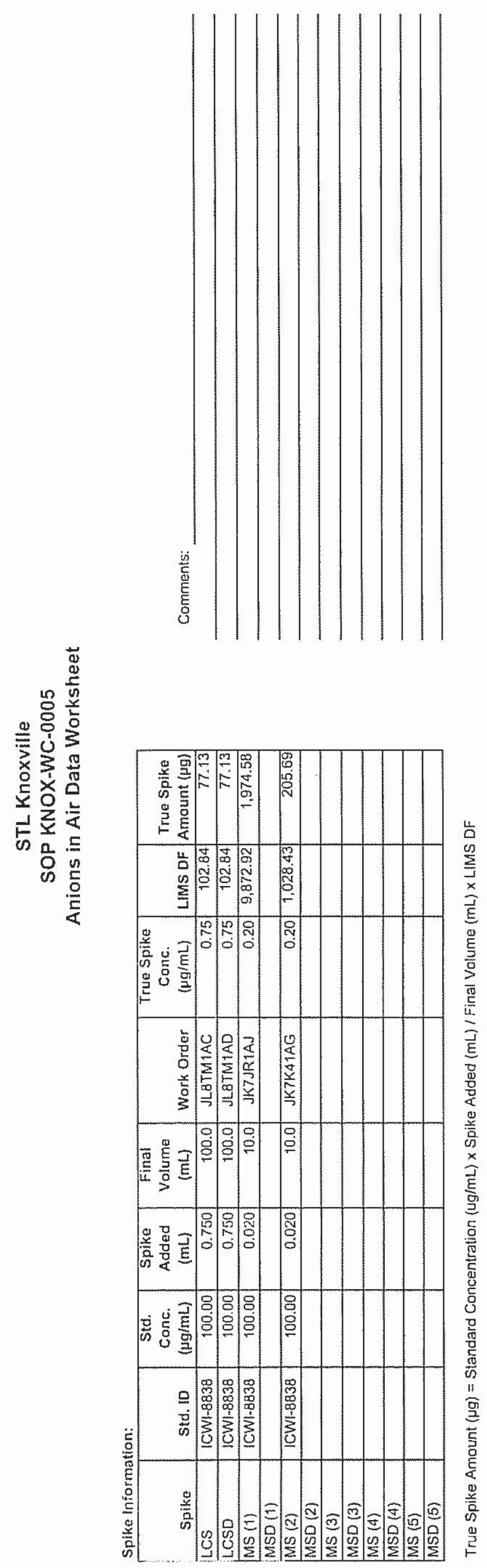




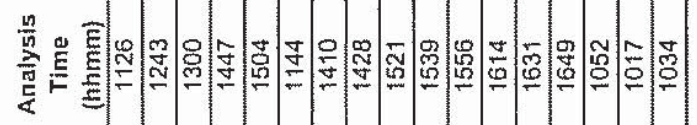

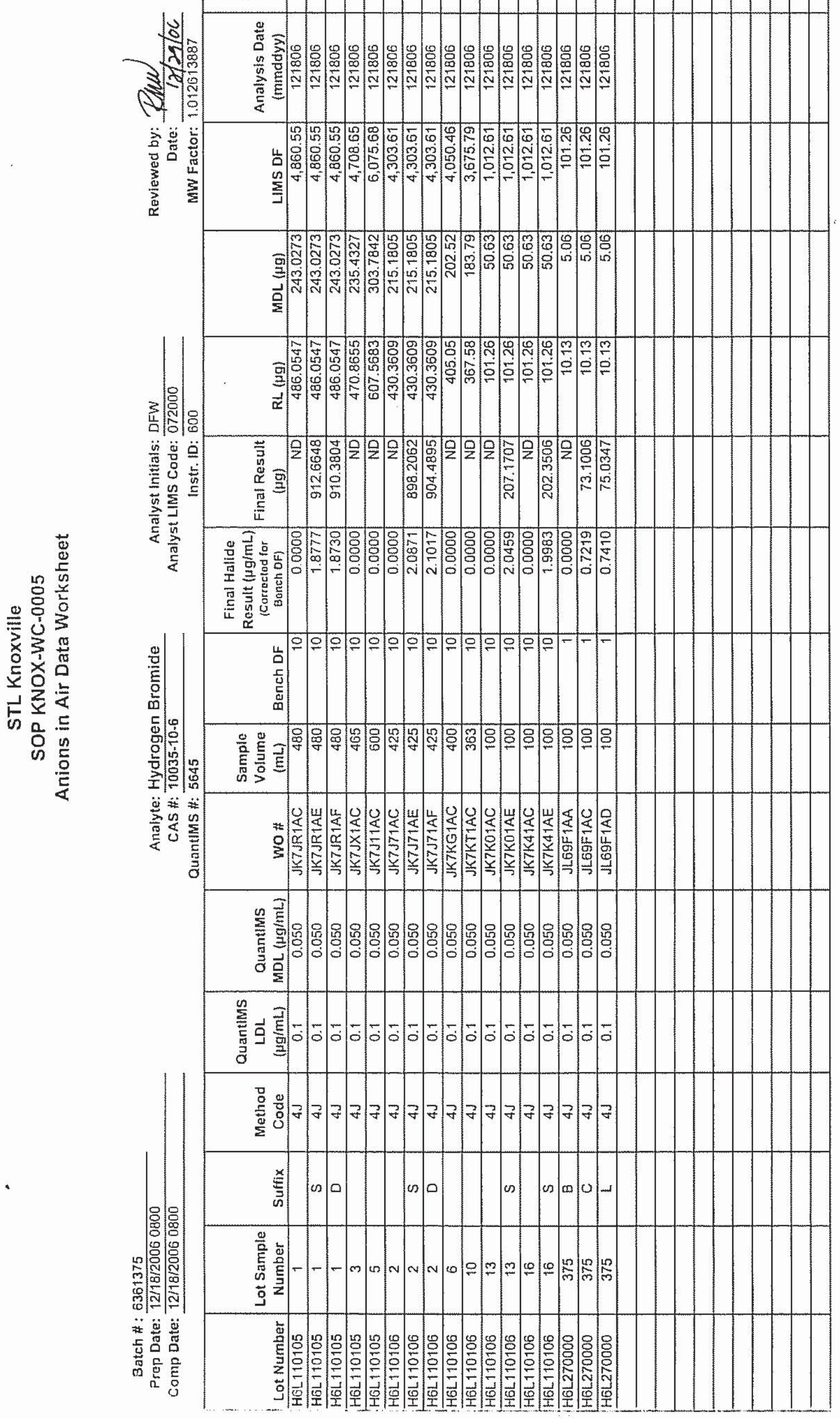



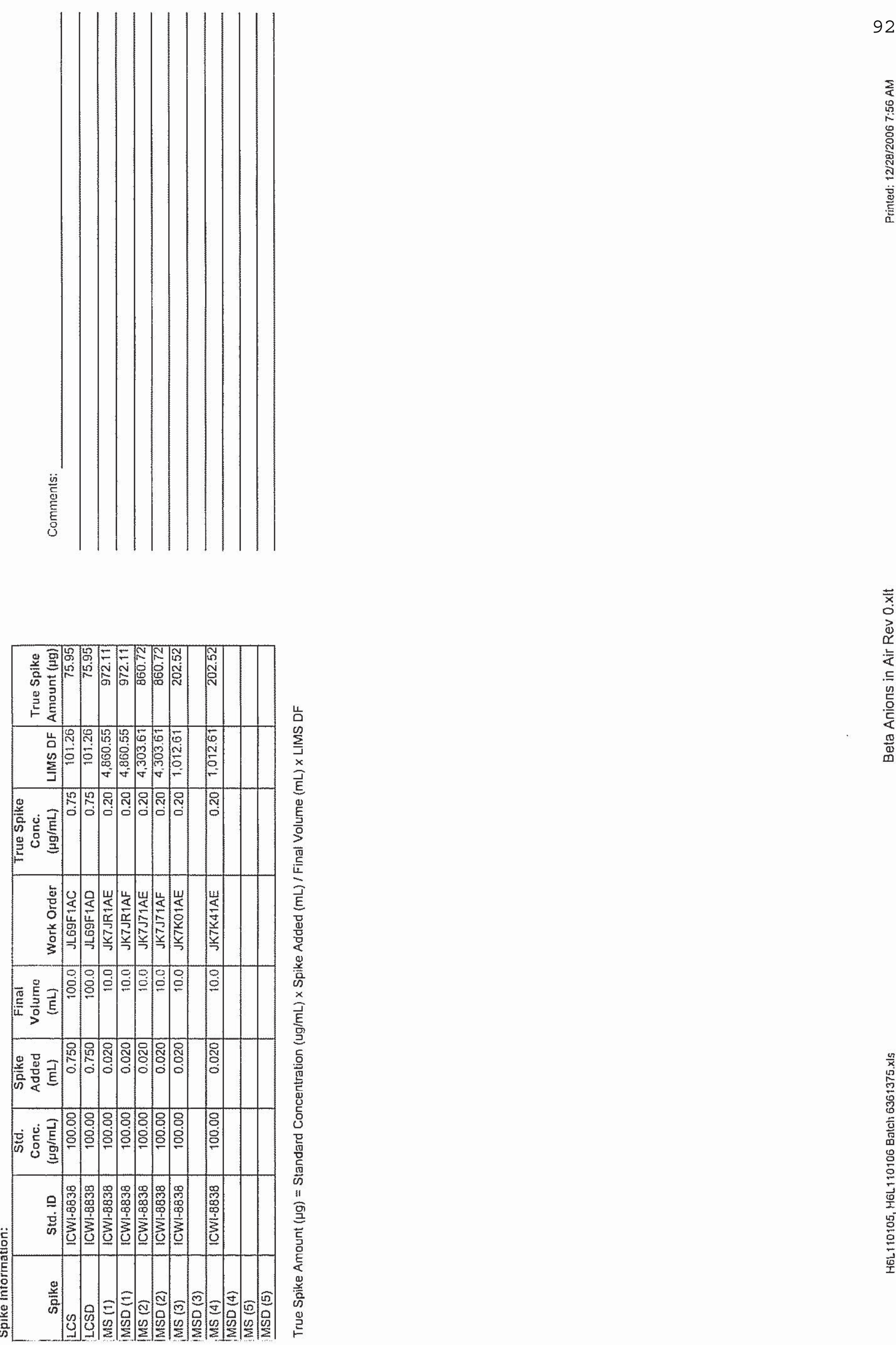


\section{Dionex IC Runlog Cover Page}

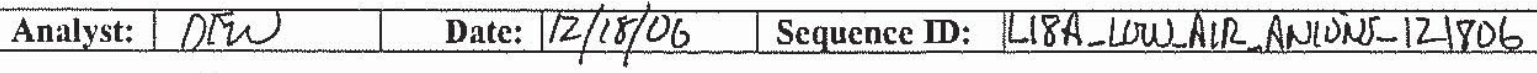

\begin{tabular}{|c|c|c|c|}
\hline \multirow[t]{3}{*}{ Instrument: } & DDX-600 & \multirow[t]{3}{*}{ Method: } & D KNOX-WC-0003, SW-8460061/7199 \\
\hline & DICS -1500 & & $\square \mathrm{KNOX}-W \mathrm{C}-0005, \mathrm{~S}$ SW-846 $9056 \square \mathrm{EPA} 300.0$ \\
\hline & DDX-320 & & D KNOX-WC-0014, EPA 314.0 \\
\hline
\end{tabular}

\section{Preventive Maintenance}

Dailv:

C Check pump and gas pressure

$\checkmark$ Check all lines for crimping, leaks and discoloration

\section{As Needed:}

$\square$ Change column and guard column

$\square$ Change column and/or guard column bed support

$\square$ Clean conductivity cell

$\square$ De-gas pump head when flow is erratic

口 Check/replace eluant end line filter

\section{Instrument Conditions}

\begin{tabular}{rll|}
\hline Flow Rate $=$ & 1.00 & $\mathrm{~mL} / \mathrm{min}$ \\
\hline Pressure $=$ & 2200. & $\mathrm{psi}$ \\
\hline Conductance $=$ & 22.8 & $\mu \mathrm{S}$ \\
\hline Suppressor Current $=$ & 43. & $\mathrm{~mA}$ \\
\hline Eluent Generator $=\mathrm{N} / \mathrm{A}$ & $\mathrm{mM} \mathrm{KOH}$
\end{tabular}

MS/MSD Spike Information

\begin{tabular}{|c|c|c|c|c|c|c|}
\hline WO \# & Compound & Spike ID & Parent Conc. & Spike Added (mL) & Final Volume $(\mathrm{mL})$ & Final Conc. \\
\hline JK7JR & $F^{-}$ & Icwi-8838 & $100 . p p m$ & $\varnothing .02$ & $10 \mathrm{ml}$ & $0.20 \mathrm{ppm}$ \\
\hline & $\mathrm{Cl}^{-}$ & & & & & \\
\hline$\downarrow$ & $\mathrm{Br}^{-}$ & & $\downarrow$ & $\downarrow$ & & \\
\hline \multirow[t]{3}{*}{$5 K 757$} & $F^{-}$ & & & & & \\
\hline & $\mathrm{Cl}^{-}$ & & & & & \\
\hline & $\mathrm{Br}^{-}$ & & & & & \\
\hline \multirow[t]{3}{*}{ JKIKO } & $F^{-}$ & & & & & \\
\hline & $\mathrm{Cl}^{-}$ & & & & & \\
\hline & $\mathrm{Br}^{-}$ & & & & & \\
\hline \multirow[t]{5}{*}{ JK $1 K 4$} & $F-$ & & & & & \\
\hline & $\mathrm{Cl}^{-}$ & & & & & \\
\hline & $B^{r}$ & $\downarrow$ & $\downarrow$ & $\downarrow$ & $\forall$ & $\downarrow$ \\
\hline & & & & Em 12 & & \\
\hline & & & & & & \\
\hline
\end{tabular}

Comments:

$$
\begin{aligned}
& \text { HF Batch - } 6361376 \\
& \text { HBr Batch- } 6361375
\end{aligned}
$$


Title:

Datasource: Aragorn_nel

Location: IC_ARAGORN

Timebase: $\quad$ IC_Aragorn

Created:

\#Samples:

36

Last Update:

Printed: $12 / 19 / 20067: 35: 58$ AM

\begin{tabular}{|c|c|c|c|c|c|c|c|}
\hline No. & Name & Sample ID & Inj. Vol. & Inj. Date/Time & Dil. Factor & $\begin{array}{r}\text { "Multiplier } \\
\text { [Liters] }\end{array}$ & Weight \\
\hline 1 & (1) CAL STD $1=1$ ICWS-9045 @ (0.075ppm) & & 50.0 & $12 / 14 / 20064: 54: 12 \mathrm{PM}$ & 1.0000 & & 1.0000 \\
\hline 2 & 10 CAL STD $2=$ ICWS-9046 @ (0.10ppm) & & 50.0 & 12/14/2006 5:11:38 PM & 1.0000 & & 1.0000 \\
\hline 3 & 0 CAL STD $3=$ ICWS $9047 @(0.25 \mathrm{ppm})$ & & 50.0 & 12/14/2006 5:24:03 PM & 1.0000 & & 1.0000 \\
\hline 4 & (1) CAL STD $4=1$ CW S-9048 @ (0.50ppm) & & 50.0 & 12/14/2006 5:36:29 PM & 1,0000 & & 1.0000 \\
\hline 5 & (1) CAL STD $5=$ ICWS-9049@ (1.ppm) & & 50.0 & 12/14/2006 5:48:54 PM & 1.0000 & & 1.0000 \\
\hline 6 & (1) CAL STD $6=1$ ICWS-9050 @ (2.ppm) & & 50.0 & 12/14/2006 6:01:20 PM & 1.0000 & & 1.0000 \\
\hline 7 & ICV ILCS $=$ ICWS-9056 & & 50.0 & 12/18/2006 10:17:27 AM & 1.0000 & & 1.0000 \\
\hline 8 & 6 ICV/LCSD = ICWS-9057 & & 50.0 & $12 / 18 / 200610: 34: 53 \mathrm{AM}$ & 1.0000 & & 1.0000 \\
\hline 9 & II ICB/METHOD BLANK & & 50.0 & 12/18/2006 10:52:18 AM & 1.0000 & & 1.0000 \\
\hline 10 & 䇛 H6L110105-JK7JR-1/10 & & 50,0 & $12 / 18 / 2006$ 11:26:40 AM & 10.0000 & & 1.0000 \\
\hline 11 & (7) H6L110106-JK7J7-1/10 & & 50.0 & 12/18/2006 11:44:06 AM & 10.0000 & & 1.0000 \\
\hline 12 & 筧 H6L110105-JK7JR-1/20 & & 50.0 & 12/18/2006 12:08:40 PM & 20.0000 & & 1.0000 \\
\hline 13 & 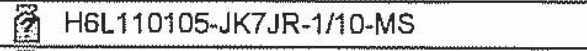 & & 50.0 & 12/18/2006 12:43:28 PM & 10.0000 & & 1.0000 \\
\hline 14 & (86L110105-JK7JR/1/10-MSD & & 50.0 & 12/18/2006 1:00:54 PM & 10.0000 & & 1.0000 \\
\hline 15 & 要 H6L110105-JK7JR-1/20-MS & & 50.0 & 12/18/2006 1:18:20 PM & 20.0000 & & 1.0000 \\
\hline 16 & CCV $=1$ ICWS -9058 & & 50.0 & 12/18/2006 1:35:45 PM & 1.0000 & & 1.0000 \\
\hline 17 & $\mathrm{CCCB}$ & & 50.0 & $12 / 18 / 20061: 53: 11 \mathrm{PM}$ & 1.0000 & & 1.0000 \\
\hline 18 & H6L110106-JK7J7-1/10-MS & & 50.0 & $12 / 18 / 20062: 10: 37 \mathrm{PM}$ & 10.0000 & & 1.0000 \\
\hline 19 & H6L110106-JK7J7-1/10-MSD & & 50.0 & 12/18/2006 2:28:03 PM & 10.0000 & & 1.0000 \\
\hline 20 & (1) H6L110105-JK7JX-1/10 & & 50.0 & $12 / 18 / 20062: 47: 03 \mathrm{PM}$ & 10.0000 & & 1.0000 \\
\hline 21 & (2) H6L110105-JK7J1-1/10 & & 50.0 & 12/18/2006 3:04:28 PM & 10.0000 & & 1.0000 \\
\hline 22 & (2) H6L110106-JK7KG-1/10 & & 50.0 & 12/18/2006 3:21:54 PM & 10.0000 & & 1.0000 \\
\hline 23 & (7) H6L110105-JK7KT-1/10 & & 50.0 & 12/18/2006 3:39:19 PM & 10.0000 & & 1.0000 \\
\hline 24 & 筧 H6L110106-JK7KO-1/10 & & 50.0 & 12/18/2006 3:56:45 PM & 10.0000 & & 1.0000 \\
\hline 25 & (2) H6L110106-JK7KO-1/10-MS & & 50.0 & $12 / 18 / 2006$ 4:14:11 PM & 10.0000 & & 1.0000 \\
\hline 26 & 管 H6L110106-JK7K4-1/10 & & 50.0 & 12/18/2006 4:31:36 PM & 10.0000 & & 1.0000 \\
\hline 27 & (2) H6L110106-JK7K4-1/10-MS & & 50.0 & $12 / 18 / 2006$ 4:49:02 PM & 10.0000 & & 1.0000 \\
\hline 28 & 拿 $C C V=1 C W S-9058$ & & 50.0 & 12/18/2006 5:06:27 PM & 1.0000 & & 1.0000 \\
\hline 29 & 登 $\mathrm{CCB}$ & & 50.0 & 12/18/2006 5:23:52 PM & 1.0000 & & 1.0000 \\
\hline 30 & 箘 H6L110106-JK7K0-1/20 & & 50.0 & 12/18/2006 5:41:18 PM & 20.0000 & & 1.0000 \\
\hline 31 & 完 H6L110106-JK7KO-1/20-MS & & 50.0 & 12/18/2006 5:58:43 PM & 20.0000 & & 1.0000 \\
\hline 32 & 管 H6L110106-JK7K0-1/40 & & 50.0 & 12/18/2006 6:16:09 PM & 40.0000 & & 1.0000 \\
\hline 33 & 冤 H6L110106-JK7K0-1/40-MS & & 50.0 & 12/18/2006 6:33:34 PM & 40.0000 & & 1.0000 \\
\hline 34 & 2. $C C V=1 C W S-9058$ & & 50.0 & $12 / 18 / 20066: 50: 59 \mathrm{PM}$ & 1.0000 & & 1.0000 \\
\hline 35 & 篎 $\mathrm{CCB}$ & & 50.0 & 12/18/2006 7:08:24 PM & 1.0000 & & 1.0000 \\
\hline 36 & 湾 SHUTDOWN & & 50.0 & $12 / 18 / 2006$ 7:25:50 PM & 1.0000 & & 1.0000 \\
\hline
\end{tabular}




\section{ICV/LCS $=$ ICWS -9056}

\begin{tabular}{ll}
\hline Sample Name: & ICV/LCS=ICWS-9056 \\
Vial Number: & $\mathbf{1 0 4}$ \\
Sample Type: & unknown \\
Control Program: & ANIONS_AS14A \\
Quantif. Method: & ANIONS \\
Recording Time: & $\mathbf{1 2 / 1 8 / 2 0 0 6 ~ 1 0 : 1 7}$ \\
Run Time (min): & $\mathbf{1 5 . 0 0}$
\end{tabular}

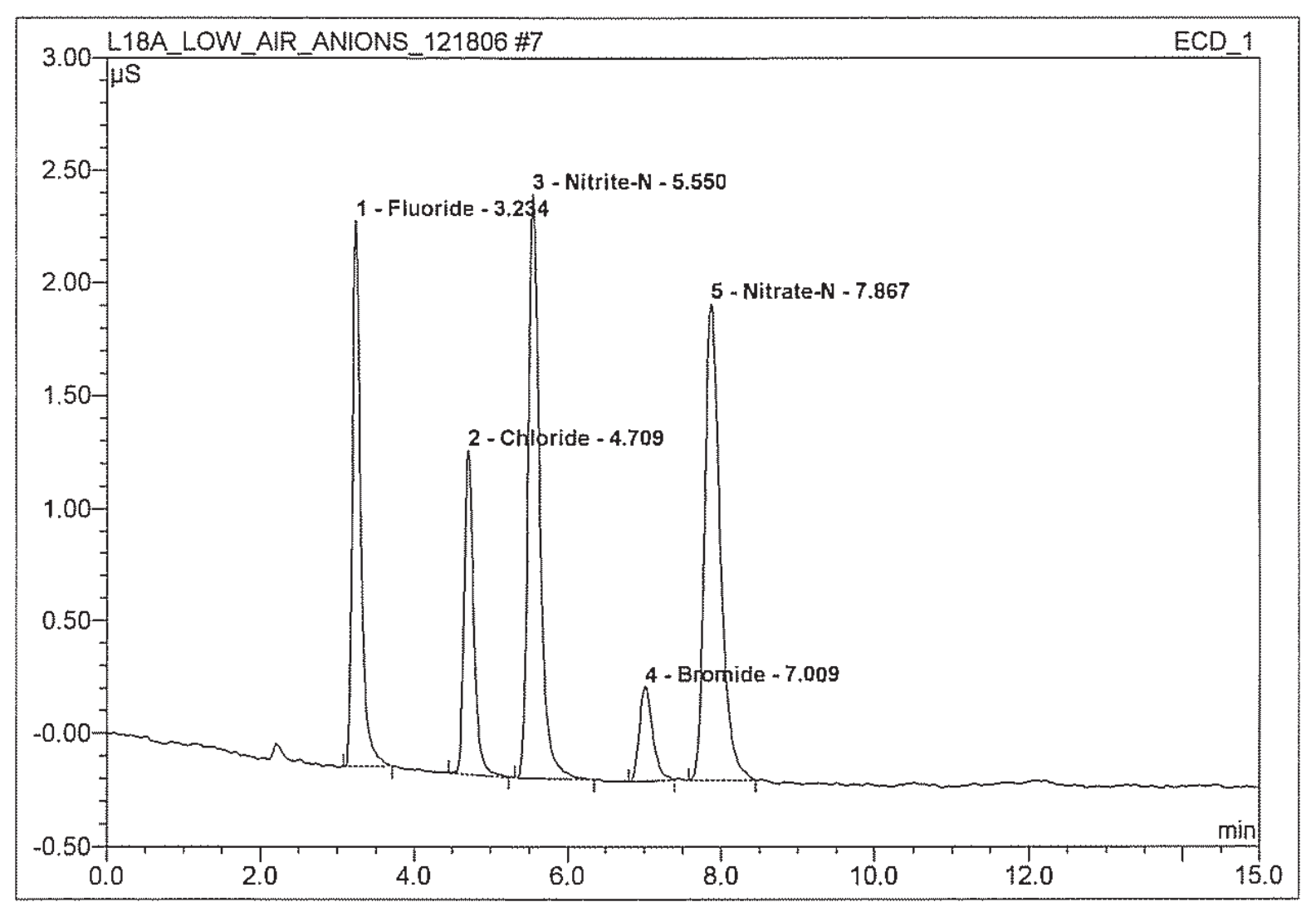

\begin{tabular}{|c|c|l|r|r|r|r|c|}
\hline No. & $\begin{array}{c}\text { Ret.Time } \\
\text { (min.) }\end{array}$ & \multicolumn{1}{|c|}{ Peak Name } & $\begin{array}{c}\text { Height } \\
(\mathbf{u S})\end{array}$ & $\begin{array}{c}\text { Area } \\
\mu \mathrm{S}^{*} \min \end{array}$ & $\begin{array}{c}\text { Rel.Area } \\
(\%)\end{array}$ & $\begin{array}{c}\text { Amount } \\
(\mathrm{mg} / \mathrm{L})\end{array}$ & $\begin{array}{r}\text { Peak } \\
\text { Type }\end{array}$ \\
\hline 1 & 3.23 & Fluoride & 2.42157 & 0.305 & 19.82 & 0.7480 & BMB \\
\hline 2 & 4.71 & Chloride & 1.43770 & 0.207 & 13.45 & 0.7502 & BMB \\
\hline 3 & 5.55 & Nitrite-N & 2.59076 & 0.450 & 29.23 & 0.7442 & BMB \\
\hline 4 & 7.01 & Bromide & 0.41601 & 0.083 & 5.39 & 0.7219 & BMB \\
\hline 5 & 7.87 & Nitrate-N & 2.11264 & 0.495 & 32.11 & 0.7415 & BMB \\
\hline
\end{tabular}

$$
\frac{\frac{H F-J \angle 6 R G-I A C}{H B_{r}-J \angle 69 F-1 A C}}{H C l-J \angle 8 T M-1 A C}
$$




\section{$8 \quad I C V / L C S D=I C W S-9057$}

\begin{tabular}{llll|}
\hline Sample Name: & ICV/LCSD=ICWS-9057 & Injection Volume: & $\mathbf{5 0 . 0}$ \\
Vial Number: & $\mathbf{1 0 5}$ & Channel: & ECD_1 \\
Sample Type: & unknown & Wavelength: & n.a. \\
Control Program: & ANIONS_AS14A & Bandwidth: & n.a. \\
Quantif. Method: & ANIONS & Dilution Factor: & $\mathbf{1 . 0 0 0 0}$ \\
Recording Time: & $\mathbf{1 2 / 1 8 / 2 0 0 6 ~ 1 0 : 3 4}$ & Sample Weight: & $\mathbf{1 . 0 0 0 0}$ \\
Run Time (min): & $\mathbf{1 5 . 0 0}$ & Sample Amount: & $\mathbf{1 . 0 0 0 0}$ \\
\hline
\end{tabular}

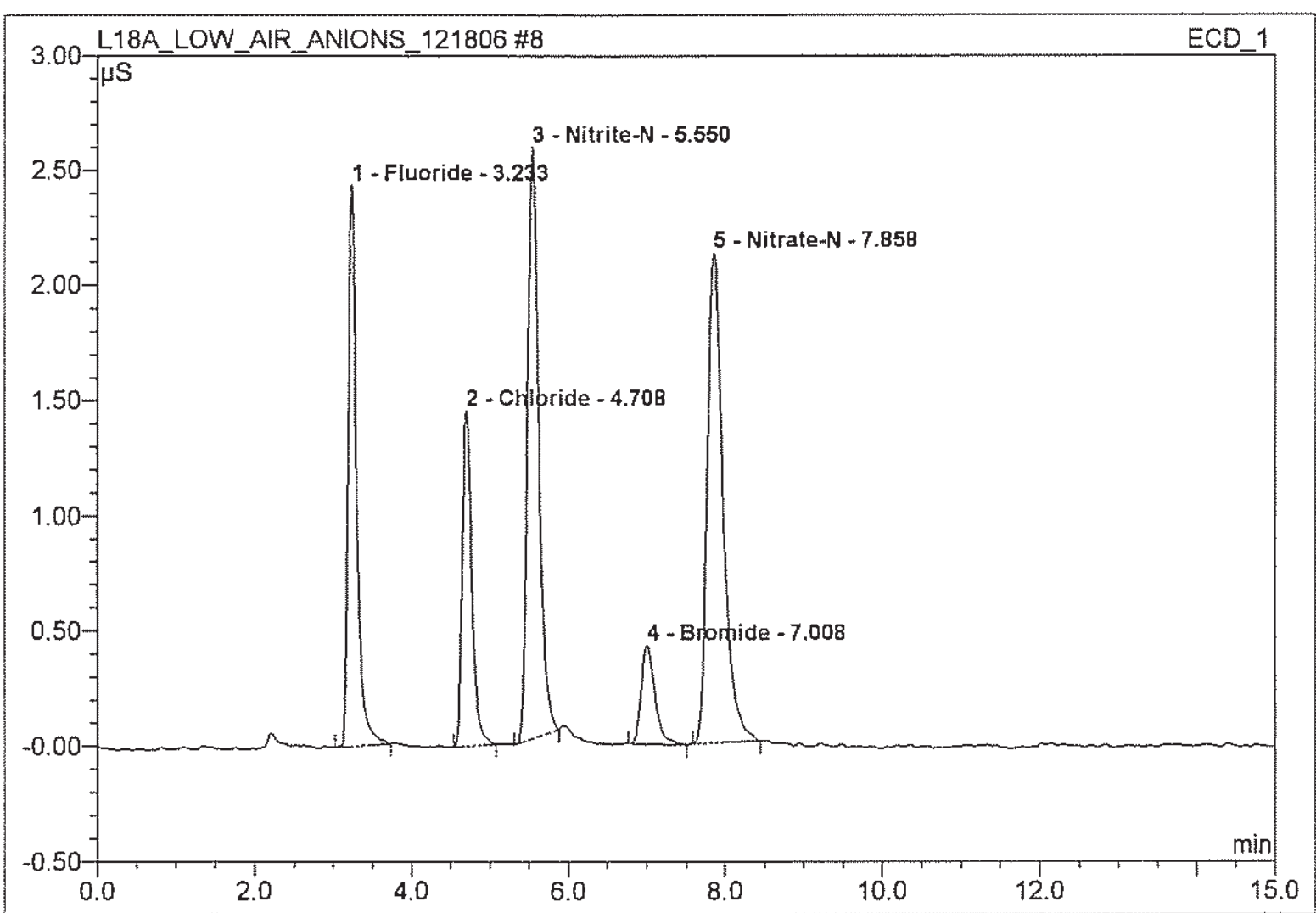

\begin{tabular}{|c|c|l|r|r|r|r|c|}
\hline No. & $\begin{array}{c}\text { Ret.Time } \\
\text { (min.) }\end{array}$ & \multicolumn{1}{|c|}{ Peak Name } & $\begin{array}{c}\text { Height } \\
\text { (uS) }\end{array}$ & $\begin{array}{c}\text { Area } \\
\mu S^{\star} \min \end{array}$ & $\begin{array}{c}\text { Rel.Area } \\
\text { (\%) }\end{array}$ & $\begin{array}{c}\text { Amount } \\
\text { (mg/L) }\end{array}$ & $\begin{array}{r}\text { Peak } \\
\text { Type }\end{array}$ \\
\hline 1 & 3.23 & Fluoride & 2.43474 & 0.307 & 20.23 & 0.7519 & BMB \\
\hline 2 & 4.71 & Chloride & 1.45569 & 0.205 & 13.51 & 0.7593 & BMB \\
\hline 3 & 5.55 & Nitrite-N & 2.56761 & 0.424 & 27.92 & 0.7377 & BMB \\
\hline 4 & 7.01 & Bromide & 0.42719 & 0.086 & 5.70 & 0.7410 & BMB \\
\hline 5 & 7.86 & Nitrate-N & 2.12412 & 0.495 & 32.64 & 0.7454 & BMB \\
\hline
\end{tabular}

$$
\frac{H F-J L 69 G-1 A D}{\frac{H B r-J L 69 F-I A D}{H C l-J \angle 8 T M-1 A D}}
$$




\section{ICB/ METHOD BLANK}

\begin{tabular}{ll}
\hline Sample Name: & ICB/ METHOD BLANK \\
Vial Number: & 139 \\
Sample Type: & unknown \\
Control Program: & ANIONS_AS14A \\
Quantif. Method: & ANIONS \\
Recording Time: & $12 / 18 / 200610: 52$ \\
Run Time (min): & 15.00
\end{tabular}

$\begin{array}{ll}\text { Injection Volume: } & \mathbf{5 0 . 0} \\ \text { Channel: } & \text { ECD_1 } \\ \text { Wavelength: } & \text { n.a. } \\ \text { Bandwidth: } & \text { n.a. } \\ \text { Dilution Factor: } & 1.0000 \\ \text { Sample Weight: } & 1.0000 \\ \text { Sample Amount: } & 1.0000\end{array}$

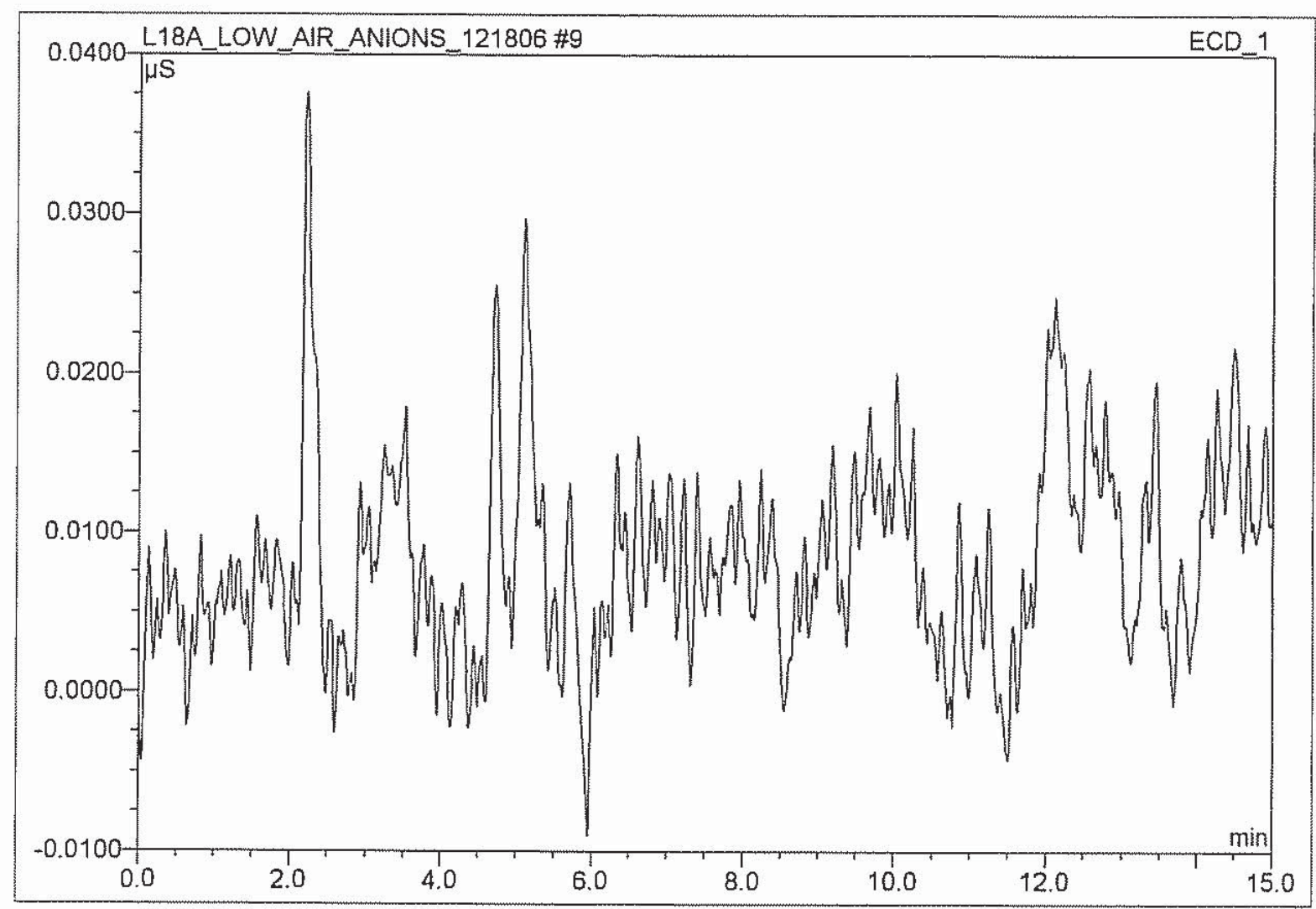

\begin{tabular}{|c|c|c|c|c|c|c|c|}
\hline No. & $\begin{array}{c}\text { Ret.Time } \\
\text { (min.) }\end{array}$ & Peak Name & $\begin{array}{c}\text { Height } \\
\text { (uS) }\end{array}$ & $\begin{array}{c}\text { Area } \\
\mu S^{\star} m i n\end{array}$ & $\begin{array}{c}\text { Rel.Area } \\
(\%)\end{array}$ & $\begin{array}{c}\text { Amount } \\
(\mathrm{mg} / \mathrm{L})\end{array}$ & $\begin{array}{c}\text { Peak } \\
\text { Type }\end{array}$ \\
\hline
\end{tabular}
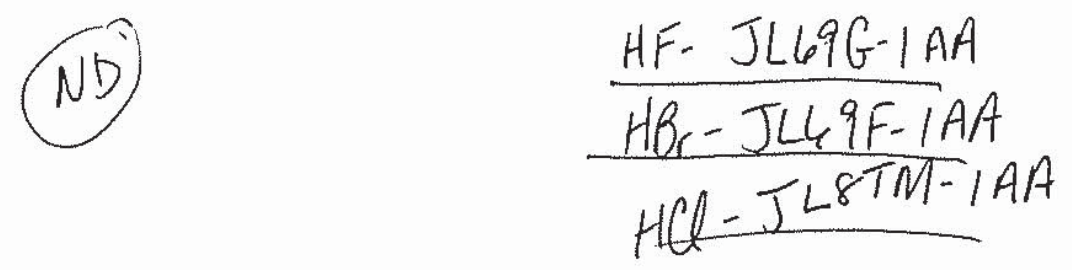


\section{H6L110106-JK7J7-1/10}

\begin{tabular}{|llll|}
\hline Sample Name: & H6L110106-JK7J7-1/10 & Injection Volume: & $\mathbf{5 0 . 0}$ \\
Vial Number: & $\mathbf{1 4 1}$ & Channel: & ECD_1 \\
Sample Type: & unknown & Wavelength: & n.a. \\
Control Program: & ANIONS_AS14A & Bandwidth: & n.a. \\
Quantif. Method: & ANIONS & Dilution Factor: & $\mathbf{1 0 . 0 0 0 0}$ \\
Recording Time: & $\mathbf{1 2 / 1 8 / 2 0 0 6 ~ 1 1 : 4 4}$ & Sample Weight: & $\mathbf{1 . 0 0 0 0}$ \\
Run Time (min): & $\mathbf{1 5 . 0 0}$ & Sample Amount: & $\mathbf{1 . 0 0 0 0}$ \\
\hline
\end{tabular}

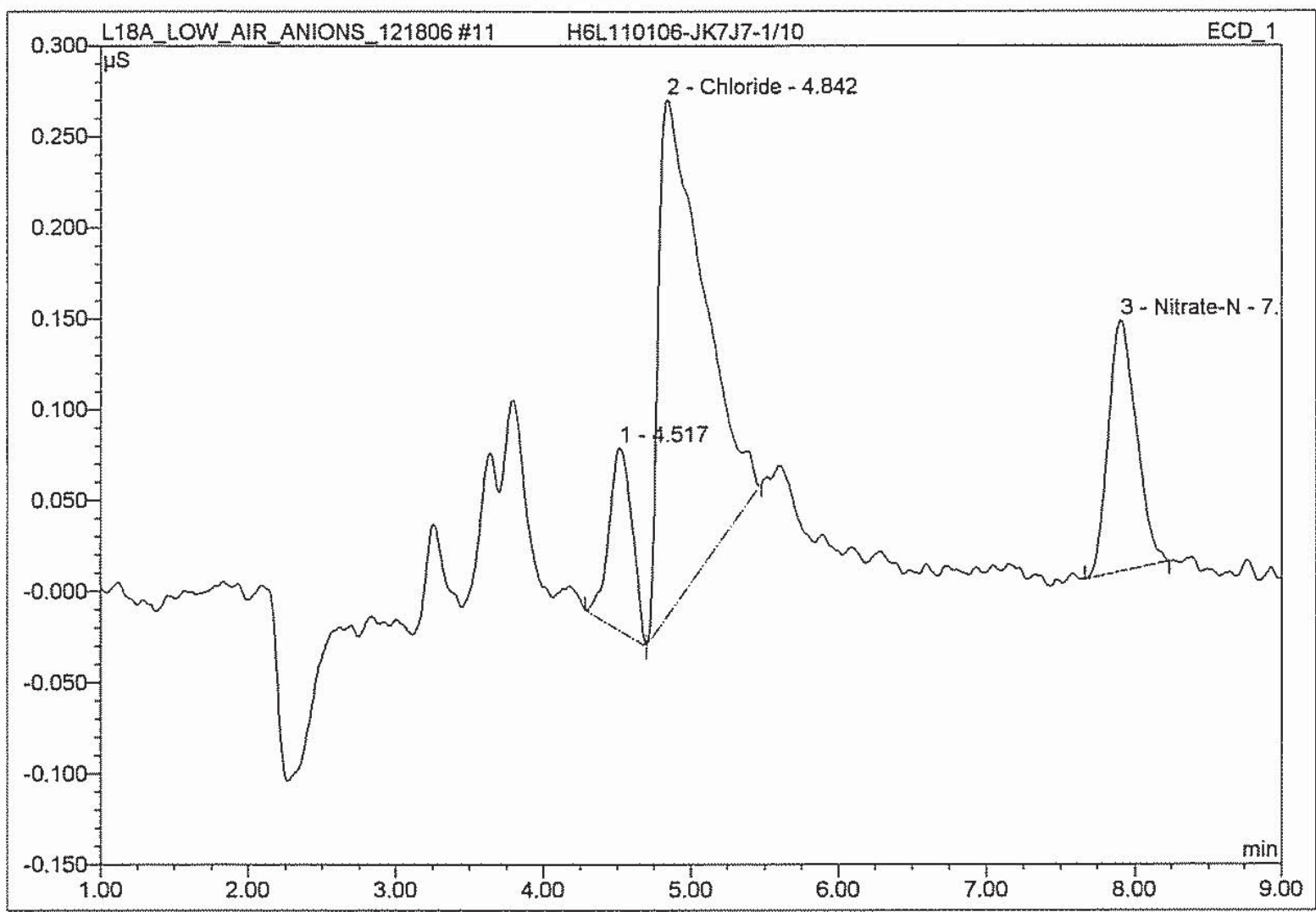

\begin{tabular}{|c|c|l|r|r|r|r|r|}
\hline No. & $\begin{array}{c}\text { Ret.Time } \\
\text { (min.) }\end{array}$ & \multicolumn{1}{|c|}{ Peak Name } & $\begin{array}{c}\text { Height } \\
\text { (uS) }\end{array}$ & $\begin{array}{c}\text { Area } \\
\mu S^{*} \min \end{array}$ & $\begin{array}{r}\text { Rel.Area } \\
(\%)\end{array}$ & $\begin{array}{r}\text { Amount } \\
\text { (mg/L) }\end{array}$ & $\begin{array}{r}\text { Peak } \\
\text { Type }\end{array}$ \\
\hline 1 & 4.52 & n.a. & 0.10057 & 0.018 & 0.03 & n.a. & BMb \\
\hline 2 & 4.84 & Chloride & 0.28417 & 0.098 & 0.13 & 1.5138 & bMB \\
\hline 3 & 7.91 & Nitrate-N & 0.13805 & 0.030 & 0.04 & 0.5027 & BMB \\
\hline 4 & 10.79 & n.a. & 0.19479 & 0.056 & 0.08 & n.a. & BMB \\
\hline 5 & 11.87 & n.a. & 72.927 & 99.72 & n.a. & BMB \\
\hline
\end{tabular}

$$
\frac{H F-N D}{H B r-N D}
$$




\section{H6L110106-JK7J7-1/10}

\begin{tabular}{ll}
\hline Sample Name: & H6L110106-JK7J7-1/10 \\
Vial Number: & 141 \\
Sample Type: & unknown \\
Control Program: & ANIONS_AS14A \\
Quantif. Method: & ANIONS \\
Recording Time: & $12 / 18 / 2006$ 11:44 \\
Run Time (min): & 15.00
\end{tabular}

$\begin{array}{ll}\text { Injection Volume: } & \mathbf{5 0 . 0} \\ \text { Channel: } & \text { ECD_1 } \\ \text { Wavelength: } & \text { n.a. } \\ \text { Bandwidth: } & \text { n.a. } \\ \text { Dilution Factor: } & 10.0000 \\ \text { Sample Weight: } & \mathbf{1 . 0 0 0 0} \\ \text { Sample Amount: } & \mathbf{1 . 0 0 0 0}\end{array}$

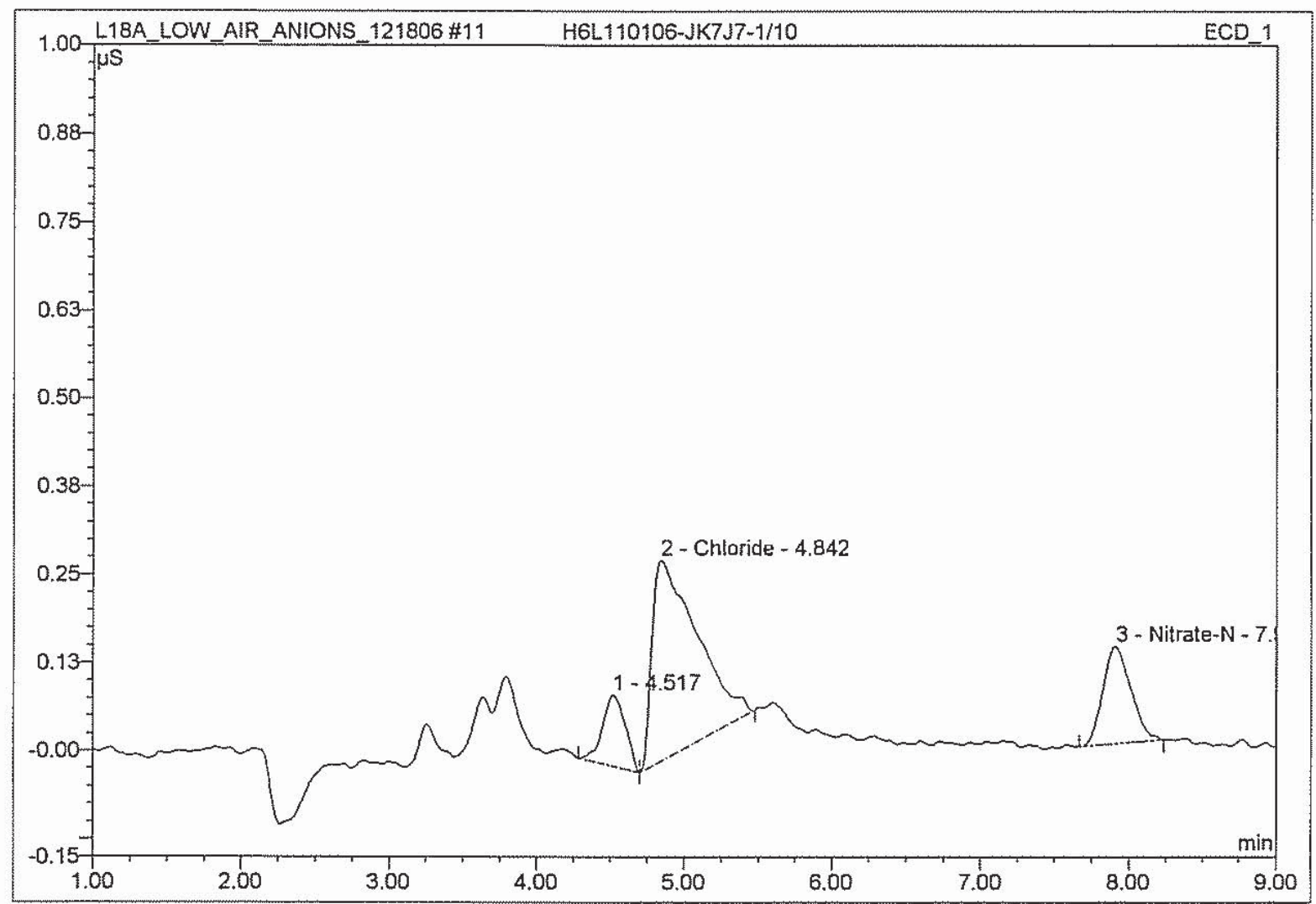

\begin{tabular}{|c|c|l|r|r|r|r|r|}
\hline No. & $\begin{array}{c}\text { Ret.Time } \\
\text { (min.) }\end{array}$ & \multicolumn{1}{|c|}{ Peak Name } & $\begin{array}{c}\text { Height } \\
\text { (uS) }\end{array}$ & $\begin{array}{c}\text { Area } \\
\mu S^{*} \text { min }\end{array}$ & $\begin{array}{r}\text { Rel.Area } \\
(\%)\end{array}$ & $\begin{array}{c}\text { Amount } \\
\text { (mg/L) }\end{array}$ & $\begin{array}{r}\text { Peak } \\
\text { Type }\end{array}$ \\
\hline 1 & 4.52 & n.a. & 0.10057 & 0.018 & 0.03 & n.a. & BMb \\
\hline 2 & 4.84 & Chloride & 0.28417 & 0.098 & 0.13 & 1.5138 & bMB \\
\hline 3 & 7.91 & Nitrate-N & 0.13805 & 0.030 & 0.04 & 0.5027 & BMB \\
\hline 4 & 10.79 & n.a. & 0.19479 & 0.056 & 0.08 & n.a. & BMB \\
\hline 5 & 11.87 & n.a. & 72.927 & 99.72 & n.a. & BMB \\
\hline
\end{tabular}




\section{$16 \mathrm{CCV}=\mathrm{ICWS}-9058$}

\begin{tabular}{|llll|}
\hline Sample Name: & CCV =ICWS-9058 & Injection Volume: & $\mathbf{5 0 . 0}$ \\
Vial Number: & $\mathbf{1 4 7}$ & Channel: & ECD_1 \\
Sample Type: & unknown & Wavelength: & n.a. \\
Control Program: & ANIONS_AS14A & Bandwidth: & n.a. \\
Quantif. Method: & ANIONS & Dilution Factor: & 1.0000 \\
Recording Time: & $\mathbf{1 2 / 1 8 / 2 0 0 6 ~ 1 3 : 3 5}$ & Sample Weight: & 1.0000 \\
Run Time (min): & $\mathbf{1 5 . 0 0}$ & Sample Amount: & $\mathbf{1 . 0 0 0 0}$ \\
\hline
\end{tabular}

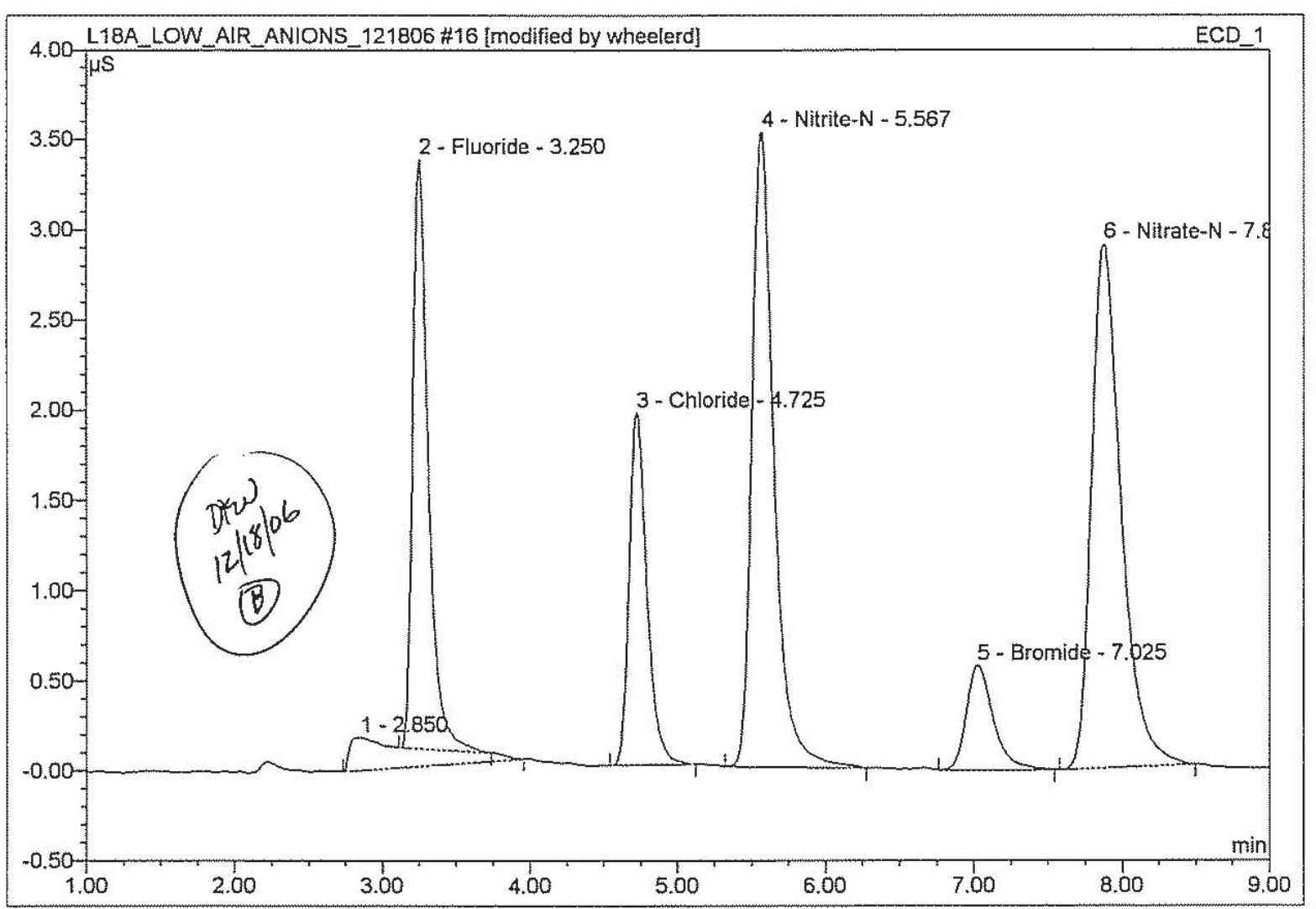

\begin{tabular}{|c|c|c|c|c|c|c|c|}
\hline No. & $\begin{array}{c}\text { Ret.Time } \\
\text { (min.) }\end{array}$ & Peak Name & $\begin{array}{l}\text { Height } \\
\text { (uS) }\end{array}$ & $\begin{array}{c}\text { Area } \\
\mu S^{\star} \min \end{array}$ & $\begin{array}{c}\text { Rel.Area } \\
(\%)\end{array}$ & $\begin{array}{c}\text { Amount } \\
(\mathrm{mg} / \mathrm{L})\end{array}$ & $\begin{array}{l}\text { Peak } \\
\text { Type }\end{array}$ \\
\hline 1 & 2.85 & n.a. & 0.18302 & 0.106 & 4.79 & n.a. & $\mathrm{BMB}^{\star}$ \\
\hline 2 & 3.25 & Fluoride & 3.26791 & 0.404 & 18.23 & 0.9974 & $\mathrm{Rd}^{*}$ \\
\hline 3 & 4.73 & Chloride & 1.95319 & 0.274 & 12.36 & 1.0101 & $B M B$ \\
\hline 4 & 5.57 & Nitrite-N & 3.51969 & 0.608 & 27.45 & 1.0007 & $\mathrm{BMB}$ \\
\hline 5 & 7.03 & Bromide & 0.58477 & 0.123 & 5.55 & 1.0095 & $\mathrm{BMB}$ \\
\hline 6 & 7.88 & Nitrate-N & 2.90661 & 0.677 & 30.56 & 1.0062 & $\mathrm{BMB}$ \\
\hline 7 & 12.05 & n.a. & 0.07024 & 0.023 & 1.05 & n.a. & $\mathrm{BMB}$ \\
\hline
\end{tabular}




\section{$16 \mathrm{CCV}=\mathrm{ICWS}-9058$}

\begin{tabular}{llll}
\hline Sample Name: & CCV = ICWS-9058 & Injection Volume: & $\mathbf{5 0 . 0}$ \\
Vial Number: & 147 & Channel: & ECD_1 \\
Sample Type: & unknown & Wavelength: & n.a. \\
Control Program: & ANIONS_AS14A & Bandwidth: & n.a. \\
Quantif. Method: & ANIONS & Dilution Factor: & 1.0000 \\
Recording Time: & $12 / 18 / 200613: 35$ & Sample Weight: & 1.0000 \\
Run Time (min): & 15.00 & Sample Amount: & 1.0000 \\
\hline
\end{tabular}

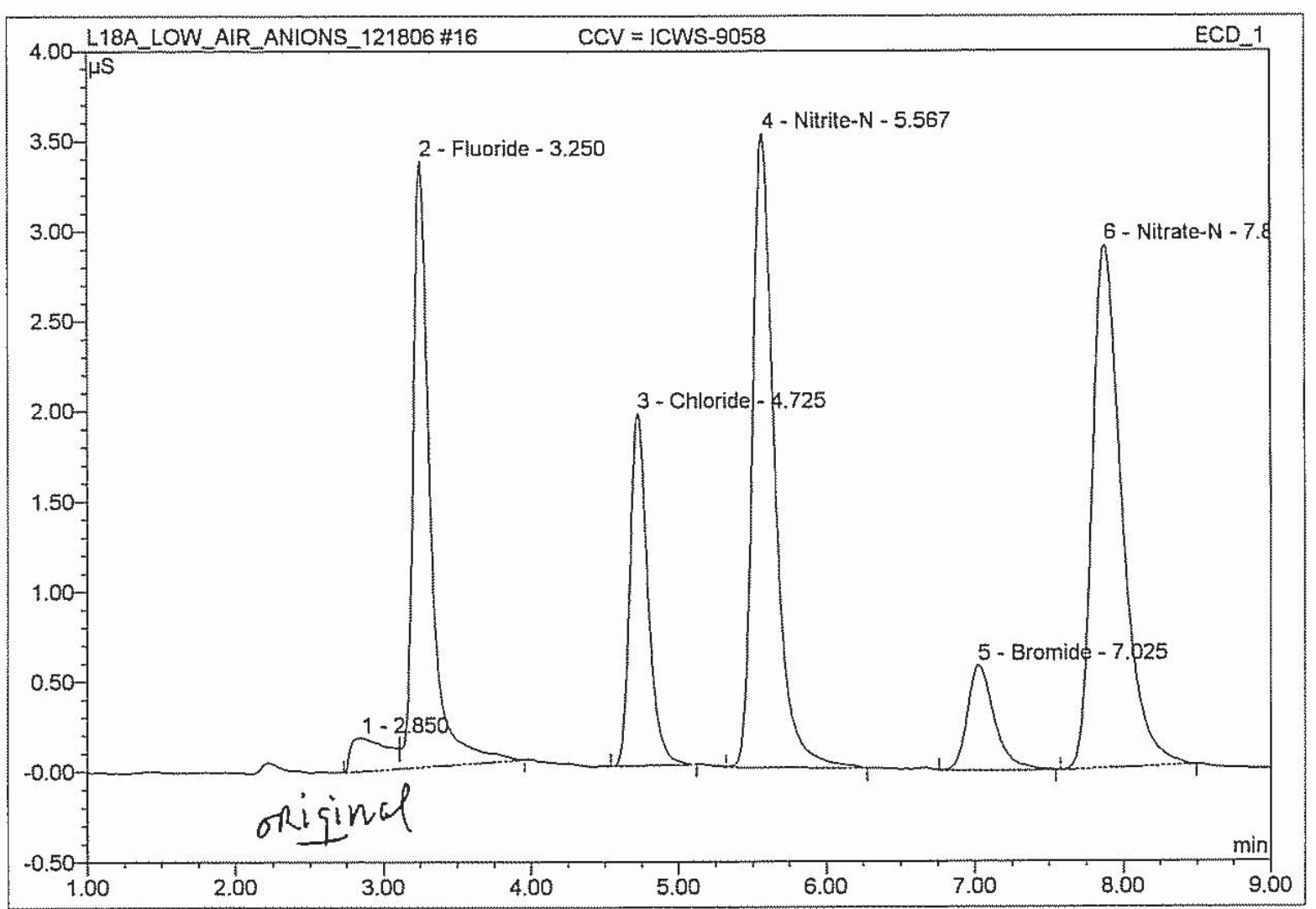

\begin{tabular}{|c|c|l|r|r|r|r|c|}
\hline No. & $\begin{array}{c}\text { Ret.Time } \\
\text { (min.) }\end{array}$ & \multicolumn{1}{|c|}{ Peak Name } & $\begin{array}{c}\text { Height } \\
\text { (uS) }\end{array}$ & $\begin{array}{c}\text { Area } \\
\mu S^{\star} \text { min }\end{array}$ & $\begin{array}{c}\text { Rel.Area } \\
(\%)\end{array}$ & $\begin{array}{c}\text { Amount } \\
\text { (mg/L) }\end{array}$ & $\begin{array}{r}\text { Peak } \\
\text { Type }\end{array}$ \\
\hline 1 & 2.85 & n.a. & 0.18302 & 0.052 & 2.35 & n.a. & BM \\
\hline 2 & 3.25 & Fluoride & 3.36406 & 0.458 & 20.68 & 1.0254 & MB \\
\hline 3 & 4.73 & Chloride & 1.95319 & 0.274 & 12.36 & 1.0101 & BMB \\
\hline 4 & 5.57 & Nitrite-N & 3.51969 & 0.608 & 27.45 & 1.0007 & BMB \\
\hline 5 & 7.03 & Bromide & 0.58477 & 0.123 & 5.55 & 1.0095 & BMB \\
\hline 6 & 7.88 & Nitrate-N & 2.90661 & 0.677 & 30.56 & 1.0062 & BMB \\
\hline 7 & 12.05 & n.a. & 0.07024 & 0.023 & 1.05 & n.a. & BMB \\
\hline
\end{tabular}




\section{CCB}

\begin{tabular}{llll|}
\hline Sample Name: & CCB & Injection Volume: & $\mathbf{5 0 . 0}$ \\
Vial Number: & $\mathbf{1 4 8}$ & Channel: & ECD_1 \\
Sample Type: & unknown & Wavelength: & n.a. \\
Control Program: & ANIONS_AS14A & Bandwidth: & n.a. \\
Quantif. Method: & ANIONS & Dilution Factor: & 1.0000 \\
Recording Time: & $\mathbf{1 2 / 1 8 / 2 0 0 6 1 3 : 5 3}$ & Sample Weight: & $\mathbf{1 . 0 0 0 0}$ \\
Run Time (min): & $\mathbf{1 5 . 0 0}$ & Sample Amount: & $\mathbf{1 . 0 0 0 0}$ \\
\hline
\end{tabular}

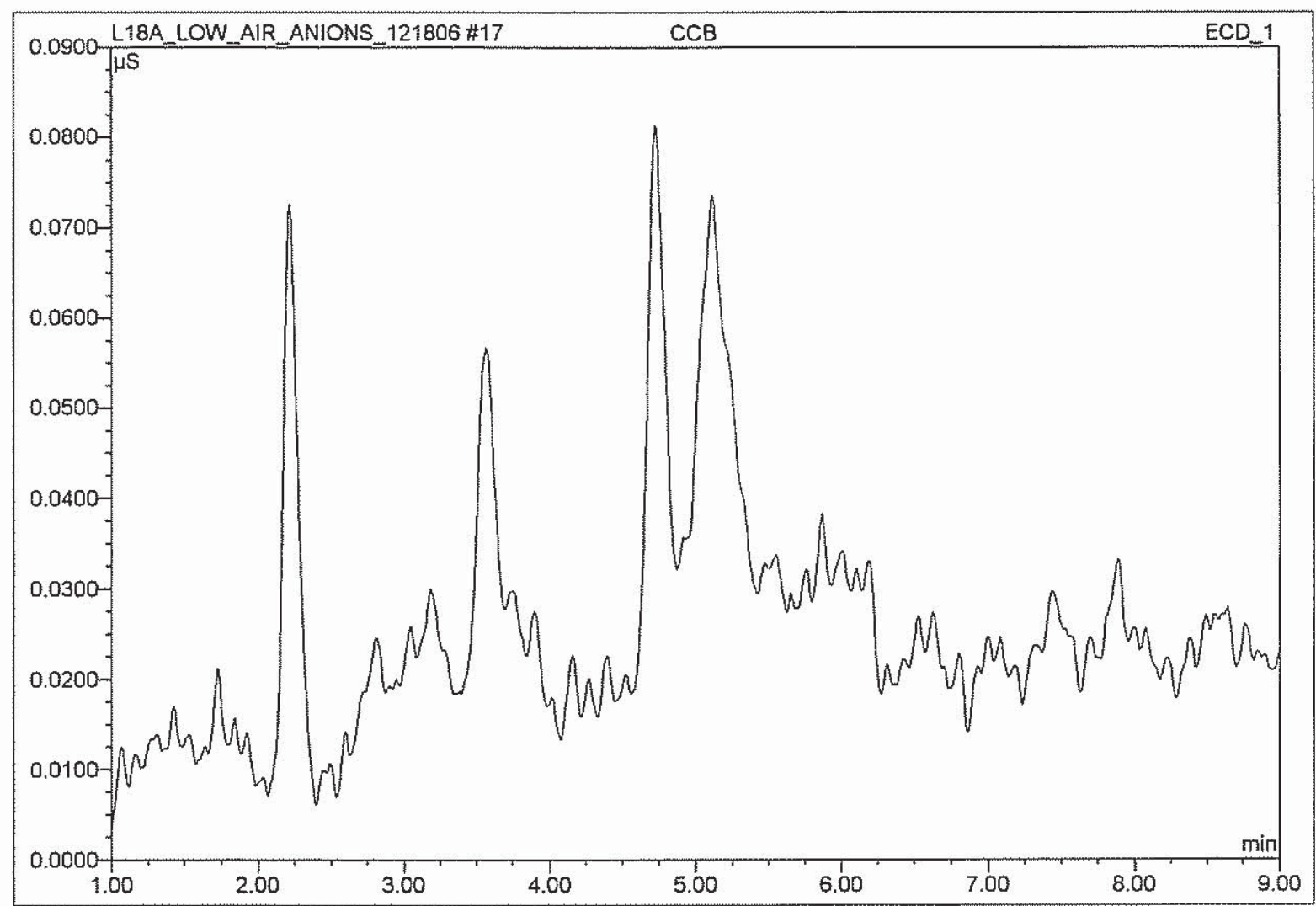

\begin{tabular}{|c|c|c|c|c|c|c|c|}
\hline No. & $\begin{array}{c}\text { Ret.Time } \\
(\mathrm{min} .)\end{array}$ & Peak Name & $\begin{array}{c}\text { Height } \\
(\mathrm{uS})\end{array}$ & $\begin{array}{c}\text { Area } \\
\mu \mathrm{S}^{*} \mathrm{~min}\end{array}$ & $\begin{array}{c}\text { Rel.Area } \\
(\%)\end{array}$ & $\begin{array}{c}\text { Amount } \\
(\mathrm{mg} / \mathrm{L})\end{array}$ & $\begin{array}{c}\text { Peak } \\
\text { Type }\end{array}$ \\
\hline
\end{tabular}

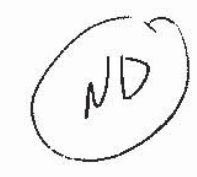




\section{H6L110106-JK7J7-1/10-MS}

\begin{tabular}{ll}
\hline Sample Name: & H6L110106-JK7J7-1/10-MS \\
Vial Number: & 149 \\
Sample Type: & unknown \\
Control Program: & ANIONS_AS14A \\
Quantif. Method: & ANIONS \\
Recording Time: & $12 / 18 / 200614: 10$ \\
Run Time (min): & 15.00
\end{tabular}

$\begin{array}{ll}\text { Injection Volume: } & \mathbf{5 0 . 0} \\ \text { Channel: } & \text { ECD_1 } \\ \text { Wavelength: } & \text { n.a. } \\ \text { Bandwidth: } & \text { n.a. } \\ \text { Dilution Factor: } & \mathbf{1 0 . 0 0 0 0} \\ \text { Sample Weight: } & \mathbf{1 . 0 0 0 0} \\ \text { Sample Amount: } & \mathbf{1 . 0 0 0 0}\end{array}$

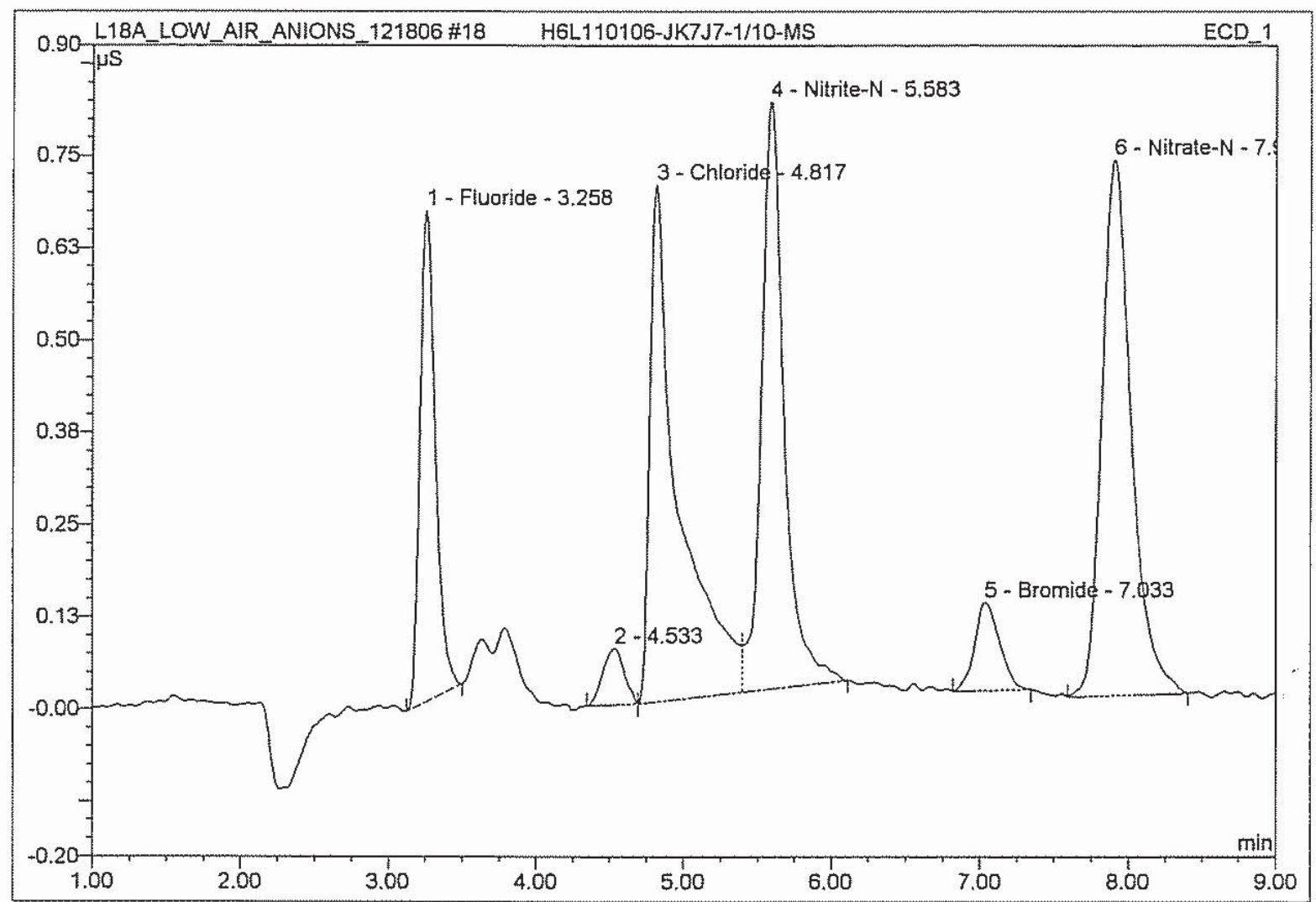

\begin{tabular}{|c|c|l|r|r|r|r|c|}
\hline No. & $\begin{array}{c}\text { Ret.Time } \\
\text { (min.) }\end{array}$ & \multicolumn{1}{|c|}{ Peak Name } & $\begin{array}{c}\text { Height } \\
\text { (uS) }\end{array}$ & $\begin{array}{c}\text { Area } \\
\mu S^{*} \text { min }\end{array}$ & $\begin{array}{r}\text { Rel.Area } \\
(\%)\end{array}$ & $\begin{array}{r}\text { Amount } \\
(\mathrm{mg} / \mathrm{L})\end{array}$ & $\begin{array}{r}\text { Peak } \\
\text { Type }\end{array}$ \\
\hline 1 & 3.26 & Fluoride & 0.66476 & 0.081 & 0.11 & 2.1079 & BMB \\
\hline 2 & 4.53 & n.a. & 0.07663 & 0.013 & 0.02 & n.a. & BMb \\
\hline 3 & 4.82 & Chloride & 0.70076 & 0.158 & 0.21 & 3.7046 & bM \\
\hline 4 & 5.58 & Nitrite-N & 0.79567 & 0.143 & 0.19 & 2.3336 & MB \\
\hline 5 & 7.03 & Bromide & 0.11918 & 0.023 & 0.03 & 2.0871 & BMB \\
\hline 6 & 7.90 & Nitrate-N & 0.72528 & 0.168 & 0.23 & 2.6111 & BMB \\
\hline 7 & 10.77 & n.a. & 0.15082 & 0.045 & 0.06 & n.a. & BMB \\
\hline 8 & 11.86 & n.a. & 73.413 & 99.15 & n.a. & BMB \\
\hline
\end{tabular}




\section{H6L110106-JK7J7-1/10-MSD}

\begin{tabular}{llll|}
\hline Sample Name: & H6L110106-JK7J7-1/10-MSD & Injection Volume: & $\mathbf{5 0 . 0}$ \\
Vial Number: & $\mathbf{1 5 0}$ & Channel: & ECD_1 \\
Sample Type: & unknown & Wavelength: & n.a. \\
Control Program: & ANIONS_AS14A & Bandwidth: & n.a. \\
Quantif. Method: & ANIONS & Dilution Factor: & $\mathbf{1 0 . 0 0 0 0}$ \\
Recording Time: & $\mathbf{1 2 / 1 8 / 2 0 0 6 1 4 : 2 8}$ & Sample Weight: & $\mathbf{1 . 0 0 0 0}$ \\
Run Time (min): & $\mathbf{1 5 . 0 0}$ & Sample Amount: & $\mathbf{1 . 0 0 0 0}$ \\
\hline
\end{tabular}

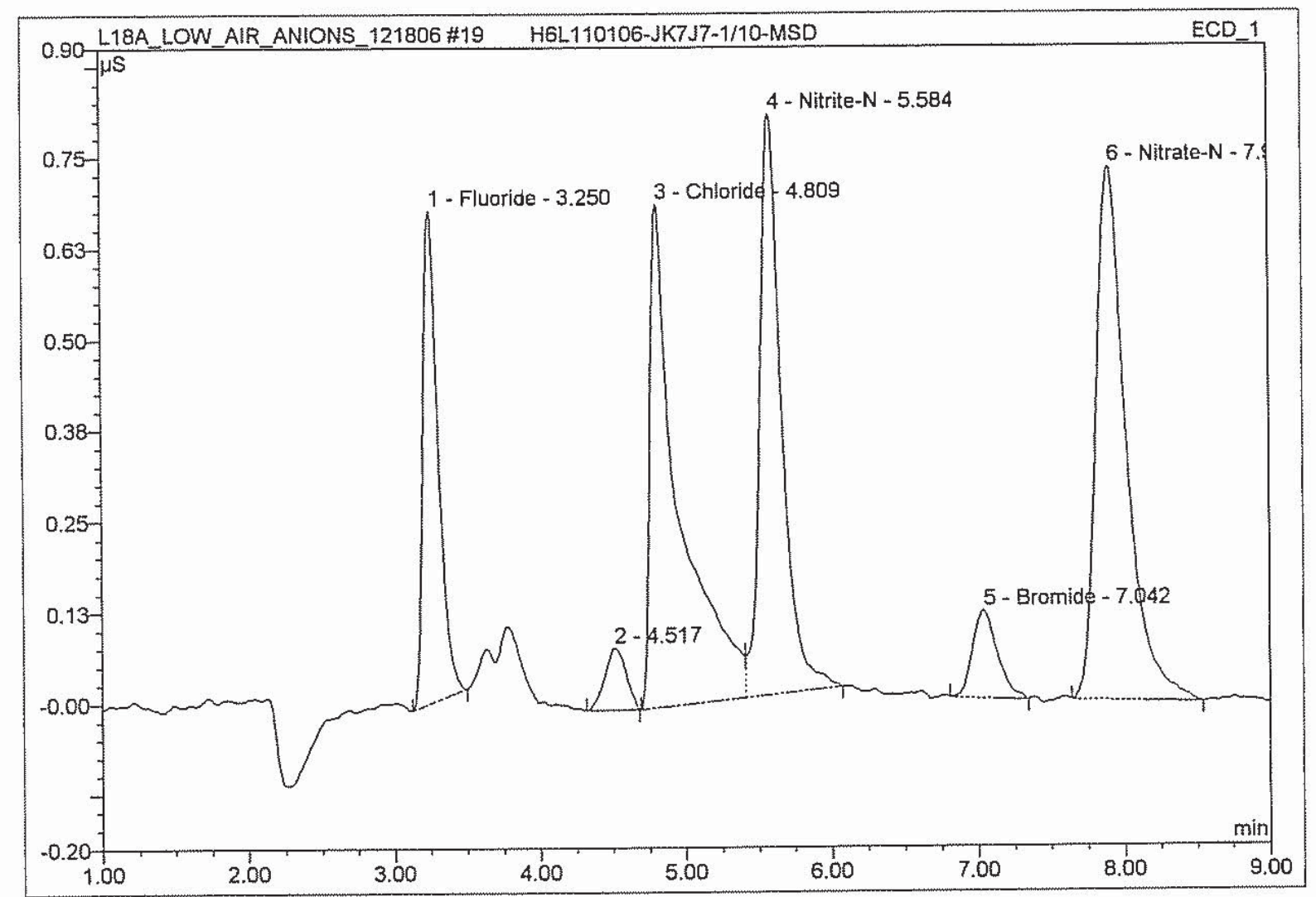

\begin{tabular}{|r|c|l|r|r|r|r|c|}
\hline No. & $\begin{array}{c}\text { Ret.Time } \\
\text { (min.) }\end{array}$ & \multicolumn{1}{|c|}{ Peak Name } & $\begin{array}{c}\text { Height } \\
\text { (uS) }\end{array}$ & $\begin{array}{c}\text { Area } \\
\mu S^{*} \min \end{array}$ & $\begin{array}{r}\text { Rel.Area } \\
(\%)\end{array}$ & $\begin{array}{r}\text { Amount } \\
(\mathrm{mg} / \mathrm{L})\end{array}$ & $\begin{array}{r}\text { Peak } \\
\text { Type }\end{array}$ \\
\hline 1 & 3.25 & Fluoride & 0.67613 & 0.083 & 0.11 & 2.1436 & BMB \\
\hline 2 & 4.52 & n.a. & 0.08511 & 0.014 & 0.02 & n.a. & BMB \\
\hline 3 & 4.81 & Chloride & 0.69145 & 0.160 & 0.22 & 3.6560 & BM \\
\hline 4 & 5.58 & Nitrite-N & 0.79716 & 0.139 & 0.19 & 2.3380 & MB \\
\hline 5 & 7.04 & Bromide & 0.12001 & 0.023 & 0.03 & 2.1017 & BMB \\
\hline 6 & 7.90 & Nitrate-N & 0.73241 & 0.175 & 0.24 & 2.6364 & BMB \\
\hline 7 & 10.79 & n.a. & 0.13646 & 0.039 & 0.05 & n.a. & BMB \\
\hline 8 & 11.86 & n.a. & 73.451 & 99.15 & n.a. & BMB \\
\hline
\end{tabular}




\section{H6L110106-JK7KG-1/10}

\begin{tabular}{|llll|}
\hline Sample Name: & H6L110106-JK7KG-1/10 & Injection Volume: & $\mathbf{5 0 . 0}$ \\
Vial Number: & $\mathbf{1 5 3}$ & Channel: & ECD_1 \\
Sample Type: & unknown & Wavelength: & n.a. \\
Control Program: & ANIONS_AS14A & Bandwidth: & n.a. \\
Quantif. Method: & ANIONS & Dilution Factor: & 10.0000 \\
Recording Time: & $\mathbf{1 2 / 1 8 / 2 0 0 6 ~ 1 5 : 2 1}$ & Sample Weight: & $\mathbf{1 . 0 0 0 0}$ \\
Run Time (min): & $\mathbf{1 5 . 0 0}$ & Sample Amount: & $\mathbf{1 . 0 0 0 0}$ \\
\hline
\end{tabular}

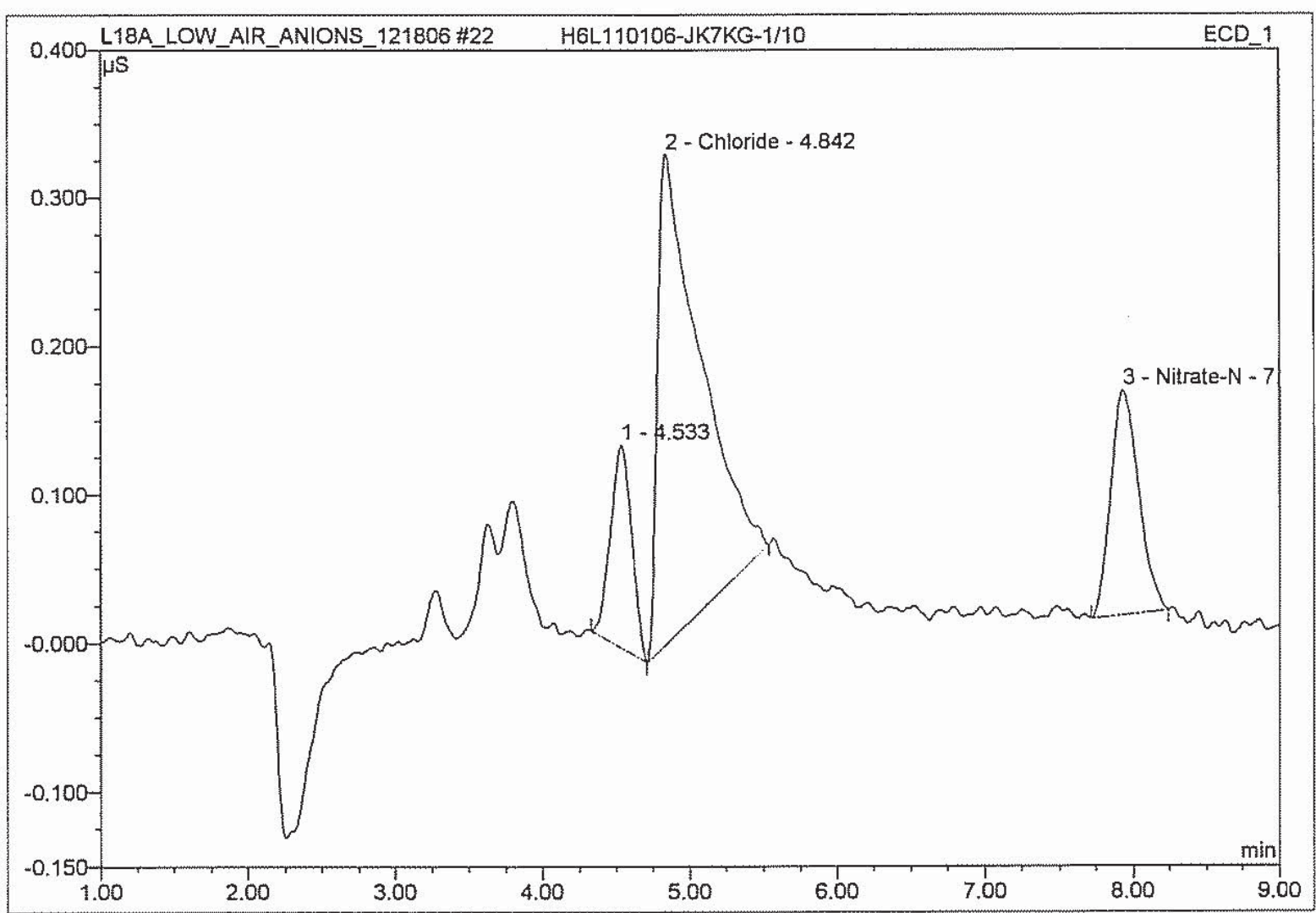

\begin{tabular}{|c|c|l|r|r|r|r|r|}
\hline No. & $\begin{array}{c}\text { Ret.Time } \\
\text { (min.) }\end{array}$ & \multicolumn{1}{|c|}{ Peak Name } & $\begin{array}{c}\text { Height } \\
\text { (uS) }\end{array}$ & $\begin{array}{c}\text { Area } \\
\text { us*min }\end{array}$ & $\begin{array}{r}\text { Rel.Area } \\
(\%)\end{array}$ & $\begin{array}{c}\text { Amount } \\
\text { (mg/L) }\end{array}$ & $\begin{array}{r}\text { Peak } \\
\text { Type }\end{array}$ \\
\hline 1 & 4.53 & n.a. & 0.13641 & 0.023 & 0.03 & n.a. & BMB \\
\hline 2 & 4.84 & Chloride & 0.32998 & 0.111 & 0.14 & 1.7564 & BMB \\
\hline 3 & 7.93 & Nitrate-N & 0.15141 & 0.033 & 0.04 & 0.5512 & BMB \\
\hline 4 & 10.79 & n.a. & 1.62974 & 0.480 & 0.62 & n.a. & BMB \\
\hline 5 & 11.86 & n.a. & 76.555 & 99.16 & n.a. & bMB \\
\hline
\end{tabular}

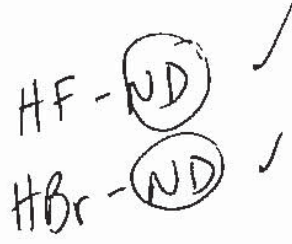


$6 \mathrm{en}$ dontor

\section{H6L110105-JK7KT-1/10}

\begin{tabular}{ll}
\hline Sample Name: & H6L110105-JK7KT-1/10 \\
Vial Number: & 161 \\
Sample Type: & unknown \\
Control Program: & ANIONS_AS14A \\
Quantif. Method: & ANIONS \\
Recording Time: & $\mathbf{1 2 / 1 8 / 2 0 0 6 1 5 : 3 9}$ \\
Run Time (min): & $\mathbf{1 5 . 0 0}$
\end{tabular}

$\begin{array}{ll}\text { Injection Volume: } & \mathbf{5 0 . 0} \\ \text { Channel: } & \text { ECD_1 } \\ \text { Wavelength: } & \text { n.a. } \\ \text { Bandwidth: } & \text { n.a. } \\ \text { Dilution Factor: } & \mathbf{1 0 . 0 0 0 0} \\ \text { Sample Weight: } & \mathbf{1 . 0 0 0 0} \\ \text { Sample Amount: } & \mathbf{1 . 0 0 0 0}\end{array}$

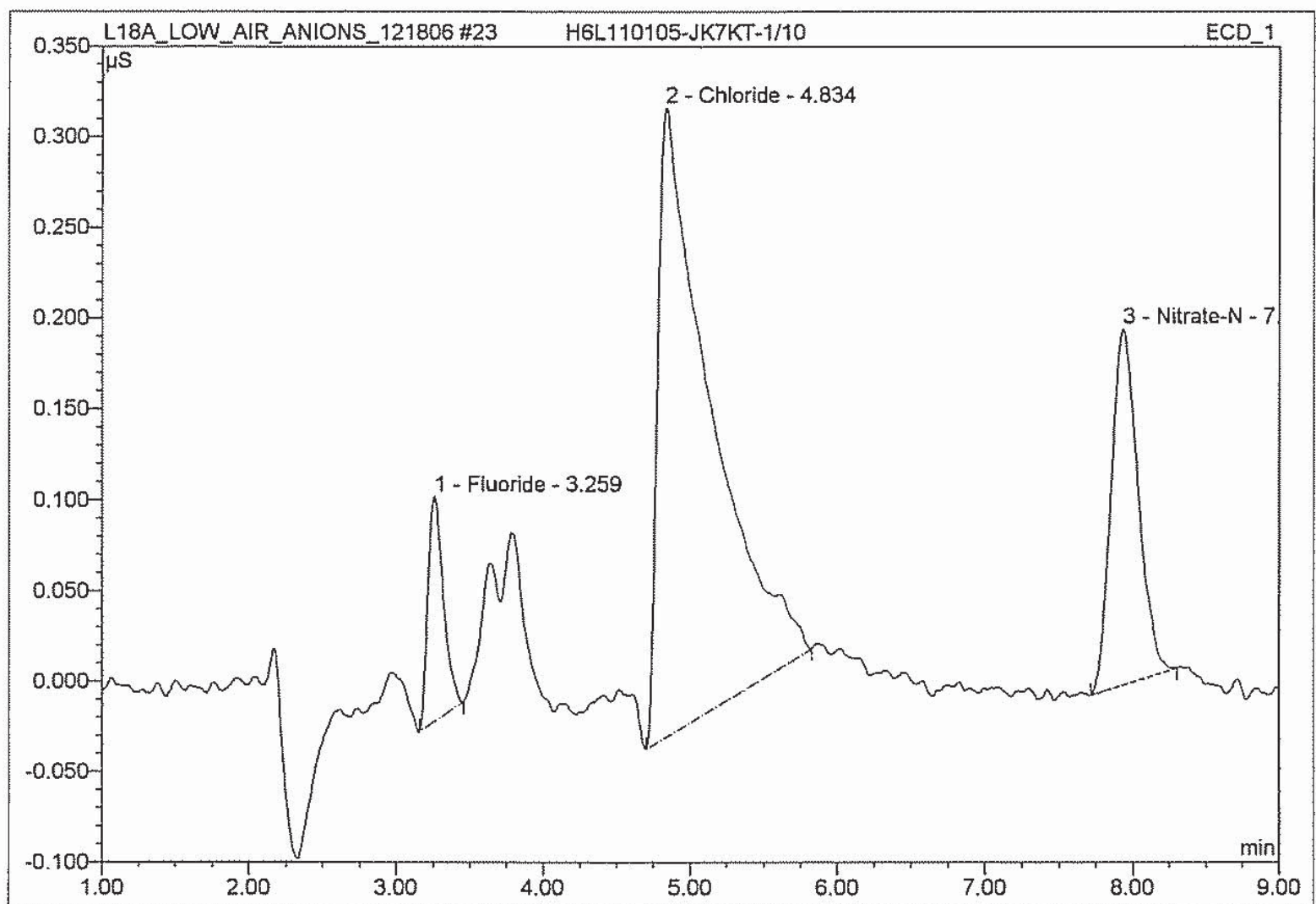

\begin{tabular}{|c|c|l|r|r|r|r|c|}
\hline No. & $\begin{array}{c}\text { Ret.Time } \\
\text { (min.) }\end{array}$ & \multicolumn{1}{|c|}{ Peak Name } & $\begin{array}{c}\text { Height } \\
\text { (uS) }\end{array}$ & $\begin{array}{c}\text { Area } \\
\mu S^{\star} \min \end{array}$ & $\begin{array}{r}\text { Rel.Area } \\
(\%)\end{array}$ & $\begin{array}{c}\text { Amount } \\
(\mathrm{mg} / \mathrm{L})\end{array}$ & $\begin{array}{r}\text { Peak } \\
\text { Type }\end{array}$ \\
\hline 1 & 3.26 & Fluoride & 0.12412 & 0.015 & 0.02 & 0.3969 & BMB \\
\hline 2 & 4.83 & Chloride & 0.34716 & 0.144 & 0.17 & 1.8472 & BMB \\
\hline 3 & 7.93 & Nitrate-N & 0.19611 & 0.042 & 0.05 & 0.7133 & BMB \\
\hline 4 & 10.19 & n.a. & 0.06112 & 0.018 & 0.02 & n.a. & BMB \\
\hline 5 & 11.83 & n.a. & 86.331 & 99.75 & n.a. & BMB \\
\hline
\end{tabular}

$H B r-N D$ 


\section{H6L110106-JK7K0-1/10}

\begin{tabular}{|llll|}
\hline Sample Name: & H6L110106-JKTK0-1/10 & Injection Volume: & $\mathbf{5 0 . 0}$ \\
Vial Number: & $\mathbf{1 6 2}$ & Channel: & ECD_1 \\
Sample Type: & unknown & Wavelength: & n.a. \\
Control Program: & ANIONS_AS14A & Bandwidth: & n.a. \\
Quantif. Method: & ANIONS & Dilution Factor: & $\mathbf{1 0 . 0 0 0 0}$ \\
Recording Time: & $\mathbf{1 2 / 1 8 / 2 0 0 6 ~ 1 5 : 5 6}$ & Sample Weight: & $\mathbf{1 . 0 0 0 0}$ \\
Run Time (min): & $\mathbf{1 5 . 0 0}$ & Sample Amount: & $\mathbf{1 . 0 0 0 0}$ \\
\hline
\end{tabular}

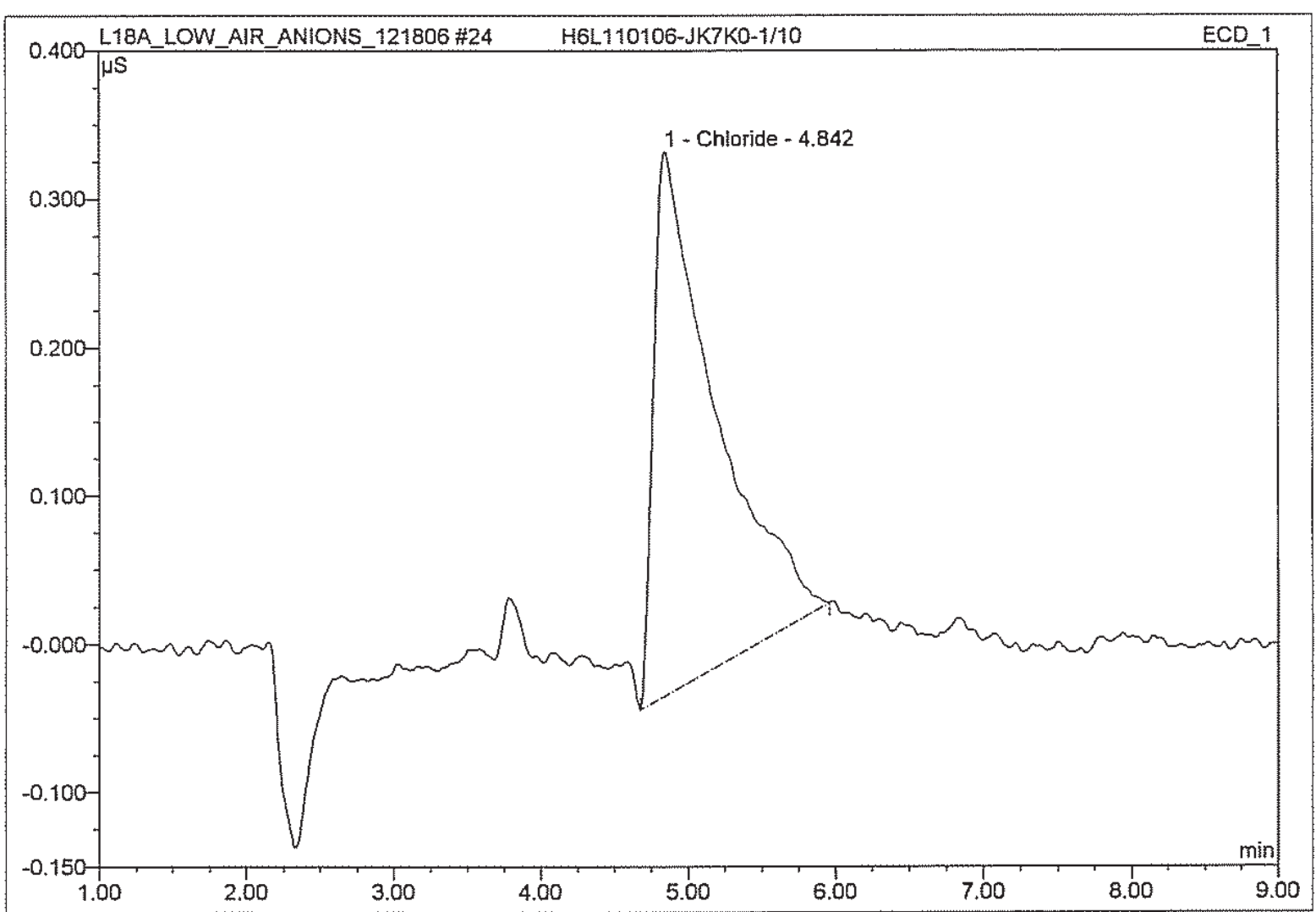

\begin{tabular}{|c|c|l|r|r|r|r|r|}
\hline No. & $\begin{array}{c}\text { Ret.Time } \\
(\mathrm{min} \text { ) }\end{array}$ & \multicolumn{1}{|c|}{ Peak Name } & $\begin{array}{c}\text { Height } \\
\text { (uS) }\end{array}$ & $\begin{array}{c}\text { Area } \\
\mu \mathrm{S}^{\star} \mathrm{min}\end{array}$ & $\begin{array}{c}\text { Rel.Area } \\
(\%)\end{array}$ & $\begin{array}{c}\text { Amount } \\
(\mathrm{mg} / \mathrm{L})\end{array}$ & $\begin{array}{r}\text { Peak } \\
\text { Type }\end{array}$ \\
\hline 1 & 4.84 & Chloride & 0.36692 & 0.177 & 0.16 & 1.9517 & BMB \\
\hline 2 & 11.78 & n.a. & 112.940 & 99.84 & n.a. & BMB \\
\hline
\end{tabular}

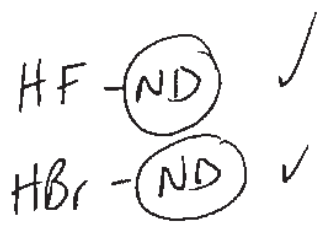




\section{H6L110106-JK7K0-1/10-MS}

$\begin{array}{ll}\text { Sample Name: } & \text { H6L110106-JK7K0-1/10-MS } \\ \text { Vial Number: } & 163 \\ \text { Sample Type: } & \text { unknown } \\ \text { Control Program: } & \text { ANIONS_AS14A } \\ \text { Quantif. Method: } & \text { ANIONS } \\ \text { Recording Time: } & 12 / 18 / 200616: 14 \\ \text { Run Time (min): } & 15.00\end{array}$

$\begin{array}{ll}\text { Injection Volume: } & \mathbf{5 0 . 0} \\ \text { Channel: } & \text { ECD_1 } \\ \text { Wavelength: } & \text { n.a. } \\ \text { Bandwidth: } & \text { n.a. } \\ \text { Dilution Factor: } & \mathbf{1 0 . 0 0 0 0} \\ \text { Sample Weight: } & \mathbf{1 . 0 0 0 0} \\ \text { Sample Amount: } & \mathbf{1 . 0 0 0 0}\end{array}$

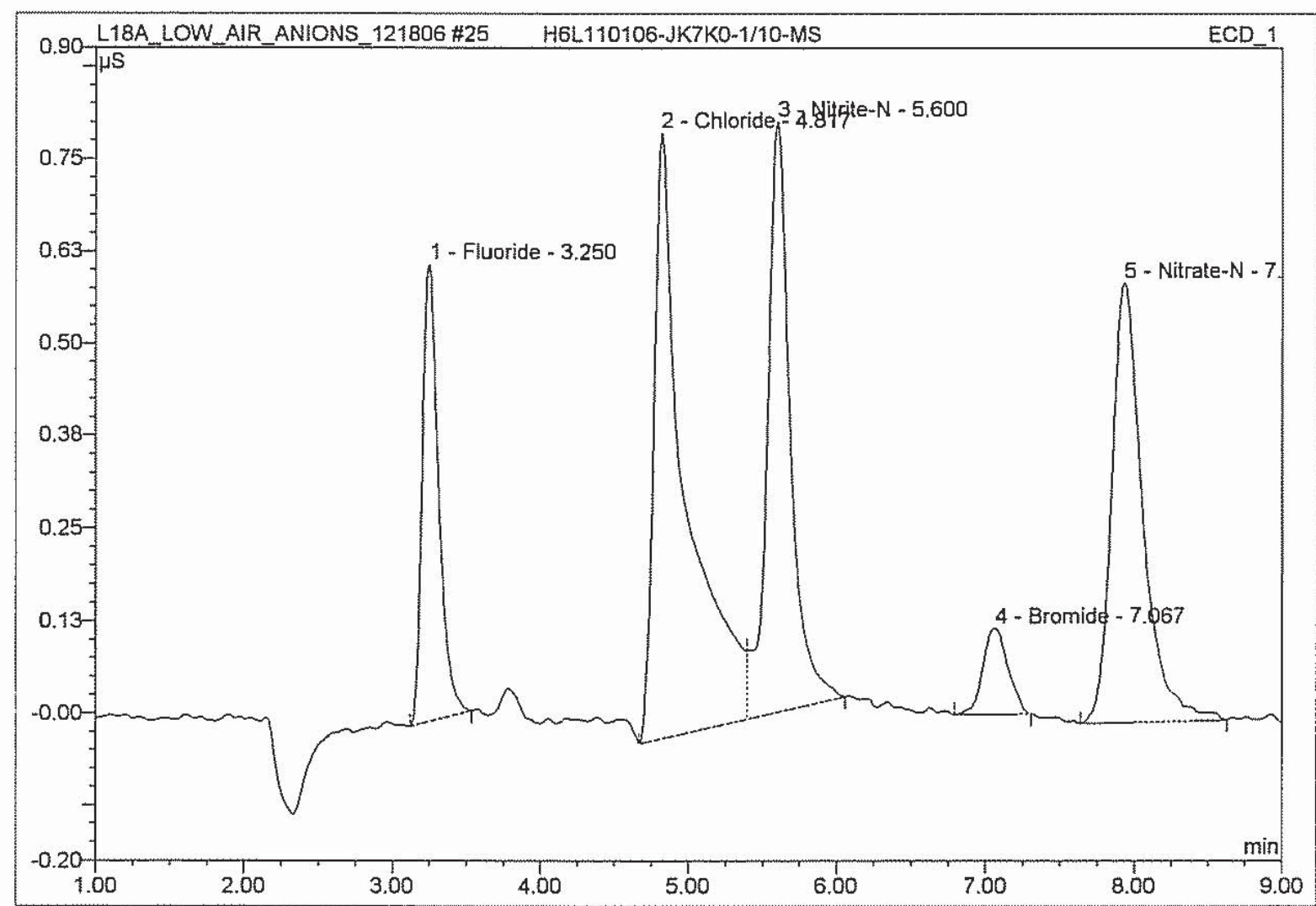

\begin{tabular}{|c|c|l|r|r|r|r|c|}
\hline No. & $\begin{array}{c}\text { Ret.Time } \\
\text { (min.) }\end{array}$ & \multicolumn{1}{|c|}{ Peak Name } & $\begin{array}{c}\text { Height } \\
\text { (uS) }\end{array}$ & $\begin{array}{c}\text { Area } \\
\mu S^{*} \min \end{array}$ & $\begin{array}{c}\text { Rel.Area } \\
(\%)\end{array}$ & $\begin{array}{c}\text { Amount } \\
\text { (mg/L) }\end{array}$ & $\begin{array}{c}\text { Peak } \\
\text { Type }\end{array}$ \\
\hline 1 & 3.25 & Fluoride & 0.61755 & 0.080 & 0.07 & 1.9596 & BMB \\
\hline 2 & 4.82 & Chloride & 0.81881 & 0.204 & 0.18 & 4.3195 & BM \\
\hline 3 & 5.60 & Nitrite-N & 0.79855 & 0.145 & 0.13 & 2.3420 & MB \\
\hline 4 & 7.07 & Bromide & 0.11681 & 0.023 & 0.02 & 2.0459 & BMB \\
\hline 5 & 7.93 & Nitrate-N & 0.59481 & 0.145 & 0.13 & 2.1467 & BMB \\
\hline 6 & 11.78 & n.a. & 113.040 & 99.47 & n.a. & BMB \\
\hline
\end{tabular}




\section{H6L110106-JK7K4-1/10}

\begin{tabular}{ll}
\hline Sample Name: & H6L110106-JK7K4-1/10 \\
Vial Number: & 164 \\
Sample Type: & unknown \\
Control Program: & ANIONS_AS14A \\
Quantif. Method: & ANIONS \\
Recording Time: & $12 / 18 / 200616: 31$ \\
Run Time (min): & 15.00
\end{tabular}

$\begin{array}{ll}\text { Injection Volume: } & \mathbf{5 0 . 0} \\ \text { Channel: } & \text { ECD_1 } \\ \text { Wavelength: } & \text { n.a. } \\ \text { Bandwidth: } & \text { n.a. } \\ \text { Dilution Factor: } & \mathbf{1 0 . 0 0 0 0} \\ \text { Sample Weight: } & \mathbf{1 . 0 0 0 0} \\ \text { Sample Amount: } & \mathbf{1 . 0 0 0 0}\end{array}$

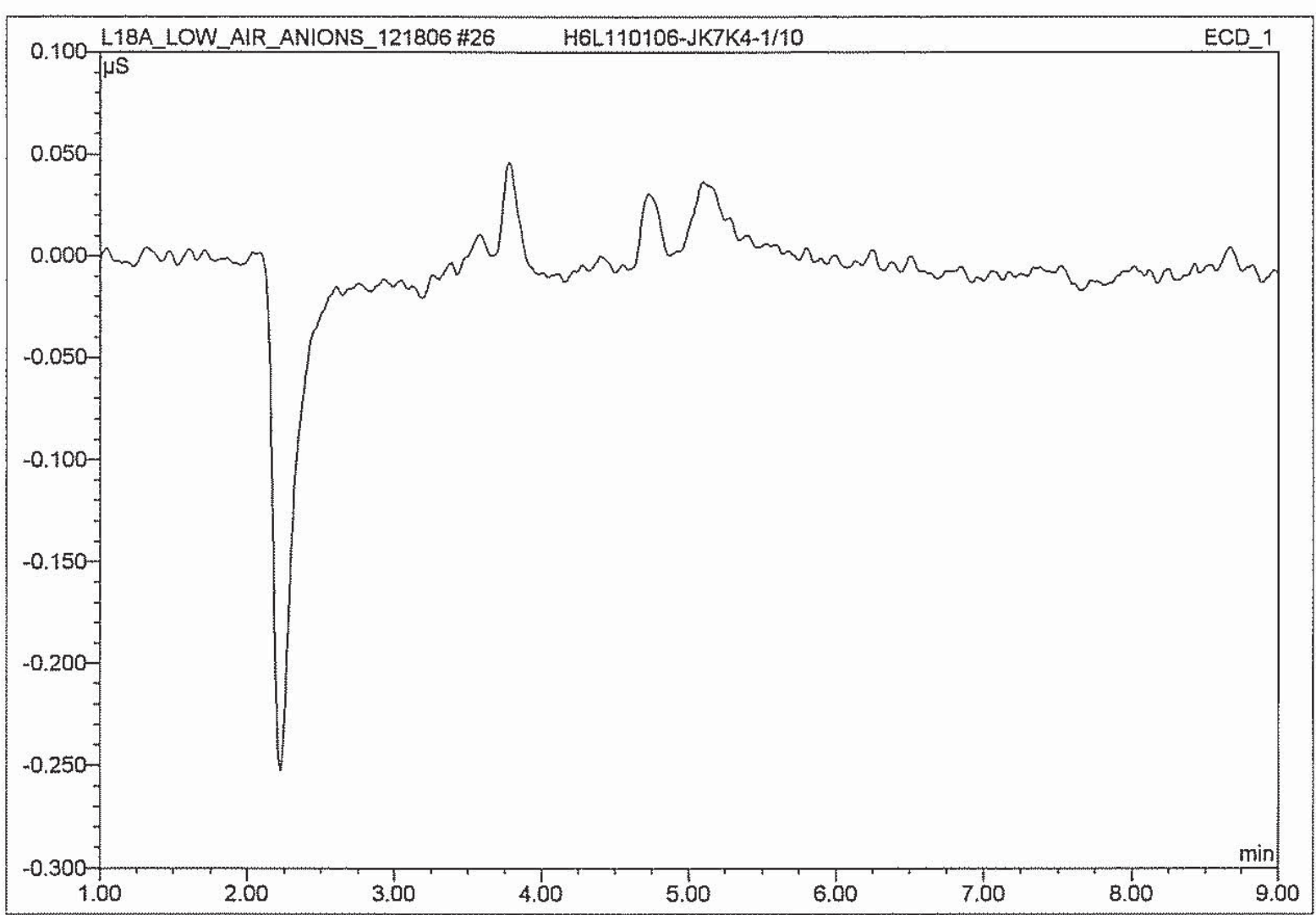

\begin{tabular}{|c|c|c|c|c|c|c|c|}
\hline No. & $\begin{array}{c}\text { Ret.Time } \\
\text { (min.) }\end{array}$ & Peak Name & $\begin{array}{c}\text { Height } \\
(\mathrm{uS})\end{array}$ & $\begin{array}{c}\text { Area } \\
\mu \mathrm{S}^{*} \mathrm{~min}\end{array}$ & $\begin{array}{c}\text { Rel.Area } \\
(\%)\end{array}$ & $\begin{array}{c}\text { Amount } \\
(\mathrm{mg} / \mathrm{L})\end{array}$ & $\begin{array}{c}\text { Peak } \\
\text { Type }\end{array}$ \\
\hline 1 & 12.08 & n.a. & 0.16774 & 0.068 & 100.00 & n.a. & BMB \\
\hline
\end{tabular}

\section{All (ND)}




\section{H6L110106-JK7K4-1/10-MS}

\begin{tabular}{llll|}
\hline Sample Name: & H6L110106-JK7K4-1/10-MS & Injection Volume: & $\mathbf{5 0 . 0}$ \\
Vial Number: & $\mathbf{1 6 5}$ & Channel: & ECD_1 \\
Sample Type: & unknown & Wavelength: & n.a. \\
Control Program: & ANIONS_AS14A & Bandwidth: & n.a. \\
Quantif. Method: & ANIONS & Dilution Factor: & $\mathbf{1 0 . 0 0 0 0}$ \\
Recording Time: & $\mathbf{1 2 / 1 8 / 2 0 0 6 ~ 1 6 : 4 9}$ & Sample Weight: & $\mathbf{1 . 0 0 0 0}$ \\
Run Time (min): & $\mathbf{1 5 . 0 0}$ & Sample Amount: & $\mathbf{1 . 0 0 0 0}$ \\
\hline
\end{tabular}

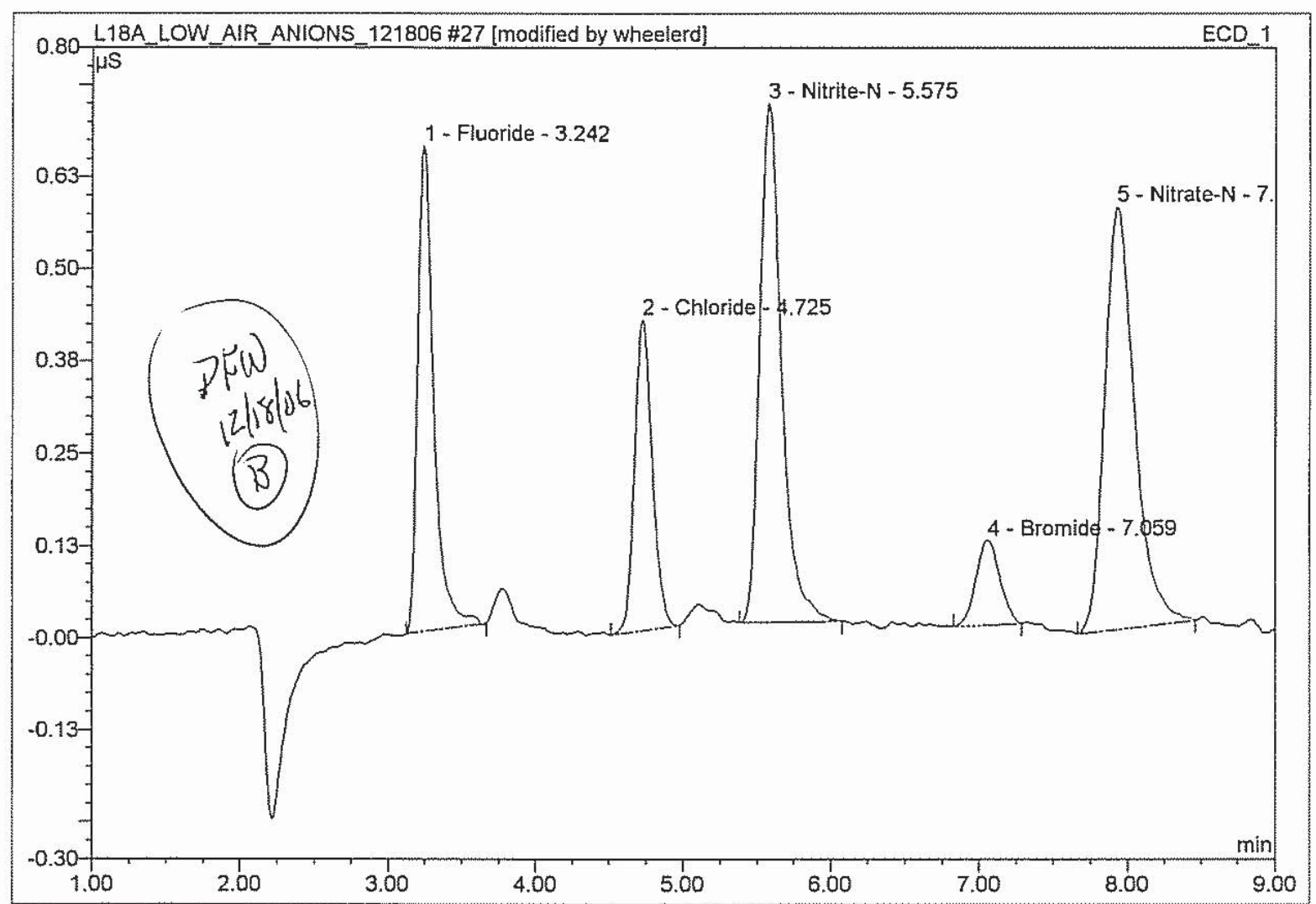

\begin{tabular}{|c|c|l|r|r|r|r|c|}
\hline No. & $\begin{array}{c}\text { Ret.Time } \\
\text { (min.) }\end{array}$ & \multicolumn{1}{|c|}{ Peak Name } & $\begin{array}{c}\text { Height } \\
\text { (uS) }\end{array}$ & $\begin{array}{c}\text { Area } \\
\mu S^{*} \min \end{array}$ & $\begin{array}{r}\text { Rel.Area } \\
(\%)\end{array}$ & $\begin{array}{c}\text { Amount } \\
\text { (mg/L) }\end{array}$ & $\begin{array}{c}\text { Peak } \\
\text { Type }\end{array}$ \\
\hline 1 & 3.24 & Fluoride & 0.65758 & 0.084 & 18.29 & 2.0853 & BMB $^{*}$ \\
\hline 2 & 4.73 & Chloride & 0.42054 & 0.058 & 12.74 & 2.2346 & BMB $^{*}$ \\
\hline 3 & 5.58 & Nitrite-N & 0.70290 & 0.121 & 26.39 & 2.0638 & BMB \\
\hline 4 & 7.06 & Bromide & 0.11409 & 0.021 & 4.66 & 1.9983 & BMB \\
\hline 5 & 7.93 & Nitrate-N & 0.57178 & 0.135 & 29.45 & 2.0645 & BMB \\
\hline 6 & 12.08 & n.a. & 0.08212 & 0.039 & 8.47 & n.a. & BMB \\
\hline
\end{tabular}




\section{H6L110106-JK7K4-1/10-MS}

\begin{tabular}{|llll|}
\hline Sample Name: & H6L110106-JK7K4-1/10-MS & Injection Volume: & $\mathbf{5 0 . 0}$ \\
Vial Number: & $\mathbf{1 6 5}$ & Channel: & ECD_1 \\
Sample Type: & unknown & Wavelength: & n.a. \\
Control Program: & ANIONS_AS14A & Bandwidth: & n.a. \\
Quantif. Method: & ANIONS & Dilution Factor: & $\mathbf{1 0 . 0 0 0 0}$ \\
Recording Time: & $\mathbf{1 2 / 1 8 / 2 0 0 6 ~ 1 6 : 4 9}$ & Sample Weight: & $\mathbf{1 . 0 0 0 0}$ \\
Run Time (min): & $\mathbf{1 5 . 0 0}$ & Sample Amount: & $\mathbf{1 . 0 0 0 0}$ \\
\hline
\end{tabular}

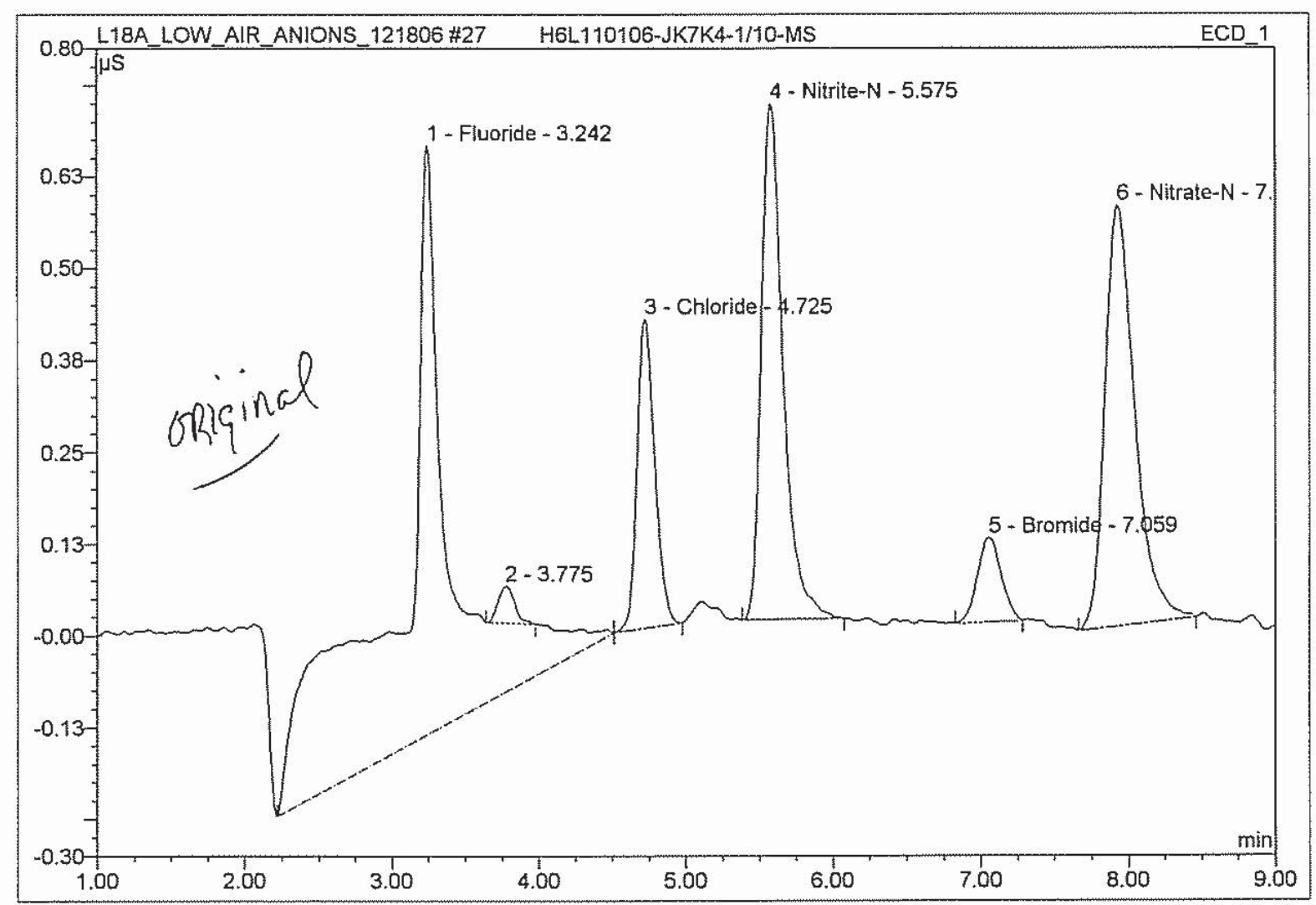

\begin{tabular}{|r|c|l|r|r|r|r|c|}
\hline No. & $\begin{array}{c}\text { Ret.Time } \\
\text { (min.) }\end{array}$ & \multicolumn{1}{|c|}{ Peak Name } & $\begin{array}{c}\text { Height } \\
\text { (uS) }\end{array}$ & $\begin{array}{c}\text { Area } \\
\mu S^{*} \text { min }\end{array}$ & $\begin{array}{r}\text { Rel.Area } \\
(\%)\end{array}$ & $\begin{array}{r}\text { Amount } \\
\text { (mg/L) }\end{array}$ & $\begin{array}{r}\text { Peak } \\
\text { Type }\end{array}$ \\
\hline 1 & 3.24 & Fluoride & 0.80083 & 0.347 & 47.67 & 2.5340 & BMB \\
\hline 2 & 3.78 & n.a. & 0.05067 & 0.007 & 0.92 & n.a. & Rd \\
\hline 3 & 4.73 & Chloride & 0.42054 & 0.058 & 8.02 & 2.2346 & bMB \\
\hline 4 & 5.58 & Nitrite- $N$ & 0.70290 & 0.121 & 16.60 & 2.0638 & BMB \\
\hline 5 & 7.06 & Bromide & 0.11409 & 0.021 & 2.93 & 1.9983 & BMB \\
\hline 6 & 7.93 & Nitrate-N & 0.57178 & 0.135 & 18.53 & 2.0645 & BMB \\
\hline 7 & 12.08 & n.a. & 0.08212 & 0.039 & 5.33 & n.a. & BMB \\
\hline
\end{tabular}




\section{$28 C C V=I C W S-9058$}

\begin{tabular}{llll|}
\hline Sample Name: & CCV=ICWS-9058 & Injection Volume: & $\mathbf{5 0 . 0}$ \\
Vial Number: & $\mathbf{1 6 6}$ & Channel: & ECD_1 \\
Sample Type: & unknown & Wavelength: & n.a. \\
Control Program: & ANIONS_AS14A & Bandwidth: & n.a. \\
Quantif. Method: & ANIONS & Dilution Factor: & $\mathbf{1 . 0 0 0 0}$ \\
Recording Time: & $\mathbf{1 2 / 1 8 / 2 0 0 6 ~ 1 7 : 0 6}$ & Sample Weight: & $\mathbf{1 . 0 0 0 0}$ \\
Run Time (min): & $\mathbf{1 5 . 0 0}$ & Sample Amount: & $\mathbf{1 . 0 0 0 0}$ \\
\hline
\end{tabular}

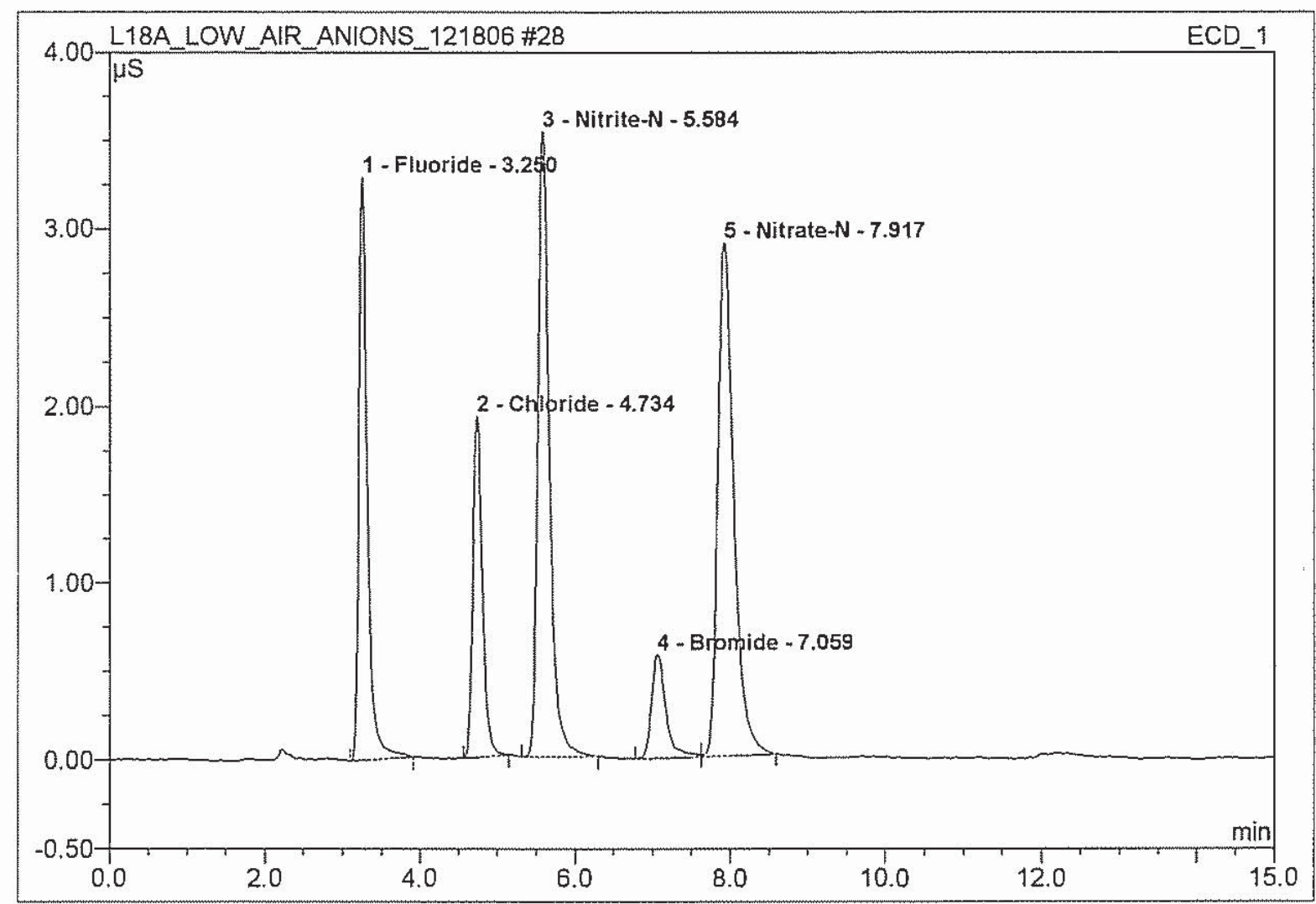

\begin{tabular}{|c|c|l|r|r|r|r|c|}
\hline No. & $\begin{array}{c}\text { Ret.Time } \\
\text { (min.) }\end{array}$ & \multicolumn{1}{|c|}{ Peak Name } & $\begin{array}{c}\text { Height } \\
\text { (uS) }\end{array}$ & $\begin{array}{c}\text { Area } \\
\mu \mathrm{S}^{*} \min \end{array}$ & $\begin{array}{c}\text { Rel.Area } \\
(\%)\end{array}$ & $\begin{array}{c}\text { Amount } \\
(\mathrm{mg} / \mathrm{L})\end{array}$ & $\begin{array}{c}\text { Peak } \\
\text { Type }\end{array}$ \\
\hline 1 & 3.25 & Fluoride & 3.29330 & 0.422 & 19.95 & 1.0048 & $\mathrm{BMB}$ \\
\hline 2 & 4.73 & Chloride & 1.92845 & 0.274 & 12.94 & 0.9978 & $\mathrm{BMB}$ \\
\hline 3 & 5.58 & Nitrite-N & 3.53011 & 0.610 & 28.81 & 1.0035 & $\mathrm{BMB}$ \\
\hline 4 & 7.06 & Bromide & 0.58345 & 0.124 & 5.88 & 1.0073 & $\mathrm{BM}$ \\
\hline 5 & 7.92 & Nitrate-N & 2.89375 & 0.686 & 32.42 & 1.0020 & $\mathrm{MB}$ \\
\hline
\end{tabular}




\section{CCB}

\begin{tabular}{llll|}
\hline Sample Name: & CCB & Injection Volume: & $\mathbf{5 0 . 0}$ \\
Vial Number: & 167 & Channel: & ECD_1 \\
Sample Type: & unknown & Wavelength: & n.a. \\
Control Program: & ANIONS_AS14A & Bandwidth: & n.a. \\
Quantif. Method: & ANIONS & Dilution Factor: & 1.0000 \\
Recording Time: & $\mathbf{1 2 / 1 8 / 2 0 0 6 ~ 1 7 : 2 3}$ & Sample Weight: & 1.0000 \\
Run Time (min): & $\mathbf{1 5 . 0 0}$ & Sample Amount: & $\mathbf{1 . 0 0 0 0}$ \\
\hline
\end{tabular}

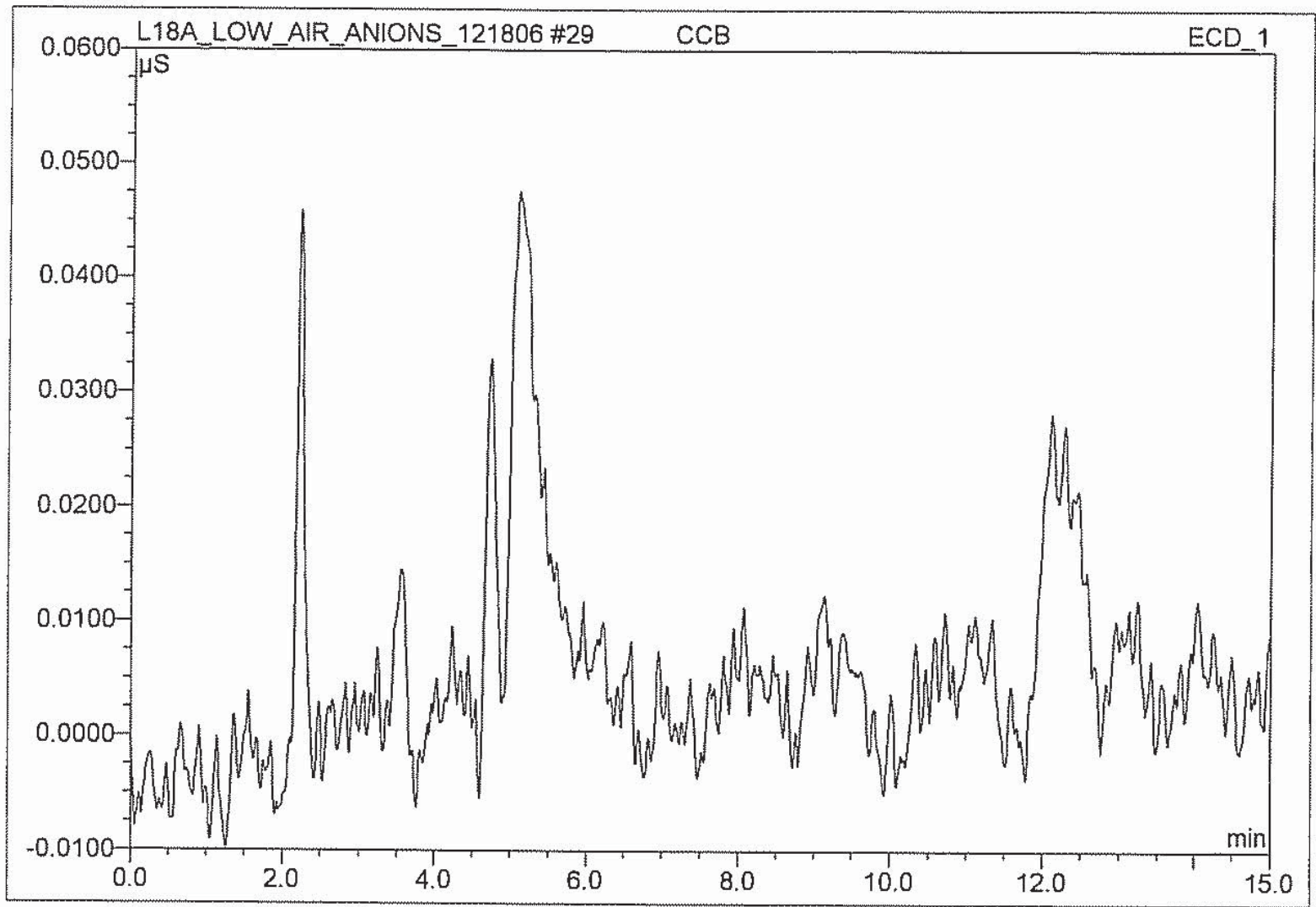

\begin{tabular}{|c|c|c|c|c|c|c|c|}
\hline No. & $\begin{array}{c}\text { Ret.Time } \\
\text { (min.) }\end{array}$ & Peak Name & $\begin{array}{c}\text { Height } \\
\text { (uS) }\end{array}$ & $\begin{array}{c}\text { Area } \\
\mu S^{\star} \mathrm{min}\end{array}$ & $\begin{array}{c}\text { Rel.Area } \\
(\%)\end{array}$ & $\begin{array}{c}\text { Amount } \\
(\mathrm{mg} / \mathrm{L})\end{array}$ & $\begin{array}{c}\text { Peak } \\
\text { Type }\end{array}$ \\
\hline
\end{tabular}

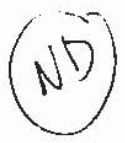




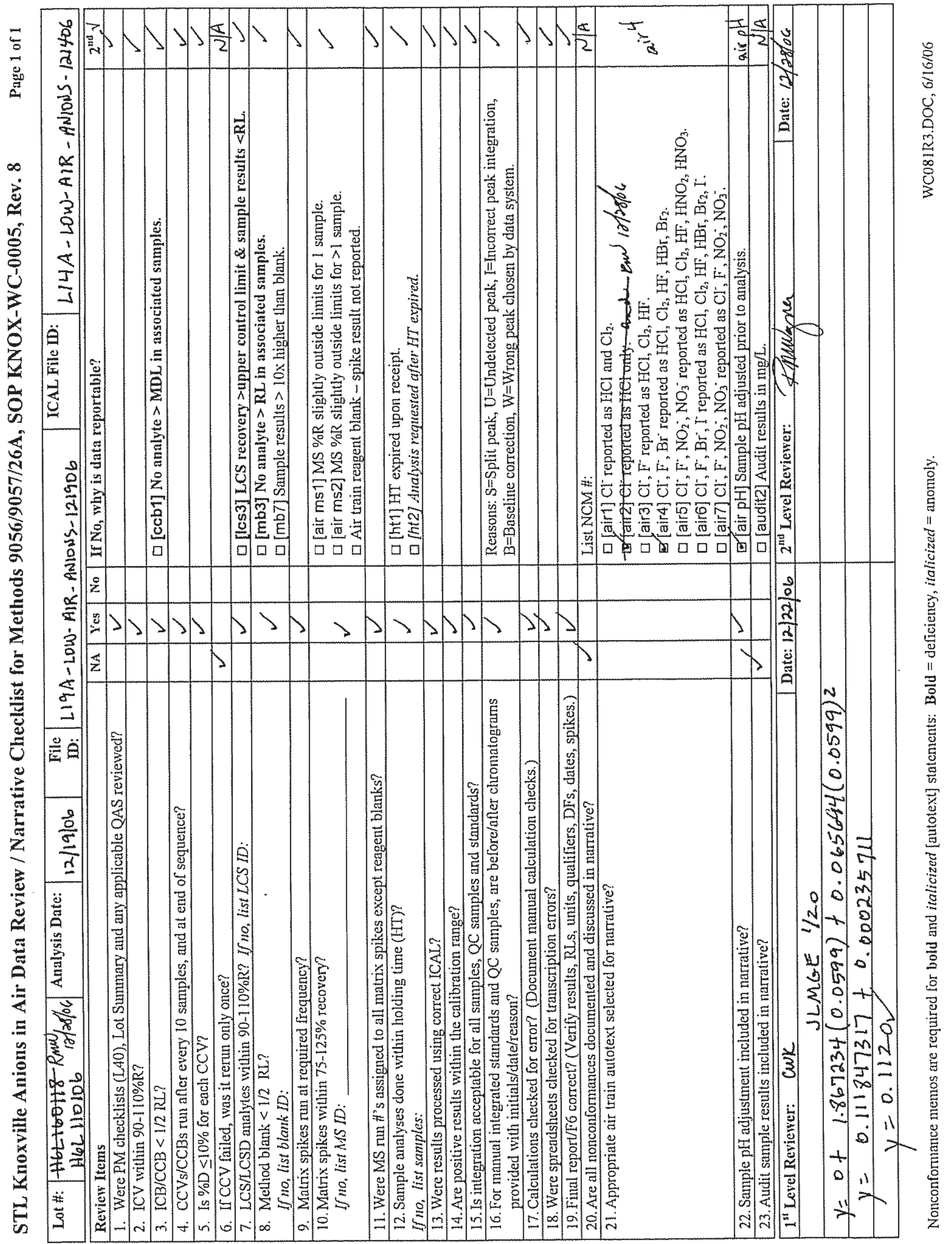




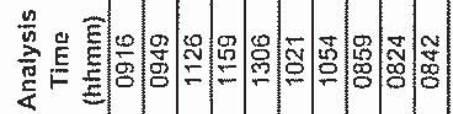

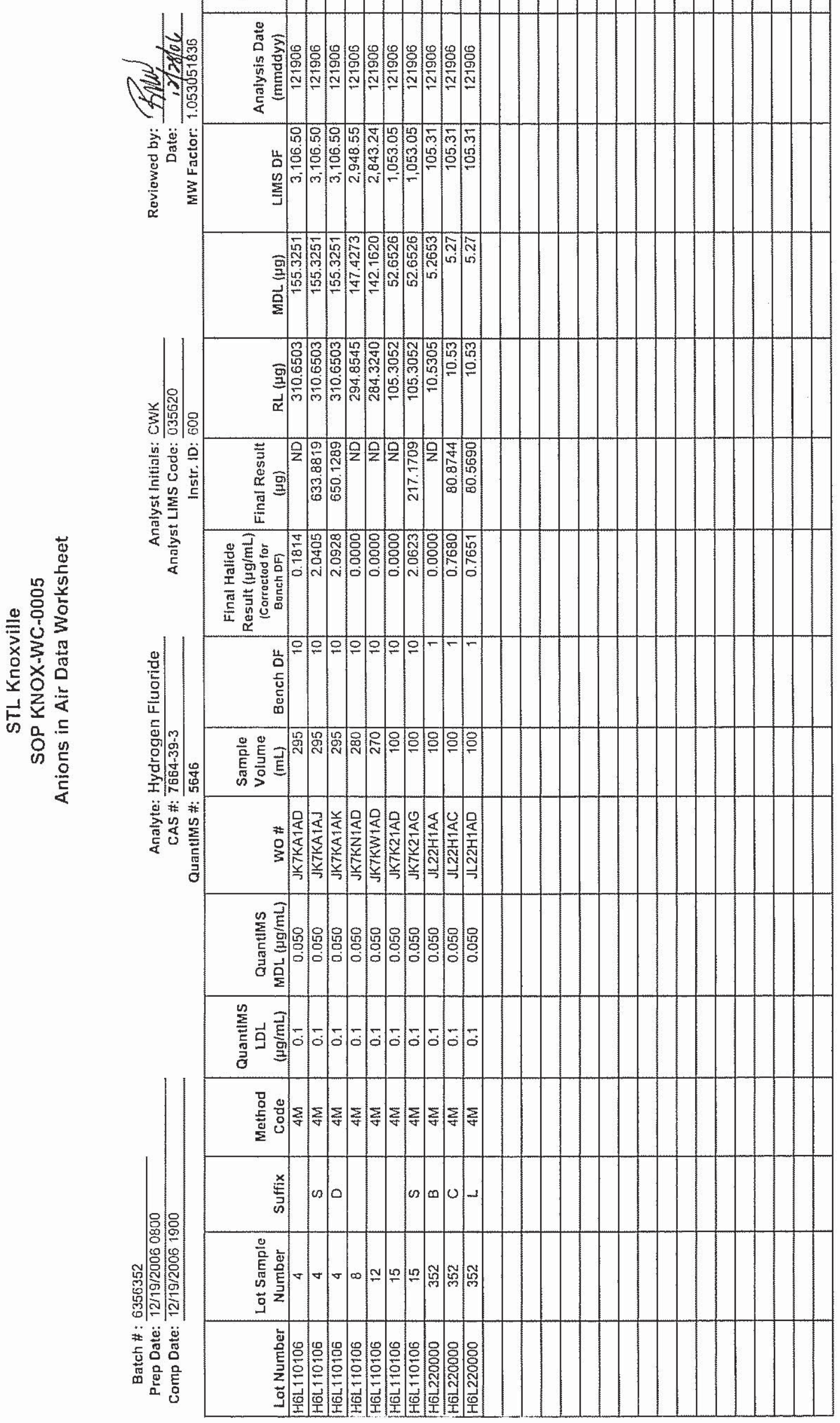

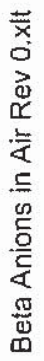




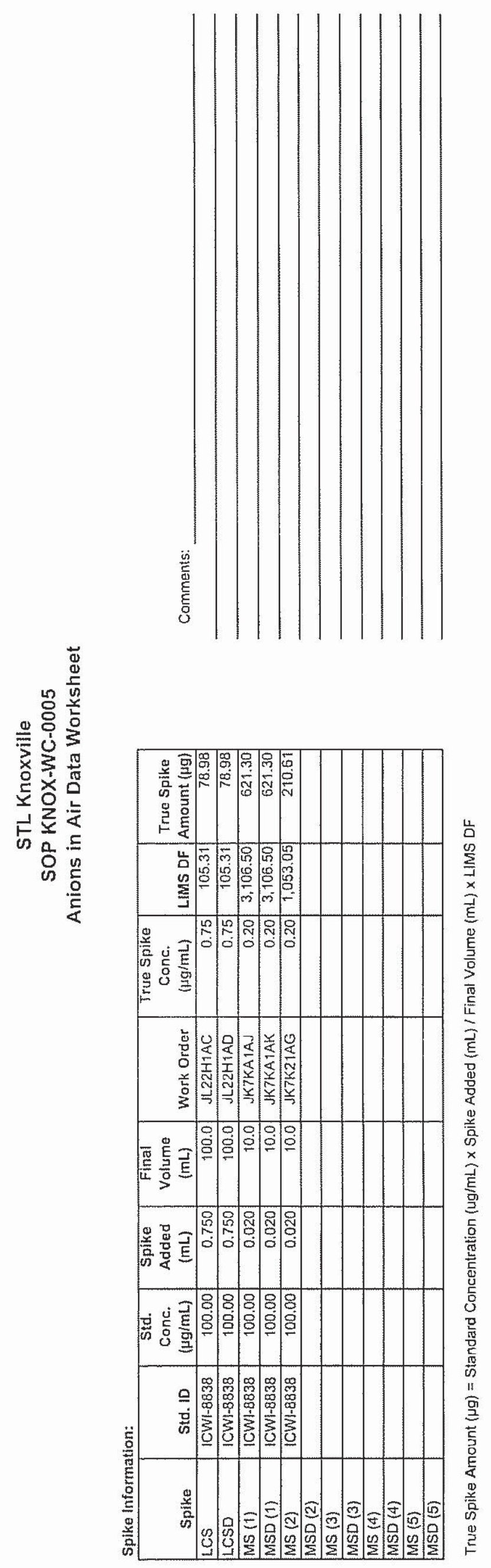




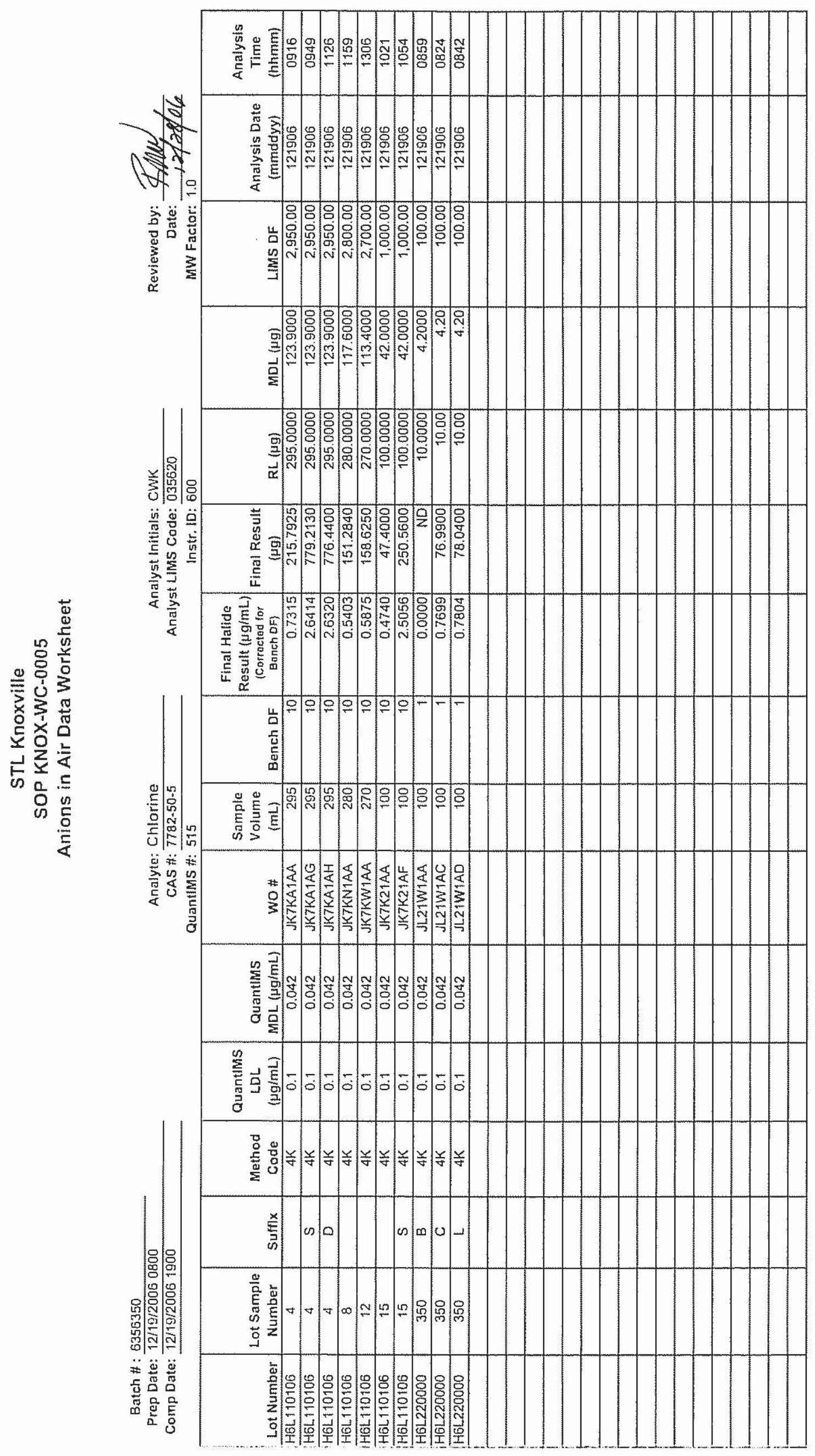




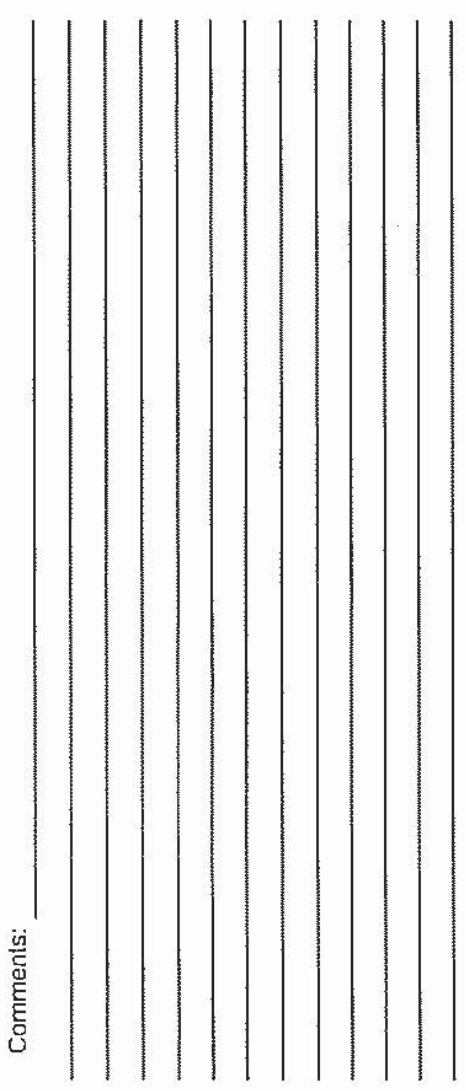

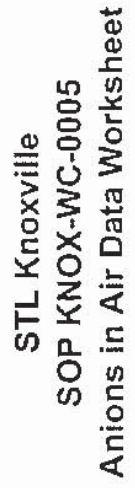

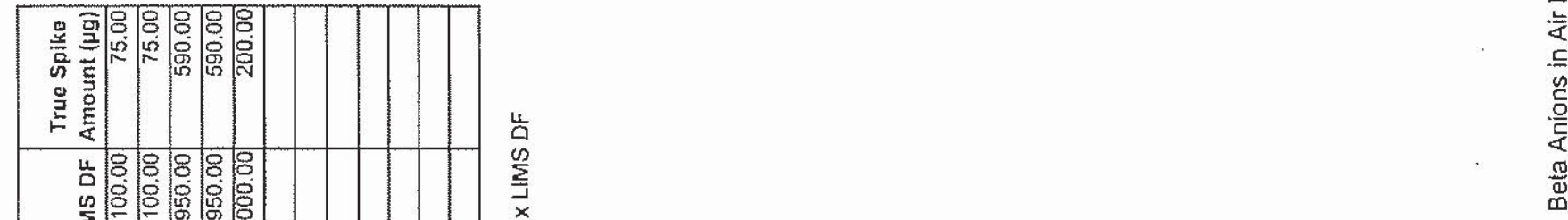

历

医

产 吾

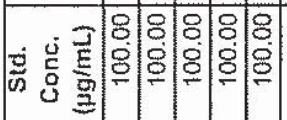

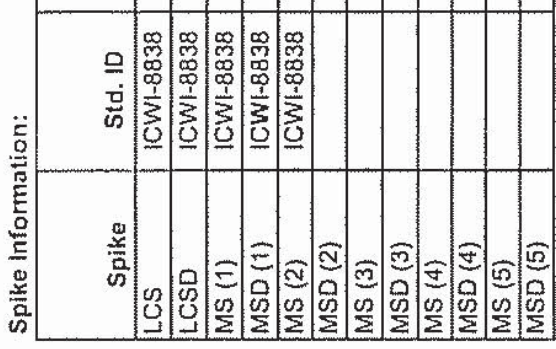




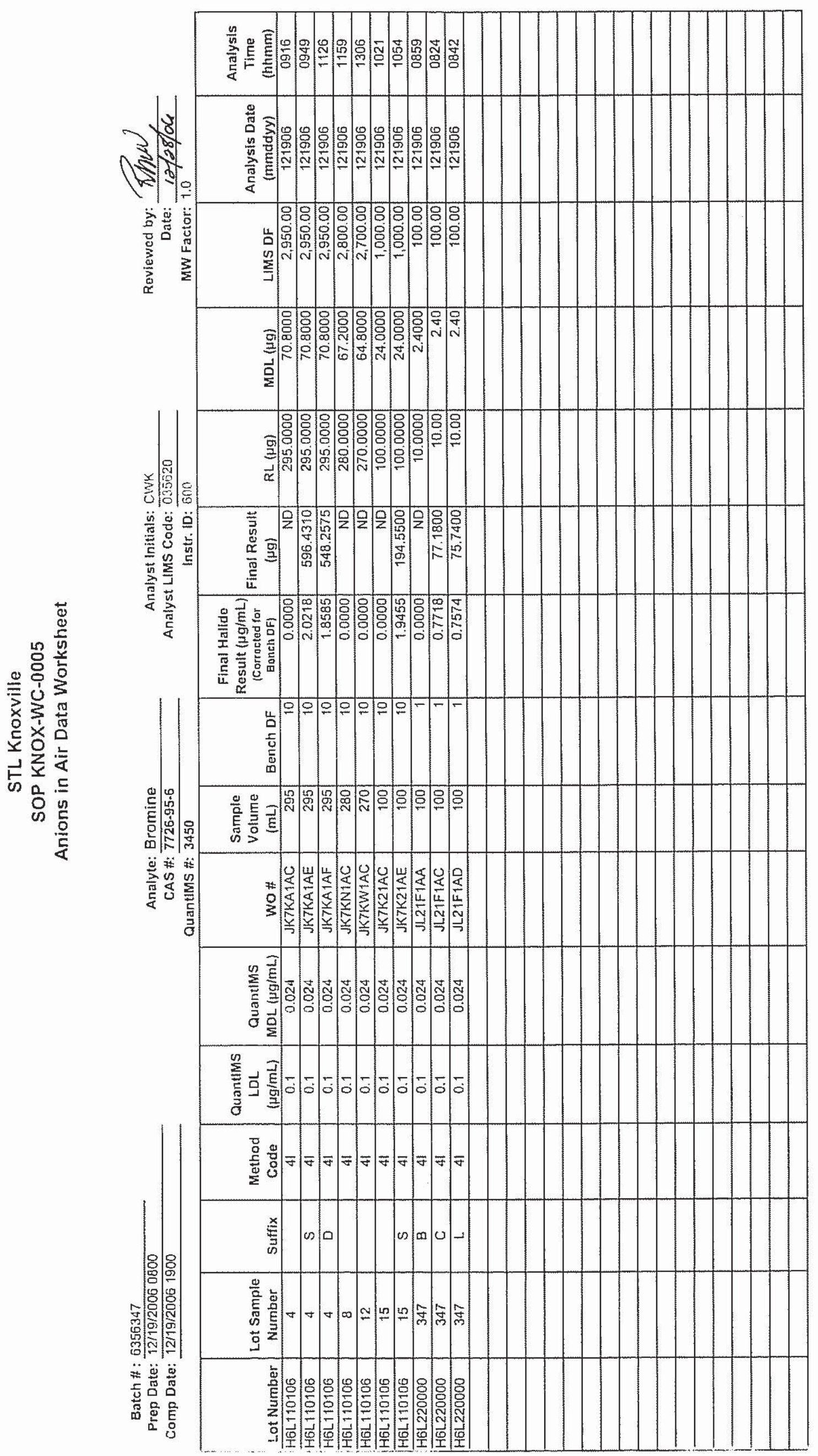







Dionex IC Runlog Cover Page

\begin{tabular}{|c|c|c|c|c|c|c|}
\hline Analyst: & cwk & Date: & $12|19| 06$ & Sequence ID: & \multicolumn{2}{|c|}{ L19A-LDW-A1R - ANIDNS- 121906} \\
\hline \multirow{3}{*}{ Instrument: } & DX -600 & \multirow{3}{*}{ Method: } & \multicolumn{4}{|c|}{ [KNOX-WC-0003, SW-846 0061/7199 } \\
\hline & GICS-1500 & & \multicolumn{4}{|c|}{ Q KNOX-WC-0005, DSW-846 $9056 \quad$ QEPA 300.0} \\
\hline & $\square D X-320$ & & \multicolumn{4}{|c|}{ D KNOX-WC-0014, EPA 314.0} \\
\hline \multicolumn{4}{|c|}{ Preventive Maintenance } & & \multicolumn{2}{|c|}{ Instrument Conditions } \\
\hline \multicolumn{4}{|l|}{ Daily: } & & Flow Rate $=$ & $\mathrm{mL} / \mathrm{min}$ \\
\hline \multicolumn{4}{|c|}{ 乙Check pump and gas pressure } & & Pressure $=$ & psi \\
\hline \multicolumn{4}{|c|}{ DCheck all lines for crimping, leaks and discoloration } & & Conductance $=$ & $\mu \mathrm{S}$ \\
\hline \multicolumn{4}{|l|}{ As Needed: } & Suppr & ssor Current $=$ & $\mathrm{mA}$ \\
\hline \multicolumn{4}{|c|}{ ¿ Change column and guard column } & Elue & t Generator = & $\mathrm{mM} \mathrm{KOH}$ \\
\hline \multicolumn{7}{|c|}{$\square$ Change column and/or guard column bed support } \\
\hline \multicolumn{7}{|c|}{$\checkmark$ Clean conductivity cell } \\
\hline \multicolumn{7}{|c|}{$\square$ De-gas pump head when flow is erratic } \\
\hline \multicolumn{4}{|c|}{$\square$ Check/replace eluant end line filter } & & & \\
\hline
\end{tabular}

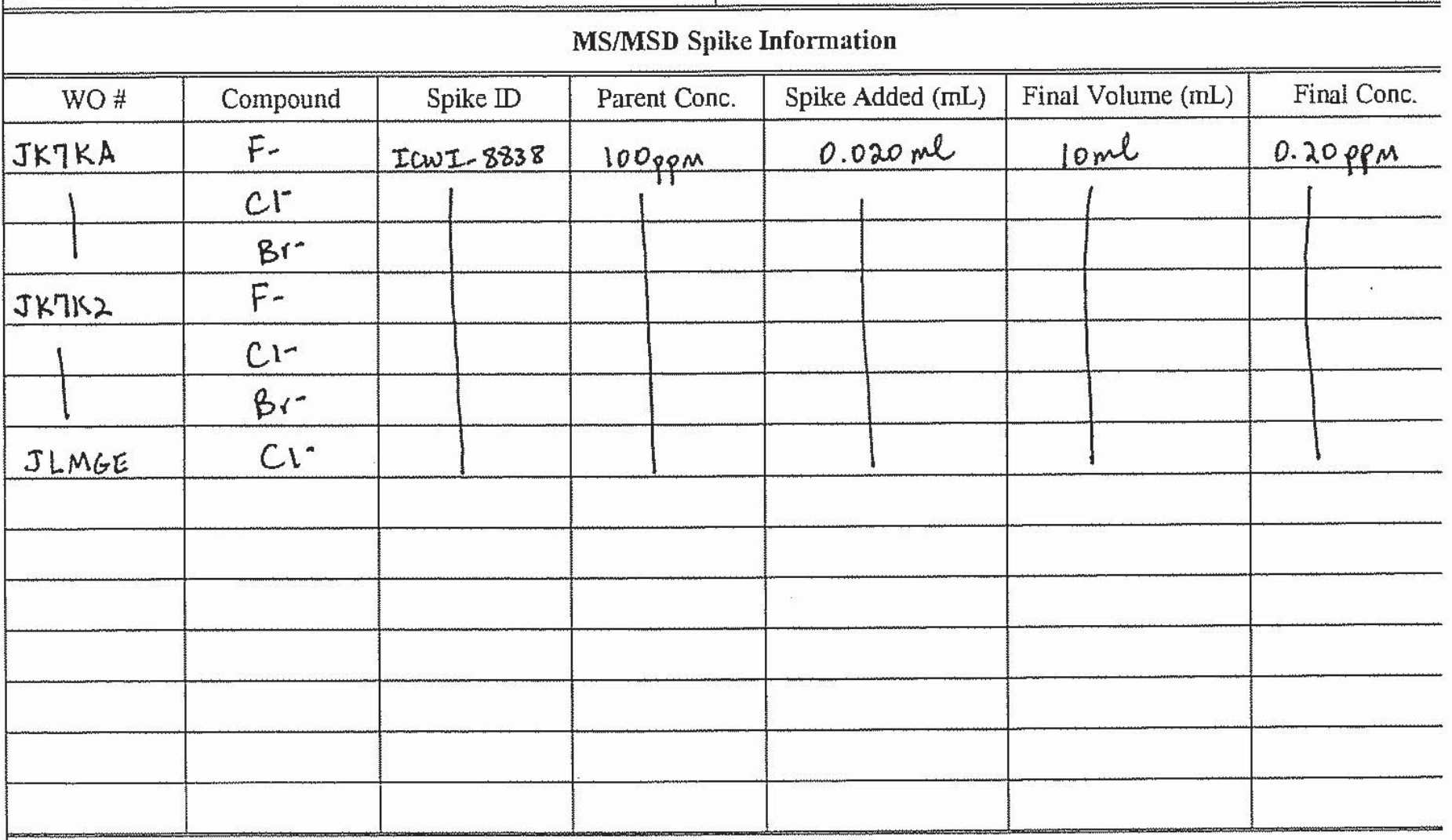

\section{Comments:}

Batch $\mathrm{HCl}$ for $\mathrm{H6L160118:6356131}$

Bateh Bri - 6356347

Bateh $\mathrm{Cl}_{2}-6356350$

Batch HF - 6356352

$\sqrt{\text { Sodium Thiosulfate added to } \mathrm{NaOH} \text { impinger samples. }}$ 
Title:

Datasource:

Location:

Timebase:

\#Samples:

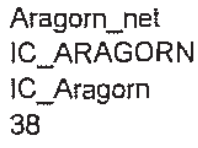

Cur

$12 / 20 / 06$

Created:

Last Update:
12/19/2006 8:06:15 AM by kaukerc 12/19/2006 1:44:16 PM by kaukerc

\begin{tabular}{|c|c|c|c|c|c|c|}
\hline No. & Name & Sample ID & Inj. Vol. & Inj. Date/Time & Dil. Factor & $\begin{array}{l}\text { "Multiplier } \\
\text { [Liters] }\end{array}$ \\
\hline 1 & (9) CAL STD $1=1$ CWS-9045 @ (0.075ppm) & & 50.0 & $12 / 14 / 20064: 54: 12 \mathrm{PM}$ & 1.0000 & \\
\hline 2 & 1 CAL STD $2=1$ CWS.9046 @ (0.10ppm) & & 50.0 & 12/14/2006 5:11:38 PM & 1.0000 & \\
\hline 3 & (1) CAL STD $3=1$ CWS $-9047 @(0.25 \mathrm{ppm})$ & & 50.0 & 12/14/2006 5:24:03 PM & 1.0000 & \\
\hline 4 & $(1)$ CAL STD $4=1$ CWS-9048@ (0.50ppm) & & 50.0 & 12/14/2006 5:36:29 PM & 1.0000 & \\
\hline 5 & (1) CAL STD $5=$ ICWS-9049 @ (1.ppm) & & 50.0 & $12 / 14 / 20065: 48: 54 \mathrm{PM}$ & 1.0000 & \\
\hline 6 & D CAL STD $6=1$ ICWS-9050 @ (2.ppm) & & 50.0 & 12/14/2006 6:01:20 PM & 1.0000 & \\
\hline 7 & ICV/LCS = ICWS-9059 & & 50.0 & $12 / 19 / 20068: 24: 36 \mathrm{AM}$ & 1.0000 & \\
\hline 8 & ICV/LCSD = ICWS-9060 & & 50.0 & 12/19/2006 8:42:02 AM & 1.0000 & \\
\hline 9 & ICB/METHOD BLANK & & 50.0 & 12/19/2006 8:59:27 AM & 1.0000 & \\
\hline 10 & H6L110106 JK7KA $1 / 10$ & & 50.0 & $12 / 19 / 20069: 16: 53 \mathrm{AM}$ & 10.0000 & \\
\hline 11 & H6L110106 JK7KA MS 1/10 0.2 PPM F, CL, BR & & 50.0 & $12 / 19 / 20069: 49: 19 \mathrm{AM}$ & 10.0000 & \\
\hline 12 & H6L110106 JK7K2 1/10 & & 50.0 & $12 / 19 / 200610: 21: 44$ AM & 10.0000 & \\
\hline 13 & H6L110106 JK7K2 MS 1/10 0.2 PPM F, CL, BR & & 50.0 & $12 / 19 / 2006 \quad 10: 54: 09$ AM & 10.0000 & \\
\hline 14 & (3) H6L110106 JK7KA MSD 1/100.2 PPM F, CL, BR & & 50.0 & 12/19/2006 11:26:35 AM & 10.0000 & \\
\hline 15 & H6L110106 JK7KN $1 / 10$ & & 50.0 & 12/19/2006 11:59:00 AM & 10.0000 & \\
\hline 16 & CCV $=1$ ICWS-9061 & & 50.0 & $12 / 19 / 200612: 31: 25 \mathrm{PM}$ & 1.0000 & \\
\hline 17 & CCB & & 50.0 & $12 / 19 / 2006$ 12:48:51 PM & 1.0000 & \\
\hline 18 & 逄 $\mathrm{H} 6 \mathrm{~L} 110106 \mathrm{JK} 7 \mathrm{KW} 1 / 10$ & & 50.0 & $12 / 19 / 20061: 06: 16 \mathrm{PM}$ & 10.0000 & \\
\hline 19 & H6L160118 JLMGE 1/10 & & 50.0 & $12 / 19 / 2006$ 1:38:41 PM & 10.0000 & \\
\hline 20 & H6L160118 JLMGE 1/20 & & 50.0 & $12 / 19 / 2006$ 1:56:07 PM & 20.0000 & \\
\hline 21 & H6L160118 JLMGE $1 / 40$ & & 50.0 & $12 / 19 / 20062: 13: 32 \mathrm{PM}$ & 40.0000 & \\
\hline 22 & H6L160118 JLMGE MS 1/10 0.2 PPM CL & & 50.0 & $12 / 19 / 20062: 30: 57$ PM & 10.0000 & \\
\hline 23 & (3) H6L160118 JLMGE MSD 1/10 0.2 PPM CL & & 50.0 & 12/19/2006 2:48:23 PM & 10.0000 & \\
\hline 24 & H6L160118 JLMGE MS 1/20 0.2 PPM CL & & 50.0 & $12 / 19 / 20063: 05: 48 \mathrm{PM}$ & 20.0000 & \\
\hline 25 & H6L160118 JLMGE MSD 1/20 0.2 PPM CL & & 50.0 & 12/19/2006 3:23:13 PM & 20.0000 & \\
\hline 26 & H6L160118 JLMGE MS 1/40 0,2 PPM CL & & 50.0 & 12/19/2006 3:40:39 PM & 40.0000 & \\
\hline 27 & (3) H6L160118 JLMGE MSD $1 / 400.2$ PPM CL & & 50.0 & 12/19/2006 3:58:04 PM & 40.0000 & \\
\hline 28 & OCV $=$ ICWS-9061 & & 50.0 & 12/19/2006 4:15:30 PM & 1.0000 & \\
\hline 29 & CCB & & 50.0 & $12 / 19 / 20064: 32: 54 \mathrm{PM}$ & 1.0000 & \\
\hline 30 & H6L160118 JLMGG 1/10 & & 50.0 & 12/19/2006 4:50:20 PM & 10.0000 & \\
\hline 31 & H6L160118 JLMGG 1/20 & & 50.0 & 12/19/2006 5:07:45 PM & 20.0000 & \\
\hline 32 & H6L160118 JLMGG 1/40 & & 50.0 & 12/19/2006 5:25:11 PM & 40.0000 & \\
\hline 33 & 第 H6L160118 JLMGJ 1/10 & & 50.0 & $12 / 19 / 20065: 42: 36 \mathrm{PM}$ & 10.0000 & \\
\hline 34 & 竞 H6L160118 JLMGJ $1 / 20$ & & 50.0 & 12/19/2006 6:00:02 PM & 20.0000 & \\
\hline 35 & 拿 H6L160118 JLMGJ 1/40 & & 50.0 & 12/19/2006 6:17:27 PM & 40.0000 & \\
\hline 36 & S CCV $=1 C W S-9061$ & & 50.0 & 12/19/2006 6:34:53 PM & 1.0000 & \\
\hline 37 & 挣 CCB & & 50.0 & $12 / 19 / 2006$ 6:52:18 PM & 1.0000 & \\
\hline 38 & SHUTDOWN & & 50.0 & $12 / 19 / 2006$ 7:09:43 PM & 1.0000 & \\
\hline
\end{tabular}




\section{$7 \quad$ ICV/LCS $=$ ICWS -9059}

\begin{tabular}{llll|}
\hline Sample Name: & ICV/LCS= ICWS-9059 & Injection Volume: & $\mathbf{5 0 . 0}$ \\
Vial Number: & $\mathbf{1 0 4}$ & Channel: & ECD_1 \\
Sample Type: & unknown & Wavelength: & n.a. \\
Control Program: & ANIONS_AS14A & Bandwidth: & n.a. \\
Quantif. Method: & ANIONS & Dilution Factor: & 1.0000 \\
Recording Time: & $\mathbf{1 2 / 1 9 / 2 0 0 6 ~ 8 : 2 4}$ & Sample Weight: & 1.0000 \\
Run Time (min): & $\mathbf{1 5 . 0 0}$ & Sample Amount: & $\mathbf{1 . 0 0 0 0}$ \\
\hline
\end{tabular}

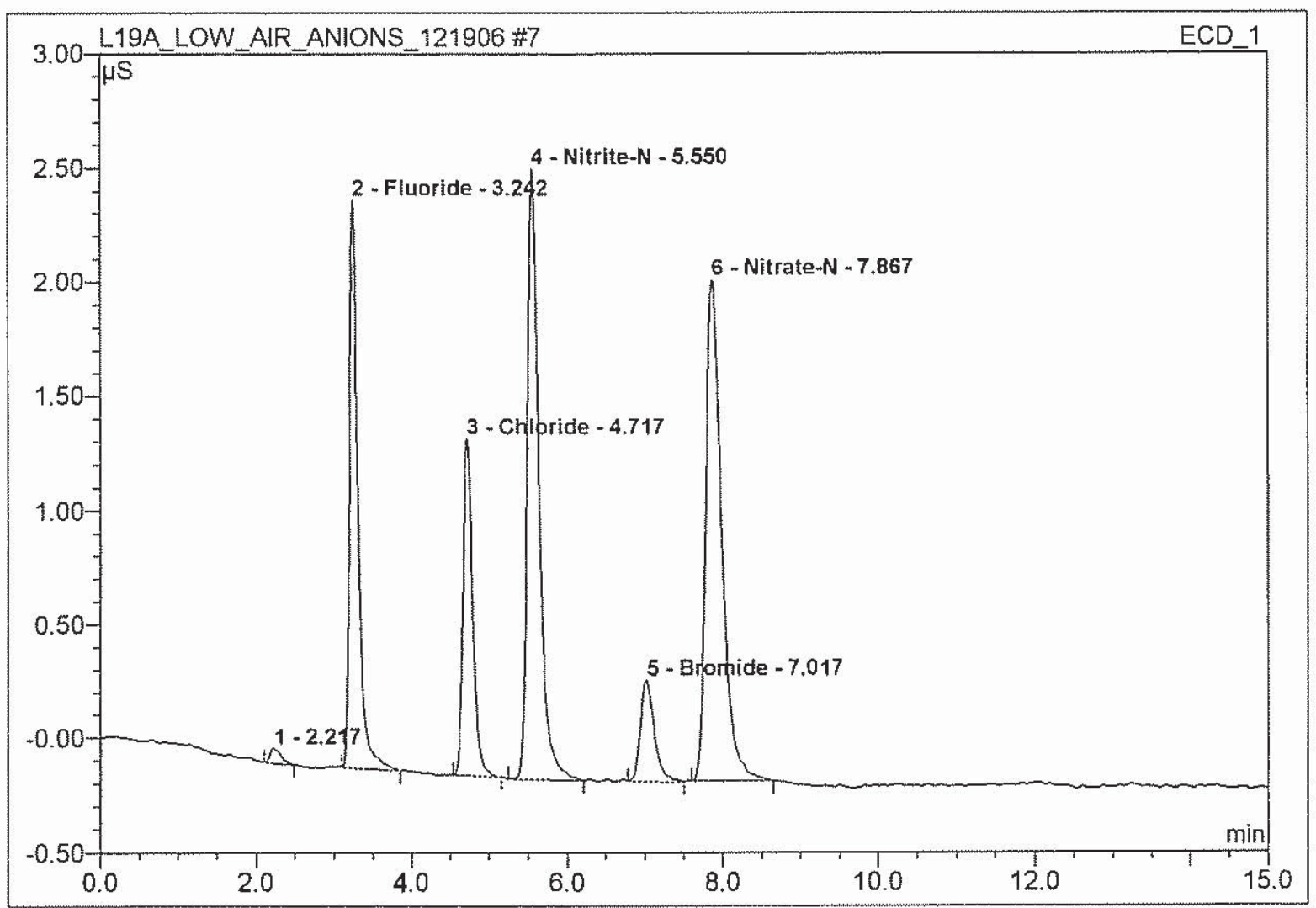

\begin{tabular}{|c|c|l|r|r|r|r|r|}
\hline No. & $\begin{array}{c}\text { Ret.Time } \\
\text { (min.) }\end{array}$ & \multicolumn{1}{|c|}{ Peak Name } & $\begin{array}{c}\text { Height } \\
\text { (uS) }\end{array}$ & $\begin{array}{c}\text { Area } \\
\mu S^{\star} \min \end{array}$ & $\begin{array}{c}\text { Rel.Area } \\
\text { (\%) }\end{array}$ & $\begin{array}{c}\text { Amount } \\
\text { (mg/L) }\end{array}$ & $\begin{array}{r}\text { Peak } \\
\text { Type }\end{array}$ \\
\hline 1 & 2.22 & n.a. & 0.06381 & 0.011 & 0.66 & n.a. & BMB \\
\hline 2 & 3.24 & Fluoride & 2.48867 & 0.321 & 19.80 & 0.7680 & BMB \\
\hline 3 & 4.72 & Chloride & 1.47644 & 0.210 & 12.99 & 0.7699 & $\checkmark$ BMB \\
\hline 4 & 5.55 & Nitrite-N & 2.67428 & 0.469 & 28.97 & 0.7675 & BMB \\
\hline 5 & 7.02 & Bromide & 0.44520 & 0.091 & 5.65 & 0.7718 & BMB \\
\hline 6 & 7.87 & Nitrate-N & 2.19530 & 0.517 & 31.92 & 0.7694 & BMB \\
\hline
\end{tabular}

$B_{2}$-JL2IFIAACC Rov 12128104

$\mathrm{Cl}_{2}-\mathrm{JLa} \omega \mathrm{W}$ IAC

JLIRSIAC HCI

HF-JL2JHIAC 


\section{$8 \quad I C V / L C S D=I C W S-9060$}

\begin{tabular}{llll|}
\hline Sample Name: & ICV/LCSD=ICWS-9060 & Injection Volume: & $\mathbf{5 0 . 0}$ \\
Vial Number: & $\mathbf{1 0 5}$ & Channel: & ECD_1 \\
Sample Type: & unknown & Wavelength: & n.a. \\
Control Program: & ANIONS_AS14A & Bandwidth: & n.a. \\
Quantif. Method: & ANIONS & Dilution Factor: & 1.0000 \\
Recording Time: & $\mathbf{1 2 / 1 9 / 2 0 0 6 8 : 4 2}$ & Sample Weight: & $\mathbf{1 . 0 0 0 0}$ \\
Run Time (min): & $\mathbf{1 5 . 0 0}$ & Sample Amount: & $\mathbf{1 . 0 0 0 0}$ \\
\hline
\end{tabular}

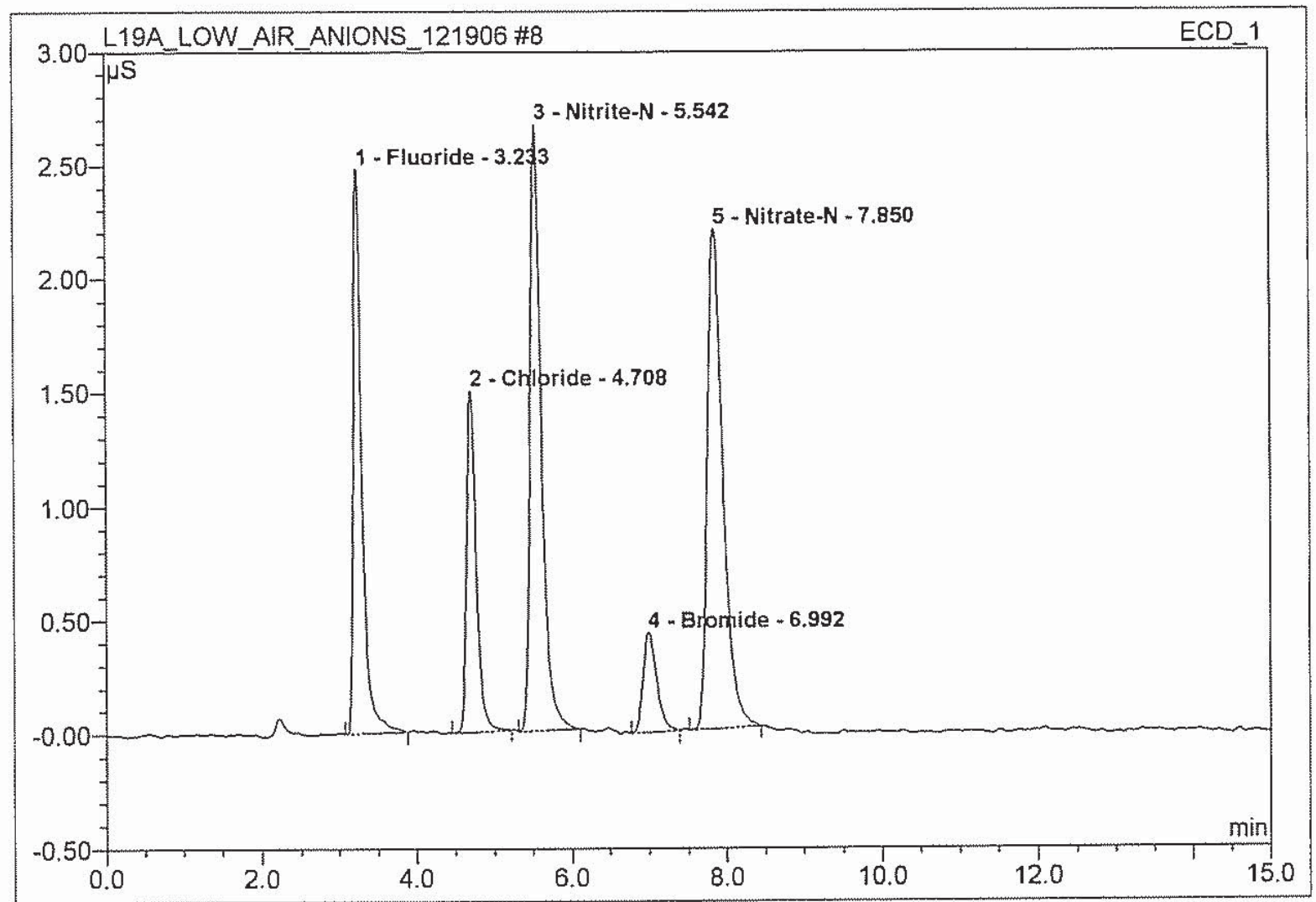

\begin{tabular}{|c|c|l|r|r|r|r|r|}
\hline No. & $\begin{array}{c}\text { Ret.Time } \\
\text { (min.) }\end{array}$ & \multicolumn{1}{|c|}{ Peak Name } & $\begin{array}{c}\text { Height } \\
\text { (uS) }\end{array}$ & $\begin{array}{c}\text { Area } \\
\mathbf{S S}^{*} \mathrm{~min}\end{array}$ & $\begin{array}{c}\text { Rel.Area } \\
(\%)\end{array}$ & $\begin{array}{c}\text { Amount } \\
\text { (mg/L) }\end{array}$ & $\begin{array}{r}\text { Peak } \\
\text { Type }\end{array}$ \\
\hline 1 & 3.23 & Fluoride & 2.47891 & 0.322 & 20.25 & 0.7651 & BMB \\
\hline 2 & 4.71 & Chloride & 1.49722 & 0.215 & 13.50 & 0.7804 & BMB \\
\hline 3 & 5.54 & Nitrite-N & 2.66310 & 0.454 & 28.58 & 0.7644 & BMB \\
\hline 4 & 6.99 & Bromide & 0.43676 & 0.088 & 5.55 & 0.7574 & BMB \\
\hline 5 & 7.85 & Nitrate-N & 2.19377 & 0.511 & 32.13 & 0.7689 & BMB \\
\hline
\end{tabular}

$$
\begin{aligned}
& B_{r_{2}}-J L 2 I F \mid A D \\
& Q_{2}-J L_{2}|W| A D \\
& H F-J L 22 H I A D
\end{aligned}
$$

\section{JLIRSIAD HCl}

Chromeleon (c) Dionex 1996-2001

default_letter/Integration 


\section{ICB/ METHOD BLANK}

Sample Name: $\quad$ ICB/ METHOD BLANK

Vial Number: $\quad 139$

Sample Type:

Control Program:

Quantif. Method:

Recording Time:

Run Time ( $\mathrm{min}$ ): unknown

ANIONS_AS14A

ANIONS

12/19/2006 8:59

15.01
Injection Volume:

Channel:

Wavelength:

Bandwidth:

Dilution Factor:

Sample Weight:

Sample Amount:
50.0

ECD_1

n.a.

n.a.

1.0000

1.0000

1.0000

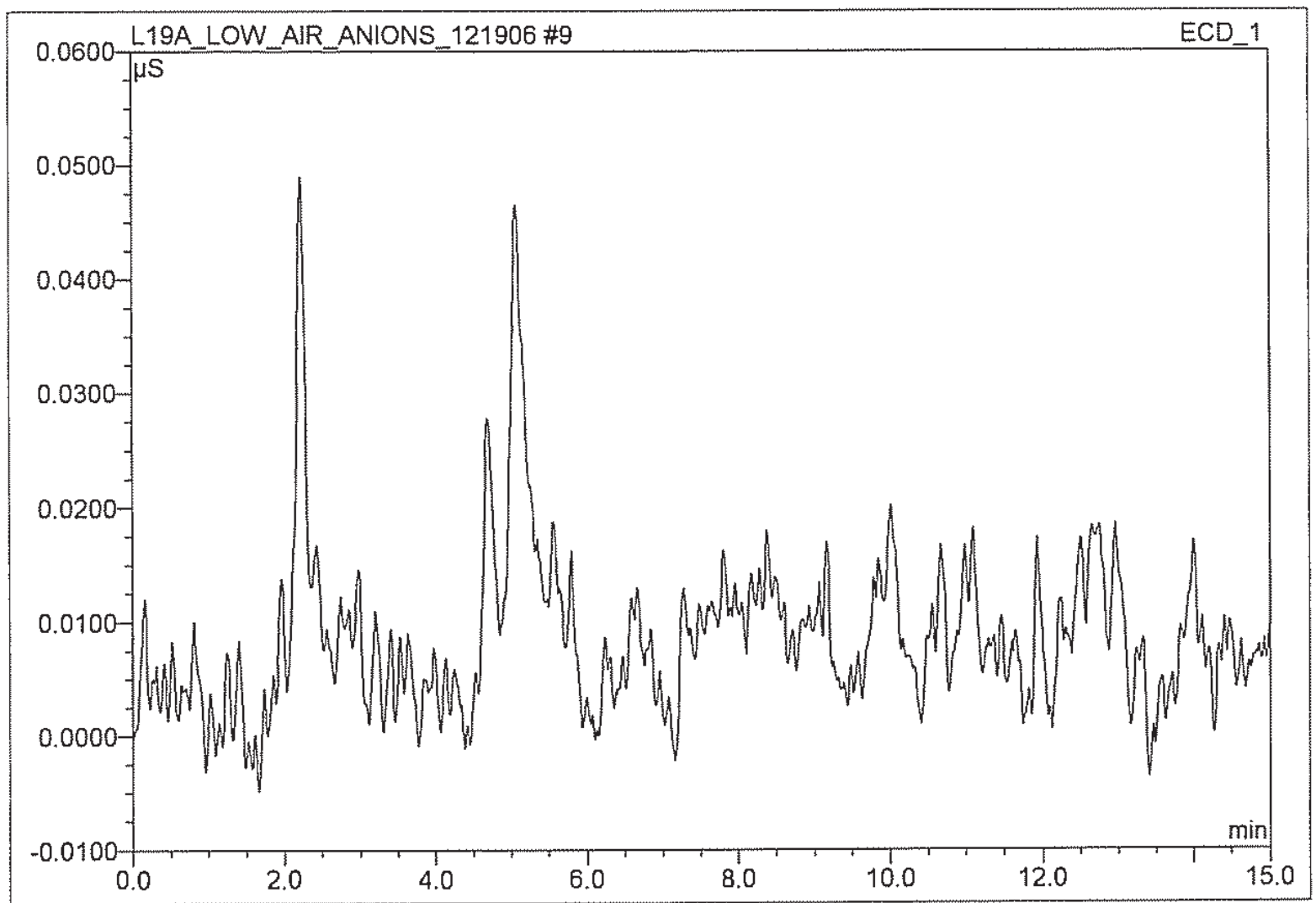

\begin{tabular}{|c|c|c|c|c|c|c|c|}
\hline No. & $\begin{array}{c}\text { Ret.Time } \\
(\text { min. })\end{array}$ & Peak Name & $\begin{array}{c}\text { Height } \\
(\mathrm{uS})\end{array}$ & $\begin{array}{c}\text { Area } \\
\mu S^{*} \mathrm{~min}\end{array}$ & $\begin{array}{c}\text { Rel.Area } \\
(\%)\end{array}$ & $\begin{array}{c}\text { Amount } \\
(\mathrm{mg} / \mathrm{L})\end{array}$ & $\begin{array}{c}\text { Peak } \\
\text { Type }\end{array}$ \\
\hline
\end{tabular}

Brg- JLJIFIAA

JLIRSIAA

$\mathrm{HCl}$

$\left(l_{2}-J L \partial|\omega| A A\right.$

$H F-J L \partial \partial H \mid A A$ 


\section{H6L110106 JK7KA 1/10}

\begin{tabular}{llll|}
\hline Sample Name: & H6L110106 JK7KA 1/10 & Injection Volume: & $\mathbf{5 0 . 0}$ \\
Vial Number: & 140 & Channel: & ECD_1 \\
Sample Type: & unknown & Wavelength: & n.a. \\
Control Program: & ANIONS_AS14A_Cl2 & Bandwidth: & n.a. \\
Quantif. Method: & ANIONS & Dilution Factor: & $\mathbf{1 0 . 0 0 0 0}$ \\
Recording Time: & $\mathbf{1 2 / 1 9 / 2 0 0 6 ~ 9 : 1 6}$ & Sample Weight: & $\mathbf{1 . 0 0 0 0}$ \\
Run Time (min): & $\mathbf{3 0 . 0 0}$ & Sample Amount: & $\mathbf{1 . 0 0 0 0}$ \\
\hline
\end{tabular}

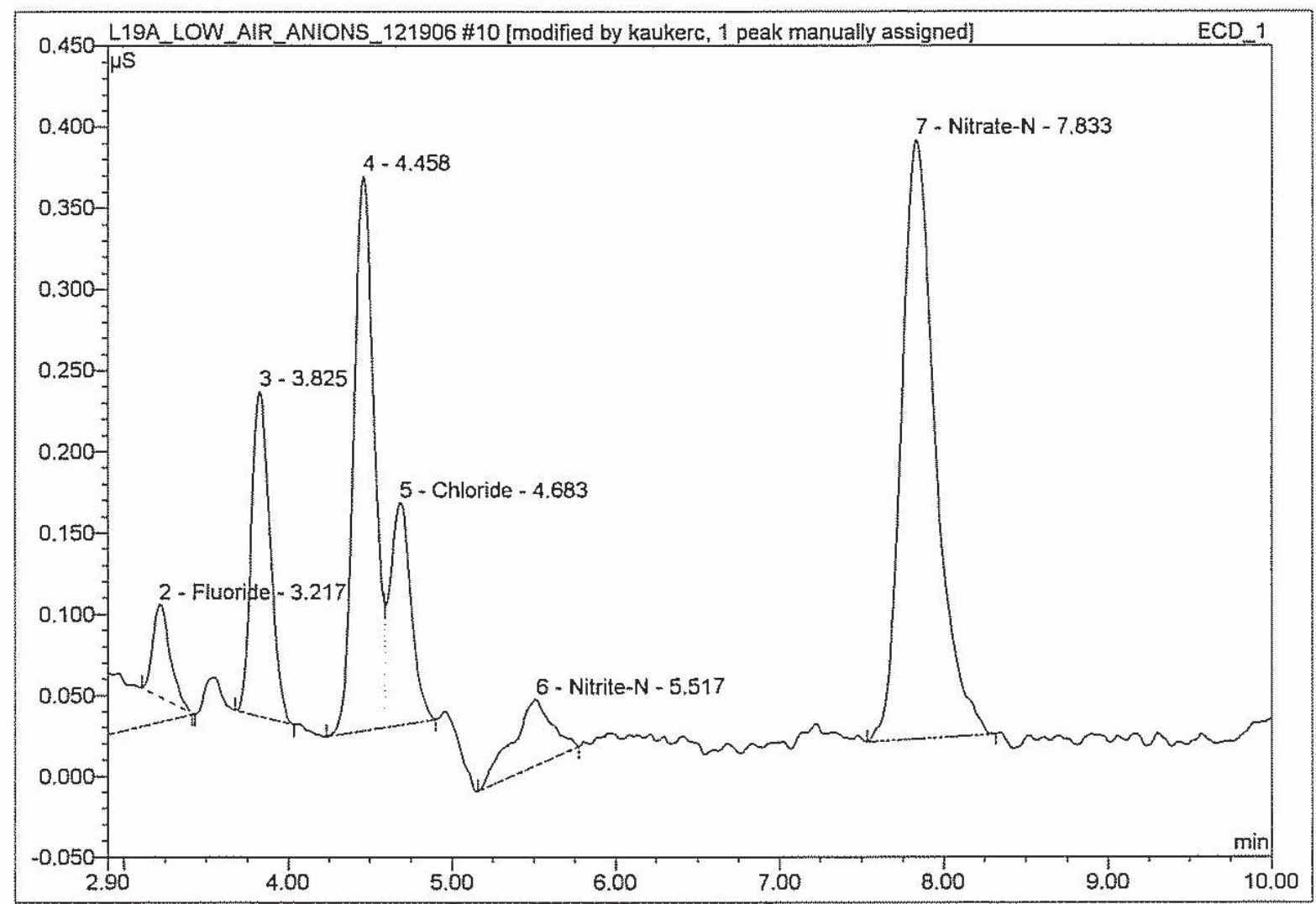

\begin{tabular}{|c|c|c|c|c|c|c|c|}
\hline No. & $\begin{array}{l}\text { Ret.Time } \\
\text { (min.) }\end{array}$ & Peak Name & $\begin{array}{l}\text { Height } \\
\text { (uS) }\end{array}$ & $\begin{array}{c}\text { Area } \\
\mu S^{\star} \min \end{array}$ & $\begin{array}{c}\text { Rel.Area } \\
(\%)\end{array}$ & $\begin{array}{l}\text { Amount } \\
(\mathrm{mg} / \mathrm{L})\end{array}$ & $\begin{array}{l}\text { Peak } \\
\text { Type }\end{array}$ \\
\hline 1 & 2.22 & n.a. & 1.67848 & 0.308 & 0.19 & n.a. & $\mathrm{BMB}^{*}$ \\
\hline 2 & 3.22 & Fluoride & 0.05666 & 0.007 & 0.00 & 0.1814 & $\mathrm{Rd}^{*}$ \\
\hline 3 & 3.83 & n.a. & 0.20009 & 0.026 & 0.02 & n.a. & $\mathrm{BMB}$ \\
\hline 4 & 4.46 & n.a. & 0.34155 & 0.050 & 0.03 & n.a. & $\mathrm{BM}$ \\
\hline 5 & 4.68 & Chloride & 0.13695 & 0.020 & 0.01 & 0.7315 & $\mathrm{MB}^{\wedge}$ \\
\hline 6 & 5.52 & Nitrite-N & 0.04065 & 0.012 & 0.01 & 0.1203 & $\mathrm{BMB}$ \\
\hline 7 & 7.83 & Nitrate-N & 0.36919 & 0.089 & 0.05 & 1.3383 & BMB \\
\hline 8 & 10.66 & n.a. & 19.82899 & 5.673 & 3.51 & n.a. & $\mathrm{BM}$ \\
\hline 9 & 11.69 & n.a. & 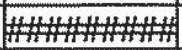 & 103.018 & 63.80 & n.a. & $\mathrm{MB}$ \\
\hline 10 & 21.93 & n.a. & 56.70455 & 52.270 & 32.37 & n.a. & $\mathrm{BMB}$ \\
\hline
\end{tabular}

manual integration $F$.

(2) culk $12 \mid 19106$

default_letter/Integration
Chloride peak misiduntified Chromeleon (c) Dionex 1996-2001 based on spike recovery. Version 6.50 SP4 Build 1000 Peak manually identified cuK $12 / 19 / 06$ 


\section{H6L110106 JK7KA 1/10}

\begin{tabular}{llll|}
\hline Sample Name: & H6L110106 JK7KA 1/10 & Injection Volume: & $\mathbf{5 0 . 0}$ \\
Vial Number: & $\mathbf{1 4 0}$ & Channel: & ECD_1 \\
Sample Type: & unknown & Wavelength: & n.a. \\
Control Program: & ANIONS_AS14A_CI2 & Bandwidth: & n.a. \\
Quantif. Method: & ANIONS & Dilution Factor: & $\mathbf{1 0 . 0 0 0 0}$ \\
Recording Time: & $\mathbf{1 2 / 1 9 / 2 0 0 6} 9: 16$ & Sample Weight: & $\mathbf{1 . 0 0 0 0}$ \\
Run Time (min): & $\mathbf{3 0 . 0 0}$ & Sample Amount: & $\mathbf{1 . 0 0 0 0}$ \\
\hline
\end{tabular}

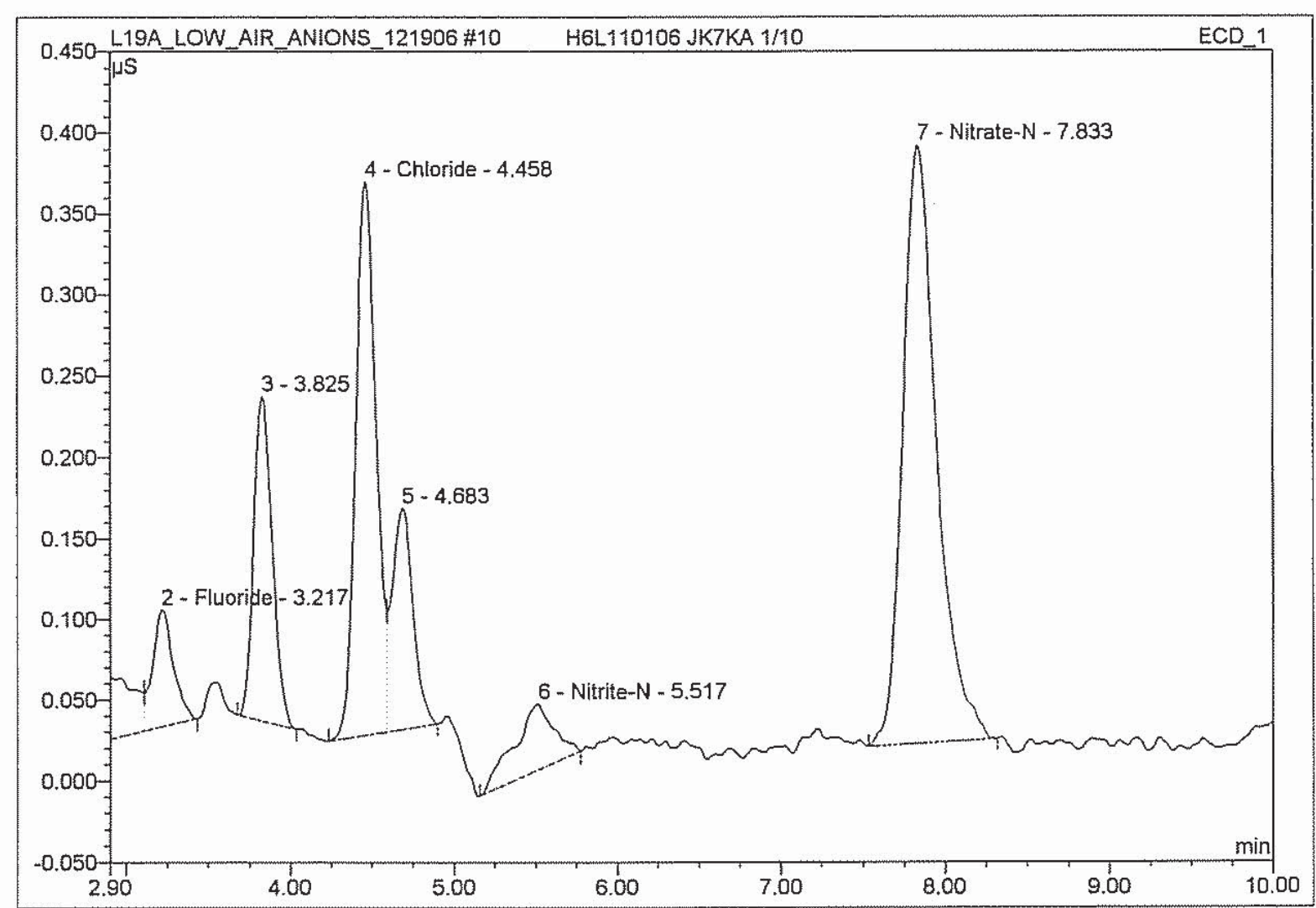

\begin{tabular}{|r|r|l|r|r|r|r|c|}
\hline No. & $\begin{array}{c}\text { Ret.Time } \\
\text { (min.) }\end{array}$ & \multicolumn{1}{|c|}{ Peak Name } & $\begin{array}{c}\text { Height } \\
\text { (uS) }\end{array}$ & $\begin{array}{c}\text { Area } \\
\mu S^{*} \mathrm{~min}\end{array}$ & $\begin{array}{r}\text { Rel.Area } \\
(\%)\end{array}$ & $\begin{array}{c}\text { Amount } \\
\text { (mg/L) }\end{array}$ & $\begin{array}{r}\text { Peak } \\
\text { Type }\end{array}$ \\
\hline 1 & 2.22 & n.a. & 1.67848 & 0.304 & 0.19 & n.a. & BM \\
\hline 2 & 3.22 & Fluoride & 0.07242 & 0.011 & 0.01 & 0.2318 & MB \\
\hline 3 & 3.83 & n.a. & 0.20009 & 0.026 & 0.02 & n.a. & BMB \\
\hline 4 & 4.46 & Chloride & 0.34155 & 0.050 & 0.03 & 1.8175 & BM \\
\hline 5 & 4.68 & n.a. & 0.13695 & 0.020 & 0.01 & n.a. & MB \\
\hline 6 & 5.52 & Nitrite-N & 0.04065 & 0.012 & 0.01 & 0.1203 & BMB \\
\hline 7 & 7.83 & Nitrate-N & 0.36919 & 0.089 & 0.05 & 1.3383 & BMB \\
\hline 8 & 10.66 & n.a. & 19.82899 & 5.673 & 3.51 & n.a. & BM \\
\hline 9 & 11.69 & n.a. & 56.70455 & 52.270 & 32.37 & n.a. & BMB \\
\hline 10 & 21.93 & n.a. & & & & & BB \\
\hline
\end{tabular}




\section{H6L110106 JK7KA MS 1/10 0.2 PPM F, CL, BR}

\begin{tabular}{llll|}
\hline Sample Name: & H6L110106 JK7KA MS 1/10 0.2 PPM F, CL, Injection Volume: & $\mathbf{5 0 . 0}$ \\
Vial Number: & $\mathbf{1 4 1}$ & Channel: & ECD_1 \\
Sample Type: & unknown & Wavelength: & n.a. \\
Control Program: & ANIONS_AS14A_Cl2 & Bandwidth: & n.a. \\
Quantif. Method: & ANIONS & Dilution Factor: & 10.0000 \\
Recording Time: & $\mathbf{1 2 / 1 9 / 2 0 0 6 ~ 9 : 4 9}$ & Sample Weight: & 1.0000 \\
Run Time (min): & $\mathbf{1 3 . 8 8}$ & Sample Amount: & 1.0000 \\
\hline
\end{tabular}

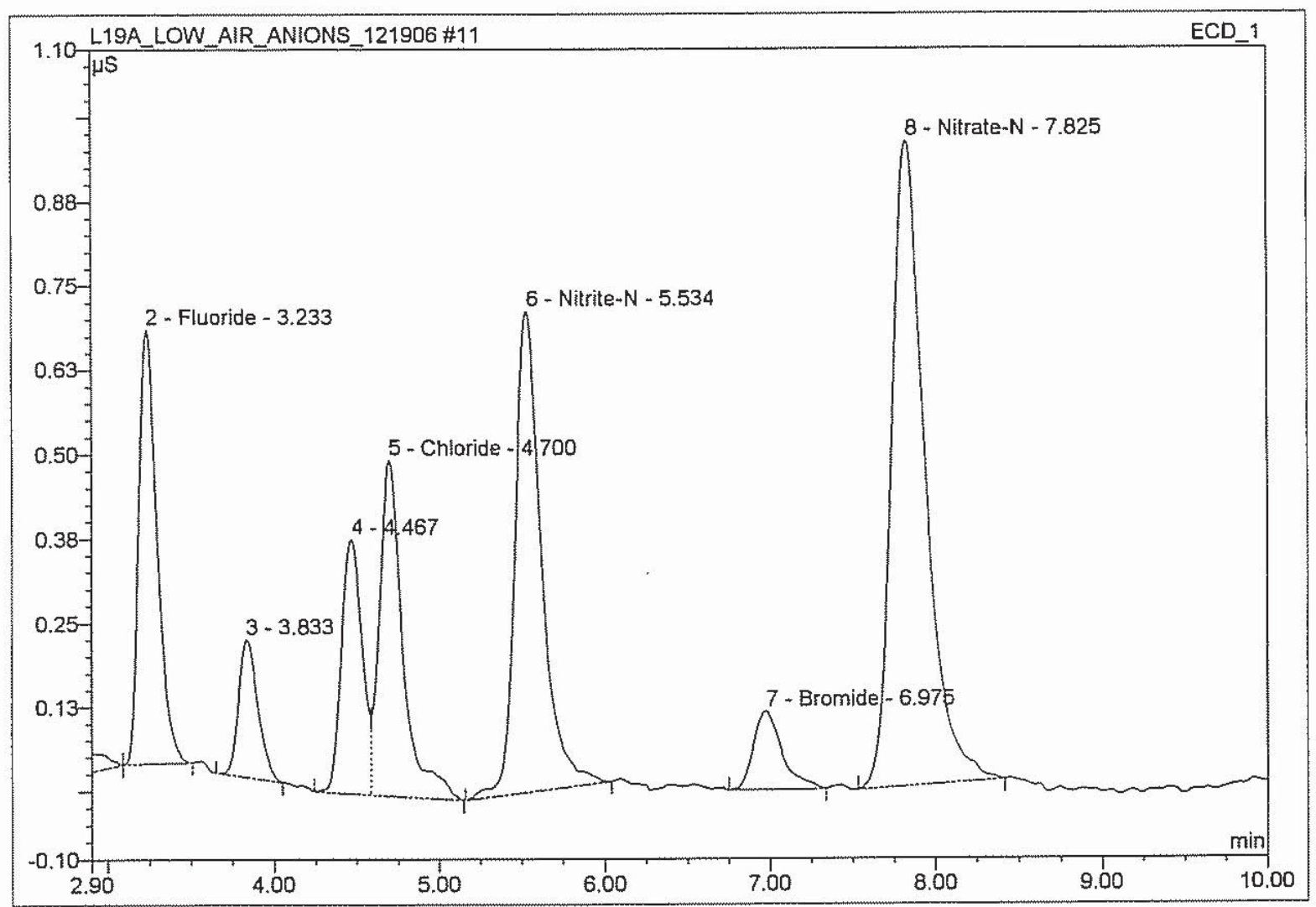

\begin{tabular}{|r|r|l|r|r|r|r|c|}
\hline No. & $\begin{array}{c}\text { Ret.Time } \\
\text { (min.) }\end{array}$ & \multicolumn{1}{|c|}{ Peak Name } & $\begin{array}{c}\text { Height } \\
\text { (uS) }\end{array}$ & $\begin{array}{c}\text { Area } \\
\mu S^{*} \text { min }\end{array}$ & $\begin{array}{r}\text { Rel.Area } \\
(\%)\end{array}$ & $\begin{array}{c}\text { Amount } \\
\text { (mg/L) }\end{array}$ & $\begin{array}{r}\text { Peak } \\
\text { Type }\end{array}$ \\
\hline 1 & 2.23 & n.a. & 1.72838 & 0.298 & 0.27 & n.a. & BMB \\
\hline 2 & 3.23 & Fluoride & 0.64330 & 0.083 & 0.08 & 2.0405 & bMB \\
\hline 3 & 3.83 & n.a. & 0.20493 & 0.027 & 0.02 & n.a. & BMB \\
\hline 4 & 4.47 & n.a. & 0.37660 & 0.055 & 0.05 & n.a. & BM \\
\hline 5 & 4.70 & Chloride & 0.49779 & 0.082 & 0.07 & 2.6414 & MB \\
\hline 6 & 5.53 & Nitrite-N & 0.71269 & 0.133 & 0.12 & 2.0923 & BMB \\
\hline 7 & 6.98 & Bromide & 0.11543 & 0.023 & 0.02 & 2.0218 & BMB \\
\hline 8 & 7.83 & Nitrate-N & 0.95547 & 0.223 & 0.20 & 3.4249 & BMB \\
\hline 9 & 10.68 & n.a. & 19.53185 & 5.569 & 5.07 & n.a. & BM \\
\hline 10 & 11.71 & n.a. & 103.405 & 94.09 & n.a. & MB \\
\hline
\end{tabular}

$$
F=2.0405-0.1814=1.8591 / 2.0 \% 92.96 \% R
$$

default_letter/Integration $B 1-2.0218 / 2=101.1 \% R$ 


\section{H6L110106 JK7K2 1/10}

\begin{tabular}{llll|}
\hline Sample Name: & H6L110106 JK7K2 1/10 & Injection Volume: & $\mathbf{5 0 . 0}$ \\
Vial Number: & $\mathbf{1 4 2}$ & Channel: & ECD_1 \\
Sample Type: & unknown & Wavelength: & n.a. \\
Control Program: & ANIONS_AS14A_Cl2 & Bandwidth: & n.a. \\
Quantif. Method: & ANIONS & Dilution Factor: & 10.0000 \\
Recording Time: & $12 / 19 / 200610: 21$ & Sample Weight: & 1.0000 \\
Run Time (min): & $\mathbf{3 0 . 0 0}$ & Sample Amount: & $\mathbf{1 . 0 0 0 0}$ \\
\hline
\end{tabular}

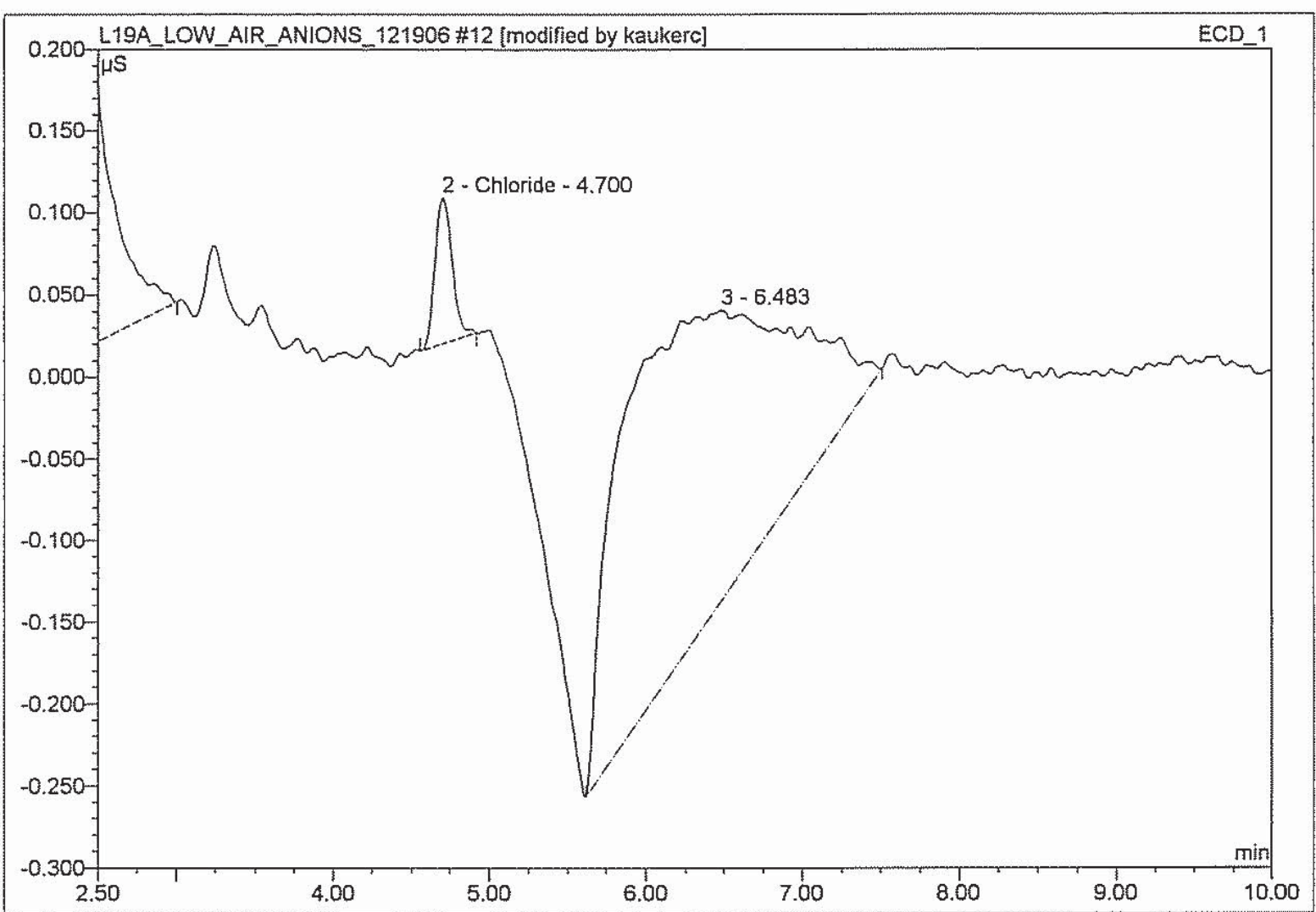

\begin{tabular}{|r|c|l|r|r|r|r|c|}
\hline No. & $\begin{array}{c}\text { Ret.Time } \\
\text { (min.) }\end{array}$ & \multicolumn{1}{|c|}{ Peak Name } & $\begin{array}{c}\text { Height } \\
\text { (uS) }\end{array}$ & $\begin{array}{c}\text { Area } \\
\mu S^{*} \text { min }\end{array}$ & $\begin{array}{c}\text { Rel.Area } \\
(\%)\end{array}$ & $\begin{array}{c}\text { Amount } \\
\text { (mg/L) }\end{array}$ & $\begin{array}{r}\text { Peak } \\
\text { Type }\end{array}$ \\
\hline 1 & 2.23 & n.a. & 1.44714 & 0.254 & 0.48 & n.a. & BMB \\
\hline 2 & 4.70 & Chloride & 0.08865 & 0.011 & 0.02 & 0.4740 & BMB $^{*}$ \\
\hline 3 & 6.48 & n.a. & 0.17716 & 0.247 & 0.47 & n.a. & BMB \\
\hline 4 & 11.98 & n.a. & 0.50966 & 0.176 & 0.33 & n.a. & BMB \\
\hline 5 & 21.97 & n.a. & 56.57459 & 52.193 & 98.70 & n.a. & BMB \\
\hline
\end{tabular}

manual integration $\mathrm{Cl}$ -

(B) Cuk $12 / 19 / 06$ 


\section{H6L110106 JK7K2 1/10}

\begin{tabular}{llll|}
\hline Sample Name: & H6L110106 JK7K2 1/10 & Injection Volume: & $\mathbf{5 0 . 0}$ \\
Vial Number: & $\mathbf{1 4 2}$ & Channel: & ECD_1 \\
Sample Type: & unknown & Wavelength: & n.a. \\
Control Program: & ANIONS_AS14A_CI2 & Bandwidth: & n.a. \\
Quantif. Method: & ANIONS & Dilution Factor: & 10.0000 \\
Recording Time: & $12 / 19 / 200610: 21$ & Sample Weight: & 1.0000 \\
Run Time (min): & $\mathbf{3 0 . 0 0}$ & Sample Amount: & $\mathbf{1 . 0 0 0 0}$ \\
\hline
\end{tabular}

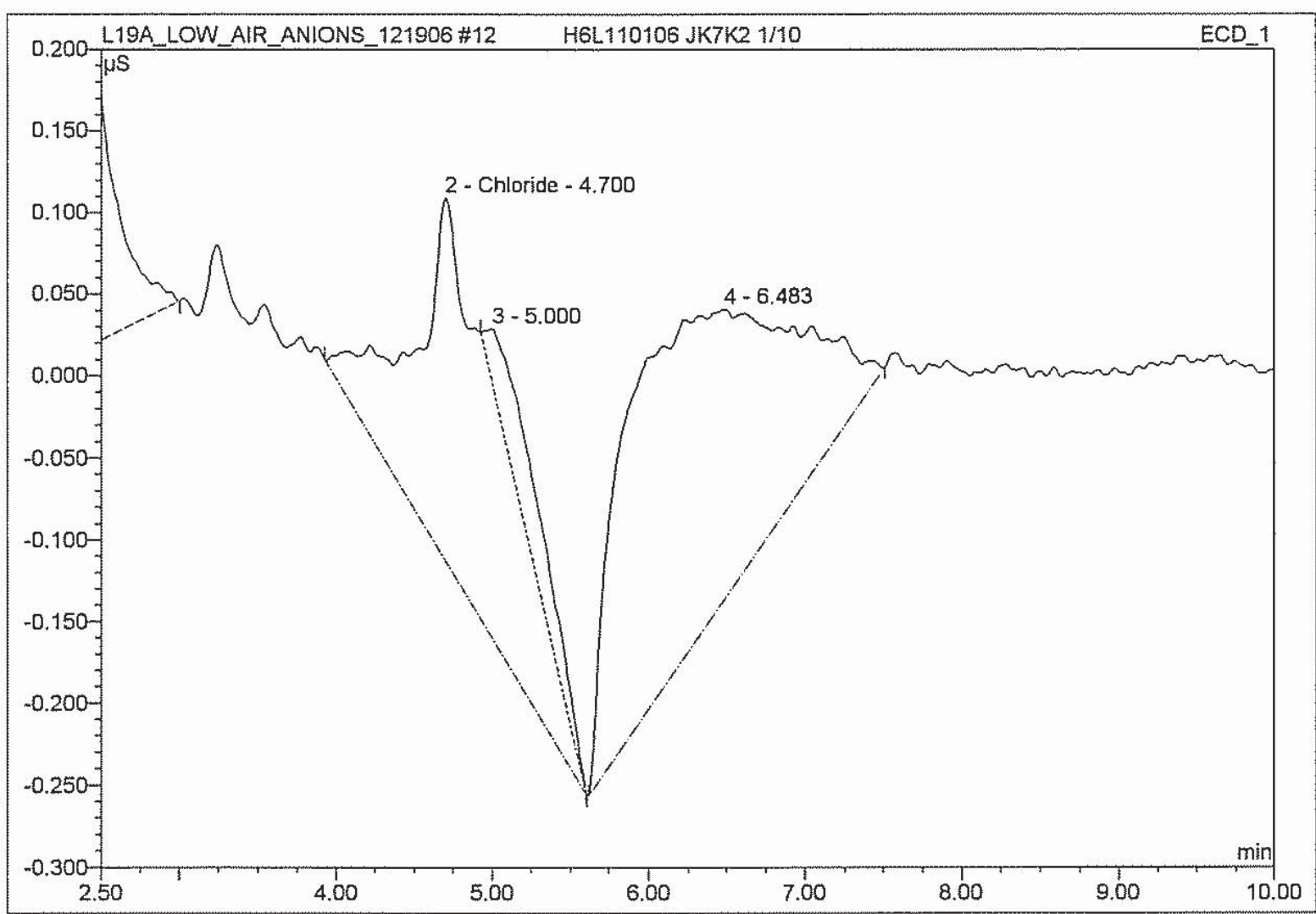

\begin{tabular}{|c|c|l|r|r|r|r|c|}
\hline No. & $\begin{array}{c}\text { Ret.Time } \\
\text { (min.) }\end{array}$ & \multicolumn{1}{|c|}{ Peak Name } & $\begin{array}{c}\text { Height } \\
\text { (uS) }\end{array}$ & $\begin{array}{c}\text { Area } \\
\mu S^{*} \text { min }\end{array}$ & $\begin{array}{c}\text { Rel.Area } \\
(\%)\end{array}$ & $\begin{array}{c}\text { Amount } \\
\text { (mg/L) }\end{array}$ & $\begin{array}{r}\text { Peak } \\
\text { Type }\end{array}$ \\
\hline 1 & 2.23 & n.a. & 1.44714 & 0.254 & 0.48 & n.a. & BMB \\
\hline 2 & 4.70 & Chloride & 0.22151 & 0.156 & 0.29 & 1.1814 & BMB \\
\hline 3 & 5.00 & n.a. & 0.03334 & 0.024 & 0.04 & n.a. & Rd \\
\hline 4 & 6.48 & n.a. & 0.17716 & 0.247 & 0.47 & n.a. & BMB \\
\hline 5 & 11.98 & n.a. & 0.50966 & 0.176 & 0.33 & n.a. & BMB \\
\hline 6 & 21.97 & n.a. & 56.57459 & 52.193 & 98.39 & n.a. & BMB \\
\hline
\end{tabular}

original 


\section{H6L110106 JK7K2 MS 1/10 0.2 PPM F, CL, BR}

\begin{tabular}{llll|}
\hline Sample Name: & H6L110106 JK7K2 MS 1/10 0.2 PPM F, CL, lnjection Volume: & $\mathbf{5 0 . 0}$ \\
Vial Number: & $\mathbf{1 4 3}$ & Channel: & ECD_1 \\
Sample Type: & unknown & Wavelength: & n.a. \\
Control Program: & ANIONS_AS14A_Cl2 & Bandwidth: & n.a. \\
Quantif. Method: & ANIONS & Dilution Factor: & 10.0000 \\
Recording Time: & $\mathbf{1 2 / 1 9 / 2 0 0 6 ~ 1 0 : 5 4}$ & Sample Weight: & $\mathbf{1 . 0 0 0 0}$ \\
Run Time (min): & $\mathbf{3 0 . 0 0}$ & Sample Amount: & $\mathbf{1 . 0 0 0 0}$ \\
\hline
\end{tabular}

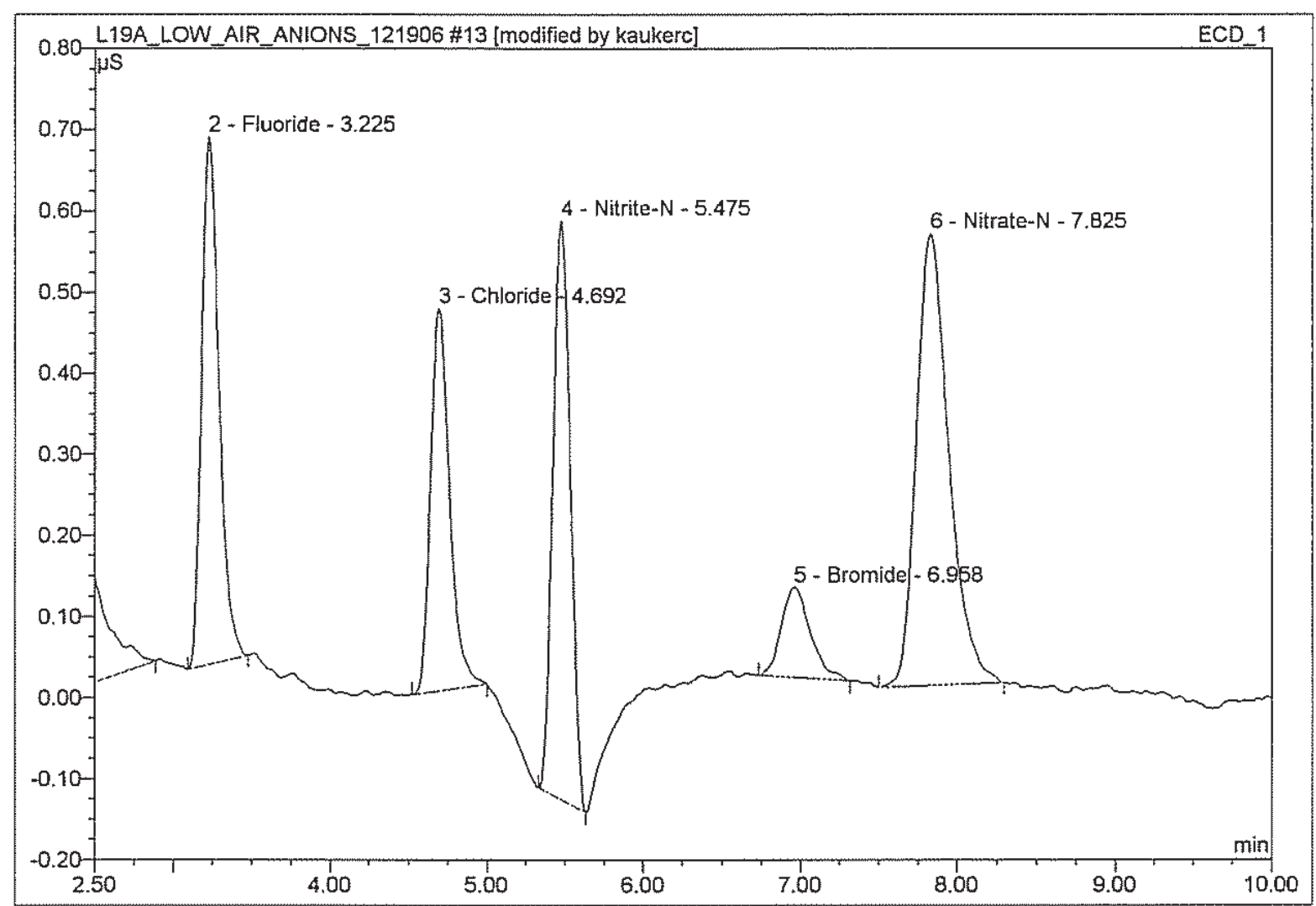

\begin{tabular}{|c|c|l|r|r|r|r|c|}
\hline No. & $\begin{array}{c}\text { Ret.Time } \\
(\mathrm{min} .)\end{array}$ & \multicolumn{1}{|c|}{ Peak Name } & $\begin{array}{c}\text { Height } \\
(\mathbf{u S})\end{array}$ & $\begin{array}{c}\text { Area } \\
\boldsymbol{\mu} \mathrm{S}^{*} \mathrm{~min}\end{array}$ & $\begin{array}{r}\text { Rel.Area } \\
(\%)\end{array}$ & $\begin{array}{r}\text { Amount } \\
(\mathrm{mg} / \mathrm{L})\end{array}$ & $\begin{array}{r}\text { Peak } \\
\text { Type }\end{array}$ \\
\hline 1 & 2.22 & n.a. & 1.45986 & 0.249 & 0.47 & n.a. & BMB \\
\hline 2 & 3.23 & Fluoride & 0.65024 & 0.083 & 0.16 & 2.0623 & BMB \\
\hline 3 & 4.69 & Chloride & 0.47198 & 0.066 & 0.13 & 2.5056 & BMB $^{*}$ \\
\hline 4 & 5.48 & Nitrite-N & 0.71363 & 0.092 & 0.17 & 2.0951 & BMB \\
\hline 5 & 6.96 & Bromide & 0.11106 & 0.024 & 0.05 & 1.9455 & BMB \\
\hline 6 & 7.83 & Nitrate-N & 0.55673 & 0.133 & 0.25 & 2.0108 & BMB \\
\hline 7 & 11.96 & n.a. & 0.42070 & 0.151 & 0.28 & n.a. & BMB \\
\hline 8 & 21.96 & n.a. & 56.64823 & 52.175 & 98.49 & n.a. & BMB \\
\hline
\end{tabular}

$$
\mathrm{Cl}^{-} \quad 2.5056-0.4740=\left.2.0316\right|_{2.0}=101.6 \% \mathrm{R}
$$




\section{H6L110106 JK7K2 MS 1/10 0.2 PPM F, CL, BR}

\begin{tabular}{llll|}
\hline Sample Name: & H6L110106 JK7K2 MS 1/10 0.2 PPM F, CL, & Injection Volume: & $\mathbf{5 0 . 0}$ \\
Vial Number: & 143 & Channel: & ECD_1 \\
Sample Type: & unknown & Wavelength: & n.a. \\
Control Program: & ANIONS_AS14A_Cl2 & Bandwidth: & n.a. \\
Quantif. Method: & ANIONS & Dilution Factor: & 10.0000 \\
Recording Time: & $12 / 19 / 200610: 54$ & Sample Weight: & 1.0000 \\
Run Time (min): & 30.00 & Sample Amount: & 1.0000 \\
\hline
\end{tabular}

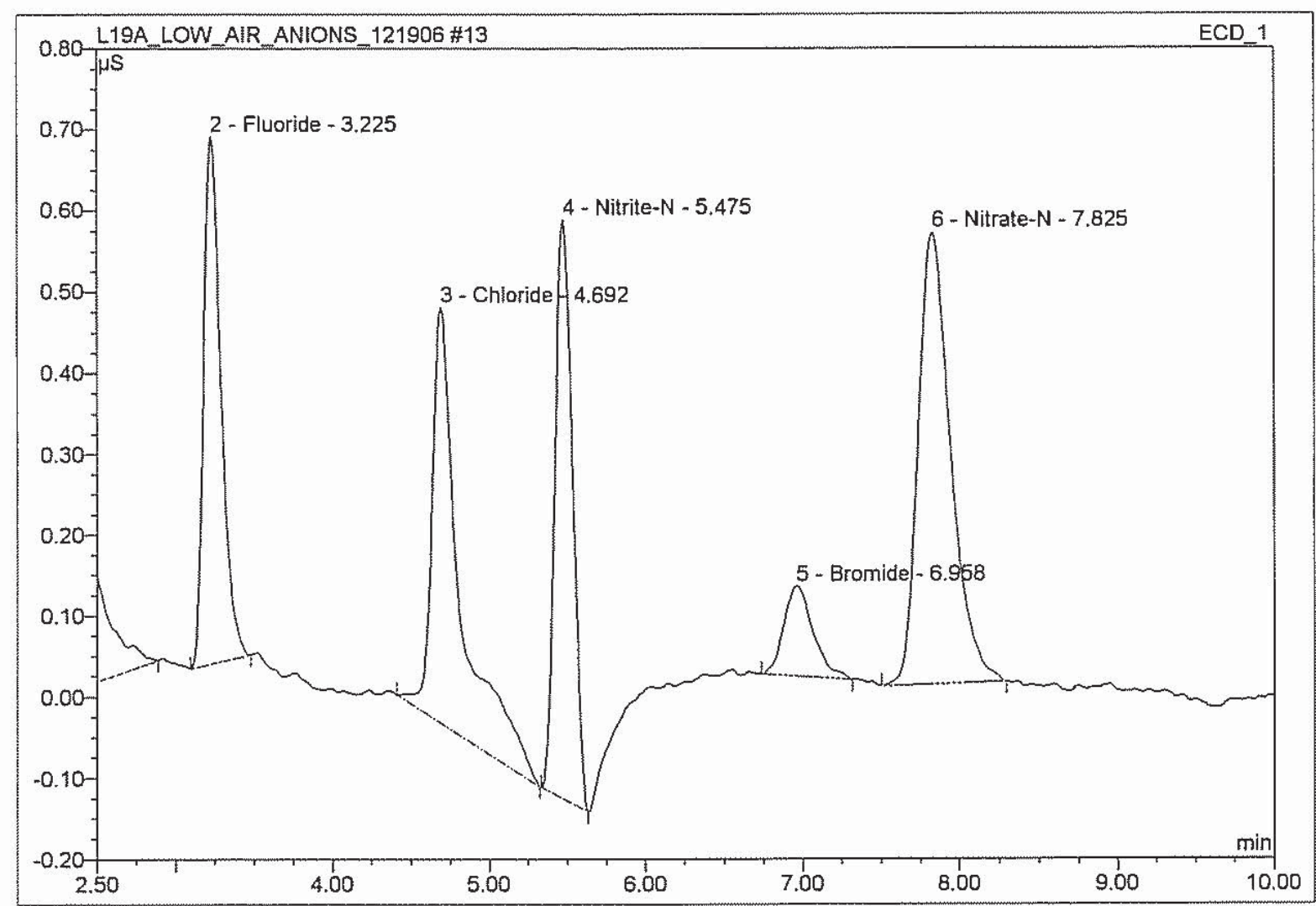

\begin{tabular}{|c|c|l|r|r|r|r|r|}
\hline No. & $\begin{array}{c}\text { Ret.Time } \\
\text { (min.) }\end{array}$ & \multicolumn{1}{|c|}{ Peak Name } & $\begin{array}{c}\text { Height } \\
\text { (uS) }\end{array}$ & $\begin{array}{c}\text { Area } \\
\mu S^{*} \min \end{array}$ & $\begin{array}{r}\text { Rel.Area } \\
(\%)\end{array}$ & $\begin{array}{r}\text { Amount } \\
\text { (mg/L) }\end{array}$ & $\begin{array}{r}\text { Peak } \\
\text { Type }\end{array}$ \\
\hline 1 & 2.22 & n.a. & 1.45986 & 0.249 & 0.47 & n.a. & BMB \\
\hline 2 & 3.23 & Fluoride & 0.65024 & 0.083 & 0.16 & 2.0623 & BMB \\
\hline 3 & 4.69 & Chloride & 0.51228 & 0.107 & 0.20 & 2.7176 & BMB \\
\hline 4 & 5.48 & Nitrite-N & 0.71363 & 0.092 & 0.17 & 2.0951 & BMB \\
\hline 5 & 6.96 & Bromide & 0.11106 & 0.024 & 0.05 & 1.9455 & BMB \\
\hline 6 & 7.83 & Nitrate-N & 0.55673 & 0.133 & 0.25 & 2.0108 & BMB \\
\hline 7 & 11.96 & n.a. & 0.42070 & 0.151 & 0.28 & n.a. & BMB \\
\hline 8 & 21.96 & n.a. & 56.64823 & 52.175 & 98.42 & n.a. & BMB \\
\hline
\end{tabular}

$$
\text { original }
$$




\section{H6L110106 JK7KA MSD 1/10 0.2 PPM F, CL, BR}

\begin{tabular}{llll|}
\hline Sample Name: & H6L110106 JK7KA MSD 1/10 0.2 PPM F, CL Injection Volume: & $\mathbf{5 0 . 0}$ \\
Vial Number: & $\mathbf{1 4 3}$ & Channel: & ECD_1 \\
Sample Type: & unknown & Wavelength: & n.a. \\
Control Program: & ANIONS_AS14A_Cl2 & Bandwidth: & n.a. \\
Quantif. Method: & ANIONS & Dilution Factor: & $\mathbf{1 0 . 0 0 0 0}$ \\
Recording Time: & $\mathbf{1 2 / 1 9 / 2 0 0 6 ~ 1 1 : 2 6}$ & Sample Weight: & $\mathbf{1 . 0 0 0 0}$ \\
Run Time (min): & $\mathbf{3 0 . 0 0}$ & Sample Amount: & $\mathbf{1 . 0 0 0 0}$ \\
\hline
\end{tabular}

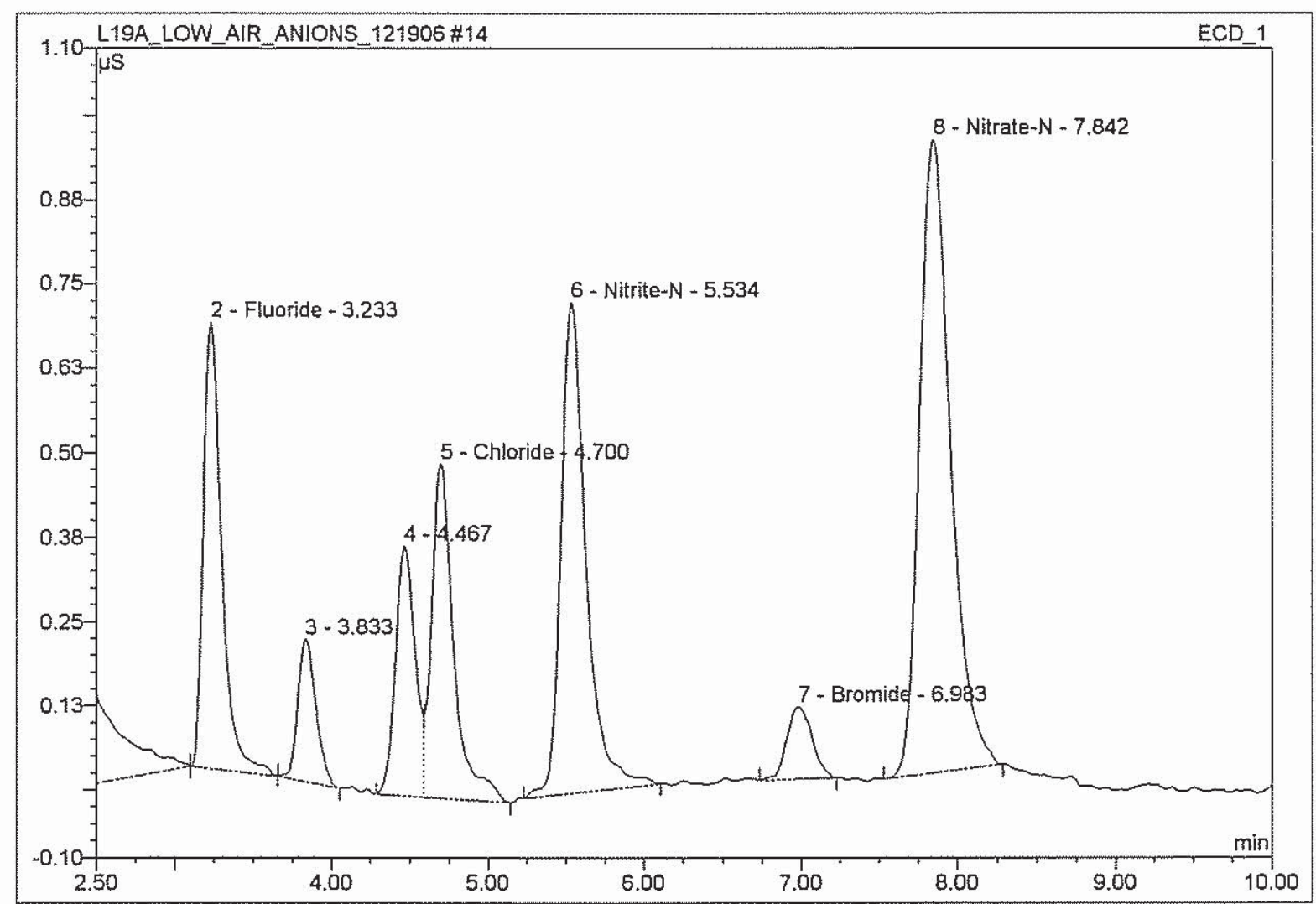

\begin{tabular}{|r|r|l|r|r|r|r|c|}
\hline No. & $\begin{array}{c}\text { Ret.Time } \\
(\mathbf{m i n})\end{array}$ & \multicolumn{1}{|c|}{ Peak Name } & $\begin{array}{c}\text { Height } \\
(\mathbf{u S})\end{array}$ & $\begin{array}{c}\text { Area } \\
\mu S^{*} \text { min }\end{array}$ & $\begin{array}{r}\text { Rel.Area } \\
(\%)\end{array}$ & $\begin{array}{r}\text { Amount } \\
(\mathrm{mg} / \mathrm{L})\end{array}$ & $\begin{array}{r}\text { Peak } \\
\text { Type }\end{array}$ \\
\hline 1 & 2.23 & n.a. & 1.77246 & 0.299 & 0.18 & n.a. & BMB \\
\hline 2 & 3.23 & Fluoride & 0.65994 & 0.089 & 0.05 & 2.0928 & bMB \\
\hline 3 & 3.83 & n.a. & 0.21125 & 0.028 & 0.02 & n.a. & BMB \\
\hline 4 & 4.47 & n.a. & 0.37079 & 0.055 & 0.03 & n.a. & BM \\
\hline 5 & 4.70 & Chloride & 0.49601 & 0.081 & 0.05 & 2.6320 & MB \\
\hline 6 & 5.53 & Nitrite-N & 0.72648 & 0.135 & 0.08 & 2.1325 & BMB \\
\hline 7 & 6.98 & Bromide & 0.10608 & 0.020 & 0.01 & 1.8585 & BMB \\
\hline 8 & 7.84 & Nitrate-N & 0.93800 & 0.216 & 0.13 & 3.3633 & BMB \\
\hline 9 & 10.68 & n.a. & 18.87528 & 5.394 & 3.31 & n.a. & BM \\
\hline 10 & 11.71 & n.a. & 56.91333 & 52.722 & 32.38 & n.a. & BMB \\
\hline 11 & 21.96 & n.a. & & & & & \\
\hline
\end{tabular}




\section{H6L110106 JK7KN 1/10}

$\begin{array}{ll}\text { Sample Name: } & \text { H6L110106 JK7KN 1/10 } \\ \text { Vial Number: } & \mathbf{1 4 4} \\ \text { Sample Type: } & \text { unknown } \\ \text { Control Program: } & \text { ANIONS_AS14A_CI2 } \\ \text { Quantif. Method: } & \text { ANIONS } \\ \text { Recording Time: } & \mathbf{1 2 / 1 9 / 2 0 0 6 ~ 1 1 : 5 9} \\ \text { Run Time (min): } & \mathbf{2 2 . 9 0}\end{array}$

$\begin{array}{ll}\text { Injection Volume: } & \mathbf{5 0 . 0} \\ \text { Channel: } & \text { ECD_1 } \\ \text { Wavelength: } & \text { n.a. } \\ \text { Bandwidth: } & \text { n.a. } \\ \text { Dilution Factor: } & \mathbf{1 0 . 0 0 0 0} \\ \text { Sample Weight: } & \mathbf{1 . 0 0 0 0} \\ \text { Sample Amount: } & \mathbf{1 . 0 0 0 0}\end{array}$

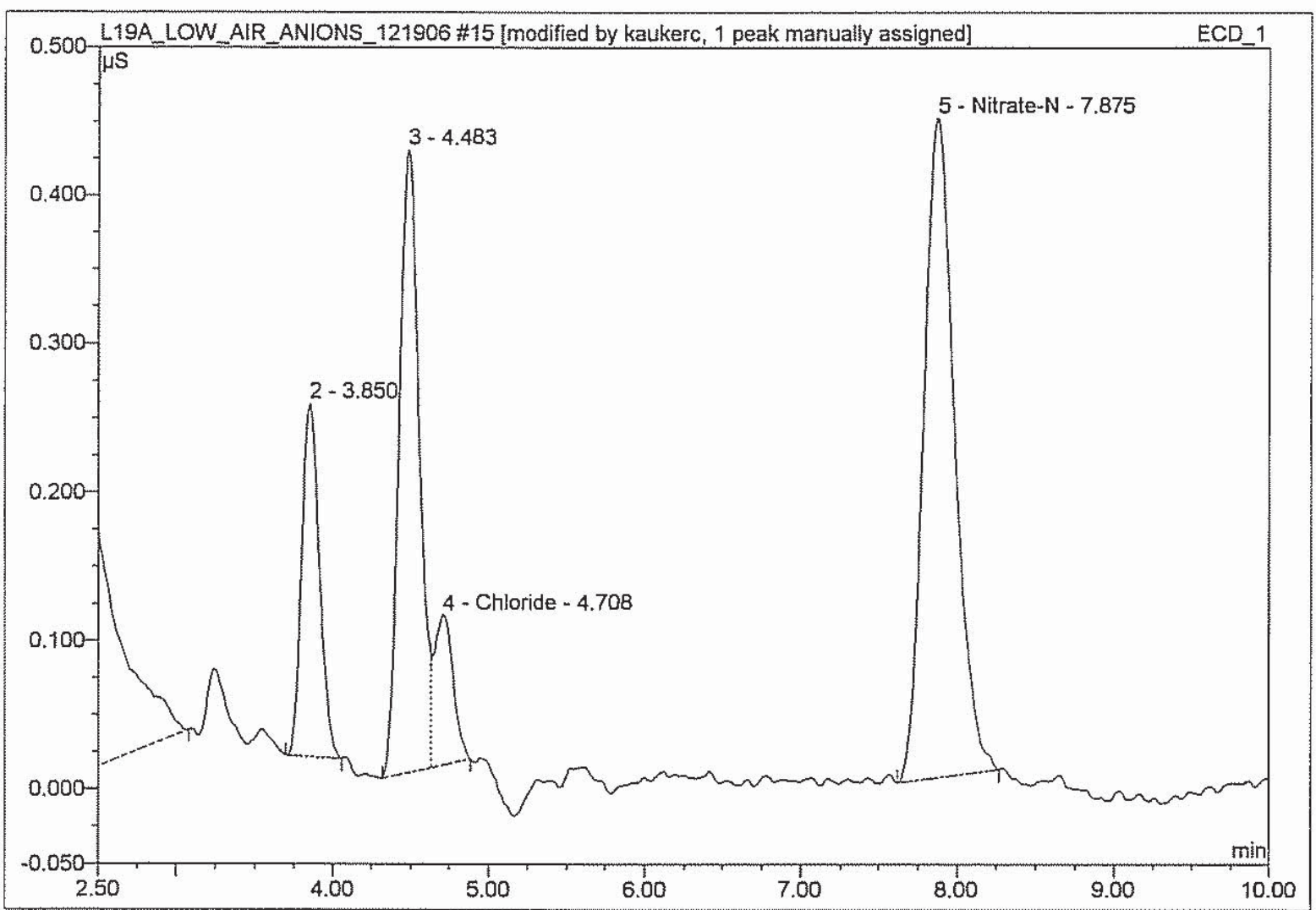

\begin{tabular}{|c|c|l|r|r|r|r|r|}
\hline No. & $\begin{array}{c}\text { Ret.Time } \\
\text { (min.) }\end{array}$ & \multicolumn{1}{|c|}{ Peak Name } & $\begin{array}{c}\text { Height } \\
\text { (uS) }\end{array}$ & $\begin{array}{c}\text { Area } \\
\mu S^{*} \min \end{array}$ & $\begin{array}{r}\text { Rel.Area } \\
(\%)\end{array}$ & $\begin{array}{r}\text { Amount } \\
\text { (mg/L) }\end{array}$ & $\begin{array}{r}\text { Peak } \\
\text { Type }\end{array}$ \\
\hline 1 & 2.23 & n.a. & 1.92701 & 0.322 & 0.21 & n.a. & BMB \\
\hline 2 & 3.85 & n.a. & 0.23754 & 0.031 & 0.02 & n.a. & BMB \\
\hline 3 & 4.48 & n.a. & 0.41921 & 0.063 & 0.04 & n.a. & $B^{*}$ \\
\hline 4 & 4.71 & Chloride & 0.10109 & 0.014 & 0.01 & 0.5403 & $M^{\star \wedge}$ \\
\hline 5 & 7.88 & Nitrate-N & 0.44389 & 0.101 & 0.07 & 1.6067 & BMB \\
\hline 6 & 10.68 & n.a. & 34.84426 & 9.882 & 6.53 & n.a. & BM \\
\hline 7 & 11.72 & n.a. & 105.466 & 69.67 & n.a. & MB \\
\hline 8 & 21.97 & n.a. & 52.22795 & 35.502 & 23.45 & n.a. & BMB \\
\hline
\end{tabular}

$$
\begin{aligned}
& \text { Split Peak / misidentified peak } \\
& \text { cuk } 12119106
\end{aligned}
$$




\section{H6L110106 JK7KN 1/10}

\begin{tabular}{llll|}
\hline Sample Name: & H6L110106 JK7KN 1/10 & Injection Volume: & $\mathbf{5 0 . 0}$ \\
Vial Number: & $\mathbf{1 4 4}$ & Channel: & ECD_1 \\
Sample Type: & unknown & Wavelength: & n.a. \\
Control Program: & ANIONS_AS14A_Cl2 & Bandwidth: & n.a. \\
Quantif. Method: & ANIONS & Dilution Factor: & $\mathbf{1 0 . 0 0 0 0}$ \\
Recording Time: & $\mathbf{1 2 / 1 9 / 2 0 0 6 1 1 : 5 9}$ & Sample Weight: & $\mathbf{1 . 0 0 0 0}$ \\
Run Time (min): & $\mathbf{1 7 . 8 8}$ & Sample Amount: & $\mathbf{1 . 0 0 0 0}$ \\
\hline
\end{tabular}

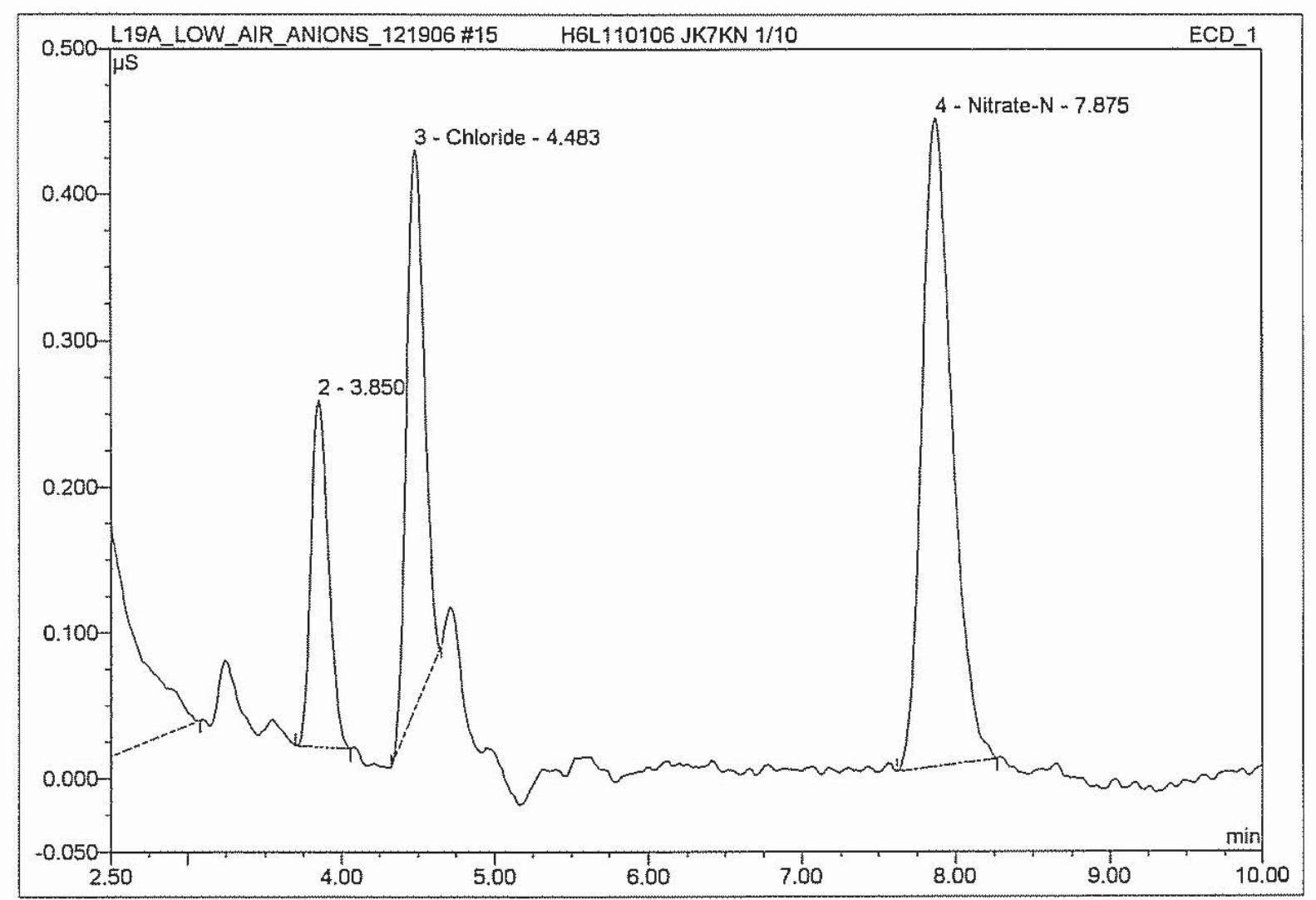

\begin{tabular}{|c|c|l|r|r|r|r|r|}
\hline No. & $\begin{array}{c}\text { Ret.Time } \\
\text { (min.) }\end{array}$ & \multicolumn{1}{|c|}{ Peak Name } & $\begin{array}{c}\text { Height } \\
\text { (uS) }\end{array}$ & $\begin{array}{c}\text { Area } \\
\mu S^{*} \min \end{array}$ & $\begin{array}{r}\text { Rel.Area } \\
(\%)\end{array}$ & $\begin{array}{c}\text { Amount } \\
\text { (mg/L) }\end{array}$ & $\begin{array}{r}\text { Peak } \\
\text { Type }\end{array}$ \\
\hline 1 & 2.23 & n.a. & 1.92701 & 0.322 & 0.28 & n.a. & BMB \\
\hline 2 & 3.85 & n.a. & 0.23754 & 0.031 & 0.03 & n.a. & BMB \\
\hline 3 & 4.48 & Chloride & 0.38160 & 0.051 & 0.04 & 2.0292 & BMB \\
\hline 4 & 7.88 & Nitrate-N & 0.44389 & 0.101 & 0.09 & 1.6067 & BMB \\
\hline 5 & 10.68 & n.a. & 34.84426 & 9.882 & 8.53 & n.a. & BM \\
\hline 6 & 11.72 & n.a. & 105.466 & 91.03 & n.a. & MB \\
\hline
\end{tabular}

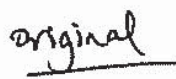




\section{$16 \mathrm{CCV}=$ ICWS -9061}

\begin{tabular}{llll|}
\hline Sample Name: & CCV = ICWS-9061 & Injection Volume: & $\mathbf{5 0 . 0}$ \\
Vial Number: & $\mathbf{1 4 7}$ & Channel: & ECD_1 \\
Sample Type: & unknown & Wavelength: & n.a. \\
Control Program: & ANIONS_AS14A & Bandwidth: & n.a. \\
Quantif. Method: & ANIONS & Dilution Factor: & 1.0000 \\
Recording Time: & $\mathbf{1 2 / 1 9 / 2 0 0 6 ~ 1 2 : 3 1}$ & Sample Weight: & 1.0000 \\
Run Time $(\mathrm{min}):$ & $\mathbf{1 5 . 0 0}$ & Sample Amount: & 1.0000 \\
\hline
\end{tabular}

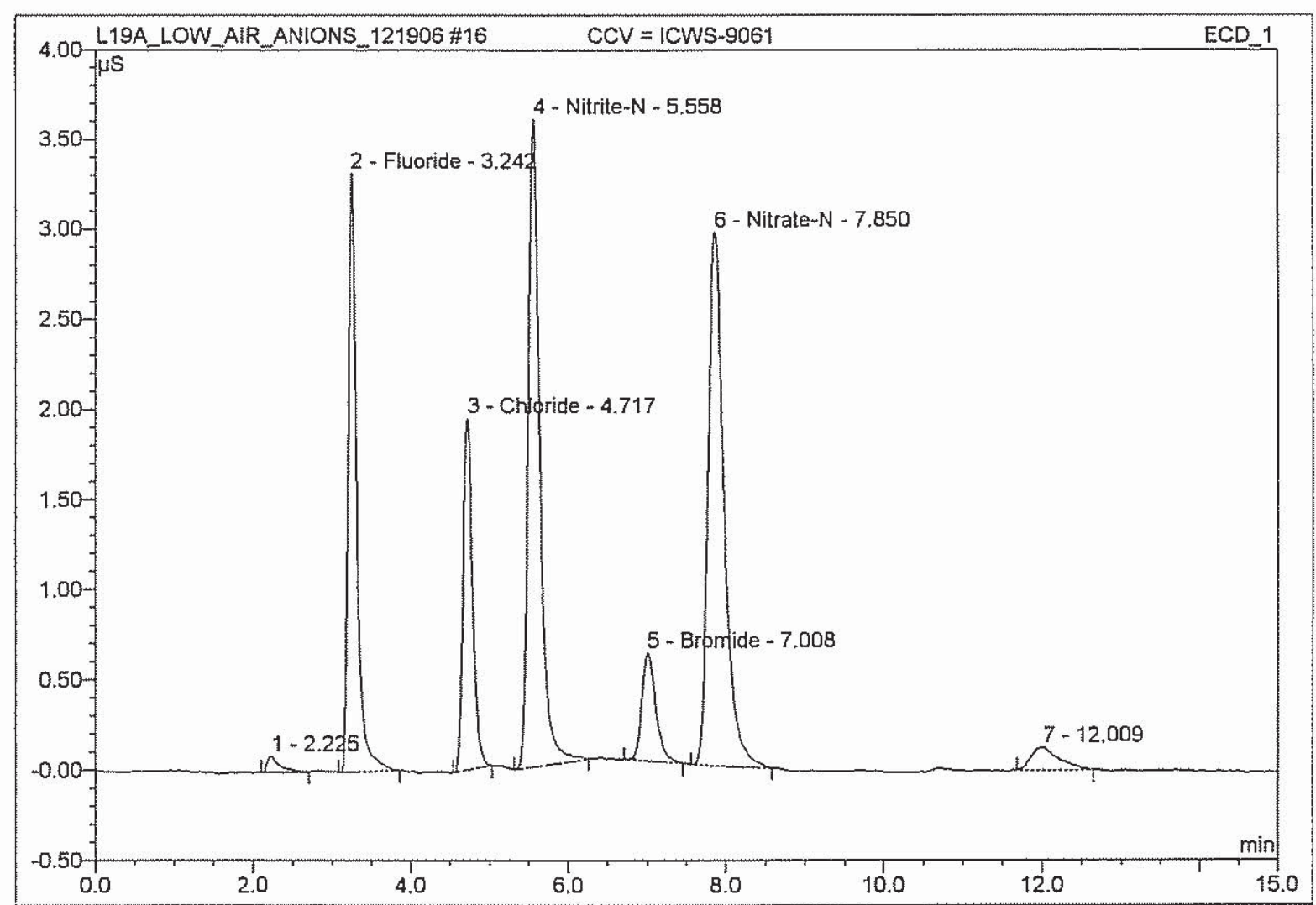

\begin{tabular}{|c|c|l|r|r|r|r|r|}
\hline No. & $\begin{array}{c}\text { Ret.Time } \\
\text { (min.) }\end{array}$ & \multicolumn{1}{|c|}{ Peak Name } & $\begin{array}{c}\text { Height } \\
\text { (uS) }\end{array}$ & $\begin{array}{c}\text { Area } \\
\mu S^{*} \text { min }\end{array}$ & $\begin{array}{r}\text { Rel.Area } \\
(\%)\end{array}$ & $\begin{array}{r}\text { Amount } \\
\text { (mg/L) }\end{array}$ & $\begin{array}{r}\text { Peak } \\
\text { Type }\end{array}$ \\
\hline 1 & 2.23 & n.a. & 0.09026 & 0.017 & 0.76 & n.a. & BMB \\
\hline 2 & 3.24 & Fluoride & 3.31997 & 0.424 & 19.27 & 1.0126 & BMB \\
\hline 3 & 4.72 & Chloride & 1.94952 & 0.272 & 12.35 & 1.0083 & BMB \\
\hline 4 & 5.56 & Nitrite-N & 3.59510 & 0.619 & 28.12 & 1.0213 & BMB \\
\hline 5 & 7.01 & Bromide & 0.59911 & 0.122 & 5.55 & 1.0339 & BMB \\
\hline 6 & 7.85 & Nitrate-N & 2.95797 & 0.696 & 31.63 & 1.0231 & BMB \\
\hline 7 & 12.01 & n.a. & 0.12386 & 0.051 & 2.32 & n.a. & BMB \\
\hline
\end{tabular}




\section{CCB}

\begin{tabular}{llll}
\hline Sample Name: & CCB & Injection Volume: & $\mathbf{5 0 . 0}$ \\
Vial Number: & $\mathbf{1 4 8}$ & Channel: & ECD_1 \\
Sample Type: & unknown & Wavelength: & n.a. \\
Control Program: & ANIONS_AS14A & Bandwidth: & n.a. \\
Quantif. Method: & ANIONS & Dilution Factor: & $\mathbf{1 . 0 0 0 0}$ \\
Recording Time: & $\mathbf{1 2 / 1 9 / 2 0 0 6 1 2 : 4 8}$ & Sample Weight: & $\mathbf{1 . 0 0 0 0}$ \\
Run Time (min): & $\mathbf{1 5 . 0 0}$ & Sample Amount: & $\mathbf{1 . 0 0 0 0}$ \\
\hline
\end{tabular}

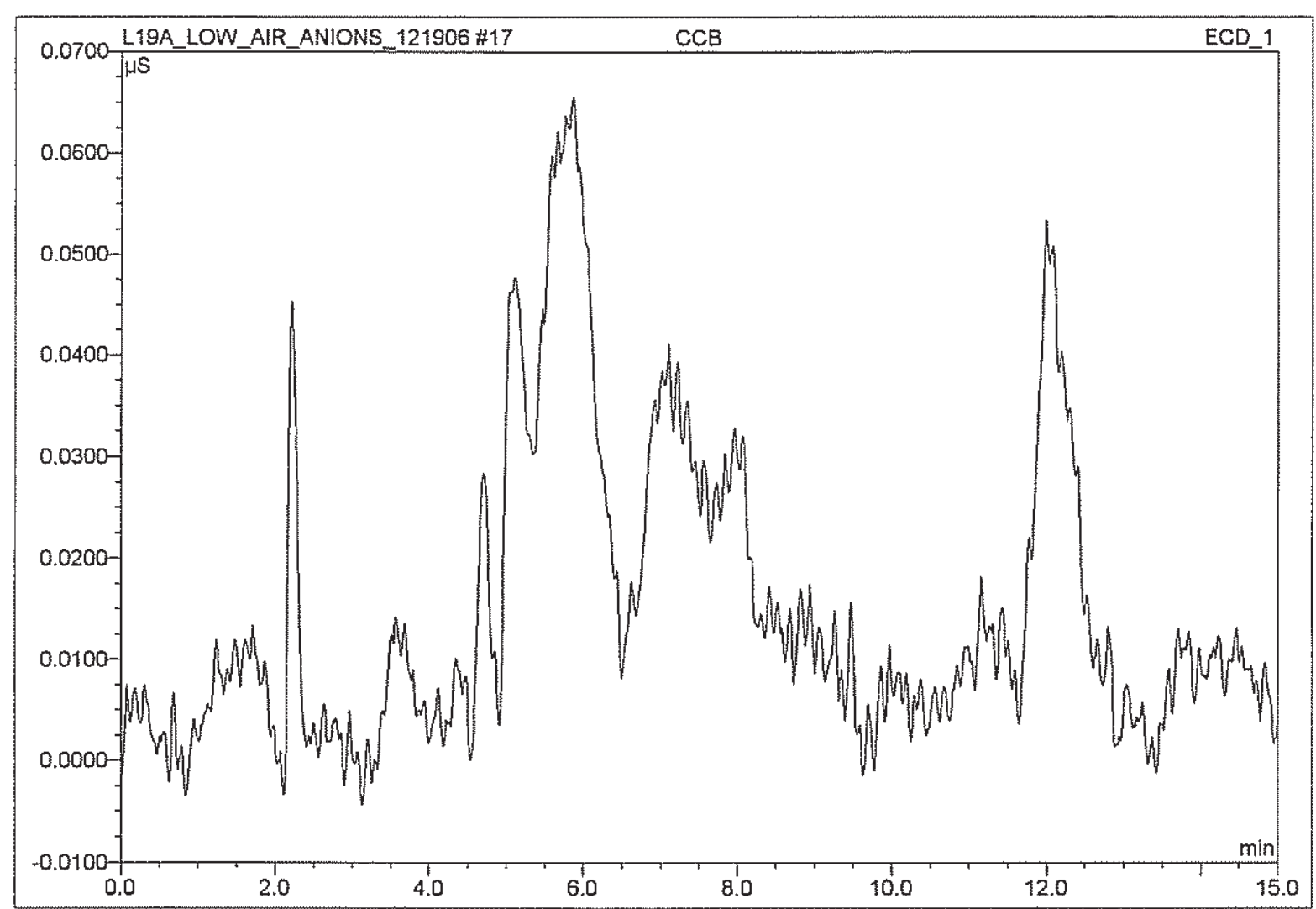

\begin{tabular}{|c|c|c|c|c|c|c|c|}
\hline No. & $\begin{array}{c}\text { Ret.Time } \\
(\mathrm{min})\end{array}$ & Peak Name & $\begin{array}{c}\text { Height } \\
(\mathrm{uS})\end{array}$ & $\begin{array}{c}\text { Area } \\
\mu \mathrm{S}^{*} \mathrm{~min}\end{array}$ & $\begin{array}{c}\text { Rel.Area } \\
(\%)\end{array}$ & $\begin{array}{c}\text { Amount } \\
(\mathrm{mg} / \mathrm{L})\end{array}$ & $\begin{array}{c}\text { Peak } \\
\text { Type }\end{array}$ \\
\hline
\end{tabular}




\section{H6L110106 JK7KW 1/10}

\begin{tabular}{llll}
\hline Sample Name: & H6L110106 JK7KW 1/10 & Injection Volume: & $\mathbf{5 0 . 0}$ \\
Vial Number: & $\mathbf{1 4 9}$ & Channel: & ECD_1 \\
Sample Type: & unknown & Wavelength: & n.a. \\
Control Program: & ANIONS_AS14A_Cl2 & Bandwidth: & n.a. \\
Quantif. Method: & ANIONS & Dilution Factor: & 10.0000 \\
Recording Time: & $\mathbf{1 2 / 1 9 / 2 0 0 6 1 3 : 0 6}$ & Sample Weight: & 1.0000 \\
Run Time (min): & $\mathbf{3 0 . 0 0}$ & Sample Amount: & 1.0000 \\
\hline
\end{tabular}

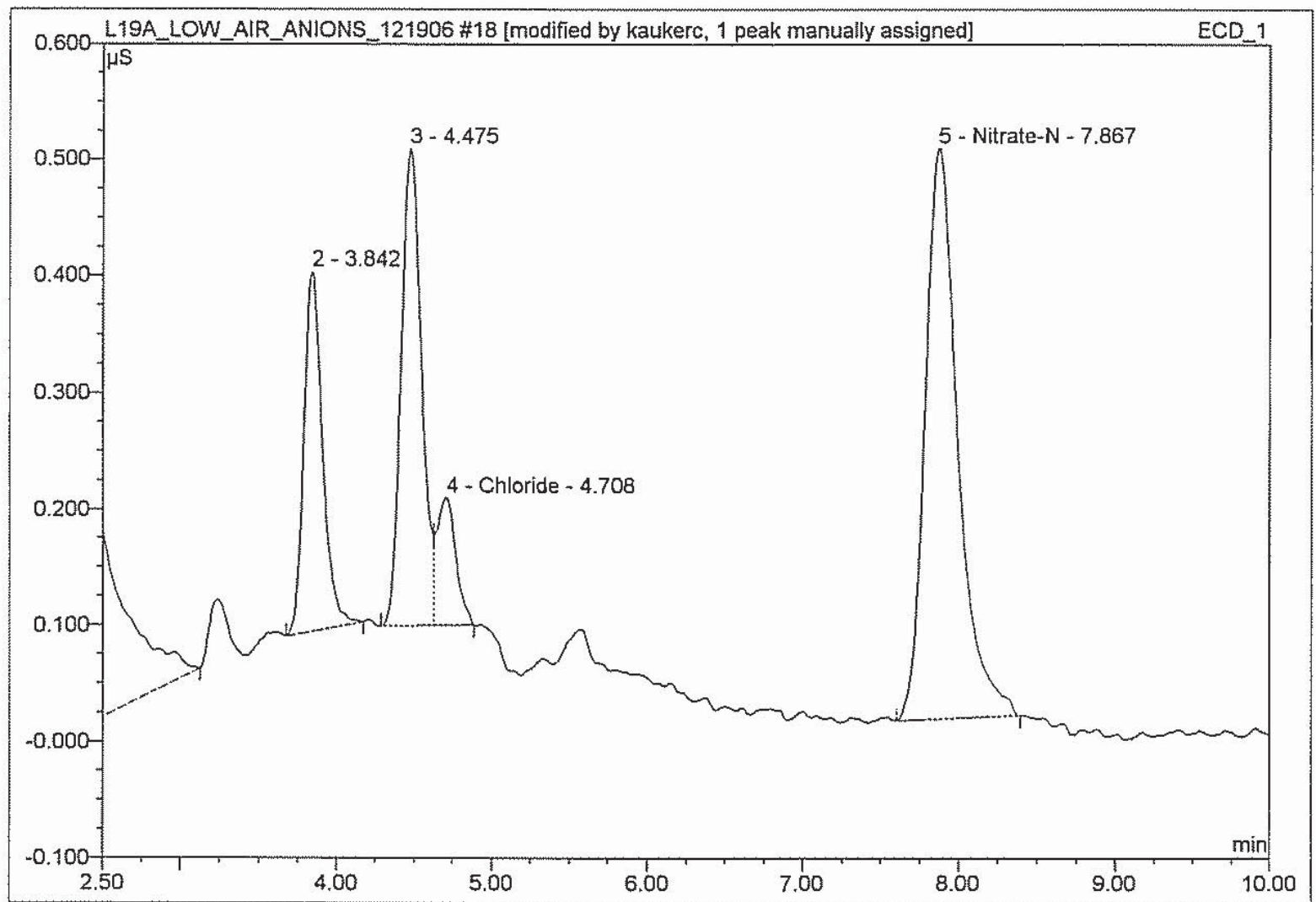

\begin{tabular}{|r|r|l|r|r|r|r|r|}
\hline No. & $\begin{array}{c}\text { Ret.Time } \\
\text { (min.) }\end{array}$ & \multicolumn{1}{|c|}{ Peak Name } & $\begin{array}{c}\text { Height } \\
\text { (uS) }\end{array}$ & $\begin{array}{c}\text { Area } \\
\mu S^{*} \min \end{array}$ & $\begin{array}{r}\text { Rel.Area } \\
(\%)\end{array}$ & $\begin{array}{r}\text { Amount } \\
\text { (mg/L) }\end{array}$ & $\begin{array}{r}\text { Peak } \\
\text { Type }\end{array}$ \\
\hline 1 & 2.23 & n.a. & 2.11949 & 0.350 & 0.19 & n.a. & BMB \\
\hline 2 & 3.84 & n.a. & 0.30890 & 0.043 & 0.02 & n.a. & BMB \\
\hline 3 & 4.48 & n.a. & 0.40994 & 0.062 & 0.03 & n.a. & BM $^{*}$ \\
\hline 4 & 4.71 & Chloride & 0.10993 & 0.016 & 0.01 & 0.5875 & $M^{* \wedge}$ \\
\hline 5 & 7.87 & Nitrate-N & 0.49048 & 0.120 & 0.07 & 1.7737 & BMB \\
\hline 6 & 10.65 & n.a. & 39.88411 & 11.262 & 6.15 & n.a. & BM \\
\hline 7 & 11.68 & n.a. & 56.72228 & 52.338 & 28.60 & n.a. & BMB \\
\hline 8 & 21.97 & n.a. & 118.828 & 64.93 & n.a. \\
\hline
\end{tabular}

\section{(5) cwk 12/19/06}




\section{H6L110106 JK7KW 1/10}

\begin{tabular}{llll|}
\hline Sample Name: & H6L110106 JK7KW 1/10 & Injection Volume: & $\mathbf{5 0 . 0}$ \\
Vial Number: & $\mathbf{1 4 9}$ & Channel: & ECD_1 \\
Sample Type: & unknown & Wavelength: & n.a. \\
Control Program: & ANIONS_AS14A_Cl2 & Bandwidth: & n.a. \\
Quantif. Method: & ANIONS & Dilution Factor: & $\mathbf{1 0 . 0 0 0 0}$ \\
Recording Time: & $\mathbf{1 2 / 1 9 / 2 0 0 6 1 3 : 0 6}$ & Sample Weight: & $\mathbf{1 . 0 0 0 0}$ \\
Run Time (min): & $\mathbf{3 0 . 0 0}$ & Sample Amount: & $\mathbf{1 . 0 0 0 0}$ \\
\hline
\end{tabular}

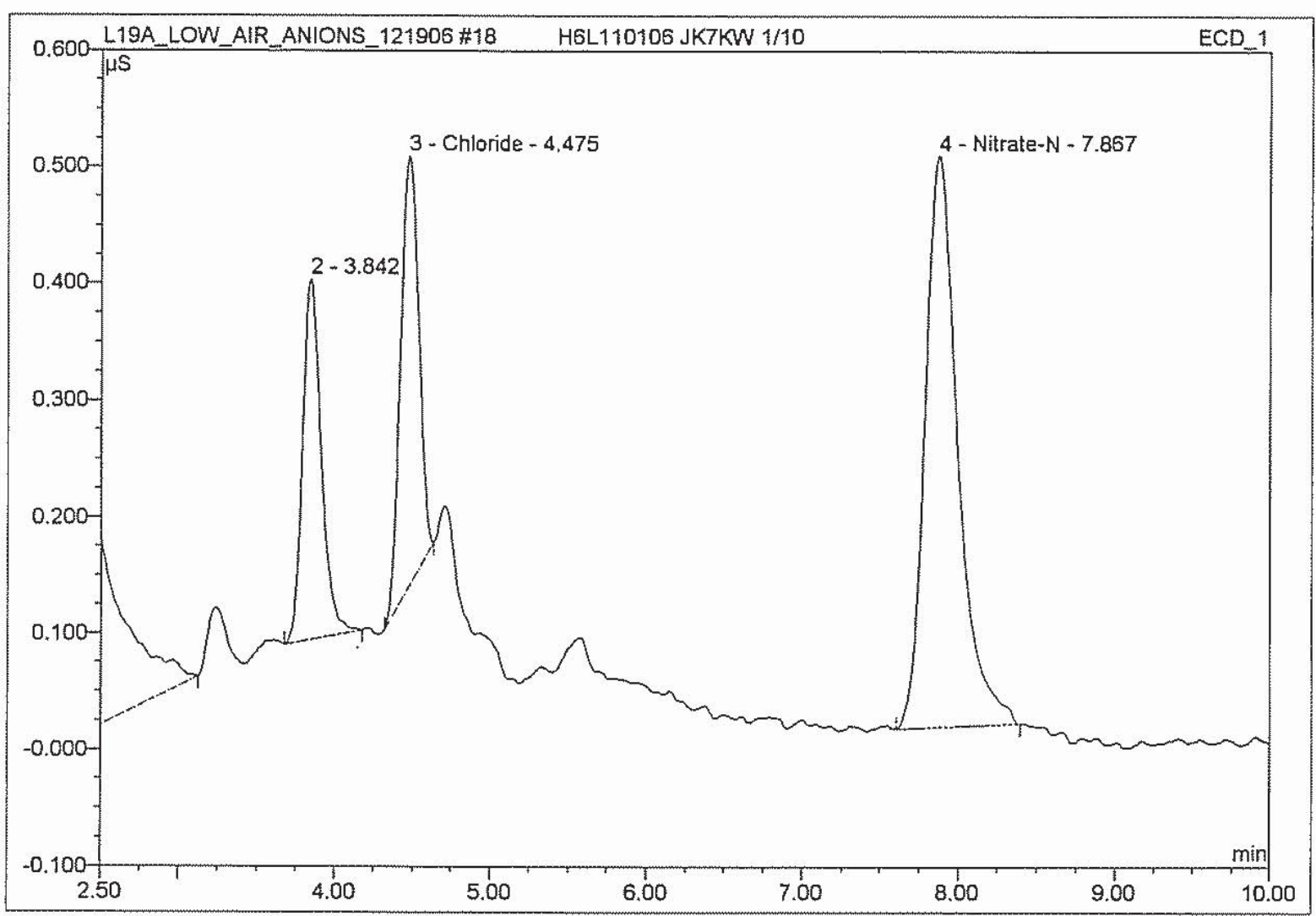

\begin{tabular}{|c|c|l|r|r|r|r|r|}
\hline No. & $\begin{array}{c}\text { Ret.Time } \\
\text { (min.) }\end{array}$ & \multicolumn{1}{|c|}{ Peak Name } & $\begin{array}{c}\text { Height } \\
\text { (uS) }\end{array}$ & $\begin{array}{c}\text { Area } \\
\mu S^{*} \text { min }\end{array}$ & $\begin{array}{c}\text { Rel.Area } \\
\text { (\%) }\end{array}$ & $\begin{array}{c}\text { Amount } \\
\text { (mg/L) }\end{array}$ & $\begin{array}{r}\text { Peak } \\
\text { Type }\end{array}$ \\
\hline 1 & 2.23 & n.a. & 2.11949 & 0.350 & 0.19 & n.a. & BMB \\
\hline 2 & 3.84 & n.a. & 0.30890 & 0.043 & 0.02 & n.a. & BMB \\
\hline 3 & 4.48 & Chloride & 0.36885 & 0.050 & 0.03 & 1.9618 & BMB \\
\hline 4 & 7.87 & Nitrate-N & 0.49048 & 0.120 & 0.07 & 1.7737 & BMB \\
\hline 5 & 10.65 & n.a. & 39.88411 & 11.262 & 6.15 & n.a. & BM \\
\hline 6 & 11.68 & n.a. & 118.828 & 64.94 & n.a. & MB \\
\hline 7 & 21.97 & n.a. & 56.72228 & 52.338 & 28.60 & n.a. & BMB \\
\hline
\end{tabular}

original 


\section{$28 \mathrm{CCV}=\mathrm{ICWS}-9061$}

\begin{tabular}{|llll|}
\hline Sample Name: & CCV=ICWS-9061 & Injection Volume: & $\mathbf{5 0 . 0}$ \\
Vial Number: & 166 & Channel: & ECD_1 \\
Sample Type: & unknown & Wavelength: & n.a. \\
Control Program: & ANIONS_AS14A & Bandwidth: & n.a. \\
Quantif. Method: & ANIONS & Dilution Factor: & 1.0000 \\
Recording Time: & $12 / 19 / 200616: 15$ & Sample Weight: & 1.0000 \\
Run Time (min): & $\mathbf{1 5 . 0 0}$ & Sample Amount: & $\mathbf{1 . 0 0 0 0}$ \\
\hline
\end{tabular}

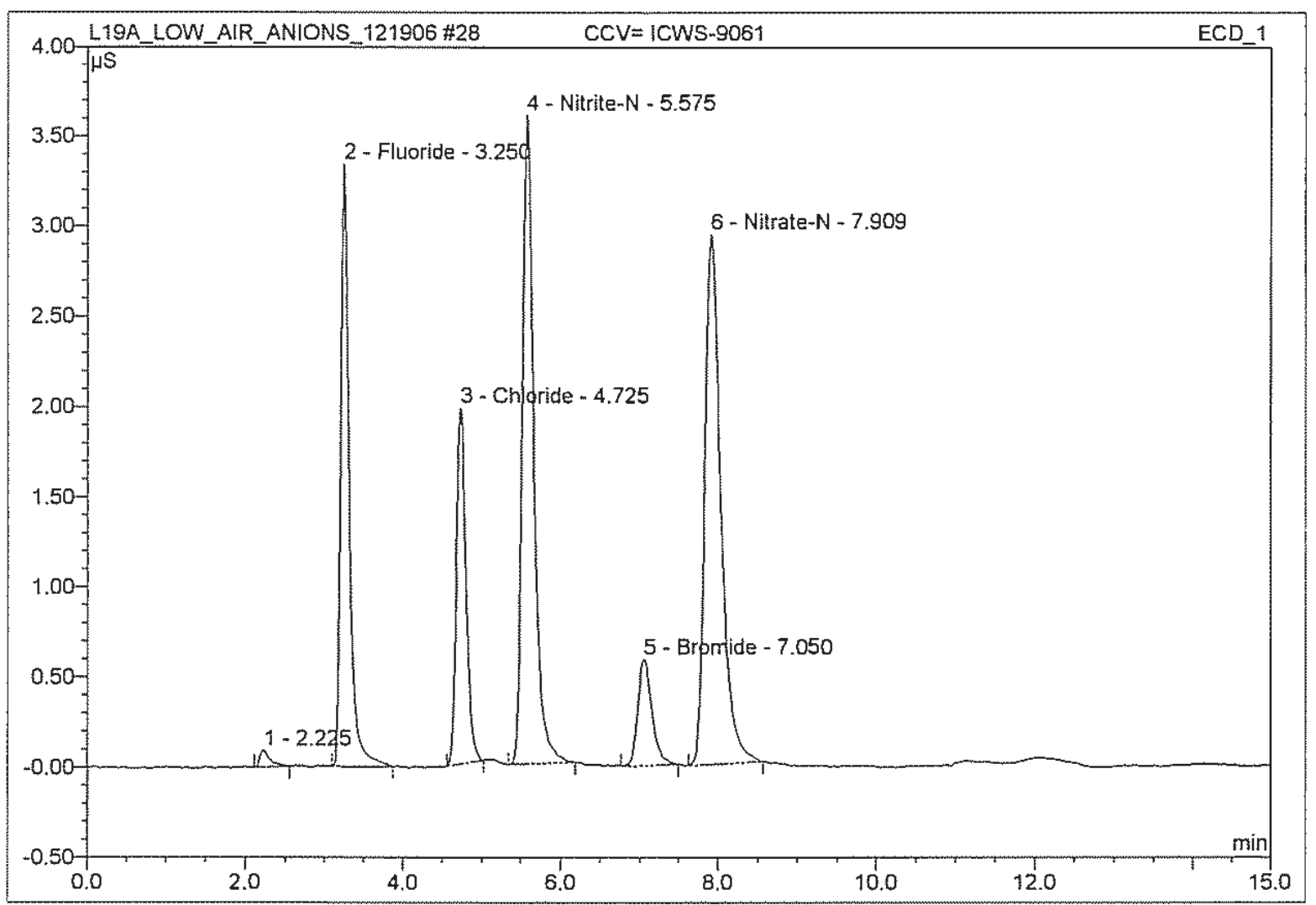

\begin{tabular}{|c|c|l|r|r|r|r|r|}
\hline No. & $\begin{array}{c}\text { Ret.Time } \\
\text { (min.) }\end{array}$ & \multicolumn{1}{|c|}{ Peak Name } & $\begin{array}{c}\text { Height } \\
(\mathbf{u S})\end{array}$ & $\begin{array}{c}\text { Area } \\
\mu S^{\star} \text { min }\end{array}$ & $\begin{array}{r}\text { Rel.Area } \\
(\%)\end{array}$ & $\begin{array}{c}\text { Amount } \\
\text { (mg/L) }\end{array}$ & $\begin{array}{r}\text { Peak } \\
\text { Type }\end{array}$ \\
\hline 1 & 2.23 & n.a. & 0.09051 & 0.013 & 0.63 & n.a. & BMB \\
\hline 2 & 3.25 & Fluoride & 3.33715 & 0.425 & 19.80 & 1.0176 & BMB \\
\hline 3 & 4.73 & Chloride & 1.97217 & 0.277 & 12.89 & 1.0196 & BMB \\
\hline 4 & 5.58 & Nitrite-N & 3.59591 & 0.614 & 28.59 & 1.0215 & BMB \\
\hline 5 & 7.05 & Bromide & 0.58861 & 0.122 & 5.66 & 1.0161 & BMB \\
\hline 6 & 7.91 & Nitrate-N & 2.94017 & 0.697 & 32.44 & 1.0173 & BMB \\
\hline
\end{tabular}




\section{9 ССВ}

\begin{tabular}{|llll|}
\hline Sample Name: & CCB & Injection Volume: & $\mathbf{5 0 . 0}$ \\
Vial Number: & $\mathbf{1 6 7}$ & Channel: & ECD_1 \\
Sample Type: & unknown & Wavelength: & n.a. \\
Control Program: & ANIONS_AS14A & Bandwidth: & n.a. \\
Quantif. Method: & ANIONS & Dilution Factor: & $\mathbf{1 . 0 0 0 0}$ \\
Recording Time: & $\mathbf{1 2 / 1 9 / 2 0 0 6 1 6 : 3 2}$ & Sample Weight: & $\mathbf{1 . 0 0 0 0}$ \\
Run Time (min): & $\mathbf{1 5 . 0 0}$ & Sample Amount: & $\mathbf{1 . 0 0 0 0}$ \\
\hline
\end{tabular}

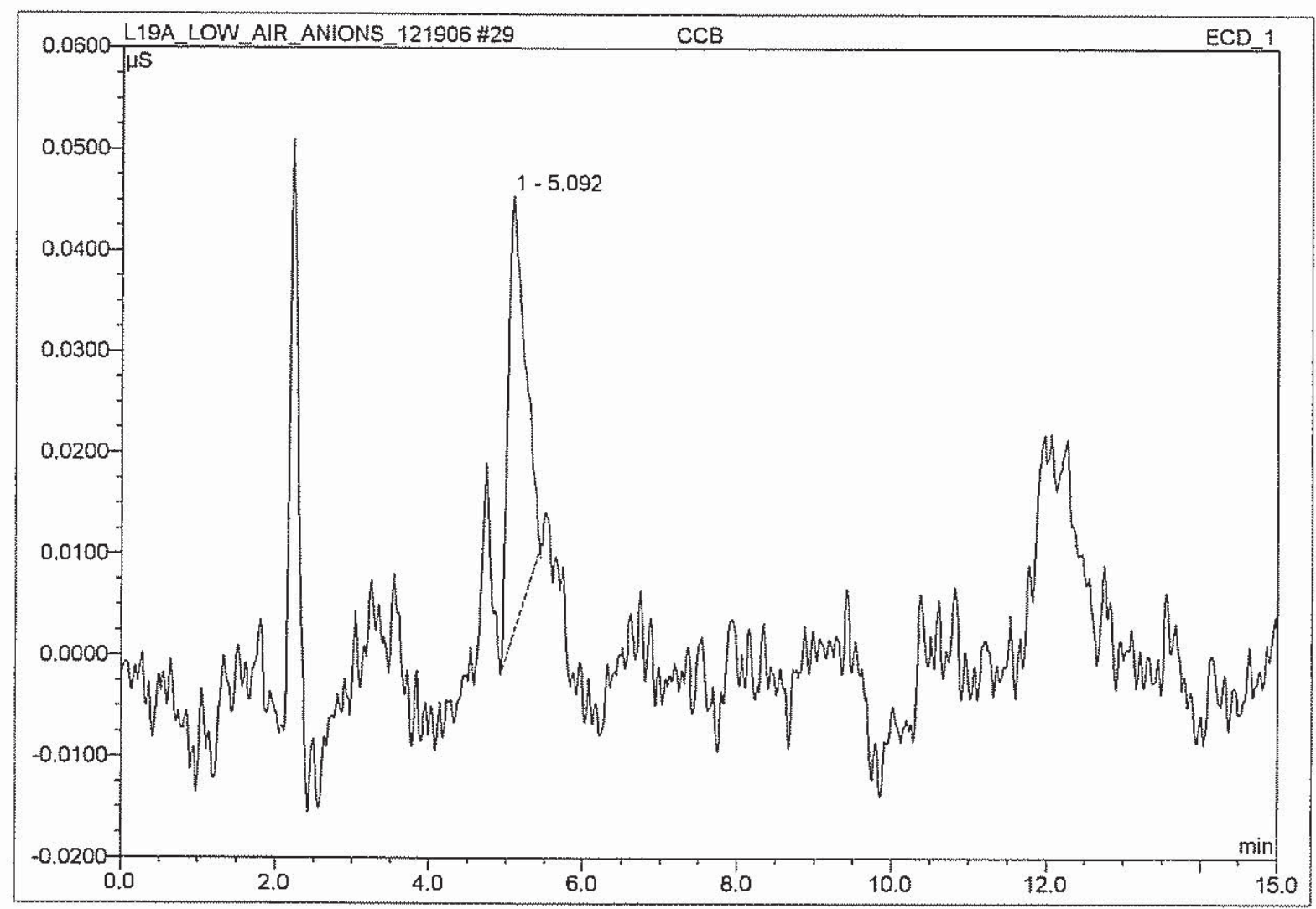

\begin{tabular}{|c|c|c|c|c|c|c|c|}
\hline No. & $\begin{array}{c}\text { Ret.Time } \\
\text { (min.) }\end{array}$ & $\begin{array}{c}\text { Peak Name } \\
(\mathbf{u S})\end{array}$ & $\begin{array}{c}\text { Area } \\
\mu S^{*} \min \end{array}$ & $\begin{array}{c}\text { Rel.Area } \\
(\%)\end{array}$ & $\begin{array}{c}\text { Amount } \\
(\mathrm{mg} / \mathrm{L})\end{array}$ & $\begin{array}{c}\text { Peak } \\
\text { Type }\end{array}$ \\
\hline 1 & 5.09 & n.a. & 0.04319 & 0.011 & 100.00 & n.a. & BMB \\
\hline
\end{tabular}

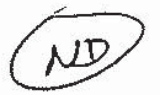




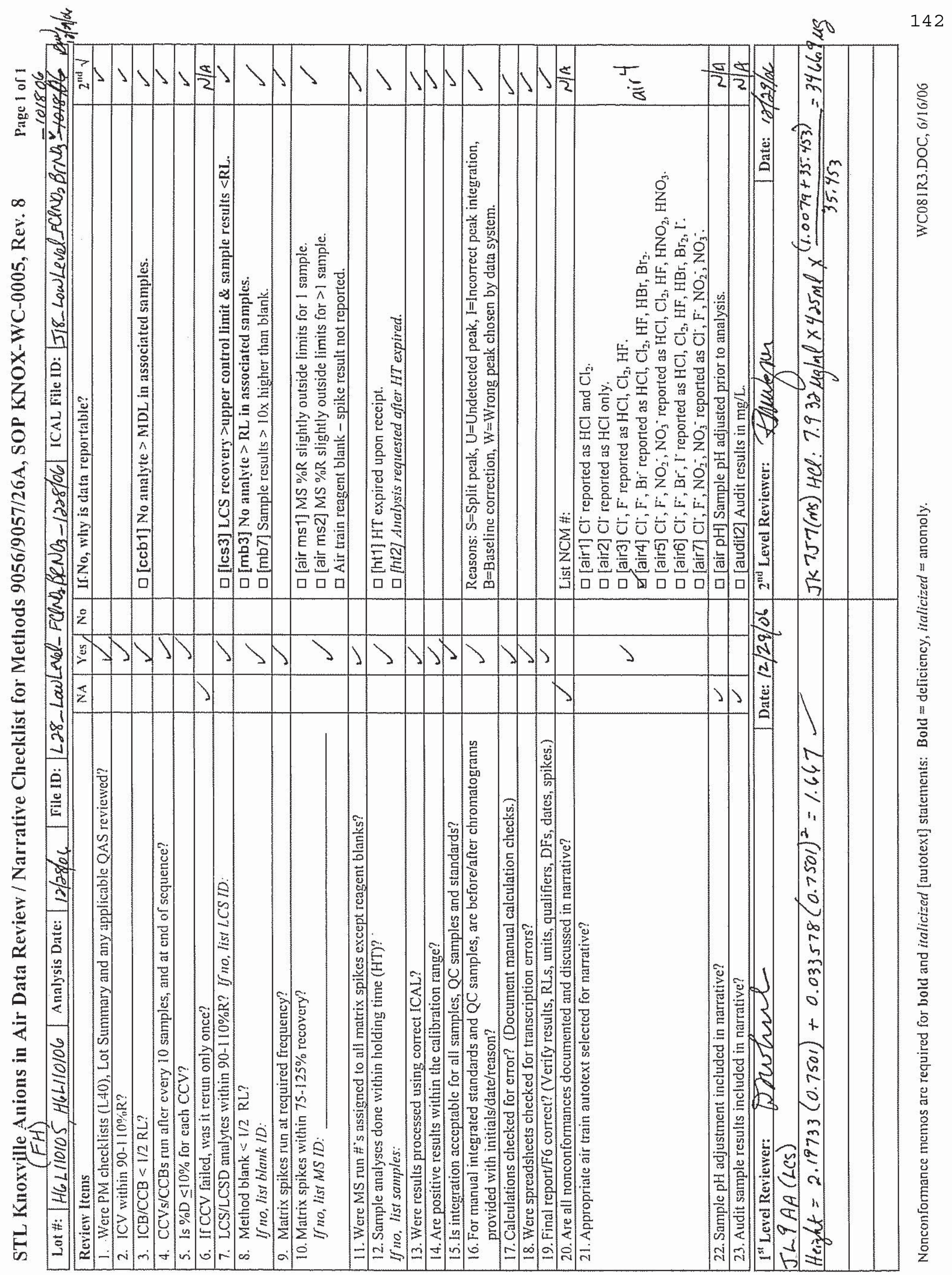




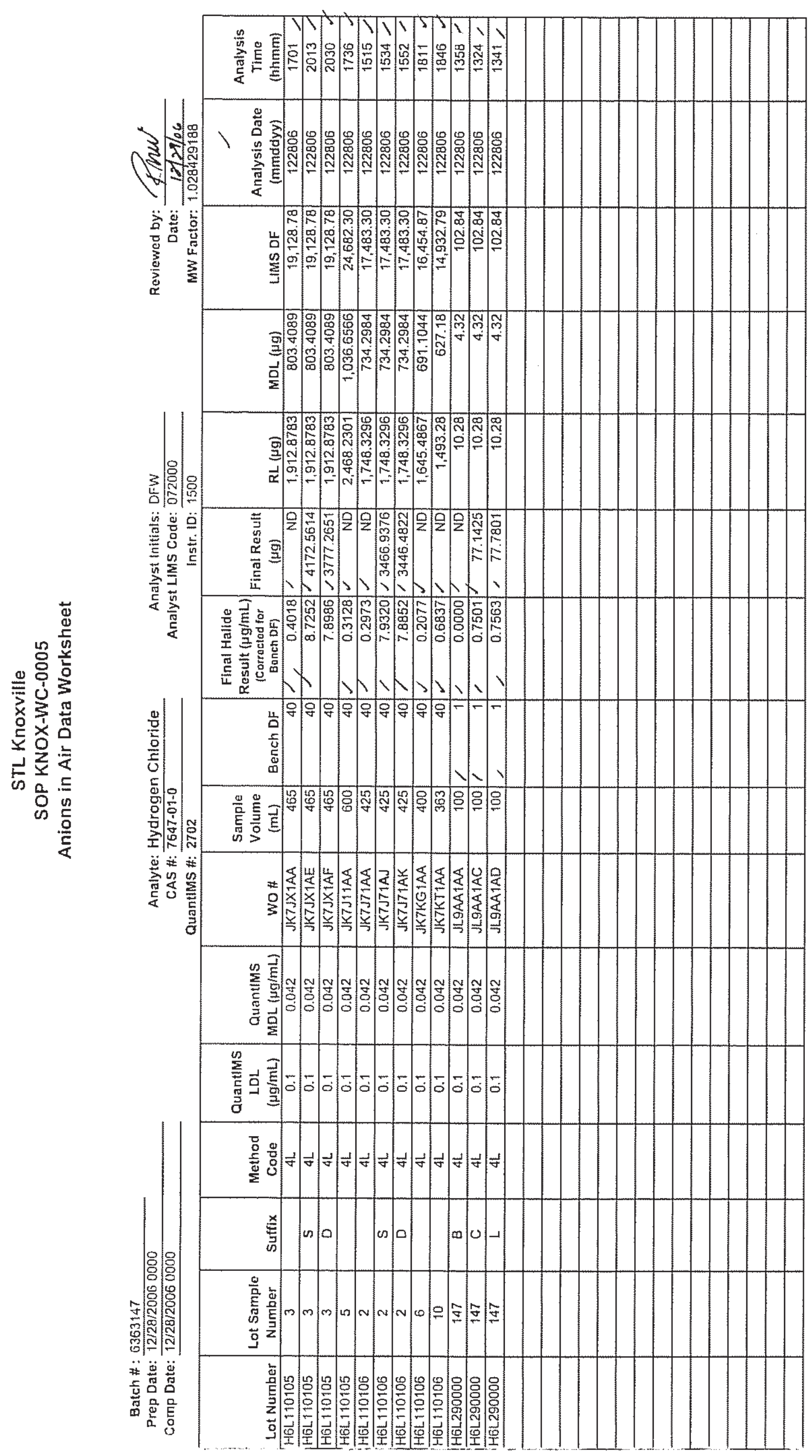




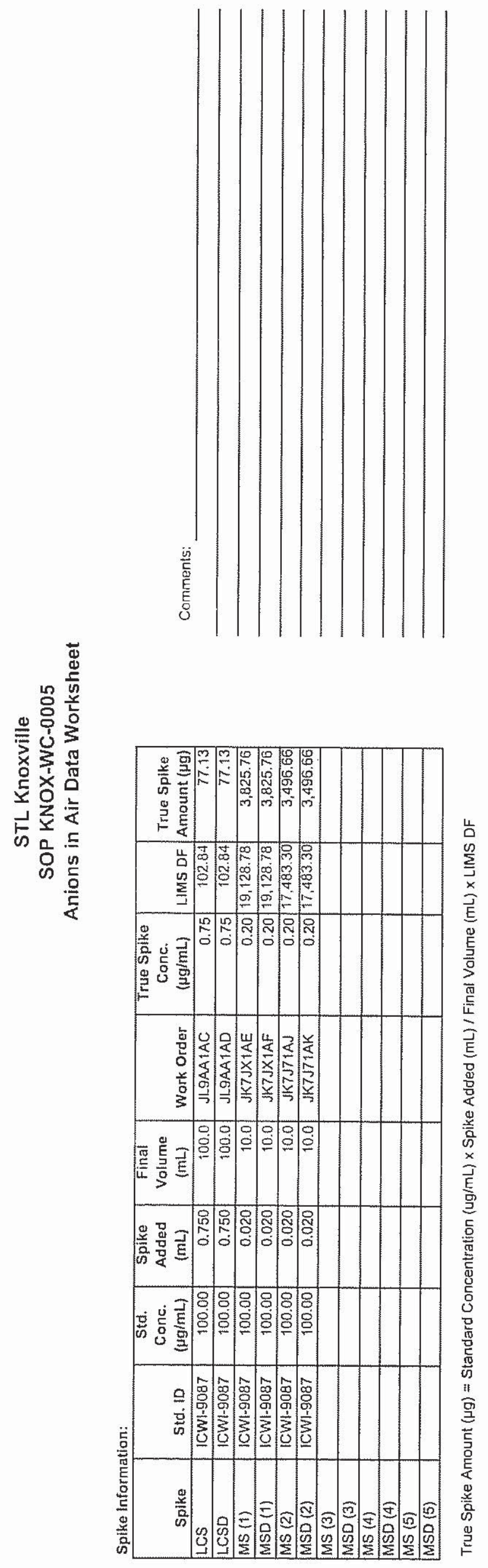

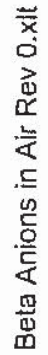




\section{Dionex IC Runlog Cover Page}

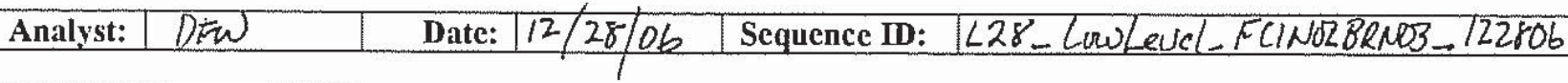

\begin{tabular}{|l|l|}
\hline Instrument: & $\square \mathrm{DX}-600$ \\
\cline { 2 - 2 } & $\mathrm{Q} \mathrm{ICS}-1500$ \\
\cline { 2 - 2 } & $\square \mathrm{DX}-320$ \\
\hline
\end{tabular}

Method: $\quad$ IKNOX-WC-0003, SW-846 0061/7199

\begin{tabular}{|c|}
\hline$\square \mathrm{KNOX}-W C-0005, \square S W-8469056$ DEPA 300.0 \\
\hline
\end{tabular}

\section{Preventive Maintenance}

\section{Dailv:}

${ }^{\top}$ Check pump and gas pressure

$\checkmark$ Check all lines for crimping, leaks and discoloration

\section{As Needed:}

[) Change column and guard column

$\square$ Change column and/or guard column bed support

$\square$ Clean conductivity cell

प De-gas pump head when flow is erratic

$\square$ Check/replace eluant end line filter

\section{Instrument Conditions}

\begin{tabular}{rll|}
\hline Flow Rate $=1.00$ & $\mathrm{~mL} / \mathrm{min}$ \\
\hline Pressure $=1840$. & $\mathrm{psi}$ \\
\hline Conductance $=24.9$ & $\mu \mathrm{S}$ \\
\hline Suppressor Current $=$ & 43 & $\mathrm{~mA}$ \\
\hline Eluent Generator $=$ & $N / \Delta$ & $\mathrm{mM} \mathrm{KOH}$
\end{tabular}

\section{MS/MSD Spilke Information}

\begin{tabular}{|c|c|c|c|c|c|c|}
\hline WO \# & Compound & Spike ID & Parent Conc. & Spike Added $(\mathrm{mL})$ & Final Volume (mL) & Final Conc. \\
\hline IKJ 7 & Chloride & Icurt-9087 & 100. PPM & 8.02 & 10. & $\varnothing .2 \mathrm{ppm}$ \\
\hline JK $J \mathrm{JX}$ & 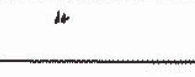 & $n$ & $n$ & 8.02 & 10 & - \\
\hline & & & & & & \\
\hline & & & & & & \\
\hline & & & & & & \\
\hline & & & & & & \\
\hline & & & & & & \\
\hline & & & & & & \\
\hline & & & & & & \\
\hline & & & & & & \\
\hline mments. & $\mathrm{HCl} B$ & 4636314 & & & & \\
\hline
\end{tabular}

$\square$ Sodium Tluosulfate added to $\mathrm{NaOH}$ impinger samples. 
Title:

Datasource:

Location:

Timebase:

\#Samples:
1CS_1500_net

ICS1500

IC51500

34
Created:

Last Update:
Printed: $12 / 29 / 2006$ 8:55:10 AM

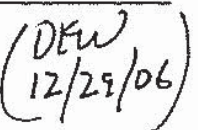

12/28/2006 10:49:27 AM by wheelerd 12/28/2006 4:28:05 PM by wheelerd

\begin{tabular}{|c|c|c|c|c|c|c|c|}
\hline No. & Name & Sample ID & Inj. Vol. & Inj. Date/Time & Dil. Factor & $\begin{array}{c}\text { "Multiplier } \\
\text { [Liters] }\end{array}$ & Weight \\
\hline 1 & (1) CAL STD \#1 ICWS-8915 & & 50.0 & 10/18/2006 9:14:56 AM & 1.0000 & & 1.0000 \\
\hline 2 & 19 CAL STD \#2 ICWS-8916 & & 50.0 & 10/18/2006 9:32:20 AM & 1.0000 & & 1.0000 \\
\hline 3 & (1) CAL STD \#3 ICWS-8917 & & 50.0 & 10/18/2006 9:49:45 AM & 1.0000 & & 1.0000 \\
\hline 4 & (1) CAL STD \#4 ICWS-8918 & & 50.0 & 10/18/2006 10:07:09 AM & 1.0000 & & 1.0000 \\
\hline 5 & (1) CAL STD \#5ICWS-8919 & & 50.0 & 10/18/2006 10:24:33 AM & 1.0000 & & 1.0000 \\
\hline 6 & (1) CAL STD \#6 ICWS-8920 & & 50.0 & 10/18/2006 10:41:57 AM & 1.0000 & & 1.0000 \\
\hline 7 & 第 ICVILCS = ICWS-9088 & & 50.0 & 12/28/2006 1:24:09 PM & 1.0000 & & 1.0000 \\
\hline 8 & ICVILCSD=ICWS-9089 & & 50.0 & 12/28/2006 1:41:33 PM & 1.0000 & & 1.0000 \\
\hline 9 & ICB/METHOD BLANK & & 50.0 & $12 / 28 / 2006$ 1:58:57 PM & 1.0000 & & 1.0000 \\
\hline 10 & 置 H6L110106-JK7J7-1/20 & & 50.0 & 12/28/2006 2:16:22 PM & 20.0000 & & 1.0000 \\
\hline 11 & 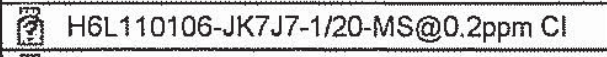 & & 50.0 & 12/28/2006 2:40:20 PM & 20.0000 & & 1.0000 \\
\hline 12 & 通 H6L110106-JK7J7-1/20-MSD@0.2ppm Cl & & 50.0 & $12 / 28 / 20062: 57: 44 \mathrm{PM}$ & 20.0000 & & 1.0000 \\
\hline 13 & 湑 H6L110106-JK 7J7-1/40 & & 50.0 & 12/28/2006 3:15:08 PM & 40.0000 & & 1.0000 \\
\hline 14 & (7) H6L110106-JK7J7-1/40-MS@0.2ppm Cl & & 50.0 & 12/28/2006 3:34:42 PM & 40.0000 & & 1.0000 \\
\hline 15 & 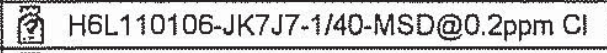 & & 50,0 & 12/28/2006 3:52:06 PM & 40.0000 & & 1.0000 \\
\hline 16 & CCV $=$ ICWS-9090 & & 50.0 & 12/28/2006 4:09:30 PM & 1.0000 & & 1.0000 \\
\hline 17 & CCB & & 50.0 & 12/28/2006 4:26:54 PM & 1.0000 & & 1.0000 \\
\hline 18 & 筩 H6L110105-JK7JX-1/20 & & 50.0 & $12 / 28 / 2006$ 4:44:18 PM & 20.0000 & & 1.0000 \\
\hline 19 & 筧 H6L110105-JK7JX-1/40 & & 50.0 & 12/28/2006 5:01:43 PM & 40.0000 & & 1.0000 \\
\hline 20 & 㗐 H6L110105-JK7J1-1/20 & & 50.0 & 12/28/2006 5:19:07 PM & 20.0000 & & 1.0000 \\
\hline 21 & 国 H6L110105-JK7J1-1/40 & & 50.0 & 12/28/2006 5:36:31 PM & 40.0000 & & 1.0000 \\
\hline 22 & 管 H6L110106-JK7KG-1/20 & & 50.0 & 12/28/2006 5:53:56 PM & 20.0000 & & 1.0000 \\
\hline 23 & 啇 H6L110106-JK7KG-1/40 & & 50.0 & 12/28/2006 6:11:20 PM & 40.0000 & & 1.0000 \\
\hline 24 & 箇 H6L110106-JK7KT-1/20 & & 50.0 & $12 / 28 / 20066: 28: 44 \mathrm{PM}$ & 20.0000 & & 1.0000 \\
\hline 25 & 常 H6L110106-JK7KT-1/40 & & 50.0 & 12/28/2006 6:46:08 PM & 40.0000 & & 1.0000 \\
\hline 26 & 息 CCV $=1$ ICWS-9090 & & 50.0 & 12/28/2006 7:03:32 PM & 1.0000 & & 1.0000 \\
\hline 27 & (2) $\mathrm{CCB}$ & & 50.0 & 12/28/2006 7:20:56 PM & 1.0000 & & 1.0000 \\
\hline 28 & 10 H6L110105-JK7JX-1/20-MS@0.2ppm Cl & & 50.0 & 12/28/2006 7:38:20 PM & 20.0000 & & 1.0000 \\
\hline 29 & (2) H6L110105-JK7JX-1/20-MSD@0.2ppm Cl & & 50.0 & 12/28/2006 7:55:44 PM & 20.0000 & & 1.0000 \\
\hline 30 & H6L110105-JK7JX-1/40-MS@0.2ppm Cl & & 50.0 & 12/28/2006 8:13:09 PM & 40.0000 & & 1.0000 \\
\hline 31 & (1) H6L110105-JK7JX-1/40-MSD@0.2ppm Cl & & 50.0 & 12/28/2006 8:30:33 PM & 40.0000 & & 1.0000 \\
\hline 32 & 盗 CCV $=1 \mathrm{CWS}-9090$ & & 50.0 & $12 / 28 / 20068: 47: 58 \mathrm{PM}$ & 1.0000 & & 1.0000 \\
\hline 33 & 坣 $\mathrm{CCB}$ & & 50.0 & 12/28/2006 9:05:22 PM & 1.0000 & & 1.0000 \\
\hline 34 & 盆 SHUTDOWN & & 50.0 & $12 / 28 / 20069: 22: 46 \mathrm{PM}$ & 1.0000 & & 1.0000 \\
\hline
\end{tabular}




\section{$7 \quad$ ICV/LCS $=I C W S-9088$}

\begin{tabular}{llll}
\hline Sample Name: & ICV/LCS= ICWS-9088 & Injection Volume: & $\mathbf{5 0 . 0}$ \\
Vial Number: & $\mathbf{1 2 9 6}$ & Channel: & ECD_1 \\
Sample Type: & unknown & Wavelength: & n.a. \\
Control Program: & AS14A ANIONS METHOD & Bandwidth: & n.a. \\
Quantif. Method: & AS4A-SC ANION METHOD & Dilution Factor: & 1.0000 \\
Recording Time: & $12 / 28 / 200613: 24$ & Sample Weight: & 1.0000 \\
Run Time (min): & 15.00 & Sample Amount: & 1.0000 \\
\hline
\end{tabular}

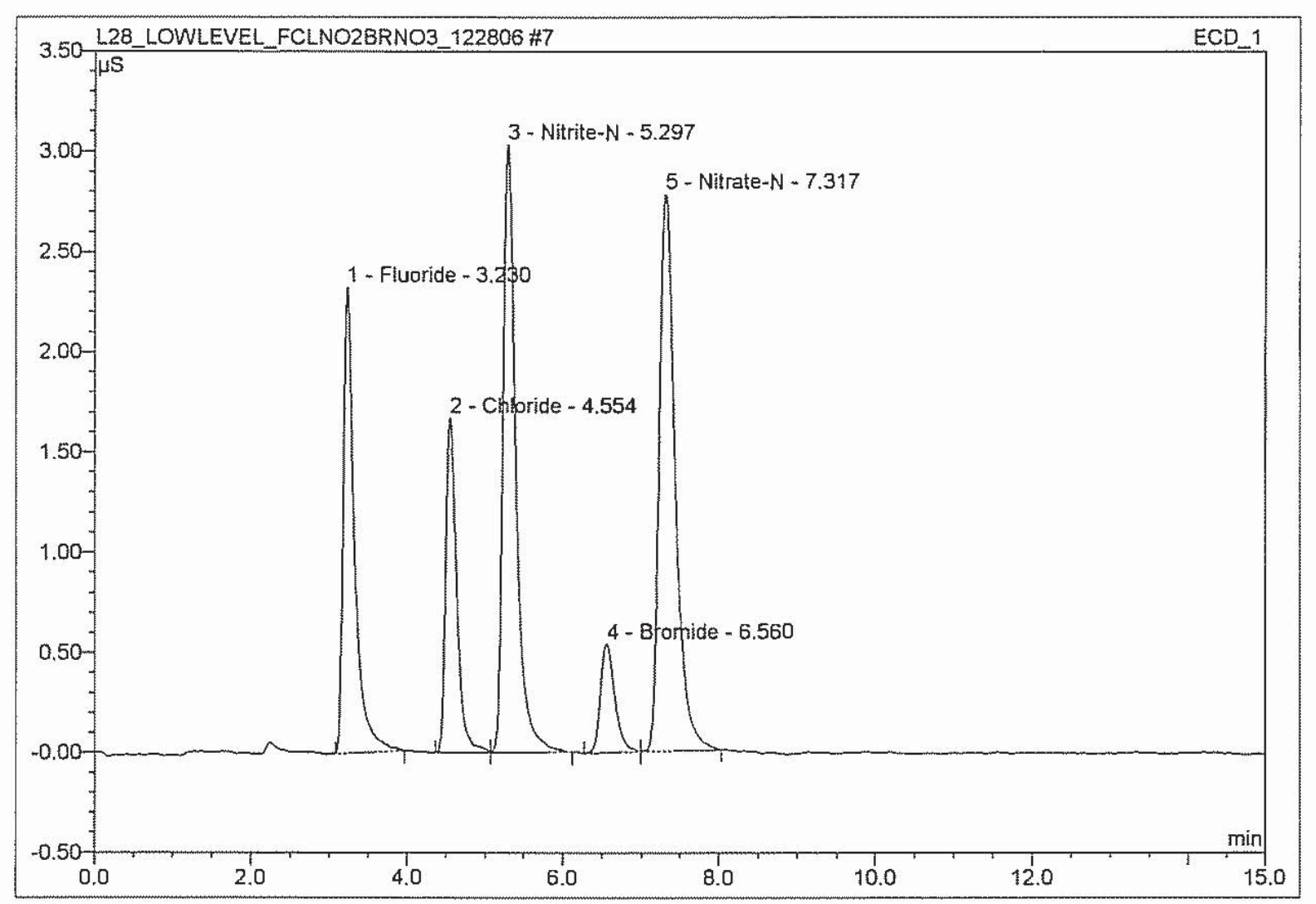

\begin{tabular}{|c|c|l|r|r|r|r|c|}
\hline No. & $\begin{array}{c}\text { Ret.Time } \\
\text { (min.) }\end{array}$ & \multicolumn{1}{|c|}{ Peak Name } & $\begin{array}{c}\text { Height } \\
\text { (uS) }\end{array}$ & $\begin{array}{c}\text { Area } \\
\mu S^{\star} \min \end{array}$ & $\begin{array}{r}\text { Rel.Area } \\
(\%)\end{array}$ & $\begin{array}{c}\text { Amount } \\
(\mathrm{mg} / \mathrm{L})\end{array}$ & $\begin{array}{c}\text { Peak } \\
\text { Type }\end{array}$ \\
\hline 1 & 3.23 & Fluoride & 2.32322 & 0.397 & 19.53 & 0.8109 & $\mathrm{BMB}$ \\
\hline 2 & 4.55 & Chloride & 1.66709 & 0.273 & 13.44 & 0.7501 & $\mathrm{BM}$ \\
\hline 3 & 5.30 & Nitrite-N & 3.02897 & 0.586 & 28.80 & 0.7761 & $\mathrm{MB}$ \\
\hline 4 & 6.56 & Bromide & 0.54320 & 0.115 & 5.64 & 0.7617 & $\mathrm{BMb}$ \\
\hline 5 & 7.32 & Nitrate-N & 2.77714 & 0.663 & 32.59 & 0.7720 & $\mathrm{bMB}$ \\
\hline
\end{tabular}

HCl JLIAA-IAC 


\section{$8 \quad I C V / L C S D=I C W S-9089$}

\begin{tabular}{llll|}
\hline Sample Name: & ICV/LCSD= ICWS-9089 & Injection Volume: & $\mathbf{5 0 . 0}$ \\
Vial Number: & $\mathbf{1 2 9 7}$ & Channel: & ECD_1 \\
Sample Type: & unknown & Wavelength: & n.a. \\
Control Program: & AS14A ANIONS METHOD & Bandwidth: & n.a. \\
Quantif. Method: & AS4A-SC ANION METHOD & Dilution Factor: & 1.0000 \\
Recording Time: & $12 / 28 / 200613: 41$ & Sample Weight: & 1.0000 \\
Run Time (min): & 15.00 & Sample Amount: & 1.0000 \\
\hline
\end{tabular}

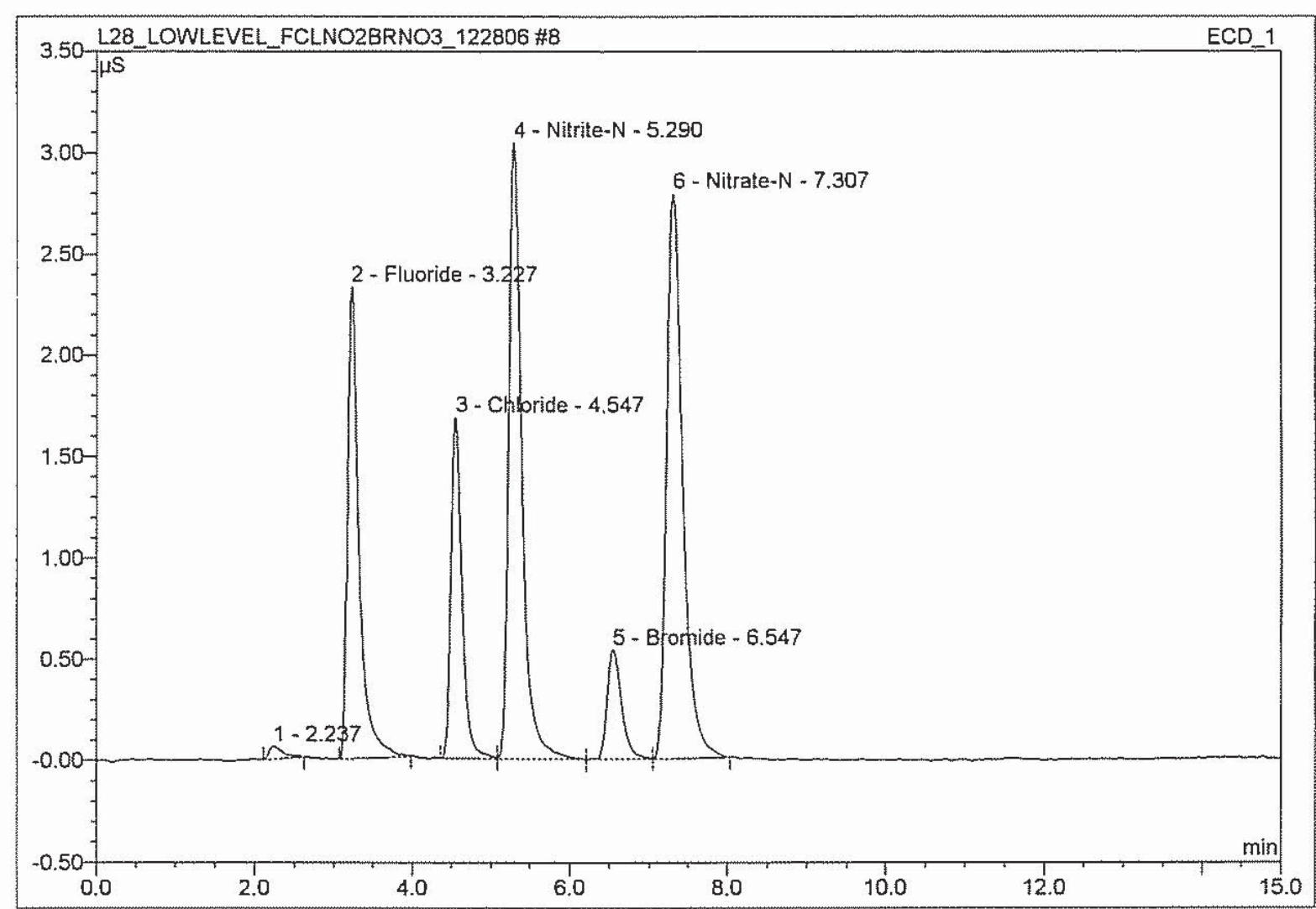

\begin{tabular}{|c|c|l|r|r|r|r|c|}
\hline No. & $\begin{array}{c}\text { Ret.Time } \\
\text { (min.) }\end{array}$ & \multicolumn{1}{|c|}{ Peak Name } & $\begin{array}{c}\text { Height } \\
\text { (uS) }\end{array}$ & $\begin{array}{c}\text { Area } \\
\mu S^{*} \min \end{array}$ & $\begin{array}{r}\text { Rel.Area } \\
(\%)\end{array}$ & $\begin{array}{c}\text { Amount } \\
\text { (mg/L) }\end{array}$ & $\begin{array}{r}\text { Peak } \\
\text { Type }\end{array}$ \\
\hline 1 & 2.24 & n.a. & 0.06095 & 0.013 & 0.61 & n.a. & BMB \\
\hline 2 & 3.23 & Fluoride & 2.32775 & 0.399 & 19.45 & 0.8124 & BMB \\
\hline 3 & 4.55 & Chloride & 1.68114 & 0.274 & 13.35 & 0.7563 & $\mathrm{BM}$ \\
\hline 4 & 5.29 & Nitrite-N & 3.03772 & 0.587 & 28.59 & 0.7783 & $\mathrm{M}$ \\
\hline 5 & 6.55 & Bromide & 0.53922 & 0.114 & 5.54 & 0.7561 & $\mathrm{MB}$ \\
\hline 6 & 7.31 & Nitrate-N & 2.78963 & 0.666 & 32.46 & 0.7754 & $\mathrm{BMB}$ \\
\hline
\end{tabular}

$$
\text { HCl JL9AA-IA/AD }
$$




\section{ICB/ METHOD BLANK}

\begin{tabular}{llll|}
\hline Sample Name: & ICB/ METHOD BLANK & Injection Volume: & $\mathbf{5 0 . 0}$ \\
Vial Number: & $\mathbf{1 2 9 8}$ & Channel: & ECD_1 \\
Sample Type: & unknown & Wavelength: & n.a. \\
Control Program: & AS14A ANIONS METHOD & Bandwidth: & n.a. \\
Quantif. Method: & AS4A-SC ANION METHOD & Dilution Factor: & 1.0000 \\
Recording Time: & $12 / 28 / 200613: 58$ & Sample Weight: & 1.0000 \\
Run Time (min): & $\mathbf{1 5 . 0 0}$ & Sample Amount: & $\mathbf{1 . 0 0 0 0}$ \\
\hline
\end{tabular}

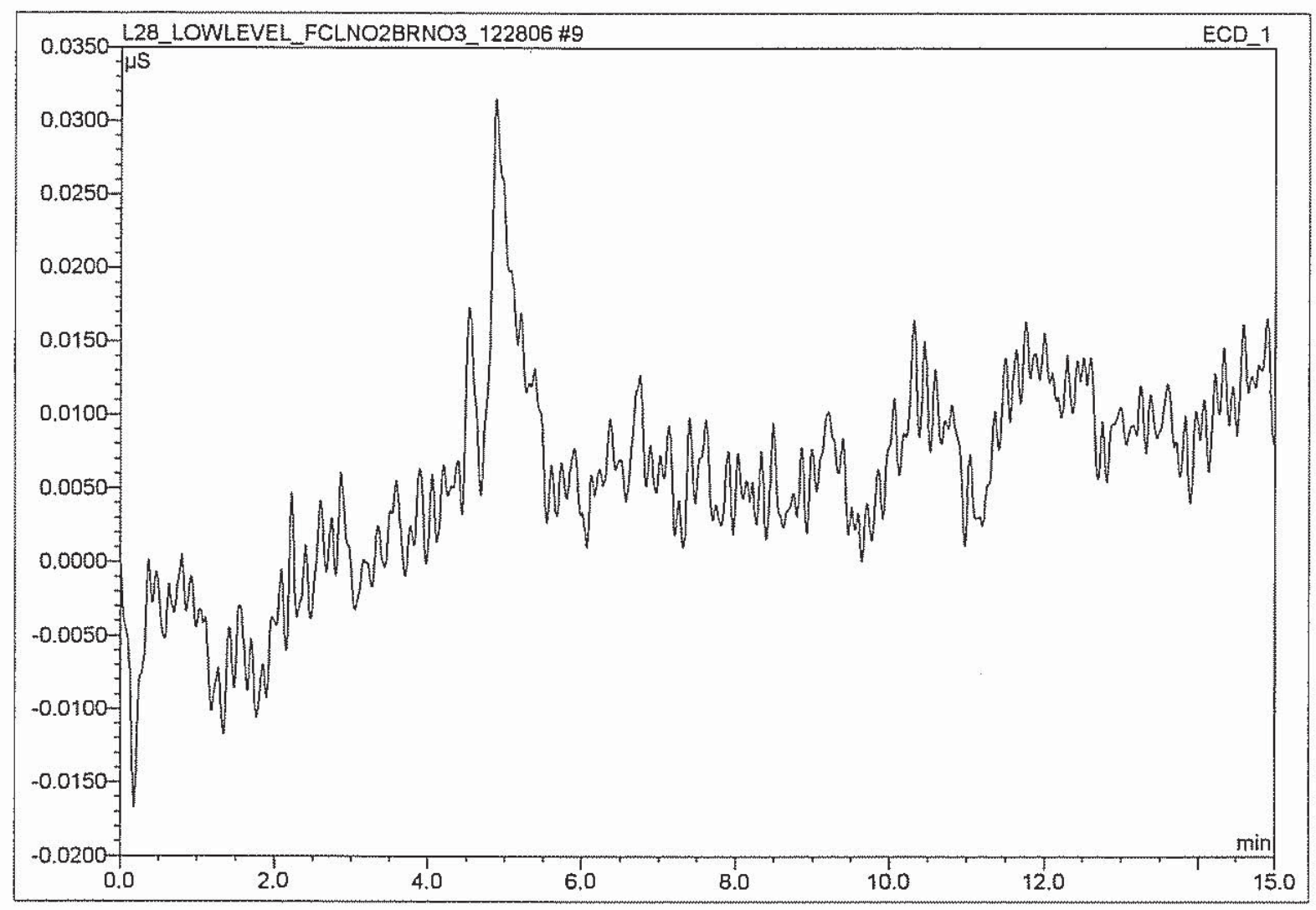

\begin{tabular}{|c|c|c|c|c|c|c|c|}
\hline No. & $\begin{array}{c}\text { Ret.Time } \\
(\mathrm{min} .)\end{array}$ & Peak Name & $\begin{array}{c}\text { Height } \\
(\mathrm{uS})\end{array}$ & $\begin{array}{c}\text { Area } \\
\mu \mathrm{S}^{*} \mathrm{~min}\end{array}$ & $\begin{array}{c}\text { Rel.Area } \\
(\%)\end{array}$ & $\begin{array}{c}\text { Amount } \\
(\mathrm{mg} / \mathrm{L})\end{array}$ & $\begin{array}{c}\text { Peak } \\
\text { Type }\end{array}$ \\
\hline
\end{tabular}

(ND)

HCl JL9AA-IAA 


\section{H6L110106-JK7J7-1/20}

\begin{tabular}{llll|}
\hline Sample Name: & H6L110106-JK7J7-1/20 & Injection Volume: & $\mathbf{5 0 . 0}$ \\
Vial Number: & 1294 & Channel: & ECD_1 \\
Sample Type: & unknown & Wavelength: & n.a. \\
Control Program: & AS14A ANIONS_CI2 METHOD & Bandwidth: & n.a. \\
Quantif. Method: & AS4A_SC ANION METHOD & Dilution Factor: & 20.0000 \\
Recording Time: & $12 / 28 / 200614: 16$ & Sample Weight: & 1.0000 \\
Run Time (min): & 20.95 & Sample Amount: & 1.0000 \\
\hline
\end{tabular}

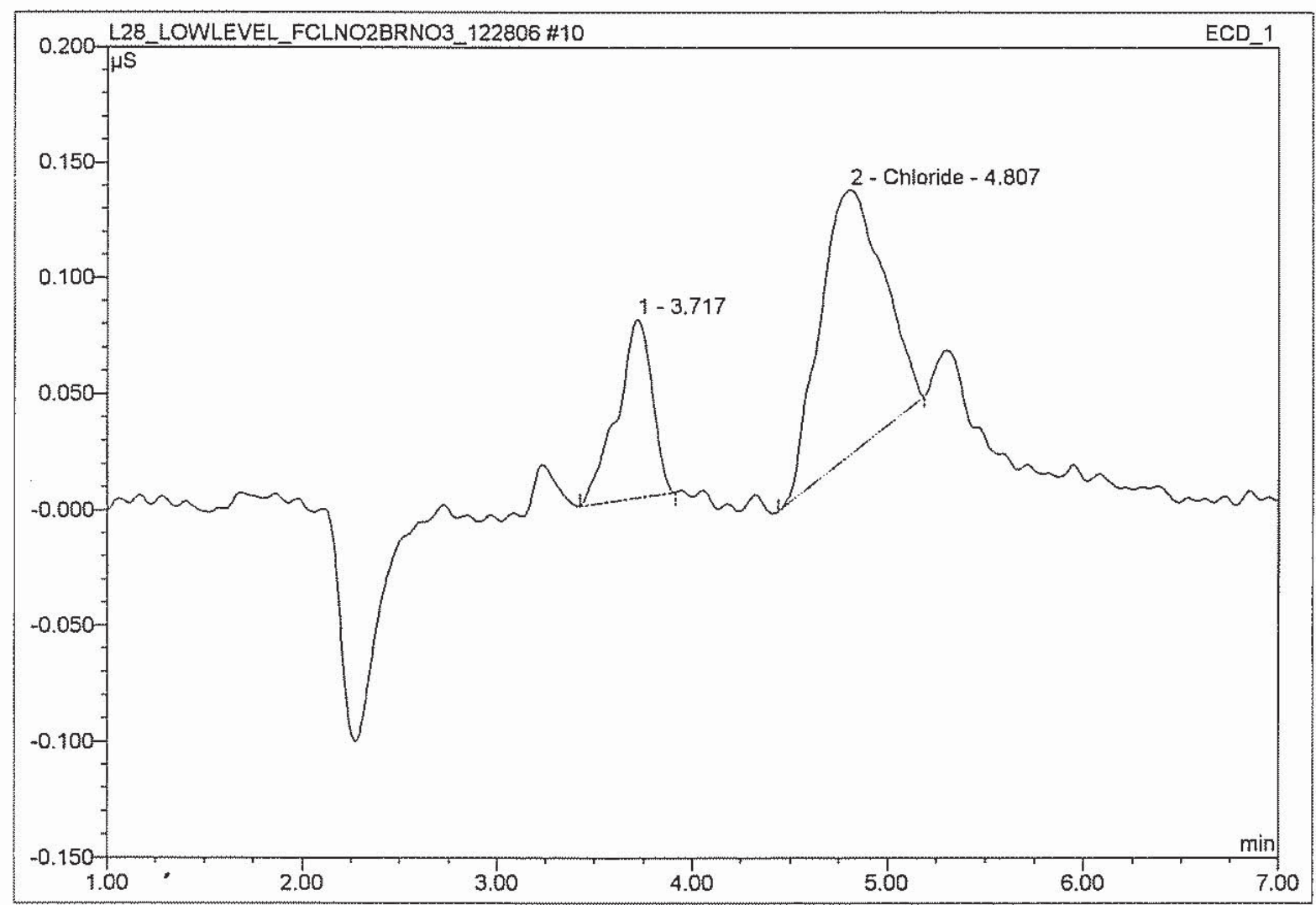

\begin{tabular}{|c|c|l|r|r|r|r|r|}
\hline No. & $\begin{array}{c}\text { Ret.Time } \\
\text { (min.) }\end{array}$ & \multicolumn{1}{|c|}{ Peak Name } & $\begin{array}{c}\text { Height } \\
\text { (uS) }\end{array}$ & $\begin{array}{c}\text { Area } \\
\mu S^{*} \min \end{array}$ & $\begin{array}{c}\text { Rel.Area } \\
(\%)\end{array}$ & $\begin{array}{c}\text { Amount } \\
\text { (mg/L) }\end{array}$ & $\begin{array}{r}\text { Peak } \\
\text { Type }\end{array}$ \\
\hline 1 & 3.72 & n.a. & 0.07689 & 0.016 & 0.03 & n.a. & BMB \\
\hline 2 & 4.81 & Chloride & 0.11415 & 0.043 & 0.09 & 1.0382 & BMB \\
\hline 3 & 7.33 & Nitrate-N & 0.11481 & 0.027 & 0.06 & 0.6629 & BMB \\
\hline 4 & 8.02 & n.a. & 0.08998 & 0.016 & 0.04 & n.a. & BMB \\
\hline 5 & 11.41 & n.a. & 45.896 & 99.78 & n.a. & BMB \\
\hline
\end{tabular}




\section{H6L110106-JK7J7-1/20}

\begin{tabular}{llll|}
\hline Sample Name: & H6L110106-JK7J7-1/20 & Injection Volume: & $\mathbf{5 0 . 0}$ \\
Vial Number: & $\mathbf{1 2 9 4}$ & Channel: & ECD_1 \\
Sample Type: & unknown & Wavelength: & n.a. \\
Control Program: & AS14A ANIONS_CI2 METHOD & Bandwidth: & n.a. \\
Quantif. Method: & AS4A-SC ANION METHOD & Dilution Factor: & $\mathbf{2 0 . 0 0 0 0}$ \\
Recording Time: & $\mathbf{1 2 / 2 8 / 2 0 0 6 ~ 1 4 : 1 6}$ & Sample Weight: & $\mathbf{1 . 0 0 0 0}$ \\
Run Time (min): & $\mathbf{2 0 . 9 5}$ & Sample Amount: & $\mathbf{1 . 0 0 0 0}$ \\
\hline
\end{tabular}

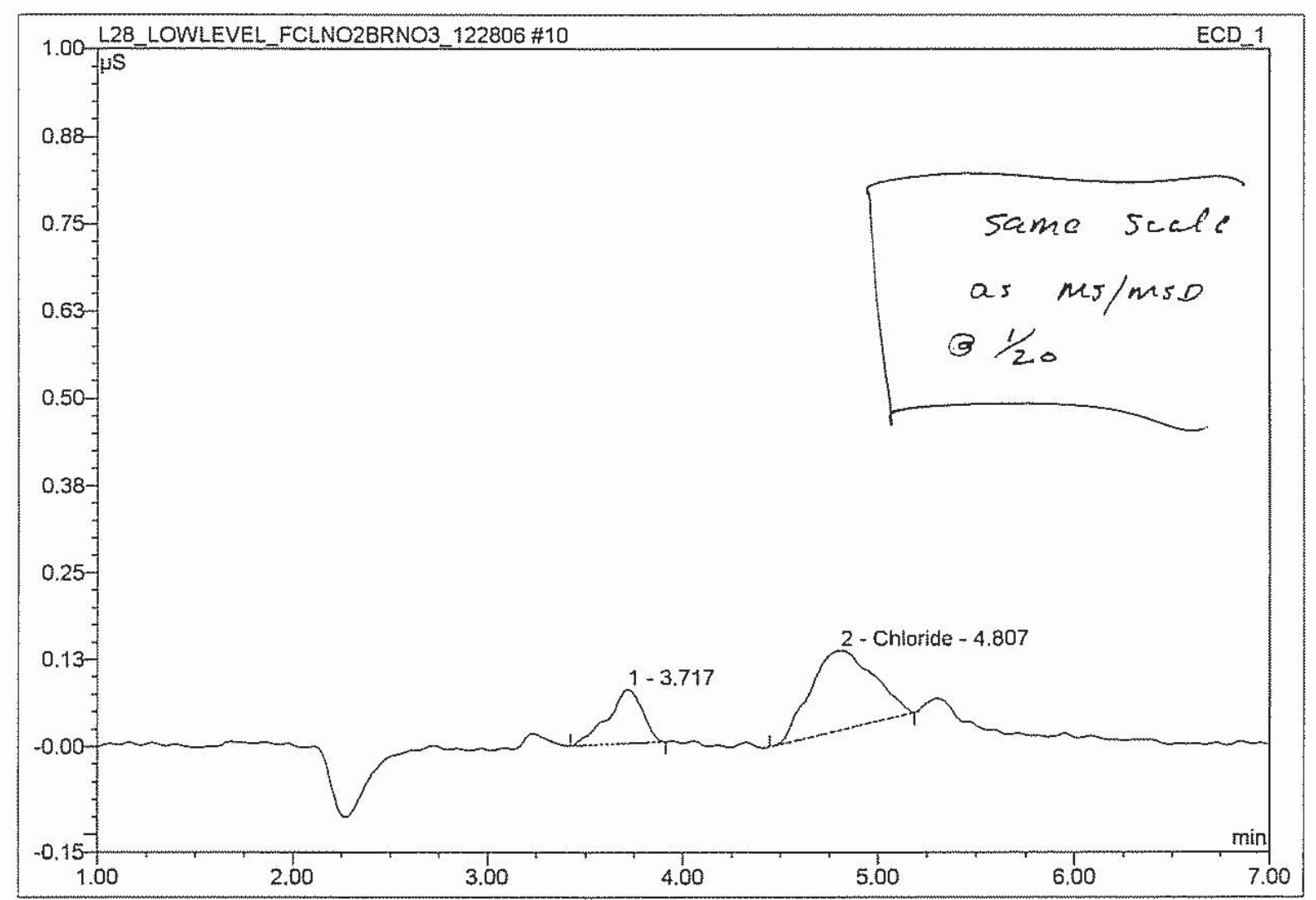

\begin{tabular}{|r|c|l|r|r|r|r|r|}
\hline No. & $\begin{array}{c}\text { Ret.Time } \\
\text { (min.) }\end{array}$ & \multicolumn{1}{|c|}{ Peak Name } & $\begin{array}{c}\text { Height } \\
\text { (uS) }\end{array}$ & $\begin{array}{c}\text { Area } \\
\mu S^{*} \min \end{array}$ & $\begin{array}{c}\text { Rel.Area } \\
(\%)\end{array}$ & $\begin{array}{c}\text { Amount } \\
\text { (mg/L) }\end{array}$ & $\begin{array}{r}\text { Peak } \\
\text { Type }\end{array}$ \\
\hline 1 & 3.72 & n.a. & 0.07689 & 0.016 & 0.03 & n.a. & BMB \\
\hline 2 & 4.81 & Chloride & 0.11415 & 0.043 & 0.09 & 1.0382 & BMB \\
\hline 3 & 7.33 & Nitrate-N & 0.11481 & 0.027 & 0.06 & 0.6629 & BMB \\
\hline 4 & 8.02 & n.a. & 0.08998 & 0.016 & 0.04 & n.a. & BMB \\
\hline 5 & 11.41 & n.a. & 45.896 & 99.78 & n.a. & BMB \\
\hline
\end{tabular}




\section{H6L110106-JK7J7-1/20-MS@0.2ppm CI}

\begin{tabular}{llll}
\hline Sample Name: & H6L110106-JK7J7-1/20-MS@0.2ppm Cl & Injection Volume: & $\mathbf{5 0 . 0}$ \\
Vial Number: & $\mathbf{1 2 9 4}$ & Channel: & ECD_1 \\
Sample Type: & unknown & Wavelength: & n.a. \\
Control Program: & AS14A ANIONS METHOD & Bandwidth: & n.a. \\
Quantif. Method: & AS4A-SC ANION METHOD & Dilution Factor: & $\mathbf{2 0 . 0 0 0 0}$ \\
Recording Time: & $12 / 28 / 200614: 40$ & Sample Weight: & 1.0000 \\
Run Time (min): & $\mathbf{1 5 . 0 0}$ & Sample Amount: & $\mathbf{1 . 0 0 0 0}$ \\
\hline
\end{tabular}

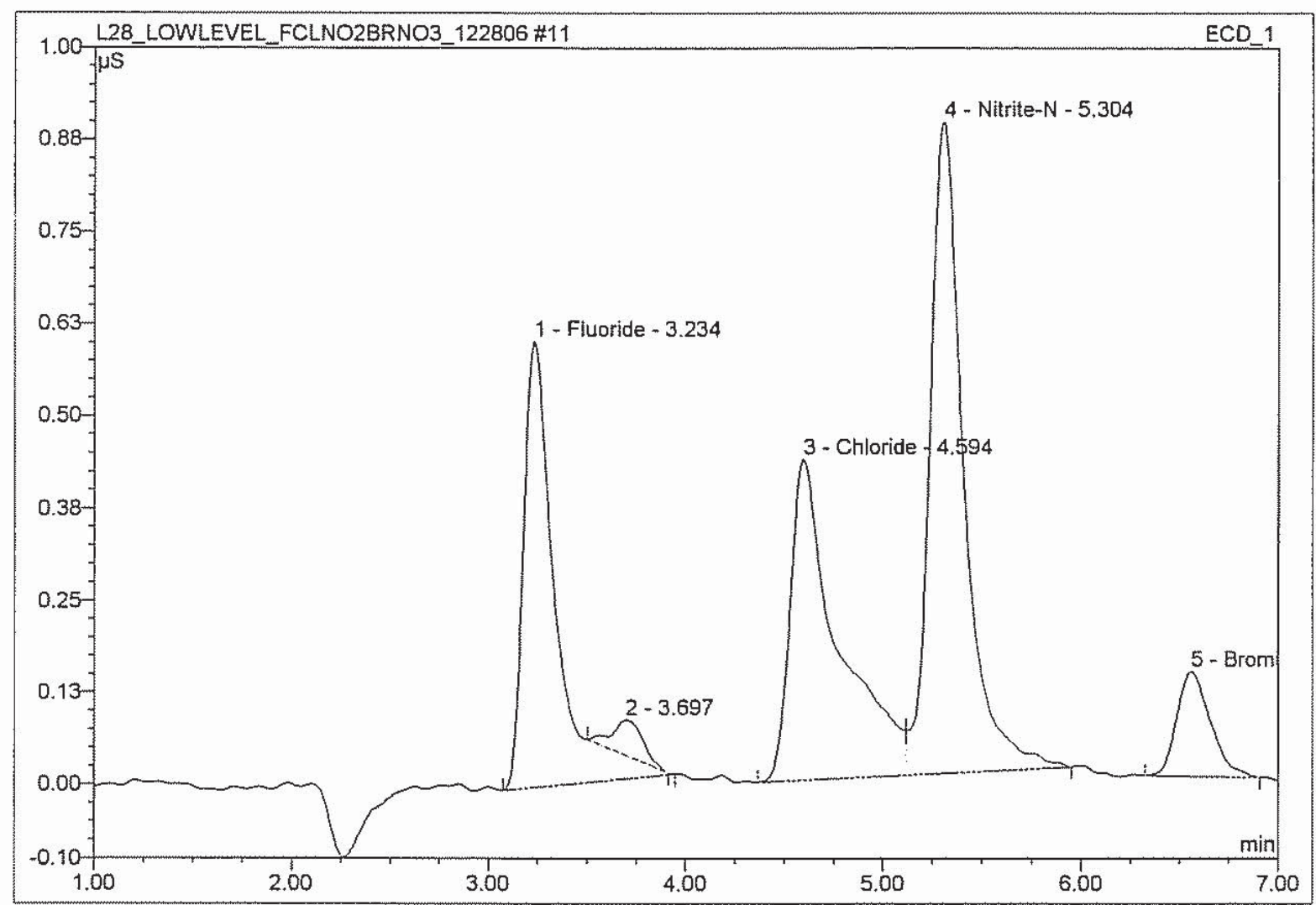

\begin{tabular}{|r|r|l|r|r|r|r|r|}
\hline No. & $\begin{array}{c}\text { Ret.Time } \\
\text { (min.) }\end{array}$ & \multicolumn{1}{|c|}{ Peak Name } & $\begin{array}{c}\text { Height } \\
(\mathrm{uS})\end{array}$ & $\begin{array}{c}\text { Area } \\
\mu \mathrm{S}^{*} \mathrm{~min}\end{array}$ & $\begin{array}{r}\text { Rel.Area } \\
(\%)\end{array}$ & $\begin{array}{r}\text { Amount } \\
(\mathrm{mg} / \mathrm{L})\end{array}$ & $\begin{array}{r}\text { Peak } \\
\text { Type }\end{array}$ \\
\hline 1 & 3.23 & Fluoride & 0.60402 & 0.115 & 0.25 & 4.4141 & BMB \\
\hline 2 & 3.70 & n.a. & 0.04813 & 0.009 & 0.02 & n.a. & Rd \\
\hline 3 & 4.59 & Chloride & 0.43484 & 0.122 & 0.26 & 3.9460 & $\mathrm{BM}$ \\
\hline 4 & 5.30 & Nitrite-N & 0.88289 & 0.176 & 0.38 & 4.6088 & $\mathrm{MB}$ \\
\hline 5 & 6.56 & Bromide & 0.14211 & 0.028 & 0.06 & 4.0035 & BMB \\
\hline 6 & 7.32 & Nitrate-N & 0.83916 & 0.196 & 0.42 & 4.7938 & BMB \\
\hline 7 & 11.41 & n.a. & 45.573 & 98.60 & n.a. & BMB \\
\hline
\end{tabular}




\section{H6L110106-JK7J7-1/20-MSD@0.2ppm Cl}

\begin{tabular}{llll}
\hline Sample Name: & H6L110106-JK7J7-1/20-MSD@0.2ppm Cl & Injection Volume: & $\mathbf{5 0 . 0}$ \\
Vial Number: & $\mathbf{1 3 1 6}$ & Channel: & ECD_1 \\
Sample Type: & unknown & Wavelength: & n.a. \\
Control Program: & AS14A ANIONS METHOD & Bandwidth: & n.a. \\
Quantif. Method: & AS4A-SC ANION METHOD & Dilution Factor: & $\mathbf{2 0 . 0 0 0 0}$ \\
Recording Time: & $\mathbf{1 2 / 2 8 / 2 0 0 6 1 4 : 5 7}$ & Sample Weight: & $\mathbf{1 . 0 0 0 0}$ \\
Run Time (min): & $\mathbf{1 3 . 9 0}$ & Sample Amount: & $\mathbf{1 . 0 0 0 0}$ \\
\hline
\end{tabular}

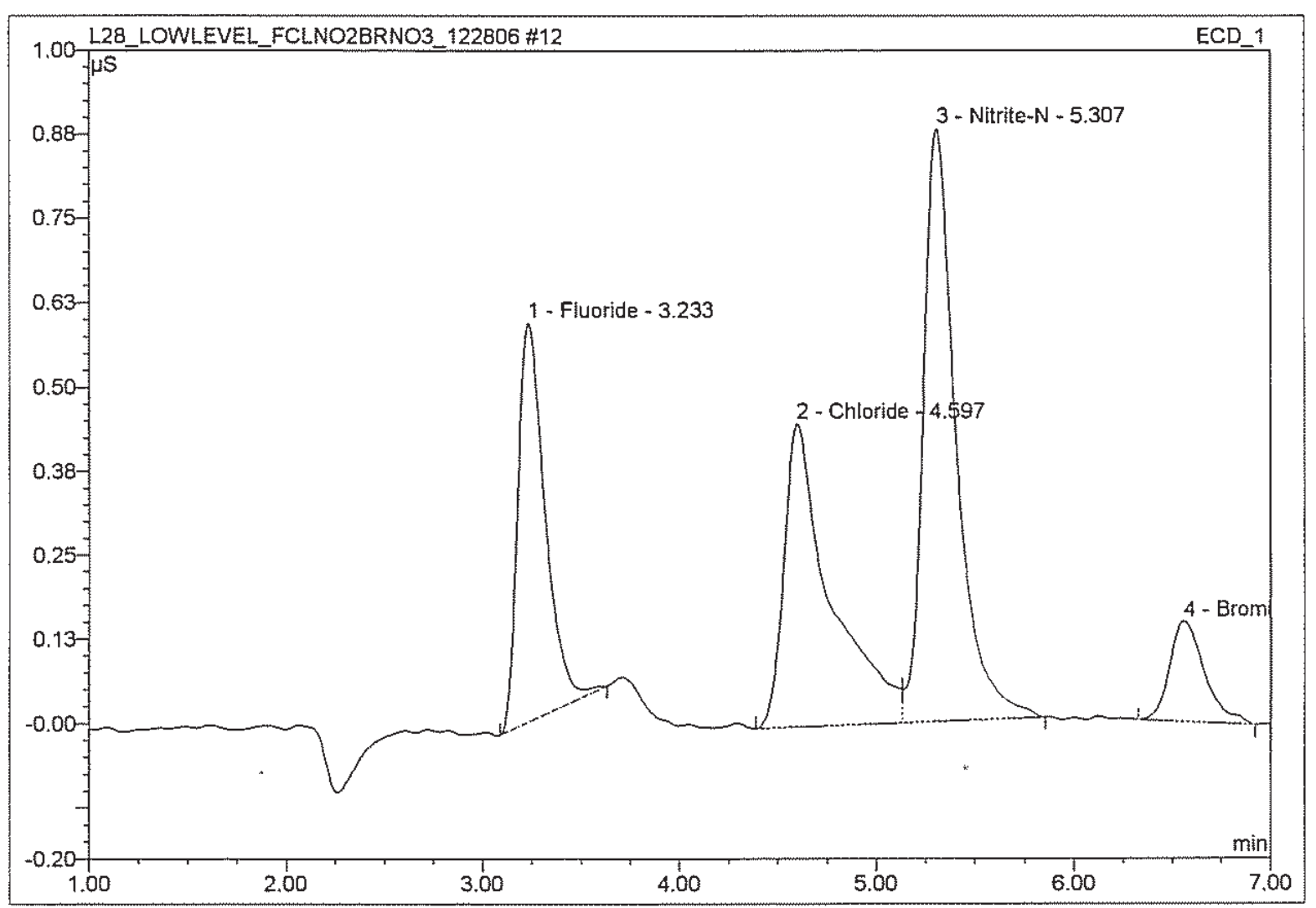

\begin{tabular}{|c|c|l|r|r|r|r|c|}
\hline No. & $\begin{array}{c}\text { Ret.Time } \\
\text { (min.) }\end{array}$ & \multicolumn{1}{|c|}{ Peak Name } & $\begin{array}{c}\text { Height } \\
\text { (uS) }\end{array}$ & $\begin{array}{c}\text { Area } \\
\mu S^{*} \min \end{array}$ & $\begin{array}{c}\text { Rel.Area } \\
(\%)\end{array}$ & $\begin{array}{c}\text { Amount } \\
\text { (mg/L) }\end{array}$ & $\begin{array}{r}\text { Peak } \\
\text { Type }\end{array}$ \\
\hline 1 & 3.23 & Fluoride & 0.59252 & 0.095 & 0.20 & 4.3315 & BMB \\
\hline 2 & 4.60 & Chloride & 0.45078 & 0.123 & 0.27 & 4.0902 & $\mathrm{BM}$ \\
\hline 3 & 5.31 & Nitrite-N & 0.88058 & 0.170 & 0.37 & 4.5969 & $\mathrm{MB}$ \\
\hline 4 & 6.56 & Bromide & 0.14858 & 0.031 & 0.07 & 4.1856 & $\mathrm{BMB}$ \\
\hline 5 & 7.33 & Nitrate-N & 0.85559 & 0.208 & 0.45 & 4.8865 & $\mathrm{BMB}$ \\
\hline 6 & 11.41 & n.a. & 45.813 & 98.65 & n.a. & BMB \\
\hline
\end{tabular}




\section{H6L110106-JK7J7-1/40}

\begin{tabular}{|llll|}
\hline Sample Name: & H6L110106-JK7J7-1/40 & Injection Volume: & $\mathbf{5 0 . 0}$ \\
Vial Number: & $\mathbf{1 3 1 7}$ & Channel: & ECD_1 \\
Sample Type: & unknown & Wavelength: & n.a. \\
Control Program: & AS14A ANIONS METHOD & Bandwidth: & n.a. \\
Quantif. Method: & AS4A-SC ANION METHOD & Dilution Factor: & $\mathbf{4 0 . 0 0 0 0}$ \\
Recording Time: & $\mathbf{1 2 / 2 8 / 2 0 0 6 ~ 1 5 : 1 5}$ & Sample Weight: & $\mathbf{1 . 0 0 0 0}$ \\
Run Time (min): & $\mathbf{1 5 . 0 0}$ & Sample Amount: & $\mathbf{1 . 0 0 0 0}$ \\
\hline
\end{tabular}

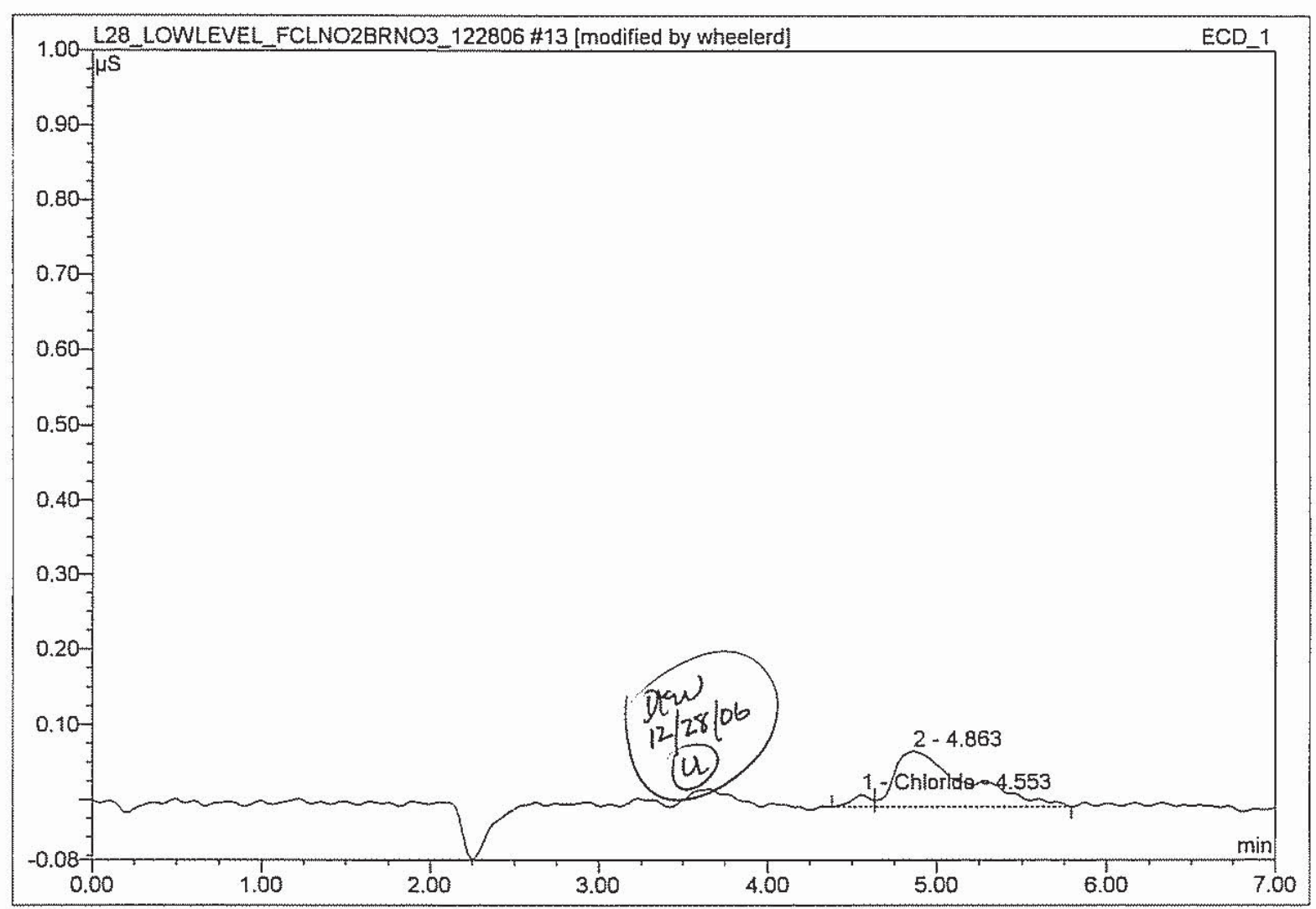

\begin{tabular}{|r|c|l|r|r|r|r|r|}
\hline No. & $\begin{array}{c}\text { Ret.Time } \\
\text { (min.) }\end{array}$ & \multicolumn{1}{|c|}{ Peak Name } & $\begin{array}{c}\text { Height } \\
(\mathbf{u S})\end{array}$ & $\begin{array}{c}\text { Area } \\
\mu \mathrm{S}^{*} \min \end{array}$ & $\begin{array}{r}\text { Rel.Area } \\
(\%)\end{array}$ & $\begin{array}{r}\text { Amount } \\
(\mathrm{mg} / \mathrm{L})\end{array}$ & $\begin{array}{r}\text { Peak } \\
\text { Type }\end{array}$ \\
\hline 1 & 4.55 & Chloride & 0.01633 & 0.002 & 0.01 & 0.2973 & $\mathrm{BM}^{*}$ \\
\hline 2 & 4.86 & n.a. & 0.07384 & 0.036 & 0.17 & n.a. & $\mathrm{MB}^{*}$ \\
\hline 3 & 7.33 & Nitrate-N & 0.05437 & 0.012 & 0.06 & 0.6285 & $\mathrm{BMB}$ \\
\hline 4 & 11.46 & n.a. & 68.39477 & 21.339 & 99.76 & n.a. & BMB \\
\hline
\end{tabular}




\section{H6L110106-JK7J7-1/40}

\begin{tabular}{llll|}
\hline Sample Name: & H6L110106-JK7J7-1/40 & Injection Volume: & $\mathbf{5 0 . 0}$ \\
Vial Number: & $\mathbf{1 3 1 7}$ & Channel: & ECD_1 \\
Sample Type: & unknown & Wavelength: & n.a. \\
Control Program: & AS14A ANIONS METHOD & Bandwidth: & n.a. \\
Quantif. Method: & AS4A-SC ANION METHOD & Dilution Factor: & $\mathbf{4 0 . 0 0 0 0}$ \\
Recording Time: & $\mathbf{1 2 / 2 8 / 2 0 0 6 1 5 : 1 5}$ & Sample Weight: & $\mathbf{1 . 0 0 0 0}$ \\
Run Time (min): & $\mathbf{1 5 . 0 0}$ & Sample Amount: & $\mathbf{1 . 0 0 0 0}$ \\
\hline
\end{tabular}

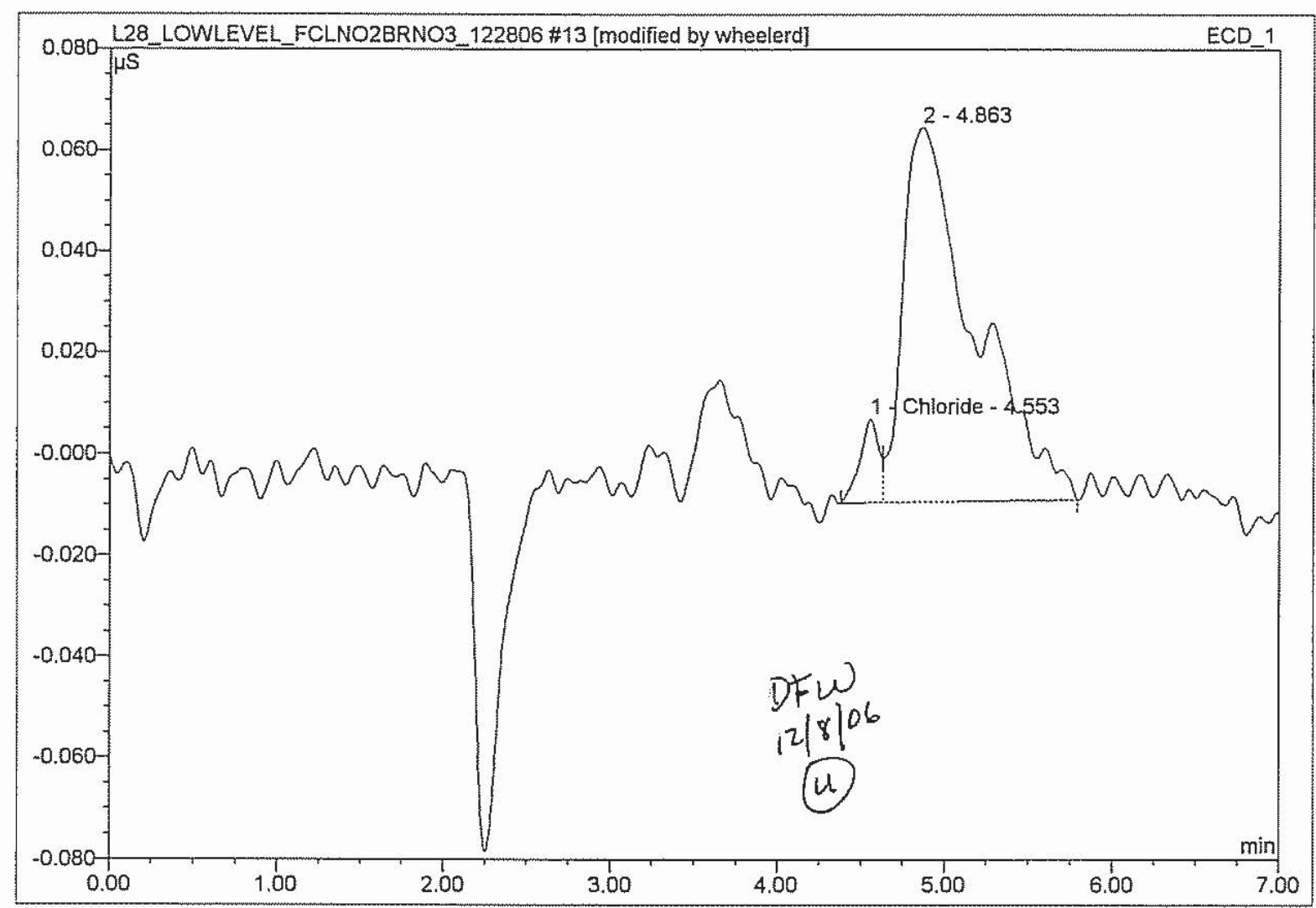

\begin{tabular}{|r|r|l|r|r|r|r|r|}
\hline No. & $\begin{array}{c}\text { Ret.Time } \\
\text { (min.) }\end{array}$ & \multicolumn{1}{|c|}{ Peak Name } & $\begin{array}{c}\text { Height } \\
(\mathbf{u S})\end{array}$ & $\begin{array}{c}\text { Area } \\
\mu S^{*} \min \end{array}$ & $\begin{array}{r}\text { Rel.Area } \\
(\%)\end{array}$ & $\begin{array}{r}\text { Amount } \\
(\mathrm{mg} / \mathrm{L})\end{array}$ & $\begin{array}{r}\text { Peak } \\
\text { Type }\end{array}$ \\
\hline 1 & 4.55 & Chloride & 0.01633 & 0.002 & 0.01 & 0.2973 & $\mathrm{BM}^{*}$ \\
\hline 2 & 4.86 & n.a. & 0.07384 & 0.036 & 0.17 & n.a. & $\mathrm{MB}^{*}$ \\
\hline 3 & 7.33 & Nitrate-N & 0.05437 & 0.012 & 0.06 & 0.6285 & $\mathrm{BMB}$ \\
\hline 4 & 11.46 & n.a. & 68.39477 & 21.339 & 99.76 & n.a. & $\mathrm{BMB}$ \\
\hline
\end{tabular}




\section{H6L110106-JK7J7-1/40}

\begin{tabular}{llll|}
\hline Sample Name: & H6L110106-JK7J7-1/40 & Injection Volume: & $\mathbf{5 0 . 0}$ \\
Vial Number: & $\mathbf{1 3 1 7}$ & Channel: & ECD_1 \\
Sample Type: & unknown & Wavelength: & n.a. \\
Control Program: & AS14A ANIONS METHOD & Bandwidth: & n.a. \\
Quantif. Method: & AS4A-SC ANION METHOD & Dilution Factor: & 40.0000 \\
Recording Time: & $\mathbf{1 2 / 2 8 / 2 0 0 6 ~ 1 5 : 1 5}$ & Sample Weight: & $\mathbf{1 . 0 0 0 0}$ \\
Run Time (min): & $\mathbf{1 5 . 0 0}$ & Sample Amount: & $\mathbf{1 . 0 0 0 0}$ \\
\hline
\end{tabular}

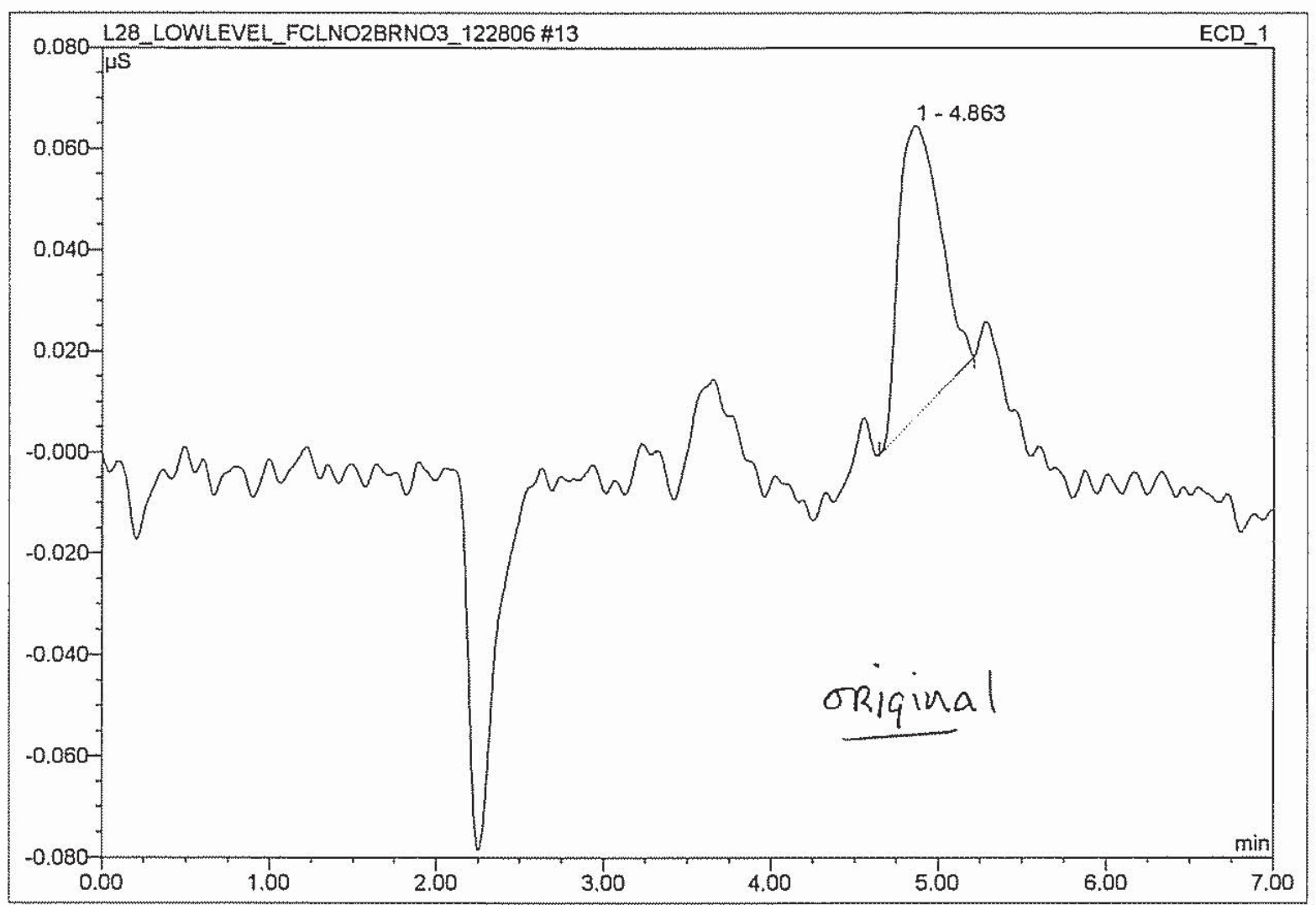

\begin{tabular}{|r|c|l|r|r|r|r|r|}
\hline No. & $\begin{array}{c}\text { Ret.Time } \\
\text { (min.) }\end{array}$ & \multicolumn{1}{|c|}{ Peak Name } & $\begin{array}{c}\text { Height } \\
\text { (uS) }\end{array}$ & $\begin{array}{c}\text { Area } \\
\mu S^{\star} \min \end{array}$ & $\begin{array}{r}\text { Rel.Area } \\
(\%)\end{array}$ & $\begin{array}{c}\text { Amount } \\
\text { (mg/L) }\end{array}$ & $\begin{array}{r}\text { Peak } \\
\text { Type }\end{array}$ \\
\hline 1 & 4.86 & n.a. & 0.05739 & 0.016 & 0.08 & n.a. & BMB \\
\hline 2 & 7.33 & Nitrate-N & 0.05437 & 0.012 & 0.06 & 0.6285 & BMB \\
\hline 3 & 11.46 & n.a. & 68.39477 & 21.339 & 99.87 & n.a. & BMB \\
\hline
\end{tabular}




\section{H6L110106-JK7J7-1/40-MS@0.2ppm Cl}

\begin{tabular}{llll}
\hline Sample Name: & H6L110106-JK7J7-1/40-MS@0.2ppm Cl & Injection Volume: & $\mathbf{5 0 . 0}$ \\
Vial Number: & 1317 & Channel: & ECD_1 \\
Sample Type: & unknown & Wavelength: & n.a. \\
Control Program: & AS14A ANIONS METHOD & Bandwidth: & n.a. \\
Quantif. Method: & AS4A-SC ANION METHOD & Dilution Factor: & 40.0000 \\
Recording Time: & $12 / 28 / 200615: 34$ & Sample Weight: & 1.0000 \\
Run Time (min): & $\mathbf{1 5 . 0 0}$ & Sample Amount: & $\mathbf{1 . 0 0 0 0}$ \\
\hline
\end{tabular}

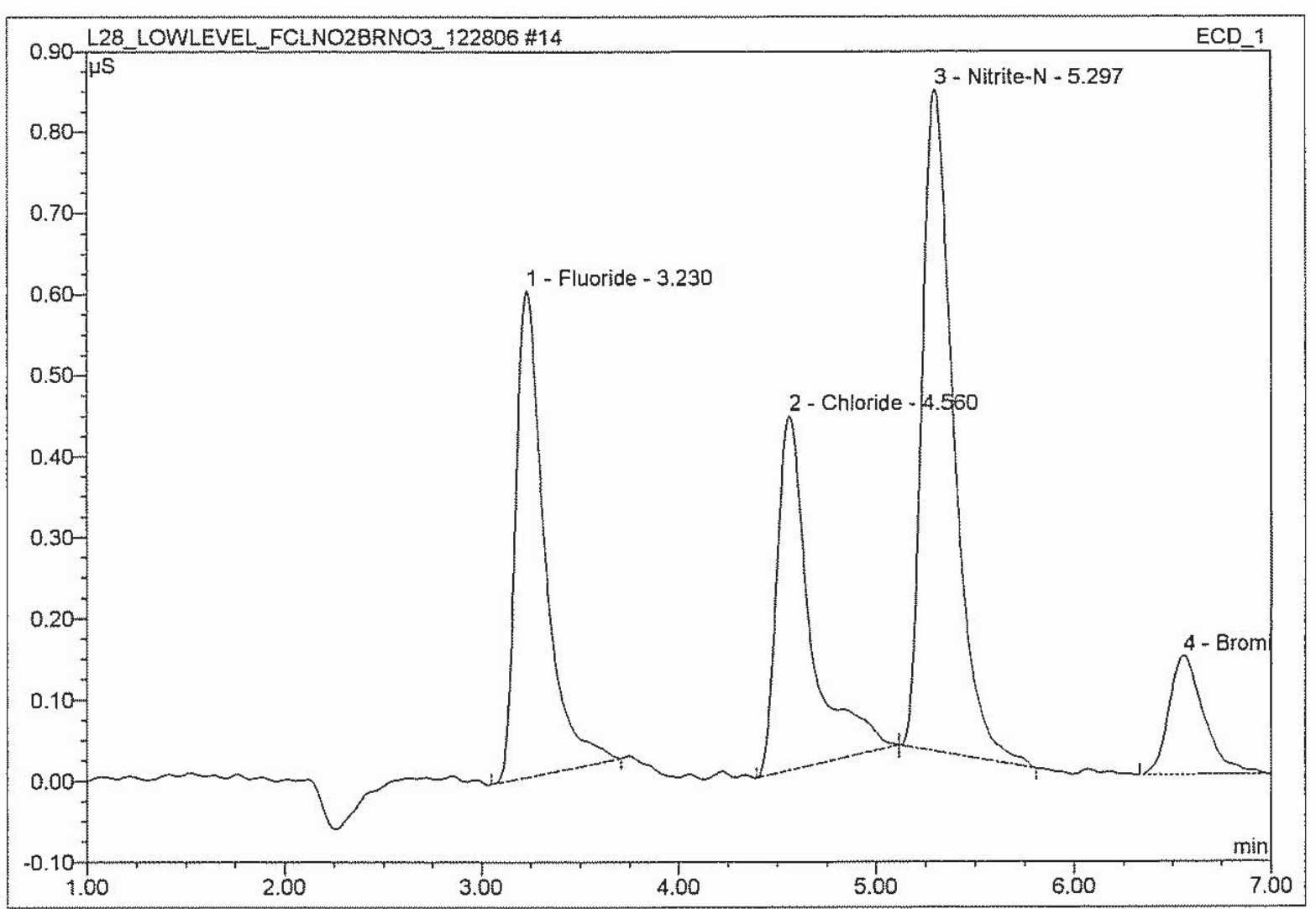

\begin{tabular}{|c|c|l|r|r|r|r|c|}
\hline No. & $\begin{array}{c}\text { Ret.Time } \\
\text { (min.) }\end{array}$ & \multicolumn{1}{|c|}{ Peak Name } & $\begin{array}{c}\text { Height } \\
\text { (uS) }\end{array}$ & $\begin{array}{c}\text { Area } \\
\mu S^{*} \text { min }\end{array}$ & $\begin{array}{c}\text { Rel.Area } \\
(\%)\end{array}$ & $\begin{array}{c}\text { Amount } \\
(\mathrm{mg} / \mathrm{L})\end{array}$ & $\begin{array}{c}\text { Peak } \\
\text { Type }\end{array}$ \\
\hline 1 & 3.23 & Fluoride & 0.60020 & 0.102 & 0.48 & 8.7734 & BMB \\
\hline 2 & 4.56 & Chloride & 0.43705 & 0.086 & 0.40 & 7.9320 & $\mathrm{BMB}$ \\
\hline 3 & 5.30 & Nitrite-N & 0.81527 & 0.150 & 0.70 & 8.5168 & $\mathrm{bMB}$ \\
\hline 4 & 6.55 & Bromide & 0.14598 & 0.030 & 0.14 & 8.2249 & $\mathrm{BM}$ \\
\hline 5 & 7.32 & Nitrate-N & 0.78173 & 0.187 & 0.87 & 8.9389 & $\mathrm{MB}$ \\
\hline 6 & 11.47 & n.a. & 66.89217 & 20.869 & 97.41 & n.a. & BMB \\
\hline
\end{tabular}




\section{H6L110106-JK7J7-1/40-MSD@0.2ppm Cl}

\begin{tabular}{llll|}
\hline Sample Name: & H6L110106-JK7J7-1/40-MSD@0.2ppm Cl & Injection Volume: & $\mathbf{5 0 . 0}$ \\
Vial Number: & $\mathbf{1 3 1 8}$ & Channel: & ECD_1 \\
Sample Type: & unknown & Wavelength: & n.a. \\
Control Program: & AS14A ANIONS METHOD & Bandwidth: & n.a. \\
Quantif. Method: & AS4A-SC ANION METHOD & Dilution Factor: & $\mathbf{4 0 . 0 0 0 0}$ \\
Recording Time: & $\mathbf{1 2 / 2 8 / 2 0 0 6 ~ 1 5 : 5 2}$ & Sample Weight: & $\mathbf{1 . 0 0 0 0}$ \\
Run Time (min): & $\mathbf{1 5 . 0 0}$ & Sample Amount: & $\mathbf{1 . 0 0 0 0}$ \\
\hline
\end{tabular}

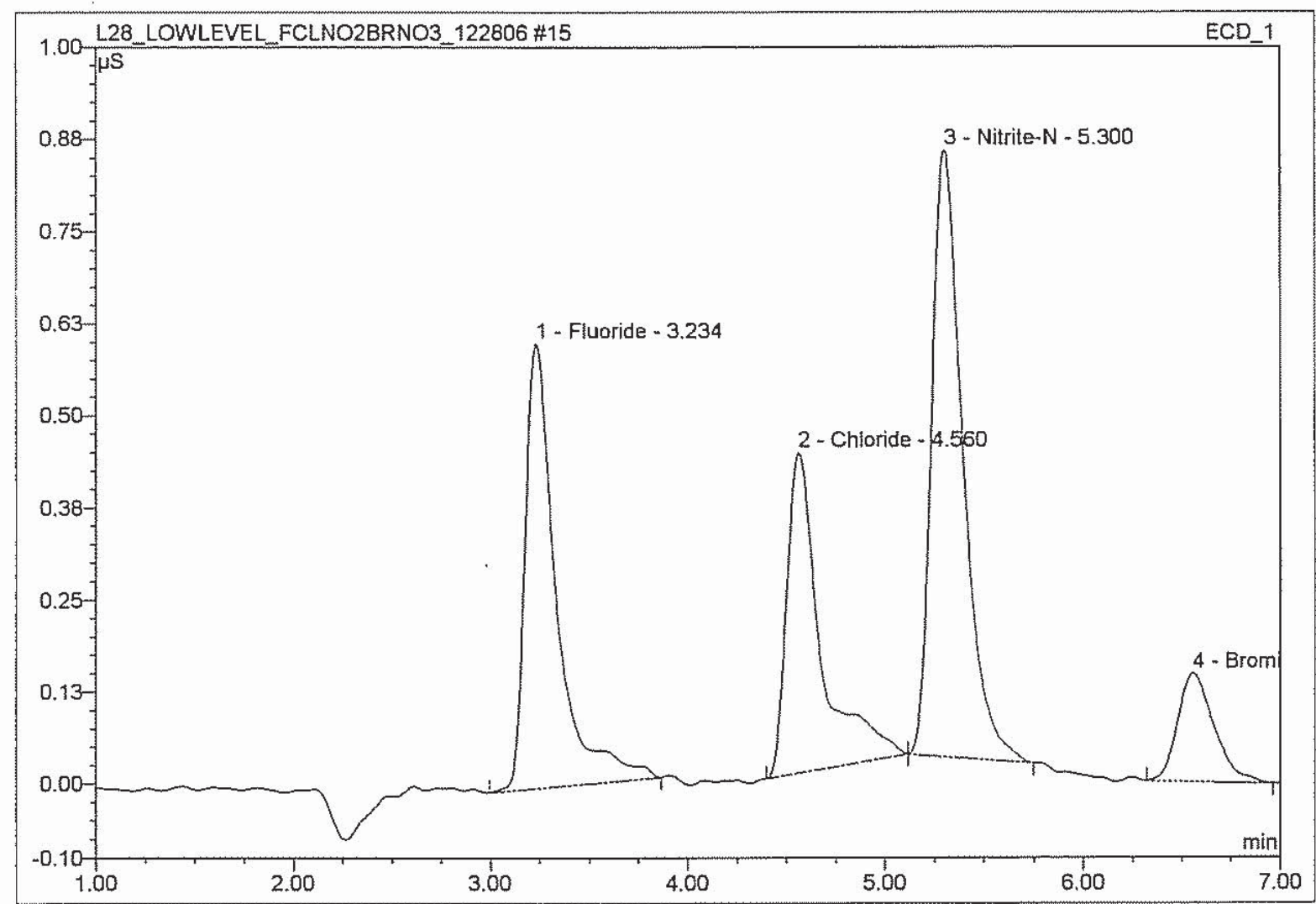

\begin{tabular}{|c|c|l|r|r|r|r|c|}
\hline No. & $\begin{array}{c}\text { Ret.Time } \\
\text { (min.) }\end{array}$ & \multicolumn{1}{|c|}{ Peak Name } & $\begin{array}{c}\text { Height } \\
(\mathrm{uS})\end{array}$ & $\begin{array}{c}\text { Area } \\
\boldsymbol{\mu S}^{\star} \mathrm{min}\end{array}$ & $\begin{array}{c}\text { Rel.Area } \\
(\%)\end{array}$ & $\begin{array}{c}\text { Amount } \\
(\mathbf{m g} / \mathrm{L})\end{array}$ & $\begin{array}{c}\text { Peak } \\
\text { Type }\end{array}$ \\
\hline 1 & 3.23 & Fluoride & 0.60384 & 0.111 & 0.51 & 8.8257 & BMB \\
\hline 2 & 4.56 & Chloride & 0.43447 & 0.087 & 0.40 & 7.8852 & BMB \\
\hline 3 & 5.30 & Nitrite-N & 0.82309 & 0.150 & 0.70 & 8.5978 & bMB \\
\hline 4 & 6.55 & Bromide & 0.14688 & 0.032 & 0.15 & 8.2750 & BMB \\
\hline 5 & 7.32 & Nitrate-N & 0.78556 & 0.187 & 0.87 & 8.9822 & BMB \\
\hline 6 & 11.46 & n.a. & 67.25044 & 20.977 & 97.37 & n.a. & BMB \\
\hline
\end{tabular}




\section{$16 \mathrm{CCV}=1 \mathrm{CWS}-9090$}

\begin{tabular}{llll}
\hline Sample Name: & CCV=ICWS-9090 & Injection Volume: & $\mathbf{5 0 . 0}$ \\
Vial Number: & $\mathbf{1 3 7 0}$ & Channel: & ECD_1 \\
Sample Type: & unknown & Wavelength: & n.a. \\
Control Program: & AS14A ANIONS METHOD & Bandwidth: & n.a. \\
Quantif. Method: & AS4A-SC ANION METHOD & Dilution Factor: & $\mathbf{1 . 0 0 0 0}$ \\
Recording Time: & $\mathbf{1 2 / 2 8 / 2 0 0 6 ~ 1 6 : 0 9}$ & Sample Weight: & $\mathbf{1 . 0 0 0 0}$ \\
Run Time (min): & $\mathbf{1 5 . 0 0}$ & Sample Amount: & $\mathbf{1 . 0 0 0 0}$ \\
\hline
\end{tabular}

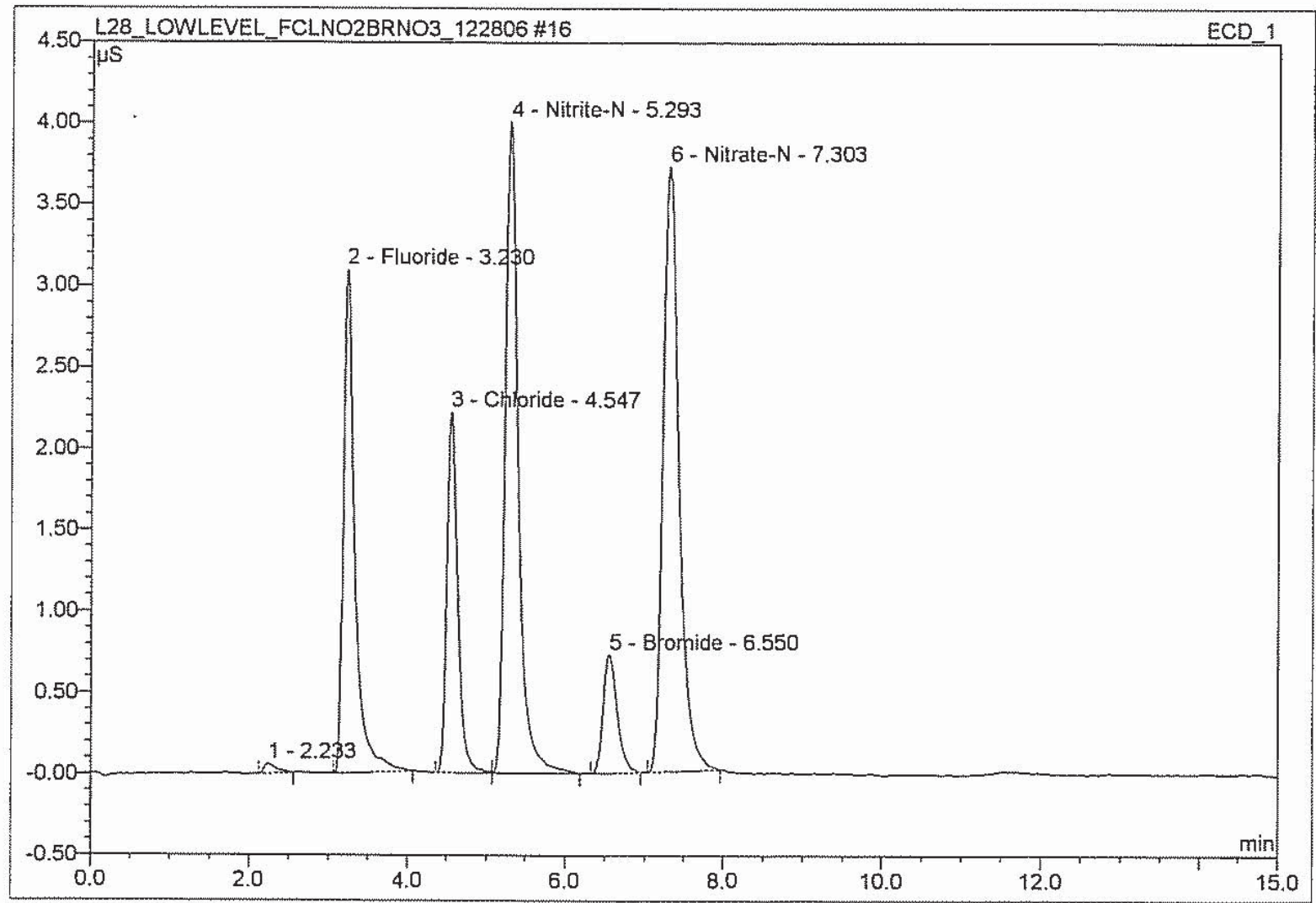

\begin{tabular}{|c|c|l|r|r|r|r|c|}
\hline No. & $\begin{array}{c}\text { Ret.Time } \\
\text { (min.) }\end{array}$ & \multicolumn{1}{|c|}{ Peak Name } & $\begin{array}{c}\text { Height } \\
\text { (uS) }\end{array}$ & $\begin{array}{c}\text { Area } \\
\mu S^{*} \text { min }\end{array}$ & $\begin{array}{c}\text { Rel.Area } \\
(\%)\end{array}$ & $\begin{array}{c}\text { Amount } \\
\text { (mg/L) }\end{array}$ & $\begin{array}{r}\text { Peak } \\
\text { Type }\end{array}$ \\
\hline 1 & 2.23 & n.a. & 0.06059 & 0.011 & 0.42 & ..a. & BMB \\
\hline 2 & 3.23 & Fluoride & 3.09242 & 0.528 & 19.53 & 1.0594 & BMB \\
\hline 3 & 4.55 & Chloride & 2.21582 & 0.356 & 13.19 & 0.9933 & BM \\
\hline 4 & 5.29 & Nitrite-N & 4.00209 & 0.777 & 28.76 & 1.0173 & MB \\
\hline 5 & 6.55 & Bromide & 0.72968 & 0.151 & 5.60 & 1.0210 & BMB \\
\hline 6 & 7.30 & Nitrate-N & 3.71828 & 0.878 & 32.50 & 1.0209 & BMB \\
\hline
\end{tabular}




\section{$17 \mathrm{CCB}$}

\begin{tabular}{llll|}
\hline Sample Name: & CCB & Injection Volume: & $\mathbf{5 0 . 0}$ \\
Vial Number: & $\mathbf{1 3 7 1}$ & Channel: & ECD_1 \\
Sample Type: & unknown & Wavelength: & n.a. \\
Control Program: & AS14A ANIONS METHOD & Bandwidth: & n.a. \\
Quantif. Method: & AS4A-SC ANION METHOD & Dilution Factor: & $\mathbf{1 . 0 0 0 0}$ \\
Recording Time: & $\mathbf{1 2 / 2 8 / 2 0 0 6 1 6 : 2 6}$ & Sample Weight: & $\mathbf{1 . 0 0 0 0}$ \\
Run Time (min): & $\mathbf{1 5 . 0 0}$ & Sample Amount: & $\mathbf{1 . 0 0 0 0}$ \\
\hline
\end{tabular}

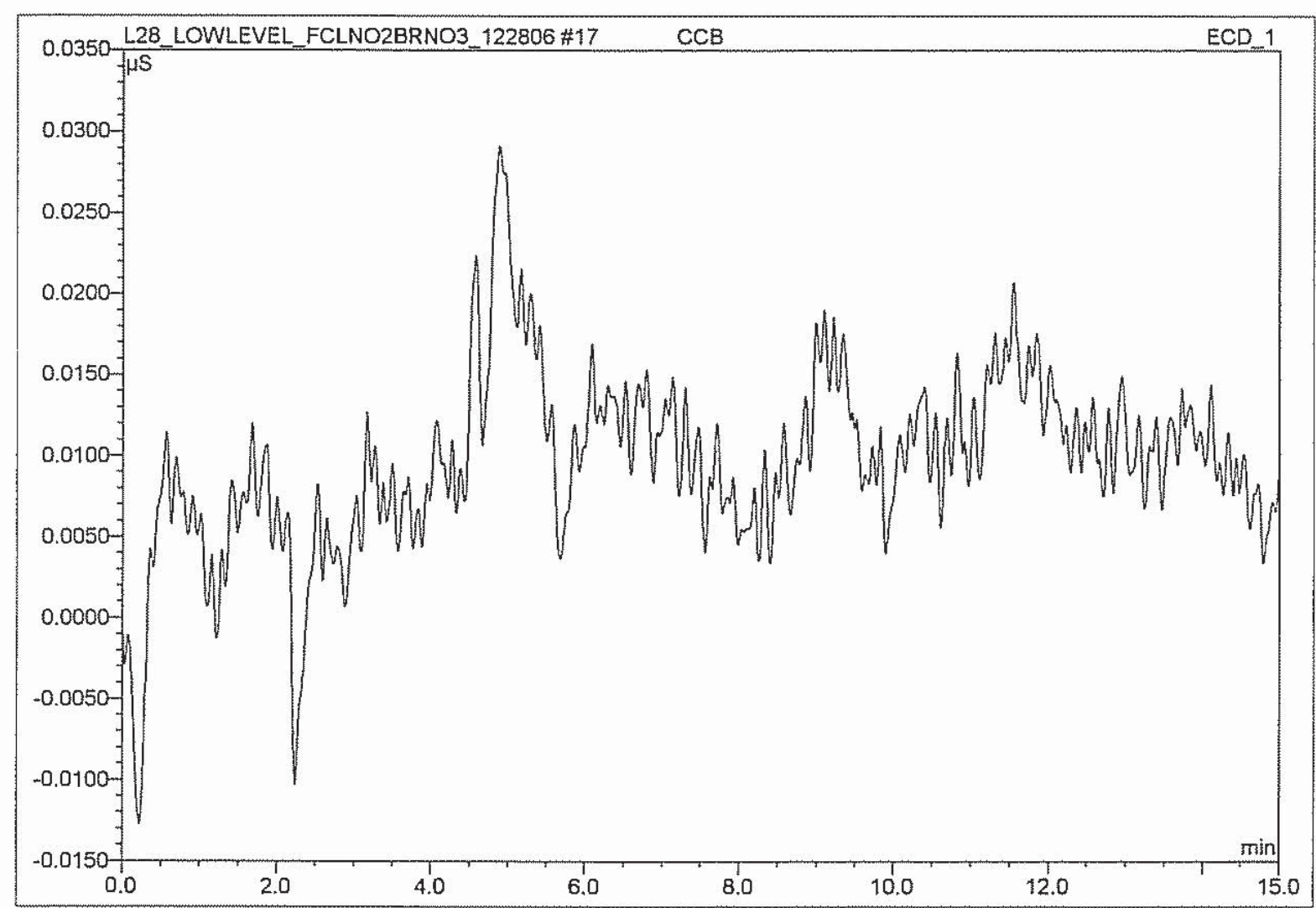

\begin{tabular}{|l|c|c|c|c|c|c|c|}
\hline No. & $\begin{array}{c}\text { Ret.Time } \\
(\min )\end{array}$ & Peak Name & $\begin{array}{c}\text { Height } \\
(\mathrm{uS})\end{array}$ & $\begin{array}{c}\text { Area } \\
\mu \mathrm{S}^{*} \mathrm{~min}\end{array}$ & $\begin{array}{c}\text { Rel.Area } \\
(\%)\end{array}$ & $\begin{array}{c}\text { Amount } \\
(\mathrm{mg} / \mathrm{L})\end{array}$ & $\begin{array}{c}\text { Peak } \\
\text { Type }\end{array}$ \\
\hline
\end{tabular}




\section{H6L110106-JK7KG-1/20}

\begin{tabular}{llll|}
\hline Sample Name: & H6L110106-JK7KG-1/20 & Injection Volume: & $\mathbf{5 0 . 0}$ \\
Vial Number: & $\mathbf{1 3 9 7}$ & Channel: & ECD_1 \\
Sample Type: & unknown & Wavelength: & n.a. \\
Control Program: & AS14A ANIONS METHOD & Bandwidth: & n.a. \\
Quantif. Method: & AS4A-SC ANION METHOD & Dilution Factor: & $\mathbf{2 0 . 0 0 0 0}$ \\
Recording Time: & $\mathbf{1 2 / 2 8 / 2 0 0 6 ~ 1 7 : 5 3}$ & Sample Weight: & $\mathbf{1 . 0 0 0 0}$ \\
Run Time (min): & $\mathbf{1 5 . 0 0}$ & Sample Amount: & 1.0000 \\
\hline
\end{tabular}

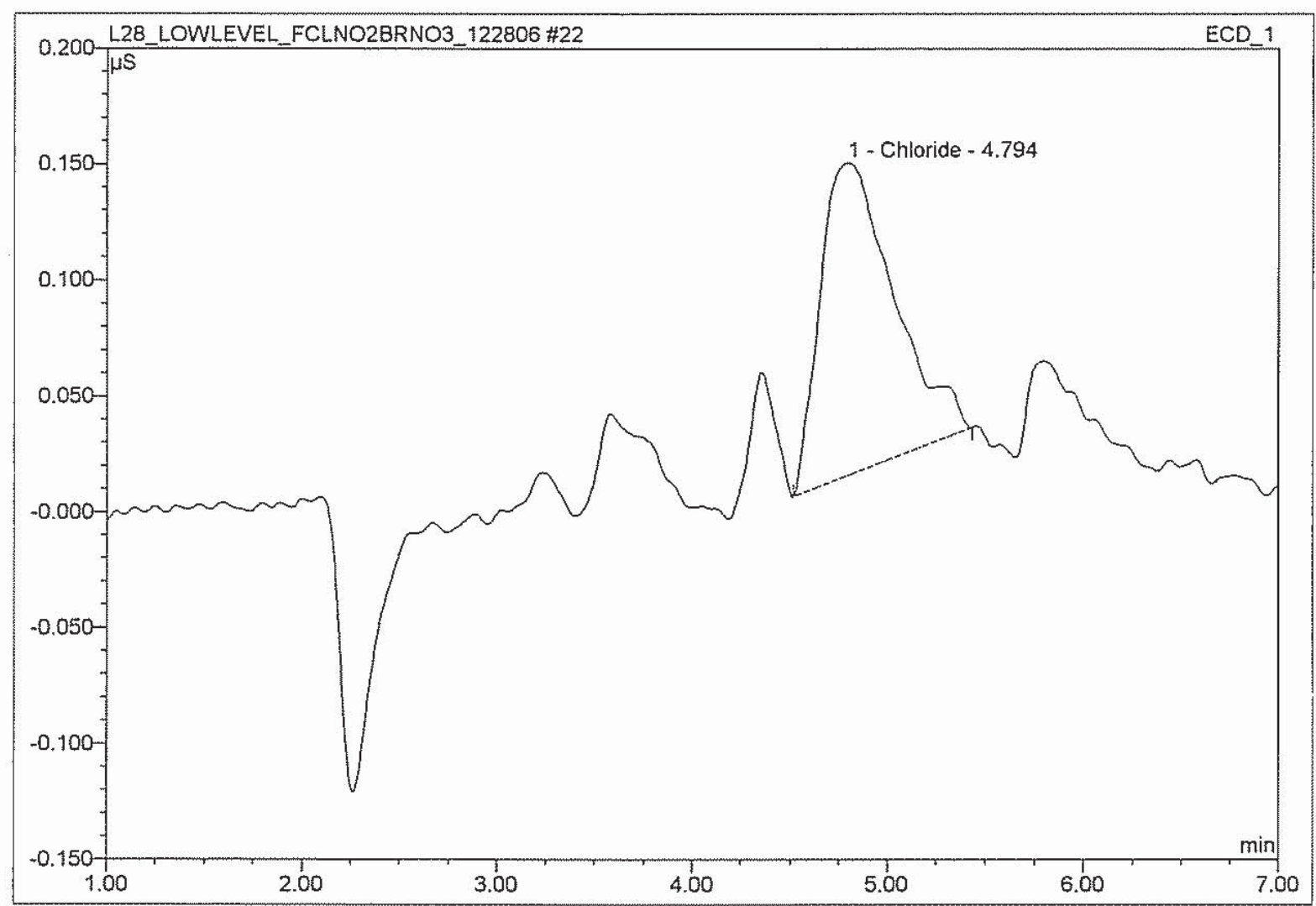

\begin{tabular}{|c|c|l|r|r|r|r|r|}
\hline No. & $\begin{array}{c}\text { Ret.Time } \\
(\mathrm{min})\end{array}$ & \multicolumn{1}{|c|}{ Peak Name } & $\begin{array}{c}\text { Height } \\
(\mathrm{uS})\end{array}$ & $\begin{array}{c}\text { Area } \\
\mu \mathrm{S}^{*} \mathrm{~min}\end{array}$ & $\begin{array}{r}\text { Rel.Area } \\
(\%)\end{array}$ & $\begin{array}{c}\text { Amount } \\
(\mathrm{mg} / \mathrm{L})\end{array}$ & $\begin{array}{r}\text { Peak } \\
\text { Type }\end{array}$ \\
\hline 1 & 4.79 & Chloride & 0.13461 & 0.059 & 0.12 & 1.2241 & BMB \\
\hline 2 & 7.33 & Nitrate-N & 0.09886 & 0.023 & 0.05 & 0.5710 & BMB \\
\hline 3 & 10.32 & n.a. & 0.76053 & 0.227 & 0.47 & n.a. & BMB \\
\hline 4 & 11.40 & n.a. & 47.768 & 99.36 & n.a. & BMB \\
\hline
\end{tabular}

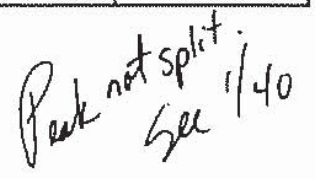




\section{H6L110106-JK7KG-1/40}

\begin{tabular}{llll|}
\hline Sample Name: & H6L110106-JK7KG-1/40 & Injection Volume: & $\mathbf{5 0 . 0}$ \\
Vial Number: & $\mathbf{1 3 9 8}$ & Channel: & ECD_1 \\
Sample Type: & unknown & Wavelength: & n.a. \\
Control Program: & AS14A ANIONS METHOD & Bandwidth: & n.a. \\
Quantif. Method: & AS4A-SC ANION METHOD & Dilution Factor: & $\mathbf{4 0 . 0 0 0 0}$ \\
Recording Time: & $\mathbf{1 2 / 2 8 / 2 0 0 6 1 8 : 1 1}$ & Sample Weight: & $\mathbf{1 . 0 0 0 0}$ \\
Run Time (min): & $\mathbf{1 5 . 0 0}$ & Sample Amount: & $\mathbf{1 . 0 0 0 0}$ \\
\hline
\end{tabular}

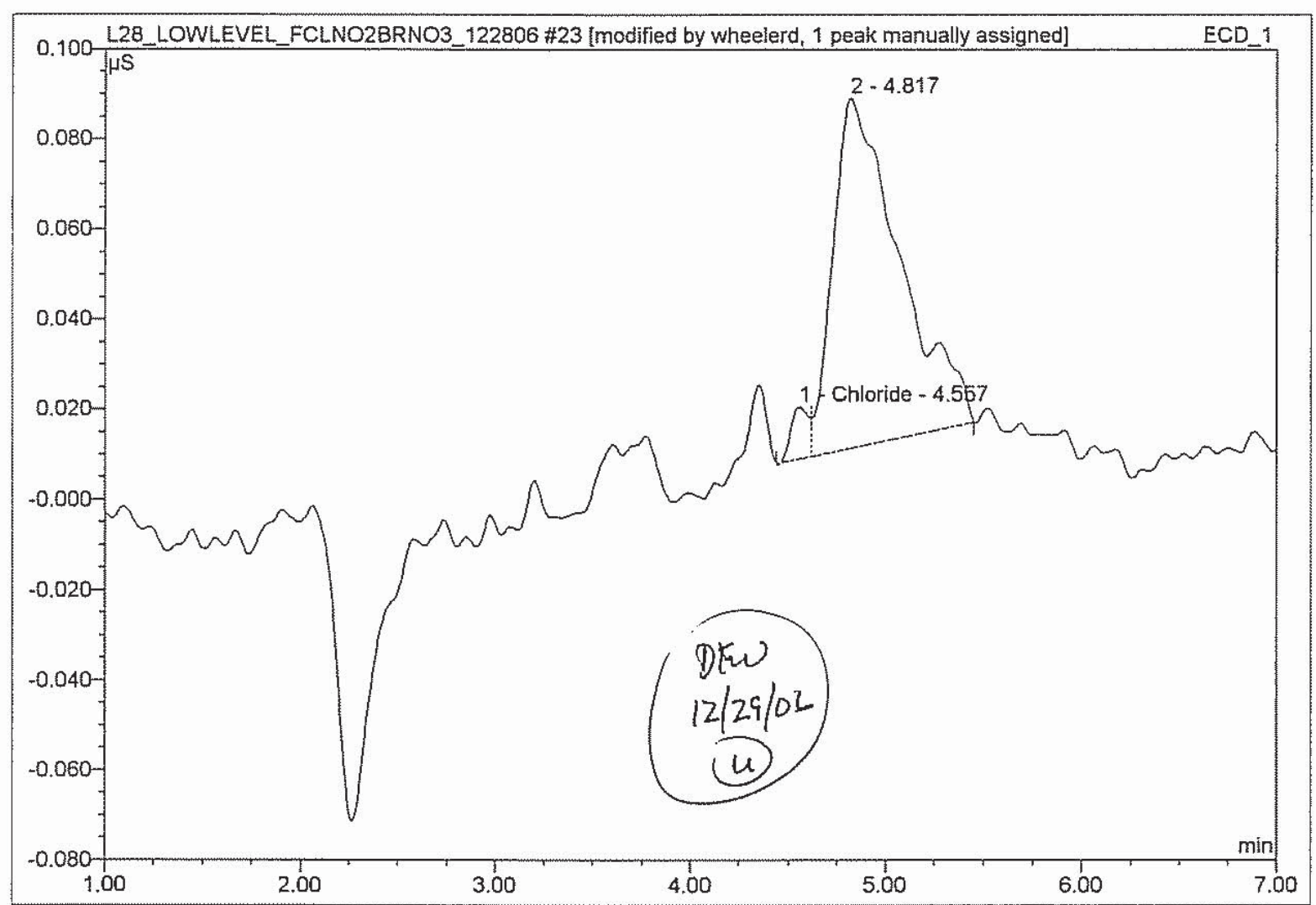

\begin{tabular}{|r|c|l|r|r|r|r|r|}
\hline No. & $\begin{array}{c}\text { Ret.Time } \\
\text { (min.) }\end{array}$ & \multicolumn{1}{|c|}{ Peak Name } & $\begin{array}{c}\text { Height } \\
\text { (uS) }\end{array}$ & $\begin{array}{c}\text { Area } \\
\mu S^{\star} \min \end{array}$ & $\begin{array}{r}\text { Rel.Area } \\
(\%)\end{array}$ & $\begin{array}{r}\text { Amount } \\
(\mathrm{mg} / \text { L) }\end{array}$ & $\begin{array}{r}\text { Peak } \\
\text { Type }\end{array}$ \\
\hline 1 & 4.56 & Chloride & 0.01141 & 0.001 & 0.01 & 0.2077 & $\mathrm{BM}^{\star \wedge}$ \\
\hline 2 & 4.82 & n.a. & 0.07763 & 0.031 & 0.14 & n.a. & $\mathrm{MB}^{\star}$ \\
\hline 3 & 7.32 & Nitrate-N & 0.05905 & 0.015 & 0.07 & 0.6826 & $\mathrm{BMB}$ \\
\hline 4 & 10.32 & n.a. & 0.37844 & 0.114 & 0.51 & n.a. & BMB \\
\hline 5 & 11.46 & n.a. & 70.85893 & 22.110 & 99.28 & n.a. & BMB \\
\hline
\end{tabular}




\section{H6L110106-JK7KG-1/40}

\begin{tabular}{llll|}
\hline Sample Name: & H6L110106-JK7KG-1/40 & Injection Volume: & $\mathbf{5 0 . 0}$ \\
Vial Number: & $\mathbf{1 3 9 8}$ & Channel: & ECD_1 \\
Sample Type: & unknown & Wavelength: & n.a. \\
Control Program: & AS14A ANIONS METHOD & Bandwidth: & n.a. \\
Quantif. Method: & AS4A-SC ANION METHOD & Dilution Factor: & $\mathbf{4 0 . 0 0 0 0}$ \\
Recording Time: & $\mathbf{1 2 / 2 8 / 2 0 0 6} 18: 11$ & Sample Weight: & $\mathbf{1 . 0 0 0 0}$ \\
Run Time (min): & $\mathbf{1 5 . 0 0}$ & Sample Amount: & $\mathbf{1 . 0 0 0 0}$ \\
\hline
\end{tabular}

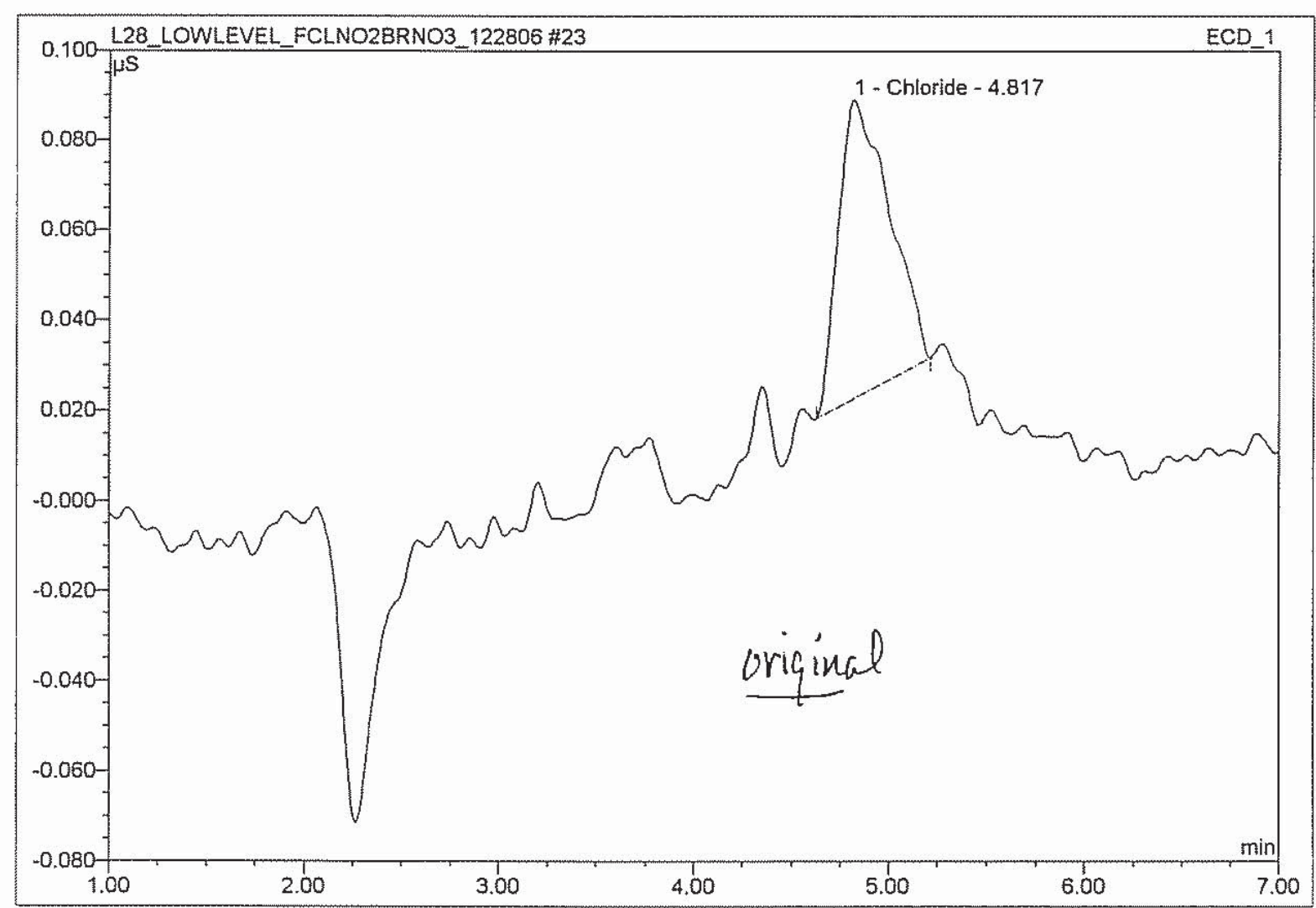

\begin{tabular}{|c|c|l|r|r|r|r|r|}
\hline No. & $\begin{array}{c}\text { Ret.Time } \\
(\mathrm{min} .)\end{array}$ & \multicolumn{1}{|c|}{ Peak Name } & $\begin{array}{c}\text { Height } \\
(\mathbf{u S})\end{array}$ & $\begin{array}{c}\text { Area } \\
\mu S^{*} \min \end{array}$ & $\begin{array}{r}\text { Rel.Area } \\
(\%)\end{array}$ & $\begin{array}{c}\text { Amount } \\
(\mathrm{mg} / \mathrm{L})\end{array}$ & $\begin{array}{r}\text { Peak } \\
\text { Type }\end{array}$ \\
\hline 1 & 4.82 & Chloride & 0.06637 & 0.020 & 0.09 & 1.2076 & BMB \\
\hline 2 & 7.32 & Nitrate-N & 0.05905 & 0.015 & 0.07 & 0.6826 & BMB \\
\hline 3 & 10.32 & n.a. & 0.37844 & 0.114 & 0.51 & n.a. & BMB \\
\hline 4 & 11.46 & n.a. & 70.85893 & 22.110 & 99.33 & n.a. & BMB \\
\hline
\end{tabular}




\section{H6L110106-JK7KT-1/20}

\begin{tabular}{llll|}
\hline Sample Name: & H6L110106-JK7KT-1/20 & Injection Volume: & $\mathbf{5 0 . 0}$ \\
Vial Number: & 1399 & Channel: & ECD_1 \\
Sample Type: & unknown & Wavelength: & n.a. \\
Control Program: & AS14A ANIONS METHOD & Bandwidth: & n.a. \\
Quantif. Method: & AS4A-SC ANION METHOD & Dilution Factor: & $\mathbf{2 0 . 0 0 0 0}$ \\
Recording Time: & $12 / 28 / 200618: 28$ & Sample Weight: & $\mathbf{1 . 0 0 0 0}$ \\
Run Time (min): & $\mathbf{1 5 . 0 0}$ & Sample Amount: & $\mathbf{1 . 0 0 0 0}$ \\
\hline
\end{tabular}

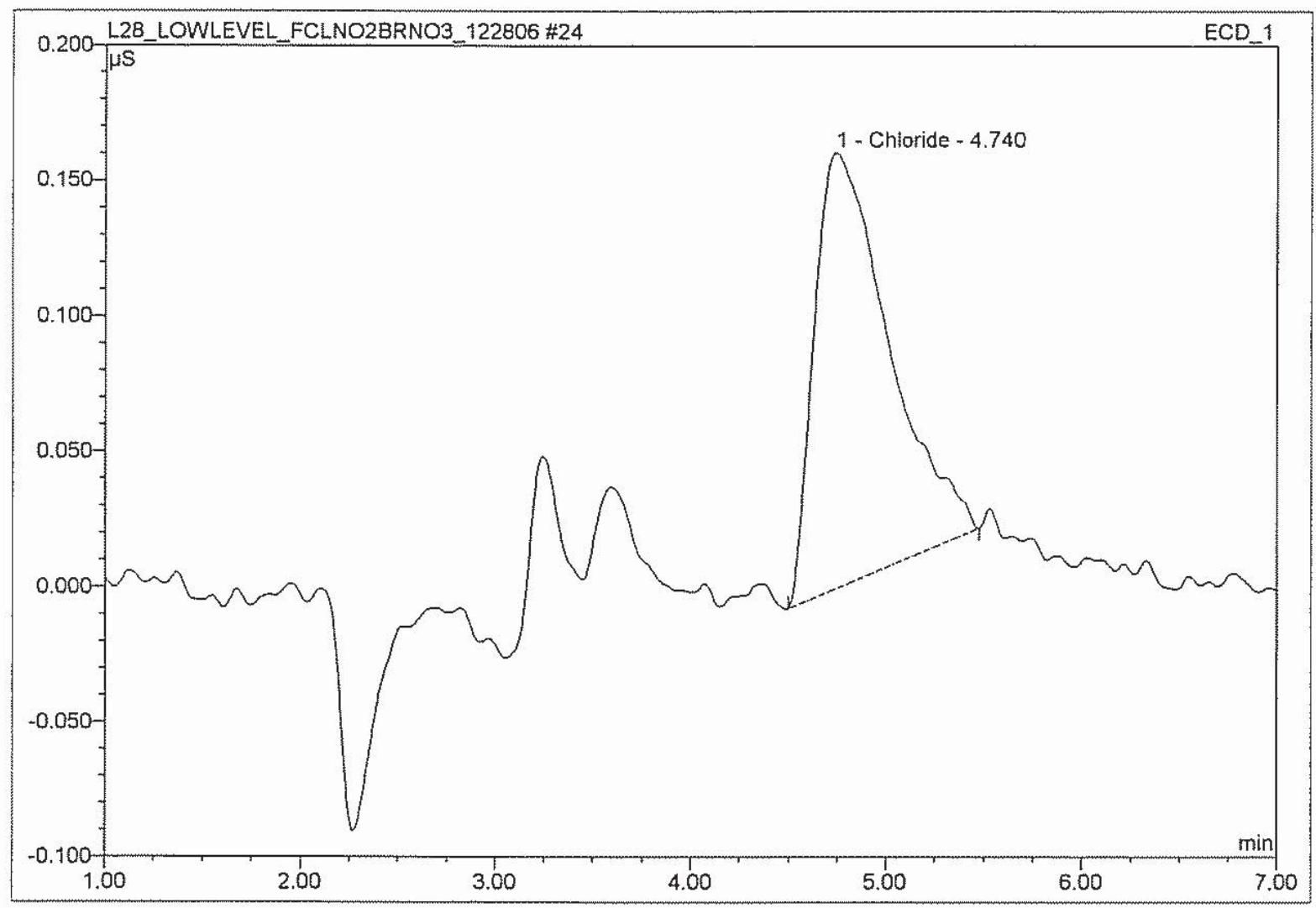

\begin{tabular}{|c|c|c|c|c|c|c|c|}
\hline No. & $\begin{array}{l}\text { Ret.Time } \\
\text { (min.) }\end{array}$ & Peak Name & $\begin{array}{l}\text { Height } \\
\text { (uS) }\end{array}$ & $\begin{array}{l}\text { Area } \\
\mu S^{*} \min \end{array}$ & $\begin{array}{c}\text { Rel.Area } \\
(\%)\end{array}$ & $\begin{array}{l}\text { Amount } \\
(\mathrm{mg} / \mathrm{L})\end{array}$ & $\begin{array}{l}\text { Peak } \\
\text { Type }\end{array}$ \\
\hline 1 & 4.74 & Chloride & 0.16098 & 0.071 & 0.13 & 1.4636 & BMB \\
\hline 2 & 7.33 & Nitrate-N & 0.12915 & 0.030 & 0.06 & 0.7456 & BMB \\
\hline 3 & 9.67 & n.a. & 0.06562 & 0.020 & 0.04 & n.a. & $\mathrm{BMB}$ \\
\hline 4 & 11.39 & n.a. & (H\#\#) & 53.520 & 99.77 & n.a. & $\mathrm{BMB}$ \\
\hline
\end{tabular}




\section{H6L110106-JK7KT-1/40}

\begin{tabular}{llll}
\hline Sample Name: & H6L110106-JK7KT-1/40 & Injection Volume: & $\mathbf{5 0 . 0}$ \\
Vial Number: & 1400 & Channel: & ECD_1 \\
Sample Type: & unknown & Wavelength: & n.a. \\
Control Program: & AS14A ANIONS METHOD & Bandwidth: & n.a. \\
Quantif. Method: & AS4A-SC ANION METHOD & Dilution Factor: & $\mathbf{4 0 . 0 0 0 0}$ \\
Recording Time: & $12 / 28 / 200618: 46$ & Sample Weight: & 1.0000 \\
Run Time (min): & 15.00 & Sample Amount: & $\mathbf{1 . 0 0 0 0}$ \\
\hline
\end{tabular}

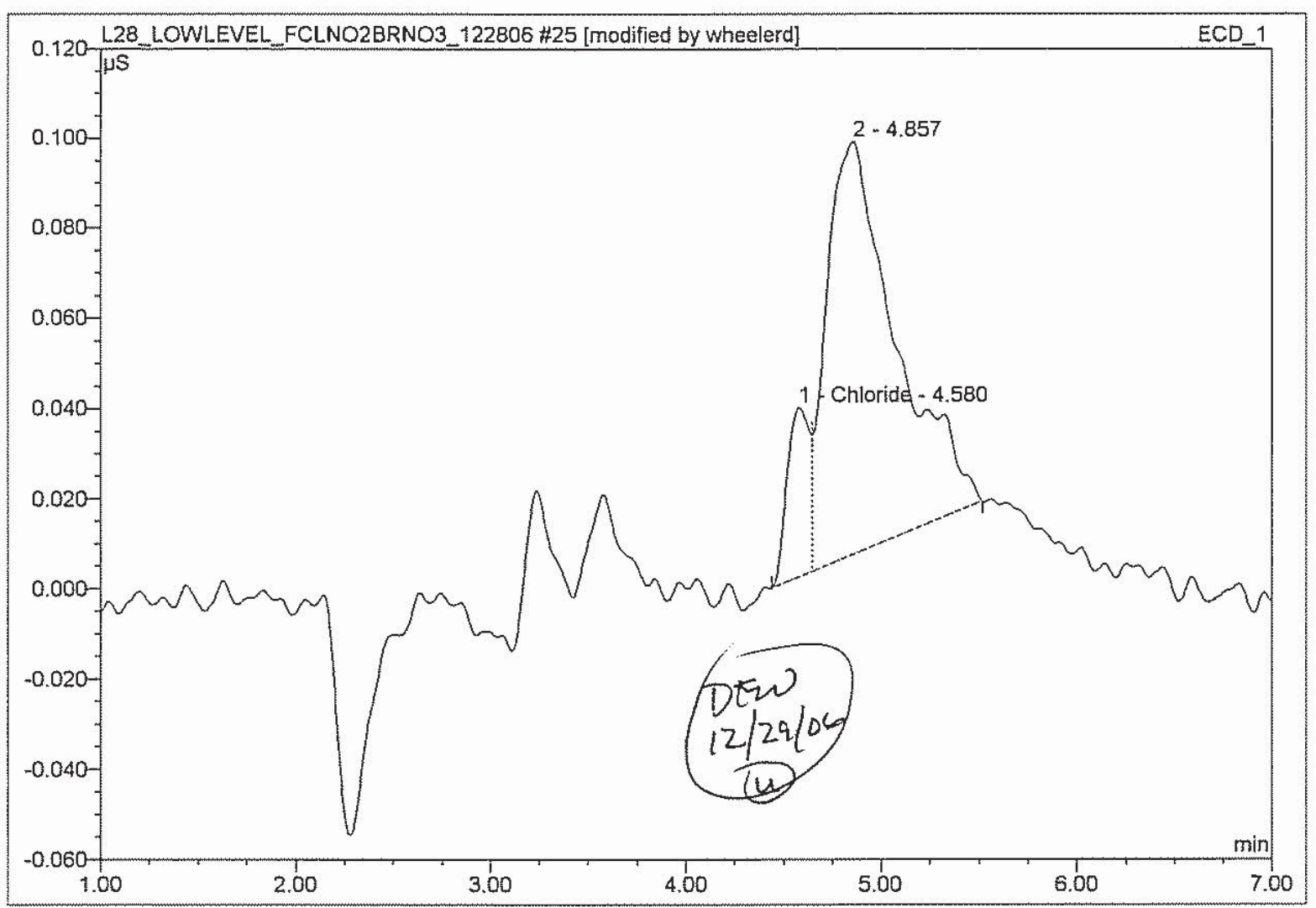

\begin{tabular}{|c|c|l|r|r|r|r|r|}
\hline No. & $\begin{array}{c}\text { Ret.Time } \\
\text { (min.) }\end{array}$ & \multicolumn{1}{|c|}{ Peak Name } & $\begin{array}{c}\text { Height } \\
\text { (uS) }\end{array}$ & $\begin{array}{c}\text { Area } \\
\mu S^{*} \min \end{array}$ & $\begin{array}{r}\text { Rel.Area } \\
(\%)\end{array}$ & $\begin{array}{c}\text { Amount } \\
\text { (mg/L) }\end{array}$ & $\begin{array}{r}\text { Peak } \\
\text { Type }\end{array}$ \\
\hline 1 & 4.58 & Chloride & 0.03757 & 0.005 & 0.02 & 0.6837 & BM $^{*}$ \\
\hline 2 & 4.86 & n.a. & 0.09163 & 0.038 & 0.15 & n.a. & MB $^{*}$ \\
\hline 3 & 7.35 & Nitrate-N & 0.06197 & 0.014 & 0.06 & 0.7162 & BMB \\
\hline 4 & 11.45 & n.a. & 78.97294 & 24.839 & 99.77 & n.a. & BMB \\
\hline
\end{tabular}




\section{H6L110106-JK7KT-1/40}

\begin{tabular}{llll|}
\hline Sample Name: & H6L110106-JK7KT-1/40 & Injection Volume: & $\mathbf{5 0 . 0}$ \\
Vial Number: & $\mathbf{1 4 0 0}$ & Channel: & ECD_1 \\
Sample Type: & unknown & Wavelength: & n.a. \\
Control Program: & AS14A ANIONS METHOD & Bandwidth: & n.a. \\
Quantif. Method: & AS4A-SC ANION METHOD & Dilution Factor: & $\mathbf{4 0 . 0 0 0 0}$ \\
Recording Time: & $\mathbf{1 2 / 2 8 / 2 0 0 6 ~ 1 8 : 4 6}$ & Sample Weight: & $\mathbf{1 . 0 0 0 0}$ \\
Run Time (min): & $\mathbf{1 5 . 0 0}$ & Sample Amount: & $\mathbf{1 . 0 0 0 0}$ \\
\hline
\end{tabular}

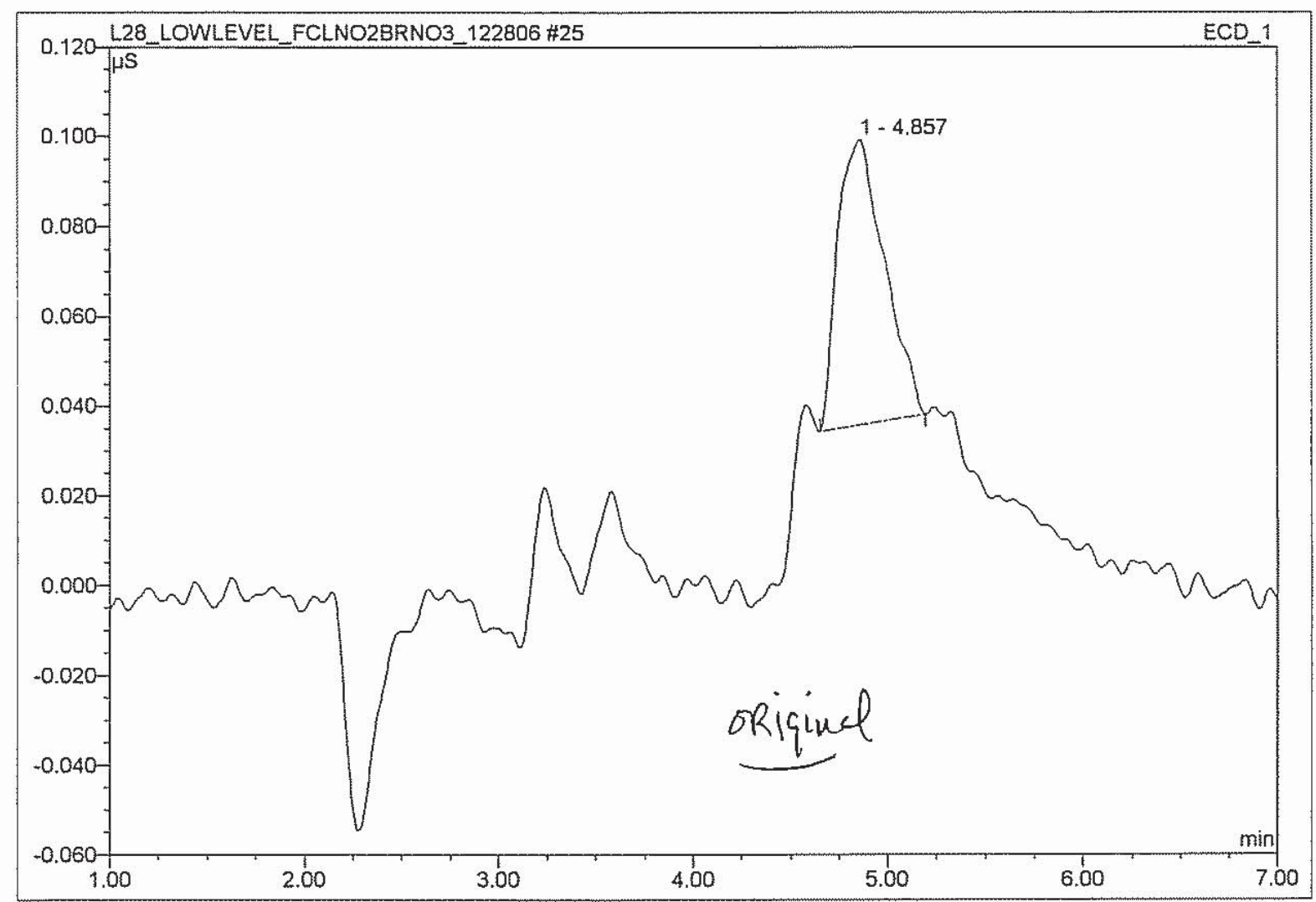

\begin{tabular}{|c|c|l|r|r|r|r|r|}
\hline No. & $\begin{array}{c}\text { Ret.Time } \\
\text { (min.) }\end{array}$ & \multicolumn{1}{|c|}{ Peak Name } & $\begin{array}{c}\text { Height } \\
\text { (uS) }\end{array}$ & $\begin{array}{c}\text { Area } \\
\mu S^{*} \min \end{array}$ & $\begin{array}{r}\text { Rel.Area } \\
(\%)\end{array}$ & $\begin{array}{r}\text { Amount } \\
\text { (mg/L) }\end{array}$ & $\begin{array}{r}\text { Peak } \\
\text { Type }\end{array}$ \\
\hline 1 & 4.86 & n.a. & 0.06340 & 0.018 & 0.07 & n.a. & BMB \\
\hline 2 & 7.35 & Nitrate-N & 0.06197 & 0.014 & 0.06 & 0.7162 & BMB \\
\hline 3 & 11.45 & n.a. & 78.97294 & 24.839 & 99.87 & n.a. & BMB \\
\hline
\end{tabular}




\section{$26 \mathrm{CCV}=$ ICWS -9090}

\begin{tabular}{llll}
\hline Sample Name: & CCV=ICWS-9090 & Injection Volume: & $\mathbf{5 0 . 0}$ \\
Vial Number: & 1401 & Channel: & ECD_1 \\
Sample Type: & unknown & Wavelength: & n.a. \\
Control Program: & AS14A ANIONS METHOD & Bandwidth: & n.a. \\
Quantif. Method: & AS4A-SC ANION METHOD & Dilution Factor: & 1.0000 \\
Recording Time: & $12 / 28 / 200619: 03$ & Sample Weight: & 1.0000 \\
Run Time (min): & 15.00 & Sample Amount: & 1.0000
\end{tabular}

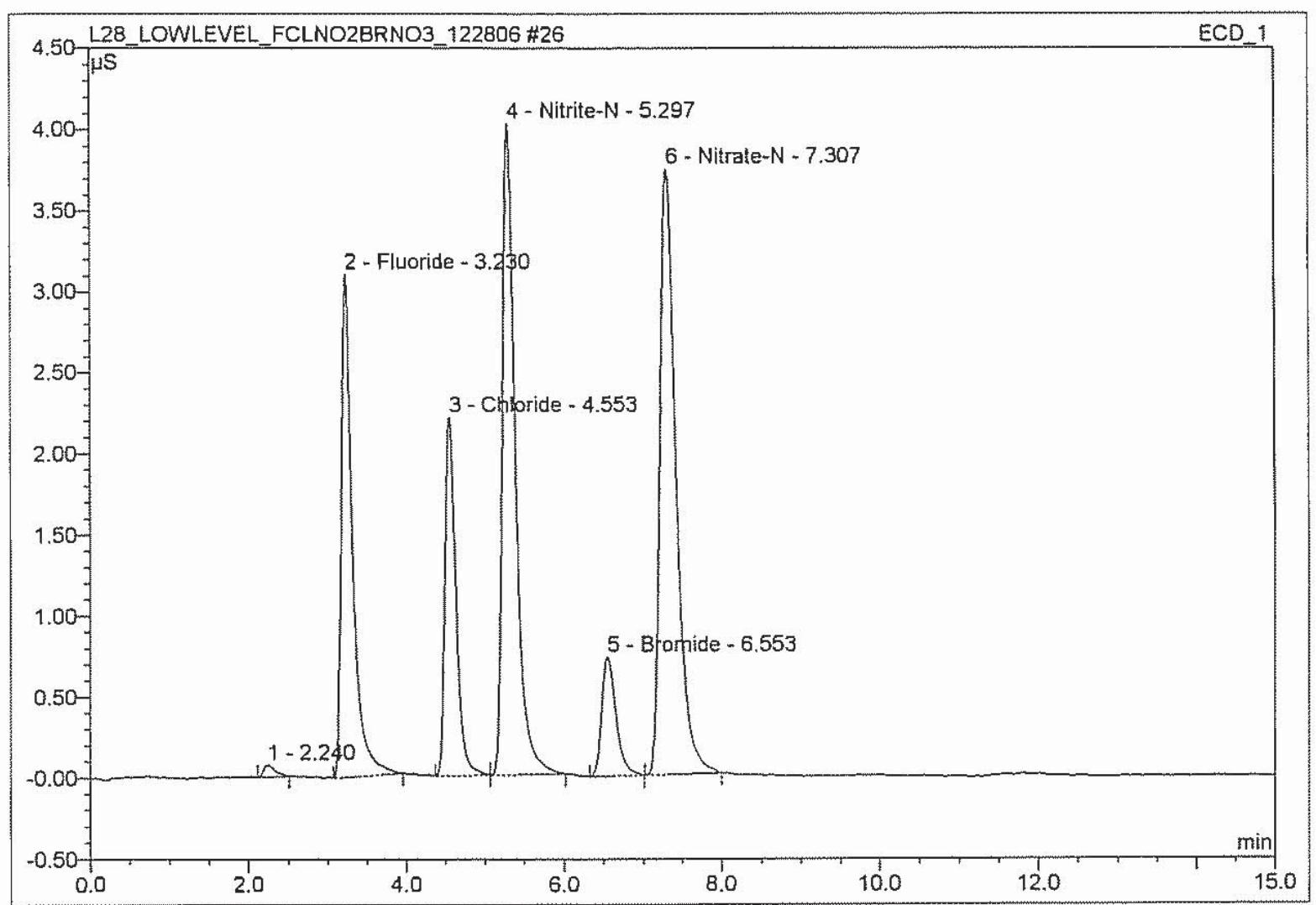

\begin{tabular}{|c|c|l|r|r|r|r|c|}
\hline No. & $\begin{array}{c}\text { Ret.Time } \\
\text { (min.) }\end{array}$ & \multicolumn{1}{|c|}{ Peak Name } & $\begin{array}{c}\text { Height } \\
(\mathbf{u S})\end{array}$ & $\begin{array}{c}\text { Area } \\
\mu S^{*} \text { min }\end{array}$ & $\begin{array}{c}\text { Rel.Area } \\
(\%)\end{array}$ & $\begin{array}{c}\text { Amount } \\
(\mathbf{m g} / \mathbf{L})\end{array}$ & $\begin{array}{r}\text { Peak } \\
\text { Type }\end{array}$ \\
\hline 1 & 2.24 & n.a. & 0.07266 & 0.013 & 0.48 & n.a. & BMB \\
\hline 2 & 3.23 & Fluoride & 3.10205 & 0.520 & 19.26 & 1.0624 & BMB \\
\hline 3 & 4.55 & Chloride & 2.21173 & 0.358 & 13.26 & 0.9915 & BM \\
\hline 4 & 5.30 & Nitrite-N & 4.02336 & 0.768 & 28.45 & 1.0225 & MB \\
\hline 5 & 6.55 & Bromide & 0.73552 & 0.155 & 5.74 & 1.0291 & BMB \\
\hline 6 & 7.31 & Nitrate-N & 3.73776 & 0.886 & 32.82 & 1.0260 & BMB \\
\hline
\end{tabular}




\section{CCB}

\begin{tabular}{llll|}
\hline Sample Name: & ССВ & Injection Volume: & $\mathbf{5 0 . 0}$ \\
Vial Number: & $\mathbf{1 4 0 2}$ & Channel: & ECD_1 \\
Sample Type: & unknown & Wavelength: & n.a. \\
Control Program: & AS14A ANIONS METHOD & Bandwidth: & n.a. \\
Quantif. Method: & AS4A-SC ANION METHOD & Dilution Factor: & 1.0000 \\
Recording Time: & $\mathbf{1 2 / 2 8 / 2 0 0 6 ~ 1 9 : 2 0}$ & Sample Weight: & $\mathbf{1 . 0 0 0 0}$ \\
Run Time (min): & $\mathbf{1 5 . 0 0}$ & Sample Amount: & $\mathbf{1 . 0 0 0 0}$ \\
\hline
\end{tabular}

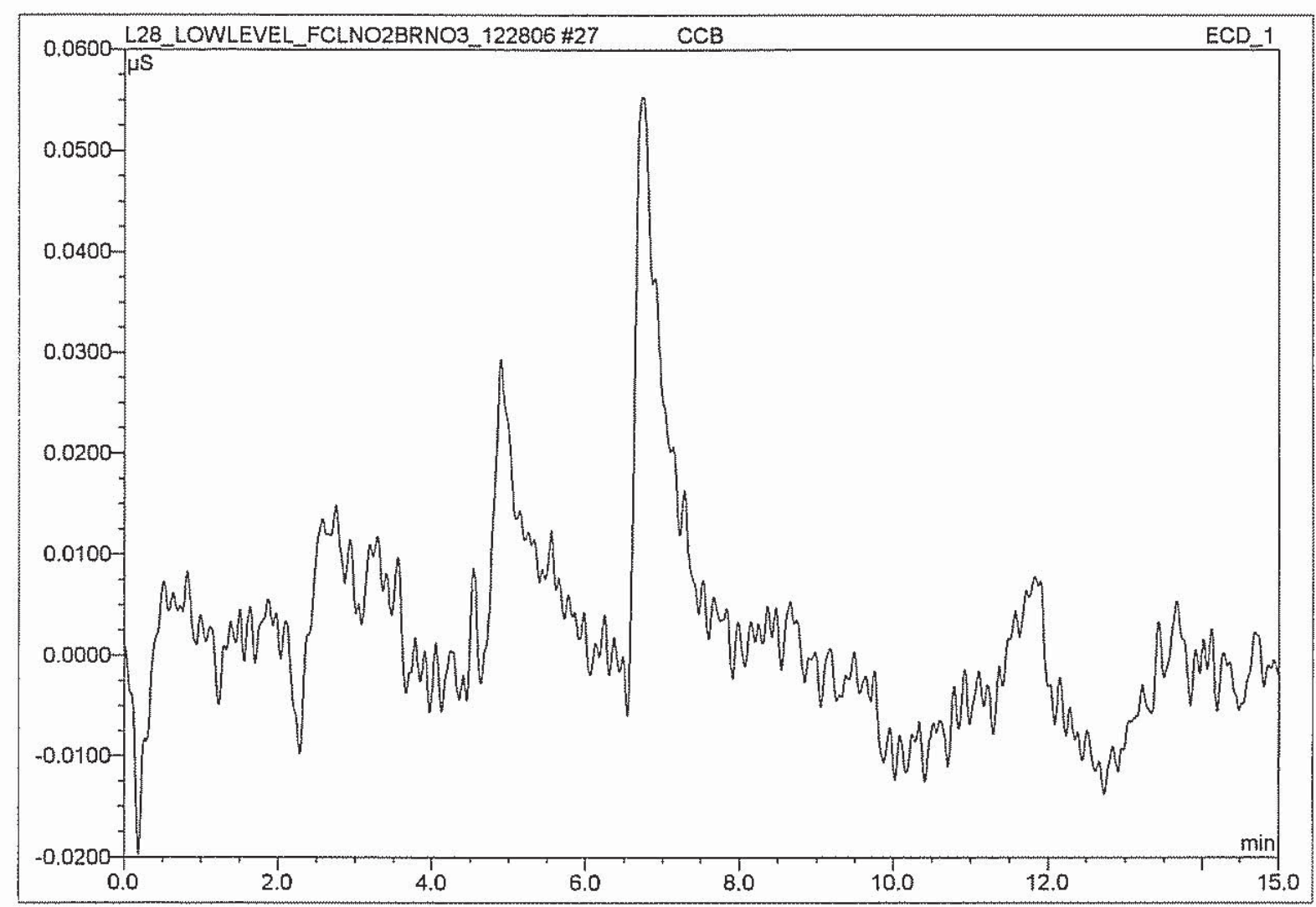

\begin{tabular}{|c|c|c|c|c|c|c|c|}
\hline No. & $\begin{array}{c}\text { Ret.Time } \\
(\text { min.) }\end{array}$ & Peak Name & $\begin{array}{c}\text { Height } \\
(\mathrm{uS})\end{array}$ & $\begin{array}{c}\text { Area } \\
\mu \mathrm{S}^{*} \mathrm{~min}\end{array}$ & $\begin{array}{c}\text { Rel.Area } \\
(\%)\end{array}$ & $\begin{array}{c}\text { Amount } \\
(\mathrm{mg} / \mathrm{L})\end{array}$ & $\begin{array}{c}\text { Peak } \\
\text { Type }\end{array}$ \\
\hline
\end{tabular}

(ND) 
来四

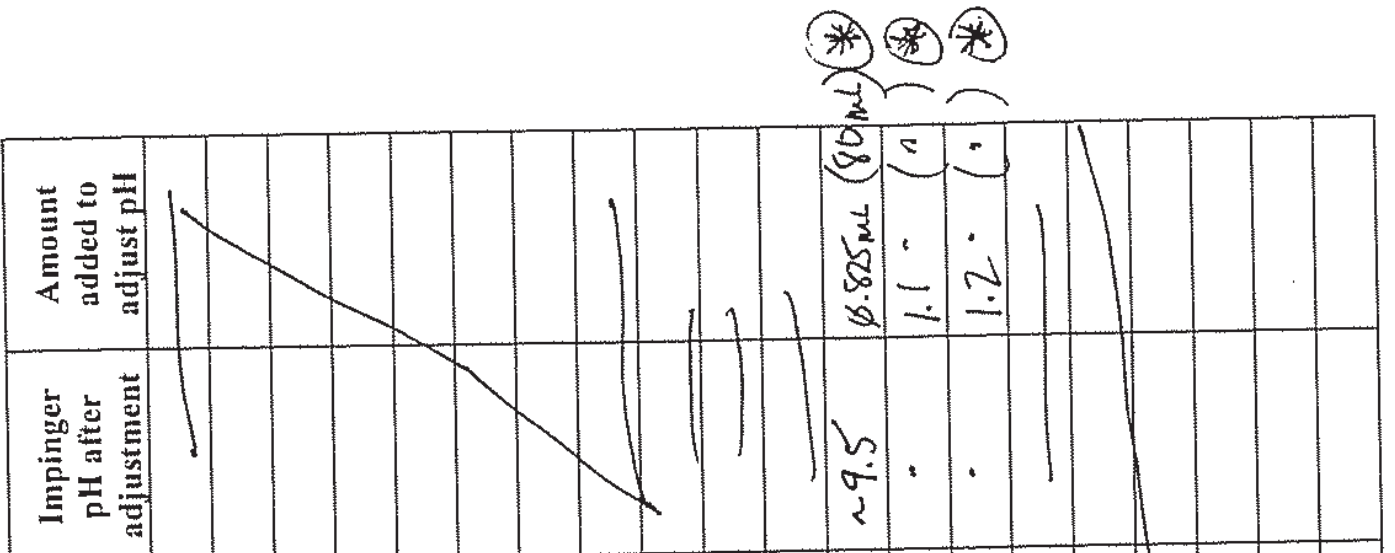

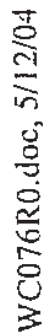

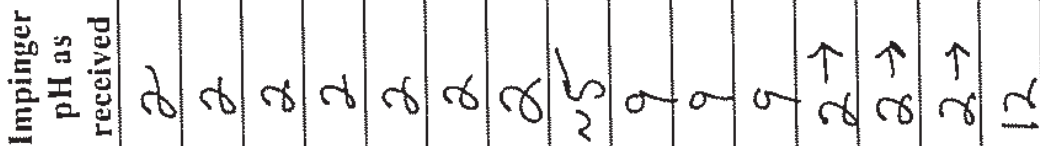

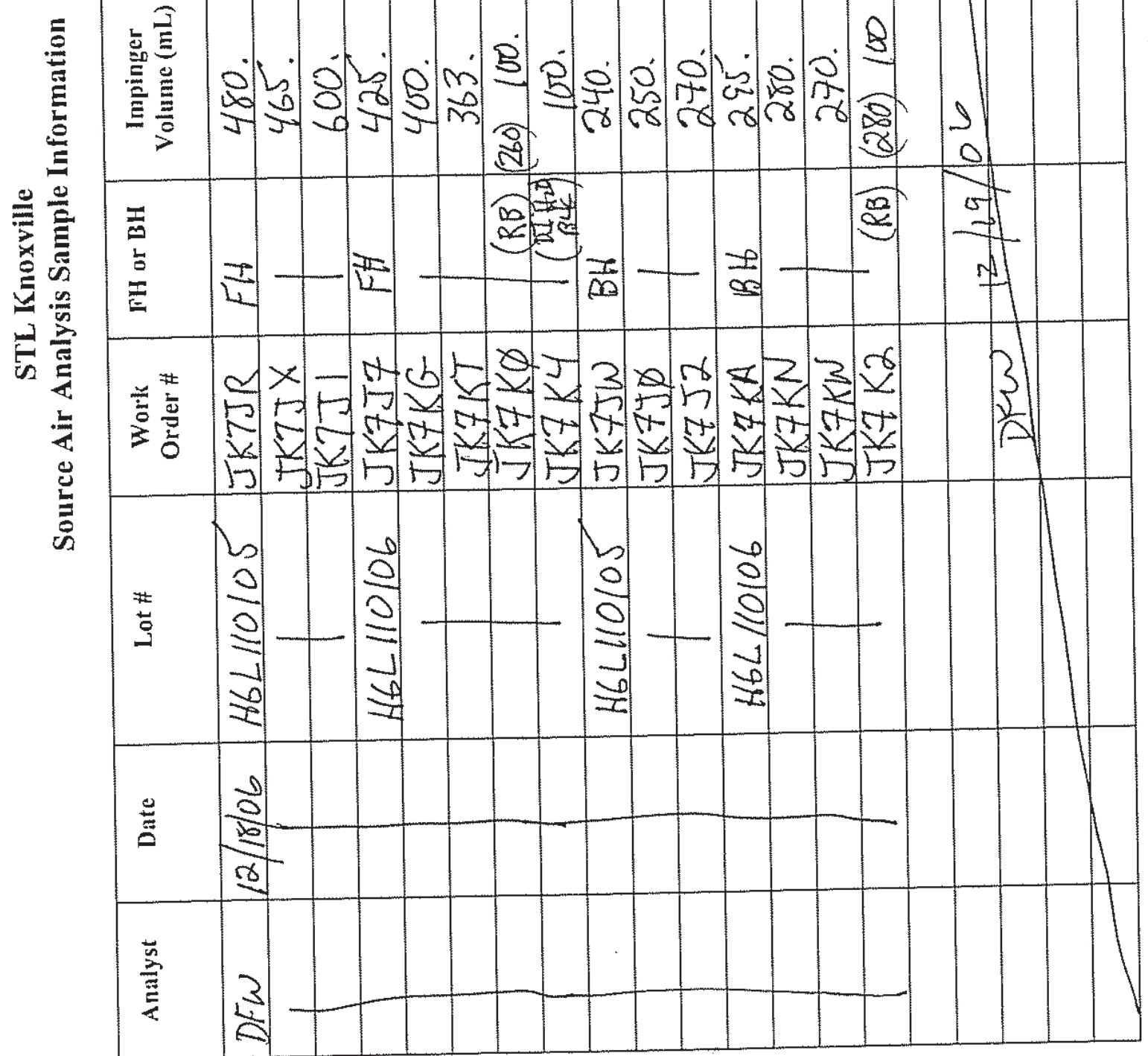



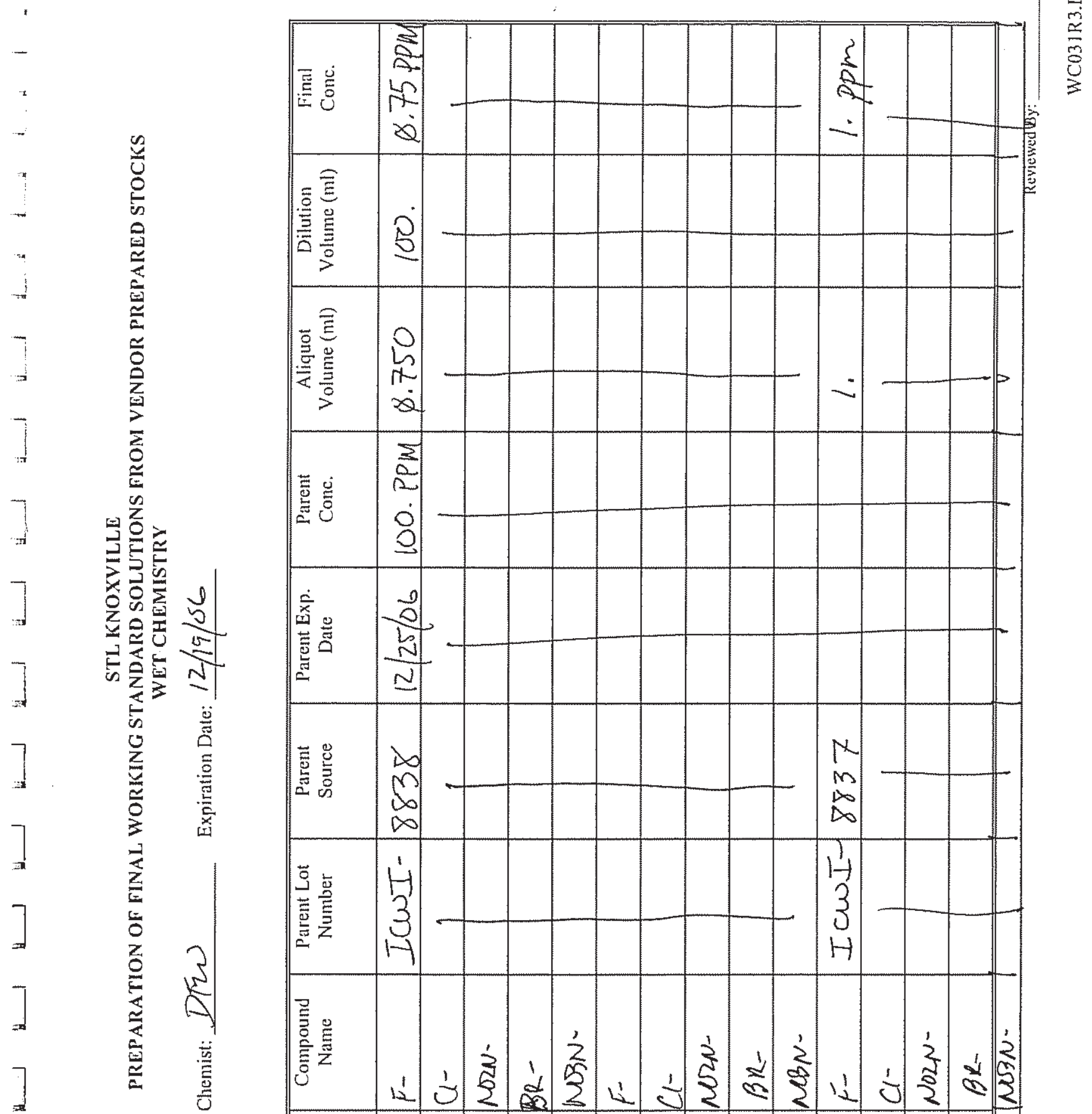

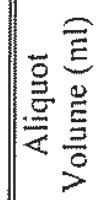

0
$x$
0

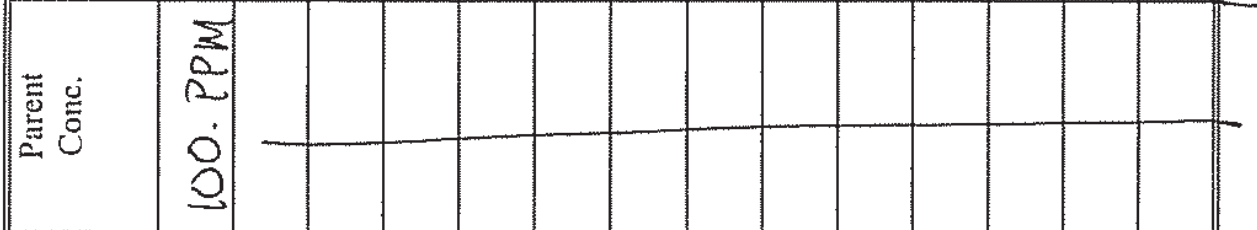

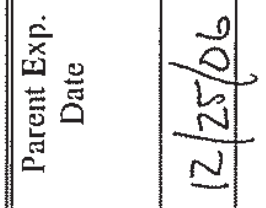

递总

$\infty$

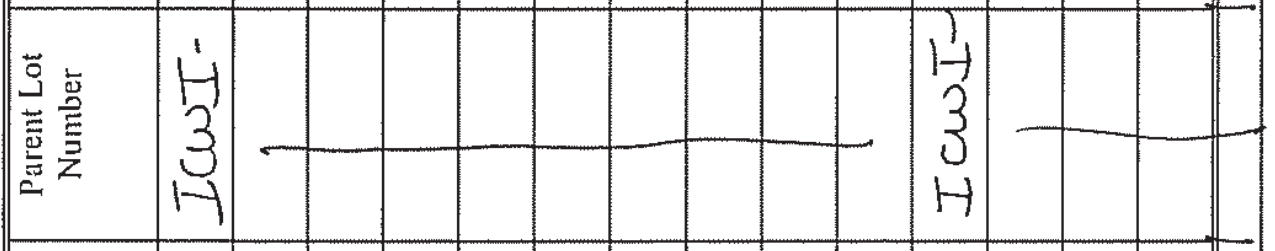

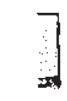

高高高

$\frac{0}{\frac{8}{80}}$

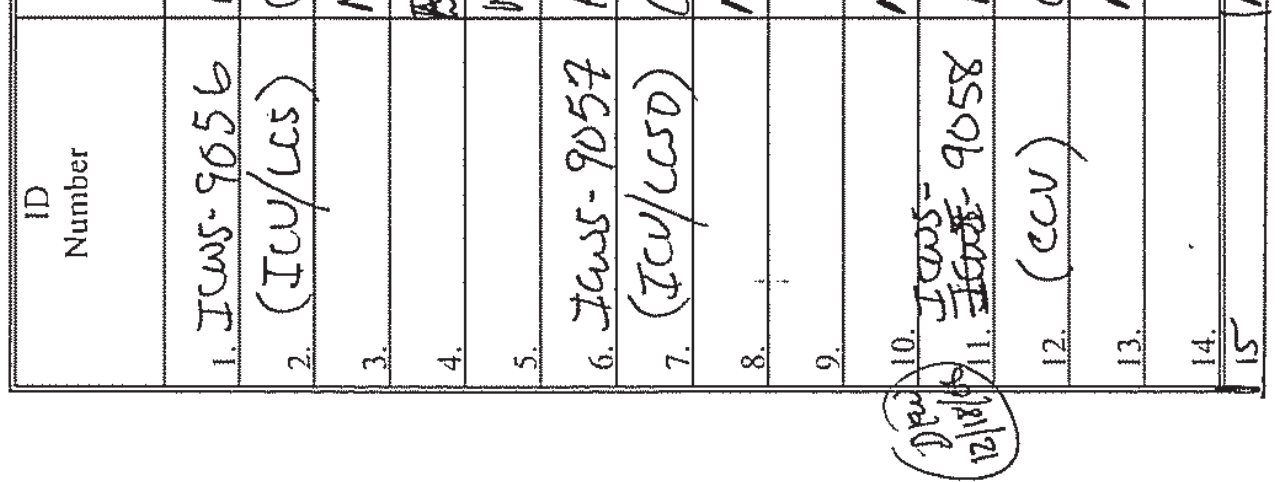


c.
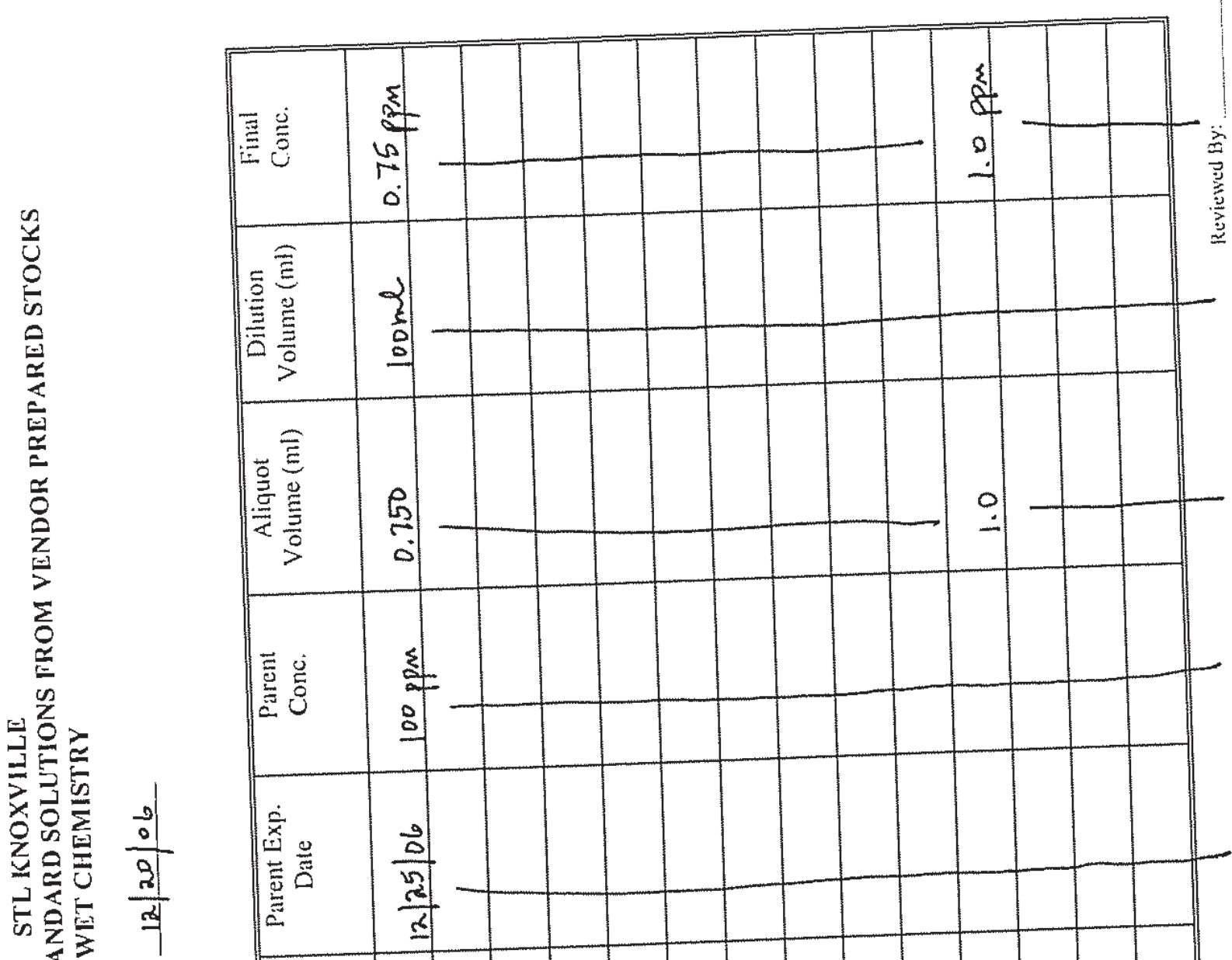

I.

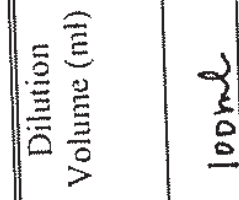

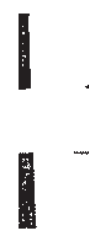

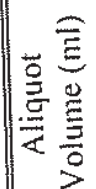

(1)

.

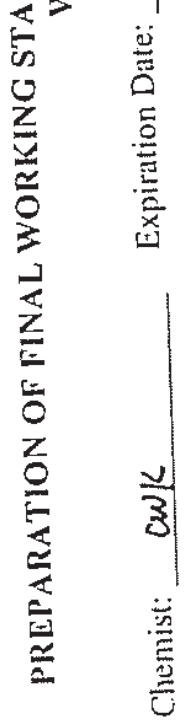

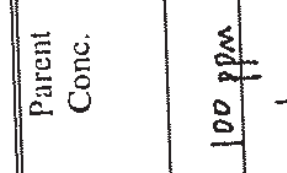

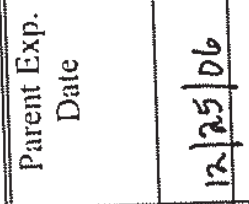

莺总

号

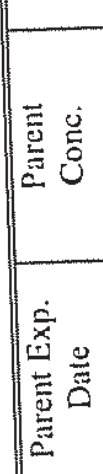

竞㐫

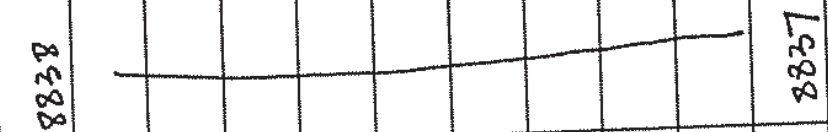

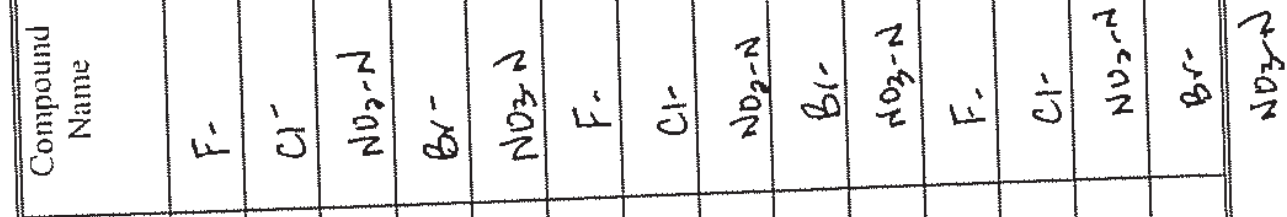

-

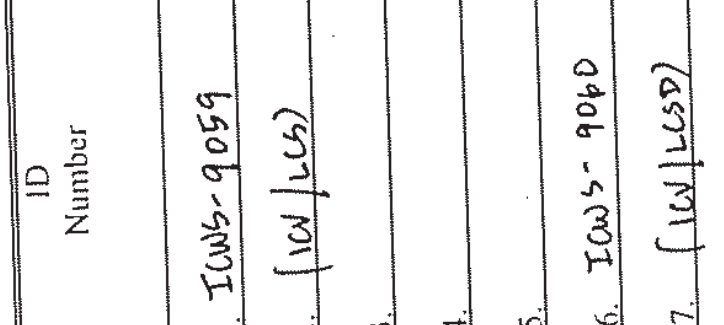

$\begin{array}{lll}- & \\ 0 & \\ 0 & 3 \\ 3 & 3 & 0\end{array}$

$H \longrightarrow$

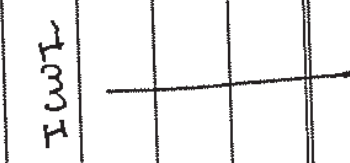

.

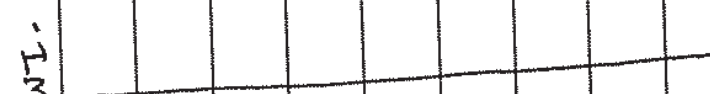

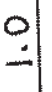

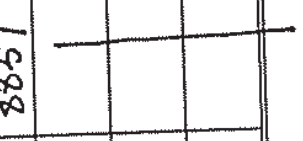


㶽
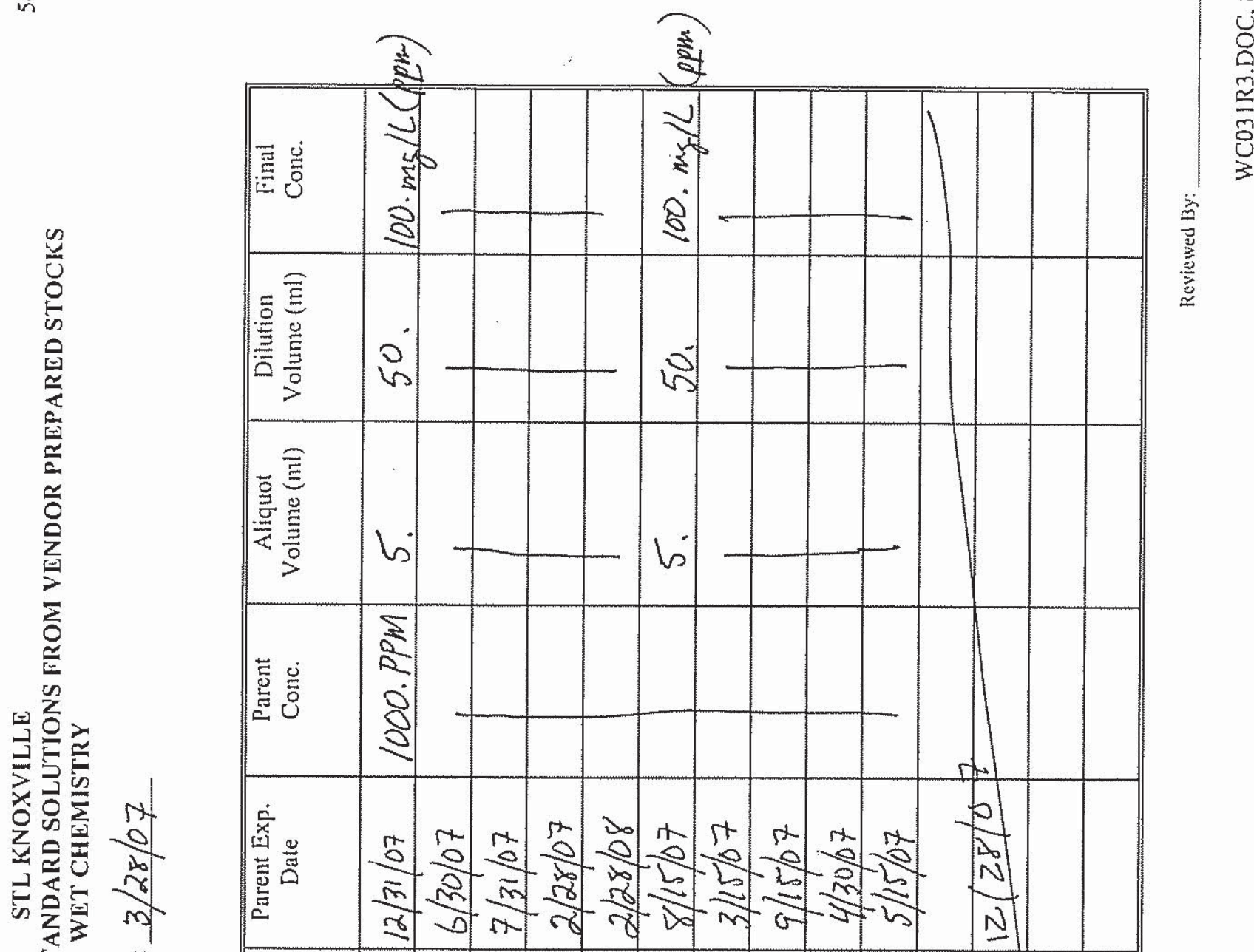

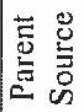

离

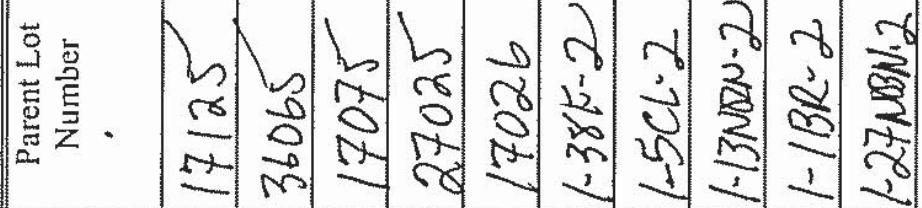

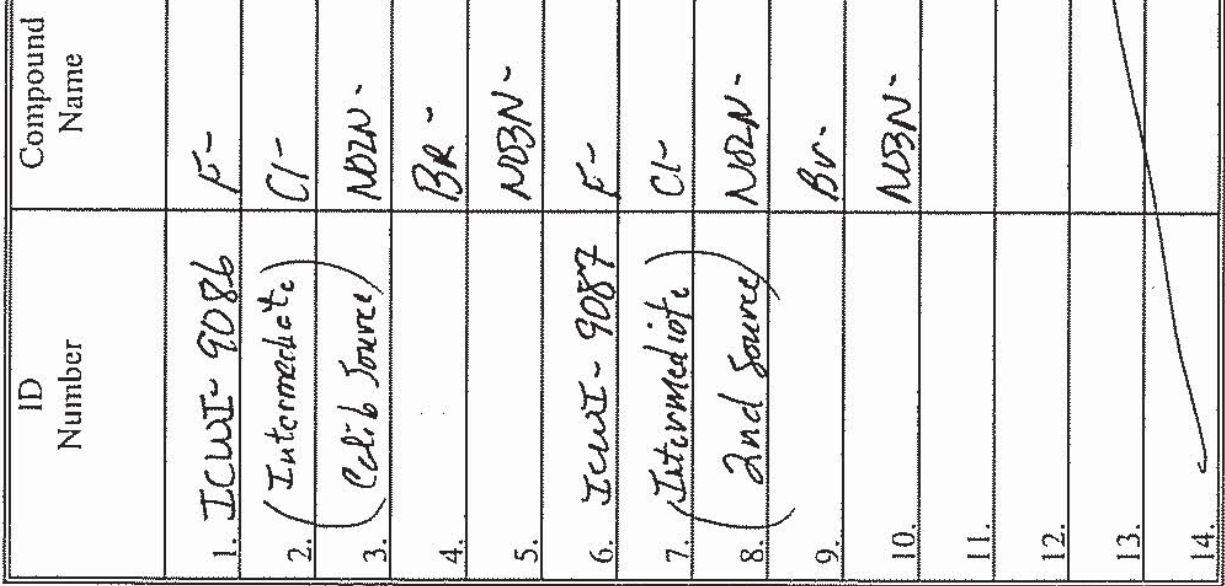




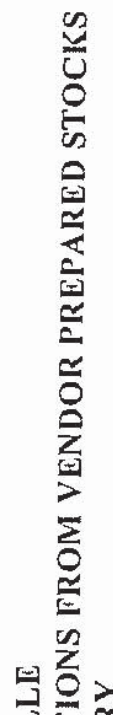

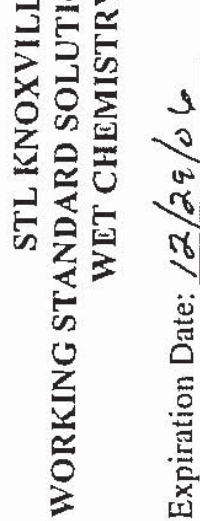

|
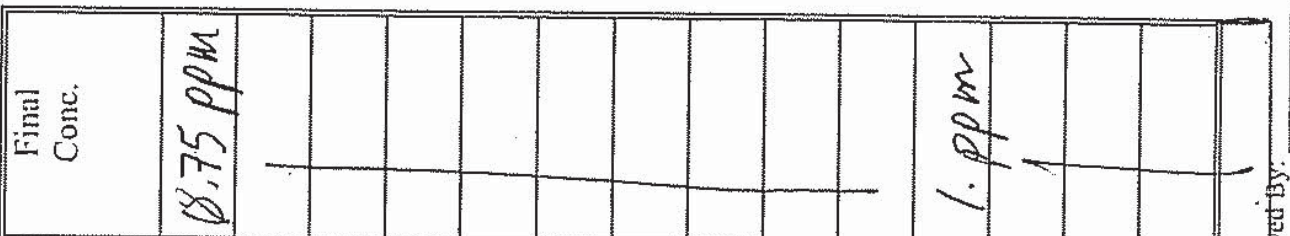

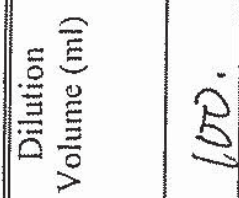

$\frac{\widehat{\bar{E}}}{>}$

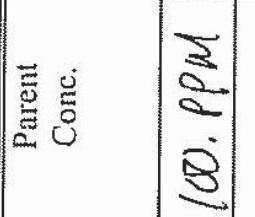

离

蒙造

|

$\mathrm{H}$
$-\mathrm{H}$

总

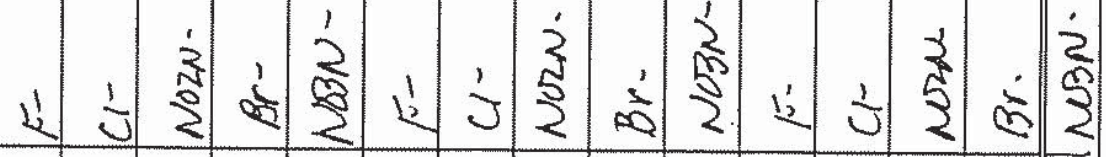

$\frac{0}{0}$

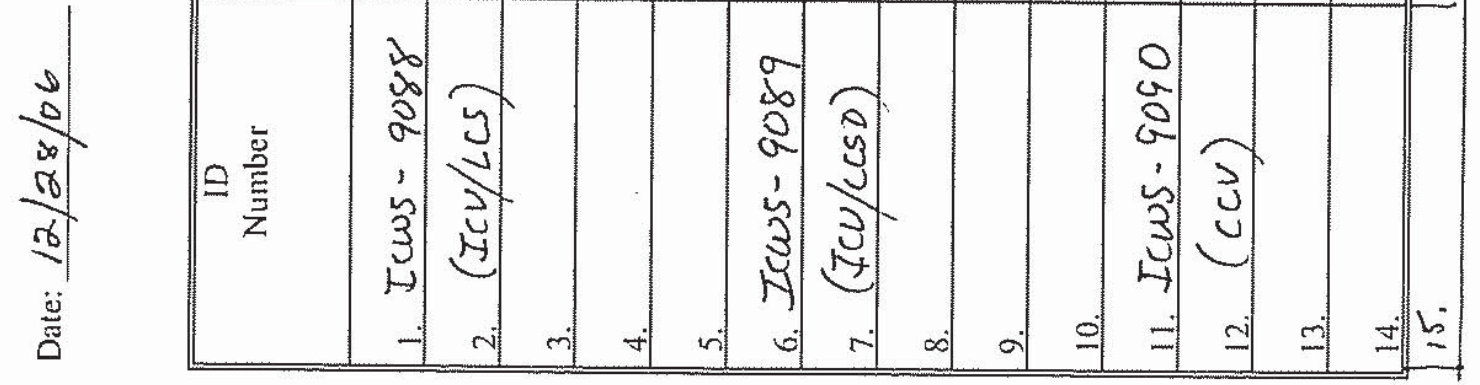

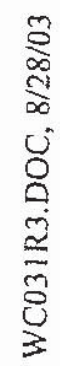


II

$\infty$

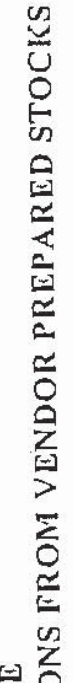

닐을

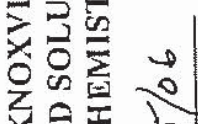

¿

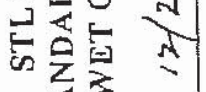

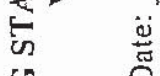

¿

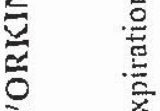

]

|

ن

2

N
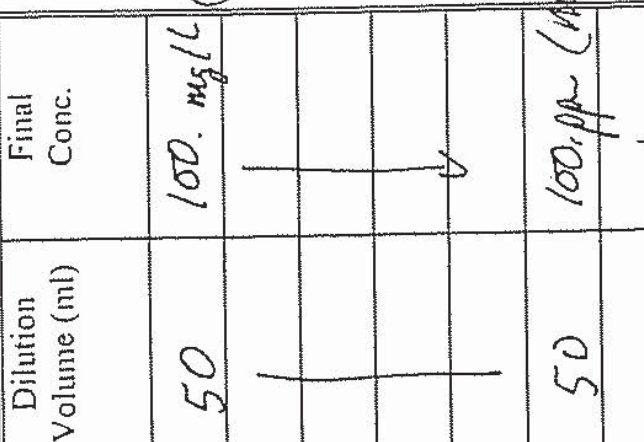

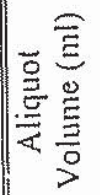

$\operatorname{los}$

in

言产

$\frac{2}{8}$

离

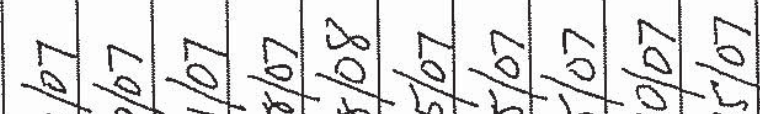

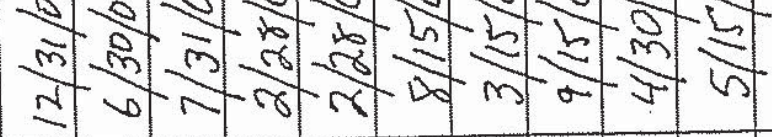

莺总

కุ

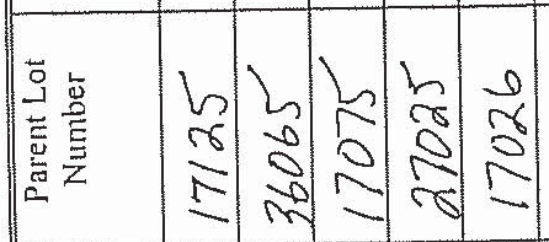

2u

总总总

$\frac{5}{\frac{5}{2}}$

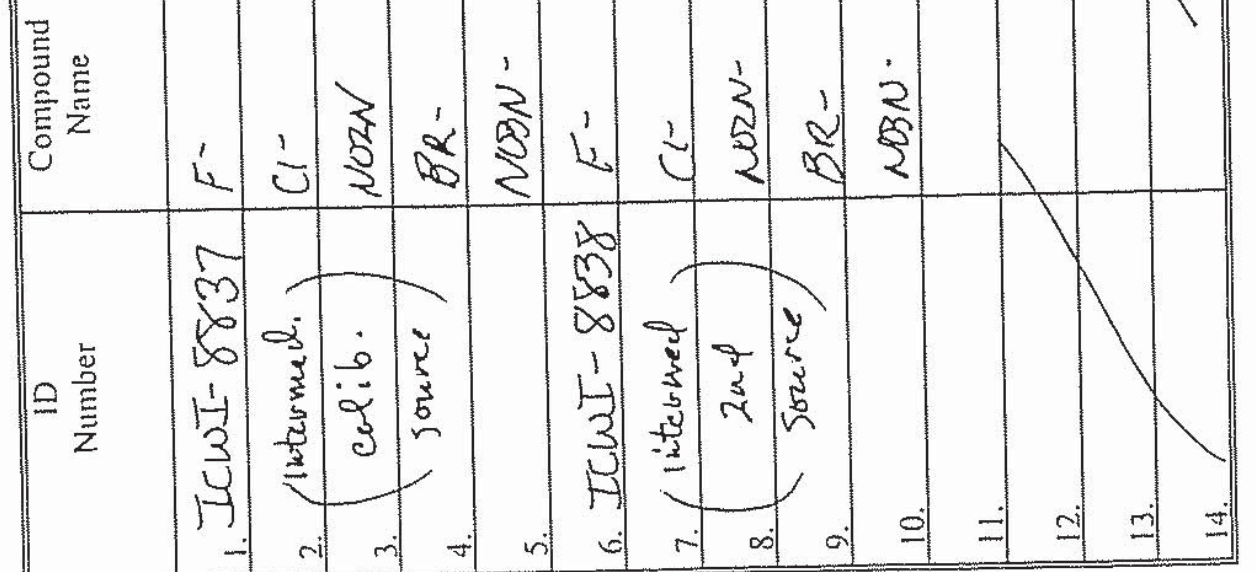




\section{Total Particulates}




\section{STL Knoxville Particulate Matter Determination Data Review/Narrative Checklist Method: SW-846 Method 0050 by SOP KNOX-WC-0006, Rev. 2 \\ Page 1 of 1}

\begin{tabular}{|l|l|}
\hline Batch Number: & 6349313 \\
\hline Lot Number(s): & H6L110106 \\
\hline
\end{tabular}

\begin{tabular}{|c|c|c|c|c|c|}
\hline $\begin{array}{l}\text { Reviene Items } \\
\text { A. Calibrntion }\end{array}$ & N/A & $\mathrm{Y}$ & $\mathrm{N}$ & If No, why is data reportable? & 2nd \\
\hline $\begin{array}{l}\text { 1. Was the balance calibration checked with } 5,50 \& 100 \\
\text { gram weights prior to use? }\end{array}$ & & $\checkmark$ & & & $\checkmark$ \\
\hline $\begin{array}{l}\text { 2. Was the balance checked with } 100 \text { gram weight after } \\
\text { every } 10 \text { samples? }\end{array}$ & & $\sqrt{ }$ & & & $\checkmark$ \\
\hline 3. Was the balance tared before each weighing? & & $\sqrt{ }$ & & & 1 \\
\hline 4. Was tbe balance ID documented? & & $\sqrt{1}$ & & & $\nearrow$ \\
\hline \multicolumn{6}{|l|}{ B. Client Sample and QC Sample Results } \\
\hline $\begin{array}{l}\text { 1. Were all special project requirements met? (Were PM } \\
\text { Checklists, Lot Summary, and any applicable QAS } \\
\text { reviewed?) }\end{array}$ & & $\checkmark$ & & & $\checkmark$ \\
\hline 2. Were sample IDs verified? & & $\checkmark$ & & & 7 \\
\hline 3. Were all transcriptions checked? & & $\checkmark$ & & & $\checkmark$ \\
\hline 4. Calculations checked for error? & & $\checkmark$ & & . & $\checkmark$ \\
\hline $\begin{array}{l}\text { 5. Final report acceptable? (Results correct, units correct, } \\
\text { deviations noted in narrative, and analysis dates } \\
\text { correct.) }\end{array}$ & & $\checkmark$ & & & 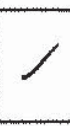 \\
\hline \multicolumn{6}{|l|}{ C. Preparation/Matrix QC } \\
\hline $\begin{array}{l}\text { 1. Were all sample weighings performed in duplicate (at } \\
\text { least)? }\end{array}$ & & $\checkmark$ & & & \\
\hline 2. Was the average of the last two weighings used? & & $\sqrt{ }$ & & & $\checkmark$ \\
\hline \multicolumn{6}{|l|}{ D. Other } \\
\hline 1. Are all nonconformances documented appropriately? & $\checkmark$ & & & NCM No.: & NA \\
\hline
\end{tabular}

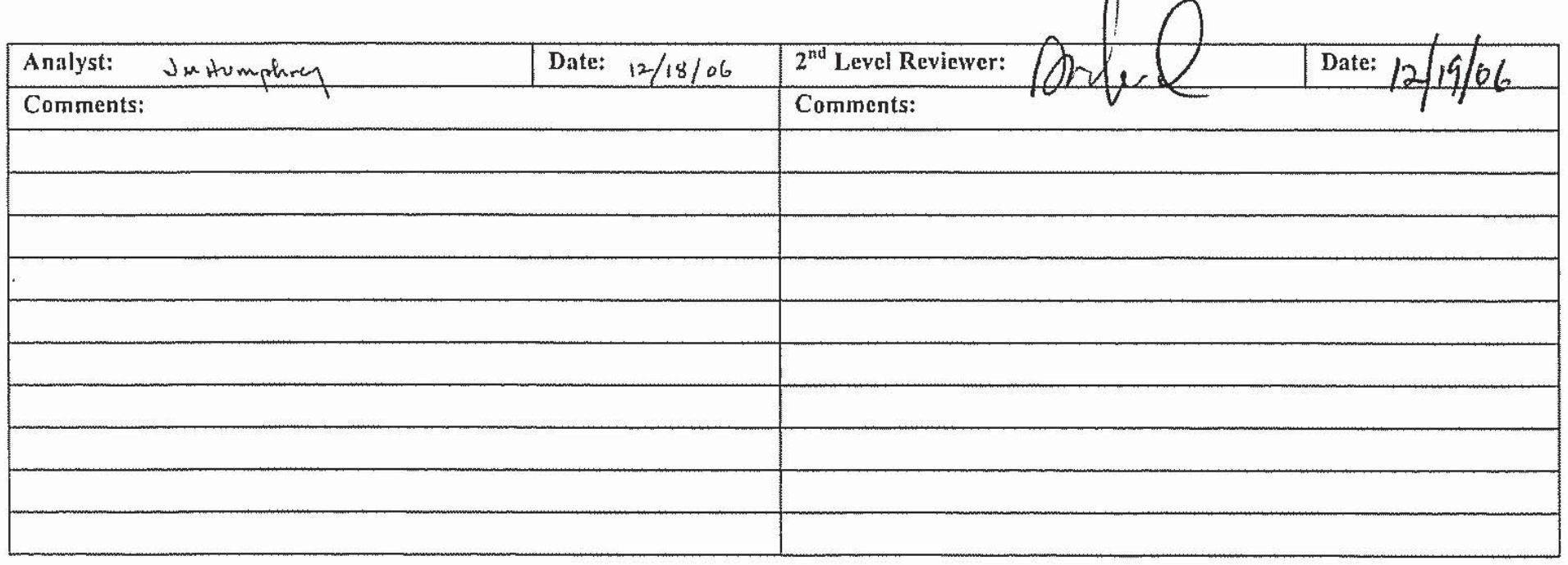




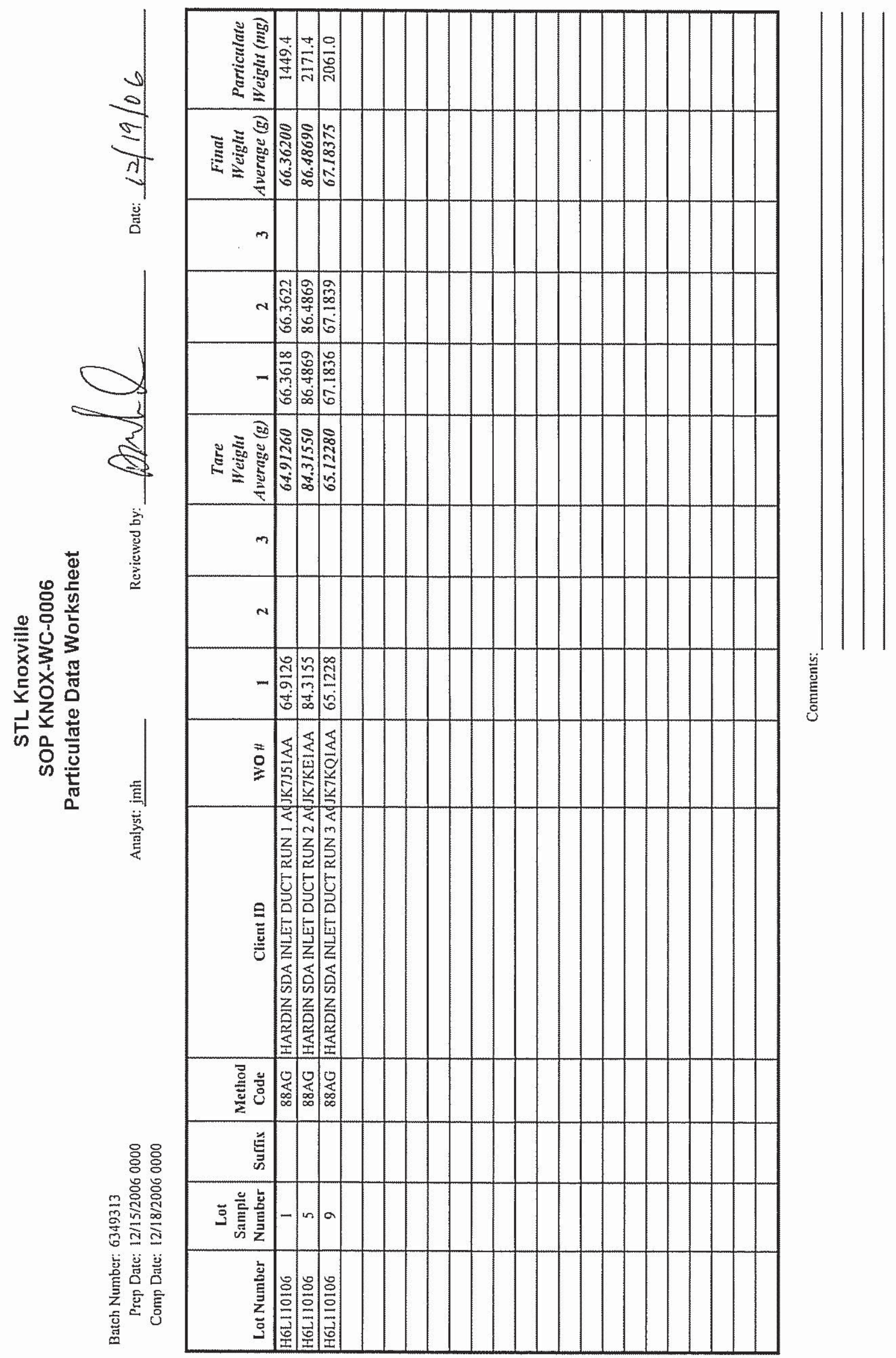

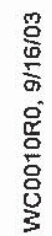



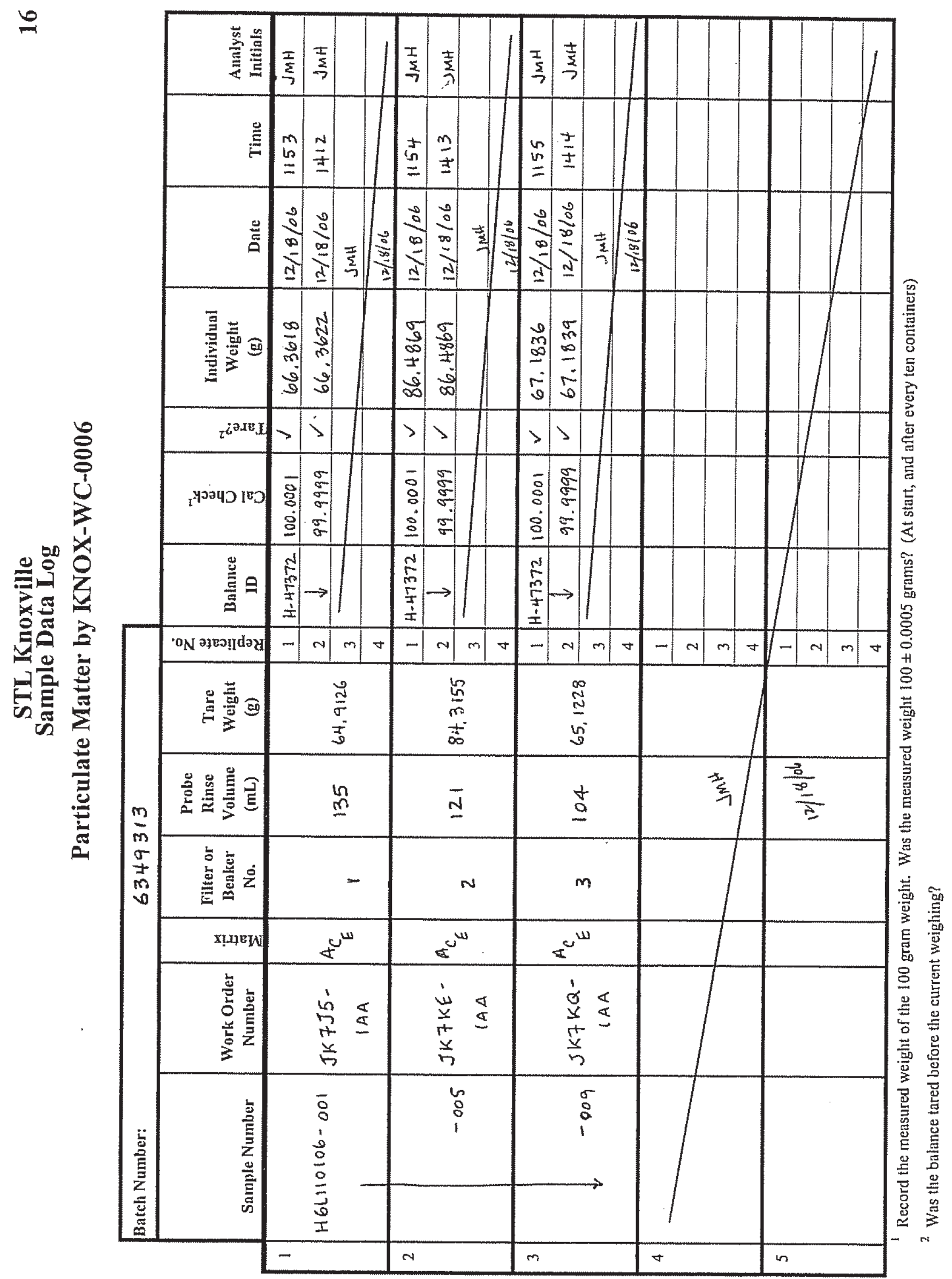


\begin{tabular}{|c|c|c|c|c|c|c|c|c|c|c|c|}
\hline & $\begin{array}{c}\text { Filter or } \\
\text { Beaker } \\
\text { No. }\end{array}$ & $\stackrel{x}{\stackrel{x}{E}}$ & 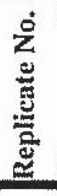 & Balance ID & 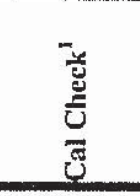 & हैं & $\begin{array}{r}\text { Individual } \\
\text { Weight (g) } \\
\end{array}$ & Date & Time & $\begin{array}{l}\text { Analyst } \\
\text { Initials }\end{array}$ & $\begin{array}{c}\text { Tare } \\
\text { Weight } \\
\text { (g) }\end{array}$ \\
\hline \multirow[t]{4}{*}{1} & \multirow{4}{*}{$\begin{array}{c}\text { JK₹35 } \\
1\end{array}$} & \multirow{4}{*}{${ }^{A} C_{C_{E}}$} & 1 & $H-47372$ & 100.0050 & $\sqrt{ }$ & 64.9126 & $12 / 15 / 06$ & 1354 & $\mathrm{JMH}$ & \multirow{4}{*}{64.9126} \\
\hline & & & 2 & 7 & $=$ & & & & & & \\
\hline & & & 3 & & & & & JWH & & & \\
\hline & & & 4 & & & & & $12 / 15 / 06$ & & $=$ & \\
\hline \multirow[t]{4}{*}{2} & \multirow{4}{*}{$\begin{array}{c}\text { JKFKE } \\
2\end{array}$} & \multirow{4}{*}{${ }^{A C_{E}}$} & 1 & $\mathrm{H}-47372$ & 100.0000 & $N$ & 84.3155 & $12 / 15 / 06$ & 1355 & Jimtt & \multirow{4}{*}{84.3155} \\
\hline & & & 2 & & 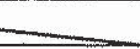 & & & & & & \\
\hline & & & 3 & & & & & JMH & & & \\
\hline & & & 4 & & & & & $12 / 15 / 06$ & & $=$ & \\
\hline \multirow[t]{4}{*}{3} & \multirow{4}{*}{$\begin{array}{c}J K F K Q \\
3\end{array}$} & \multirow{4}{*}{${ }^{A} C_{k}$} & 1 & $\mathrm{H}-47372$ & 100.0000 & $\checkmark$ & 65.1228 & $12 / 15 / 06$ & 1356 & $\mathrm{JMH}$ & \multirow{4}{*}{65.1228} \\
\hline & & & 2 & & 7 & & & & & & \\
\hline & & & 3 & & & & & JMH & & & \\
\hline & & & 4 & & & & & $12 / 15 / 06$ & & $m$ & \\
\hline \multirow[t]{4}{*}{4} & & & 1 & & & & & & & & \\
\hline & & & 2 & & & & & & & & \\
\hline & & & 3 & & & & & & & & \\
\hline & & & 4 & & & & & & & & \\
\hline \multirow[t]{4}{*}{5} & & & 1 & & & & & & & & \\
\hline & & & 2 & & & & & & & & \\
\hline & & & 3 & & & & & & & & \\
\hline & & & 4 & & & & & & & & \\
\hline \multirow[t]{4}{*}{6} & & & 1 & & & & & & & & \\
\hline & & & 2 & & & & & & & & \\
\hline & & & 3 & & & & & & & & \\
\hline & & & 4 & & & & & & & & \\
\hline \multirow[t]{4}{*}{7} & & & 1 & & & & & & & & \\
\hline & & & 2 & & & & & & & & \\
\hline & & & 3 & & & & & & & & \\
\hline & & & 4 & & & & & & & & \\
\hline \multirow[t]{4}{*}{8} & & & 1 & & & & & & & & \\
\hline & & & 2 & & & & & & & & \\
\hline & & & 3 & & & & & & & & \\
\hline & & & 4 & & & & & & & & \\
\hline \multirow[t]{4}{*}{9} & & & 1 & & & & & & & & \\
\hline & & & 2 & & & & & & & & \\
\hline & & & 3 & & & & & & & & \\
\hline & & & 4 & & & & & & & & \\
\hline \multirow[t]{4}{*}{10} & & & 1 & & & & & & & & \\
\hline & & & 2 & & & & & & $\cdot$ & & \\
\hline & & & 3 & & & & & & & & \\
\hline & & & 4 & & & & & & & & \\
\hline
\end{tabular}

Record the measured weight of the 100 gram weight. Was the measured weight $100 \pm 0.0005$ grams?

(At start, and after every ten containers)

- Was the balance tared before the current weighing? 
Subcontract 


\section{SIVthe STL}

\section{GENERAL CHEMISTRY DATA}




\section{$\frac{\text { SEVERN }}{\text { TRENT }} S \amalg$}

SAMPLE DATA 
Air Sampling Associates, Inc.

Client Sample ID: HARDIN SDA INLET DUCT RUN $\mathbb{1}$ ACE FW

General Chemistry

Lot-Sample \#...: H6L110106-001

Work Order \#...: JK7J5

Matrix.......: AIR

Date Sampled...: 11/30/06

Date Received..: 12/06/06

PREPARATION- PREP

PARAMETER

RESULT

$\underline{\mathrm{RL}}$

UNITS

METHOD

ANALYSIS DATE BATCH \#

Particulates (total) 1450

$$
\text { Dilution Factor: } 1
$$

CF'R60A 5

$\overline{12 / 15-12 / 18 / 06} \overline{6349313}$

MDL........ 0.50 
Air Sampling Associates, Inc.

Client Sample ID: HARDIN SDA INLET DUCT RUN $\mathbb{1} 0.1 \mathrm{~N}$ H2SO4

General Chemistry

Lot-Sample \#...: H6L110106-003

Work Order \#...: JK7 J8

Matrix.......: WATER

Date Sampled...: $11 / 30 / 06$

Date Received..: 12/06/06

PREPARATION- PREP

PARAMETER

RESULT

RL

UNITS

METHOD

ANALYSIS DATE BATCH \#

Nitrogen, as Ammonia 4.8

$0.20 \mathrm{mg} / \mathrm{L}$

MCAWW 350.3

$12 / 14 / 06$

6348460

Dilution Factor: 1

MDL......... 0.057 
Air Sampling Associates, Inc.

Client Sample ID: HARDIN SDA INLET DUCT RUN 2 ACE FW

General Chemistry

Lot-Sample \#...: H6L110106-005

Date Sampled...: 12/01/06
Work Order \#...: JK $7 \mathrm{KE}$

Date Received..: 12/06/06
Matrix.......: AIR

PREPARATION- PREP ANALYSIS DATE BATCH \#
PARAMETER

Particulates (total) 2170
RESULT

$\mathrm{RL}$

0.50

Dilution Factor: 1
METHOD

CFR60A 5 MDL.........: 0.50 
Air Sampling Associates, Inc.

Client Sample ID: HARDIN SDA INLET DUCT RUN $2 \quad 0.1 N$ H2SO4

General Chemistry

Lot-Sample \#...: H6L110106-007

Work Order \#...: JK $7 \mathrm{KK}$

Matrix.......: WATER

Date Sampled...: 12/01/06

Date Received..: 12/06/06

PREPARATION- PREP

PARAMETER

RESULT

$\underline{R L}$

UNITS

METHOD

ANALYSIS DATE BATCH \#

Nitrogen, as Ammonia 1.6

$0.20 \mathrm{mg} / \mathrm{L}$

Dilution Factor: 1
MCAWW $350.3 \quad 12 / 14 / 06$

MDL........: 0.057 
Air Sampling Associates, Inc.

Client Sample ID: HARDIN SDA INLET DUCT RUN 3 ACE FW

General Chemistry

Lot-Sample \#...: H6L110106-009

Date Sampled...: 12/02/06
Work Order \#...: JK $7 \mathrm{KQ}$

Date Received..: 12/06/06
Matrix.......: AIR

PREPARATION- PREP ANALYSIS DATE BATCH \#
PARAMETER

Particulates (total) 2060
RESULT

$\mathrm{RL}$

0.50

Dilution Factor: 1
METHOD

CFR60A 5 MDL.........: 0.50 
Air Sampling Associates, Inc.

Client Sample ID: HARDIN SDA INLET DUCT RUN $3 \quad 0.1 N$ H2SO4

General Chemistry

Lot-Sample \#...: H6L110106-011

Work Order \#...: JK7KV

Matrix.......: WATER

Date Sampled...: 12/02/06

Date Received..: 12/06/06

PREPARATION- PREP

PARAMETER

RESULT

$\underline{R L}$

UNITS

METHOD

ANALYSIS DATE BATCH \#

Nitrogen, as Ammonia 3.3

$0.20 \mathrm{mg} / \mathrm{L}$

MCAWW 350.3

$12 / 14 / 06$

6348460

Dilution Factor: 1

MDL......... 0.057 
Air Sampling Associates, Inc.

Client Sample ID: HARDIN STACK \& SDA INLET RB $0.1 \mathrm{~N}$ H2SO4 BLANK

General Chemistry

Lot-Sample \#...: H6L110106-014 Work Order \#...: JK7K1

Matrix.......: WATER

Date Sampled...: 12/01/06

Date Received..: 12/06/06

PREPARATION- PREP

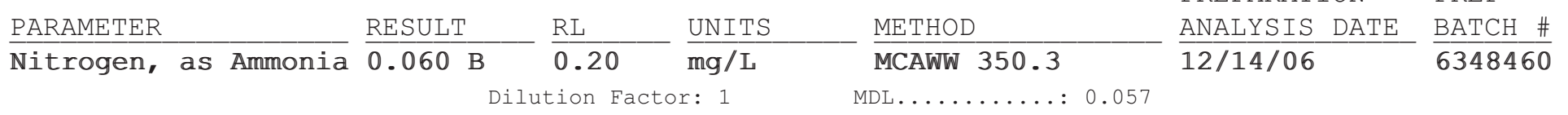

NOTE (S) :

RL Reporting Limit

B Estimated result. Result is less than RL. 


\section{ME'THOD BLANK RËPORT}

\section{Genera1 Chemistry}

Client Lot \#...: H6L110106

Matrix.......: WATER

\begin{tabular}{|c|c|c|c|c|c|c|}
\hline PARAMETER & RESULT & $\begin{array}{l}\text { REPORTINC } \\
\text { LIMIT }\end{array}$ & UNITS & METHOD & $\begin{array}{l}\text { PREPARATION- } \\
\text { ANALYSIS DATE }\end{array}$ & $\begin{array}{l}\text { PREP } \\
\text { BATCH \# }\end{array}$ \\
\hline \multirow{2}{*}{ Nitrogen, as } & Ammonia & Work Order & $\#:$ JLG661AA & MB Lot-Sample \#: & A6L140000-460 & \\
\hline & $\mathrm{ND}$ & 0.20 & $\mathrm{mg} / \mathrm{L}$ & MCAWW 350.3 & $12 / 14 / 06$ & 6348460 \\
\hline
\end{tabular}

NOTE (S) :

Calculations are performed before rounding to avoid round-off errors in calculated results. 
LABORATORY CONTROL SAMPLE EVALUATION REPORT

\section{Genera1 Chemistry}

Client Lot \#...: H6L110106

Matrix......: WATER

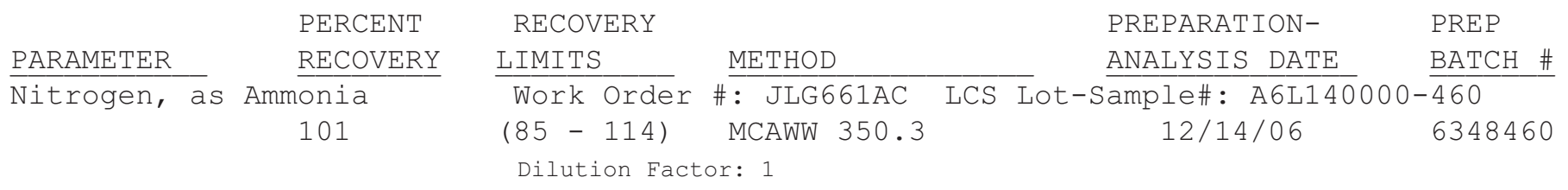

NOTE (S) :

Calculations are performed before rounding to avoid round-off errors in calculated results. 


\section{LABORATORY CONTROL SAMPLE DATA REPORT}

\section{General Chemistry}

C1ient Lot \#...: H6L110106

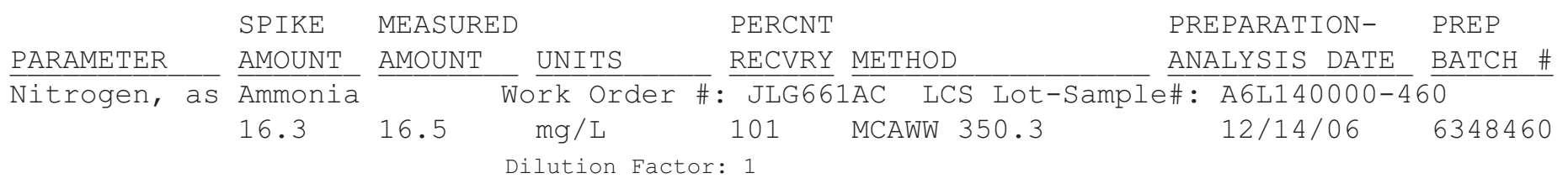

NOTE (S) :

Calculations are performed before rounding to avoid round-off errors in calculated results.

Matrix....... WATER

PREPARATION- PREP ANALYSIS DATE BATCH \#

A6L140000-460 Dilution Factor: 1

(1)


MATRIX SPIKE SAMPLE EVVALUATION RE"PORT

\section{General Chemistry}

Client Lot \#...: H6L110106

Date Sampled...: 12/13/06
Date Received..: 12/13/06

Matrix.......: WATER

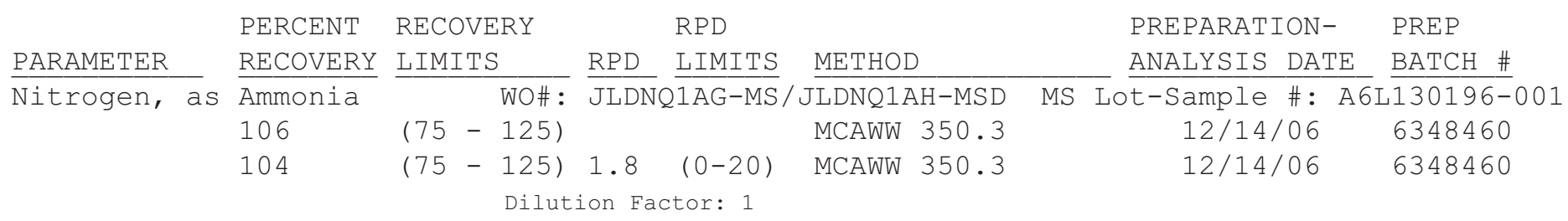

\section{NOTE (S) :}

Calculations are performed before rounding to avoid round-off errors in calculated results. 


\section{MATRIX SPIKE SAMPLE DATA REPORT}

\section{General Chemistry}

Client Lot \#...: H6L110106

Date Sampled...: 12/13/06
Matrix.......: WATER

Date Received..: 12/13/06

\begin{tabular}{|c|c|c|c|c|c|c|c|c|}
\hline PARAMETER & $\begin{array}{l}\text { SAMPLE } \\
\text { AMOUNT }\end{array}$ & $\begin{array}{l}\text { SPIKE } \\
\text { AMT }\end{array}$ & $\begin{array}{l}\text { MEASRD } \\
\text { AMOUNT }\end{array}$ & UNITS & $\begin{array}{l}\text { PERCNT } \\
\text { RECVRY RPD }\end{array}$ & $\underline{\text { METHOD }}$ & $\begin{array}{l}\text { PREPARATION- } \\
\text { ANALYSIS DATE }\end{array}$ & $\begin{array}{l}\text { PREP } \\
\text { BATCH \# }\end{array}$ \\
\hline \multirow[t]{3}{*}{ Nitrogen, } & as Ammor & ia & WO\# : & JLDNQ1Z & / JLDNQ1AH-M & D MS Lot-Sam & le \#: A6L130196 & -001 \\
\hline & 0.21 & 2.50 & 2.87 & $\mathrm{mg} / \mathrm{L}$ & 106 & MCAWW 350.3 & $12 / 14 / 06$ & 6348460 \\
\hline & 0.21 & 2.50 & 2.82 & $\mathrm{mg} / \mathrm{L}$ & 104 & MCAWW 350.3 & $12 / 14 / 06$ & 6348460 \\
\hline
\end{tabular}

NOTE (S) :

Calculations are performed before rounding to avoid round-off errors in calculated results. 


\section{$\frac{\text { SEVERN }}{\text { TRENT }}$ SIL}

SUPPORTIVE RAW DATA 


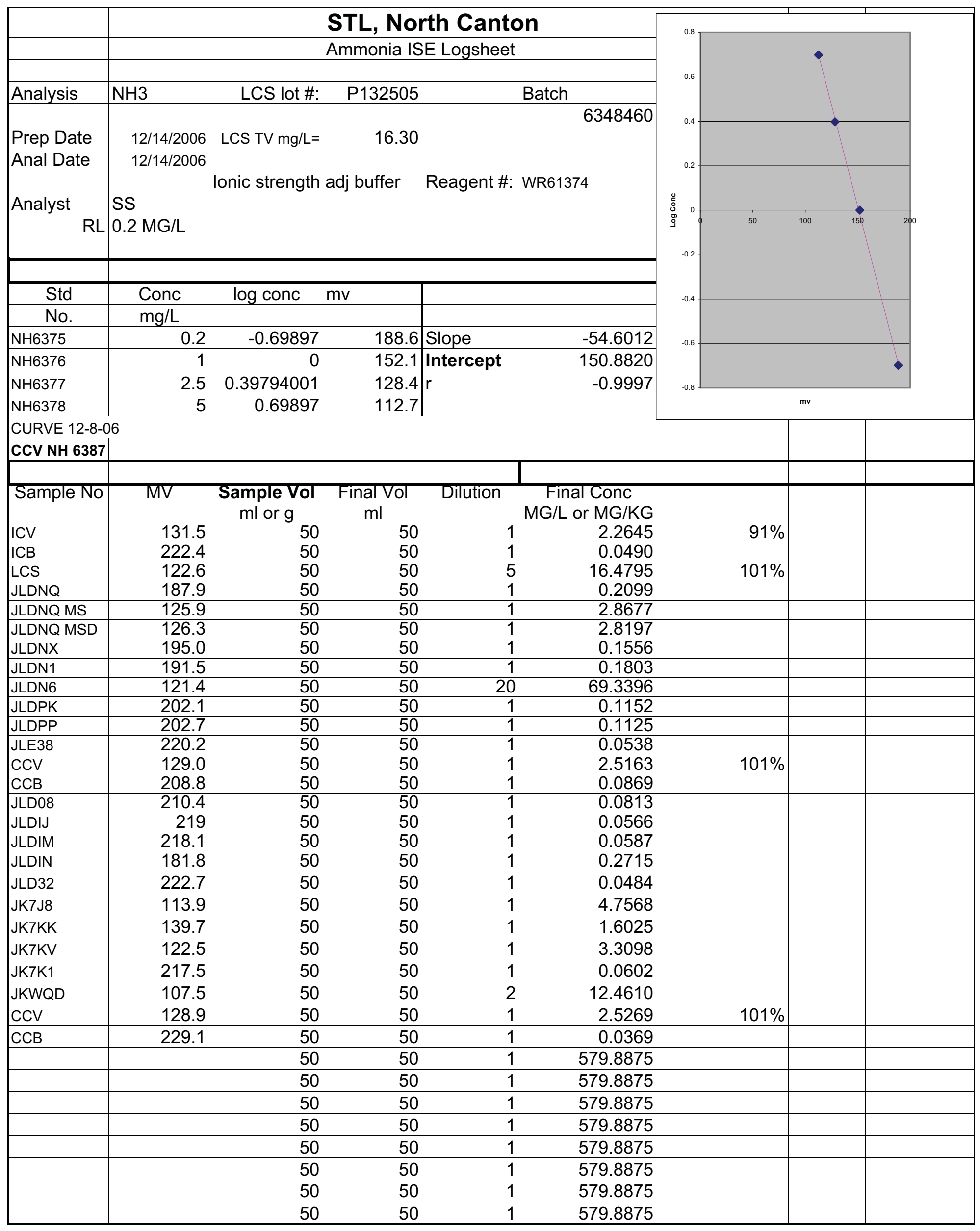




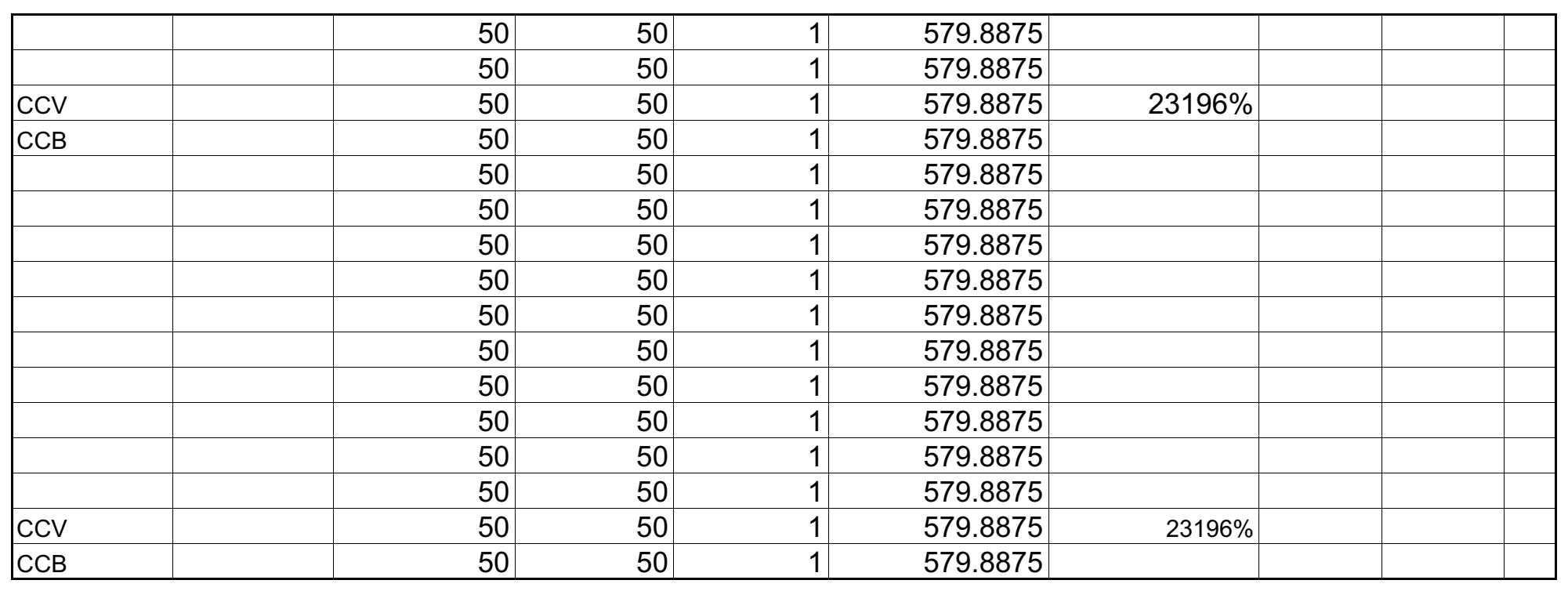




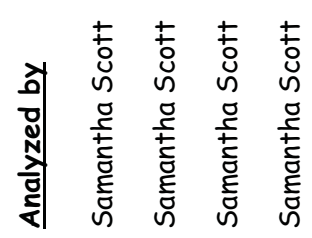

章

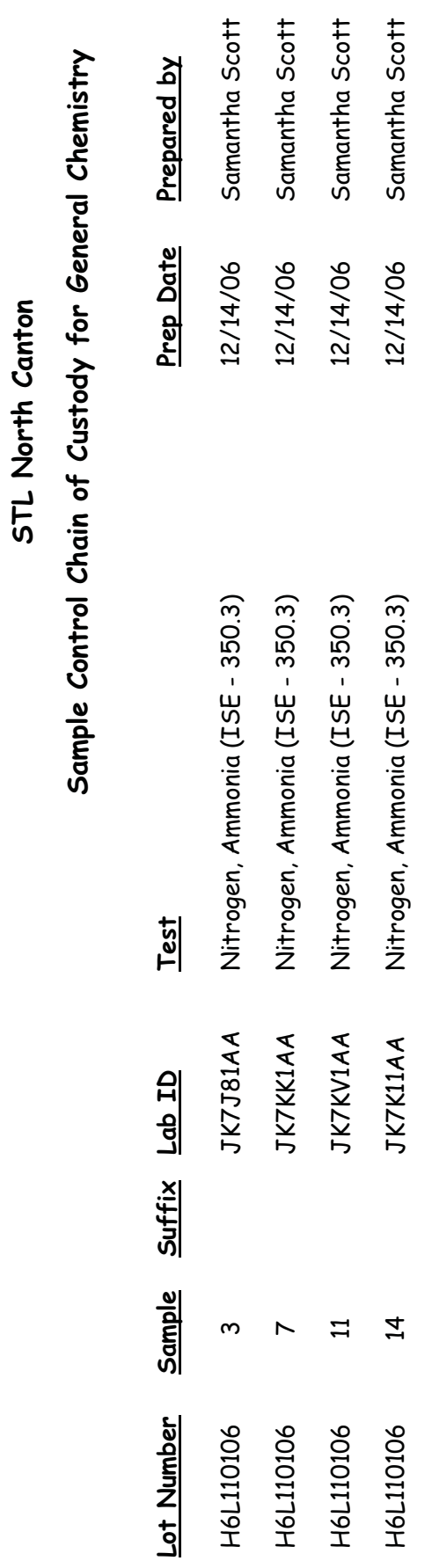




\section{Sample Receipt Documentation}




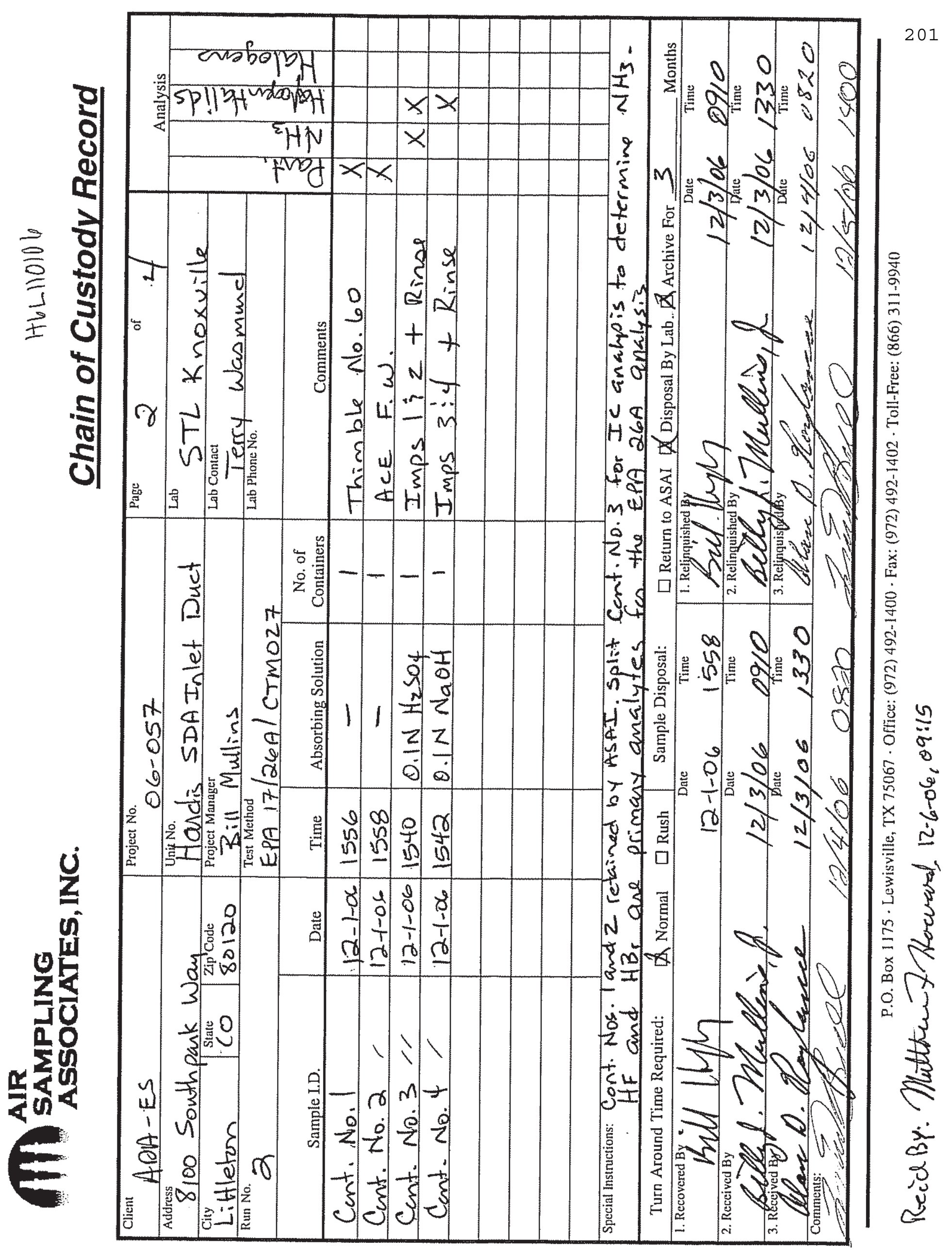




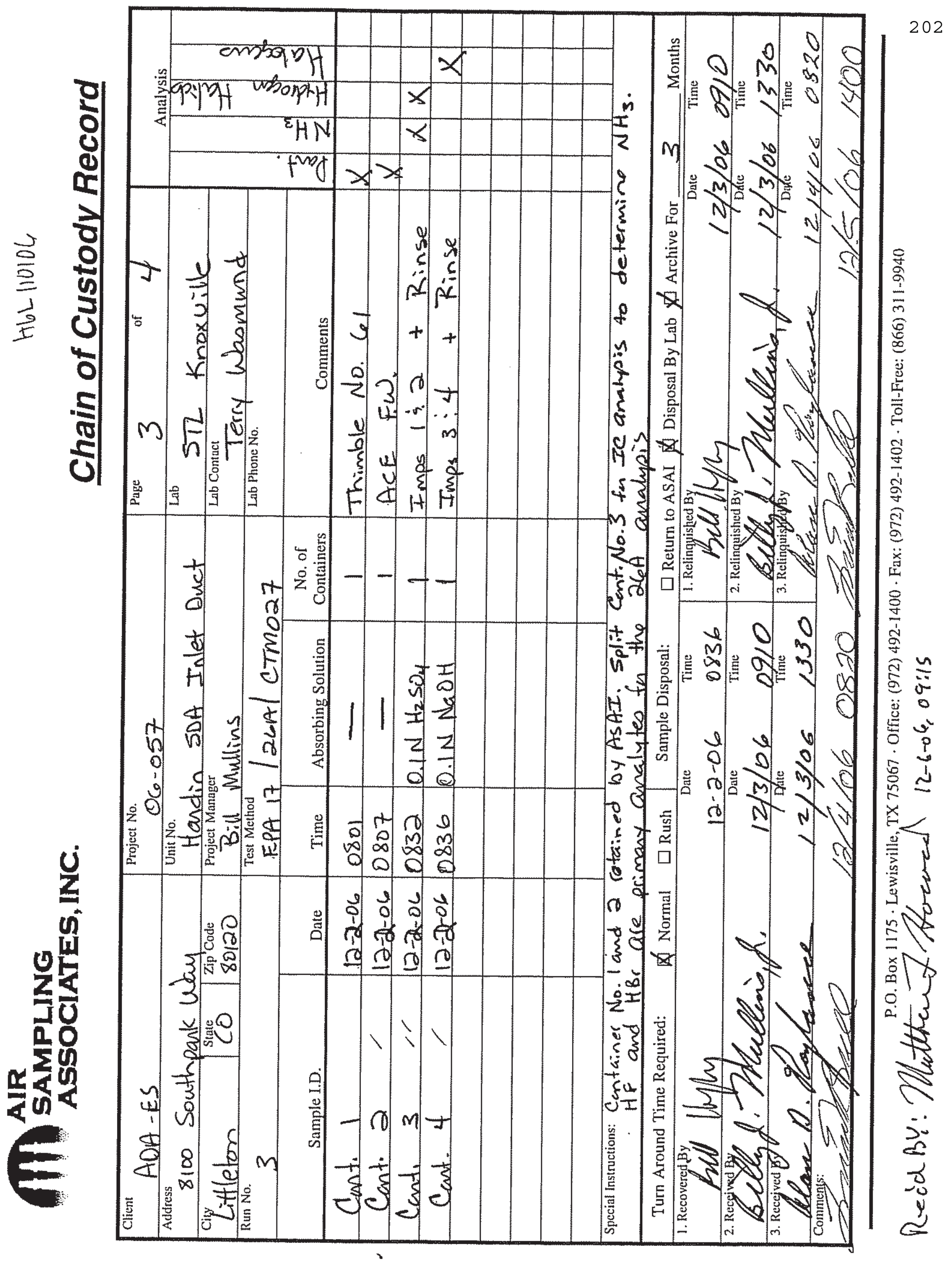




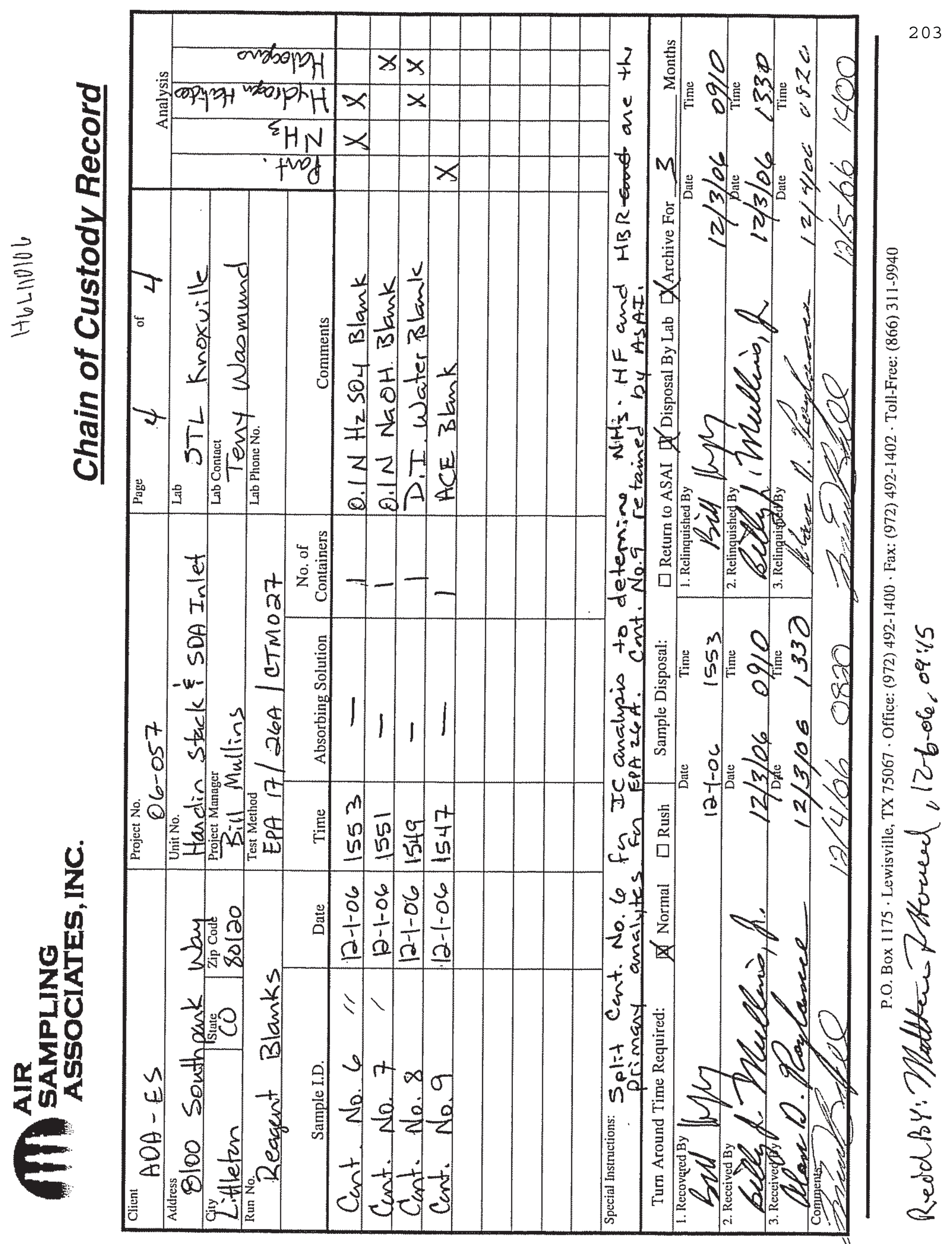




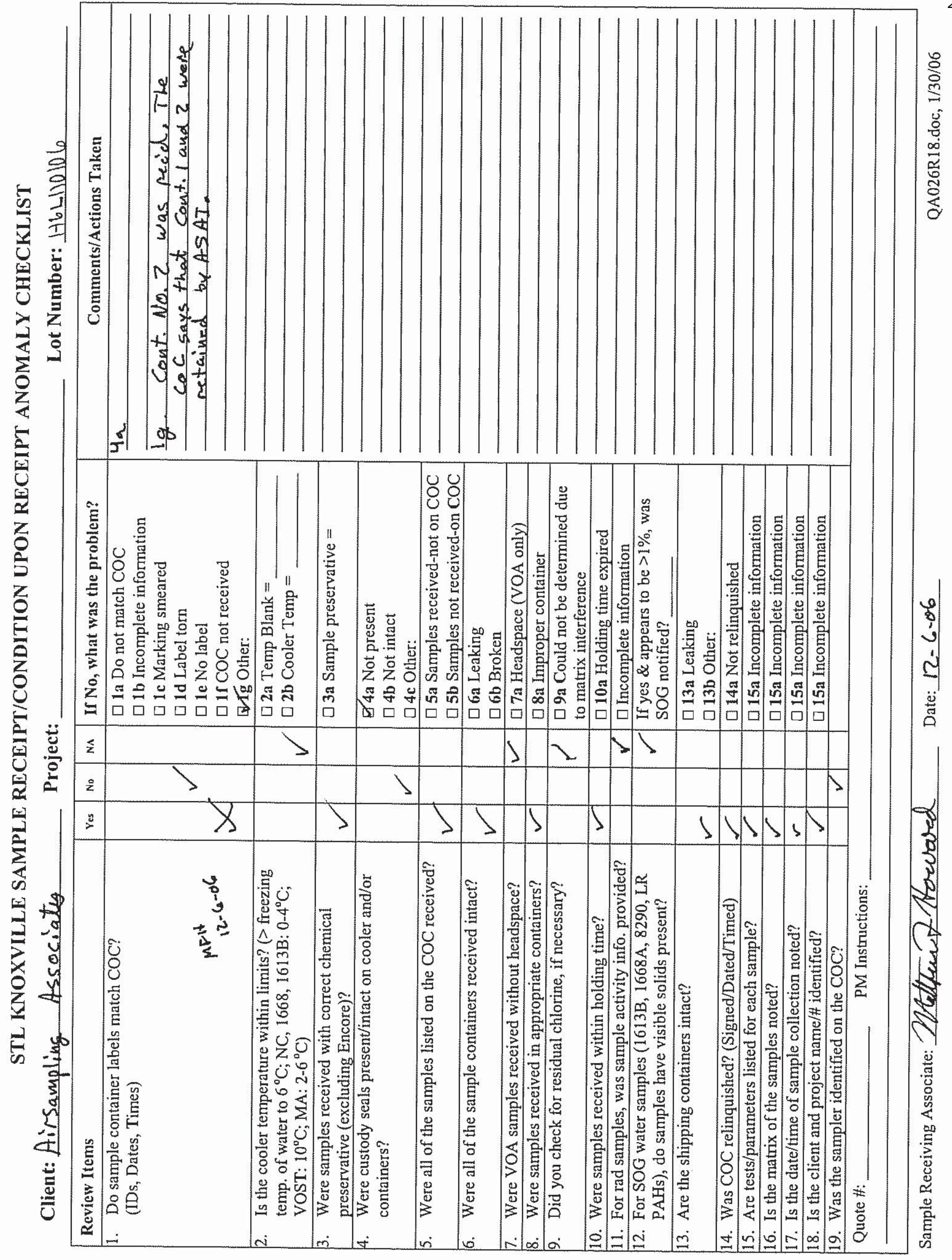


Severn Trent Laboratories, Inc SAMPLE ANALYSIS REQUISITION

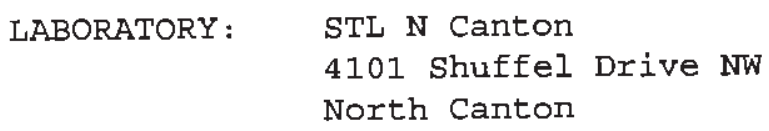

ATTN :
OH 44720 ,

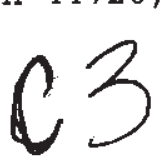

NEED ANALYTICAL REPORT BY $12 / 25 / 06$

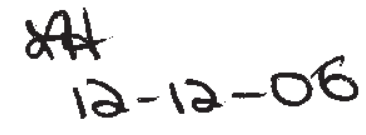

LAB PURCHASE ORDER: SR087884

CLIENT CODE: 1353236 PROJECT MANAGER: Terry Wasmund

NUMBER OF SAMPLES IN LOT: 0000

\begin{tabular}{|c|c|c|}
\hline $\begin{array}{l}\text { SAMPLE I.D. } \\
\text { H6L110106-003 } \\
\text { JK7J8-1-AA }\end{array}$ & $\frac{\text { SAMPLING DATE }}{0^{1 / 30 / 06}}$ & $\begin{array}{l}\frac{\text { ANALYSIS REQUIRED }}{\text { Nitrogen, Ammonia (ISE }-350.3 \text { ) }} \\
\text { (NH3 , METHOD: } 350.3\end{array}$ \\
\hline $\begin{array}{l}\mathrm{H} 6 \mathrm{~L} 110106-007 \\
\text { JK7KK-1-AA }\end{array}$ & $12 / 01 / 06$ & $\begin{array}{l}\text { Nitrogen, Ammonia (ISE - 350.3) } \\
(\mathrm{NH} 3, \text { METHOD: } 350.3\end{array}$ \\
\hline $\begin{array}{l}\text { H6L110106-011 } \\
\text { JK7KV-1-AA }\end{array}$ & $12 / 02 / 06$ & $\begin{array}{l}\text { Nitrogen, Ammonia (ISE - 350.3) } \\
(\mathrm{NH} 3 \text { ) METHOD: } 350.3\end{array}$ \\
\hline $\begin{array}{l}\text { H6L110106-014 } \\
\text { JK7K1-1-AA }\end{array}$ & $12 / 01 / 06$ & $\begin{array}{l}\text { Nitrogen, Ammonia (ISE - } 350.3) \\
\text { (NH3 ) METHOD: } 350.3\end{array}$ \\
\hline
\end{tabular}

NEED DETECTION LIMIT AND ANALYSIS DATE INCLUDED IN REPORT.

SHIPPING METHOD: FEDX

DATE : $12 / 11 / 06$

SEND REPORT TO: TERRY WASMUND

SAMPLE RECEIVED BY:

DATE :

PLEASE SEND A SIGNED COPY OF THIS FORM WITH REPORT AT COMPLETION OF ANALYSIS.

THANK YOU.

STL Knoxville

STL $\mathrm{N}$ Canton

INT :

$12 / 11 / 06 \quad 9: 22: 52$

4101 Shuffel Drive NW

North Canton

$\mathrm{OH} 44720$,

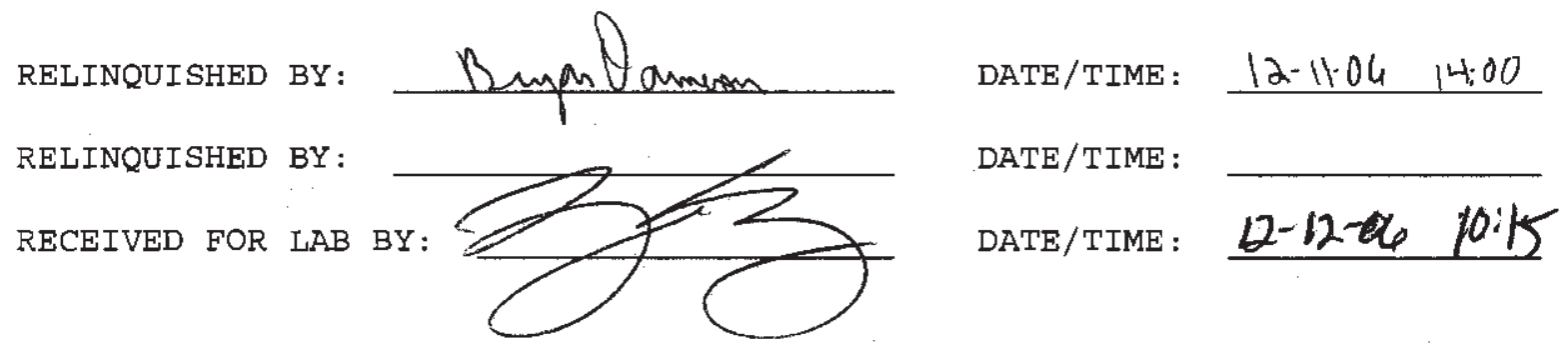


STL Cooler Receipt Form/Narrative

North Canton Facility

Client: sit knotvilte

Cooler Received on: $12-12-06$

Fedx $\square$ Client Drop Off $\square$ UPS $\square$

Stetson $\square$ US Cargo

STL Cooler No\#
Project:

Opened on

Dropection

DHL

Other:

Foam Box $\square$ Client Coolef 9 Other

\section{Lot Number: HeL 110 rob}

Quote\#:

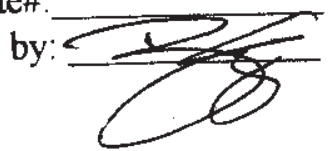

(Signature)

1. Were custody seals on the outside of the cooler? Yes $\square$ No $\square$ Intact? Yes $\square$ No $\square$ NA $\square$ If YES, Quantity Were the custody seals signed and dated?

2. Shipper's packing slip attached to this form?

3. Did custody papers accompany the samples?Yes $Q$ No $\square$

4. Did you sign the custody papers in the appropriate place?

5. Packing material used: Bubble Wrap $\square$. Foam $\square$

None $\square \quad$ Other :

6. Cooler temperature upon receipt $|8 .|^{\circ} \mathrm{C}$ (see back of form for multiple coolers/temp)

METHOD: Temp Vial $\square$ Coolant \& Sample $\square$ Against Bottles $\square$ COOLANT: Wettce Blue Ice $\square$. Dry Ice $\square$ Water $\square$

7. Did all bottles arrive in good condition (Unbroken)?

8. Could all bottle labels and/or tags be reconciled with the COC?

9. Were samples at the correct $\mathrm{pH}$ upon receipt?

10. Were correct bottles used for the tests indicated?

11. Were air bubbles $>6 \mathrm{~mm}$ in any. VOA vials?

12. Sufficient quantity received to perform indicated analyses?

13. Was a Trip Blank present in the cooler? Yes $\square$ No $\square$

Contacted PM LDE Date: 12-12-06by: LH

$\begin{array}{ll}\text { Yes } & \text { No } \square \text { NA } \square \\ \text { Yes } \square \text { No } \square \text { NA } \square\end{array}$

Relinquished by client? Yes $\square$ No $\square$ Yes No $\square$

Concerning:

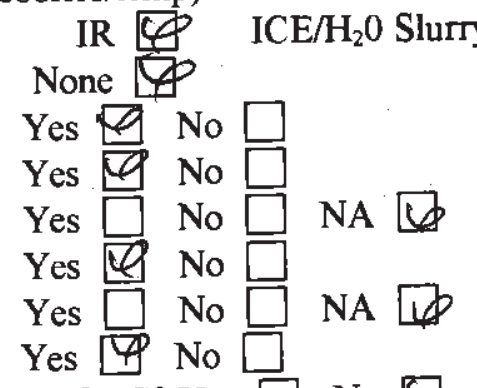

Were VOAs on the COC? Yes $\square$ No $\square$ via Voice Mail $\square$ Verbal $\square$ Other $\square$

$\sqrt{1}$

1. CHAIN OF CUSTODY

The following discrepancies occurred:

High temp no Ice in coder

2. SAMPLE CONDITION

Sample(s)

Sample(s)

were received after the recommended holding time had expired.

were received in a broken container.

\section{SAMPLE PRESERVATION}

Sample(s) were further preserved in sample receiving to meet recommended pH level(s). Nitric Acid Lot \# 092006 - Sulfuric Acid Lor \# 071805-H2SO4; Sodium Hydroxide Lot \#-122805 -NaOH; Hydrochloric Acid Lot \# 100504-HCl; Sodium Hydroxide and Zinc Acetate Lot \# 071604-CH3COO2ZNNaOH

Sample(s)

were received with bubble $>6 \mathrm{~mm}$ in diameter (cc: PM)

\section{Other (see below or back)}

\begin{tabular}{|l|c|c|c|}
\hline Client ID & $\mathrm{pH}$ & Date & Initials \\
\hline & & & \\
\hline & & & \\
\hline
\end{tabular}


Appendix G:

EPA Conditional Test Methods 5 and 26A (Particulate Matter and Hydrogen Halides \& Halogens) Analytical Data - Stack 
AIR

SAMPLING

ASSOCIATES, INC.

Air Sampling Associates, Inc.

Particulate Analysis Summary

Project Number: $06-057$

Project Name: $A D A-E S$

Project Location: Hardin, NT
Date Analysis Completed: $12 / 12 / 06$

Unit Tested: 5 tack

EPA Method 26A

Run Number:

Particulate Matter on Filter (mg):

Particulate Matter in Front Wash (mg):

Total Particulate Matter in "Front-Half" - MF (mg):

Particulate Matter in "Back-HalP” (mg):

Total Particulate Matter in Sample - MT (mg): $\frac{1}{10.6} \frac{2}{13.2} \frac{3}{\frac{15.7}{23.8}} \frac{\frac{14.0}{25.1}}{\frac{9.7}{23.7}}$
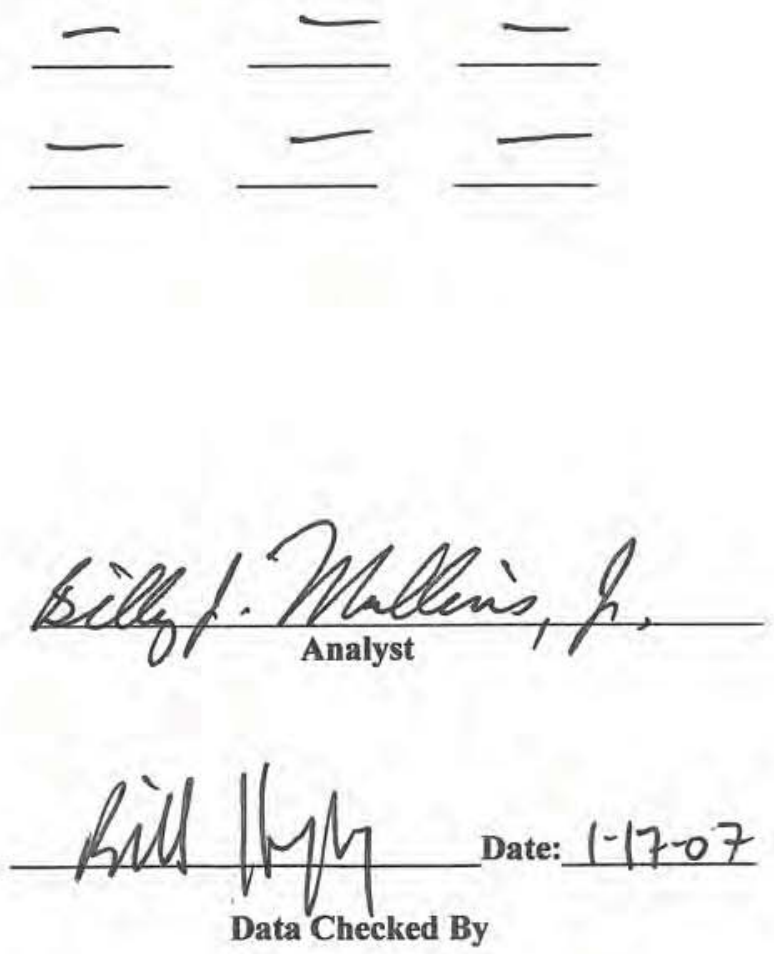

Version No. 1 5/30/06

G-2 
Particulate Analysis EPA Method $\underline{26 \mathrm{~A}}$

Stack Filters

Project No.

Project Name
$06-057$

ADA-ES
Location Unit Tested

\section{Handin, MT
stack}

Desiccator Time In $12 / 05 / 06 / 530 / 2 / 07 / 060855$

Desiccator Time Out $/ 2 / 040$ do $0855 / 2 / 07 / 061505$

\begin{tabular}{|c|c|c|c|c|}
\hline Run No. & 1 & Filter No. A092 & \multicolumn{1}{c|}{ Sample I.D. } \\
\hline Filter \& Particulate (g) & 0.3573 & 0.3573 & & \\
\hline
\end{tabular}

Filter \& Particulate Average $(\mathrm{g}) \quad 0,3573$

Initial Filter Weight $(\mathrm{g}) 0.3467$

Total Particulate (mg)

\begin{tabular}{|c|l|l|l|l|}
\hline Run No. & Filter No. $\mathrm{A} / / 2$ & \multicolumn{2}{c|}{ Sample I.D. } \\
\hline Filter \& Particulate (g) & 0.3989 & 0.3986 & & \\
\hline
\end{tabular}

Filter \& Particulate Average (g) 0.3986 Initial Filter Weight $(\mathrm{g}) 0.3832$

Total Particulate (mg) 15.4

\begin{tabular}{|l|l|l|l|l|}
\hline Run No. 3 & Filter No. A//3 Sample I.D. \\
\hline Filter \& Particulate (g) & $0.39 / 7$ & $0.39 / 8$ & & \\
\hline
\end{tabular}

Filter \& Particulate Average (g) 0,3918 Initial Filter Weight $(\mathrm{g}) \quad 0.3778$ Total Particulate (mg)

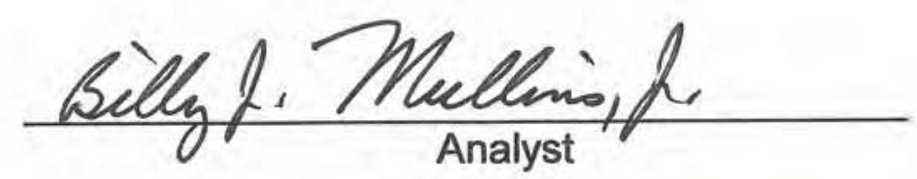




\section{Im AIR \\ SAMPLING \\ ASSOCIATES, INC.}

\begin{tabular}{|c|c|c|c|c|c|c|c|}
\hline \multicolumn{8}{|c|}{$\begin{array}{l}\text { Filter Weight Log } \\
\text { EPA Method } 5\end{array}$} \\
\hline \multirow[b]{3}{*}{ Filter No. } & Into Desicator & Weight & Weight & Weight & Weight & Weight & \multirow{3}{*}{$\begin{array}{l}\text { Weight } \\
\text { Used }\end{array}$} \\
\hline & Date & Date & Date & Date & Date & Date & \\
\hline & Time & Time & Time & Time & Time & Time & \\
\hline \multirow{3}{*}{ A091 } & & 0.3484 & 0.3484 & & & & 0.3489 \\
\hline & $8 / 25 \% 06$ & 9120106 & 9121106 & & & & \\
\hline & 0900 & 1400 & 1410 & & & & \\
\hline \multirow{3}{*}{4092} & & 0.3467 & 0.3467 & & & & 0.3467 \\
\hline & 8125106 & $9 / 20 / 06$ & 9121106 & & & & \\
\hline & 0900 & 1400 & $1+10$ & & & & \\
\hline \multirow{3}{*}{ A693 } & & 0.3457 & 0.3455 & & & & 0.3455 \\
\hline & $69 / 2106$ & $90 / 3106$ & $10 / 3 / 06$ & & & & \\
\hline & 0,300 & 0830 & 1615 & & & & \\
\hline \multirow{3}{*}{$A \phi 94$} & & 0.3514 & 0.3514 & & & & 0.3514 \\
\hline & & $10 / 3104$ & $10 / 2 / 06$ & & & & \\
\hline & & 0831 & $1 6 \longdiv { 7 }$ & & & & \\
\hline \multirow{3}{*}{ A $\$ 95$} & & 0.3522 & 0.3519 & & & & 0.3519 \\
\hline & & 1013104 & $10 / 3 / 06$ & & & & \\
\hline & & 0832 & 1619 & & & & \\
\hline \multirow{3}{*}{$A \phi 96$} & & 0.3653 & 0.5652 & & & & 0.3652 \\
\hline & & 1013106 & $1013 / 06$ & & & & \\
\hline & & 0833 & 1620 & & & & \\
\hline \multirow{3}{*}{$A \varnothing 97$} & & 0.3622 & 0.3619 & & & & 0.3619 \\
\hline & & 1013106 & $10 / 3 / 06$ & & & & \\
\hline & & 0834 & 1620 & & & & \\
\hline \multirow{3}{*}{ A 698} & & 0,3637 & 0.3636 & & & & 0.3636 \\
\hline & & 1013106 & $10 / 5 / 06$ & & & & \\
\hline & & 0835 & 1621 & & & & \\
\hline \multirow{3}{*}{ Ad 999} & & 0.3695 & 0.3694 & & & & 0.3694 \\
\hline & & $10 / 3106$ & $10 / 3 / 06$ & & & & \\
\hline & & 0836 & 1622 & & & & \\
\hline \multirow{3}{*}{ A 100} & & 0.3691 & 0.3691 & & & & 0.3691 \\
\hline & & $10 / 3 / 06$ & $10 / 3 / 06$ & & & & \\
\hline & & 0837 & 1623 & & & & \\
\hline \multirow{3}{*}{ Alol } & & 0.3745 & 0.3745 & & & & 0.3745 \\
\hline & & 1013106 & $10 / 3 / \alpha$ & & & & \\
\hline & & 0838 & 1624 & & & & \\
\hline \multirow{3}{*}{$A 102$} & & 0.3789 & 0.3789 & & & & 0.3789 \\
\hline & & 1013106 & $10 / 3106$ & & & & \\
\hline & & 0839 & 1625 & & & & \\
\hline \multirow{3}{*}{$A 103$} & & 0.3801 & 0.3802 & & & & 0.3802 \\
\hline & & $\mathrm{CO}_{3} / \mathrm{Ob}$ & $18 / 3 / 06$ & & & & \\
\hline & & 0840 & 1626 & & & & \\
\hline \multirow{5}{*}{$\$ A 164$} & & 0.3836 & 0.3837 & & & & 0.3837 \\
\hline & & $1013 \% 6$ & $10 / 3 / 06$ & & & & \\
\hline & V & 0841 & 1626 & & & & \\
\hline & & & & & & & \\
\hline & & & & & & & \\
\hline
\end{tabular}




\section{TI}

Filter Weight Log

EPA Method 5

\begin{tabular}{|c|c|c|c|c|c|c|c|}
\hline \multirow[b]{3}{*}{ Filter No. } & Into Desicator & Weight & Weight & Weight & Weight & Weight & \multirow{3}{*}{$\begin{array}{l}\text { Weight } \\
\text { Used }\end{array}$} \\
\hline & Date & Date & Date & Date & Date & Date & \\
\hline & Time & Time & Time & Time & Time & Time & \\
\hline \multirow{3}{*}{ A 105} & & 0.3801 & 0.3801 & & & & 0.3801 \\
\hline & $10 / 2 / 06$ & $10 / 12 / 10$ & $10 / 13 / 06$ & & & & \\
\hline & 6800 & 1000 & 0826 & & & & \\
\hline \multirow{3}{*}{ A106 } & $60 / 2 / 06$ & 0,3827 & 0.3825 & & & & 0.3825 \\
\hline & oseo & $10 / 12 / 66$ & $10 / 13 / 06$ & & & & \\
\hline & & 1001 & 0827 & & & & \\
\hline \multirow{2}{*}{$A 107$} & $01=1006$ & 0.3808 & $0.38 / 0$ & & & & $0.38 / 0$ \\
\hline & $\frac{10 / 2 / 06}{0800}$ & $\frac{10 / 12 / 06}{1002}$ & 0828 & & & & \\
\hline \multirow{3}{*}{$A 108$} & & 0.3843 & 0.3845 & & & & 0.3845 \\
\hline & $10 / 2106$ & $10 / 12 / 06$ & $10 / 13 / 06$ & & & & \\
\hline & 6800 & 1003 & 0829 & & & & \\
\hline \multirow{3}{*}{ Alo? } & & 0.3872 & 0.3873 & & & & 0.3873 \\
\hline & $10 / 2106$ & $10 / 12 / 06$ & $10 / 13 / 86$ & & & & \\
\hline & 6860 & 1004 & 0830 & & & & \\
\hline \multirow{2}{*}{$A \| 0$} & & 0.3885 & 0,3886 & & & & 0.3886 \\
\hline & $10 / 2 / 06$ & $10 / 12 / 106$ & $10 / 13 / 06$ & & & & \\
\hline \multirow{3}{*}{$A \| z$} & 0800 & $\frac{10015}{0.3833}$ & $\frac{0.831}{0,3832}$ & & & & 0.3832 \\
\hline & $10 / 2 / 06$ & $18 / 12 / 06$ & $10 / 13 / 06$ & & & & \\
\hline & 0800 & $100 \mathrm{k}$ & 6832 & & & & \\
\hline \multirow{2}{*}{$A \| B$} & & 0.3781 & 0.3778 & & & & 0.3778 \\
\hline & $1 0 \longdiv { 2 / 0 6 }$ & $10 / 12 / 06$ & $10 / 13 / 86$ & & & & \\
\hline \multirow{3}{*}{ A 114} & 6800 & 1007 & 6833 & & & & \\
\hline & 1012106 & 0.3814 & 0.3812 & & & & 0.3812 \\
\hline & $\frac{10 \% 2106}{0800}$ & $10 / 12106$ & $\frac{0 / 13106}{0834}$ & & & & \\
\hline \multirow{3}{*}{$A 115$} & & 0.3701 & 0,3700 & & & & 0.3700 \\
\hline & $10 / 2 / 06$ & $10 / 12 / d 6$ & $10 / / 3 / 06$ & & & & \\
\hline & 6860 & 1009 & 0835 & & & & \\
\hline \multirow{2}{*}{$A 116$} & & 0.3678 & 0.3679 & & & & 0,3679 \\
\hline & $10 / 2 / 06$ & $10 / 1306$ & $10 / 13 / 06$ & & & & \\
\hline \multirow{3}{*}{$A \| 1$} & 10800 & $\frac{1010}{0.3644}$ & $\frac{0.836}{0.3644}$ & & & & 0.3644 \\
\hline & $10 / 2 / 06$ & $10 / 12 \sqrt{26}$ & $10 / 13 / 06$ & & & & \\
\hline & 0800 & 1011 & 0837 & & & & \\
\hline \multirow{2}{*}{$A \| g$} & & 0,3636 & 0.3635 & & & & 0.3635 \\
\hline & $10 / 2 / 06$ & $11 / 20 / 06$ & $11 / 21 / 06$ & & & & \\
\hline \multirow{3}{*}{$A 119$} & 10800 & $\frac{1245}{3656}$ & $\frac{\cos 27}{12150}$ & & & & $2 / 5$ \\
\hline & $1012 / 06$ & $\frac{0.5653}{11 / 20 / 96}$ & $\frac{26}{11 / 21 / 26}$ & & & & 0.3655 \\
\hline & 0800 & 1246 & 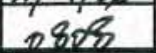 & & & & \\
\hline \multirow{2}{*}{$A 120$} & & 0.3616 & $0.36 / 5$ & & & & 0.3615 \\
\hline & $\frac{10}{0807}$ & 1120106 & $\frac{11 / 21 / 26}{0809}$ & & & & \\
\hline
\end{tabular}




\section{Im \\ ASSOCIATES, INC.}

\section{Particulate Analysis EPA Method Z6 A}

Page___ of

\section{Front Wash}
Project No.
$\frac{06-057}{A 0 A-E S}$
Location Hardin, MT
Project Nam

Desiccator Time In $1 / 2 / 08 / 061650 / 12 / 1 / 060820$ /2/12/06 820

Desiccator Time Out /2/11/060817/2/12/060815/12/12/06 1530

\begin{tabular}{|c|l|l|l|l|l|}
\hline Run No. & \multicolumn{1}{|c|}{ Volume (ml) 140} & \multicolumn{2}{c|}{ Sample I.D. } \\
\hline Final Weight $(\mathrm{g})$ & 106.6097 & 106.6048 & 106.6046 & & \\
\hline Initial Weight (g) & 106.5904 & 106.5904 & 106.590 & & \\
\hline Particulate Weight $(\mathrm{g})$ & & & & & \\
\hline
\end{tabular}

Particulate Average $(\mathrm{mg}) \quad 14.2$

Less Acetone Blank (mg) 1.0

Total Particulate $(\mathrm{mg}) \quad / 3.2$

\begin{tabular}{|c|c|c|c|c|c|}
\hline Run No. & \multicolumn{3}{|c|}{ Volume (ml) 150} & \multicolumn{1}{c|}{ Sample I.D. } \\
\hline Final Weight (g) & $104.061 /$ & 104.0568 & 104.0563 & & \\
\hline Initial Weight $(\mathrm{g})$ & 104.0455 & 104.0455 & 104.0455 & & \\
\hline Particulate Weight (g) & & & & & \\
\hline
\end{tabular}

Particulate Average (mg)

Less Acetone Blank (mg)

Total Particulate (mg)

$\frac{10.8}{1.1}$

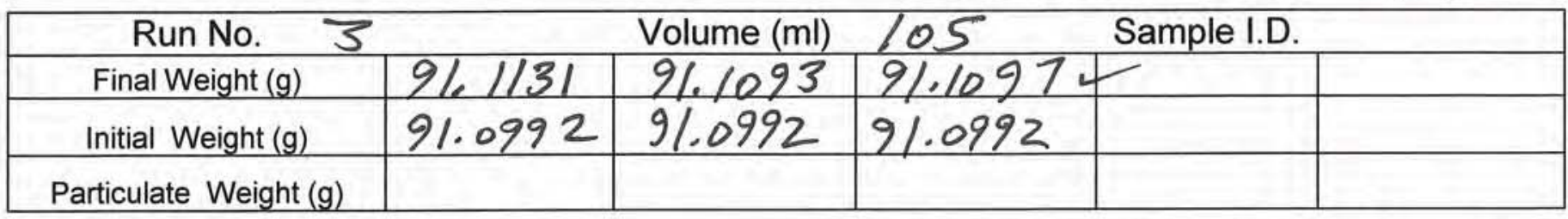

Particulate Average $(\mathrm{mg}) \quad 10,5$

Less Acetone Blank $(\mathrm{mg})-0.8$

Total Particulate $(\mathrm{mg}) \quad 9.7$

\begin{tabular}{|c|l|l|l|l|l|}
\hline \multicolumn{5}{|c|}{ Volume (ml) 200} & \multicolumn{3}{c|}{ Sample I.D. } \\
\hline Acetone Blank & 104.8397 & 104.8349 & 104.83492 & & \\
\hline Final Weight (g) & 104.8334 & 104.8334 & 104.8334 & & \\
\hline Initial Weight $(\mathrm{g})$ & 104.834 & & \\
\hline Particulate Weight (g) & & & & & \\
\hline
\end{tabular}

$$
\text { Average }(\mathrm{mg}) \frac{1.5}{* \mathrm{mg} / \mathrm{l}} \frac{2.5}{}
$$

* Note: if greater than $7.9 \mathrm{mg} / \mathrm{l}$, use $7.9 \mathrm{mg} / \mathrm{l}$ 
Particulate Analysis EPA Method Z6A

Front Half Tare Weights

Project No. $\quad 06-057$

Project Name ADA-ES

Location Hardin, $M T$

Desiccator Time in /2/05/06/530 $12 / 06 / 06 / 645 / 12 / 07 / 06$ a840/2/00/06/515

Desiccator Time Out 12/06/06/640 12/07/06 0840/2/07/06 /515 /2/08/06 0815

\begin{tabular}{|l|l|l|l|l|}
\hline Run No. & \multicolumn{3}{|c|}{ Sample I.D. } \\
\hline Weight $(\mathrm{g})$ & 106.5926 & 106.5913 & 106.5900 & 106.5904 \\
\hline
\end{tabular}

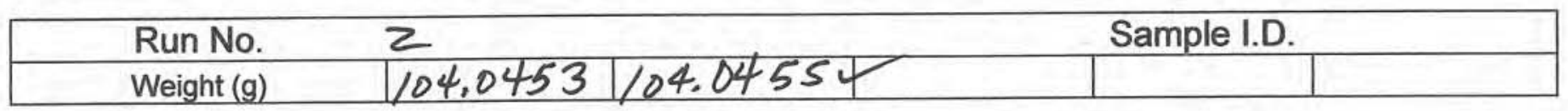

\begin{tabular}{|l|l|l|l|l|}
\hline Run No. 3 & \multicolumn{3}{|c|}{ Sample I.D. } \\
\hline Weight (g) & 91.0995 & 91.09924 & & \\
\hline
\end{tabular}

Acetone Blank

Weight (g)
Sample I.D.

104.8332104 .83344

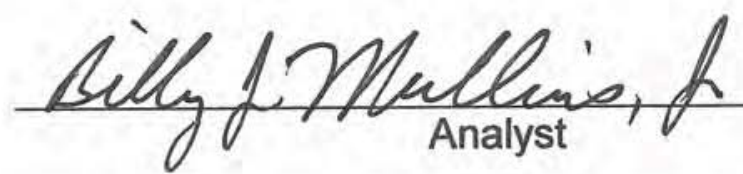


H6L110105 Analytical Report............................................. 1

Sample Receipt Documentation ......................................... 21

Wet Chemistry ................................................................ 26

Sample Summary ................................................. 27

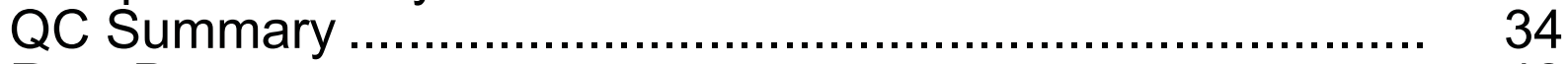

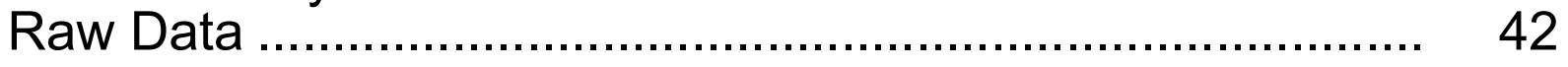

Sample Receipt Documentation ....................................... 152

Total Number of Pages ...................................................... 156 


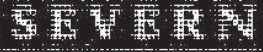

$+$

STL Knoxville

5815 Middlebrook Pike

Knoxville, TN 37921

Tel: 8652913000 Fax: 8655844315

www.stl-inc.com

\section{ANALYTICAL REPORT}

PROJECT NO. 06-057

Hardin, Montana Hardin Stack

Lot \# : H6L110105

Bill Hefley

Air Sampling Associates, Inc. 407-2B Holford's Prairie Road Lewisville, TX 75056

SEVERN TRENT LABBORATORIBS, INC.

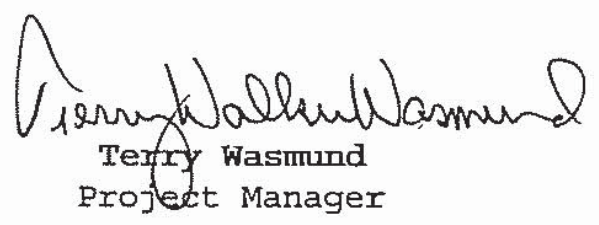

January 2, 2007 


\section{ANALYTICAL METHODS SUMMARY}

H6L110105

$\begin{array}{ll}\text { PARAMETER } & \begin{array}{l}\text { ANAIYTICAL } \\ \text { METHOD }\end{array} \\ \text { Bromine Emissions } & \text { KNOX 0050/26A Mod } \\ \text { Chlorine Emissions } & \text { KNOX 0050/26A Mod } \\ \text { Hydrogen Bromide Emissions } & \text { KNOX 0050/26A Mod } \\ \text { Hydrogen Chloride Emissions } & \text { KNOX 0050/26A Mod } \\ \text { Hydrogen Fluoride Emissions } & \text { KNOX 0050/26A Mod } \\ \text { References: } & \\ \text { KNoX Severn Trent Laboratories Knoxville, Facility Standard } \\ \quad \text { Operating Procedure. }\end{array}$




\section{QC DATA ASSOCIATION SUMMARY}

H6L110105

Sample Preparation and Analysis Control Numbers

\begin{tabular}{|c|c|c|c|c|c|}
\hline SAMPLE\# & MATRIX & $\begin{array}{l}\text { ANALYTICAL } \\
\text { METHOD }\end{array}$ & $\begin{array}{l}\text { LEACH } \\
\text { BATCH \# }\end{array}$ & $\begin{array}{l}\text { PREP } \\
\text { BATCH \# }\end{array}$ & MS RUN\# \\
\hline \multirow[t]{3}{*}{001} & AIR & KNOX $0050 / 26 \mathrm{~A}$ Mod & & 6361375 & 6362028 \\
\hline & AIR & KNOX $0050 / 26 \mathrm{~A}$ Mod & & 6363098 & 6363067 \\
\hline & AIR & KNOX $0050 / 26 \mathrm{~A}$ Mod & & 6361376 & 6362030 \\
\hline \multirow[t]{3}{*}{002} & AIR & KNOX $0050 / 26 \mathrm{~A}$ Mod & & 6354402 & 6354235 \\
\hline & AIR & KNOX $0050 / 26 \mathrm{~A}$ MOd & & 6354401 & 6354234 \\
\hline & AIR & KNOX $0050 / 26 \mathrm{~A}$ Mod & & 6354400 & 6354230 \\
\hline \multirow[t]{3}{*}{003} & AIR & KNOX $0050 / 26 \mathrm{~A}$ Mod & & 6361375 & \\
\hline & AIR & KNOX $0050 / 26 \mathrm{~A}$ MOd & & 6363147 & 6363101 \\
\hline & AIR & KNOX $0050 / 26 \mathrm{~A}$ Mod & & 6361376 & \\
\hline \multirow[t]{3}{*}{004} & AIR & KNOX $0050 / 26 \mathrm{~A}$ Mod & & 6354402 & \\
\hline & AIR & KNOX $0050 / 26 \mathrm{~A}$ Mod & & 6354401 & \\
\hline & AIR & KNOX $0050 / 26 \mathrm{~A}$ Mod & & 6354400 & \\
\hline \multirow[t]{3}{*}{005} & AIR & KNOX $0050 / 26 \mathrm{~A}$ Mod & & 6361375 & \\
\hline & AIR & KNOX $0050 / 26 \mathrm{~A}$ Mod & & 6363147 & \\
\hline & AIR & KNOX $0050 / 26 \mathrm{~A}$ Mod & & 6361376 & \\
\hline \multirow[t]{3}{*}{006} & AIR & KNOX $0050 / 26 \mathrm{~A}$ Mod & & 6354402 & \\
\hline & AIR & KNOX $0050 / 26 \mathrm{~A}$ Mod & & 6354401 & \\
\hline & AIR & KNOX $0050 / 26 \mathrm{~A}$ Mod & & 6354400 & \\
\hline
\end{tabular}


SAMPLE SUMMARY

H6L110105

$\begin{array}{ll}\text { JK7JR } & 001 \\ \text { JK7JW } & 002 \\ \text { JK7JX } & 003 \\ \text { JK7J0 } & 004 \\ \text { JK7J1 } & 005 \\ \text { JK7J2 } & 006\end{array}$

$\begin{array}{lllll}\text { HARDIN STACK RUN } & 1 & 0.1 \mathrm{~N} & \mathrm{H} 2 \mathrm{SO} 4 \\ \text { HARDIN STACK RUN } & 1 & 0.1 \mathrm{~N} & \mathrm{NAOH} \\ \text { HARDIN STACK RUN } & 2 & 0.1 \mathrm{~N} & \mathrm{H} 2 \mathrm{SO} 4 \\ \text { HARDIN STACK RUN } & 2 & 0.1 \mathrm{~N} & \mathrm{NAOH} \\ \text { HARDIN STACK RUN } & 3 & 0.1 \mathrm{~N} & \mathrm{H} 2 \mathrm{SO} 4 \\ \text { HARDIN STACK RUN } & 3 & 0.1 \mathrm{~N} & \mathrm{NAOH}\end{array}$

$11 / 30 / 06 \quad 19: 28$

$11 / 30 / 06 \quad 19: 24$

12/01/06 18:23

$12 / 01 / 06 \quad 18: 19$

$12 / 02 / 06 \quad 22: 35$

12/02/06 22:26

\section{NOTE $(S):$}

- The analytical resuls of the sarmples fisted above are presented on the following pages.

- All calculations are performed before rounding to avoid round-off errors in calculated resulis.

- Results noted as "ND" were not detected at or above the stated limit.

- This report must not be reproduced, except in full, without the written approval of tie laboratory.

- Results for the following parameters ate never reported on a dry weight basis: color, corrosivity, density, nashpoint, ignitability, layers, odor. paint filter test, pH, porosity pressure, reactivity, redox potential, specific gravity, spot tests, solids, solubility, temperature, viscosity, and weight. 


\section{PROJECT NARRATIVE \\ H6L110105}

The results reported herein are applicable to the samples submitted for analysis only.

This report shall not be reproduced except in full, without the written approval of the laboratory.

\section{The original chain of custody documentation is included with this report.}

\section{Sample Receipt}

Custody seals were not present upon sample receipt at STL Knoxville.

\section{Quality Control and Data Interpretation}

Unless otherwise noted, all holding times and QC criteria were met and the test results shown in this report meet all applicable NELAC requirements.

Samples were analyzed for chloride $\left(\mathrm{Cl}^{*}\right)$, fluoride $\left(\mathrm{F}^{*}\right)$ and bromide $(\mathrm{Br})$ by ion chromatography using SOP number KNOX-WC-005 (based on EPA methods 9056, 9057 and 26A). Results for the $\mathrm{H}_{2} \mathrm{SO}_{4}$ impinger samples were reported as total $\mu \mathrm{g}$ hydrogen chloride $(\mathrm{HCl})$, total $\mu \mathrm{g}$ hydrogen fluoride $(\mathrm{HF})$ and total $\mu \mathrm{g}$ hydrogen bromide $(\mathrm{HBr})$. Results for the $\mathrm{NaOH}$ impinger samples were reported as total $\mu \mathrm{g}$ chlorine $\left(\mathrm{Cl}_{2}\right)$, total $\mu \mathrm{g}$ hydrogen fluoride (HF) and total $\mu \mathrm{g}$ hydrogen bromine $\left(\mathrm{Br}_{2}\right)$.

Please note that the halogen fluorine $(F)$ is not expected to be present in stack gas as diatomic fluorine $\left(\mathrm{F}_{2}\right)$. Fluorine reacts with water vapor in a favored reaction that forms $\mathrm{HF}: 2 \mathrm{~F}_{2}+2 \mathrm{H}_{2} \mathrm{O} \rightarrow 4 \mathrm{HF}+\mathrm{O}_{2}$. Therefore, the results from the $\mathrm{H}_{2} \mathrm{SO}_{4}$ impingers and the $\mathrm{NaOH}$ impingers are reported as $\mathrm{HF}$, and no $\mathrm{F}_{2}$ is expected in the samples.

Results were calculated using the following equations:

$\mathrm{HX}, \mathrm{ug}=\left(\mathrm{X}^{-}, \mathrm{ug} / \mathrm{mL}\right) *($ Sample Volume, $\mathrm{mL}) *\left(\frac{\text { Molecular Weight HX }}{\text { Molecular Weight } \mathrm{X}^{-}}\right) *($ Bench Dilution $)$

STL Knoxville maintains the following certifications, approvals and accreditations: Arkansas DEQ Cert. $405-043-0$, Califormia DHS ELAP Cert. \#2423, Colorado DPHE, Connecticut DPH Cert. \#PH^0223, Florida DOH Cert. \#E87177, Georgia DNR Cert. \#906, Hawaii DOH, Illinois EPA Cert. ${ }_{\pi} 000687$, Indiana DOH Cert. ${ }_{\pi}$ C-TN-02, Iowa DNR Cert. \#375, Kansas DHE Cert. \#E-10349, Kentucky DEP Lab ID \#90101, Louisiana DEQ Cert. \#03079, Louisiana DOHH Cert. \#LA030024, Maryland DHMH Cert. ${ }_{\pi}^{\prime 277, ~ M a s s a c h u s e t t s ~ D E P ~ C e r t . ~ \# M-T N 009, ~ M i c h i g a n ~ D E Q ~ L a b ~ I D ~}$ New Jersey DEP Cert. \#TN001, New York DOH Lab $\frac{\|}{\pi} 10781$, North Carolina DPH Lab ID $\frac{\Perp 1}{\pi 2} 1705$, North Carolina DEHNR Cert. \#64, Ohio EPA VAP Cert. \#CL0059, Oklahoma DEQ ID \#9415, Pennsylvania DEP Cert. \#68-00576, South Carolina DHEC Lab ID \#84001001, Tennessee DOH Lab ID \#02014, Utah DOH Cert. \# QUAN3, Virginia DGS Lab ID \#00165, Washington DOE Lab \#C120, West Virginia DEP Cert. \#345, Wisconsin DNR Lab ID \#998044300, Naval Facilities Engineering Service Center and USDA Soil Permit \#S-46424. This list of approvals is subject to change and does not imply that laboratory certification is available for all parameters reported in this environmental sample data report. 


\section{PROJECT NARRATIVE} H6L110105

$\mathrm{Cl}_{2}, \mathrm{Br} 2 \mathrm{ug}=\left(\mathrm{X}^{-}, \mathrm{ug} / \mathrm{mL}\right) *($ Sample Volume, $\mathrm{mL}) *($ Bench Dilution $)$

$\mathrm{NaOH}$ impinger samples were treated with sodium thiosulfate $\left(\mathrm{Na}_{2} \mathrm{~S}_{2} \mathrm{O}_{3}\right)$ prior to the final analysis in order to convert residual hypochlorite $\left(\mathrm{OCl}^{-}\right)$to chloride ion. The presence of hypobromite is also assumed to be converted to bromide under these conditions.

Note: A sample volume of $100 \mathrm{~mL}$ was used to convert the results to total $\mu \mathrm{g}$ for the method blanks, laboratory control samples, and client reagent blanks.

For demonstration of analytical method performance on these samples, STL Knoxville analyzed matrix spikes (MS) and matrix spike duplicates (MSD). Acceptable recoveries of these spikes demonstrate that quantitation from this particular stack gas matrix is accurate and acceptable. Impinger samples containing $0.1 \mathrm{~N} \mathrm{H}_{2} \mathrm{SO} 4$ and $0.1 \mathrm{~N} \mathrm{NaOH}$ display matrix interference effects causing poor method performance and possibly giving unreliable data unless the interference is removed. Therefore, the samples were diluted in the lab to remove the interference for a more accurate chloride response. The samples may be analyzed at increasing dilutions along with matrix spikes until matrix spikes recover from the sample within laboratory control limits. The ion chromatograph calibration range used to quantitate the sample results permits a standard ten-fold sample dilution while supporting the reporting limit with the low calibration standard.

The dilution factor reported on the sample result form does not represent the bench dilution factor. It is actually the combination of factors required by the method to convert the anion reporting limit and method detection limit from $\mu \mathrm{g} / \mathrm{mL}$ to total $\mu \mathrm{g}$. It may appear to be elevated because it includes the total sample volume in $\mathrm{mL}$.

STL Knoxville maintains the following certifications, approvals and accreditations: Arkansas DEQ Cert. California DHS ELAP Cert. \#2423, Colorado DPHE, Connecticut DPH Cert. \#PH-0223, Florida DOH Cert. \#E87177, Georgia DNR Cert. \#906, Hawaii DOH, Illinois EPA Cert. \#000687, Indiana DOH Cert. \#C-TN-02, lowa DNR Cert. \#375, Kansas DHE Cert. \#E-10349, Kentucky DEP Lab ID \#90101, Louisiana DEQ Cert. \#03079, Louisiana DOHH Cert. \#LA030024, Maryland DHMH Cert. \#277, Massachusetts DEP Cert. \#M-TN009, Michigan DEQ Lab ID \#9933, New Jersey DEP Cert. \#TN001, New York DOH Lab DEHNR Cert. \#64, Ohio EPA vAP Cert. \#CL0059, Oklahoma DEQ ID \#9415, Pennsylvania DEP Cert. \#68-00576, South Carolina DHEC Lab ID \#84001001, Tennessee DOH Lab ID \#02014, Utah DOH Cert. \# QUAN3, Virginia DGS

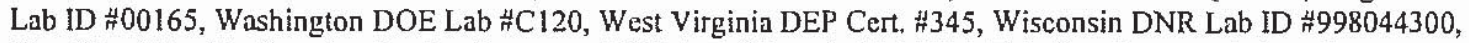
Naval Facilities Engineering Service Center and USDA Soil Permit \#S-46424. This list of approvals is subject to change and does not imply that laboratory certification is available for all parameters reported in this environmental sample data report. 
Sample Data Summary 
Air Sampling Associates, Inc.

Client Sample ID: HARDIN STACK RUN 1 0.IN H2SO4

General Chemistry

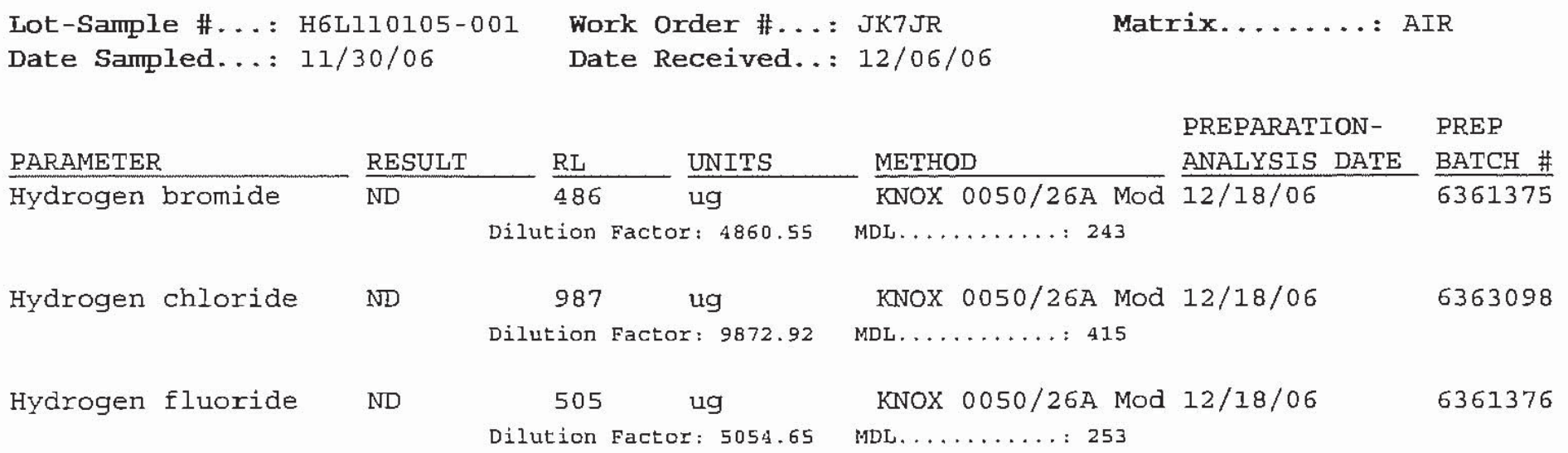


Air Sampling Associates, Inc.

client Sample ID: HARDIN STACK RON 1 0.1N NAOH

General Chemistry

Lot-Sample \#...: H6L110105-002

Date Sampled...: 11/30/06
Work Order \#...: JK7JW

Date Received. .: 12/06/06
Matrix....... A AIR

PREPARATION - PREP ANALYSIS DATE BATCH \#

PARAMETER RESULT $\underline{R L}$ UNITS METHOD KNOX 0050/26A Mod 12/18/06 MDL . . . . . . : 57.6 Dilution Factor: 2400

440 240

ug Dilution Factor: 2400

KNOX 0050/26A Mod 12/18/06

MDL......... 101

Hydrogen fluoride ND
6354402

6354401

6354400
253 ug Dilution Factor: 2527.32
KNOX 0050/26A Mod 12/18/06 MDL........ 126 
Aix Sampling Associates, Inc.

Client Sample ID: HARDIN STACK RON 2 0.IN H2SO4

General Chemistry

Lot-Sample \#... : H6L110105-003

Date Sampled...: 12/01/06
Work Ordex \#...: JK7JX

Date Received..: 12/06/06
Matrix....... : AIR

PREPARATION- PREP

ANALYSIS DATE BATCH \#

\section{PARAMETER}

RESULT

RL

UNITS

471

ug

Dilution Factor: 4708.65

KNOX 0050/26A Mod 12/18/06

MDL........ 235

Hydrogen chloride

ND

1910

ug

Dilution Factor: 19128.78

KNOX 0050/26A Mod 12/28/06

MDL........ 803

Hydrogen fluoride
ND
6361375

6363147

6361376 ug

Dilution Factor: 4896.69
KNOX 0050/26A Mod 12/18/06

MDL......... 245 
Air Sampling Associates, Inc.

Client Sample ID: HARDIN STACK RUN $20.1 \mathrm{~N}$ NAOH

General Chemistry

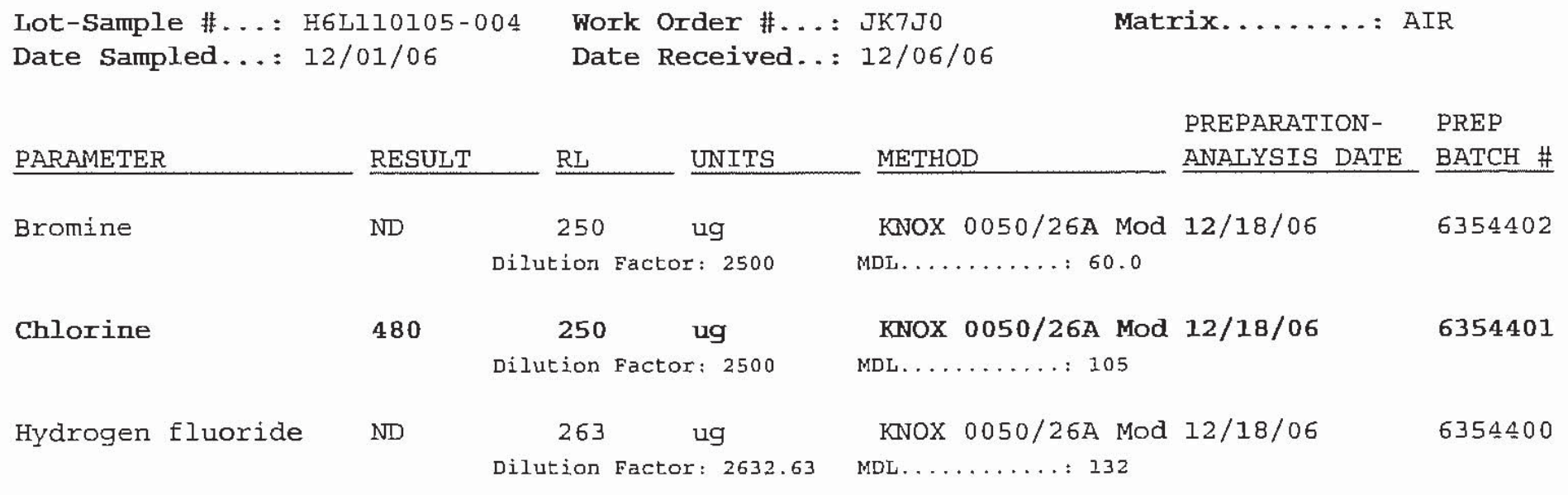


Air Sampling Associates, Inc.

Client Sample ID: HARDIN STACK RUN $3 \quad 0.1 \mathrm{~N}$ H2SO4

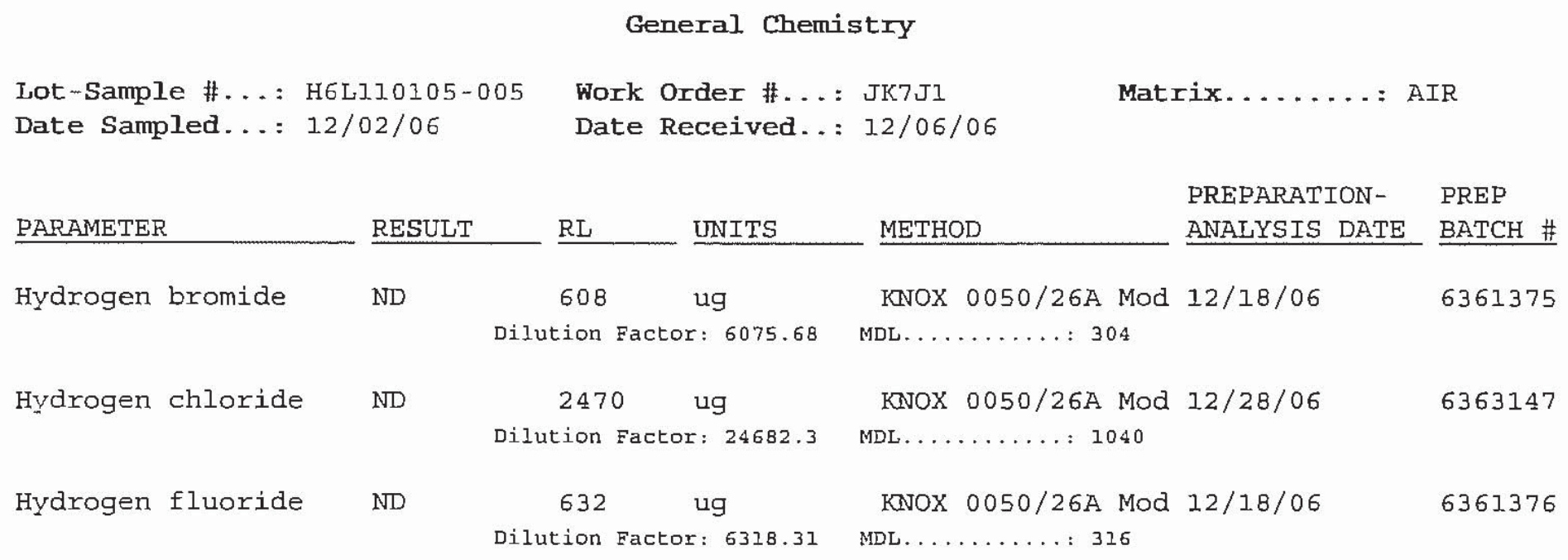


Air Sampling Associates, Inc.

Client Sample ID: HARDIN STACK RUN $3 \quad 0.1 \mathrm{~N}$ NAOH

General Chemistxy

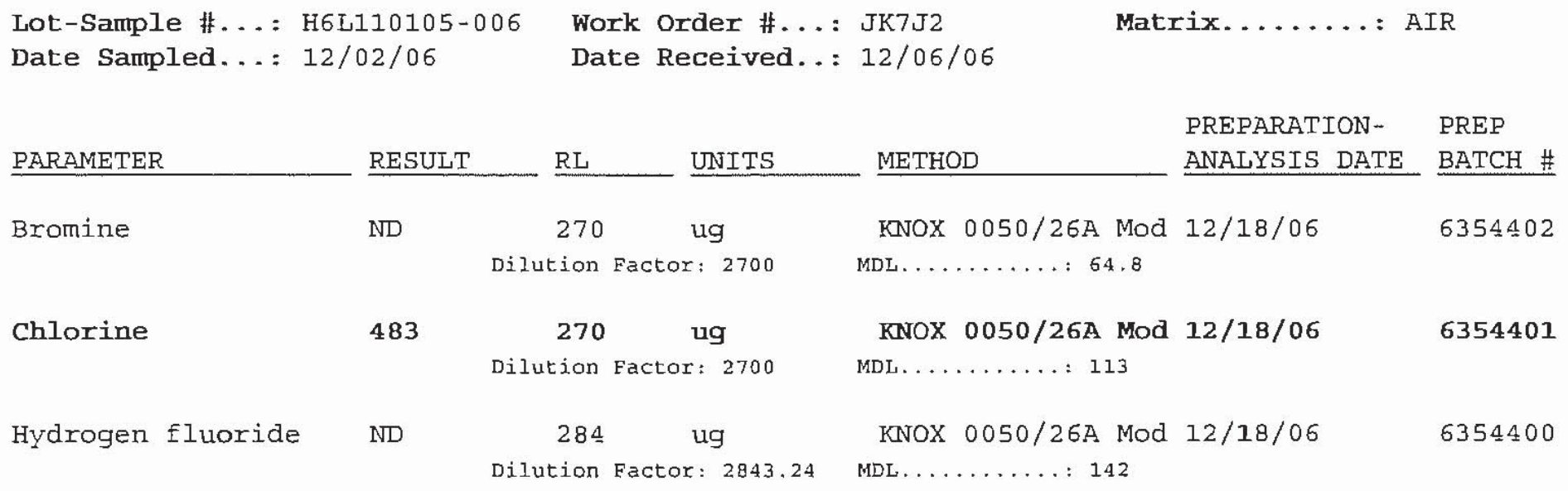




\section{METHOD BLANK REPPORT}

\section{General Chemistry}

Client Lot \#...: H6L110105

Matrix....... A AIR

\begin{tabular}{|c|c|c|c|c|c|}
\hline PARAMETER & RESULT & $\begin{array}{l}\text { REPORTING } \\
\text { LIMIT UNITS }\end{array}$ & METHOD & $\begin{array}{l}\text { PREPARATION- } \\
\text { ANALYSIS DATE }\end{array}$ & $\begin{array}{l}\text { PREP } \\
\text { BATCH \# }\end{array}$ \\
\hline \multirow[t]{3}{*}{ Bromine } & & Work Order \#: JLWCC1AA & MB Lot-Sample \#: & H6L $200000-402$ & \\
\hline & ND & $10.0 \quad$ ug & KNOX $0050 / 26 \mathrm{~A}$ Mod & $12 / 18 / 06$ & 6354402 \\
\hline & & Dilution Factor: 100 & & & \\
\hline \multirow[t]{3}{*}{ Chlorine } & & Work Order \#: JLWAA1AA & MB Lot-Sample \#: & $\mathrm{H} 6 \mathrm{~L} 200000-401$ & \\
\hline & ND & $10.0 \quad$ ug & KNOX $0050 / 26 \mathrm{~A}$ Mod & $12 / 18 / 06$ & 6354401 \\
\hline & & Dilution Factor: 100 & & & \\
\hline \multirow[t]{3}{*}{ Hydrogen bromide } & & Work Order \#: JL69F1AA & MB Lot-Sample \#: & $\mathrm{H} 6 \mathrm{~L} 270000-375$ & \\
\hline & ND & $10.1 \quad$ ug & KNOX $0050 / 26 \mathrm{~A}$ Mod & $12 / 18 / 06$ & 6361375 \\
\hline & & Dilution Factor: 101.2 & & & \\
\hline \multirow[t]{3}{*}{ Hydrogen chloride } & & Work Order \#: JL8TM1AA & MB Lot-Sample \#: & H6L $290000-098$ & \\
\hline & ND & $10.3 \quad$ ug & KNOX $0050 / 26 \mathrm{~A}$ Mod & $12 / 18 / 06$ & 6363098 \\
\hline & & Dilution Factor: 102.8 & & & \\
\hline \multirow[t]{3}{*}{ Hydrogen chloride } & & Work Order \#: JL9AA.AAA. & MB Lot-Sample \#: & H6I $290000-147$ & \\
\hline & ND & $10.3 \quad$ ug & KNOX $0050 / 26 \mathrm{~A}$ Mod & $12 / 28 / 06$ & 6363147 \\
\hline & & Dilution Factor: 102.8 & & & \\
\hline \multirow[t]{3}{*}{ Hydrogen fluoride } & & Work order \#: JLV9M1AA & MB Lot-Sample \#: & $\mathrm{H} 6 \mathrm{~L} 200000-400$ & \\
\hline & ND & $10.5 \quad$ ug & KNOX $0050 / 26 \mathrm{~A}$ Mod & $12 / 18 / 06$ & 6354400 \\
\hline & & Dilution Factor: 105.3 & & & \\
\hline \multirow[t]{2}{*}{ Hydrogen fluoride } & & Work Order \#: JL69G1AA & MB Lot-Sample \#: & $\mathrm{H} 6 \mathrm{~L} 270000-376$ & \\
\hline & ND & $10.5 \quad$ ug & KNOX $0050 / 26 \mathrm{~A}$ Mod & $12 / 18 / 06$ & 6361376 \\
\hline
\end{tabular}

NOTE (5) :

Catculations are performed before rounding to avoid round-off errors in calculated results. 
LABORATORY CONTROL SAMPLE EVALUATION REPORT

General Chemistry

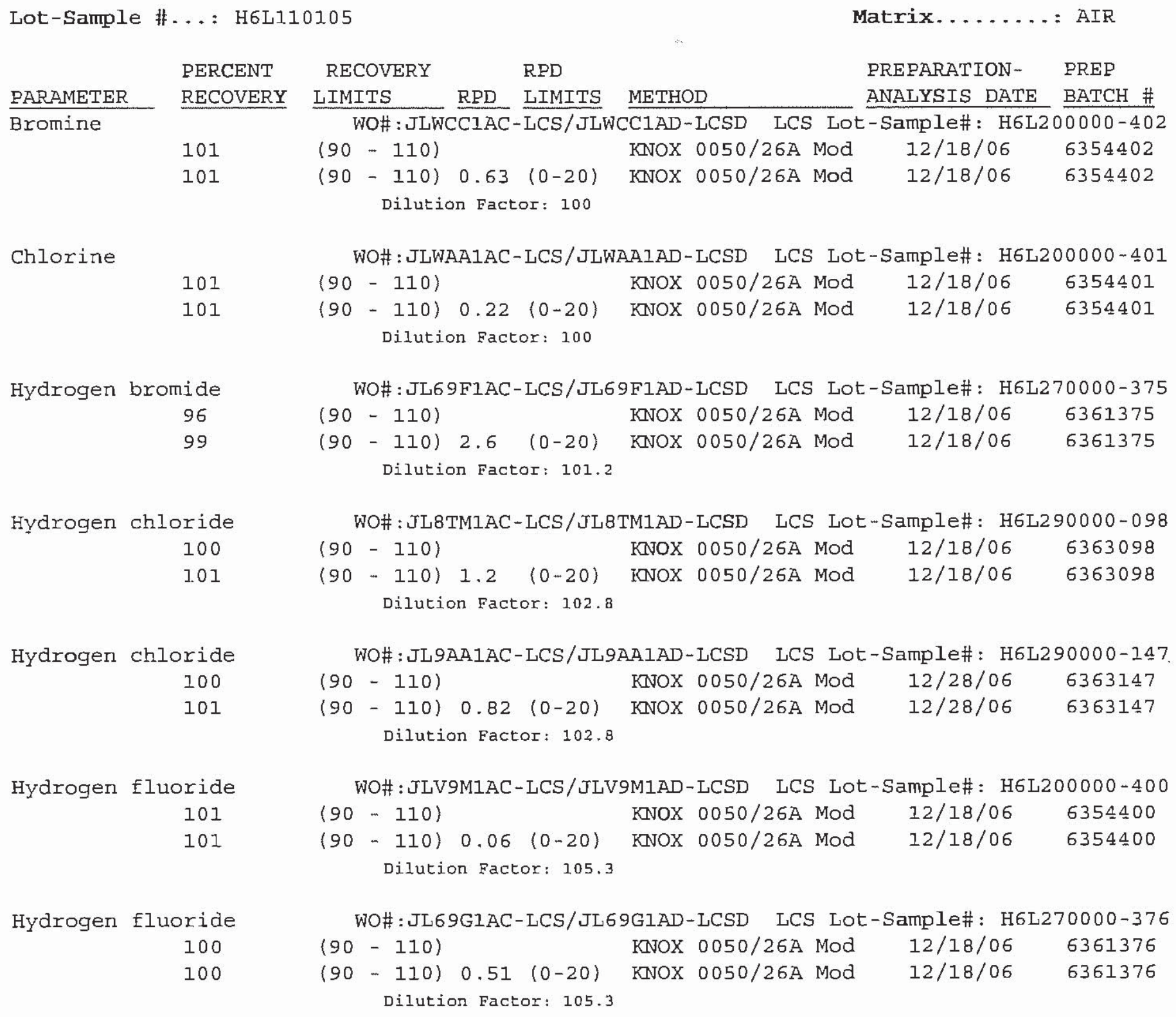

NOTE (S) :

Calculations are performed before rounding to avoid round-aff errors in calculated results. 


\section{IAABORATORY CONTROL SAMPLE DATA REPORT}

General Chemistry

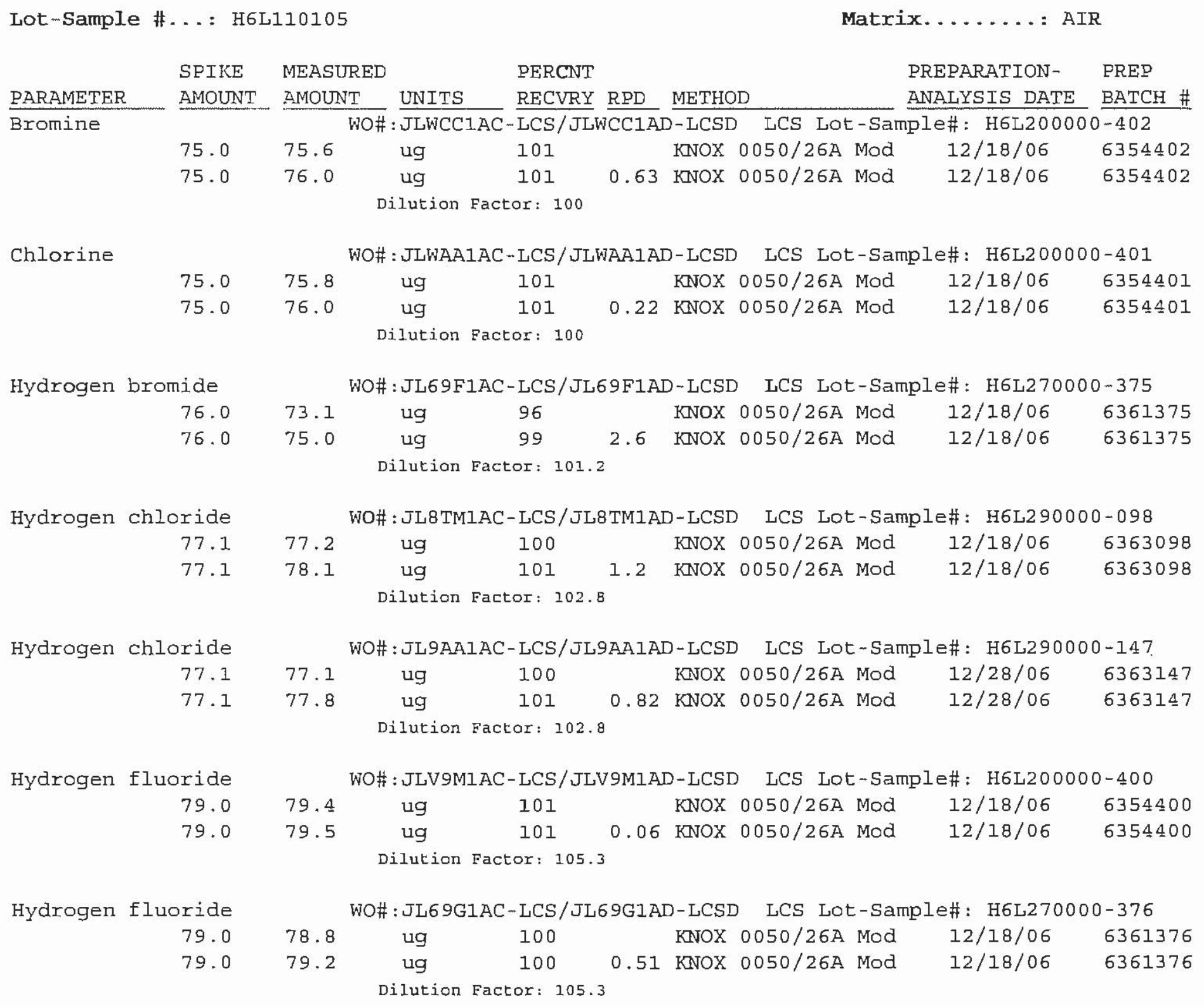

NOTE (S) :

Calcuiations are performed before rounding to avoid round-off errors in calculated results. 
MATRIX SPIKE SAMPLB EVALUATION REPORT

General Chemistry

Client Lot \#...: H6L110105

Date Sampled...: 11/30/06
Date Received. : : 12/06/06

PERCENT RECOVER

PARAMETER

Hydrogen chloride

RECOVERY

105
LIMITS

Work Order \#...: JK7JRIAJ

$(75$ - 125) KNOX 0050/26A Mod

Dilution Factor: 9872 .
Matrix....... AIR

PREPARATION- PREP

ANALYSIS DATE BATCH \#

MS Lot-Sample \#: H6L110105-001

$12 / 18 / 06 \quad 6363098$

NOTE (S) :

Calculations are performed before rounding to avoid round-off errors in calculated results. 
MATRIX SPIKE SAMPLE DATA REPORT

\section{General Chemistry}

Client Lot \#...: H6L110105

Date Sampled...: 11/30/06

SAMPLE SPIKE
PARAMETER AMOUNT AMT

Hydrogen chloride

ND

1970

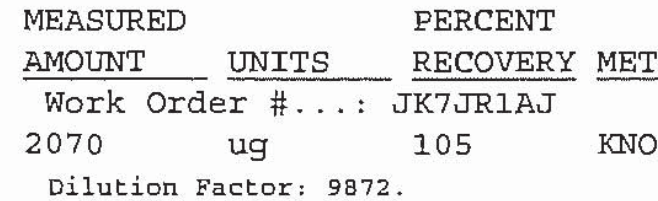

Date Received..: 12/06/06

Matrix....... AIR

PREPARATION - PREP ANALYSIS DATE BATCH \#

MS Lot-Sample \#: H6L110105-001

NOX $0050 / 26 \mathrm{~A} \quad 12 / 18 / 06 \quad 6363098$

NOTE (S) :

Calculations are performed before rounding to avoid round-off errors in calculated tesults. 
MATRIX SPIKE SAMPIE EVALUATION REPORT

General Chemistry

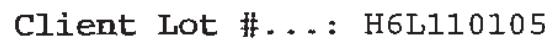

Date Sampled...: 12/01/06
Date Received..: 12/06/06
Matrix....... : AIR

PREPARATION- PREP ANALYSIS DATE BATCH \#

PARAMETER PERCENT RECOVERY

RPD RPD LIMITS METHOD WO\#: JK7JW1AJ-MS/JK7JW1AK-MSD MS Lot-Sample \#: H6L11.0105-002

Bromine RECOVERY LIMITS

$(75-125)$
KNOX 0050/26A Mod

$12 / 18 / 06$

$12 / 18 / 06$ 6354402

$\begin{array}{lll}(75-125) & 3.2 \quad(0-20)\end{array}$ KNOX 0050/26A Mod Dilution Factor: 2400

Chlorine

114

118

Hydrogen bromide 94 94

Hydrogen chloride 109 99

Hydrogen fluoride 103 104

Hydrogen fluoride 99 98
WO\#: JK7JWIAG-MS/JK7JWIAH-MSD MS Lot-Sample \#: H6L110105-002 $(75$ - 125) KNOX 0050/26A Mod 12/18/06 $(75-125) 1.8(0-20)$ KNOX 0050/26A Mod 12/18/06 6354401 6354401 Dilution Factor: 2400

\section{2}

WO\#: JK7JR1AE-MS/JK7JR1AF-MSD MS Lot-Sample \#: H6L110105-001

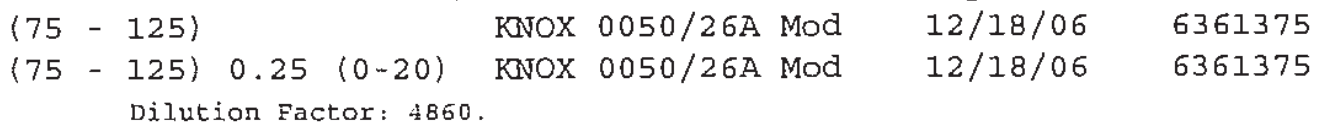

WO\#: JK7JXIAE-MS/JK7JX1AF-MSD MS Lot-Sample \#: H6L110105-003 $(75$ - 125) KNOX 0050/26A Mod 12/28/06 6363147

$(75-125) 9.9(0-20) \quad$ KNOX 0050/26A Mod 12/28/06 6363147

Dilution Factor: 19128

WO\#: JK7JRIAG-MS/JK7JRIAH-MSD MS Lot-Sample \#: H6L110105-001

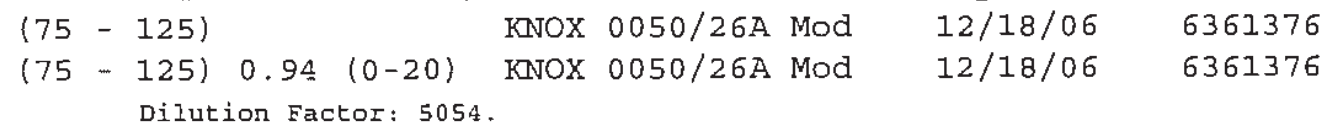

NOTE $(S):$

Caleulations are perforned before rounding to avoid round-off errors in calculated results. 


\section{MATRIX SPIKE SAMPLE DATA REPORT}

\section{General Chemistry}

Client Lot \#...: H6L110105

Date Sampled...: 12/01/06
Date Received..: 12/06/06
Matrix....... AIR

PREPARATION - PREP ANALYSIS DATE BATCH \# AMOUNT UNITS RECVRY RPD METHOD WO\#: JK7JW1AJ-MS/JK7JWIAK-MSD MS Lot-Sample \#: H6L110105-002 $510 \mathrm{ug} \quad 106 \quad \mathrm{KNOX} 0050 / 26 \mathrm{~A} \quad 12 / 18 / 06 \quad 6354402$ 494 ug $\quad 103 \quad 3.2$ KNOX 0050/26A $\quad 12 / 18 / 06 \quad 6354402$ Dilution Factor: 2400

WO\#: JK7JW1AG-MS/JK7JW1AH-MSD MS Lot-Sample \#: H6L110105-002 987 ug $\quad 114 \quad$ KNOX 0050/26A $\quad 12 / 18 / 06 \quad 6354401$ $1000 \mathrm{ug} \quad 118 \quad 1.8 \quad \mathrm{KNOX} 0050 / 26 \mathrm{~A} \quad 12 / 18 / 06 \quad 6354401$

Dilution Factor: 2400

WO\#: JK7JR1AE-MS/JK7JR1AF-MSD MS Lot-Sample \#: H6L110105-001

\begin{tabular}{|c|c|c|c|c|c|c|c|}
\hline 913 & ug & 94 & & KNOX & $0050 / 26 \mathrm{~A}$ & $12 / 18 / 06$ & 6361375 \\
\hline 910 & ug & 94 & 0.25 & KNOX & $0050 / 26 \mathrm{~A}$ & $12 / 18 / 06$ & 6361375 \\
\hline
\end{tabular}

Hydrogen chloride ND $\quad 3830$ $\mathrm{ND} \quad 3830$

WO\#: JK7JX1AE-MS/JK7JX1AF-MSD MS Lot-Sample \#: H6L110105-003 $\begin{array}{llllll}4170 & \text { ug KNOX } & 0050 / 26 \mathrm{~A} & 12 / 28 / 06 & 6363147\end{array}$

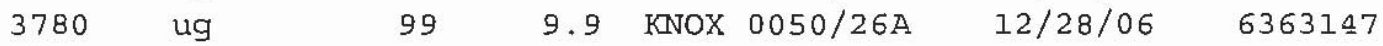

Dilution Factor: 19128

Hydrogen fluoride ND 1010

WO\#: JK7JR1AG-MS/JK7JR1AH-MSD MS Lot-Sample \#: H6L110105-001. ND $\quad 1010$

1040 ug 103

104 KNOX 0050/26A $12 / 18 / 06$ $12 / 18 / 06$ 6361376 Dilution Eactor: 5054. 0.94 KNOX 0050/26A 6361376
Hydrogen fluoride $\begin{array}{ll}\text { ND } & 505 \\ \text { ND } & 505\end{array}$
WO\#: JK7JW1AE-MS/JK7JW1AF-MSD MS Lot-Sample \#: H6L110105-002

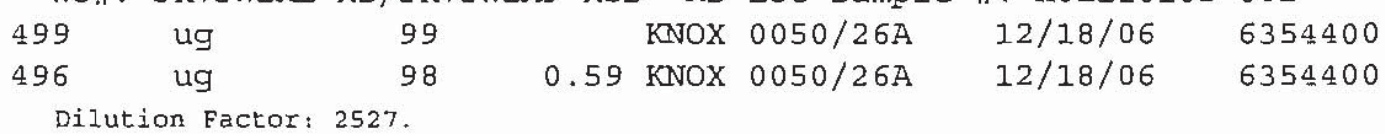

NOTE $(S)$ :

Calculations are performed before rounding to avoid round-off errots in calculated results. 
Sample Receipt Documentation 


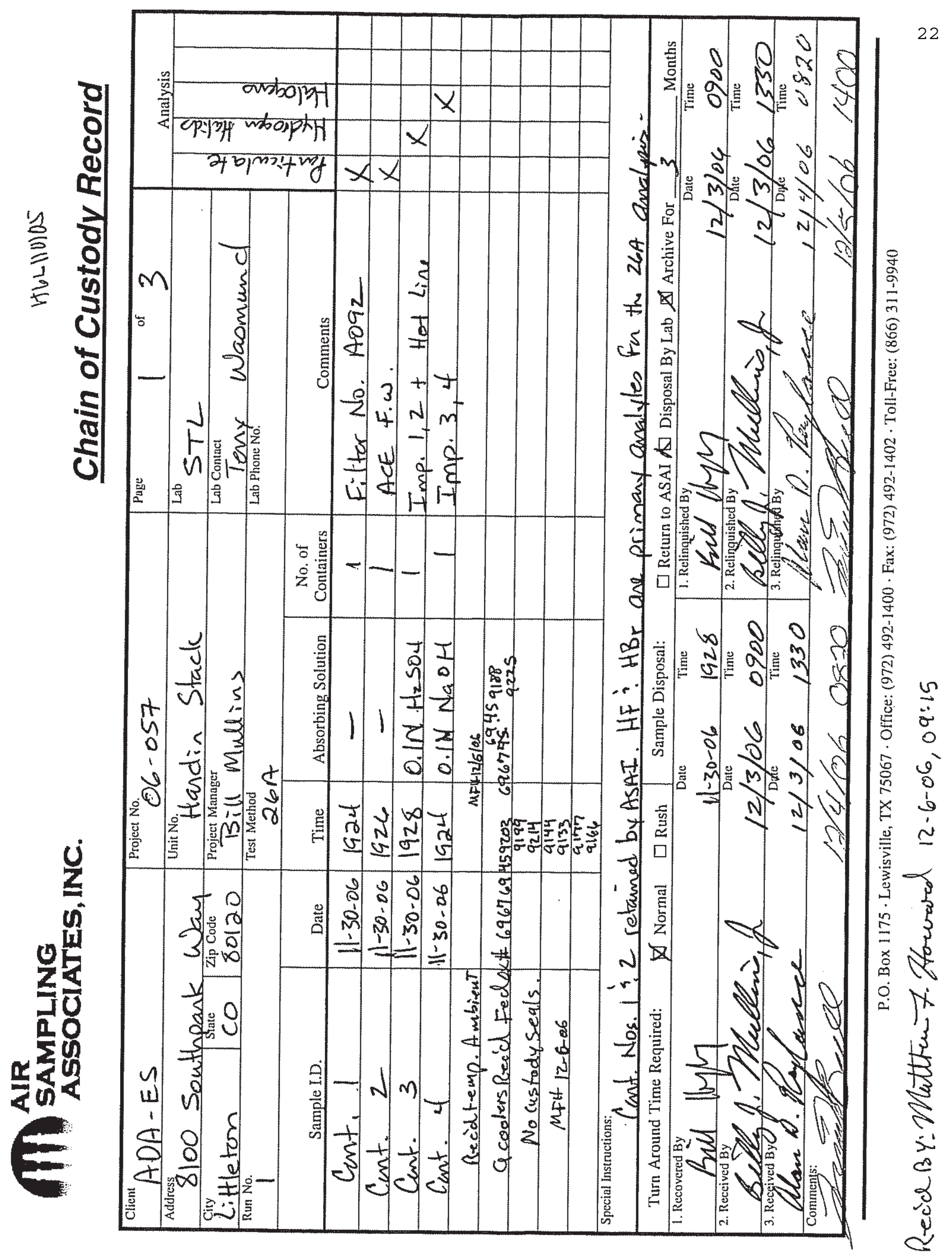




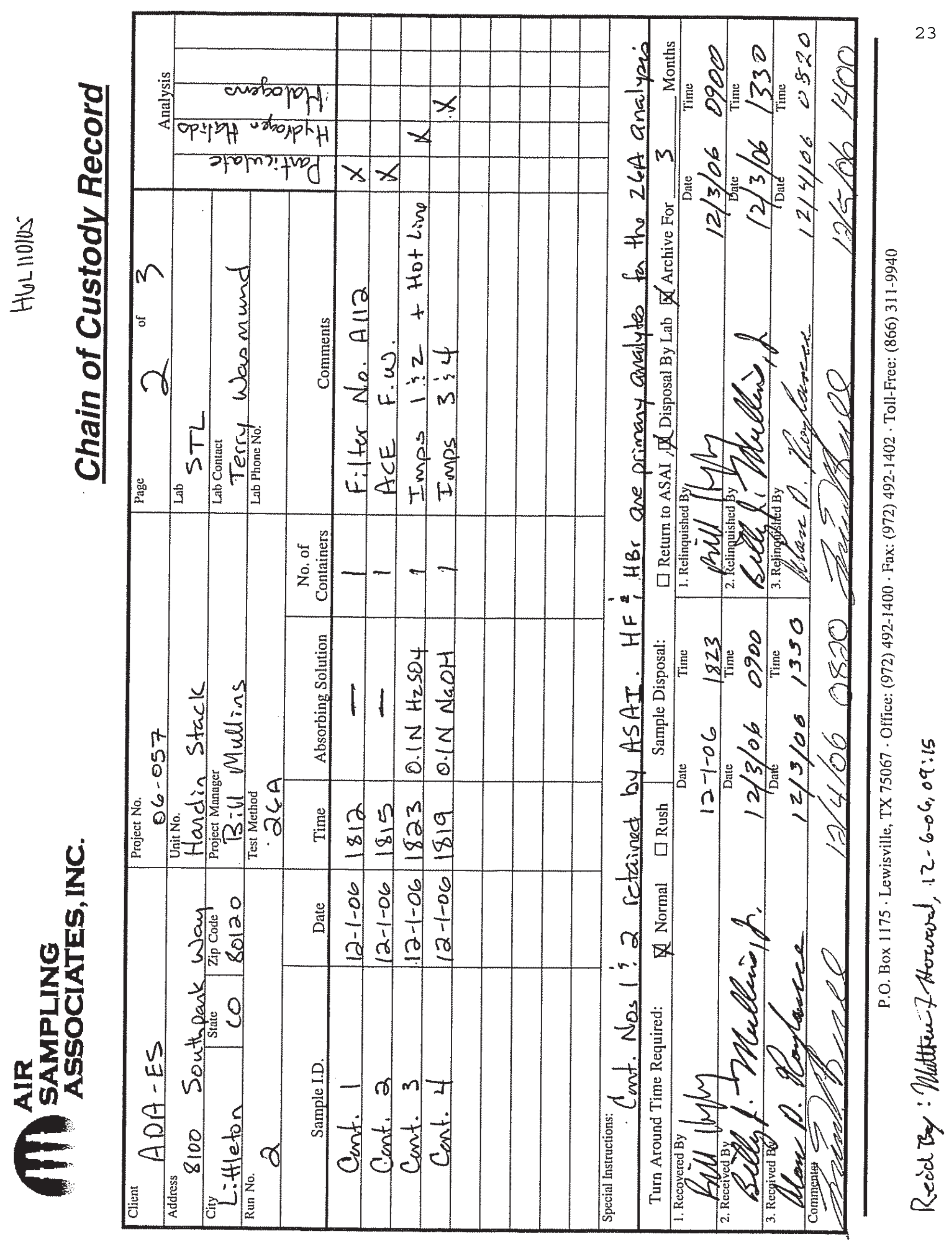




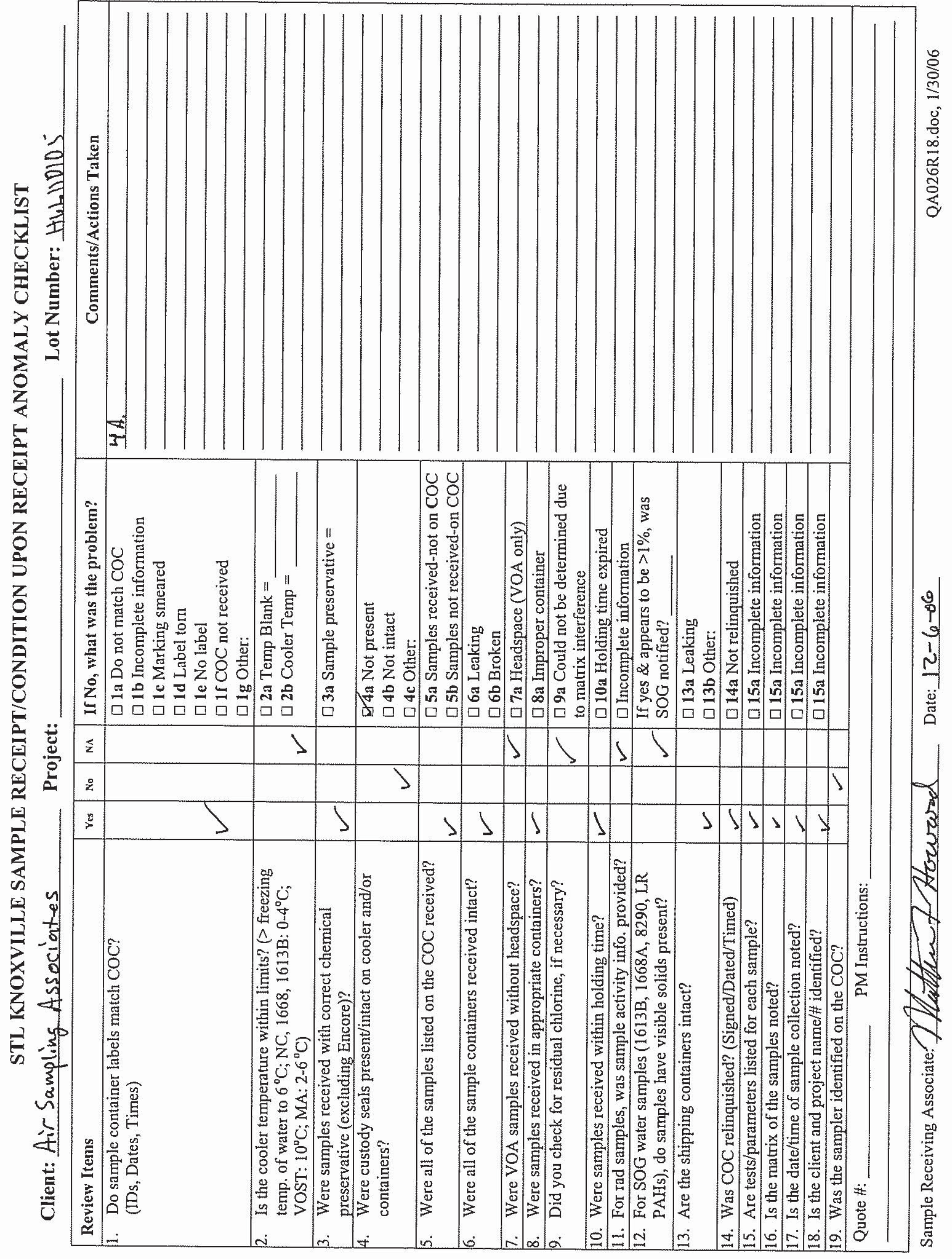


Wet Chemistry 
Sample Summary 
Air Sampling Associates, Inc.

Client Sample ID: HARDIN STACK RUN 10. IN H2SO4

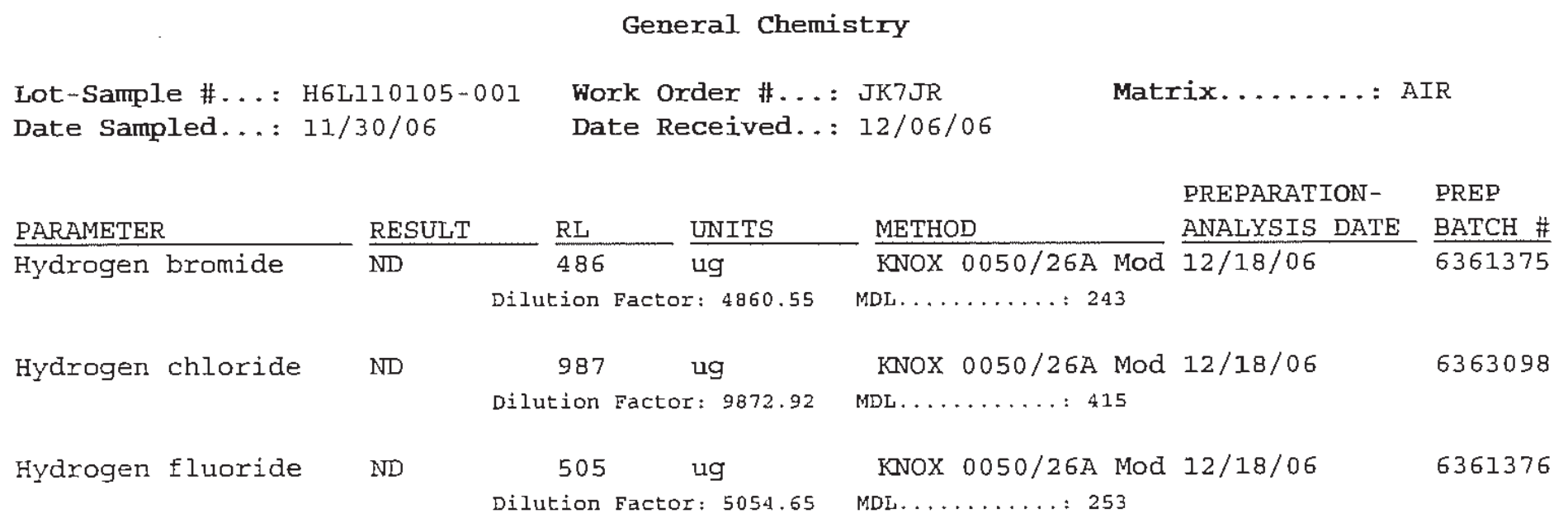


Air Sampling Associates, Inc.

Client Sample ID: HARDIN STACK RUN 1 0.IN NAOH

General Chemistry

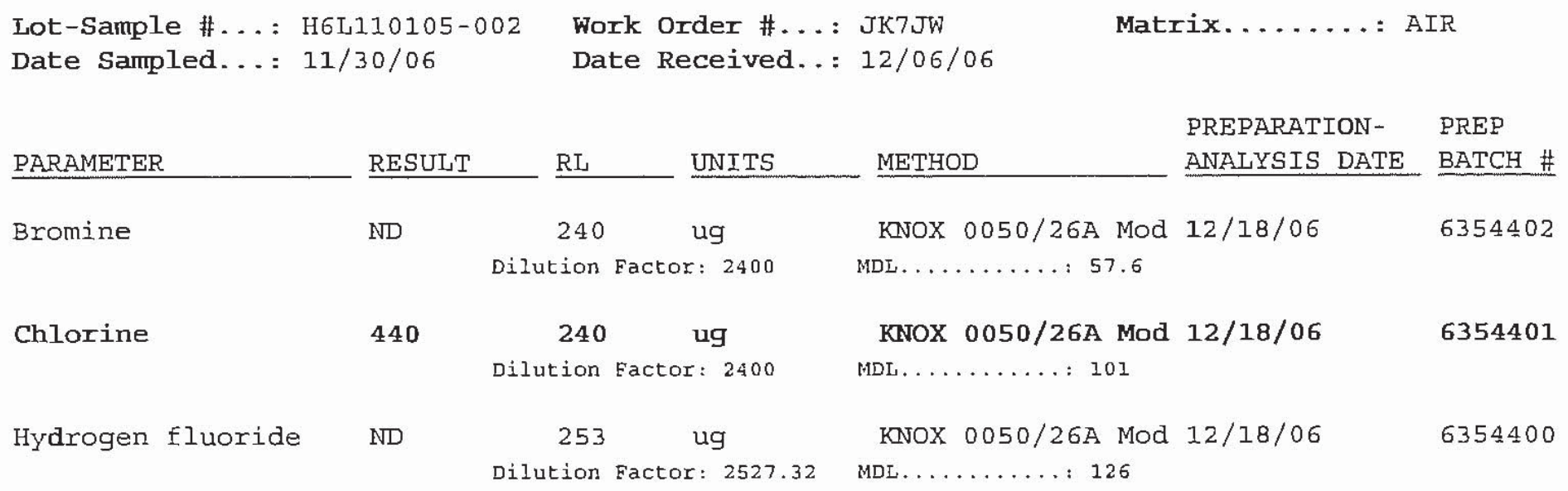


Air Sampling Associates, Inc.

Client Sample ID: HARDIN STACK RUN 2 0.IN H2SO4

General Chemistry

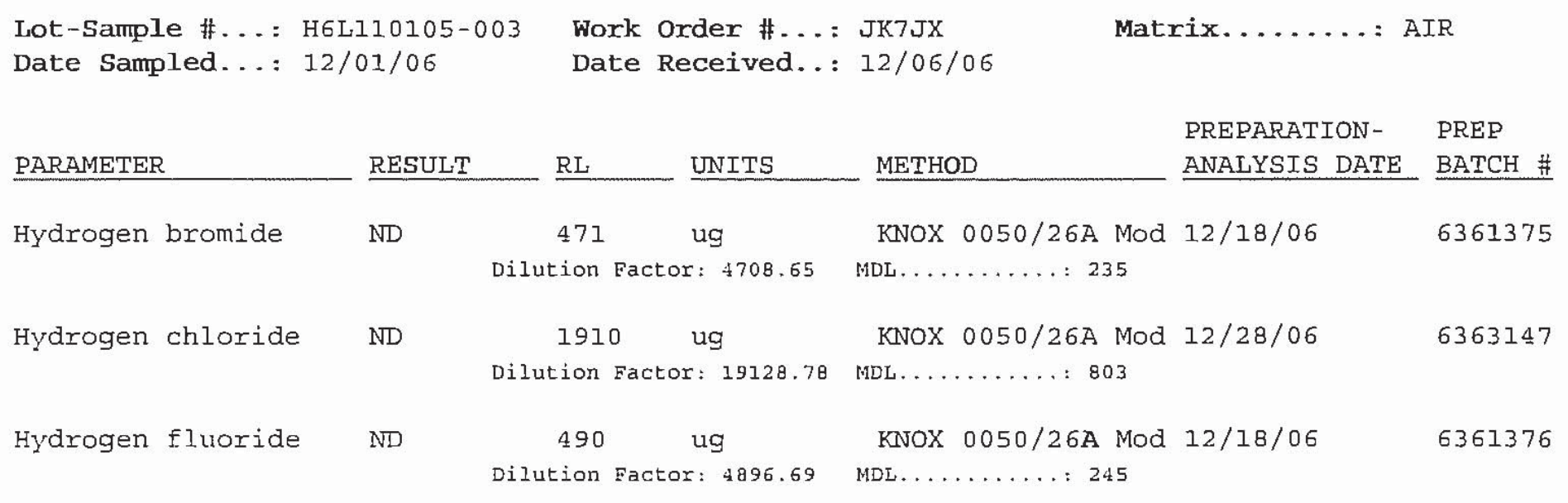


Air Sampling Associates, Inc.

Client Sample ID: HARDIN STACK RUN $20.1 \mathrm{~N}$ NAOH

General Chemistry

Lot-Sample \#...: H6L110105-004

Date Sampled...: 12/01/06
Work Order \#...: JK7J0

Date Received..: 12/06/06
Matrix....... AIR

PREPARATION - PREP ANALYSIS DATE BATCH \#

PARAMETER

RESULT

RI UNITS

METHOD

KNOX $0050 / 26 A$ Mod $12 / 18 / 06$ MDL . ....... 60.0

Dilution Factor: 2500

480

250

ug

Dilution Factor: 2500

KNOX 0050/26A Mod 12/18/06

MDL......... 105

Hydrogen fluoride ND
6354402

6354401

6354400
$263 \mathrm{ug}$

Dilution Factor: 2632.63
KNOX 0050/26A Mod 12/18/06 MDL......... 132 
Air Sampling Associates, Inc.

Client Sample ID: HARDIN STACK RUN 3 O.IN H2SO4

General Chemistry

Lot-Sample \#...: H6L110105-005

Date Sampled...: 12/02/06
Work Order \#...: JK7JI

Date Received. . : 12/06/06
Matrix.......: AIR

PREPARATION- PREP ANALYSIS DATE BATCH \#

\section{PARAMETER} RESULT

$\underline{R L}$ UNITS

METHOD

KNOX 0050/26A Mod 12/18/06 MDL......., : : 304

Hydrogen bromide

Hydrogen chloride

Hydrogen fluoride
$\mathrm{ND}$

ND

ND
$608 \quad u g$ Dilution Factor: $6075.6 \mathrm{~B}$

2470

$\mathrm{ug}$

$632 \mathrm{ug}$

Dilution Factor: 6318.31
Dilution Factor: 24682.3
KNOX 0050/26A Mod 12/28/06

MDL. . . . . . . 1040

KNOX 0050/26A Mod 12/18/06 MDL . . . . . . . 316
6361375

6363147

6361376 
Air Sampling Associates, Inc.

Client Sample ID: HARDIN STACK RUN 3 o.IN NAOH

General Chemistry

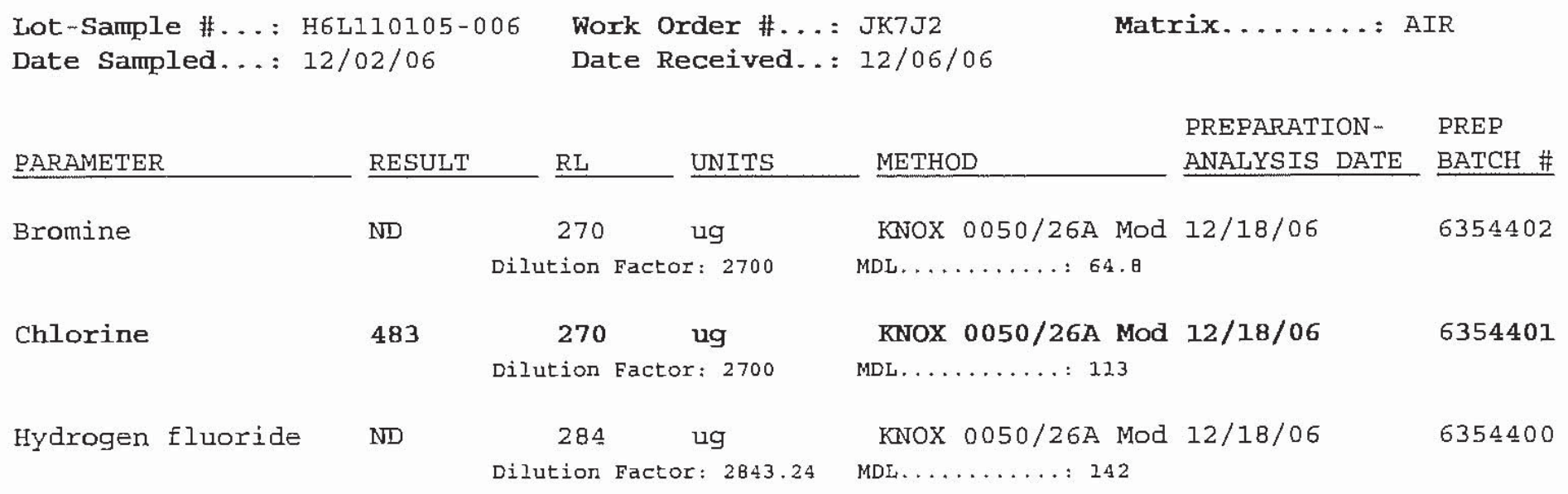


QC Summary 
Client Lot \#...: H6LI10105
Matrix....... AIR

\begin{tabular}{|c|c|c|c|c|c|}
\hline PARAMETER & RESULT & $\begin{array}{l}\text { REPORTING } \\
\text { LIMIT UNITS }\end{array}$ & METHOD & $\begin{array}{l}\text { PREPARATION- } \\
\text { ANALYSIS DATE }\end{array}$ & $\begin{array}{l}\text { PREP } \\
\text { BATCH \# }\end{array}$ \\
\hline Bromine & $\mathrm{ND}$ & $\begin{array}{l}\text { Work Order \#: JLWCCIAA } \\
10.0 \text { ug } \\
\text { Dilution Eactor: } 100\end{array}$ & $\begin{array}{l}\text { MB Lot-Sample \#: } \\
\text { KNOX } 0050 / 26 \mathrm{~A} \text { Mod }\end{array}$ & $\begin{array}{l}\mathrm{H} 6 \mathrm{~L} 200000-402 \\
12 / 18 / 06\end{array}$ & 6354402 \\
\hline Chlorine & $\mathrm{ND}$ & $\begin{array}{l}\text { Work Order \#: JLWAAIAA } \\
10.0 \text { ug } \\
\text { Dilution Factor: } 100\end{array}$ & $\begin{array}{l}\text { MB Lot-Sample \#: } \\
\text { KNOX 0050/26A Mod }\end{array}$ & $\begin{array}{l}\text { H6L } 200000-401 \\
12 / 18 / 06\end{array}$ & 6354401 \\
\hline Hydrogen bromide & $\mathrm{ND}$ & $\begin{array}{l}\text { Work order \#: JL69F1AA } \\
10.1 \text { ug } \\
\text { Dilution Factor: } 101.2\end{array}$ & $\begin{array}{l}\text { MB Lot-Sample \#: } \\
\text { KNOX 0050/26A Mod }\end{array}$ & $\begin{array}{l}\text { H } 6 \text { L } 270000-375 \\
12 / 18 / 06\end{array}$ & 6361375 \\
\hline Hydrogen chloride & $\mathrm{ND}$ & $\begin{array}{l}\text { Work Order \#: JL8TM1AA } \\
10.3 \text { ug } \\
\text { Dilution Factor: } 102.8\end{array}$ & $\begin{array}{l}\text { MB Lot-Sample \#: } \\
\text { KNOX 0050/26A Mod }\end{array}$ & $\begin{array}{l}\text { H6L290000-098 } \\
12 / 18 / 06\end{array}$ & 6363098 \\
\hline Hydrogen chloride & ND & $\begin{array}{l}\text { Work Order \#: JL9AAlAA } \\
10.3 \text { ug } \\
\text { Dilution Factor: } 102.8\end{array}$ & $\begin{array}{l}\text { MB Lot-Sample \#: } \\
\text { KNOX 0050/26A Mod }\end{array}$ & $\begin{array}{l}\text { H } 6 \text { L } 290000-147 \\
12 / 28 / 06\end{array}$ & 6363147 \\
\hline Hydrogen fluoride & ND & $\begin{array}{l}\text { Work Order \#: JLV9M1AA } \\
10.5 \text { ug } \\
\text { Dilution Factor: } 105.3\end{array}$ & $\begin{array}{l}\text { MB Lot-Sample \#: } \\
\text { KNOX 0050/26A Mod }\end{array}$ & $\begin{array}{l}\text { H } 6 \mathrm{~L} 200000-400 \\
12 / 18 / 06\end{array}$ & 6354400 \\
\hline Hydrogen fluoride & ND & $\begin{array}{l}\text { Work Order \#: JL69GIAA } \\
10.5 \text { ug } \\
\text { Dilution Factor: } 105.3\end{array}$ & $\begin{array}{l}\text { MB Lot-Sample \#: } \\
\text { KNOX 0050/26A Mod }\end{array}$ & $\begin{array}{l}\mathrm{H} 6 \mathrm{~L} 270000-376 \\
12 / 18 / 06\end{array}$ & 6361376 \\
\hline
\end{tabular}

NOTE (S) :

Calculations are performed beforc rounding to avoid round-off crrors in calculated results. 
LABORATORY CONTROL SAMPLIS EVALUATION REPORT

General Chemistry

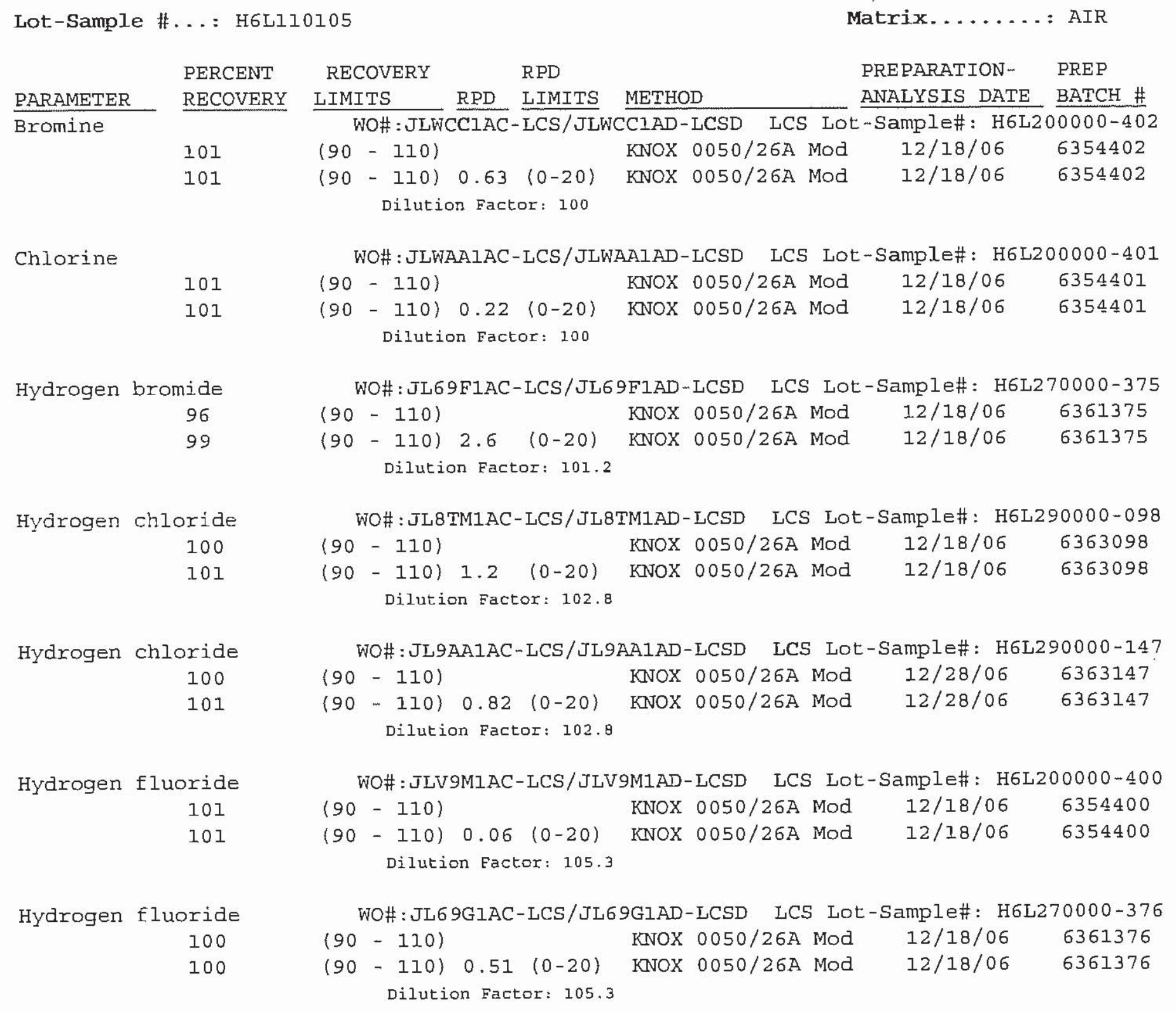

NOTE (S) :

Calculations are performed before rounding to avoid round-off errors in calculated results. 


\section{LABORATORY CONTROL SAMPLE DATA REPORT}

\section{General Chemistry}

Lot-Sample \#...: H6L110105

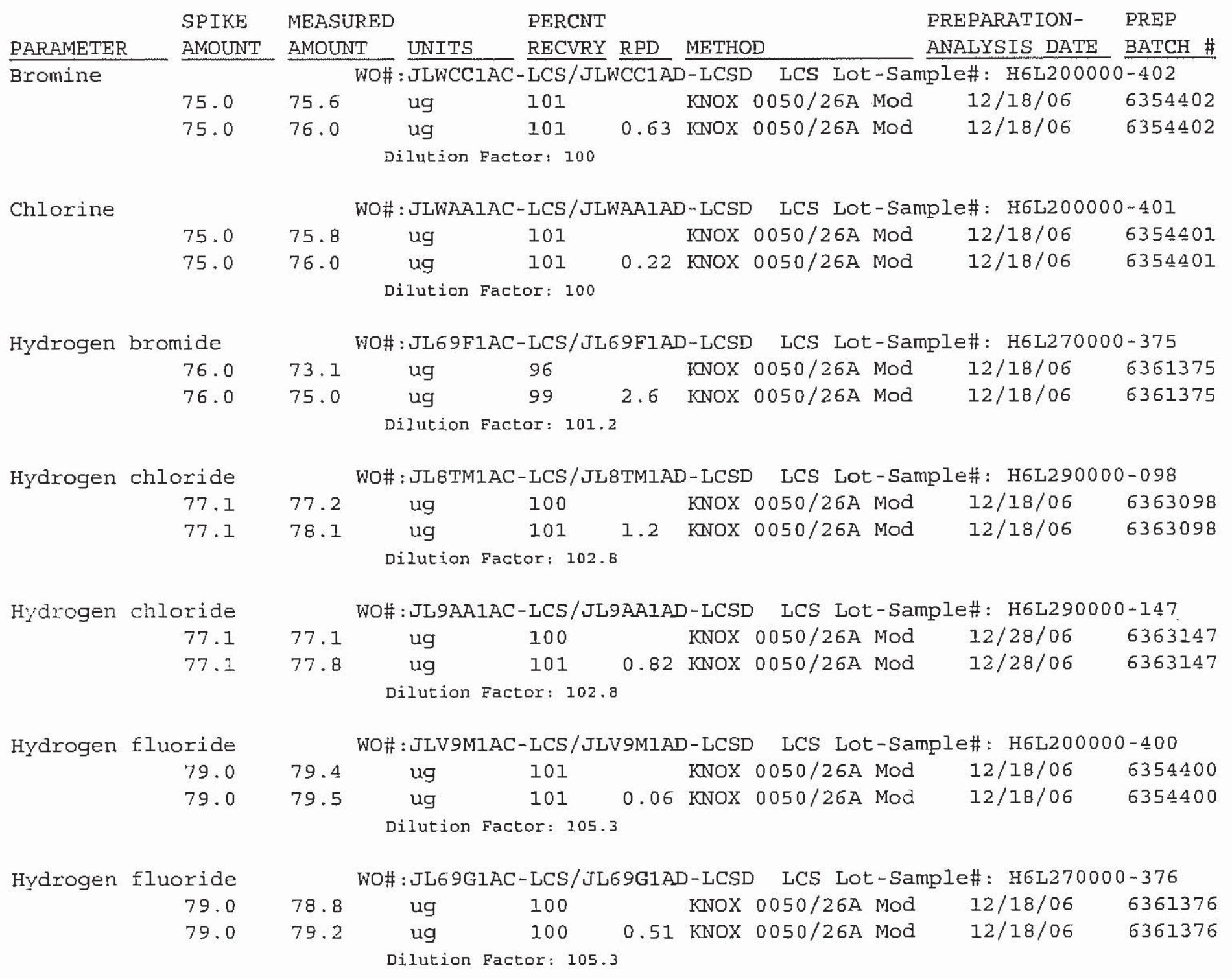


MATRIX SPIKE SAMPLE EVALUATION REPORT

General Chemistry

Client Lot \#... : H6L110105

Date Sampled...: 11/30/06

$\begin{array}{ll}\text { PARAMETER } & \text { PERCENT } \\ \text { Hydrogen chloride } & \text { RECOVERY } \\ \text { Hyd }\end{array}$

Date Received. .: 12/06/06

\begin{tabular}{|c|c|c|c|}
\hline RECOVERY & & PREPARATION- & PREP \\
\hline LIMITS & METHOD & ANALYSIS DATE & BATCH \# \\
\hline $\begin{array}{l}\text { Work Order } \\
(75-125)\end{array}$ & $\begin{aligned} \# \ldots . . & \text { JK7JRIAJ } \\
\text { KNOX } & 0050 / 26 \mathrm{~A} \text { MOd }\end{aligned}$ & $\begin{array}{l}\text { MS Lot-Sample } \\
12 / 18 / 06\end{array}$ & $\begin{array}{l}\text { \#: H6L110105-001 } \\
6363098\end{array}$ \\
\hline
\end{tabular}

Matrix....... A AIR

Dilution Factor: 9872.

NOTE (S) :

Calculations are performed hefore rounding to avoid round-off errors in calcufated results. 


\section{MATRIX SPIKE SAMPLE DATA REPOR'T}

\section{General Chemistry}

Client Lot \#...: H6L110105

Date Sampled...: 11/30/06

SAMPLE SPIKE
PARAMETER AMOUNT AMT

Hydrogen chloride

ND

1970

\section{ME}

Work Order $\#$ : JK7JR1AJ

Date Received..: 12/06/06
Matrix....... AIR

PREPARATION- PREP ANALYSIS DATE BATCH \#

MS Lot-Sample \#: H6L110105-001.

2070 ug 105 KNOX $0050 / 26 \mathrm{~A} \quad 12 / 18 / 06 \quad 6363098$

NOTE (S) :

Calculations are performed before tounding to avoid round-off errors in calculated results. 


\section{MATRIX SPIKF SAMPLE BVALUATION REPORT}

\section{General Chemistry}

Client Lot \#...: H6L110105

Date sampled...: 12/01/06
Date Received..: 12/06/06
Matrix....... AIR

PREPARATION- PREP ANALYSIS DATE BATCH \#

PARAMETER PERCENT RECOVERY

RPD RPD LIMITS METHOD WO\#: JK7JW1AJ-MS/JK7JW1AK-MSD MS Lot-Sample \#: H6L110105-002

Bromine RECOVERY LIMITS KNOX 0050/26A Mod

$12 / 18 / 06$ 6354402

106

$(75-125)$

KNOX 0050/26A Mod

$12 / 18 / 06$ 6354402 Dilution Factor: 2400

Chlorine

114 WO\# : JK7JWIAG-MS/J

$(75-125)$

JK7JWIAH-MSD MS L
KNOX 0050/26A Mod

Sample \#:

H6L110105-002

118

$(75-125) 1.8 \quad(0-20)$

KNOX 0050/26A Mod

$12 / 18 / 06$

6354401

Dilution Factor: 2400

Hydrogen bromide

94

94

WO\#: JK7JR1AE-MS/JK

$(75-125)$

JK7JRIAF - MS KNOX $0050 / 26$ MOd

KNOX 0050/26A Mod

$(75-125) 0.25(0-20)$

Dilution Factor: 4860 .
Hydrogen chloride 109

99

Hydrogen fluoride 103

104

Hydrogen fluoride 99

98
WO\#: JK7JX1AE-MS/JK7JXIAF-MSD MS Lot-Sample \#: H $\begin{array}{lllll}(75-125) & & \text { KNOX 0050/26A Mod } & 12 / 28 / 06 \\ (75-125) & 9.9 & (0-20) & \text { KNOX 0050/26A Mod } & 12 / 28 / 06\end{array}$

Dilution Factor: 19128
Sample \#: H6L110105-001 $12 / 18 / 06 \quad 6361375$

$12 / 18 / 06 \quad 6361375$
WO\#: JK7JRIAG-MS/JK7JRIAH-MSD MS Lot-Sample \#: H6LI10105-001 $\begin{array}{llllll}(75-125) & & \text { KNOX 0050/26A Mod } & 12 / 18 / 06 & 6361376 \\ (75-125) & 0.94(0-20) & \text { KNOX 0050/26A Mod } & 12 / 18 / 06 & 6361376\end{array}$ Dilution Eactor: 5054 .
6363147 6363147
WO\#: JK7JWIAE-MS/JK7JWIAF-MSD MS Lot-Sample \#: H6Ll10105-002

$(75$ - 125) KNOX 0050/26A Mod 12/18/06 6354400

$(75-125) 0.59(0-20)$ KNOX 0050/26A Mod $12 / 18 / 06 \quad 6354400$ Dilution Factor: 2527.

NOTE (S) :

Calculations are performed before rounding to avnid mnund-of errors in calculated results. 


\section{MATRIX SPIKE SAMPLE DATA REPORT}

General Chemistry

Client Lot \#...: H6L110105

Date Sampled. . : 12/01/06
Date Received. .: 12/06/06
Matrix....... AIR

PREPARATION- PREP ANALYSIS DATE BATCH \# AMOUNT UNITS RECVRY RPD METHOD WO\#: JK7JWIAJ-MS/JK7JWIAK-MSD MS Lot-Sample \#: H6L110105-002 510 ug $106 \quad$ KNOX $0050 / 26 \mathrm{~A} \quad 12 / 18 / 06 \quad 635402$ $494 \quad \mathrm{ug} \quad 103 \quad 3.2 \quad$ KNOX $0050 / 26 \mathrm{~A} \quad 12 / 18 / 06 \quad 6354402$ Dilution Factor: 2400

Chlorine

$\begin{array}{ll}440 & 480 \\ 440 & 480\end{array}$

WO\#: JK7JW1AG-MS/JK7JWIAH-MSD MS Lot-Sample \#: H6L110105-002

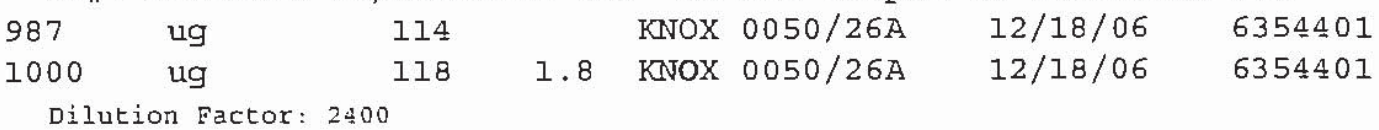

Hydrogen bromide ND 972 ND $\quad 972$

WO\#: JK7JRIAE-MS/JK7JRIAF-MSD MS Lot-Sample \#: H6L110105-001

\begin{tabular}{|c|c|c|c|c|c|c|c|}
\hline 913 & ug & 94 & & KNOX & $0050 / 26 \mathrm{~A}$ & $12 / 18 / 06$ & 6361375 \\
\hline 910 & ug & 94 & 0.25 & KNOX & $0050 / 26 \mathrm{~A}$ & $12 / 18 / 06$ & 6361375 \\
\hline
\end{tabular}

Hydrogen chloride $\begin{array}{ll}\text { ND } & 3830 \\ \text { ND } & 3830\end{array}$

WO\#: JK7JX1AE-MS/JK7JX1AF-MSD MS Lot-Sample \#: H6L110105-003

\begin{tabular}{|c|c|c|c|c|c|c|c|}
\hline 4170 & ug & 109 & & KNOX & $0050 / 26 \mathrm{~A}$ & $12 / 28 / 06$ & 6363147 \\
\hline 3780 & ug & 99 & 9.9 & KNOX & $0050 / 26 \mathrm{~A}$ & $12 / 28 / 06$ & 6363147 \\
\hline
\end{tabular}

Hydrogen fluoride

ND $\quad 1010$

\begin{tabular}{|c|c|c|c|c|c|c|c|}
\hline 1040 & ug & 103 & & KNOX & $0050 / 26 \mathrm{~A}$ & $12 / 18 / 06$ & 6361376 \\
\hline 1050 & ug & 104 & 0.94 & KNOX & $0050 / 26 \mathrm{~A}$ & $12 / 18 / 06$ & 6361376 \\
\hline
\end{tabular}

Hydrogen fluoride $\begin{array}{ll}\text { ND } & 505 \\ \text { ND } & 505\end{array}$

WO\#: JK7JW1AE-MS/JK7JW1AF-MSD MS Lot-Sample \#: H6L110105-002

\begin{tabular}{|c|c|c|c|c|c|c|c|}
\hline 499 & ug & 99 & & KNOX & $0050 / 26 \mathrm{~A}$ & $12 / 18 / 06$ & 6354400 \\
\hline 96 & ug & 98 & 0.59 & KNOX & $0050 / 26 \mathrm{~A}$ & $12 / 18 / 06$ & 6354400 \\
\hline
\end{tabular}

NOTE $(S):$

Calculations are performed hefore rounding to avoid round-off errors in calculated results. 
Raw Data 
Anions 


\section{STL Knoxville IC Initial Calibration Data Review / Narrative Checklist \\ Methods: 300.0, 9056, 9057 and 26A, SOP: KNOX-WC-0005, Rev. 8}

\section{Page 1 of 1}

(ICS- 1500)

Analvsis Date: $10 / 18 / 06$

File ID: 518 - LOWLEVEL- FULNOZBRNO3-101806

\begin{tabular}{|c|c|c|c|c|c|}
\hline Initial Calibration Review Items & N/A & Yes & No & If No, why is data reportable? & $\begin{array}{l}\text { 2nd } \\
V\end{array}$ \\
\hline 1. Were at least 5 levels of each analyte analyzed? & & & & & \\
\hline 2. Is low level standard concentration $\leq R L$ ? & & & & & $\checkmark$ \\
\hline $\begin{array}{l}\text { 3. Are the correlation coefficients }(r) \geq 0.995 \text {; } \\
r^{2} \geq 0.990 \text { ? }\end{array}$ & & & & 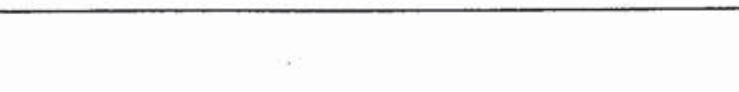 & \\
\hline $\begin{array}{l}\text { 4. For method } 300.0 \text {, was the calibration curve } \\
\text { processed using linear reqression? }\end{array}$ & $\sqrt{1}$ & & & & $N A$ \\
\hline $\begin{array}{l}\text { 5. For manual integrated standards, are before/after } \\
\text { cliromatograms provided with initials/date/reason? }\end{array}$ & 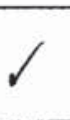 & & & $\begin{array}{l}\text { Reasons: } S=\text { Split peak, } U=\text { Undetected peak, I=Incorrect } \\
\text { peak integration, } B=B \text { aseline correction, } W=\text { Wrong peak } \\
\text { chosen by data system }\end{array}$ & $N A$ \\
\hline
\end{tabular}

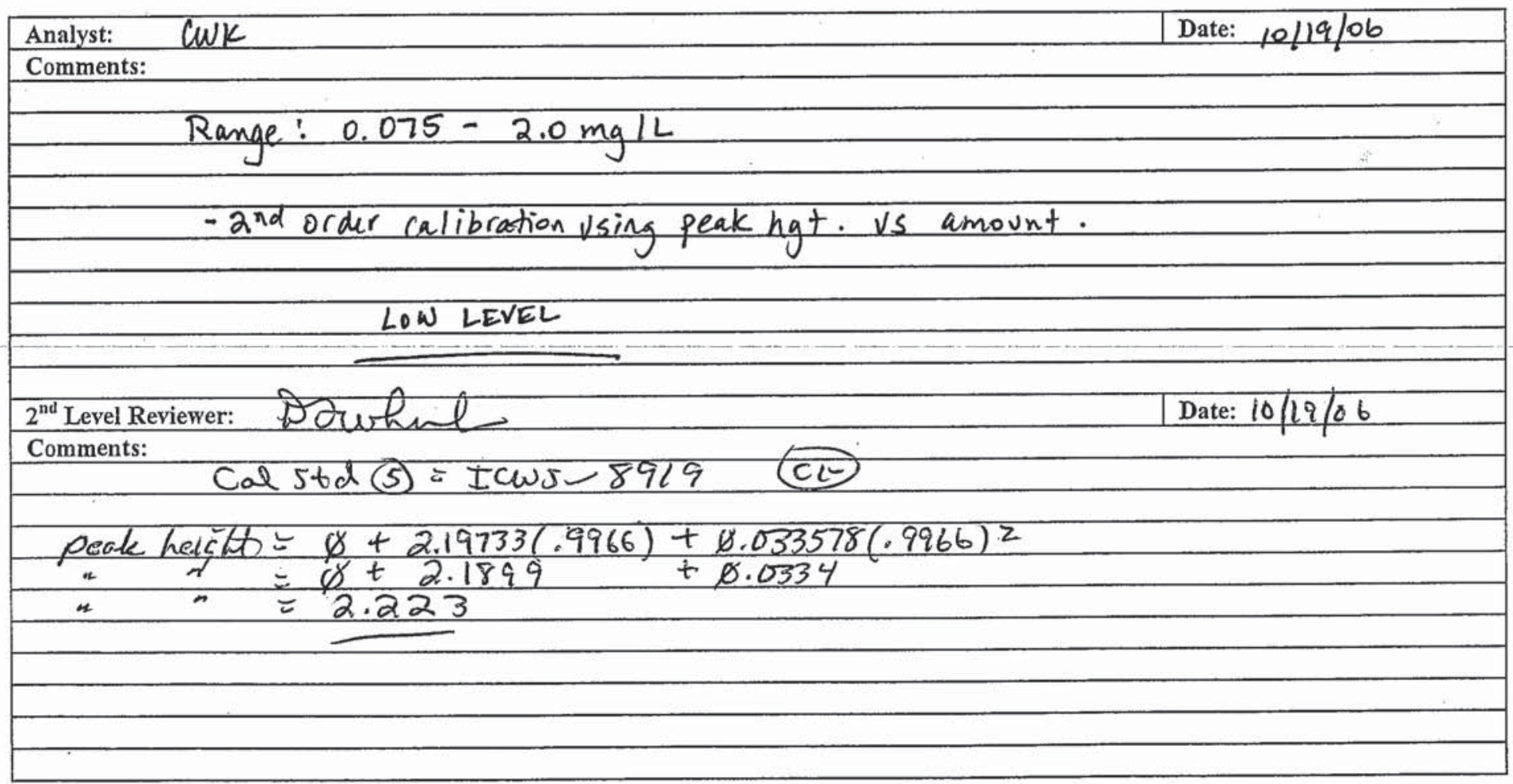

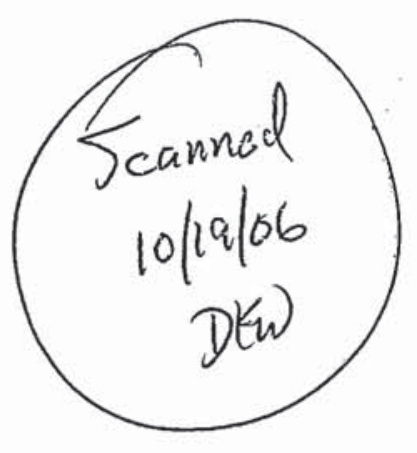




\section{CAL STD \#1 ICWS-8915}

Sample Name: $\quad$ CAL STD \#1 ICWS-8915

Vial Number:

Sample Type:

Control Program: AS14A ANIONS METHOD

Quantif. Method: $\quad$ AS4A-SC ANION METHOD

Recording Time:

Run Time (min):
1292

10/18/2006 9:14

15.00
Injection Volume:

Channel:

Wavelength:

Bandwidth:

Dilution Factor:

Sample Weight:

Sample Amount:
50.0

ECD_1

n.a.

n.a.

1.0000

1.0000

1.0000

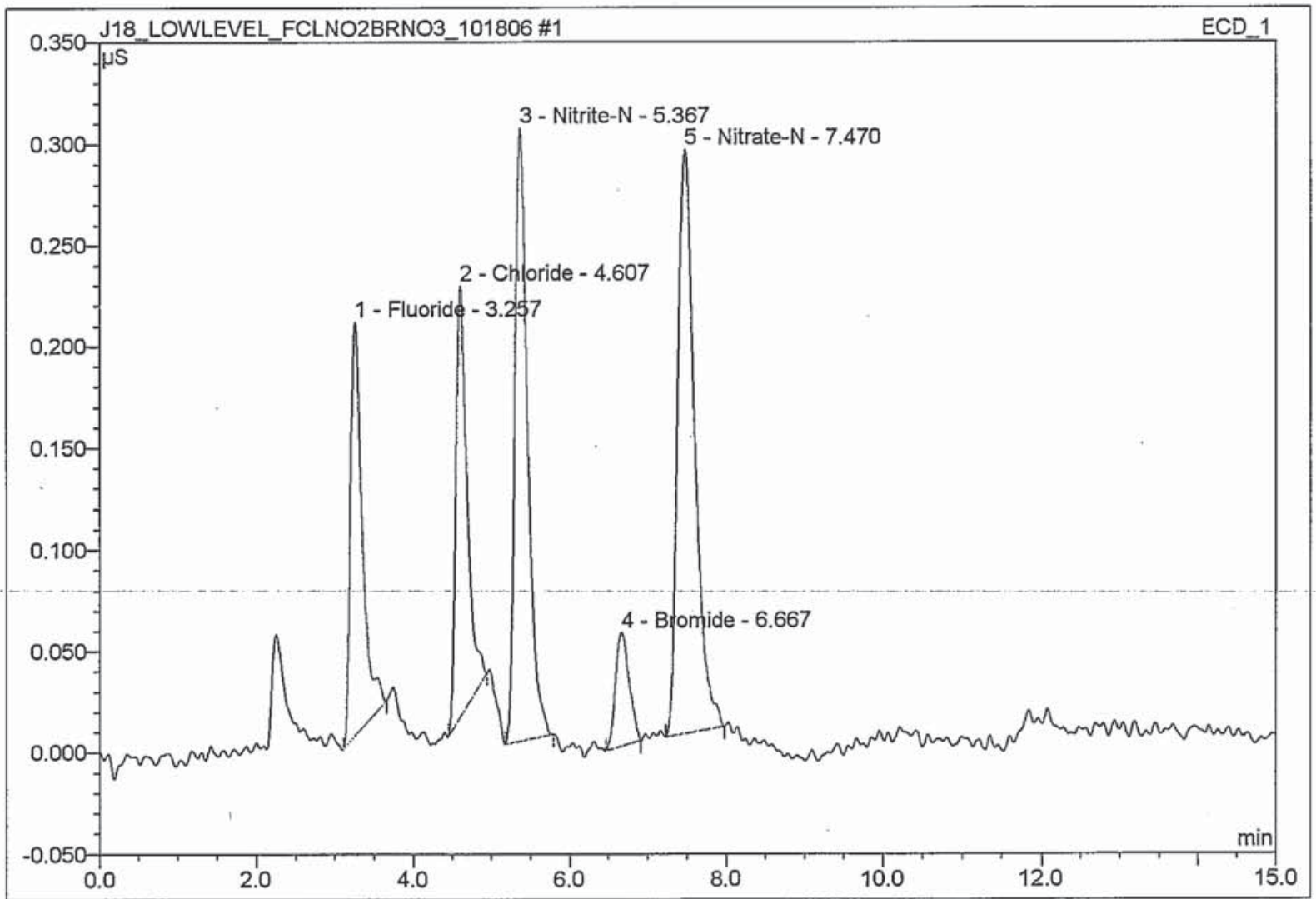

\begin{tabular}{|c|c|l|r|r|r|r|c|}
\hline No. & $\begin{array}{c}\text { Ret.Time } \\
\text { (min.) }\end{array}$ & \multicolumn{1}{|c|}{ Peak Name } & $\begin{array}{c}\text { Height } \\
\text { (uS) }\end{array}$ & $\begin{array}{c}\text { Area } \\
\mu \text { S }^{*} \text { min }\end{array}$ & $\begin{array}{c}\text { Rel.Area } \\
(\%)\end{array}$ & $\begin{array}{c}\text { Amount } \\
\text { (mg/L) }\end{array}$ & $\begin{array}{c}\text { Peak } \\
\text { Type }\end{array}$ \\
\hline 1 & 3.26 & Fluoride & 0.20347 & 0.035 & 16.69 & 0.0752 & BMB \\
\hline 2 & 4.61 & Chloride & 0.21212 & 0.036 & 16.87 & 0.0964 & BMB \\
\hline 3 & 5.37 & Nitrite-N & 0.30167 & 0.057 & 26.98 & 0.0791 & BMB \\
\hline 4 & 6.67 & Bromide & 0.05610 & 0.011 & 5.39 & 0.0791 & BMB \\
\hline 5 & 7.47 & Nitrate-N & 0.28758 & 0.072 & 34.07 & 0.0828 & BMB \\
\hline
\end{tabular}




\section{CAL STD \#2 ICWS-8916}

Sample Name: $\quad$ CAL STD \#2 ICWS-8916

Vial Number:

Sample Type:

Control Program: AS14A ANIONS METHOD

Quantif. Method:

Recording Time:

Run Time (min):
1293

standard

AS4A-SC ANION METHOD

10/18/2006 9:32

15.00
Injection Volume: $\quad \mathbf{5 0 . 0}$

Channel: ECD_1

Wavelength: n.a.

Bandwidth: n.a.

Dilution Factor: $\quad \mathbf{1 . 0 0 0 0}$

Sample Weight: $\quad \mathbf{1 . 0 0 0 0}$

Sample Amount: $\quad 1.0000$

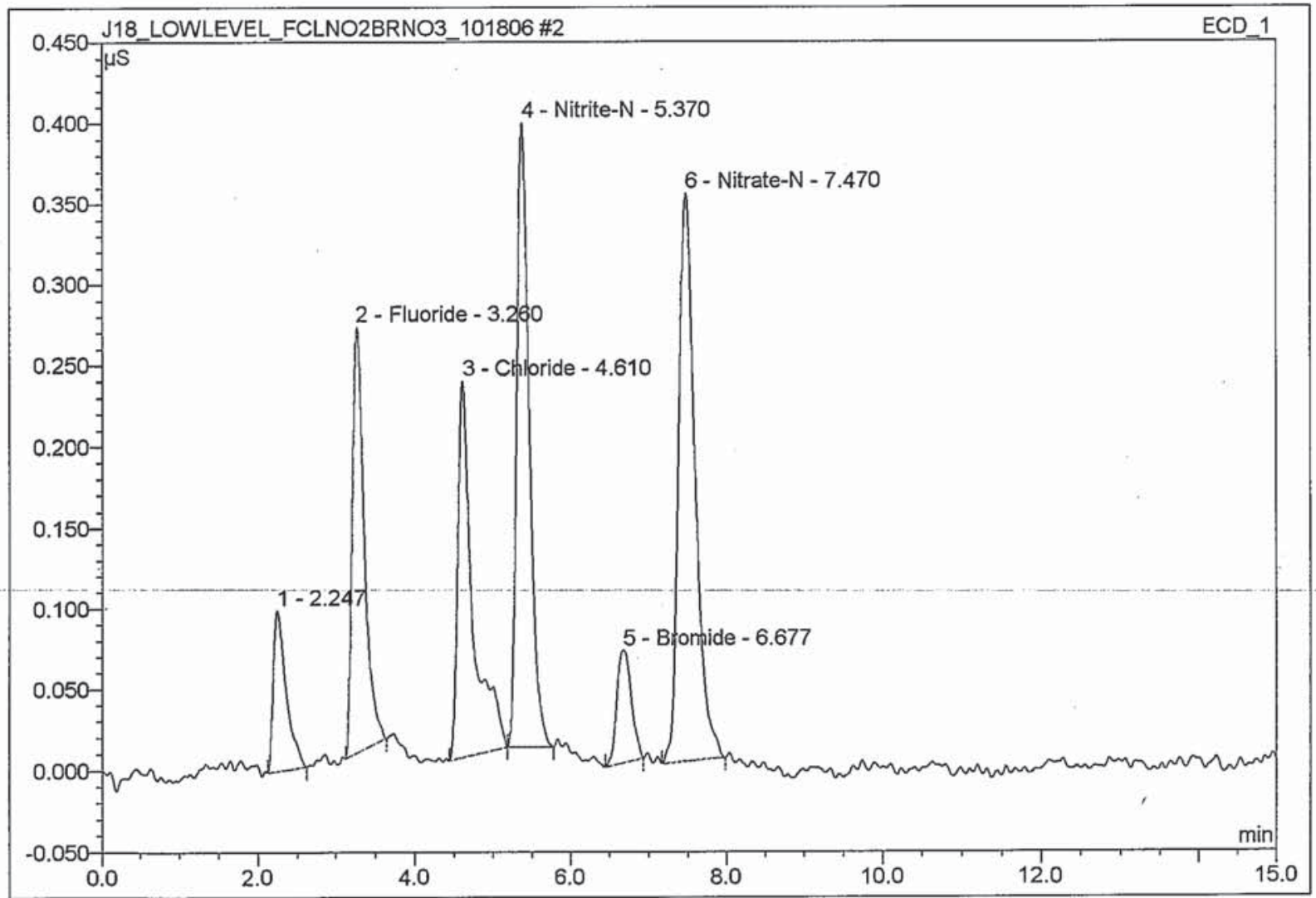

\begin{tabular}{|r|c|l|r|r|r|r|r|}
\hline No. & $\begin{array}{c}\text { Ret.Time } \\
\text { (min.) }\end{array}$ & \multicolumn{1}{|c|}{ Peak Name } & $\begin{array}{c}\text { Height } \\
\text { (uS) }\end{array}$ & $\begin{array}{c}\text { Area } \\
\mu S^{*} \text { min }\end{array}$ & $\begin{array}{c}\text { Rel.Area } \\
\text { (\%) }\end{array}$ & $\begin{array}{c}\text { Amount } \\
\text { (mg/L) }\end{array}$ & $\begin{array}{r}\text { Peak } \\
\text { Type }\end{array}$ \\
\hline 1 & 2.25 & n.a. & 0.09910 & 0.019 & 6.45 & n.a. & BMB \\
\hline 2 & 3.26 & Fluoride & 0.26277 & 0.046 & 15.73 & 0.0970 & BMB \\
\hline 3 & 4.61 & Chloride & 0.23228 & 0.052 & 17.83 & 0.1055 & BMB \\
\hline 4 & 5.37 & Nitrite-N & 0.38584 & 0.072 & 24.74 & 0.1012 & BMB \\
\hline 5 & 6.68 & Bromide & 0.06928 & 0.015 & 5.09 & 0.0977 & BMB \\
\hline 6 & 7.47 & Nitrate-N & 0.35086 & 0.088 & 30.16 & 0.1009 & BMB \\
\hline
\end{tabular}




\section{CAL STD \#3 ICWS-8917}

\begin{tabular}{llll|}
\hline Sample Name: & CAL STD \#3 ICWS-8917 & Injection Volume: & $\mathbf{5 0 . 0}$ \\
Vial Number: & $\mathbf{1 2 9 3}$ & Channel: & ECD_1 \\
Sample Type: & standard & Wavelength: & n.a. \\
Control Program: & AS14A ANIONS METHOD & Bandwidth: & n.a. \\
Quantif. Method: & AS4A-SC ANION METHOD & Dilution Factor: & $\mathbf{1 . 0 0 0 0}$ \\
Recording Time: & $\mathbf{1 0 / 1 8 / 2 0 0 6} 9: 49$ & Sample Weight: & $\mathbf{1 . 0 0 0 0}$ \\
Run Time (min): & $\mathbf{1 5 . 0 0}$ & Sample Amount: & $\mathbf{1 . 0 0 0 0}$ \\
\hline
\end{tabular}

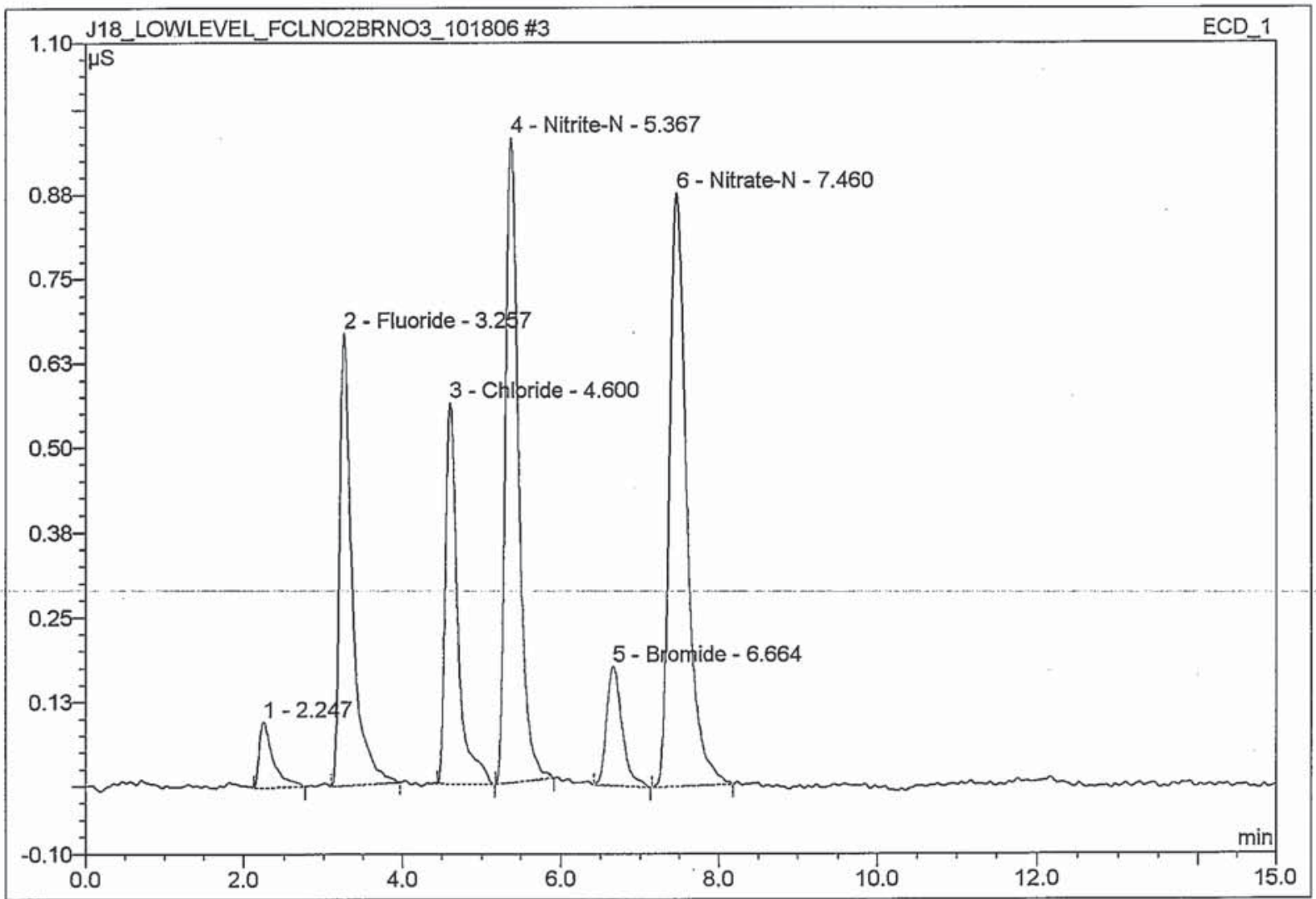

\begin{tabular}{|r|c|l|r|r|r|r|r|}
\hline No. & $\begin{array}{c}\text { Ret.Time } \\
\text { (min.) }\end{array}$ & \multicolumn{1}{|c|}{ Peak Name } & $\begin{array}{c}\text { Height } \\
\text { (uS) }\end{array}$ & \multicolumn{1}{c|}{$\begin{array}{c}\text { Area } \\
\mu \mathbf{S}^{*} \text { min }\end{array}$} & $\begin{array}{c}\text { Rel.Area } \\
(\%)\end{array}$ & $\begin{array}{c}\text { Amount } \\
\text { (mg/L) }\end{array}$ & $\begin{array}{r}\text { Peak } \\
\text { Type }\end{array}$ \\
\hline 1 & 2.25 & n.a. & 0.09667 & 0.019 & 2.79 & n.a. & BMB \\
\hline 2 & 3.26 & Fluoride & 0.66838 & 0.127 & 18.21 & 0.2438 & BMB \\
\hline 3 & 4.60 & Chloride & 0.56206 & 0.103 & 14.73 & 0.2548 & BMB \\
\hline 4 & 5.37 & Nitrite-N & 0.95211 & 0.184 & 26.44 & 0.2484 & BMB \\
\hline 5 & 6.66 & Bromide & 0.17667 & 0.040 & 5.79 & 0.2488 & BMB \\
\hline 6 & 7.46 & Nitrate-N & 0.87649 & 0.223 & 32.04 & 0.2502 & BMB \\
\hline
\end{tabular}




\section{CAL STD \#4 ICWS-8918}

Sample Name: $\quad$ CAL STD \#4 ICWS-8918

Vial Number:

Sample Type:

Control Program: AS14A ANIONS METHOD

Quantif. Method:

Recording Time:

Run Time (min):
1295

standard

AS4A-SC ANION METHOD

10/18/2006 10:07

15.00
Injection Volume: $\quad \mathbf{5 0 . 0}$

Channel: $\quad$ ECD_1

Wavelength: n.a.

Bandwidth: n.a.

Dilution Factor: $\quad \mathbf{1 . 0 0 0 0}$

Sample Weight: $\quad 1.0000$

Sample Amount: $\quad 1.0000$

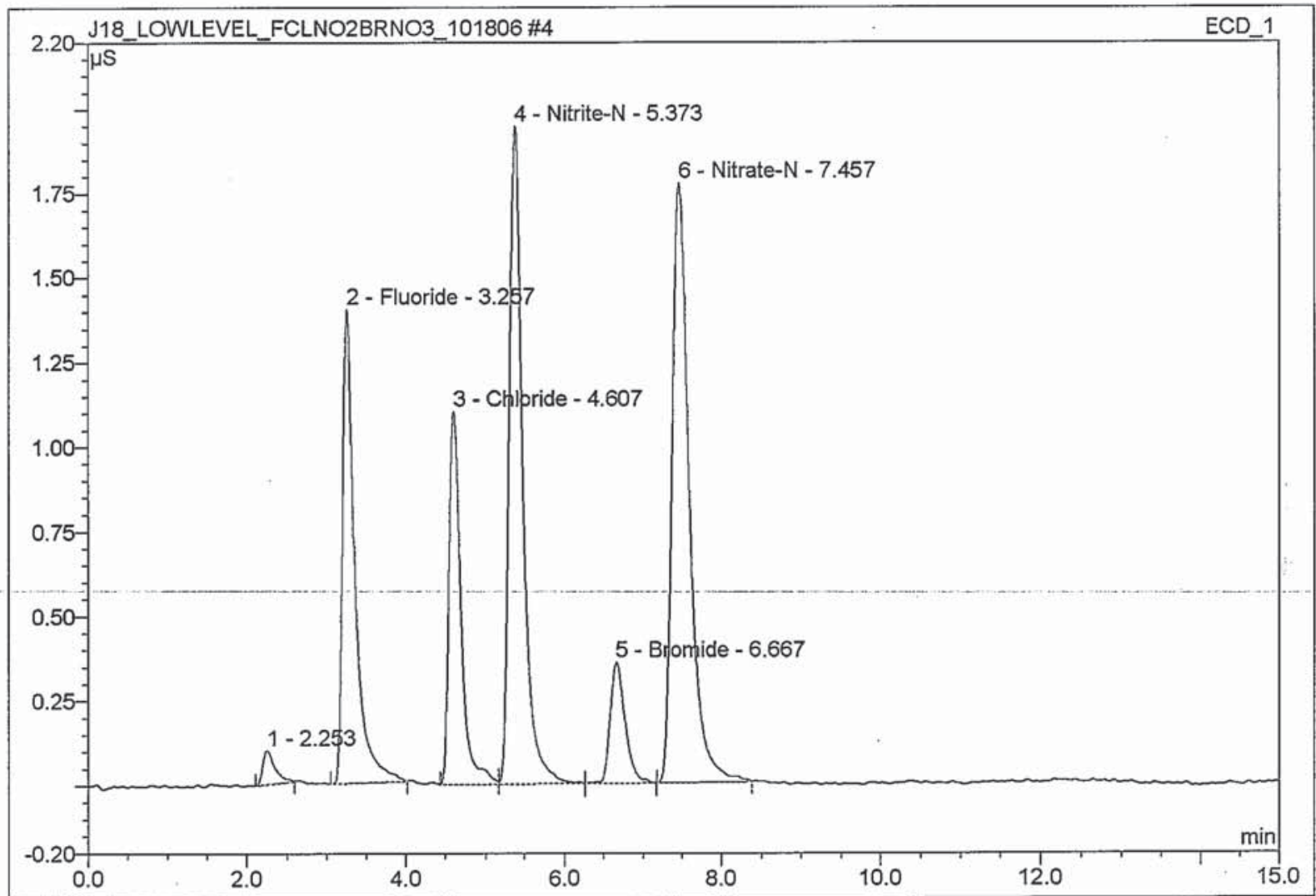

\begin{tabular}{|c|c|l|r|r|r|r|c|}
\hline No. & $\begin{array}{c}\text { Ret.Time } \\
\text { (min.) }\end{array}$ & \multicolumn{1}{|c|}{ Peak Name } & $\begin{array}{c}\text { Height } \\
(\mathbf{u S})\end{array}$ & $\begin{array}{c}\text { Area } \\
\mu \mathbf{S}^{*} \mathrm{~min}\end{array}$ & $\begin{array}{c}\text { Rel.Area } \\
(\%)\end{array}$ & $\begin{array}{c}\text { Amount } \\
(\mathrm{mg} / \mathrm{L})\end{array}$ & $\begin{array}{c}\text { Peak } \\
\text { Type }\end{array}$ \\
\hline 1 & 2.25 & n.a. & 0.10012 & 0.018 & 1.29 & n.a. & BMB \\
\hline 2 & 3.26 & Fluoride & 1.39754 & 0.256 & 18.63 & 0.4996 & BMB \\
\hline 3 & 4.61 & Chloride & 1.09898 & 0.191 & 13.89 & 0.4964 & BM \\
\hline 4 & 5.37 & Nitrite-N & 1.94194 & 0.385 & 27.97 & 0.5022 & M \\
\hline 5 & 6.67 & Bromide & 0.35570 & 0.078 & 5.68 & 0.4998 & MB \\
\hline 6 & 7.46 & Nitrate-N & 1.76858 & 0.448 & 32.55 & 0.4985 & BMB \\
\hline
\end{tabular}




\section{CAL STD \#5 ICWS-8919}

Sample Name: Vial Number:

Sample Type:

Control Program:

Quantif. Method:

Recording Time:

Run Time (min):
CAL STD \#5 ICWS-8919

1295

standard

AS14A ANIONS METHOD

AS4A-SC ANION METHOD

10/18/2006 10:24

15.00
Injection Volume: $\quad \mathbf{5 0 . 0}$

Channel: $\quad$ ECD_1

Wavelength: n.a.

Bandwidth: n.a.

Dilution Factor: $\quad \mathbf{1 . 0 0 0 0}$

Sample Weight: $\quad \mathbf{1 . 0 0 0 0}$

Sample Amount: $\quad \mathbf{1 . 0 0 0 0}$

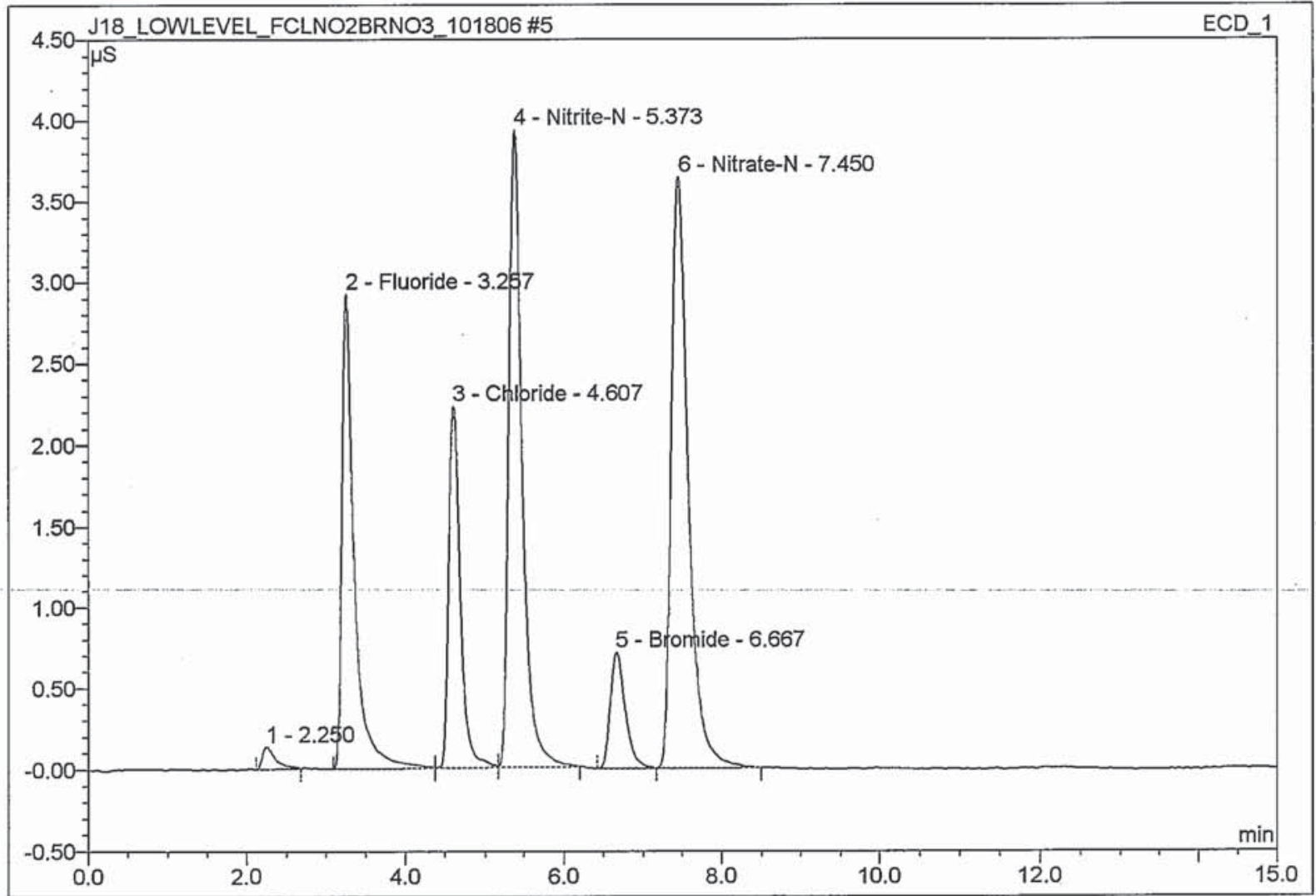

\begin{tabular}{|c|c|l|r|r|r|r|c|}
\hline No. & $\begin{array}{c}\text { Ret.Time } \\
\text { (min.) }\end{array}$ & \multicolumn{1}{|c|}{ Peak Name } & $\begin{array}{c}\text { Height } \\
\text { (uS) }\end{array}$ & $\begin{array}{c}\text { Area } \\
\mu \mathbf{S}^{*} \text { min }\end{array}$ & $\begin{array}{c}\text { Rel.Area } \\
(\%)\end{array}$ & $\begin{array}{c}\text { Amount } \\
\text { (mg/L) }\end{array}$ & $\begin{array}{r}\text { Peak } \\
\text { Type }\end{array}$ \\
\hline 1 & 2.25 & n.a. & 0.13527 & 0.026 & 0.94 & n.a. & BMB \\
\hline 2 & 3.26 & Fluoride & 2.91620 & 0.530 & 19.16 & 1.0032 & BM \\
\hline 3 & 4.61 & Chloride & 2.22320 & 0.373 & 13.49 & 0.9966 & M \\
\hline 4 & 5.37 & Nitrite-N & 3.92501 & 0.773 & 27.95 & 0.9983 & MB \\
\hline 5 & 6.67 & Bromide & 0.71491 & 0.156 & 5.62 & 1.0005 & Ru \\
\hline 6 & 7.45 & Nitrate-N & 3.63765 & 0.908 & 32.83 & 0.9998 & BMB \\
\hline
\end{tabular}




\section{CAL STD \#6 ICWS-8920}

\begin{tabular}{llll|}
\hline Sample Name: & CAL STD \#6 ICWS-8920 & Injection Volume: & $\mathbf{5 0 . 0}$ \\
Vial Number: & 1295 & Channel: & ECD_1 \\
Sample Type: & standard & Wavelength: & n.a. \\
Control Program: & AS14A ANIONS METHOD & Bandwidth: & n.a. \\
Quantif. Method: & AS4A-SC ANION METHOD & Dilution Factor: & 1.0000 \\
Recording Time: & $10 / 18 / 200610: 41$ & Sample Weight: & 1.0000 \\
Run Time (min): & 15.00 & Sample Amount: & $\mathbf{1 . 0 0 0 0}$ \\
\hline
\end{tabular}

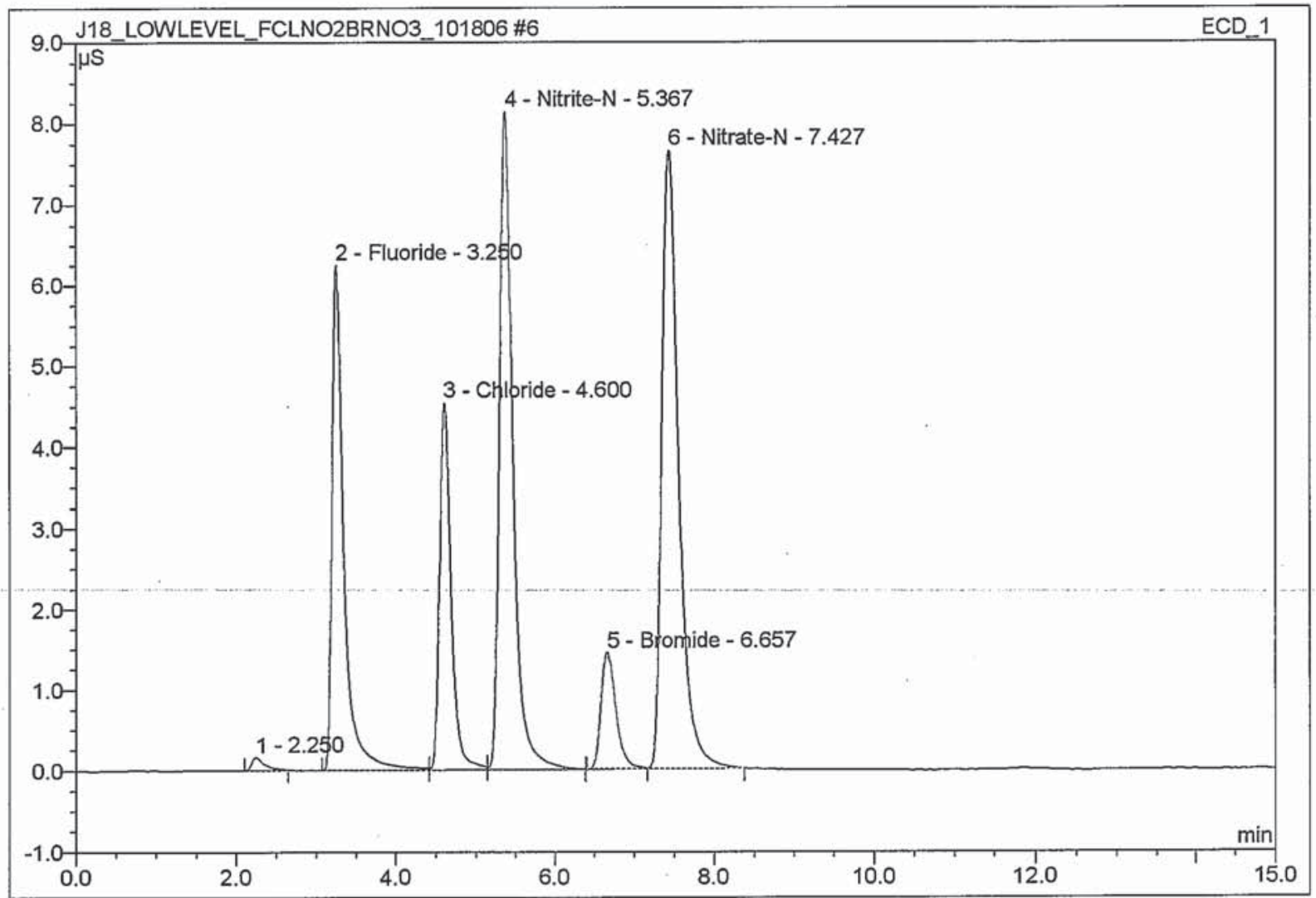

\begin{tabular}{|c|c|l|r|r|r|r|c|}
\hline No. & $\begin{array}{c}\text { Ret.Time } \\
\text { (min.) }\end{array}$ & \multicolumn{1}{|c|}{ Peak Name } & $\begin{array}{c}\text { Height } \\
\text { (uS) }\end{array}$ & $\begin{array}{c}\text { Area } \\
\text { uS*min }\end{array}$ & $\begin{array}{c}\text { Rel.Area } \\
(\%)\end{array}$ & $\begin{array}{c}\text { Amount } \\
\text { (mg/L) }\end{array}$ & $\begin{array}{r}\text { Peak } \\
\text { Type }\end{array}$ \\
\hline 1 & 2.25 & n.a. & 0.15975 & 0.030 & 0.53 & n.a. & BMB \\
\hline 2 & 3.25 & Fluoride & 6.24513 & 1.086 & 19.22 & 1.9994 & BM \\
\hline 3 & 4.60 & Chloride & 4.53115 & 0.754 & 13.35 & 2.0009 & $\mathrm{M}$ \\
\hline 4 & 5.37 & Nitrite-N & 8.12633 & 1.598 & 28.28 & 2.0003 & $\mathrm{M}$ \\
\hline 5 & 6.66 & Bromide & 1.44051 & 0.306 & 5.42 & 1.9999 & Ru \\
\hline 6 & 7.43 & Nitrate-N & 7.63891 & 1.876 & 33.19 & 2.0001 & MB \\
\hline
\end{tabular}




\begin{tabular}{|lllll|}
\hline 4 CALSTD-\#4-IGWS-8918- D/W \\
& & & \\
& & & \\
\hline Sample Name: & CAL STD \#4 ICWS-8918 & Injection Volume: & 50.0 \\
Vial Number: & 1295 & Channel: & ECD_1 \\
Sample Type: & standard & Wavelength: & n.a. \\
Control Program: & AS14A ANIONS METHOD & Bandwidth: & n.a. \\
Quantif. Method: & AS4A-SC ANION METHOD & Dilution Factor: & 1.0000 \\
Recording Time: & \#\#\#\#\#\#\#\#\#\# & Sample Weight: & 1.0000 \\
Run Time (min): & 15.00 & Sample Amount: & 1.0000 \\
\hline
\end{tabular}

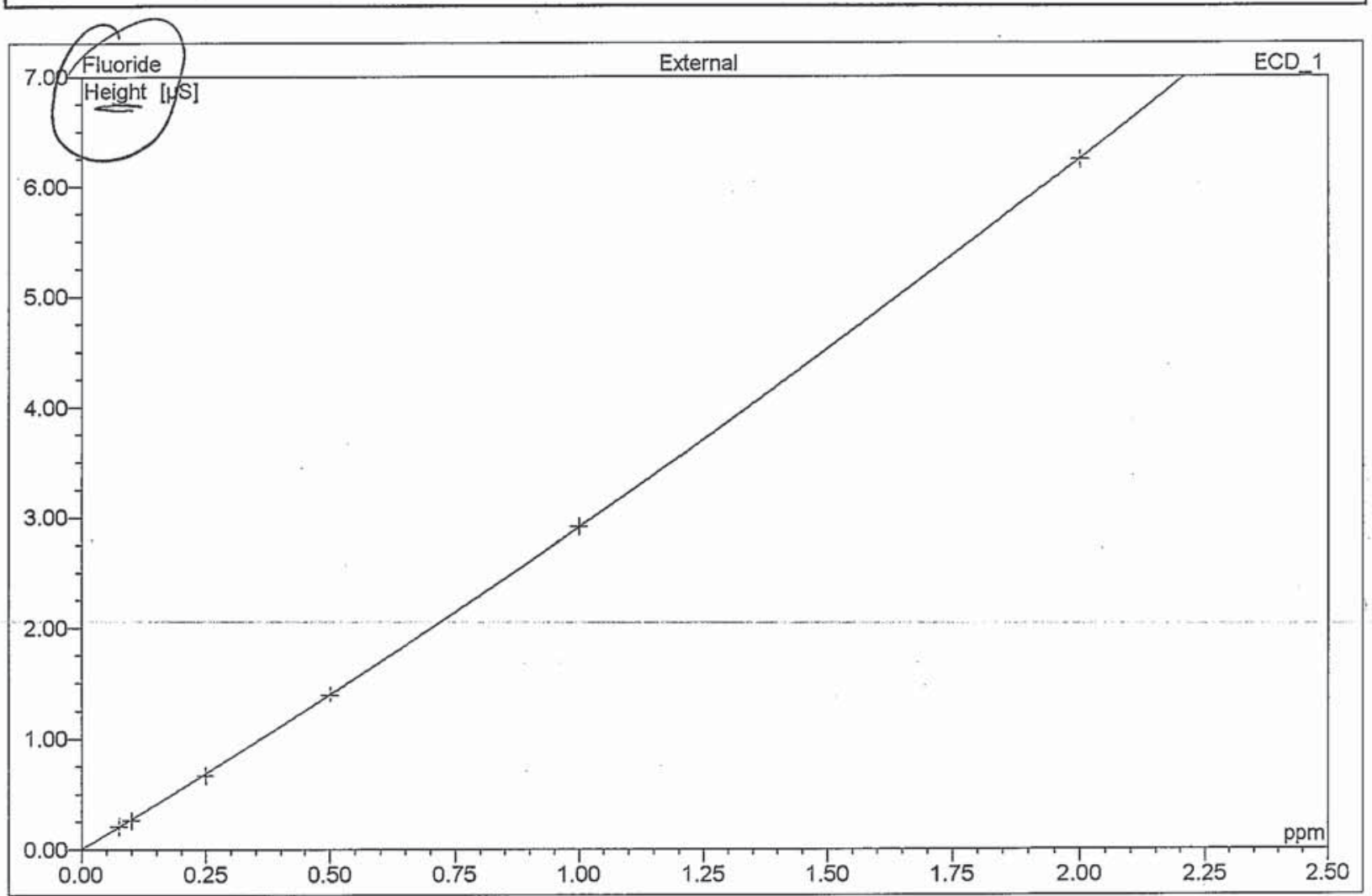

\begin{tabular}{|r|rlrrrrrr|}
\hline No. & $\begin{array}{c}\text { Ret.Time } \\
\text { min }\end{array}$ & Peak Name & Cal.Type & Points & R-Square & Offset & Slope & Curve \\
\hline 1 & 2.25 & n.a. & n.a. & n.a. & n.a. & n.a. & n.a. & n.a. \\
2 & 3.26 & Fluoride & Quad & 6 & 1.0000 & 0.000000 & 2.68877 & 0.217432 \\
3 & 4.61 & Chloride & Quad & 6 & 0.9998 & 0.000000 & 2.19733 & 0.033578 \\
4 & 5.37 & Nitrite-N & Quad & 6 & 1.0000 & 0.000000 & 3.80119 & 0.130678 \\
5 & 6.67 & Bromide & Quad & 6 & 1.0000 & 0.000000 & 0.70878 & 0.005755 \\
6 & 7.46 & Nitrate-N & Quad & 6 & 1.0000 & 0.000000 & 3.45770 & 0.180759 \\
\hline Average: & & & & & 1.0000 & 0.0000 & 2.5708 & 0.1136 \\
\hline
\end{tabular}




\begin{tabular}{|lllll|}
\hline 4 CAL STD\#4-ICWS-8948-(DFw \\
& & & \\
& & & \\
\hline Sample Name: & CAL STD \#4 ICWS-8918 & Injection Volume: & 50.0 \\
Vial Number: & 1295 & Channel: & ECD_1 \\
Sample Type: & standard & Wavelength: & n.a. \\
Control Program: & AS14A ANIONS METHOD & Bandwidth: & n.a. \\
Quantif. Method: & AS4A-SC ANION METHOD & Dilution Factor: & 1.0000 \\
Recording Time: & \#\#\#\#\#\#\#\#\#\# & Sample Weight: & 1.0000 \\
Run Time (min): & 15.00 & Sample Amount: & 1.0000 \\
\hline
\end{tabular}

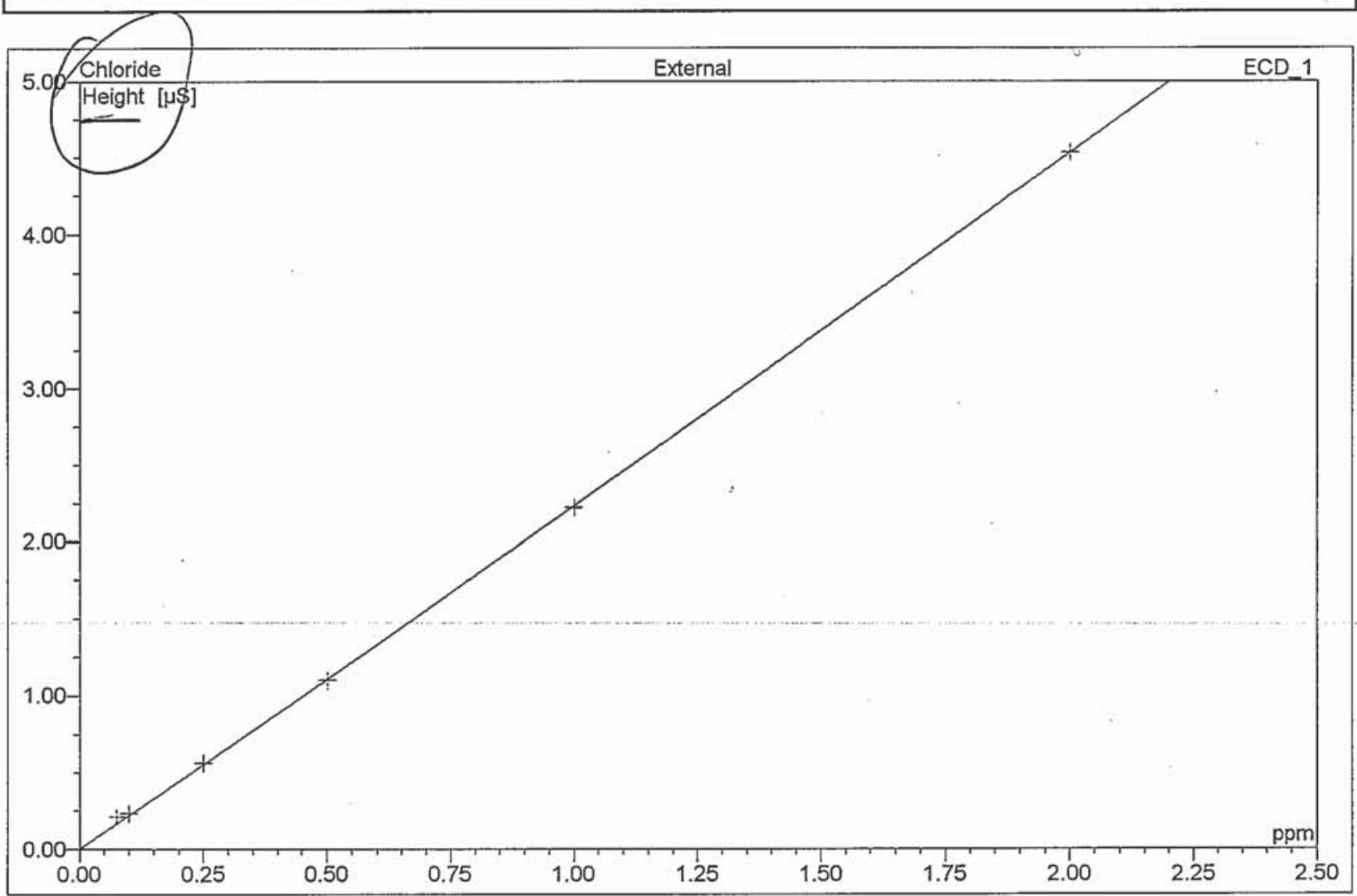

\begin{tabular}{|c|ccccccrr|}
\hline No. & $\begin{array}{c}\text { Ret.Time } \\
\text { min }\end{array}$ & Peak Name & Cal.Type & Points & R-Square & Offset & Slope & Curve \\
\hline 1 & 2.25 & n.a. & n.a. & n.a. & n.a. & n.a. & n.a. & n.a. \\
2 & 3.26 & Fluoride & Quad & 6 & 1.0000 & 0.000000 & 2.68877 & 0.217432 \\
3 & 4.61 & Chloride & Quad & 6 & 0.9998 & 0.000000 & 2.19733 & 0.033578 \\
4 & 5.37 & Nitrite-N & Quad & 6 & 1.0000 & 0.000000 & 3.80119 & 0.130678 \\
5 & 6.67 & Bromide & Quad & 6 & 1.0000 & 0.000000 & 0.70878 & 0.005755 \\
6 & 7.46 & Nitrate-N & Quad & 6 & 1.0000 & 0.000000 & 3.45770 & 0.180759 \\
\hline Average: & & & & & 1.0000 & 0.0000 & 2.5708 & 0.1136 \\
\hline
\end{tabular}




\begin{tabular}{|c|c|c|c|}
\hline \multicolumn{2}{|c|}{4 CALSTD\#41CWS-8918 } & \multirow{3}{*}{$\begin{array}{l}\text { Injection Volume: } \\
\text { Channel: }\end{array}$} & \multirow{3}{*}{$\begin{array}{l}50.0 \\
\text { ECD_1 }\end{array}$} \\
\hline Sample Name: & CAL STD \#4 ICWS-8918 & & \\
\hline Vial Number: & 1295 & & \\
\hline Sample Type: & standard & Wavelength: & n.a. \\
\hline Control Program: & AS14A ANIONS METHOD & Bandwidth: & n.a. \\
\hline Quantif. Method: & AS4A-SC ANION METHOD & Dilution Factor: & 1.0000 \\
\hline Recording Time: & \#\#\#\#\#\#\#\#\#\#\#\# & Sample Weight: & 1.0000 \\
\hline Run Time (min): & 15.00 & Sample Amount: & 1.0000 \\
\hline
\end{tabular}

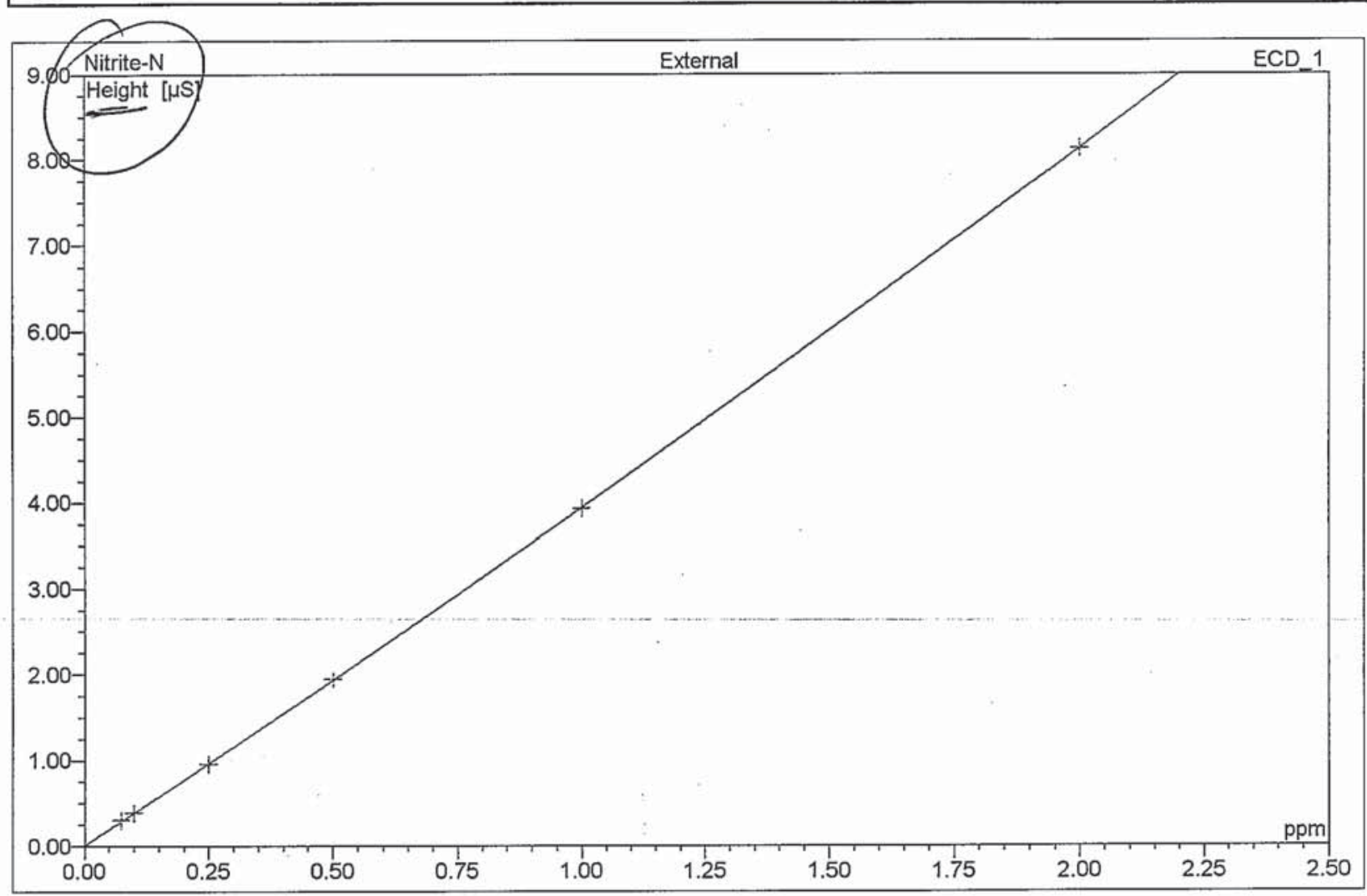

\begin{tabular}{|c|ccccccrrr|}
\hline No. & $\begin{array}{c}\text { Ret.Time } \\
\text { min }\end{array}$ & Peak Name & Cal.Type & Points & R-Square & Offset & Slope & Curve \\
\hline 1 & 2.25 & n.a. & n.a. & n.a. & n.a. & n.a. & n.a. & n.a. \\
2 & 3.26 & Fluoride & Quad & 6 & 1.0000 & 0.000000 & 2.68877 & 0.217432 \\
3 & 4.61 & Chloride & Quad & 6 & 0.9998 & 0.000000 & 2.19733 & 0.033578 \\
4 & 5.37 & Nitrite-N & Quad & 6 & -1.0000 & 0.000000 & 3.80119 & 0.130678 \\
5 & 6.67 & Bromide & Quad & 6 & 1.0000 & 0.000000 & 0.70878 & 0.005755 \\
6 & 7.46 & Nitrate-N & Quad & 6 & 1.0000 & 0.000000 & 3.45770 & 0.180759 \\
\hline Average: & & & & & 1.0000 & 0.0000 & 2.5708 & 0.1136 \\
\hline
\end{tabular}




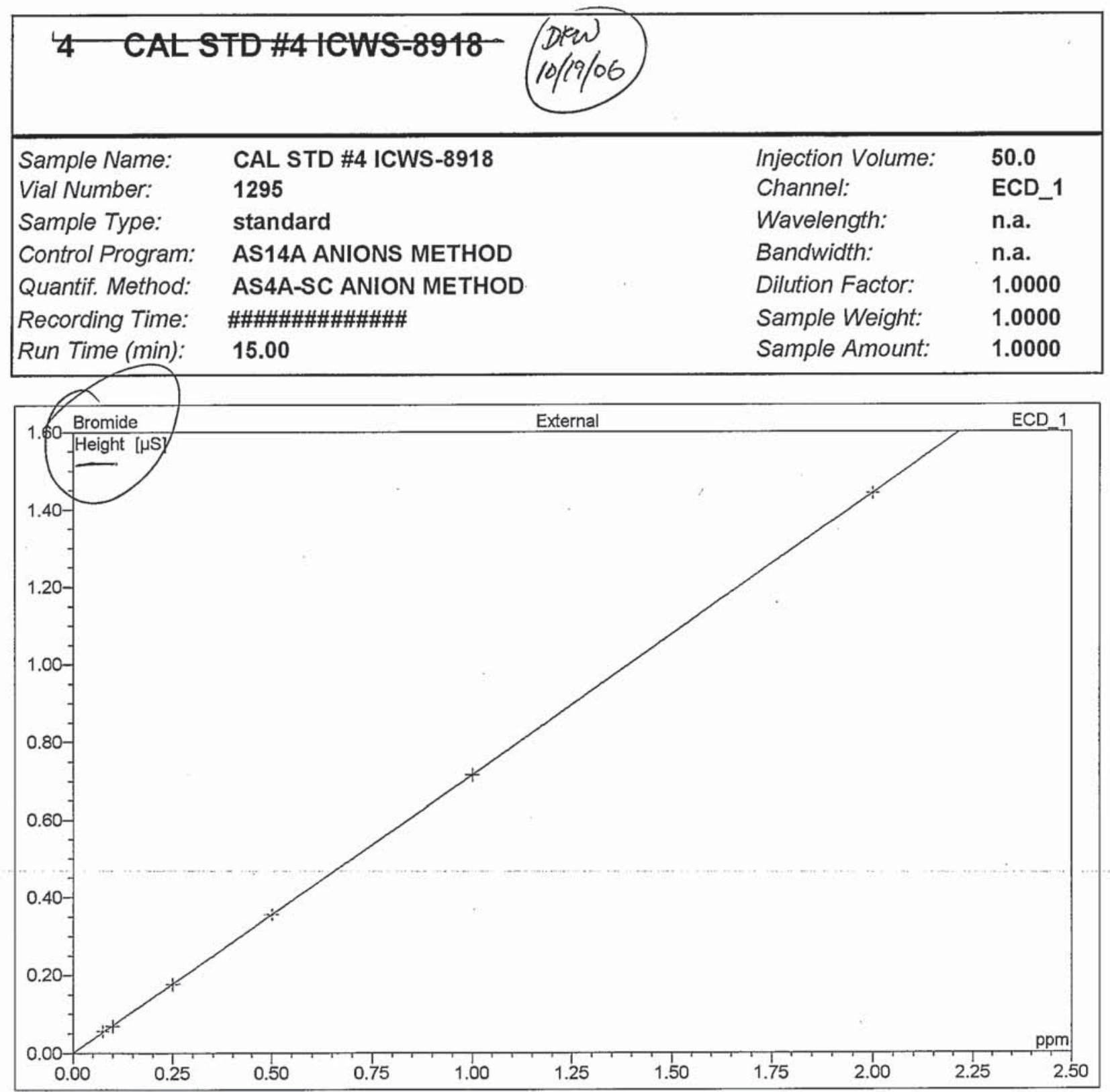

\begin{tabular}{|c|rlcrrrrr|}
\hline No. & $\begin{array}{c}\text { Ret.Time } \\
\text { min }\end{array}$ & Peak Name & Cal.Type & Points & R-Square & Offset & Slope & Curve \\
\hline 1 & 2.25 & n.a. & n.a. & n.a. & n.a. & n.a. & n.a. & n.a. \\
2 & 3.26 & Fluoride & Quad & 6 & 1.0000 & 0.000000 & 2.68877 & 0.217432 \\
3 & 4.61 & Chloride & Quad & 6 & 0.9998 & 0.000000 & 2.19733 & 0.033578 \\
4 & 5.37 & Nitrite-N & Quad & 6 & 1.0000 & 0.000000 & 3.80119 & 0.130678 \\
5 & 6.67 & Bromide & Quad & 6 & $\checkmark 1.0000$ & 0.000000 & 0.70878 & 0.005755 \\
6 & 7.46 & Nitrate-N & Quad & 6 & 1.0000 & 0.000000 & 3.45770 & 0.180759 \\
\hline Average: & & & & & 1.0000 & 0.0000 & 2.5708 & 0.1136 \\
\hline
\end{tabular}




\begin{tabular}{|c|c|c|c|}
\hline \multicolumn{4}{|c|}{4 - CALSTD \#4 ICWS-8918 } \\
\hline Sample Name: & CAL STD \#4 ICWS-8918 & Injection Volume: & 50.0 \\
\hline Vial Number: & 1295 & Channel: & ECD_1 \\
\hline Sample Type: & standard & Wavelength: & n.a. \\
\hline Control Program: & AS14A ANIONS METHOD & Bandwidth: & n.a. \\
\hline Quantif. Method: & AS4A-SC ANION METHOD & Dilution Factor: & 1.0000 \\
\hline Recording Time: & \#\#\#\#\#\#\#\#\#\#\#\# & Sample Weight: & 1.0000 \\
\hline Run Time (min): & 15.00 & Sample Amount: & 1.0000 \\
\hline
\end{tabular}

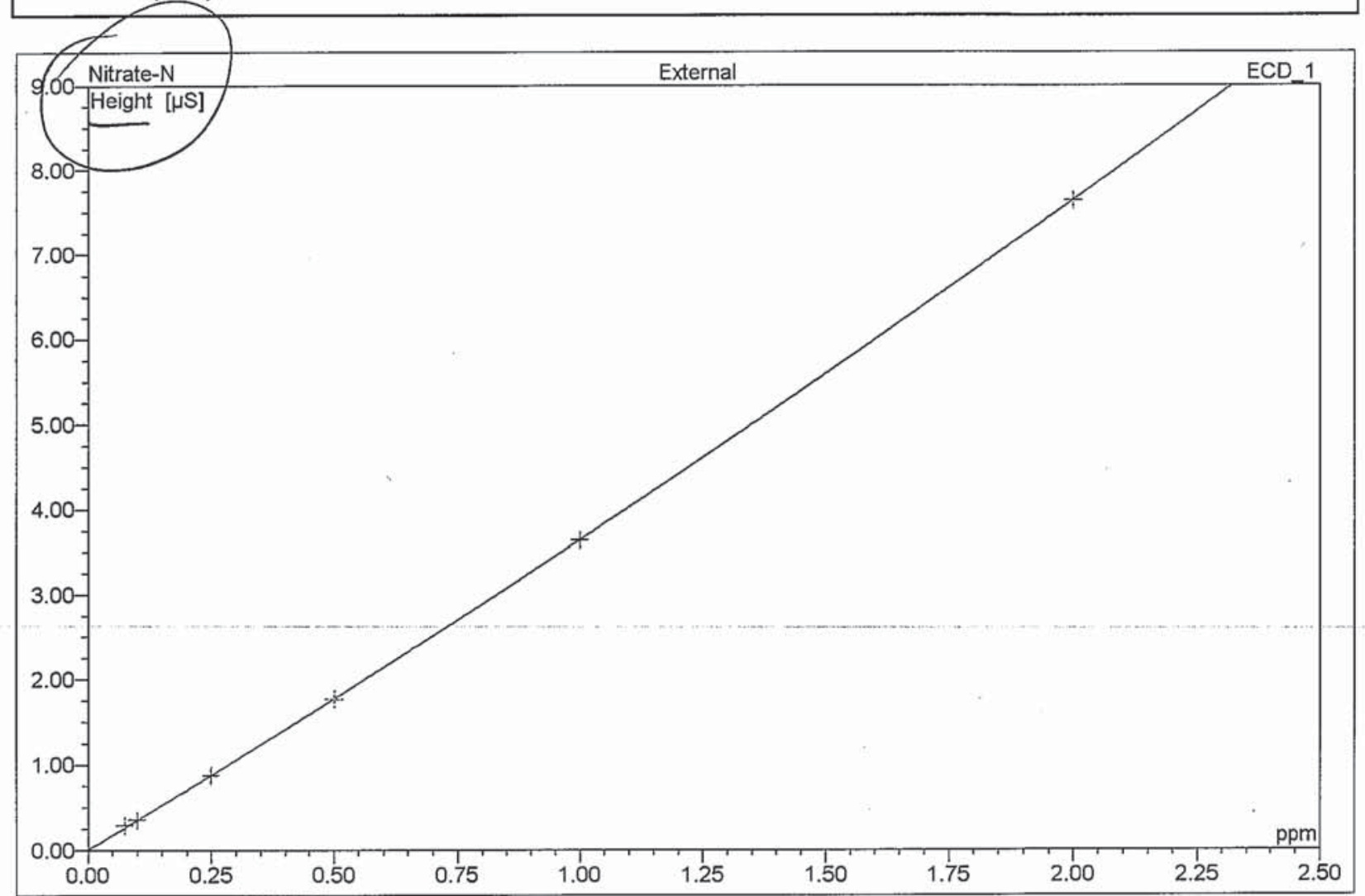

\begin{tabular}{|c|c|c|c|c|c|c|c|c|}
\hline No. & $\begin{array}{c}\text { Ret.Time } \\
\min \end{array}$ & Peak Name & Cal.Type & Points & R-Square & Offset & Slope & Curve \\
\hline 1 & 2.25 & n.a. & n.a. & n.a. & n.a. & n.a. & n.a. & n.a. \\
\hline 2 & 3.26 & Fluoride & Quad & 6 & 1.0000 & 0.000000 & 2.68877 & 0.217432 \\
\hline 3 & 4.61 & Chloride & Quad & 6 & 0.9998 & 0.000000 & 2.19733 & 0.033578 \\
\hline 4 & 5.37 & Nitrite-N & Quad & 6 & 1.0000 & 0.000000 & 3.80119 & 0.130678 \\
\hline 5 & 6.67 & Bromide & Quad & 6 & 1.0000 & 0.000000 & 0.70878 & 0.005755 \\
\hline 6 & 7.46 & Nitrate-N & Quad & 6 & $\checkmark 1.0000$ & 0.000000 & 3.45770 & 0.180759 \\
\hline Average: & & & & & 1.0000 & 0.0000 & 2.5708 & 0.1136 \\
\hline
\end{tabular}




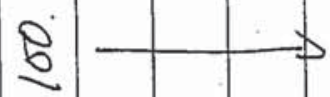

5

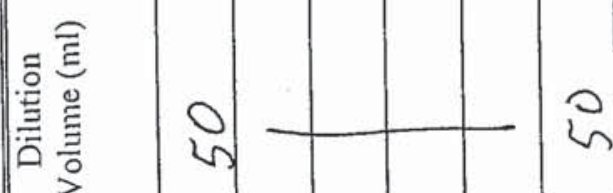

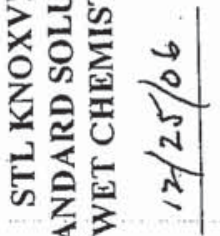

क लैं

ํ.

능

暒

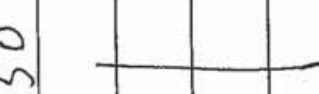

\section{高管}

$\frac{8}{8}$

ก

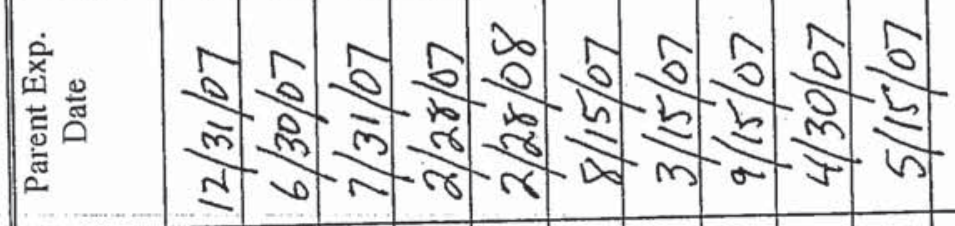

崖 递

इु)

离

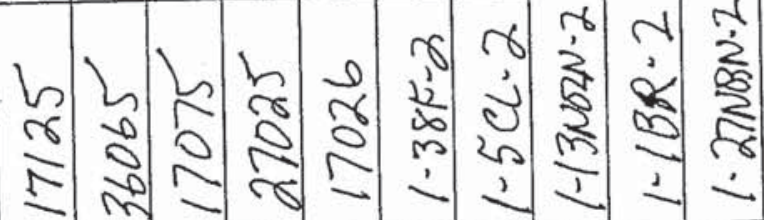

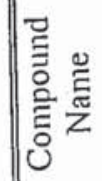

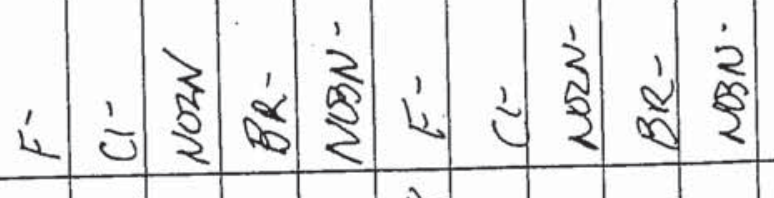

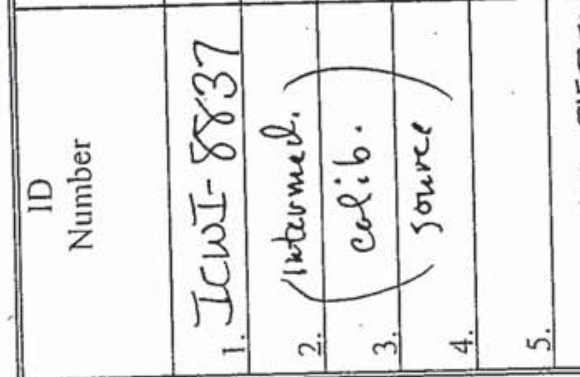

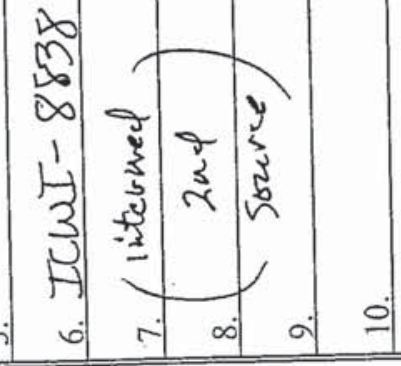




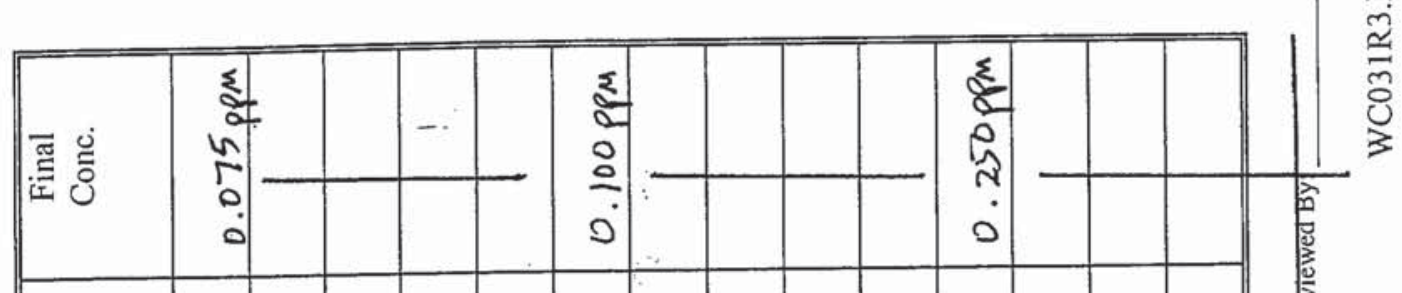

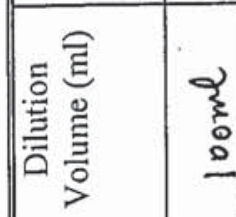

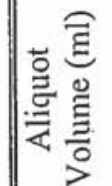

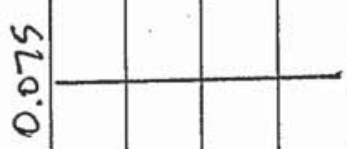

움

คิ

镸高

इ

임

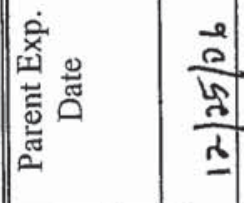

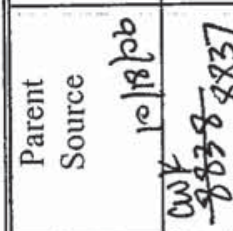

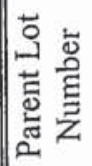

苫

总

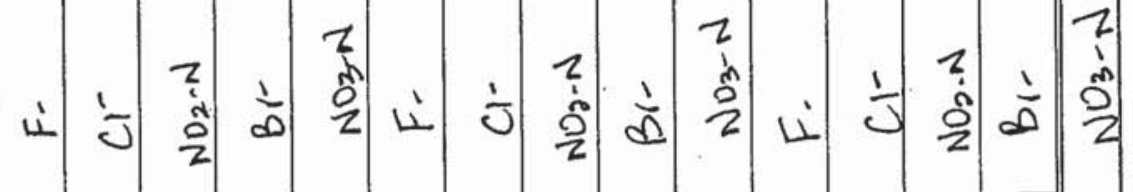

$\frac{\text { 을 }}{\frac{\infty}{0}}$

ญ्ञ

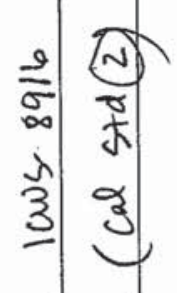

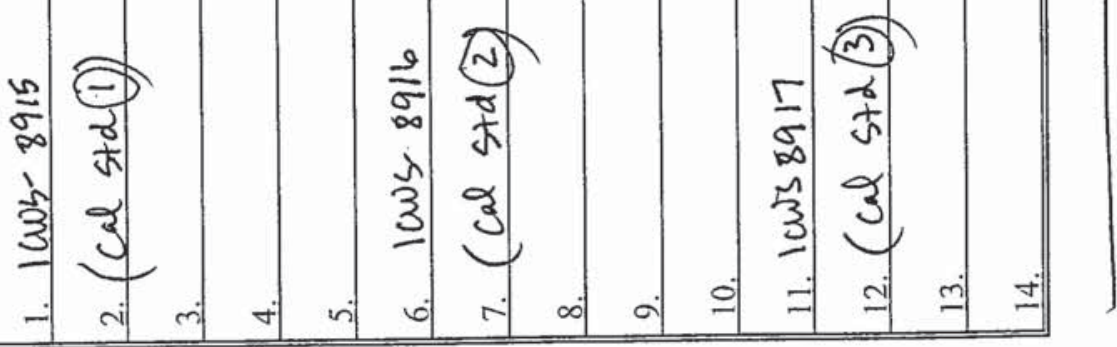




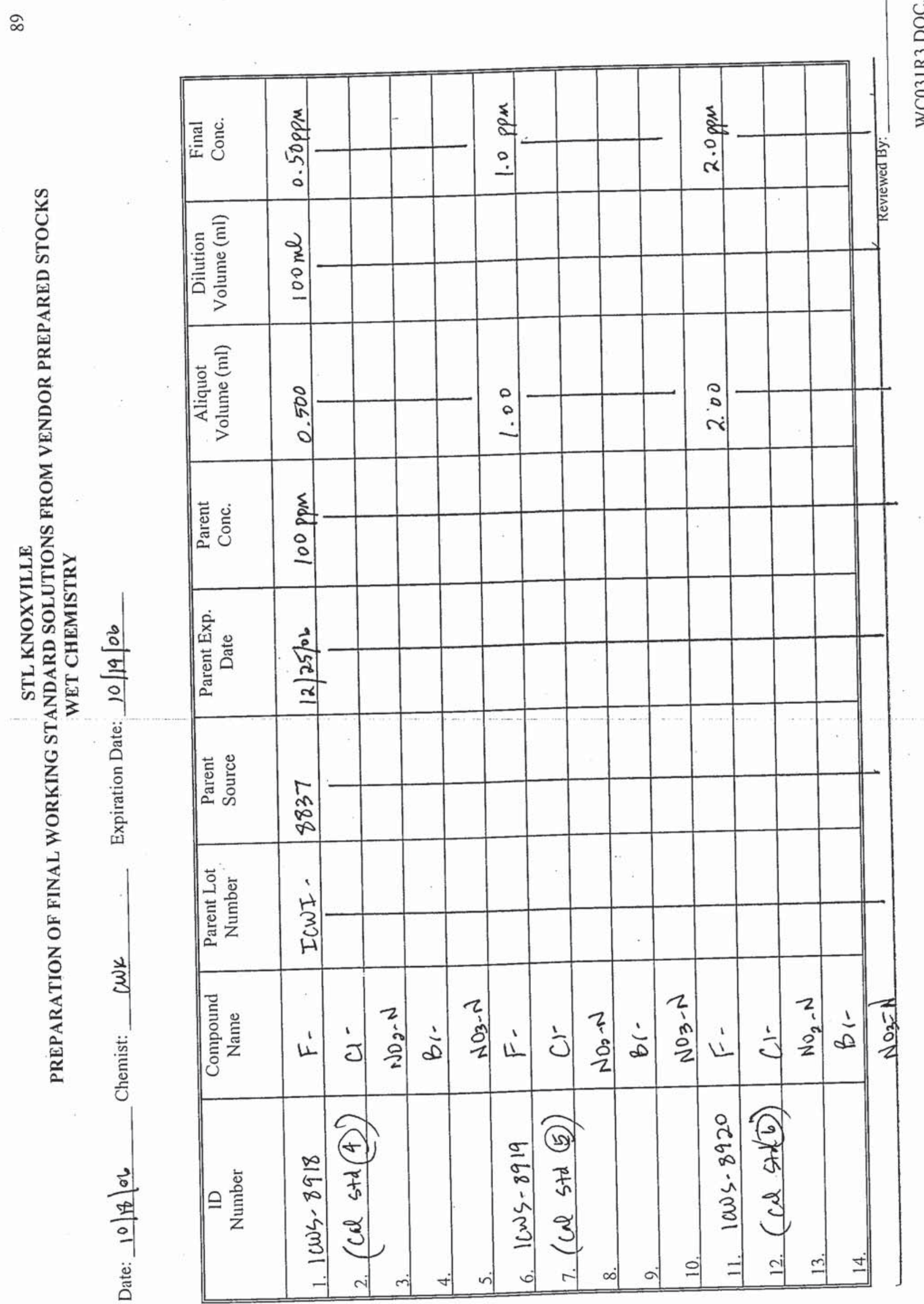




\section{STL Knoxville IC Initial Calibration Data Review / Narrative Checklist \\ Methods: 300.0, 9056, 9057 and 26A, SOP: KNOX-WC-0005, Rev. 8 \\ Page 1 of 1 \\ DXGUO (ARKGORN)}

Analysis Date:

$12 / 14 / 06$

File D: $\quad$ L14A-COW_AIR-ANIÓNS - 121406

\begin{tabular}{|c|c|c|c|c|c|}
\hline Initial Calibration Review Items & N/A & Yes & No & If No, why is data reportable? & $\begin{array}{c}\text { 2nd } \\
\sqrt{ }\end{array}$ \\
\hline 1. Were at least 5 levels of each analyte analyzed? & & $\checkmark$ & 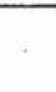 & & \\
\hline 2. Is low level standard concentration $\leq \mathrm{RL}$ ? & & & & & \\
\hline $\begin{array}{l}\text { 3. Are.the correlation coefficients }(r) \geq 0.995 \text {; } \\
r^{2} \geq 0.990 \text { ? }\end{array}$ & & $\checkmark$ & & . & \\
\hline $\begin{array}{l}\text { 4. For method } 300.0 \text {, was the calibration curve } \\
\text { processed using linear reqression? }\end{array}$ & $\checkmark$ & & - & & $N$ \\
\hline $\begin{array}{l}\text { 5. For manual integrated standards, are before/after } \\
\text { cluromatograms provided with initials/date/reason? }\end{array}$ & & $\mathcal{J}$ & & $\begin{array}{l}\text { Reasons: } S=\text { Split peak, } U=\text { Undetected peak, } I=\text { Incorrect } \\
\text { peak integration, } B=\text { =Baseline correction, } W=\text { Wrong peak } \\
\text { chosen by data system }\end{array}$ & \\
\hline
\end{tabular}

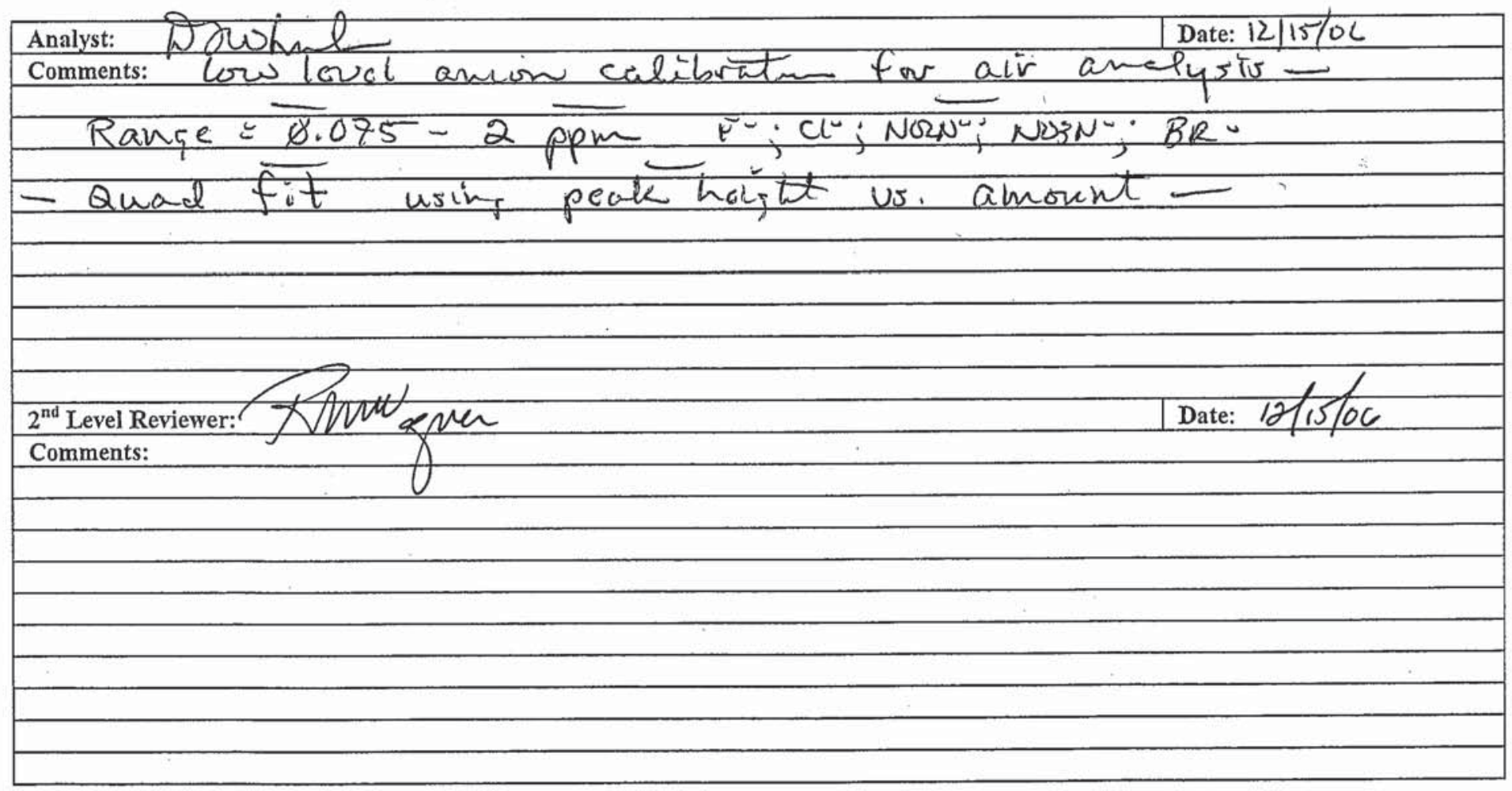




\section{CAL STD $1=$ ICWS-9045 @ (0.075ppm)}

\begin{tabular}{|llll|}
\hline Sample Name: & CAL STD 1 = ICWS-9045 @ (0.075ppm) & Injection Volume: & $\mathbf{5 0 . 0}$ \\
Vial Number: & $\mathbf{9 8}$ & Channel: & ECD_1 \\
Sample Type: & standard & Wavelength: & n.a. \\
Control Program: & ANIONS_AS14A & Bandwidth: & n.a. \\
Quantif. Method: & ANIONS & Dilution Factor: & 1.0000 \\
Recording Time: & $12 / 14 / 200616: 54$ & Sample Weight: & 1.0000 \\
Run Time (min): & 15.00 & Sample Amount: & 1.0000 \\
\hline
\end{tabular}

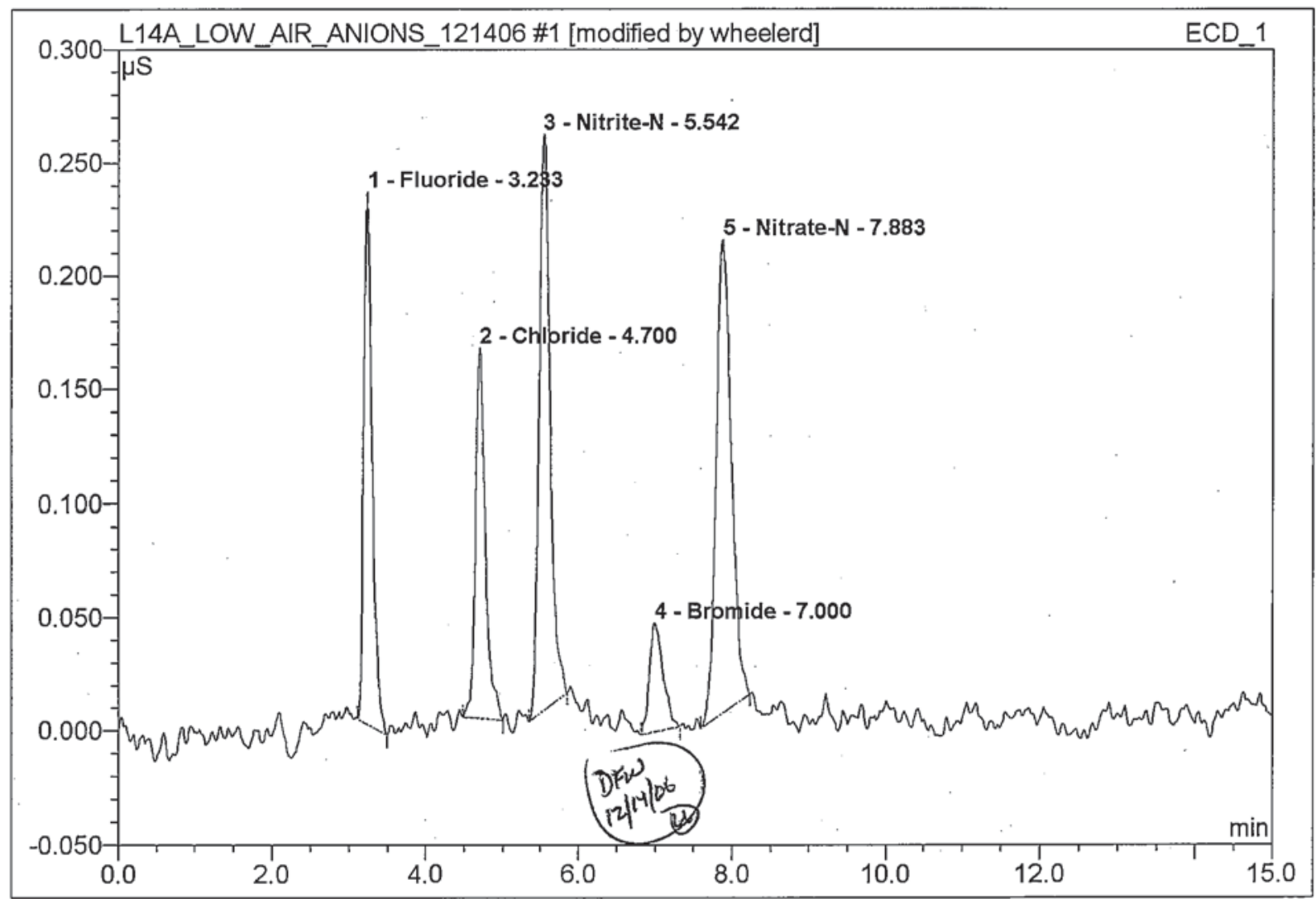

\begin{tabular}{|c|c|l|r|r|r|r|c|}
\hline No. & $\begin{array}{c}\text { Ret.Time } \\
\text { (min.) }\end{array}$ & \multicolumn{1}{|c|}{ Peak Name } & $\begin{array}{c}\text { Height } \\
\text { (uS) }\end{array}$ & $\begin{array}{c}\text { Area } \\
\mu \mathbf{S}^{*} \text { min }\end{array}$ & $\begin{array}{c}\text { Rel.Area } \\
(\%)\end{array}$ & $\begin{array}{c}\text { Amount } \\
\text { (mg/L) }\end{array}$ & $\begin{array}{c}\text { Peak } \\
\text { Type }\end{array}$ \\
\hline 1 & 3.23 & Fluoride & 0.23417 & 0.030 & 19.30 & 0.0748 & BMB \\
\hline 2 & 4.70 & Chloride & 0.16248 & 0.024 & 15.76 & 0.0868 & BMB \\
\hline 3 & 5.54 & Nitrite-N & 0.25345 & 0.043 & 27.70 & 0.0748 & BMB \\
\hline 4 & 7.00 & Bromide & 0.04768 & 0.010 & 6.42 & 0.0837 & BMB $^{*}$ \\
\hline 5 & 7.88 & Nitrate-N & 0.20803 & 0.048 & 30.83 & 0.0756 & BMB \\
\hline
\end{tabular}




\section{CAL STD $1=$ ICWS-9045 @ $(0.075 \mathrm{ppm})$}

Sample Name:

Vial Number:

Sample Type:

Control Program:

Quantif. Method:

Recording Time:

Run Time (min):
CAL STD $1=$ ICWS-9045 @ (0.075ppm)

98

standard

ANIONS_AS14A

ANIONS

12/14/2006 16:54

15.00
Injection Volume:

Channel:

Wavelength:

Bandwidth:

Dilution Factor:

Sample Weight:

Sample Amount:
50.0

ECD_1

n.a.

n.a.

1.0000

1.0000

1.0000

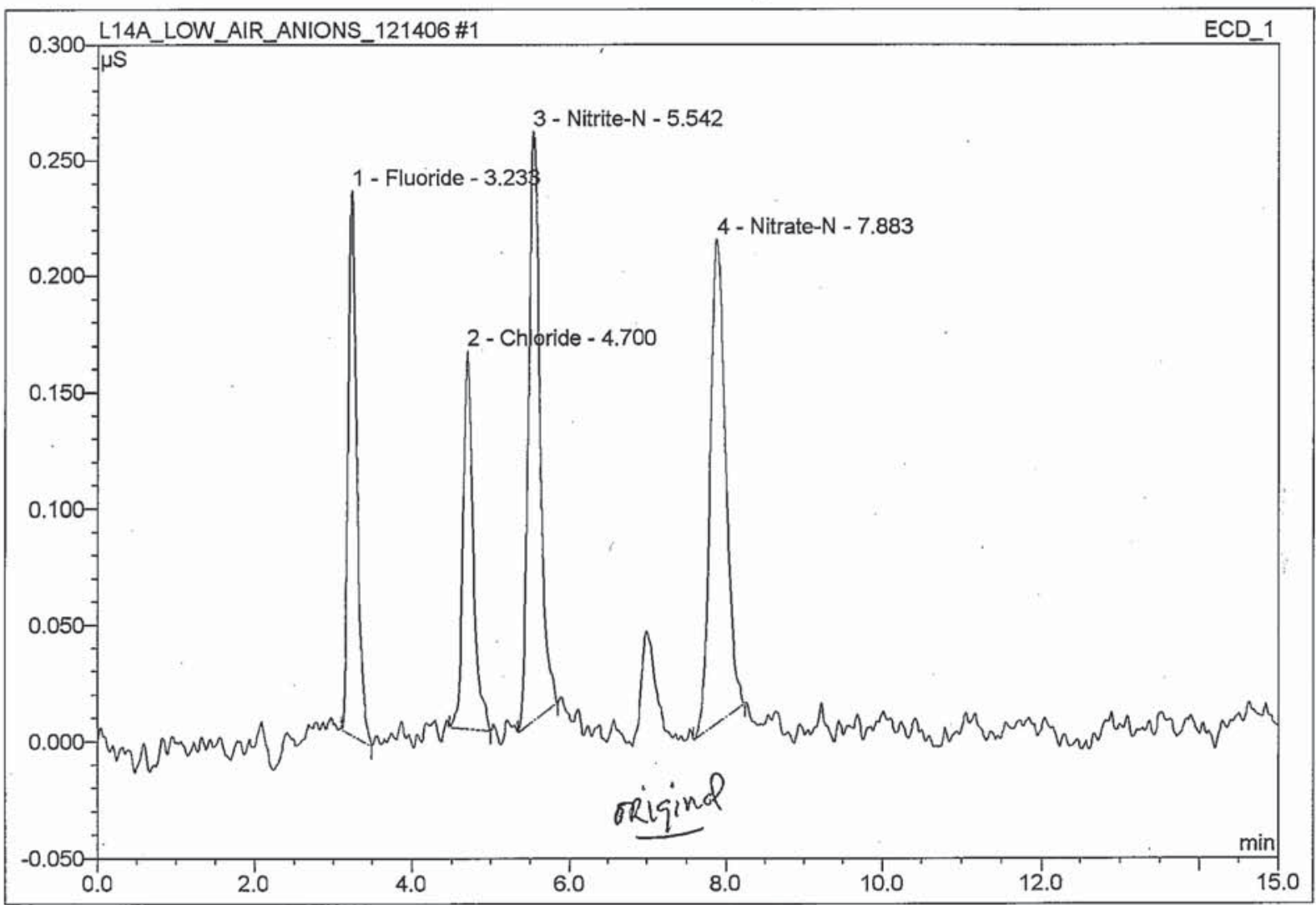

\begin{tabular}{|c|c|l|r|r|r|r|c|}
\hline No. & $\begin{array}{c}\text { Ret.Time } \\
\text { (min.) }\end{array}$ & \multicolumn{1}{|c|}{ Peak Name } & $\begin{array}{c}\text { Height } \\
\text { (uS) }\end{array}$ & $\begin{array}{c}\text { Area } \\
\text { IS }^{\star} \text { min }\end{array}$ & $\begin{array}{c}\text { Rel.Area } \\
(\%)\end{array}$ & $\begin{array}{c}\text { Amount } \\
\text { (mg/L) }\end{array}$ & $\begin{array}{c}\text { Peak } \\
\text { Type }\end{array}$ \\
\hline 1 & 3.23 & Fluoride & 0.23417 & 0.030 & 20.62 & n.a. & BMB \\
\hline 2 & 4.70 & Chloride & 0.16248 & 0.024 & 16.84 & n.a. & BMB \\
\hline 3 & 5.54 & Nitrite-N & 0.25345 & 0.043 & 29.60 & n.a. & BMB \\
\hline 4 & 7.88 & Nitrate-N & 0.20803 & 0.048 & 32.94 & n.a. & BMB \\
\hline
\end{tabular}




\section{CAL STD 2 = ICWS-9046 @ (0.10ppm)}

Sample Name: Vial Number:

Sample Type:

Control Program:

Quantif. Method:

Recording Time:

Run Time ( $\mathrm{min})$ :
CAL STD 2 = ICWS-9046@ (0.10ppm)

99

standard

ANIONS_AS14A

ANIONS

12/14/2006 17:11

10.00
Injection Volume: $\quad \mathbf{5 0 . 0}$

Channel: ECD_1

Wavelength: n.a.

Bandwidth: n.a.

Dilution Factor: $\quad 1.0000$

Sample Weight: $\quad \mathbf{1 . 0 0 0 0}$

Sample Amount: $\quad \mathbf{1 . 0 0 0 0}$

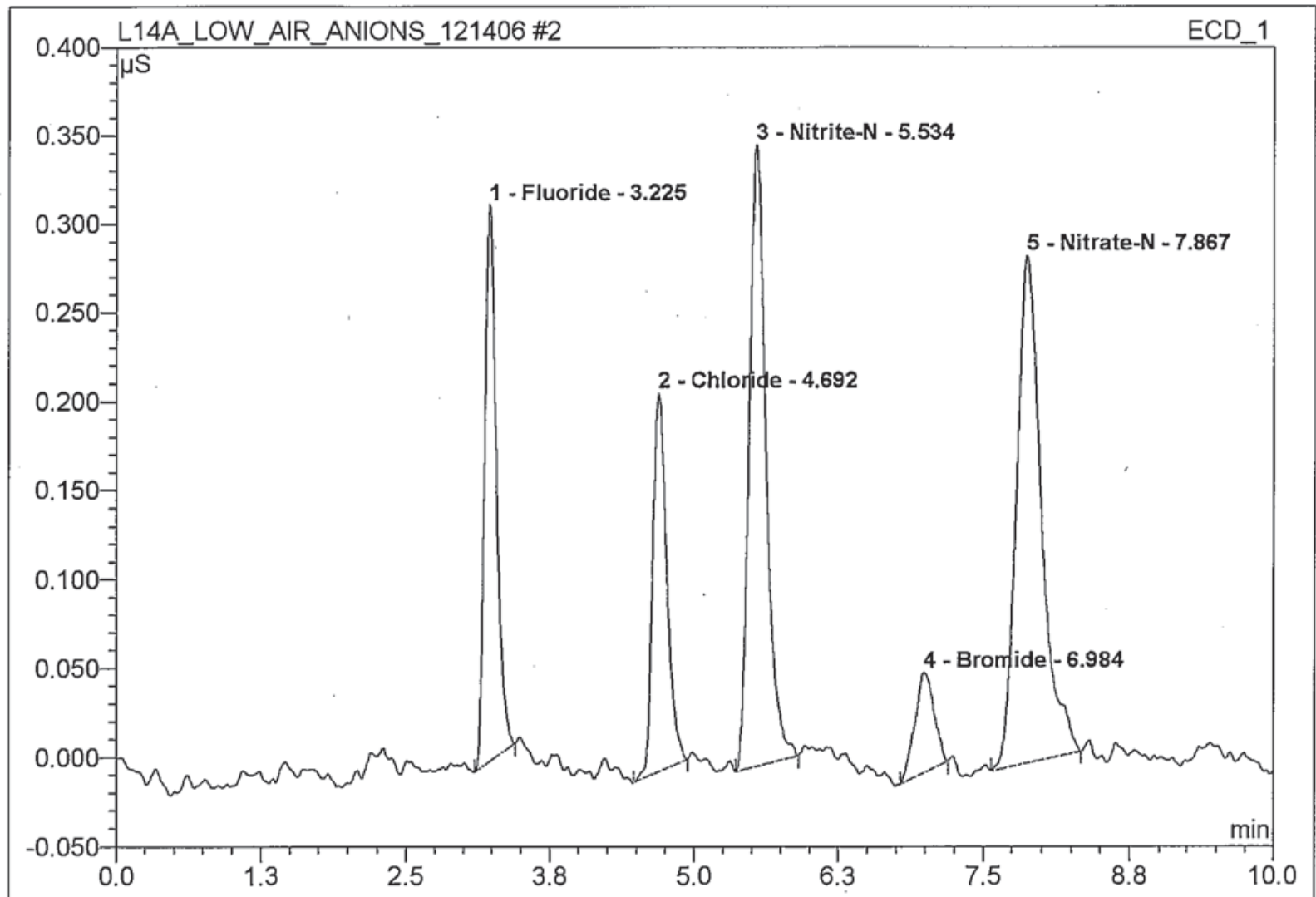

\begin{tabular}{|c|c|l|r|r|r|r|c|}
\hline No. & $\begin{array}{c}\text { Ret.Time } \\
(\mathbf{m i n} .)\end{array}$ & \multicolumn{1}{|c|}{ Peak Name } & $\begin{array}{c}\text { Height } \\
(\mathbf{u S})\end{array}$ & $\begin{array}{c}\text { Area } \\
\boldsymbol{\mu} \mathbf{S}^{*} \mathrm{~min}\end{array}$ & $\begin{array}{c}\text { Rel.Area } \\
(\%)\end{array}$ & $\begin{array}{c}\text { Amount } \\
(\mathrm{mg} / \mathrm{L})\end{array}$ & $\begin{array}{c}\text { Peak } \\
\text { Type }\end{array}$ \\
\hline 1 & 3.23 & Fluoride & 0.31346 & 0.037 & 18.04 & 0.0999 & BMB \\
\hline 2 & 4.69 & Chloride & 0.21253 & 0.030 & 14.47 & 0.1134 & BMB \\
\hline 3 & 5.53 & Nitrite-N & 0.34978 & 0.059 & 28.59 & 0.1031 & BMB \\
\hline 4 & 6.98 & Bromide & 0.05646 & 0.011 & 5.19 & 0.0991 & BMB \\
\hline 5 & 7.87 & Nitrate-N & 0.28533 & 0.070 & 33.71 & 0.1036 & BMB \\
\hline
\end{tabular}




\section{CAL STD 3 = ICWS-9047 @ (0.25ppm)}

Sample Name: Vial Number:

Sample Type:

Control Program:

Quantif. Method:

Recording Time:

Run Time ( $\mathrm{min})$ :

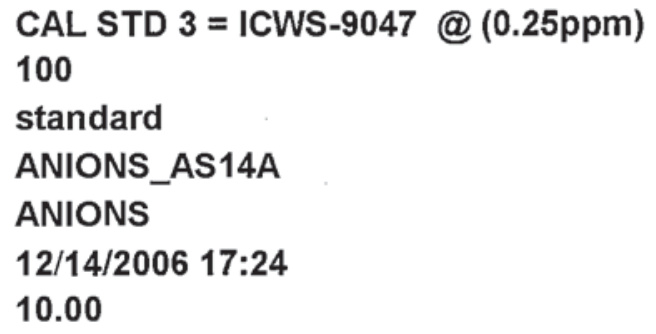

ANIONS_AS14A

ANIONS

12/14/2006 17:24

10.00

Injection Volume:

Channel:

Wavelength:

Bandwidth:

Dilution Factor:

Sample Weight:

Sample Amount:
50.0

ECD_1

n.a.

n.a.

1.0000

1.0000

1.0000

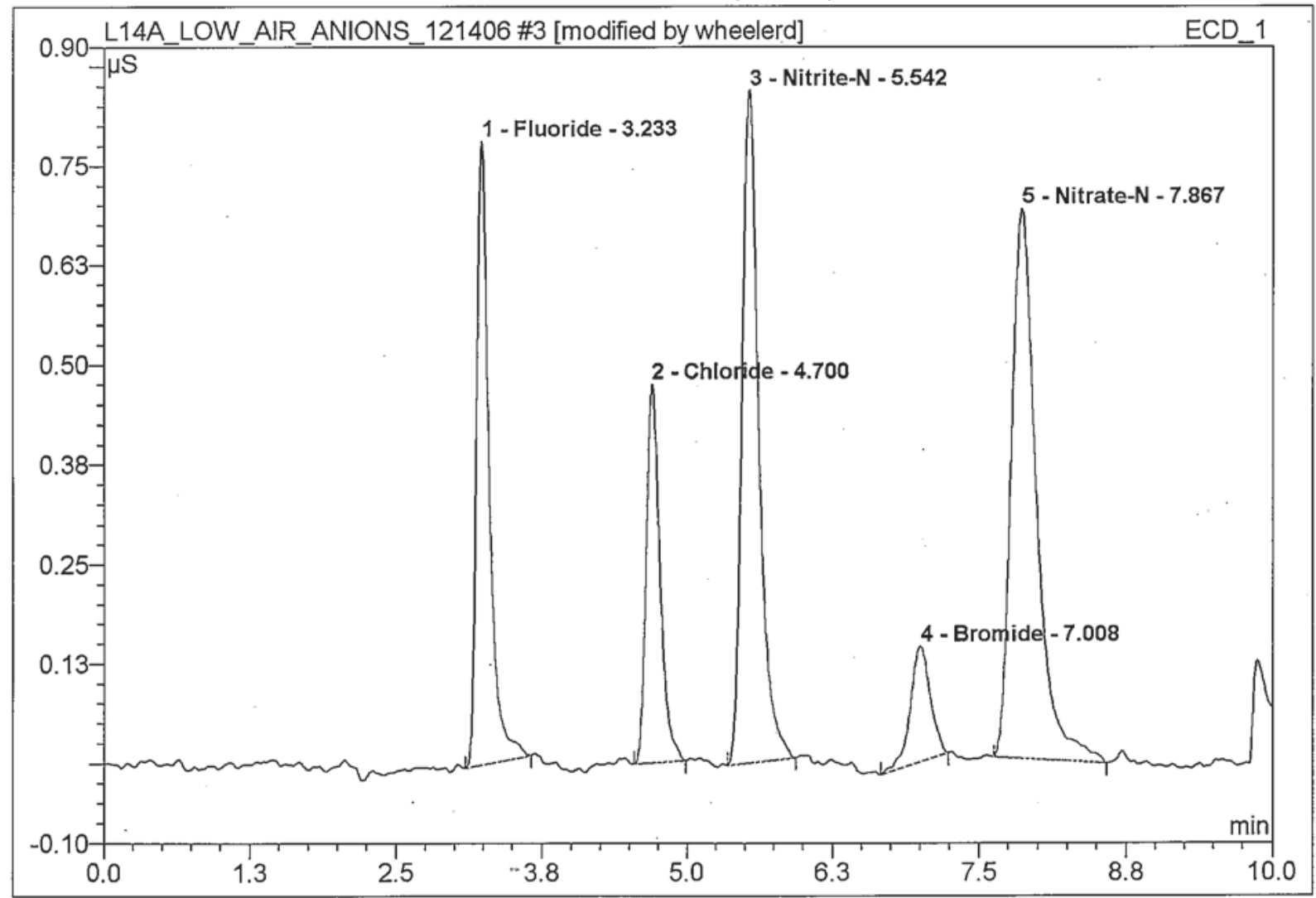

\begin{tabular}{|c|c|l|r|r|r|r|c|}
\hline No. & $\begin{array}{c}\text { Ret.Time } \\
\text { (min.) }\end{array}$ & \multicolumn{1}{|c|}{ Peak Name } & $\begin{array}{c}\text { Height } \\
\text { (uS) }\end{array}$ & $\begin{array}{c}\text { Area } \\
\text { is*min }\end{array}$ & $\begin{array}{c}\text { Rel.Area } \\
(\%)\end{array}$ & $\begin{array}{c}\text { Amount } \\
\text { (mg/L) }\end{array}$ & $\begin{array}{c}\text { Peak } \\
\text { Type }\end{array}$ \\
\hline 1 & 3.23 & Fluoride & 0.78262 & 0.100 & 19.79 & 0.2477 & BMB \\
\hline 2 & 4.70 & Chloride & 0.47425 & 0.066 & 13.11 & 0.2518 & BMB \\
\hline 3 & 5.54 & Nitrite-N & 0.84353 & 0.144 & 28.39 & 0.2473 & BMB \\
\hline 4 & 7.01 & Bromide & 0.14435 & 0.029 & 5.64 & 0.2526 & BMB \\
\hline 5 & 7.87 & Nitrate-N & 0.68927 & 0.167 & 33.06 & 0.2483 & BMB \\
\hline
\end{tabular}




\section{CAL STD $4=$ ICWS-9048 @ (0.50ppm)}

\begin{tabular}{|llll|}
\hline Sample Name: & CAL STD 4 = ICWS-9048 @ (0.50ppm) & Injection Volume: & $\mathbf{5 0 . 0}$ \\
Vial Number: & 101 & Channel: & ECD_1 \\
Sample Type: & standard & Wavelength: & n.a. \\
Control Program: & ANIONS_AS14A & Bandwidth: & n.a. \\
Quantif. Method: & ANIONS & Dilution Factor: & 1.0000 \\
Recording Time: & $\mathbf{1 2 / 1 4 / 2 0 0 6 ~ 1 7 : 3 6}$ & Sample Weight: & 1.0000 \\
Run Time (min): & $\mathbf{1 0 . 0 0}$ & Sample Amount: & $\mathbf{1 . 0 0 0 0}$ \\
\hline
\end{tabular}

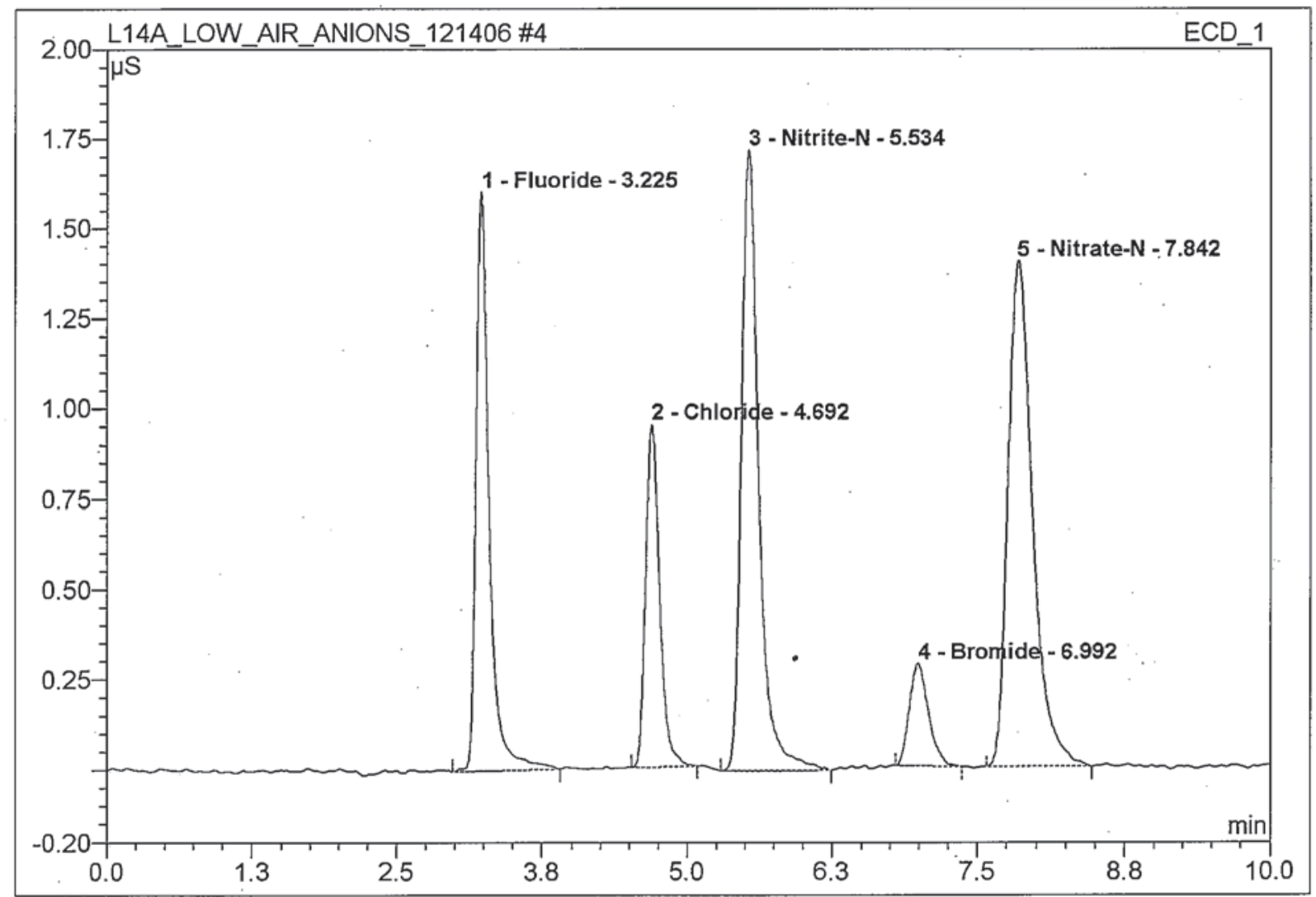

\begin{tabular}{|c|c|l|r|r|r|r|c|}
\hline No. & $\begin{array}{c}\text { Ret.Time } \\
(\mathbf{m i n})\end{array}$ & \multicolumn{1}{|c|}{ Peak Name } & $\begin{array}{c}\text { Height } \\
(\mathbf{u S})\end{array}$ & $\begin{array}{c}\text { Area } \\
\boldsymbol{\mu} \mathbf{S}^{*} \text { min }\end{array}$ & $\begin{array}{c}\text { Rel.Area } \\
(\%)\end{array}$ & $\begin{array}{c}\text { Amount } \\
\text { (mg/L) }\end{array}$ & $\begin{array}{c}\text { Peak } \\
\text { Type }\end{array}$ \\
\hline 1 & 3.23 & Fluoride & 1.60279 & 0.210 & 20.40 & 0.5010 & BMB \\
\hline 2 & 4.69 & Chloride & 0.94632 & 0.132 & 12.83 & 0.4981 & BMB \\
\hline 3 & 5.53 & Nitrite-N & 1.71930 & 0.302 & 29.30 & 0.4988 & BMB \\
\hline 4 & 6.99 & Bromide & 0.28167 & 0.054 & 5.25 & 0.4908 & BMB \\
\hline 5 & 7.84 & Nitrate-N & 1.39855 & 0.332 & 32.22 & 0.4972 & BMB \\
\hline
\end{tabular}




\section{$5 \quad$ CAL STD 5 = ICWS-9049 @ (1.ppm)}

Sample Name:

Vial Number:

Sample Type:

Control Program:

Quantif. Method:

Recording Time:

Run Time ( $\min )$ :

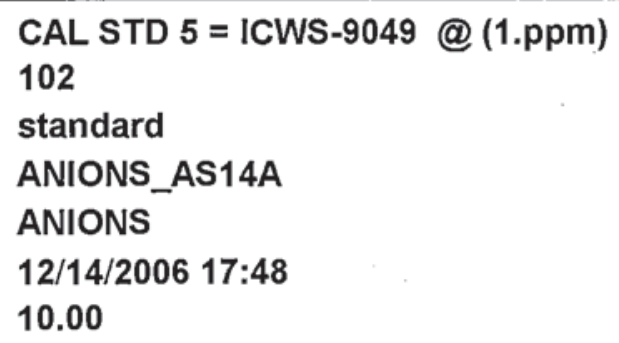

ANIONS

12/14/2006 17:48

10.00

Injection Volume:

Channel:

Wavelength:

Bandwidth:

Dilution Factor:

Sample Weight:

Sample Amount:
50.0

ECD_1

n.a.

n.a.

1.0000

1.0000

1.0000

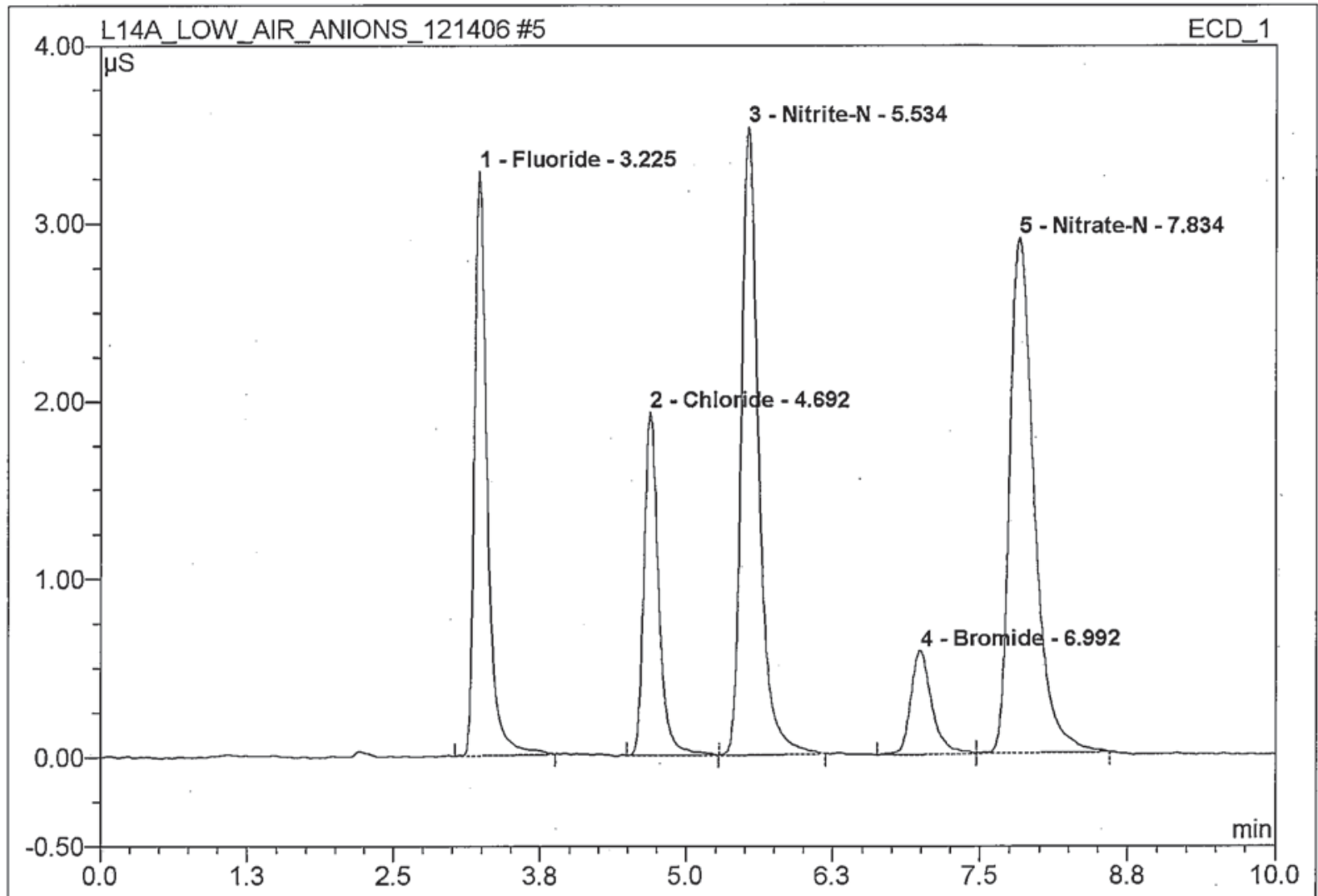

\begin{tabular}{|c|c|l|r|r|r|r|c|}
\hline No. & $\begin{array}{c}\text { Ret.Time } \\
\text { (min.) }\end{array}$ & \multicolumn{1}{|c|}{ Peak Name } & $\begin{array}{c}\text { Height } \\
\text { (uS) }\end{array}$ & $\begin{array}{c}\text { Area } \\
\mu \mathbf{S}^{*} \text { min }\end{array}$ & $\begin{array}{c}\text { Rel.Area } \\
(\%)\end{array}$ & $\begin{array}{c}\text { Amount } \\
\text { (mg/L) }\end{array}$ & $\begin{array}{c}\text { Peak } \\
\text { Type }\end{array}$ \\
\hline 1 & 3.23 & Fluoride & 3.27751 & 0.412 & 19.61 & 1.0002 & BMB \\
\hline 2 & 4.69 & Chloride & 1.92630 & 0.278 & 13.23 & 0.9967 & BMB \\
\hline 3 & 5.53 & Nitrite-N & 3.52256 & 0.606 & 28.87 & 1.0015 & BMB \\
\hline 4 & 6.99 & Bromide & 0.58187 & 0.122 & 5.80 & 1.0046 & BM \\
\hline 5 & 7.83 & Nitrate-N & 2.89372 & 0.682 & 32.48 & 1.0020 & MB \\
\hline
\end{tabular}




\section{CAL STD $6=$ ICWS-9050 @ (2.ppm)}

\begin{tabular}{llll|}
\hline Sample Name: & CAL STD 6 = ICWS-9050 @ (2.ppm) & Injection Volume: & $\mathbf{5 0 . 0}$ \\
Vial Number: & $\mathbf{1 0 3}$ & Channel: & ECD_1 \\
Sample Type: & standard & Wavelength: & n.a. \\
Control Program: & ANIONS_AS14A & Bandwidth: & n.a. \\
Quantif. Method: & ANIONS & Dilution Factor: & $\mathbf{1 . 0 0 0 0}$ \\
Recording Time: & $\mathbf{1 2 / 1 4 / 2 0 0 6 ~ 1 8 : 0 1}$ & Sample. Weight: & $\mathbf{1 . 0 0 0 0}$ \\
Run Time (min): & $\mathbf{1 0 . 0 0}$ & Sample Amount: & $\mathbf{1 . 0 0 0 0}$ \\
\hline
\end{tabular}

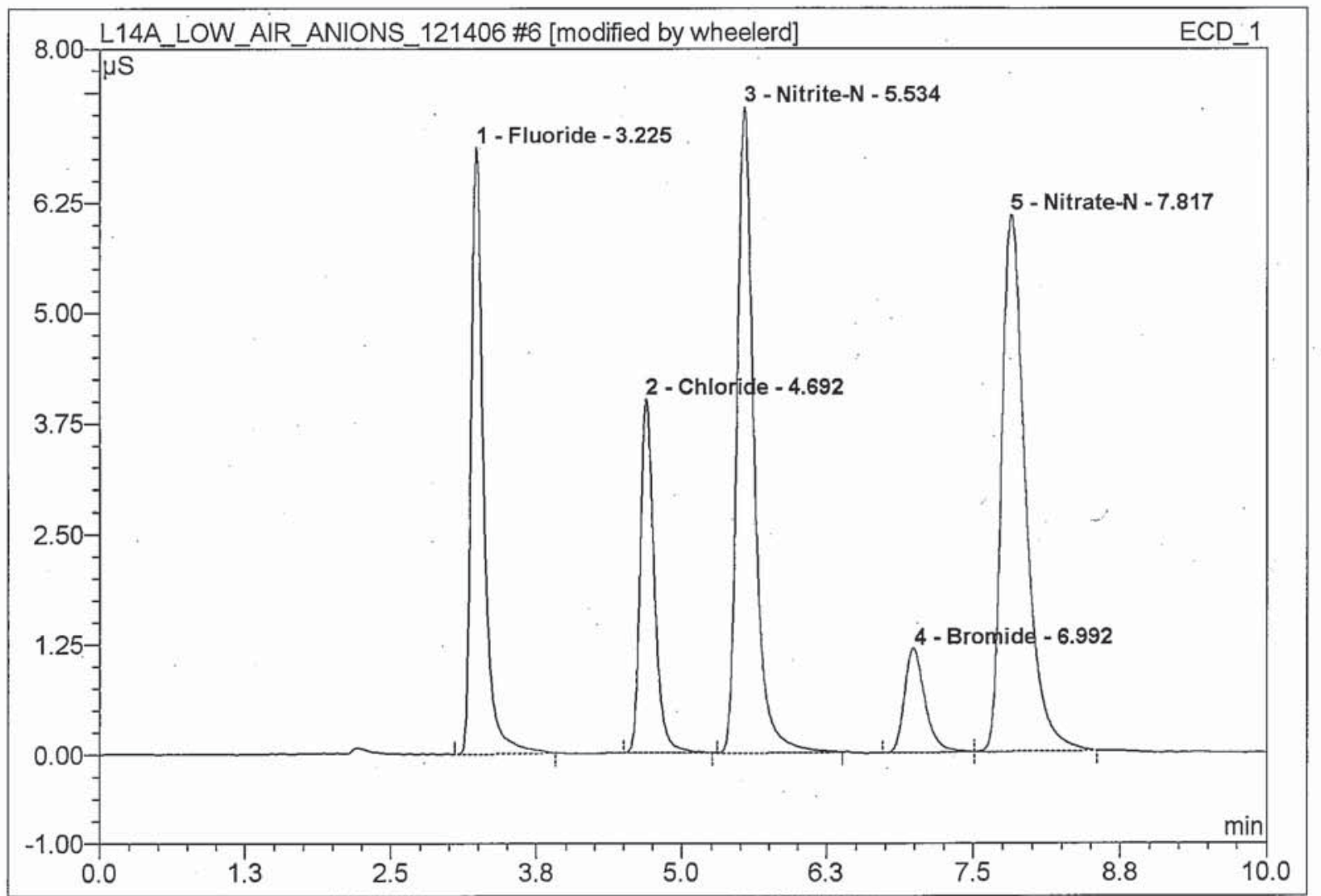

\begin{tabular}{|c|c|l|r|r|r|r|c|}
\hline No. & $\begin{array}{c}\text { Ret.Time } \\
(\mathbf{m i n} .)\end{array}$ & \multicolumn{1}{|c|}{ Peak Name } & $\begin{array}{c}\text { Height } \\
(\mathbf{u S})\end{array}$ & $\begin{array}{c}\text { Area } \\
\boldsymbol{\mu} \mathbf{S}^{*} \text { min }\end{array}$ & $\begin{array}{c}\text { Rel.Area } \\
(\%)\end{array}$ & $\begin{array}{c}\text { Amount } \\
(\mathbf{m g} / \mathbf{L})\end{array}$ & $\begin{array}{c}\text { Peak } \\
\text { Type }\end{array}$ \\
\hline 1 & 3.23 & Fluoride & 6.86489 & 0.858 & 19.88 & 1.9999 & BMB \\
\hline 2 & 4.69 & Chloride & 3.99899 & 0.564 & 13.08 & 2.0008 & BMB \\
\hline 3 & 5.53 & Nitrite-N & 7.31424 & 1.247 & 28.92 & 1.9998 & BMB \\
\hline 4 & 6.99 & Bromide & 1.17848 & 0.240 & 5.56 & 1.9994 & BM \\
\hline 5 & 7.82 & Nitrate-N & 6.07244 & 1.404 & 32.55 & 1.9997 & MB \\
\hline
\end{tabular}




\begin{tabular}{|c|c|c|c|}
\hline \multicolumn{4}{|c|}{ 6_GALSTB6-1CWS-9050-@(2.ppm) } \\
\hline Sample Name: & CAL STD $6=$ ICWS-9050 @ (2.ppm) & Injection Volume: & 50.0 \\
\hline Vial Number: & 103 & Channel: & ECD_1 \\
\hline Sample Type: & standard & Wavelength: & n.a. \\
\hline Control Program: & ANIONS_AS14A & Bandwidth: & n.a. \\
\hline Quantif. Method: & ANIONS & Dilution Factor: & 1.0000 \\
\hline Recording Time: & \#\#\#\#\#\#\#\#\#\#\# & Sample Weight: & 1.0000 \\
\hline Run Time (min): & 10.00 & Sample Amount: & 1.0000 \\
\hline
\end{tabular}

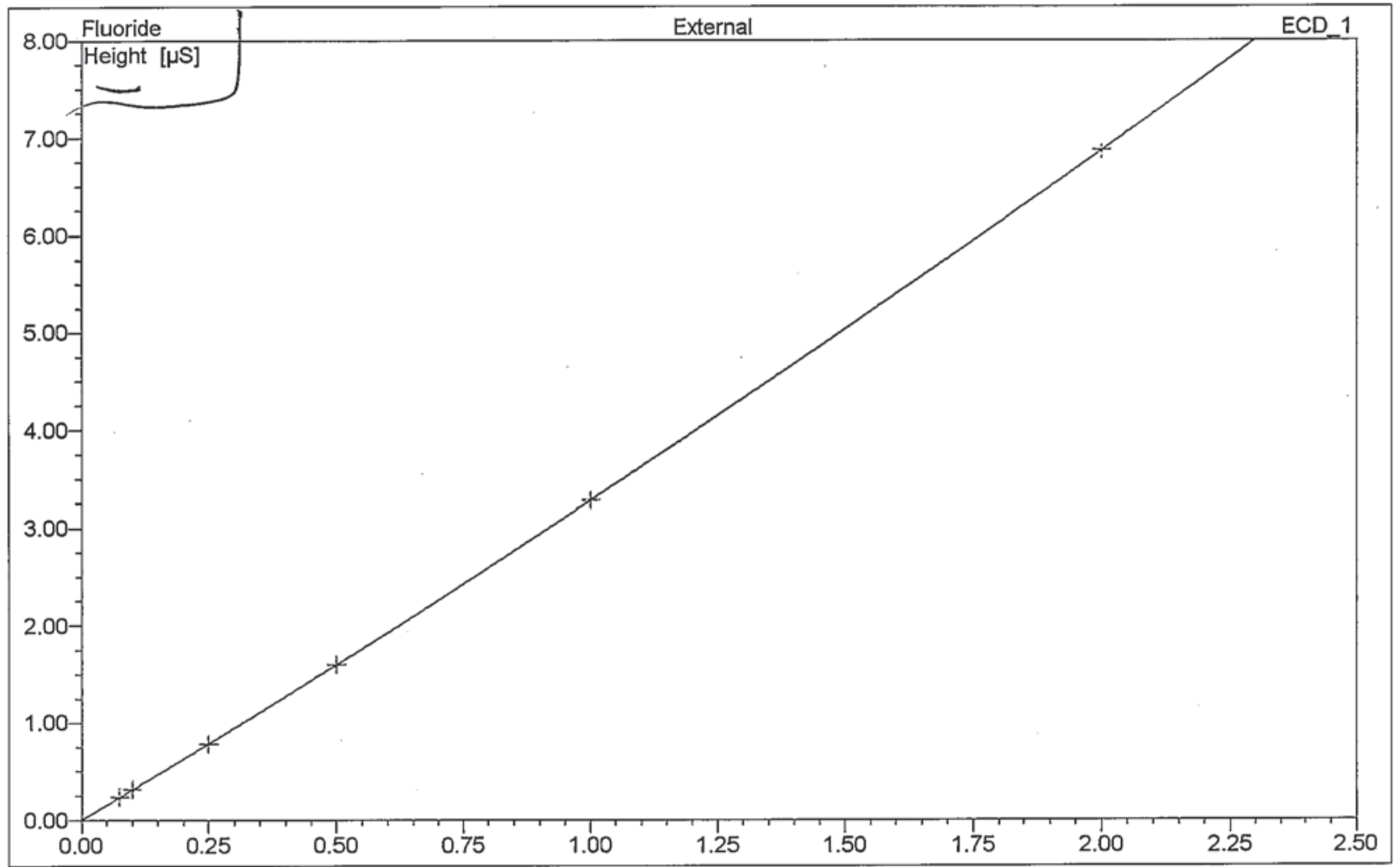

\begin{tabular}{|c|cllccccc|}
\hline No. & $\begin{array}{c}\text { Ret.Time } \\
\text { min }\end{array}$ & Peak Name & Cal.Type & Points & $\begin{array}{c}\text { Corr.Coeff. } \\
\text { (R) }\end{array}$ & Offset & Slope & Curve \\
\hline 1 & 3.23 & Fluoride & Quad & 6 & 0.9997 & 0.0000 & 3.120830 & 0.155880 \\
2 & 4.69 & Chloride & Quad & 6 & 0.9997 & 0.0000 & 1.867234 & 0.065694 \\
3 & 5.53 & Nitrite-N & Quad & 6 & 0.9998 & 0.0000 & 3.376824 & 0.140386 \\
4 & 6.99 & Bromide & Quad & 6 & 0.9999 & 0.0000 & 0.568855 & 0.010287 \\
5 & 7.82 & Nitrate-N & Quad & 6 & 0.9997 & 0.0000 & 2.738783 & 0.148955 \\
\hline Average: & & & & & 0.9998 & 0.0000 & 2.3345 & 0.1042 \\
\hline
\end{tabular}




\section{CALSTD 6 $=1$ CWS-9050@(2.ppm)- $\left(\begin{array}{c}D K \omega \\ 12 / 15 \% 6\end{array}\right)$}

Sample Name: $\quad$ CAL STD 6 = ICWS-9050 @ (2.ppm)

Vial Number:

Sample Type:

Control Program:

Quantif. Method:

Recording Time:

Run Time (min):
103

standard

ANIONS_AS14A

ANIONS

\#\#\#\#\#\#\#\#\#\#\#

10.00
Injection Volume: $\quad \mathbf{5 0 . 0}$

Channel:

Wavelength:

Bandwidth:

Dilution Factor:

Sample Weight:

Sample Amount:
ECD_1

n.a.

n.a.

1.0000

1.0000

1.0000

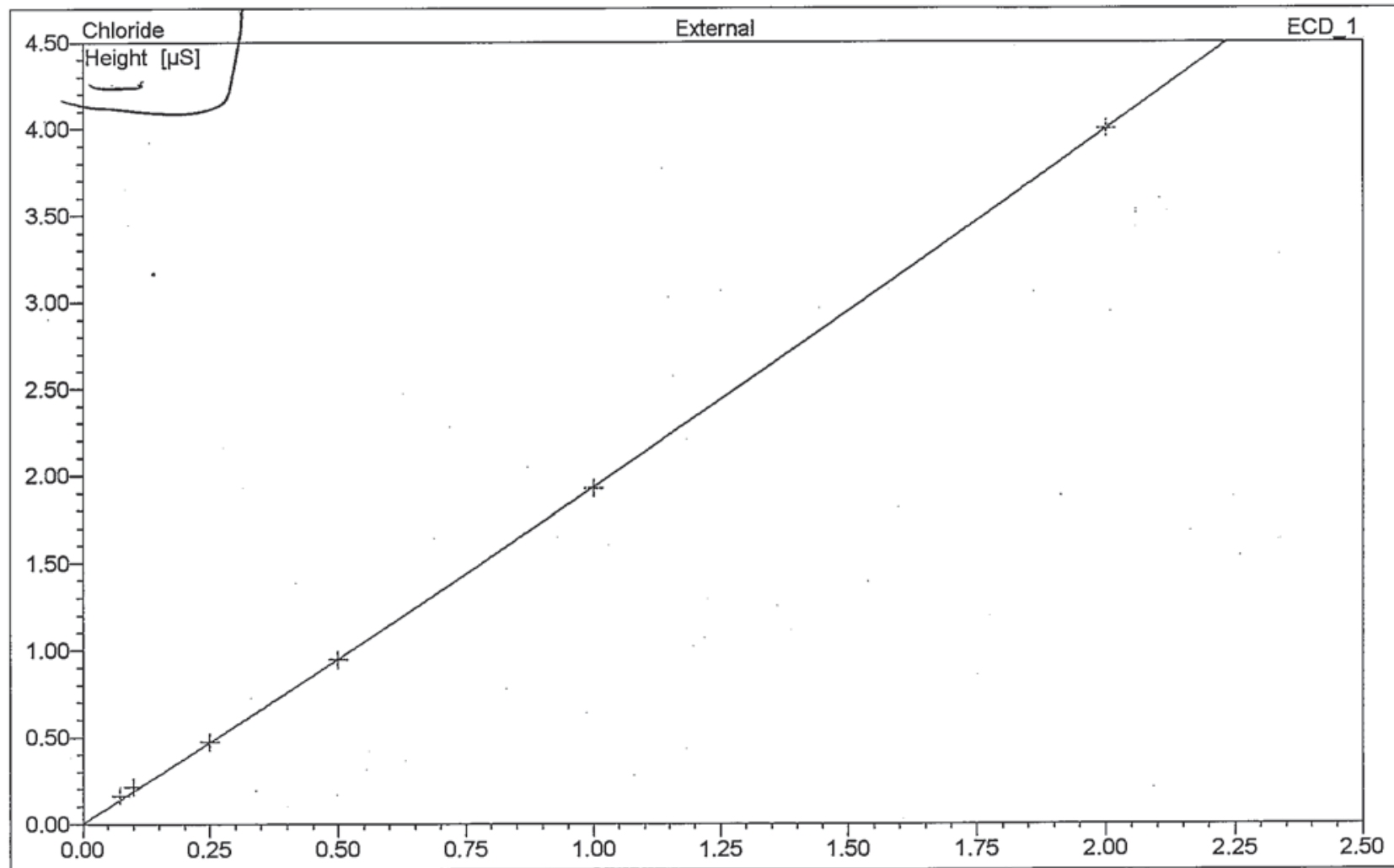

\begin{tabular}{|r|clcccccc|}
\hline No. & $\begin{array}{c}\text { Ret.Time } \\
\text { min }\end{array}$ & Peak Name & Cal.Type & Points & $\begin{array}{c}\text { Corr.Coeff. } \\
(\mathbf{R})\end{array}$ & Offset & Slope & Curve \\
\hline 1 & 3.23 & Fluoride & Quad & 6 & 0.9997 & 0.0000 & 3.120830 & 0.155880 \\
2 & 4.69 & Chloride & Quad & 6 & 0.9997 & 0.0000 & 1.867234 & 0.065694 \\
\cline { 2 - 7 } & 5.53 & Nitrite-N & Quad & 6 & 0.9998 & 0.0000 & 3.376824 & 0.140386 \\
4 & 6.99 & Bromide & Quad & 6 & 0.9999 & 0.0000 & 0.568855 & 0.010287 \\
5 & 7.82 & Nitrate-N & Quad & 6 & 0.9997 & 0.0000 & 2.738783 & 0.148955 \\
\hline Average: & & & & & 0.9998 & 0.0000 & 2.3345 & 0.1042 \\
\hline
\end{tabular}




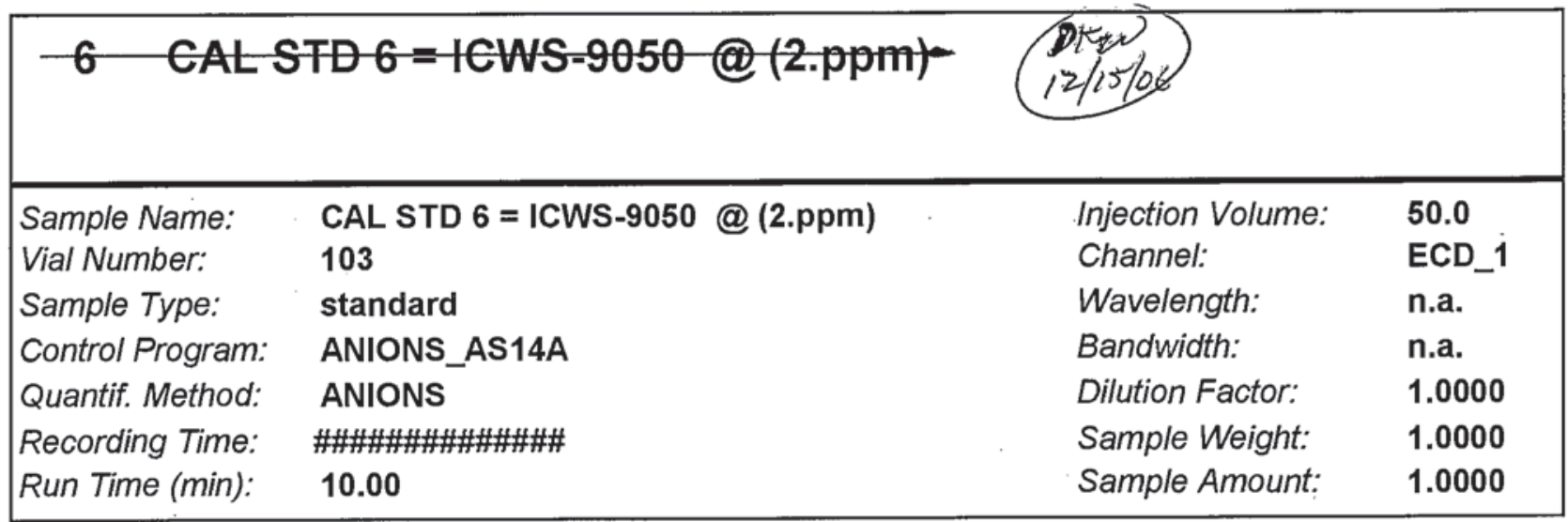

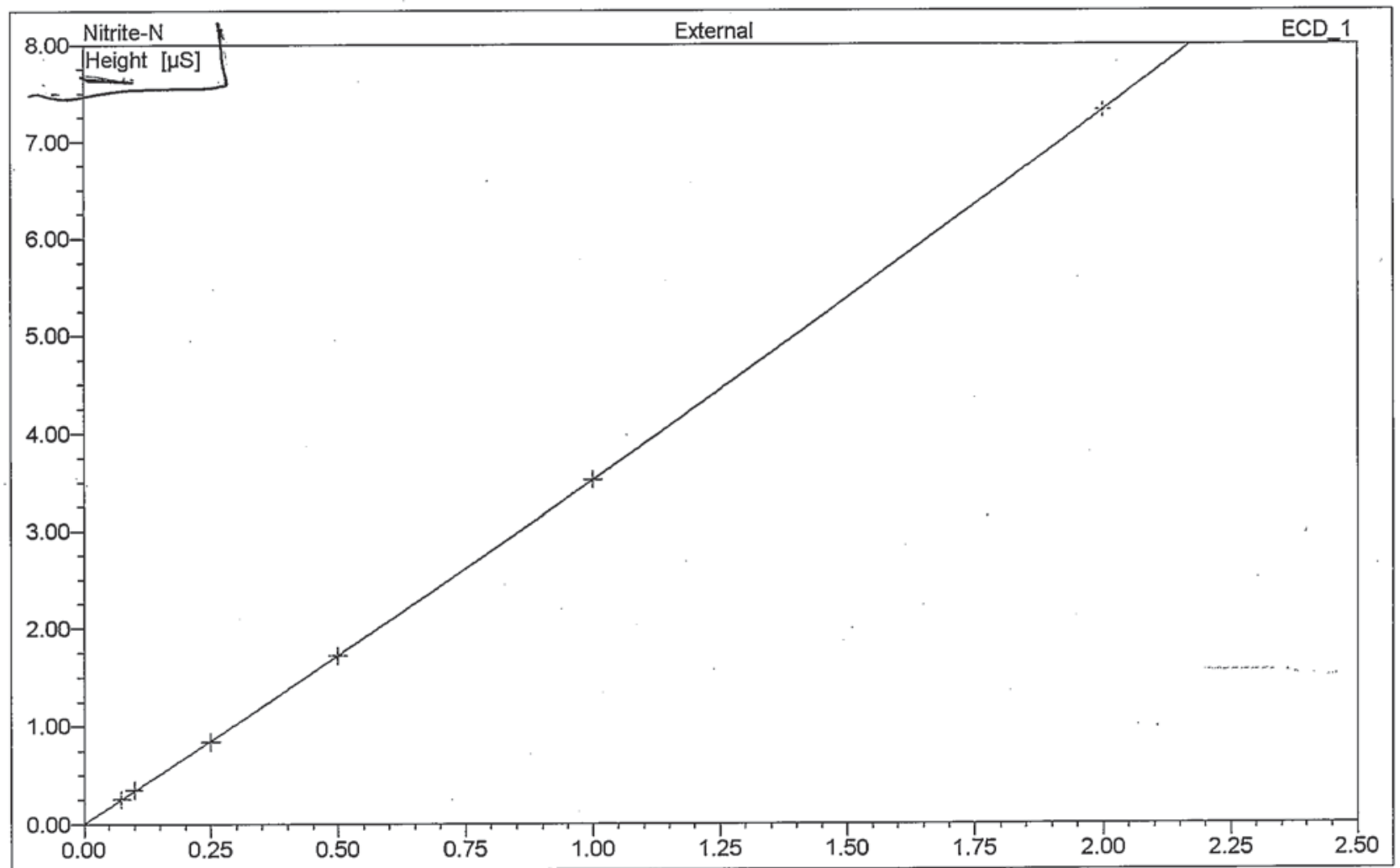

\begin{tabular}{|c|cccccccc|}
\hline No. & $\begin{array}{c}\text { Ret.Time } \\
\text { min }\end{array}$ & Peak Name & Cal.Type & Points & $\begin{array}{c}\text { Corr.Coeff. } \\
\text { (R) }\end{array}$ & Offset & Slope & Curve \\
\hline 1 & 3.23 & Fluoride & Quad & 6 & 0.9997 & 0.0000 & 3.120830 & 0.155880 \\
2 & 4.69 & Chloride & Quad & 6 & 0.9997 & 0.0000 & 1.867234 & 0.065694 \\
3 & 5.53 & Nitrite-N & Quad & 6 & 0.9998 & 0.0000 & 3.376824 & 0.140386 \\
4 & 6.99 & Bromide & Quad & 6 & 0.9999 & 0.0000 & 0.568855 & 0.010287 \\
5 & 7.82 & Nitrate-N & Quad & 6 & 0.9997 & 0.0000 & 2.738783 & 0.148955 \\
\hline Average: & & & & & 0.9998 & 0.0000 & 2.3345 & 0.1042 \\
\hline
\end{tabular}




\begin{tabular}{|c|c|c|c|}
\hline G CAL & TD6 $6=1$ CNS-9050@(2.pp & & \\
\hline $\begin{array}{l}\text { Sample Name: } \\
\text { Vial Number: } \\
\text { Sample Type: } \\
\text { Control Program: } \\
\text { Quantif. Method: } \\
\text { Recording Time: } \\
\text { Run Time (min): }\end{array}$ & $\begin{array}{l}\text { CAL STD } 6=\text { ICWS-9050 @ (2.ppm) } \\
103 \\
\text { standard } \\
\text { ANIONS_AS14A } \\
\text { ANIONS } \\
\# \# \# \# \# \# \# \# \text { } 10.00\end{array}$ & $\begin{array}{l}\text { Injection Volume: } \\
\text { Channel: } \\
\text { Wavelength: } \\
\text { Bandwidth: } \\
\text { Dilution Factor: } \\
\text { Sample Weight: } \\
\text { Sample Amount: }\end{array}$ & $\begin{array}{l}50.0 \\
\text { ECD_1 } \\
\text { n.a. } \\
\text { n.a. } \\
1.0000 \\
1.0000 \\
1.0000\end{array}$ \\
\hline
\end{tabular}

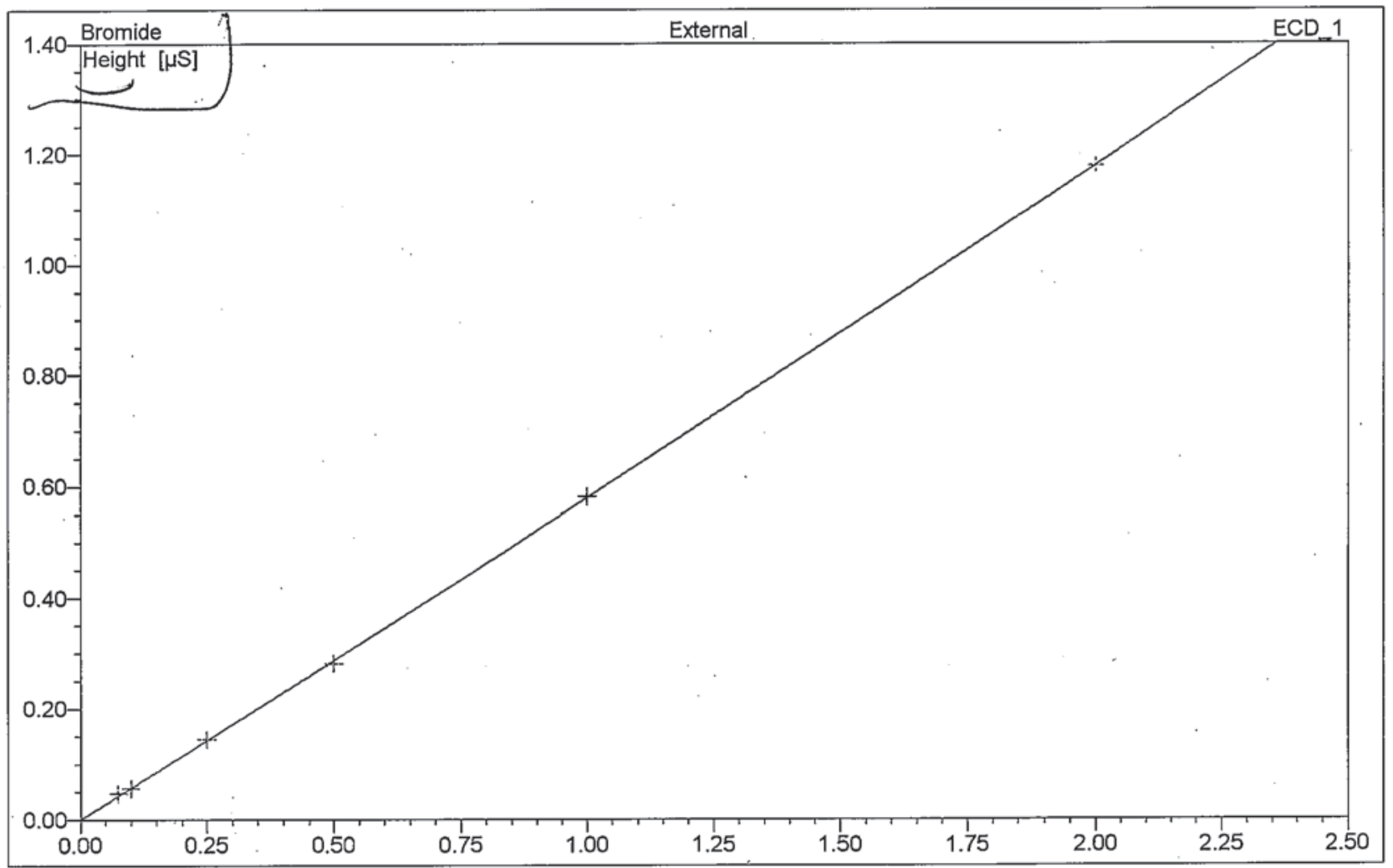

\begin{tabular}{|r|cllccccc|}
\hline No. & $\begin{array}{c}\text { Ret.Time } \\
\text { min }\end{array}$ & Peak Name & Cal.Type & Points & $\begin{array}{c}\text { Corr.Coeff. } \\
\text { (R) }\end{array}$ & Offset & Slope & Curve \\
\hline 1 & 3.23 & Fluoride & Quad & 6 & 0.9997 & 0.0000 & 3.120830 & 0.155880 \\
2 & 4.69 & Chloride & Quad & 6 & 0.9997 & 0.0000 & 1.867234 & 0.065694 \\
3 & 5.53 & Nitrite-N & Quad & 6 & 0.9998 & 0.0000 & 3.376824 & 0.140386 \\
4 & 6.99 & Bromide & Quad & 6 & 0.9999 & 0.0000 & 0.568855 & 0.010287 \\
5 & 7.82 & Nitrate-N & Quad & 6 & 0.9997 & 0.0000 & 2.738783 & 0.148955 \\
\hline Average: & & & & & 0.9998 & 0.0000 & 2.3345 & 0.1042 \\
\hline
\end{tabular}




\begin{tabular}{|c|c|c|c|}
\hline \multicolumn{4}{|c|}{ 6 CALSTD6 =1CWS-9050@(2.ppm) } \\
\hline Sample Name: & CAL STD $6=$ ICWS-9050 @ (2.ppm) & Injection Volume: & 50.0 \\
\hline Vial Number: & 103 & Channel: & ECD_1 \\
\hline Sample Type: & standard & Wavelength: & n.a. \\
\hline Control Program: & ANIONS_AS14A & Bandwidth: & n.a. \\
\hline Quantif. Method: & ANIONS & Dilution Factor: & 1.0000 \\
\hline Recording Time: & \#\#\#\#\#\#\#\#\#\#\#\# & Sample Weight: & 1.0000 \\
\hline Run Time (min): & 10.00 & Sample Amount: & 1.0000 \\
\hline
\end{tabular}

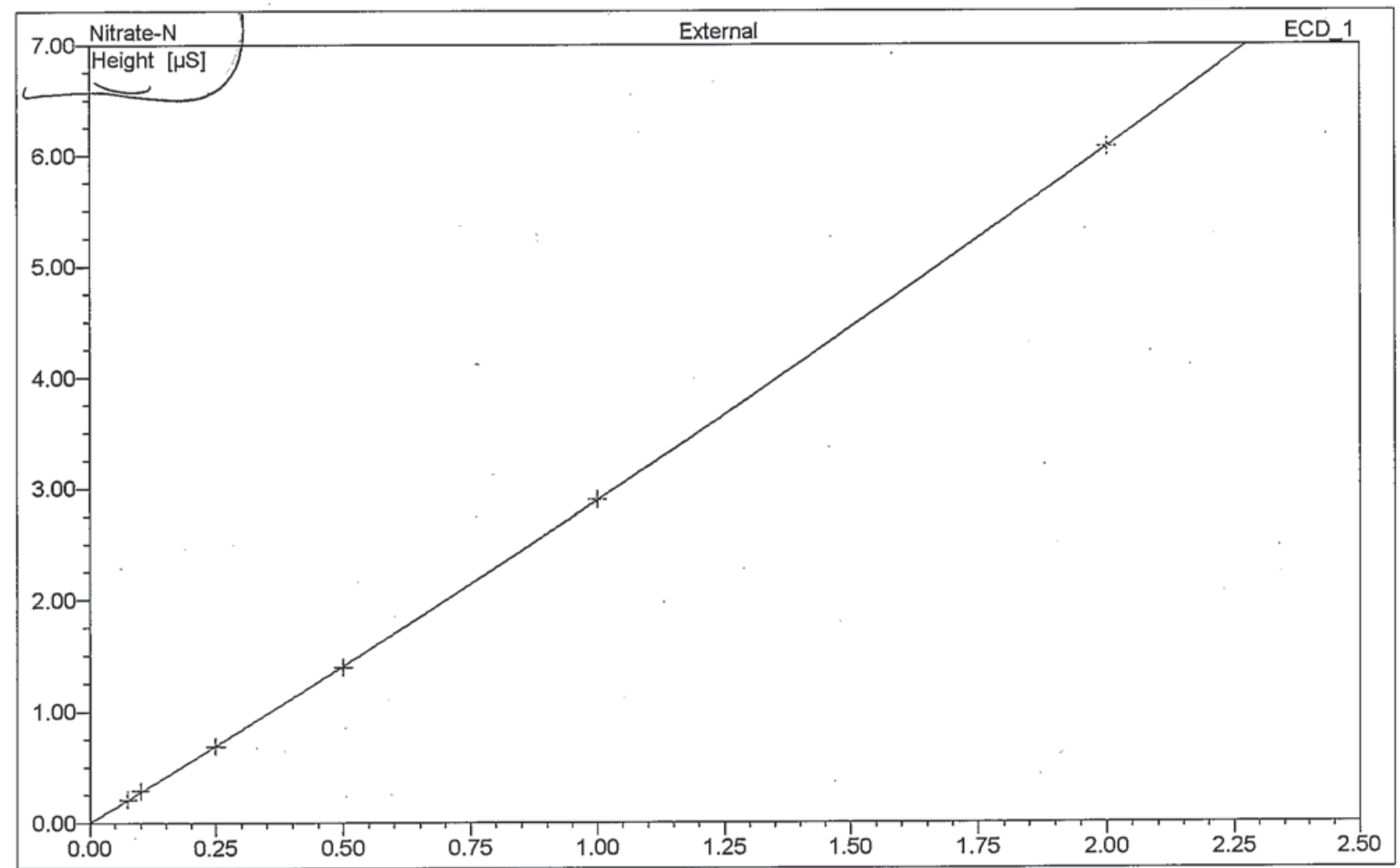

\begin{tabular}{|r|clcccccc|}
\hline No. & $\begin{array}{c}\text { Ret.Time } \\
\text { min }\end{array}$ & Peak Name & Cal.Type & Points & $\begin{array}{c}\text { Corr.Coeff. } \\
\text { (R) }\end{array}$ & Offset & Slope & Curve \\
\hline 1 & 3.23 & Fluoride & Quad & 6 & 0.9997 & 0.0000 & 3.120830 & 0.155880 \\
2 & 4.69 & Chloride & Quad & 6 & 0.9997 & 0.0000 & 1.867234 & 0.065694 \\
3 & 5.53 & Nitrite-N & Quad & 6 & 0.9998 & 0.0000 & 3.376824 & 0.140386 \\
4 & 6.99 & Bromide & Quad & 6 & 0.9999 & 0.0000 & 0.568855 & 0.010287 \\
5 & 7.82 & Nitrate-N & Quad & 6 & 0.9997 & 0.0000 & 2.738783 & 0.148955 \\
\hline Average: & & & & & 0.9998 & 0.0000 & 2.3345 & 0.1042 \\
\hline
\end{tabular}




\section{踣}

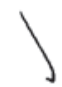

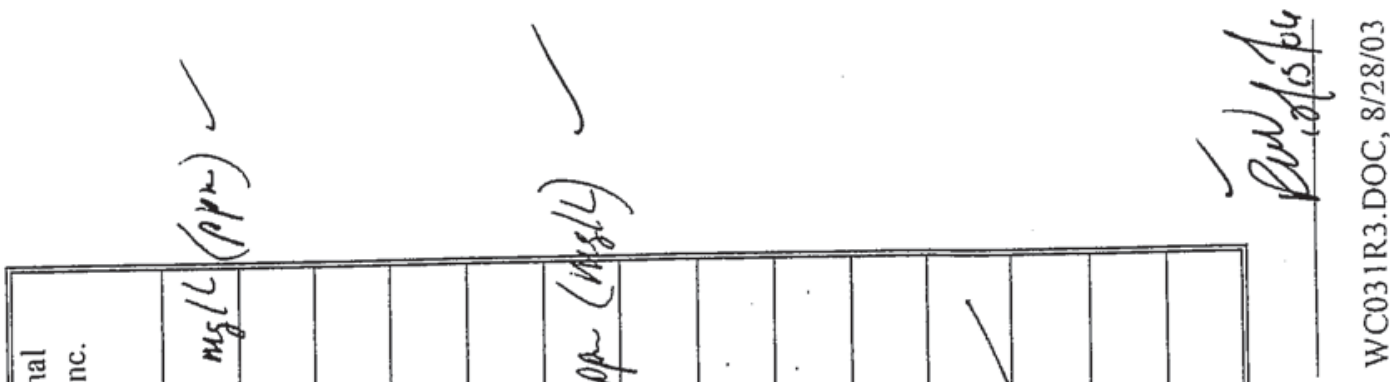

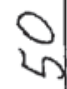

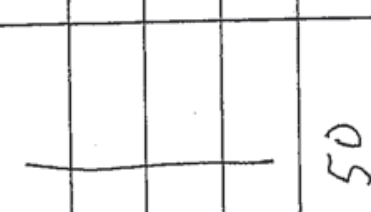

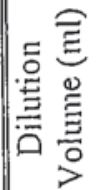

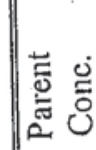

$b$

in
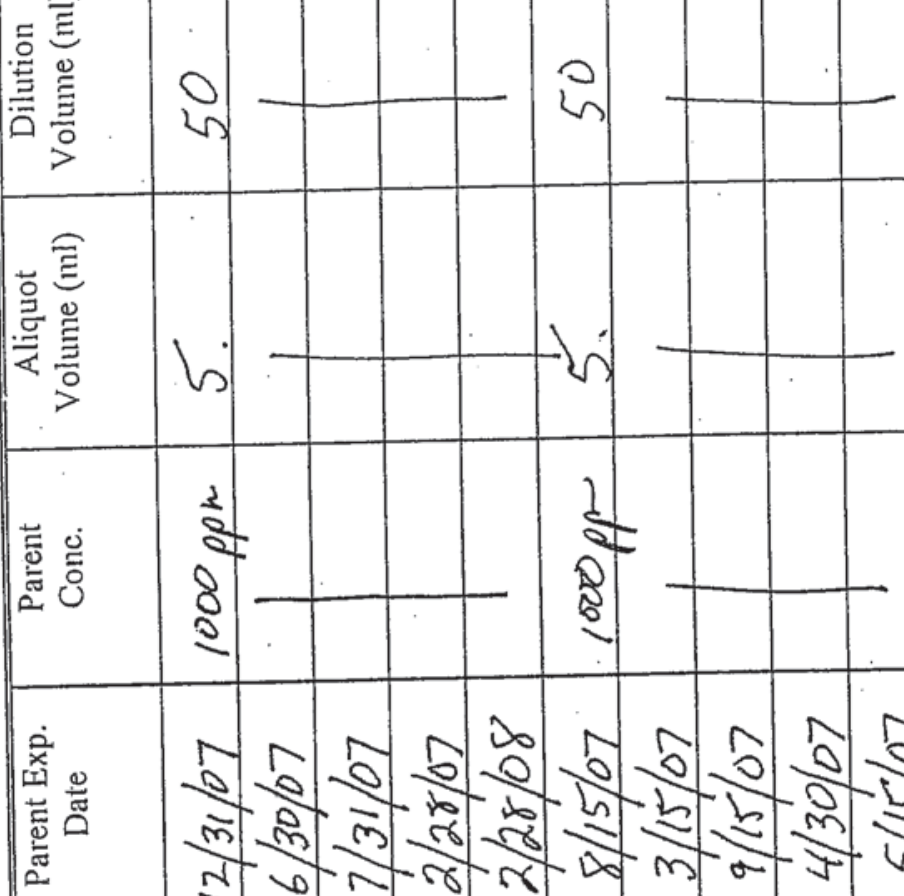

\begin{tabular}{ll|l|l}
$\frac{3}{2}$ & & \\
\hline & & & \\
\hline
\end{tabular}

อิ

$5 N-50$

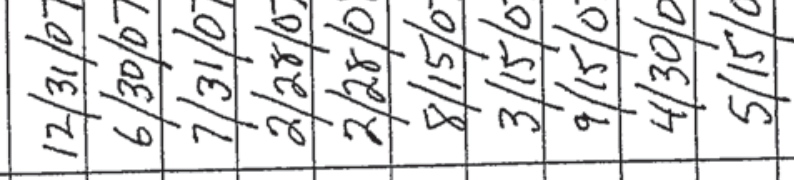

$\hat{\sigma} \approx \hat{\sigma} \sigma$

蓠

కุ

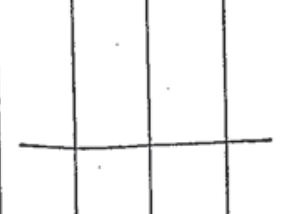

永

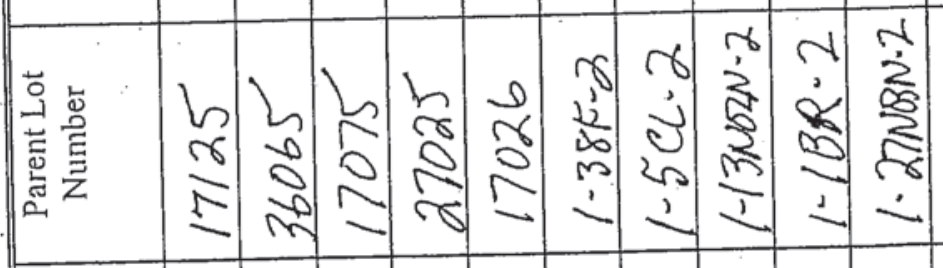

譬善

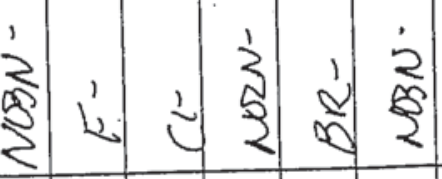

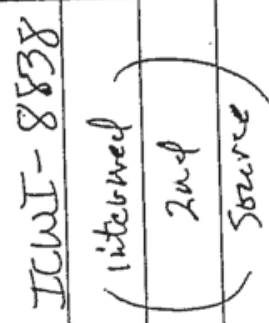


告

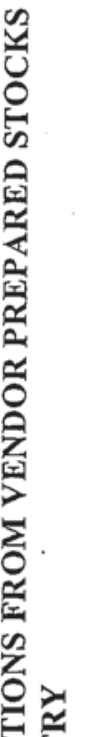

罗密

点

응

的式

है क

领昆 N

虫 d

ป

乙

瞚

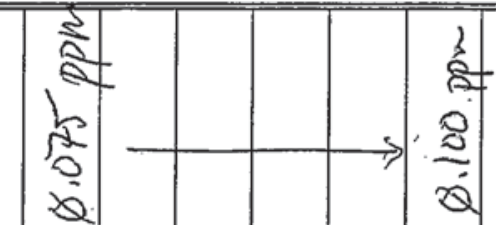

1

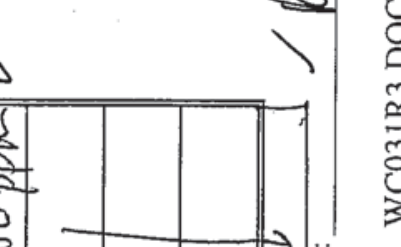

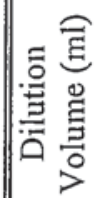

5

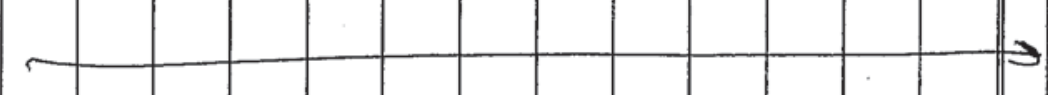

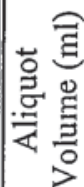

2
3
0
2

占

帒

泀

5
0
8
8

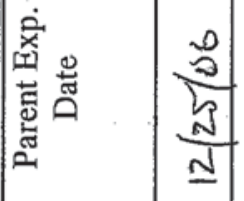

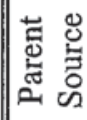

5

$\infty$

空

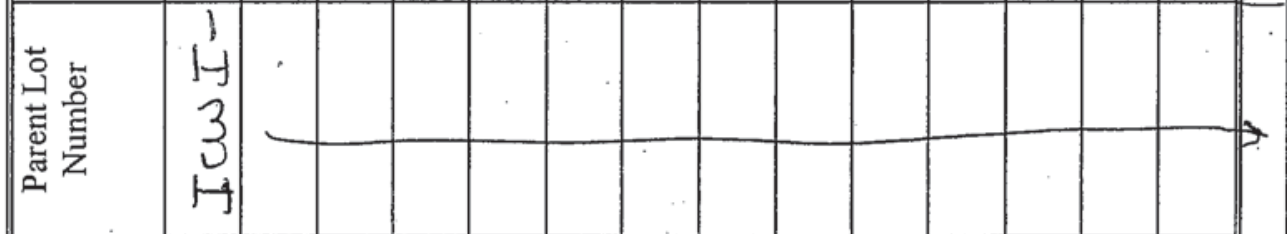

$\frac{7}{\frac{7}{2}} \frac{7}{2}$

施

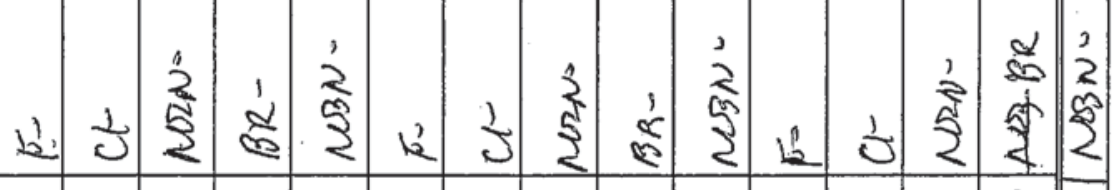

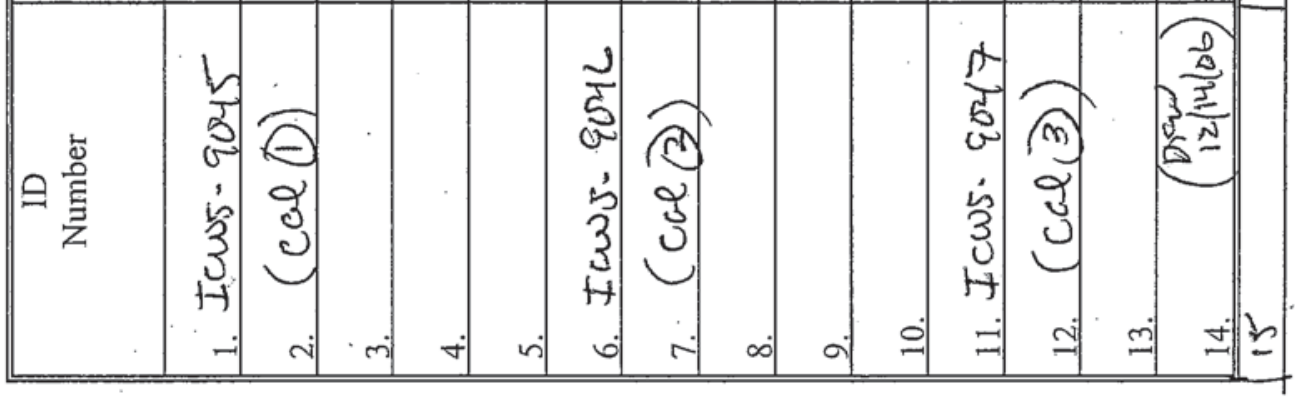



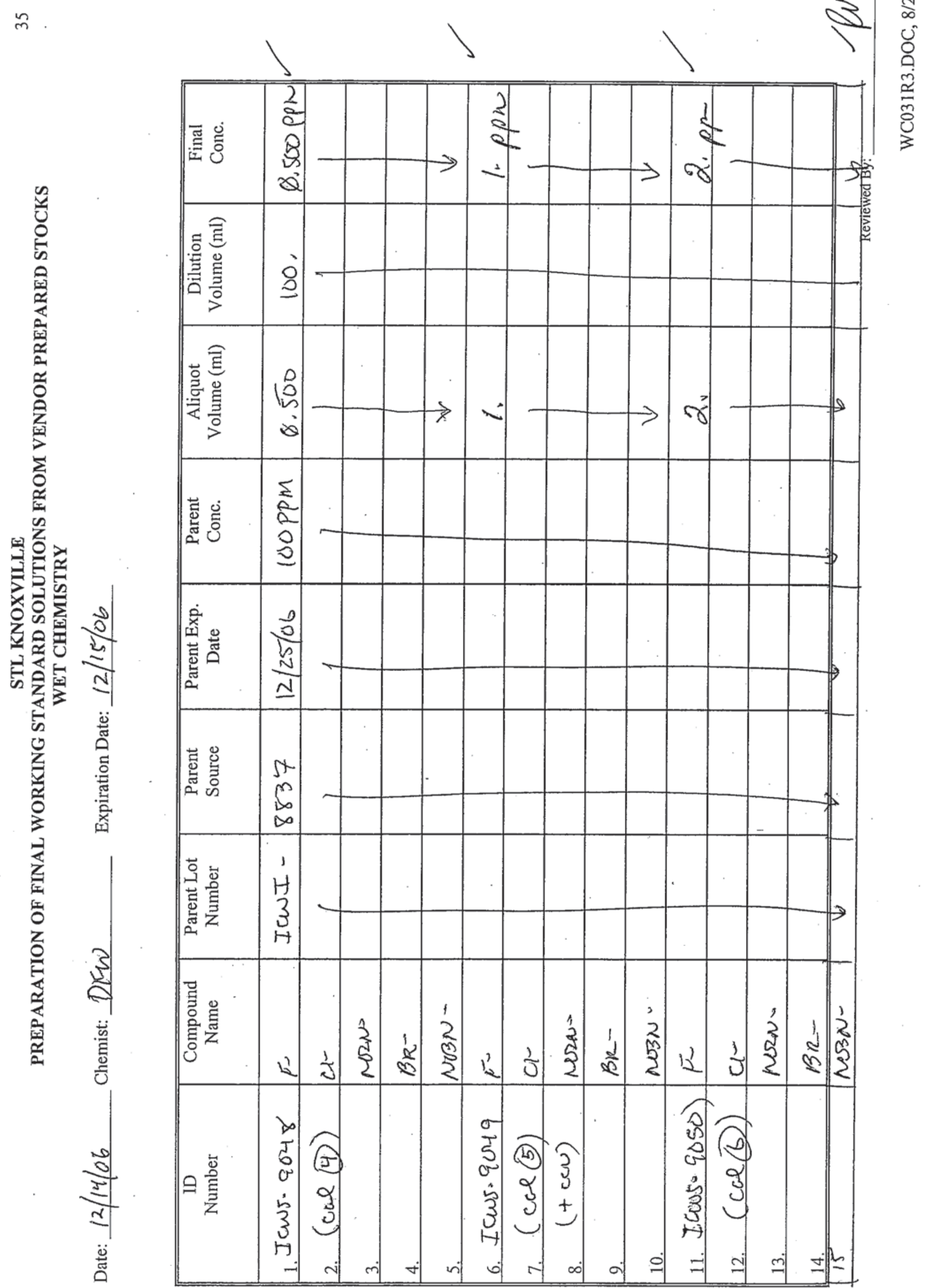

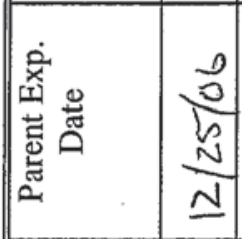

泀递

$\sum_{\infty}^{\infty}$

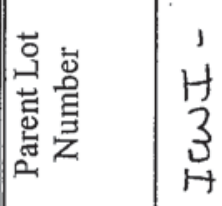

壱

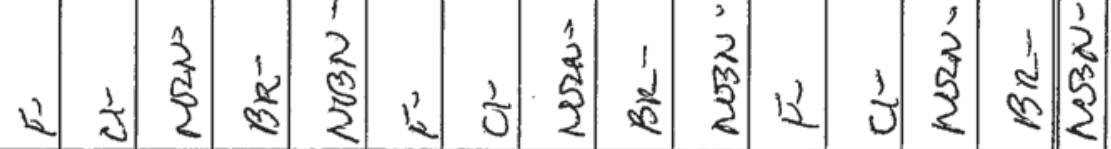

$\frac{\sqrt{3}}{\frac{3}{2}}$

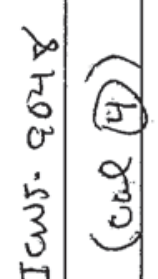

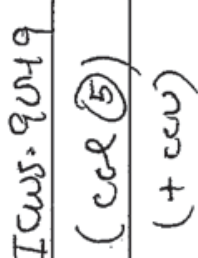

$\ddot{\ddot{\omega}}$

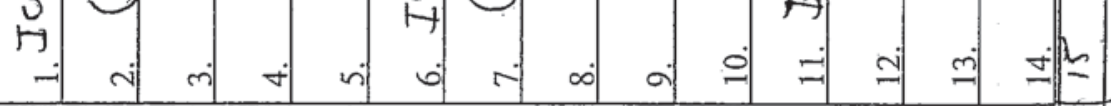




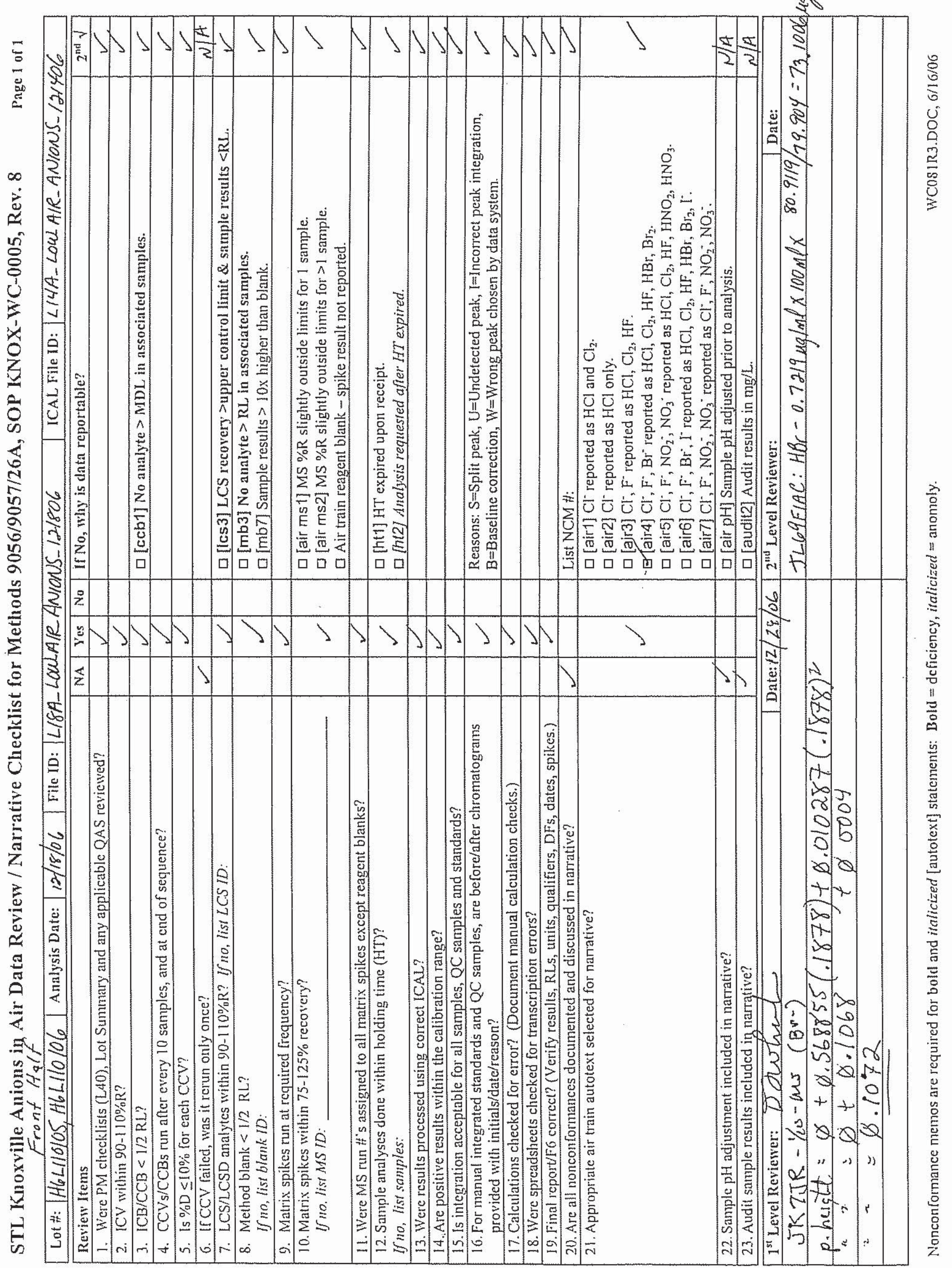




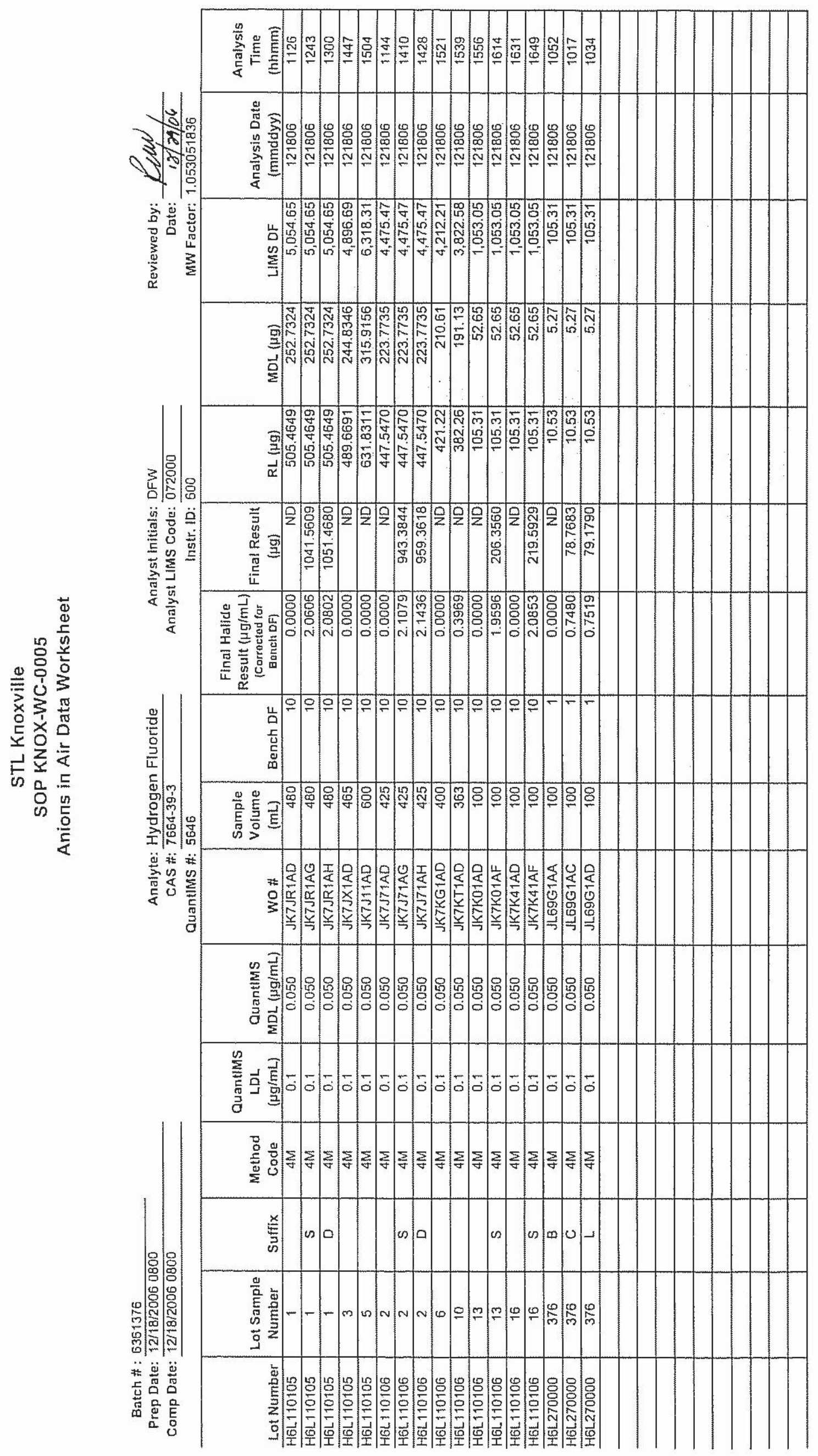




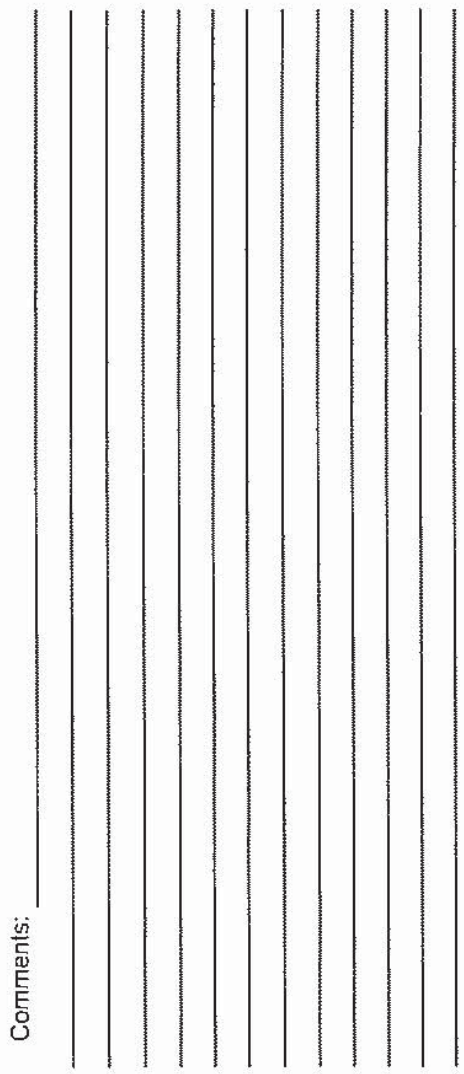

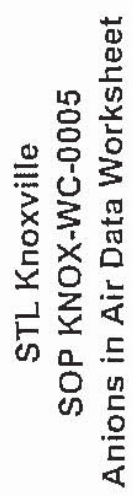
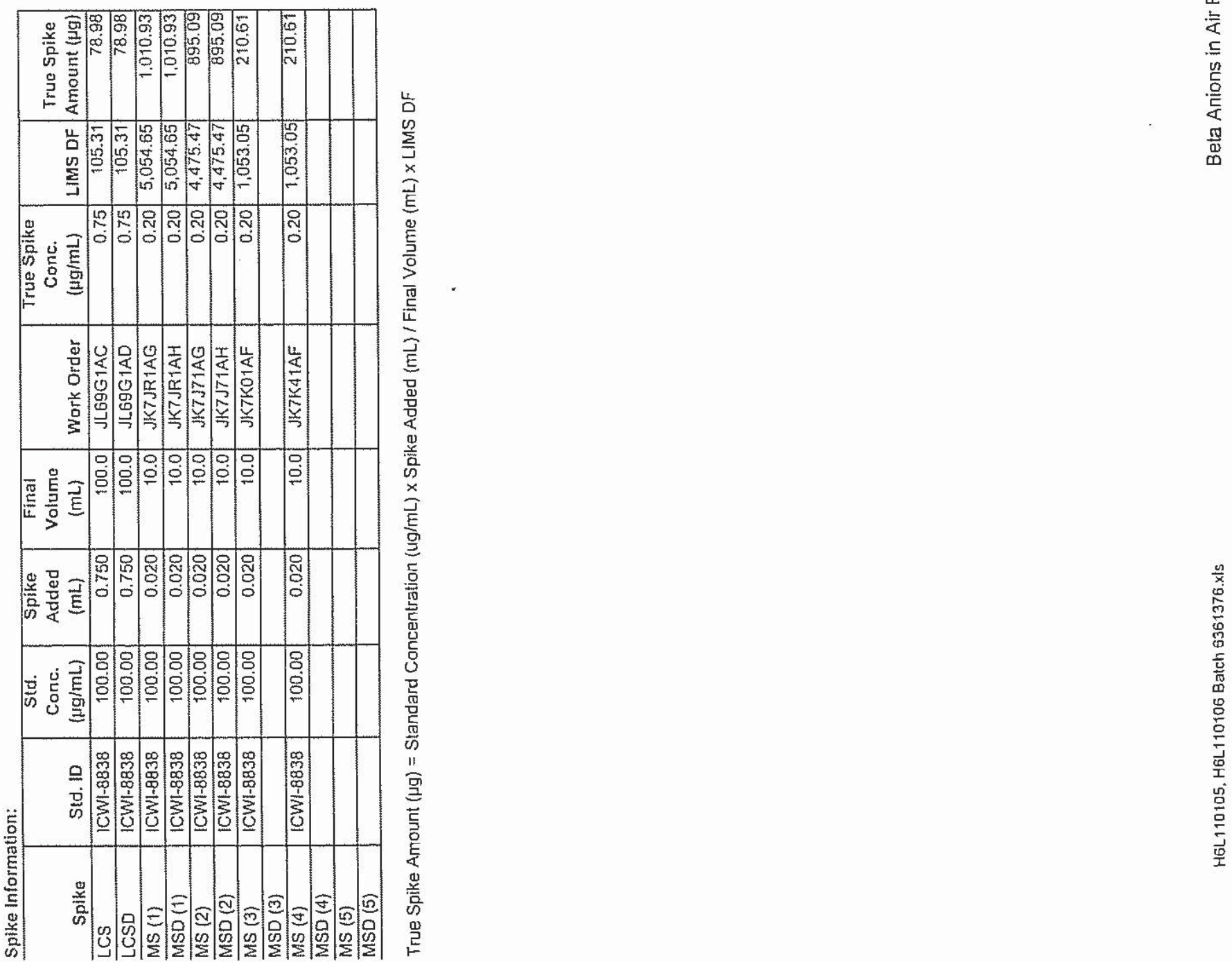


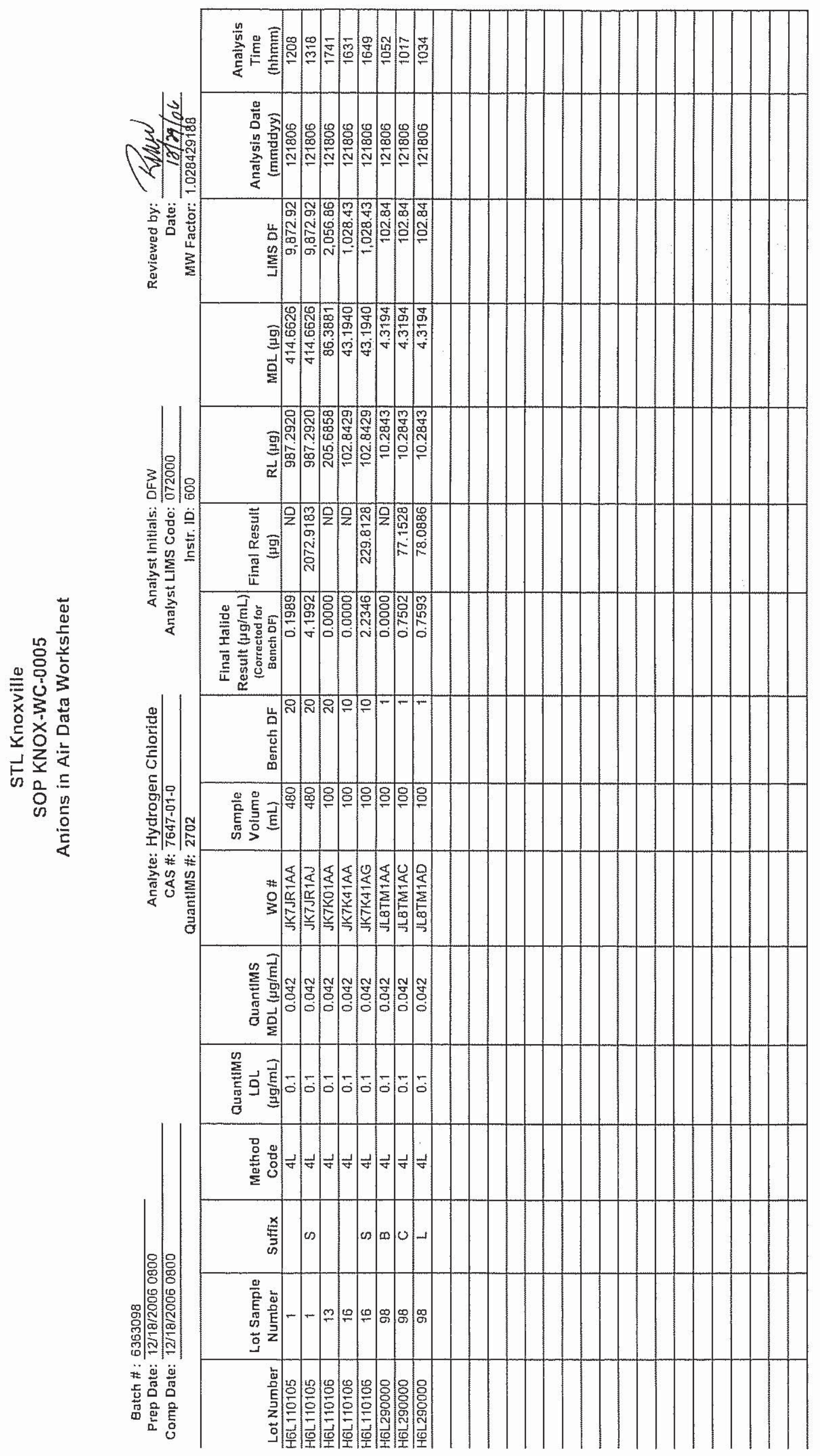




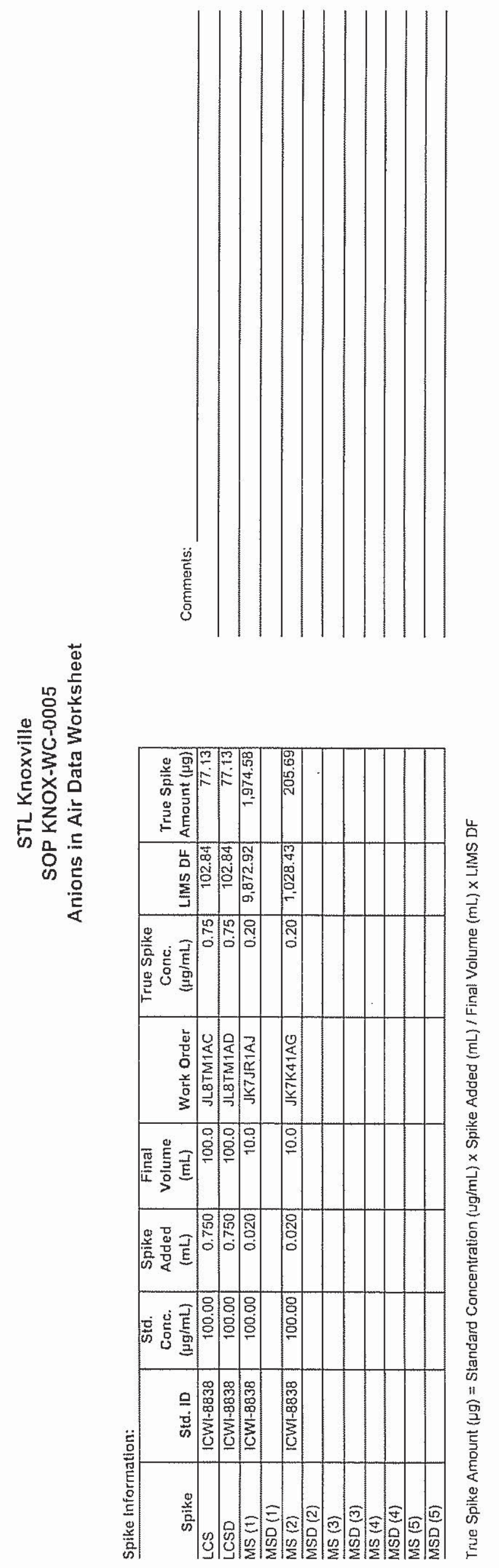




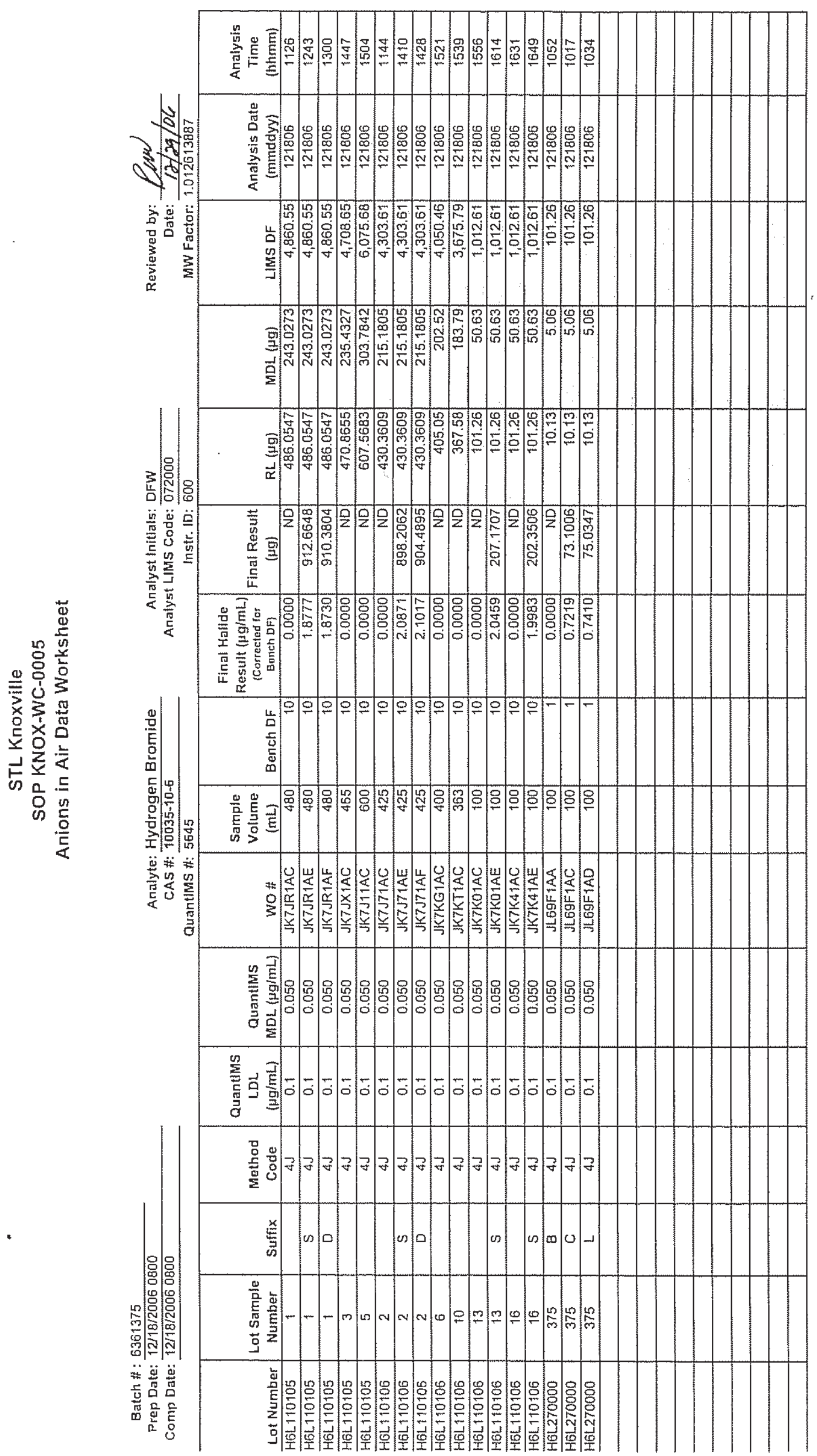




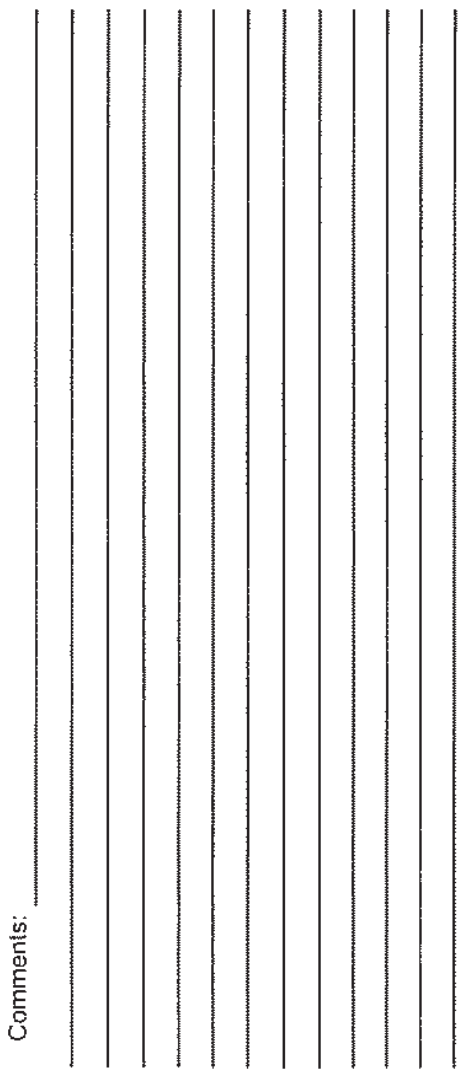

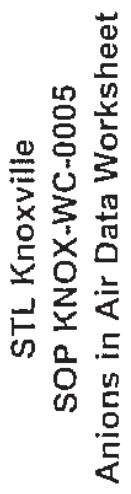

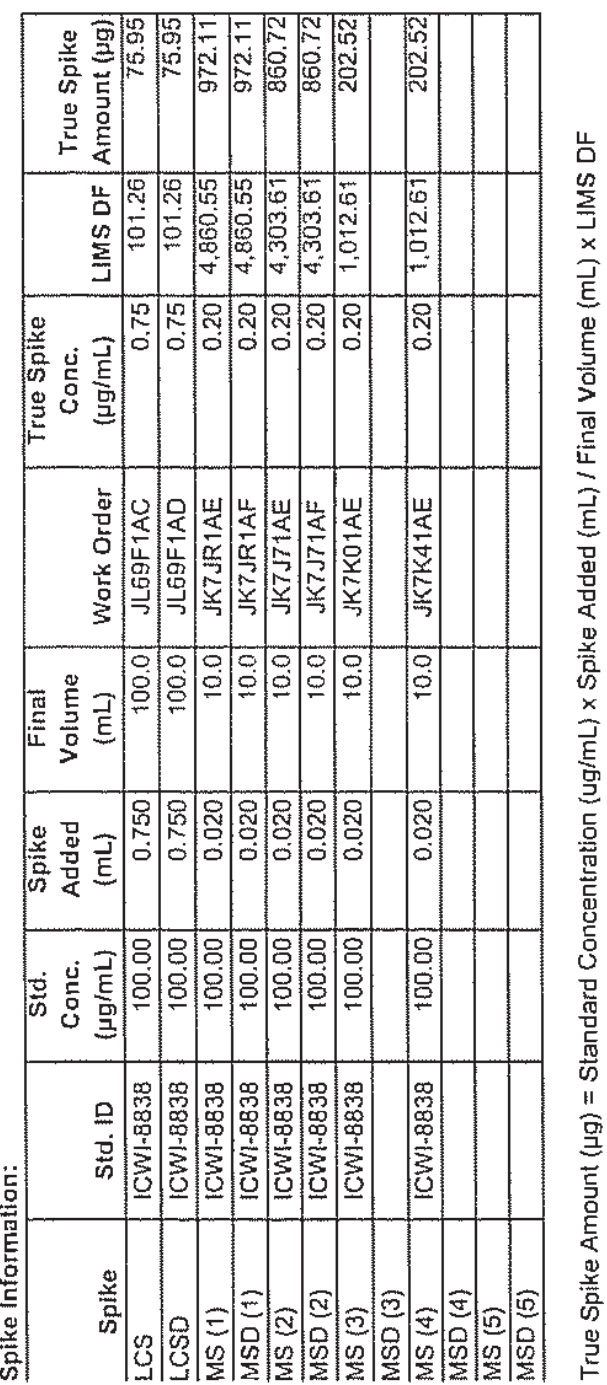

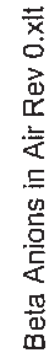




\section{Dionex IC Runlog Cover Page}

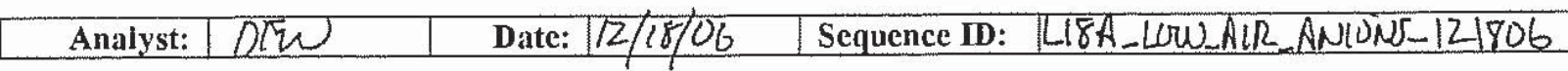

\begin{tabular}{|c|c|c|c|}
\hline \multirow{3}{*}{$\begin{array}{l}\text { Instrument: } \\
\text { "Aragorn }\end{array}$} & QDX-600 & \multirow[t]{3}{*}{ Method: } & DKNOX-WC-0003, SW-846 0061/7199 \\
\hline & DICS-1500 & & 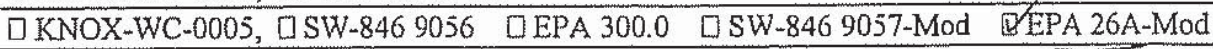 \\
\hline & $\square D X-320$ & & 口KNOX-WC-0014, EPA 314.0 \\
\hline
\end{tabular}

\begin{tabular}{|c|c|c|c|}
\hline Preventive Maintenanee & \multicolumn{3}{|c|}{ Instrument Conditions } \\
\hline \multirow{4}{*}{$\begin{array}{l}\text { Dailv: } \\
\square \text { Check pump and gas pressure } \\
\square \text { Check all lines for crimping, leaks and discoloration } \\
\text { As Needled: }\end{array}$} & Flow Rate $=$ & 1.00 & $\mathrm{~mL} / \mathrm{min}$ \\
\hline & Pressure $=$ & 2200 & psi \\
\hline & Conductance $=$ & 22.8 & $\mu \mathrm{S}$ \\
\hline & Suppressor Current $=$ & 43. & $\mathrm{~mA}$ \\
\hline \multirow{3}{*}{$\begin{array}{l}\square \text { Change column and guard colunn } \\
\square \text { Change column and/or guard column bed support } \\
\square \text { Clean conductivity cell }\end{array}$} & Eluent Generator $=$ & $N / A$ & $\mathrm{mM} \mathrm{KOH}$ \\
\hline & & & \\
\hline & & & \\
\hline \multicolumn{4}{|l|}{$\square$ De-gas pump head when flow is erratic } \\
\hline$\square$ Check/replace eluant end line filter & & & \\
\hline
\end{tabular}

MS/MSD Spike Information

\begin{tabular}{|c|c|c|c|c|c|c|}
\hline WO \# & Compound & Spike ID & Parent Conc. & Spike Added (mL) & Final Volume $(m \mathrm{~L})$ & Final Conc. \\
\hline JK TJR & $F^{-}$ & IcuII-8838 & $100 . p p m$ & $\$ .02$ & $10 \mathrm{ml}$ & $0.20 \mathrm{epm}$ \\
\hline & $\mathrm{Cl}^{-}$ & & & & & \\
\hline$\downarrow$ & $B r^{-}$ & $\downarrow$ & $\downarrow$ & $\downarrow$ & & \\
\hline $5 K 757$ & $F-$ & & & & & \\
\hline & $Q^{-}$ & & & & & \\
\hline & $B r^{-}$ & & & & & \\
\hline JK $7 K O$ & $F-$ & & & & & \\
\hline & $\mathrm{Cl}^{-}$ & & & & & \\
\hline & $B r-$ & & & & & \\
\hline JK $7 K 4$ & $F-$ & & & & & \\
\hline & $\mathrm{Cl}^{-}$ & & & & & \\
\hline & Br & $\downarrow$ & $\downarrow$ & $\checkmark$ & $\downarrow$ & $\downarrow$ \\
\hline & & & & En & & \\
\hline & & & & & & \\
\hline
\end{tabular}

Comments:

HF Batch- 6361376
HBr Batch- 6361375

$\square$ Sodium Thiosulfate added to $\mathrm{NaOH}$ inpinger samples. 
Sequence: $\quad$ L18A_LOW_AIR_ANIONS_ 121806 Operator: wheelerd

Title:

Datasource;

Aragorn_net

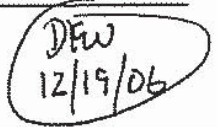

Location:

Timebase: IC_ARAGORN

IC_Aragorn

Created:

\#Samples:

36

Last Update:

12/18/2006 10:16:29 AM by wheelerd 12/19/2006 7:35:45 AM by wheelerd

\begin{tabular}{|c|c|c|c|c|c|c|c|}
\hline No. & Name & Sample ID & Inj. Vol. & Inj. Date/Time & Dil. Facior & $\begin{array}{r}\text { Multiplier } \\
\text { [Liters] }\end{array}$ & Weight \\
\hline 1 & CAL STD $1=1$ CWS-9045@(0.075ppm) & & 50.0 & 12/14/2006 4:54:12 PM & 1.0000 & & 1.0000 \\
\hline 2 & (1) CAL STD $2=1$ CWS $-9046 @(0.10 \mathrm{ppm})$ & & 50.0 & 12/14/2006 5:11:38 PM & 1.0000 & & 1.0000 \\
\hline 3 & (1) CAL STD $3=1 \mathrm{CWS}-9047 @(0.25 \mathrm{ppm})$ & & 50.0 & 12/14/2006 5:24:03 PM & 1.0000 & & 1.0000 \\
\hline 4 & $(1)$ CAL STD $4=1$ ICWS-9048 @ (0.50ppm) & & 50.0 & 12/4 4/2006 5:36:29 PM & 1.0000 & & 1.0000 \\
\hline 5 & (1) CAL STD $5=1$ CWS-9049 @ (1.ppm) & & 50.0 & 12/14/2006 5:48:54 PM & 1.0000 & & 1.0000 \\
\hline 6 & (1) CAL STD 6 = ICWS-9050 @ (2.ppm) & & 50.0 & 12/14/2006 6:01:20 PM & 1.0000 & & 1.0000 \\
\hline 7 & ICVILCS = ICWS-9056 & & 50.0 & 12/18/2006 10:17:27 AM & 1.0000 & & 1.0000 \\
\hline 8 & ICVILCSD $=1$ ICWS -9057 & & 50.0 & 12/18/2006 10:34:53 AM & 1.0000 & & 1.0000 \\
\hline 9 & 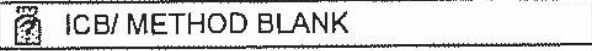 & & 50.0 & 12/18/2006 10:52:18 AM & 1.0000 & & 1.0000 \\
\hline 10 & T6L110105-JK7JR-1/10 & & 50.0 & 12/18/2006 11:26:40 AM & 10.0000 & & 1.0000 \\
\hline 11 & 筩 H6L110106-JK7J7-1/10 & & 50.0 & 12/18/2006 11:44:06 AM & 10.0000 & & 1.0000 \\
\hline 12 & H6L110105-JK7JR-1/20 & & 50.0 & $12 / 18 / 200612: 08: 40 \mathrm{PM}$ & 20.0000 & & 1.0000 \\
\hline 13 & 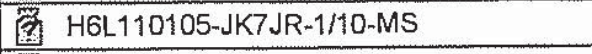 & & 50.0 & 12/18/2006 12:43:28 PM & 10.0000 & & 1.0000 \\
\hline 14 & H6L110105-JK7JR/1/10-MSD & & 50.0 & 12/18/2006 1:00:54 PM & 10.0000 & & 1.0000 \\
\hline 15 & 图 H6L110105-JK7JR-1/20-MS & & 50.0 & 12/18/2006 1:18:20 PM & 20.0000 & & 1.0000 \\
\hline 16 & CCV = ICWS -9058 & & 50.0 & 12/18/2006 1:35:45 PM & 1.0000 & & 1.0000 \\
\hline 17 & $\mathrm{CCB}$ & & 50.0 & 12/18/2006 1:53:11 PM & 1.0000 & & 1.0000 \\
\hline 18 & 絪 H6L110106-JK7J7-1/10-MS & & 50.0 & 12/18/2006 2:10:37 PM & 10.0000 & & 1.0000 \\
\hline 19 & H6L110106-JK7J7-1/10-MSD & & 50.0 & 12/18/2006 2:28:03 PM & 10.0000 & & 1.0000 \\
\hline 20 & (2) H6L110105-JK7JX-1/10 & & 50.0 & 12/18/2006 2:47:03 PM & 10.0000 & & 1.0000 \\
\hline 21 & (2) H6L110105-JK7J1-1/10 & & 50.0 & 12/18/2006 3:04:28 PM & 10.0000 & & 1.0000 \\
\hline 22 & (3) H6L110106-JK7KG-1/10 & & 50.0 & 12/18/2006 3:21:54 PM & 10.0000 & & 1.0000 \\
\hline 23 & \% H6L110105-JK7KT-1/10 & & 50.0 & 12/18/2006 3:39:19 PM & 10.0000 & & 1.0000 \\
\hline 24 & H6L110106-JK7KO-1/10 & & 50.0 & 12/18/2006 3:56:45 PM & 10.0000 & & 1.0000 \\
\hline 25 & (2) H6L110106-JK7KO-1/10-MS & & 50.0 & 12/18/2006 4:14:11 PM & 10.0000 & & 1.0000 \\
\hline 26 & 2 H6L110106-JK7K4-1/10 & & 50.0 & 12/18/2006 4:31:36 PM & 10.0000 & & 1.0000 \\
\hline 27 & 箩 H6L110106-JK7K4-1/10-MS & & 50.0 & 12/18/2006 4:49:02 PM & 10.0000 & & 1.0000 \\
\hline 28 & (2) $C$ CV $=1$ WS -9058 & & 50.0 & 12/18/2006 5:06:27 PM & 1.0000 & & 1.0000 \\
\hline 29 & $\mathrm{CCB}$ & & 50.0 & 12/18/2006 5:23:52 PM & 1.0000 & & 1.0000 \\
\hline 30 & 瓷 H6L110106-JK7KO-1/20 & & 50.0 & $12 / 18 / 20065: 41: 18 \mathrm{PM}$ & 20.0000 & & 1.0000 \\
\hline 31 & (2) H6L110106-JK7KD-1/20-MS & & 50.0 & 12/18/2006 5:58:43 PM & 20.0000 & & 1.0000 \\
\hline 32 & H6L110106-JK7KO-1/40 & & 50.0 & 12/18/2006 6:16:09 PM & 40.0000 & & 1.0000 \\
\hline 33 & 魚 H6L110106-JK7KO-1/40-MS & & 50.0 & 12/18/2006 6:33:34 PM & 40.0000 & & 1.0000 \\
\hline 34 & (9) $\mathrm{CCV}=1 \mathrm{CWS}-9058$ & & 50.0 & 12/18/2006 6:50:59 PM & 1.0000 & & 1.0000 \\
\hline 35 & $\mathrm{CCB}$ & & 50.0 & 12/18/2006 7:08:24 PM & 1.0000 & & 1.0000 \\
\hline 36 & THUTDOWN & & 50.0 & $12 / 18 / 20067: 25: 50 \mathrm{PM}$ & 1.0000 & & 1.0000 \\
\hline
\end{tabular}




\section{$7 \quad$ ICV/LCS $=$ ICWS -9056}

\begin{tabular}{llll|}
\hline Sample Name: & ICV/LCS=ICWS-9056 & Injection Volume: & $\mathbf{5 0 . 0}$ \\
Vial Number: & 104 & Channel: & ECD_1 \\
Sample Type: & unknown & Wavelength: & n.a. \\
Control Program: & ANIONS_AS14A & Bandwidth: & n.a. \\
Quantif. Method: & ANIONS & Dilution Factor: & 1.0000 \\
Recording Time: & $12 / 18 / 200610: 17$ & Sample Weight: & 1.0000 \\
Run Time (min): & 15.00 & Sample Amount: & 1.0000 \\
\hline
\end{tabular}

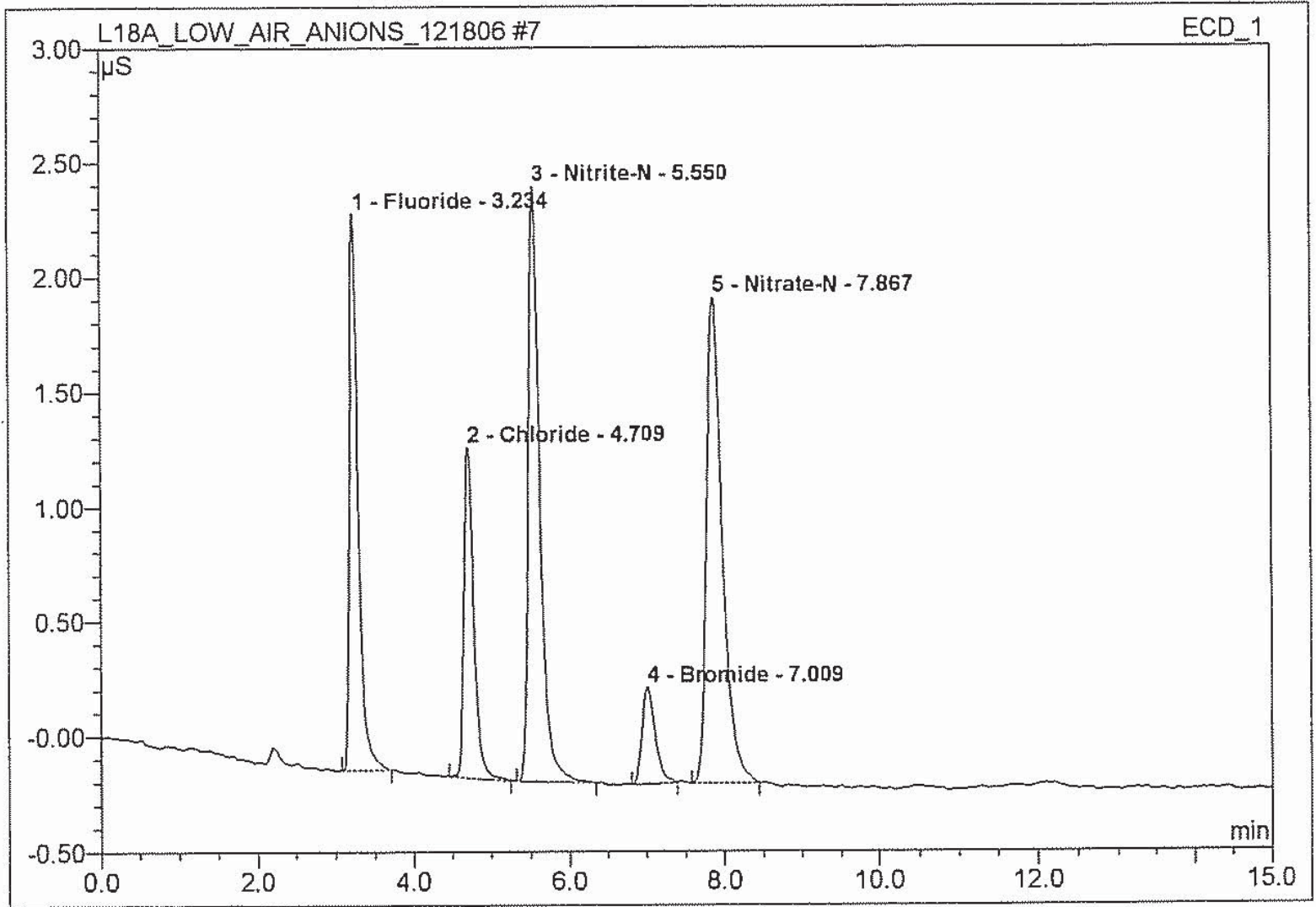

\begin{tabular}{|c|c|l|c|c|c|c|c|}
\hline No. & $\begin{array}{c}\text { Ret.Time } \\
\text { (min.) }\end{array}$ & \multicolumn{1}{|c|}{ Peak Name } & $\begin{array}{c}\text { Height } \\
(\mathrm{uS})\end{array}$ & $\begin{array}{c}\text { Area } \\
\mu \mathrm{S}^{*} \min \end{array}$ & $\begin{array}{c}\text { Rel.Area } \\
(\%)\end{array}$ & $\begin{array}{c}\text { Amount } \\
\text { (mg/L) }\end{array}$ & $\begin{array}{c}\text { Peak } \\
\text { Type }\end{array}$ \\
\hline 1 & 3.23 & Fluoride & 2.42157 & 0.305 & 19.82 & 0.7480 & BMB \\
\hline 2 & 4.71 & Chloride & 1.43770 & 0.207 & 13.45 & 0.7502 & $\mathrm{BMB}$ \\
\hline 3 & 5.55 & Nitrite-N & 2.59076 & 0.450 & 29.23 & 0.7442 & $\mathrm{BMB}$ \\
\hline 4 & 7.01 & Bromide & 0.41601 & 0.083 & 5.39 & 0.7219 & $\mathrm{BMB}$ \\
\hline 5 & 7.87 & Nitrate-N & 2.11264 & 0.495 & 32.11 & 0.7415 & $\mathrm{BMB}$ \\
\hline
\end{tabular}

$$
\frac{H F-J \angle 6 R G-1 A C}{\frac{H Q r-J L 69 F-1 A C}{H C l-J L 8 T M-1 A C}}
$$




\section{$8 \quad I C V / L C S D=I C W S-9057$}

\begin{tabular}{|llll|}
\hline Sample Name: & ICV/LCSD=ICWS-9057 & Injection Volume: & $\mathbf{5 0 . 0}$ \\
Vial Number: & $\mathbf{1 0 5}$ & Channel: & ECD_1 \\
Sample Type: & unknown & Wavelength: & n.a. \\
Control Program: & ANIONS_AS14A & Bandwidth: & n.a. \\
Quantif. Method: & ANIONS & Dilution Factor: & $\mathbf{1 . 0 0 0 0}$ \\
Recording Time: & $\mathbf{1 2 / 1 8 / 2 0 0 6 ~ 1 0 : 3 4}$ & Sample Weight: & $\mathbf{1 . 0 0 0 0}$ \\
Run Time (min): & $\mathbf{1 5 . 0 0}$ & Sample Amount: & $\mathbf{1 . 0 0 0 0}$ \\
\hline
\end{tabular}

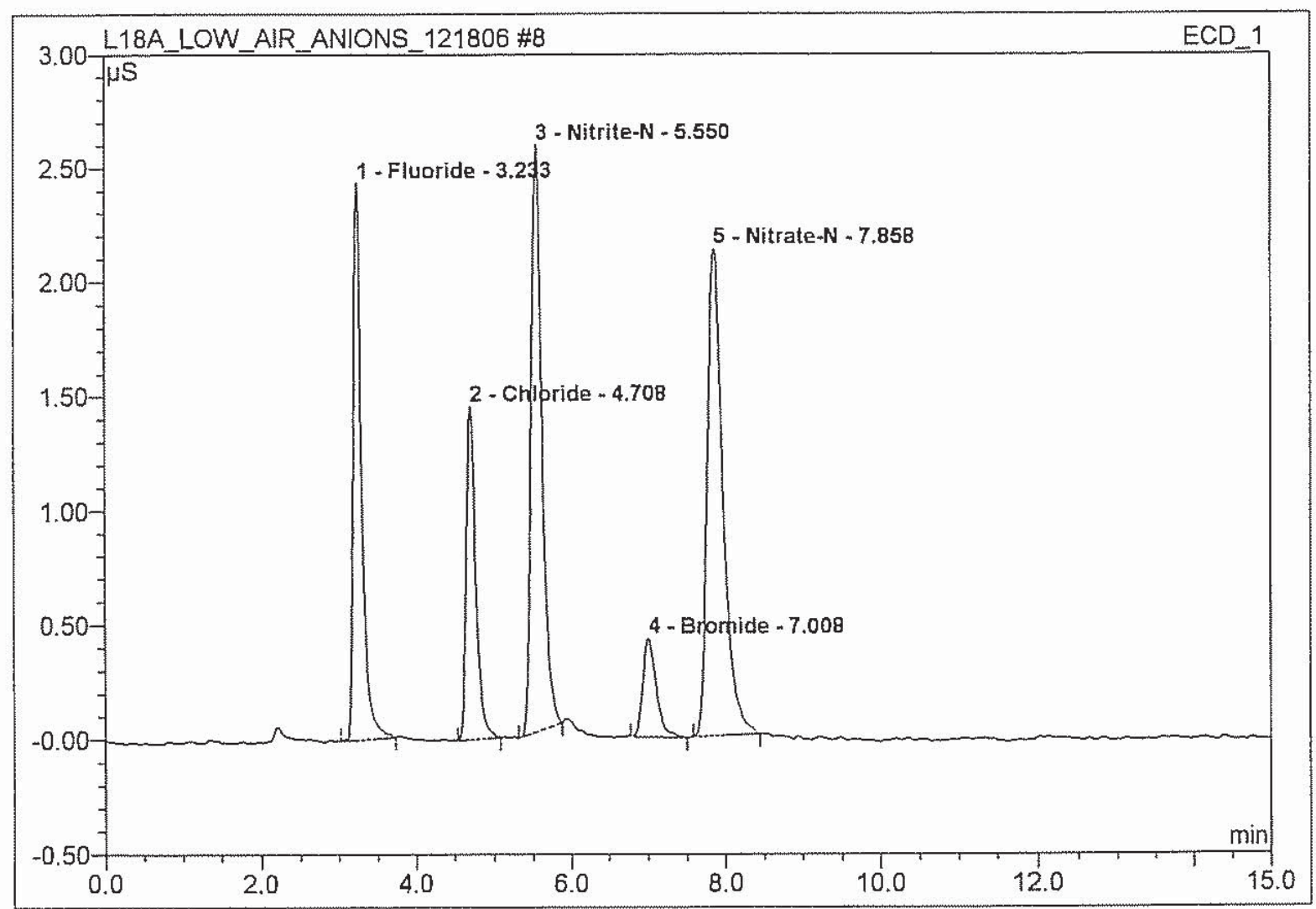

\begin{tabular}{|c|c|l|r|r|r|r|c|}
\hline No. & $\begin{array}{c}\text { Ret.Time } \\
\text { (min.) }\end{array}$ & \multicolumn{1}{|c|}{ Peak Name } & $\begin{array}{c}\text { Height } \\
(\mathrm{uS})\end{array}$ & $\begin{array}{c}\text { Area } \\
\mu \mathrm{S}^{*} \mathrm{~min}\end{array}$ & $\begin{array}{c}\text { Rel.Area } \\
(\%)\end{array}$ & $\begin{array}{c}\text { Amount } \\
(\mathrm{mg} / \mathrm{L})\end{array}$ & $\begin{array}{c}\text { Peak } \\
\text { Type }\end{array}$ \\
\hline 1 & 3.23 & Fluoride & 2.43474 & 0.307 & 20.23 & 0.7519 & $\mathrm{BMB}$ \\
\hline 2 & 4.71 & Chloride & 1.45569 & 0.205 & 13.51 & 0.7593 & $\mathrm{BMB}$ \\
\hline 3 & 5.55 & Nitrite-N & 2.56761 & 0.424 & 27.92 & 0.7377 & $\mathrm{BMB}$ \\
\hline 4 & 7.01 & Bromide & 0.42719 & 0.086 & 5.70 & 0.7410 & $\mathrm{BMB}$ \\
\hline 5 & 7.86 & Nitrate-N & 2.12412 & 0.495 & 32.64 & 0.7454 & $\mathrm{BMB}$ \\
\hline
\end{tabular}

$$
\frac{H F-J L 69 G-1 A D}{\frac{H B r-J L 69 F-1 A D}{H C l-J \angle 8 T M-1 A D}}
$$




\section{ICB/METHOD BLANK}

\begin{tabular}{llll|}
\hline Sample Name: & ICB/ METHOD BLANK & Injection Volume: & $\mathbf{5 0 . 0}$ \\
Vial Number: & 139 & Channel: & ECD_1 \\
Sample Type: & unknown & Wavelength: & n.a. \\
Control Program: & ANIONS_AS14A & Bandwidth: & n.a. \\
Quantif. Method: & ANIONS & Dilution Factor: & $\mathbf{1 . 0 0 0 0}$ \\
Recording Time: & $12 / 18 / 200610: 52$ & Sample Weight: & $\mathbf{1 . 0 0 0 0}$ \\
Run Time (min): & $\mathbf{1 5 . 0 0}$ & Sample Amount: & $\mathbf{1 . 0 0 0 0}$ \\
\hline
\end{tabular}

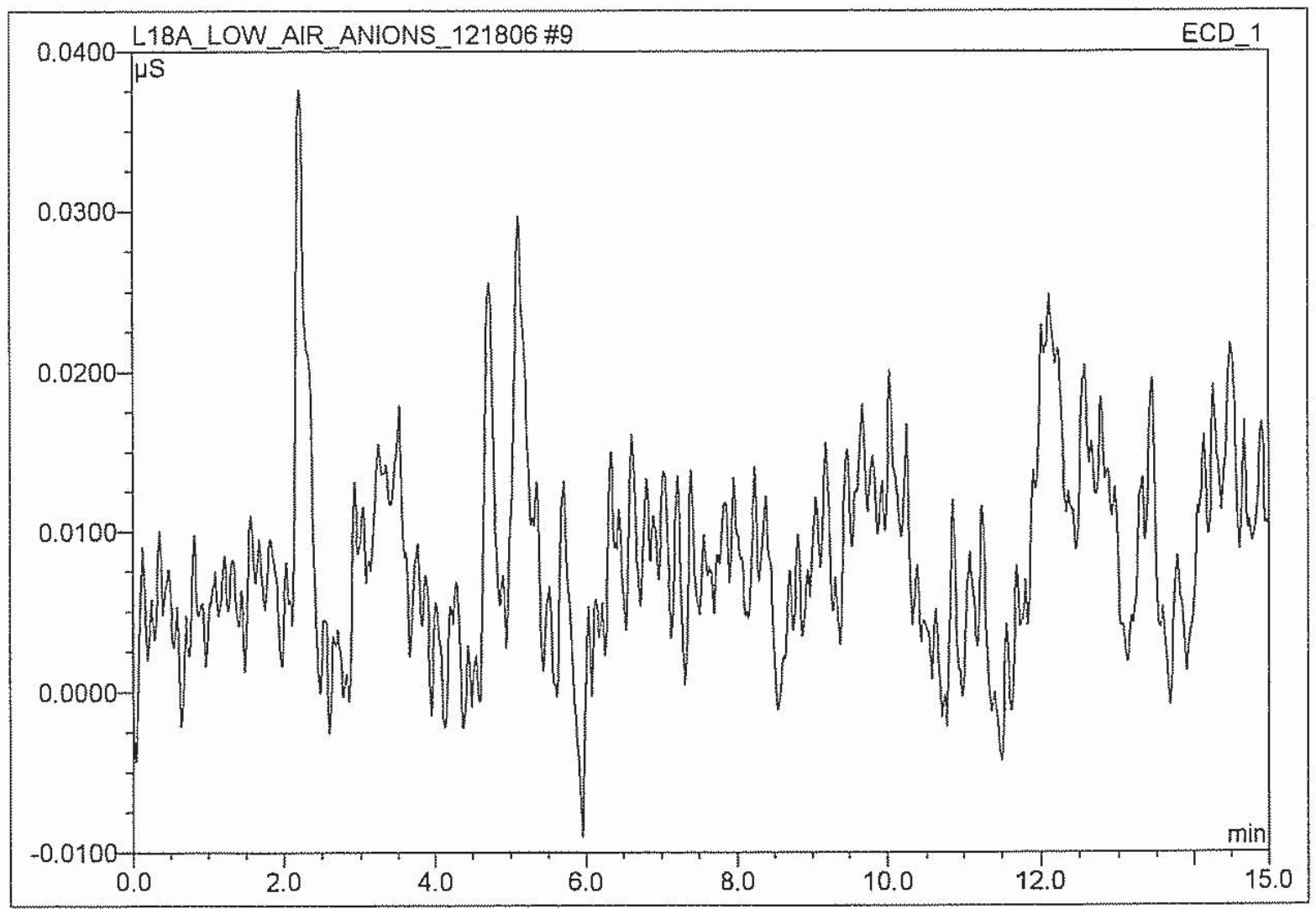

\begin{tabular}{|c|c|c|c|c|c|c|c|}
\hline No. & $\begin{array}{c}\text { Ret.Time } \\
\text { (min.) }\end{array}$ & Peak Name & $\begin{array}{c}\text { Height } \\
(\mathrm{uS})\end{array}$ & $\begin{array}{c}\text { Area } \\
\mu \mathrm{S}^{\star} \mathrm{min}\end{array}$ & $\begin{array}{c}\text { Rel.Area } \\
(\%)\end{array}$ & $\begin{array}{c}\text { Amount } \\
(\mathrm{mg} / \mathrm{L})\end{array}$ & $\begin{array}{c}\text { Peak } \\
\text { Type }\end{array}$ \\
\hline
\end{tabular}
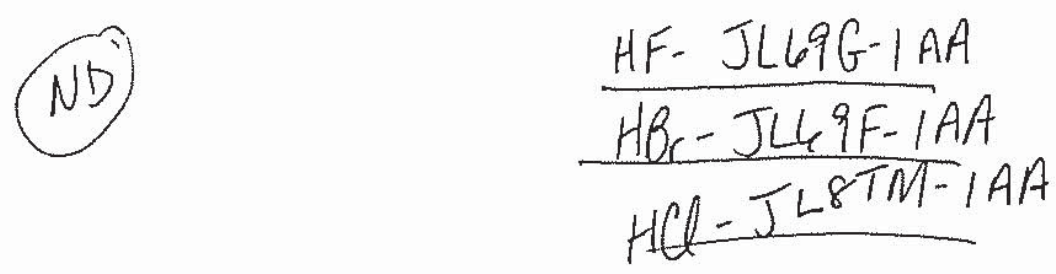


\section{H6L110105-JK7JR-1/10}

\begin{tabular}{llll|}
\hline Sample Name: & H6L110105-JK7JR-1/10 & Injection Volume: & $\mathbf{5 0 . 0}$ \\
Vial Number: & 140 & Channel: & ECD_1 \\
Sample Type: & unknown & Wavelength: & n.a. \\
Control Program: & ANIONS_AS14A & Bandwidth: & n.a. \\
Quantif. Method: & ANIONS & Dilution Factor: & $\mathbf{1 0 . 0 0 0 0}$ \\
Recording Time: & $\mathbf{1 2 / 1 8 / 2 0 0 6 1 1 : 2 6}$ & Sample Weight: & $\mathbf{1 . 0 0 0 0}$ \\
Run Time (min): & $\mathbf{1 5 . 0 0}$ & Sample Amount: & $\mathbf{1 . 0 0 0 0}$ \\
\hline
\end{tabular}

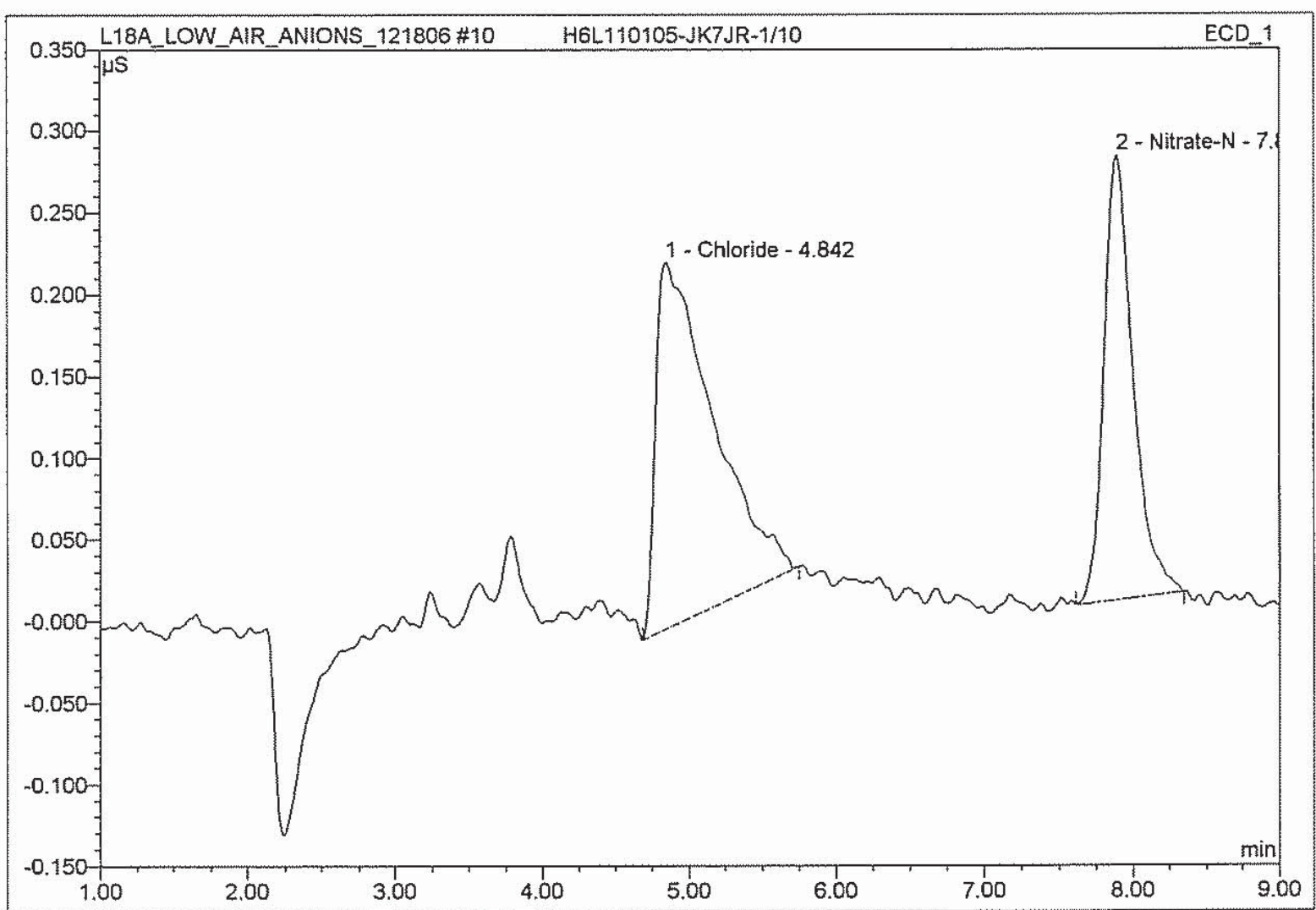

\begin{tabular}{|c|c|l|r|r|r|r|r|}
\hline No. & $\begin{array}{c}\text { Ret.Time } \\
\text { (min.) }\end{array}$ & \multicolumn{1}{|c|}{ Peak Name } & $\begin{array}{c}\text { Height } \\
\text { (uS) }\end{array}$ & $\begin{array}{c}\text { Area } \\
\mu \mathbf{S}^{*} \min \end{array}$ & $\begin{array}{c}\text { Rel.Area } \\
(\%)\end{array}$ & $\begin{array}{c}\text { Amount } \\
\text { (mg/L) }\end{array}$ & $\begin{array}{r}\text { Peak } \\
\text { Type }\end{array}$ \\
\hline 1 & 4.84 & Chloride & 0.22437 & 0.101 & 0.17 & 1.1966 & BMB \\
\hline 2 & 7.89 & Nitrate-N & 0.27174 & 0.062 & 0.10 & 0.9869 & BMB \\
\hline 3 & 11.88 & n.a. & 59.905 & 99.73 & n.a. & BMB \\
\hline
\end{tabular}

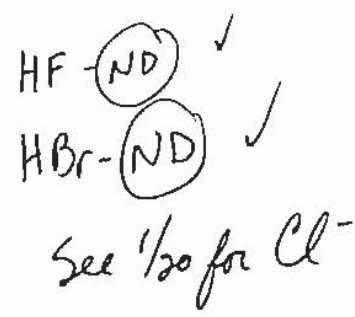




\section{H6L110105-JK7JR-1/20}

\begin{tabular}{llll|}
\hline Sample Name: & H6L110105-JK7JR-1/20 & Injection Volume: & $\mathbf{5 0 . 0}$ \\
Vial Number: & $\mathbf{1 4 2}$ & Channel: & ECD_1 \\
Sample Type: & unknown & Wavelength: & n.a. \\
Control Program: & ANIONS_AS14A & Bandwidth: & n.a. \\
Quantif. Method: & ANIONS & Dilution Factor: & $\mathbf{2 0 . 0 0 0 0}$ \\
Recording Time: & $\mathbf{1 2 / 1 8 / 2 0 0 6 1 2 : 0 8}$ & Sample Weight: & $\mathbf{1 . 0 0 0 0}$ \\
Run Time (min): & $\mathbf{1 5 . 0 0}$ & Sample Amount: & $\mathbf{1 . 0 0 0 0}$ \\
\hline
\end{tabular}

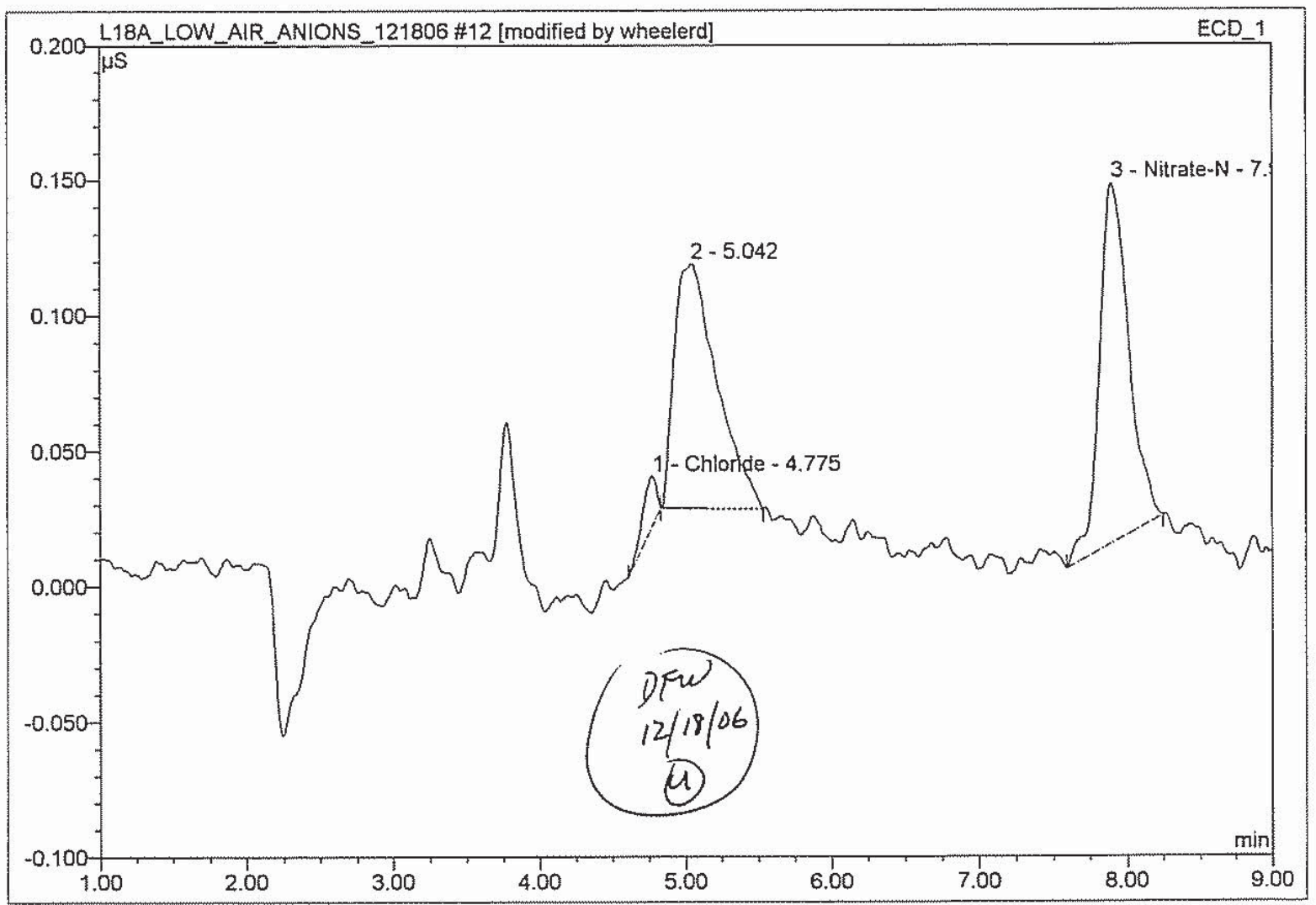

\begin{tabular}{|r|c|l|r|r|r|r|r|}
\hline No. & $\begin{array}{c}\text { Ret.Time } \\
\text { (min.) }\end{array}$ & \multicolumn{1}{|c|}{ Peak Name } & $\begin{array}{c}\text { Height } \\
\text { (uS) }\end{array}$ & $\begin{array}{c}\text { Area } \\
\mu S^{*} \min \end{array}$ & $\begin{array}{r}\text { Rel.Area } \\
(\%)\end{array}$ & $\begin{array}{c}\text { Amount } \\
(\mathrm{mg} / \mathrm{L})\end{array}$ & $\begin{array}{r}\text { Peak } \\
\text { Type }\end{array}$ \\
\hline 1 & 4.78 & Chloride & 0.01857 & 0.002 & 0.01 & 0.1989 & BMb $^{\star}$ \\
\hline 2 & 5.04 & n.a. & 0.09017 & 0.030 & 0.11 & n.a. & bMB $^{*}$ \\
\hline 3 & 7.90 & Nitrate-N & 0.13289 & 0.031 & 0.11 & 0.9679 & BMB \\
\hline 4 & 11.98 & n.a. & 87.71361 & 28.254 & 99.78 & n.a. & BMB \\
\hline
\end{tabular}




\section{H6L110105-JK7JR-1/20}

\begin{tabular}{llll}
\hline Sample Name: & H6L110105-JK7JR-1/20 & Injection Volume: & $\mathbf{5 0 . 0}$ \\
Vial Number: & $\mathbf{1 4 2}$ & Channel: & ECD_1 \\
Sample Type: & unknown & Wavelength: & n.a. \\
Control Program: & ANIONS_AS14A & Bandwidth: & n.a. \\
Quantif. Method: & ANIONS & Dilution Factor: & $\mathbf{2 0 . 0 0 0 0}$ \\
Recording Time: & $\mathbf{1 2 / 1 8 / 2 0 0 6 1 2 : 0 8}$ & Sample Weight: & $\mathbf{1 . 0 0 0 0}$ \\
Run Time (min): & $\mathbf{1 5 . 0 0}$ & Sample Amount: & $\mathbf{1 . 0 0 0 0}$ \\
\hline
\end{tabular}

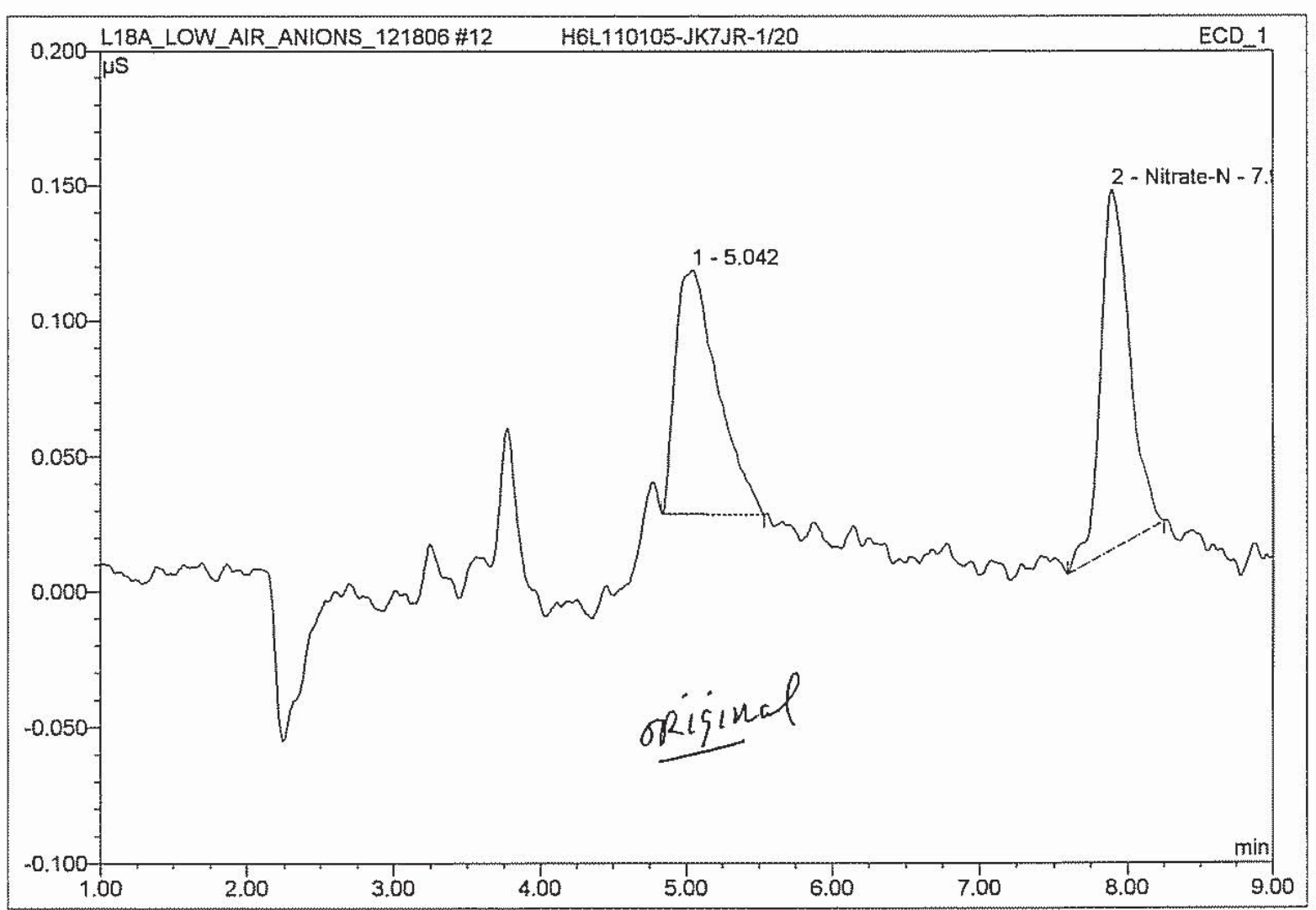

\begin{tabular}{|c|c|l|r|r|r|r|r|}
\hline No. & $\begin{array}{c}\text { Ret.Time } \\
\text { (min.) }\end{array}$ & \multicolumn{1}{|c|}{ Peak Name } & $\begin{array}{c}\text { Height } \\
\text { (uS) }\end{array}$ & $\begin{array}{c}\text { Area } \\
\mu \mathrm{S}^{*} \mathrm{~min}\end{array}$ & $\begin{array}{c}\text { Rel.Area } \\
(\%)\end{array}$ & $\begin{array}{c}\text { Amount } \\
\text { (mg/L) }\end{array}$ & $\begin{array}{r}\text { Peak } \\
\text { Type }\end{array}$ \\
\hline 1 & 5.04 & n.a. & 0.09017 & 0.030 & 0.11 & n.a. & BMB \\
\hline 2 & 7.90 & Nitrate-N & 0.13289 & 0.031 & 0.11 & 0.9679 & BMB \\
\hline 3 & 11.98 & n.a. & 87.71361 & 28.254 & 99.78 & n.a. & BMB \\
\hline
\end{tabular}




\section{H6L110105-JK7JR-1/10-MS}

\begin{tabular}{llll}
\hline Sample Name: & H6L110105-JK7JR-1/10-MS & Injection Volume: & $\mathbf{5 0 . 0}$ \\
Vial Number: & $\mathbf{1 4 3}$ & Channel: & ECD_1 \\
Sample Type: & unknown & Wavelength: & n.a. \\
Control Program: & ANIONS_AS14A & Bandwidth: & n.a. \\
Quantif. Method: & ANIONS & Dilution Factor: & $\mathbf{1 0 . 0 0 0 0}$ \\
Recording Time: & $\mathbf{1 2 / 1 8 / 2 0 0 6 1 2 : 4 3}$ & Sample Weight: & $\mathbf{1 . 0 0 0 0}$ \\
Run Time (min): & $\mathbf{1 5 . 0 0}$ & Sample Amount: & $\mathbf{1 . 0 0 0 0}$ \\
\hline
\end{tabular}

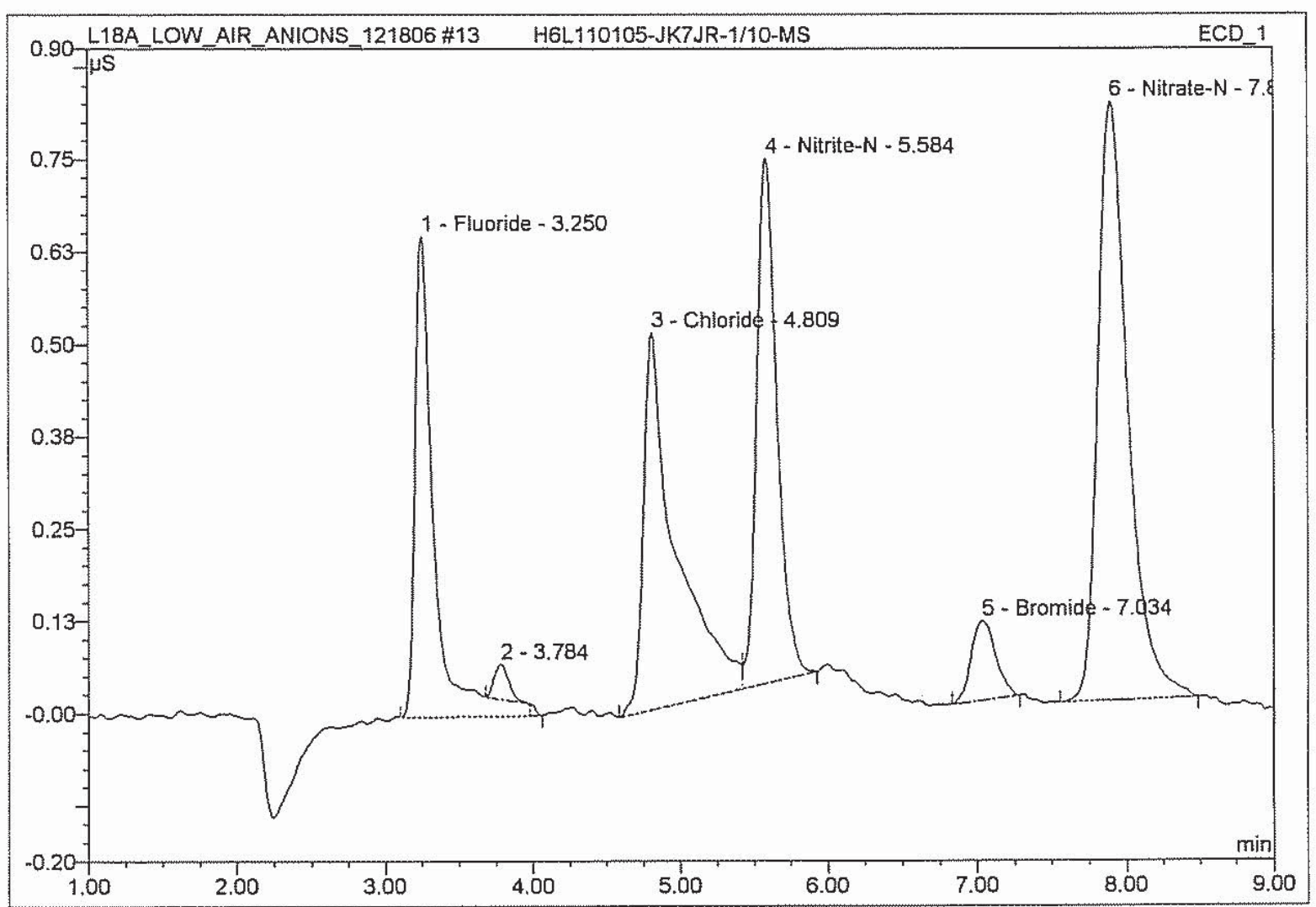

\begin{tabular}{|c|c|l|r|r|r|r|c|}
\hline No. & $\begin{array}{c}\text { Ret.Time } \\
\text { (min.) }\end{array}$ & \multicolumn{1}{|c|}{ Peak Name } & $\begin{array}{c}\text { Height } \\
(\mathrm{uS})\end{array}$ & $\begin{array}{c}\text { Area } \\
\boldsymbol{\mu S}^{*} \mathrm{~min}\end{array}$ & $\begin{array}{c}\text { Rel.Area } \\
(\%)\end{array}$ & $\begin{array}{c}\text { Amount } \\
(\mathrm{mg} / \mathrm{L})\end{array}$ & $\begin{array}{r}\text { Peak } \\
\text { Type }\end{array}$ \\
\hline 1 & 3.25 & Fluoride & 0.64968 & 0.098 & 0.17 & 2.0606 & BMB \\
\hline 2 & 3.78 & n.a. & 0.04771 & 0.005 & 0.01 & n.a. & Rd \\
\hline 3 & 4.81 & Chloride & 0.50954 & 0.129 & 0.22 & 2.7031 & $\mathrm{BM}$ \\
\hline 4 & 5.58 & Nitrite-N & 0.70996 & 0.114 & 0.20 & 2.0844 & $\mathrm{MB}$ \\
\hline 5 & 7.03 & Bromide & 0.10718 & 0.020 & 0.04 & 1.8777 & BMB \\
\hline 6 & 7.89 & Nitrate-N & 0.81102 & 0.190 & 0.33 & 2.9150 & BMB \\
\hline 7 & 11.90 & n.a. & 57.455 & 99.04 & n.a. & BMB \\
\hline
\end{tabular}

$$
(\mathrm{Cl}-Q 1 \% \mathrm{O})
$$




\section{H6L110105-JK7JR/1/10-MSD}

\begin{tabular}{llll|}
\hline Sample Name: & H6L110105-JK7JR/1/10-MSD & Injection Volume: & $\mathbf{5 0 . 0}$ \\
Vial Number: & 143 & Channel: & ECD_1 \\
Sample Type: & unknown & Wavelength: & n.a. \\
Control Program: & ANIONS_AS14A & Bandwidth: & n.a. \\
Quantif. Method: & ANIONS & Dilution Factor: & 10.0000 \\
Recording Time: & $12 / 18 / 200613: 00$ & Sample Weight: & 1.0000 \\
Run Time (min): & $\mathbf{1 5 . 0 0}$ & Sample Amount: & 1.0000 \\
\hline
\end{tabular}

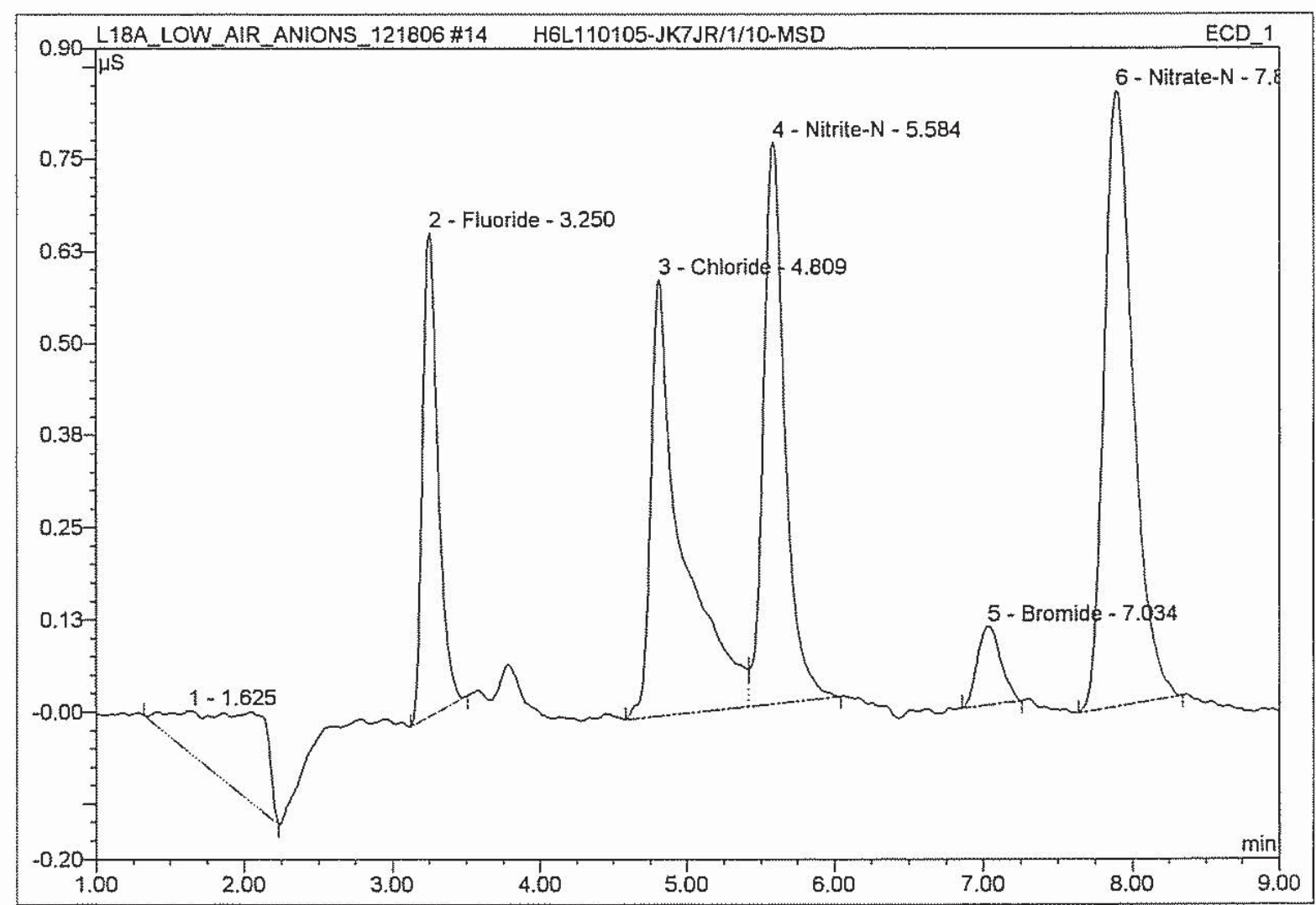

\begin{tabular}{|c|c|l|r|r|r|r|c|}
\hline No. & $\begin{array}{c}\text { Ret.Time } \\
\text { (min.) }\end{array}$ & \multicolumn{1}{|c|}{ Peak Name } & $\begin{array}{c}\text { Height } \\
\text { (uS) }\end{array}$ & $\begin{array}{c}\text { Area } \\
\mu \mathrm{S}^{\star} \min \end{array}$ & $\begin{array}{c}\text { Rel.Area } \\
(\%)\end{array}$ & $\begin{array}{c}\text { Amount } \\
\text { (mg/L) }\end{array}$ & $\begin{array}{r}\text { Peak } \\
\text { Type }\end{array}$ \\
\hline 1 & 1.63 & n.a. & 0.05595 & 0.061 & 0.10 & n.a. & BMB \\
\hline 2 & 3.25 & Fluoride & 0.65594 & 0.080 & 0.13 & 2.0802 & BMB \\
\hline 3 & 4.81 & Chloride & 0.59188 & 0.145 & 0.24 & 3.1352 & BM \\
\hline 4 & 5.58 & Nitrite-N & 0.76124 & 0.129 & 0.21 & 2.2336 & MB \\
\hline 5 & 7.03 & Bromide & 0.10691 & 0.019 & 0.03 & 1.8730 & BMB \\
\hline 6 & 7.89 & Nitrate-N & 0.83533 & 0.189 & 0.31 & 3.0010 & BMB \\
\hline 7 & 11.89 & n.a. & 60.336 & 98.98 & n.a. & BMB \\
\hline
\end{tabular}

$$
(C 1 \cdot 0,1 / 2)
$$

default_letter/Integration

Chromeleon (c) Dionex 1996-2001

Version 6.60 Build 1428 


\begin{tabular}{|llll|}
\hline 15 H6L110105-JK7JR-1/20-MS & & \\
& & & \\
\hline Sample Name: & H6L110105-JK7JR-1/20-MS & Injection Volume: & $\mathbf{5 0 . 0}$ \\
Vial Number: & $\mathbf{1 4 4}$ & Channel: & ECD_1 \\
Sample Type: & unknown & Wavelength: & n.a. \\
Control Program: & ANIONS_AS14A & Bandwidth: & n.a. \\
Quantif. Method: & ANIONS & Dilution Factor: & $\mathbf{2 0 . 0 0 0 0}$ \\
Recording Time: & $\mathbf{1 2 / 1 8 / 2 0 0 6 ~ 1 3 : 1 8}$ & Sample Weight: & 1.0000 \\
Run Time (min): & $\mathbf{1 5 . 0 0}$ & Sample Amount: & $\mathbf{1 . 0 0 0 0}$ \\
\hline
\end{tabular}

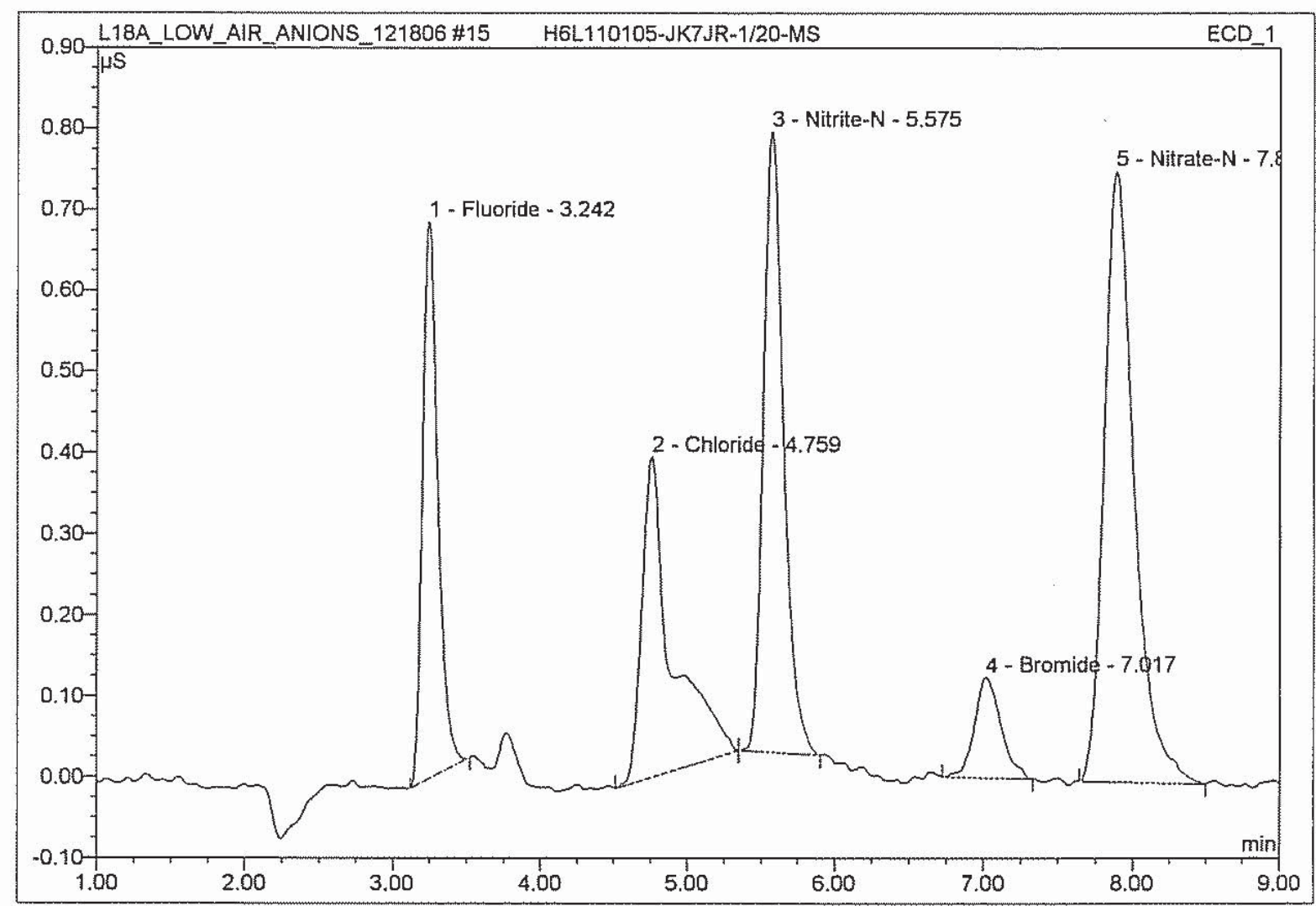

\begin{tabular}{|c|c|l|r|r|r|r|c|}
\hline No. & $\begin{array}{c}\text { Ret.Time } \\
\text { (min.) }\end{array}$ & \multicolumn{1}{|c|}{ Peak Name } & $\begin{array}{c}\text { Height } \\
\text { (uS) }\end{array}$ & $\begin{array}{c}\text { Area } \\
\mu S^{\star} \text { min }\end{array}$ & $\begin{array}{c}\text { Rel.Area } \\
(\%)\end{array}$ & $\begin{array}{c}\text { Amount } \\
\text { (mg/L) }\end{array}$ & $\begin{array}{c}\text { Peak } \\
\text { Type }\end{array}$ \\
\hline 1 & 3.24 & Fluoride & 0.68741 & 0.083 & 0.27 & 4.3579 & BMB \\
\hline 2 & 4.76 & Chloride & 0.39494 & 0.093 & 0.31 & 4.1992 & BMB \\
\hline 3 & 5.58 & Nitrite-N & 0.76522 & 0.122 & 0.40 & 4.4903 & bMB \\
\hline 4 & 7.02 & Bromide & 0.12440 & 0.025 & 0.08 & 4.3565 & BMB \\
\hline 5 & 7.89 & Nitrate-N & 0.75269 & 0.177 & 0.58 & 5.4168 & BMB \\
\hline 6 & 11.97 & n.a. & 92.95436 & 30.056 & 98.36 & n.a. & BMB \\
\hline
\end{tabular}




\section{$16 \mathrm{CCV}=$ ICWS -9058}

\begin{tabular}{llll}
\hline Sample Name: & CCV = ICWS-9058 & Injection Volume: & 50.0 \\
Vial Number: & 147 & Channel: & ECD_1 \\
Sample Type: & unknown & Wavelength: & n.a. \\
Control Program: & ANIONS_AS14A & Bandwidth: & n.a. \\
Quantif. Method: & ANIONS & Dilution Factor: & 1.0000 \\
Recording Time: & $12 / 18 / 200613: 35$ & Sample Weight: & 1.0000 \\
Run Time (min): & 15.00 & Sample Amount: & 1.0000 \\
\hline
\end{tabular}

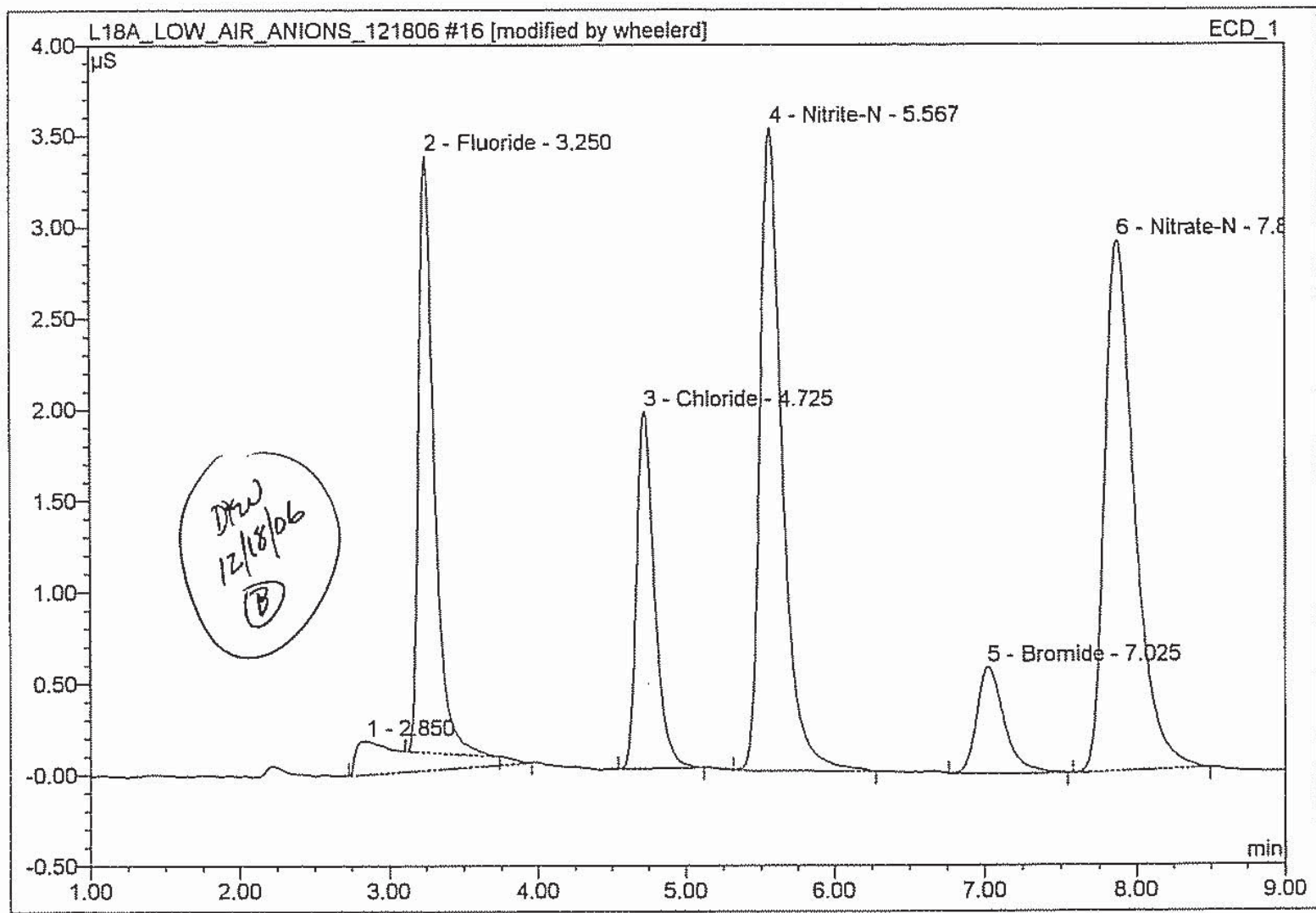

\begin{tabular}{|c|c|l|r|r|r|r|c|}
\hline No. & $\begin{array}{c}\text { Ret.Time } \\
\text { (min.) }\end{array}$ & \multicolumn{1}{|c|}{ Peak Name } & $\begin{array}{c}\text { Height } \\
\text { (uS) }\end{array}$ & $\begin{array}{c}\text { Area } \\
\mu S^{*} \min \end{array}$ & $\begin{array}{r}\text { Rel.Area } \\
\text { (\%) }\end{array}$ & $\begin{array}{r}\text { Amount } \\
\text { (mg/L) }\end{array}$ & $\begin{array}{r}\text { Peak } \\
\text { Type }\end{array}$ \\
\hline 1 & 2.85 & n.a. & 0.18302 & 0.106 & 4.79 & n.a. & BMB $^{*}$ \\
\hline 2 & 3.25 & Fluoride & 3.26791 & 0.404 & 18.23 & 0.9974 & Rd $^{*}$ \\
\hline 3 & 4.73 & Chloride & 1.95319 & 0.274 & 12.36 & 1.0101 & BMB \\
\hline 4 & 5.57 & Nitrite-N & 3.51969 & 0.608 & 27.45 & 1.0007 & BMB \\
\hline 5 & 7.03 & Bromide & 0.58477 & 0.123 & 5.55 & 1.0095 & BMB \\
\hline 6 & 7.88 & Nitrate-N & 2.90661 & 0.677 & 30.56 & 1.0062 & BMB \\
\hline 7 & 12.05 & n.a. & 0.07024 & 0.023 & 1.05 & n.a. & BMB \\
\hline
\end{tabular}




\section{$16 \mathrm{CCV}=\mathrm{ICWS}-9058$}

\begin{tabular}{llll|}
\hline Sample Name: & CCV = ICWS-9058 & Injection Volume: & $\mathbf{5 0 . 0}$ \\
Vial Number: & 147 & Channel: & ECD_1 \\
Sample Type: & unknown & Wavelength: & n.a. \\
Control Program: & ANIONS_AS14A & Bandwidth: & n.a. \\
Quantif. Method: & ANIONS & Dilution Factor: & $\mathbf{1 . 0 0 0 0}$ \\
Recording Time: & $\mathbf{1 2 / 1 8 / 2 0 0 6 1 3 : 3 5}$ & Sample Weight: & $\mathbf{1 . 0 0 0 0}$ \\
Run Time (min): & $\mathbf{1 5 . 0 0}$ & Sample Amount: & $\mathbf{1 . 0 0 0 0}$ \\
\hline
\end{tabular}

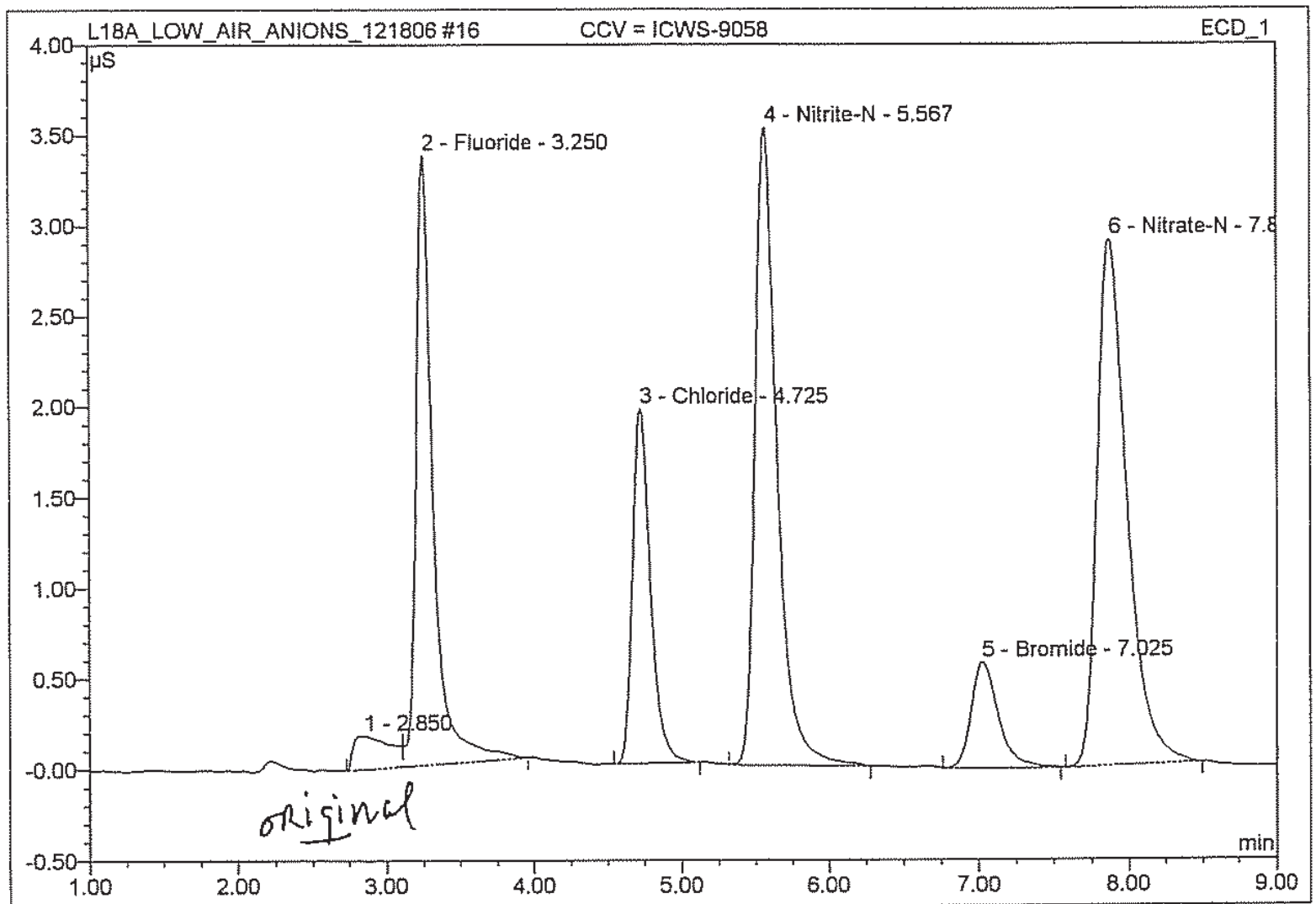

\begin{tabular}{|r|c|l|r|r|r|r|c|}
\hline No. & $\begin{array}{c}\text { Ret.Time } \\
\text { (min.) }\end{array}$ & \multicolumn{1}{|c|}{ Peak Name } & $\begin{array}{c}\text { Height } \\
\text { (uS) }\end{array}$ & $\begin{array}{c}\text { Area } \\
\mu \mathrm{S}^{*} \mathrm{~min}\end{array}$ & $\begin{array}{c}\text { Rel.Area } \\
(\%)\end{array}$ & $\begin{array}{r}\text { Amount } \\
\text { (mg/L) }\end{array}$ & $\begin{array}{r}\text { Peak } \\
\text { Type }\end{array}$ \\
\hline 1 & 2.85 & n.a. & 0.18302 & 0.052 & 2.35 & n.a. & BM \\
\hline 2 & 3.25 & Fluoride & 3.36406 & 0.458 & 20.68 & 1.0254 & MB \\
\hline 3 & 4.73 & Chloride & 1.95319 & 0.274 & 12.36 & 1.0101 & BMB \\
\hline 4 & 5.57 & Nitrite-N & 3.51969 & 0.608 & 27.45 & 1.0007 & BMB \\
\hline 5 & 7.03 & Bromide & 0.58477 & 0.123 & 5.55 & 1.0095 & BMB \\
\hline 6 & 7.88 & Nitrate-N & 2.90661 & 0.677 & 30.56 & 1.0062 & BMB \\
\hline 7 & 12.05 & n.a. & 0.07024 & 0.023 & 1.05 & n.a. & BMB \\
\hline
\end{tabular}




\section{$17 \mathrm{CCB}$}

\begin{tabular}{llll}
\hline Sample Name: & CCB & Injection Volume: & $\mathbf{5 0 . 0}$ \\
Vial Number: & 148 & Channel: & ECD_1 \\
Sample Type: & unknown & Wavelength: & n.a. \\
Control Program: & ANIONS_AS14A & Bandwidth: & n.a. \\
Quantif. Method: & ANIONS & Dilution Factor: & $\mathbf{1 . 0 0 0 0}$ \\
Recording Time: & $\mathbf{1 2 / 1 8 / 2 0 0 6 1 3 : 5 3}$ & Sample Weight: & $\mathbf{1 . 0 0 0 0}$ \\
Run Time (min): & $\mathbf{1 5 . 0 0}$ & Sample Amount: & $\mathbf{1 . 0 0 0 0}$ \\
\hline
\end{tabular}

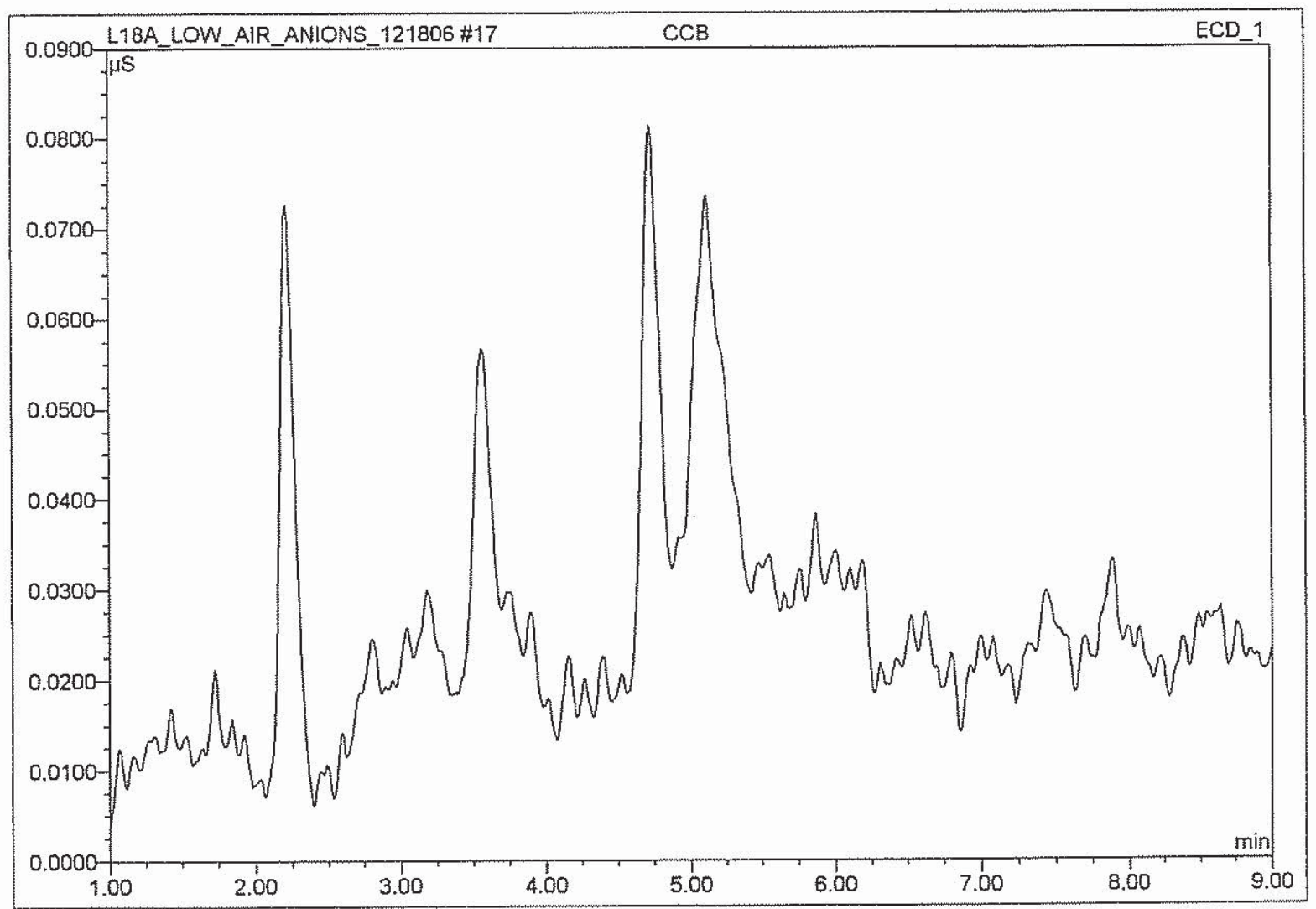

\begin{tabular}{|c|c|c|c|c|c|c|c|}
\hline No. & $\begin{array}{c}\text { Ret.Time } \\
(\min .)\end{array}$ & Peak Name & $\begin{array}{c}\text { Height } \\
(\mathrm{uS})\end{array}$ & $\begin{array}{c}\text { Area } \\
\mu \mathrm{S}^{*} \mathrm{~min}\end{array}$ & $\begin{array}{c}\text { Rel.Area } \\
(\%)\end{array}$ & $\begin{array}{c}\text { Amount } \\
(\mathrm{mg} / \mathrm{L})\end{array}$ & $\begin{array}{c}\text { Peak } \\
\text { Type }\end{array}$ \\
\hline
\end{tabular}

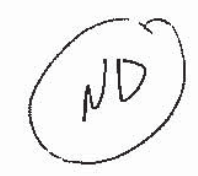




\section{H6L110105-JK7JX-1/10}

\begin{tabular}{llll|}
\hline Sample Name: & H6L110105-JK7JX-1/10 & Injection Volume: & $\mathbf{5 0 . 0}$ \\
Vial Number: & $\mathbf{1 5 1}$ & Channel: & ECD_1 \\
Sample Type: & unknown & Wavelength: & n.a. \\
Control Program: & ANIONS_AS14A & Bandwidth: & n.a. \\
Quantif. Method: & ANIONS & Dilution Factor: & 10.0000 \\
Recording Time: & $\mathbf{1 2 / 1 8 / 2 0 0 6 1 4 : 4 7}$ & Sample Weight: & 1.0000 \\
Run Time (min): & $\mathbf{1 5 . 0 0}$ & Sample Amount: & $\mathbf{1 . 0 0 0 0}$ \\
\hline
\end{tabular}

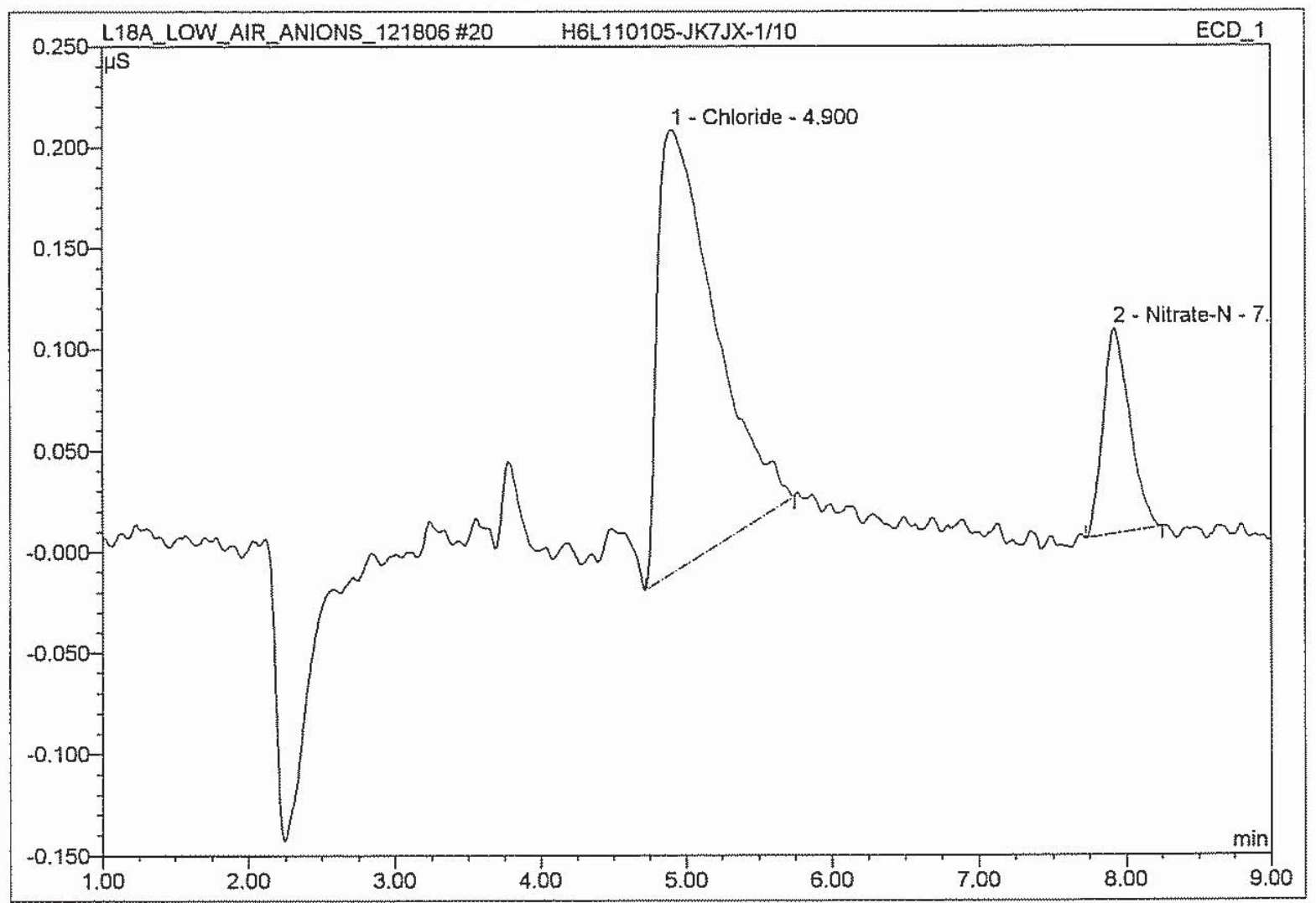

\begin{tabular}{|c|c|l|r|r|r|r|c|}
\hline No. & $\begin{array}{c}\text { Ret.Time } \\
\text { (min.) }\end{array}$ & \multicolumn{1}{|c|}{ Peak Name } & $\begin{array}{c}\text { Height } \\
\text { (uS) }\end{array}$ & $\begin{array}{c}\text { Area } \\
\mu S^{*} \min \end{array}$ & $\begin{array}{r}\text { Rel.Area } \\
(\%)\end{array}$ & $\begin{array}{c}\text { Amount } \\
\text { (mg/L) }\end{array}$ & $\begin{array}{r}\text { Peak } \\
\text { Type }\end{array}$ \\
\hline 1 & 4.90 & Chloride & 0.21936 & 0.099 & 0.16 & 1.1700 & BMB \\
\hline 2 & 7.92 & Nitrate-N & 0.10116 & 0.021 & 0.03 & 0.3686 & BMB \\
\hline 3 & 10.78 & n.a. & 0.15002 & 0.046 & 0.07 & n.a. & BMB \\
\hline 4 & 11.89 & n.a. & 61.095 & 99.73 & n.a. & BMB \\
\hline
\end{tabular}

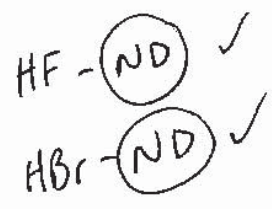




\section{H6L110105-JK7J1-1/10}

\begin{tabular}{llll|}
\hline Sample Name: & H6L110105-JK7J1-1/10 & Injection Volume: & $\mathbf{5 0 . 0}$ \\
Vial Number: & $\mathbf{1 5 2}$ & Channel: & ECD_1 \\
Sample Type: & unknown & Wavelength: & n.a. \\
Control Program: & ANIONS_AS14A & Bandwidth: & n.a. \\
Quantif. Method: & ANIONS & Dilution Factor: & 10.0000 \\
Recording Time: & $\mathbf{1 2 / 1 8 / 2 0 0 6 ~ 1 5 : 0 4}$ & Sample Weight: & $\mathbf{1 . 0 0 0 0}$ \\
Run Time (min): & $\mathbf{1 5 . 0 0}$ & Sample Amount: & $\mathbf{1 . 0 0 0 0}$ \\
\hline
\end{tabular}

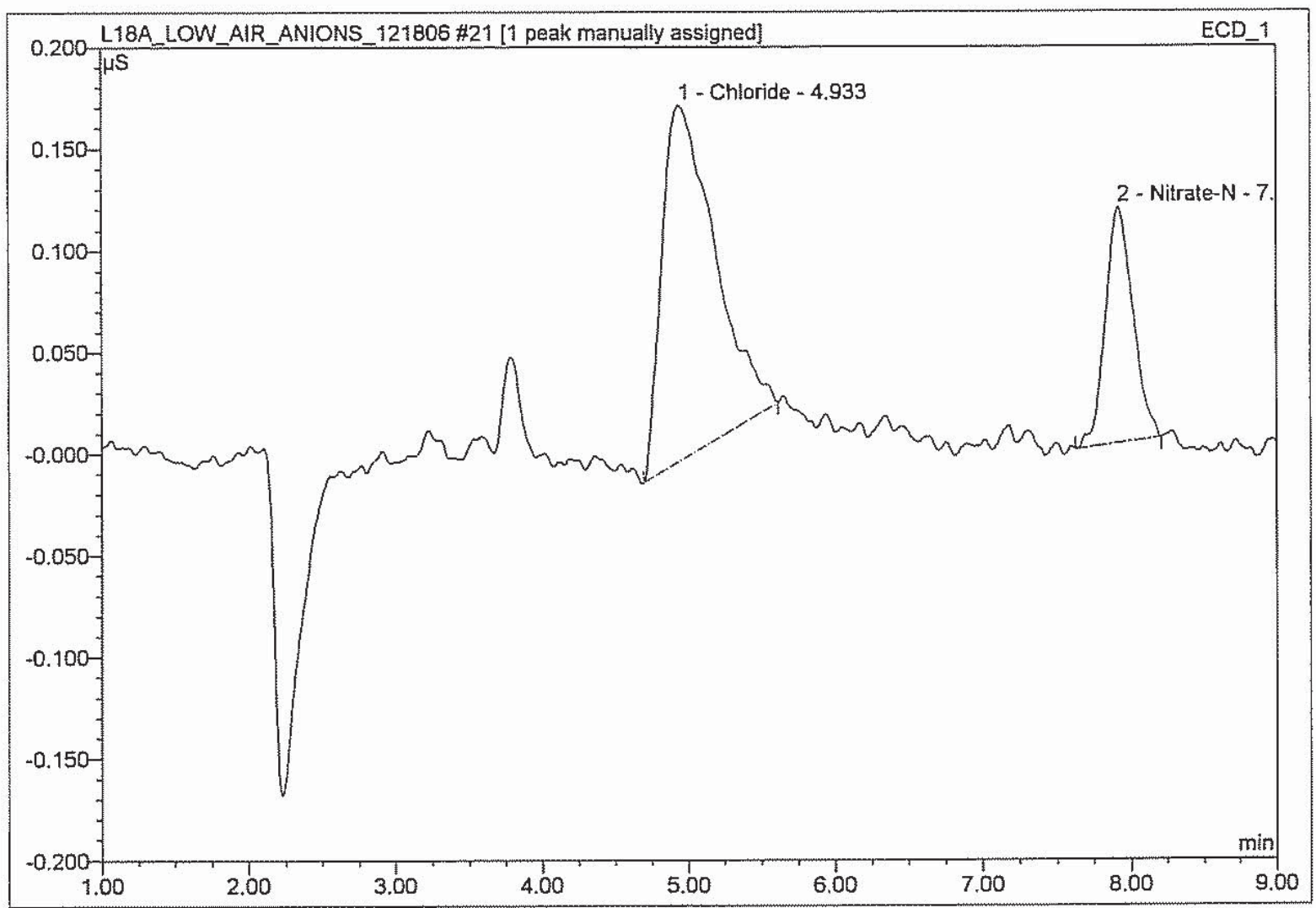

\begin{tabular}{|c|c|l|r|r|r|r|c|}
\hline No. & $\begin{array}{c}\text { Ret.Time } \\
\text { (min.) }\end{array}$ & \multicolumn{1}{|c|}{ Peak Name } & $\begin{array}{c}\text { Height } \\
\text { (uS) }\end{array}$ & $\begin{array}{c}\text { Area } \\
\mu S^{\star} \text { min }\end{array}$ & $\begin{array}{c}\text { Rel.Area } \\
(\%)\end{array}$ & $\begin{array}{c}\text { Amount } \\
\text { (mg/L) }\end{array}$ & $\begin{array}{r}\text { Peak } \\
\text { Type }\end{array}$ \\
\hline 1 & 4.93 & Chloride & 0.17515 & 0.073 & 0.15 & 0.9350 & BMB $^{\wedge}$ \\
\hline 2 & 7.92 & Nitrate-N & 0.11589 & 0.025 & 0.05 & 0.4222 & BMB \\
\hline 3 & 11.92 & n.a. & 47.743 & 99.79 & n.a. & BMB \\
\hline
\end{tabular}

$$
H F-(N D) /
$$




\section{$28 C C V=I C W S-9058$}

\begin{tabular}{llll|}
\hline Sample Name: & CCV=ICWS-9058 & Injection Volume: & $\mathbf{5 0 . 0}$ \\
Vial Number: & 166 & Channel: & ECD_1 \\
Sample Type: & unknown & Wavelength: & n.a. \\
Control Program: & ANIONS_AS14A & Bandwidth: & n.a. \\
Quantif. Method: & ANIONS & Dilution Factor: & $\mathbf{1 . 0 0 0 0}$ \\
Recording Time: & $\mathbf{1 2 / 1 8 / 2 0 0 6 1 7 : 0 6}$ & Sample Weight: & $\mathbf{1 . 0 0 0 0}$ \\
Run Time (min): & $\mathbf{1 5 . 0 0}$ & Sample Amount: & $\mathbf{1 . 0 0 0 0}$ \\
\hline
\end{tabular}

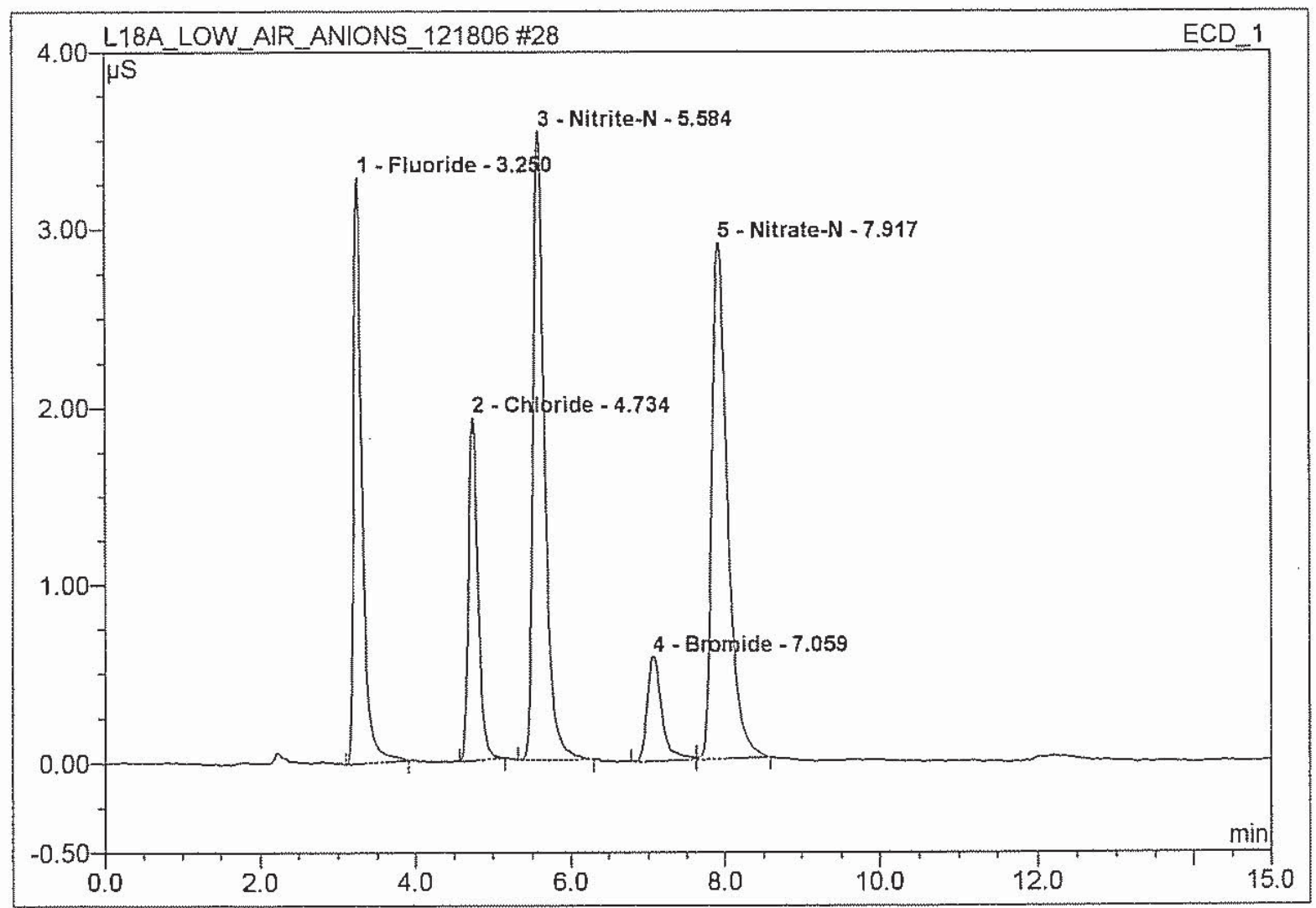

\begin{tabular}{|c|c|l|r|r|r|r|c|}
\hline No. & $\begin{array}{c}\text { Ret.Time } \\
\text { (min.) }\end{array}$ & \multicolumn{1}{|c|}{ Peak Name } & $\begin{array}{c}\text { Height } \\
(\mathrm{uS})\end{array}$ & $\begin{array}{c}\text { Area } \\
\mu \mathrm{S}^{*} \mathrm{~min}\end{array}$ & $\begin{array}{c}\text { Rel.Area } \\
(\%)\end{array}$ & $\begin{array}{c}\text { Amount } \\
(\mathrm{mg} / \mathrm{L})\end{array}$ & $\begin{array}{c}\text { Peak } \\
\text { Type }\end{array}$ \\
\hline 1 & 3.25 & Fluoride & 3.29330 & 0.422 & 19.95 & 1.0048 & $\mathrm{BMB}$ \\
\hline 2 & 4.73 & Chloride & 1.92845 & 0.274 & 12.94 & 0.9978 & $\mathrm{BMB}$ \\
\hline 3 & 5.58 & Nitrite-N & 3.53011 & 0.610 & 28.81 & 1.0035 & $\mathrm{BMB}$ \\
\hline 4 & 7.06 & Bromide & 0.58345 & 0.124 & 5.88 & 1.0073 & $\mathrm{BM}$ \\
\hline 5 & 7.92 & Nitrate-N & 2.89375 & 0.686 & 32.42 & 1.0020 & $\mathrm{MB}$ \\
\hline
\end{tabular}




\section{$29 \mathrm{CCB}$}

Sample Name:

Vial Number:

Sample Type:

Control Program:

Quantif. Method:

Recording Time:

Run Time (min):
ССB

167

unknown

ANIONS_AS14A

ANIONS

12/18/2006 17:23

15.00
Injection Volume: $\quad \mathbf{5 0 . 0}$

Channel: ECD_1

Wavelength:

Bandwidth:

Dilution Factor:

n.a.

n.a.

Sample Weight:

Sample Amount: $\quad \mathbf{1 . 0 0 0 0}$

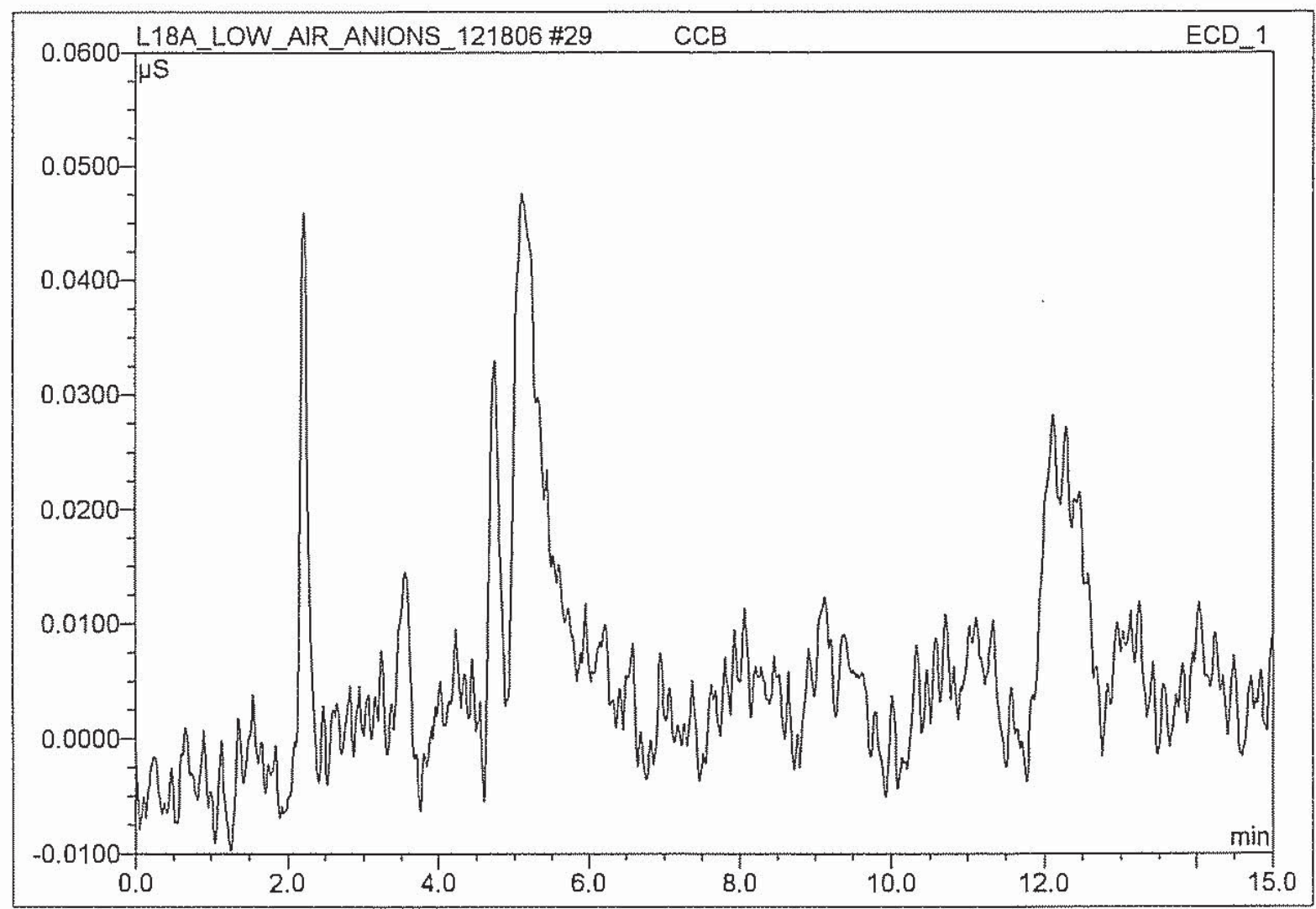

\begin{tabular}{|c|c|c|c|c|c|c|c|}
\hline No. & $\begin{array}{c}\text { Ret.Time } \\
(\min .)\end{array}$ & Peak Name & $\begin{array}{c}\text { Height } \\
(\mathrm{uS})\end{array}$ & $\begin{array}{c}\text { Area } \\
\mu \mathrm{S}^{*} \mathrm{~min}\end{array}$ & $\begin{array}{c}\text { Rel.Area } \\
(\%)\end{array}$ & $\begin{array}{c}\text { Amount } \\
(\mathrm{mg} / \mathrm{L})\end{array}$ & $\begin{array}{c}\text { Peak } \\
\text { Type }\end{array}$ \\
\hline
\end{tabular}

(Ni) 


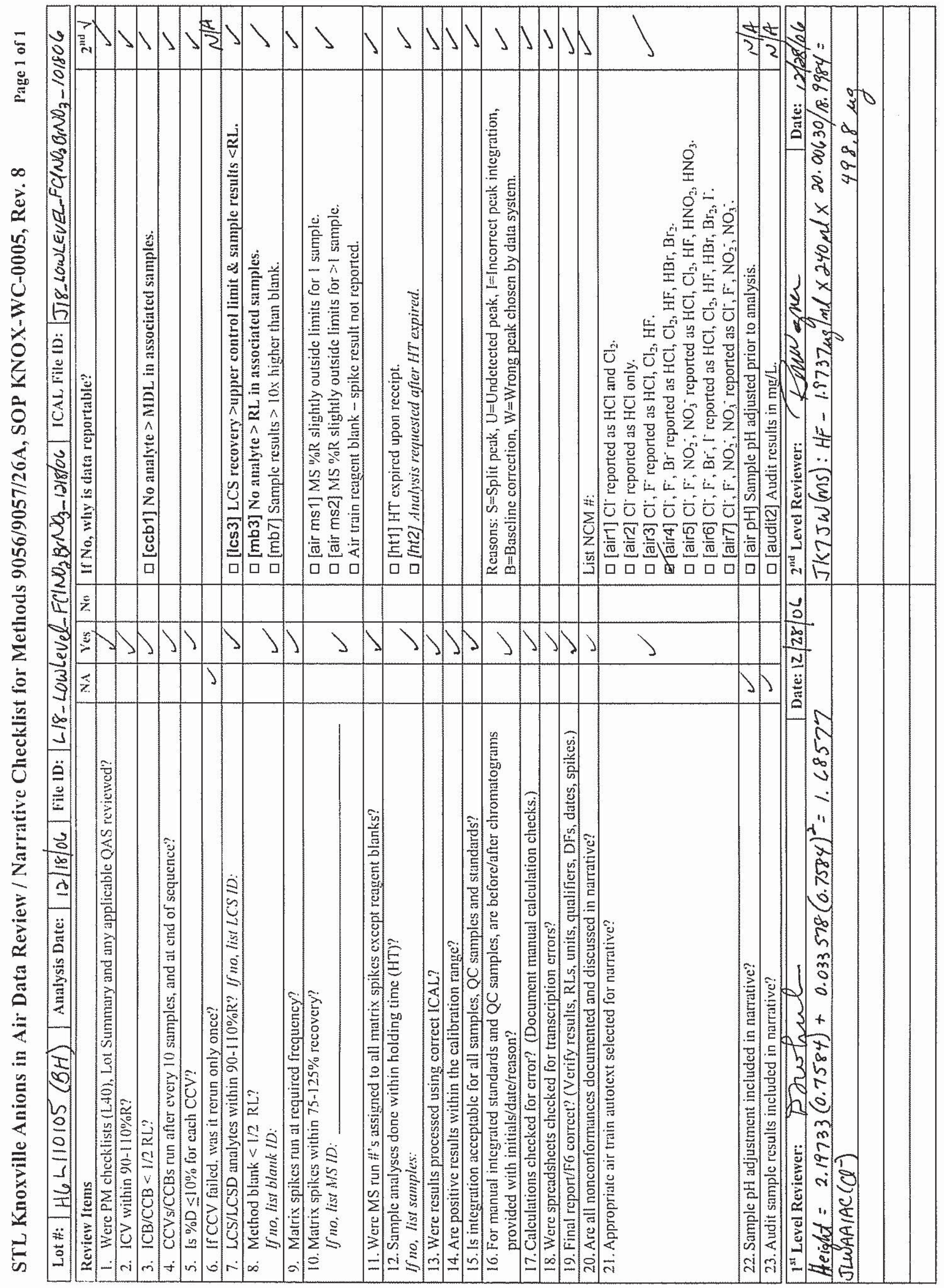

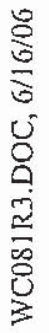

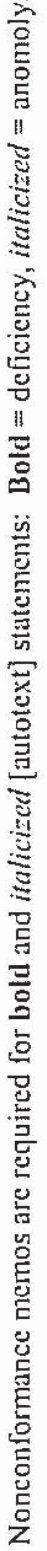




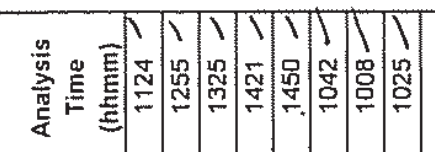

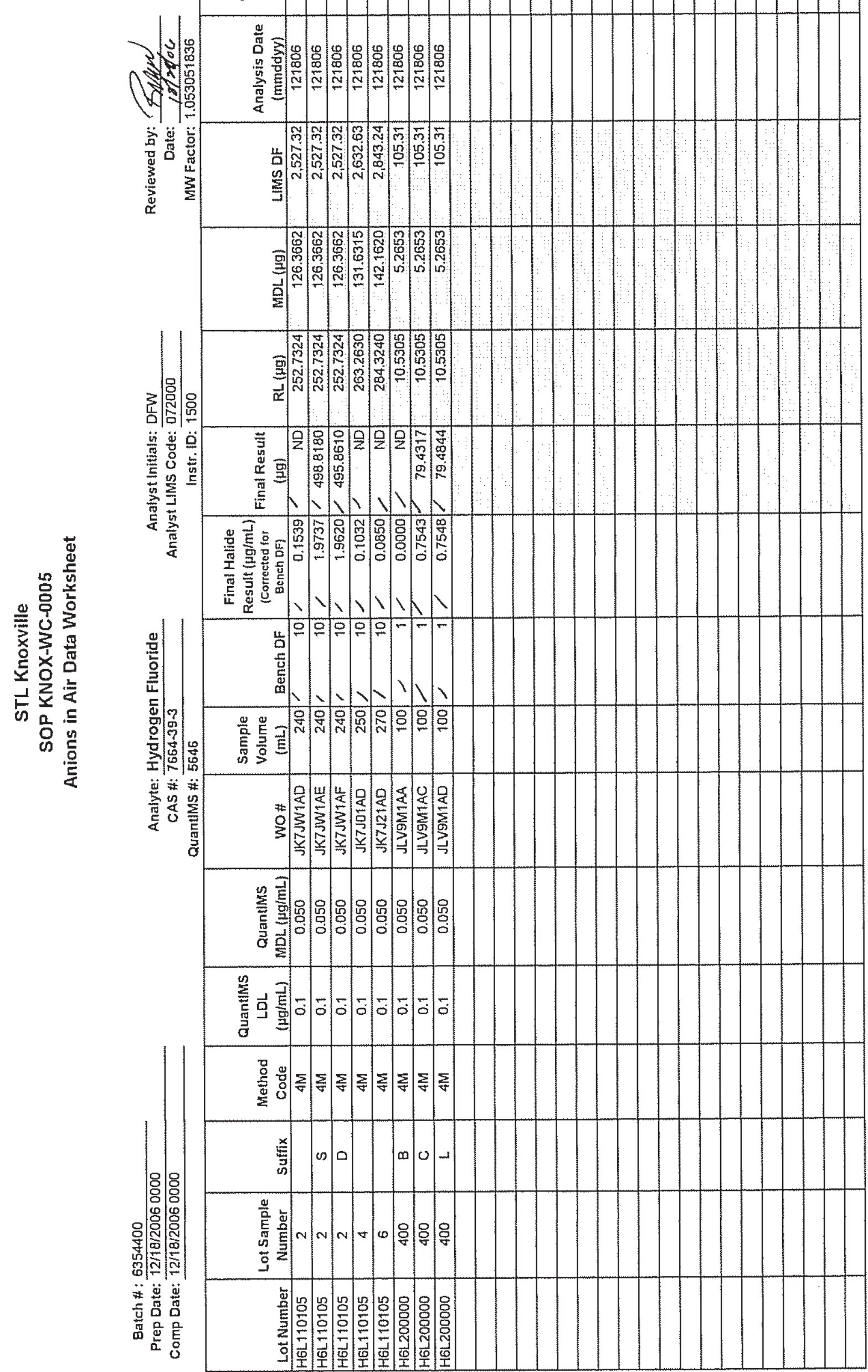




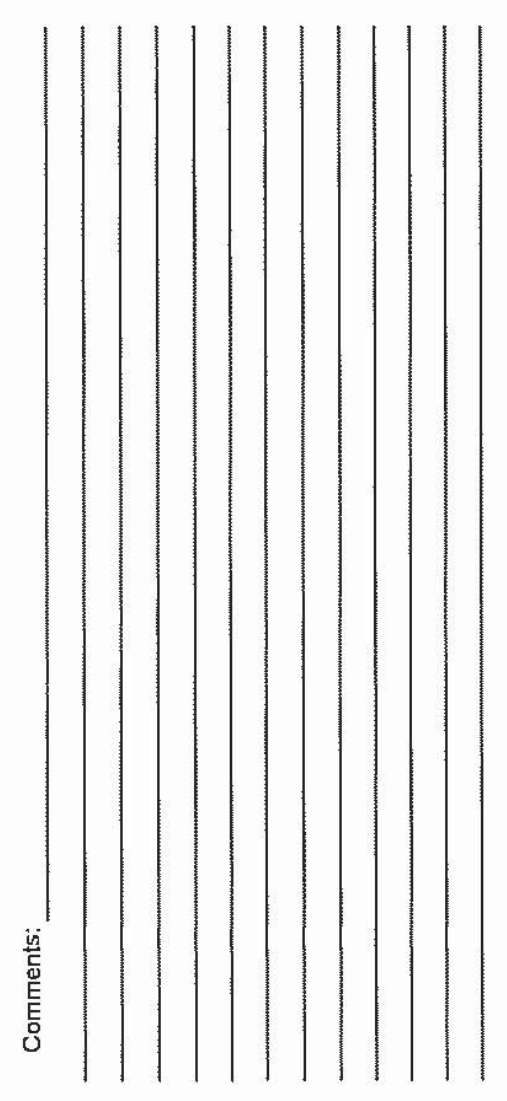

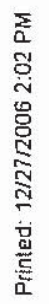

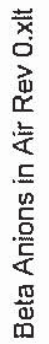
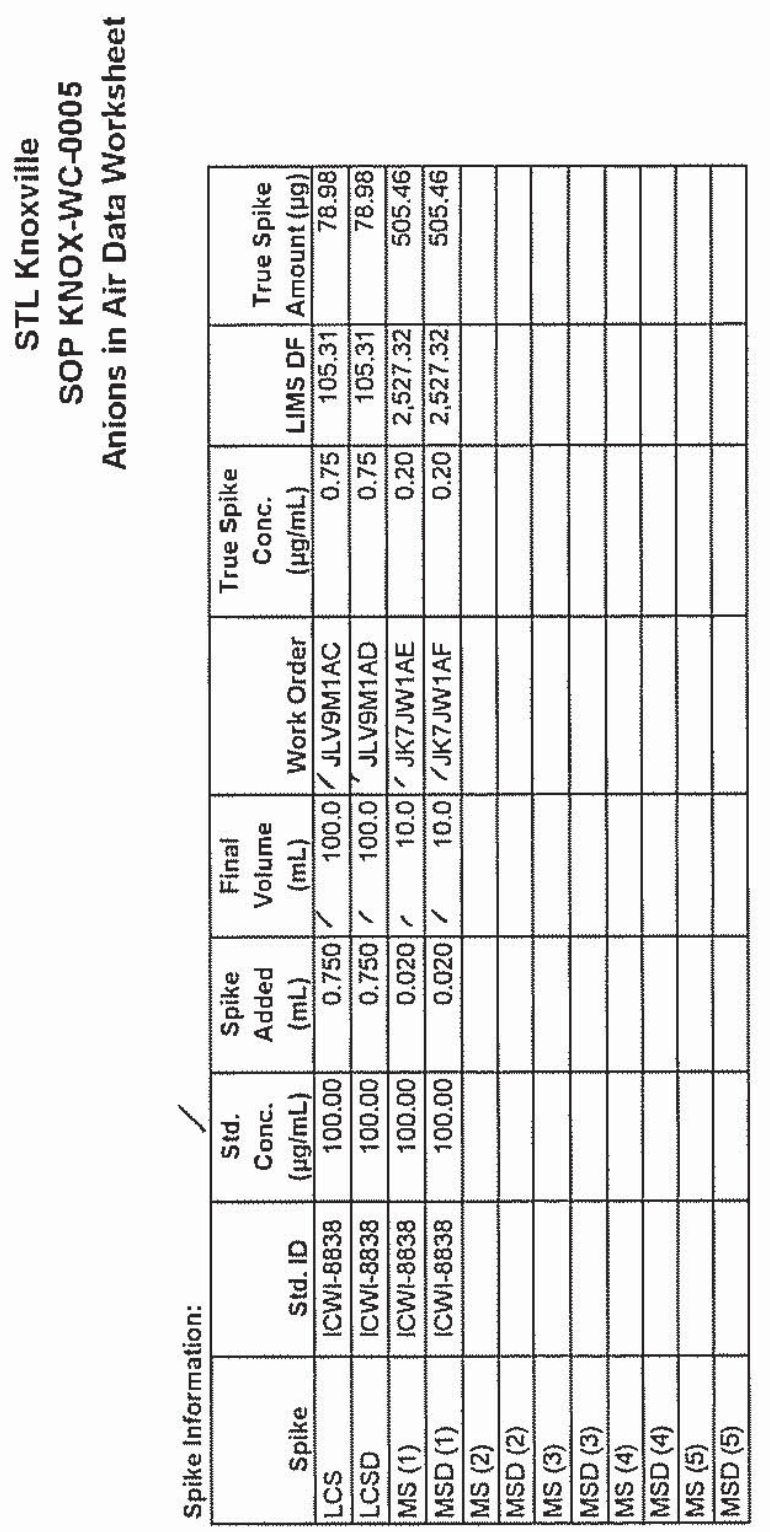

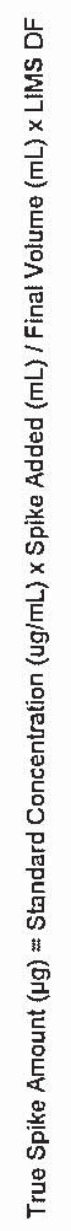




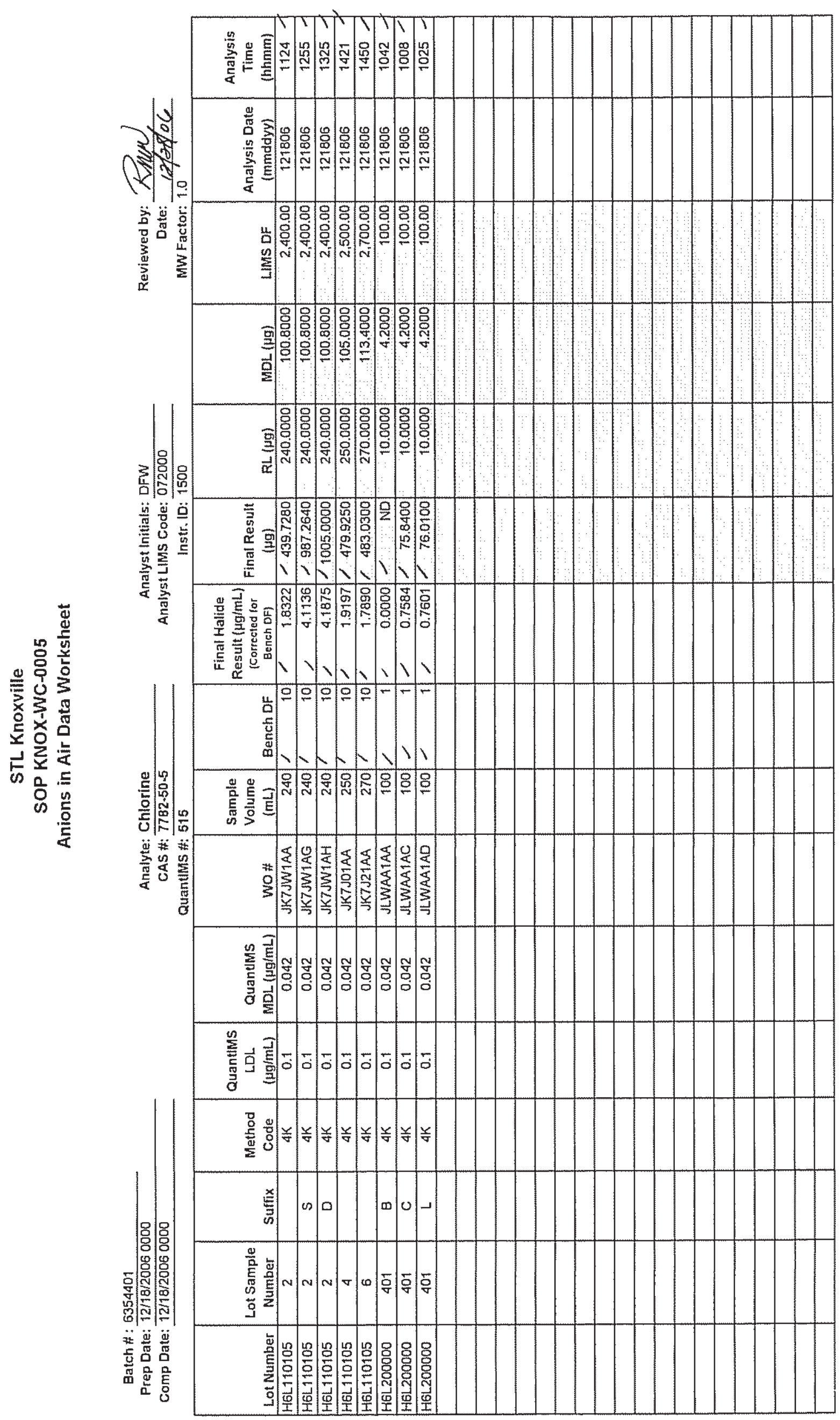




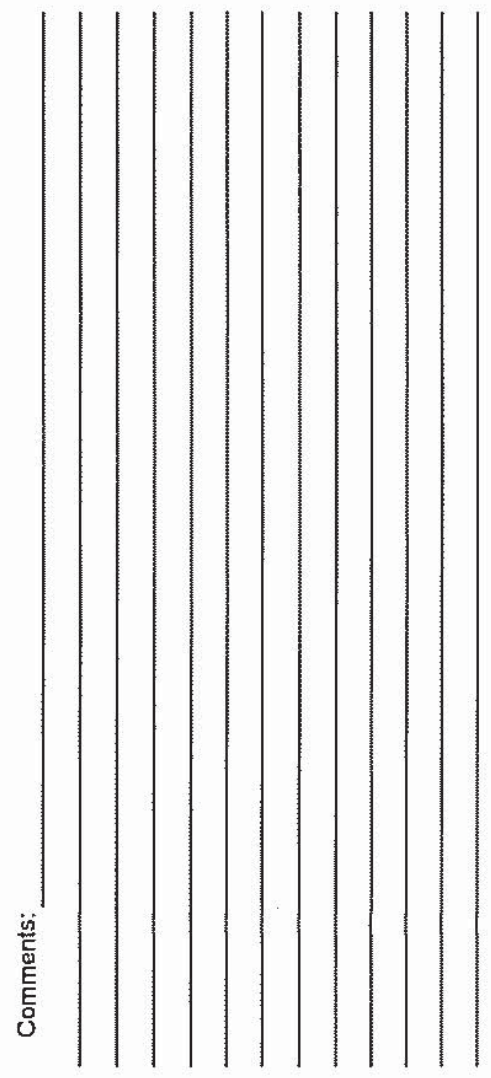

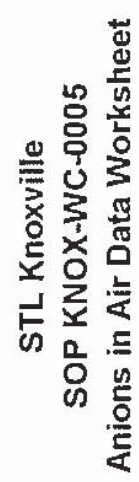

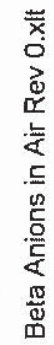

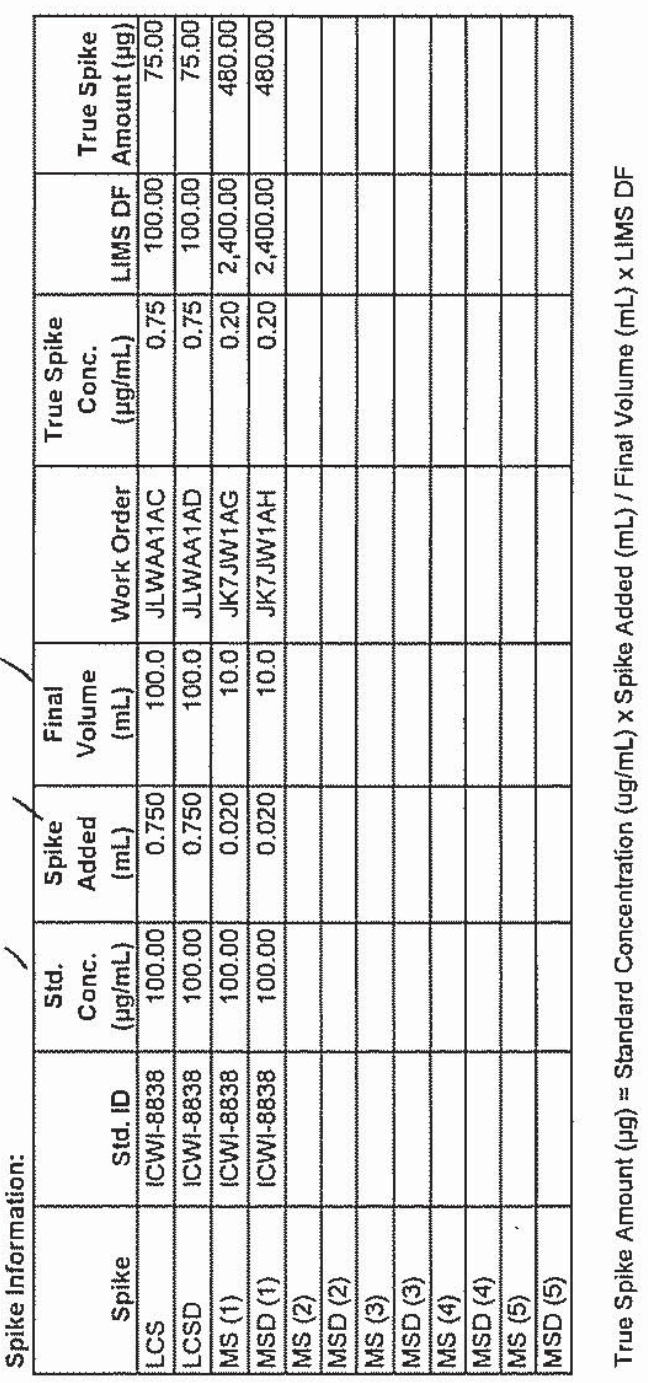




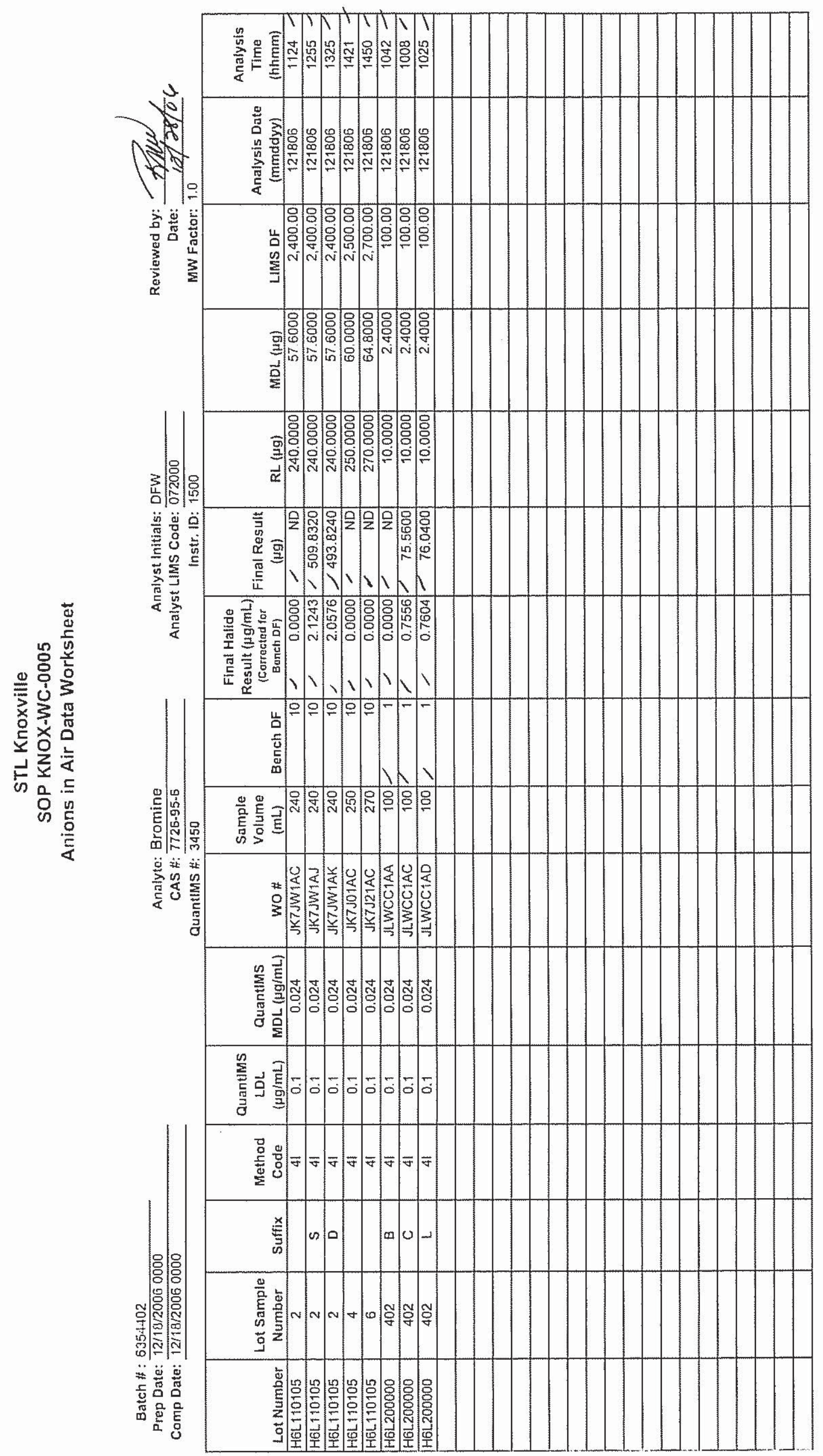




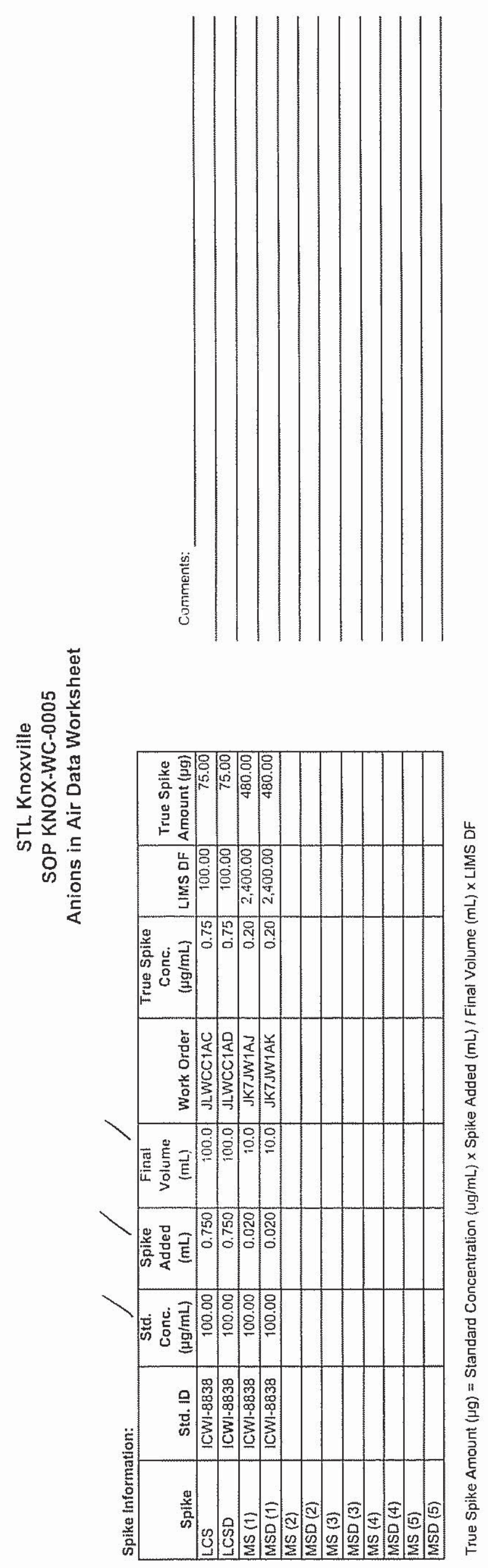




\section{Dionex IC Runlog Cover Page}

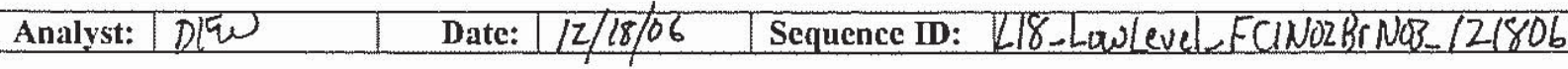

\begin{tabular}{|l|l|}
\hline Instrument: & $\square \mathrm{DX}-600$ \\
\cline { 2 - 2 } & $\square \mathrm{ICS}-1500$ \\
\cline { 2 - 3 } & $\square \mathrm{DX}-320$ \\
\hline
\end{tabular}

Method: $\square$ KNOX-WC-0003, SW-846 0061/7199

\begin{tabular}{|c|c|c|}
\hline \multirow{2}{*}{ 27. } & & \\
\hline & $\square$ KNOX-WC-0005, $\square$ SW-846 9056 QEPA 300.0 & 口 SW-846 9057-Mod \\
\hline
\end{tabular}

\section{Preventive Maintenance}

Dailv:

¿ Check pump and gas pressure

$\checkmark$ Check all lines for crimping, leaks and discoloration

\section{As Needed:}

$\square$ Change column and guard column

$\square$ Change column and/or guard column bed support

$\square$ Clean conduclívity cell

$\square$ De-gas pump head when flow is erratic

$\square$ Check/replace eluant end line filter

\section{Instrument Conditions}

\begin{tabular}{rll|}
\hline Flow Rate $=1.00$ & $\mathrm{~mL} / \mathrm{min}$ \\
\hline Pressure $=1850$, & $\mathrm{psi}$ \\
\hline Conductance $=24.9$ & $\mu \mathrm{S}$ \\
\hline Suppressor Current $=43$. & $\mathrm{mA}$ \\
\hline Eluent Generator $=$ & $N / \mathrm{AM} \mathrm{KOH}$ & $\mathrm{mM} \mathrm{KO}$
\end{tabular}

MS/MSD Spike Information

\begin{tabular}{|c|c|c|c|c|c|c|}
\hline WO \# & Compound & Spike ID & Parent Conc. & Spike Added (mL) & Final Volume (mL) & Final Conc. \\
\hline JKTJW & Fluoride & ICWI $=8838$ & $100 \mathrm{ppr}$ & 0.02 & 10. $\quad(1 / 10)$ & (8.2ppo (2) \\
\hline 1 & Chloride & 1 & 1 & 1 & $1 \quad 1$ & 111 \\
\hline$\downarrow$ & Buonside & 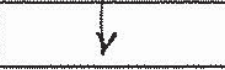 & $\downarrow$ & $\downarrow$ & $\downarrow$ & $\psi$ \\
\hline & & & & & & \\
\hline & & & & & & \\
\hline & & & & & & \\
\hline & & & & & & \\
\hline & & & & $\mid 18$ & & \\
\hline & & & & $12 x$ & & \\
\hline & & & $y<<$ & & & \\
\hline & & & & & & \\
\hline & & & & & & \\
\hline & & & & & & \\
\hline & & & & & & \\
\hline Comments & Canstic & impinger & frecti & - & & \\
\hline
\end{tabular}

$\left(\begin{array}{cccc}F^{-} & B a t c h & \# 635400 \\ C^{-} & \cdots & \# 6354401 \\ B r- & * & \# 6354402\end{array}\right)$

$\checkmark$ Sodium Thiosulfate added to $\mathrm{NaOH}$ impinger samples. 
Title:

Datasource:

Location:

Timebase:

\#Samples:

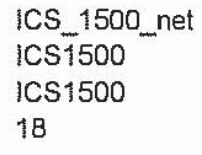

Printed: $12 / 18 / 2006$ 4:41:28 PM

Created: Last Update:
12/18/2006 10:07:19 AM by wheelerd 12/18/2006 4:41:08 PM by wheelerd

\begin{tabular}{|c|c|c|c|c|c|c|c|}
\hline No. & Name & Sample ID & Inj. Vol. & Inj. Date/Time & Dil. Factor & $\begin{array}{l}\text { Multiplier } \\
\text { [Liters] }\end{array}$ & Weight \\
\hline 1 & (1) CAL STD \#1 ICWS-8915 & & 50.0 & $10 / 18 / 20069: 14: 56$ AM & 1.0000 & & 1.0000 \\
\hline 2 & (1) CAL STD \#2 ICWS-8916 & & 50.0 & $10 / 18 / 20069: 32: 20 \mathrm{AM}$ & 1.0000 & & 1.0000 \\
\hline 3 & (1) CAL STD \#3 ICWS-8917 & & 50.0 & 10/18/2006 9:49:45 AM & 1.0000 & & 1.0000 \\
\hline 4 & (1) CAL STD \#4 ICWS-8918 & & 50.0 & $10 / 18 / 2006$ 10:07:09 AM & 1.0000 & & 1.0000 \\
\hline 5 & (1) CAL STD \#5 ICWS-8919 & & 50.0 & 10/18/2006 10:24:33 AM & 1.0000 & & 1.0000 \\
\hline 6 & (7) CAL STD \#6 ICWS-8920 & & 50.0 & $10 / 18 / 200610: 41: 57 \mathrm{AM}$ & 1.0000 & & 1.0000 \\
\hline 7 & ICV/LCS $=1$ ICWS-9056 & & 50.0 & 12/18/2006 10:08:03 AM & 1.0000 & & 1.0000 \\
\hline 8 & 䈍 ICV/LCSD $=$ ICWS -9057 & & 50.0 & 12/18/2006 10:25:28 AM & 1.0000 & & 1.0000 \\
\hline 9 & 蜀 ICB/METHOD BLANK & & 50.0 & $12 / 18 / 200610: 42: 51 \mathrm{AM}$ & 1.0000 & & 1.0000 \\
\hline 10 & 盖 H6L110105-JK7JW-1/10 & & 50.0 & 12/18/2006 11:24:20 AM & 10.0000 & & 1.0000 \\
\hline 11 & 曋 H6L110105-JK7JW-1/20 & & 50.0 & 12/18/2006 12:04:01 PM & 20.0000 & & 1.0000 \\
\hline 12 & 漗 H6L110105-JK7JW-1/10-MS & & 50.0 & $12 / 18 / 200612: 55: 50 \mathrm{PM}$ & 10.0000 & & 1.0000 \\
\hline 13 & H6L110105-JK7JW-1/10-MSD & & 50.0 & 12/18/2006 1:25:14 PM & 10.0000 & & 1.0000 \\
\hline 14 & H6L110105-JK7J0-1/10 & & 50.0 & 12/18/2006 2:21:35 PM & 10.0000 & & 1.0000 \\
\hline 15 & 篅 H6L110105-JK7J2-1/10 & & 50.0 & 12/18/2006 2:50:59 PM & 10.0000 & & 1.0000 \\
\hline 16 & CCV $=1$ ICWS -9058 & & 50.0 & 12/18/2006 3:42:58 PM & 1.0000 & & 1.0000 \\
\hline 17 & 罗 $\mathrm{CCB}$ & & 50.0 & 12/18/2006 4:00:23 PM & 1.0000 & & 1.0000 \\
\hline 18 & S SHUTDOWN & & 50.0 & 12/11/2006 6:12:53 PM & 1.0000 & & 1.0000 \\
\hline
\end{tabular}




\section{$7 \quad$ ICV/LCS $=I C W S-9056$}

\begin{tabular}{llll|}
\hline Sample Name: & ICV/LCS= ICWS-9056 & Injection Volume: & $\mathbf{5 0 . 0}$ \\
Vial Number: & $\mathbf{1 2 9 6}$ & Channel: & ECD_1 \\
Sample Type: & unknown & Wavelength: & n.a. \\
Control Program: & AS14A ANIONS METHOD & Bandwidth: & n.a. \\
Quantif. Method: & AS4A-SC ANION METHOD & Dilution Factor: & $\mathbf{1 . 0 0 0 0}$ \\
Recording Time: & $\mathbf{1 2 / 1 8 / 2 0 0 6 ~ 1 0 : 0 8}$ & Sample Weight: & $\mathbf{1 . 0 0 0 0}$ \\
Run Time (min): & $\mathbf{1 5 . 0 0}$ & Sample Amount: & $\mathbf{1 . 0 0 0 0}$ \\
\hline
\end{tabular}

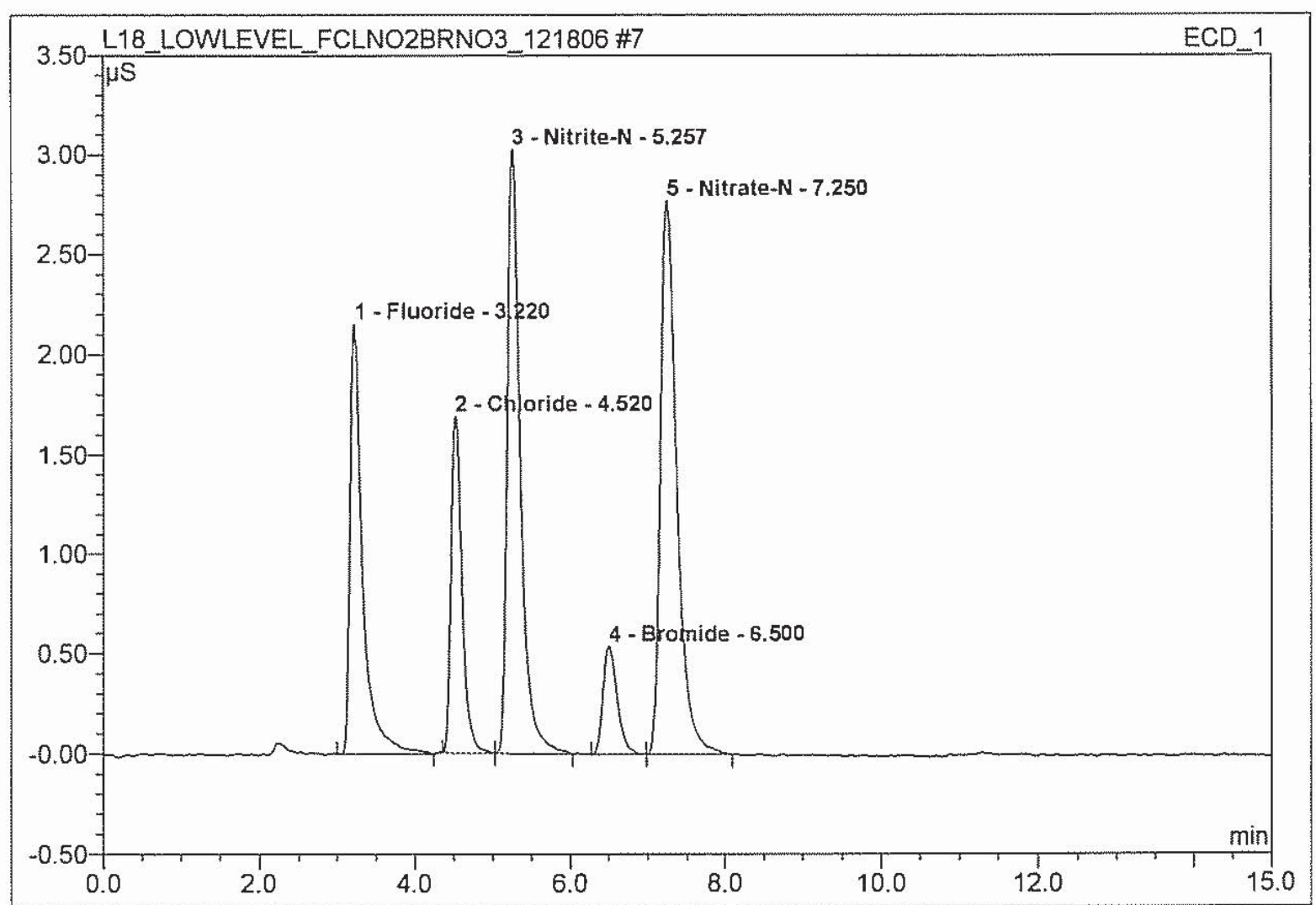

\begin{tabular}{|c|c|l|c|c|c|c|c|}
\hline No. & $\begin{array}{c}\text { Ret.Time } \\
(\min )\end{array}$ & \multicolumn{1}{|c|}{ Peak Name } & $\begin{array}{c}\text { Height } \\
\text { (uS) }\end{array}$ & $\begin{array}{c}\text { Area } \\
\mu S^{*} \min \end{array}$ & $\begin{array}{c}\text { Rel.Area } \\
(\%)\end{array}$ & $\begin{array}{c}\text { Amount } \\
\text { (mg/L) }\end{array}$ & $\begin{array}{c}\text { Peak } \\
\text { Type }\end{array}$ \\
\hline 1 & 3.22 & Fluoride & 2.15196 & 0.402 & 19.55 & 0.7543 & BMB \\
\hline 2 & 4.52 & Chloride & 1.68575 & 0.272 & 13.22 & 0.7584 & BMB \\
\hline 3 & 5.26 & Nitrite-N & 3.02418 & 0.590 & 28.69 & 0.7749 & BMB \\
\hline 4 & 6.50 & Bromide & 0.53885 & 0.114 & 5.54 & 0.7556 & BM \\
\hline 5 & 7.25 & Nitrate-N & 2.77486 & 0.679 & 33.00 & 0.7714 & MB \\
\hline
\end{tabular}

$$
\begin{aligned}
F^{-} & =J L V G M \mid A C \\
C^{-} & =J L W A A \mid A C \\
B^{-} & =J L W C C \mid A C
\end{aligned}
$$




\section{$8 \quad$ ICV/LCSD $=$ ICWS -9057}

\begin{tabular}{llll}
\hline Sample Name: & ICV/LCSD= ICWS-9057 & Injection Volume: & $\mathbf{5 0 . 0}$ \\
Vial Number: & $\mathbf{1 2 9 7}$ & Channel: & ECD_1 \\
Sample Type: & unknown & Wavelength: & n.a. \\
Control Program: & AS14A ANIONS METHOD & Bandwidth: & n.a. \\
Quantif. Method: & AS4A-SC ANION METHOD & Dilution Factor: & $\mathbf{1 . 0 0 0 0}$ \\
Recording Time: & $\mathbf{1 2 / 1 8 / 2 0 0 6 ~ 1 0 : 2 5}$ & Sample Weight: & $\mathbf{1 . 0 0 0 0}$ \\
Run Time (min): & $\mathbf{1 5 . 0 0}$ & Sample Amount: & $\mathbf{1 . 0 0 0 0}$ \\
\hline
\end{tabular}

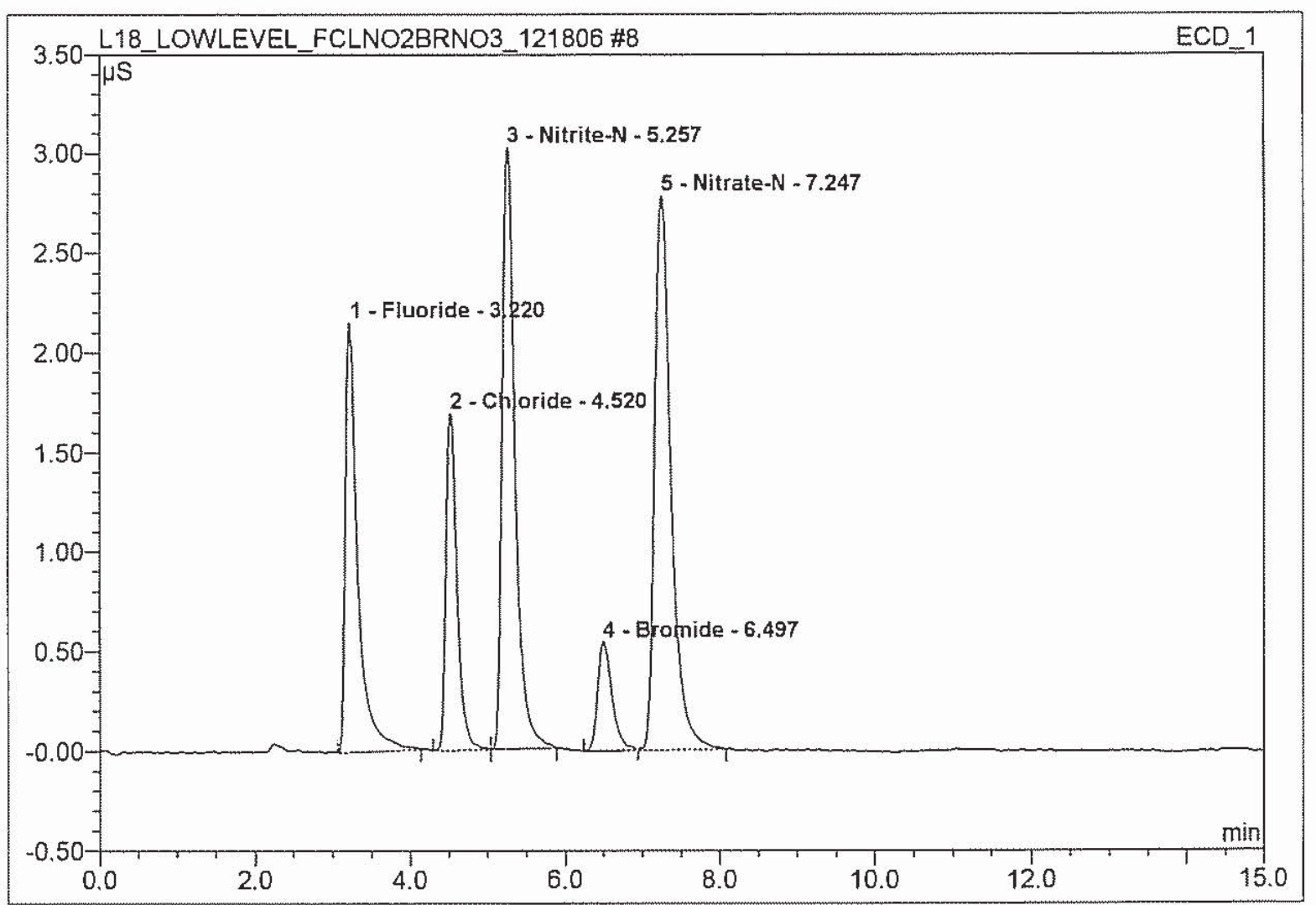

\begin{tabular}{|c|c|l|r|r|r|r|c|}
\hline No. & $\begin{array}{c}\text { Ret.Time } \\
\text { (min.) }\end{array}$ & \multicolumn{1}{|c|}{ Peak Name } & $\begin{array}{c}\text { Height } \\
(\mathbf{u S})\end{array}$ & $\begin{array}{c}\text { Area } \\
\mu S^{*} \min \end{array}$ & $\begin{array}{c}\text { Rel.Area } \\
(\%)\end{array}$ & $\begin{array}{c}\text { Amount } \\
(\mathbf{m g} / \mathrm{L})\end{array}$ & $\begin{array}{c}\text { Peak } \\
\text { Type }\end{array}$ \\
\hline 1 & 3.22 & Fluoride & 2.15346 & 0.399 & 19.43 & 0.7548 & BMB \\
\hline 2 & 4.52 & Chloride & 1.68956 & 0.275 & 13.40 & 0.7601 & BM \\
\hline 3 & 5.26 & Nitrite-N & 3.01778 & 0.579 & 28.25 & 0.7733 & MB \\
\hline 4 & 6.50 & Bromide & 0.54226 & 0.115 & 5.60 & 0.7604 & Ru \\
\hline 5 & 7.25 & Nitrate-N & 2.78137 & 0.684 & 33.33 & 0.7732 & BMB \\
\hline
\end{tabular}

$$
\begin{aligned}
& F^{-}=J L V q M \mid A D \\
& C l^{-}=J L W A A \mid A D \\
& B r^{-}=J L W C C I A D
\end{aligned}
$$




\section{ICB/ METHOD BLANK}

\section{Sample Name: ICB/ METHOD BLANK}

Vial Number:

Sample Type:

Control Program:

Quantif. Method:

Recording Time:

Run Time (min):
1298

unknown

AS14A ANIONS METHOD

AS4A-SC ANION METHOD

12/18/2006 10:42

15.00

$\begin{array}{ll}\text { Injection Volume: } & \mathbf{5 0 . 0} \\ \text { Channel: } & \text { ECD_1 } \\ \text { Wavelength: } & \text { n.a. } \\ \text { Bandwidth: } & \text { n.a. } \\ \text { Dilution Factor: } & 1.0000 \\ \text { Sample Weight: } & 1.0000 \\ \text { Sample Amount: } & 1.0000\end{array}$

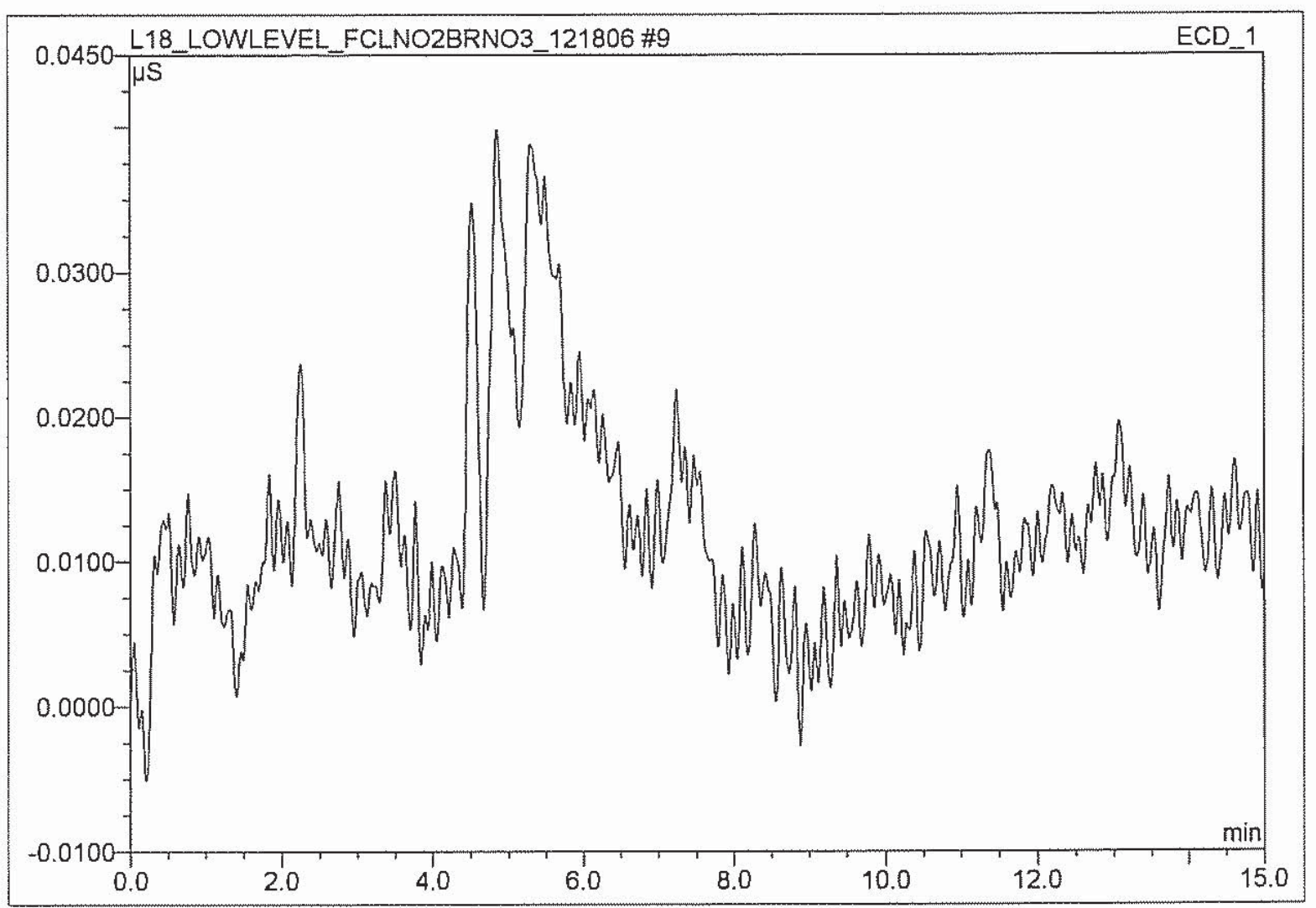

\begin{tabular}{|c|c|c|c|c|c|c|c|}
\hline No. & $\begin{array}{c}\text { Ret.Time } \\
\text { (min.) }\end{array}$ & Peak Name & $\begin{array}{c}\text { Height } \\
(\mathrm{uS})\end{array}$ & $\begin{array}{c}\text { Area } \\
\mu \mathrm{S}^{*} \mathrm{~min}\end{array}$ & $\begin{array}{c}\text { Rel.Area } \\
(\%)\end{array}$ & $\begin{array}{c}\text { Amount } \\
(\mathrm{mg} / \mathrm{L})\end{array}$ & $\begin{array}{c}\text { Peak } \\
\text { Type }\end{array}$ \\
\hline
\end{tabular}

$$
\begin{aligned}
& F-=J L V G m \mid A A \\
& C t=J L W A A \mid A A \\
& B r^{-}=J L W C C \mid A A
\end{aligned}
$$




\section{H6L-110105-JK7JW-1/10}

\begin{tabular}{llll}
\hline Sample Name: & H6L110105-JK7JW-1/10 & Injection Volume: & $\mathbf{5 0 . 0}$ \\
Vial Number: & $\mathbf{1 2 9 4}$ & Channel: & ECD_1 \\
Sample Type: & unknown & Wavelength: & n.a. \\
Control Program: & AS14A ANIONS_CI2 METHOD & Bandwidth: & n.a. \\
Quantif. Method: & AS4A_SC ANION METHOD & Dilution Factor: & 10.0000 \\
Recording Time: & $\mathbf{1 2 / 1 8 / 2 0 0 6 1 1 : 2 4}$ & Sample Weight: & $\mathbf{1 . 0 0 0 0}$ \\
Run Time (min): & $\mathbf{2 7 . 0 0}$ & Sample Amount: & $\mathbf{1 . 0 0 0 0}$ \\
\hline
\end{tabular}

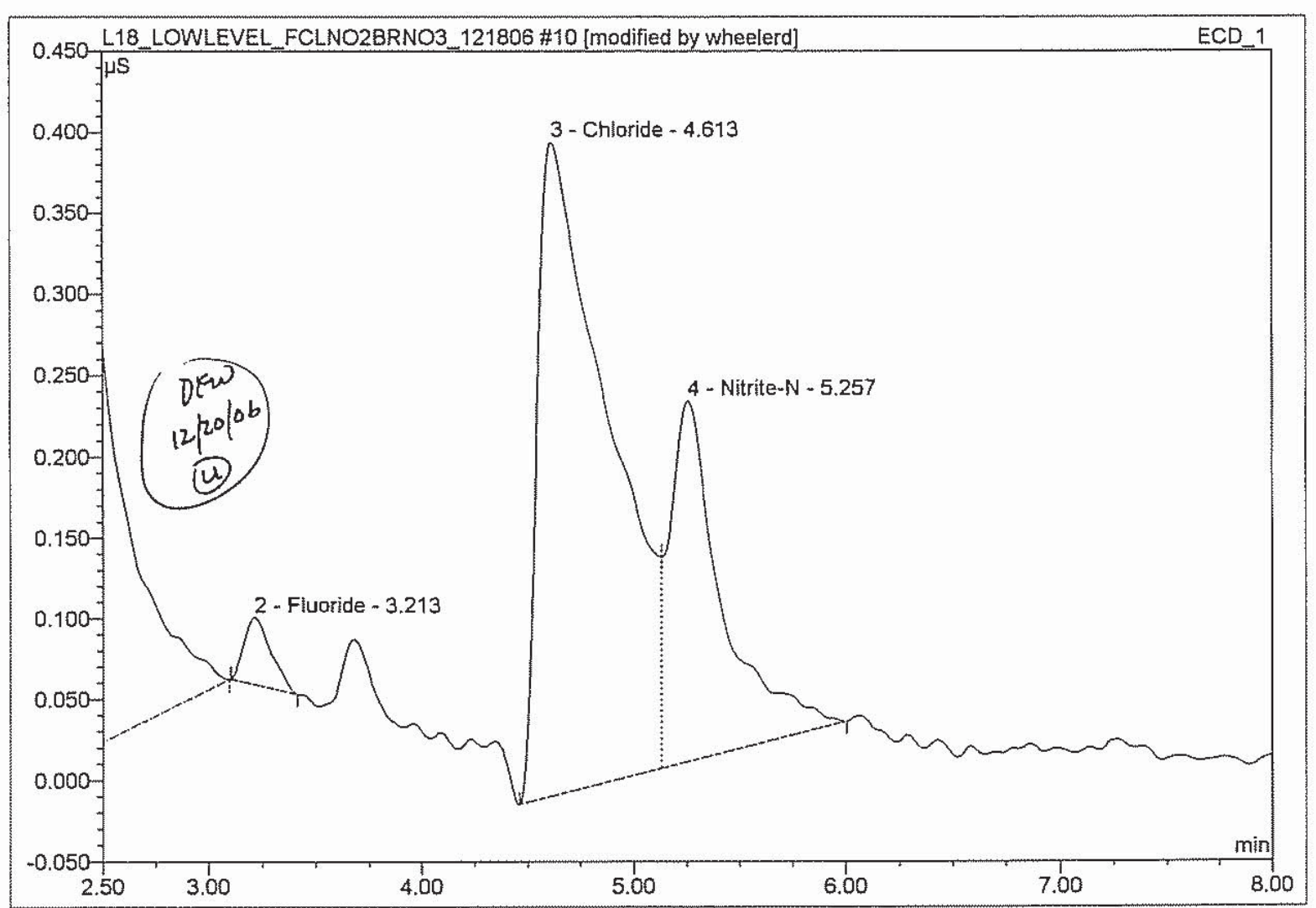

\begin{tabular}{|r|c|l|r|r|r|r|c|}
\hline No. & $\begin{array}{c}\text { Ret.Time } \\
(\mathrm{min})\end{array}$ & \multicolumn{1}{|c|}{ Peak Name } & $\begin{array}{c}\text { Height } \\
(\mathrm{uS})\end{array}$ & $\begin{array}{c}\text { Area } \\
\mu S^{*} \mathrm{~min}\end{array}$ & $\begin{array}{c}\text { Rel.Area } \\
(\%)\end{array}$ & $\begin{array}{c}\text { Amount } \\
(\mathrm{mg} / \mathrm{L})\end{array}$ & $\begin{array}{r}\text { Peak } \\
\text { Type }\end{array}$ \\
\hline 1 & 2.24 & n.a. & 1.86348 & 0.365 & 0.39 & n.a. & BMB \\
\hline 2 & 3.21 & Fluoride & 0.04144 & 0.006 & 0.01 & 0.1539 & $\mathrm{BMB}^{*}$ \\
\hline 3 & 4.61 & Chloride & 0.40372 & 0.157 & 0.17 & 1.8322 & BM \\
\hline 4 & 5.26 & Nitrite-N & 0.22267 & 0.065 & 0.07 & 0.5846 & MB \\
\hline 5 & 11.21 & n.a. & 69.83583 & 22.220 & 24.01 & n.a. & BMB \\
\hline 6 & 20.05 & n.a. & 74.82854 & 69.717 & 75.35 & n.a. & BMB \\
\hline
\end{tabular}<smiles>C1=CC=[N+]C=C1</smiles> 


\section{H6L110105-JK7JW-1/10}

\begin{tabular}{llll}
\hline Sample Name: & H6L110105-JK7JW-1/10 & Injection Volume: & $\mathbf{5 0 . 0}$ \\
Vial Number: & $\mathbf{1 2 9 4}$ & Channel: & ECD_1 \\
Sample Type: & unknown & Wavelength: & n.a. \\
Control Program: & AS14A ANIONS_CI2 METHOD & Bandwidth: & n.a. \\
Quantif. Method: & AS4A-SC ANION METHOD & Dilution Factor: & 10.0000 \\
Recording Time: & $12 / 18 / 200611: 24$ & Sample Weight: & 1.0000 \\
Run Time (min): & $\mathbf{2 7 . 0 0}$ & Sample Amount: & $\mathbf{1 . 0 0 0 0}$ \\
\hline
\end{tabular}

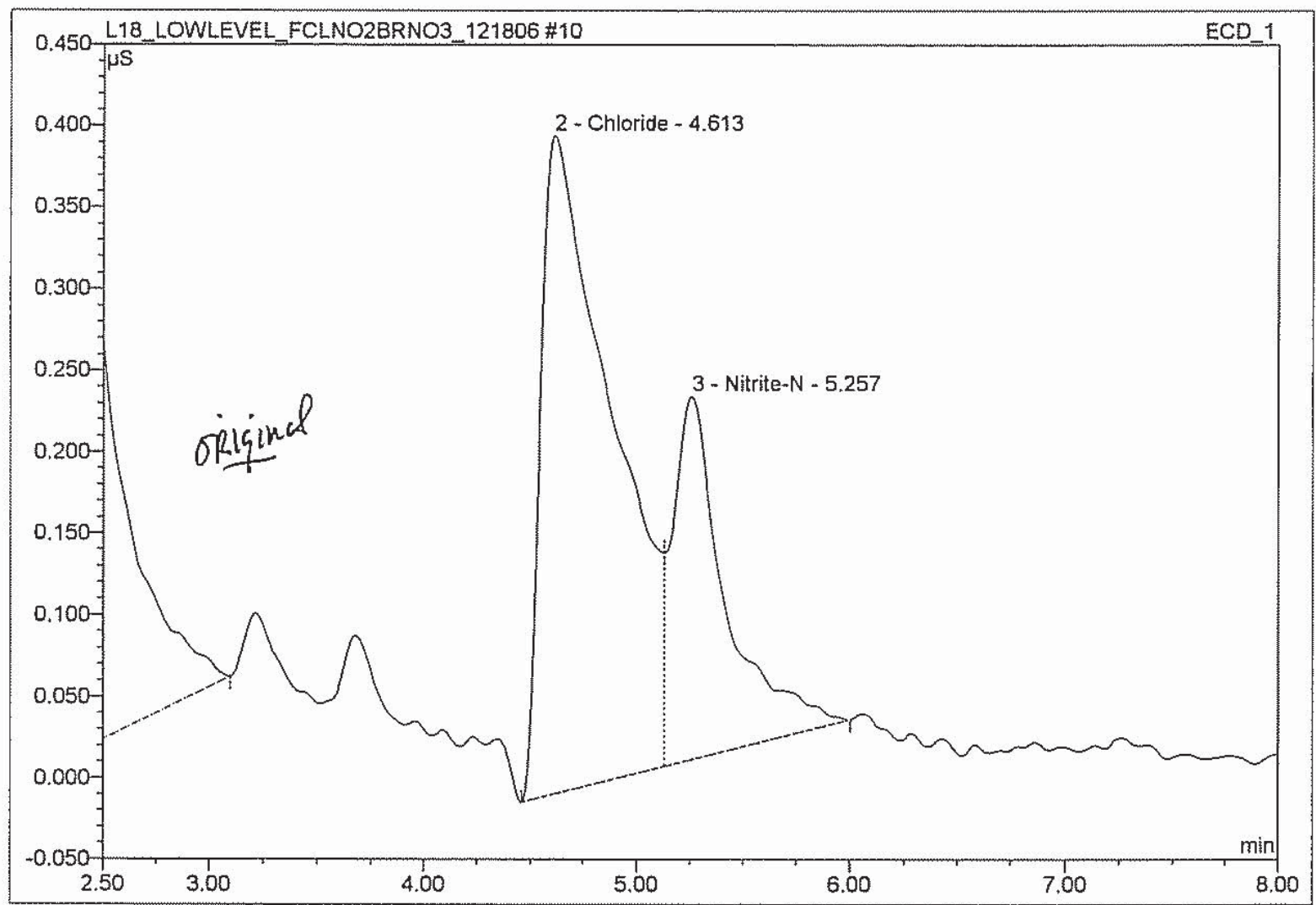

\begin{tabular}{|c|c|l|r|r|r|r|c|}
\hline No. & $\begin{array}{c}\text { Ret.Time } \\
\text { (min.) }\end{array}$ & \multicolumn{1}{|c|}{ Peak Name } & $\begin{array}{c}\text { Height } \\
\text { (uS) }\end{array}$ & $\begin{array}{c}\text { Area } \\
\mu S^{*} \text { min }\end{array}$ & $\begin{array}{c}\text { Rel.Area } \\
(\%)\end{array}$ & $\begin{array}{c}\text { Amount } \\
\text { (mg/L) }\end{array}$ & $\begin{array}{r}\text { Peak } \\
\text { Type }\end{array}$ \\
\hline 1 & 2.24 & n.a. & 1.86348 & 0.365 & 0.39 & n.a. & BMB \\
\hline 2 & 4.61 & Chloride & 0.40372 & 0.157 & 0.17 & 1.8322 & BM \\
\hline 3 & 5.26 & Nitrite-N & 0.22267 & 0.065 & 0.07 & 0.5846 & MB \\
\hline 4 & 11.21 & n.a. & 69.83583 & 22.220 & 24.02 & n.a. & BMB \\
\hline 5 & 20.05 & n.a. & 74.82854 & 69.717 & 75.35 & n.a. & BMB \\
\hline
\end{tabular}




\section{H6L110105-JK7JW-1/20}

\begin{tabular}{llll|}
\hline Sample Name: & H6L110105-JK7JW-1/20 & Injection Volume: & $\mathbf{5 0 . 0}$ \\
Vial Number: & $\mathbf{1 2 9 4}$ & Channel: & ECD_1 \\
Sample Type: & unknown & Wavelength: & n.a. \\
Control Program: & AS14A ANIONS_CI2 METHOD & Bandwidth: & n.a. \\
Quantif. Method: & AS4A-SC ANION METHOD & Dilution Factor: & $\mathbf{2 0 . 0 0 0 0}$ \\
Recording Time: & $\mathbf{1 2 / 1 8 / 2 0 0 6 1 2 : 0 4}$ & Sample Weight: & $\mathbf{1 . 0 0 0 0}$ \\
Run Time (min): & $\mathbf{2 7 . 0 0}$ & Sample Amount: & $\mathbf{1 . 0 0 0 0}$ \\
\hline
\end{tabular}

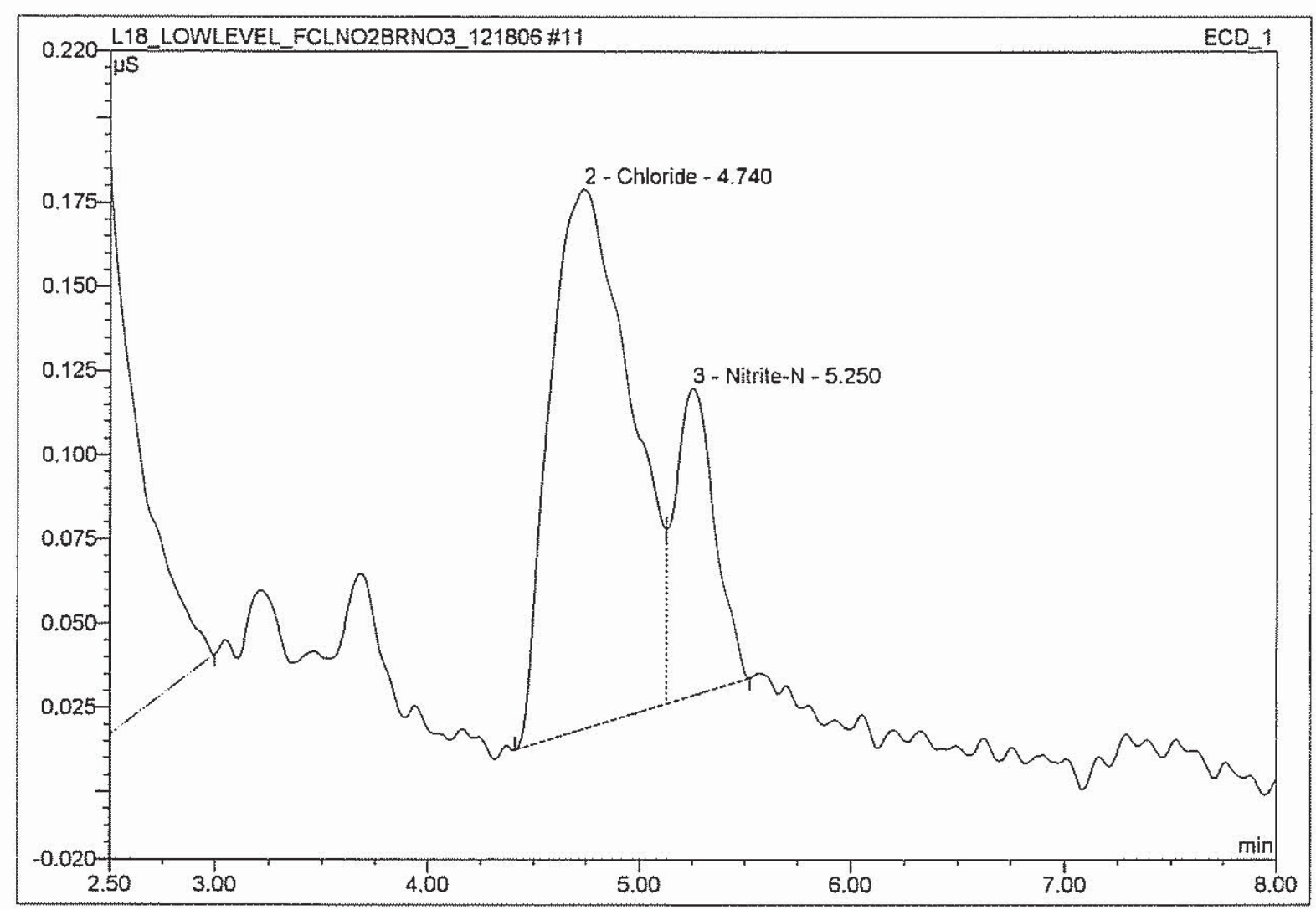

\begin{tabular}{|r|r|l|r|r|r|r|r|}
\hline No. & $\begin{array}{c}\text { Ret.Time } \\
\text { (min.) }\end{array}$ & \multicolumn{1}{|c|}{ Peak Name } & $\begin{array}{c}\text { Height } \\
\text { (uS) }\end{array}$ & $\begin{array}{c}\text { Area } \\
\mu S^{*} \min \end{array}$ & $\begin{array}{c}\text { Rel.Area } \\
\text { (\%) }\end{array}$ & $\begin{array}{r}\text { Amount } \\
\text { (mg/L) }\end{array}$ & $\begin{array}{r}\text { Peak } \\
\text { Type }\end{array}$ \\
\hline 1 & 2.24 & n.a. & 1.26942 & 0.250 & 0.32 & n.a. & BMB \\
\hline 2 & 4.74 & Chloride & 0.16018 & 0.071 & 0.09 & 1.4563 & BM \\
\hline 3 & 5.25 & Nitrite-N & 0.09131 & 0.020 & 0.03 & 0.4800 & MB \\
\hline 4 & 11.24 & n.a. & 32.26087 & 10.131 & 12.85 & n.a. & BMB \\
\hline 5 & 20.06 & n.a. & 73.77920 & 68.344 & 86.71 & n.a. & BMB \\
\hline
\end{tabular}




\section{H6L110105-JK7JW-1/10-MS}

\begin{tabular}{llll}
\hline Sample Name: & H6L110105-JK7JW-1/10-MS & Injection Volume: & $\mathbf{5 0 . 0}$ \\
Vial Number: & 1316 & Channel: & ECD_1 \\
Sample Type: & unknown & Wavelength: & n.a. \\
Control Program: & AS14A ANIONS_CI2 METHOD & Bandwidth: & n.a. \\
Quantif. Method: & AS4A-SC ANION METHOD & Dilution Factor: & 10.0000 \\
Recording Time: & $12 / 18 / 200612: 55$ & Sample Weight: & 1.0000 \\
Run Time (min): & $\mathbf{2 7 . 0 0}$ & Sample Amount: & $\mathbf{1 . 0 0 0 0}$ \\
\hline
\end{tabular}

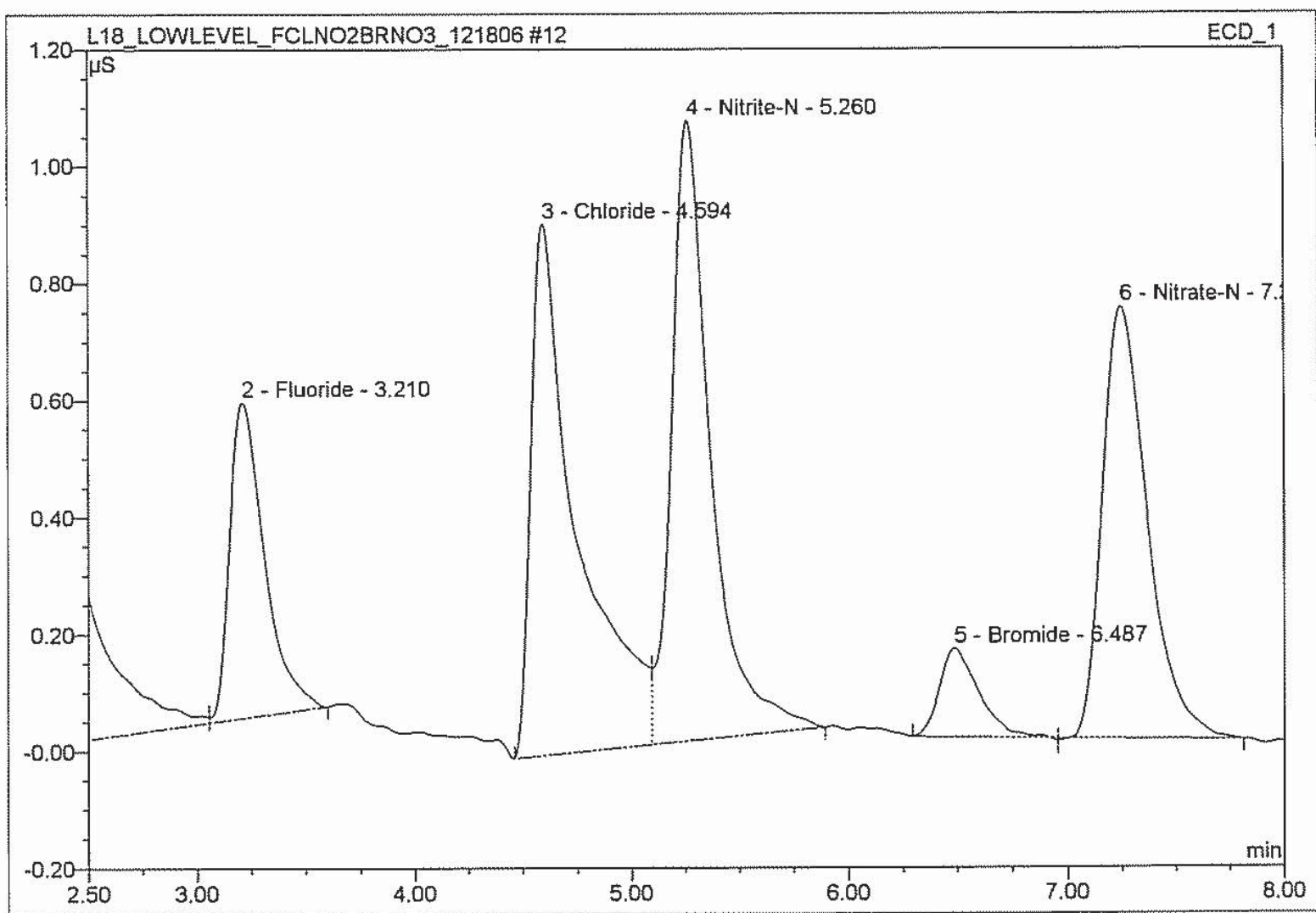

\begin{tabular}{|c|c|l|r|r|r|r|c|}
\hline No. & $\begin{array}{c}\text { Ret.Time } \\
\text { (min.) }\end{array}$ & \multicolumn{1}{|c|}{ Peak Name } & $\begin{array}{c}\text { Height } \\
(\mathbf{u S})\end{array}$ & $\begin{array}{c}\text { Area } \\
\mu \mathrm{S}^{*} \text { min }\end{array}$ & $\begin{array}{r}\text { Rel.Area } \\
(\%)\end{array}$ & $\begin{array}{r}\text { Amount } \\
\text { (mg/L) }\end{array}$ & $\begin{array}{r}\text { Peak } \\
\text { Type }\end{array}$ \\
\hline 1 & 2.24 & n.a. & 1.85981 & 0.362 & 0.39 & n.a. & BM \\
\hline 2 & 3.21 & Fluoride & 0.53915 & 0.100 & 0.11 & 1.9737 & $\mathrm{MB}$ \\
\hline 3 & 4.59 & Chloride & 0.90957 & 0.224 & 0.24 & 4.1136 & $\mathrm{BM}$ \\
\hline 4 & 5.26 & Nitrite-N & 1.06034 & 0.222 & 0.24 & 2.7633 & $\mathrm{MB}$ \\
\hline 5 & 6.49 & Bromide & 0.15083 & 0.031 & 0.03 & 2.1243 & $\mathrm{BM}$ \\
\hline 6 & 7.25 & Nitrate-N & 0.73745 & 0.176 & 0.19 & 2.1095 & $\mathrm{MB}$ \\
\hline 7 & 11.20 & n.a. & 70.20606 & 22.386 & 23.92 & n.a. & BMB \\
\hline 8 & 20.03 & n.a. & 75.25857 & 70.079 & 74.89 & n.a. & BMB \\
\hline
\end{tabular}

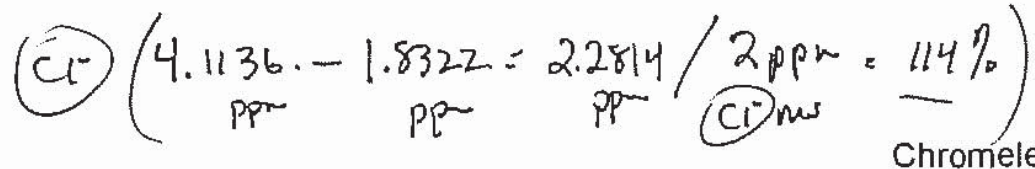

default_letter/Integration 


\section{H6L-110105-JK7JW-1/10-MSD}

\begin{tabular}{llll}
\hline Sample Name: & H6L110105-JK7JW-1/10-MSD & Injection Volume: & $\mathbf{5 0 . 0}$ \\
Vial Number: & $\mathbf{1 3 1 7}$ & Channel: & ECD_1 \\
Sample Type: & unknown & Wavelength: & n.a. \\
Control Program: & AS14A ANIONS_CI2 METHOD & Bandwidth: & n.a. \\
Quantif. Method: & AS4A-SC ANION METHOD & Dilution Factor: & 10.0000 \\
Recording Time: & $\mathbf{1 2 / 1 8 / 2 0 0 6 ~ 1 3 : 2 5}$ & Sample Weight: & $\mathbf{1 . 0 0 0 0}$ \\
Run Time (min): & $\mathbf{2 7 . 0 0}$ & Sample Amount: & $\mathbf{1 . 0 0 0 0}$ \\
\hline
\end{tabular}

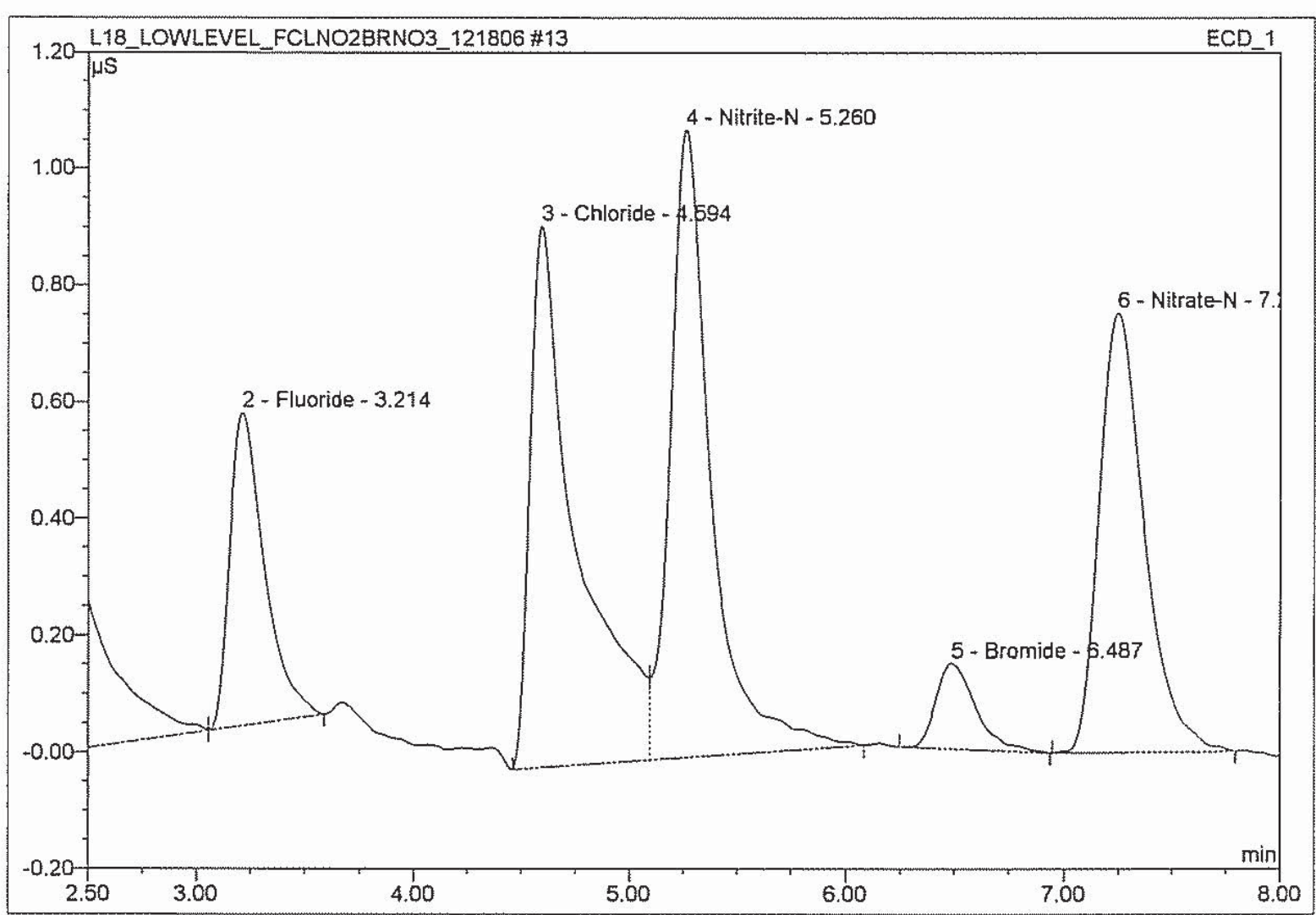

\begin{tabular}{|r|c|l|r|r|r|r|c|}
\hline No. & $\begin{array}{c}\text { Ret.Time } \\
\text { (min.) }\end{array}$ & \multicolumn{1}{|c|}{ Peak Name } & $\begin{array}{c}\text { Height } \\
(\mathbf{u S})\end{array}$ & $\begin{array}{c}\text { Area } \\
\mu S^{*} \min \end{array}$ & $\begin{array}{r}\text { Rel.Area } \\
(\%)\end{array}$ & $\begin{array}{c}\text { Amount } \\
(\mathrm{mg} / \mathrm{L})\end{array}$ & $\begin{array}{r}\text { Peak } \\
\text { Type }\end{array}$ \\
\hline 1 & 2.24 & n.a. & 1.87485 & 0.366 & 0.39 & n.a. & BM \\
\hline 2 & 3.21 & Fluoride & 0.53591 & 0.099 & 0.11 & 1.9620 & MB \\
\hline 3 & 4.59 & Chloride & 0.92603 & 0.232 & 0.25 & 4.1875 & BM \\
\hline 4 & 5.26 & Nitrite-N & 1.07515 & 0.236 & 0.25 & 2.8015 & MB \\
\hline 5 & 6.49 & Bromide & 0.14608 & 0.031 & 0.03 & 2.0576 & BMB \\
\hline 6 & 7.25 & Nitrate-N & 0.75239 & 0.181 & 0.19 & 2.1518 & BMB \\
\hline 7 & 11.20 & n.a. & 70.38196 & 22.422 & 23.82 & n.a. & BMB \\
\hline 8 & 20.02 & n.a. & 75.60729 & 70.554 & 74.96 & n.a. & BMB \\
\hline
\end{tabular}




\section{H6L110105-JK7J0-1/10}

\begin{tabular}{llll|}
\hline Sample Name: & H6L110105-JK7J0-1/10 & Injection Volume: & $\mathbf{5 0 . 0}$ \\
Vial Number: & $\mathbf{1 3 1 7}$ & Channel: & ECD_1 \\
Sample Type: & unknown & Wavelength: & n.a. \\
Control Program: & AS14A ANIONS_CI2 METHOD & Bandwidth: & n.a. \\
Quantif. Method: & AS4A-SC ANION METHOD & Dilution Factor: & $\mathbf{1 0 . 0 0 0 0}$ \\
Recording Time: & $\mathbf{1 2 / 1 8 / 2 0 0 6} 14: 21$ & Sample Weight: & $\mathbf{1 . 0 0 0 0}$ \\
Run Time (min): & $\mathbf{2 7 . 0 0}$ & Sample Amount: & $\mathbf{1 . 0 0 0 0}$ \\
\hline
\end{tabular}

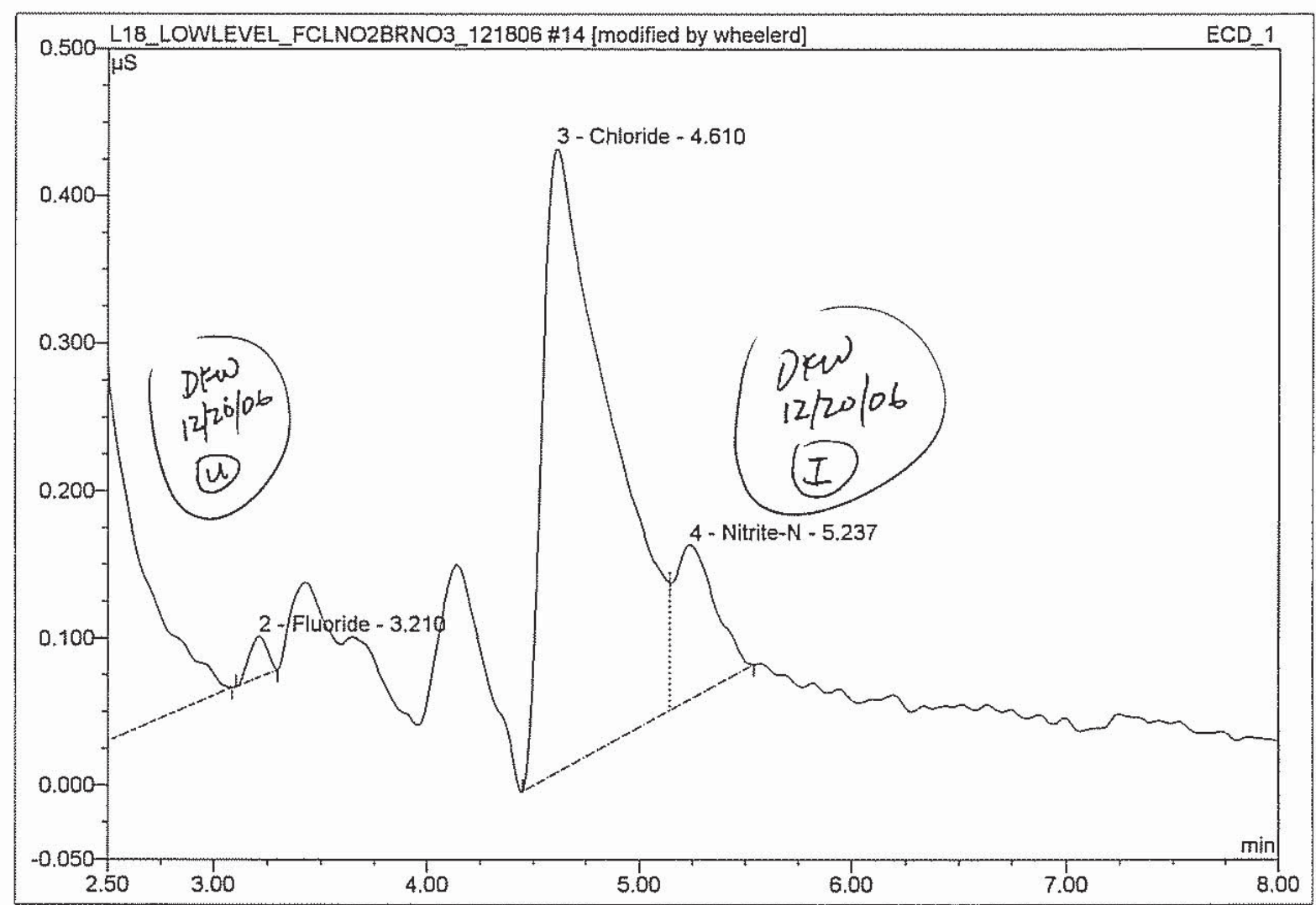

\begin{tabular}{|c|c|l|r|r|r|r|r|}
\hline No. & $\begin{array}{c}\text { Ret.Time } \\
\text { (min.) }\end{array}$ & \multicolumn{1}{|c|}{ Peak Name } & $\begin{array}{c}\text { Height } \\
\text { (uS) }\end{array}$ & $\begin{array}{c}\text { Area } \\
\mu S^{*} \min \end{array}$ & $\begin{array}{c}\text { Rel.Area } \\
(\%)\end{array}$ & $\begin{array}{c}\text { Amount } \\
\text { (mg/L) }\end{array}$ & $\begin{array}{r}\text { Peak } \\
\text { Type }\end{array}$ \\
\hline 1 & 2.24 & n.a. & 1.95991 & 0.383 & 0.39 & n.a. & BMB $^{*}$ \\
\hline 2 & 3.21 & Fluoride & 0.02778 & 0.003 & 0.00 & 0.1032 & $\mathrm{BMB}^{*}$ \\
\hline 3 & 4.61 & Chloride & 0.42305 & 0.155 & 0.16 & 1.9197 & $\mathrm{BM}^{*}$ \\
\hline 4 & 5.24 & Nitrite-N & 0.10530 & 0.023 & 0.02 & 0.2767 & $\mathrm{MB}^{*}$ \\
\hline 5 & 11.17 & n.a. & 81.46681 & 26.162 & 26.90 & n.a. & BMB \\
\hline 6 & 20.00 & n.a. & 75.82434 & 70.516 & 72.52 & n.a. & BMB \\
\hline
\end{tabular}

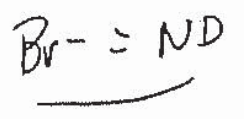




\section{H6L110105-JK7J0-1/10}

\begin{tabular}{|llll|}
\hline Sample Name: & H6L110105-JK7J0-1/10 & Injection Volume: & $\mathbf{5 0 . 0}$ \\
Vial Number: & $\mathbf{1 3 1 7}$ & Channel: & ECD_1 \\
Sample Type: & unknown & Wavelength: & n.a. \\
Control Program: & AS14A ANIONS_CI2 METHOD & Bandwidth: & n.a. \\
Quantif. Method: & AS4A-SC ANION METHOD & Dilution Factor: & $\mathbf{1 0 . 0 0 0 0}$ \\
Recording Time: & $\mathbf{1 2 / 1 8 / 2 0 0 6} 14: 21$ & Sample Weight: & $\mathbf{1 . 0 0 0 0}$ \\
Run Time $(\mathrm{min}):$ & $\mathbf{2 7 . 0 0}$ & Sample Amount: & $\mathbf{1 . 0 0 0 0}$ \\
\hline
\end{tabular}

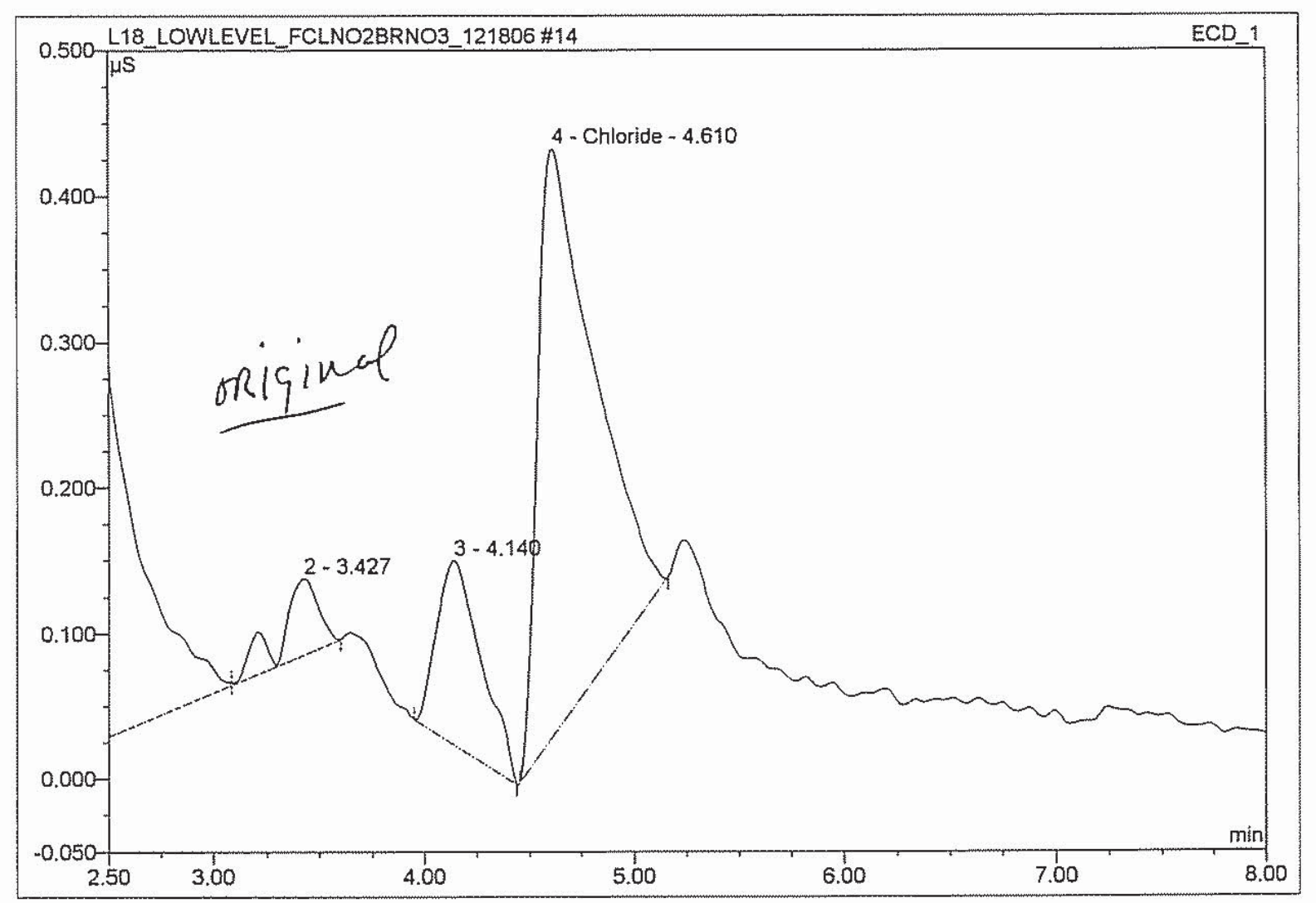

\begin{tabular}{|c|c|l|r|r|r|r|r|}
\hline No. & $\begin{array}{c}\text { Ret.Time } \\
\text { (min.) }\end{array}$ & \multicolumn{1}{|c|}{ Peak Name } & $\begin{array}{c}\text { Height } \\
\text { (uS) }\end{array}$ & $\begin{array}{c}\text { Area } \\
\mu S^{*} \text { min }\end{array}$ & $\begin{array}{c}\text { Rel.Area } \\
(\%)\end{array}$ & $\begin{array}{c}\text { Amount } \\
\text { (mg/L) }\end{array}$ & $\begin{array}{r}\text { Peak } \\
\text { Type }\end{array}$ \\
\hline 1 & 2.24 & n.a. & 1.96014 & 0.384 & 0.39 & n.a. & BM \\
\hline 2 & 3.43 & n.a. & 0.05222 & 0.011 & 0.01 & n.a. & MB \\
\hline 3 & 4.14 & n.a. & 0.12638 & 0.031 & 0.03 & n.a. & BMB \\
\hline 4 & 4.61 & Chloride & 0.40312 & 0.126 & 0.13 & 1.8295 & BMB \\
\hline 5 & 11.17 & n.a. & 81.46681 & 26.162 & 26.91 & n.a. & BMB \\
\hline 6 & 20.00 & n.a. & 75.82434 & 70.516 & 72.53 & n.a. & BMB \\
\hline
\end{tabular}




\section{H6L110105-JK7J2-1/10}

\begin{tabular}{llll|}
\hline Sample Name: & H6L110105-JK7J2-1/10 & Injection Volume: & $\mathbf{5 0 . 0}$ \\
Vial Number: & $\mathbf{1 3 1 8}$ & Channel: & ECD_1 \\
Sample Type: & unknown & Wavelength: & n.a. \\
Control Program: & AS14A ANIONS METHOD & Bandwidth: & n.a. \\
Quantif. Method: & AS4A-SC ANION METHOD & Dilution Factor: & 10.0000 \\
Recording Time: & $\mathbf{1 2 / 1 8 / 2 0 0 6 ~ 1 4 : 5 0}$ & Sample Weight: & $\mathbf{1 . 0 0 0 0}$ \\
Run Time (min): & $\mathbf{2 7 . 0 1}$ & Sample Amount: & $\mathbf{1 . 0 0 0 0}$ \\
\hline
\end{tabular}

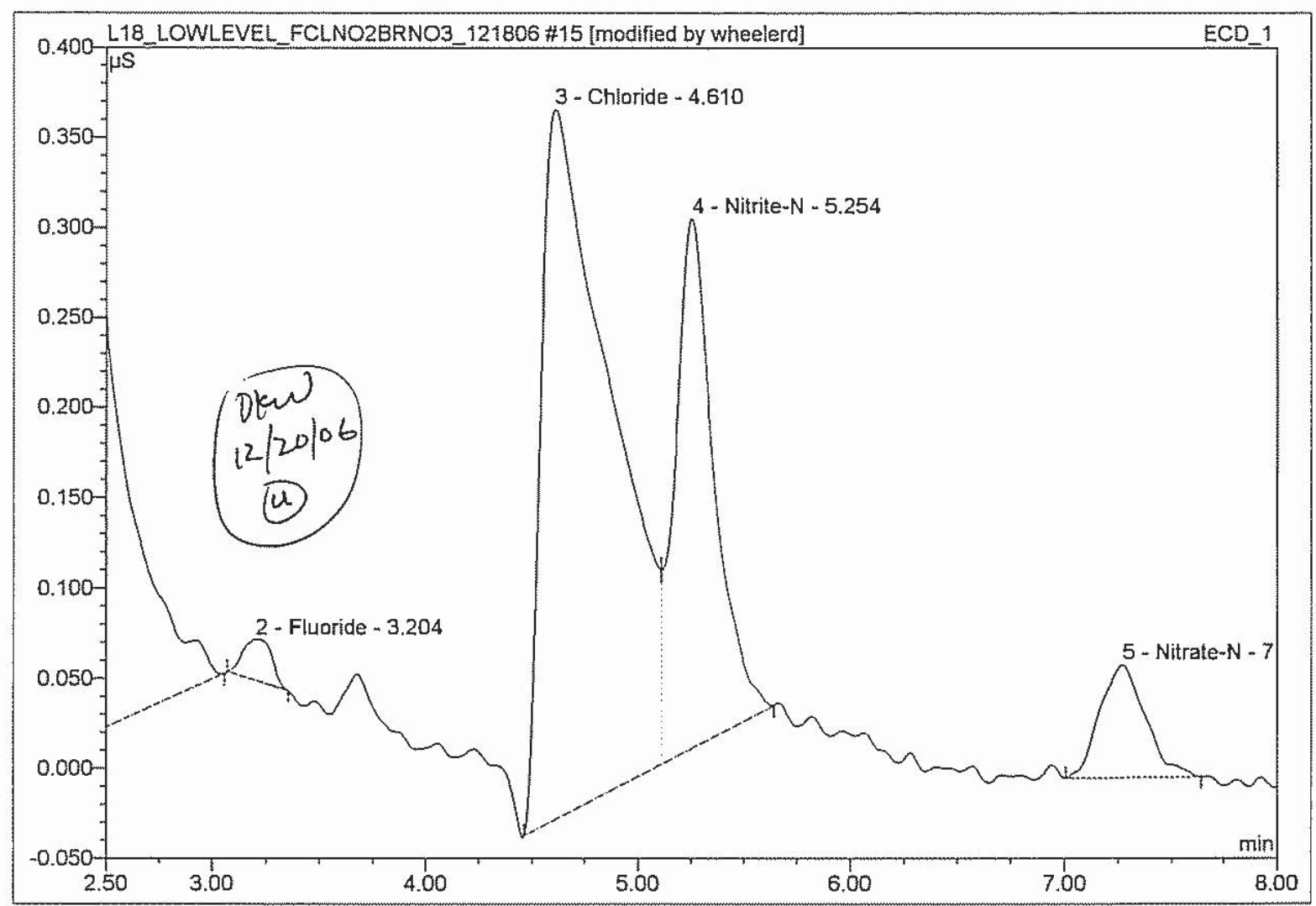

\begin{tabular}{|c|c|l|r|r|r|r|c|}
\hline No. & $\begin{array}{c}\text { Ret.Time } \\
\text { (min.) }\end{array}$ & \multicolumn{1}{|c|}{ Peak Name } & $\begin{array}{c}\text { Height } \\
\text { (uS) }\end{array}$ & $\begin{array}{c}\text { Area } \\
\mu S^{*} \text { min }\end{array}$ & $\begin{array}{r}\text { Rel.Area } \\
(\%)\end{array}$ & $\begin{array}{c}\text { Amount } \\
\text { (mg/L) }\end{array}$ & $\begin{array}{r}\text { Peak } \\
\text { Type }\end{array}$ \\
\hline 1 & 2.24 & n.a. & 1.83224 & 0.353 & 0.38 & n.a. & BMB \\
\hline 2 & 3.20 & Fluoride & 0.02288 & 0.004 & 0.00 & 0.0850 & BMB \\
\hline 3 & 4.61 & Chloride & 0.39417 & 0.149 & 0.16 & 1.7890 & BM \\
\hline 4 & 5.25 & Nitrite-N & 0.29412 & 0.064 & 0.07 & 0.7717 & MB \\
\hline 5 & 7.27 & Nitrate-N & 0.06279 & 0.016 & 0.02 & 0.1814 & BMB \\
\hline 6 & 11.19 & n.a. & 70.42751 & 22.416 & 23.99 & n.a. & BMB \\
\hline 7 & 20.00 & n.a. & 75.72053 & 70.444 & 75.39 & n.a. & BMB \\
\hline
\end{tabular}

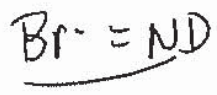




\section{H6L110105-JK7J2-1/10}

\begin{tabular}{llll|}
\hline Sample Name: & H6L110105-JK7J2-1/10 & Injection Volume: & $\mathbf{5 0 . 0}$ \\
Vial Number: & $\mathbf{1 3 1 8}$ & Channel: & ECD_1 \\
Sample Type: & unknown & Wavelength: & n.a. \\
Control Program: & AS14A ANIONS_CI2 METHOD & Bandwidth: & n.a. \\
Quantif. Method: & AS4A-SC ANION METHOD & Dilution Factor: & $\mathbf{1 0 . 0 0 0 0}$ \\
Recording Time: & $\mathbf{1 2 / 1 8 / 2 0 0 6 1 4 : 5 0}$ & Sample Weight: & $\mathbf{1 . 0 0 0 0}$ \\
Run Time (min): & $\mathbf{2 7 . 0 1}$ & Sample Amount: & $\mathbf{1 . 0 0 0 0}$ \\
\hline
\end{tabular}

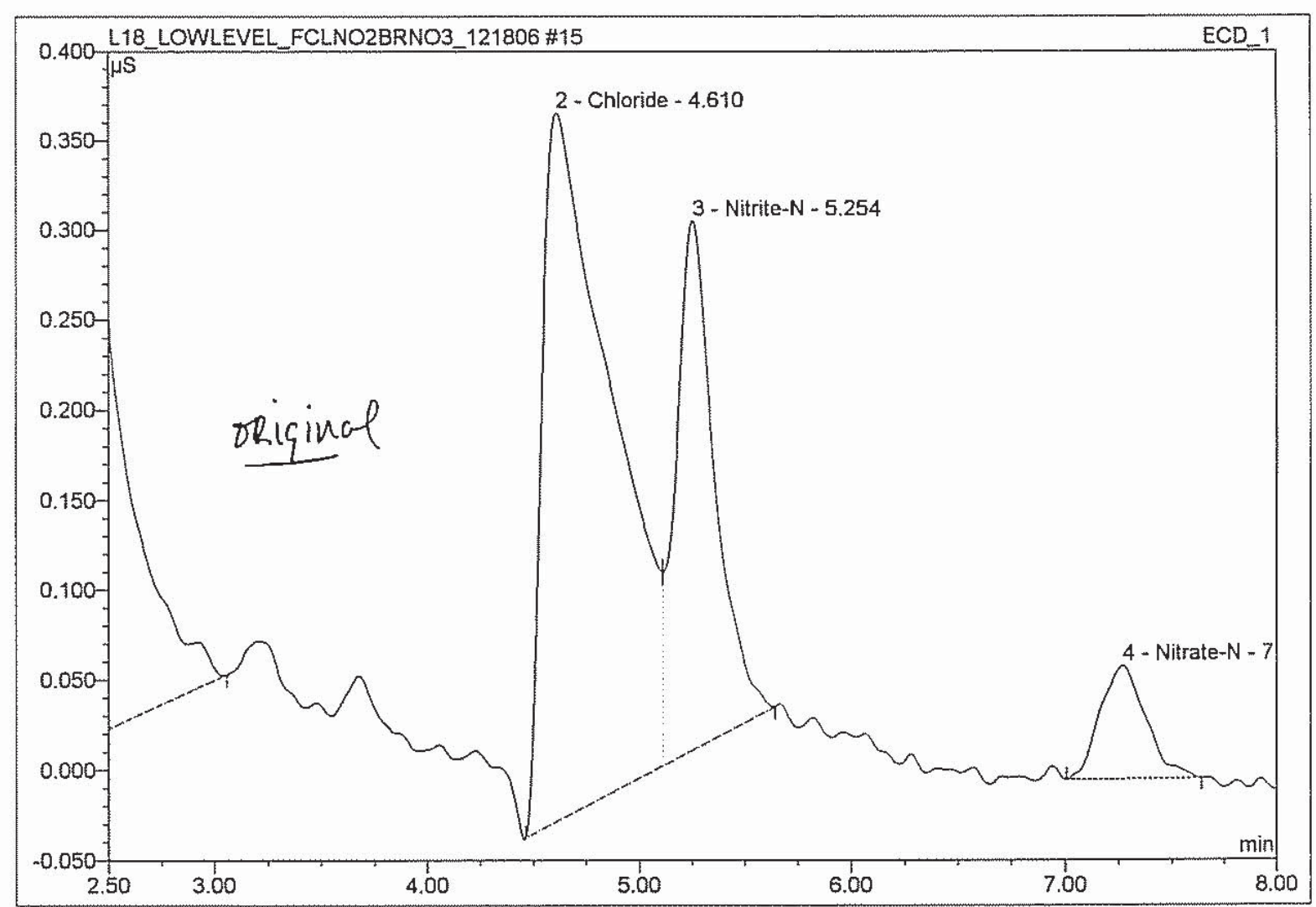

\begin{tabular}{|c|c|l|r|r|r|r|r|}
\hline No. & $\begin{array}{c}\text { Ret.Time } \\
\text { (min.) }\end{array}$ & \multicolumn{1}{|c|}{ Peak Name } & $\begin{array}{c}\text { Height } \\
\text { (uS) }\end{array}$ & $\begin{array}{c}\text { Area } \\
\mu \mathbf{S}^{*} \mathrm{~min}\end{array}$ & $\begin{array}{c}\text { Rel.Area } \\
(\%)\end{array}$ & $\begin{array}{c}\text { Amount } \\
\text { (mg/L) }\end{array}$ & $\begin{array}{r}\text { Peak } \\
\text { Type }\end{array}$ \\
\hline 1 & 2.24 & n.a. & 1.83224 & 0.353 & 0.38 & n.a. & BMB \\
\hline 2 & 4.61 & Chloride & 0.39417 & 0.149 & 0.16 & 1.7890 & BM \\
\hline 3 & 5.25 & Nitrite-N & 0.29412 & 0.064 & 0.07 & 0.7717 & MB \\
\hline 4 & 7.27 & Nitrate-N & 0.06279 & 0.016 & 0.02 & 0.1814 & BMB \\
\hline 5 & 11.19 & n.a. & 70.42751 & 22.416 & 23.99 & n.a. & BMB \\
\hline 6 & 20.00 & n.a. & 75.72053 & 70.444 & 75.39 & n.a. & BMB \\
\hline
\end{tabular}




\section{$16 \quad C C V=I C W S-9058$}

\begin{tabular}{llll}
\hline Sample Name: & CCV=ICWS-9058 & Injection Volume: & $\mathbf{5 0 . 0}$ \\
Vial Number: & $\mathbf{1 3 7 0}$ & Channel: & ECD_1 \\
Sample Type: & unknown & Wavelength: & n.a. \\
Control Program: & AS14A ANIONS METHOD & Bandwidth: & n.a. \\
Quantif. Method: & AS4A-SC ANION METHOD & Dilution Factor: & $\mathbf{1 . 0 0 0 0}$ \\
Recording Time: & $\mathbf{1 2 / 1 8 / 2 0 0 6 ~ 1 5 : 4 2}$ & Sample Weight: & $\mathbf{1 . 0 0 0 0}$ \\
Run Time (min): & $\mathbf{1 5 . 0 0}$ & Sample Amount: & $\mathbf{1 . 0 0 0 0}$ \\
\hline
\end{tabular}

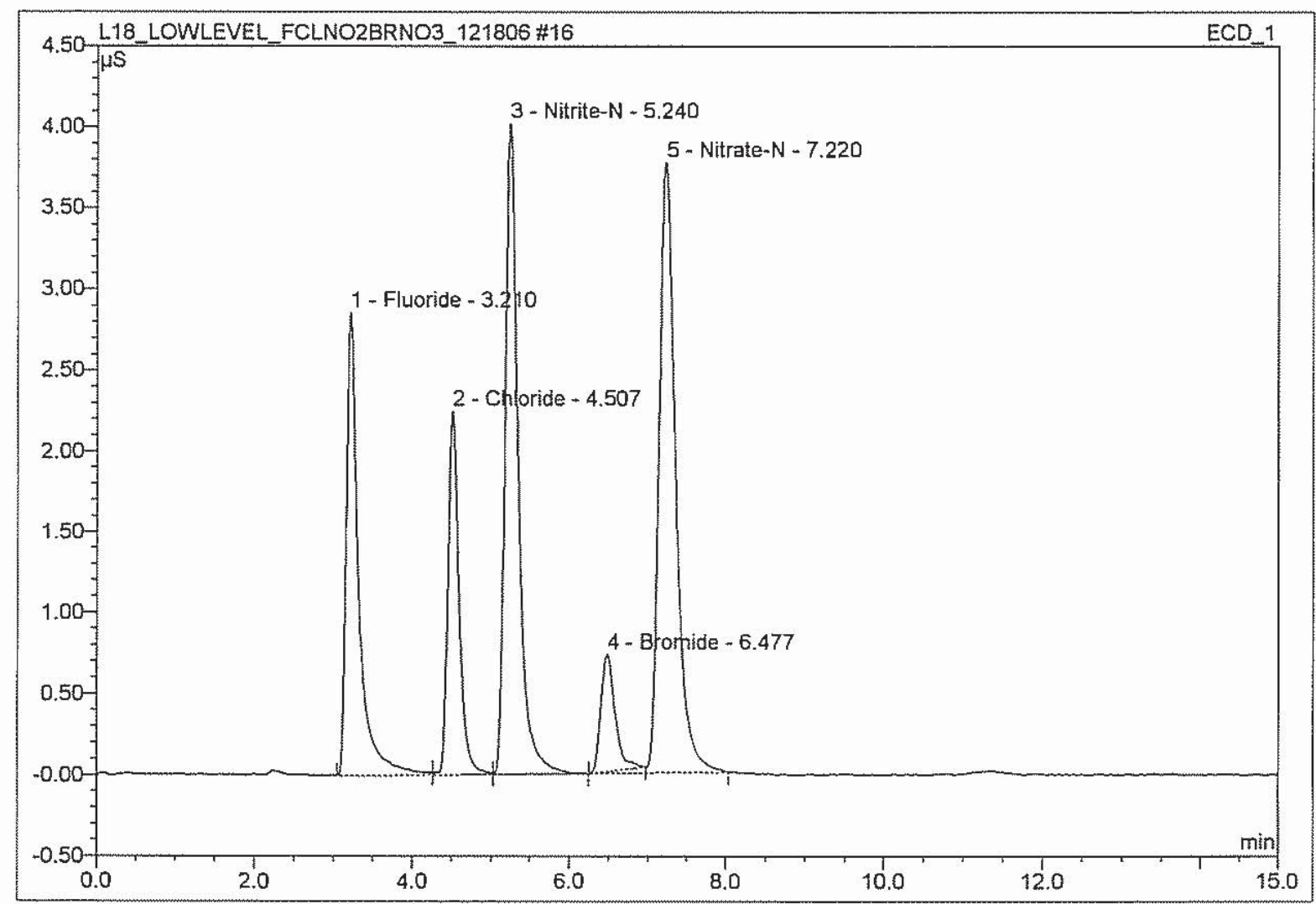

\begin{tabular}{|c|c|l|c|r|r|r|c|}
\hline No. & $\begin{array}{c}\text { Ret.Time } \\
\text { (min.) }\end{array}$ & \multicolumn{1}{|c|}{ Peak Narne } & $\begin{array}{c}\text { Height } \\
\text { (uS) }\end{array}$ & $\begin{array}{c}\text { Area } \\
\mu S^{*} \min \end{array}$ & $\begin{array}{c}\text { Rel.Area } \\
(\%)\end{array}$ & $\begin{array}{c}\text { Amount } \\
(\mathbf{m g} / \mathrm{L})\end{array}$ & $\begin{array}{c}\text { Peak } \\
\text { Type }\end{array}$ \\
\hline 1 & 3.21 & Fluoride & 2.86013 & 0.531 & 19.13 & 0.9852 & $\mathrm{BM}$ \\
\hline 2 & 4.51 & Chloride & 2.24631 & 0.369 & 13.32 & 1.0068 & $\mathrm{M}$ \\
\hline 3 & 5.24 & Nitrite-N & 4.01998 & 0.788 & 28.41 & 1.0217 & $\mathrm{M}$ \\
\hline 4 & 6.48 & Bromide & 0.72019 & 0.152 & 5.49 & 1.0078 & $\mathrm{Ru}$ \\
\hline 5 & 7.22 & Nitrate-N & 3.76823 & 0.934 & 33.65 & 1.0339 & $\mathrm{MB}$ \\
\hline
\end{tabular}




\section{CCB}

\begin{tabular}{llll|}
\hline Sample Name: & CCB & Injection Volume: & $\mathbf{5 0 . 0}$ \\
Vial Number: & $\mathbf{1 3 7 1}$ & Channel: & ECD_1 \\
Sample Type: & unknown & Wavelength: & n.a. \\
Control Program: & AS14A ANIONS METHOD & Bandwidth: & n.a. \\
Quantif. Method: & AS4A-SC ANION METHOD & Dilution Factor: & 1.0000 \\
Recording Time: & $\mathbf{1 2 / 1 8 / 2 0 0 6 ~ 1 6 : 0 0}$ & Sample Weight: & $\mathbf{1 . 0 0 0 0}$ \\
Run Time (min): & $\mathbf{1 5 . 0 0}$ & Sample Amount: & $\mathbf{1 . 0 0 0 0}$ \\
\hline
\end{tabular}

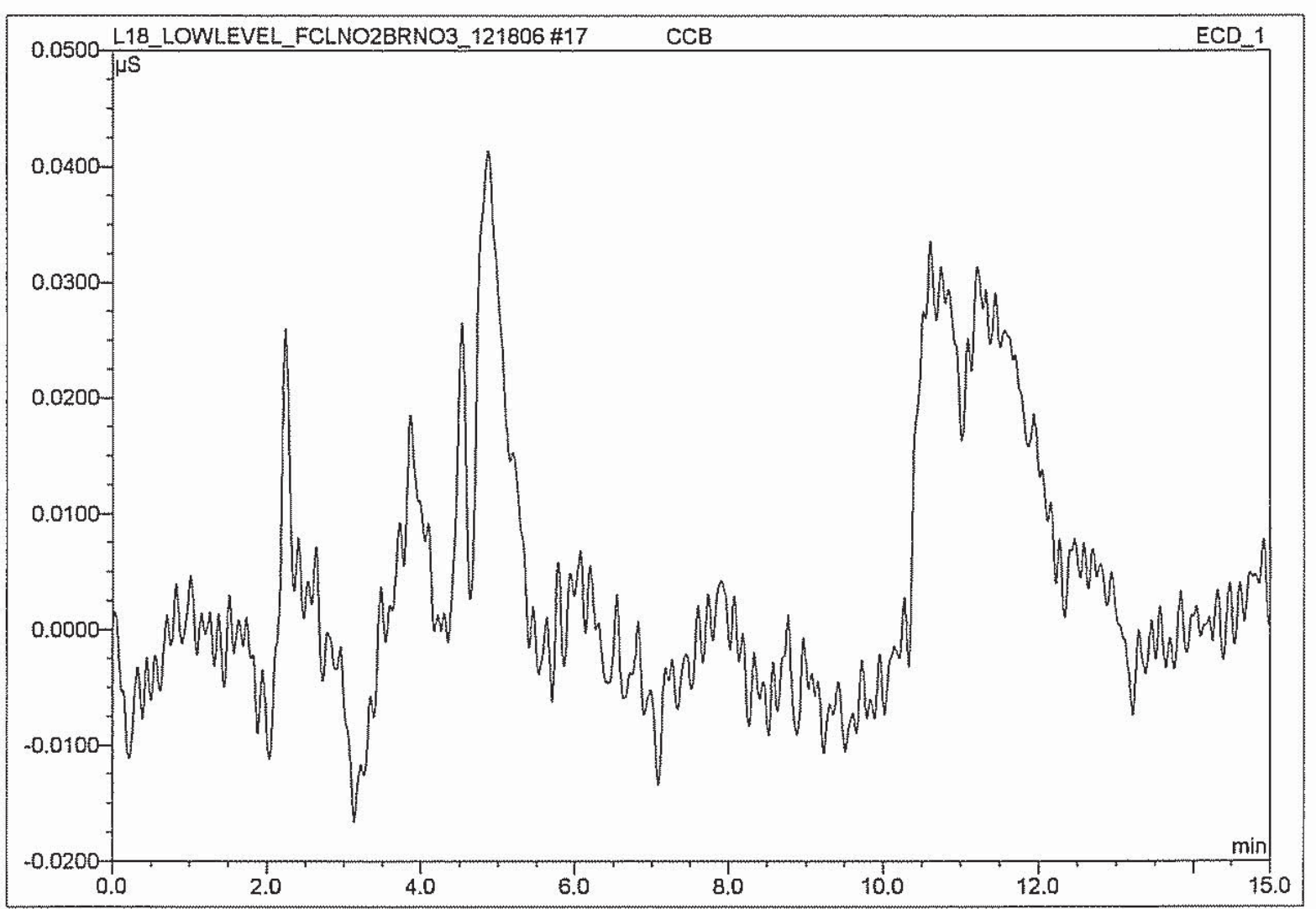

\begin{tabular}{|c|c|c|c|c|c|c|c|}
\hline No. & $\begin{array}{c}\text { Ret.Time } \\
\text { (min.) }\end{array}$ & Peak Name & $\begin{array}{c}\text { Height } \\
(\mathbf{u S})\end{array}$ & $\begin{array}{c}\text { Area } \\
\mu \mathrm{S}^{*} \mathrm{~min}\end{array}$ & $\begin{array}{c}\text { Rel.Area } \\
(\%)\end{array}$ & $\begin{array}{c}\text { Amount } \\
(\mathrm{mg} / \mathrm{L})\end{array}$ & $\begin{array}{c}\text { Peak } \\
\text { Type }\end{array}$ \\
\hline
\end{tabular}

ND 


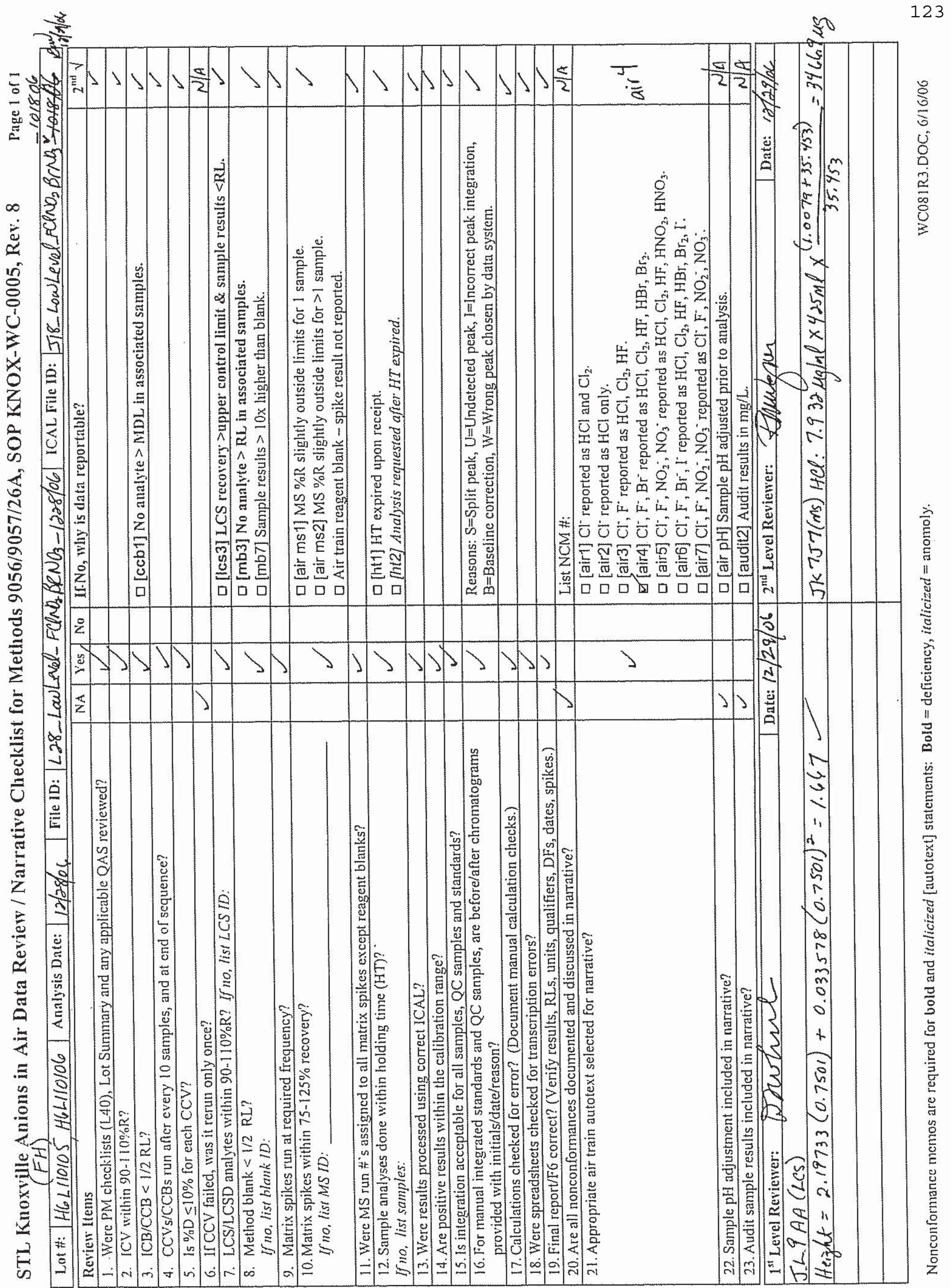




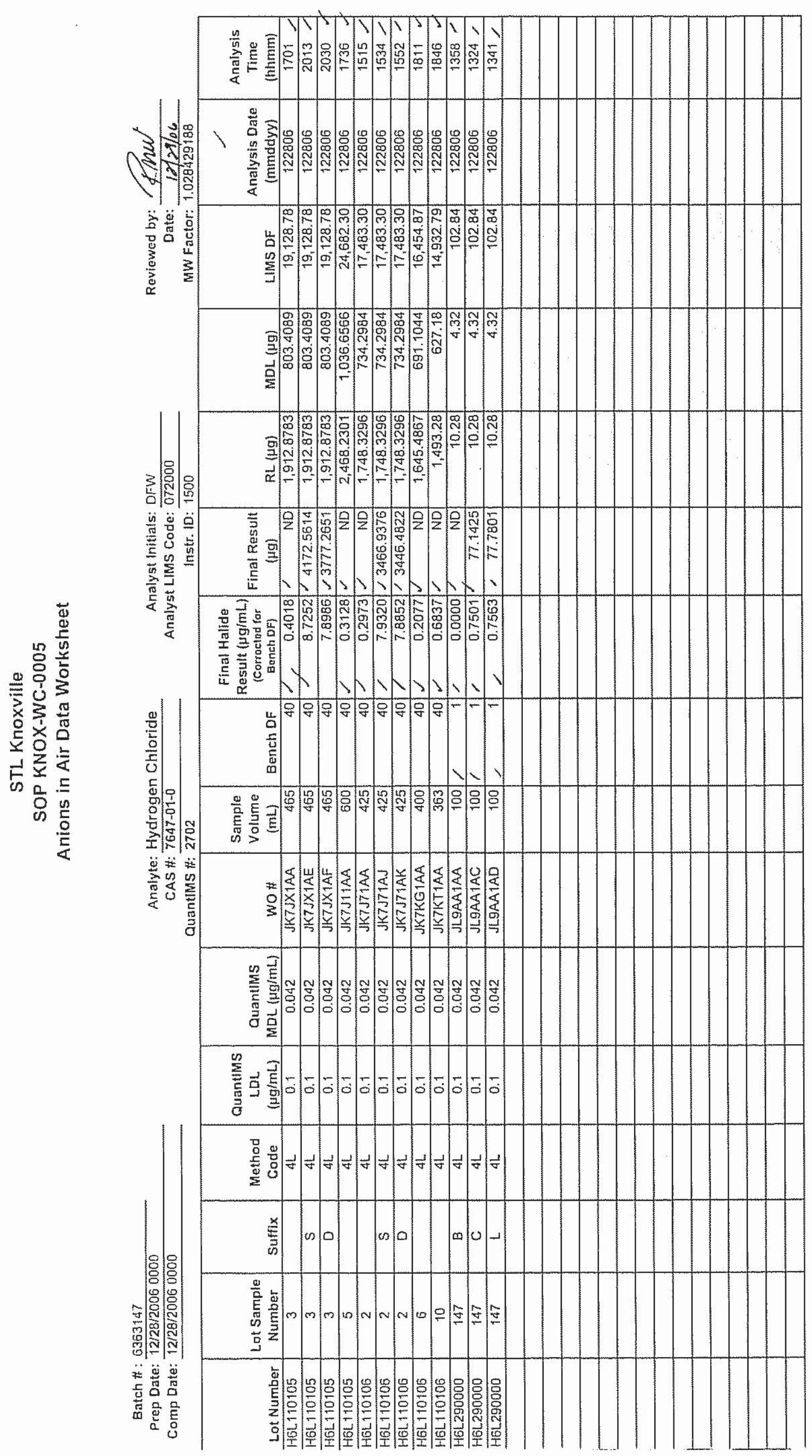




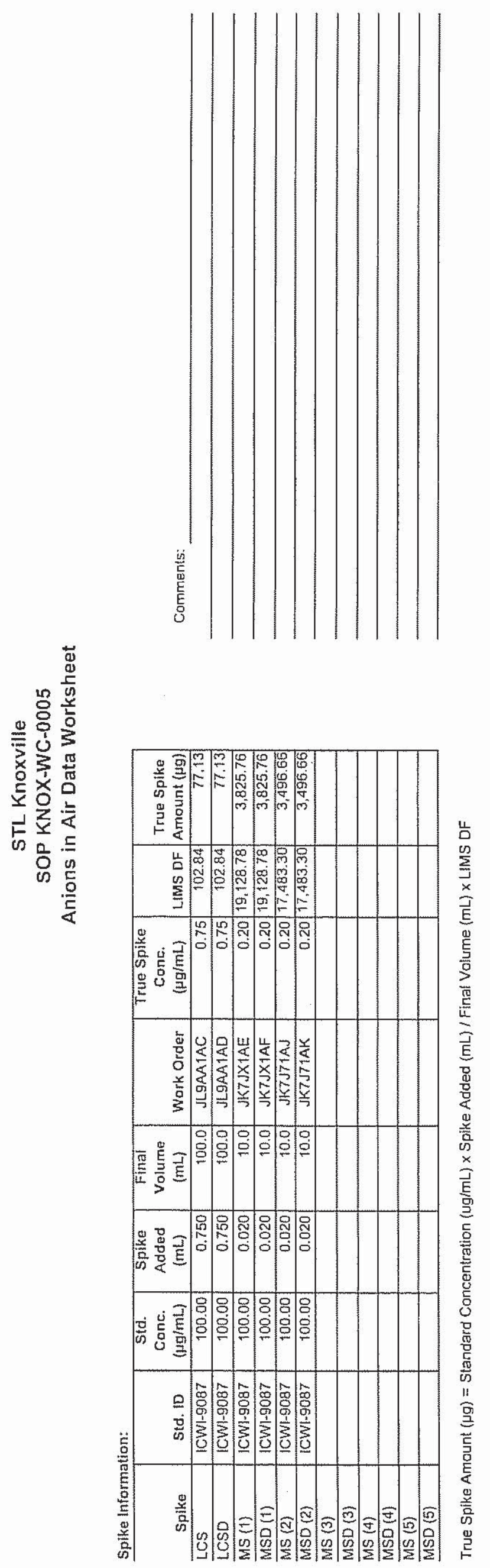


STL Knoxville

\section{Dionex IC Runlog Cover Page}

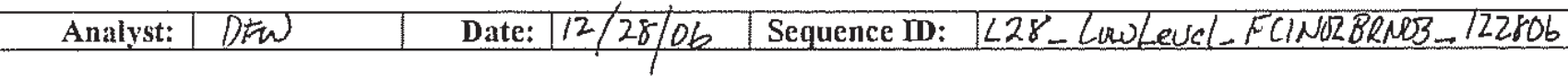

\begin{tabular}{|l|l|}
\hline Instrument: & $\square \mathrm{DX}-600$ \\
\cline { 2 - 2 } & $\mathrm{Q}$ ICS-1500 \\
\cline { 2 - 2 } & $\square \mathrm{DX}-320$
\end{tabular}

\begin{tabular}{|c|c|}
\hline \multirow[t]{3}{*}{ Method: } & 口KNOX-WC-0003, SW-846 0061/7199 \\
\hline & DKNOX-WC-0005, Q SW-8469056 एEPA 300.0 \\
\hline & DKNOX-WC-0014, EPA 314.0 \\
\hline
\end{tabular}

Preventive Maintenance

\section{Dailv:}

$\checkmark$ Check pump and gas pressure

$\checkmark$ Check all lines for crimping, leaks and discoloration

As Needed:

$\square$ Change column and guard column

$\square$ Change column and/or guard column bed support

$\mathrm{C}$ Clean conductivity cell

$\square$ De-gas pump head when flow is erratic

$\square$ Check/replace eluant end line filter

\section{Instrument Conditions}

\begin{tabular}{rll}
\hline Flow Rate $=1.00$ & $\mathrm{~mL} / \mathrm{min}$ \\
\hline Pressure $=1840$. & $\mathrm{psi}$ \\
\hline Conductance $=24.9$ & $\mu \mathrm{S}$ \\
\hline Suppressor Current $=43$ & $\mathrm{~mA}$ \\
\hline Eluent Generator $=$ & $\mathrm{N} / \mathrm{A}$ & $\mathrm{mM} \mathrm{KOH}$ \\
\hline
\end{tabular}

MS/MSD Spilic Information

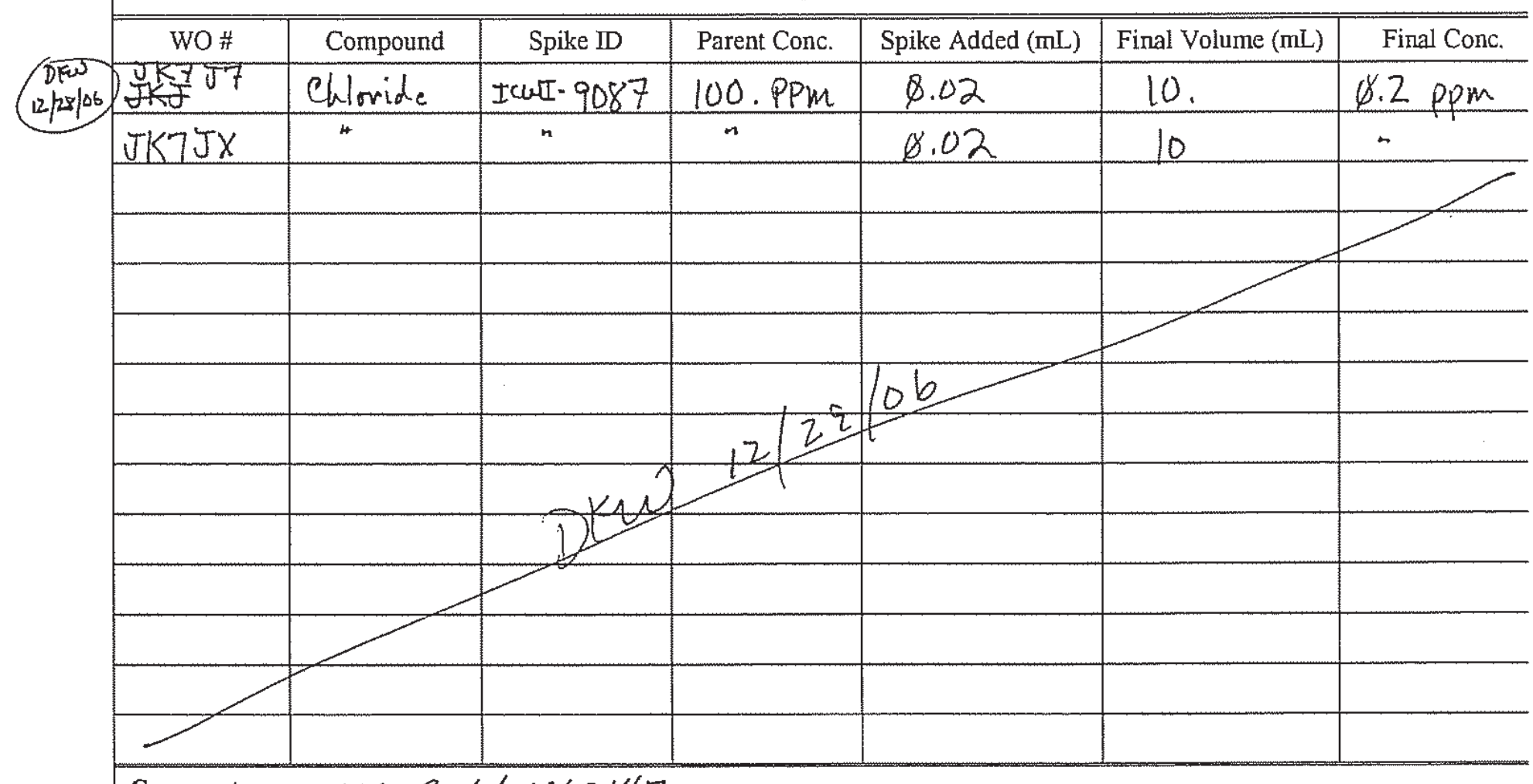

Comments: HCl Batch 6363147

$\square$ Sodium Thiosulfate added to $\mathrm{NaOH}$ impinger samples. 
Sequence:

Operator:

L28_LOWLEVEL_FCLNO2BRNO3_122806

wheelerd

Title:

Datasource:

Location:

Timebase:

\#Samples:
ICS 1500 net

ICS1500

ICS1500

34
Page 1 of $\not \gamma$ Printed: $12 / 29 / 2006$ 8:55:10 AM

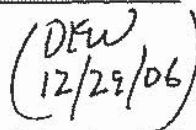

Created:

Last Update:
12/28/2006 10:49:27 AM by wheelerd 12/28/2006 4:28:05 PM by wheelerd

\begin{tabular}{|c|c|c|c|c|c|c|c|}
\hline No. & Name & Sample ID & In!. Vol, & Inj. Date/Time & Dil. Factor & "Multipiler & Weight \\
\hline 11 & (1) CAL STD \#1 ICWS-8915 & & 50.0 & $10 / 18 / 2006$ 9:14:56 AM & 1.0000 & & 1.0000 \\
\hline 2 & (1) CAL STD \#2 ICWS-8916 & & 50.0 & $10 / 18 / 2006$ 9:32:20 AM & 1.0000 & & 1.0000 \\
\hline 3 & (1) CAL STD \#3 ICWS-8917 & & 50.0 & $10 / \$ 8 / 2006$ 9:49:45 AM & 1.0000 & & 1.0000 \\
\hline 4 & (9) CAL STD \#4 ICWS-8918 & & 50.0 & 10/18/2006 10:07:09 AM & 1.0000 & & 1.0000 \\
\hline 5 & (1) CAL STD \#5 ICWS-8919 & & 50.0 & $10 / 18 / 200610: 24: 33 \mathrm{AM}$ & 1.0000 & & 1.0000 \\
\hline 6 & 1) CAL STD \#6 ICWS.8920 & & 50.0 & $10 / 18 / 2006$ 10:41:57 AM & 1.0000 & & 1.0000 \\
\hline 7 & ICVILCS $=1$ ICWS-9088 & & 50.0 & $12 / 28 / 2006$ 1:24:09 PM & 1.0000 & & 1.0000 \\
\hline 8 & ICVILCSD= ICWS-9089 & & 50.0 & $12 / 28 / 20061: 41: 33 \mathrm{PM}$ & 1.0000 & & 1.0000 \\
\hline 9 & ICB/METHOD BLANK & & 50.0 & 12/28/2006 1:58:57 PM & 1.0000 & & 1.0000 \\
\hline 10 & 菌 H6L110106-JK7J7-1/20 & & 50.0 & 12/28/2006 2:16:22 PM & 20.0000 & & 1.0000 \\
\hline 11 & H6L110106-JK7J7-1/20-MS@0.2ppm Cl & & 50.0 & $12 / 28 / 20062: 40: 20 \mathrm{PM}$ & 20.0000 & & 1.0000 \\
\hline 12 & 3 HGL110106-JK7J7-1/20-MSD@0.2ppm Cl & & 50.0 & $12 / 28 / 20062: 57: 44 \mathrm{PM}$ & 20.0000 & & 1.0000 \\
\hline 13 & H H $1110106-J K 7 J 7-1 / 40$ & & 50.0 & $12 / 28 / 20063: 15: 08 \mathrm{PM}$ & 40.0000 & & 1.0000 \\
\hline 14 & H H6L110106-JK7J7-1/40-MS@0.2ppm Cl & & 50.0 & $12 / 28 / 20063: 34: 42 \mathrm{PM}$ & 40.0000 & & 1.0000 \\
\hline 15 & H6L110106-JK7J7-1/40-MSD@0.2ppm Cl & & 50.0 & 12/28/2006 3:52:06 PM & 40.0000 & & 1.0000 \\
\hline 16 & CCV $=1 C W S-9090$ & & 50.0 & 12/28/2006 4:09:30 PM & 1.0000 & & 1.0000 \\
\hline 17 & $\mathrm{CCB}$ & & 50.0 & $12 / 28 / 20064: 26: 54$ PM & 1.0000 & & 1.0000 \\
\hline 18 & H6L110105-JK7JX-1/20 & & 50.0 & 12/28/2006 4:44:18 PM & 20.0000 & & 1.0000 \\
\hline 19 & HEL110105-JK7JX-1/40 & & 50.0 & 12/28/2006 5:01:43 PM & 40.0000 & & 1.0000 \\
\hline 20 & H6L110105-JK7J1-1/20 & & 50.0 & 12/28/2006 5:19:07 PM & 20.0000 & & 1.0000 \\
\hline 21 & I H6L110105-JK7J1-1/40 & & 50.0 & 12/28/2006 5:36:31 PM & 40.0000 & & 1.0000 \\
\hline 22 & (3) H6L110106-JK7KG-1/20 & & 50.0 & 12/28/2006 5:53:56 PM & 20.0000 & & 1.0000 \\
\hline 23 & H6L110106-JK7KG-1/40 & & 50.0 & 12/28/2006 6:11:20 PM & 40.0000 & & 1.0000 \\
\hline 24 & (2) H6L110106-JK7KT-1/20 & & 50.0 & 12/28/2006 6:28:44 PM & 20.0000 & & 1.0000 \\
\hline 25 & 筧 H6L110106-JK7KT-1/40 & & 50.0 & $12 / 28 / 2006$ 6:46:08 PM & 40.0000 & & 1.0000 \\
\hline 26 & (i) $C C V=1 C W S-9090$ & & 50.0 & 12/28/2006 7:03:32 PM & 1.0000 & & 1.0000 \\
\hline 27 & (2) $\mathrm{CCB}$ & & 50.0 & $12 / 28 / 20067: 20: 56 \mathrm{PM}$ & 1.0000 & & 1.0000 \\
\hline 28 & (2) H6L-110105-JK7JX-1/20-MS@0.2ppm Cl & & 50.0 & 12/28/2006 7:38:20 PM & 20.0000 & & 1.0000 \\
\hline 29 & H6L110105-JK7JX-1/20-MSD@0.2ppm Cl & & 50.0 & $12 / 28 / 20067: 55: 44 \mathrm{PM}$ & 20.0000 & & 1.0000 \\
\hline 30 & (3) HEL110105-JK7JX-1/40-MS@0.2ppm Cl & & 50.0 & 12/28/2006 8:13:09 PM & 40.0000 & & 1.0000 \\
\hline 31 & $2 \mathrm{H} 6 \mathrm{~L} 110105-\mathrm{KK} 7 \mathrm{JX}-1 / 40-\mathrm{MSD} @ 0.2 \mathrm{ppm} \mathrm{Cl}$ & & 50.0 & 12/28/2006 8:30:33 PM & 40.0000 & & 1.0000 \\
\hline 32 & CCV $=1 C W S-9090$ & & 50.0 & 12/28/2006 8:47:58 PM & 1.0000 & & 1.0000 \\
\hline 33 & CCB & & 50.0 & $12 / 28 / 20069: 05: 22 \mathrm{PM}$ & 1.0000 & & 1.0000 \\
\hline 34 & SHUTDOWN & & 50.0 & $12 / 28 / 20069: 22: 46 \mathrm{PM}$ & 1.0000 & & 1.0000 \\
\hline
\end{tabular}




\section{ICV/LCS $=$ ICWS -9088}

\begin{tabular}{llll}
\hline Sample Name: & ICV/LCS= ICWS-9088 & Injection Volume: & $\mathbf{5 0 . 0}$ \\
Vial Number: & $\mathbf{1 2 9 6}$ & Channel: & ECD_1 \\
Sample Type: & unknown & Wavelength: & n.a. \\
Control Program: & AS14A ANIONS METHOD & Bandwidth: & n.a. \\
Quantif. Method: & AS4A-SC ANION METHOD & Dilution Factor: & 1.0000 \\
Recording Time: & $\mathbf{1 2 / 2 8 / 2 0 0 6 ~ 1 3 : 2 4}$ & Sample Weight: & 1.0000 \\
Run Time (min): & $\mathbf{1 5 . 0 0}$ & Sample Amount: & $\mathbf{1 . 0 0 0 0}$ \\
\hline
\end{tabular}

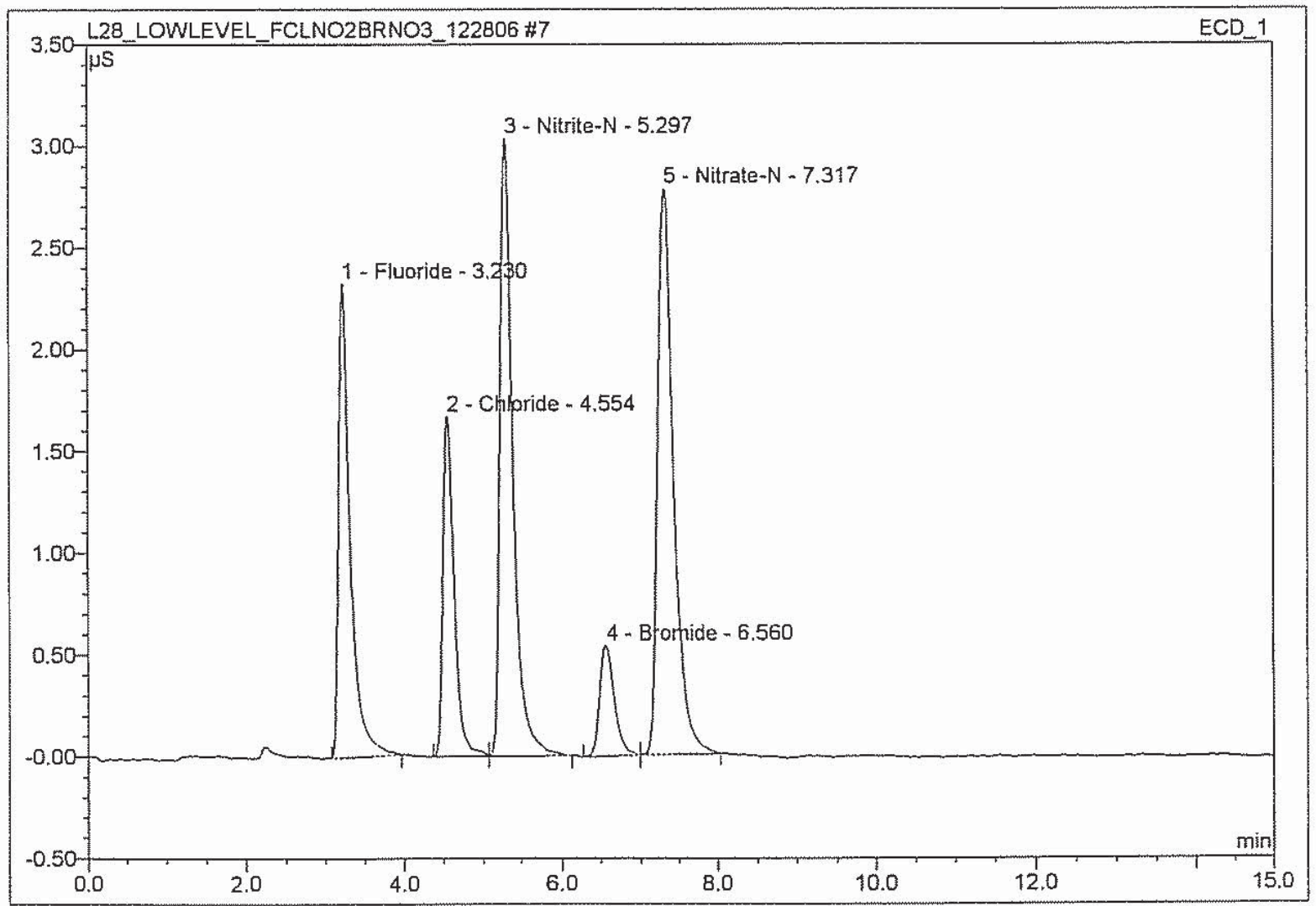

\begin{tabular}{|c|c|l|r|r|r|r|c|}
\hline No. & $\begin{array}{c}\text { Ret.Time } \\
\text { (min.) }\end{array}$ & \multicolumn{1}{|c|}{ Peak Name } & $\begin{array}{c}\text { Height } \\
\text { (uS) }\end{array}$ & $\begin{array}{c}\text { Area } \\
\mu S^{\star} \mathrm{min}\end{array}$ & $\begin{array}{c}\text { Rel.Area } \\
(\%)\end{array}$ & $\begin{array}{c}\text { Amount } \\
\text { (mg/L) }\end{array}$ & $\begin{array}{c}\text { Peak } \\
\text { Type }\end{array}$ \\
\hline 1 & 3.23 & Fluoride & 2.32322 & 0.397 & 19.53 & 0.8109 & $\mathrm{BMB}$ \\
\hline 2 & 4.55 & Chloride & 1.66709 & 0.273 & 13.44 & 0.7501 & $\mathrm{BM}$ \\
\hline 3 & 5.30 & Nitrite-N & 3.02897 & 0.586 & 28.80 & 0.7761 & $\mathrm{MB}$ \\
\hline 4 & 6.56 & Bromide & 0.54320 & 0.115 & 5.64 & 0.7617 & $\mathrm{BMb}$ \\
\hline 5 & 7.32 & Nitrate-N & 2.77714 & 0.663 & 32.59 & 0.7720 & $\mathrm{bMB}$ \\
\hline
\end{tabular}

$$
\text { HCl JL9AA-IAC }
$$




\section{$8 \quad I C V / L C S D=I C W S-9089$}

\begin{tabular}{llll}
\hline Sample Name: & ICV/LCSD=ICWS-9089 & Injection Volume: & $\mathbf{5 0 . 0}$ \\
Vial Number: & 1297 & Channel: & ECD_1 \\
Sample Type: & unknown & Wavelength: & n.a. \\
Control Program: & AS14A ANIONS METHOD & Bandwidth: & n.a. \\
Quantif. Method: & AS4A-SC ANION METHOD & Dilution Factor: & 1.0000 \\
Recording Time: & $12 / 28 / 200613: 41$ & Sample Weight: & 1.0000 \\
Run Time (min): & 15.00 & Sample Amount: & 1.0000 \\
\hline
\end{tabular}

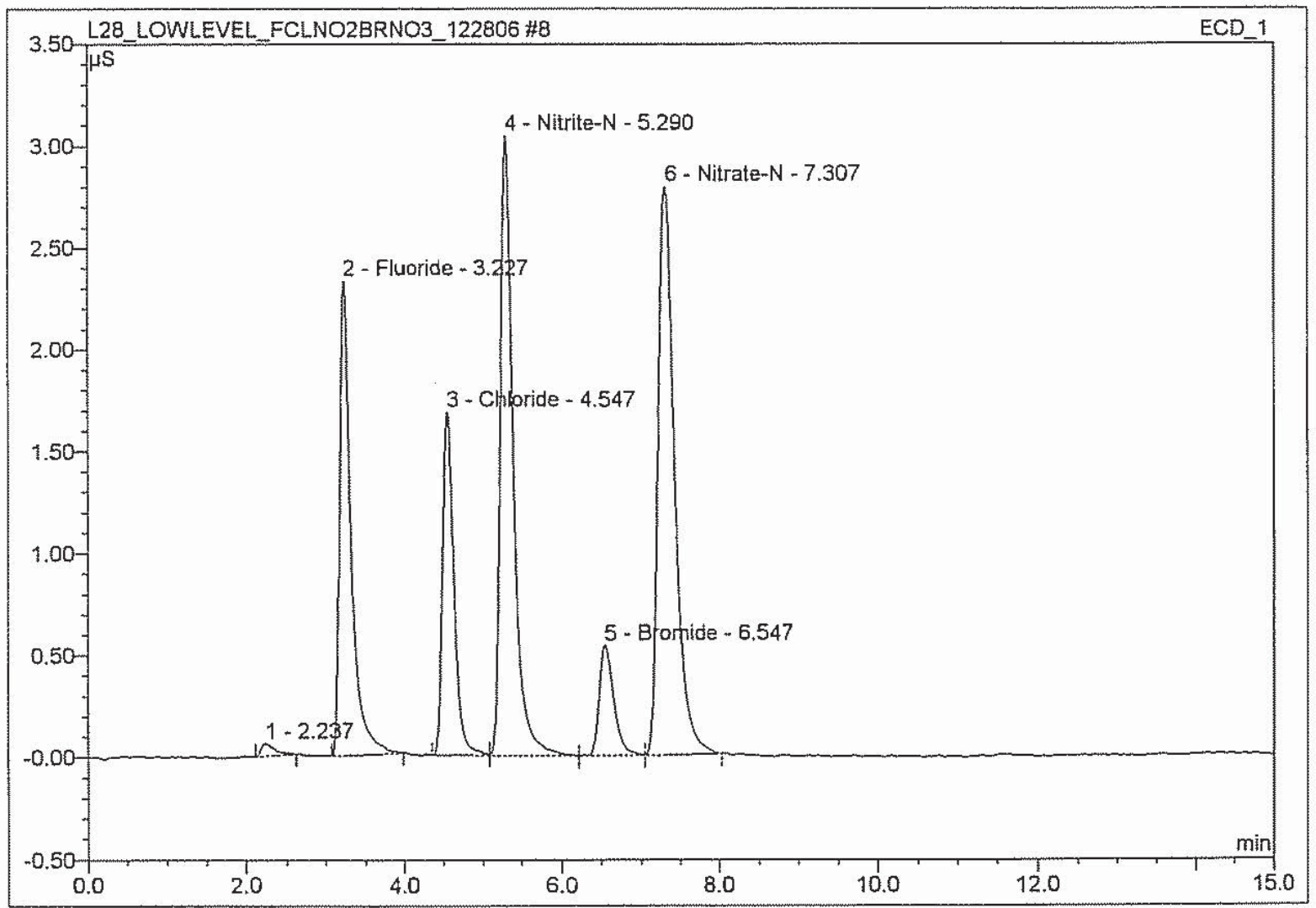

\begin{tabular}{|c|c|l|r|r|r|r|c|}
\hline No. & $\begin{array}{c}\text { Ret.Time } \\
\text { (min.) }\end{array}$ & \multicolumn{1}{|c|}{ Peak Name } & $\begin{array}{c}\text { Height } \\
\text { (uS) }\end{array}$ & $\begin{array}{c}\text { Area } \\
\mu S^{*} \min \end{array}$ & $\begin{array}{c}\text { Rel.Area } \\
(\%)\end{array}$ & $\begin{array}{c}\text { Amount } \\
\text { (mg/L) }\end{array}$ & $\begin{array}{r}\text { Peak } \\
\text { Type }\end{array}$ \\
\hline 1 & 2.24 & n.a. & 0.06095 & 0.013 & 0.61 & n.a. & BMB \\
\hline 2 & 3.23 & Fluoride & 2.32775 & 0.399 & 19.45 & 0.8124 & $\mathrm{BMB}$ \\
\hline 3 & 4.55 & Chloride & 1.68114 & 0.274 & 13.35 & 0.7563 & $\mathrm{BM}$ \\
\hline 4 & 5.29 & Nitrite-N & 3.03772 & 0.587 & 28.59 & 0.7783 & $\mathrm{M}$ \\
\hline 5 & 6.55 & Bromide & 0.53922 & 0.114 & 5.54 & 0.7561 & $\mathrm{MB}$ \\
\hline 6 & 7.31 & Nitrate-N & 2.78963 & 0.666 & 32.46 & 0.7754 & $\mathrm{BMB}$ \\
\hline
\end{tabular}

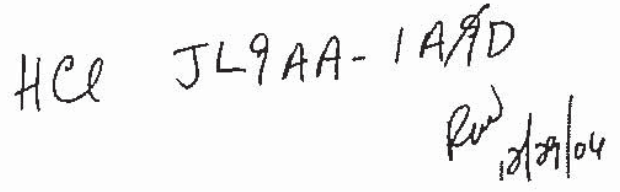




\section{ICB/METHOD BLANK}

\begin{tabular}{llll|}
\hline Sample Name: & ICB/ METHOD BLANK & Injection Volume: & $\mathbf{5 0 . 0}$ \\
Vial Number: & 1298 & Channel: & ECD_1 \\
Sample Type: & unknown & Wavelength: & n.a. \\
Control Program: & AS14A ANIONS METHOD & Bandwidth: & n.a. \\
Quantif. Method: & AS4A-SC ANION METHOD & Dilution Factor: & 1.0000 \\
Recording Time: & $12 / 28 / 200613: 58$ & Sample Weight: & $\mathbf{1 . 0 0 0 0}$ \\
Run Time (min): & $\mathbf{1 5 . 0 0}$ & Sample Amount: & $\mathbf{1 . 0 0 0 0}$ \\
\hline
\end{tabular}

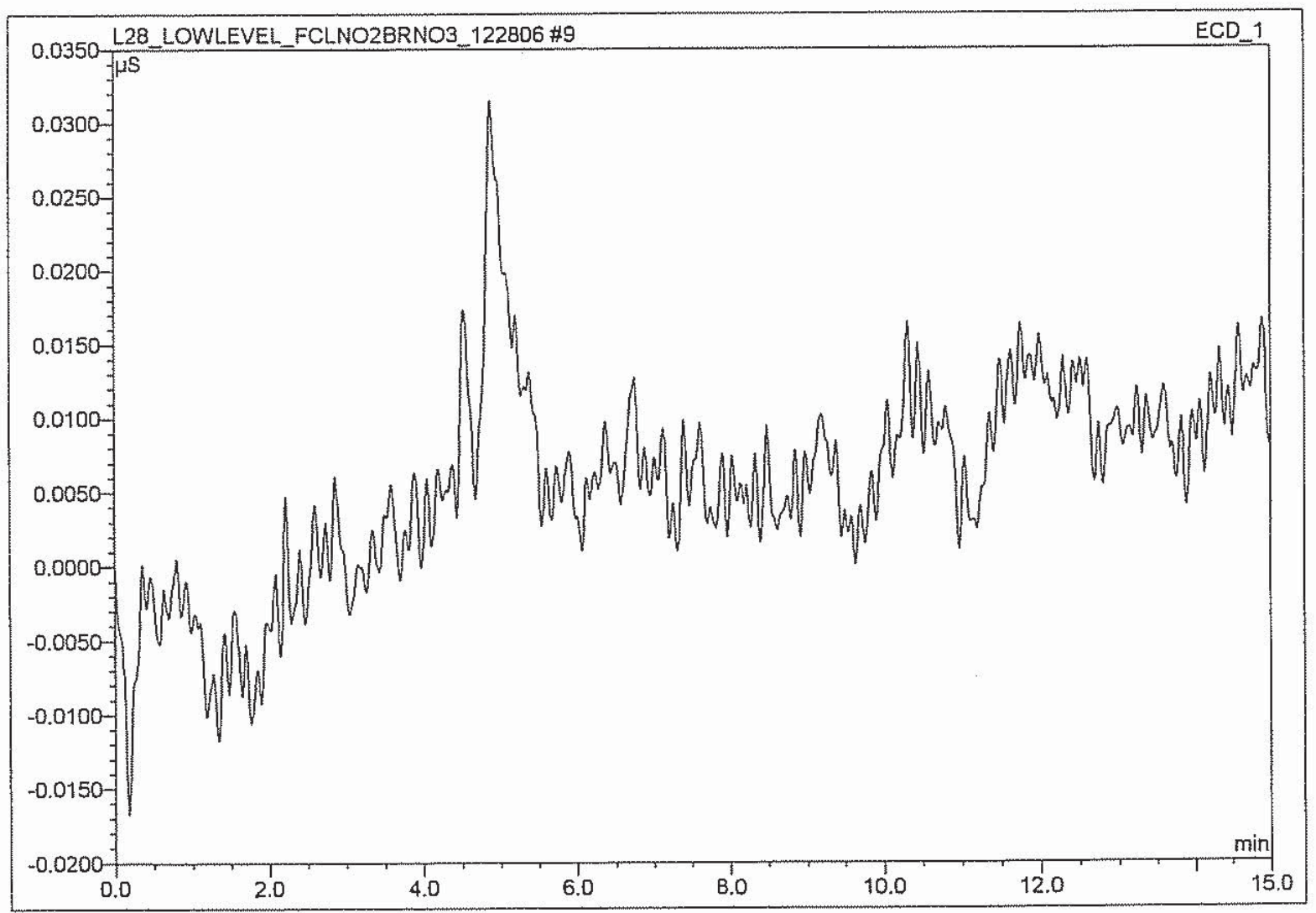

\begin{tabular}{|l|c|c|c|c|c|c|c|}
\hline No. & $\begin{array}{c}\text { Ret.Time } \\
\text { (min.) }\end{array}$ & Peak Name & $\begin{array}{c}\text { Height } \\
\text { (uS) }\end{array}$ & $\begin{array}{c}\text { Area } \\
\mu S^{*} \min \end{array}$ & $\begin{array}{c}\text { Rel.Area } \\
(\%)\end{array}$ & $\begin{array}{c}\text { Amount } \\
\text { (mg/L) }\end{array}$ & $\begin{array}{c}\text { Peak } \\
\text { Type }\end{array}$ \\
\hline
\end{tabular}




\section{$16 \quad \mathrm{CCV}=\mathrm{ICWS}-9090$}

\begin{tabular}{llll|}
\hline Sample Name: & CCV=ICWS-9090 & Injection Volume: & $\mathbf{5 0 . 0}$ \\
Vial Number: & $\mathbf{1 3 7 0}$ & Channel: & ECD_1 \\
Sample Type: & unknown & Wavelength: & n.a. \\
Control Program: & AS14A ANIONS METHOD & Bandwidth: & n.a. \\
Quantif. Method: & AS4A-SC ANION METHOD & Dilution Factor: & 1.0000 \\
Recording Time: & $12 / 28 / 200616: 09$ & Sample Weight: & 1.0000 \\
Run Time (min): & $\mathbf{1 5 . 0 0}$ & Sample Amount: & 1.0000 \\
\hline
\end{tabular}

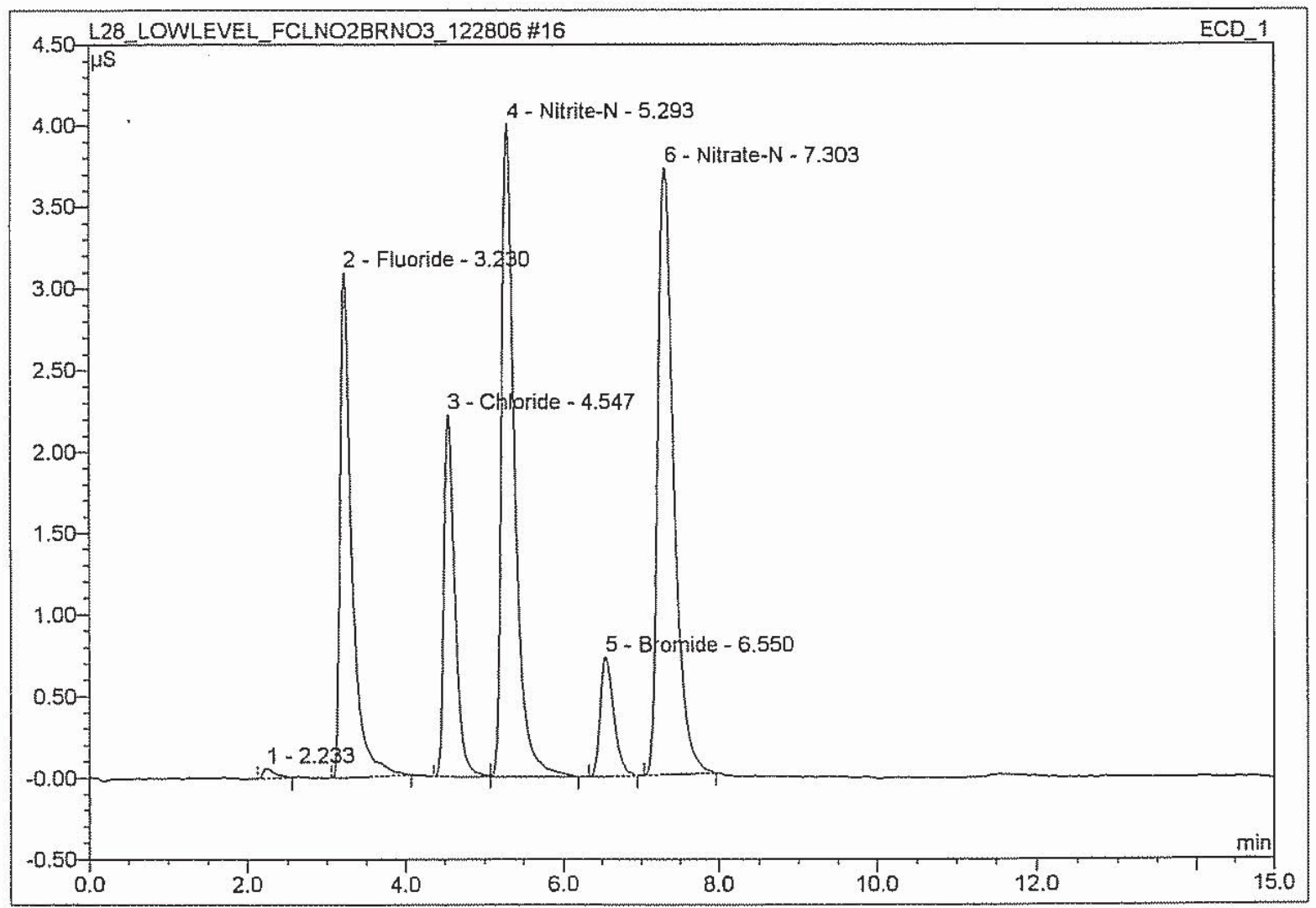

\begin{tabular}{|c|c|l|r|r|r|r|c|}
\hline No. & $\begin{array}{c}\text { Ret.Time } \\
(\min )\end{array}$ & \multicolumn{1}{|c|}{ Peak Name } & $\begin{array}{c}\text { Height } \\
(\mathrm{uS})\end{array}$ & $\begin{array}{c}\text { Area } \\
\mu \mathrm{S}^{*} \mathrm{~min}\end{array}$ & $\begin{array}{c}\text { Rel.Area } \\
(\%)\end{array}$ & $\begin{array}{c}\text { Amount } \\
(\mathrm{mg} / \mathrm{L})\end{array}$ & $\begin{array}{r}\text { Peak } \\
\text { Type }\end{array}$ \\
\hline 1 & 2.23 & n.a. & 0.06059 & 0.011 & 0.42 & n.a. & BMB \\
\hline 2 & 3.23 & Fluoride & 3.09242 & 0.528 & 19.53 & 1.0594 & BMB \\
\hline 3 & 4.55 & Chloride & 2.21582 & 0.356 & 13.19 & 0.9933 & BM \\
\hline 4 & 5.29 & Nitrite-N & 4.00209 & 0.777 & 28.76 & 1.0173 & MB \\
\hline 5 & 6.55 & Bromide & 0.72968 & 0.151 & 5.60 & 1.0210 & BMB \\
\hline 6 & 7.30 & Nitrate-N & 3.71828 & 0.878 & 32.50 & 1.0209 & BMB \\
\hline
\end{tabular}




\section{$17 \mathrm{CCB}$}

Sample Name: $\quad$ CCB

Vial Number: $\quad 1371$

Sample Type: $\quad$ unknown

Control Program: AS14A ANIONS METHOD

Quantif. Method: AS4A-SC ANION METHOD

Recording Time: $\quad$ 12/28/2006 16:26

Run Time (min): $\quad \mathbf{1 5 . 0 0}$
Injection Volume: $\quad \mathbf{5 0 . 0}$

Channel:

Wavelength:

Bandwidth:

Dilution Factor:

Sample Weight:

Sample Amount:
ECD_1

n.a.

n.a.

1.0000

1.0000

1.0000

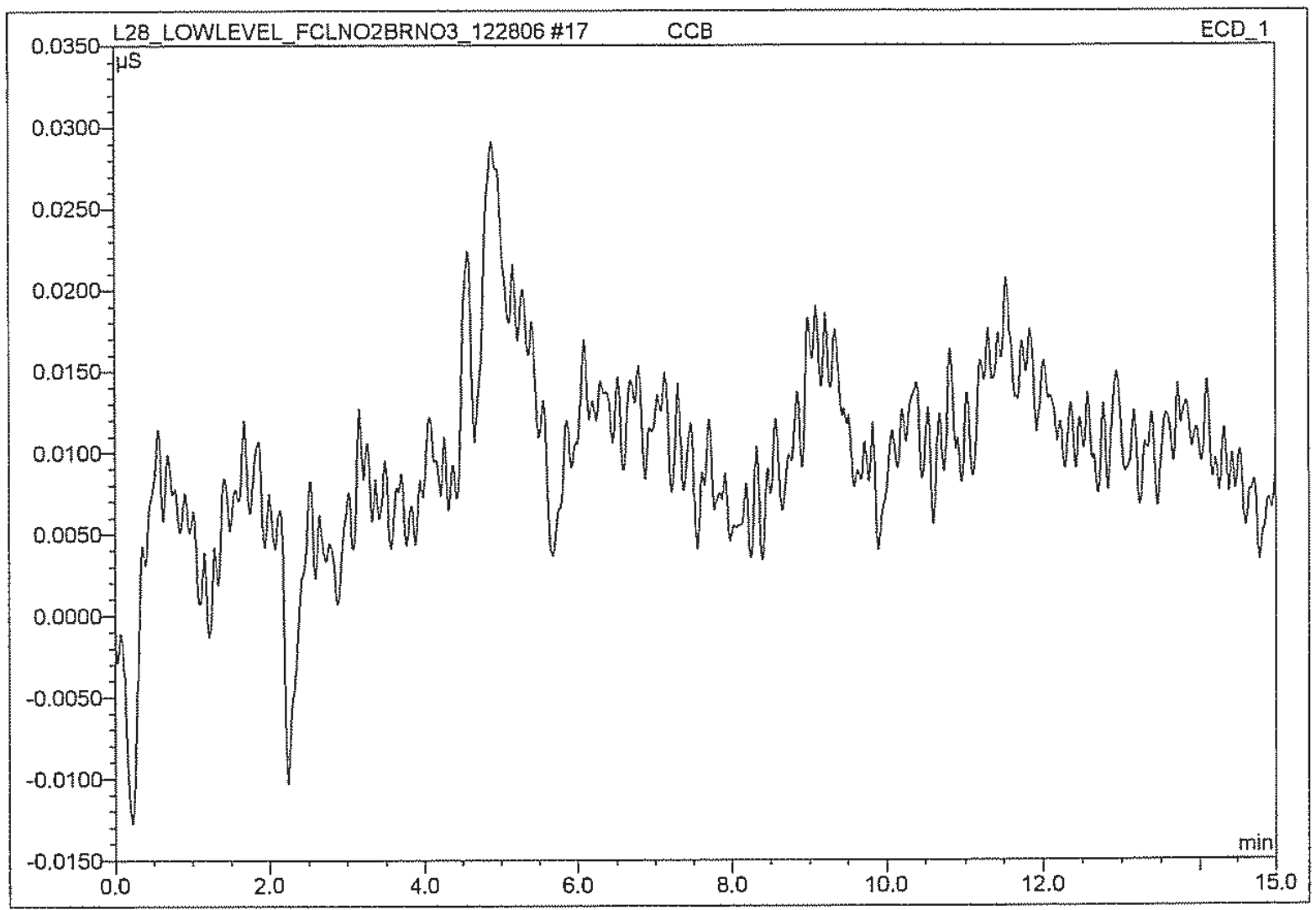

\begin{tabular}{|c|c|c|c|c|c|c|c|}
\hline No. & $\begin{array}{c}\text { Ret.Time } \\
\text { (min.) }\end{array}$ & Peak Name & $\begin{array}{c}\text { Height } \\
(\mathrm{uS})\end{array}$ & $\begin{array}{c}\text { Area } \\
\mu \mathrm{S}^{\star} \mathrm{min}\end{array}$ & $\begin{array}{c}\text { Rel.Area } \\
(\%)\end{array}$ & $\begin{array}{c}\text { Amount } \\
(\mathrm{mg} / \mathrm{L})\end{array}$ & $\begin{array}{c}\text { Peak } \\
\text { Type }\end{array}$ \\
\hline
\end{tabular}




\section{H6L110105-JK7JX-1/20}

\begin{tabular}{llll}
\hline Sample Name: & H6L110105-JK7JX-1/20 & Injection Volume: & $\mathbf{5 0 . 0}$ \\
Vial Number: & 1393 & Channel: & ECD_1 \\
Sample Type: & unknown & Wavelength: & n.a. \\
Control Program: & AS14A ANIONS METHOD & Bandwidth: & n.a. \\
Quantif. Method: & AS4A-SC ANION METHOD & Dilution Factor: & 20.0000 \\
Recording Time: & $12 / 28 / 200616: 44$ & Sample Weight: & 1.0000 \\
Run Time (min): & 15.00 & Sample Amount: & 1.0000 \\
\hline
\end{tabular}

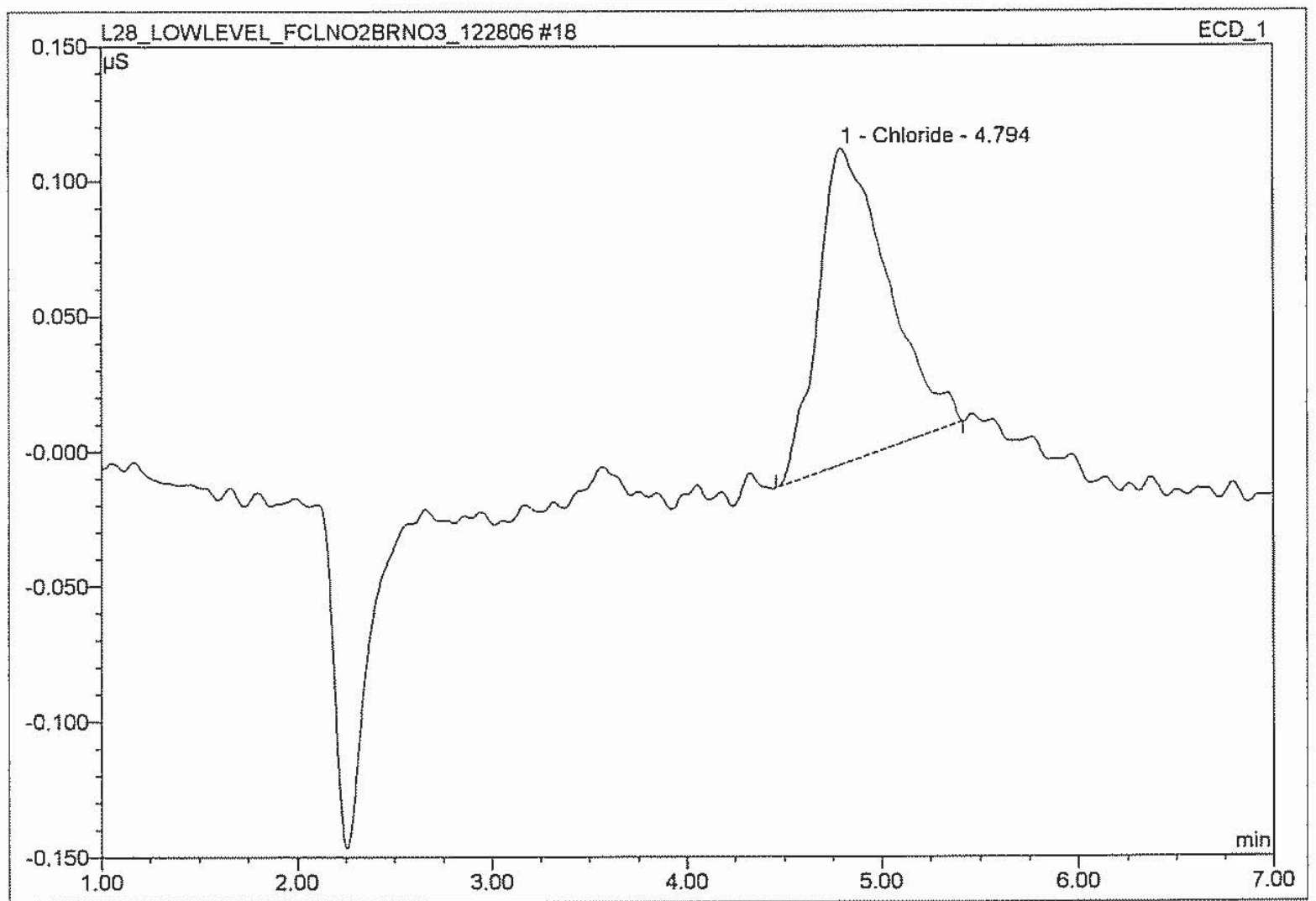

\begin{tabular}{|r|c|l|r|r|r|r|r|}
\hline No. & $\begin{array}{c}\text { Ret.Time } \\
\text { (min.) }\end{array}$ & \multicolumn{1}{|c|}{ Peak Name } & $\begin{array}{c}\text { Height } \\
(\mathbf{u S})\end{array}$ & $\begin{array}{c}\text { Area } \\
\mu S^{*} \min \end{array}$ & $\begin{array}{r}\text { Rel.Area } \\
(\%)\end{array}$ & $\begin{array}{r}\text { Amount } \\
\text { (mg/L) }\end{array}$ & $\begin{array}{r}\text { Peak } \\
\text { Type }\end{array}$ \\
\hline 1 & 4.79 & Chloride & 0.11696 & 0.048 & 0.13 & 1.0637 & BMB \\
\hline 2 & 7.33 & Nitrate-N & 0.06450 & 0.014 & 0.04 & 0.3727 & BMB \\
\hline 3 & 10.34 & n.a. & 0.08770 & 0.024 & 0.06 & n.a. & BMB \\
\hline 4 & 11.43 & n.a. & 37.681 & 99.77 & n.a. & BMB \\
\hline
\end{tabular}




\section{H6L110105-JK7JX-1/40}

\begin{tabular}{llll|}
\hline Sample Name: & H6L110105-JK7JX-1/40 & Injection Volume: & $\mathbf{5 0 . 0}$ \\
Vial Number: & $\mathbf{1 3 9 4}$ & Channel: & ECD_1 \\
Sample Type: & unknown & Wavelength: & n.a. \\
Control Program: & AS14A ANIONS METHOD & Bandwidth: & n.a. \\
Quantif. Method: & AS4A-SC ANION METHOD & Dilution Factor: & 40.0000 \\
Recording Time: & $\mathbf{1 2 / 2 8 / 2 0 0 6 1 7 : 0 1}$ & Sample Weight: & 1.0000 \\
Run Time (min): & $\mathbf{1 5 . 0 0}$ & Sample Amount: & $\mathbf{1 . 0 0 0 0}$ \\
\hline
\end{tabular}

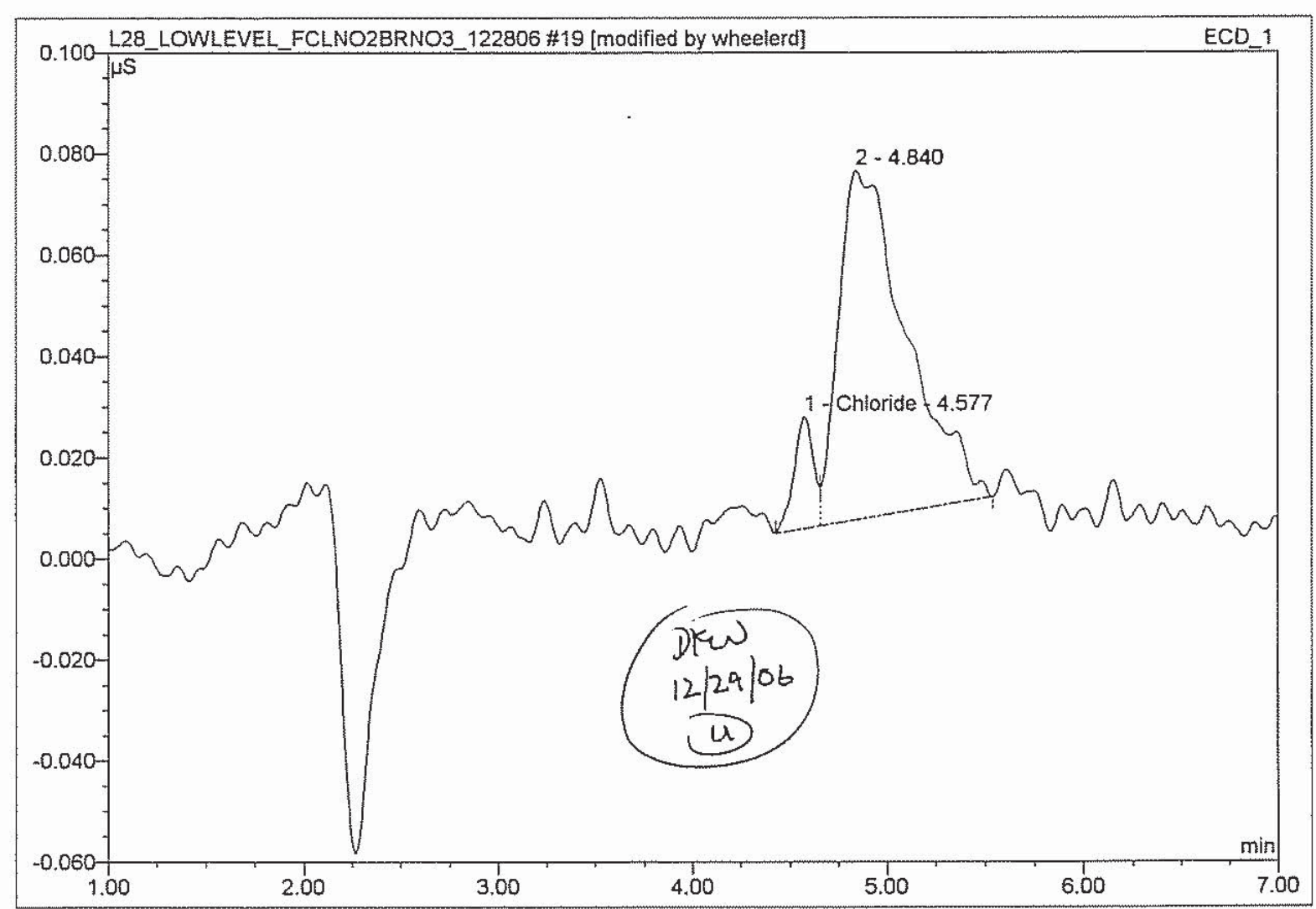

\begin{tabular}{|c|c|c|c|c|c|c|c|}
\hline No. & $\begin{array}{l}\text { Ret.Time } \\
\text { (min.) }\end{array}$ & Peak Name & $\begin{array}{l}\text { Height } \\
\text { (uS) }\end{array}$ & $\begin{array}{c}\text { Area } \\
\mu S^{\star} \min \end{array}$ & $\begin{array}{c}\text { Rel.Area } \\
(\%)\end{array}$ & $\begin{array}{l}\text { Amount } \\
\text { (mg/L) }\end{array}$ & $\begin{array}{l}\text { Peak } \\
\text { Type }\end{array}$ \\
\hline 1 & 4.58 & Chloride & 0.02208 & 0.003 & 0.01 & 0.4018 & $\mathrm{BM}^{*}$ \\
\hline 2 & 4.84 & n.a. & 0.06881 & 0.028 & 0.16 & n.a. & $M B^{*}$ \\
\hline 3 & 11.47 & n.a. & 55.60983 & 17.227 & 99.82 & n.a. & $\mathrm{BMB}$ \\
\hline
\end{tabular}




\section{H6L110105-JK7JX-1/40}

\begin{tabular}{llll|}
\hline Sample Name: & H6L110105-JK7JX-1/40 & Injection Volume: & $\mathbf{5 0 . 0}$ \\
Vial Number: & 1394 & Channel: & ECD_1 \\
Sample Type: & unknown & Wavelength: & n.a. \\
Control Program: & AS14A ANIONS METHOD & Bandwidth: & n.a. \\
Quantif. Method: & AS4A-SC ANION METHOD & Dilution Factor: & $\mathbf{4 0 . 0 0 0 0}$ \\
Recording Time: & $\mathbf{1 2 / 2 8 / 2 0 0 6 1 7 : 0 1}$ & Sample Weight: & $\mathbf{1 . 0 0 0 0}$ \\
Run Time (min): & $\mathbf{1 5 . 0 0}$ & Sample Amount: & $\mathbf{1 . 0 0 0 0}$ \\
\hline
\end{tabular}

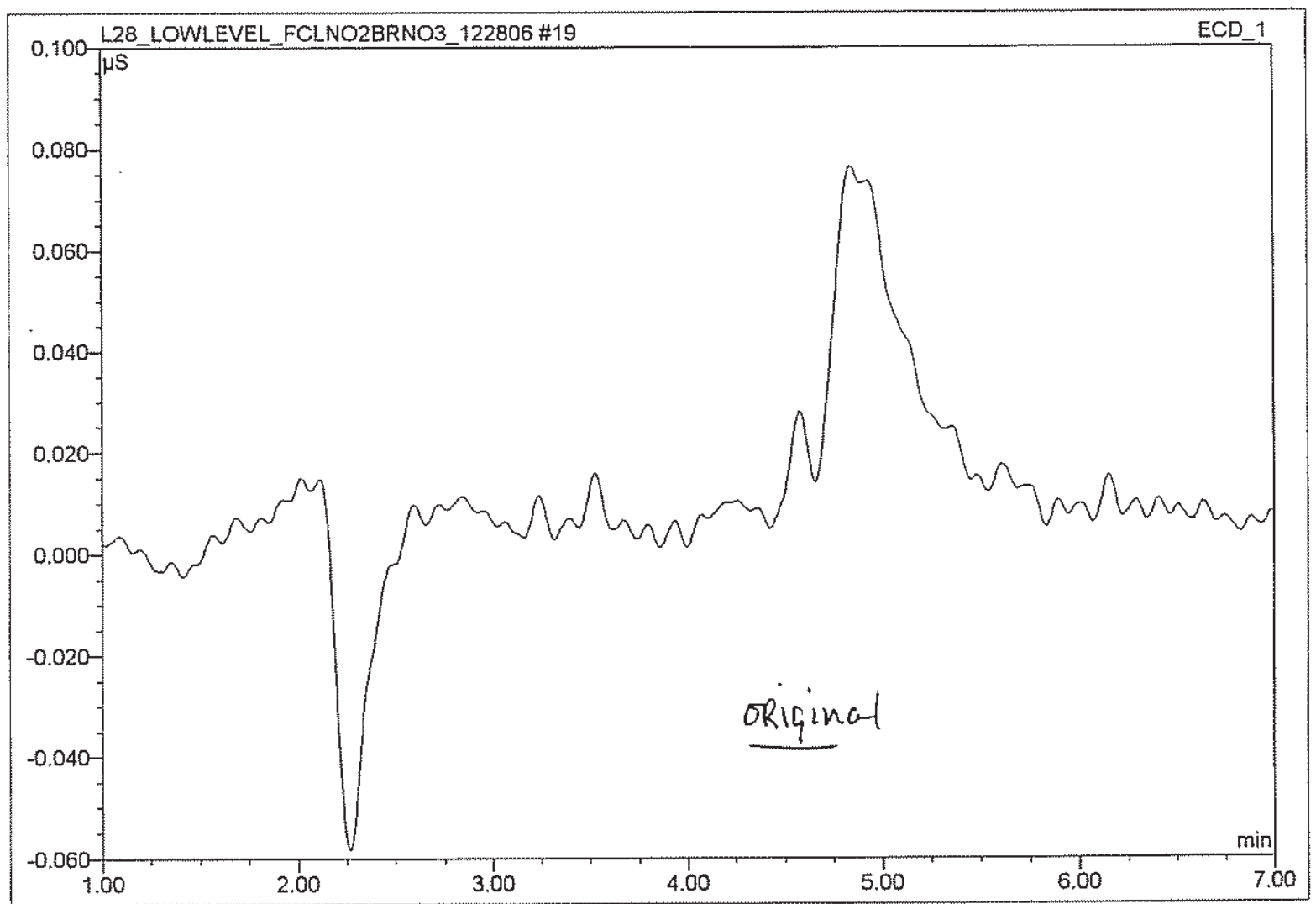

\begin{tabular}{|c|c|c|c|c|c|c|c|}
\hline No. & $\begin{array}{c}\text { Ret.Time } \\
\text { (min.) }\end{array}$ & Peak Name & $\begin{array}{c}\text { Height } \\
\text { (uS) }\end{array}$ & $\begin{array}{c}\text { Area } \\
\mu S^{*} \min \end{array}$ & $\begin{array}{c}\text { Rel.Area } \\
(\%)\end{array}$ & $\begin{array}{c}\text { Amount } \\
(\mathrm{mg} / \mathrm{L})\end{array}$ & $\begin{array}{r}\text { Peak } \\
\text { Type }\end{array}$ \\
\hline 1 & 11.47 & n.a. & 55.60983 & 17.227 & 100.00 & n.a. & BMB \\
\hline
\end{tabular}




\section{H6L110105-JK7J1-1/20}

\begin{tabular}{|llll|}
\hline Sample Name: & H6L110105-JK7J1-1/20 & Injection Volume: & $\mathbf{5 0 . 0}$ \\
Vial Number: & $\mathbf{1 3 9 5}$ & Channel: & ECD_1 \\
Sample Type: & unknown & Wavelength: & n.a. \\
Control Program: & AS14A ANIONS METHOD & Bandwidth: & n.a. \\
Quantif. Method: & AS4A-SC ANION METHOD & Dilution Factor: & $\mathbf{2 0 . 0 0 0 0}$ \\
Recording Time: & $\mathbf{1 2 / 2 8 / 2 0 0 6 ~ 1 7 : 1 9}$ & Sample Weight: & $\mathbf{1 . 0 0 0 0}$ \\
Run Time (min): & $\mathbf{1 5 . 0 0}$ & Sample Amount: & $\mathbf{1 . 0 0 0 0}$ \\
\hline
\end{tabular}

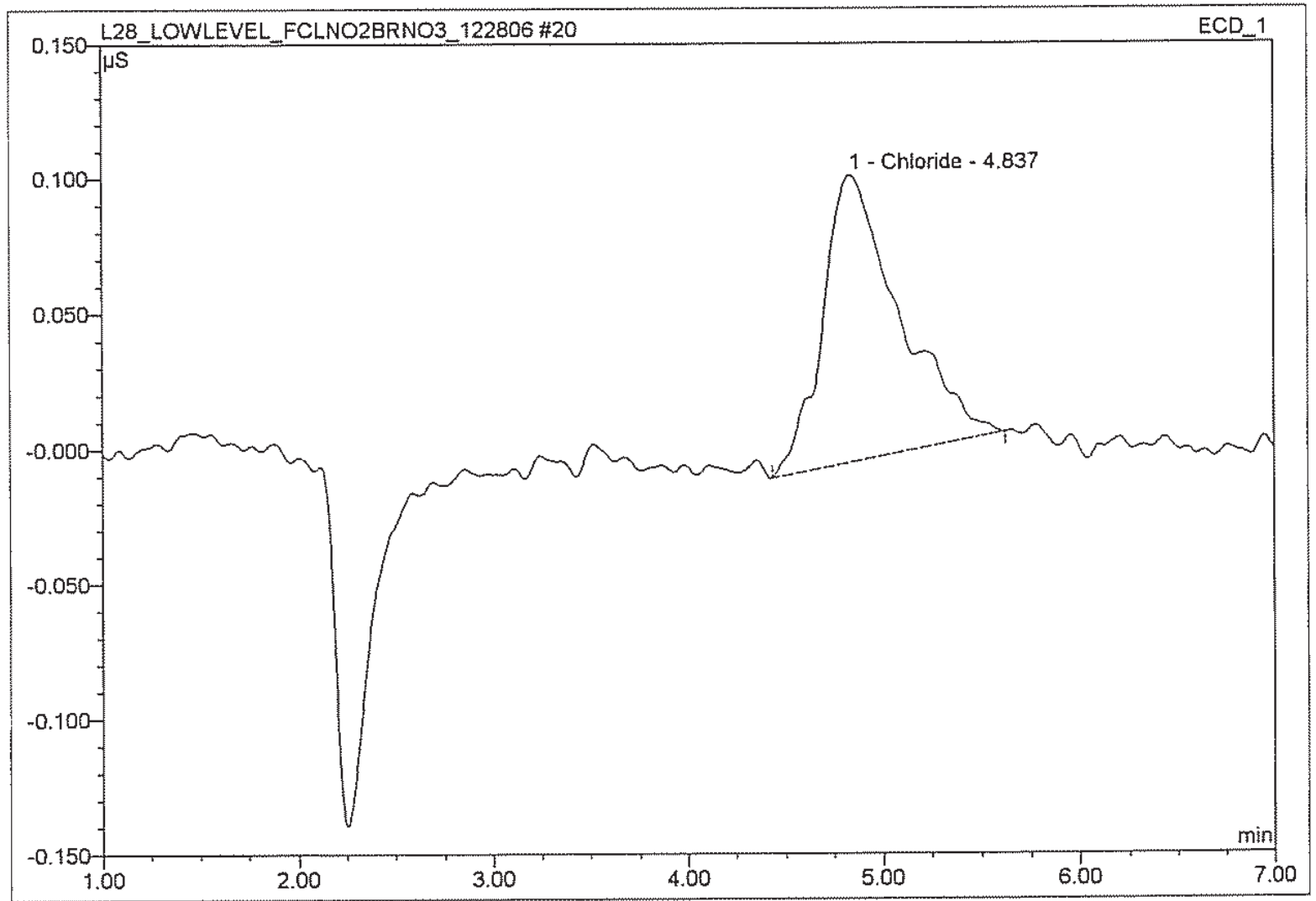

\begin{tabular}{|c|c|l|r|r|r|r|r|}
\hline No. & $\begin{array}{c}\text { Ret.Time } \\
\text { (min.) }\end{array}$ & \multicolumn{1}{|c|}{ Peak Name } & $\begin{array}{c}\text { Height } \\
\text { (uS) }\end{array}$ & $\begin{array}{c}\text { Area } \\
\mu S^{*} \min \end{array}$ & $\begin{array}{r}\text { Rel.Area } \\
(\%)\end{array}$ & $\begin{array}{c}\text { Amount } \\
(\mathrm{mg} / \mathrm{L})\end{array}$ & $\begin{array}{r}\text { Peak } \\
\text { Type }\end{array}$ \\
\hline 1 & 4.84 & Chloride & 0.10600 & 0.048 & 0.16 & 0.9641 & BMB \\
\hline 2 & 7.35 & Nitrate-N & 0.06416 & 0.015 & 0.05 & 0.3708 & BMB \\
\hline 3 & 11.44 & n.a. & 91.75063 & 29.118 & 99.78 & n.a. & BMB \\
\hline
\end{tabular}

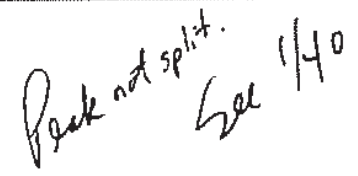




\section{H6L110105-JK7J1-1/40}

Sample Name: H6L110105-JK7J1-1/40

Vial Number: $\quad 1396$

Sample Type: $\quad$ unknown

Control Program: AS14A ANIONS METHOD

Quantif. Method: AS4A-SC ANION METHOD

Recording Time:

Run Time (min):
$12 / 28 / 200617: 36$

15.00

$\begin{array}{ll}\text { Injection Volume: } & 50.0 \\ \text { Channel: } & \text { ECD_1 } \\ \text { Wavelength: } & \text { n.a. } \\ \text { Bandwidth: } & \text { n.a. } \\ \text { Dilution Factor: } & \mathbf{4 0 . 0 0 0 0} \\ \text { Sample Weight: } & \mathbf{1 . 0 0 0 0} \\ \text { Sample Amount: } & \mathbf{1 . 0 0 0 0}\end{array}$

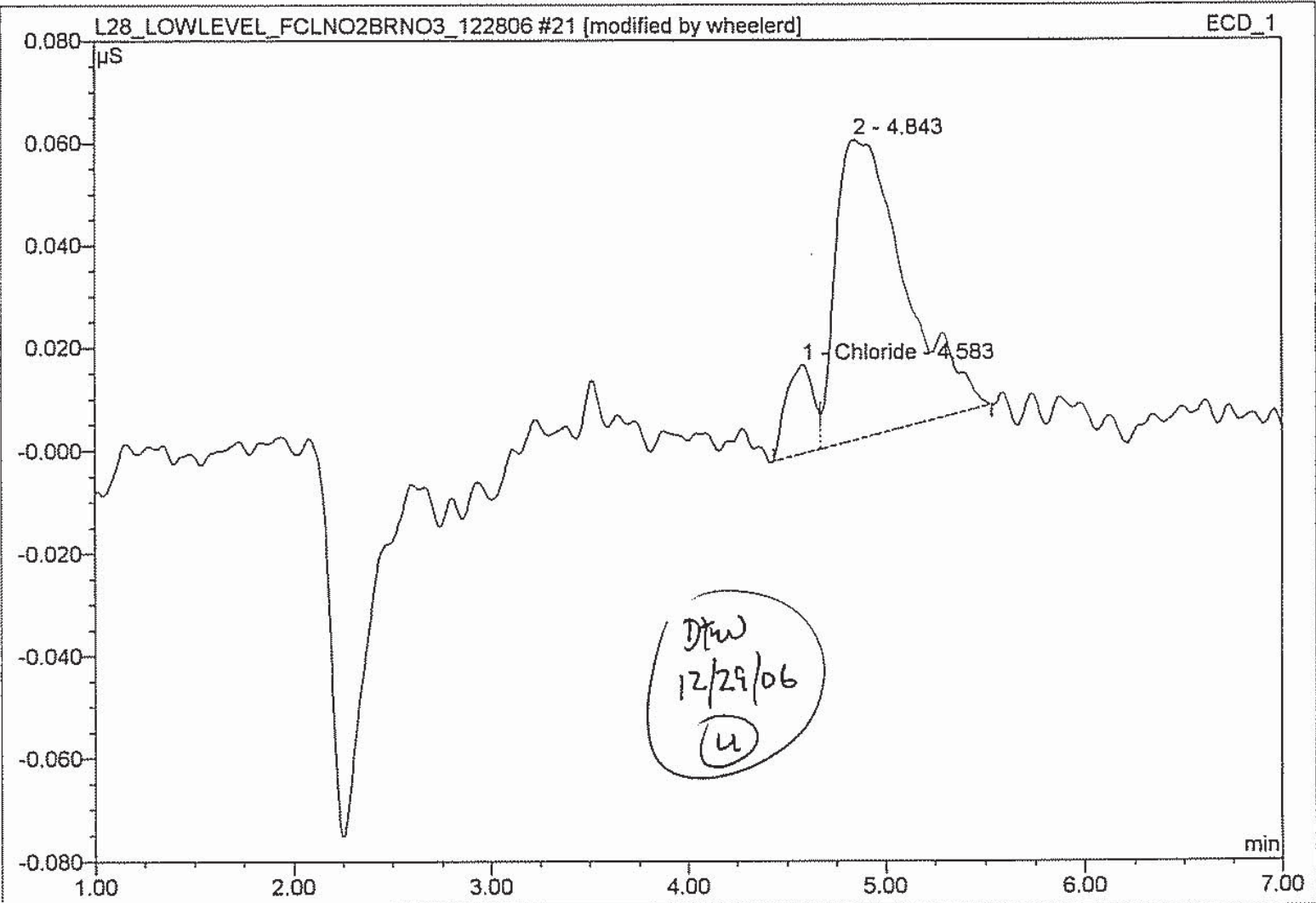

\begin{tabular}{|c|c|l|r|r|r|r|r|}
\hline No. & $\begin{array}{c}\text { Ret.Time } \\
\text { (min.) }\end{array}$ & \multicolumn{1}{|c|}{ Peak Name } & $\begin{array}{c}\text { Height } \\
\text { (uS) }\end{array}$ & $\begin{array}{c}\text { Area } \\
\mu S^{*} \min \end{array}$ & $\begin{array}{c}\text { Rel.Area } \\
(\%)\end{array}$ & $\begin{array}{c}\text { Amount } \\
(\mathrm{mg} / \mathrm{L})\end{array}$ & $\begin{array}{r}\text { Peak } \\
\text { Type }\end{array}$ \\
\hline 1 & 4.58 & Chloride & 0.01719 & 0.003 & 0.02 & 0.3128 & $\mathrm{BM}^{*}$ \\
\hline 2 & 4.84 & n.a. & 0.05852 & 0.023 & 0.18 & n.a. & $\mathrm{MB}^{*}$ \\
\hline 3 & 11.49 & n.a. & 43.00368 & 13.267 & 99.80 & n.a. & $\mathrm{BMB}^{\mathrm{B}}$ \\
\hline
\end{tabular}




\section{H6L110105-JK7J1-1/40}

\section{Sample Name:}

Vial Number:

Sample Type: Control Program: Quantif. Method: Recording Time: Run Time (min):

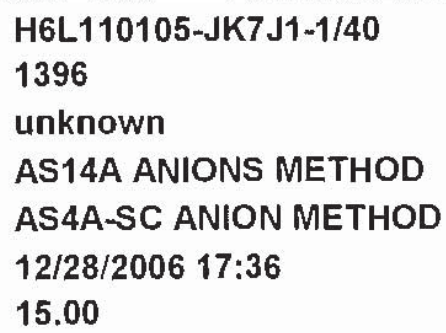

$\begin{array}{ll}\text { Injection Volume: } & \mathbf{5 0 . 0} \\ \text { Channel: } & \text { ECD_1 } \\ \text { Wavelength: } & \text { n.a. } \\ \text { Bandwidth: } & \text { n.a. } \\ \text { Dilution Factor: } & \mathbf{4 0 . 0 0 0 0} \\ \text { Sample Weight: } & \mathbf{1 . 0 0 0 0} \\ \text { Sample Amount: } & \mathbf{1 . 0 0 0 0}\end{array}$

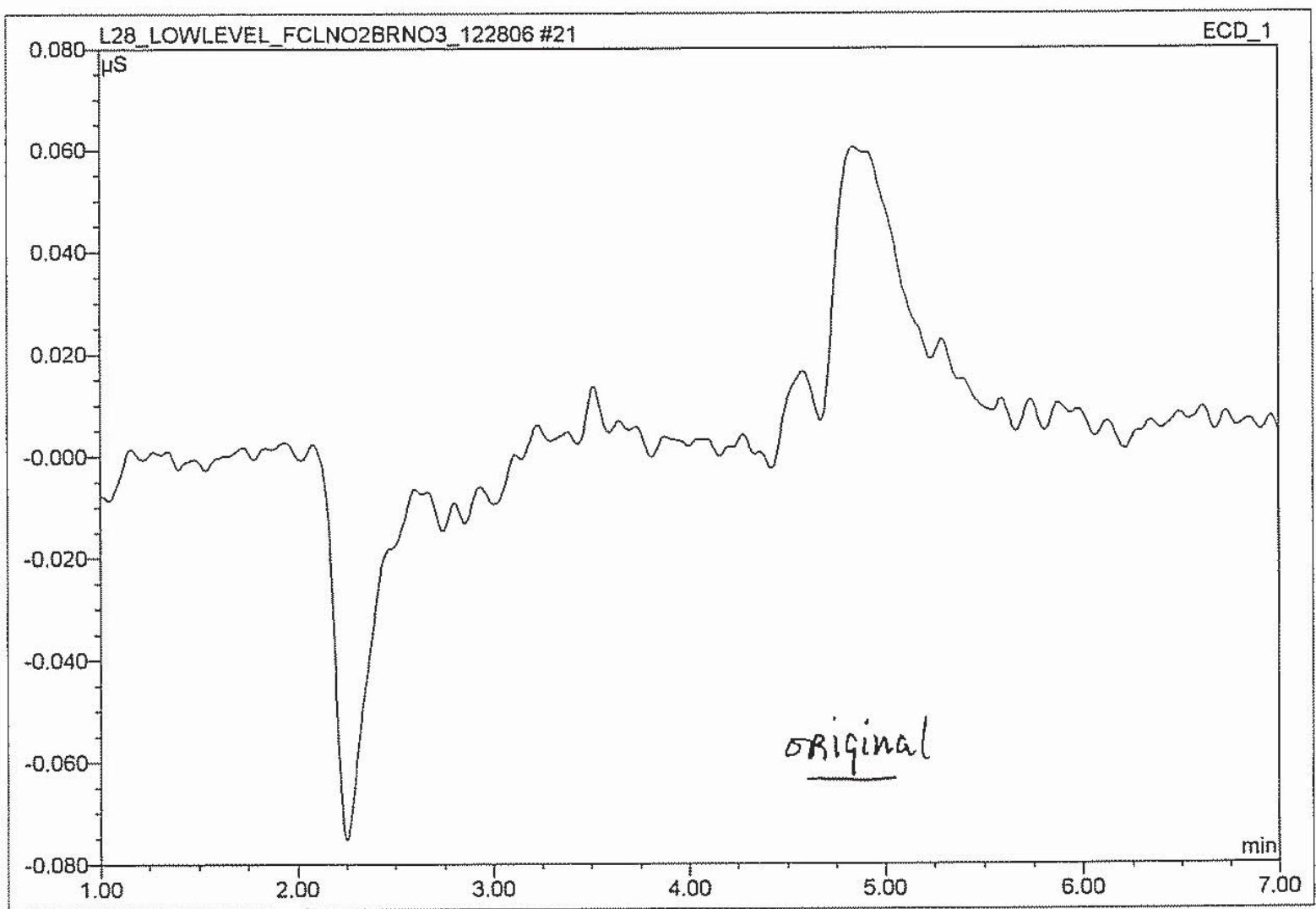

\begin{tabular}{|c|c|c|c|c|c|c|c|}
\hline No. & $\begin{array}{c}\text { Ret.Time } \\
\text { (min.) }\end{array}$ & Peak Name & $\begin{array}{c}\text { Height } \\
(\mathrm{uS})\end{array}$ & $\begin{array}{c}\text { Area } \\
\mu S^{\star} \mathrm{min}\end{array}$ & $\begin{array}{c}\text { Rel.Area } \\
(\%)\end{array}$ & $\begin{array}{c}\text { Amount } \\
(\mathrm{mg} / \mathrm{L})\end{array}$ & $\begin{array}{c}\text { Peak } \\
\text { Type }\end{array}$ \\
\hline 1 & 11.49 & n.a. & 43.00368 & 13.267 & 100.00 & n.a. & BMB \\
\hline
\end{tabular}




\section{$26 \mathrm{CCV}=\mathrm{ICWS}-9090$}

\begin{tabular}{llll|}
\hline Sample Name: & CCV=ICWS-9090 & Injection Volume: & $\mathbf{5 0 . 0}$ \\
Vial Number: & 1401 & Channel: & ECD_1 \\
Sample Type: & unknown & Wavelength: & n.a. \\
Control Program: & AS14A ANIONS METHOD & Bandwidth: & n.a. \\
Quantif. Method: & AS4A-SC ANION METHOD & Dilution Factor: & 1.0000 \\
Recording Time: & $12 / 28 / 200619: 03$ & Sample Weight: & 1.0000 \\
Run Time (min): & 15.00 & Sample Amount: & 1.0000 \\
\hline
\end{tabular}

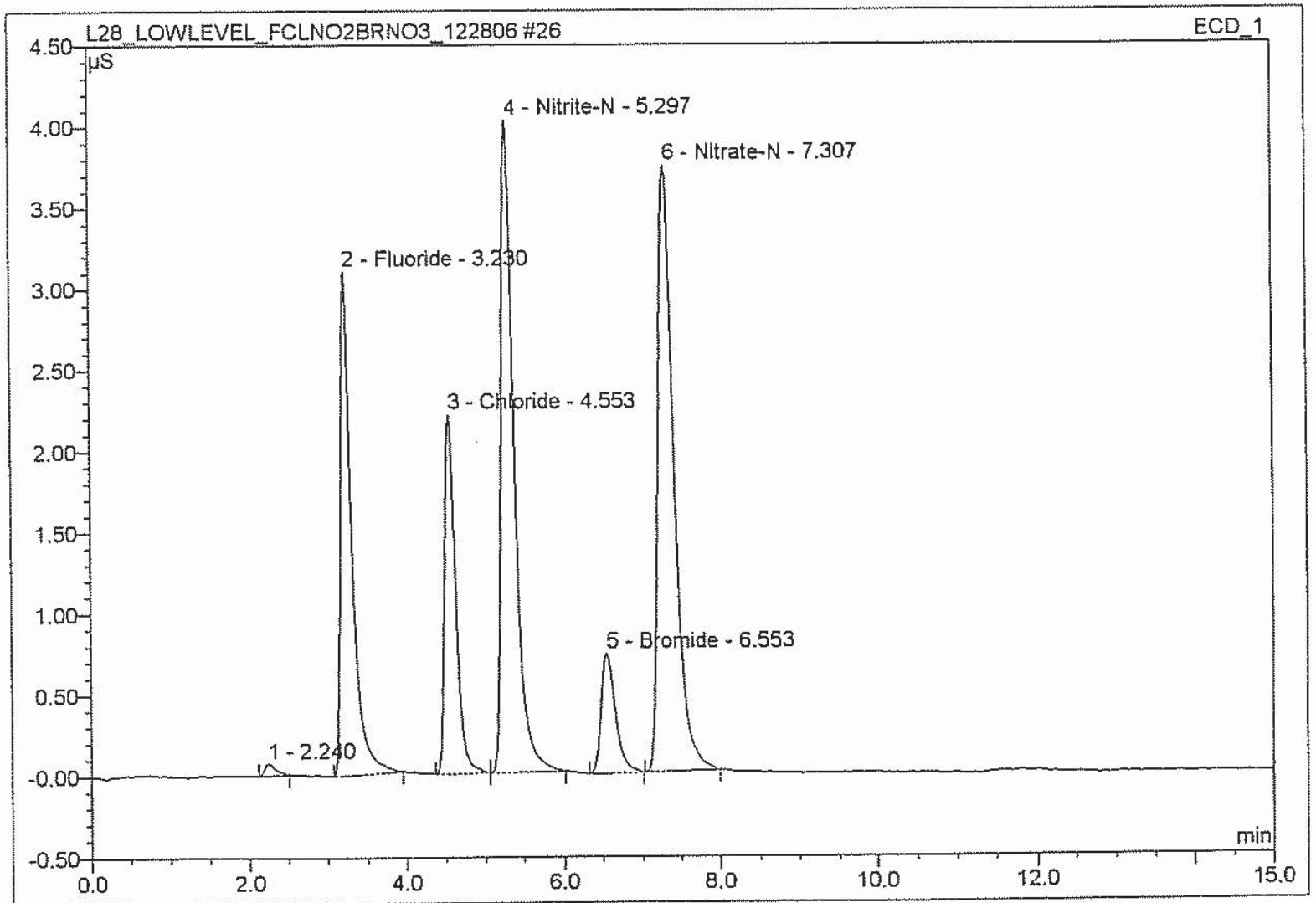

\begin{tabular}{|c|c|l|r|r|r|r|c|}
\hline No. & $\begin{array}{c}\text { Ret.Time } \\
\text { (min.) }\end{array}$ & \multicolumn{1}{|c|}{ Peak Name } & $\begin{array}{c}\text { Height } \\
(\mathbf{u S})\end{array}$ & $\begin{array}{c}\text { Area } \\
\mu S^{\star} \text { min }\end{array}$ & $\begin{array}{r}\text { Rel.Area } \\
(\%)\end{array}$ & $\begin{array}{r}\text { Amount } \\
(\mathrm{mg} / \mathrm{L})\end{array}$ & $\begin{array}{r}\text { Peak } \\
\text { Type }\end{array}$ \\
\hline 1 & 2.24 & n.a. & 0.07266 & 0.013 & 0.48 & n.a. & BMB \\
\hline 2 & 3.23 & Fluoride & 3.10205 & 0.520 & 19.26 & 1.0624 & BMB \\
\hline 3 & 4.55 & Chloride & 2.21173 & 0.358 & 13.26 & 0.9915 & BM \\
\hline 4 & 5.30 & Nitrite-N & 4.02336 & 0.768 & 28.45 & 1.0225 & MB \\
\hline 5 & 6.55 & Bromide & 0.73552 & 0.155 & 5.74 & 1.0291 & BMB \\
\hline 6 & 7.31 & Nitrate-N & 3.73776 & 0.886 & 32.82 & 1.0260 & BMB \\
\hline
\end{tabular}




\section{CCB}

\begin{tabular}{llll|}
\hline Sample Name: & CCB & Injection Volume: & $\mathbf{5 0 . 0}$ \\
Vial Number: & 1402 & Channel: & ECD_1 \\
Sample Type: & unknown & Wavelength: & n.a. \\
Control Program: & AS14A ANIONS METHOD & Bandwidth: & n.a. \\
Quantif. Method: & AS4A-SC ANION METHOD & Dilution Factor: & 1.0000 \\
Recording Time: & $12 / 28 / 200619: 20$ & Sample Weight: & 1.0000 \\
Run Time (min): & 15.00 & Sample Amount: & 1.0000 \\
\hline
\end{tabular}

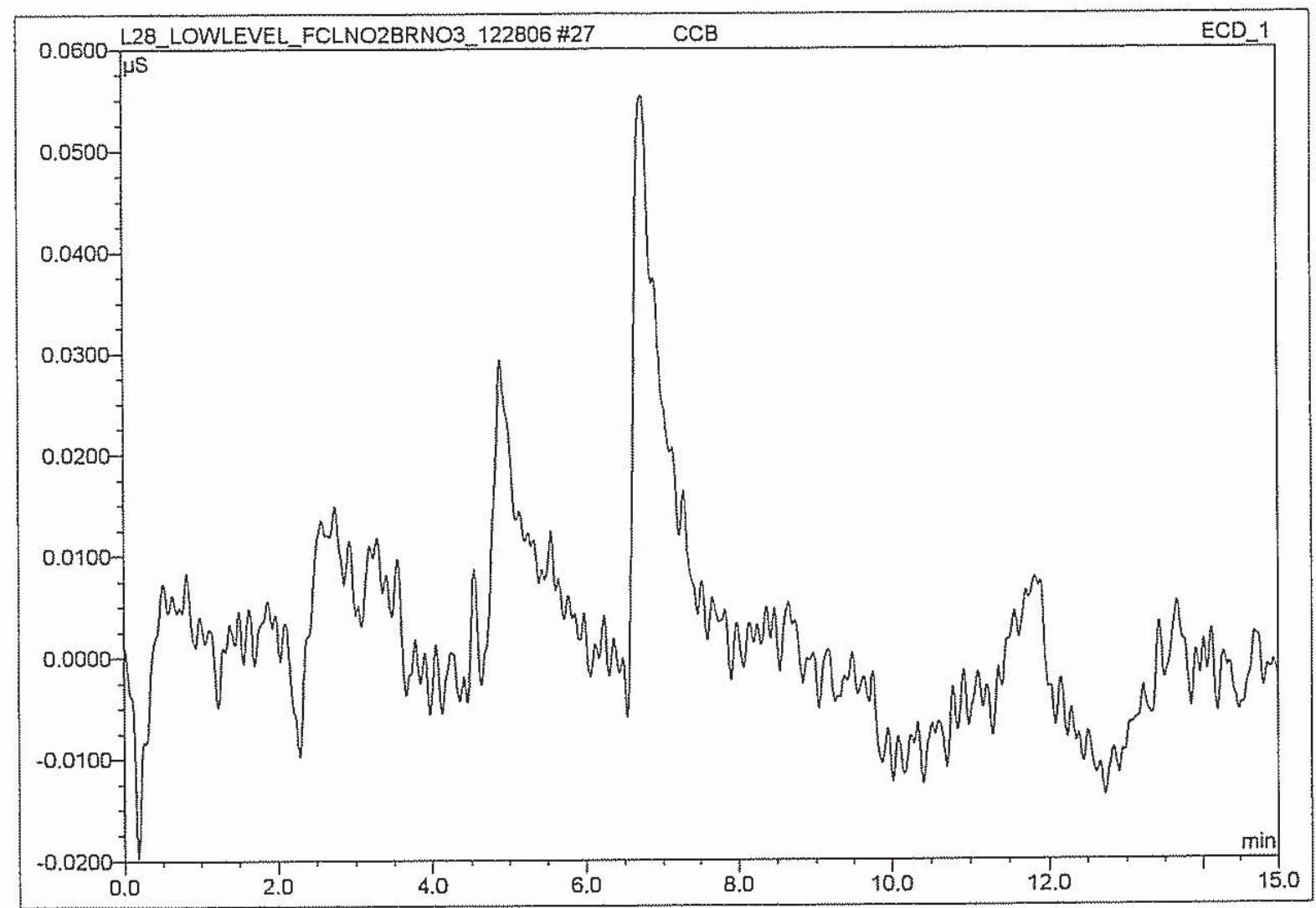

\begin{tabular}{|c|c|c|c|c|c|c|c|}
\hline No. & $\begin{array}{c}\text { Ret.Time } \\
\text { (min.) }\end{array}$ & Peak Name & $\begin{array}{c}\text { Height } \\
\text { (uS) }\end{array}$ & $\begin{array}{c}\text { Area } \\
\mu S^{*} \min \end{array}$ & $\begin{array}{c}\text { Rel.Area } \\
(\%)\end{array}$ & $\begin{array}{c}\text { Amount } \\
(\mathrm{mg} / \mathrm{L})\end{array}$ & $\begin{array}{c}\text { Peak } \\
\text { Type }\end{array}$ \\
\hline
\end{tabular}

(ND) 


\section{H6L110105-JK7JX-1/20-MS@0.2ppm Cl}

Sample Name:

Vial Number:

Sample Type:

Control Program:

Quantif. Method:

Recording Time:

Run Time ( $\mathrm{min})$ :
H6L110105-JK7JX-1/20-MS@0.2ppm Cl

1403

unknown

AS14A ANIONS METHOD

AS4A-SC ANION METHOD

12/28/2006 19:38

15.00
Injection Volume:

Channel:

Wavelength:

Bandwidth:

Dilution Factor:

Sample Weight:

Sample Amount:
50.0

ECD_1

n.a.

n.a.

20.0000

1.0000

1.0000

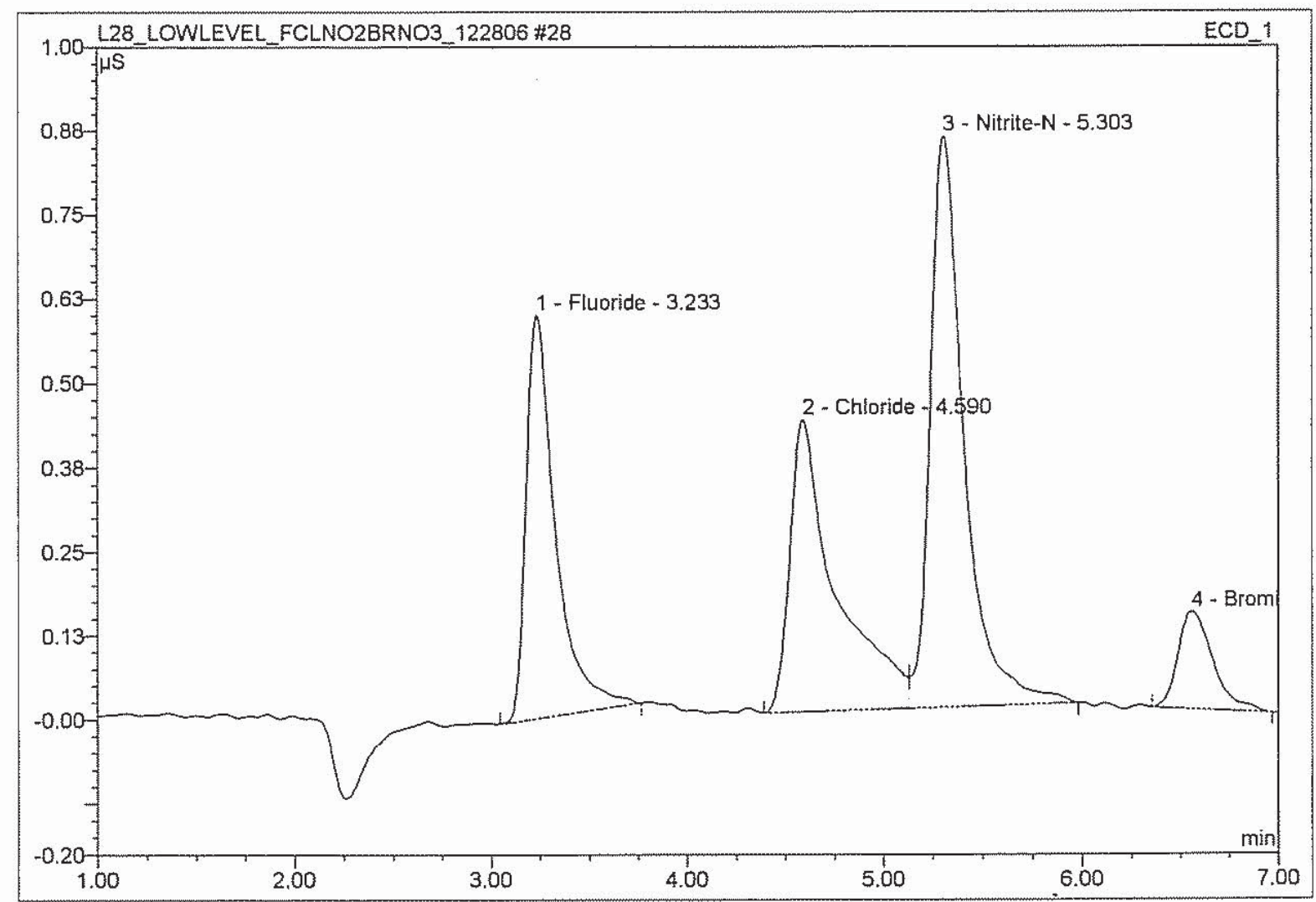

\begin{tabular}{|c|c|l|r|r|r|r|c|}
\hline No. & $\begin{array}{c}\text { Ret.Time } \\
\text { (min.) }\end{array}$ & \multicolumn{1}{|c|}{ Peak Name } & $\begin{array}{c}\text { Height } \\
\text { (uS) }\end{array}$ & $\begin{array}{c}\text { Area } \\
\mu S^{*} \text { min }\end{array}$ & $\begin{array}{c}\text { Rel.Area } \\
(\%)\end{array}$ & $\begin{array}{c}\text { Amount } \\
\text { (mg/L) }\end{array}$ & $\begin{array}{r}\text { Peak } \\
\text { Type }\end{array}$ \\
\hline 1 & 3.23 & Fluoride & 0.59844 & 0.105 & 0.27 & 4.3741 & BMB \\
\hline 2 & 4.59 & Chloride & 0.43381 & 0.118 & 0.31 & 3.9367 & BM \\
\hline 3 & 5.30 & Nitrite-N & 0.84863 & 0.169 & 0.44 & 4.4313 & MB \\
\hline 4 & 6.56 & Bromide & 0.14527 & 0.030 & 0.08 & 4.0922 & BMB \\
\hline 5 & 7.33 & Nitrate-N & 0.80123 & 0.191 & 0.50 & 4.5796 & BMB \\
\hline 6 & 10.33 & n.a. & 0.08327 & 0.025 & 0.06 & n.a. & BMB \\
\hline 7 & 11.43 & n.a. & 37.595 & 98.33 & n.a. & BMB \\
\hline
\end{tabular}




\section{H6L-110105-JK7JX-1/20-MSD@0.2ppm Cl}

\begin{tabular}{|llll|}
\hline Sample Name: & H6L110105-JK7JX-1/20-MSD@0.2ppm Cl & Injection Volume: & $\mathbf{5 0 . 0}$ \\
Vial Number: & $\mathbf{1 4 0 4}$ & Channel: & ECD_1 \\
Sample Type: & unknown & Wavelength: & n.a. \\
Control Program: & AS14A ANIONS METHOD & Bandwidth: & n.a. \\
Quantif. Method: & AS4A-SC ANION METHOD & Dilution Factor: & $\mathbf{2 0 . 0 0 0 0}$ \\
Recording Time: & $\mathbf{1 2 / 2 8 / 2 0 0 6 \text { 19:55 }}$ & Sample Weight: & $\mathbf{1 . 0 0 0 0}$ \\
Run Time (min): & $\mathbf{1 5 . 0 0}$ & Sample Amount: & $\mathbf{1 . 0 0 0 0}$ \\
\hline
\end{tabular}

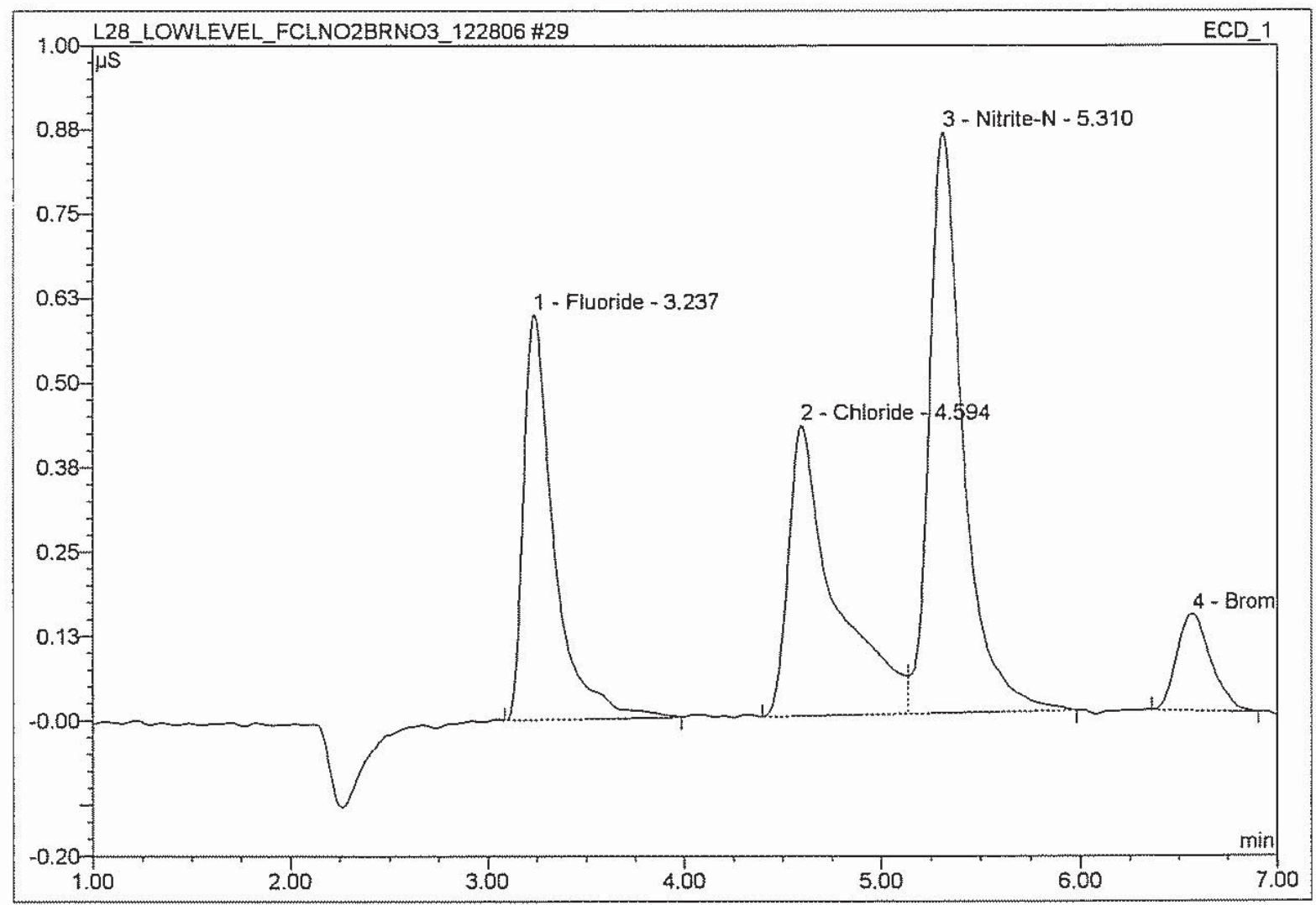

\begin{tabular}{|c|c|l|r|r|r|r|c|}
\hline No. & $\begin{array}{c}\text { Ret.Time } \\
\text { (min.) }\end{array}$ & \multicolumn{1}{|c|}{ Peak Name } & $\begin{array}{c}\text { Height } \\
\text { (uS) }\end{array}$ & $\begin{array}{c}\text { Area } \\
\mu S^{*} \text { min }\end{array}$ & $\begin{array}{c}\text { Rel.Area } \\
(\%)\end{array}$ & $\begin{array}{c}\text { Amount } \\
\text { (mg/L) }\end{array}$ & $\begin{array}{r}\text { Peak } \\
\text { Type }\end{array}$ \\
\hline 1 & 3.24 & Fluoride & 0.59858 & 0.107 & 0.28 & 4.3750 & BMB \\
\hline 2 & 4.59 & Chloride & 0.42985 & 0.118 & 0.31 & 3.9008 & BM \\
\hline 3 & 5.31 & Nitrite-N & 0.86030 & 0.171 & 0.45 & 4.4918 & MB \\
\hline 4 & 6.56 & Bromide & 0.14284 & 0.028 & 0.07 & 4.0240 & BMB \\
\hline 5 & 7.33 & Nitrate-N & 0.79967 & 0.191 & 0.50 & 4.5709 & BMB \\
\hline 6 & 10.34 & n.a. & 0.08231 & 0.024 & 0.06 & n.a. & BMB \\
\hline 7 & 11.44 & n.a. & 37.550 & 98.33 & n.a. & BMB \\
\hline
\end{tabular}




\section{H6L110105-JK7JX-1/40-MS@0.2ppm Cl}

\begin{tabular}{llll}
\hline Sample Name: & H6L110105-JK7JX-1/40-MS@0.2ppm Cl & Injection Volume: & $\mathbf{5 0 . 0}$ \\
Vial Number: & $\mathbf{1 4 0 5}$ & Channel: & ECD_1 \\
Sample Type: & unknown & Wavelength: & n.a. \\
Control Program: & AS14A ANIONS METHOD & Bandwidth: & n.a. \\
Quantif. Method: & AS4A-SC ANION METHOD & Dilution Factor: & 40.0000 \\
Recording Time: & $\mathbf{1 2 / 2 8 / 2 0 0 6 ~ 2 0 : 1 3}$ & Sample Weight: & $\mathbf{1 . 0 0 0 0}$ \\
Run Time (min): & $\mathbf{1 5 . 0 0}$ & Sample Amount: & $\mathbf{1 . 0 0 0 0}$ \\
\hline
\end{tabular}

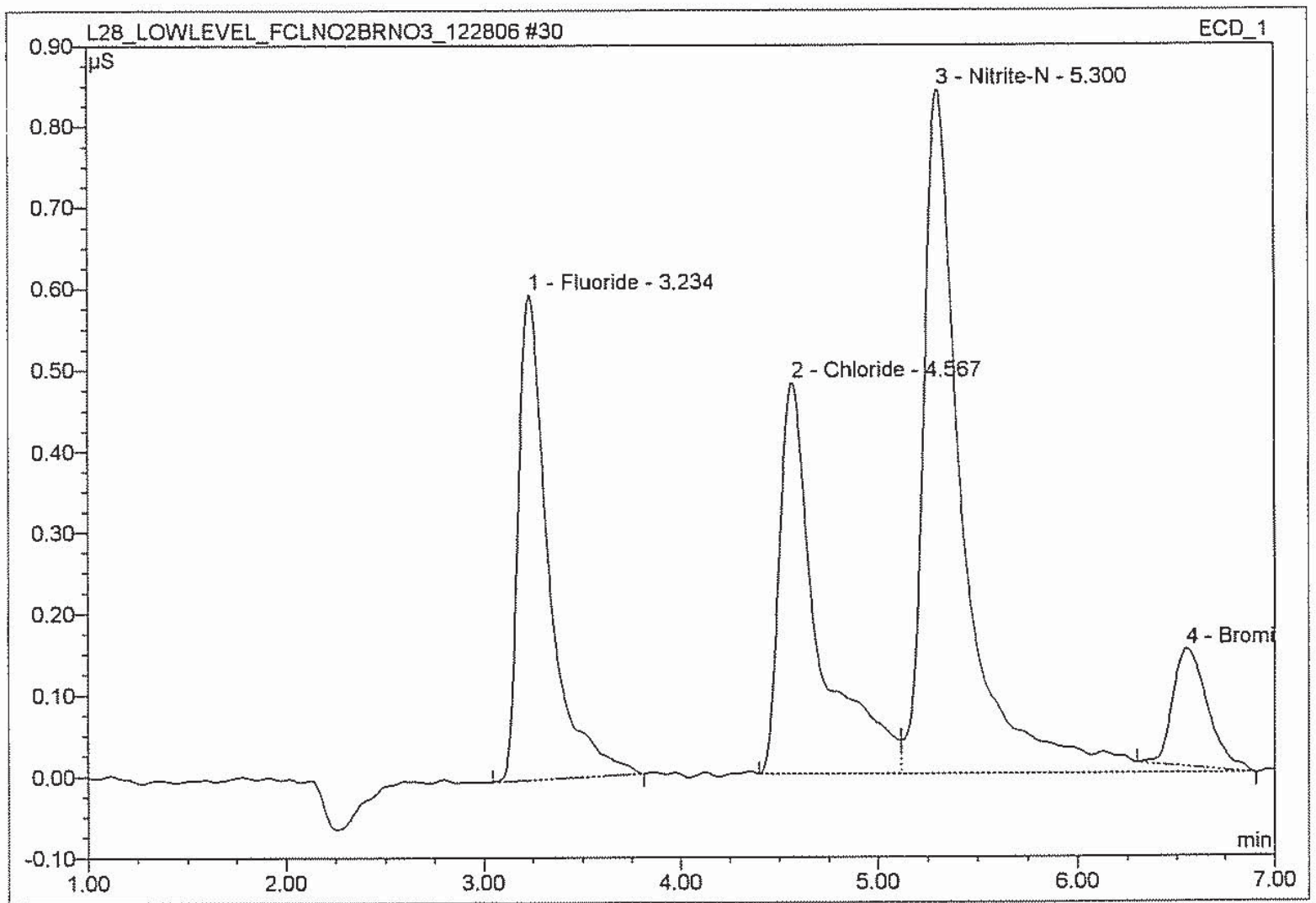

\begin{tabular}{|c|c|l|r|r|r|r|c|}
\hline No. & $\begin{array}{c}\text { Ret.Time } \\
\text { (min.) }\end{array}$ & \multicolumn{1}{|c|}{ Peak Name } & $\begin{array}{c}\text { Height } \\
\text { (uS) }\end{array}$ & $\begin{array}{c}\text { Area } \\
\mu S^{\star} \mathrm{min}\end{array}$ & $\begin{array}{c}\text { Rel.Area } \\
(\%)\end{array}$ & $\begin{array}{c}\text { Amount } \\
\text { (mg/L) }\end{array}$ & $\begin{array}{c}\text { Peak } \\
\text { Type }\end{array}$ \\
\hline 1 & 3.23 & Fluoride & 0.59636 & 0.107 & 0.60 & 8.7182 & $\mathrm{BMB}$ \\
\hline 2 & 4.57 & Chloride & 0.48090 & 0.110 & 0.62 & 8.7252 & $\mathrm{BM}$ \\
\hline 3 & 5.30 & Nitrite-N & 0.84211 & 0.196 & 1.10 & 8.7951 & $\mathrm{MB}$ \\
\hline 4 & 6.55 & Bromide & 0.14384 & 0.030 & 0.17 & 8.1041 & Rd \\
\hline 5 & 7.32 & Nitrate-N & 0.76578 & 0.183 & 1.03 & 8.7586 & BMB \\
\hline 6 & 11.48 & n.a. & 55.30554 & 17.095 & 96.47 & n.a. & BMB \\
\hline
\end{tabular}




\section{H6L110105-JK7JX-1/40-MSD@0.2ppm Cl}

\begin{tabular}{llll|}
\hline Sample Name: & H6L110105-JK7JX-1/40-MSD@0.2ppm Cl & Injection Volume: & $\mathbf{5 0 . 0}$ \\
Vial Number: & 1406 & Channel: & ECD_1 \\
Sample Type: & unknown & Wavelength: & n.a. \\
Control Program: & AS14A ANIONS METHOD & Bandwidth: & n.a. \\
Quantif. Method: & AS4A-SC ANION METHOD & Dilution Factor: & $\mathbf{4 0 . 0 0 0 0}$ \\
Recording Time: & $\mathbf{1 2 / 2 8 / 2 0 0 6 ~ 2 0 : 3 0}$ & Sample Weight: & $\mathbf{1 . 0 0 0 0}$ \\
Run Time (min): & $\mathbf{1 5 . 0 0}$ & Sample Amount: & $\mathbf{1 . 0 0 0 0}$ \\
\hline
\end{tabular}

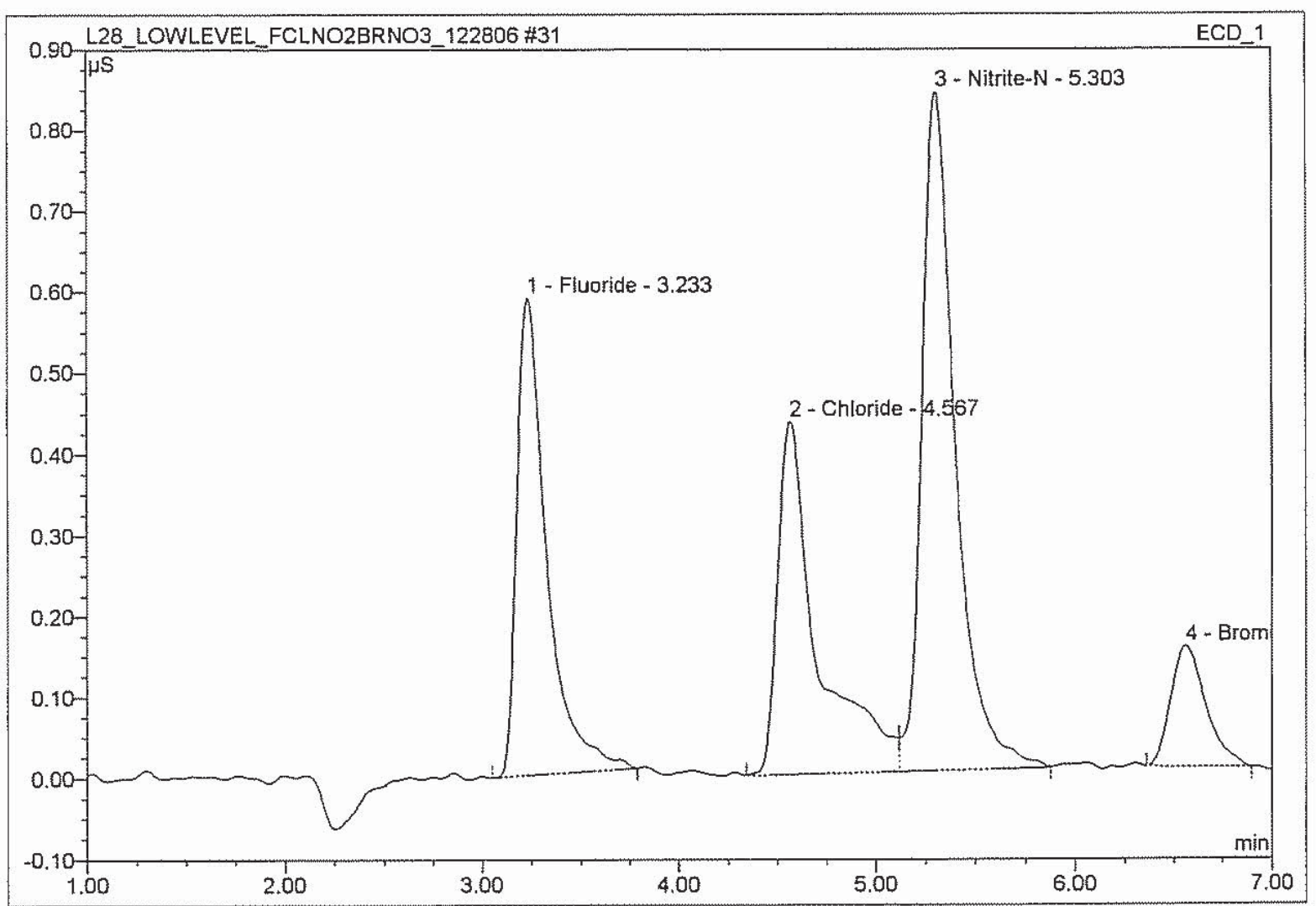

\begin{tabular}{|c|c|l|r|r|r|r|c|}
\hline No. & $\begin{array}{c}\text { Ret.Time } \\
\text { (min.) }\end{array}$ & \multicolumn{1}{|c|}{ Peak Name } & $\begin{array}{c}\text { Height } \\
(\mathbf{u S})\end{array}$ & $\begin{array}{c}\text { Area } \\
\mu S^{*} \text { min }\end{array}$ & $\begin{array}{c}\text { Rel.Area } \\
(\%)\end{array}$ & $\begin{array}{c}\text { Amount } \\
\text { (mg/L) }\end{array}$ & $\begin{array}{c}\text { Peak } \\
\text { Type }\end{array}$ \\
\hline 1 & 3.23 & Fluoride & 0.58874 & 0.103 & 0.58 & 8.6087 & BMB \\
\hline 2 & 4.57 & Chloride & 0.43521 & 0.102 & 0.58 & 7.8986 & BM \\
\hline 3 & 5.30 & Nitrite-N & 0.83691 & 0.163 & 0.92 & 8.7411 & MB \\
\hline 4 & 6.56 & Bromide & 0.14881 & 0.031 & 0.17 & 8.3841 & BMB \\
\hline 5 & 7.33 & Nitrate-N & 0.76523 & 0.185 & 1.04 & 8.7524 & BMB \\
\hline 6 & 11.48 & n.a. & 55.36865 & 17.161 & 96.70 & n.a. & BMB \\
\hline
\end{tabular}




\section{CCV $=$ ICWS -9090}

\begin{tabular}{llll}
\hline Sample Name: & CCV=ICWS-9090 & Injection Volume: & $\mathbf{5 0 . 0}$ \\
Vial Number: & 1407 & Channel: & ECD_1 \\
Sample Type: & unknown & Wavelength: & n.a. \\
Control Program: & AS14A ANIONS METHOD & Bandwidth: & n.a. \\
Quantif. Method: & AS4A-SC ANION METHOD & Dilution Factor: & 1.0000 \\
Recording Time: & $12 / 28 / 200620: 47$ & Sample Weight: & 1.0000 \\
Run Time (min): & $\mathbf{1 5 . 0 0}$ & Sample Amount: & $\mathbf{1 . 0 0 0 0}$ \\
\hline
\end{tabular}

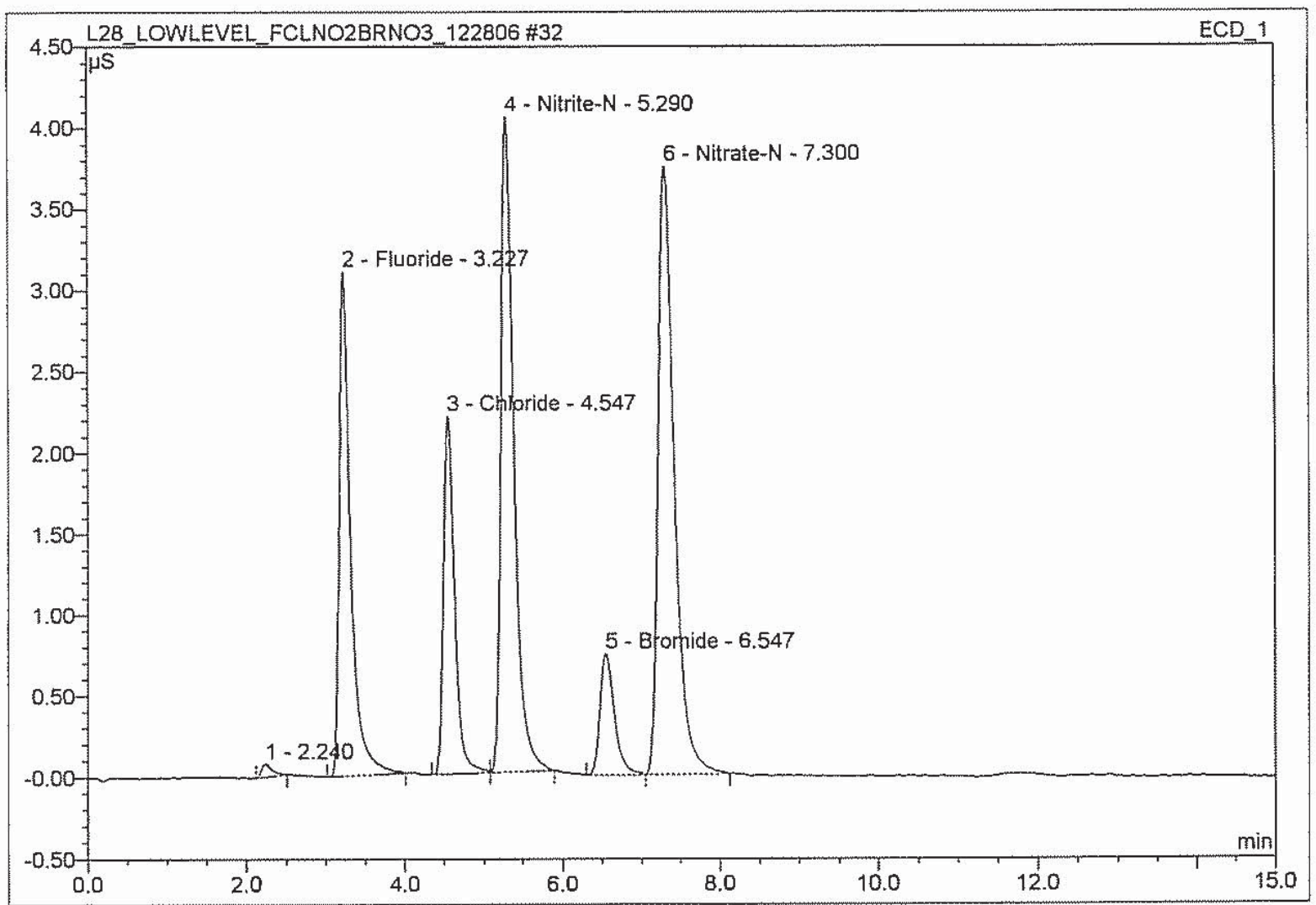

\begin{tabular}{|c|c|l|r|r|r|r|c|}
\hline No. & $\begin{array}{c}\text { Ret.Time } \\
\text { (min.) }\end{array}$ & \multicolumn{1}{|c|}{ Peak Name } & $\begin{array}{c}\text { Height } \\
(\mathbf{u S})\end{array}$ & $\begin{array}{c}\text { Area } \\
\mu \mathbf{S}^{*} \mathrm{~min}\end{array}$ & $\begin{array}{c}\text { Rel.Area } \\
(\%)\end{array}$ & $\begin{array}{c}\text { Amount } \\
(\mathrm{mg} / \mathrm{L})\end{array}$ & $\begin{array}{r}\text { Peak } \\
\text { Type }\end{array}$ \\
\hline 1 & 2.24 & n.a. & 0.07895 & 0.012 & 0.46 & n.a. & $\mathrm{BMB}$ \\
\hline 2 & 3.23 & Fluoride & 3.10738 & 0.524 & 19.32 & 1.0641 & $\mathrm{BMB}$ \\
\hline 3 & 4.55 & Chloride & 2.20398 & 0.361 & 13.32 & 0.9881 & $\mathrm{BM}$ \\
\hline 4 & 5.29 & Nitrite-N & 4.04019 & 0.762 & 28.10 & 1.0266 & $\mathrm{MB}$ \\
\hline 5 & 6.55 & Bromide & 0.74338 & 0.158 & 5.82 & 1.0400 & $\mathrm{Ru}$ \\
\hline 6 & 7.30 & Nitrate-N & 3.74585 & 0.894 & 32.97 & 1.0281 & $\mathrm{BMB}$ \\
\hline
\end{tabular}




\section{$33 \mathrm{CCB}$}

\section{Sample Name: $\quad \mathrm{CCB}$ \\ Vial Number: $\quad 1408$}

Sample Type: unknown

Control Program: AS14A ANIONS METHOD

Quantif. Method: AS4A-SC ANION METHOD

Recording Time:

Run Time ( $\mathrm{min})$ :

\section{2/28/2006 21:05}

15.00
Injection Volume:

Channel:

Wavelength:

Bandwidth:

Dilution Factor:

Sample Weight:

Sample Amount:
50.0

ECD_1

n.a.

n.a.

1.0000

1.0000

1.0000

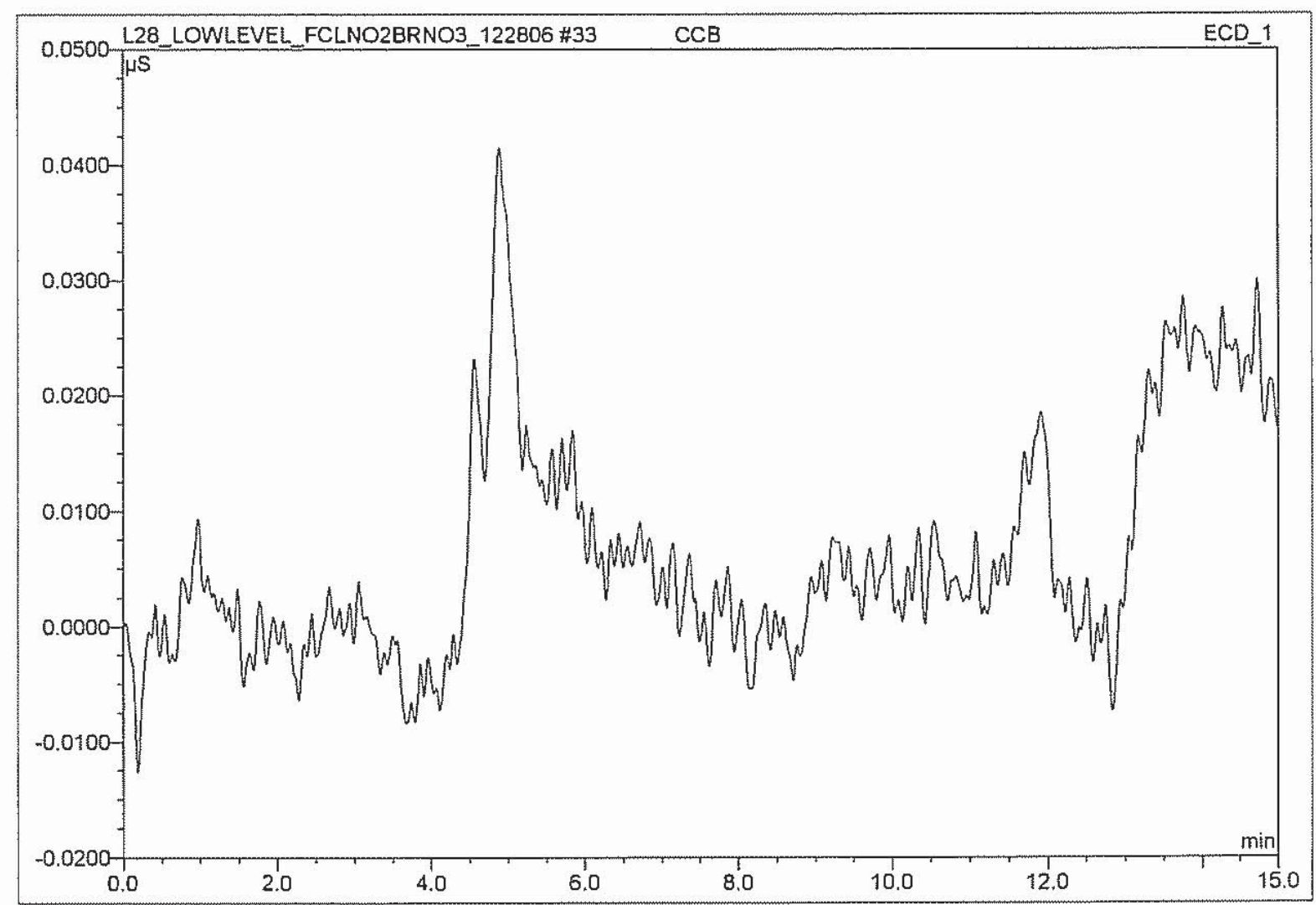

\begin{tabular}{|l|c|c|c|c|c|c|c|}
\hline No. & $\begin{array}{c}\text { Ret.Time } \\
(\mathrm{min} .)\end{array}$ & Peak Name & $\begin{array}{c}\text { Height } \\
(\mathrm{uS})\end{array}$ & $\begin{array}{c}\text { Area } \\
\mu \mathrm{S}^{*} \mathrm{~min}\end{array}$ & $\begin{array}{c}\text { Rel.Area } \\
(\%)\end{array}$ & $\begin{array}{c}\text { Amount } \\
(\mathrm{mg} / \mathrm{L})\end{array}$ & $\begin{array}{c}\text { Peak } \\
\text { Type }\end{array}$ \\
\hline
\end{tabular}

(ND) 


\section{*迷米}

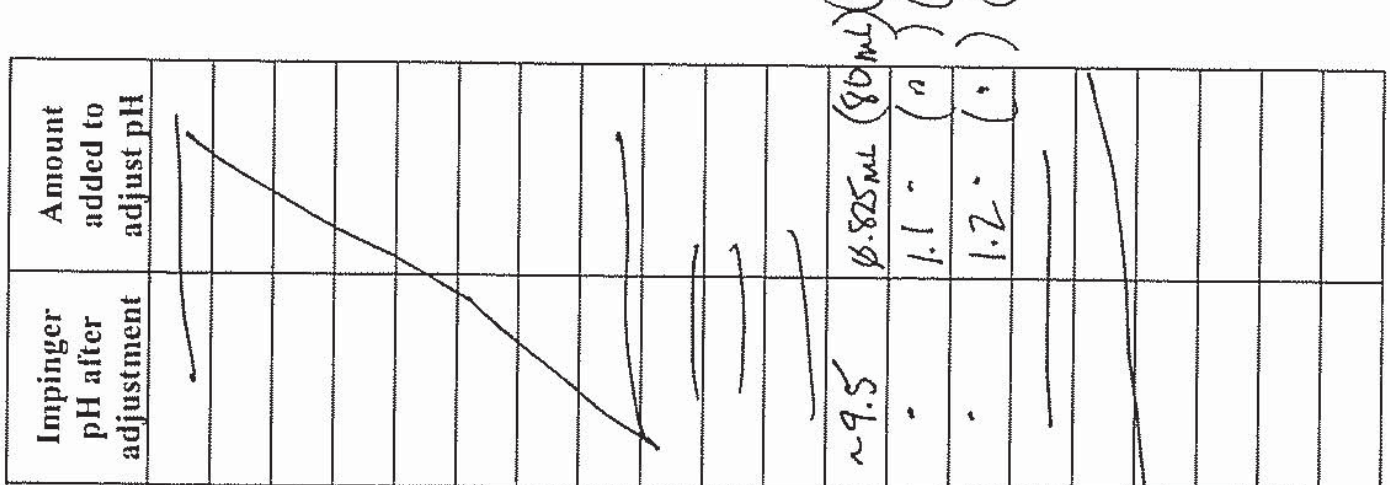

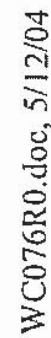

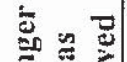

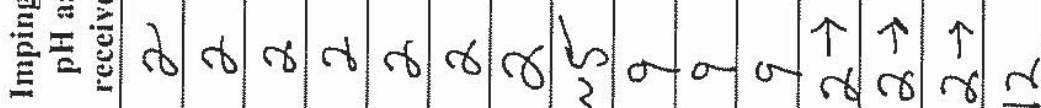

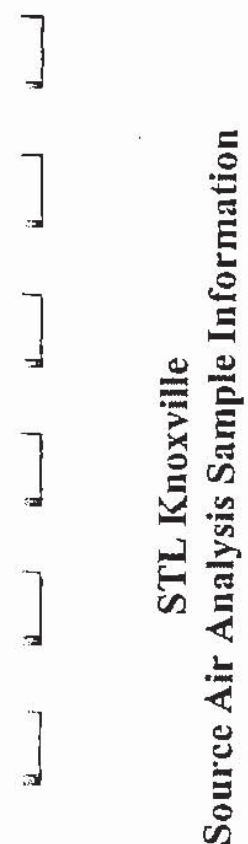

.

总总

(1)

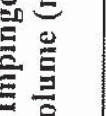

จ.

$$
\text { त्: }
$$

$\pm-\frac{\pi}{2}$

काष्टें

$+\square$

$\frac{\pi}{10}$

$-1$

竞望

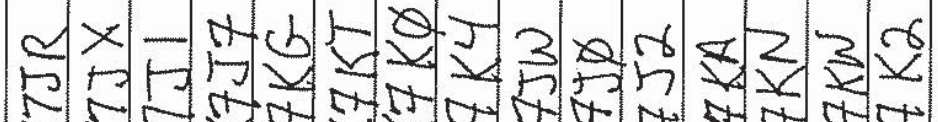

165525250505

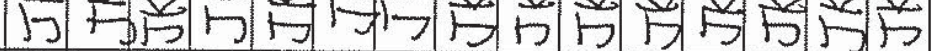

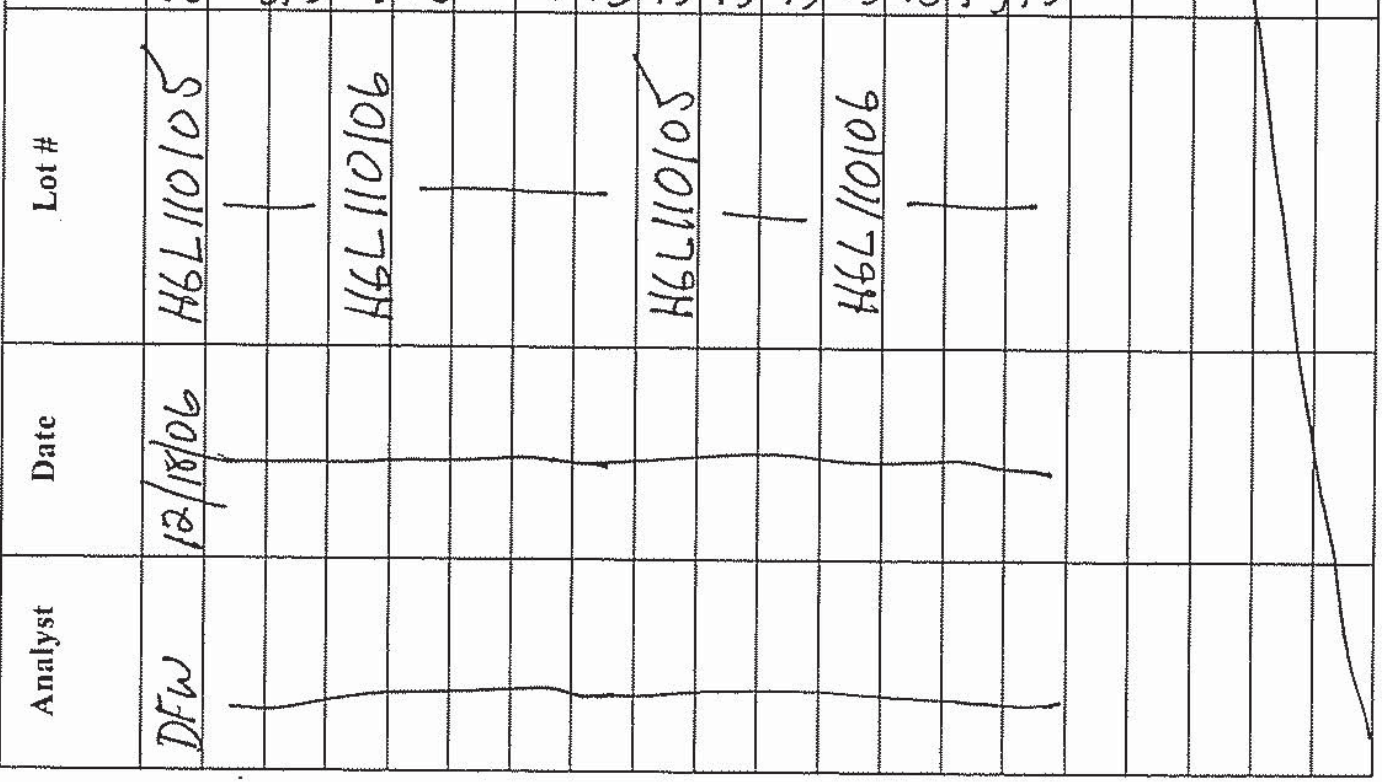



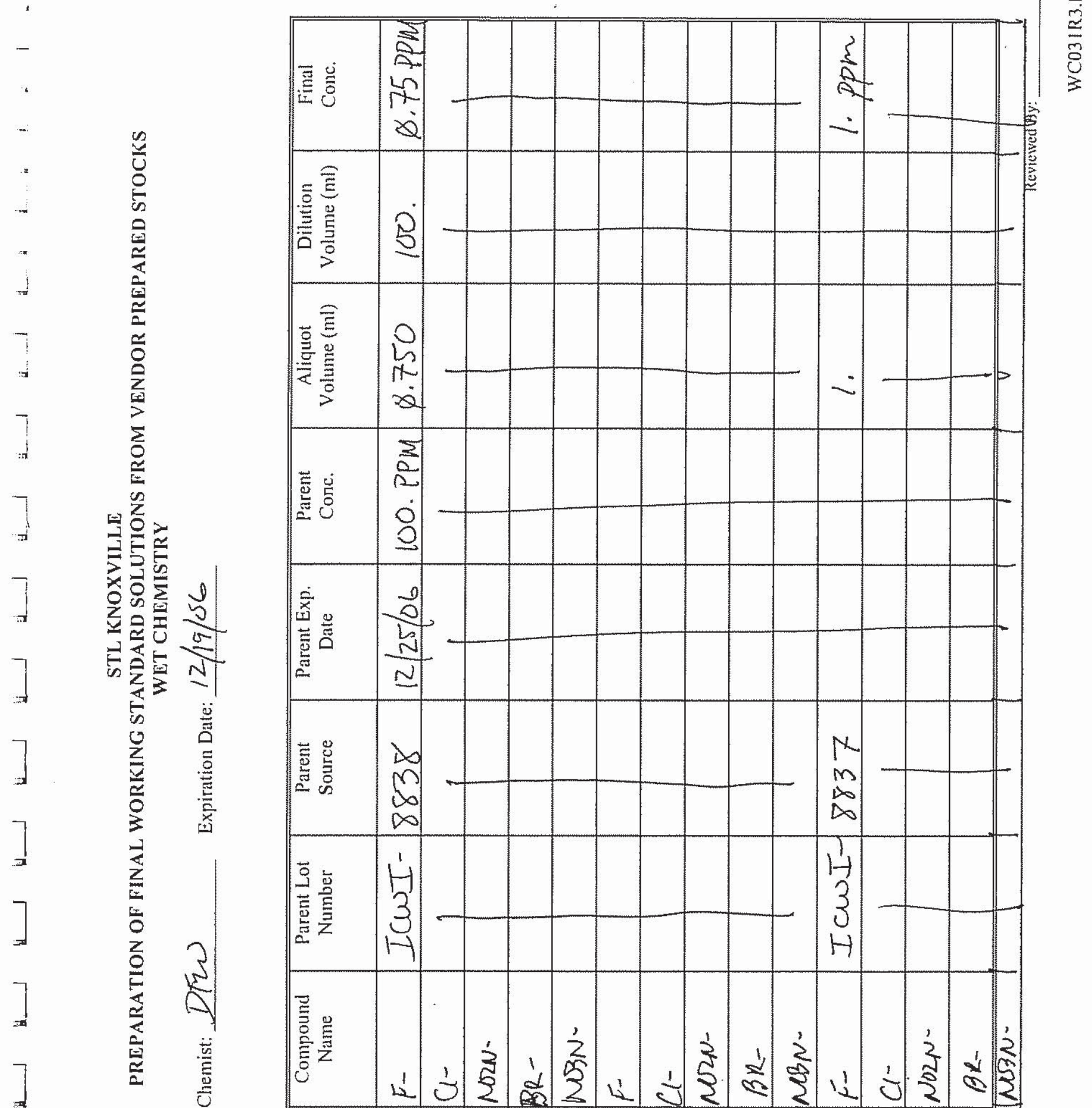

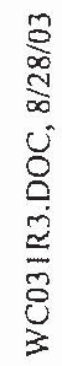

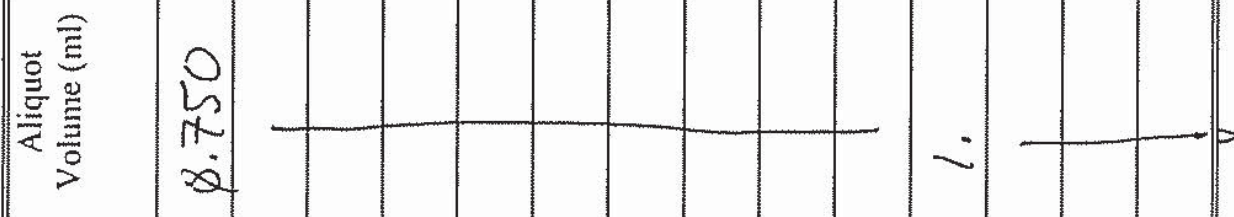

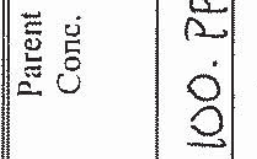

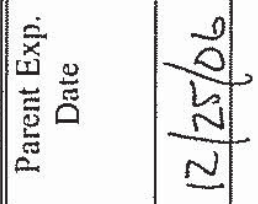

7

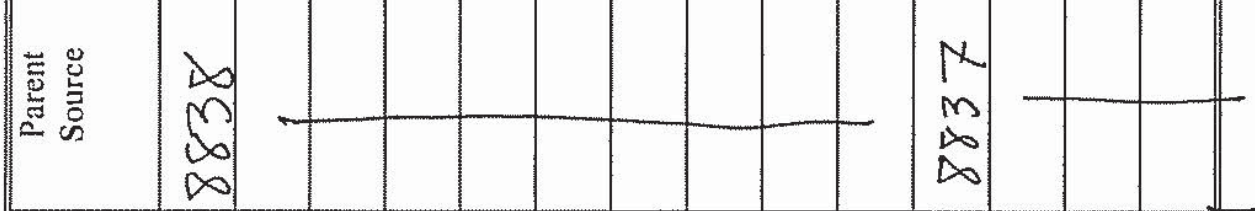

7
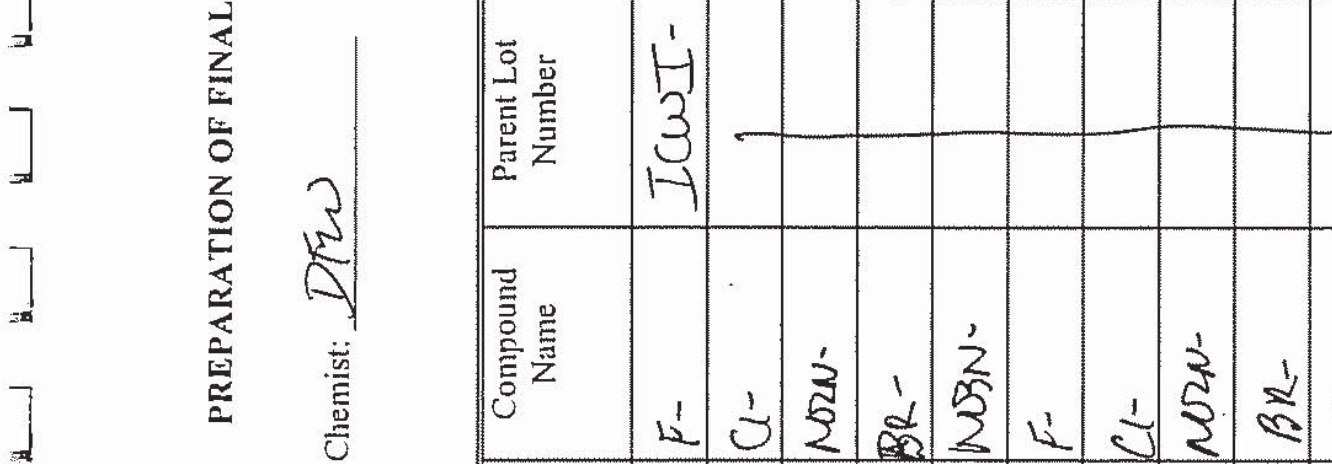

$1+$
3
$H$

总

7

7
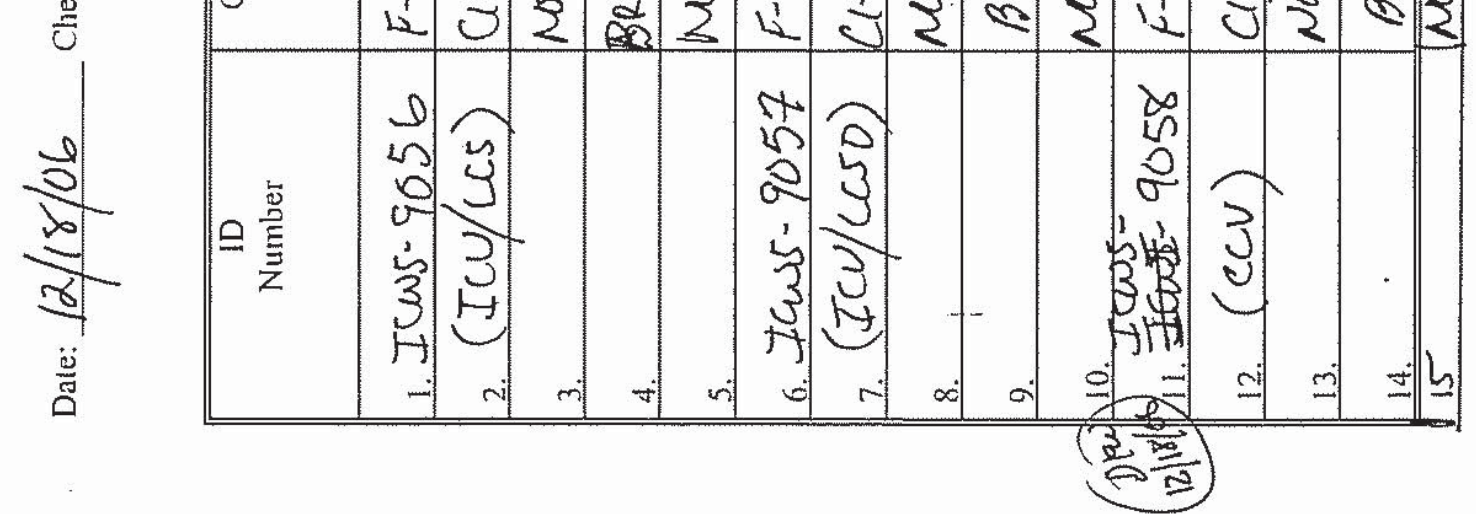


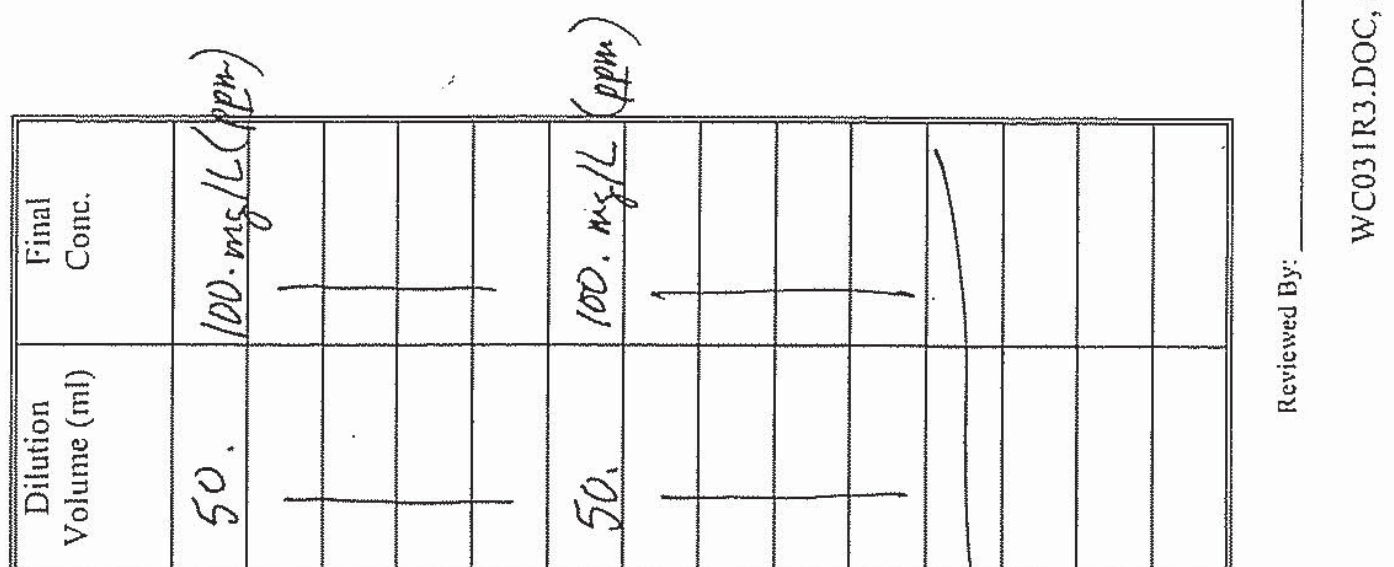

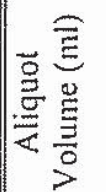

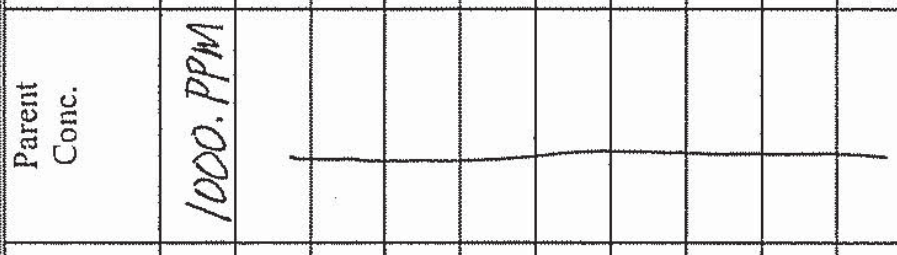

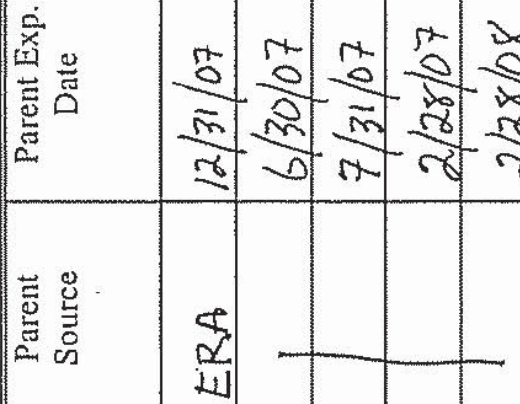

at

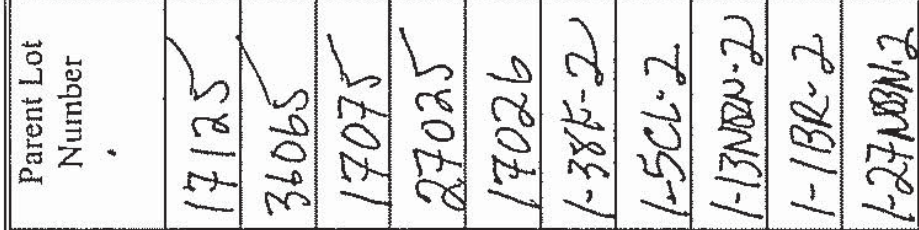

总

-
-
$=$
-
$=$
$=$

\begin{tabular}{|c|c|c|c|c|c|c|c|c|c|c|c|c|c|c|}
\hline 0 & 2 & \multicolumn{2}{|c|}{$\sigma 8$} & w. & 2 & \multicolumn{2}{|r|}{$\mathcal{U}$} & \multicolumn{3}{|c|}{200} & 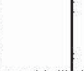 & & \\
\hline 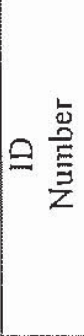 & $\begin{array}{l}0 \\
0 \\
0 \\
3 \\
3 \\
4 \\
-1\end{array}$ & 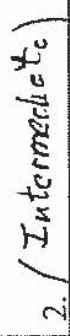 & है & $\theta$ & in & $\begin{array}{l}x \\
0 \\
0 \\
3 \\
5 \\
3 \\
5 \\
\text { जे } \\
0\end{array}$ & +5 & $\frac{5}{5}$ & ol & 요 & $=$ & $\therefore$ & $m$ & $\exists$ \\
\hline
\end{tabular}


in
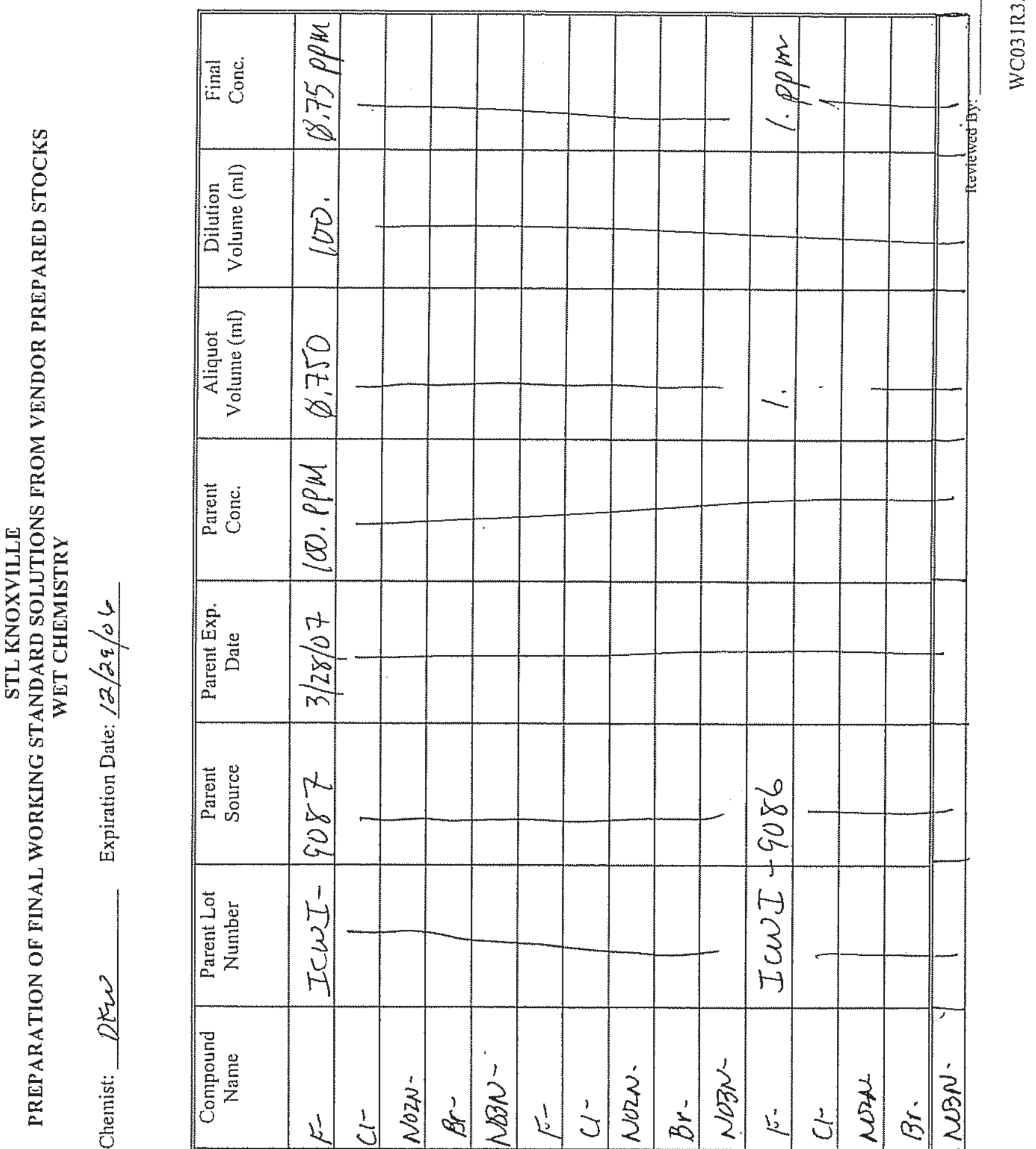

]

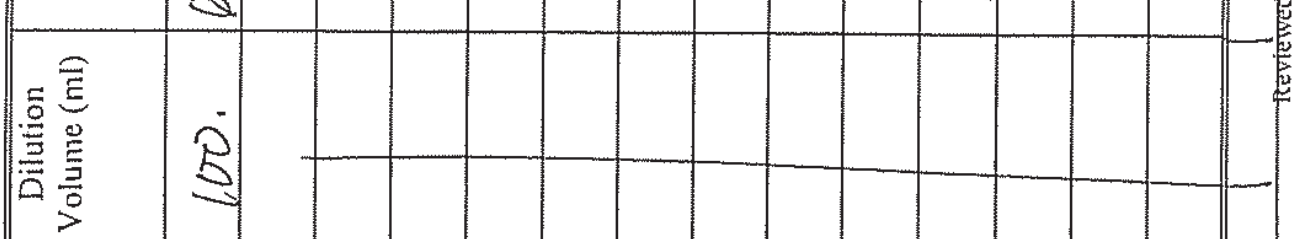

7

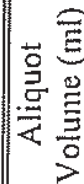

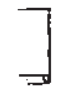

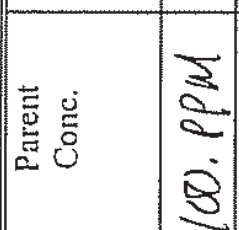

.

4

展

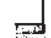

te

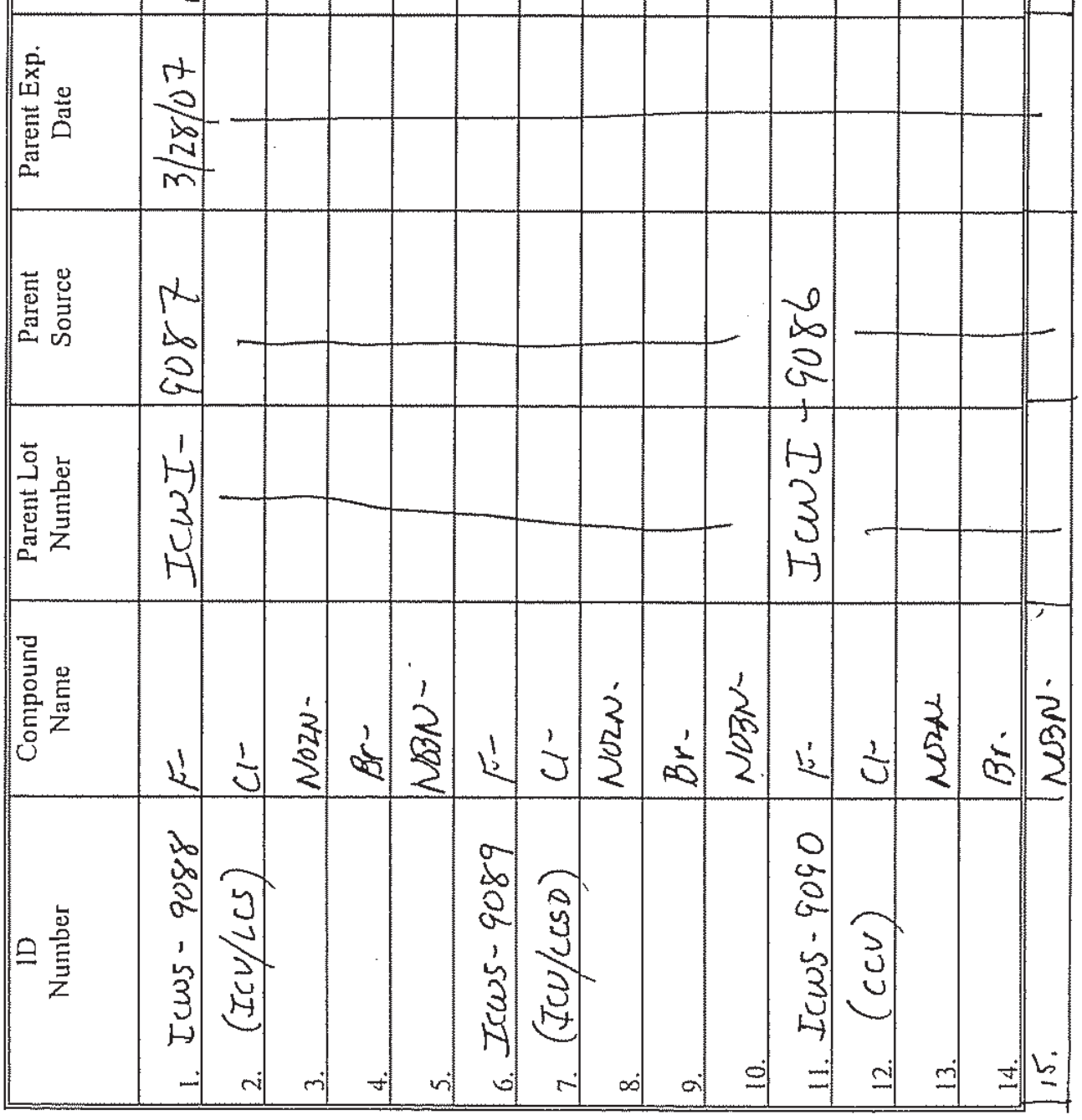



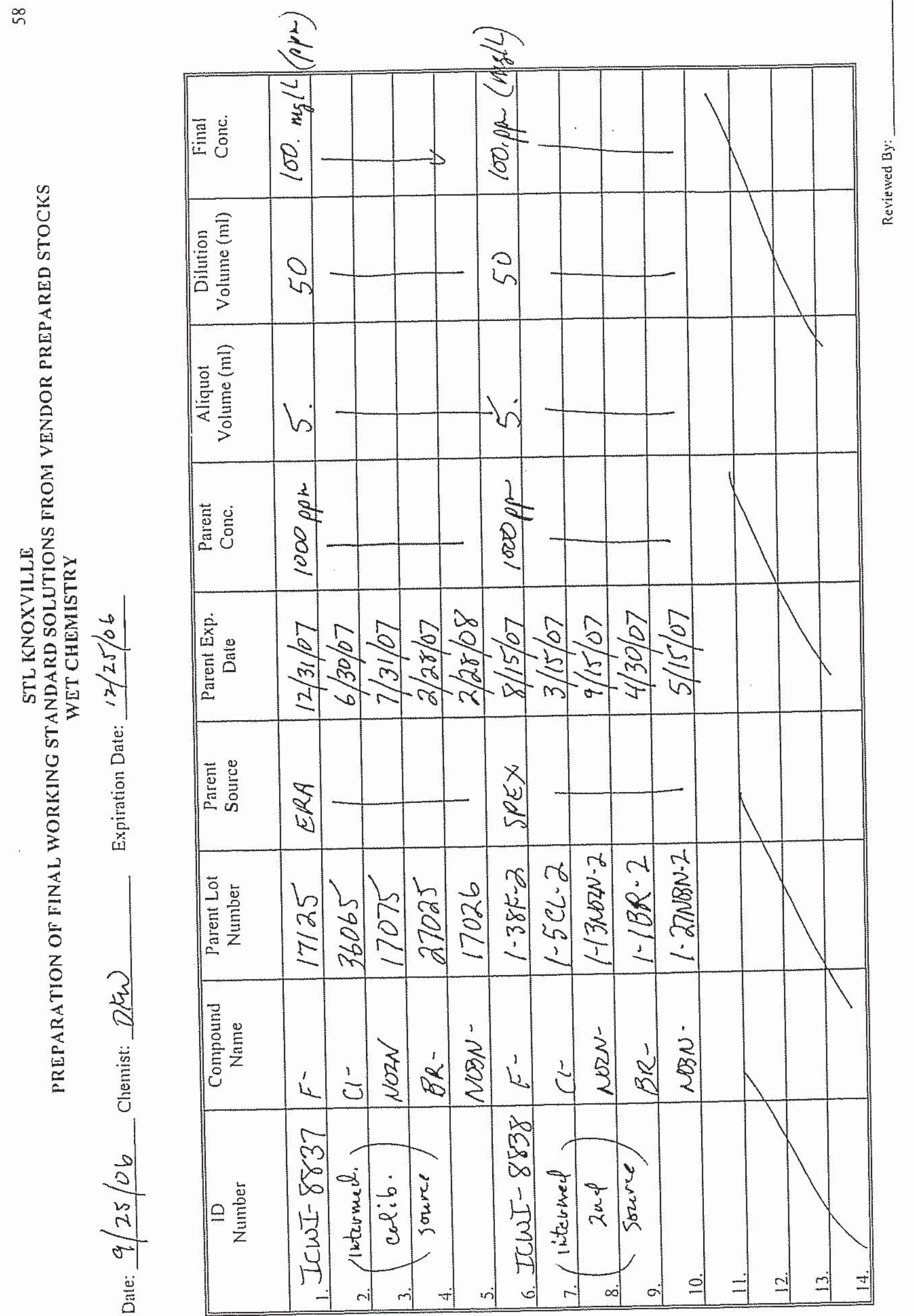

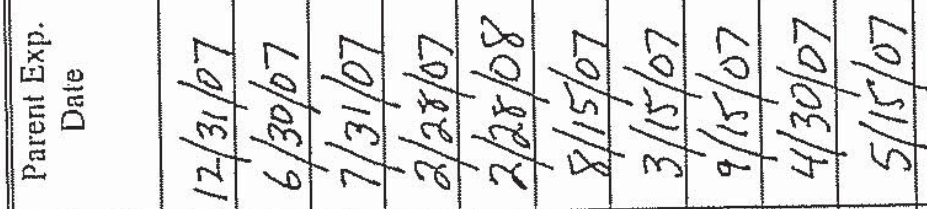

咅

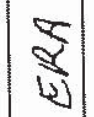

蕰总

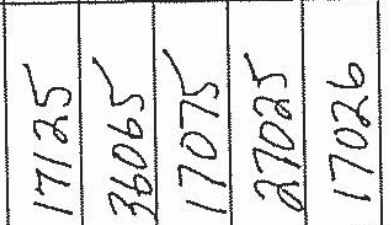

स्रे

总总

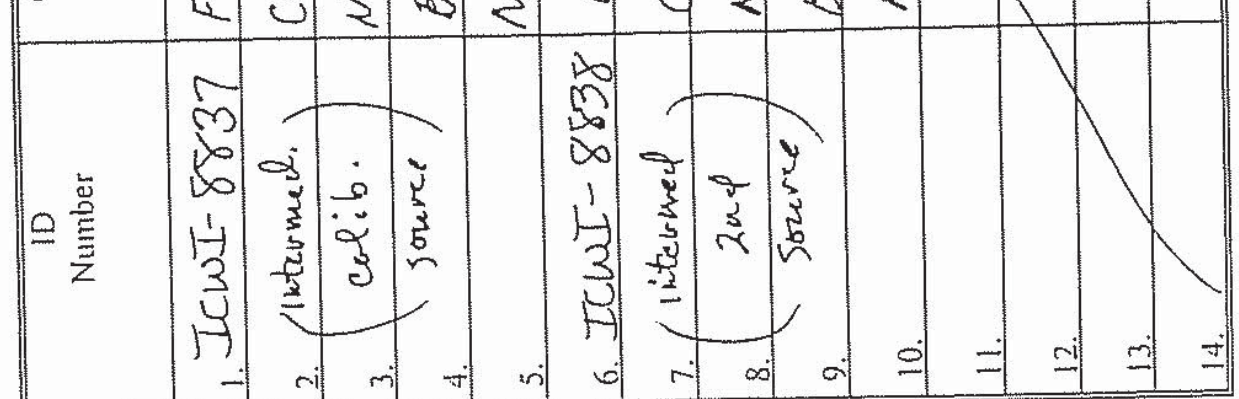


Sample Receipt Documentation 


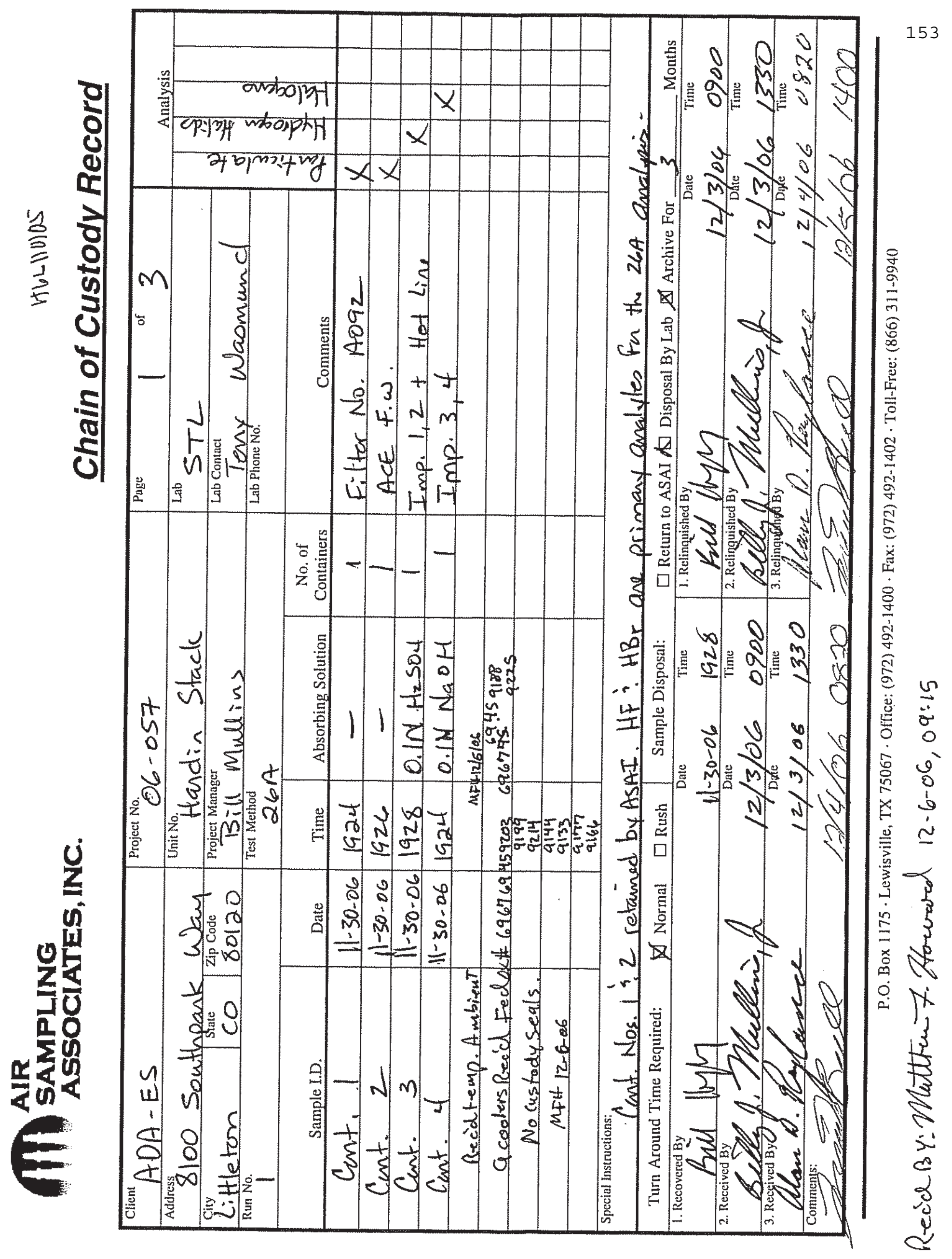




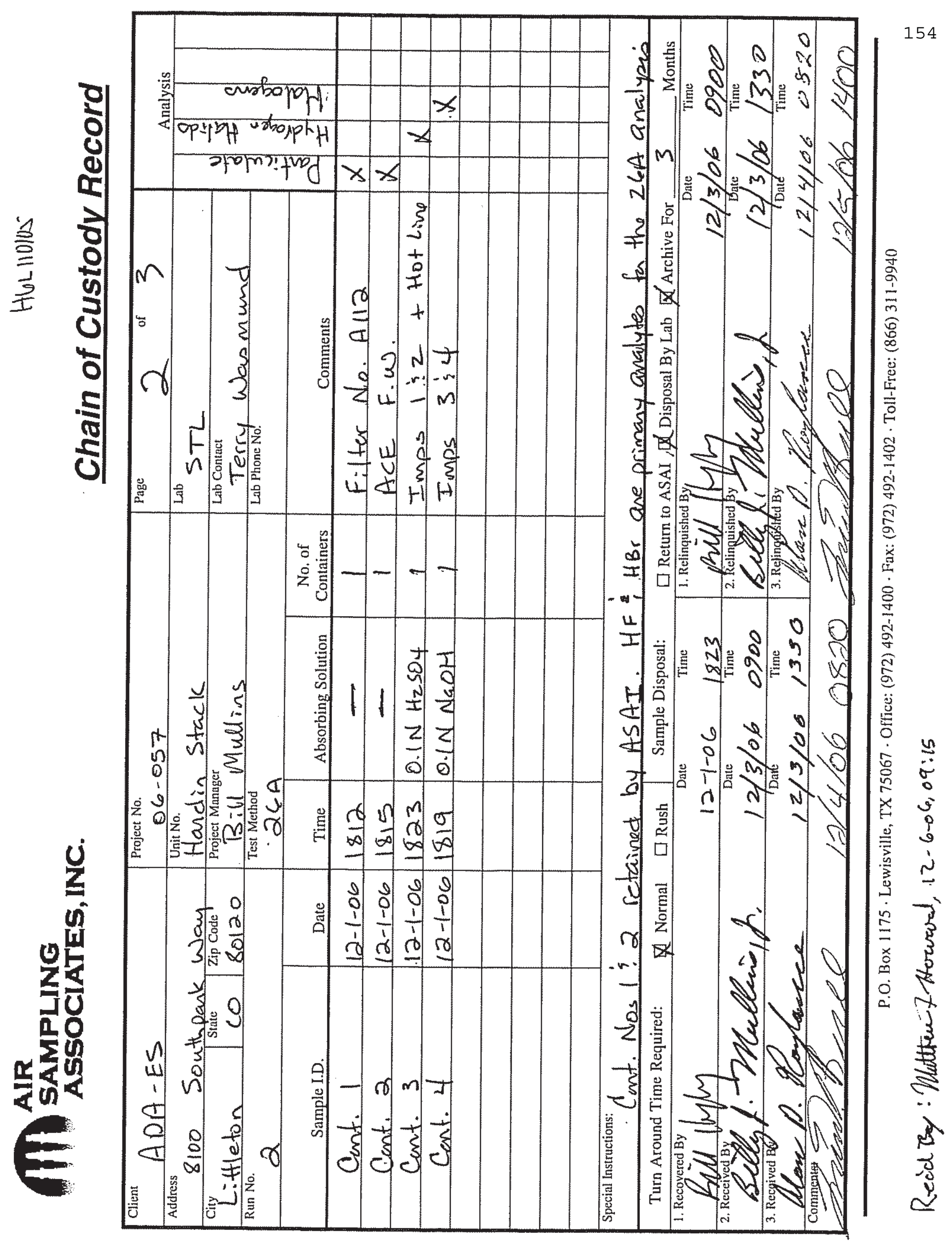




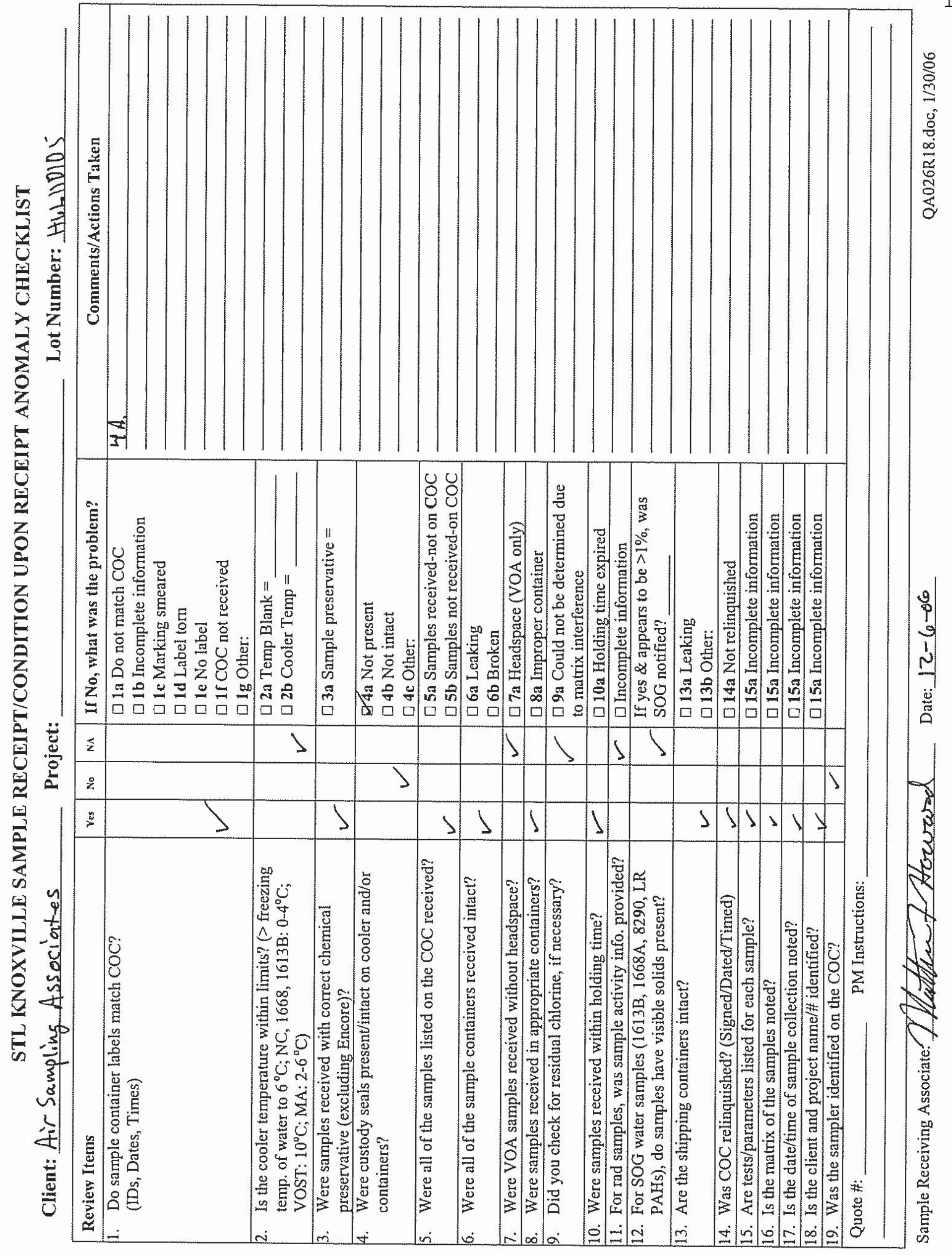


Appendix H:

EPA Test Methods 5, 17 (Particulate Matter), and ASTM D6784-02 (Ontario Hydro) Mercury Speciation Test Method Analytical Data 


\section{II}

Air Sampling Associates, Inc.

\section{Particulate Analysis Summary}

Project Number: $06-057$

Date Analysis Completed: $12-15-06$

Project Name: ADA-ES

Unit Tested: SDA Inlet

Project Location: Handin, $M T$

Run Number:

Particulate Matter on Filter (mg):

Particulate Matter in Front Wash (mg):

Total Particulate Matter in "Front-Half" - MF (mg):

Particulate Matter in "Back-Half" (mg):

Total Particulate Matter in Sample-MT (mg):
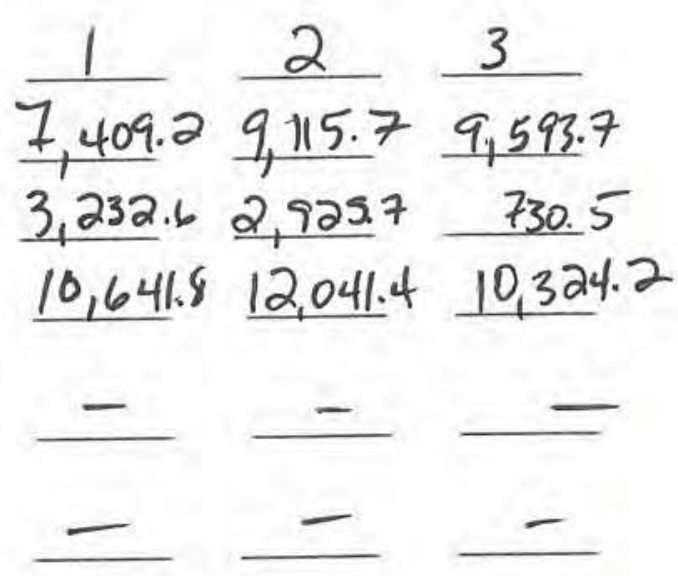
Analyst

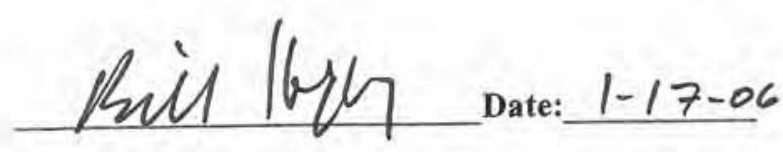

Data Checked By 
Particulate Analysis EPA Method 17

Stack Filters

Project No. 06-057

Project Name APA-ES

Location Hardin, $m T$

Unit Tested SDA Inlet

\begin{tabular}{|r|l|l|l|l|l|}
\hline Desiccator Time In & & & & \\
\hline Desiccator Time Out & & & & & \\
\hline
\end{tabular}

\begin{tabular}{|c|l|l|l|l|}
\hline Run No. I Filter No. 53 & \multicolumn{3}{|c|}{ Sample I.D. } \\
\hline Filter \& Particulate (g) & & & & \\
\hline
\end{tabular}

Filter \& Particulate Average (g) 10.1444

Initial Filter Weight $(\mathrm{g}) \quad 2.7352$

Total Particulate $(\mathrm{mg}) \quad 7,409.2$

\begin{tabular}{|c|l|l|l|l|}
\hline \multicolumn{2}{|c|}{ Run No. 2} & Filter No. 54 & & \\
\hline Filter \& Particulate (g) & & & & \\
\hline
\end{tabular}

Filter \& Particulate Average (g) 12.6952

Initial Filter Weight (g) 3.5795

Total Particulate $(\mathrm{mg}) \quad 9,115.7$

\begin{tabular}{|c|l|l|l|l|}
\hline Run No. 3 & Filter No. 55 & & \\
\hline Filter \& Particulate (g) & & & & \\
\hline
\end{tabular}

Filter \& Particulate Average (g) 12.4725

Initial Filter Weight $(\mathrm{g}) \quad 2.8788$

Total Particulate $(\mathrm{mg}) \quad 9,593.7$

STL Knoxville 
ASSOCIATES, INC.

Thimble Tare Weight Log

EPA Method 17

\begin{tabular}{|c|c|c|c|c|c|c|c|}
\hline \multirow[b]{3}{*}{ Filter No. } & Into Desicator & Weight & Weight & Weight & Weight & Weight & \multirow{3}{*}{$\begin{array}{l}\text { Weight } \\
\text { Used }\end{array}$} \\
\hline & Date & Date & Date & Date & Date & Date & \\
\hline & Time & Time & Time & Time & Time & Time & \\
\hline \multirow{3}{*}{45} & & 2.7 .941 & 2.7944 & & & & $2.79+4$ \\
\hline & 9129100 & $10 \mathrm{l} / \alpha_{\infty}$ & $10 / 3104$ & & & & \\
\hline & 1200 & 1635 & 1100 & & & & \\
\hline \multirow{3}{*}{46} & & 2.7987 & $2.7990^{\circ}$ & & & & 2.7990 \\
\hline & & $10 / 2 / 06$ & $10 / 3 / 06$ & & & & \\
\hline & & 1636 & 1101 & & & & \\
\hline \multirow{3}{*}{47} & & $2,55,14$ & $2.55 \mathrm{kf}$ & & & & 2.5514 \\
\hline & & $10 / 2 / 06$ & 1013106 & & & & \\
\hline & & 1637 & 1102 & & & & \\
\hline \multirow{3}{*}{48} & & 2.7781 & 2.7785 & & & & 2.7785 \\
\hline & & $10 / 2106$ & 1013106 & & & & \\
\hline & & 1638 & 103 & & & & \\
\hline \multirow{3}{*}{49} & & 2.7795 & 2.7799 & & & & 2.7799 \\
\hline & & $10 / 2 / 06$ & $10 / 3106$ & & & & \\
\hline & & 1639 & 1104 & & & & \\
\hline \multirow{2}{*}{50} & & 2.6485 & 2.6487 & & & & 2.6487 \\
\hline & & $10 / 2 / 06$ & 1013106 & & & & \\
\hline \multirow{3}{*}{51} & & $\frac{1640}{2.8600}$ & $\frac{1105}{2.8605}$ & & & & 2.8605 \\
\hline & & $10 / 2106$ & 1013104 & & & & \\
\hline & & 1641 & 1106 & & & & \\
\hline \multirow{3}{*}{52} & & $2.8+70$ & 2.8474 & & & & 2.8474 \\
\hline & & $10 / 2 / 0 x$ & 1013104 & & & & \\
\hline & & 1642 & 1107 & & & & \\
\hline \multirow{3}{*}{53} & & 2.3349 & 2.7352 & E & & & 2.7352 \\
\hline & E & $10 / 2106$ & 1013106 & & & & \\
\hline & & 1623 & 1108 & & & & \\
\hline \multirow{3}{*}{54} & & 3.5794 & 3,5795 & $\angle$ & & & 3,5795 \\
\hline & $11 / 28 / 06$ & $11 / 21 / 06$ & $11 / 22 / 06$ & & & & \\
\hline & $1 / 360$ & 1350 & 0745 & & & & \\
\hline \multirow{2}{*}{55} & & 2.8785 & 2.8788 & $\angle$ & & & 2.8788 \\
\hline & & $11 / 21 / 06$ & $14 / 22 / 06$ & & & & \\
\hline \multirow{3}{*}{56} & & $\frac{135 \%}{2.4725}$ & $07+6$ & & & & \\
\hline & & $\frac{2.4 / 25}{11 / 21 / 06}$ & $\frac{2.9724}{122}$ & $=$ & & & 2.4724 \\
\hline & & 352 & 0247 & & & & \\
\hline \multirow{2}{*}{57} & & 2.9916 & $2.9911=$ & E & & & 2.9911 \\
\hline & & $11 / 21 / 06$ & $11 / 22 / 06$ & & & & \\
\hline \multirow{3}{*}{58} & & $\frac{1353}{13460}$ & 2748 & & & & \\
\hline & & $\frac{3.4660}{11 / 21 / 06}$ & 3.4656 & E & & & 3,4656 \\
\hline & & 354 & $11 / 22 / 06$ & & & & \\
\hline \multirow{3}{*}{59} & & 3,1165 & 3.1160 & 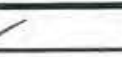 & & & 3.1160 \\
\hline & & $11 / 21 / 06$ & $11 / 22 / 06$ & & & & \\
\hline & 4 & 1355 & 16750 & & & & \\
\hline
\end{tabular}




\section{Front Wash}

Project No.

06.057

Location Hardin, MT

Project Name ADA-ES Unit Tested

SDA Inlet

\begin{tabular}{|r|l|l|l|l|l|}
\hline Desiccator Time In & & & & \\
\hline Desiccator Time Out & & & & & \\
\hline
\end{tabular}

\begin{tabular}{|c|c|c|c|c|c|}
\hline Run No. Iolume (ml) 209 & & \\
\hline Final Weight (g) & 69.8884 & & & & \\
\hline Initial Weight (g) & 66.6558 & & & & \\
\hline Particulate Weight (g) & 3.2326 & & & & \\
\hline
\end{tabular}

Particulate Average (mg) 3,2326 Less Acetone Blank (mg)

Total Particulate $(\mathrm{mg}) \quad 3,232.6$

\begin{tabular}{|c|c|c|c|c|c|}
\hline \multicolumn{2}{|c|}{ Run No. 2 } & & \\
\hline Final Weight (g) & 68.8045 & & & & \\
\hline Initial Weight (g) & 65.8788 & & & & \\
\hline Particulate Weight (g) & & & & & \\
\hline
\end{tabular}

Particulate Average (mg) 2,925.7

Less Acetone Blank (mg)

Total Particulate $(\mathrm{mg}) 2,925.7$

\begin{tabular}{|c|c|c|c|c|c|}
\hline \multicolumn{2}{|c|}{ Run No. 3 Volume (ml) 87} & & \\
\hline Final Weight (g) & 67.9099 & & & \\
\hline Initial Weight (g) & 67.1794 & & & & \\
\hline Particulate Weight (g) & & & & & \\
\hline
\end{tabular}

Particulate Average (mg)

Less Acetone Blank (mg)

730.5

Total Particulate $(\mathrm{mg})$

$\frac{730.5}{730.5}$

\begin{tabular}{|c|l|l|l|l|l|}
\hline Acetone Blank & & & & \\
\hline Final Weight (g) & & & & & \\
\hline Initial Weight (g) & & & & & \\
\hline Particulate Weight (g) & & Average (mg) \\
\hline
\end{tabular}

* Note: if greater than $7.9 \mathrm{mg} / \mathrm{l}$, use $7.9 \mathrm{mg} / \mathrm{l}$

STL Knoxville Date: 12-15.06 
III AIR

SAMPLING

ASSOCIATES, INC.

Air Sampling Associates, Inc.

Particulate Analysis Summary

Project Number: $06-057$

Project Name: ADA-ES
Date Analysis Completed: $12 / 15 / 06$

Unit Tested: Stack

Project Location: Hardin, $M T$

Run Number:

Particulate Matter on Filter (mg):

Particulate Matter in Front Wash (mg):

Total Particulate Matter in "Front-Half" - MF (mg):

Particulate Matter in "Back-Half" (mg):

Total Particulate Matter in Sample - MT (mg): $\frac{\frac{1}{22.5}}{\frac{16.3}{38.8}}$\begin{tabular}{lll}
$\frac{2}{19.4}$ & $\frac{3}{13.9}$ & $\frac{26.3}{12.1}$ \\
\hline 33.3 & $\frac{38.4}{n}$
\end{tabular}

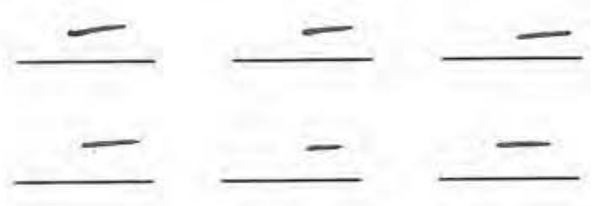

STL Knoxville

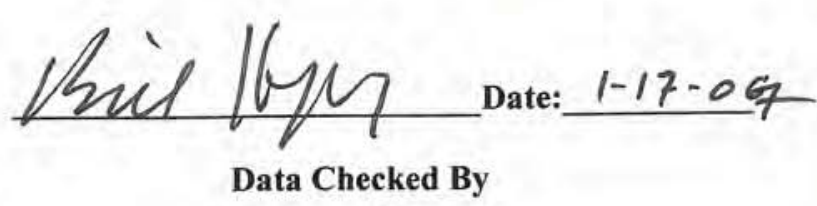

Version No. 1 5/30/06

H-6 


\section{Particulate Analysis EPA Method $\quad 5$}

\section{Stack Filters}

Project No. Q6- 057

Location Hardin: $M T$

Project Name ADA-ES

Unit Tested Stack

\begin{tabular}{|r|l|l|l|l|l|}
\hline Desiccator Time In & & & & \\
\hline Desiccator Time Out & & & & & \\
\hline
\end{tabular}

\begin{tabular}{|c|l|l|l|l|}
\hline Run No. I I & \multicolumn{1}{c|}{ Sample I.D. No. A 117} & & \\
\hline Filter \& Particulate (g) & & & & \\
\hline
\end{tabular}

Filter \& Particulate Average $(\mathrm{g}) \quad 0.3869$ Initial Filter Weight $(\mathrm{g}) 0.3644$ Total Particulate $(\mathrm{mg})$ $22 \cdot 5$

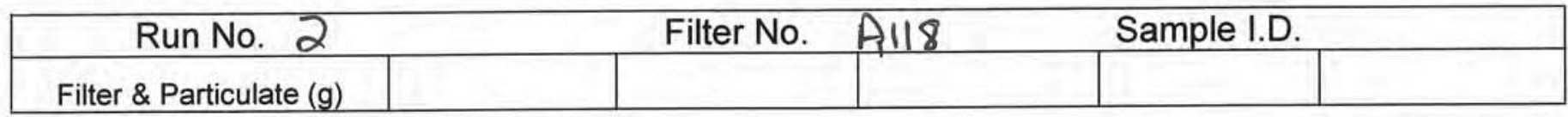

Filter \& Particulate Average (g) 0.3829 Initial Filter Weight $(\mathrm{g}) 0.3635$ Total Particulate $(\mathrm{mg}) \quad 19.4$

Run No. 3

Filter \& Particulate (g)

\section{Filter No. A 119}

Sample I.D.
Filter \& Particulate Average (g) 0.3918 Initial Filter Weight $(\mathrm{g}) \quad 0.3655$ Total Particulate $(\mathrm{mg}) \quad 26 \cdot 3$

STL Knoxville Analyst 
Filter Weight Log

EPA Method 5

\begin{tabular}{|c|c|c|c|c|c|c|c|}
\hline \multirow[b]{3}{*}{ Filter No. } & Into Desicator & Weight & Weight & Weight & Weight & Weight & \multirow{3}{*}{ Weight } \\
\hline & Date & Date & Date & Date & Date & Date & \\
\hline & Time & Time & Time & Time & Time & Time & \\
\hline \multirow{3}{*}{ A105 } & & 0.3801 & 0.3801 & & & & 0.3801 \\
\hline & $10 / 2 / 06$ & $10 / 12 / 104$ & $10 / 13 / 06$ & & & & \\
\hline & 0800 & 1000 & 0826 & & & & \\
\hline \multirow{3}{*}{ A106 } & $10 / 2 / 06$ & 0,3827 & 0.3825 & & & & 0.3825 \\
\hline & 6820 & $10 / 12 / 66$ & $10 / 13 / 06$ & & & & \\
\hline & & 1001 & 0827 & & & & \\
\hline \multirow{3}{*}{$A 107$} & & 0.3808 & 0.3810 & & & & $0.38 / 0$ \\
\hline & $10 / 2 / 06$ & $10 / 12 / 06$ & $10 / 13 / 06$ & & & & \\
\hline & 0800 & 1002 & 0828 & & & & \\
\hline \multirow{2}{*}{$A 108$} & & 0,3843 & 0.3845 & & & & 0.3845 \\
\hline & $10 / 2 / 06$ & $10 / 12106$ & $10 / 13 / 06$ & & & & \\
\hline \multirow{3}{*}{ Alo? } & 6800 & 1003 & 0829 & & & & \\
\hline & & 0.3872 & 0.3873 & & & & 0,3873 \\
\hline & $\frac{10 / 2100}{6800}$ & $\frac{10 / 12 / 06}{1004}$ & $\frac{10 / 1 / 3 / 06}{0.830}$ & & & & \\
\hline \multirow{3}{*}{$A \| 0$} & & 0.3885 & 0,3886 & & & & 0.3886 \\
\hline & $10 / 2 / 06$ & $10 / 12 / 06$ & $10 / 13 / 06$ & & & & \\
\hline & 0860 & 1005 & 0831 & & & & \\
\hline \multirow{2}{*}{$A \| z$} & & 0.3833 & 0,3832 & & & & 0.3832 \\
\hline & $10 / 2 / 06$ & $10 / 12 / 06$ & $\frac{10 / 13 / 06}{3832}$ & & & & \\
\hline \multirow{3}{*}{$A \| B$} & & 0.3781 & 0.3778 & & & & 0.3778 \\
\hline & $10 / 2 / 06$ & $10 / 1206$ & $10 / 13 / 86$ & & & & \\
\hline & 6800 & 1007 & 6833 & & & & \\
\hline \multirow{2}{*}{ A114 } & 1012127 & $\frac{0.3814}{0.12106}$ & 0.3812 & & & & 0,3812 \\
\hline & $\frac{10 / 2 / 06}{0800}$ & $\frac{10112106}{1008}$ & 0 & & & & \\
\hline \multirow{3}{*}{ A115 } & & 0.3701 & 0,3700 & & & & 0.3700 \\
\hline & $10 / 2 / 06$ & $10 / 12 / 06$ & $10 / / 3 / 06$ & & & & \\
\hline & 6860 & 1009 & 0835 & & & & \\
\hline \multirow{2}{*}{$A 116$} & & 0.3678 & 0.3679 & & & & 0,3679 \\
\hline & $10 / 2 / 06$ & $10 / 13 / 06$ & $10 / 13) d 6$ & & & & \\
\hline \multirow{3}{*}{$A \| 1$} & $080 \mathrm{~V}$ & $\frac{1010}{0.3644}$ & 0.3644 & & & & 0.3644 \\
\hline & $10 / 2 / 06$ & $10 / 12 / 25$ & $10 / 13) 06$ & & & & \\
\hline & .800 & 1011 & 0831 & & & & \\
\hline \multirow{2}{*}{$A \| S$} & & 0,3636 & 0.3635 & & & & 0.3635 \\
\hline & $\frac{10 / 2 / 06}{0800}$ & $11 / 20 / 06$ & $\frac{11 / 21 / 06}{0507}$ & & & & \\
\hline \multirow{3}{*}{$A 119$} & & 0.3655 & 0.3655 & & & & 0.3655 \\
\hline & $10 / 2 / 06$ & $1 1 / 2 0 \longdiv { 2 6 }$ & $11 / 21 / 06$ & & & & \\
\hline & 0800 & 1246 & 0800 & & & & \\
\hline \multirow{2}{*}{$A 120$} & $10 / 2 / 06$ & $\frac{0.3616}{11 / 20 / 06}$ & \begin{tabular}{|l|}
$0.36 / 5$ \\
$1 / 21 / 26$ \\
\end{tabular} & & & & 0.3615 \\
\hline & 800 & 1247 & 0809 & & & & \\
\hline
\end{tabular}




\section{II

\section{Particulate Analysis EPA Method}

Front Wash

Project No. $06-057$
Project Name ADA-ES
\begin{tabular}{|r|l|l|l|l|} 
Lnit Tested & Hardin, $M T$ \\
\hline Desiccator Time In & & & & \\
\hline Desiccator Time Out & & & & \\
\hline
\end{tabular}

\begin{tabular}{|c|l|l|l|l|l|}
\hline Run No. I I & & & \\
\hline Final Weight (g) & 68.1454 & & & & \\
\hline Initial Weight (g) & 68.1291 & & & & \\
\hline Particulate Weight (g) & & & & & \\
\hline
\end{tabular}

Particulate Average $(\mathrm{mg}) \quad 16 \cdot 3$

Less Acetone Blank (mg)

Total Particulate $(\mathrm{mg}) \quad / 6.3$

\begin{tabular}{|c|l|l|l|l|l|}
\hline \multicolumn{2}{|c|}{ Run No. 2 } & & \\
\hline Final Weight (g) & 66.2084 & & & \\
\hline Initial Weight (g) & 66.1945 & & & & \\
\hline Particulate Weight (g) & & & & & \\
\hline
\end{tabular}

Particulate Average (mg) Less Acetone Blank (mg)

Total Particulate $(\mathrm{mg}) \quad 13.9$

\begin{tabular}{|c|c|c|c|c|c|}
\hline \multicolumn{2}{|c|}{ Run No. 3 3} & & \\
\hline Final Weight (g) & 67.5197 & & & & \\
\hline Initial Weight (g) & 67.5076 & & & & \\
\hline Particulate Weight (g) & & & & & \\
\hline
\end{tabular}

Particulate Average $(\mathrm{mg}) \quad 12-1$

Less Acetone Blank (mg) -

Total Particulate $(\mathrm{mg}) \quad 12.1$

\begin{tabular}{|c|l|l|l|l|l|}
\hline Acetone Blank & & & & \\
\hline Final Weight (g) & & & & & \\
\hline Initial Weight (g) & & & & & \\
\hline Particulate Weight (g) & & & Average (mg) \\
\hline
\end{tabular}

* Note: if greater than $7.9 \mathrm{mg} / \mathrm{l}$, use $7.9 \mathrm{mg} / \mathrm{l}$ 
H6L070246 Analytical Report............................................ 1

Sample Receipt Documentation ......................................... 65

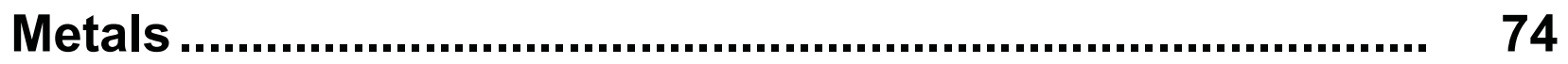

Sample Results ............................................... 75

QC Summary ..................................................... 104

Quality Control Results Mercury ...................................... 117

Raw Data Mercury .......................................................... 137

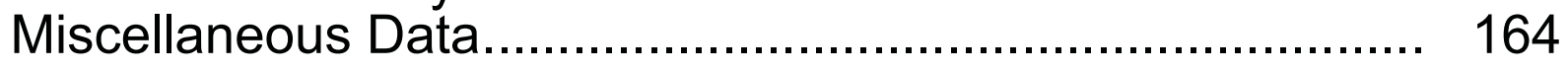

Wet Chemistry ................................................................ 174

Sample Summary …................................................ 175

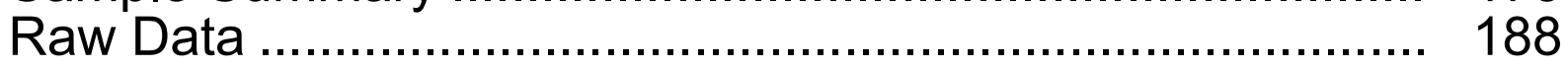

Sample Receipt Documentation ........................................ 196

Total Number of Pages ...................................................... 204 


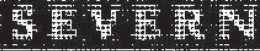

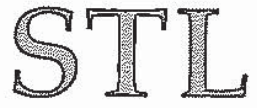

STL Knoxville

5815 Middlebrook Pike

Knoxville, TN 37921

Tel: $8652913000 \quad$ Fax: 8655844315

www.st-inc.com

\section{ANALYTICAL REPORT}

PROJECT NO. 06-057

Hardin, Montana

Lot \#: H6L070246

Bill Hefley

Air Sampling Associates, Inc.

407-2B Holford's Prairie Road

Lewisville, TX 75056

SEVERN TRENT LABORATORIES, INC.

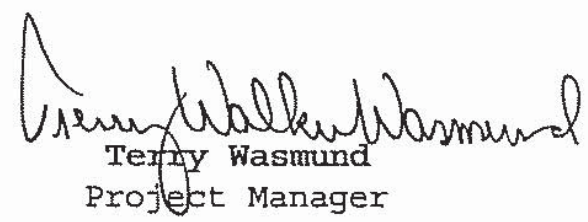

January 8, 2007 


\section{ANALYTICAL ME'THODS SUMMARY}

H6L070246

$\begin{array}{ll}\text { PARAMETER } & \begin{array}{l}\text { ANALYTICAL } \\ \text { METHOD }\end{array} \\ \begin{array}{l}\text { Mercury (Ontario Hydro) } \\ \text { Particulate Emissions }\end{array} & \begin{array}{l}\text { ASTM D6784-02 } \\ \text { CFR60A 5 }\end{array} \\ \text { References: } & \\ \text { ASTM Annual Book Of ASTM Standards. } & \\ \text { CFR60A "Test Methods", 40 CFR, Part 60, Appendix A, July 1, } 1993 .\end{array}$




\section{SAMPLE SUMMARY}

H6L070246

\begin{tabular}{|c|c|c|c|c|c|}
\hline WO \# & SAMPLE\# & CLIENT & SAMPLE ID & & \\
\hline JK1V2 & 001 & HARDIN & STACK RUN & 1 FILTER A117 & \\
\hline JK1V7 & 002 & HARDIN & STACK RUN & 1 ACETONE & \\
\hline JK1WA & 003 & HARDIN & STACK RUN & $1 \mathrm{FH}$ & \\
\hline JKIWE & 004 & HARDIN & STACK RUN & $1 \mathrm{KCL}$ & \\
\hline JKIWF & 005 & HARDIN & STACK RUN & $1 \mathrm{HNO} 3 / \mathrm{H} 2 \mathrm{O} 2$ & \\
\hline JKIWG & 006 & HARDIN & STACK RUN & $1 \mathrm{KMNO} 4 / \mathrm{H} 2 \mathrm{SO} 4$ & \\
\hline JK1WB & 007 & HARDIN & STACK RUN & 2 FILTER A118 & \\
\hline JKIXA & 008 & HARDIN & STACK RUN & 2 ACETONE & \\
\hline JKIXD & 009 & HARDIN & STACK RUN & $2 \mathrm{FH}$ & \\
\hline JKIXE & 010 & HARDIN & STACK RUN & $2 \mathrm{KCL}$ & \\
\hline JKIXR & 011 & HARDIN & STACK RUN & $2 \mathrm{HNO} 3 / \mathrm{H}_{2} \mathrm{O}_{2}$ & \\
\hline JK1XT & 012 & HARDIN & STACK RUN & $2 \mathrm{KMNO} 4 / \mathrm{H} 2 \mathrm{SO}^{4}$ & \\
\hline JKIXI & 013 & HARDIN & STACK RUN & 3 FILTER A119 & \\
\hline JKIX4 & 014 & HARDIN & STACK RUN & 3 ACETONE & \\
\hline JK1X5 & 015 & HARDIN & STACK RUN & $3 \mathrm{FH}$ & \\
\hline JK1X8 & 016 & HARDIN & STACK RUN & $3 \mathrm{KCL}$ & \\
\hline JKIOA & 017 & HARDIN & STACK RUN & $3 \mathrm{HNO} 3 / \mathrm{H} 2 \mathrm{O} 2$ & \\
\hline JK10E & 018 & HARDIN & STACK RUN & $3 \mathrm{KMNO} 4 / \mathrm{H} 2 \mathrm{SO} 4$ & \\
\hline JKIOX & 019 & HARDIN & SDA INLET & DUCT RUN 1 FILTER (THIMBLE & 53) \\
\hline JK101 & 020 & HARDIN & SDA INLET & DUCT RUN 1 ACETONE & \\
\hline JK105 & 021 & HARDIN & SDA INLET & DUCT RUN $1 \mathrm{FH}$ & \\
\hline JK106 & 022 & HARDIN & SDA INLET & DUCT RUN 1 KCL & \\
\hline JK107 & 023 & HARDIN & SDA INLET & DUCT RUN 1 HNO3/H2O2 & \\
\hline JKIIA & 024 & HARDIN & SDA INLET & DUCT RUN 1 KMNO $4 / \mathrm{H} 2 \mathrm{SO} 4$ & \\
\hline JKI1C & 025 & HARDIN & SDA INLET & DUCT RUN 2 FILTER (THIMBLE & 54) \\
\hline JKIID & 026 & HARDIN & SDA INLET & DUCT RUN 2 ACETONE & \\
\hline JK\IF & 027 & HARDIN & SDA INLET & DUCT RUN $2 \mathrm{FH}$ & \\
\hline JK11K & 028 & HARDIN & SDA INLET & DUCT RUN 2 KCL & \\
\hline JKIIL & 029 & HARDIN & SDA INLET & DUCT RUN 2 HNO3/H2O2 & \\
\hline JKI1Q & 030 & HARDIN & SDA INLET & DUCT RUN 2 KMNO4/H2SO4 & \\
\hline JKIIX & 031 & HARDIN & SDA INLET & DUCT RUN 3 FILTER (THIMBLE & 55) \\
\hline JK111 & 032 & HARDIN & SDA INLET & DUCT RUN 3 ACETONE & \\
\hline JK112 & 033 & HARDIN & SDA INLET & DUCT RUN $3 \mathrm{FH}$ & \\
\hline JK113 & 034 & HARDIN & SDA INLET & DUCT RUN 3 KCL & \\
\hline JK114 & 035 & HARDIN & SDA INLET & DUCT RUN 3 HNO3/H2O2 & \\
\hline JKI17 & 036 & HARDIN & SDA INLET & DUCT RUN 3 KMNO4/H2SO4 & \\
\hline
\end{tabular}

SAMPLED SAMP

DATE TIME

$12 / 01 / 06 \quad 13: 58$

$12 / 01 / 06 \quad 14: 45$

$12 / 01 / 06 \quad 14: 50$

$12 / 01 / 06 \quad 14: 20$

$12 / 01 / 06 \quad 14: 25$

$12 / 01 / 06 \quad 14: 36$

$12 / 02 / 06 \quad 13: 05$

$12 / 02 / 06 \quad 13: 16$

12/02/06 13:17

$12 / 02 / 06 \quad 13: 45$

12/02/06 13:25

$12 / 02 / 06 \quad 13: 38$

$12 / 02 / 06 \quad 21: 14$

12/02/06 21:24

12/02/06 21:29

12/02/06 21:11

$12 / 02 / 06 \quad 20: 51$

$12 / 02 / 06 \quad 20: 04$

$12 / 01 / 06 \quad 12: 53$

12/01/06 13:03

$12 / 01 / 06 \quad 13: 07$

$12 / 01 / 06 \quad 12: 48$

$12 / 01 / 06 \quad 13: 10$

$12 / 01 / 06 \quad 13: 23$

$12 / 02 / 06 \quad 12: 28$

$12 / 02 / 06 \quad 12: 35$

$12 / 02 / 06 \quad 12: 36$

$12 / 02 / 06 \quad 12: 10$

$12 / 02 / 06 \quad 11: 51$

$12 / 02 / 06 \quad 12: 03$

$12 / 02 / 06 \quad 20: 36$

$12 / 02 / 06 \quad 20: 38$

$12 / 02 / 06 \quad 20: 40$

$12 / 02 / 06 \quad 20: 18$

12/02/06 20:04

$12 / 02 / 06 \quad 20: 29$

(Continued on next page) 
SAMPLE SUMMARY

H6L070246

SAMPLED SAMP

WO \# SAMPLE\# CLIENT SAMPLE ID

DATE

TIME

JKI2A 037 HARDIN SDA INLET+STACK RB $0.1 \mathrm{~N}$ HNO3

$12 / 01 / 06 \quad 09: 14$

JKI2F 038 HARDIN SDA INLET+STACK RB KCL

JKI2G 039 HARDIN SDA INLET+STACK RB HNO3/H2O2

JKI2H 040 HARDIN SDA INLET+STACK RB KMNO4/H2SO4/HYD

12/01/06 09:17

12/01/06 09:20

$12 / 01 / 06 \quad 09: 22$

NOTB $(S)$ :

- The analytical results of the samples listed above are presented on the following pages.

- All calculations are performed before rounding to avoid round-off errors in calculated results.

- Results noted as "ND" were not deceted at or above the stated limit.

- This report must not be reproduced, except in full, without the written approval of the haboratory.

- Resuits for the following parameters are never reported on a dry weight basis: color, corrosivity, density, flashpoint, ignitability, layers, odor, paint filter test, pH, porosicy pressure, reactivily, redox potential, specific gravity, spot tesls, solids, solubility, temperature, viscosity, and weight. 
QC DATA ASSOCIATION SUMMARY

H6L070246

Sample Preparation and Analysis Control Numbers

\begin{tabular}{|c|c|c|c|c|c|}
\hline SAMPLE\# & MATRIX & $\begin{array}{l}\text { ANALYTICAL } \\
\text { METHOD }\end{array}$ & $\begin{array}{l}\text { LEACH } \\
\text { BATCH \# }\end{array}$ & $\begin{array}{l}\text { PREP } \\
\text { BATCH \# }\end{array}$ & MS RUN\# \\
\hline 001 & AIR & CFR60A 5 & & 6346334 & \\
\hline 002 & AIR & CFR60A 5 & & 6346334 & \\
\hline 003 & AIR & ASTM D6784-02 & & 7002025 & \\
\hline 004 & AIR & ASTM D6784-02 & & 7002028 & 7002013 \\
\hline 005 & AIR & ASTM D6784-02 & & 7002026 & 7002012 \\
\hline 006 & AIR & ASTM D6784-02 & & 7002028 & 7002015 \\
\hline 007 & AIR & CFRGOA 5 & & 6346334 & \\
\hline 008 & AIR & CFR60A 5 & & 6346334 & \\
\hline 009 & AIR & ASTM D6784-02 & & 7002025 & \\
\hline 010 & AIR & ASTM D6784-02 & & 7002028 & \\
\hline 011 & AIR & ASTM D6784-02 & & 7002026 & \\
\hline 012 & AIR & ASTM D6784-02 & & 7002028 & \\
\hline 013 & AIR & CFR60A 5 & & 6346334 & \\
\hline 014 & AIR & CFR60A 5 & & 6346334 & \\
\hline 015 & AIR & ASTM D6784-02 & & 7002025 & \\
\hline 016 & AIR & ASTM D6784-02 & & 7002028 & \\
\hline 017 & AIR & AsTM D6784-02 & & 7002026 & \\
\hline 018 & AIR & ASTM D6784-02 & & 7002028 & \\
\hline 019 & AIR & CER60A 5 & & 6346334 & \\
\hline 020 & AIR & CFR60A 5 & & 6346334 & \\
\hline 021 & AIR & ASTM D6784-02 & & 7002025 & \\
\hline
\end{tabular}

(Continued on next page) 


\section{QC DATA ASSOCIATION SUMMARY}

H6L070246

Sample Preparation and Analysis Control Numbers

\begin{tabular}{|c|c|c|c|c|c|}
\hline SAMPLE\# & MATRIX & $\begin{array}{l}\text { ANALYTICAL } \\
\text { METHOD }\end{array}$ & $\begin{array}{l}\text { LEACH } \\
\text { BATCH \# }\end{array}$ & $\begin{array}{l}\text { PREP } \\
\text { BATCH \# }\end{array}$ & MS RUN\# \\
\hline 022 & AIR & AstM D6784-02 & & 7002028 & \\
\hline 023 & AIR & AsTM D6784-02 & & 7002026 & \\
\hline 024 & $\mathrm{AIR}$ & ASTM D6784-02 & & 7002028 & \\
\hline 025 & AIR & CFR60A 5 & & 6346334 & \\
\hline 026 & AIR & CFR60A 5 & & 6346334 & \\
\hline 027 & AIR & ASTM D6784-02 & & 7002025 & \\
\hline 028 & AIR & ASTM D6784-02 & & 7002028 & \\
\hline 029 & AIR & ASTM D6784-02 & & 7002026 & \\
\hline 030 & AIR & AsTM D6784-02 & & 7002028 & \\
\hline 031 & AIR & CFR60A 5 & & 6346334 & \\
\hline 032 & AIR & CFR60A 5 & & 6346334 & \\
\hline 033 & AIR & ASTM D6784-02 & & 7002025 & \\
\hline 034 & AIR & ASTM D6784-02 & & 7002028 & \\
\hline 035 & AIR & ASTM D6784-02 & & 7002026 & \\
\hline 036 & AIR & ASTM D6784-02 & & 7002028 & \\
\hline 037 & AIR & ASTM D6784-02 & & 7002025 & \\
\hline 038 & AIR & ASTM D6784-02 & & 7002028 & \\
\hline 039 & AIR & ASTM D6784-02 & & 7002026 & \\
\hline 040 & $\mathrm{AIR}$ & ASTM D6784-02 & & 7002028 & \\
\hline
\end{tabular}




\section{PROJECT NARRATIVE H6L070246}

The results reported herein are applicable to the samples submitted for analysis only.

This report shall not be reproduced except in full, without the written approval of the laboratory.

The original chain of custody documentation is included with this report.

\section{Sample Receipt}

Custody seals were not present upon sample receipt at STL Knoxville.

\section{Quality Control and Data Interpretation}

Unless otherwise noted, all holding times and QC criteria were met and the test results shown in this report meet all applicable NELAC requirements.

$\underline{\text { Metals }}$

These stack gas samples were prepared and analyzed using STL Knoxville standard operating procedure KNOX-IP-0006 which is based on ASTM Method D6784-02, "Standard Test Method for Elemental, Oxidized, Particle-Bound and Total Mercury in Flue Gas Generated from Coal-Fired Stationary Sources (Ontario Hydro Method)" with modifications from EPA Method 29. SW-846 Method 7470A, as incorporated in STL Knoxville standard operating procedure KNOX-MT-0009, was used to perform the final instrument analysis.

Acid digestion was performed on the front half particulate filter and the acetone and nitric acid probe rinse fractions separately using $\mathrm{HNO}_{3}, \mathrm{HCl}$ and $\mathrm{HF}$. After digestion, the $\mathrm{HF}$ was sequestered using $\mathrm{H}_{3} \mathrm{BO}_{3}$ followed by another heating cycle. These digestates were adjusted to final volume, combined and a portion was digested for CVAA analysis in order to determine the particle-bound mercury. Results were calculated using the following equation:

STL Knoxville maintains the following certifications, approvals and accreditations: Arkansas DEQ Cert. \#05-043 0,

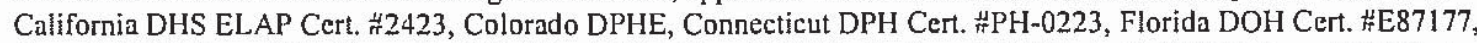

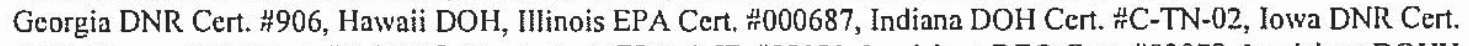
\#375, Kansas DHE Cert. \#E-10349, Kentucky DEP Lab ID \#90101, Louisiana DEQ Cert. \#03079, Louisiana DOHH Cert. \#LA030024, Maryland DHMH Cert. $ّ 277$, Massachusetts DEP Cert. \#M-TN009, Michigan DEQ Lab ID \#9933, New Jersey DEP Cert. \#TN001, New York DOH Lab \#10781, North Carolina DPH Lab ID \#21705, North Carolina DEHNR Cert. \#64, Ohio EPA VAP Cert. \#CL0059, Oklahoma DEQ ID 先9415, Pennsylvania DEP Cert. \#68-00576, South Carolina DHEC Lab ID \#84001001, Tennessee DOH Lab ID \#02014, Utah DOH Cert. \# QUAN3, Virginia DGS Lab ID \#00165, Washington DOE Lab \#C120, West Virginia DEP Cert. \#345, Wisconsin DNR Lab ID Naval Facilities Engineering Service Center and USDA Soil Permit \#S-46424. This list of approvals is subject to change and does not imply that laboratory certification is available for all parameters reported in this environmental sample data report. 


\section{PROJECT NARRATIVE H6L070246}

$H g, u g=(H g, u g / L) *($ Micr. Digestate Volume, $L) *\left(\frac{\text { Final Volume Hg Digestate }(m L)}{\text { Volume Micr. Digestate Used }(m L)}\right) *$ Bench Dilution

Thimbles were received instead of filters for three of the front half samples. Each thimble, probe rinse and acetone particulate were combined and digested on a hot plate using $\mathrm{HNO}_{3}, \mathrm{HCL}$ and $0.1 \mathrm{~N} \mathrm{HNO}_{3}$. After digestion the samples were filtered and brought to a final volume of $100 \mathrm{~mL}$. A portion was digested for CVAA analysis in order to determine the particle-bound mercury. Results were calculated using the following equation:

$H g, u g=(H g, u g / L) *($ Micr. Digestate Volume, $L) *\left(\frac{\text { Final Volume Hg Digestate }(m L)}{\text { Volume Micr. Digestate Used }(m L)}\right) *$ Bench Dilution

Please note that the dilution factor reported on the sample result form for the front half samples is actually a combination of preparation factors and bench dilution factors.

For the $5 \% \mathrm{HNO}_{3} / 10 \% \mathrm{H}_{2} \mathrm{O}_{2}$ impinger samples, a 10 milliliter portion of the sample as received was processed for mercury. The $\mathrm{KCl}$ and $4 \% \mathrm{KMnO}_{4} / 10 \% \mathrm{H}_{2} \mathrm{SO}_{4}$ impinger samples were treated with hydroxylamine hydrochloride, followed by removal of a $25 \mathrm{~mL}$ portion of sample for mercury processing. Results were calculated using the equation listed below. For the $\mathrm{KCl}$ and $4 \% \mathrm{KMnO}_{4} / 10 \% \mathrm{H}_{2} \mathrm{SO}_{4}$ impinger samples, the sample volume includes the volume of hydroxylamine hydrochloride added to the sample.

$H g, u g=(H g, u g / L) *($ Sample Volume, $L) *\left(\frac{\text { FinalVolume Hg Digestate }(m L)}{\text { Volume Sample Digested }(m L)}\right) *$ Bench Dilution

Please note that the dilution factor reported on the sample result form for the back half impingers is actually the combination of preparation factors (not just a dilution factor) required by the method to convert the $\mathrm{Hg}$ reporting limits and method detection limits in concentration units from $\mathrm{ug} / \mathrm{L}$ to a total ug unit:

DilutionFactor $=($ Volume, $L) *\left(\frac{\text { FinalVolume } H g \text { Digestate }(m L)}{\text { Volume Sample Digested }(m L)}\right) *$ Bench Dilution

STL Knoxville maintains the following certifications, approvals and accreditations: Arkansas DEQ Cert. H05-043-0,

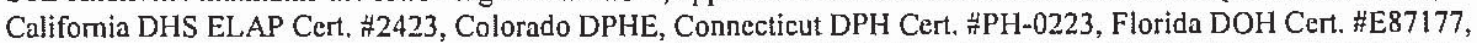
Georgia DNR Cert. \#906, Hawaii DOH, Illinois EPA Cert. \#000687, Indiana DOH Cert. \#C-TN-02, Iowa DNR Cert. \#375, Kansas DHE Cert. "̈E 10349 , Kentucky DEP Lab ID \#90101, Louisiana DEQ Cert. \#03079, Louisiana DOHH Cert. \#LA030024, Maryland DHMH Cert. New Jersey DEP Cert. \#TN001, New York DOH Lab \#10781, North Carolina DPH Lab ID \#21705, North Carolina

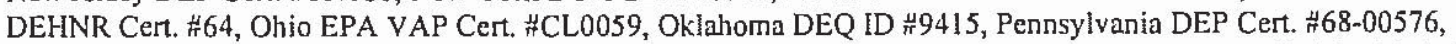
South Carolina DHEC Lab ID $\# 84001001$, Tennessee DOH Lab ID \#02014, Utah DOH Cert. \# QUAN3, Virginia DGS Lab ID \#00165, Washington DOE Lab \#C120, West Virginia DEP Cert. \#345, Wisconsin DNR Lab ID $\# 998044300$, Naval Facilities Engineering Service Center and USDA Soil Permit HS-46424. This list of approvals is subject to change and does not imply that laboratory certification is available for all parameters reported in this environmental sample data report. 


\section{PROJECT NARRATIVE H6L070246}

For the $5 \% \mathrm{HNO}_{3} / 10 \% \mathrm{H}_{2} \mathrm{O}_{2}$ impinger samples, a 10 milliliter portion of the sample as received was processed for mercury. The $\mathrm{KCl}$ and $4 \% \mathrm{KMnO}_{4} / 10 \% \mathrm{H}_{2} \mathrm{SO}_{4}$ impinger samples were treated with hydroxylamine hydrochloride, followed by removal of a $25 \mathrm{~mL}$ portion of sample for mercury processing. Results were calculated using the equation listed below. For the $\mathrm{KCl}$ and $4 \% \mathrm{KMnO}_{4} / 10 \% \mathrm{H}_{2} \mathrm{SO}_{4}$ impinger samples, the sample volume includes the volume of hydroxylamine hydrochloride added to the sample.

$H g, u g=(H g, u g / L) *($ Sample Volume, $L) *\left(\frac{\text { FinalVolume Hg Digestate }(m L)}{\text { Volume Sample Digested }(m L)}\right) *$ Bench Dilution

Please note that the dilution factor reported on the sample result form is actually the combination of preparation factors (not just a dilution factor) required by the method to convert the $\mathrm{Hg}$ reporting limits and method detection limits in concentration units from $\mathrm{ug} / \mathrm{L}$ to a total ug unit:

DilutionFactor $=($ Volume, $L) *\left(\frac{\text { FinalVolume Hg Digestate }(m L)}{\text { Volume Sample Digested }(m L)}\right) *$ Bench Dilution

The matrix spike recoveries for sample Hardin Stack Run 1 KMN04/H2S04 were outside control limits for mercury because the native analyte concentration in the sample was at least four times greater than the spike level. The laboratory control samples showed acceptable results indicating that the analysis was in control.

\section{Wet Chemistry}

The measurement of the mass of particulate matter trapped by the particulate filter and probe rinse derived from an M-5 sampling train was performed using SOP number KNOX-WC-0006 (based on EPA Methods 0050 and 5). Microfiber filters, Petri dishes, and $150 \mathrm{~mL}$ beakers are carefully inspected and tare weighed to constant weight. After sample collection, the filters are dried, and then carefully weighed to constant weight to determine the mass of particulate matter trapped on the filters. The acetone probe rinse solution is evaporated to dryness, and then weighed to constant weight to determine the

STL Knoxville maintains the following certifications, approvals and accreditations: Arkansas DEQ Cert. \#05-043-0, California DHS ELAP Cert. \#2423, Colorado DPHE, Connecticut DPH Cert. \#PH-0223, Florida DOH Cert. \#E87177, Georgia DNR Cert. \#906, Hawaii DOH, Illinois EPA Cert. \#000687, Indiana DOH Cert. \#C-TN-02, Jowa DNR Cert. \#375, Kansas DHE Cert. \#E-10349, Kentucky DEP Lab ID \#90101, Louisiana DEQ Cert. \#03079, Louisiana DOHH Cert. \#LA030024, Maryland DHMH Cert. \#277, Massachusetts DEP Cert. HM-TN009, Michigan DEQ Lab ID \#9933, New Jersey DEP Cert. \#TN001, New York DOH Lab \#10781, North Carolina DPH Lab ID \#21705, North Carolina DEHNR Cert. \#64, Ohio EPA VAP Cert. 든 0059 , Oklahoma DEQ ID \#9415, Pennsylvania DEP Cert. \#68-00576, South Carolina DHEC Lab ID \#84001001, Tennessee DOH Lab ID $\# 02014$, Utah DOH Cert. \# QUAN3, Virginia DGS Lab ID \#00165, Washington DOE Lab \#C120, West Virginia DEP Cert. \#345, Wisconsin DNR Lab ID \#998044300, Naval Facilities Engineering Service Center and USDA Soil Permit \#S-46424. This list of approvals is subject to change and does not imply that laboratory certification is available for all parameters reported in this environmental sample data report. 


\section{PROJECT NARRATIVE H6L070246}

total particulate mass collected in the rinse. The total particulate mass collected by an M5 train is the sum of the particulate filter and the acetone probe rinse residue weights.

Filter thimbles and disks that were not prepared by STL Knoxville were submitted for analysis. The reported weight is the gross weight, which includes the total weight of the filter and the entrained particulate material. Unfortunately, the laboratory information system will not report sufficient digits to obtain a precise net particulate weight when the tare weight is subtracted from the gross weight. The actual raw data is tabulated below for the user's convenience.

\begin{tabular}{|c|c|c|c|}
\hline $\begin{array}{c}\text { Lot-Sample } \\
\text { Number } \\
\ddots\end{array}$ & $\begin{array}{c}\text { Work } \\
\text { Order } \\
\text { Number }\end{array}$ & Client ID & $\begin{array}{c}\text { Gross } \\
\text { Weight } \\
\text { Average } \\
\text { (mg) }\end{array}$ \\
\hline H6L070246-001 & JK1V21AA & HARDIN STACK RUN 1 FILTER & 382.9 \\
\hline H6L070246-007 & $\begin{array}{c}\text { JK1W81A } \\
\text { A }\end{array}$ & HARDIN STACK RUN 2 FILTER & 382.9 \\
\hline H6L070246-013 & JK1X11AA & HARDIN STACK RUN 3 FILTER & 391.8 \\
\hline H6L070246-019 & JK10X1AA & HARDIN SDA INLET DUCT RUN 1 FILTER & 10144.4 \\
\hline H6L070246-025 & JK11C1AA & HARDIN SDA INLET DUCT RUN 2 FILTER & 12695.2 \\
\hline H6L070246-031 & JK1111AA & HARDIN SDA INLET DUCT RUN 3 FILTER & 12472.5 \\
\hline
\end{tabular}

STL Knoxvilie maintains the following certifications, approvals and accreditations: Arkansas DEQ Cert. \#05-043-0, California DHS ELAP Cert. \#2423, Colorado DPHE, Connecticut DPH Cert. HPH-0223, Florida DOH Cert. \#E87177, Georgia DNR Cert. \#906, Hawaii DOH, Illinois EPA Cert. \#000687, Indiana DOH Cert. \#C-TN-02, Iowa DNR Cert. \#375, Kansas DHE Cert. \#E-10349, Kentucky DEP Lab ID \#90101, Louisiana DEQ Cert. \#03079, Louisiana DOHH Cert. \#LA030024, Maryland DHMH Cert. \#277, Massachusetts DEP Cert. \#M-TN009, Michigan DEQ Lab ID \#9933, New Jersey DEP Cert. \#TN001, New York DOH Lab \#10781, North Carolina DPH Lab ID \#21705, North Carolina DEHNR Cert. \#64, Ohio EPA VAP Cert. \#CL0059, Oklahoma DEQ ID \#9415, Pennsylvania DEP Cert. \#68-00576, South Carolina DHEC Lab ID \#84001001, Tennessee DOH Lab ID \#02014, Utah DOH Cert. \# QUAN3, Virginia DGS Lab ID \#00165, Washington DOE Lab \#C120, West Virginia DEP Cert. \#345, Wisconsin DNR Lab ID \#998044300, Naval Facilities Engineering Service Center and USDA Soil Permit \#S-46424. This list of approvals is subject to change and does not imply that laboratory certification is available for all parameters reported in this environmental sample data report. 
Sample Data Summary 
Air Sampling Associates, Inc.

Client Sample ID: HARDIN STACK RUN 1 FH

TOTAL Metals

Lot-Sample \#...: H6L070246-003

Date Sampled...: 12/01/06

PARAMETER

Prep Batch \#...: 7002025

Mercury
0.038
0.010 ug

Dilution Factor: 0.1
Date Received..: 12/06/06

REPORTING

UNITS METHOD

ASTM D6784-02

Analysis Time..: $11: 21$
Matrix......: AIR

PREPARATION- WORK ANALYSIS DATE ORDER \#

01/02-01/05/07 JKIWAIAA MDL.......... 0.0060 
Air Sampling Associates, Inc.

Client sample ID: HARDIN STACK RON 1 KCL

TOTAL, Metals

Lot-Sample \#...: H6L070246-004

Date Sampled...: 12/01/06

PARAMETER

Prep Batch \#...: 7002028

Mercury

$0.11 \mathrm{~B}$

Date Received..: 12/06/06

REPORTING

UNITS

LIMIT

0.13 ug

Dilution Factor: 1.32

NOTE (S) :

B Estimated result. Result is less than RL. METHOD

Matrix...... AIR

PREPARATION- WORK ANALYSIS DATE ORDER \#

ASTM D6784-02

$01 / 04 / 07$ JKIWEIAA

Analysis Time..: 10:51 
Air Sampling Associates, Inc.

Client Sample ID: HARDIN STACK RUN 1 HNO3/H2O2

TOTAL, Metals

Lot-Sample \#...: H6L070246-005

Date Sampled...: 12/01/06

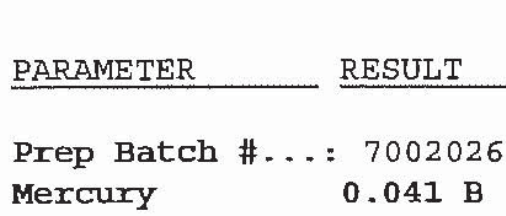

Date Received. .: 12/06/06

REPORTING

LIMIT

UNITS

METHOD

$\begin{array}{ccc}0.060 & \text { ug } & \text { ASTM D6784-02 } \\ \text { Dilution Factor: } 0.6 & \text { Analysis Time..: 11:46 }\end{array}$

Matrix.....: AIR

PREPARATION- WORK ANALYSIS DATE ORDER \#

01/03-01/05/07 JKIHFIAA MDL......... 0.036

$\operatorname{NOTB}(S)$ :

B Estimated result. Result is less than RL. 
Air Sampling Associates, Inc.

Client Sample ID: HARDIN STACK RUN 1 KMNO4/H2SO4

TOTAL Metals

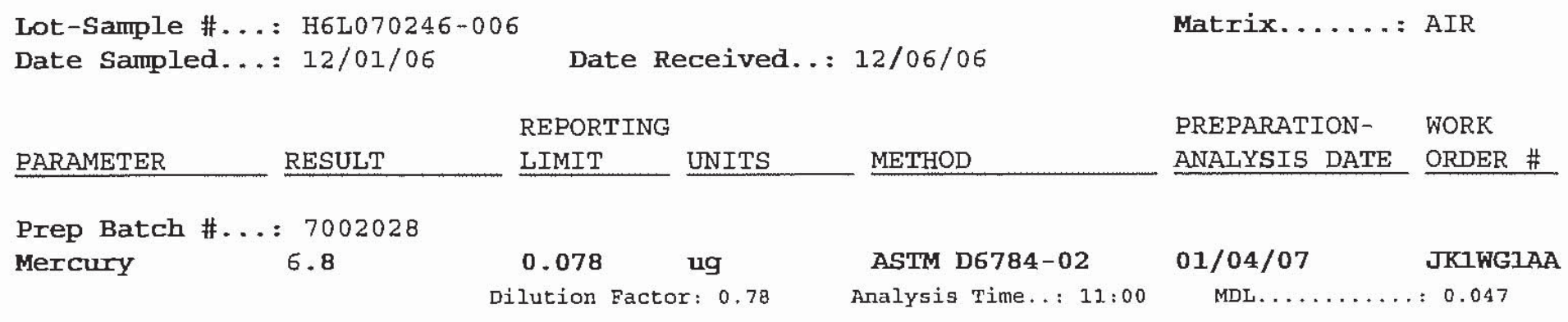


Air Sampling Associates, Inc.

\section{Client Sample ID: HARDIN STACK RUN 2 FH}

TOTAL Metals

Lot-Sample \#...: H6L070246-009

Date Sampled...: 12/02/06

PARAMETER

RESULT

Prep Batch \#...: 7002025

Mercury

ND

0.010 ug

Dilution Factor: 0.1
Date Received. .: 12/06/06

REPORTING

LIMIT

UNITS METHOD

ASTM D6784-02

Analysis Time..: 11:25
Matrix....... AIR

PREPARATION- WORK ANALYSIS DATE ORDER \#

01/02-01/05/07 JKIXDIAA MDL.......... 0.0060 
Air Sampling Associates, Inc.

\section{Client Sample ID: HARDIN STACK RUN 2 KCL}

TOTAL Metals

Lot-Sample \#... : H6L070246-010

Date Sampled...: 12/02/06

PARAMETER

Prep Batch \#...: 7002028

Mercury

RESULT
7002028
ND

Date Received..: 12/06/06

REPORTING

LIMIT

UNITS

ug

0.15

Dilution Factor: 1.47
Matrix...... AIR

PREPARATION- WORK ANALYSIS DATE ORDER \#

01/04/07 JK1XE1AA MDL.......... 0.088 